30 +

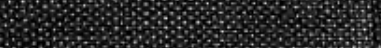

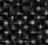


ts Harvard Medical Library in the Francis A. Countway Library of Medicine $\sim$ Boston

VERITATEM PER MEDICINAM QUAERAMUS 
D. Peater iston.

$$
\underbrace{H}_{s=11-17}
$$




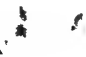

m. . 


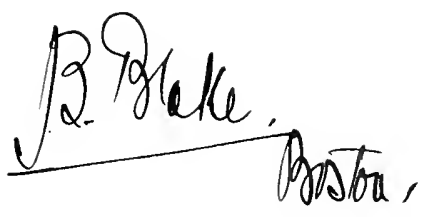

THE BREAST:

ITS ANOMALIES, ITS DISEASES,

AND THEIR

TREATMENT

DEAVER AND MCFARLAND 
Digitized by the Internet Archive in 2010 with funding from

Open Knowledge Commons and Harvard Medical School 


\section{THE BREAST:}

\section{ITS ANOMALIES, ITS DISEASES,}

AND THEIR

\section{TREATMENT}

BY

JOHN B. DEAVER, M. D., LL. D., SC. D.,

PROFESSOR OF THE PRACTICE OF SURGERY, UNIVERSITY OF PENNSYLVANIA; SURGEON-IN-CHIEF TO THE GERMAN HOSPITAL; VISITING BURGEON TO THE HOSPITAL OF THE UNIVERSITY OF PENNSYLVANIA; CONBULTING SURGEON TO THE GERMANTOWN HOSPITAL, THE PHILADELPHIA GENERAL HOSPITAL,

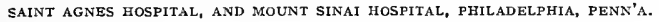

AND

JOSEPH MCFARLAND, M. D., SC. D., PROFESSOR OF PATHOLOGY AND BACTERIOLOGY IN THE MEDICAL DEPARTMENT OF THE UNIVERSITY OF PENNSYlVANIA; PATHOLOGIST TO THE PHILADELPHIA GENERAL HOSPITAL;

PELLOW OF THE COLLEGE OF PHYSICIANS, PHILADELPHIA, ETC.

ASSISTED BY

J. LEON HERMAN, B. S., M. D.,

Assistant surgeon to the Methodist hospital of philadelphia; instructor [in anatomy, MEDICAL SCHOOL OF THE UNIVERSITY OF PENNSYLVANIA

WITH 8 COLORED PLATES AND

277 ILLUSTRATIONS IN TEXT

PHILADELPHIA

P. BLAKISTON'S SON \& CO.

1012 WALNUT STREET 
Copyright, i9i7, by P. Blakiston's Son \& Co. 


\section{PREFACE}

In presenting this book to the profession, its authors(have been moved by two prime considerations: first, the importance of collecting individual experience in order that deductions and generalizations may follow, and, second, the dissemination of known facts of vital importance in the treatment of the malignant diseases of the breast.)

However much we may deplore the fact that the essential cause of the neoplastic diseases remains unknown, and our inability, in the absence of that knowledge, to prevent such diseases, there are certain responsibilities arising from what we do know but do not properly utilize. The critical examination of the results of any large series of cases cannot but produce a profound impression and lead to the distressing realization of the fact, that we, as a profession, are far from the scientific application of much of the knowledge already at our disposal.

Were we properly alive to the situation as it exists to-day, a death from external cancer would be the exception rather than the rule and it would be universally recognized and admitted that to temporize with a suspicion of malignant disease is criminal.

Anyone acquainted with the excellent treatises of Velpeau, Cooper, John Rodman, Birkett, Billroth, Bryant, Williams, Binaud and Braquehaye, Sheild, Handley, W. L. Rodman and others will realize how much all later students of the subject owe to these authors; a debt which we freely acknowledge.

The sections on pathology reflect the personal views of Dr. McFarland, and are based upon the study of 575 cases, which are not the same as those from which the surgical statistics are compiled. The latter are derived from the German Hospital of Philadelphia, where approximately rooo records of surgical breast cases were at our disposal, though unfortunately many of them were too incomplete to permit utilization in detail. We have, however, been able to keep a sufficient number of operative cases under observation, to learn that we have established no high-water mark in the cure of malignant disease of the breast; we cannot even lay claim to as great success as has been claimed by some of our contemporaries.

Had it not been for the indefatigable labors of Dr. J. Leon Herman this book would not now be existing. We desire, therefore, especially to acknowledge his part in the work and our obligations to him. We also wish very particularly to acknowledge our indebtedness to Dr. Pfähler for his contribution upon "The Non-Operative Treatment of Cancer," and to Dr. A. D. Whiting for the preparation of the index.

We likewise desire to express our thanks to many who have contributed to the value of the book in ways that only the authors can thoroughly appreciate. We make special acknowledgment of the courtesy and promptness of Dr. Halsted of Johns Hopkins University and of Dr. J. Coliins Warren of Harvard University, in responding to our request for assistance in the preparation of the chapter on "The Operative Treatment of Carcinoma," a phase of our subject with which the names of these gentlemen must ever be associated.

We must mention with praise the translation of many papers in foreign journals by Miss A. M. Jastrow, and the numerous original drawings by Mr. Charles F. Bauer. 
. 


\section{TABLE OF CONTENTS}

Chapter
PAge

I. The Evolution and Involution of the Normal Breast $\ldots \ldots \ldots \ldots \ldots \ldots \ldots \ldots$

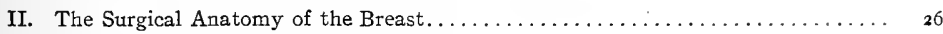

III. The Congenital Anomalies of the Breast. $\ldots \ldots \ldots \ldots \ldots \ldots \ldots \ldots \ldots \ldots \ldots \ldots$

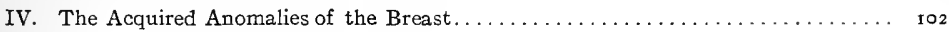

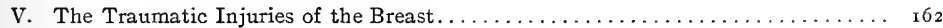

VI. The Infectious Diseases of the Breast. $\ldots \ldots \ldots \ldots \ldots \ldots \ldots \ldots \ldots \ldots \ldots \ldots$

VII. Cysts and the Cystic Diseases of the Breast. . . . . . . . . . . . . . 254

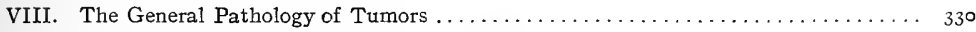

IX. The Non-Indigenous Tumors of the Breast. $\ldots \ldots \ldots \ldots \ldots \ldots \ldots \ldots \ldots \ldots \ldots \ldots$

Sarcoma of the Breast. . . . .

The Fibro-Epithelial Tumors of the Breast. . . . . . . . . . . . . . . 442

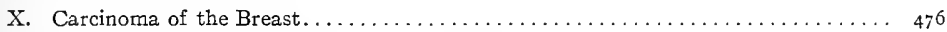

XI. The Non-Operative Treatment of Tumors of the Breast . . . . . . . . . . 637

XII. The Diseases of the Nipple and Areola of the Breast . . . . . . . . . . . $67 \mathrm{r}$

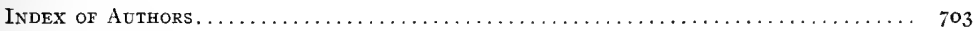

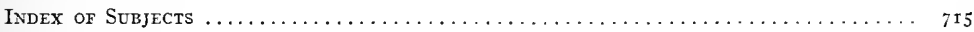


. 


\title{
THE BREAST
}

\author{
CHAPTER I
}

\section{THE NORMAL BREAST}

\section{EVOLUTION}

Embryology.-At an early period in the development of certain mammals, $O$. Schultze (Sitzungsberichte der physic.-med. Gesellschaft zu Würzburg, I892, p. 77) discovered that a slight ectodermal ridge could be seen, passing along each side of the body from the axillæ to the groins. To these he gave the name "milch-leisten" or milk-lines, because they mark the general location of the future mammary glands. Such milk-lines have now been observed in the embryos of pigs, guinea-pigs, rabbits, rats, cats, foxes, squirrels, moles, sheep, cattle, deer, bats, monkeys and other mammals. What O. Schultze discovered for the lower mammals, Kallius and Brouha (Anatomischer Anzeiger, 1905) Schmidt, Schmitt, Strahl, Hirshland, Elze and others have shown to be true for human embryos as well. On the latter they can first been seen in 9-mm. embryos and are quite distinct in $15-\mathrm{mm}$. embryos. When the embryos attain to a length of

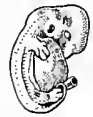

$a$

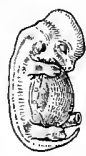

b

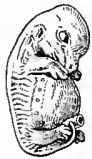

$c$

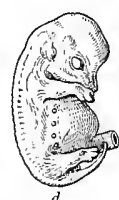

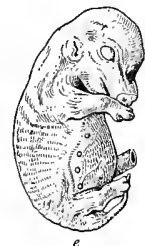

Fig. I.-A series of pig embryos, showing the "milk line" in $a$, the interrupted line and appearance of the future nipples in $b$, and their further development in $c, d$ and $e$.

26-60 $\mathrm{mm}$. the lines cease to exist as such, but become broken up into a series of points, each forming a minute elevation through accumulation of the ectodermal cells. These constitute the "burgeons primordeaux" or "anlagen" of future mammary glands. Their number in the embryo bears no definite relation to the number of mammary glands that will finally appear in the adult animal, except that there can never be more mammary glands than there are primitive "anlagen." Unless we except certain marsupial mammals (Didelphys) and insectivorous mammals, the number of "burgeons primordeaux" is always in excess of the number of mammary glands normal to the species.

Thus Schickele (Zeitschrift für Morph. u. Anthrop., Vol. I) found that the embryo guinea-pig exhibited to of the primitive "anlagen," though the adult is provided with only two mammary glands, and H. Schmidt (Anatomischer Anzeiger, I896, XI, No. 23) found that such primitive "anlagen" appeared in varying numbers upon the thorax and abdomen of human embryos, although human beings normally have but two mammary glands. The explanation of this numerical variation is to be found in the 
suppression of the superfluous "anlagen" as the further embryonal development of the animal takes place. If the development takes place normally, the animal develops the number of mammæ normal to its kind. If the suppression of the "anlagen" be excessive there may be no mammary glands-Amastia-a very rare anomaly, q.v.; if it fail, there may be too many, and a more frequent anomaly-Polymastia, q.v.results.

The final number of mammary glands bears a close correspondence with the number of young usual to the species. Animals with many young have many mammæ; those

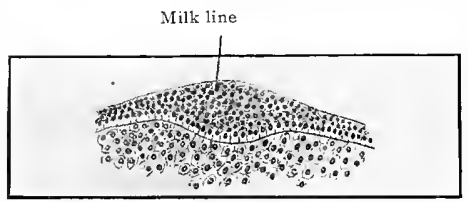

FIG. 2,-Transverse section through the mammary "anlage" of a I cm. pig embryo. (Bonnet.) with one or two, few. Human beings have but two mammary glands, the smallest number known.

Langer (Denkschrift der k. Akad. der Wissenschaft, etc., Wien, $185^{2}$ ) found the center of each collection of ectodermal cells constituting the primitive "anlage," marked by a depression that marked the position of the future nipple. There seems to be no actual development of the gland until the fourth month in human embryos, when the hair follicles begin to form, and at the same time the ectoderm, now differentiated, begins to send down, into the mammary area, long exaggerations of the epithelial pegs of the rete mucosum. This downward growth of the epiderm consists of solid cylinders, and occurs in the area that is later to become the areola. The central cylinders are large and rapidly grow broader and longer to form the milk ducts from which the mammary parenchyma is to form; the peripheral cylinders are much more slender and shorter, and lay the foundations of the glands of Montgomery, which many writers look upon as rudimentary mammary lobules.

As the parenchyma is thus forming in the cutis, unstriped muscular tissue appears in small quantity about the primary depression, and being for the most part circularly arranged, is soon followed by a circular contraction that causes the central part of the mammary area to project slightly beyond the general surface. Thus the foundation of the future nipple is laid. In cases

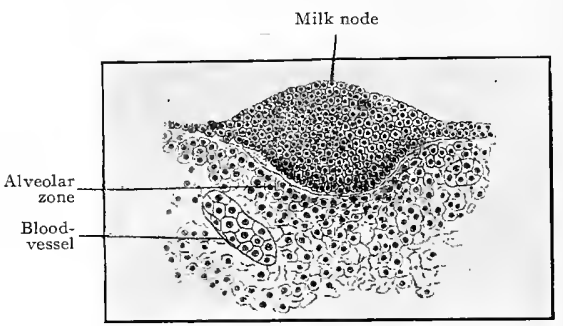

FIG. 3.- -Transverse section through the mammary "anlage" of a $1.5 \mathrm{~cm}$. pig embryo. (Bonnet.) in which no muscular tissue develops, or in which its contraction fails at the proper moment, no nipple is formed and Athelia or a nippleless mamma results - a condition normal to the mammæ of certain of the prototheria or lowest mammals.

The office of this muscular tissue is unimportant in the human breast except in assisting in its perfect development. It no doubt aids in the erection of the perfected structure when in adult life it is called into functional activity, but beyond this is of little, if any, importance. In some of the lower mammals, it is, however, indispensable either for closing the orifices of the nipples so that no milk is lost as in the cetacea, or for 
forcing the milk in jets into the mouths of very rudimentary young mammals as in such marsupials as kangaroos.

At the time of birth, the human breast consists of a slightly depressed rounded area over each pectoral region, in the center of which is a tiny rounded node of insignificant size and elevation. When examined microscopically it is found that the epithelium of the surface descends through the little nipple in the form of slender cylinders which spread out in the cutis and usually are dichotomously divided at the ends which are expanded and rounded. The epithelial cylinders are solidly composed of cells, the lower layers of which are of cylindrical shape and not enclosed by any definable basement membrane. The nipple is composed of fibrillar tissue, blood-vessels, lymphatics, and muscular tissue surrounding the epithelial cylinders.

Development-Infancy.-A few days after birth the mammary glands of both male and female infants show signs of internal activity. They swell to a varying extent, become slightly reddened, are tender to the touch, and when pressed, permit a small quantity of milky fluid

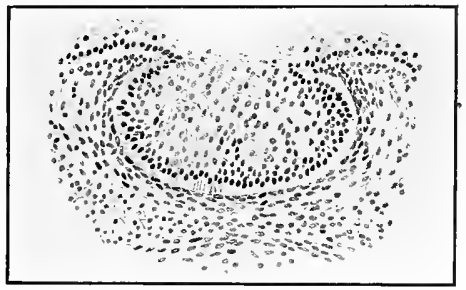

FIG. 4.- Transverse section through the mammary "anlage" of a $16 \mathrm{~cm}$. human embryo. (Bonnet.) to escape. This condition is almost invariable, though it is commonly so slight as to be overlooked. In 25 infants that the writer studied, haphazard, it was found in every one. Sometimes it is so marked as to attract attention and require treatment in the form of sedative applications. Sometimes it is attended by complicating infection that may go on to suppuration. Probably the name commonly applied to the condition-Mastitis neonatorum-is the result of the erroneous supposition that it is not a normal, but a morbid process occasioned by infection, and the opinion of

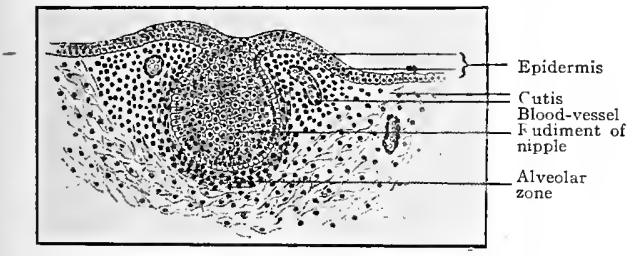

FIG. 5--Transverse section of the mammary "anlage" of a 6.5 cm. pig embryo. (Bonnet.) many is probably expressed by Handley who describes it as the "first onslaught of bacteria upon the aseptic babe."

There is no evidence that the infantile secretory activity depends upon infection, though it undoubtedly predisposes to it. The name Mastitis neonatorum should be restricted to the rare cases in which actual, demonstrable, pyogenic infection takes place, and constitutes a definite clinical entity comparable to pyogenic mastitis in the lactating adult. It is in that connection that we propose to discuss it in our chapter upon the Infectious Diseases of the Breast (q.v.).

In keeping with modern views concerning the internal secretions, it seems more correct to regard the secretory changes in the breasts of the new-born as normal and physiological effects of autocthonous internal secretions newly generated and for which no equilibrium has yet been established. A few physiologists, while in thorough concord with this doctrine of internal secretions as the chief factor concerned in this in- 
fantile activity, look for them outside of the body of the infant itself. Thus Halban (Zeitschrift für Geburtshülfe und Gynäkologie, 1904, 53) supposes that it is the same hormone in the blood of mother and child that stimulates the glands of each and Knopfelmacher (Archiv für Gynäkologie, r903 and r906) supports the same view.

Consistent with this doctrine is the fact that it is not sero-pus that escapes when the glands are pressed, but colostrum, or in some cases true milk. There may even be a considerable quantity of milk secreted in such cases. Thus, Darby (Dublin Medical Press, $r 850$, p. 246) saw a child eight days old whose breasts were so full of milk that the mother had to express it several times a day. Gibb (Lancet, 1859, II, I 87 ) describes a similar case.

Variot (Bull. et mém. de la Société méd. des Hôp. de Paris, r89o, 3. s. VII, 697) made a careful study of this subject and by the examination of a large number of infants found that the secretion generally begins between the eighth and fifteenth day, and continues longer than the "few days" commonly said, for out of 32 children between the ages of six and nine months that he examined, all but six showed the presence of milk in the breasts. Instead of the usual teaching that care should be taken not to disturb the breasts at this

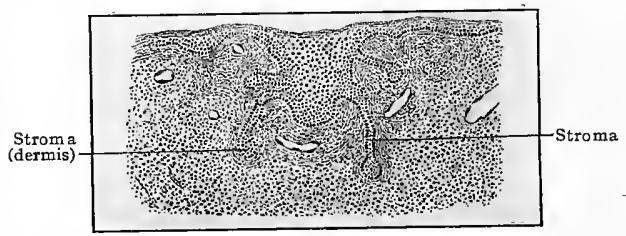
time, Variot believes that mammary abscesses in the new-born might be avoided if care. were taken to empty the breasts during the first few days of the secretion.

After this period of infantile activity has subsided, FIG. 6.-Vertical section of the "anlage" of the mammary gland the breasts are a little larger
of a human fotus of $25 \mathrm{~cm}$. (Nagel.) than before, and are commonly changed in their minute structure, for when sections are examined with the microscope it is found that the parenchyma no longer consists of solid cylinders of epithelial cells, but of hollow tubes with cæcal expanded terminations, and that instead of single dichotomous branchings, there are now several, so that the quantity of parenchyma has materially increased.

From the first year to the advent of puberty the changes in the breasts are slight and unimportant and consist chiefly in an added number and complexity of the tubules which become more numerous in the breasts of girls than in those of boys.

Development-Puberty.-With the advent of puberty come developmental changes in the breasts of both sexes. These are comparatively unimportant in boys but are striking in girls. The changes are again to be referred to the occurrence of internal secretions, as will be pointed out below.

The activities of the male breasts have been studied by Luschka ("Die Anatomie der männlichen Brustdrüse," Archiv f. Anatomie, r $85^{2}$ ) who found that at and subsequent to puberty the male breasts continued to consist of tubules or ducts with cylindrical epithelium terminating in vesicles with a more flattened epithelium. There were no acini. Th. Kölliker (Beiträge zur Kenntniss der Brustdrüse," Verhandl. der med. Gesellschaft zu Würzburg, N. F., Bd. XIV), found that up to the time of puberty it was not possible to differentiate microscopically between the male and female glands. At the time of birth the glandular parenchyma was, at most, only $2 \mathrm{~cm}$. broad and $r$ $\mathrm{cm}$. thick and composed of $x_{5^{-20}}$ glandular ducts with one end opening upon the nipple 
and the other terminating in a flask-like expansion. The more deeply placed tubules divided dichotomously. In boys the tubules showed more or less distinct ectasia, with desquamation of some of the epithelium, which was in a single layer, cylindrical in form and upon a structureless basement membrane. The ectasia followed the infantile activity. Up to the tenth year there was no important change except that the ectasia of the first year was gradually lost through the compressing effect of fatty tissue deposited in and about the tubules. From the tenth to the twentieth years the gland did not progress. In the best developed male mammæ there might be a few groups of terminal vesicles but there were no true acini. The perfection of the gland seemed to be reached between the twentieth and thirtieth year when as many as Io vesicles were sometimes found forming a group. They were always at the ends of tubules, and were lined by a tall epithelium. After the thirtieth year the male gland seemed to regress. The terminal vesicles disappeared from the tubules, the tubules in the deeper parts of the gland atrophied almost to disappearance, while the ducts in the nipple dilated.

In marked contrast with these scarcely perceptible changes in the male gland the female gland underwent a remarkable development at puberty. The activity of growth usually began about the tenth year, but was at first so gradual as to escape observation. Later, about the fourteenth and sixteenth years they progressed rapidly; then again there was slow progress until about the eighteenth year when the gland became mature. Race, climate, heredity, bodily condition, temperament and habit all had modifying influences in accelerating or retarding the development of the mammary glands, so that it was as difficult to fix the periods of development of the mammæ as of other phenomena of puberty.

The microscopic changes coincide with external morphological changes in the appearance of the breasts. These have been followed with much care by C. H. Stratz (Der Körper des Kindes, etc., Stuttgart, I903).

According to this author the first developmental changes consist in division and extension of the glandular parenchyma beneath and beyond the areola, and a deposition of adipose tissue between the forming lobules of glandular tissue. The external visible result is a bluntly conical elevation of the areola and nearby mammary area, which he describes as the "Knospen-brust" or budding breast. As time goes on the gradual growth and extension of the mammary parenchyma with a simultaneous increase in the adipose tissue, causes the growing gland to increase in diameter and elevation until its maximum size is attained and a hemispherical shape assumed. It is; however, still surmounted by the small cone of the areola and nipple, which may persist for a long time. Finally, the development of a firm union between the overlying skin and milk ducts, the perfection of the areolar and muscular tissue of the nipple, and the final contraction of these tissues cause the disappearance of the conical apical area, and the perfected nipple and areola appear.

During the period of adolescence secretory activities may appear in the developing breasts of both sexes. Like the infantile secretory activity, it has been misunderstood, and has been mistaken for inflammation, hence it is commonly known as Mastitis adolescentium, or, when affecting boys, Mastitis adolescentium virilis, or as Albers (Correspondenzbl. der rheinsch. und westfälisch. Aerzte, I843, No. 13), who first described it, called it "Mastitis pubescentium virilis." The breasts swell, become sensitive to contact with the clothing and upon pressure, yield a milky fluid. In well-marked cases the breasts of boys temporarily develop the size and appearance of those of girls of similar age. In girls in whom the enlargement of the breasts is expected it at- 
tracts no solicitation, unless there is pain, and the presence of secretion is frequently overlooked.

The causes of both the ana tomical and physiological excitations are no doúbt identical, and referable to hormones or internal secretions produced at the time of puberty to regulate the anatomical and physiological activities incidental to that period. When these secretions are deficient, the development of the reproductive organs may be retarded or may fail; if the supply be normal, the progress of events is normal; if excessive, the development and activities of the organs may be premature or excessive.

The Breast in Maturity.-Morphology.-The mature male breast is rudimentary. It consists of an areola, the diameter of which is rarely more than $2 \mathrm{~cm}$., in the center of which there is a tiny nipple like a minute hemisphere, with feeble erectile powers. . Beneath the areola, and scarcely extending beyond the confines it represents is a gland of such inconsiderable size as to cause little if any elevation, so embedded in the superficial fascia as to elude palpation. It is, however, an error to speak only of nipples, when referring to the mammary glands of men, for glands are there, and in them are latent potentialities that sometimes lead to unexpected activities as will be pointed out below.

The female virginal Caucasian breast is almost hemispherical in shape, the perfect symmetry of the hemisphere being destroyed by a slight increase in the length of the radii extending toward the axillæ. The size of the breast varies according to hereditary, familial and individual peculiarities, both in diameter and elevation. It is surmounted by a pigmented center of wrinkled, slightly warty skin, with a thin and slightly shining quality, the areola, in the middle of which a rounded, warty nipple is situated.

The exact position of the breasts, is subject to slight variations. The nipples in virginal non-pendulous breasts are usually in the fifth costal interspace upon the anterior thoracic wall, but the breasts may be so situated that the nipples may be above or below this point.

The configuration of the female breast has been studied with considerable care by H. H. Ploss (Das Weib in der Natur und Völkerkunde, Leipzig, 8th Ed., r9०4-०5) who finds that there are certain definite types, some of which are racial, some familial and some individual. His classification is as follows:

I. According to size, mammary glands may be described as:

r. Luxurious or voluptuous

2. Full

3. Medium

4. Small

II. According to density:

I. Prominent

2. Sinking

3. Pendulous

III. According to form:

I. Saucer-shaped

2. Hemispherical

3. Conical

4. Goat-udder-like.
The areolæ upon different breasts are also subject to variations:

I. According to the diameter:
r. Narrow
2. Medium
3. Broad
4. Enormous.

II. According to form:

r. Disk-shaped

2. Saucer-shaped

3. Hemispherical

4. Globular. 
The nipples also vary and may be described:

I. According to size:
r. Hollow or inverted
2. Absent
3. Small
4. Medium
5. Large

II. According to shape:
I. Flattened
2. Button-shaped
3. Short cylindrical
4. Hemispherical
5. Peg-like
6. Digital.

In the lowest races the breasts are commonly acutely conical- "goat-udder-like" or bluntly conical, large, heavy and pendulous. In the higher races the hemispherical type is looked upon as the most perfect. The largest and most pendulous normal breasts are to be found among the African negroes, the most striking among the Hottentots, who are said not infrequently to carry their infants on the back, nursing them by passing the large pendulous breasts over the shoulders.

Normal breasts are not always uniform in volume or position, the left commonly being the larger and having the lower position. This difference not of ten observed among Caucasians is often strikingly conspicuous among the lower races. Care must be taken, however, not to confuse inequalities of size and position appearing after the infant has einptied one breast with real inequalities of permanent character.

Among the lower races the variations in areola and nipple are of much more frequent occurrence than among Caucasians. Thus, the retention of the "Knospe" or little cone upon the virginal breast resulting from incomplete development of the nipple and areola, and the consequent appearance called the "Knospen-brust" or budding breast, may persist long in the lower races-even after the first lactation, at times.

The appearance of mammary glands of inferior types, goat-udder-breasts and conical breasts, upon Caucasians, may be looked upon as evidences of "reversion " or "atavism." The same may be said of undue persistence of the "Knospen-brust."

The mammary glands are included among the cutaneous glands, and were formerly looked upon as enlarged and specialized sebaceous glands. This idea has now been abandoned by the best embryologists and histologists who follow Benda, (Histologischer Handatlas, I895) in regarding them as the analogues of the sweat glands, a view that is supported not only by their histological structure, but also by their method of functionating. The sebaceous glands are holokrine glands, i.e., glands whose cells are completely destroyed in the process of secretion, while the sweat and mammary glands, are merokrine glands, whose secretory cells are not so destroyed. von Saar (Ergebnisse d. Chirurgie u. Orthopädie, I9IO, 4II) points out that the mammary glands stand at one extreme of a series of dermal glands beginning with the tiny coil or sweat glands, including the Moll perineal and auditory meatus glands, the great sweat glands of the axilla and ending with the mammary glands.

In the mammary glands the lobules nearest the nipple closely resemble exaggerated coil glands. von Saar observed great similarity between the sweat glands and the structures seen in certain adenomas of the mamma, Creighton has written an entire book, "Cancers and Other Tumors of the Breast," London, 1902, for the purpose of proving the existence of aberrant sweat glands in the mamma and their importance as the startingpoint of certain mammary tumors and Krompecher (Verhandl. d. deutsch. path. Gesellschaft, Jena, I9I3, XVI, 365) has shown the presence of sweat-gland cysts in the mamma, by means of modern histological methods, in a most convincing fashion. There is a strong homology between sweat glands and the mammary glands of the Prototheria or lowest mammals, whose secretion is serous rather than milky, and there is a considerable 
homology between the mammary glands of the higher animals and the axillary sweat glands of man that not infrequently give off a milky-appearing secretion.

The Nipple.-The normal nipple of the Caucasian breast forms a hemispherical eminence in the center of the areola, upon the center of the breast. It is covered with a modified integument that gives it a wrinkled or even warty appearance. It is not actually hemispherical, but when examined closely, and especially when mechanically stimulated so as to become "erected" and prominent, is found to be cylindrical and truncated so as to be flattened on the top. It is pinkish or brownish in color, the quantity of pigment varying according to the complexion of the individual.

When examined microscopically the nipple is found to consist of a rather dense areolar tissue without adipose deposits and with considerable unstriped muscular tissue that extends beneath the areola, and consists of bundles of cells so arranged that about one-half is perpendicular to the surface, while the other half is circularly disposed about the deeper structures. There are a few blood-vessels, lymphatics and nerves. The "erection" of the nipple has no association with the vascular supply as in cavernous tissues, but depends entirely upon the contraction of the muscular tissue at its base.

The most striking structures in the nipples are the ducts of the mammary lobes, each of which passes vertically through it from the glandular tissue below.

The Areola.-The nipple is surrounded by the areola. This is a more or less wellmarked zone of skin of a shining, wrinkled and slightly warty appearance, containing a quantity of pigment varying according to the complexion of the individual. In blondes it may be scarcely noticeable; in very dark brunettes it may be very dark colored.

Virginity and pregnancy modify the breadth and darkness of the areola, as will be explained below.

The warty appearance depends upon the presence of the Glands of Montgomery, to which reference has already been made, whose ducts open upon the surface of the areola itself. They are racemose glands and are variously regarded as enlarged and specialized sebaceous glands and as accessory mammary glands by different authors.

One of the first signs of mammary activity in pregnancy is the appearance of a greasy secretion from these glands and an altered appearance of the areola. The skin of the areola also contains a few hair folliclës, ordinary sebaceous glands and a few coil or sweat glands.

The Gland.-A dissection of the breast is difficult because of the close blending of the lobes, the quantity of adipose tissue, and the density of the connective tissue of which it consists. It is composed of a varying number of (I 2-20) lobes, of irregular, pyramidal shape, the apex of each corresponding to the nipple where the major duct of each lobe opens, the base flattened to a fringe, corresponding to the circumference of the breast. The lobes, therefore, all radiate from a common center, but are more or less blended by the extension of the minute structures of each into the borders of its neighbors, so that it is not possible to completely separate them. The glandular tissue of each lobe consists of a system of branching and ramifying, dendritic tubules varying greatly in quantity in different individuals. Between the glandular elements are fibrillar connective and adipose tissues in varying proportions and quantities.

Remembering that considerable variations are possible in the absolute and relative quantities of the glandular tissue, of the adipose tissue and of the areolar tissue, it is easy to understand that the microscopic appearances presented by sections of breast tissue, will vary as greatly as the gross appearances of the breasts from which the sections have been made. 
Histology.-A scientific study of the minute anatomy and histology of the breast that is to form the basis of pathological studies and comparisons should take cognizance of the age of the patient, the sexual condition of the patient, whether menstruating, pregnant, lactating, recovering from lactation, climacteric, senile, or suffering from ovarian or uterine disease, for each produces some modification in the breast which should be considered normal to the time of life or condition of the patient.

Few studies of this nature have been made as the necessary material is difficult to obtain. The best work of the kind that we have been able to find is by F. Berka, "Die Brustdrüse verschiedener Altersstufen und während der Schwangerschaft" (Frankfurter Zeitschrift für Pathologie, rgr 1 , VIII, 203).

The Parenchyma.- Should we select for study the shapely mammary gland of a young but sexually mature virgin, we would find each lobe of the glandular parenchyma be-

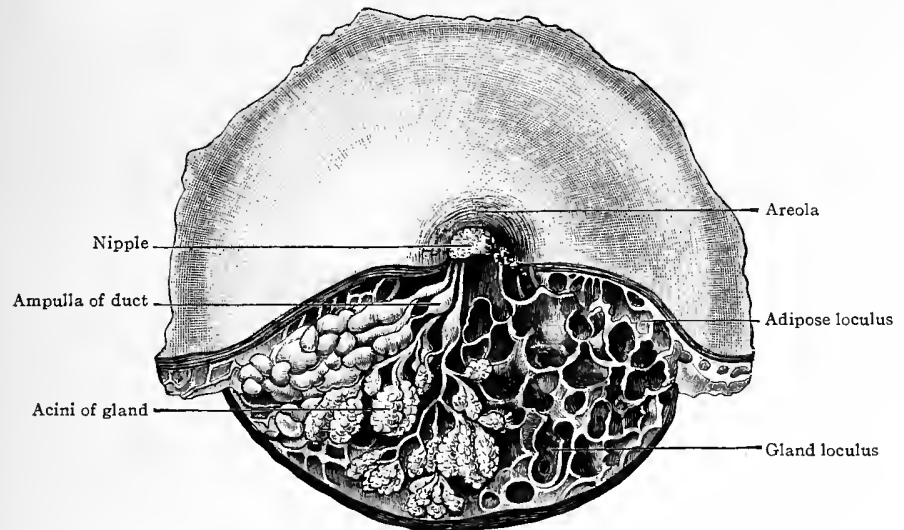

FIG. 7.-The female mamma during lactation. (After Luschka.)

ginning-or rather ending, but for purposes of description the order will be reversedin the orifice of a duct upon the flattened surface of the nipple. These openings are normally collapsed as are the ducts below, and cannot be found by external inspection. The squamous epithelium of the epiderm of the nipple is continued in a stratified layer, into the glandular duct below, to a varying depth, and sometimes, if not commonly, to spindle-shaped expansions beginning just at the base of the nipple, and known as the ampulle or tubuli lactiferi or tubuli galactophori. These correspond to the milk sinuses of the udders of cattle and serve to collect the milk, and it is from them that tiny streams of milk are sometimes momentarily ejected by the contraction of the muscular tissue at the moment a nursing mother is ready to apply the child to the breast. Their size is small and their capacity not great in human beings. The squamous stratified epithelium descending to the ampulla, gives place to a single layer of columnar epithelial cells regularly and beautifully arranged upon a structureless basement membrane, the nuclei of the cells commonly alternating so that one is near the base, the next near the top of the cell. In the virginal breast or any other long inactive breast the ducts are empty and more or less collapsed. Descending but a short distance from the ampulla, the duct 
begins to give off branches of narrow diameter and varying length which pass to tiny lobules of glandular tissue packed in between converging ducts and dense bands of fascia. Further away the branches become more and more numerous until ramifying and dendritic ducts, some short, some long, some straight, some curved and some tortuous, end the series.

Each of the ductules terminates in a lobule that may in a general way be said to have an "alveolar" structure. By the use of this term we escape a dilemma caused by the fact that all of the lobules have not identical structure, but vary as shall hereafter be shown.

The alveoli are the expanded, flask-shaped terminations of the arborescent ductules, grouped together in somewhat compact aggregation.

The chief difference in the histology of the adult male and female breast is found in the absence in the former and presence in the latter of this alveolar structure. In boys at puberty it has already been shown that there is a brief period of disturbance, following which developmental changes in the breast cease. The male breast, if examined at or subsequent to this time, is found to show no other glandular structure than a series of good-sized ducts with few branchings, widely separated from one another in the matricial fascia and terminating in irregular extremities without cæcal expansion.

The female breast presents much the same appearance until the advent of puberty causes the ducts to grow and branch as has been described until a great collection of minute tubules-each with a cæcal, bulbous end-is formed. The finest of these tubules constitute the alveolar structure of the virginal breast.

The columnar epithelium lining the larger ducts gradually becomes less columnar and more cuboidal as the ducts are descended, until when the terminations are reached it is distinctly cuboidal. The terminations are commonly more or less bulbous at the extremities, and the cells are crowded so that many of them appear to be entirely filled with cells and devoid of any lumen. It is not improbable that some of them being unusually active during the period of adolescent activity, progress somewhat further toward secretory perfection, for it is not uncommon to find many or even all of the alveoli in lobules of virginal breasts possessed of a lumen. The farther the point of observation is removed from the bulbous terminal expansion, the more likely the ductule is to be lumenated. When an open alveolus is carefully examined in transverse section, it is found that there is a single layer of cuboidal epithelium, beneath which there is another layer of cells, commonly spoken of as the "basket cells."

These were looked upon by Benda, von Saar and Krompecher as unstriated muscle cells having a longitudinal direction, and thought to be the homologues of the unstriated muscle cells of the coil or sweat glands which serve as the prototype of the lobe of the mammary gland. Many histologists adhere to this view of the "basket cells," though others regard them as cells of the connective tissue. In the virginal and inactive states neither of these cells possesses much cytoplasm.

The Intra-lobular or Peri-ductal Tissue.-Each duct is surrounded by a very narrow zone of connective tissue of loose cellular character, the intra-lobular stroma of connective tissue, or "peri-ductal tissue." As the ducts are descended, the peri-ductal tissue increases. In the lobules it shows to best advantage, the collection of ductules being both individually and collectively surrounded by it, so that a more or less rounded bodythe lobule-is formed. The peri-ductal tissue is fibro-elastic, loose, rich in cells and bloodvessels, never contains any fat cells, and serves as a support for the parenchyma, the capillary blood-vessels and the lymphatics. Its loose, soft and elastic character, also 
affords an opportunity for the glandular tissue to increase. The peri-ductal tissue contains fibers of collagen, fibroglia and elastica, the elastic fibers running longitudinally for the most part. It stains metachromatically and contains a varying number of tibroblasts, lymphocytes and plasma cells.

The disposition, size and number of lobules differ greatly in different breasts and seem to bear no relation to their size or external appearance. Many large breasts are composed largely of adipose and fibrillar tissue with little of the parenchyma, as the lobular mammary structure is called. Other breasts of a very similar appearance contain great numbers of large lobules. Some of the lobules occur high up among the ducts; the great mass of them occupy the corpus mammæ or general substance of the breast; many spread out beyond the visible confines of the base of the breast as an irregular fringe: Sometimes an occasional duct grows much longer than its fellows so that an outlying lobule may be actually apart from the breast proper. It is toward the axilla that the lobular extensions and aberrant lobules are apt to extend the greatest distance, and it is doubtless on this account that the axillary diameter of most breasts is greatest. In this direction they extend under the edge of the pectoralis major muscle, and constitute what has been called by Spence the "tail" of the mamma.

The matrix or stroma of the breast is that part of its substance which holds the parenchyma or glandular tissue together. It consists of fascia or dense areolar tissue connecting the superficial and deep fasciæ and contains varying proportions of adipose tissue. It is of importance, and in estimating its variations in health and disease, care should be taken in removing the fragment of breast tissue for microscopic study, to determine in what degree it is representative of the whole, so that no erroneous deductions as to excess are made. There is reason to believe that great differences in the density, elasticity and adiposity of this tissue obtain among normal breasts.

The virginal breast cannot be regarded as quiescent. At each catamenial period it is the probable recipient of some hormone or internal secretion by which it is influenced. In most cases the influence is so mild as to pass unnoticed, in other cases tenseness, tenderness, and an increase in the activity of the glands of Montgomery are observed. In rare cases milk is secreted in each monthly period.

Gravidity acts as an extraordinary stimulus to the breast, and conception is followed by such rapid changes as to make the breasts among the first organs to be examined when its occurrence is suspected.

It is improbable that any observer has been afforded an opportunity to determine the quantity of parenchyma in the virginal breast and subsequently to determine the quantity in the same breast during pregnancy, in order to demonstrate that the popular view of increase of the parenchyma is correct. It would be a rare opportunity indeed. But anyone accustomed to examine inactive breasts and lactating breasts, will find it difficult to convince himself that considerable increase has not taken place. It is not certain, though by no means impossible, that new lobules can be formed, but it is certain that in each already existing lobule further growth takes place in the form of many small pocket-like extensions from the tips and sides of the alveoli or ductules, thus originating the true glandular acini. By these means every lobule becomes increased to several times its virginal volume and this increase together with the possible formation of new lobules by extensions from the ducts, causes the breast to become tense and increased in size. During a large part of the period of gestation the glandular or parenchymatous tissue continues to develop, while the adipose tissue, pressed upon, slowly disappears by atrophy until the entire mamma is sometimes composed of the glandular 
tissue. The varying ability of women to provide enough milk to nourish their children may depend primarily upon the original quantity of lobular parenchymatous tissue in the breast, secondarily upon the ability of new lobular tissue to form in the breast, and lastly upon the adequacy of the stimulation to secretion which comes later.

As the result of these proliferative changes, the active breast of pregnancy and the still more active breast of lactation, present quite different gross and microscopic appearance from the virginal breast. To be certain of the import of the early changes, however, one should know something of the normal condition of the breasts of the particular case. In general it may be said that with the beginning of pregnancy there is a considerable enlargement of the mammæ which stand out more prominently from the chest, and later because of their increased weight begin to sink more and more. The superficial veins which are scarcely seen beneath the skin of the inactive breast now increase in size and become distinctly visible. The areola widens and its pigment increases, sometimes to a surprising extent-becoming a source of embarrassing disfigurement in some cases. The skin of the areola is also apt to have a slightly greasy quality, and the enlarged glands of Montgomery which appeared as tiny eminences in

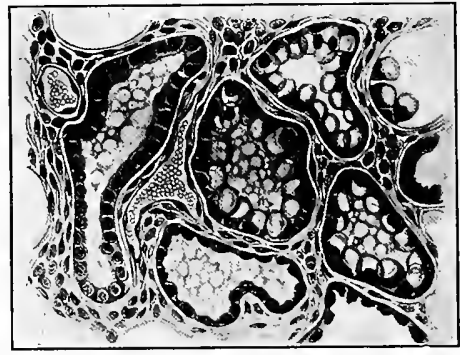

FIG. 8.-Microscopic drawing of mammary tissue during milk secretion. (Bumm.) the virginal breast, may stand out as large as $\mathrm{BB}$ shot. The nipples vary, but in general they appear more prominent than normal.

Upon microscopic examination it is found that the adipose tissue has largely disappeared, and that the lobules -are numerous, large and transformed in appearance through the development of distinct acini of true secreting type. The acini are more or less widely dilated, as are also the ductules, and are filled with a slightly albuminous fluid containing few or many cells crowded with small and large globules of fat. The acini are lined by a single layer of epithelial cells, whose cytoplasm greatly exceeds in volume that of the cells of the inactive breast. They contain a single nucleus-sometimes two. In the actively developing tissue occasional mitotic figures can be found. Beneath the cells the membrana propria can with difficulty be made out and many histologists assert that it disappears.

Considerable difference obtains between the appearances presented by different lobules. Some are scarcely changed from the inactive state, others are actually producing milk. It is very probable that in this microscopic appearance we find one of the sources of variation in the volume of the milk secretion. If the stimulus to secretory activity experienced by the breast is not uniformly distributed among its lobules, some remain inactive and less secretion will result than in uniform stimulation.

Physiology.-The exact mode of secretion is differently interpreted by different authors. The contents of the acini and ducts described above as consisting of clear fluid with a few fatty granules and cells filled with large and small fatty granules is not true milk. It can be expressed from the nipple in small amounts, by manipulation, and presents a thin, watery appearance, the microscope showing the same morphological composition as the contents of the acini and ducts. It is known as colostrum. 
Actual secretion of milk does not begin until two or three days after parturition, when some sudden stimulation upon the perfected glandular structure causes a copious formation of fluid rich in proteins, sugars and fats. The sources of the proteins and sugars cannot be determined by morphological studies but the origin of the fat component may readily be observed in appropriate material. All observers agree that the fat appears in molecular form in the central half of the secretory cells from which it enters the fluid in the lumen. More or less controversy still surrounds the question of the effect of the fat production upon the cells. According to the older writers, the formation of the fat was at the expense of the cell, the inner half of the cytoplasm of which was destroyed and shed at the time the fatty molecules were liberated, to be renewed by subsequent growth from the undisturbed remainder. Some cells were supposed to be entirely destroyed in the process, but to be replaced by mitosis and multiplication of the remaining cells. Later writers reject the idea of partial or total cell destruction, and believe that the molecular fat collected in the cells is liberated without destruction of the cytoplasm. This latter view is more in accord with secretory activities as seen in other glands.

To account for the development of the mammary glands and the activities that take place at birth, puberty, pregnancy and lactation, and the final changes yet to be described as coinciding with the climacteric, is a difficult matter for the physiologist. Many factors must be considered, the most important of which are without doubt hormones or internal secretions. Whether some one internal secretion regulates all of the activities of the glands or not, is, at present, problematical. The conditions are so complex that we are prone to believe that many different internal secretions engage in the process either directly or indirectly.

Thus, for example, after the period of infantile activity is passed, we find a few cases (see Infantile Hypertrophy) in which the breast proceeds to enlarge as though to prepare for immediate functional activity, and in two or three years has attained its full size and development, though the subject of the development is but a little girl in most respects. In these cases, and sometimes independently of antecedent growth of the kind described, the gland is stimulated to functionate at a very early age. Such was the case in the little girl reported by Chaussier (Murat et Patissier, article "Mamelle" in the Dictionaire des Sciences Médicale, Paris, XXX, 386) who being placed in charge of an infant and becoming wearied of its cries, applied it to her breast to hush it. The local and emotional stimuli quickly aroused the gland to activity and milk appeared in the enlarged gland increasing daily as the demands upon it increased. Several such cases occur in the literature.

Taking children of more advanced years, apparently normal and approaching the period of adolescence, we find that sometimes the mammæ do not develop as they should in girls, but maintain the infantile type. This condition usually occurs in association with defective development of the reproductive organs, and immediately suggests a sympathetic correlation between the reproductive and mammary organs, and tends to refer the development of the mammæ to substances-internal secretions-originating in the reproductive organs. This is supported by the fact that when the glands develop precociously in little girls, there is antecedent or accompanying development and activity of the sexual organs.

Experimental evidence also favors this view, for when the ovaries are removed before puberty sexual development does not occur and the mammæ fail to develop. In cretinism with infantilism there may be neither development of the reproductive 
organs nor of the mammæ, so that the failure of mammary development may be indirect and referred to the failure of the ovarian development, which in turn may be referred to failure of the thyroid secretion. In Fröhlich's syndrome known as "dystrophia adiposogenitalis" with the conditions to which Lorain gave the term "obese sexual infantilism" there is failure of genital development together with failure of mammary development, referable less to the thyroid than to the pituitary gland. Here we seem to have a still more round-about disturbance, in which the failure of the pituitary secretion is followed by the failure of the thyroid secretion, which then leads to sexual imperfection and finally to failure of the mammary development.

In a few women mammary activities coincide with the periods of menstruation and vary from a slight swelling and tenderness to actual and considerable lactation at each period. In these cases it seems as though the disturbance which takes place at the period of menstruation is in some way the source of the mammary activity. . This is not the result of menstruation, in all probability, but of ovulation, for Bouin and Ancel (Compt. rendu de la Société de Biologie de Paris, I9o8, et seq.) have shown that the ovarian corpus luteum is the source of a hormone that activates the mammæ whether gestation occurs or not. In I9I2 the same investigators found that the myometrial gland, a structure found in the uterine wall of the pregnant rabbit, between the stroma and the muscular fibers of the uterus, produces a hormone that further develops the activity of the mammary glands.

Hammond and Marshall (Proc. Royal Society of London, I9I4, LXXXVII, B. 422) have shown that mammary hypertrophy can take place in animals from which the uterus was removed in immaturity, thus proving that it is not the uterus but the ovaries that initiate the changes. The result of ovulation is the formation of the corpus luteum, and as ovulation and the formation of corpora begin at puberty, when the mammary glands undergo rapid development; as the periods of menstruation usually pretty well coincide with the periods of ovulation at which time some women manifest activities of the mammary glands; as the corpus luteum of pregnancy outweighs all others in magnitude and importance and the mammary glands reach their maximum of growth and activity during the presence of corpus luteum of pregnancy, and finally, since retrogressive changes in the mammary glands take place when ovulation and the formation of corpora lutea cease, either because of operative removal of the ovaries, destructive disease of the ovaries or because of the occurrence of the menopause, it seems as though the belief in a correlation obtaining between the corpora lutea of the ovaries and the activities in the mammary glands is justified.

If additional but less certain evidence be desired it may be pointed out that in pseudocyesis or false pregnancy associated with pelvic disease of varied character, and in disease of the ovaries of various forms, all of which may be associated with ovarian disturbances in which the corpora lutea may be concerned, the mammæ may become active to the point of lactation.

But it is quite clear that other factors than the corpora lutea must beconcerned, for in a few women otherwise apparently normal the breasts develop but slightly, and in others though developed to all appearances they never become capable of lactation; in some little girls the breasts develop prior to the time that ovulation can be supposed to have begun; in boys without ovaries and without corpora lutea, the glands-one or both-may begin at puberty to take on a development like that normal to the female, and there are numerous cases in the literature not only of men with breasts of the size and development of those of women, but of men that have lactated to the extent of nourishing chil- 
dren at their breasts. Such cases must naturally be accounted for upon other hypotheses than those given, and it is somewhat puzzling to note that inhibition of the sexual development of men, such as is seen in pseudohermaphroditism depending upon hypospadias and hypoplasia, is attended by a marked increase in the mammary development, so that the examination of the mammary regions and glands affords no clue to sex where the external genitalia are so defective as to cause confusion.

In castrati or boys castrated for the preservation of the soprano voice, the mammary glands appear larger than normal after puberty, but do not assume the feminine type. The enlargement is probably fatty, but there seem to be no studies by which the exact state of these glands can be known.

In pseudocyesis or false or imaginary pregnancy in women past the climacteric, and occasionally in elderly women, the breasts appear enlarged and full like those of pregnant women. It was the opinion of S. Weir Mitchell that the condition of the breast in these cases was the result of the psychic condition, as it usually quickly subsided to normality when the patient was convinced of the error of her supposition of pregnancy. It would seem equally possible that activities in the breasts, ephemeral in nature, but arising in consequence of abnormal stimuli, such as have been discussed with reference to the internal secretions, might explain the belief on the part of the woman that she was pregnant and also account for the condition of the breasts.

Hammond and Marshall have also studied the question with particular regard to pseudo-pregnancy resulting from sterile connection of doe rabbits with vasectomized buck rabbits. They found that the development of the corpus luteum of pregnancy (corpus luteum verum) or of pseudo-pregnancy (corpus luteum spuriosum) in the doerabbit is functionally correlated with the hypertrophy of the mammary glands as has been shown by Ancel and Bouin and others. In the pseudo-pregnant rabbits the hypertrophy is followed on about the nineteenth day by a definite secretion of milk, the quantity of which may be temporarily increased by an injection of pituitary extract, just as in normal lactation. It was also noticed by the observers mentioned that the development of the corpus luteum of pseudo-pregnancy is correlated with uterine hypertrophy and hyperemia, followed by the extravasation of blood. These uterine changes are clearly comparable with those that occur in true pregnancy. About the nineteenth day after the sterile connection the mammary hypertrophy retrogresses and all these changes take place without any demonstrable hypertrophy or activity in the myometrial gland. Hammond and Marshall record the case of a cat that failed to become pregnant after connection, yet began to secrete milk four weeks after the last copulation and continued to do so for two weeks. Hill and O'Donoghue record the case of a marsupial cat (Dasyurus viverrinus) that was seen to clean out its pouch for the reception of expected young, although it was not pregnant. One of Hammond's and Marshall's rabbits, 28 days after a sterile coitus plucked fur from its breast and made a nest as if preparing for parturition, while at the same time milk could be expressed from its mammæ.

The experimental data regarding the enlargement of the mammary gland and the stimulation of its activities contain several matters of considerable though puzzling intercst. In I906 Lane-Claypon and Starling (Proceedings Royal Society, I 906, LXXVII, 505) showed that an extract made of the pulverized dried fotuses of a rabbit, when injeeted beneath the skin of a virgin rabbit caused the mammary glands to develop and secrete milk. Their experiments were repeated and confirmed in 1908 by Foá who used bovine fotal extracts on animals of different species. This would indicate that the fotus 
developing in the uterus of the mother probably adds something to the sum total of factors that influence the mammary gland, and which when present in great quantity is capable of doing it alone. But that other factors are concerned is shown by the work of von Basch in $\mathrm{rgr}$, who found that a similar lactatory hormone existed in placental extract and proved that its administration to other animals as well as its action upon transplanted portions of mammary gland was unquestionable.

Ott and Scott (Proceedings of the Society for Experimental Biology and Medicine, I9I0, p. 49) have found that "infundibulin," an extract made of the infundibulum and posterior lobe of the pituitary body is a powerful galactogogue, and that its injection beneath the skin of a milch goat shortly provoked a great acceleration of the milk secretion.

That the nervous system has some influence upon the growth and secretory activity of the mammary gland can hardly be doubted. The literature affords curious examples of this. Murat et Patissier (article "Mamelle" in the Dictionaire des Sciences Médicale, Paris, XXX, p. 387) record the case of a woman 68 years old, who offered her breast to an infant whose mother had recently died, and soon had sufficient secretion of milk to support the child; Dargan (Charleston Medical Journal and Review, I874) tells of a woman 60 years of age who offered her breast, in play, to an infant, and was surprised after three weeks of this amusement to find that she began to secrete milk in excess of its young mother; a similar result in the person of an old woman of 70 occurred in the experience of Montauban (Murat et Patissier (loc. cit.) and another in a woman 65 was observed by Montègre (Murat et Patissier, loc. cit.). Similar results have even occurred in men; Sir John Franklin in his "Voyages to the Polar Sea" tells of an old Chippewa Indian, who on losing his wife in childbirth, put the infant to his own breast, earnestly praying that he might be able to nourish it, and eventually produced enough milk to do so. Humboldt (in his "Reise in die Aequinoctialgegend des neuen Continents, II, 40) relates the story of a South American peasant 32 years old, who losing his wife immediately after confinement sustained the child with his own milk. The emotional stimulation may be quite apart from any local mechanical stimulation; thus Mitchell (Brit. Med. Journal, r 884, I, p. 493) relates how a highly emotional man was so disturbed by his wife's sufferings in childbirth that he fell ill, experienced fulness and pain in the breasts, and began to secrete milk. Other cases are on record and might be cited. In all these cases the emotional disturbance, the sympathetic nervous system probably stimulates the flow of internal secretions by which the mammary gland is influenced. That it is the sympathetic system alone that is concerned is shown by the experiment of Goltz (Pfluger's Archiv, IX) who found that division of the spinal cord at the altitude of the second lumbar vertebra did not inhibit lactation in a parturient bitch, and that the nervous connections themselves have nothing to do with it is shown by the experiment of Ribbert who transplanted a rabbit's mammary gland to its ear, thus cutting off all nervous connections, and observed that when the rabbit subsequently became pregnant, the transplanted gland, like the others, enlarged and secreted milk.

So it becomes evident that the physiological activities of the mammary gland are by no means simple and the mechanism by which it is controlled complicated.

This inability to understand and correlate the essential factors engaged in lactation make it correspondingly difficult to account for, or to know what to do for cases in which the physiological activities become morbid. Thus, in the condition known as agalactia, the breasts may appear normal, or may even grow to monstrous size during 
pregnancy, yet when the time of lactation arrives, no milk appears. Such cases have been reported by Busch (Neue Zeitschrift für Geburtshülfe, V, 27 r), by O'Flynn (Dublin Medical Press, XII, 302), in the latter's experience the agalactia ran through two generations of the family, although the women had normal appearing breasts, by Harlan (Medico-Chirurgical Review, July, I839) who observed a woman who bore I3 children, yet never had a drop of milk in either of her breasts, and by Puech ("Les Mamelles et leurs Anomalies," Paris, I876, p. 28) who observed a young woman with perfect appearing breasts, twice pregnant, yet continually without a drop of lacteal secretion. Is this to be referred to ana tomical conditions in the gland itself or to lack of the necessary internal secretions? In lieu of what has been said about the physiology of lactation one might be inclined to attribute it to the latter. To do so, however, leads us into further mystification, for what are we then to do with the four sisters about whom Young has written (Trans. Edinburgh Obstetrical Society, 1875, iii, I22), each of whom had a family, one eight, one six, and two four children, yet not one of whom ever found any milk in the left breast. He says that the left breast was "to all appearances perfectly normal and healthy," yet never secreted any milk. How is such unilateral agalactia to be accounted for by the theory of internal secretion? The matter seems to become more and more involved, the further it is pursued. Moreover, the growth of the gland during pregnancy depends upon some stimulus apart from that that subsequently calls the grown gland into action, for in the chapter upon the Acquired Anomalies of the Mammary Gland, in considering the subject of "Hypertrophy," it will be found that the gland frequently grows to a monstrous size during pregnancy yet fails to secrete a drop of milk when the proper time arrives.

Equally interesting is the reverse condition in which the gland becomes excessively active, and an abnormal flow of milk ensues. This is known as galactorrhoa, and ranges from a slight excess of milk to quantities that are almost beyond belief.

The most extreme case that has come under our observation of the literature, is believed by the reporter to be the most extreme case on record. It was a young woman in Japan, from whom Remy (Medical Times and Gazette, I883, ii, $58 \mathrm{I}$ ) says $\mathrm{I} 2 \frac{1}{2} 2$ pints of milk were taken from the breasts each day.

Presumably the condition that leads to galactorrhœa is the reverse of that leading to agalactia, but we do not know, and are as ill informed about the one as about the other.

\section{INVOLUTION}

In cases of abortion, miscarriage, parturition without subsequent lactation, and in all cases in which the period of lactation comes normally to a close, a new series of changes in the mammary glands presents itself in the form of "involution." To somewhat similar changes occurring independently of lactation in virginal breasts, or long after lactation, or in the aged, such terms as "presenile involution," "senile involution" and "abnormal involution" have been applied.

In its ordinary meaning, involution signifies the return of the gland from the size and complexity attending its anticipated or perfected function, to its original smaller and simpler structure. It is easy to conjecture, and probably not without much truth, that these changes take place in an order that is the reverse of that by which they made their appearance. Such is indeed the accepted understanding of the case. The vascularity diminishes, the function of secretion ceases, the inactive cells shrink and their cytoplasm becomes less distinct; the acini flatten out and disappear; the glandular 
tissue of which the whole breast seemed full returns to a bulk contained in small scattered lobules; adipose tissue reappears as the glandular tissue disappears, and something approximating the original condition is regained.

It is never a perfect return to the original condition, however, for during the en. largement incidental to lactation the skin over the breast is stretched and the matricial fibrillar and elastic tissues are disturbed, so that with the exception of very young individuals with tissues rich in elastica, or in already large breasts in which the lactation hypertrophy has caused more internal changes than external enlargement, or in breasts in which the function of lactation failed, the involuted mamma, as contrasted with the virginal mamma, is loose, more or less flabby, pendulous, and marked by minute striæ on the skin. Repeated evolution and involution usually lead to an intensification of these conditions, until the breasts sink to a low level, flatten out and present a withered appearance. Considerable fatty deposits in the mammæ may prevent the flattening and withering, but are apt to increase the sinking by adding to the weight.

The process of involution may progress to such an extreme degree as to cause the breasts to become quite small, though their virginal size was large. Indeed in a few cases the breasts almost disappear. Variot (Jour. de méd. et chir. prat., Paris, r9I3, LXXXIV, 97) has reported such a case. During lactation the breasts were large and well formed but subsequently they underwent such extreme involution that the chest was flat, and it was only by palpation that the mammary tissue, flat and the diameter of a five-franc piece, could be recognized. When the patient had another child, however, they enlarged again to the full size, and gave an abundance of milk. The chief factor in the diminution in these cases is probably the failure of the usual fatty deposits between the lobes and lobules of the mammary tissue.

The involutional process is not infrequently complicated by retention of the products of secretion. It is not known how long milk may remain in the breast after lactation, in the sense of active secretion, has come to an end, but it probably varies greatly in different individuals. In some it quickly disappears by absorption; in other cases it remains for a long time. Engström (Ann. de Gynécologie, 1 889, XXXI, 284) has observed five cases in which milk was still present a number of years after the last accouchement. Such retained milk undergoes stow inspissation, and the ducts become filled with a residuum that is partly fatty partly protein in composition. Its presence is the exciting cause of an infiltration of mononuclear cells-lymphocytes and plasma cellsand occasional small giant cells into the peri-ductal tissues. These cells are no doubt engaged in the general scavenging or cleansing process, and must not be mistaken for inflammatory exudates or signs of infection. The presence of such milk residua and the associated cellular collections should be kept in mind, as part of the normal conditions incidental to involution, when the so-called "abnormal involution" is under consideration.

When a breast, the seat of post-lactation involution, is examined microscopically, a very varied picture is presented, by no means all parts of it appearing the same. Thus, all of the lobules of mammary tissue may not have engaged in the function of lactation, as has already been pointed out, so that it is not unusual to find occasional areas of tissue presenting a virginal appearance. Some of the ducts are empty and collapsed; in others a certain amount of secretion may have been retained in the form of creamy inspissation or transformed to a translucent amorphus substance in which are many cells whose partial degeneration makes their exact histogenesis difficult or impossible to determine. In some lobules the appearance of mammary hypertrophy may be retained; in others 
the acini have disappeared, but the peri-ductal tissue contains abundant lymphocytes and perhaps some foreign-body giant cells. In other lobules there are no lymphocytes, the acini have disappeared, but the alveoli appear unequal in size, some more or less confluent or coalescent, and the epithelial cells crowded. In still other lobules the process of involution appears to have advanced to an extreme degree and some of the alveoli are atrophic.

A vertical section through the entire breast and nipple shows more diffuse fatty deposits than are found in the virginal breast.

The precise order and duration of the involutional changes following lactation, and their completeness or incompleteness in the various details, appear not to have been determined. It is certain that they may extend over months or even years, when not interrupted by recurrence of lactation hypertrophy incidental to the recurrence of pregnancy.

Senile Involution of the Breast.- With the advent of the menopause come the final changes to which the mammary gland is subject, and which may be described as senile involution. Presumably they are to be referred to loss of the internal secretion or other factors by which the growth of the mamma was primarily due and its functional potentiality maintained. That these factors are not suddenly and regularly dispensed with is shown by the peculiar behavior of the glands at and for some time subsequent to the menopause. Thus, they may enlarge slightly, for a time, are not rarely the seat of fugitive pains of varying character, and an examination of the gland may show swelling, sometimes general, sometimes limited to one quadrant, associated with tenderness that sooner or later disappears. In the rare cases of pseudocyesis, to which attention has already been called, both glands have been known to enlarge so uniformly as to lead the patient to believe herself pregnant, though they later regained their normal size and involution progressed.

In general, senile involution is characterized by progressive atrophy and disappearance of the alveolar structure of the parenchyma, progressive destruction of the lobular tissue, increase in the density of the fibrillar tissue, and by a deposit of adipose tissue throughout the breast. In naturally fat glands the changes may go on without detection; in breasts with very little fat, there is a slight increase in density. In both, the breasts may feel corded.

The microscopic appearances vary according to the past quiescence or activities of the mammary tissue. In the breasts of virgins, and those of women who have born no children for years before the occurrence of the menopause, the changes are comparatively simple. In breasts that have lactated but a short time before, they may be complicated by the presence of incomplete post-lactation involution. In all cases in which mammary tissue is to be examined for morbid processes, the investigator should be informed concerning past and recent activities of the breast, lest he confuse incomplete normal involution with the so-called "abnormal involution."

The changes that characterize senile involution are not difficult to recognize. In some, many, or all of the lobules of the parenchyma, alveoli can be seen whose smaller size and disappearing cells indicate that they are the seat of progressive atrophy. In lobules in which the atrophy has progressed to a marked degree, the intra-lobular connective tissue no longer shows a clear separation from the surrounding inter-lobular stroma or matrix, but more and more blends with it. When the disappearance of the alveoli is complete, the lobules may actually cease to exist because the peri-ductal tissue has so thoroughly blended with the inter-lobular stroma, or may appear as partly differ- 
entiated fibrous nodes in a slightly different matricial tissue. Vestiges of alveoli are sometimes to be found in such fibrillar nodes, appearing as epithelial-lined tubules devoid of a basement membrane and so deformed as not to be easily classed either as alveoli or ducts.

Prior to the alveolar atrophy the peri-ductal tissue sometimes shows increase in quantity and density; neighboring alveoli may be drawn upon and caused to coalesce. Approximated and closely related alveoli dilate and coalesce to form minute cavities with incomplete partitions, then small epithelial-lined cavities with wrinkled or puckered walls, and finally minute cysts that occur singly or in groups, at first surrounded by peri-ductal tissue, but sometimes in the undifferentiated stroma of the breast. The atrophy is progressive. In virgins and women who have never born children it seems to begin before the menopause; in women who have had children, usually not until the menopause. How long it continues, how regularly it advances, and to what final stage it eventually reaches, appear not to have been definitely followed. It is not improbable that it advances slowly throughout the entire remainder of the subject's life. Careful study of many breasts, shows of involution what it shows of evolution, viz., that it is apt to be unequal in distribution. Some lobules appear quite normal; some show atrophy of some alveoli while others are unchanged; some show coalescence of alveoli and minute cysts; some have almost disappeared through loss of the epithelium and the loss of differentiation between the intra-lobular connective tissue. All of these changes commonly coexist in the same breast. It is commonly stated that there is a marked decrease in the intra-lobular connective tissue, but this may be relative rather than absolute. With the loss of the lobular structure and the transformation of the intra-lobular into interlobular tissue the density and apparent fibrosity may be readily accounted for. The inter-lobular tissue shows none of the cellular activities commonly present in cases of hyperplasia.

That senile involution ever leads to the complete extinction of the mammary tissue is extremely doubtful, for complete extinction of the gland never occurs in men in whom atrophic changes begin shortly after puberty. Some of the changes of involution and senile involution bear no inconsiderable resemblance to what is seen in incomplete evolution. It is not impossible that some of the areas that appear to the observer to be in process of disappearance are in reality areas that have never perfectly developed.

The most complete microscopic studies of the mammary gland, with reference to its various quiescent and active states, and with particular reference to the age and condition of the patient, seem to have been made by Berka ("Die Brustdrüse verschiedene Altersstufen und während der Schwangerschaft." Frankfurter Zeitschrift für Pathologie, r 9 I I, VIII, 203.)

He found "Involution to be characterized hy the stagnation of secretion, dilatation of the terminal vesicles, apparent increase of connective tissue between the acini, and diminution in the size of the lohules, by which the connective-tissue septx are made more evident. At the same time the number of cells in the connective tissue increases, though not to the same degree as at the beginning of pregnancy. Finally, the lobules disappear altogether or only remnants of them remain in the form of groups of terminal vesicles (acini)-incomplete involution. The cellular infiltration may persist after the disappearance of the lobules. The newly formed connective tissue that takes the place of the lobules commonly contains numerous new elastic tissue fibers.

"In the quiescent breasts of women who have borne children some time before, but are now inactive, one finds an appearance that may perfectly correspond with that seen in nulliparous women, but there may also be found evidences of incomplete involution, indicative of gravidity activities of the past. Such are more frequent in older patients who have been pregnant many times.

"Senile breasts have the same general appearance as quiescent breasts, but all of the constituents 
become diminished according to the age of the individual. In the senile mamma, epithelial proliferations of the parenchyma, and degenerative changes in the stroma may also be found. Such form an immediate evidence of transformation from the physiological into the pathological state (chronic cystic mastitis; carcinoma).

"The proportion of elastic tissue in the breast increases in proportion to the age of the patient. It appears to depend only in part upon the alterations incidental to pregnancy, and makes its appearance, by preference, round about the milk ducts, round about the blood-vessels, and in the stroma. Only occasionally does it appear in the glandular lobules.

"The senile breast presents an appearance that corresponds with that of the quiescent breast. It is reduced in volume, and it contains a preponderance of connective tissue. The almost exclusive representation of the glandular parenchyma is the milk ducts. These occur in transverse and longitudinal section, in microscopic preparations, mostly in small groups. Many of them are cystically dilated; ail of them show double-layered epithelium. Acini (terminal vesicles) may be found in the senile breast, though they are not of regular occurrence. After lactation in middle life, when involution is complete, they disappear entirely; when involution is recent, or when it has been imperfect, group of acini may persist in the senile mamma. They are easy to recognize because of their single layer of epithelium, and vary in appearance from collapsed terminal vesicles with very little lumina, lined with cells rich in chromatin, to widely open acini with flattened cells with vesicular nuclei. The protoplasm of the cells, as well as the lumina of the vesicles, may contain fat. Glandular lobules of acinous appearance are not of frequent occurrence in the senile breast. In general the epithelium is scanty but sometimes, on the contrary, it is proliferated.

"The following evidences of proliferation may be found:

A. On the part of the milk ducts:

r. The epithelium lining the milk ducts may be in three or more layers, without disturbance of the lumina. This occurs when there is otherwise very little departure from the normal.

2. The lumina, originally simple, may be divided once, twice or several times, through multiplication of the cells. Simultaneous stratification of the epithelial cells may occasion the formation of considerable-sized epithelial islands, in whose neighborhood numerous rounded lumina may he found-appearances very common in so-called chronic cystic mastitis (Samelsobn). These form the starting points of the transformation of the normal into the pathological, just as all general involutional disturbances lead into the domain of the pathology of the breast.

3. The lumina of the milk ducts may be filled with cells, so as to form solid processes-pictures that are not unlike carcinoma, but separate themselves from it by not manifesting any further signs of malignant change.

"Tietze has described analogous changes. He examined seventeen normal breasts from persons over 40 years of age, and found that 25 per cent. of them showed changes like those described in paragraphs 2 and 3 , in the peripheral parts of the gland. He believes that they are indications of physiological epithelial production in the senile state [in which Berka agrees with him]. Tietze brings them into close etiological relationships with the occurrence of cancers in such breasts, because of the occurrence of similar changes in the parenchyma of mammary glands, in which there are cancers, apart from the actual tumors.

"But the epithelium of the alveoli may show appearances still more suggestive of pathological condition in the form of alveoli with dilated lumina lined with a single layer of epithelium, whose cells differ conspicuously from those of the mamma elsewhere. They are of cylindrical form, with pale cytoplasm, large nuclei and nucleoli, whose size is from two to four times that of the normal mammary epithelium, and remind one of the atypical elements of large-cell carcinoma, without any actual malignant change having taken place. Some think that these also represent a transformation of the cells leading to carcinoma, but they are not malignant through proliferation. von Saar looked upon them as homologues of the phylogenetic stage of sweat-gland differentiation in the mamma. [Krompecher (Verhandl. d. deutsch. path. Gesellschaft, Jena, I9r3, XVI, 365) gives the same explanation, and it is not improbable that they are the same structures discovered by Creighton ("Cancers and Other Tumors of the Breast; Researches Showing Their True Seat and Cause,' London, r902).]

"In the literature, these cells are commonly spoken of as 'blasse Zellen' (Borst, Thiele, v. Saar, Kurn) and have been described only in chronic cystic mastitis,' [but Berka has found them in senile mammary glands, and believes that they arise from the alveoli].

"Not one of these alterations of the epithelium constitutes a regular attribute of the senile breast. Ordinarily, only double-layered epithelium is found in milk ducts occurring isolated or in small groups. 
Acini in groups originate through imperfect involution of the breast after pregnancy. Senile pathological conditions in the acini in old age are only to be found in women that have borne children.

"The elastic tissue makes itself evident in the senile breast as contrasted with the breast of earlier age. It is found in greatest quantity in the circumference of the larger milk ducts, where it forms a thick fibrillar layer. When the epithelium has proliferated and stratified in such ducts, the surrounding tangle of elastic filaments may give the impression of being pressed together and injured by the compression. "The elastic fibers are also rich about the blood-vessels.

"The elastic filaments of the serile breast are mostly thick with stout ends, often forming a dense tangle with an appearance of degeneration. Fine flaments are few. The quantity of elastica differs in different cases; when the quantity is large, it always tends to degenerate, but in such cases the connective tissue and epithelium also degenerate.

"In such cases the connective tissue is structureless, stains very red by van Giesen's stain, and shows cracks and fissures like a dead mass. The two-layered epithelium becomes one-layered, flattened, or may disappear. In such cases, when the epithelium is gone, the lumina may close and nothing remain but a ring of elastica. Thus comes about the obliteration of the milk ducts in the senile breast-mastitis obliterans senescentium.

"Similar obliteration occurs in carcinoma, as has been shown by Langhans, where elastic rings filled with connective tissue are frequently found. In such cases there is no proliferation of the epithelium, but on the contrary a pressure atrophy caused hy the connective tissue. There is no sign of inflammation in either case; the changes are atrophic and degenerative."

In our own studies of the senile breast we have frequently observed disease of the blood-vessels - endarteritis-sometimes accompanied with extensive calcification, sometimes with sub-endothelial intimal proliferation, sometimes with thrombosis and thrombo-arteritis obliterans. Such changes can scarcely occur without inducing changes in the structural integrity of the tissues, both parenchymatous and interstitial, and it may be assumed that some of the retrogressive changes that have already been pointed out, as well as the frequent hyaline and calcareous changes of the inter-lobular tissue of the breast, may thus be explained.

A knowledge of the process of senile involution, the diversified appearances it assumes and the course it runs must be looked upon as of paramount importance to an intelligent investigation of the interesting process so commonly spoken of, at present, as "abnormal involution" (see "Cystic Disease of the Breast").

\section{Literature upon the Evolution of the Mammary Gland}

\section{Embryology :}

BowlBy, A.- "The Development of the Mammary Glands," British Medical Journal, I882, ii, I I43. BrouHA.- "Recherches sur les diverse phases du développement et de l'activité de la mammelon," Archiv. de biologie, Liège et Paris, I904-05, XXI, 459-603.

"Sur la hande et la crète mammaires et sur les pretendues évanches hyperthelies chez l'homme et le murin," Anat. Anz., Jena, I905, XXVII, 462.

"Sur la signification morphologiques de la mamelle," Anıt. Anzeiger, I905, XXVII, 3 I I. Brugnatelli, E.- "Cellule lipodifere e mastzellen nella mamella," Boll. d. Soc. med. chir. di Pavia, I9I 2, XXVI, 357 .

BURKHARD.- " 'Über embryonale Hypermastie und Hyperthelie," Anatomische Hefte, I 897.

Chirié, J. L.-_"La glande mammaire; les phases qu'elle présente au cours de son évolution et de leur determinisme d'après les recherches du Bouin et Ancel," Archiv mens. d'obstet. et de gynéc., Par., 1912, i, 184 .

Curtis, F.- “Le développement de la mamelle et du mamelon d'aprés les travaux les plus recents," Rev. hiol. du nord. de la France, Lille, 1888-89, i, 441.

Hirschland.- "Beiträge zur ersten Entwickelung der Mammaorgane beim Menschen," Anatomische Hefte, XI, $22 \mathrm{I}$.

KAllivs._-"Ein Fall von Milchleiste hei einem menschlichen Embryo," Anatomische Hefte, Bd. II, Heft i. 
Kólliker, TH.-“Beiträge zur Kenntniss der Brustdrüse, "Verhandl.d.med. Ges. zu Würzburg, N.F., XIV.

Letulle, M.--"Contribution à l'étude des malfaçons embryonnaires de la glande mammaire; dysembryoplasmones du sein," Bull. Acad. de méd. Paris, I9II, 3 s., LXV, 287.

ReIN, G.- "Zur Entwickelungsgeschichte der Milchdrüse," Archiv f. mikr. Anat., Bonn, I881-82, XX, 43 ; I $882, \mathrm{XXI}, 678$.

Schultze, O.--"Beiträge zur Entwickelungsgeschichte der Milchdrüsen," Verhandl. d. phys.-med. Gesellschaft zu Würzburg, I $89 I-92,2$ n. F., XXVI, I7I.

"Über die erste Anlage des Milchdrüsenapparats," Anatomischer Anzeiger, I 892.

STRAHL. - "Die erste Entwickelung der Mammaorgane beim Menschen," Anatomischer Anzeiger, XIV, Ergänzungsheft, 1898,236 .

Histology :

BenEKE, R.- "Zur Histologie der fötaler Mamma und der gutartigen Mammatumoren," PathologischeAnatomische Arbeiten *** Johannes Orth. Prof. Jubil., Berlin, 1903, 570 .

BERKA.- "Die Brustdrüse verschiedener Altersstufen und während der Schwangerschaft," Frankf. Zeitschrift für Pathologie, Wiesbaden, igıI, VIII, 203.

Bizzozero und Ottolenghi.- "Histologie der Milchdrüse," Ergebnisse der Anat. u. Entwickelungsgeschichte, I899, LX, 253.

Bonner.- "Die Mammaorgane im Lichte der Ontogenese und Phylogenese," Ergebnisse d. Anat. u. Entwickelungsgeschichte, Bd. ii and Bd. vii.

COEN, E.- "Beiträge zur normalen und pathologischen Histologie der Milchdrüse," Beiträge zur path. Anat. u. Physiol., Jena, $188_{7}$, ii, 83 .

LANGer.- "Über den Bau und die Entwickelung der Milchdrüsen bei beiden Geschlechten," Denkschrift der kaiserl. Akad. der Wissenschaft, Mathemat.-Naturwissenschaft Klasse, Wien, $185^{2}$.

Moullix, C. W. M.- "The Membrana Propria of the Mammary Glands," Jour. Anat. and Phys., Lond., $1880-8 \mathrm{r}, \mathrm{XV}, 346$.

Natanson und Goldschmidt.- "Ü̈ber das morphologische Verhalten der montgomeryschen Drüsen," Monatsschrift für Geburtshülfe und Gynäk., Berlin, I909, XXX, 34 .

Profé, O.- "Beiträge zur Ontogenese und Phylogenese der Mammaorgane," Anatomische Hefte, XI, 247 .

RAUber.- “Bemerkungen über den feineren Bau der Milchdrïse," Schmidt's Jahrbücher, i879, CLXXXII, No. I, p. 7 .

RetTeRer et LeLiÈ'Re. - "De la membrane ou paroi propre des tubuli de la glande mammaire," Compte rendu de la Soc. de Biol. de Paris, I910, LXIX, 559.

SAEFfTigen, A.- "Zur feineren Anatomie der Milchdriise während der Laktationsperiode," Melanges. biol. Acad. imp. d. sc. de St. Petersburg, I88 I, XI, I3.

Schickele, G.- "Die Bedeutung der Keimdrüsen für das Auftreten der Brustveränderungen," Zeitschrift für d. ges. exp. Med., Berlin, igr 3, i, 539 .

SchIL, L. - "Recherches sur la glande mammaire; sur les phases qu'elle présente au cours de son évolution et leur determinisme," Nancy, I912, 263.

Schmid, - H.- "Morphologische Arbeiten über die normale Hyperthelie menschlicher Embryonen und über die ersten Anlagen der menschlichen Milchdrüsen," Morphologische Arbeiten, Jena, 1897, VII, 157; Anatomischer Anzeiger, 1896, XI, 23.

\section{Morphology :}

Bloch, A.- "Présentation de portraits de jeunes négresses pour faire voir la forme particulière de l'auréole de la mamelle," Bull. et mém. de Ia Soc. d'Anthropologie de Paris, r 9o9, vi, I 4 I.

CorSey, F.— "Conformation curieuse des seins," Marseilles méd., igi r, XLVIII, 7 Ig.

Hoerschelirann, E.- "Üher die Form der Mamma bei der Estin, etc.," Zeitschr. f. Morph. u. Anthropol., 1904, VII, 22.

Hutchinson, J.- "Pendulous Mammæ in Young Women," Archives of Surgery, Lond., I 896 , vii, 38 ○

LuschкA.- "Die Anatomie der männlichen Brustdruse," Archiv f. Anatomie, i 852.

RaubitscheK.- " "Über die Brustdrüsen menschlicher Neugeborenen," Zeitschrift für Heilkunde, XXT. Ploss.- "Das Weib in der Natur und Völkerkunde," Leipzig, I904-05.

Stewart, J. C.--"The Mammary Gland-A Study in Evolution," Univ. Durham Coll. Med. Gaz., Newcastle, 1907-08, viii, 107.

Stratz.- "Der Körper des Kindes," Stuttgart, I903.

“Die Schönheit des weiblichen Körpers," Stuttgart, I9ro. 
VARIOT ET LASSABLiÈRE.-- "Sur. l'inegalité de volume des glandes mammaires chez la femme. Conséquences physiologiques," Compt. rendu de l'Acad. dęs Sciences, Paris, I908, CXLVII, 270.

von Mikiucho-Maclay.- "Mammae mit eingeschnürten areolaren Theil," Verhandl. d. Berliner Gesellschaft f. Anthropologie, Berlin, 1878, 104.

Williams, W. R.- "The Ontogeny and Philogeny of the Breast," Lancet, London, r892, ii, 304.

Physiology:

MEYNIER, E.- "Influenza dell'inanizione sulla struttura delle ghiandola mammaria funzionante," Rev. di clin. pediat., Firenza, Igo6, iv, 881.

Michaelis.- "Beiträge zur Kenntniss der Milchsekretion," Archiv f. mikr. Anatomie, li, 7 Ir.

Prü̈GER, H.- “Zur Morphologie der Brustdrüse, etc.," Inaug. Diss., München, Regenshurg, r886.

SchiffManN, J. UND Vystavel.- "Versuche zur Frage einer inneren Sekretion der Mamma," Wiener klin. Wochenschrift, I913, XXVI, 26r.

Tremensvary, R.- "The Connection between the Female Breast and Genitals," Jour. Obstet. and Gynecology of the British Empire, London, I 903, iii, 513.

Boutn ET ANCEL.- "Le développement de la glande mammaire pendent la gestation est déterminé par le corps jaune," Compte rendu de la Soc. de Biol., rgog, LXVII, 466.

FogES, A.- "Das Ovarium allein durch seine innere Sekretion notwendig für Milchproduction," Wiener klin. Wochenschrift, 1908, XXI, I37.

Frank, R. T.- "An Experimental Study of the Causes which Produce Growth of the Mammary Gland," Archives of Internal Medicine, Chicago, rgrr, VII, 8I 2.

Lane-Claypon and Starling.- "An Experimental Inquiry into the Factors which Determine the Growth and Activity of the Mammary Glands," Proc. Royal Society of London, I905-06, s. B., LXXVII, 505 .

O'Donoghue, C. H.-The Relation between the Corpus Luteum and the Growth of the Mammary Gland," Proc. Physiol. Society, London, I9II, XVI.

Scherbak, A. L.- "Versuche über innere Sekretion der Brustdrüse," Wiener klin. Wochenschrift, I $1912, \mathrm{XX}, 199$.

Solovyorf, F. A.- "The Influence of Testicular Extracts and Those of the Corpus Luteum upon the Breast," Russky Vratch., St. Petersburg, Igr2, XI, 466.

\section{Virginal Lactation:}

Chaussier.-Vide Murat et Patissier, article "Mamelle," Dict. des Sciences Médicale, I81 8, XXX, 386.

Drx.-Medical Times and Gazette, London, 1856 , i, 89 .

Engstrom, O.-Annal. de Gynécologie, I889, XXXI, 285.

Lucas.-Gen. Ber. d. k. rhein-Med. Coll. Koblenz, 1839 , I88.

OLIVER, J.-Edinburgh Medical Journal, I9I 2, IX, 530.

Richer.-Vide Murat et Patissier, article "Mamelle," Dict. des Sciences Médicale, 1818, XXX, 386.

Scrönheim.-Pest. med.-chir. Presse, Budapest, I909, XLV, 175.

Adolescent Mammary Activity:

Albers.- "Mastitis neonatorum und mastitis pubescentium virilis," Med. Cor.-Bl. rhein. u. westfäl. Aerzte, 1843 , No. 13 .

Baumgarten.- "Mastitis adolescentium virilis," Zeitschrift für Chirurgie, I84I, I, 45 (Osterode und Goslar).

Schuchardr.- " "Über die Vergrösserung der männlichen Brüste," Archiv f. klin. Chir., Berlin, I885, XXXI, 59 .

LEISRINK.- "Bemerkungen über die Entzündung der Mamma bei jungen Männer," Deutsche Zeitschrift für Chirurgie, I874, IV, I9.

STUMCKE.- "Mastitis pubescentium virilis," Jour. f. Kinderheilkunde, 1847, IX, 406.

ZAPPERT, J.- "Über die akute schmerzhafte Brustdrüsenschweilung grösserer Kinde" (Mastitis adolescentium). M. Kossowitz.-Festschrift, Berlin, IgI 2, 398.

Lactation by Males:

Benedictus, Alex.-Cited by Murat et Patissier, Dict. des Sci. Méd., r8I8, XXX, 384 .

Donald, W. M.- "Lactation in a Male," Montreal Medical Journal, I890-9I, XIX, 383.

Frankiln, Sir John.- "Voyages to the Polar Seas."

Horner and Pulido y Fernandez.-Independence méd., Barcelona, XI, 274, 297, 309.

Humboldt.- " Reise in die Aequinoctialgegend des neuen Continents," ii, ५०.

Mrtchell, T. A.-"Secretion of Milk in the Male," British Med. Journal, I884, i, 493.

Murat et Pattssier.-Dict. des Sciences Méd., r8I8, XXX, 384.

Schmetzer.-Med. Cor.-Bl. d. württemb. aerztl. Ver., vi, 33 . 
Schurerdt-Medical Council, Phila., I9ro, XV, 244.

WIItShIRE.-British Medical Journal, r884, i, 654 .

Lactation by Old Women:

Montadban.—Vide Murat et Patissier, article "Mamelle," Dict. des Sciences Médical, I8I \&, XXX, 387 . MONTEGRE.-Medico-Chirurgical Review, I832, XVII, 201.

StACk.-Philosophical Transactions of the Royal Society, I 739-4I, XII, r4c; abridged Vol. IX, Part iii, p. 206.

Excessive Lactation-Preternatural Lactation:

KenNEDy.- “Preternatural Lactation," Medico-Chirurgical Review, I832, XVII, $20 \mathrm{r}$.

Gomez Pamo.-Medical Times and Gazette, I883, ii, $58 \mathrm{r}$.

REMy.-Medical Times and Gazette, $\mathrm{r} 88_{3}$, ii, $58 \mathbf{r}$. 


\section{CHAPTER II}

\section{SURGICAL ANATOMY OF THE BREAST}

For purposes of clinico-anatomical study. the breast may be divided into quadrants by vertical and longitudinal lines meeting and crossing at the nipple, and further divided, as suggested by Handley, by oblique lines, "one of which extends from the upper border of the third costal cartilage, a little outside the sternum, downward and outward to the

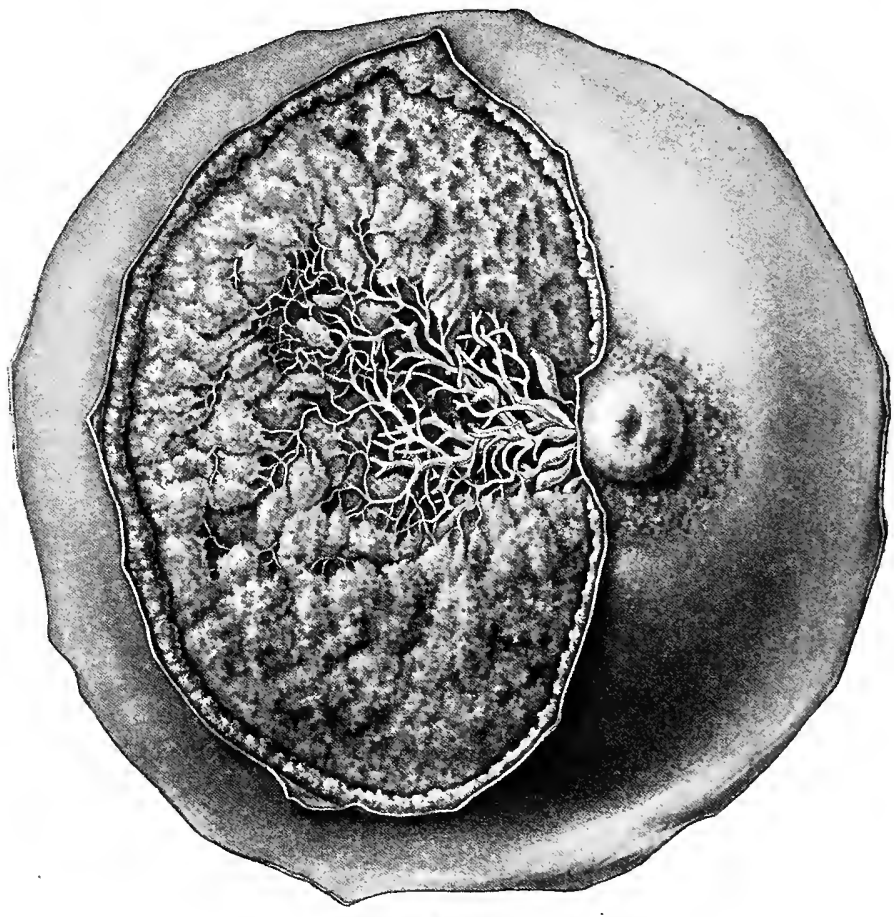

Fig. 9.-Mammary gland.

seventh rib, a little in front of the mid-axillary line; the other from the third rib, a little beyond the anterior axillary fold downward and inward to the sixth costal cartilage midway between its angle and its sternal end." It will be noted that the lower end of the latter line is about $I$ inch distant from the epigastric triangle and that its upper end extends into the axilla. This axillary extension may be entirely separate from the corpus 
mamme, and a primary tumor arising in this isolated portion of parenchyma would seem to be of axillary rather than mammary origin.

The anterior thoracic sub-group of lymph nodes is practically in contact with the breast when it extends in this manner around and beneath the axillary edge of the great pectoral muscle, the deep fascia alone intervening. The upper serrations of the serratus magnus muscle are separated from the "axillary extension" by the deep pectoral fascia. In its lower inner portion, the breast overlaps the point of origin of the greater pectoral, the upper portion of the rectus abdominalis from which the former takes origin, and

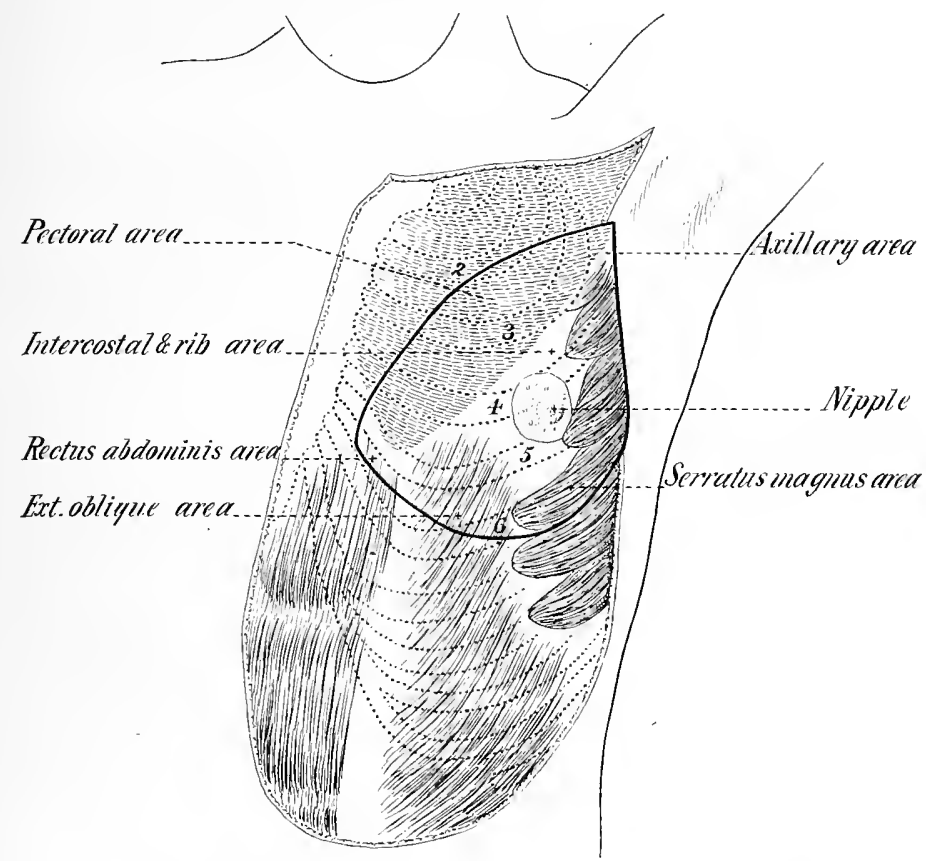

FIG. I0.-Outline of area of the chest wall covered by the breast. (Leaf.)

overlaps to some extent the external oblique muscle where it arises from the sixth and seventh ribs.

The major portion of the lower outer quadrant of the breast is situated over the upper portion of the aponeurosis of the external oblique and the fifth, sixth and seventh digitations of the serratus magnus muscles, while only a small segment behind and to the outer side of the nipple overlies the pectoralis major muscle. It follows that the only quadrant of the breast that is entirely supported by the latter muscle, is the upper inner one, and that approximately one-third of the organ extends beyond the axillary border of this muscle. $]$ 
Stroma and Adipose Tissue.-The corpus mammæ, as we have stated, is enclosed between the two layers of the superficial fascia, which form its so-called capsule. These layers are continuous with the lamellæ that subdivide the organ into lobes and lobules. The main septæ are radially arranged and connected in front with the corium of the skin and behind with the deep pectoral fascia.

The breast does not rest upon the deep pectoral fascia but upon a loose reticulum of fibrous tissue with a bursa frequently intervening between the latter and the fascia. The breast is firmly attached to the deep fascia by prolongations of the mammary stroma, many of which enclose portions of its parenchyma. The body of the nulliparous breast lacks the admixture of adipose tissue found in multiparous subjects and usually shows very little upon its posterior surface. The stroma of the sub-areolar area is of loose texture and is in all cases devoid of adipose tissue. In multiparous women, the

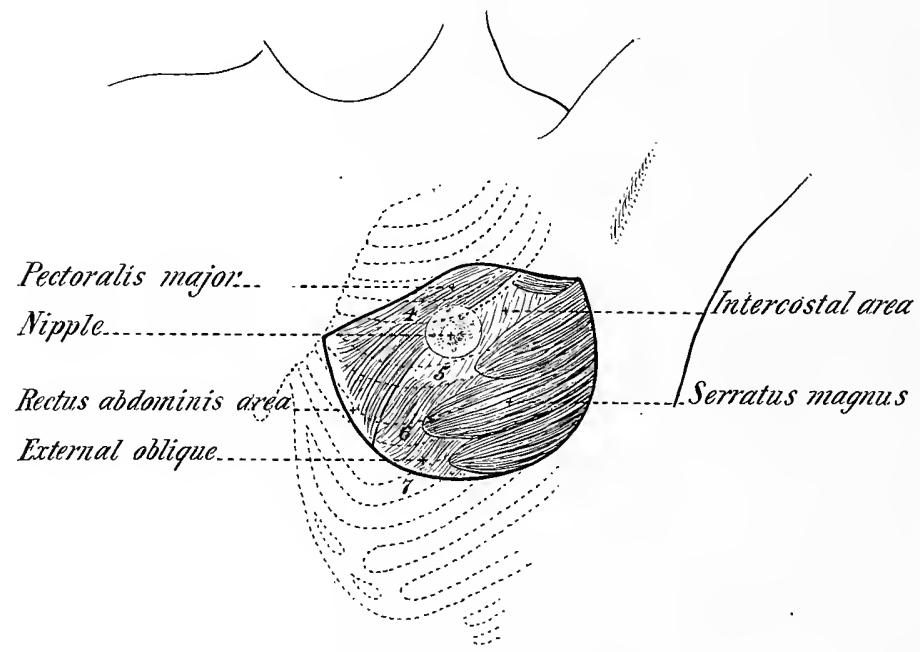

FIG. $\mathrm{rr}$.-Outline of area of the chest wall covered by the breast. (Leaf.)

stroma of the corpus mammæ and the retro-mammary tissue is infiltrated with lobules of adipose tissue in some instances to a very marked degree. Coincident with this infiltration at the occurrence of pregnancy, a decided increase in the circum-mammary adipose tissue occurs. Similar changes also occur and may be marked in association with the involutional changes of the parenchyma at the time of the climacteric.

The Superficial Pectoral Fascia.-The superficial fascia which is generally distributed over the entire body is everywhere divisible into a superficial fibro-adipose layer in which the cutaneous vessels and nerves ramify and a deep fibro-membranous layer to which the superficial layer is more or less firmly attached; the superficial fascia is loosely bound to the underlying deep fascia.

In certain parts of the body, the deep layer of the superficial fascia presents an increased density and has certain peculiarities of distribution and attachment that are of great surgical importance, as for example in the perineum-Colles fascia-the attach- 
ment of which determines the course of urine extravasated from the ruptured bulbomembraneous urethra, and on the anterior surface of the thigh where the attachment determines the direction of a hernial protrusion through the saphenous opening. In the pectoral region the superficial fascia reaches its highest development on the deep surface of the breast, so that intra-mammary abscesses often do not involve the retro-mammary

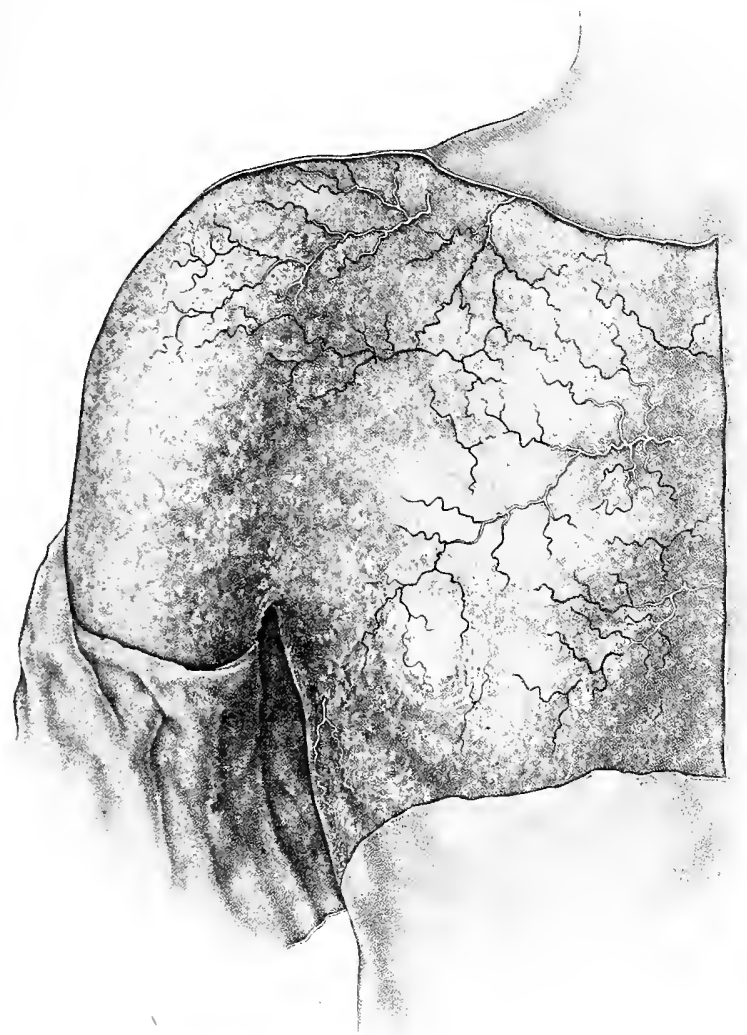

FIG. 12,-Superficial fascia of the pectoral region. Showing the superficial branches of the acromiothoracic, long thoracic and internal mammary arteries and the mammary gland in the superficial fascia.

space but point either anteriorly or along the outer margins of the breast where the two layers of the superficial fascia fuse. At the inferior margin of the breast, the deep layer in turning forward to join the superficial layer, forms a shelving edge which aids in the support of the breast. In the mid-line this layer is firmly attached to the deep pectoral 
fascia and the latter in turn to the periosteum of the sternum thus producing the intermammary sulcus.

Deep Pectoral Fascia.-A deep layer of fascia is also found covering all parts of the surface of the body and in general it immediately underlies the superficial fascia, but in certain areas, such as the cervical and pectoral regions, it forms inter-muscular septa that permit of its division into two or more planes. The deep pectoral fascia is composed of an anterior and a posterior layer. The anterior layer covers the superficial aspect of the great pectoral muscle. It is attached above to the clavicle, medially to the periosteum of the sternum and is continuous below with the deep fascia covering the rectus abdominis and cxternal oblique muscles, and laterally with that covering the serratus magnus muscle below, and the deltoid muscle above. Between these muscles, the same fascia spans the base of the axilla, of which space it constitutes the floor.

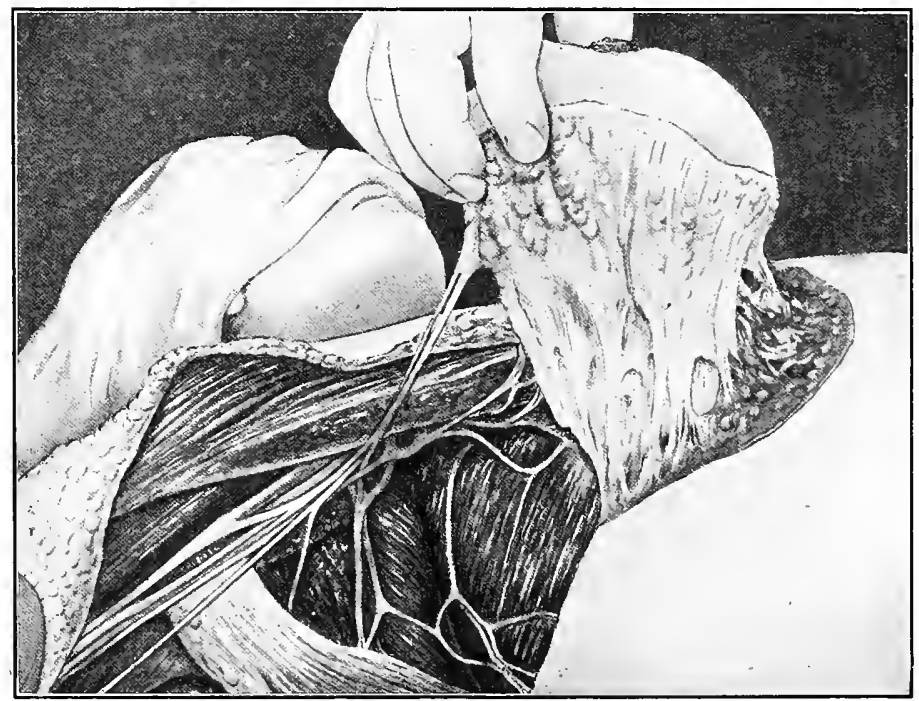

FIG. I.3.--Dissection to show the attachments of the stroma of the breast to the deep pectoral fascia and to the superficial fascia with both of which it is continuous.

As the anterior layer turns around the outer border of the pectoralis major to become the axillary fascia, it gives off a prolongation that separates the two pectoral muscles. This splits to enclose the pectoralis minor muscle, at the upper inner margin of which it again unites and is continued upward, as the costo-coracoid membrane, to the under-surface of the clavicle, where it again divides to enclose the subclavius muscle and to be inserted into the lips of the subclavian groove. These layers are collectively known as the posterior layer of the deep pectoral fascia or the clavi-pectoral fascia.

Purulent collections between the pectoral muscles or behind the pectoralis major muscle are directed to the anterior border of the axilla or to the upper end of the deltopectoral groove by the clavi-pectoral fascia. When situated beneath the pectoralis minor muscle and therefore posterior to the fascia, abscesses are either confined to the 
axillary space, pointing at the base of the axilla through the foramen of Langer (see axillary fascia), or follow the axillary sheath upward to point above the clavicle in the supra-clavicular triangle. The costo-coracoid membrane, a dense quadrilateral sheet of the clavi-pectoral fascia, extends from the upper inner edge of the pectoralis minor muscle to the undersurface of the clavicle. It is attached externally to the upper surface of the coracoid process of the scapula and fuses internally with the fascia covering the two upper intercostal spaces. The costo-coracoid membrane is attached to the

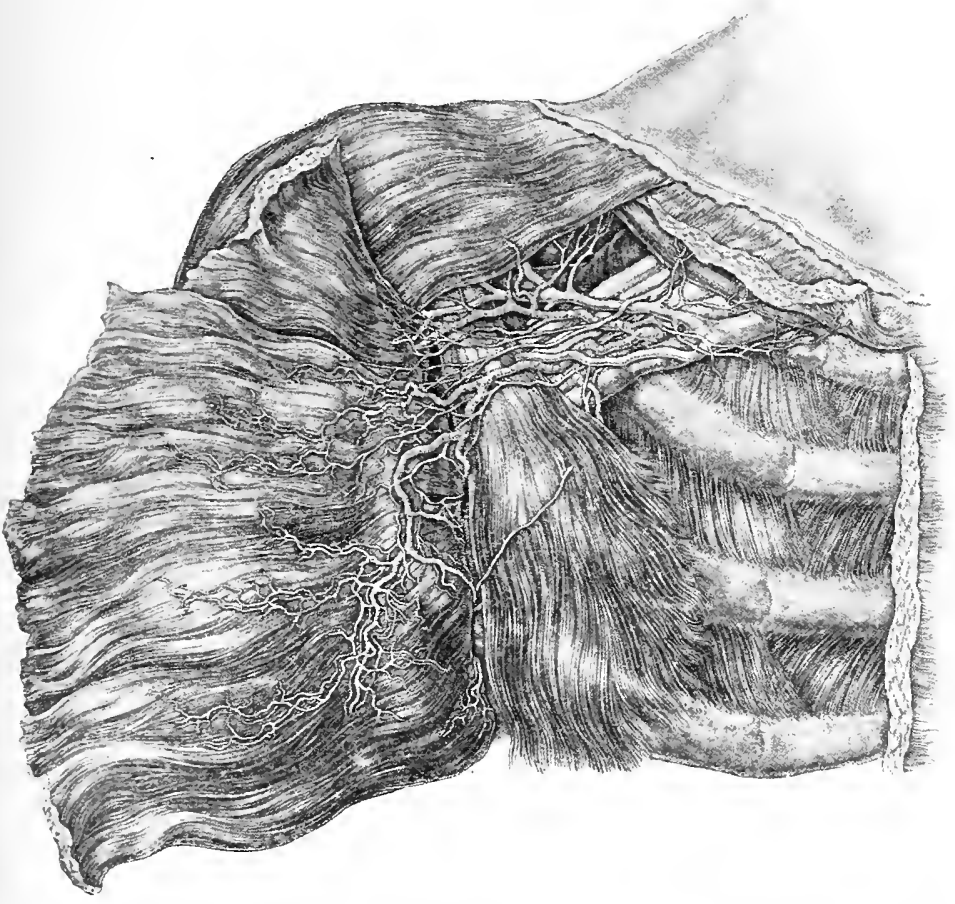

FIG. I4.-Deep infra-clavicular triangle. The pectoralis major muscle and the clavi-pectoral (costocoracoid membrane) fascia have been removed thus exposing the apex of the axillary space. The latter is sometimes called the deep infra-clavicular triangle.

sheath of the axillary vein (third portion) above and is therefore directly continuous with the pre-vertebral layer of the deep cervical fascia. The practical importance of a knowledge of this relationship will be shown in the description of the axillary lymph nodes.

Infra-clavicular Triangles. - The space beneath that portion of the clavicle interna! to the anterior edge of the deltoid muscle and under cover of the clavicular head of the 
pectoralis major muscle is subdivided into two triangles by the costo-coracoid membrane. The anterior of these, the superficial infra-clavicular triangle, not infrequently contains several small lymph nodes, which, as Poirier has shown, receive vessels from the upper segment of the breast. Grossman and Schmidt have demonstrated lymphatic vessels arising in the deep portion of the breast that reach this group of nodes by piercing the pectoralis major muscle and running upward in the clavi-pectoral fascia. The superficial triangle is traversed by the cephalic vein, the acromio-thoracic artery and vein and

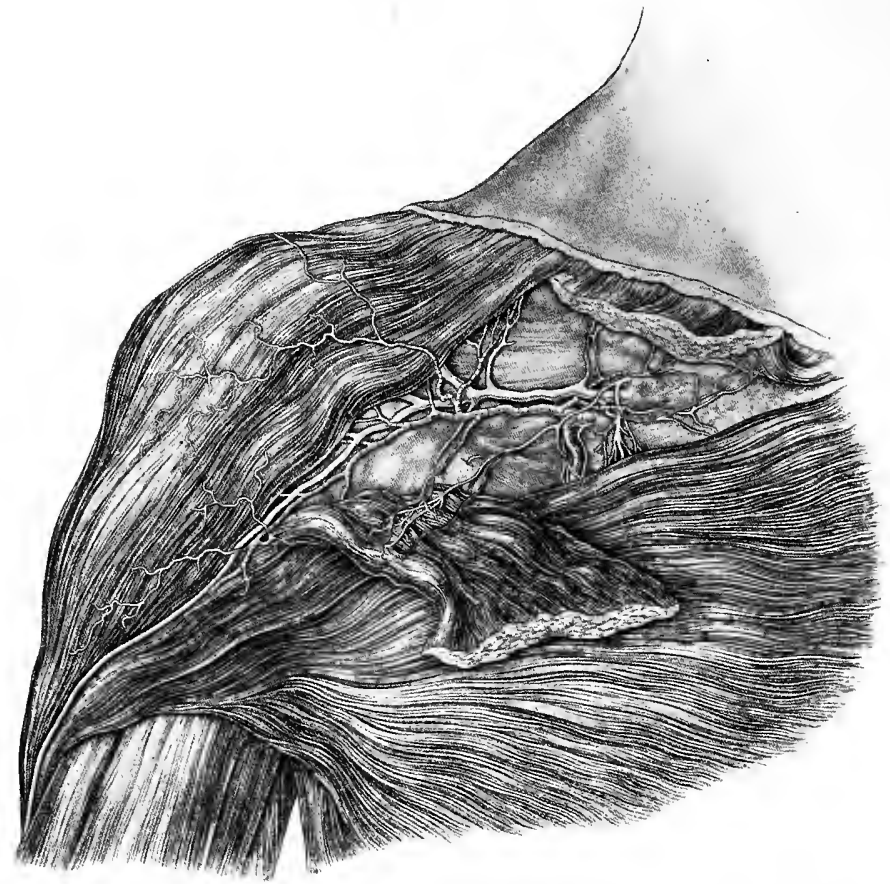

Fig. 15.-Superficial infra-clavicular triangle. The clavicular portion of the pectoralis major muscle has been reflected. The costo-coracoid membrane is thus exposed together with the vessels and nerves which pierce this structure.

the external anterior thoracic nerve, all of which pierce its floor-the costo-coracoid membrane-to enter the deep infra-clavicular space or triangle.

The posterior of these spaces, the deep infra-clavicular triangle, the apex of the axilla or the space of Morenheim, as it is variously called, can be fully exposed by removing the sternal portion of the pectoralis major muscle and the costo-coracoid membrane. The exposure of this space in the operation for mammary carcinoma is of paramount importance because it lodges the subclavian lymph nodes, which are especially liable to escape removal owing to their sheltered position, which communicate with all of the 
other axillary sub-groups of lymph nodes and which may, as Stiles has shown, become involved in the cancerous process without involvement of the lower groups. In the majority of cases the lymphatic nodes of the subclavian group are situated behind, as well as above and below the pectoralis minor muscle, so that one cannot be sure of the complete removal of these isolated structures if the muscle be left in situ. The deep infraclavicular triangle contains the third portion of the axillary vein, the sheath of which,

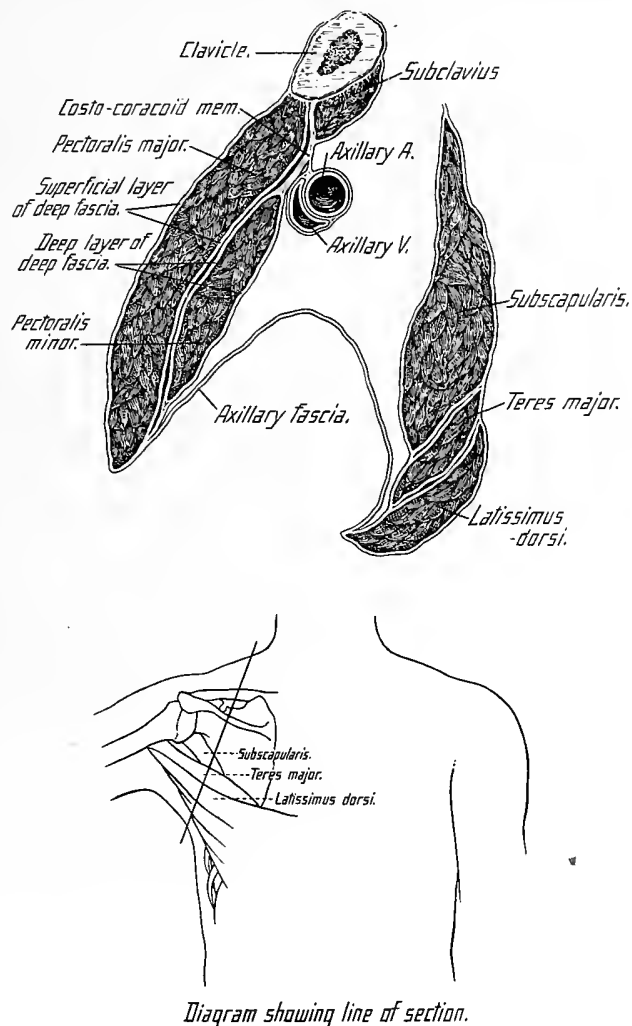

FIG. I6.-Diagram of the pectoral fascia and"the axillary fascia.

a process of the pre-vertebral layer of the deep cervical fascia, is, as stated above, attached to the costo-coracoid membrane. Both structures may be inseparably attached to the adjacent lymph nodes when the latter show advanced cancerous involvement. In the latter event edema of the arm may result from pressure upon the axillary vein. An attachment of the lymph nodes to the wall of the vein necessitates excision of the involved segment. This space contains in addition the first portion of the axillary artery, 
the acromo-thoracic artery and vein, and the cords of the brachial plexus. Successful surgical treatment of mammary cancer can only be hoped for through effacement of the infra-clavicular triangles, removal of the anterior wall of the axillary space, consisting of the clavicular and sternal portions of the pectoralis major, the pectoralis minor muscle and the clavi-pectoral fascia, with resulting exposure and removal of the lymph node contents of the axilla, as well as removal of the breast itself.

Axillary Fascia.-The axillary fascia forms the floor of the axilla and is continuous, in front, with the anterior layer of the deep pectoral fascia, and, behind, splits to enclose the latissimus dorsi muscle, the posterior lamella being continuous with the deep fascia of the back. It is continuous, outward, with the deep fascia of the arm, and below and inward with that covering the serratus magnus muscle. The axillary fascia is thinnest in its central portion, a feature to which Langer first drew attention; this portion of the axillary fascia, to which the name, foramen of Langer is applied, determines the position at which purulent collections in the axilla point.

Leaf has described a central chain of small lymph nodes which underlies the axillary fascia at this point and can therefore readily be palpated when enlarged. The axillary fascia together with that covering the anterior surface of the latissimus dorsi, and that in relation to the serratus magnus muscle and long thoracic nerve must be removed in operations for the radical excision of the breast. In this connection attention may be called to the fact that the depth of the axillary space varies with the degree of tension of the axillary fascia. The space is shallowest and narrowest when the arm is most strongly abducted, the fascia thereby made taut, and the contents of the axilla brought nearer the surface. In operations in this region, the arm should be held in an abducted position to facilitate approach to the axillary contents and after a radical breast operation the dressings should be applied with the arm somewhat abducted as it has been observed that better support is afforded the axillary vessels by thus decreasing the depth of the space. During axillary examination by palpation the arm should be adducted to permit invagination of the axillary fascia beneath the axillary margin in the search for enlarged lymph nodes.

The Epigastric Triangle.-The space between the upper portion of the recti abdominales muscles and just below and to either side of the xiphoid process of the sternum is said by Handley to be the most frequent portal of entry for the cells of a malignant mammary neoplasm to both the peritoneal and thoracic cavities. At this point the linea alba is wide and in its mid-portion very thin. There is a decussation of those fibers of those portions of the pectorales majores muscles arising from the rectus sheaths, many crossing the mid-line. In many places small lobules of pre-peritoneal adipose tissue protrude through the interstices of this fascial sheath, which poorly protects the peritoneal cavity from overlying malignant foci. The deep pectoral and abdominal fasciæ are inseparable from the overlying muscular sheath in this area, so that malignant permeation in the deep fascial planes at this point must invite peritoneal invasion. If we recall that the lower inner portion of the breast overlies the sixth costal cartilage, it is evident that the epigastric triangle which is approximately an inch distant is in danger of involvement especially when the tumor arises in the adjacent segment of the breast. Many of the lymphatic vessels arising in the parieties of the lower thorax and upper abdomen traverse this fascial triangle to reach the falciform ligament of the liver within the folds of which they run to the diaphragmatic group of lymph nodes. 
Blood Supply.-The mammary gland is supplied with blood through branches of the axillary, internal mammary and intercostal arteries. The axillary branches are the long thoracic or deep external mammary, the short thoracic or superficial external mammary, the superior thoracic and the pectoral branch of the acromio-thoracic arteries. The long thoracic artery although the largest vessel cut in radical excision of the breast, sends only a few small twigs to the deep surface of its upper outer quadrant and several to the superficial surface of the same area. The short thoracic artery arises from

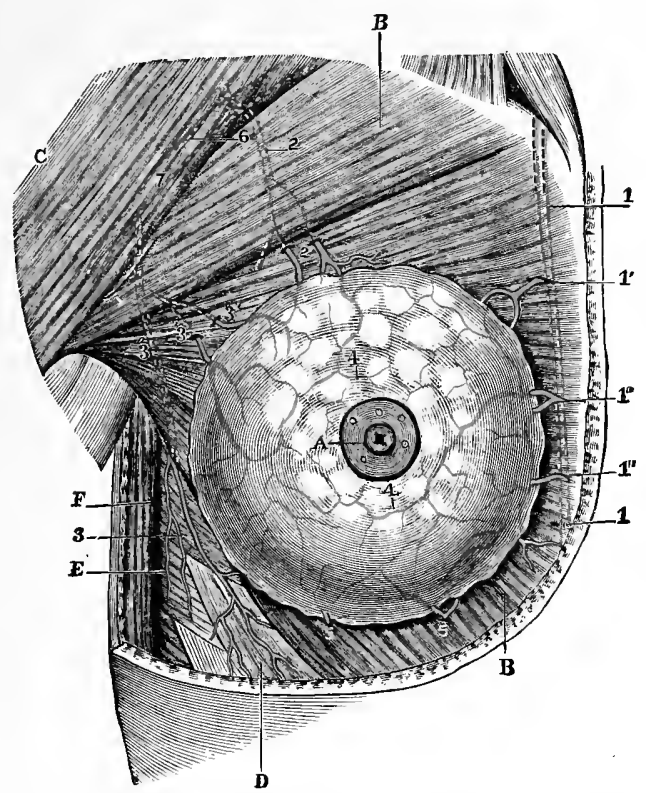

FIG. I7.-Arterial supply of breast. (Testut.) A. Nipple. B, B. Pectoralis major. C. Deltoid. $D$. External oblique. E. Serratus magnus. F. Latissimus dorsi. $x$, I. Internal mammary artery following the external border of the sternum. $\mathrm{I}^{\prime}$. Perforating branch of that artery, later passing between the pectoralis major and the deep surface of the gland. I". Two perforating branches surrounding the internal border of the breast. 2. Superior thoracic artery. $2 \prime$. Branches of the superior thoracic. 3. Inferior thoracic or external mammary artery, with: $3^{\prime}, 3^{\prime}$. Two branches running to the breast. 4, 4. Vascular circle surrounding the areola. 5, 5. Two branches coming from the intercostals. 6. Axillary artery. (Testut: Traité d'Anatom. Humaine, iii, p. 60, Paris, I895, 3d ed.)

the terminal portion of the axillary artery and crosses the axillary space in the superficial tissues to reach the superficial aspect of the breast where it anastomoses with the preceding vessel. The superior thoracic artery supplies, in small part, the anterior surface of the upper segment. Branches from the pectoral division of the acromio-thoracic artery pierce the pectoralis major muscle and enter the deep surface of the breast. The upper three perforating branches of the internal mammary artery and smaller branches from the upper five or six anterior intercostal arteries supply the breast. The former which furnish the main arterial supply of the breast emerge from the intercostal spaces on each side 
of the sternum, pierce the pectoralis major muscle, turn outward, ramify in the anterior layer of the superficial fascia and send branches to the parenchyma. The anterior intercostal branches of the internal mammary and the mammary branches of the intercostal arteries run between the deep pectoral fascia and the deep layer of the superficial fascia, which they pierce to enter the deep surface of the breast. Subdivisions of the above vessels form two plexuses, one on the anterior, and the other on the posterior surface of the breast. Branches from the anterior plexus unite to form a secondary sub-areolar plexus from which branches are given to the nipple, areola and subjacent parenchyma. The remaining branches of the two plexuses form an anastomotic circle around the organ and send vessels to both parenchyma and stroma.

The veins, like the arteries, are most numerous over the anterior portions of the breast where they form an anastomosis encircling the nipple-the circulus venosus of Haller-from which large branches run to the periphery of the gland and thence to the axillary and internal mammary veins.

Nerves.-The nerves of the breast are derived from the anterior cutaneous branches of the third, fourth and fifth intercostal nerves, the anterior divisions of the lateral cutaneous branches of the third, fourth and fifth intercostal nerves, the descending branches of the superficial cervical plexus, and from the internal and external anterior thoracic branches of the brachial plexus. The parenchyma is but poorly supplied with sensory nerve filaments which explains the absence of pain in the early stages of tumor. The exquisite pain associated with fissured nipple bespeaks the rich sensory nerve supply of that area. The pain felt in the shoulder, neck and back in painful diseases of the breast is due to involvement of the stroma, the pain being referred to these localities.

Pain referred down the arm in mammary cancer results from compression of the intercosto-humeral, a nerve trunk formed by union of the lateral branch of the second intercostal and the lesser internal cutaneous branch of the brachial plexus. Such pain usually denotes extensive axillary involvement.

Lymphatics.-The usual description of the lymphatic system is based upon the findings of investigators, who, like Gerota, have charted the lymphatic distribution by means of injection preparations, and secondly upon clinical ând operative experience with the avenues of metastasis in malignant disease. The results, however, by no means determine the disposition of the lymphatic trunks and nodes of any individual case nor do they take into account "the innumerable tiny interrupting nodules of lymphatic tissue along lymphatic trunks" to which Stiles has drawn attention. Our description will be based upon anatomical studies.

To secure the best results in operations for the radical cure of carcinoma, it is imperative that the correct location of the node terminals of the mammary lymphatics be known, their relative frequency in metastatic involvement understood, and all of the tissues intermediate between the primary focus of disease and the terminal lymph nodes looked upon as a part of the original tumor and, so far as possible, removed.

In addition to the lymphatics of the organ proper, the adjacent lymphatic plexuses must also be considered, as malignant disease sooner or later transgresses the confines of one to involve other lymphatic systems.

The lymph nodes receiving afferent vessels directly from the breast, comprise the following groups:

(a) Axillary, both sides.

(b) Retro-sternal.

(c) Retro-pectoral (Rotter). 
(d) Supra-clavicular, deep cervical.

(e) Para-mammary (Gerota).

The lymph nodes of adjacent systems that frequently become involved in carcinoma of the breast are, in their order of importance:

(a) Supra-clavicular, deep cervical.

(b) Axillary, opposite side.

(c) Diaphragmatic.

(d) Hepatic.

(e) Supra-xiphoid (Sappey).

(f) Upper brachial

(g) Intercostal.

(h) Inguinal.

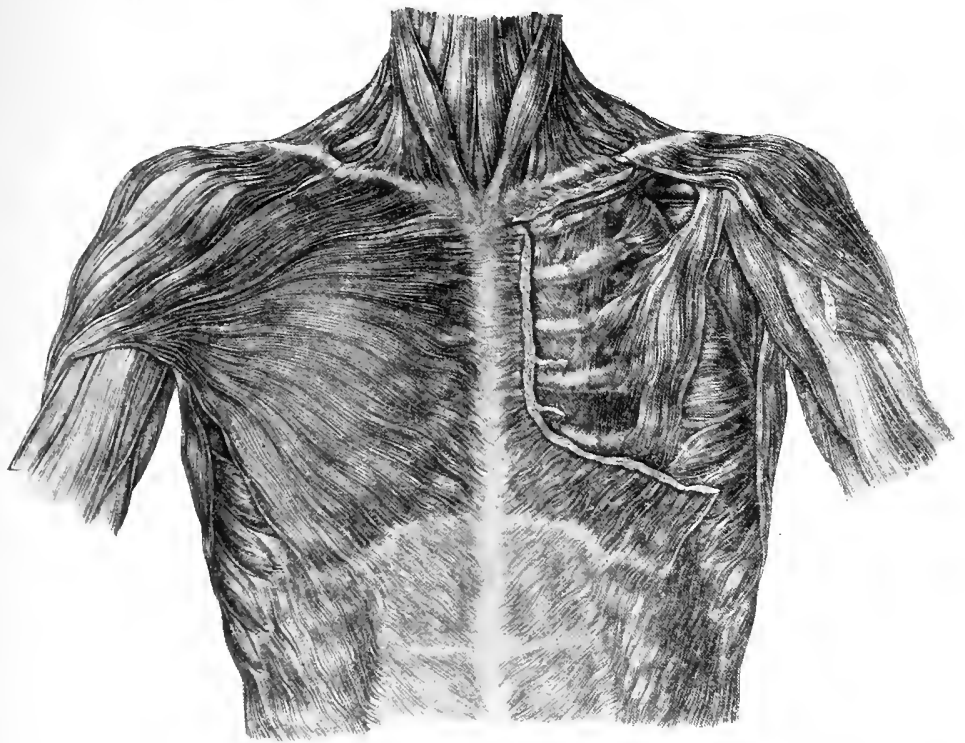

FIG. 18.-Pectoralis major muscle and pectoralis minor muscle. The cut edges of the pectoralis major muscle which has been removed show the points of origin and insertion of this muscle; the pectoralis minor muscle is shown intact.

The course of the mammary lymphatic vessels passing to these several groups' of nodes is a much disputed question. The anterior parietal lymphatic vessels of the thorax comprise the following:

Cutaneous lymphatics.

Lymphatics of the breast.

Lymphatics of the peri-thoracic muscles.

Lymphatics of the intercostal muscles.

Lymphatics of the diaphragm.

Of these the cutaneous lymphatic plexus is held to be of chief importance and to it the mammary gland lymphatics are looked upon as tributary. The drainage of the 
deeper portions of the breast into the lymph channels of the peri-thoracic muscles and their fascial coverings is held by Gerota, Poirier, Cuneo and Delamere, and Sappey to be subsidiary, under normal conditions, to the cutaneous route. The mammary lymph vessels are divided by Poirier and his co-workers into the cutaneous and the glandular. The cutaneous lymph vessels differ in distribution in the central and peripheral portions

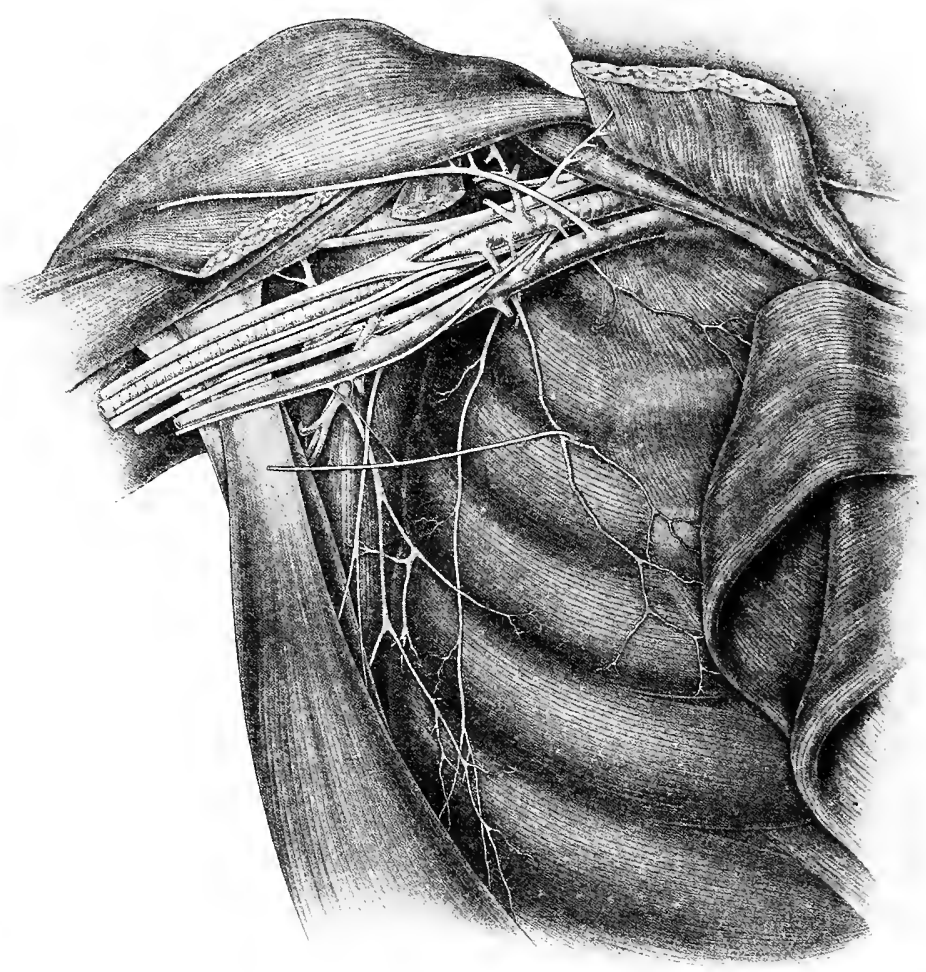

FIG. I9.-Contents of the axilla shown by dissection made from before backward.

of the organ. In the former two main trunks arise from a central sub-areolar plexus, run above and below the areola and turn transversely outward to reach the thoracic group of axillary nodes. Some small trunks arise in the upper peripheral portions and pass over the clavicle to reach the supra-clavicular nodes of the deep cervical chain. Some mammary trunks seem to cross from one side of the chest to the other, thus creating an anastomosis between the two sets of mammary lymph vessels. 
Olsner and Roeffel have demonstrated the existence of a lymphatic trunk that arises in the lower inner quadrant of one breast and goes directly to the lymph nodes of the opposite axilla.

The central cutaneous lymphatics begin in a fine network, beneath the areola, and nipple, and unite into several trunklets. These latter break up to form the sub-areolar plexus of Sappey in which a majority of the glandular lymphatics terminate. The latter arise as sacs in the peri-lobular tissue and form channels which course through the periductal tissue to reach the sub-areolar plexus.

Accessory lymph channels emerge from the periphery of the organ and go either to the axillary, subclavian or internal mammary (retro-sternal) groups of nodes. Several

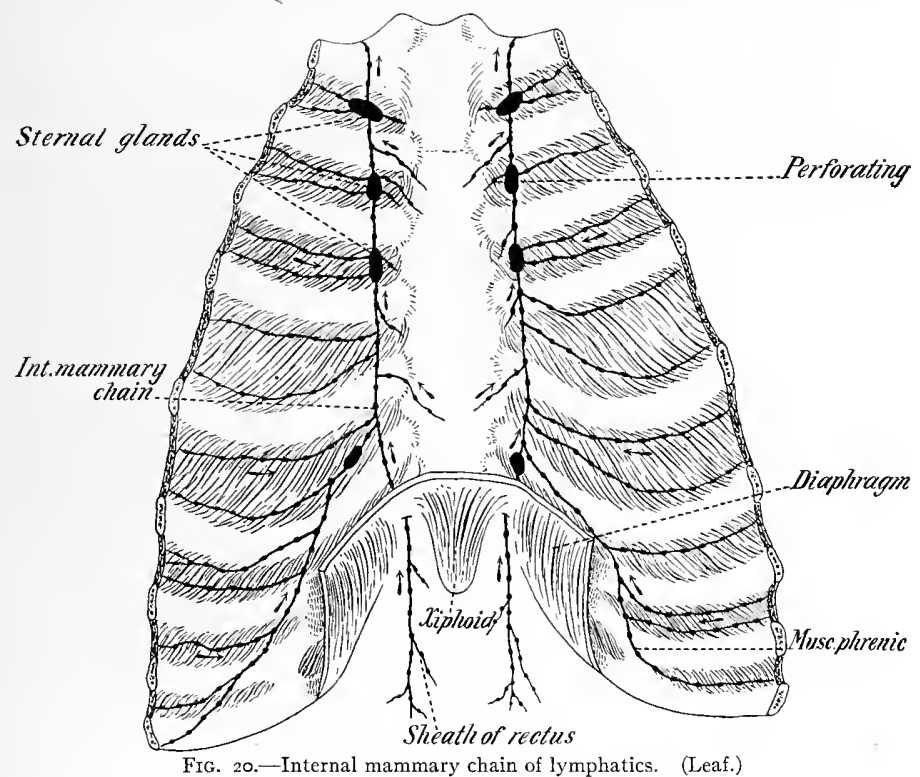

of these accessory channels detach themselves from the inferior part of the mamma and go directly to the axilla.

Grossman found, in ro per cent. of the cases studied, a lymphatic trunk that arose from the undersurface of the breast, perforated the pectoralis major and passed between the two pectoral muscles to the subclavian nodes. A final group of accessory lymph channels arises from the inner segment of the breast and follows the perforating branches of the internal mammary artery to the retro-sternal nodes. These trunks are subject to early senile atrophy, thus explaining the infrequency of the involvement of the retrosternal lymph nodes in carcinoma of the breast.

The lymphatic distribution as given above is founded on anatomical investigation. Clinical and pathological evidence indicates that the dissemination of mammary carcinoma principally occurs by way of the lymphatics contained in the deep fascia. Lang- 
hans originated this view with which Heidenhain agreed, and Stiles in confirmation of their observations divides the mammary lymphatics into five groups, viz.:

(a) Superficial, including those of the nipple, areola and surrounding skin.

(b) Sub-areolar (Sappey).

(c) Intra-mammary.

(d) Lymphatics of the circum-mammary adipose tissue.

(e) Retro-mammary.

These systems are intercommunicative, and Stiles says "the retro-mammary lymphatics receive all the efferent mammary lymphatics which leave the posterior surface of the gland." In this way therefore the efferent lymphatics of the corpus mammæ, of the adipose tissue around it, and of the nipple, areola and skin over it, open either directly or indirectly into the lymphatics of the deep fascia. Carcinomatous dissemination, frequently an embolic process, primarily depends, as Handley has shown, upon centrifugal growth from the original focus along fascial planes, by a process of peri-lymphatic permeation. Therefore, the direction of the lymph current or the convergence of lymphatic trunks at one particular point does not absolutely determine the location of secondarily involved lymph nodes, which depends rather upon the situation of the primary focus and the physical characteristics of its surroundings. Argument for or against a certain direction of the lymph current is not apropos of the question from a pathological standpoint.

Lymphatics of the Thoracic Muscles.-The pectoral muscles contain lymphatic trunks in the inter-fascicular connective tissue, which are in direct communication with the deep fascial lymphatics. Some of these channels follow the thoracic branch of the acromio-thoracic artery to terminate in the sub-clavicular group of nodes in the axillary chain; others accompany the pectoral branch of the long thoracic artery to the thoracic group of the same chain; while others are tributary to the retro-sternal group. It is probable carcinomatous permeation along these channels that necessitates the complete extirpation of the muscles in the performance of the radical breast operation.

Lymph Nodes.-The demonstration of carcinomatous invasion of lymph nodes inaccessible to the knife is rarely possible but determines the operability or inoperability of any given case of mammary carcinoma. The groups that demand special attention are the axillary, retro-pectoral and supra-clavicular nodes of the principle systems, the upper brachial and axillary nodes of the opposite side and the supra-clavicular members of the adjacent systems.

The supra-clavicular group of the deep cervical chain of nodes is involved, as a rule, secondarily from the axillary system, but may be the primary seat of metastatic cancer through the medium of the channel of Poirier from the upper inner quadrant of the breast, to which we have called attention. This group belongs therefore to both the primary and adjacent systems; while the same applies to the axillary nodes of the side opposite to the tumor.

Axillary Nodes.-The axillary lymphatic plexus is composed of from I6 to 36 nodes united by stems but divisible into sub-groups, according to the position of the nodes and the source from which their afferent vessels come. Piersol describes four terminal sub-groups for stems from the arm and chest, and two sub-groups which are in the nature of relays between these terminals and the subclavian trunk by which the lymph from the entire axillary plexus is carried to the right lymphatic duct or to the thoracic duct on the left side. 
Terminal Sub-groups.-(a) The brachial sub-group consists of nodes lying in relation with the inner side of the first portion of the axillary vein.

(b) The anterior pectoral sub-group is composed of two or three small nodes situated over the two or three intercostal spaces anterior to the long thoracic artery and under the axillary edge of the pectoralis major muscle.

(c) The inferior pectoral sub-group consists of two or three small nodes lying upon or posterior to the long thoracic artery and over the fourth and fifth intercostal spaces.

(d) The sub-scapular sub-group consists of six or more nodes lying along the subscapular artery and two or three nodes on the dorsal surface of the scapula between the teres major and teres minor muscles.

The intermediate sub-group consists of a number of large nodes situated in the interval between the lateral chest wall and the upper part of the long thoracic vein as it turns

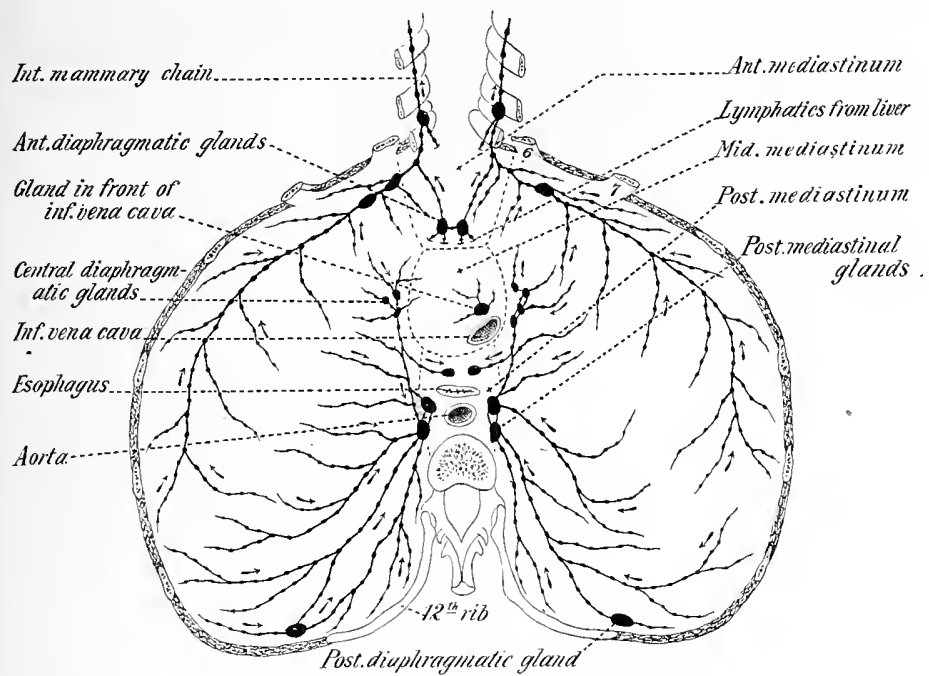

FIG. 2I.-Sub-diaphragmatic lymphatics. (Leaf.)

outward to open into the terminal part of the axillary vein. This group receives afferent vessels from all of the terminal sub-groups of the axillary plexus while its efferent vessels pass to the subclavian sub-group. The latter contains from six to twelve nodes situated at the apex of the axillary space beneath, above and behind the pectoralis minor muscle. These nodes receive afferents either directly or indirectly from all of the other sub-groups and the majority of their efferents end in the subclavian trunk while a few pass to one or more of the lower nodes of the inferior deep cervical group. Leaf has described a collection of small lymph nodes in the mid-line of the axilla, both above and below the deep fascia. They underlie the foramen of Langer, or central weak portion of the axillary fascia, and are in communication with the upper set of the brachial nodes. These are frequently involved in infections of the upper extremity and are also infrequently involved in cancer of the breast. They should, however, be examined in all cases of 
mammary neoplasm, especially since they are superficial and therefore easily palpable when enlarged.

The retro-pectoral nodes are of importance only in so far as they confirm the necessity of removing the pectoral muscles in the radical operation for cancer. They are situated between the two pectoral muscles and along the course of the subclavian accessory lymphatic trunk which Grossman first described. These nodes are found according to Rotter in 50 per cent. of cases. The deep cervical plexus is (practically) a subsidiary or adjacent system, however, but is of the utmost importance as all of the axillary subgroups are in indirect communication with some of its inferior nodes which are frequently involved in mammary carcinoma and infrequently removed. The nodes of this group

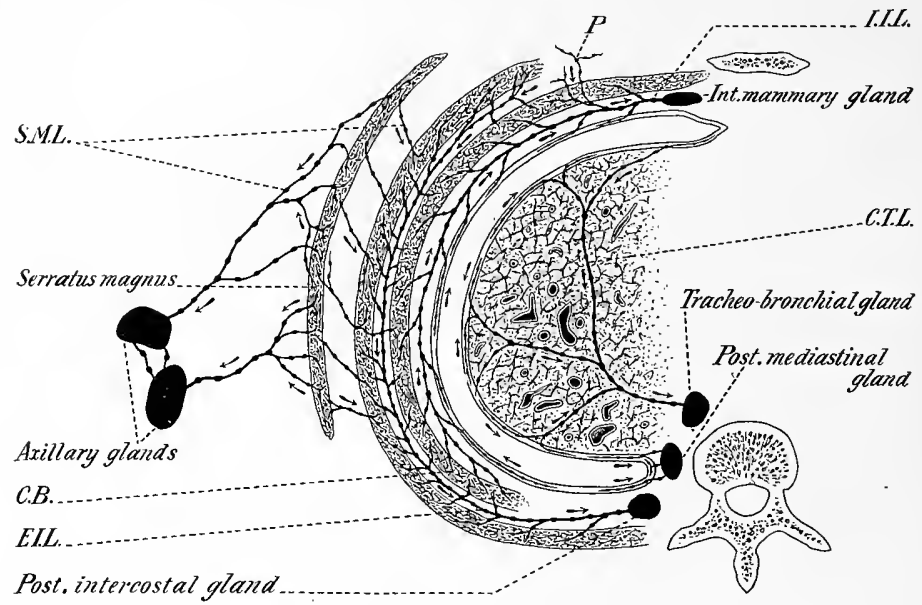

FIG. 22.-Diagram showing connections of lymphatics of serratus magnus and intércostal muscles. (Leaf.)

S.M.L. Deep lymphatics of serratus magnus joining those of external intercostal muscle. C.B. Communicating branches between external and internal intercostal muscles. E.I.L. Lymphatics of external intercostal muscle emptying into posterior intercostal glands. I.I.L. Lymphatics of internal intercostal muscle and parietal pleura emptying into sternal glands. C.T.L. Lymphatics of visceral pleura passing into collecting trunks of lung and emptying into tracheo-bronchial glands. $P$. Perforating branches passing into internal intercostal trunk.

occupy the supra-clavicular triangle and are situated anteriorly or superficially to the scalene muscles and the trunks of the brachial plexus. In addition to the afferent vessels, to which we have referred as coming from the axillary afferent nodes directly from the upper inner quadrant of the breast, these nodes receive vessels from the integument of the upper part of the anterior chest wall, and vessels which ascend from the liver and diaphragm following the course of the internal mammary artery to the left, or more rarely to the right group. Their tributaries from the head and neck do not concern us in this connection.

Anastomoses across the mid-sternal line, or a crossed origin of the trunklets, bring the axillary plexuses of the two sides into communication with one another. 
The nodes of the superficial upper brachial or delto-pectoral group are in relation with the cephalic vein in the delto-pectoral groove and their efferent vessels enter the deep cervical nodes or the subclavian sub-group of axillary nodes. The deep upper brachial nodes are in relation with the brachial artery below the point of insertion of the pectoralis major muscle and in the radical operation for cancer should be removed together with the overlying deep fascia, for as both Handley and Lockwood have shown, they are frequently involved in the cancer metastasis.

Lymph Nodes Frequently Involved in Carcinoma of the Breast but Inaccessible to the Knife.-The retro-sternal and internal mammary, intercostal, sub-diaphragmatic, hepatic and supra-xiphoid group of Sappey may be arbitrarily included under the above heading.

The retro-sternal group consists of four or six nodes lying in front of the internal mammary artery and arranged in a chain which lies near and runs parallel to the lateral borders of the sternum. Its afferent vessels come from the mammary integument of the pre-sternal region, the anterior portion of the intercostal spaces, the superior portion of the recti abdominales muscles, from the upper surface of the liver and from the diaphragm. The hepatic efferents run in the falciform ligament, to the diaphragm, which they pierce near the lateral border of the xiphoid process, to enter into the supra-xiphoid plexus of Sappey which is tributary to the internal mammary plexus. The mammary tributaries to this plexus are minute twigs which arise in the parenchyma or inner segment of the breast and follow the perforating branches of the internal mammary artery. These twigs suffer early atrophy in senility so that direct cancerous involvement of the retro-sternal lymph nodes is less.frequent than the close association between the two would lead one to expect.

The intercostal lymphatic plexus is found in association with the intercostal bloodvessels. It anastomoses in front with the internal mammary plexus and behind with the para-vertebral plexus. It contains two groups of small nodes, one at the point of origin of the lateral cutaneous branches of the arteries, the other in relation with these vessels at the angles of the ribs posteriorly. Efferent vessels from the latter communicate with vessels of the vertebral lymphatic plexus. This communication explains metastatic involvement of the vertebral bodies in some cases of cancer of the breast. The remaining tystems afferent to the internal mammary plexus have been discussed in the considerasion of the anatomy of the epigastric triangle.

\section{BIBLIOGRAPHY}

Altmann.-Virchow's Archiv, Bd. cxi, p. 318 .

BAILEY AND MIILLER. - Textbook of Embryology, IgI I.

Boutn et Ancell.-Compt. rendu soc. de Biol., i go9, lxvi, 605, 689.

BIEDI. -Ztschr. f. exper. Path. u. Therap., I9ro, vii, 350.

Bonnet.-Ergebnisse d. Anat. u. Entwick., Bd. vii, I898; Bd. ii, 1892.

BonNET.-Lehrbuch der Entwicklungsgeschichte, Berlin, I907.

Deaver.-Textbook of Surgical Anatomy, Vols. i and ii.

HANDLEy.- "Cancer of the Breast and its Operative Treatment:" Lond., I906, Clinical Jour., London, Ig08-09, xxxiii, 4II, 4 I4.

Heidenhain.-Archiv f. klin. Chir., I889, p. 97.

Hirst. -Am. Journ. of Obstet., January, 1913.

KaLIIUS.-Anat. Hefte, I897, Bd. viii.

KRAUSE.-In Hertwig's "Handbuch der Entwickelungsgeschichte des Menschen und der Wirbeltiere," Bd. ii, Text i, rgo2. 
Lane-Claypon and Staring.-Proc. Roy. Soc., London, Igo6, Series B, Ixxvii, 520. OlIVER,-Edinburg Medical Journal, I9I2.

O'Donoghue.-Journ. of Physiology, I9I2, xlvi, 6.

Prersol.-Textbook of Anatomy.

Scнмidт.-Die Verbreitungswege der Karzinome, Jena, Igo3.

ScHмidT.-Mophologische Arbeiten, I897, Bd. xvii.

Strahl.-Verhandl d. anat. Gesellsch., Bd. xii, I8g8.

STrLEs.-Edinburgh Medical Journal, 1892. 


\section{CHAPTER III}

\section{THE CONGENITAL ANOMALIES OF THE BREAST}

\section{AMASTIA OR AMAZIA}

These terms are applied to conditions in which there is congenital total absence of one or both of the mammary glands, or in which one or both glands are undeveloped or rudimentary in development. To the latter condition the term "micromastia" might more correctly be applied.

It has already been shown in discussing the embryology of the glands, that in mammalian embryos, O. Schultze ("Uber die erste Anlage des Milchdrïsen apparats," Anat. Anzeiger, I892) has shown that in Io $\mathrm{mm}$.-I $5 \mathrm{~mm}$. embryos, there is an epithelial ridge, the "milk-line," that passes along each side of the body of the embryo, from the future axillary to the future inguinal region, and sometimes beyond these limits so as to extend to the budding limbs in the neighborhood of the shoulder and pelvic girdles. A little later the line ceases to exist as such, but is represented by a certain number of tiny points in each of which the epithelium piles up and becomes the "Anlage" of a future mammary gland. In many mammals, all of these anlagen develop into mammæ, but in others, a greater or smaller number of them become suppressed or extinguished as development progresses, only the number and distribution normal to the species remaining. What Schultze showed to be true of the lower animals, H. Schmidt ("Morphologische Arbeiten über die normale Hyperthelie menschlicher Embryonen and über die ersten Anlagen der menschlichen Milchdrüsen," Morphologische Arbeiten, Jena, I897, VII, r 59-199) has shown to be true of the human embryo. If in the course of the suppression of these anlagen the total number is extinguished, the result is complete absence of mammary glands on both sides of the body. The first cause of the amastia is, therefore, referable to a period of embryonal development in which the embryo is not more than $26 \mathrm{~mm}$. $-60 \mathrm{~mm}$. in length. At a somewhat later period the primitive anlage begins to develop into the gland and if at this time, for any reason, the developmental process miscarries, the resulting gland may be rudimentary almost to the point of invisibility, or to the point of unrecognizability.

Disturbance of the developing germ sometimes results in malformation of one or the other upper extremity of the body and affects the mammary gland as well as other structures. Amastia following disturbances of this kind is usually easy to recognize because of the associated defects in the cutaneous, adipose, muscular, cartilaginous or even the body tissues of the thoracic wall, or because of defects in the structure of the arm. In nearly all of these cases the absence of the mammary gland goes hand in hand with thinning of the adipose covering of one or the other side of the chest and loss of the costosternal serrations of the pectoralis major muscle.

It is not impossible that the defect of structure in these cases is akin to the more severe disturbances that lead to sternal fissure and lateral thoracic fissure. Testut has endeavored to account for such cases by supposing that the defect is "a reversion." It is, of course, well known that carnivorous animals are without clavicles, that many quadrupeds have slightly developed clavicles, and that should there be a cessation of 
development in correspondence with what is, normal in these animals-a reversion process-a condition similar to what has been described might arise. Tentchoff (Thèse de Paris, r9oo, No. r69) in discussing this theory of amastia points out that it is invalidated by the fact that the clavicle is always present unchanged and that it is not the superior and clavicular portion of the pectoralis major muscle that is absent, but invariably the inferior costo-sternal portion.

Amastia with associated muscular and other anatomical deformity has also been accounted for upon the supposition that morbid conditions of the central nervous system, by which the influences governing the perfect development of these parts is controlled, may have occurred.

The most satisfactory explanation for cases of unilateral amastia with defect of the muscular and other subjacent tissues is offered by Froriep ("Neue Notizen," r839, X, p. 9) who thinks it caused by the pressure of the arm upon the side of the thorax of the fœtus in utero. This theory makes a strong appeal and finds support in the varying extent of the disturbance which sometimes causes hypoplasia of one gland which may be simply undersized, reduced to a mere rudiment, or entirely extinguished through atrophy, such changes being accompanied by muscular and other deformities usually corresponding in severity to what is shown by the mammary gland. The theory is further confirmed by the discovery, that in some cases, the arm can be fitted into a groove corresponding to the distribution of the atrophied tissues, as in one of Thomson's cases (Teratologia, Jan. I, I895, II, No. I, P. I), and by other signs of compression, such as slight accompanying scoliosis s $_{\text {}}$ in Haeckel's case (Virchow's Archiv, CXIII, p. 474).

It is, of course, by no means easy-if it be at all possible--to determine the cause of the deformity when the patient comes under observation during adult life. For this reason as well as because cases have been reported solely on account of the interest attending the absence of the mammæ it often happens that nothing is said of any existing associated deformity, and it becomes difficult to correctly classify the cases. In the arrangement given below, not a few of the collected cases might as correctly have been placed in one group as in another since the essential data for classification are lacking.

The correlation between the organs of generation and the mammæ has already been discussed, but must now be recalled in relation to the condition in which these organs are found in adult life. It is perhaps easy to conceive that in cases in which the sexual organs, and particularly the ovaries are deficient or defective, the mammæ might fail to develop at puberty as is commonly the case, but it is very difficult to account for such cases as Remfry's in which there were only rudiments of breasts, the diameters of the areolæ being not more than $1 / 2$ inch and the nipples very tiny, the patient having no uterus or adnexa, and still more difficult to account for the two cases of Scanzoni (Kiwische klin. Vorträge, "Die Krankheiten der weiblichen Brüste," Prague, I 855, III, p. 47) in one of which the patient had no right breast and no right ovary, and in the other the patient had no left breast or left ovary.

Neugebauer's “Hermaphroditism beim Menschen” contains a considerable number of cases of pseudohermaphroditism, in females, in which the abnormal condition of the sexual organs is attended by mammary glands of the male type-micromastia.

In a few cases of amastia some inherited defect of development seems to play a part in the production of the deformity. Thus, Geoffroy Saint-Hilaire (Analekten für Frauenkrankheiten, IV, I55) observed a woman having only one breast, whose daughter was similarly deformed. He says that Lousier saw a similar case, but in this he was mistaken. Lousier's statement is, "I know a woman and a young girl each of whom has only one 
breast." Nothing is either stated or implied that should lead to the inference that they were mother and daughter.

In a few cases prenatal maternal impressions are offered to explain the abnormality; thus in King's cases (Medical Times and Gazette, 1858, XVI, 527) the mother of the patient thus sought to account for the daughter's deformity, though the fact that the amastia was accompanied by the absence of the lower serrations of the pectoralis major muscle would seem to make the case fall in the most common group. More interesting is perhaps the case of Paull (Lancet, I862, I, p. 648) in which maternal impression was again offered to account for the condition of the patient who had one normal breast and one so rudimentary that it was represented by a small pimple in the place of a nipple. In this case nothing is said about associated deformity of the muscles, but it is quite clear that the rudimentary structure was a breast, for when the patient became pregnant it swelled and became painful.

Amastia naturally attracts greatest attention when it occurs in women, whose organs are large and prominent and are naturally called upon to nourish their children. But it also occurs in boys and men. Thus, Hutchinson (Medico-Chirurgical Transactions, I886, LXIX, 473) reports the case of a boy of three and one-half years with a peculiar and interesting atrophic skin affection, who had no mammæ. The normal location of each nipple was shown by a little mark like a scar. This boy had normal appearing sexual organs. Thomson (Teratologia, I895, II, P. I), whose studies were chiefly made with reference to the muscular deformity and whose interest in the mammæ was quite secondary, has reported the case of a man I 9 years old with complete absence of the left mamma. Whyte (Lancet, I 904, II, p. I249) has reported the case of a Chinaman 45 years of age with absence of the right breast. Young (Lancet, r894, I, p. I9; 3 I 3 ) a case of a lad 16 years old with no left breast at all, and Zimmermann (Correspondenzbl. für schweizer Aerzte, 1893, p. 36r) a man of 25 with absence of the right breast. In all of these cases of unilateral amastia in males there were associated muscular deformities.

Cases of micromastia are no more easy to explain than those of amastia. Thus, in the case reported by Caillot (Mémoires de la Société Médicale d'Émulation, I798, II, 474) a woman aged 2 I years with mammary glands like a man, was found to have almost an imperforate vulva, and one would naturally expect that the organs of generation were at fault; however, it is not stated that she lacked ovaries. Greenhow (MedicoChirurgical Transactions, I864, XLVII, p. I95) studied a case with imperfection of the sexual organs and deformity of the sternum; she had rudimentary mammæ like those of a man. In Pear's case (Philosophical Transactions of the Royal Society of London, I 865, XCV, 225), the patient had no ovaries and had never menstruated. Her breasts were no more developed than those of a man. Renauldin (Mémoirs de la Société d'Émulation, 1798, II, p. 474) saw a woman 25 years of age whose vulva was nearly closed and whose breasts were no larger than those of a man. McGillicuddy (Medical Record, I89I, XL, 448) saw a woman of 26 , a neurasthenic, with no mammary development, the condition being about the same as in the male breast, nipples alone existing. In this case nothing is said about the condition of the sexual organs.

The amastic and micromastic deformities are very rare. It was at one time supposed that polymastia was also very rare, but when interest in it became aroused and opportunity for special observation and study offered, this was found to be a mistake. The examination of the thoraces of thousands of women in tuberculosis sanatoria and dispensaries; the observation of the breasts of millions of parturient women, and the physical examination of millions of recruits and conscripts have added thousands to the 
cases of polymastia in the literature, but there have been very few additions to the small number of reported cases of amastia.

The most important synoptical papers with collected cases of amastia are those of Williams (Journal of Anatomy and Physiology, r890-9I, XXV, 304) and Hubert (Thèse de Paris, I907). We have reviewed the entire literature, looked up every reference, added a good many cases to those formerly collected, and have attempted to classify them.

The works of Thomson (Teratologia, I 895 , II, No. I, P. I) and Tentchoff (Thèse de Paris, I900, No. I69) upon the congenital absence of the pectoral and other thoracic muscles have been of assistance in tracing out a number of the cases.

In the tabulation it has been thought best to make no strict separation of cases of amastia, athelia and micromastia. In many of the cases of amastia it is said that the breast is represented by a "nipple only," or by a "pigmented spot" or that "there is no mammary development but only a rudimentary organ like that of a man." In all of these cases there may have been some mammary tissue, and in cases in which such women became pregnant it is usually found that there is a tendency for such rudiments "to swell" or to "become painful" or both. There is then an ascending series from cases with no sign of a gland at all, through glands of masculine size and appearance, to glands like one of Engström's cases (Annales de Gynécologie, I889, XXXI, p. 84) in which one gland is said to have been only one-fifth the volume of the other, or McGillicuddy's (Medical Record, I89I, XL, p. 447) in which it was one-half the size of the normal, or Neuhof's (American Journal of Surgery, I9II, XXV, I97) in which the right breast remained like that of a young virgin, while the left breast was enormous, after the patient had nursed four children.

\section{TABULATION OF THE CASES OF AMASTIA AND MICROMASTIA IN THE LITERATURE} UP TO IgI5

A. Aplasia of the mammary glands, apparently referable to total suppression of the primitive "anlagen," there being no associated deformity and no discoverable cause.

I. BiLATERAL.-Complete congenital absence of both breasts.

I. In Females.-BATcenLoR.-British Medical Journal, I888, II, p. 876 .

Lousier.-Thèse de Paris, I80I.

WyLIE.-British Medical Journal, I888, II, p. 235.

Grlix.-Courrier de Méd., I882, XXXII, p. 27 (cited by Hubert).

II. In Males.-Hutchinson:-Medico-Chirurgical Transactions, I886, LXIX, p. 473.

iII. Unilateral.-Complete congenital absence of one breast.

I. In Females.-A. Right side.

Aumont, P.-Province méd., Paris, IgI2, XXIII, 337.

FrorIEP.-Neue Notizen, I839, X, p. 9 .

KInG.-Medical Times and Gazette, $I 858$, May 22, XV, p. 257 .

RIED.-Neue Notizen, I842, XXIII, p. 254 (cited by Hubert).

B. Left side.

Engström.-Annales de Gynécologie, I889, XXXI, p. 84 .

Launois et Hubert.-Thèse de Paris, I907.

C. Side not stated by the reporter.

Foerster.-Préparation de la collection pathologique de Göttingen, Atlas PI. XI (reference given by Hubert).

LOUSIER.-Diss. sur Lactation: Thèse de Paris, I8or.

LOUSIER,-Ibidem. 
Marandel.-Murat et Patissier, Dictionaire des Sciences Médicales, Paris, 1818, XXX, p. 378, article "Mamelle."

Neunasn.-CentralbI. für Gynäkologie, r899, XXIII, I299.

PAOLL.-Lancet, I862, I, p. 648.

S.AINT-HrLAIRE.-Analekten für Frauenkrankbeiten, IV, I55.

SAINT-HILAIRE.-lbidem.

SchI.özer.-Die angeborenen Missbildungen des gesammten weiblichen Geschlechtssystems, Inaug. Diss., Erlangen, 1842 (cited by Williams, Jour. of Anat. and Phys., I890-91, XXV, p. 304).

B. Aplasia of the mammary glands from inhibition of the growth of the primitive "anlagen" associated with simultaneous aplasia of other reproductive organs.

I. Unilateral.-A. Right side with absence of the right ovary.

Scanzoni.-Kiwische klinische Vorträge, "Die Krankheiten der weiblichen Brustdrüse," I855

III, p. 47 .

B. Left side with absence of the left ovary.

SCANZONI.-Ibidem.

II. Bilateral.-The subject being a hermaphrodite.

Prlcher.--Lancet, London, I848, I, 9I5. This case is quoted by Williams in his paper in the Journal of Anatomy and Physiology, r890-9r, XXV, p. 304-305, but we have not been able to find the original contribution, the reference he gives being wrong.

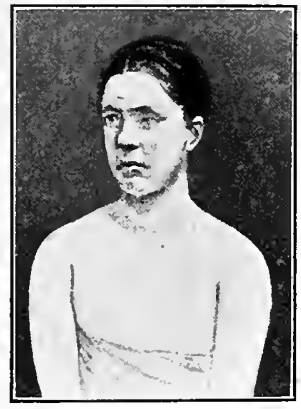

FIG. 23.-Amastia. Complete, bilateral, congenital absence of the mammary glands. (Wylie.)

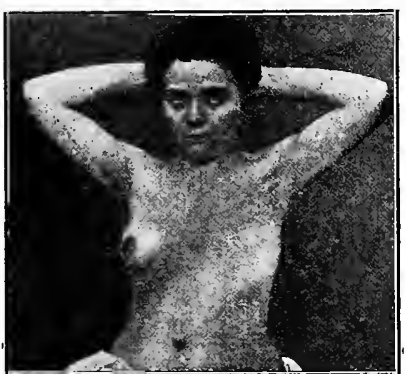

FIG. 24.-Amastia. Complete left unilateral amastia; said to be without muscular deformity. (Launois et Hubert.)

\section{Hypoplasia of the mammary glands.}

I. Micromastia associated with deformity of other reproductive organs.

Bilateral.-

Cailliot.-Mémoirs de la Société médical d'Émulation, I798, II, 474.

DeSinety.-Traité de Gynécologie, r884, p. 947; cited by Williams (Jour. Anatomy and Physiology, r89o-9r, XXV, 304).

GrennHow.-Medico-Chirurgical Transactions, I864, LXVII, I95.

McGillicuddy.-Medical Record, I891, XL, p. 448.

PEARS.-Philosophical Transactions of the Royal Society of London, I805, XCV, p. 225.

Renauldin.-Mémoirs de la Soc. Méd. d'Êmulation, r 798, II, 474.

REMFry.-Obstetrical Transactions, London, I895, XXXVII, p. I2.

BayshaM.-London Medical Gazette, III, p. $73^{2}$.

D. Hypoplasia or atrophy of the mammary glands accompanied by abnormalities of cutaneous, adipose, glandular, muscular, cartilaginous or osseous tissues of the thoracic wall. It is possible that some cases of aplasia may be among these. 
I. Cases in which there were no Mammary Glands at all.

A. In Females.

(a) On the right side.

FroRIEP.-Neue Notizen, I839, IX, X, p. ro.

Lutaud. -Archiv. gén. de Méd., I 9 ro, p. 467.

Viannax.-Rev. d'orthop., Paris, I908, 2 s., IX, 459.

(b) On the left side.

KInG.-Canstatt. Jahresberichte, I58, IV, p. I5.

PeIPER.-Deutsche med. Wochenschrift, I8gr, p. 265.

Srmpson.-British Medical Journal, 1913, I, 336.

Tномson.-T eratalogia, r895, r, No. I, p. I.

WIDMER.-Correspondenzbl. für schweizer Aerzte, r888, p. 472.

B. In Males.

(a) On the right side.

Tномson.-Teratologia, I 895, I, No. r, p. x.

Trentchoff.-Thèse de Paris, "Absence congénitale du grand et du petit pectoral," rgoo, No. 169 .

WhYTE.-Lancet, London, I904, II, p. I249.

ZmMmermanN.-Correspondenzbl. für schwei_er Aerzte, 1893, p. 36r.

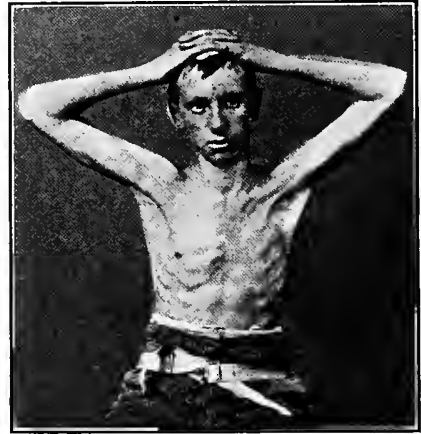

Frg. 25.-Amastia. Unilateral amastia, with absence of the left hreast and associated absence of the pectoralis muscles. (Thompson.)

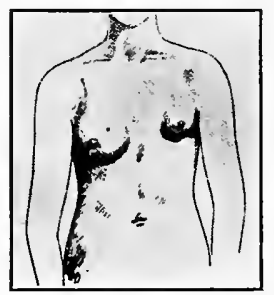

Fig. 26.- Inequality in the size of the mammary glands from left micromastia. (McGillicuddy.)

(b) On the left side.

PeIPER.-Deutsche med. Wochenschrift, I89r, p. 265.

Seitz.-Virchow's Archiv, r884, p. 336.

Tholpson.-Teratologia, 1895 , I, No. I, p. r.

Young.-Lancet, I894, I, p. 19; 313.

Ziemssen.-Inaug. Diss., Greifswald, r89I.

II. Cases in Which there is a Rudiment of a Gland.

A. Females.

(a) On the right side.

GRUBER.-Virchow's Archiv, 1886, CVI, 50r.

Kalischer.-Cited by Hubert, Thèse de Paris, I897.

(b) On the left side.

Gruber.-Archiv f. path. Arat. u. Phys., r886, CVI, 474.

HaECKel.-Ibidem, CXIII, 474. Also Centralbl. für Chirurgie, I889, No. rr, p. 200.

B. Males.

(a) On the right side.

EBstern.-Deutsch. Archiv für klin. Med., VI, 283. 
(b) On left side.

Surdt.-Deutsche Zeitschrift für Nervenheilkunde, I897, X, 402.

III. Cases in which there is a Distinct Gland Considerably Smaller than its Fellow.

A. Femates.

(a) On the left side.

ENGSiröm.-Annales de Gynécologie, I889, XXXI, p. 84.

McGillicuddy.-Medical Record, I 891 , XL, p. 448.

(b) On the right side.

Nецноғ, H.-American Journal of Surgery, New York, Igi I, XXV, I97.

\section{ATHELIA}

The absence of the nipple from one or both of the mammary glands is an infrequent deformity. The only case that seems to have found its way into the literature being reported by Chambers (Trans. Obstetrical Society of London, I897, XXI, 256). The individual was an hermaphrodite, appearing like a woman, and having a well-developed bust. Both nipples were completely absent and the place of each was occupied dy a small rose-colored spot representing the areola. More common than real absence of the essential substance of the nipple is a condition in which it may be flattened, depresseb or even excavated. In the latter case the patient is said to have "hollow nipples" or "inverted nipples." The deformity is a serious one as it makes it impossible to nurse a child. A false nipple with a glass shield to fit against the breast sometimes compensates for the absent nipple, but artificial feeding must be resorted to in perhaps the greater number of cases. The literature upon the subject is remarkably limited, Duval ("De Mamelon et de son Auréola," Thèse de Paris, I86I) having probably written the most important paper upon the nipple and its abnormalities.

Athelia is difficult to explain. Presumably it depends upon the failure of the muscular and fibrillar tissue to develop about the milk ducts at the appropriate time, but the explanation of this failure is not forthcoming. Attempts have been made to account for athelia as a reversionary phenomenon, on the ground that nippleless mammary glands occur in Echidna. This explanation may make an appeal in the absence of anything better, but does not favorably impress the writer.

\section{POLYMASTIA, POLYMAZIA, PLEIOMAZIA, HYPERMAZIA}

Polymastia is an excessive number of mammary glands. The excessive or super fluous glands are known as supernumerary, or accessory or supplementary glands in various writings on the subject.

If total suppression of the embryonal mammary "anlagen" of the milk-lines of the embryo can result in deficiency of glands or amastia, abnormal retention and development of the anlagen can equally well result in an excessive number of glands or polymastia, the condition to which attention is next to be directed. It is unlike amastia in being of frequent occurrence and therefore probably attracted attention in very early times. We have no records to guide us in the study of the history of the subject, but certain facts remain that may be looked upon as suggestive as well as interesting. Thus, the Phoenecian goddess Astarte is frequently represented as having a number of mammary glands, and the famous goddess "Diana of the Ephesians" is usually represented with the trunk covered with large and well-formed mammæ. These are undoubtedly symbolical of fecundity and of abundance but perhaps the origin of the symbol can be traced 
to the observation that human beingṣ are occasionally provided with abnormally abundant mammæ and that such individuals may be exceptionally fecund.

Early writers seem to have been interested in polymastia as a phenomenon, and busied themselves in recording such cases as came under observation, many of which are so fantastic as to remind one of the stories of "the anthropophagi, and men whose heads do beneath their shoulders grow," though others fall into line with later observations and are undoubtedly credible.

A certain glamor of romantic interest attaches to the condition and may explain why rumor, always busy with the affairs of persons of distinction, should attempt to saddle this abnormality upon certain characters in history. Thus, in most writings upon the subject the statement of Percy and Laurent (Article "Multimames" in the Dictionaire des Sciences Médicale, I8I9, XXXIV, 520) that Junia, daughter of Junius Avitus and mother of Alexander Severus had supernumerary mammæ and so earned the name "Junia Mammæ," though as Leichtenstern points out "mammæ" or "mammeæ" may mean "little mother;" and that Anne Boleyn, one of the wives of Henry VIII of England, and one of the most beautiful women of her time, suffered from polydactylism, having six fingers on each hand, and from polymastia having three breasts, is copied without authority, but without question by author after author. Later writers, such as Wyat (Extracts from the life of Queen Anne Boleyn, London, 1818) and Miss Benger ("Memoirs of Anne Boleyn," London, I82I) who have, by reference to existing documents, endeavored to confirm them have been unable so to do.

The literature upon polymastia is very large, and we have collected about 500 references, the greater number of which-all that the libraries were able to supply -were read and analyzed. It is an interesting literature, although it becomes increasingly monotonous as the unfortunate custom that modern medical writers have adapted from the Germans, makes a majority of the recent contributors feel called upon to review more or less of the antecedent literature even though they have nothing more to add than the report of a single new case. The literature consists of reports of single cases, of synopses and tabulations of cases from the previous writings, of tabulations of large numbers of cases in the experience of single individuals, and of attempts to explain the phenomenon along embryological and zoological lines.

Of the writings that deal with the subject the following are of greatest importance and usefulness:

Percy et Laurent.-Article "Multimames" in the Dictionaire des Sciences Médicale, Paris, I819, XXXIV, p. 525 .

Murat et Patrssier.-Article "Mamelle," Ibidem, XXX, p. 378.

Fournier.-Article "Cas rares," Ibidem, IV, p. I5I.

FLeChsig.- "Die Polymastie seu de foemines multimammiis," Inaugural Dissertation, Schneeherg, 1839 . Seems to have been the first to endeavor to study the subject from the standpoint of comparative anatomy and shows that the position of the supernumerary glands in man corresponds to the position of normal mammæ in many of the lower animals.

Bartels.-Archiv für Anatomie, Physiologie and Medizin (Reichert and Du Bois, Reymond's Archiv), 1872,304 .

Bartels was apparently the first to seize upon Darwin's theory of "reversion" as an explanation of polymastism.

Peuch.- "Les mamelles et leurs anomalies," Paris, i 876.

Leichtenstern.-Virchow's Archiv, 1878, LXXIII, 22.

Collected 105 cases which he tabulated and analyzed. He appears not to have known of the works of Flechsig or of Peuch. He is a follower of Darwin, and endeavors to explain polymastism by "reversion." 
J. Mitchele Bruce.--“'On Supernumerary Nipples and Mammæ,” Journal of Anatomy and Physiology, London, 1879 , XIII, 425.

Bruce was an independent worker whose observations of 3956 cases of consumption in the Brompton Hospital, resulted in the discovery of $6 \mathrm{I}$ cases of polymastism. These cases he tabulates.

Nedgebaukr.- “Eine bisher einzig dastehende Beobachtung von Polymastie mit zehn Brustwarzen," Centralblatt für Gynäkologie, ı 886, X, 729 .

Neugebauer's case heads the list of supernumerary organs, his patient having eight supernumerary in addition to the two normal mammæ. He also collected and tabulated the cases in the literature.

Hansemann.-Verhandlungen der Berliner Gesellschaft für Anthropologie, I889, p. 434.

In addition to reporting two new cases, Hansemann tabulates 263 cases collected from the literature.

Bardeleben.- "Die Haüfigkeit überzähliger Brustwarzen (Hyperthelie) besonders beim Manne," Verhandlungen d. anat. Gesellschaft, Jena, 189r, V, 247.

“Über 600 neue Fälle von Hyperthelie bei Männern," Ibidem, I892, VI, I99.

"Weitere Untersuchungen über die Hyperthelie bei Männern," Anatomische Anzeiger, Jena, I892, XIJ, 87 .

"MIassen Untersuchungen über Hyperthelie beim Manne," Verhandlungen der anatomischen Gesellschaft, Jena, I893, VII, I7I.

V. Bardeleben has attacked the subject in a new and thorough manner, using the German military conscripts and extending the observations into hundreds of thousands and compiling and tabulating the results not only with reference to the anatomical distribution of the supernumerary organs, but also with reference to their geographical distribution throughout the German empire. His work is most interesting but is entirely confined to polymastia in men among whom it is unimportant.

Wilirays, W. R.- "Polymastism, with Special Reference to Mammæ Erratica and the Development of Neoplasms from Supernumerary Structures," Journal of Anatomy and Physiology, I891, XXV, 234.

This paper is a long and masterly review of the whole subject, presented from the Darwinian point of view of "reversion" or "atavism." It is one of the most interesting papers, though it suffers somewhat from the extreme prejudice of the author's viewpoint.

IwaI.- "A Statistical Study of Polymastia in the Japanese," The Lancet, London, 1907, II, 753.

"The Relation of Polymastia to Multiple Births," The Lancet, London, I907, II, SI8.

"The Relation of Polymastia to Tuherculosis," The Lancet, London, 190\%, II, 958.

In these papers Iwai gives the results of elahorate and comprehensive studies upon polymastia made in Japan by Kurowa, Katayama, Sato, Otani, and himself. All of the cases are Japanese and comprise both men and women. They number in all 1680 . This paper is useful for comparison with those of von Bardeleben and shows the differences between the European (German) and Asiatic (Japanese) in regard to incidence and distribution.

Hug.-Correspondenzbl. für schweizer Aerzte, Basle, I9r 3 , XLIII, 366.

Collected I०3 cases corresponding in situation to the "milk-lines," and added 18 new cases observed in the clinic at Strassburg.

MARIE, P.-“Mamelon surnuméraire trànsmis héréditairement dans une famille; coincidence avec plusieures grosseuses gémellaires; rèversion ataviquè a ou création d'un type polymaste et polygène," Bull. et Mémoirs Soc. Méd. d'Hôp. de Paris, I893, 3 s., X, 457.

This paper is the best account of the hereditary nature of polymastia that has been published and the family he studied is of great interest containing no less than 19 members so affected.

From the perusal of these papers one can arrive at a very intelligent understanding of the subject, and might write a paper that would make a good showing anywhere. It occurred to us, however, that as most of the interesting cases collected by the writers of the recommended papers had first made their appearance as individual case reports, it might be possible by looking up all of the isolated case reports, in the literature, to add new and interesting ones and bring out new facts of importance bearing upon the subject. We are exceedingly glad that we carried the idea into execution, for though it 
cost many dreary hours of library research, it has furnished so many interesting additions as to make the present writing the greatest collection of cases-especially rare cases-ever brought together.

Influence of Heredity.--Like amastia, polymastia is a congenital condition, but unlike amastia, polymastia is largely a hereditary condition. The reader will remember that the only case of amastia in which heredity was claimed was that of Geoffroy SaintHillaire. But of hereditary polymastia, many cases are reported and carry complete conviction with them. Thus we find:

HACQUARD (Thèse de Strasbourg, I83r, No. 980) reported a case of polymastism whose mother and grandmother were similarly affected.

Marte (Bull. et Mém. Soc. d'Hôp. de Paris, $x 893,3$ s., X, 457) tracing the occurrence of the condition through $\mathrm{r} 9$ members in four generations of the same family.

Alexander (Med. Times and Gazette, London, 1855 , N. S., XI, $; 0$ ) reports the case of a Mulatto man with three nipples on each side of his chest. His mother was similarly deformed, as were his sisters and brothers.

ANDREW (Trans. Path. Soc. of London, I867, XVIII, 27I) reports a case of a man with four nipples whose brother also had four.

Branchard (Bull. de la Soc. d'Anthropologie, Paris, r886, 3 s., IX, 485) reports the case of a Boston man with four nipples. He has $r_{3}$ children. Six girls are free from polymastic malformation but seven boys are like their father in that particular.

Dizweli (Boston Medical and Surgical Journal, $1874, \mathrm{XC}, 274$ ) reports the case of a woman with two marks like "moles," one on each side, below the breast. When she became pregnant it became evident, through pain, enlargement and lactation, that these were supernumerary mammæ. She is the mother of several children, the oldest boy having the same polymastic condition.

Edwards (Medical News, Phila., I886, XIIII, 264) saw a young man with a supernumerary nipple on the right side, whose sister had a supernumerary mamma on the right side.

Handyside (Journal of Anatomy and Physiology, I873, VI, 56) saw two brothers each of whom had four nipples.

Peuce ("Les marnelles et leurs anomalies," I876) refers to a case credited to Scalzi in which mother and daughter were polymastic.

RoBert (Journal générale de méd., $\mathrm{C}, 57$ ) points out that the mother of his famous case of supernumerary mamma on the outer side of the thigh, was a polymastic.

Stoyanov (Bull. de la Soc. d'Anthropologie de Paris, r894, 4s., IX, 30r) states that among his nine cases, heredity appeared twice. First a man, his son and his nephew were polymastic; second, a woman and her mother were polymastic.

Petrequin (Gaz. médicale, r837, p. 195 ) reports the case of a man with three mammary glands, whose five children, three boys and two girls were all similarly malformed.

JEssien (Lancet, I826-27, XII, 6r8) reports a case of supernumerary mamma in the groin, in a patient whose mother also had a supernumerary mamma on the thorax.

Hug (Inaugural Dissertation, Strassburg, rgo8) states that the mother of one of his cases was similarly affected.

Nearly all of the synoptical writers make more or less mention of the frequency of heredity in polymastia but their results vary surprisingly. Thus Bruce was unable to trace heredity in any of his $6 \mathrm{r}$ cases, though Iwai could do so in 6 per cent. of 555 cases so studied.

The probability is that more careful studies will show that polymastism like polydactylism is an hereditary condition that makes its appearance with great regularity and according to fixed rules (Mendel's law).

Theories of Occurrence.-The hereditary character of polymastia being thus established it becomes necessary to inquire how the malformation makes its primary appearance. The earlier writers, who knew of but few cases and in whose writings fiction seems to be somewhat confused with fact, looked upon the occurrence of supernumerary 
mammary glands, as upon all other congenital anomalies as "sports of nature." This seemed sufficiently satisfactory and the matter was given but little attention until Meckel (Illustrirte Med. Zeitung, I8 $8_{2}$, I, I42) endeavored to explain polymastism upon embryological grounds. Unfortunately the data at hand were too inadequate to enable him to succeed, but it is interesting to see the conclusions at which he arrived. Either taking some case that he was fortunate enough to see - though in his writing he does not mention having seen it-or taking the case of Frau Valaque, Gorré's case of the woman with five breasts, as the maximum number possible for a human being, Meckel conceived that every human individual has "anlagen" for five mammary glands, two in the axillary region, two in the pectoral region, and one in the mid-line below the normal breasts. With observations of cases possessing a greater number than five breasts, this theory failed. In I87I Charles Darwin published "The Descent of Man" and suggested that the occurrence of supernumerary mammary glands in human beings might be included among the evidences of "reversion". or the return of ancestral characteristics. The idea seems to have impressed Bartels (Archiv für Anat. Phys. und Med., I872, p. 304) and particularly Leichtenstern (Virchow's Archiv, I878, LXXIII, 222) who wrote the first papers in which cases were collected and tabulated with the purpose of showing the validity of the theory. The greater number of subsequent writers follow Leichtenstern, though a few, like Champneys (Medico-Chirurgical Transactions, I886, LXIX, 4I9) and Leitz (Monatschrift für Geburtshülfe u. Gynäkologie, I9o6, XXIV, 266), whose experiences were chiefly confined to supernumerary axillary glands, have urged another theory of origin, viz., that they arise through modification of the sweat glands.

One other theory of the pathogeny of supernumerary mammary glands remains to be mentioned. It is the theory of Ahlfeld (Die Misbildungen des Menschen, Leipzig, I880) that their occurrence depends upon the transplantation of the primordial mammary cells by means of the amnion.

It may now be well to consider these theories one by one and see what evidence there may be for and against each. Let us take them in the reversed order, ignoring Meckel's theory as being without adequate foundation.

I. Ahlfeld's Theory that Supernumerary Mammary Glands Depend upon the Dislocation of the Primordial Mammary Cells by the Amnion.-So far as our review of the literature goes it seems as though the author of this theory is without a second. That the transplantation of the primordial mammary cells from the normal "anlage" to remote positions on the body surface could be effected by any uniform intra-amniotic pressure is palpably impossible. It must therefore, to be effective, be some kind of local disturbance by the force of which the transplantation is brought about. The only known local disturbance of this kind, is the formation of amniotic bands which occasion far greater damage than uncomplicated polymastia. This theory, therefore, is of novalidity, and is mentioned solely because of its historic interest.

II. The Theory of Champneys (Medico-Chirurgical Transactions, 1886, LXIX, 4I9) Leitz (Monatschrift für Geburtshülfe und Gynäkologie, I906, XXIV, 266) and Geyl (Centralbl. für Gynäkologie, I909, XXXIII, 952; I562) that the supernumerary mammary glands are enlarged and modified sweat glands that give off a modified and milky secretion because of the generally increased activity of the dermal glands during pregnancy and lactation. The authors mentioned are the chief supporters of this theory that appeals to those whose experiences are largely confined to such supernumerary glands as occur in the axilla. It is somewhat curious that it should have occurred to Champneys as the cases that he reports are less distinctly in favor of it than those of 
many other writers. The cases adduced to support the theory are chiefly supernumerary mammary glands occurring in the axilla, and as these form an interesting group, differing in many respects from other supernumerary glands, it seems wise to give them mention at some length at this point.

The existence of axillary mammary glands must often pass undetected, first, because they lack the external morphological characteristics by which mammary glands can be recognized, second, because they are out of sight in the axilla, and third, because they usually do not in any way call attention to themselves except during pregnancy or when they become diseased. For these reasons such formations in the axillæ of men may always escape detection and in the case of women who do not become pregnant, may commonly do so.

The usual history of these cases is, that the patient, not having the least suspicion that she is the victim of any malformation, becomes pregnant, experiences the usual hypertrophy of the pectoral mammæ, and with it, hypertrophy of the supernumerary mammæ. If this be slight, it may pass undetected; if it be more considerable the patient may become conscious of "lumps" in the axillæ; if still more considerable the patient may suffer from pain varying in intensity until in extreme cases it may be necessary to excise the glands to relieve the suffering. The unexpected occurrence of painful "lumps" in the axillæ of pregnant and parturient women has not infrequently been the source of errors of diagnosis, incisions, excisions and other operations having been done under the misapprehension that the surgeon was dealing with abscesses, enlarged lymph nodes, tumors, etc. In a few cases reported by Cameron and by Marotte (see below) the lumps in the axillæ made their appearance at the time of the puberty hypertrophy of the mammæ and remained thereafter. In a great many cases the patient was not conscious of their existence at puberty nor yet during pregnancy, but became suddenly conscious of them during lactation, either because of painful swelling or on account of the leakage of milk and the wetting of the clothing.

An analysis of the published cases enables them to be arranged into an ascending series, as follows:

I. Cases in which lumps of painful character appear in the axilla at the time of lactation or during pregnancy, either where small painless lumps have existed since puberty or where the patient was unconscious of the existence of any abnormality. With each succeeding pregnancy and lactation there is a similar enlargement of the lumps which diminish in painfulness, as a rule, with each pregnancy. The period of enlargement is usually limited to a few days or weeks after lactation begins. The size of the enlargement varies from a nut to a goose egg. The lumps are unattached to the skin-in Bacon's case it is said that they appeared to "be in the skin"-are more or less freely movable, more or less lobulated and distinctly of an alveolar texture when palpated. There is nopigmentation over them, nor are there any openings for the escape of secretion. The definite relation of the lumps to mammary tissue is recognized through the following conditions:

(a) Many such lesions having been excised and examined prove to be mammary tissue.

(b) The modifications of size and activity coincide with those of the mammæ proper.

(c) In a few cases a communication can be made out between the mamme and the axillary tumor of the corresponding side. Thus in one of Peuch's cases (Archives de tocol. et de gynéc., Paris, I892, XIX, 323) and in one of Lessueur's (Rev. méd. de la Suisse Romande, I900, p. 435) cases, and in Völker's case (Centralbl. für Gynäkologie, 1899, XXIII, 578 ) the connection is said to have been like a cord.

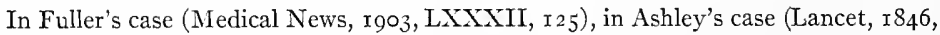
II, 227), and in one of Lessueur's (Rev. méd. de la Suisse Romande, I900, p. 435) cases, 
there must have been ducts, for when the baby nursed at the breast, the axillary tumors previously firm, became flaccid as the breast itself did. Such cases give one the impression that the axillary tail of the mamma has been unusually prolonged toward and into the axilla and partly separated from the gland proper.

When a hypodermic needle is introduced into the firm and painful swelling a drop of milk can be obtained.

In rare cases in which secretion was active and abundant, there being no means for its escape-as in Harriss's case (Savannah Journal of Medicine, 1860-6I, III, I74)-a cyst may form, fluctuation develop, and upon tapping as much as a pint of milk be removed.

Cases of this kind may be bilateral or unilateral, and have been reported as follows:

\section{A. Bilateral Occurrence.-}

Auvard.- 3 cases, Archiv. de tocol., Paris, I888, XV, 622.

BACon.-2 cases, Medical News, I902, LXXXI, 256.

ERDHEIM.-Berliner klin. Wochenschrift, I9I3, L, 943.

GARLAND.-Edinburgh Medical Journal, I877-78, XXIII, 45 .

Godfrain.- Thèse de Paris, I 877 .

GoldBerger.-(Abst.) Archiv für Gynäk., XLIX, 272, Heft. 2.

Grimoud AND EtcheverRy.-Toulouse médicale, I903, $\mathrm{V}, 149$.

HARRISS.-Gaz. hebdomadaire, 1864, p. 468; Savannah Med. Jour., I860-6I, III, I68.

HAYLes.-Lancet, London, I907, I, I 760-62.

Hıntze.-(Abst.) Centralbl. für Gynäk., I897, i6r.

Hoffstatter.-Münchener med. Wochenschrift, I9io, LVII, 2295 .

Kayser.-3 cases, Archiv für Gynäkologie, I908, LXXXV, 59. Berliner klin. Wochenschrift, I904, XLI, 76.

KeHrer.--La Riforma Medica, I896, XII, 427.

Lessueur.-2 cases, Rev. méd. de la Suisse Romande, Igoo, p. 435.

McGillicuddy.-Medical Record, I891, XL, 446.

Maschat.-Thèse de Paris, $x 883$.

Neilson, T. R.-Unpublished. Hospital of the Protestant Episcopal Church of Phila. There were

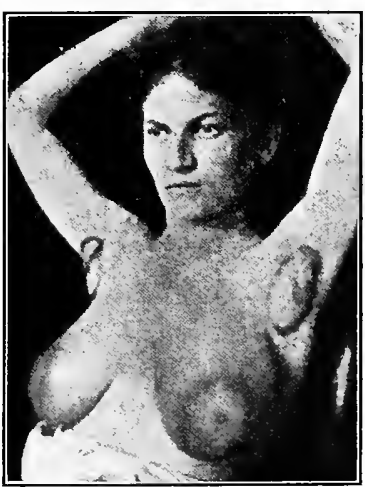

FIG. 27.-Polymastia. Supernumerary mammary glands in the axilla. (Kayser.) axillary mammary glands on both sides, but in the right axilla a large tumor grew and necessitated operative removal. When microscopically examined, it was a fibro-epithelial tumor with carcinomatous charge.

Polden.- 2 cases, Indian Medical Gazette, Calcutta, I887, XXII, $24 \mathrm{I}$.

Peuch.-Archiv de tocol. et de gynécologie, Paris, I\$92, XIX, 323. (The gland in the left axilla seemed to connect with the pectoral mamma by a kind of cord.)

Von SIebold.-Med. Zeitung, i 838 , No. 6.

Vulker.-Inaug. Diss., Bonn, I897, (Abst.)) Centralbl. für Gynäkologie, I899, XXIII, 5;8.

VON DER HErDE.-2 cases, Zeitschrift für Geburtshülfe und Gynäkologie, LXVIII, Centralbl._für Gynäkologie, I9ı $x, \mathrm{XXXV}$, ıо7.

B. Unilateral.-

(a) Right axilla.

Bubis And Graham.-Journal of the American Medical Association, I915, LXV, Ioig.

Canteron.-Journal of Anatomy and Physiology, 1897, XIII, I49.

Cuneo.-La Riforma Medica, Napoli, I894, X, 282.

CнAMPNEys.-Medico-Chirurgical Transactions, I886, LXIX, 419.

FullER.-Medical News, I903, LXXXII, I 25. 
Godfraln.-Thèse de Paris, $187 \%, 2$ cases.

Goldberger.-Archiv für Gynäkologie, XLIX; Centralbl. für Gynäkologie, r896, XX, I 2.

Maschat.--Thèse de Paris, 1883.

Mourne, P.-Bull. et mém. de la Soc. d'Anat. de Paris, r9r4, LXXIX, Ir5. Removed an ulcerating carcinoma that grew from an axillary mammary gland.

de Rouvilie.-Bull. Soc. d'ohst. et de gynéc. de Paris, rgr4, iii, 552. A tumor grew from the axillary gland in this case.

Vulker.-Inaugural Dissertation, Bonn, r897.

ZIEHEN.-Berliner klinische Wochenschrift, x904, p. 9 r 2.

(3) Left axilla.

CAMERon.-Journal of Anatomy and Physiology, r879, XIII, 149.

V. BRUnN.--Festschrift für Rindfleisch, 1907,155 .

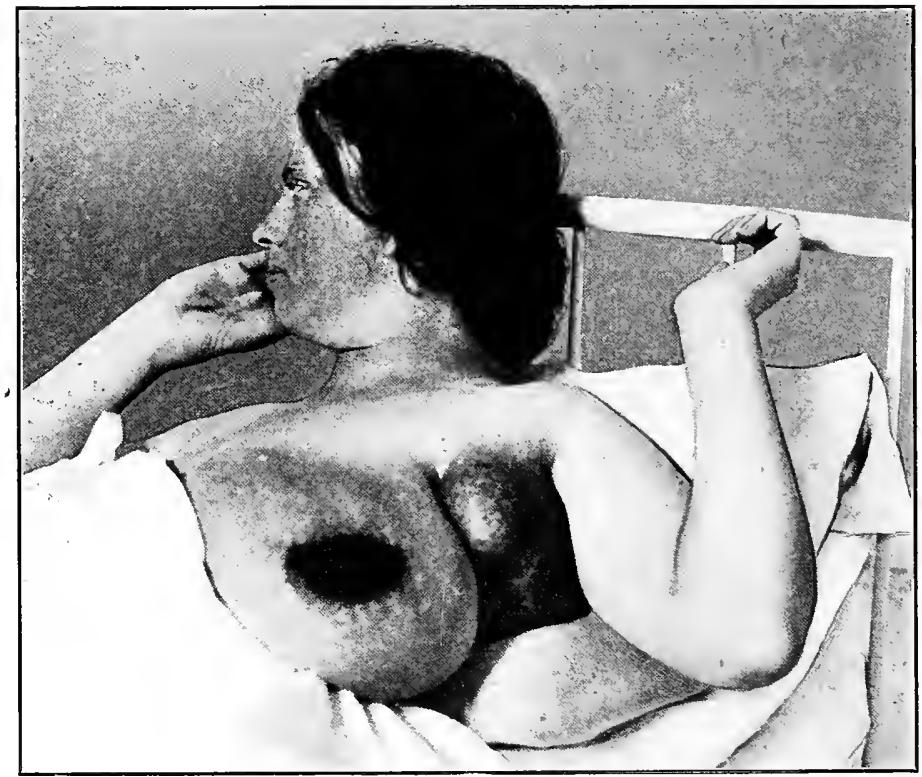

F1G. 28.- Axillary Polymastia. The mammary tissue in the axilla enlarged coincidentally with lactation in the normal mammx. The opposite axilla contained an accessory mamma in which there was fibro-adenoma that had undergone carcinomatous transformation. Patient of Dr. Thomas $R$. Neilson.

FISCHER.-Wiener klinische Wochenschrift, rgr2, XXV, r229.

GaEhlinger, M.-A male patient, Echo méd. du nord. Lille, rgo4, VIII, r5.

Gidson, E. A.-Trans. Glasgow Obstetrical and Gynæcological Society, r896-98, I, 77 .

Jacoulet, F.-Prog. méd., Par., I909, 3 s., XXV, 618 (adenoma in the axilla).

KAyser.-Archiv für Gynäkologie, I908, IXXXV, 459, 2 cases. Berliner klin. Wochenschrift, I904, XLI, 767 .

KNABEL.-Monatsschrift für Geburtshülfe und Gynäkologie, Berlin, I9ıo, XXXI, 547.

MASChat.-Thèse de Paris, 1883.

Meyer.-New York Medical Record, r\$86, XXIX, 455.

Neve.-Lancet, London, I894, I, Sor. 
Monaco.-Archiv. di ostet. e. ginecologie, Napoli, I906, XIII, 599.

Peratre ex Cornil.-Bull. et mém. de la Soc. d'Anat. de Paris, igo7, 6 s., IX, 637. A tumor grew from this gland and first called attention to it.

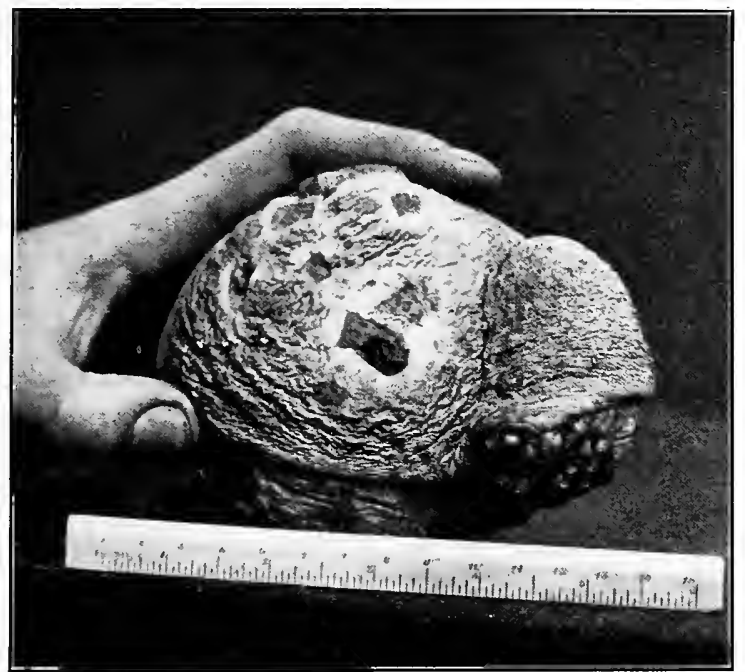

FIG. 29.-Showing the dimensions of the axillary mamma containing a tumor removed from the patient shown in the preceding figure.

(c) Side not stated.

BAKER.-Cincinnati Lancet-Clinic, $1911, \mathrm{CV}, 500$.

WHITACRE.-Cincinnati Lancet-Clinic, I911, CV, 500. This case was an old woman who developed carcinoma of the axillary gland.

McFarland aNd Laplace.-Unpublished. Small mass removed from the axilla, found upon microscopic examination to be a mammary gland.

Gillespre,-Cincinnati Lancet-Clinic, I 9 I I. $\mathrm{CV}, 500$.

HAECKel, H.-Archiv f. klin. Chirurgie, I894, XLVII, 274 .

Cameron.-Journal of Anatomy and Physiology, I879, XIII, I49.

Maschat.-Thèse de Paris, 1883 .

II. Cases in which "axillary lumps" similar to those already described occur under like. conditions, but discharge their milky se-

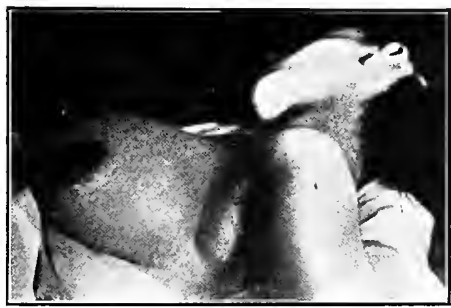

FIG. 30.-Polymastia. Supernumerary mammary gland in the axilla. (Gibson.) cretion through openings of varying size and

number. In these cases there is no areola and no nipple to suggest that the lumps are mammary glands, but their secretion is sufficient evidence of their nature. Like the others they may be bilateral or unilateral, or one of the former kind may occur in one axilla and one of the latter kind in the other. 


\section{A. Bilateral in Occurrence.-}

Champion.-Dictionaire des Sciences Médicale, Paris, I8r9, XXX, 377 (Article, "Mamelle" by Murat et Patissier).

Champneys.-Medico-Chirurgical Transactions, r886, LXIX, 4rg.

Drxon.-Gazette Medical, Paris, 1844 , p. I25.

FUller, WM. - Chicago Medical Recorder, r903, XXIV, ro6. In this case the gland in the right axilla became flaccid when the baby nursed from the right breast.

FAVR.-(Abstract) Centralbl. für Gynäkologie, I886, X, 824 .

FULlerton.-New York Medical Journal, I897, LXV, 156.

Marotte.-Union Médicale, Paris, I849, III, 424.

MARTIN, M. E., JR.-Dict. des Sciences Médicale, 1818 , XXX, 377 , article "Multimammes."

Martin.-Ann. d'ocul. et gynécol., Charleroi, I838, I, 185; 196.

Matrison.-Journal of the American Medical Assn., r9I2, LIX, 276 . Three separate glands were present in each axilla.

Turner. - Trans. of the Rhode Island Medical Society, Providence, I862, I, I7 2.

SEITz.-Monatsschrift für Geburtshülfe u. Gynäkologie, Igo6, XXIV, 266 .

B. Unilateral.-

(a) Right axilla.

Auvard.-Archiv de tocol., etc., Paris, 1888, XV, 622.

Brown.-Worthwest Lancet, St. Paul, r888, VIII, 89.

Duncan.-Obstetric Journal of Great Britian and Ireland, r873, I, 5 r6.

HaRE.-Lancet, London, r86o, Oct. 27.

HofstaetTer.-Münchener med. Wochenschrift, rgro, LVII, 2295.

Henrotay. - Bull. Soc. Belge. de Gynécologie et d'Obst., I9I r-r2, XXII, r4o.

Templeton.-British Medical Journal, r8 99 , I, ro89.

TuRney.-Nashville Jour. Med. and Surgery, r883, April.

(b) Left axilla.

FAVR-Vratch, St. Petersburg, r885, VI, 78 r. (Abstract) Centralbl. für Gynäkologie, I886, $\mathrm{X}, 824$.

CoHn.-Deutsche med. Wochenschrift, I885, XI, 173.

Fuller.-Medical News, I903, LXXXII, I 25.

Notra.-L'Union Méd. Paris, 1882, 3 s., XXXIII, I57.

III. Cases in which the axillary "lumps" are surmounted by more or less distinct areole and one or more rudimentary nipples, which together with the fact that they secrete milk brings them still more closely into line with recognizable mammary glands.

A. Bilateral. -

AsHLEY.-Lancet, London, 1846, II, 227.

CRAighild, J. M.-Gaillard's Medical Journal, New York, I903, LXXVIII, 217.

DAREY.-Montreal Medical Journal, I889-90, XVIII, 732. In Darey's case there were areolæ but no nipples on the lemon-sized axillary mammary glands.

Godfrain.-Thèse de Paris, 1877 .

MOORE.-Revue Médicale, 1838 , II, 256.

SEITZ.-Monatsschrift für Geburtshülfe und Gynäkologie, r9o6, XXIV, 266.

B. Unilateral.-

(a) Right axilla.

ChampNeys. - 2 cases, Medico-Chirurgical Transactions, r886, LXIX, 4r9.

Hofstätter.-2 cases, Münchener med. Wochenschrift, igro, LVII, 2295.

KNABEL.-Monatsschrift für Geburtshülie und Gynäkologie, Igro, XXXI, 547.

Monaco.-Archiv. di ostet. e ginec., Napoli, I906, XIII, 599 .

(b) Left axilla.

Champneys.-Medico-Chirurgical Transactions, r886, LXIX, 4I9.

IV. Cases in which there is a distinct mammary gland in the axilla, upon which there is a distinct areola and a fairly well-formed nipple. These cases leave no doubt as to their nature even when there is no lactation in progress.

A. Right Axilla.

Champneys.-Medico-Chirurgical Transactions, r886, LXIX, 419.

Dionne.-New York Medical Journal, r893, LVIII, 760. 
Hrrschboeck.-Journal American Medical Association, 19i 2, LVIII, p. I 143.

B. Left Axilla.

ChAdrpxeys.-Medico-Chirurgical Transactions, I886, LXIX, 4I9.

BRowx-- Northwest Lancet, St. Paul, i888, VIII, 89.

D'Outrepoxt.-(Cited by Leichtenstern.) Archiv für path. Anat., etc., I878, LXXIII, p. 254, Case ror.

V. Axillary mammary glands reported but without data for classification in the above groups:

Perrier.—2 cases, Gynaekolog., Helvet., Igog; Centralbl. für Gynākologie, rgio, XXXIV, 490.

Cuxeo.-Bull. d. r. Accad. Med. di Genova, I895, X, 22.

To one seeing axillary mammary glands enlarge and become painful during puberty, gestation or lactation for the first time, and without knowledge of the different forms in which they occur, it may appear that they arise through enlargement or modification of sebaceous or sweat glands, but to those acquainted with the reported cases and able to group them serially and progressively from the simple subcutaneous swelling to the fully formed supernumerary glands with areola and nipple, the theory under consideration should make no appeal. This will become all the more apparent after the discussion of the next theory, and it will then be found that the axillary mammæ fall in line with the embryological and phylogenetic distribution of supernumerary mammary glands in general.

III. The Theory of Darwin that Polymastism is a Reversionary or Atavistic Phenomenon.--This theory, brought out in the "Descent of Man" I87I, was quickly accepted by the greater number of scientific writers and is still the most applicable and the most acceptable theory. It is based upon the doctrine of evolution, i.e., the progress of living - substance from the simple and undifferentiated to the complex and highly differentiated. In the course of the transformations attending such progress new types and new structural arrangements are continually presenting themselves, while old types and old structural arrangements are eliminated. The old is apt to be forgotten unless some of its representatives survive to continue living, side by side, with the new. The world of living things is looked upon as made up of surviving types of structure of all degrees of complexity, descended from ancestral types many of which have become extinct. It has long been a pet theory of embryologists that the phylogeny-i.e., the ancestral history -of each higher creature is displayed in its embryonal development. As ordinarily expressed "the ontogeny recapitulates the phylogeny." Thus, in the development of the human ovum there are stages when it would appear as though the creature developing might become a fish; a little later, a reptile; still later, a bird; and only very late does it become certain that it will be a mammal and a human being. Thus the ontogeny of the human being displays the phylogenetic descent through the common ancestors of fishes, amphibians, reptiles, birds and mammals. The resemblances are quickly outlived and no human embryo ever does become a fish, a batrachian, a reptile, a bird, or any mammal except a man, because the inherited impulses to develop are intense according to the nearness and outgrown according to the remoteness of the ancestors. But though phylogenetic resemblances so remote as those having to do with fishes, batrachians, reptiles and birds are not known to occur in adult men, phylogenetic resemblances to mammalian ancestors not infrequently do appear. Such resemblances may be the common possession of man and some existing mammal of lower type, but more frequently of man and an "atavus" or common ancestor shared by himself and the existing mammal of lower type. The reason for this is evident. As man evolves from his early 
ancestors, other descendents of those same ancestors develop along different lines. The common ancestor may die out, but the divergent descendents remain. Thus man is not descended from any monkey now known to us, though man and the existing monkeys probably had some monkey-like ancestor in common. To go farther back, man, monkeys and bats probably had a common ancestor not like a man, nor a monkey, nor yet a bat; and to go still further back we come to more and more remote common ancestral forms less and less like the existing forms that we know, and yet always presenting certain fundamentals of structure that are common to all their descendants. It is probably true that every living creature inherits something from every one of its ancestors. The more remote they are, however, the less evident is the inheritance until it becomes unnoticed and forgotten. Under circumstances not yet explained it occasionally happens that a remote ancestral characteristic unexpectedly becomes evidentmakes its appearance anew. This phenomenon is known as "reversion" or "atavism." Thus some special feature - such as a lock of white in a head of black hair on a child's

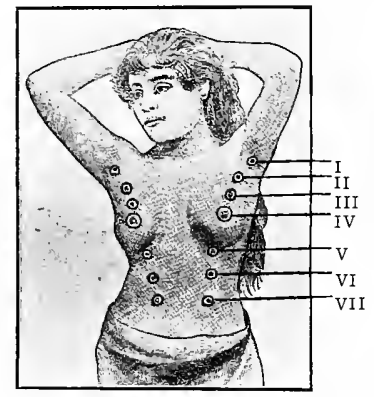

FIG. 3I:-Williams' idea of the arrangement of seven pairs of mammary glands in man's early progenitors. (Williams.)

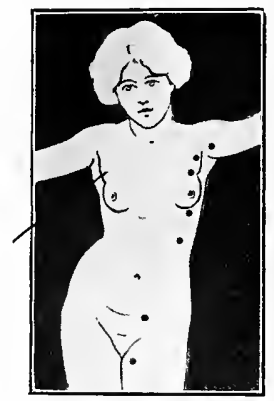

FIG. 32.-Diagram showing the positions at which supernumerary mammary glands were known to occur. (Stratz.)

head-may recall that his great-grandfather was similarly marked. The great-grandfather is then the "atavus." Or, we can suppose that excessive hairiness of the body gives the man a monkey-like appearance. The monkey-ancestor, or at least that ancestor common to man and existing monkeys, then becomes the "atavus" and so on indefinitely, but the further back we go, the less frequent do the reversionary phenomena become.

Among the phenomena of reversion manifested by human beings Mr. Darwin placed polymastism or multiplicity of mammary glands. It will occur to everyone at all familiar with comparative anatomy that human beings have but two mammæ, which is the smallest number possessed by any mammal. If the supernumerary mammary glands are the result of reversion and are atavistic in origin, this occurrence ought to be foreshadowed in the embryo and their distribution ought to correspond with that of the mammary arrangements of the lower mammals, or at least to fall into correspondence with arrangements that can be plausibly claimed for atavi or common ancestral forms.

First, let the embryological evidences be considered. We now readily recall from the numerous occasions when it has been necessary to mention it, that in the human as 
in most mammalian embryos, at an early period of development, the "milk-leisten" or "milk-lines" of $O$. Schultze can be defined, and that these shortly cease to be continuous formations but become interrupted to form a series of tiny points, each of which is the "anlage" of a mammary gland. Here we seem to have the ontogeny recapitulating the phylogeny, for this stage of the human embryo bears a close correspondence with what we see in carnivora, for example. If now the test of nearness and remoteness to the reversional appearance of supernumerary mammary glands be applied, it should be found that whatever befalls these mammary "anlage" should result most frequently in the occurrence of conditions such as obtain among the higher mammals and less frequently in conditions such as obtain among the lowest mammals. Therefore, the mammary arrangement of polymastic human beings should more closely resemble what is to be found among monkeys, bats and insectivorous mammals, than what is to be found among herbivorous, marsupial or monotreme mammals. Yet, it must not be forgotten that though such an order of occurrence should be the rule, in rare and exceptional cases the phenomena of reversion may reproduce conditions obtaining only in the marsupials or even the monotremes.

In order to further test the theory of reversion it now becomes necessary to inquire concerning the distribution of mammary glands in such mammalian forms as may suggest the atavus, and second to group the collected cases of supernumerary mammary occurrence and see how they tally.

\section{Comparative Anatomy of the Mammary Glands.-}

For the purpose of this writing the order of classification will be reversed and the scale of life descended instead of ascended as is usual. The object of this method of treatment is to enable the reader more easily to work backward in search of the "atavus" to whom the inherited "reversion" may be attributed.

\section{Eutheria Vera.-}

Primates.-Comprising man, apes, monkeys, lemurs, etc. Man and all of the apes and monkeys down to marmosets are provided with one pair of mammæ, situated in the pectoral region. Among the lemuridæ, in addition to the pectoral mammæ, there may be one or two additional pairs upon the abdomen. In Hapalemur griseus, Beddard found mammæ on the arms near the acromion processes. In Tarsius spectrum in addition to the pectoral glands there is an inguinal pair. In the Aye-aye-Chiromys madagascariensis-Owen found but one pair of nipples situated about an inch and a half in advance of the vulva and about an inch apart. The flying lemur, Galeopithicus, also has axillary mammæ.

Chiroptera.-Among bats, flying foxes, etc., there are pectoral mammæ in addition to which Pteropodidæ or fruit bats have axillary mammæ.

The Rhinolophidx or "horse-shoe-nosed" and "Jeaf-nosed" bats occasionally have rudimentary mammæ in the inguinal and pubic regions.

Insectivora.-Moles, shrews, hedgehogs, tenrecs, etc. It is probably in this group that we find the greatest number of mammæ seen in the higher mammals. They may have iI pairs, as in Centetes, and rarely have less than seven pairs. They are usually situated upon the ventral surface of the thorax and abdomen extending from the inguinal to the axillary regions in two lines converging toward the former and diverging toward the latter.

Sorex crassicaudatus, a shrew, has in addition to others, two pairs of teats, in the groins and another pair under the base of the tail near the anus.

Rodentio.-Rabbits, guinea-pigs, squirrels, rats, mice and other gnawing animals. These all have ventral mamma upon the thorax and abdomen, except a few like the guinea-pig, which has inguinal mammæ only, and only one pair. Myopotamus coypus, a small swimming rodent, has a pair of mammæ near the dorsal spine (Proc. Zool. Soc., 1835, p. I82).

Capromys fournieri has a mammary gland behind each axilla. It swims in the water together with its young, who on account of the dorsal position of the mammæ are able to nurse in the water and still keep their noses in the air outside. It also has a mammary gland on each side, in front of the thigh and nearer to the back than to the belly. 
Lagostomus trichodactylus, a South American chinchilla-like animal, belonging to the porcupine group of rodents, has a mammary gland upon the dorso-lateral aspects of each thigh.

Erethezon has mammary glands above the axilla.

Carnivora.-Carnivorous animals such as cats, dogs, wolves, etc. They all have ventral mammæ upon the thorax and abdomen.

Ungulala.-Hoofed animals, cattle, sheep, goats, horses, antelope, deer, elephants, etc. In nearly all of the animals of this group the mammary glands are in the inguinal region. There are exceptions, however, as in elephants when they are pectoral.

Sirenia.-The menatees, dugongs, etc. These animals have pectoral mammæ.

Cetacea.-The whales, dolphins, porpoises, etc. The animals of this group are somewhat important because the mammary glands are upon the labia of the vulva.

\section{Metatheria.-}

Edentata.-The ant-bears, aard-varks, pangolins, etc. These have pectoral mammæ.

Marsu pialia.-The kangaroos, wombats, Tasmanian devils, opossums, etc. These animals are mostly Australian and are provided with a pouch in which the young are carried. The young are produced in a very immature state and are at once placed in the pouch by the mother, each attaching itself to a teat where it hangs suspended for some time. The strong muscles of the nipple by contracting, force the milk into the alimentary canal of the young. The only American representation of the marsupial animals is the opossum-Didelphys virginicus. It has no pouch but it has a large number- 30 or upward- of mammæ upon the ventral surface of the thorax and abdomen, the outer in two rows corresponding to the milk-lines, the others concentrically arranged about the center of the ventral surface, chiefly of the abdomen. An odd mamma commonly occupies a central position. This is the first time that a median or central mamma has been mentioned.

III. Prototheria.-

Monotremata.-This group contains two remarkable animals, the ornithorrhynchus or duckbill platypus and the echidna. Each is almost as closely allied in structure to the birds and reptiles as to the mammalia. The animals lay eggs in nests where the young hatch. There are badly differentiated mammary glands without nipples. In the ornithorrhynchus the ducts of the glands open upon the hairy surface of the abdomen; in echidna there is a cutaneous pouch or pocket in which the milk is caught as it exudes from the ducts of the diffused glands. In the male ornithorrhynchus there is a femoral spine and an associated dermal gland commonly looked upon as a venom gland. It is in no way connected with the mammary glands and should not be confused with them.

In glancing over such a synopsis and noting the remarkably wide latitude of distribution of mammary glands among the various groups of mammals, it becomes evident that all supernumerary glands occurring in human beings, located in correspondence with any of the situations here mentioned may be phenomena of "reversion" or "atavism."

A recapitulation of the situations in which mammary glands may occur gives us the following:

I. Distribution corresponding to the "milk-line" and extending on each side of the hody from the inguinal to the axillary regions as in insectivores, carnivores and many other animals.

2. The axillæ as in the flying lemurs and the fruit bats.

3. The acromial regions as in Hapalemur griseus.

4. The inguinal region as in Chiromys madagascariensis and the Rhinolophidæ.

5. The dorsal spine as in the Myopotamus.

6. Behind each axilla as in Capromys.

7. The dorso-lateral aspects of the thigh as in Lagostomus.

8. The vulva as in the Cetacea.

9. The center of the thorax or abdomen as in Didelphys.

It next becomes important to review the reported cases of polymastia in order that it may be known in what anatomic distribution the supernumerary organs occur. In doing this it may be wise to point out that the number of supernumerary organs has 
nothing to do with proving or disproving the question. It is not a question of numbers but of distribution. The tendency of the developing human embryos is to suppress and extinguish all of the mammary "anlage" except the pair in the pectoral region. Failure of the normal process of extinction may result in the presence of one additional gland, or as in Neugebauer's extraordinary case, in the presence of eight additional glands. Nor does the perfection or imperfection of the supernumerary organ have anything to do with the proof or disproof of the argument. The most minute rudiment of an organ is of as much importance as a perfect and functional gland so long as the position is significant.

For this reason we assume that every nipple is upon a rudimentary gland, and make no distinction between polymastia and polythelia, except in the cases in which an otherwise normal breast in the normal position has two or more nipples upon it.

A. Reported cases of supernumerary mammary glands in a distribution corresponding to the primitive "milk-lines" of the embryo, and to the normal distribution in the insectivora and carnivora as well as many other animals.

\section{ONE SUPERNUMERARY MAMMA.-}

\section{r. In Male Subjects.-}

A. ON the Right Side.

(a) Exact locaticn not given.

Nevgebauer.-Centralbl. für Gynäk., r886, X, 734 .

(b) Above the normal orgon.

Wнyте, D.-Thomson and Miles, "Manual of Surgery," II, 332, Fig. 9r.

(c) Below the normal organ.

BARTELS-LEICHTENSTERN-Archiv für path, Anat., etc., r878, LXXIII, 243.

DE LAVal.-Cited by Puech, Les mamelles et leurs anomalies, Paris, 1876 , p. 113 .

Edwards.-Medical News, Phila., I886, XLIII, 264.

Gaeulinger, M. $\rightarrow 7$ cases, Echo méd. du nord., Lille, I904, VIII, 15.

'Letchtenstern.-Archiv für path. Anat., etc., r 878 , LXXIII, 244.

Marcour, R. O.-2 cases, Medical Record, New York, $x_{904}$, XLVI, 498.

McConnell, Guthrie.-Personal communication.

Murchison.--Trans. Path. Soc. of London, r866, XVII, 426.

Paravicini, G.-Archiv. di psichiat., etc., Torin,

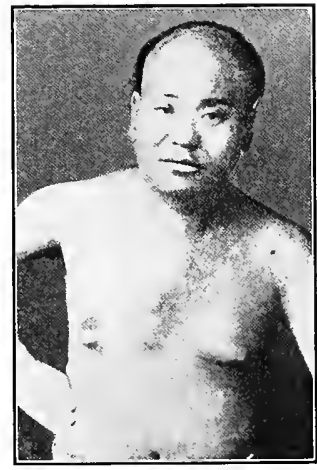

FIG. 33.-Polymastia: A supernumerary gland on the right side, above the normal one. (Thompson and Miles.) r9o3, XXIV, 249.

Stoyanov. -4 cases, Bull. de la Soc. d'Anthrop., Paris, I898, s4, IX, 30 I.

B. ON THE Left SiDE.

(a) Above the normal organ.

(b) Below the normal organ.

CAMERon.-See Sneddon's paper, Glasgow Med. Jour., r878, pp. 69, I 20.

GaEhlinger, M.-6 cases, Echo méd. du nord., Lille, r904, VIII, I 5.

HANDFORd,-Trans. Path. Soc. of London, I885, 6, XXXVII, 568.

Huriez.-2 cases, Echo méd. du nord., r900, 327.

Janssen.-Nederl. Tijdschr. v. Geneesk., Amsterdam, r9०3, 2 R, XXXIX, d. 2, r ro8.

Leichtenstern.-Archiv für path. Anat., etc., I878, LXXIII, 244.

McGillicundy.-Medical Record, New York, I89 r, XL, 446.

Marcour, R. O.-Medical Record, New York, Sept. 24, r904, LXVI, 498.

Petrequin.-Gazette médicale, r837, p. I95.

Washrourne.-Trans. Path. Soc. of London, i 867, XVIII, $27 x$.

Woodman.-Trans. Obstet. Soc. of London, r867, LX, 50. 
C. Side not Stated.

(a) Above the normal organ.

(b) Below the normal organ.

Gotrwasd, ].-Deutsche med. Wochenschrift, r903, XXIX, 340.

2. In Female Subjects.

A. ON THE Right Side.

(a) Above the normal organ.

DronNe. - 2 cases, New York Med. Jour., I893, LVIII, 760.

Hirschboek.-Journal of the Amer. Med. Assn., Igr 2, LVIII, 1443.

HUG, J.-4 cases, Inaugural Dissertation, Strassburg, rgo8.

Perrymond.-L'Union médicale, Paris, I874, 3 s., XVIII, 865.

(b) Below the normal glands.

Austin.-Therapeutic Gazette, r880, n.s., I, 95.

Blankaart.-Hollands. Jaar. Register Anat., r683, Cent. V, p. 54, Obs. 49.

Bryant.- "Diseases of the Breast:" r887, p. Io.

Cruveilmier.-Traité d'Anatom. discript., r865, 4th Ed., II, p. 5 rr.

ChampNeys.-Medico-Chirurgical Transactions, r886, XIX, 4rg.

De Montméja.-Revue phot. d'Hôp., Paris, r874, p. r8r.

EdWards.-Medical News, Phila., r886, XIIII, 264 .

HaUSER.-Zeitschrift d. Gesellschaft d. Aerzte zu Wien., July, r857.

HUG, J. -5 cases, Inaug. Dissertation, Strassburg, r908.

Johnston.-Maryland Medical Journal, Baltimore, r888-89, p. 427.

Kerkringius.-Obs. Anat., XXI, p. 49.

KLeBs.-Handbuch der path. Anat., I, 2, rr66.

Le Gendre.-Gaz. méd., Paris, 1859, 773.

LuтоснпN.-(Abstract) Centralbl, für Gynäkologie, r897, XXI, Heft $x 6$.

Pitzorno.- 3 cases, La Riforma Medica, I896, XII, Pt. i, p. 65 I.

Robinson.-St. Louis Courrier of Medicine, r884, XI, 360 .

SADLER.-Schmidt's Jahrbücher, r842, XXXIII, 66.

SNeDDon.-Glasgow Medical Journal, r878, 69; 20.

Stoyanov.-2 cases, Bull. de la Soc. d'Anthropologie de Paris, I898, s. 4, IX, 30 .

TEstut.-Bull. de la Soc. d'Anthropologie, Paris, I883, 3 s., VI, 649.

ThURSFIELD.-London Medical Gazette, 1838 , I, 898.

von Siebold.-Med. Zeitung, I838, No. 6 .

WincKEL.-4 cases, "Lehrbuch der Frauenkrankheiten," I886, 739.

(c) Far below the normal organ.

Chapman.-The Lancet, London, I856, I, I92.

Edwards:-The Medical News, Phila., I886, XIIII, 264.

Belonging to this group but with insufficient data as to situation.

AUBEAU.-Mouvement médicale, r873, p. 567.

BlaEs.-Comment. ad Veslingii syntagma Anat., Amst., r659, Cap. IX, x33g.

Blancard.-Collect. med. phys. Cent., V, No. 49.

LoRRAin.-Rev. phot. des Hôp., Paris, r870, p. 18.

ROBERT.-Journal générale de méd., $1827, \mathrm{C}, 57$.

SCHEFFreld.-The Lancet; Gaz. des Hôp., I862, p. 232.

B. ON THE LEFT Side.

(a) Above the normal organ.

Deniker.-Bull. et mém. de la Soc. d'Anat. de Paris, Igr 3, LXXXVIII, I25. (Aberrant nodule?)

Forbes.-Medical News, Mar. 5, I892, LX, 269. (Aberrant nodule?)

HUG, J.-Inaugural Dissertation, Strassburg, I 908.

(b) Below the normal organ.

Bartholinus.-2 cases, Epistolarum Medicinalum, 1662 ; Centuria IV, No. 38 , p. 17 . Cited by Leichtenstern, Archiv für path. Anat., 1878, LXXIII, 241, Cases 4 and 5.

BaUdelocque.-Coutouly, "Dict. d. sc. méd., XXXIV, 527.

Blanchard.-Bull. de la Soc. d'Anthropologie de Paris, 1885,3 s., VIII, 226.

Boreluus.-Observe. Med. Phys., Cent., IV. Francof et Lips, r676, Cent. I, Obs. 49, p.

55. See Fournier, article "Cas rares" Dict. Sc. Méd., Paris, 1819, IV, I 5. 
BRYANT.- "Diseases of the Breast," I887, p. 9.

ChaMPNEYS.-Medico-Chirurgical Transactions, rSS6, LXIX, 4 I9.

Deslongchamps.-Compt. rendu de la Soc. de Biol. de Paris, I853, IV, 9.

DreJER.-Hygaea. Dänische Zeitschrift, July-September, IS27; Froriep's Notizen, XVIII, 295; Lancet, I827, VIII, 394.

Engstrom. - 2 cases, Annales de Gynecologie, r889, XXXI, $28 \mathrm{I}$.

Godfrair.-Thèse de Paris, 1877,2 cases.

HaLl.-Quarterly Medical Journal, Sheffield, I893-94, II, 243.

Hannaeus.- Letter to Olaus Borrichius, July I, 1675 . See article "Multimammes"

by Percy and Laurent in the Dict. Sci. Med., Paris, 1819, p. 525.

HarT.-British Medical Journal, London, I892, II, 1054.

HOILER.-Schenck Obs. rar. lib., II, Obs. 8, p. 304.

HUG, J. -8 cases, Inaugural Dissertation, Strassburg, Igo8.

JoHNson.-Lancet, London, I862, II, 27.

JoSEPH.-Zeitsch. f. klin. Med., von F. Günsburg, I 857 , VIII, I87.

KLebs.-Handbuch der path. Anat., I, 2, p. II63.

Lanzonus.-Opera Omn. Med. Phys, et Phil. et Phys. Lasan, I738; Miscel. Curios sive Ephemerides Med. Phys., etc., Ann. IX, Dec. ii, Obs. 5.5, p. 87 .

Leclere.-Gazette d'Hôp., Paris, I852, $\mathrm{XXV}, 339$.

Leichtenstern.-Archiv f. path. Anat., etc., I 878 , LXXIII, 244.

ManN.-Providence Med. and Surgical Jour$\mathrm{nal}, \mathrm{I} 852$.

Martin.-Archiv für klin. Chirurgie, I893, $\mathrm{XLV}, 880$.

Murchison. -2 cases, Trans. Path. Soc. of London, I866, XVII, 426 .

Nataluccr.-La Raccoglitore Medico, Forli., I $89 \mathrm{I}, 5$ s., XI, 226.

OSIANDER, J. Fr.-De papilla mamm. numero et struct. variis., Göttingen, I8I8.

Petrequin.—2 cases, Gazette Méd., I 837 , p. I95.

Perrier.-Gynek. Helvet, I909, Centralbl. für Gynäkologie, I910, XXXIV, 490 .

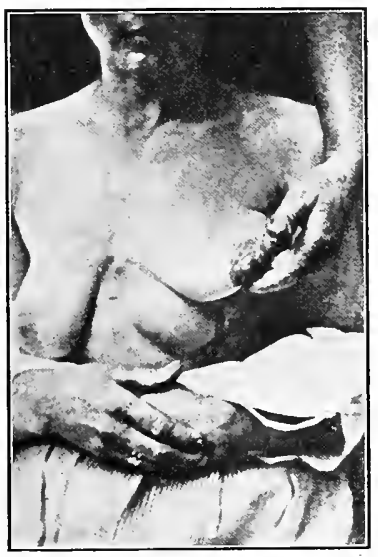

FIG. 34.-Polymastia: A supernumerary mammary gland below the left normal one (Martin). A carcinoma later developed in this supernumerary gland.

Peuch.- "Les Mamelles et leurs Anomalies," Paris, I876, p. II3.

PItzorno.-La Riforma Medica, i896, XII, pt. I, p. 65 I.

Scalzi.-Archiv. di med. chir. ed igien. Roma; Movement Medicale, I873, p. 567 (cited by Peuch).

RoBERTS, G. N.-Baltimore Medical and Surgical Journal and Revue, 1834, II, 497.

Ross.-Virginia Medical Monthly, Richmond, I874, I, 87.

Sмrтн, I. C.-Pacific Medical and Surgical Journal, I878, XX, 516.

Wiтkowski, G. J.- "Histoire des accouchements chez tous les peuples," Paris, 1887, p. 287.

WOODMAN. -2 cases, Trans. Obstetrical Society of London, I867, IX, 50.

voN SIEBold, Elias.- "Lehrbuch der thereot. Entbindungskunst, I824, p. I74, 4th Ed.

Belonging in these groups but with insufficient data for classification.

ARNOLD.-Cited by Harriss-Savannah Medical Journal, I860-6I, III, I73.

BLAsiUs.-Syntagm. Anat. Veslingi., Ams., I666, 4 c., IX, I33.

GrRARDI.-Abhandl. d. k. Acad. d. Wissenschaft zu Berlin, I83I, p. 337 (cited by Leichtenstern (loc. cit.))

FroRIEP.- "Notizen," April, I839, XVIII, 295. 
Heitzmann, C.-Medical Record, New York, I888, XXXIV, 2r. (Aberrant mammary nodule?)

Homan.-St. Louis Courrier of Medicine, St. Louis, I884, XI, 36 I.

JASTREBofF.-Cited by Neugebauer, Centralblatt für Gynäkologie, r886, X, 734.

Marie.- r9 cases, Bull. et Mémoirs Soc. Med. d'Hôp., Paris, I893.

Отто.-Erste Nachtrag z. d. Verz. d. Anat. Präpar., Breslau, r830.

PFLÜGER, H.— 4 cases, Inaugural Dissertation, Regensburg, r 886.

Petrequin.-3 cases, vide citation by Sacasa Roberto, Thèse de Paris, I867.

Prtzoni.-La Riforma Medica, I896, XII, Pt. i, p. 65 r.

von Siebold, Elias.- "Lehrbuch der theoretischen Entbindungskunst," r824, p. 174, $4^{\text {th }}$ ed., Nuremberg.

Storanoff.-Médizinski Napredak, rgor, No. 4, 427. Vide Hildebrand's Jahresbericbte für Chirurgie, rgor, p. 5 I4.

WARREN.-J. A. M. A., I905, XIV, p. I63, 2 cases of supernumerary breasts above the normal situation. Female patient. Sides not given.

Walaeus.-Fantoni. "Anat. corp. humain. Pars. I. Dissertation, XI, p. 267, August, I7I I.

II. TWO SUPERNUMERARY MAMMARY GLANDS.

r. In the Male Subject.

A. Symmetricaliy Placed, one on Each Side.

(a) Above the normal organ.

CoLEY.-Lancet, London, I894, I, I 500 .

(b) Below the normal organ.

ANDrew.-Trans. Path. Soc. of London, I867, XVIII, 27 I.

Bartels.-Archiv für Anat. Phys. u. Med., $1872,304$.

Bertherand--Gazette méd. de Paris, 1857, XII, 223.

BirkEtT.- "Diseases of the Breast," I850, p. 24.

Blanchard. -8 cases, Bull. de la Soc. d'Anthropologie, I886. 3 s., IX, 485 .

Brandin.-Vide Gardeur, Jour. de méd. de Corvisart, IX, $3_{87}$, the case of the young doctor.

Buchner. - 2 cases, "Kraft und Stoff," r876, p. I43 (r4th Ed.). (We follow Leichtenstern in supposing that the breasts were below the normal ones.)

Cameron.-See Sneddon, Glasgow

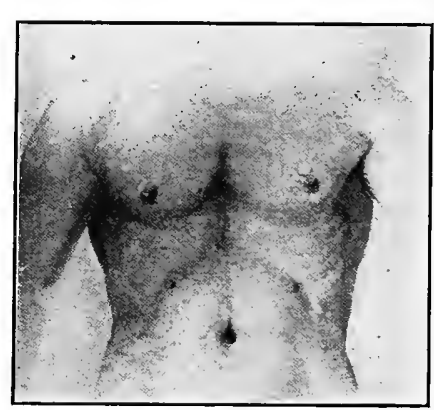

fic. 35--Polymastia: Two supernumerary mammary glands below the normal. (Barrets.)

Medical Journal, I878, pp. 69, I 20 .

Conts.-See Sneddon, Glasgow Medical Journal, r878, pp. 69, r 20.

Colex.-Lancet, London, 1894 , I, 1500.

De Sinety.-Gazette médicale de Paris, I887, 7 s., IV, 317.

DizWell.-Boston Medical and Surgical Journal, I874, XC, 274.

Everr.-Archiv für Anthropologie, Braunschweig, r89r, XXII, I05.

Finsterer.-Deutsche Zeitschrift für Chirurgie, I906, LXXXIV, 20I. (These were at different altitudes.)

Francors.-See Fournier's article "Cas rares" in the Dict. des sciences méd., Paris, r 8r9, IV, r 52 : also article "Multimammes" by Percy et Laurent, Ibid., Tome, XXXIV, p. 528 .

GLUck.-Verhandl. der Berliner Gesellschaft f. Anthropologie, p. 6r7.

GRUBER.-Archiv für path. Anat., etc., I875, LXIII, 99.

HANDYSide. - 2 cases, Journal of Anatomy and Physiology, r873, VI, 56.

Hansemann.-Verhandl. d. Berliner Gesellschaft für Anthropologie, r889, p. 434.

LegraIn.-Vide Fournier "Manifestations de Sypbilis tardive," p. 263.

Leichtenstern.—2 cases, Archiv f. path. Anat., i878, LXXIII, 244. 
Mitchell.-American Journal of the Medical Sciences, 1873 , p. 528 . (This subject is said to have been a farm servant. We assume that it was a man.)

Prackel.- Miscell. curios., Dec. I, Anno. IX and X, Obs. 8, p. 45.

SheII. M. A.- "Diseases of the Breast," London, 1898 , p. 25.

Stoyanov. - 2 cases, Bull, de la Soc. d'Anthropologie de Paris, 1898, 4 s., IX, 30r; Medizinski Napredak, Igor, No. 4, p. 427. Vide Hildebrand's Jahresbericht für Chirurgie, Igor, p. 5I4; Lyon Medicale, r883, XLII, 391 .

YARRow, T. J., JR.-New York Medical Journal, I898, LXVII, 649.

(c) Far below the normal organ.

McGillicuddy.-Medical Record, New York, I89 I, XL, 446.

\section{In the Female Subject.}

(a) Above the normal organ.

Alderson.-Medical and Physical Journal, London, ISOO, III, 402.

BIRKETt.- "Diseases of the Breast," 1850 , p. 24.

Bonnet.-Jour, de méd. de Lille, I9ri, II, 529.

Brown.-Northwestern Lancet, St. Paul, I888, VIII, 89.

BúE.-Méd. mod., Paris, I893, IV, 2 I8.

CANTwell.-Jour. Amer. Med. Ass., I91 2, LVIII, 747.

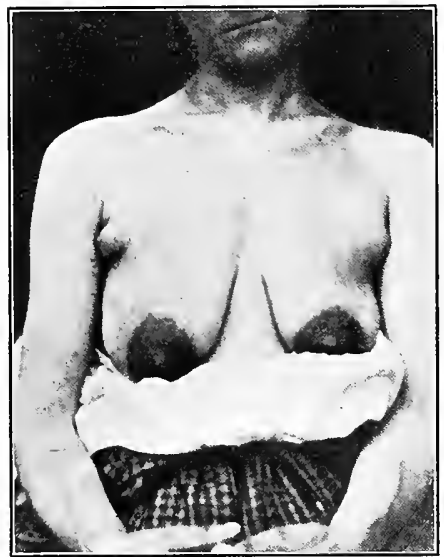

Fic. 36.-Polymastia: Two supernumerary mammary glands. (Quinquaud.)

Charpentier.-_"Traité practique des Accouchements," i 889, I, 69, $2 \mathrm{~d}$ Ed. Cooper.- "The Anatomy of the Breast," London, 18+5, p. 25.

FAVR, V. G.-Vratch., St. Petersburg, I $88_{5}$, VI, 78 I.

Foges.-Wiener klin. Wochenschrift, I901, XIV, I255.

Gardeur.-Jour. de méd., Corvisart, IX, 378 .

Girlespie.-Cincinnati Lancet Clinic, I9 I I, CV, 500.

Godfrex.-British Medical Journal, r 907 , I, i I I 9.

Hofstätter.-Münchener med. Wochenschrift, igio, LVII, 2295.

HoRinchI, K.-Medizinische Wochenschrift, Tokio, July 4, I89.

Hug, J.-Inaugural Dissertation, Strassburg, I908.

Kurowa.-Sei-i-Kwai, Tokio, ı 89 , X, I 56.

LEE.-Medico-Chirurgical Transactions, London, $1838, \mathrm{XXI}, 266$.

Lozano.-An. d. Circ. méd. Argent., Buenos Aires, I 885, VIII, 499.

Maschat.-Thèse de Paris, I $88_{3}$.

Monaco.-Archiv. di ostet. e ginecologie, Napoli, 1906, XIII, 599. 
Pick.-New York Medical Journal, I893, LVIII, 502

QuinQuaud.-Rev. phot. d'Hôp. de Paris, r87o, II, Pl. III.

Shannon.-Dublin Quarterly Medical Journal, $1848, \mathrm{~V}, 226-266$.

SкотUL.-Centralbl. für Gynäkologie, I9ro, XXXIV, 1549

Spencer, W. G.-Trans. Pathological Society of London, rgoo-or, LII, 7o. (On the right side was a kind of mole in the upper outer quadrant of the breast; on the left another near the axillary fold.)

(b) Below the normal organ.

D'AzYR.-Cited by Hartung and Leichtenstern, Dissertation "De Physiologie Mam. marum," Halae, I8or; Spec. Phys. Mammarum, Halae, r8or, l.k.s.

Bartholinds.-Epistolarum Medicinalum, Centuria IV, No. 38. p. 2I8 (reference taken from Williams).

Brickell and Keator.-New Orleans Medical News and Hospital Gazette, r856-57, III, 394 .

Cabrolius.-Ephemerid. Med. Phys. Asso. Nat. Curios., Dec. II, Ann. IX, p. 87.

Champneys.-Medico-Chirurgical Transactions, r886, XIX, 4I9.

Chatard.-Jour. de méd. de Bordeaux, r86r, 2 s., VI; 384 .

CHOWNE.-Lancet, London, 1842 , No. 14.

CHRIST.-Medizinischen Klinik, No. 52 (citation by Hug).

Drzwelx.-Boston Medical and Surgical Journal, I874, XC, 274 .

DeSinetx.-Gazette méd. de Paris, I887, July 2; Centralhl. für Gynäkologie, r888, XII, 352 .

FAVR, V. G.-Vratsch., St. Petershurg, r885, VI, $78 \mathrm{r}$ (abstract) Centralbl. für Gynäkologie, $\mathrm{r} 886, \mathrm{X}, 824$. (In this case the supernu merary glands were both on the left side.)

HACQUARD.- 3 cases, Thèse de Strasbourg, $183 \mathrm{r}$, No. 980 .

KLEBS, E.-Handbuch der pathologischen Anatomie, 1876, I, abt. 2, Ir62.

LaLoy.-L'Anthropologie, Paris, I892, III, I74-192.

LAMY.-Jon. Fantonus, "Anat. corps humain, Paris, I, Dics. XI, p. 267 , r 7 rr.

Letchtenste Rn. - 2 cases, Archiv f. Path. und Anat., I878, LXXIII, 244.

Lyncaeus. - See article "Multimammes" by Percy and Laurent in the Dictionaire des Sciences Médicales Paris, ${ }^{8}$ I $_{9}, \mathrm{XXXIV},{ }_{2} 8$.

OsIander.-Inaug. Diss., Gottingen, r8r6, p. 12.

Percy.-Article "Multimammes" Dict. des Sc. Méd. Paris, I8r9, XXIV, 383.

RaPIN.-Rev. méd. de la Suisse Rom., r882, II, 472.

RAXER.-Compt. rend. de la Soc. de Biol. de Paris, 1852 , IV, Io.

Sмгтн, A. W.-See Sneddon, Glasgow Medical Journal, 1878, pp. 69, г 20.

Stoyanov.-Bull. de la Soc. d'Anthropologie, Paris, r8g8, 4 S., IX, $30 r$.

TARnIER.- "Traité de l'Art des Acchouchements," P. Cazeau, Paris, I87o, p. 86.

Voltarre.- "Dictionaire Philosophique," article "Monstre."

VON SIEBold.-Case 70 on Leichtenstern's list, Virchow's Archiv, 1878, LXXIII, 244.

Whitefore.-The Chicago Medical Journal and Examiner, r884, p. 528.

ZAMARELla.-La Riforma Medica, r886, p. 392.

(r) Below the normal organs but asymmetrically placed.

FAVR.-Vratsch., St. Petersburg, r885, VI, 78r (abstract Centralbl. für Gynäkologie, I886, X, 824).

Cases belonging to this group but with inadequate dato for classification.

BIRKETT.- "Diseases of the Breast," 1850, p. 254.

Borgardcct.-3 cases, Delle Contemplationi Anatom., etc., r564, 8, p. 208.

CoLEY.-Lancet, London, I894, I, I 500 .

GaELinger M.-Echo méd. du nord., Lille, rgo4, VIII, 15 .

Gallard.-Revue phot. des Hôpital, Paris, 1870 , p. 18.

Haney.-Bull. de la Soc. d'Anthropologie de Paris, I885, 3 s., VIII, 239.

VAN DER Hoeven.-Cannstatt's Jahresherichte, I86I, IV, 5 .

Hodran.-St. Louis Courier of Medicine, 1884, XI, 361. Discussion following Robinson's paper.

Hug, J.-Inaugural Dissertation, Strassburg, rgo8.

Lanzonus.-Ephemerid. Nat. Curios, Dec. II, Ann. IX, p. 87.

Soctn.- "An Old Physician of Basle." See R. Lee, Medico-Chirurgical Transactions, 
London, I833, XXI, 226; also see article "Multimammes" by Percy and Laurent, Dict. d. Sci. Méd., r8ıı, XXXIV, 380.

Santisson.-Dublin Quarterly Journal of the Medical Sciences, I848, p. 266.

VAsILIN.-Centralbl, für Gynäkologie, I909, XXXIII, 647 .

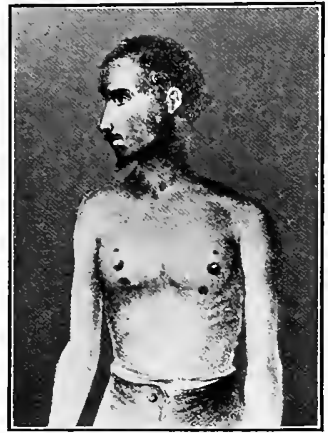

FIG. 37--Polymastia: The man has four nipples and areolæ, and two symmetrically placed "moles." (Fitzgibbon.)

\section{CASES WITH THREE SUPERNUMERARY GLANDS.}

r. In male subjects.

2. In female subjects.

(a) Symmetrically placed, one on each side below the normal and one in the median line.

GorRé.-See article "Multimammes" by Percy et Laurent in the Dictionaire des Sciences Médicales, Paris, 18 19, XXXIV, 529.

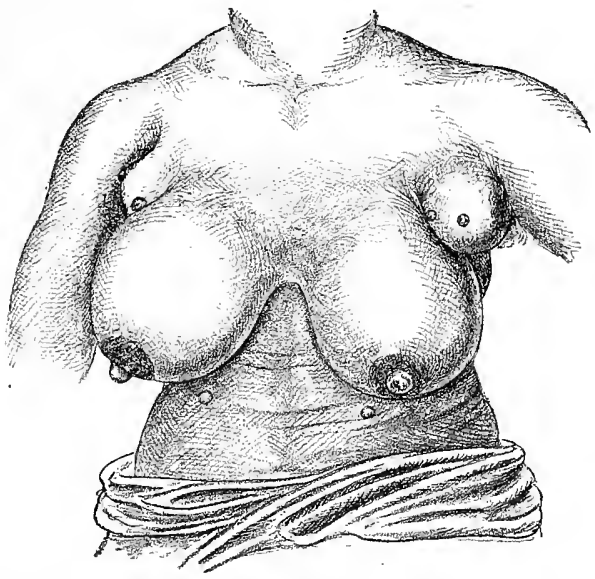

FrG. 38.-Polymastia: Nine breasts and nipples. (Seen in consultation with Dr. D. E. Kercher.)

(b) Asymmetrically placed.

FAVR.-(Abstract) Centralbl. für Gynäkologie, r886, X, 824 .

Hansemann.-Verhandl. d. Berliner Gesellschaft für Anthropologie, r889, p. 434.

Hofstätter.-Münchener med. Wochenschrift, rgro, LVII, 2295. 
IV. CASES WITH FOUR SUPE RNUMERARY MAMMARY GLANDS.

I. In male subjects.

AleXander.-Medical Times and Gazette, London, I885, n.s., XI, 70.

FitzgrbBon.-Dublin Journal of the Medical Sciences, I860, XXIX, I09.

DE Mortillet.-Bull. de la Soc. d'Anthropologie de Paris, I883, 3 s., VI, 458.

Petrone.-Progresso Med., Napoli, r889, III, 5 I6.

SrRaud.-La Province Médicale, 1897 , No. 26 (abst. Hildebrand's Jahresbericht für Chirurgie, I 897 , p. 470). Two of the supernumerary organs were below the margin of the ribs, a third below and outside the left mamma, and the fourth was on the right flank.

.2 In female subjects.

BjoRkGVist.-Mitt. aus d. gynäk. Klinik, ıgo6, 8 , VII, $30 \mathrm{r}$.

V. CASES WITH SIX SUPERNUMERARY MAMMARY GLANDS.

I. In male subjects.

Casceli.A.-Nuovo Raccoglitore Medico, October, 1902. All six supernumerary organs were in the mammary lines, and all below the normal organs. One pair was near the costal margin, the next in the hypochondriac regions, and the third pair, consisting of mere pigmented spots, were just below the level of the umbilicus.

2. In female subjects.

WARNEK.-(Abstract) Centralbl. für Gynäkologie, $1897, \mathrm{XXI}, 448$.

VI. CASES WITH SEVEN SUPERNUMERARY MAMMARY GLANDS.

I. In male subjects.

2. In female subjects.

Hirst--University Medical Magazine, Phila.,

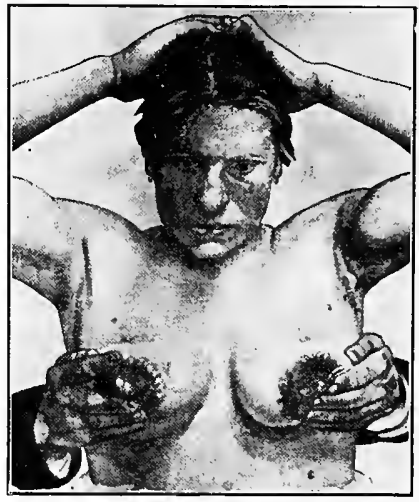

FIG. 39--Polymastia: The case with eight supernumerary glands in the distribution corresponding with the "milk-line." (Neugebauer.) I 896 , VIII, 590 .

VII. CASES WITH EIGHT SUPERNUMERARY MAMMARY GLANDS.

I. In male subjects.

2. In female subjects.

Neugebautr.-Centralbl. für Gynäkologie, I886, X, 729 .

This completes, so far as our ability to collect them goes, the published cases of mammary glands occurring in a distribution corresponding to the "milk-lines" of the embryo, and brings us to the second location for consideration.

B. Mammary Glands in the Axilla, as in the Flying Lemurs and Fruit Bats.-These we have already considered at length, so that, at present, it is necessary to do no more than mention them with reference to the theory of "reversion" or "atavism." Axillary mammæ may be viewed from two standpoints; either as the result of persistence of the highest of the "anlagen" in the series belonging to the milk-lines, or as recalling the condition normally existing in the flying lemurs and the fruit bats. From either point of view their occurrence is easily explained, and their position in support of the reversion hypothesis; they do not come in the group of "Mammæ erraticæ."

C. Mammary Glands upon the Shoulder, Corresponding to What Is Seen in Hapalemur Griseus, Have Been Reported as Follows:

Hoepfner.-Inaugural Dissertation, Jena, I899. The subject was a man of 40 years with a pigmented wart over the acromion. It was microscopically examined and Hoepfner is satisfied that it was a rudimentary mamma. 
KLoB.-Zeitschrift d.k.k. Gesellschaft der Aerzte zur Wien, $18_{5} 8$, I, No. 52 , p. 815 . The subject was a man who had a swelling surmounted hy a pigmented wart just below the left acromion over the convexity of the deltoid muscle. The wart was three lines high and was erectile. Closer investigation showed it to be the nipple belonging to a walnut-sized mammary gland imbedded in the subcutaneous adipose tissue. It was removed and studied microscopically, and proved to be a mammary gland. The gross specimen is said to be preserved in the Rokitansky Museum.

Scalzı.-Arch. di med. chir. e d'igien. Roma; Mouvement médicale, 1873, p. 567 (cited by Puech). The suhject was an aged woman who was admitted to the hospital for a scalp wound. Upon examination she was found to have a rudimentary supernumerary mammary gland on the right shoulder, posteriorly, near the axilla, another below the left breast. (This case is known to the writer through various citations, not by reference to the original writing.)

D. Mammary Glands in the Pubic and Inguinal Regions, Suggesting the Normal Position in Chiromys Madagascariensis.

BLUM,-Münchener, med. Wochenschrift, I907, LIV, 1055. The subject was a 17 -year-old girl with two normally developed mammæ in the normal situation, and a kind of udder-like formation the size of a goose egg occupying the hairy mons veneris. Upon it there were seven nipples. Shortly hefore the occurrence of menstruation and during the first day of the flow, it enlarged considerably and secreted milk in considerable quantity. This happened four times. There was no simultaneous secretion of milk by the normal pectoral mammæ.

Muraltus.-Misc. Acad. Nat. Curios. Decada, 2, II, 208, 1698. A pregnant woman, Elizaheth Lingg from the town of Turin, saw $e x$ improviso a cow's udder hanging in a butcher's yard and was so frightened that she impressed the fotus to such an extent that it was horn possessed of a mammary gland with three nipples, much like a cow's udder, in the right groin. It grew continually but more rapidly when menstruation set in. She was seen by Muraltus when 24 years old. The mass was as large as the head of a nine-year-old boy. It had a root or pedicle the thickness of the thumb and hung from the muscles of the thigh and anus. A large branch of the iliac vein passed over the pedicle to nourish the tumor and prevented its removal.

When this case came to our attention it seemed too extravagant to consider it seriously, hut with the preceding case in mind it loses much of the extravagant quality, especially when divested of the cow's udder story. The peculiar attachment by a pedicle is suspicious, but becomes of no eliminating value when one is acquainted with Hartung's case of pedunculated vulvar mamma which will be described below. Leichtenstern declared Muraltus's case to belong to the realm of fables, but was perhaps mistaken.

Jussien.-The Lancet, London, I826, XII, 618. The author reported to the Philomathic Society of Paris, the case of a woman having three breasts, one situated in the groin; she nursed her baby from all three. Her mother also had three breasts, but they were all situated upon the chest. There is some suspicion, started hy Flechsig, that this is the same case as that later to he mentioned by Rohert, Chaussier and Magendie-Thérèse Ventre. It is, however, stated in the original text that the supernumerary gland in this case was in the groin, and in that case, that it was on the outer side of the thigh.

VON BAER and Kömrr.-See Ahlfeld "Mishildungen des Menschen," p. IIr. The subject is a celebrated dipygus monstrosity named Blanche Dumas; she had a third leg arising from the pelvis posteriorly and had two fair-sized and well-shaped mammæ in the pubic region.

Coyne.-Binaud et Braquehaye "Maladies de la Mamelle" in the "Traité de Chirurgie of la Dentu et Delhet, Paris, I889, VII, 7. The subject was a woman with a third dipygus leg, and two well-developed mammary glands in the groin. It is to be noted that "Blanche Dumas" whose picture is given in Ahlfeld's Atlas to his "Misbildungen des Menschen," Leipzig, I880-82, is a case of dipygus, with precisely the same deformity, and Bechtinger (Annals of Gynecology, July ro, I888, p. 469) gives a photograph and description of a case undoubtedly identical with that ascribed to Coyne by Binaud and Braquehaye, He says that the individual was a woman aged 25 years, a native of Martinique, whose father was French and whose mother was a quadroon. She had three legs, two separate vulvæ with separate vaginæ, and two separate mammary glands of good size in the hair over the os pubis. As Bechtinger says the woman went to Paris, and that the photograph 
was taken in Paris, there is no doubt but that the two reports are about the same case, who may also have been the subject represented by Ahlfeld in his atlas. The subject was probahly an exhibitionist, fell into various hands in her travels, and was reported numerous times. There is said to have been preserved in the museum of the Faculty of Bordeaux a plaster cast of what may be the same case, or at all events it is an extremely similar one. Naturally such deformities do not fall in the scope of the argument. They are simply inserted for the purpose of completing the list of supernumerary mammæ in unusual regions.

Testut.-Bull. de la Soc. d'Anthropologie de Paris, r8gr, 4 s., II, 757. Williams in his paper upon Polymastism expresses the hope that Testut will publish the details of this case, of which he had heard but a rumor. Here is what the author says about it:

"J'ai observé en 1885 sur la cuisse droite d'une femme qui avait accouché a la Maternité de Bordeaux, une mamelle surnuméraire dont j'indiquerai tout d'ahord la situation la form et les rapport. Elle occupait la face antéro-interne de la cuisse droite et était située exactment à 65 -mm. au-dessous du pli de l'aine, sur la trajet d'une verticale passant par l'épine du pubis. Au point de vue de sa configuration extérieure, elle etait constituée par un mamelon de forme conique qui mesurait $\mathrm{r} 2 \mathrm{~mm}$. de la base au sommet. Tout autour de lui, le peau soulever par une masse arrondie, globulouse, qui etait le corps de la glande ellemême. Cette petite mass glandulaire n'était apparente de l'oeuil en raison de ses faible dimensions, mais elle était trés perceptible au touchet, et par ses contours irrégulierment basselées, par son consistence à la fois molle et resistante, elle répétait exactment une mamelle normale."

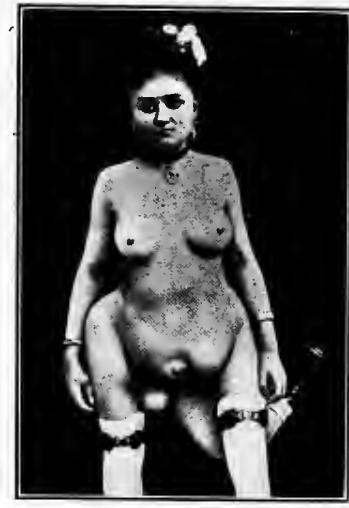

Fig. 40.-Polymastia: A case of dipygus with two mammary glands in the inguinal region. From a photograph in the museum of the faculty of Bordeaux. (Le Dentu et Delbet.)

This typical inguinal mamma with its quite typical nipple was placed immediately beneath the skin and when pressed slid along over the deeper structures. The patient had been pregnant five times and each time the inguinal mamma enlarged precisely like the pectoral mammæ which were normal. It probably secreted milk hut Testut is not certain about it.

Marshall, B.-Transactions of the Glasgow Obstetrical and Gynecological Society, 1896-98, i,. 57 . Saw a girl of $r 9$ years who had well-marked supernumerary nipples, one on each side of the thigh, a little below the folds of the groin and close to the vulva. Their size corresponded to those of the adult male breast. They were firm and erect and showed a distinct opening in the middle of the apex. The right nipple was surrounded by a blackish pigmented areola the size of a shilling piece; the left by a smaller, fainter areola. The girl was pregnant, was subsequently delivered, and lost the child. Subsequently, the areolæ ahout the supernumerary nipples entirely disappeared.

Steinborn And Mosig.-Münchener med. Wochenschrift, r900, XIVII. The subject was a man 47 years old. In Scarpa's triangle on the inner aspect of the left thigh there is a hemispherical enlargement like the mammary gland of a virgin, about puberty, surmounted by a wellformed but long nipple surrounded by a dark areola in which grow a number of dark hairs. There was no secretion.

Knox.-Reported from Dr. D. N. Knox's notes by Dr. Wm. Sneddon, Glasgow Medical Journal, I879, n.s., XI, 92. "The patient, a full-grown man, came to consult ahout a tumor in his groin which he said had always been there but which had, of late, been growing rather larger, and had given him both hodily and mental uneasiness. On examining the tumor it proved to be an extra mamma with well-formed nipple situated upon the inner side of the right thigh close below the external inguinal ring. It was about 2 inches long and $\mathrm{r} / 2$ inches broad, but was evidently tumified at the time $\mathrm{I}$ saw it, probably from some irritation." 
DiETSCh Y.--Correspondenzbl. für schweizer Aerzte, Basle, I9I3, XLIII, 366 . The subject was a man 20 years of age suffering from pulmonary tuberculosis. On the inner side of the left thigh, I $2 \mathrm{~cm}$. from the upper border of the symphysis pubis there is a typical little mammary gland. It is somewhat oval in shape and is surrounded by an areola $\mathrm{I} 2 \mathrm{~cm}$. long and 0.8 $\mathrm{cm}$. broad. The papilla is $0.4 \mathrm{~cm}$. in diameter and its height $0.2 \mathrm{~cm}$. It was a little smaller by actual measurement than his left pectoral mamma and more deeply pigmented. It also has a few dark hairs which the pectoral mamma lacks.

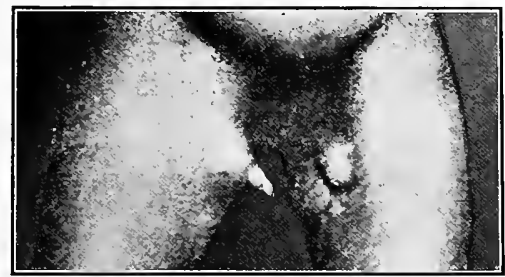

FIG. 4I.-Polymastia: A mammary gland on the upper inner aspect of the right thigh. (Steinborn and Mosig.)

HoeprNer.-Inaygural Dissertation, Jena, 1899 . The subject was a man of about 30 years. $\mathrm{He}$ had a supernumerary mammary gland upon the inner aspect of the left thigh $\mathrm{Ir} \mathrm{cm}$. below the symphysis pubis. It appeared as a darrkly pigmented wart.

Rosir1.- - Anatomia dell'Uomo, Vol. II. Is said by Fiori (Bull. d. r. Acad. Med. di Genovo, rgo5, $\mathrm{XX}, 369)$ to have described a mammary gland in Scarpa's triangle.

SACASA, RoBerto.--(Thèse de Paris, 1867 ) says that in 1863 a man appeared in Velpeau's clinic with a mamma-like formation surmounted by a kind of nipple, in the upper inner aspect of the

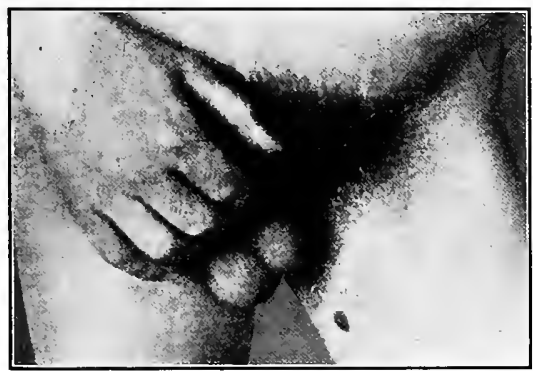

FIG. 42.-Polymastia: A small nipple and areola on the inner side of the left thigh. (Dietschy.)

left thigh. The great surgeon called it a lipoma, and discussed its resemblance to a mammary gland. The man refused to be operated upon, so the true nature of the enlarge ment is not known.

E. Mammary Glands in the Neighborhood of the Dorsal Spine as in Myopotamus, and Elsewhere upon the Back.-That mammary glands can occur upon the back has been much disputed and widely doubted. To Williams it appears to have been inconceivable. Here is a case in point:

KUMrBerg.-(Abstracted). Jahresbericht ü. d. Fortschritte der Chirurgie, 1897, III, 470. The subject was a man 28 years old, on whose back, to the left of the mid-line at the altitude of the eleventh rib, there was a mammary gland the size of a hen's egg. It had increased in 
size of late, as the operation for its removal showed, because of the pressure of a rapidly growing retro-mammary lipoma that had formed behind it:

How much latitude may be given to the expression "in the neighborhood of the dorsal spine" we are uncertain, but it may be just as well at this point to bring together the entire collection of posterior thoracic mammary glands.

Gúńniot.-Bull. de la Soc. d'Anthropologie de Par, is 1897 , No. I2. The subject was a man aged about 48 years. He had a supernumerary mammary gland upon the back about a hand. breadth inside of the posterior border of the left axilla. It consisted of a little nipple projecting nicely from a surrounding areola, deeply pigmented, brownish in color and containing some long hairs. The size of the areola was very nearly the same as that of a normal male breast. The patient had an exceptionally hairy body, and Guéniot speculates as to whether that is not an additional evidence of atavism.

Griffith.-Medical News, I903, Jan. 3. Yappa, a Bushman, aged 25 years, married to six wives, with a number of children, has a tumorous appendage which is found to extend down from the right axillary space between the third and seventh ribs. The base is oval and bounded in front by the pectoralis major and latissimi dorsi muscles and extends to below the inferior angle of the scapula. It is freely movable and has the doughy feel of the female breast. It h:s a nipple that is erectile, wellformed, and stands out conspicuously upon its areola posteriorly below the outer side of the inferior angle of the scapula. The nipple and areola are somewhat lighter in color than the surrounding skin. This is true of the normal pectoral nipples prominently placed in the usual sites. Manipulation and milking the breast demonstrated that there was no fluid present.

SALEwSky.-Ephemerides. nat. miscell. curios, etc., Ann. IXX, Dec. II, p. 456. "Bartholom Salewsky nobilis Polonus vir fide dignus in Insula Macassar (veteribus Celebes) mulierem vidit quæ mammas suas in dorso habens cas sub axillis protractors infanti dabat et firmiter asserebat integre consanguiniarum sudarum numero hanc monstrositatem esse propriam." This

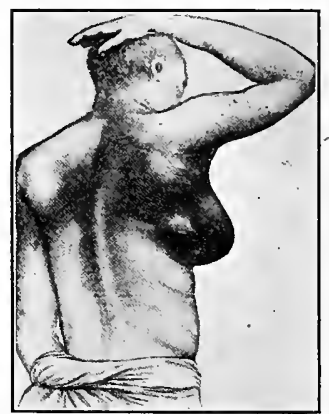

FiG. 43.-Polythelia: Yappa, the Bushman, with a large mammary gland below the right axilla. (Griffith.) remarkable case in which the mammæ were upon the back, seems to have been passed about a great deal and appears in the following writings, as well as in many later ones:

Helbig, Joh. Otto. De Rebus varius indicis, obs. I94.

Bonetus. Medicinal Septemtrionalis collatitial., Pars II, Lib. IV, p. I 55.

Miscellan. curios ch., Dec. II, Ann. IV, obs. XXXI, p. 263.

Dictionaire des Sciences Médicale, Paris, ı8I9, article "Mamelie," Vol. XXX, p. 376; article "Cas Reres," Vol. IV. The thought of the mamma on the back being drawn under the arms so that the child could nurse is so extravagant that many writers look upon the case as fabulous, but when the case is thought of in connection with the conditions presented by Griffith's case, it becomes less impossible. Further, other cases, formerly thought too extravagant to receive credence, fall more or less into line and form a group remarkable but not impossible. Such are the following:

Paulinus.-Ephemeried. Nat. Curios, Dec. II, Ann. IV, pp. 20; 203, in the appendix. Reports the following case of dorsal mammæ.

"Rustica foemmina e comitatu Winzenhorch praeter duas in loco ordinario adhoc duas alias ejusdem quantitatis et qualitatis mammas lacte foecundas, habuit e regione in tergo. Jam tertia vice peperati, gemellos, qui ante retroque suxerunt."

Sunors.- "Considerations Médicales sur les Mamelles," Thèse de Paris, I 8r2, No. 62. Relates the following case upon what, to him, seems to be sufficient testimony for publication: "Les mamelles, en nombre'de deux dans l'espece humaine, sont situées sur les parties supérieures, laterales et antérieures de la poitrine. Cette position ordinaire peut-varier, et méme eprouver des irrégularites étranges, rare à la verite, mais dont on a cependent une exemple si l'on ajute foi à celui qui rapports un moine de Corbie, d'une paysanne qui avait quatr 
mamelles, dont deux placées au dos. correspondaient par leur situation à deux autres placées comme à l'ordinaire sur le devant du thorax. Ill ajoute mème que cette femme eut trois jumeaux, q'elle nourrit indiffèrentment de ses quatrémamelles. Il eut eté curieux, et mème à desirer, si l'observation est veritable que l'on eut procédé à l'examen anatomiquement de cette femme extraordinaire." Let us remember that post-axillary mammæ occur in Capromys.

Bartholinds.-Ephemerides Med Phys., etc., Obs. 72, p. I33. Claims to have seen a woman upon whose back there was a supernumerary mammary gland without a nipple. The original text is as follows: "Cui tertia mamma in dorso conspicua eminebat, sed sine papilla. Nihil vero incommodi exinde sensit, nisi quod de tussicula et rancedme conquereretur an exinde dependest, affirmare, non ausim; ita vero illa persuasum" (Flechsig). Leichtenstern expresses the opinion that this case is "höchst unsicher und zweifelhaft." Martin inquires how it could be recognized as a mammary gland since it has no nipple, and why it was not regarded as a tumor. Geoffroy Saint-Hilaire does not believe that it was a mammary gland. There is no proof of its nature but there must have been some peculiar appearance or quality about it that suggested mammary gland to the reporter. In this connection it is well to point out that McGillicuddy has reported a mammary gland in the right flank, also without a nipple-a case that was shortly challenged by Williams.

Origrinal.-A female cadaver sent by the State Anatomical Board of Pennsylvania to the MedicoChirurgical College of Philadelphia, for purposes of dissection, had a mammary gland upon the hack over the right scapula. It was as large as either of the pectoral mammæ, provided with a normal appearing nipple of full size. From its pendulous appearance and the somewhat withered skin that covered it, which fully corresponded with what was shown by the pectoral mammx, it seemed quite likely that it had been subject to similar enlargements during lactation.

\section{F. Mammary Glands on the Dorso-lateral Aspects of the Thigh, as in Lagostomus, and} Elsewhere upon the Thigh.-For many years only one case of this kind appeared in the literature. It was most carefully investigated and reported upon, seemed most extravagant and in spite of the high authority of its reporters, was viewed with a good deal of scepticism by many. Unfortunately it has often been misquoted, especially with reference to the situation at which it occurred. The chief references to it are as follows:

RoBert.-Journal général de médicine, I 827 , VI, 57 .

Magendie et Chaussier.-Jour. gén. de méd., I827, VI, 57.

Chaussier et Magendie.-Jour. de physiol. expér., Paris, i 827, VII, 175.

The account of this case was as follows: Thérèse Ventre, a woman aged 50 years, living at Marseilles, is the daughter of a woman who had three pectoral mammæ, the supernumerary one being on the right side below the normal one. She, herself has a supernumerary mammary gland but instead of being in the pectoral region, it is situated upon the outer aspect of the left thigh, a quarter of an inch below the great trochanter, opposite to the superior extremity of the external part of the triceps muscle. It has always been there, at first as a small round body, which enlarged at the time of puberty. When the woman became pregnant it swelled up and became of the volume of a half lemon. At the time of lactation after confinement it showed the same phenomena as the normal breasts and from it lacteal fluid exuded. She regarded it as a breast, and to prove its nature it was offered to the baby who took it willingly and nursed from it. All told, five children were nursed from the pectoral and femoral mammx. It was a well-formed hemispherical mamma, surmounted by an areola and a well-formed nipple. The size is said to have been that of a half lemon.

The illustration showing the woman nursing an infant from the right breast while an older child sucks at the femoral mamma, does not accompany any of the original papers, but, so far as we have been able to determine, first appeared in Witkowshi's "Histoire des Accouchements," etc., Paris, I 887 .

Other cases of mammary glands upon the thigh are now on record and must be considered in connection with this case of Robert's. As their situation is not identical, some of them may have to be regarded as true "mammæ erraticæ," while Robert's case may be one of reversion, following what is seen in Lagostomus. 
HuG, J.-Inaugural Dissertation, Strassburg, 1908. In his essay upon "Sitz und Vorkommen überzähliger Brustdrüsen und Brustwarzen beim Weibe," Hug mentions, without particulars, two cases of supernumerary mammæ on the thigh, that came under observation in the Strassburg clinic: Frau M.-Who had supernumerary nipples in the right axillary line, on the abdomen, and "on the thigh," and Frau Louisa F., aet. 2 r years, on the outer side of whose left thigh there was a pigmented wart surrounded by a pigmented area the size of a quarter dollar. It was undoubtedly a supernumerary mammary gland with a nipple. It is not stated whether it secreted or not.

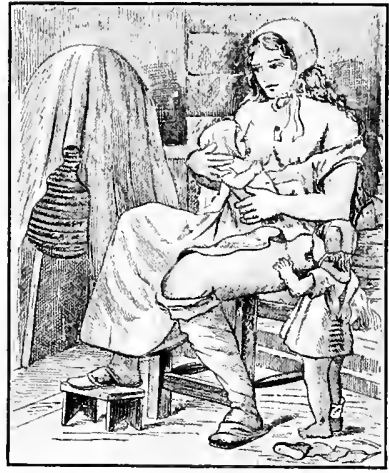

Fig. 44.- Thérèse Ventre, the famous case of mammary gland on the outer side of the thigh, reported by Robert, Chaussier and Magendie. (Witkowski.)

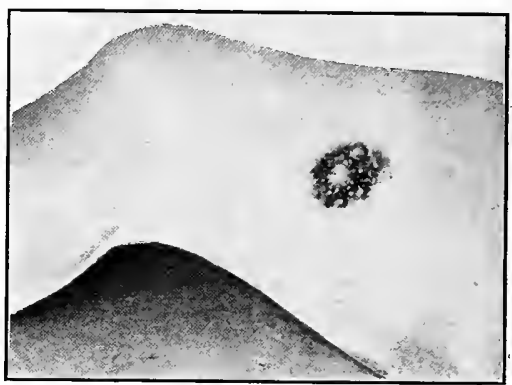

FIG. 45--Polymastia,-A small supernumerary mammary gland, with a nipple and a deeply pigmented areola, on the outer side of the left thigh of a man. (Hug.)

Pineo.-Boston Medical and Surgical Journal, r866, LXXIV, $\mathrm{x} 8 \mathrm{x}$. A negro, a man, aged 40 years' has a congenital tumor on the anterior aspect of the right thigh at about the junction of the upper and middle thirds. It is about $4 \frac{1}{2}$ inches in diameter and bas a glandular feel when palpated. In the middle there is an elevation like a nipple with a depression at its point, and it strongly resembles a female mamma. No further information is given, and no microscopic studies could be made. The evidence of the mammary nature of the formation is entirely objective and external. Had the patient been a woman and lactation occurred, no further questions could be asked.

Dronre.-Cited by Binaud and Braquehaye, article "Maladies de la Mamelle" in the Traite de Chirurgie," etc., Le Dentu et Delbet, Paris, I899, VII, 7, as baving reported a case of mammary gland on the outer aspect of the thigh. As the case was cited without reference, no further details were available.

Rhodrus.-Actes de Copenhague, 1676 . Cited by Binaud et Braquehaye in the article upon the "Maladies de la Mamelle" in the Traité de Cbirurgie," etc., by Le Dentu et Delbet, Paris, 1899, VII, 7, as having seen in Venice, a boy 13 years of age, who had upon his thighs two mammary glands with nipples. It was not possible for us to obtain further information of this case.

McGillicuddy.-New York Medical Record, $x 89 x$, XL, 446. The author gives a drawing of a supernumerary mammary gland upon the posterior aspect of the thigb of a man, just below the gluteo-femoral fold. The man's sister states that it was first observed at the time of his birth. It has a distinct lobular structure when palpated. There is neither areola nor nipple, the skin upon it being perfectly smooth. When this case was published, Williams ("Alleged Mammæ Erraticæ," Medical Record, x892, XII, 193) challenged it upon the ground that its mammary nature was not suficiently well established, and that one should be very careful in declaring anything to be a mammary gland that occurred where such structures bad never been known to occur before. If we accept this criticism 
we must not only rule out this case, but also its predecessor, and if these two, why not Robert's case? Simply because that is impossible since the gland being upon a lactating woman evinced its true nature too evidently? While it may be quite proper to hesitate with regard to the true mammary nature of these cases, we are by no means in a position to. reject them.

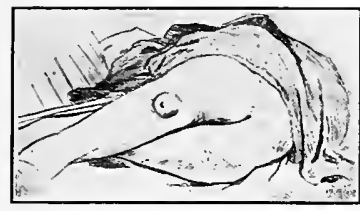

Fig. 46.-Polymastia: A supernumerary mammary gland on the posterior aspect of the left thigh. (McGillicuddy.)

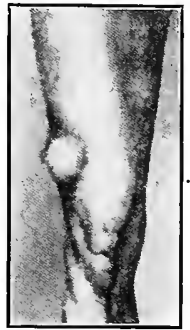

FIG. 47.-Polymastia: A supernumerary mammary gland on the outer side of the right thigh near the knee. (Cutore.)

CuTORE.-Monitore zool., r903, XIV, I28. Describes a mammary gland on the right thigh, on the outer side just above the knee. It was of conical form, its base oval in shape, the greatest diameter measuring $9 \mathrm{~cm}$. the lesser $6 \mathrm{~cm}$. It lies beneath the skin, upon the facia lata. It is surmounted by a well-formed nipple, situated ro $\mathrm{cm}$. above the external tuberosity of the femur. The patient was a woman aged 46 . She was dissected and the gland was examined microscopically and proved to be a true mammary gland.

\section{G. Mammary Glands on the Vulva as in the Cetacea.}

HARTUNG.- "Mamma accessoria," Inaugural Dissertation, Erlangen, 1872 . The remarkable tumor that forms the basis of Hartung's essay was the size of a goose egg, and was attached to the lower inner aspect of the left labium majus of a woman, aged 30 years, by a pedicle the size of a man's thumb. It was congenital, had enlarged at puberty, manifested changes that coincided with the menstrual periods, and from its surface a milky fluid escaped from an eroded area upon the upper anterior part. The growth was removed, and upon microscopic examination proved to be a large and fully formed mammary gland. The nipple was retracted and occupied the center of the eroded area as a flattened rounded prominence surrounded by a shallow depression. It is well to reflect upon this case in association with the inguinal udderlike mamma reported by de Muraltus, which Leich-

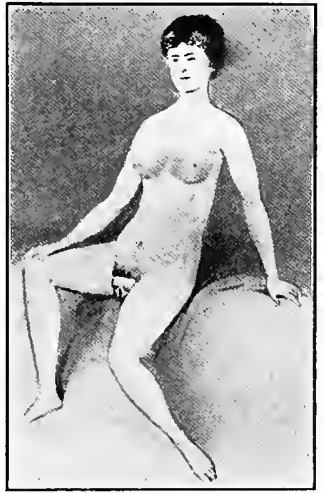

FIG. 48.-Polymastia: A supernumerary mamma situated upon each labium majus. (de Blasio.) tenstern dismisses as belonging to the realm of fables. If he had known of this case of Hartung's and had divested de Muraltus' case of the element of maternal impression, it would not have seemed so impossible to him. Hartung describes his case as a "mamma erratica" but it may possibly represent reversion to an ancestral form of cetacean character, it being remembered that all of the cetacea have the mammary glands upon the vulva, i.e., labia. This is made more probable when one compares the next case.

DE Blasio.-Archivio di Psichiatria, Neuropathlogia, Anthropologia Criminale Medicina Legale, Torino, I905, XXVI, r7r. De Blasio observed a young woman who had upon each side 
of the vulva, upon the outer side of the labium majus, a mammary gland the size of a hen's egg, surmounted by a well-formed nipple. Up to the age of puberty only the nipples were observed, the glands developing later, and only reaching their maximum size when she became pregnant. The location of these supernumerary organs is precisely that seen in cetaceous animals.

\section{H. Mammary Glands in the Mid-line of the Thorax and Abdomen as in Didelphys.}

Bartholin.-Epist. Cent., IV, No. 38, p. 2r8. Saw a mamma the size of an adult male gland situated in the epigastric region (Puech, p. I 14 ).

Gorré.-Dict. des Sciences Médicale, 1819, XXXIV, 529, article "Multimammes," by Percy and Laurent. Frau Valaque, a peasant woman dying of starvation and privation after the birth of a child, was examined for medico-legal reasons. She was found to have five wellformed mammary glands. Two were in the normal position, two others symmetrically placed, one on each side below them, while the fifth was situated in the middle line between the other two. All of the glands gave milk freely. The normal glands were large and full, the supernumerary glands about the size of a girl's at puberty. This case has appeared once before in our lists under "Three supernumerary mammary glands" in group A.

Percy et Laurent.-Dict. des Sciences Médicale, Paris, I819, XXXIV, 525, article "Multimammes." The subject was a woman, the mother of five children, who had a small median mamma hetween and helow the normal well-developed glands.

KiLPATrick.-Southern Medical Record, Atlanta, I874, IV, I44. An elderly lady named La Croix, of Rapides Parish, La., has three breasts in a line across the thorax. The outside ones are

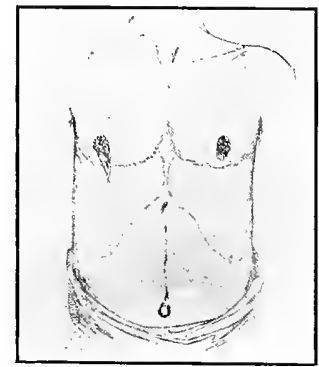

FIG. 49.-Polymastia: A supernumerary nipple in the midline of the body just below the xiphoid cartilage. (Bartels.)

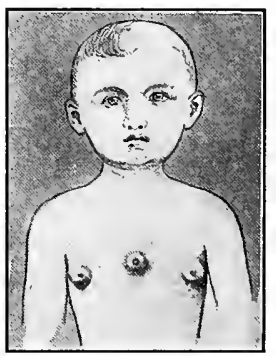

Fig. 50.-Polymastia: A supernumerary mammary gland in the mid-line of the sternum. (McGillicuddy.)

in the normal position, while the third, which is smaller, is between them directly over the sternum. It is not so large as the others, but she says that there is no difference between it and the others. All three became enlarged during pregnancy, in time of lactation milk was secreted in all, and the children nursed from all three.

McGillicuddy.-The New York Medical Record, I89r, XL, 446. Rosa R., aged seven years, has a median mammary gland slightly larger than the normal ones, on the front of the sternum, a short distance above the altitude of the normal ones.

IwAI.-Lancet, London, I907, II, 753. Mentions a case of a median supernumerary mammary gland in a male subject. No particulars are given.

Williams, W. R.-Transactions of the Pathological Society of London, I8gr, p. 224. Williams reports "A Case of Supernumerary Median Nipple and Areola in a Man." The subject was a man aged 67 years, who had a shilling-sized areola, with a pea-sized nipple, on the lower part of the sternum, 2 inches below the line of the normal nipples and a little above the sterno-xiphoid articulation. The nipple was brownish and devoid of hairs, the areola pinkish, tuberculated and containing hair. There was also a supernumerary nipple of rudimentary size and without an areola, 4 inches below the left normal nipple. He also had gynecomastia. 
Bartels.-Verhandlungen der Berliner Gesellschaft f. Anthropologie, r894, p. 20r. A young man aged 29 years has a supernumerary nipple to the left of the mid-line of the abdomen 2 $\mathrm{mm}$. from the ensiform cartilage. It is pinhead in size, sunken and more deeply pigmented than the surrounding skin. A long blond hair grew from its center.

BARTELs.-Verhandlungen der Berliner Gesellschaft f. Anthropologie, r889, p. 440. Reports a man with three breasts, two normally placed, and a third exactly in the mid-line of the thorax at the top of the xiphoid cartilage. It was surrounded by an areola and bad hairs growing from it.

Stropen, L.-Tumori, Rome, r9I5, IV, 509. Observed a woman upon the front of whose sternum an adeno-carcinoma developed. He attributed its position to an antecedent aberrant lobe of mammary tissue.

V. Supernumerary Glands are a Freak of Nature.-This was the first and the original theory. It is doubtless only our ignorance that causes us to cling to it as a means of explaining the cases which, since they conform to no theory of distribution, are often described as "Mammæ erraticæ." Upon what other theory are such cases as the following to be explained?

\section{Mammary Glands in the Flanks.}

Anams.--Lancet, r895, II, 462. A Hindu pundit, a man aged 35, had a well-developed mamma above the left hip. It proved upon examination to be a fully developed mamma, the consistency and appearance being exactly like the gland of a virgin. The nipple was small and somewhat flattened but the surrounding areola was perfect. No milky fluid could be expressed. It developed at the time of puberty. The man declined to have it removed, as it had never caused him any annoyance.

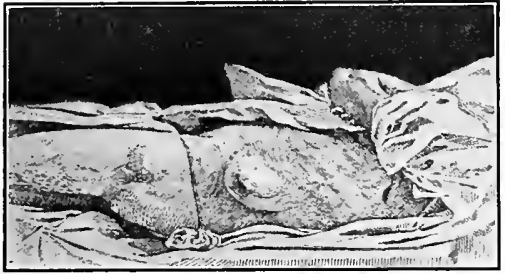

F1G. 5r,-Polymastia: Indian Pundit with large mammary gland in the left flank. (Adams.)

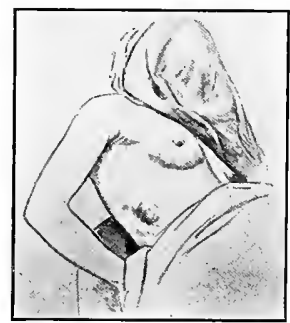

FIG. 52.-Polymastia: Mammary gland on the right flank. (McGilli cuddy.)

Siraud.-La Province médicale, I897, No. 26; vide Hildebrand's Jabresbericht für Chirurgie, r897, p. 470. This writer tells of a man with four supernumerary mammary glands. Two, small and imperfectly formed, occurred in the mammary lines below the margins of the ribs, a third was below and outside of the left mamma (a rare location). The fourth, and the largest and best formed of all, was on the right flank, was the size of a mandarin orange and had a definite nipple.

McGiliricuddy.-New York Medical Record, r89r, XL, 446. A supernumerary mammary gland on the right side extending from the seventh to the ninth ribs. It has an oval shape following the intercostal spaces. Nothing is said about nipple or areola. The patient is a woman and during menstruation she has painful sensations in this as well as in the normal glands.

Williams challenged this case as he did McGillicuddy's case of mammary gland on the thigh. He is somewhat justified in so doing, for the only evidence of the mammary nature of this tumor is the feel it gives the palpating fingers and its painful state at the time of menstruation. However, just as Williams might have been less ready to challenge the 
case of gland on the thigh had he knowledge of the similar cases, so be might have hesitated with regard to this case had he known of Adam's case.

Mammary Gland on the Buttock.

HIRsT (Textbook of Obstetrics, 1906, 5th edition, p. 547, Fig. 548) pictures a tiny mammary gland that appears to have an areola and a nipple, and is located upon the left buttock of a woman. At each time that the patient lactated, this tiny gland would always yield a drop of milk upon pressure.

Mammary Gland below the Middle of the Axilla.

Golp̣erger (Archiv für Gynäkologie, XLIX; Centralbl. für Gynäkologie, r896, XX, rra) reports a mammary gland ro $\mathrm{cm}$. below the left axilla between the anterior and mid-axillary lines.

Mammary Gland on the Upper Arm.

SAт0.-(See Iwai, Lancet, r907, II, 735.) Iwai gives an illustration, taken from Sato's second report, of a small, well-formed mamma with a distinct nipple, upon the inner side of the left upper arm of a Japanese woman.

Moschкошттсн (see article "Maladies de la Mamelle" by Binaud et Braquehaye in the "Traité de Chirurgie," etc., LeDentu et Delbet) is quoted, without reference, as having seen a supernumerary mammary gland upon the inner aspect of the arm. It was impossible to secure details in the absence of the reference to the original writing.

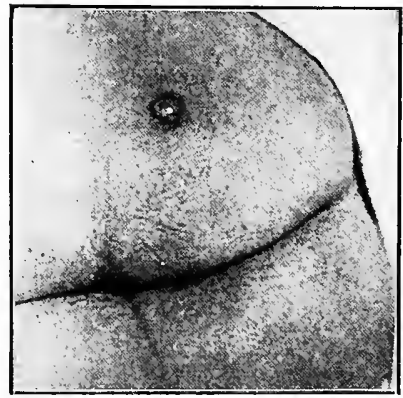

FIG. 53.-Polymastia: A tiny supernumerary mammary gland on the left buttock. Each time the patient lactated, milk could be expressed from it. (Hirst.)

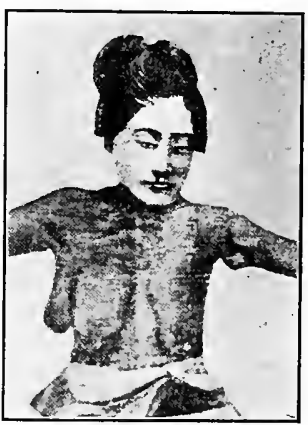

FrG. 54.-Polymastia: J a p a nese woman with a supernumerary mamma in the rigbt axilla and another on the inner aspect of the left upper arm. (Sato.)

\section{Mammary Glands wpon the Face.}

BARTH.-Archiv für path. Anat., etc., I888, CXII, 569. A 20-year-old girl asked to have a wart removed from the face. It was situated $0.75 \mathrm{~cm}$. below the attachment of the lobule of the right ear, on the face, and had been there as long as she could remember. IVhen felt, the wart became larger and more resistant, and upon careful examination it was found to resemble a nipple. This part was $4 \mathrm{~mm}$. in diameter and projected $2-3 \mathrm{~mm}$. from the skin. The wart and the surrounding skin for $\mathrm{I}-2 \mathrm{~mm}$. were pigmented and wrinkled so as to resemble an areola. The areola contained a few coarse bairs; when handled, the nipple erected, and the skin of the areola wrinkled more and more. Beneath the wart a resisting body could be felt. The structure always enlarged during menstruation. The structure was removed and examined microscopically, and Waldeyer wrote a careful description of it. The description certainly tallies with that of a mammary gland, but Waldeyer refused to commit himself, saying that it would be wiser simply to describe it and let the reader draw bis own inferences.

This same patient has another wart upon the gabella that had some erectile qualities but was much less suggestive of mammary resemblance. 
HAUG.-Ziegler's Beiträge zur path. Anat., XVI, 487. A ro-year-old girl had a wart, pigmented at the base, arising from the tragus of the left ear near the point of origin of the ascending limb of the helix and at the customary seat of fistula auris congenitalis. It was soft, but when touched quickly erected and hecame hard. It was removed and examined microscopically and was so typically constructed as to leave no doubt in Haug's mind that it was a tiny supernumerary nipple. An aunt of the child had had, what the mother said, was the same condition. The supposed supernumerary nipple was $21 / 2 \mathrm{~mm}$. long. There was no encircling areola, though its base was pigmented.
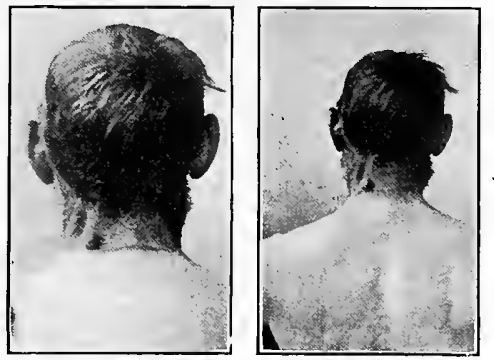

Fig. 55--Mamma erratica on the back of the neck. (Holzt.)

Mammary Gland on the Back of the Neck.

Holzr.- "Ein eigentümlicher Nackentumor," Inaug. Dissertation, Leipzig, r899. The patient was a man, upon the back of whose neck, toward the left side, there was a soft tumor the size of the end joint of a middle-sized forefinger. The man had been conscious of its presence for 12 years, though exactly how long he had had it he did not know. In the center of the tumor in a direction corresponding to its long axis there was a saucer-shaped depression. There was no opening at the bottom of the depression but, instead, from its base to the subjacent muscle a conical expanding cord-like structure can be felt. The skin over the tumor is wrinkled like that of a scrotum and bears hairs. Upon mechanical irritation it is contractile. It is rosy, pigmented in the periphery of the tumor and arranged in folds concentrically to its base. The hairs, like those of the mammary areola, project upon prominent papillæ. The hairs are mostly of a black color; some are gray and twisted. There are occasional pigmented spots in the skin. The summit of the tumor can be inverted by pressing with the index-finger, all the way to the base, like the finger of a glove. As soon as the pressure is relieved the tumor recovers its shape again. Electric stimulation of the tumor acts like mechanical irritation. The tumor was excised and set aside for microscopic study, but unfortunately fell into unskillful hands so that the outcome was not entirely satisfactory. However, taking the peculiar appearance presented to the naked eye, the peculiar tactile and erectile qualities of the tumor into consideration, and then adding the uncertain microscopic features to these, Holzt comes to the conclusion that the tumor was a diminutive mammary gland with a hypertrophied nipple. It is by no means certain that he was right, but his opinion is difficult to disprove. The patient also had intra-areola polythelia and indications of other forms of polymastia.

Mammary Gland on the Hip.

FIorI.-Boll. d. r. Accademia Medica di Genova, I905, XX, 369. The subject was a man 60 years of age, dead of pulmonary tuberculosis, and examined in the anatomical institute at Genoa. He had a mammary gland on the right side at the exact level of the anterior superior spine of the ilium, the size of a small hen's egg, with an elliptical base whose greater dimension measured $5.5 \mathrm{~cm}$., the lesser $3 \mathrm{~cm}$. It was surmounted by a nipple, pigmented and projecting like those of the pectoral mammæ and measuring $9 \mathrm{~mm}$. in diameter and $6 \mathrm{~mm}$. in length. It was surrounded by a pigmented areola. Microscopic examination showed it to be a true mammary gland. 
The morphology of supernumerary mammary glands is interesting because of their remarkable variations of size and form, on which account there is some confusion as to what shall be considered glands and what merely nipples. Von Bardeleben in his interesting writings speaks only of "polythelia," and ignores the fact that men have mammary glands, which seems to us to be a serious mistake on his part. We include his cases as examples of polymastia. Some writers decline to accept any but morphologically well-developed organs as mammary glands; others are willing to accept "pigmented spots" as such, provided they occur in the accepted situations. Fortunately this does not become a matter of much confusion except when the object under consideration is peculiarly situated, as on the face or on the acromion, when statistical studies are to be

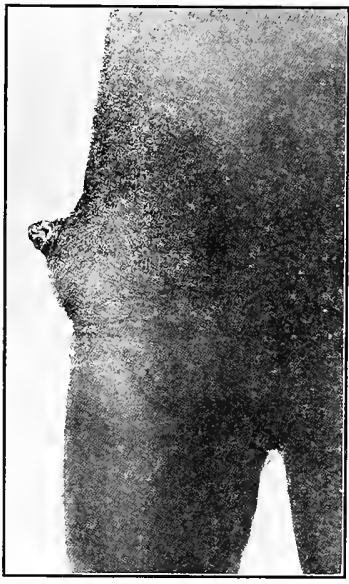

FIG. 56.--Polymastia: A large mammary gland with a nipple, over the anterior-superior spinous process of the right ilium. (Fiori.)

ing this have been reported by made, or when a sharp distinction is to be made between polymastia and polythelia. There seem to be few cases in which a nipple is present without some glandular tissue beneath it. In men, except a microscopic examination be made, it may be impossible to determine whether a rudimentary mamma consists solely of a nipple or whether some glandular tissue is present, but in women the presence of glandular tissue can be determined with certainty, if the subject becomes pregnant and lactates. Hundreds of tiny warts, not even suspected of being nipples; let alone tiny mammæ, show their true nature under the stimulation of lactation by swelling and discharging drops of milk either spontaneously or upon pressure.

This circumstance shows us that the supernumerary mammary tissue is as subject to physiological stimulation as the normal glands; when the latter are excited, the former sympathize according to their size. Not only is this true with reference to functional activity such as is seen during pregnancy and lactation, but also of vegetative activity. If the normally situated mammary glands hypertrophy, any existing supernumerary organs do the same. Cases illustratHypertrophy of the Breasts).

When the supernumerary gland is minute and inactive it may be readily overlooked; when it is large and active it may be a striking object. The subject of the malformation may have one large supernumerary gland, out of all proportion to the normal, and peculiarly situated, as Griffith's case of the retro-axillary mammæ in the Bushman, or Adam's case of the Hindu with the large gland on the left flank; or the subject, when a woman, may have two normally placed and normally developed glands, and numerous minute unobtrusive and unimportant supernumerary glands, as in Neugebauer's case where, in addition to the two normal breasts, there are eight minute supernumerary glands (nipples), or together with normal glands normally placed a woman may have a single one, or a pair, or more glands of almost equal size. Peter Paul Rubens has among the women in one of his paintings, now in the Louvre at Paris, one whose exposed bosom shows four shapely mammæ two, in the normal position, of large size, and two others, a little smaller but equally shapely, below them. Socinus, "the old physician of Basle" whose patient 
consulted him in fear lest the result of impending marriage might be multiple offspring, says that his young lady patient had four mammæ of perfect development and good size. When supernumerary mammæ are small, and therefore unobtrusive, they may become a nuisance because of the leakage of milk during lactation and because of painful swelling from unrelieved secretion. When they are large and active they may be useful. In not a few of the reported cases the women nursed their babies indifferently from the normal and supernumerary organs. When they are large, numerous and active, they may be sources of annoyance and even of distress, as in Hirst's case of the colored woman who had nine mammæ, all of which secreted milk and four of which were large enough to nurse from.

It seems to make very little difference where a functional gland is located; if its size be appropriate and its function active, use may be made of it in nursing children. In Salewsky's remarkable and reasonably questionable case in which the mammæ were upon the shoulders, the patient is said to have drawn them forward beneath the arms in order to let her children nurse. In Jessien's case the child nursed at the inguinal gland -in Scarpa's triangle - as well as from the normally placed mammæ. Therese Ventre, Robert's case with the supernumerary mamma on the outer side of the left thigh, nursed all her children at it as well as at the normal mammæ. Frau Valaque, Gorré's case with five mammæ, all of which gave milk abundantly, nursed her child from all five. Kilpatrick's patient, with three breasts on the thorax-one in the mid-line, nursed her child from all three. The cases of Birkett, Bjorkgvist, Brown, Gardener and Hirst all nursed their children from four breasts; those of Brickell and Keator and G. M. Roberts, from three breasts. In Rapin's case, although the supernumerary breasts gave an abundance of milk, the child refused them because the nipples were so small. In Ross' case the supernumerary breast gave milk abundantly, but the child declined it, probably for the same reason.

Probably the most frequent and annoying circumstance attending polymastia during lactation is the escape of milk from the supernumerary organs when the child nurses at the normal ones.

The probability of plural births in polymastia is a subject that has always been of interest. What were supernumerary breasts for if not to supply nourishment to an unusual number of offspring? It was this question that perplexed the lady patient of the "old physician of Basle." We are told, however, that she was at length sufficiently reassured, when the opinion of her medical adviser to the contrary was supported by a letter from the Faculty of Medicine of Tübingen University to whom she applied, to marry, and never had more than one child at a.birth. On the other hand, there are not a few cases in which twins have been born to polymastic mothers.

Leichtenstern found multiple births in 3 out of 70 ( 4.28 per cent.) polymastic women as against I.37 per cent. in normal women. Marie in studying the interesting polymastic family that came under his observation found that twins occurred commonly; in the father's family there were three pairs of twins and in the patient's own generation two pairs. Iwai (Lancet, 1907, II, 753) saw 24 instances of plural births, 16 of the women being polymastic -66.6 per cent. He wrote a separate paper upon "Relation of Polymastia to Multiple Births" (Lancet, $1907, \mathrm{II}, 8 \mathrm{I} 8$ ), in which after a careful analysis of the subject, he comes to the following conclusions: I. "It is probable that there is a relation between polymastia and multiple births. 2. It is probable that those who have supernumerary mammary glands have a tendency to become more frequently pregnant than those who have not. 3. The fact that the instances of multiparous births increase 
in women with the number of their conceptions and the development of their age coincides well with the opinion given heretofore by several eminent scholars. 4. According to my own observations the instances of multiparous births are found more among people of the lower class, and especially among those of a low order of intelligence."

Rare mention of the occurrence of twins is made in the accounts of recently published cases. We are therefore by no means certain that there is any considerable increase either in fecundity or in multiple births among polymastic women.

It is rare for any mention to be made of associated genital malformation accompanying polymastia. The single case that appears among our notes is that of Bryant whose patient, a little girl of six, had no vagina and a very large clitoris.

Polymastia and Predisposition to Tuberculosis.-How this idea arose it is difficult to say unless Bruce's statistics, compiled from experiences at the Brompton Hospital for Consumptives, have something to do with it. In reviewing the literature of the subject it is rare to find the matter mentioned. It was taken up, however, by Iwai (Lancet, I907, II, 958) and made the subject of a paper which concludes: "I. The cases of polymastia are found more among the tuberculous-especially the pulmonarypatients than among the non-tuberculous. The former are nearly twice as numerous as the latter. 2. Those who have polymastia are more liable to be affected by tuberculosis than those who are not; the difference between them is more than $x 5$ per cent."

Statistical studies of polymastia are numerous and the results vary, largely because of the different kinds of material studied and because each successive statistician has new data with which to work. The first study of the kind seems to have been made by Flechsig ("De Polymastia," Inaugural Dissertation, Würtzburg, I839), who carefully collected the cases in the literature, and reviewed them with reference to the position in which they occurred and the correspondence it bore to the position of the mammæ of the lower animals. Hartung (Inaugural Dissertation, Erlangen, I872) made a collection of cases, 66 in all, from the literature and tabulated them as follows:

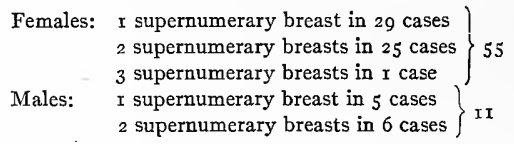

According to these statistics the females outnumber the males 5 to $\mathbf{x}$.

The seat of occurrence of the 29 cases of one supernumerary breast in female patients he found to be:

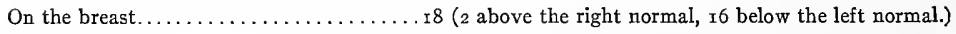

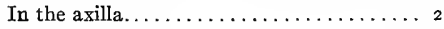

In the axillary line............... I

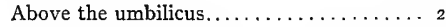

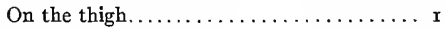

On the back................... I

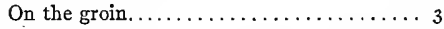

On the vulva................ r

Of the 25 cases of two supernumerary breasts in female patients, he found the following distribution:

On the breast.................. I4 ( 2 above the normal, 12 below the normal.)

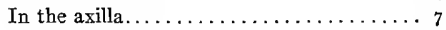

On the back.................. 4

Of the five cases of one supernumerary breast in male subjects he found: 4 on the breast below the normal; $\mathbf{r}$ on the shoulder.

Of the six cases of two supernumerary breasts in male subjects, he found all on the breast below the normal ones. 
The one case in which a female patient had three supernumerary hreasts showed: 2 below the normal; I below and between the supernumerary pair, above the umbilicus.

Peuch's ("Des mamelles et leurs anomalies," I876) compilation showed:

I supernumerary breast in 167 cases.
2 supernumerary breasts in 86 cases.
3 supernumerary breasts in 7 cases.
4 supernumerary breasts in 2 cases.
8 supernumerary breasts in 1 case.

Leichtenstern (Archiv für path. Anat., etc., I878, LXXIII, 222) collected I05 cases, as follows:

Mammæ situated upon the front of the thorax 96 cases
Mammæ situated in the axilla ......... 5 cases
Mammæ situated in the back ......... 2 cases
Mammæ situated in the acromion........ r case
Mammæ situated in the outer side of the thigh r case

Of the 96 thoracic mammæ the situation was as follows:

Below the normal glands............... 90

Above the normal glands................ 3

On the same level but outside the normal........ 2

Two pairs, one above the other below the normal.... I follows:

Of the go cases of which the supernumerary glands were below the normal their location is given as

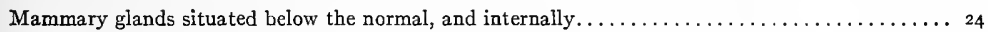

Mammary glands situated immediately below the normal in the same vertical line........... 7

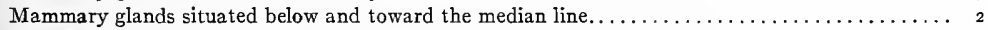

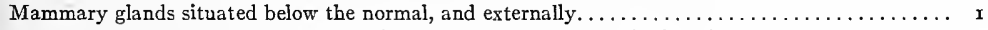

Mammary glands situated below but without mention of the precise location $\ldots \ldots \ldots \ldots \ldots \ldots, 56$

Bruce (Jour. of Anat. and Phys., London, I879, XIII, 425) examined $395^{6}$ patients in the Brompton Hospital for Consumptives between Dec. I3, I875, and Jan. I8, 1879, and found 6 I cases of supernumerary mammæ and nipples.

Of r645 male patients there were 47 cases or 2.85 per cent.

Of 23 II female patients there were $r_{4}$ cases or 0.605 per cent.

Of the $6 \mathrm{r}$ cases observed, $5 \mathrm{x}$ were single supernumerary organs, ro multiple. All were situated upon the front of the trunk below the level of the normal mammæ and somewhat nearer the middle line. Thirty cases were on the left side; $2 \mathrm{I}$ on the right side. Of the multiple cases seven were in pairs, a left and a right; one was a double left; one was a single supernumerary nipple below the ordinary left nipple with a doubtful right and a left pair of supernumerary nipples on the axillary folds. Contrary to Leichtenstern, who found no cases on the abdomen below the margin of the ribs, Bruce observed this situation in two of his cases. Inheritance was not traced in any case.

Hansemann (Verhandlung der Berliner Gesellschaft für Anthropologie, I889, p. 434) says that he easily' collected 262 cases of polymastia from the literature. Of such of these as were accompanied by sufficient data he says:

$r_{5}$ cases were on the anterior surface of the trunk below the normal and toward the middle line.

2 cases were exactly in the middle line.

$2 \mathrm{r}$ cases were above the normal situation.

3 cases were on the back.

I case was on the shoulder.

I case was on the outer side of the thigh.

$x$ case was in the groin.

I case was on the labium majus. 
Von Bardeleben (Verhandlungen der anatomischen Gesellschaft, I89r, p. 247) prefers the term hyperthelia, proposed by Virchow, to polythelia, the term in common usage. He made observation upon 2430 military conscripts in Germany and found $\mathrm{r}_{5} \mathrm{I}$ cases of polymastia (all of course in men), of which 76 were unilateral and left sided, 44 cases unilateral and right sided, and $3 \mathrm{I}$ bilateral.

In a second paper von Bardeleben (Verhandl. d. anatom. Gesellschaft, I 892, VI, I99) expanded the extent of his observations and reported 6437 men examined and go6 cases of polymastia discovered. The cases reported in the first paper are included in the second. He found a marked difference in the percentages of cases in different regiments and among men from different sections of the country, the variation being from 6.3 per cent. to 23.3 per cent. This so interested him that he secured the coopperation of friends among the German military authorities and made a most extended and comprehensive study of the subject. Von Bardeleben's third paper (Verhandlungen d. anat. Gesellschaft, 1893 , VII, I 7 r) records observations made upon 95,749 men and the discovery of 8568 cases of polymastia. Among 4708 cases studied with reference to anatomical distribution he gives the following:

$\left.\begin{array}{lll}\text { Right side } & 43^{8} & 30 \text { per cent. } \\ \text { Left side } & 562 & \text { 39 per cent. } \\ \text { Bilateral } & 44 \mathrm{I} & 30 \text { per cent. }\end{array}\right\}$ I44I cases or 30.6 per cent.

In a fourth paper v. Bardeleben (Anatomischer Anzeiger, r892, No. 3, p. 87) corrected various errors formerly made in the method of observation. In two regiments he found:

Reg. I02, 643 men $\quad 24$ cases left side $\quad 14$ cases right side $\quad 3$ cases double-sided $4 \mathrm{r}$

Artillerie

Reg. I2,

445 men: $\quad 3$ I cases left side

30 cases right side

6 cases double-sided

50

1079

55

44

9

$9 \mathbf{r}$

$\mathrm{He}$ is a firm believer in the theory of reversion. The papers are strangely interwoven and one is confused when an attempt is made to digest and abstract them, because the same cases seem to figure in various ways in each. It is clear the author was more interested in finding out how often the polymastic conditions occurred than the forms in which it occurred.

Iwai (Lancet, London, roo7, II, 753), in "A Statistical Study of Polymastia in the Japanese," endeavors to bring together the results of observation made in Japan by Kuroiwa, Sato, Katayama, Otani and himself. The paper strikes one as somewhat confused, but he gives the following tabulation of 1680 cases of polymastia collected:

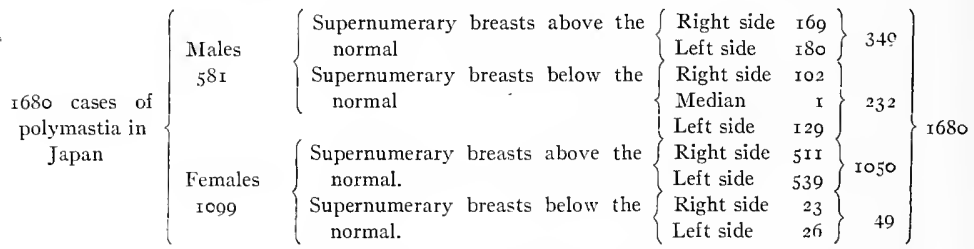

It would secm as though the observations of Iwai and his associates differed strikingly from those of other observers, first, because of the far greater number of cases in women, and second, because of the immensely greater number of cases in both men and women in which the supernumerary breasts were above the normal breasts.

Iwai found 443 cases of polymastia among I 1,897 subjects. The proportion of females to males was 
In the female.

On the right side.

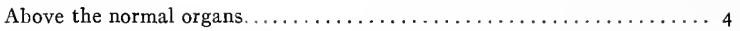

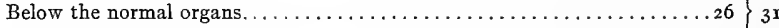

Position not stated.

On the left side.

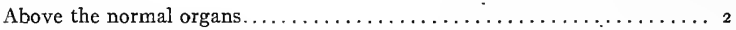

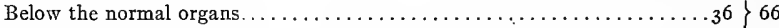

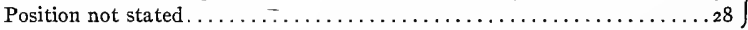

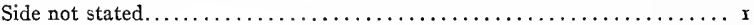

B. Two supernumerary mammary glands.

In the male.

Symmetrically placed, one on each side.

Above the normal organs. . . . . . . . . . . . . . . . . . . . .

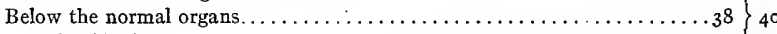

Not classifiable.........................

In the female.

Symmetrically placed, one on each side.

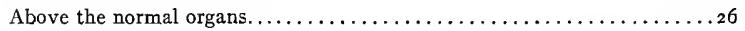

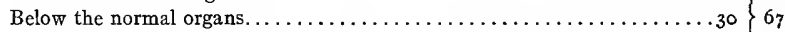

Not classifiable............................

C. Three supernumerary mammary glands.

In the male

In the female

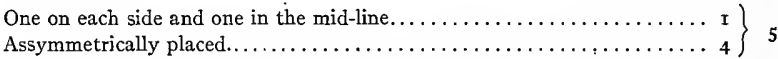

D. Cases with four supernumerary mammary glands.

In the male.

In the female.

E. Cases with six supernumerary mammary glands.

In the male.

In the female.

F. Cases with seven supernumerary mammary glands.

In the male.

In the female.

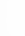

G. Cases with eight supernumerary mammary glands.

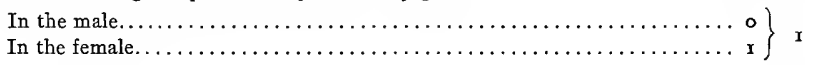

II. Mammary glands on the shoulders.

In the male

In the female

III. Mammary glands in the groins (inguinal regions) (pubic regions).

In the male.

In the female.

Sex not known.

IV. Mammary glands on the hack.

In the male.

In the female. 
V. Mammary glands on the thigh.

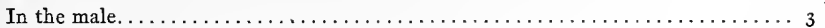

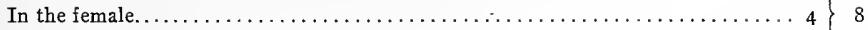

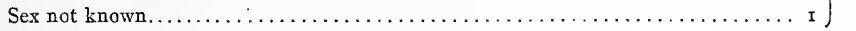

VI. Mammary glands on the vulva.

In the female. . . . . . . . . .

VII. Mammary glands in the mid-line of the thorax and abdomen.

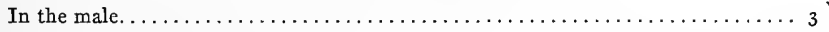

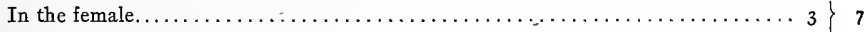

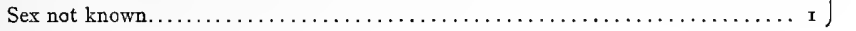

VIII. Mammary glands in the flanks.

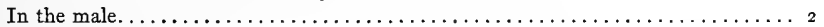

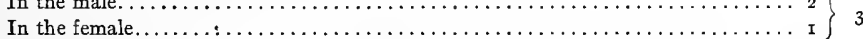

IX. Mammary glands in the mid-line of the axilla on the thoracic wall $\ldots \ldots \ldots \ldots$ I I

X. Mammary glands on the buttock.

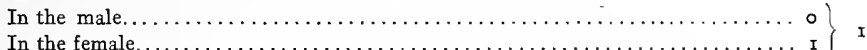

XI. Mammary glands on the upper arm.

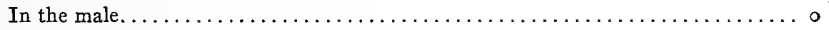

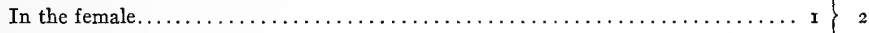

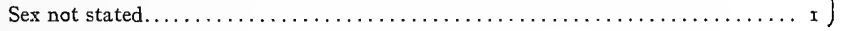

XII. Mammary glands on the face.

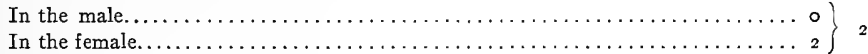

XIII. Mammary glands on the neck.

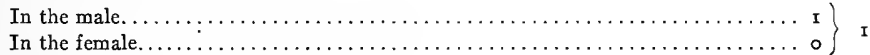

XIV. Mammary glands on the hip.

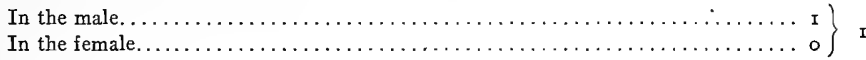

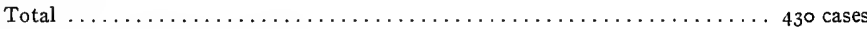

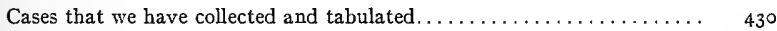

Cases of v. Bardeleben not included. . . . . . . . . . . . . . . . . . 8,568

Cases of Iwai not included . . . . . . . . . . . . . . . . . . . . . . . . .

Cases of Bruce not included.......................... $6 \mathbf{I}$

Cases of Bälz, cited by Horinchi in Hug's Dissertation. . . . . . . . . . I 20

Cases included in references not consulted because literature was not avail-

able, and allowing one case for each reference.............. 36

I0,895 cases in the literature

Our conclusions, and our recommendations regarding the treatment of polymastia will be reserved until the completion of the next closely related subject, polythelia.

\section{POLYTHELIA}

Polythelia is a rare condition in which an otherwise apparently normal breast is provided with more than one nipple.

In discussing polymastia it was pointed out that there are good reasons for supposing that wherever a bona fide nipple, even of rudimentary development is discovered, some 
mammary gland tissue is present. That being conceded, it becomes correct to call all cases of supernumerary nipples, polymastia, except those in which such a supernumerary structure is present upon what appears to be a single and otherwise normal mammary gland.

The unfortunately brief and inadequate descriptions of many of the reported cases make it difficult to classify them with accuracy, as polymastic or polythelic malformations. Such must be treated, according to the opinion of the writer, who does the best he can with the data at hand. This is an apology for any inconsistency that may be detected in the present scheme.

Supernumerary nipples in by far the greater number of cases make their appearance upon the convex surface of the breast below but in about the same vertical line with the normal nipple. The distance between the two varies considerably and measurements of the distance seem to be of no importance unless one be informed of the size of the breasts concerned. In a few-two cases-they have been' observed on the outer half of

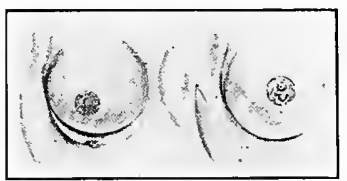

FIG. 57.-Polymastia and polythelia. The figure on the left shows a supernumerary mamma below the normal one; that on the right, two nipples in the normal areola. These illustrate Sutton's idea that the deformity is the result of dichotomy. the breast. When below they may be completely covered by the overhanging organ and remain unobserved except when lactation occurs to direct particular attention to them. When they are upon the outer half of the breast they can hardly escape attention and discovery. In some cases, especially when small they have, like supernumerary mammæ, been looked upon as moles, warts, and birthmarks.

More interesting are the cases in which three or five nipples occur upon the same breast, equally distant from one another each surrounded by its own areola. Such striking cases must early astonish the patient.

In some cases the supernumerary nipples are situated in the areola, the nipple being said to be double or divided-intra-areolar polythelia.

The supernumerary nipples may be uniform in size with the normal, and equally serviceable for nursing, but they are generally much smaller and sometimes very minute. The larger ones usually show a surrounding areola with Montgomery's glands; smaller ones may lack the areola.

In almost all cases they show that they contain lactiferous ducts as soon as lactation begins. Not only does colostrum or milk escape when the adjacent mammary tissue is compressed, but when the baby nurses from the normal nipple, milk commonly leaks from them. Sometimes when they are too small to nurse from, the breast tissue about them "cakes," showing that there are no communications between the lactiferous ducts of the different nipples and the supernumerary nipple, which is, according to its size, the outlet of a larger or smaller collection of milk ducts from some fairly well circumscribed area of the breast.

To account for the occurrence of polythelia is difficult. Sutton (American Journal of the Medical Sciences, I889, XCVII, 247) thinks that many cases arise through "dichotomy"-i.e., transverse division of the developing mamma-and thus explains not only cases of binary polythelia but also of binary polymastia. All cases in which there is a double nipple, a supernumerary nipple on the breast below or outside of the normal one, and all cases in which there is a supernumerary mamma immediately below and partly covered by the normal can thus be explained in his opinion. Remembering, however, that the primitive "anlage" of the embryonal mamma-the survival of which 
affords the best explanation of polymastia - frequently leads to the occurrence of closely approximated supernumerary organs, it seems probable to the writers that more cases result from coalescence or amalgamation of neighboring anlagen than from dichotomy.

Polythelia of this character may be looked upon as intra-mammary polymastia, that is the outgrowth and inclusion by the growing mammary germ of its more rudimentary neighbor. This explanation may apply to all cases in which the supernumerary nipple is situated in the extreme inferior margin of the breast, or anywhere between that point and the normal nipple. I t would also apply equally well to cases of the reverse kind in which the supernumerary nipples were at the extreme upper margin of the breast or at any point between it and the normal nipple. If it be conceded that the growing and maturing gland be able to exert traction or pressure upon an abortive and rudimentary gland, it might also account for the two reported cases in which the supernumerary nipples were upon the outer side of the breast.

Both of these hypotheses fail, however, when we come to account for the occurrence of three and five well-formed nipples, each with its own areola. Here the multiplicity of nipples must be referred to intrinsic developmental errors in the perfection of the breast itself. Nor will they apply to cases in which the normally located nipple is divided so as to appear as two nipples in the same areola. In such cases there must be erroneous development of the nipple itself.

Polythelia, like polymastia, may be an inherited malformation. There seems to be but one case recorded, however, where this is said to be true, the case of Hacquard (Thèse de Strasbourg, I831, No. 980) in which a woman, her mother and her grandmother are all said to have had two nipples on each breast, the supernumerary ones "under the breast." This is one of the border-line cases that may almost as well be called polymastia as polythelia.

The polythetic deformity may be a troublesome one. When the nipple is divided so that there are two in the normal areola, it may be impossible for the baby to nurse. When there are two of nearly equal size at some distance from one another, it may be necessary to disturb the baby after nursing from one-half of the breast, to apply it to the other nipple to empty the other half. If the baby cannot nurse from a very small nipple, it may be necessary to use pressure or suction to empty that part of the breast drained by it. When the child nurses, milk is apt to flow from the supernumerary nipples. The malformation is therefore liable to be attended by discomforts and disturbances that may make it impossible to nurse the child at all.

On the other hand, some cases get on without discomfort and sometimes no relief being given, the section of the breast drained by the supernumerary nipple becomes inactive and ceases to secrete after a few days or weeks.

Such cases as have been collected from the literature may be tabulated thus:

\section{POLYTHELIA}

A. INTRA-AREOLAR POLYTHELIA, more than one nipple in the normal areola.

(a) Female subjects.

1. Bilateral.

Duval.—Thèse de Paris, "De mamelon et de son auréola," I86I, p. 43.

TIEDEMan and TReviranus. - "Untersuchungen über die Natur des Menschen," I83 $\mathrm{I}_{\mathrm{I}} \mathrm{V}$, $\mathrm{I}$ ro.

2. On the left breast.

GartHon.-Lancet, London, r846, II, 304 .

3. On the right breast.

Hư, J.-Inaugural Dissertation, Strassburg, I 908. 
HofstÄTter.-Münchener med. Wochenschrift, r910, LVII, 2295.

4. No data as to the side affected.

ALbers.-Med. Correspondenzbl. rhein. u. westfäl. Aetrz., Bonn, I843, III, 400.

FeHeing.-Vide Hug, Inaugural Dissertation, Strassburg, rgo8.

(b) Male subjects.

r. Left breast.

HoLtz.-Inaugural Dissertation, Leipzig, 1899 .

(c) Sex not stated.

Stoyanov.-Bull. de la Soc. d'Anthropologie de Paris, I898, IX, 4 s., zor.

(d) Position not stated.

Cascella.-Nuova Raccoglitore Medica, October, rgo2. Two nipples on a supernumerary breast.

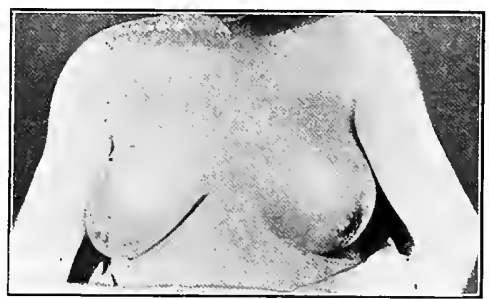

FIG. 58.-Intra-areotar polythelia: Two nipples in the right, and three in the left normal areola. (Hug.)

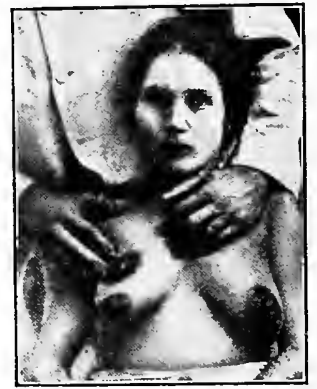

FIG. 59.-Polythelia: Two nipples and areole on the right breast. (Hofstätter.)

B. EXTRA-AREOLAR POLYTHELIA; the preșence of nipples with or without areolæ, apart from the normal nipples and areolæ.

I. Two nipples on one breast.

A. ON THE RIGHT BREAST.

(a) With an areola about each nipple.

x. Situated above the normal nipple in a vertical line.

KavroR, W. L.-Medical Record, New York, $x 898, \mathrm{LIV}, 45^{6}$.

2. Situated below the normal nipple in a vertical line.

Bartels.-Archiv für Anat. Phys. u. Med., 1876, p. 745.

HofSTäTTER.-Münchener med. Wochenschrift, rgro, LVII, 2295.

HUG, J.-Inaugural Dissertation, Strassburg, 1908, 4 cases.

Rising.-Lancet, London, I844, II, 255.

SALt, E. G.--British Medical Journal, London, rgoo, i, 509.

Sharp, E. W.-British Medical Journal, r903, i, r6. (This case probably should be placed among the polymastic deformities, but it is described as a "supernumerary nipple," without sufficient detail to enable a decision to be formed.

3. Situation not aceutratcly given.

Bryant.- "Diseases of the Breast," 1887, p. ro. A model, shown to the Hunterian Society hy Mr. Roberts, of a female breast with two nipples about an inch apart.

Dennemeyer.-Thèse de Paris, No. 29.

(b) Without an areola about the supernumerary nipple.

r. Situated below the normal nipple in a vertical line.

Champneys.-Medico-Chirurgical Transactions, r886, LXIX, 4r9.

Pateliant.-Centralbt. für Gynäkologie, r896, XX, 449.

2. Situated on the outer half of the breast.

Charcot et LeGendre.-C. r. Soc. de Biol. de Paris, I860, 3 s. I, i64. Gaz. Méd. de Paris, 1859 , p. 773. 
3. No data as to areola or position.

DE Meyer, J. J.-Thèse de Paris, I8I4, No. 29.

4. Situated belaw the normal nipple in a vertical line.

Kerkringrus.-Observ. Anat., XXI, 49, Spicileg. Anat. Amstelod, I671, Fol. p. 40.

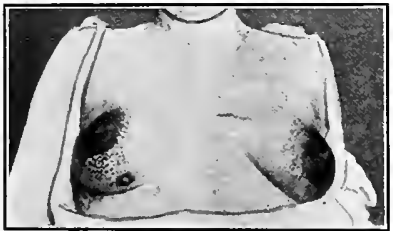

Fig. 60.-Polythelia: A small supernumerary nipple and areola on the under aspect of the right breast. (Hug.)

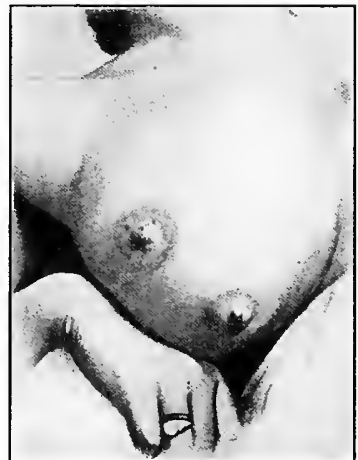

FIG. 6r.-Polythelia: Two nipples of nearly equal size upon the right breast. (Bartels.)

B. On the Left Breast.

(a) With an areala about each nipple.

I. Situcled below the normal nipple in a vertical line.

Alworthy, S. W.-Trans. Royal Academy of Ireland, Dublin, r9०3, XXI, 306.

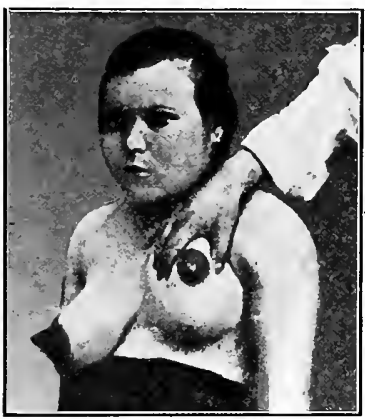

FIG. 62.-Poly thelia: The supernumerary nipple and areola are smaller than the normal, and are situated upon the under surface of the breast. (Cignozzi.)

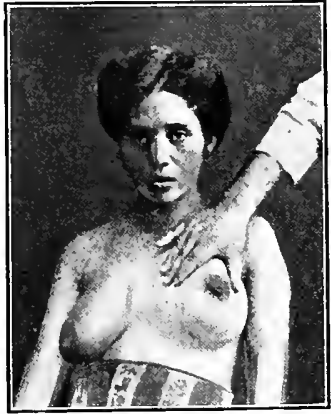

FIG. 63.-Polythelia: A tiny nipple below the normal one, and near the margin of the left normal mamma. (Cignozzi.) This is a case on the border-line of polymastia.

Cignozzr.-2 cases, Riforma med., Napoli, 1908, XXIV, z6r.

CoE.-Medical Record, New York, I888, XXXIV, 479

DeSinety.-Gaz. méd., Paris, I887, 7 s., IV, 3 I 7 .

Tiedemann.- "Untersuchungen über die Natur des Menschen," i $8_{3}$ I, V, i ro.

Young.-Boston Med. and Surgical Journal, I904, CL, 3 I9. 
2. Situated on the outer half of the breast.

Charcot et LeGendre.-C. r. Soc. de Biol. de Paris, r86o, 3 s., I, r64.

3. Situation not stated.

ENGström.- "Annals de Gynécologie," r889, XXXI, 28r.

b. No data as to the presence of an areola.

4. Situated below the normal nipple in a vertical line.

DeSinety.—Gaz. méd. de Paris, r887, July 2; Centralbl. für Gynäkologie, r888, XII, 352 .

Waite.-New York Medical Gazette, i 850, I, I2r.

C. No Data as to which Breast was Affected.

Boreluus.-Observ. Med. Phys., Cent. IV, Francof. et Lip, r676, Cent. I, Obs. 49, p. 55. Lanzonus.-Miscl. Acad. Nat. Curios., Dec. II, Ann. IX, I691, p. 228, Obs. 55 .

Отто.-Neues Verz. d. anat. Samml. d. k. anat. Inst. zu Breslau, r84r, No. r288, p. r 25.

Rryme.- "An Account of the Cape of Good Hope and the Hottentots," London, r704, Fol. IV, 829 .

D. Both Breasts Polythelic.

(a) Areole about the supcrnumerary nipples.

I. Situated below the normal nipples in a vertical line.

Rey.-(Astier) Alger. méd., vide Gazette des Hôpitaux, r880, LIII, 588 . (The lower nipples were a little outside of the vertical line.)

Rheinfuss.- Wiener med. Blätter, r 893 , XVI, 459.

2. Situation not given.

Pruckelius.-Misc. Curios. sive Ephemerides med. phys. German. curios, Dec. I, Ann. IX et $\mathrm{X}$, Obs. VIII, p. 45 .

The original text reads as follows:

“. . ostendit nobis, inquit, non ita pridem juvenis duas in utraque mamma papillas

tam affabre collocatas, ut alendis tot liberis omnino destinatæ videreutur."

(b) Arcola well marked on the right side, absent on the other, about the supernumerary nipples.

CHowne.--Lancet, London, I 84 r, 2, II, 465 .

(c) No data as to areole.

Gautherin.-Thèse de Paris, i 808 , No. 74.

1. Situated beneath the normal nipples in a vertical line.

Hacquard. - 3 cases, Thèse de Strasbourg, I831, No. 980.

2. No data as to the situation of the supernumerary nipples.

Gautherin.- Thèse de Paris, r808, No. 74.

Hollerus.-Consil. et Ohservat. rar. Lib., II, 686.

E. No Data as to the Breast or Breasts Affected.

Tarnier.-Cazeaux, "Traité de l'Art des Accouchements," r87o, 8th ed, p. 86.

(Several cases mentioned but no data given.)

Billroth.- "Diseases of the Female Mammary Glands," Cyclopedia of Obstetrics and Surgery, Gusserow and Grandin, r887, IX. Mentions a breast with two nipples in which he ohserved the development of carcinoma.

II. Three nipples on the same breast.

BIIATERAI IN OCCURRENCE.

Prackelrus.-Miscel. curios, etc., Dec. i, Ann. V, Obs. 67, p. 40, Appendix. This observer saw a Scotch woman who had three nipples on each breast arranged so as to form a triangle. The two supernumerary ones are said to have been below the normal one. Each nipple gave milk. No data are given as to the respective size of the nipples nor concerning the presence or absence of areolæ.

III. Five nipples on the left breast and two on the right.

Hannaeus.-Ex epistola M. G. Hannaei (r675) ad Olaum Borrichium. See Thomas Bartholinus, Act. Med. et Philosoph. Hafn., III, I 7 I. This is a much quoted case appearing in all of the chief writings upon medical curiosities and upon polymastia and polythelia. The subject of the malformation is said to have had five nipples on the left breast and two on the right, each with its own areola. Milk escaped from all of them at the time of lactation and from them all at once when they were irritated. The original text is as follows: "Observationem miram prafert Georg Hannaeus, scripsit einem Oleo Borricho, se vidisse mulierum, quae quamvis tantum duas, sed ambiter magnas mammas natura occepisset 
tanem quinque papillas areolis satis perspicuis in mamma sinistra, et in dextra duas areolis singulis cinctas gestavisset. Has papillas imprimis paulun tilillatis facillime valde erectas esse; omnes incitatis eodem tempore lac fadisse, quod mulieri molestissemium fuisset."

Two peculiar cases perhaps deserve mention as having slight bearing upon the subject of polythelia. One of these is reported by Hurt (St. Louis Medical and Surgical Journal, I880, XXXIX, 306).

"A month or so after confinement the patient complained of sore nipples, and on examination I found the areola to be studded with quite a number of what I supposed to be warts . . . . She replied 'they are not warts . . . . they are little nipples; whenever I nurse my child they have little drops of milk on them.' I could myself, squeeze milk out of all these little protuberances about the nipples, and she said that when the breasts were very full, all of the nipples commenced secreting."

The other case is Petrone's (Progresso Med., Napoli, I 889, III, ${ }_{5}$ I6). The patient was a man with six mammary glands, $t$ wo in the normal position, and two below on each side of the abdomen. The normal mammæ had warty formations that he interprets as three supplementary tiny nipples in addition to the normal nipple in the areola of the normally placed glands.

Surgery of Supernumerary Mammæ and Nipples.-The surgeon may be called upon to operate in polymastia in certain peculiar cases, almost always in female patients, the indications for operation being as follows:

I. When the location of the supernumerary gland is such as to occasion excessive pain at the time of enlargement during pregnancy and lactation. Such cases are usually axillary. The glands are useless, they may swell to the size of goose eggs, interfere with the movements of the arms and cause so much suffering that the operation is earnestly asked for by the patient. The swelling usually subsides in the course of a few days or weeks. It must be remembered that with each pregnancy the swelling and pain will recur, though it is rarely so severe as at the time of the first pregnancy.

In rare cases, like one reported by Ziehen (Berliner klin. Wochenschrift, I904, p. 9I2) the occurrence of neuralgic pains in young girls, coincidental with the menstrual period, and radiating down the arms, may indicate axillary mammæ that need removal.

II. When the constant dribbling of milk distresses the patient by saturating the clothing. Like the swelling and pain, this rights itself in most cases in the course of a short time. If the gland be large and the child can nurse from it, it probably soon behaves like the normal breasts; at first, each time the baby nurses there are pricking sensations and a spurt of milk from each unoccupied breast, but after the function of lactation is once well established this inconvenience passes off. When the gland is too small to use, the secretion may cease and the milk "dry up" after a few weeks. If this does not happen and the gland continues to leak, excision may be indicated.

III. When the supernumerary glands are so situated and so constructed as to resemble tumors, or are situated upon the face, neck, flank, back, buttock, back of the thigh, hip, vulva, etc., they may be unsightly or uncomfortable and may require removal for cosmetic or orthopœdic reasons.

IV. When it is feared that a malignant tumor may arise from the supernumerary mammary gland. If, as seems well established from clinical observation, traumatic injury of the normal pectoral mammæ has a predisposing or even, perhaps, an exciting influence upon the growth of malignant tumors, there is no reason why a similar injury to supernumerary mammæ may not do the same. Glands so situated as to be the seat of frequent injury-those on the back, hip, flank, buttock and thigh-should be given particular attention from this point of view and their removal advised. On account of their rarity, however, there are no data at hand to show how great the danger in such 
cases really is. Jacoulet (Prog. méd., Paris, I909, 3 s., XXV,6I8) observed a woman with an adenoma in the left breast, and a similar independent tumor in the left axilla, the latter supposedly growing from a supernumerary, axillary mammæ. A few cases are on record to show that cancer can develop in supernumerary mammary glands. Thus Busch and Whitacre have each seen cancer arise from a supernumerary mamma in the neighborhood of the axilla. We have studied Neilson's case in which a large fibro-epithelial tumor developed in a right axillary mamma and later was followed by cancer. Gluck (Berliner klin. Wochenschrift, I885, p. 292) had a case in which what was thought to be an adenoma grew in a supernumerary mamma, just above the normal mamma, and later. changed to a cancer. Billroth ("Die Krankheiten der Brustdrüsen," Deutsche Chirurgie. Leif., 4I,I880, p. 10) saw a cancer grow in a breast with two nipples upon it. Martin (Jahresb. d. schless. Gesellsch. f. vaterländ. Kultur, I893, lxx, 43,) observed cancer in a supernumerary infra-mammary mamma. Mourne (Bull. et mém. de la Soc. d'Anat. de Paris, I9I4, LXXIX, II5) saw cancer in an axillary mamma. Pitzorno (La Riforma Medica, I896, XII, Pt. I, p. 65I) is said to have seen five cases of polymastia in one year, in two of which neoplasms developed. Williams (Jour. Anat. and Phys., I890-gr, XXV, p. 245) mentions half a cancerous tumor removed from the axilla of a lady aged 35 years. The breast and skin over it were normal. It was easily detached. The specimen is now in the Hunterian Museum. Williams seems anxious to impress his readers with the probability of tumors of various kinds arising from supernumerary mammary tissue and from his own experiences concludes that out of 50 cases of fibro-adenoma of the mamma consecutively under observation, seven, or 14 per cent., originated in supernumerary structures just outside the normal ones. Of 132 cases of cancer of the mammary region in women, he found that 13 , or 9.8 per cent., had originated in supernumerary structures quite outside of the normal mammæ. If the reader be interested in this matter and will take the trouble to read the protocols of the cases collected and published by Williams, he will find that they do not fall in line with such polymastic malformations as have previously been discussed by Williams in his paper, or by ourselves in this chapter, but that the mammary tissue from which the tumors seemed to have grown, were rather outlying lobules of the normal mammæ to which the name "fringe" has been applied, and to which reference was made in describing the anatomy of the mammary gland. Somewhat similar cases of tumor formation in outlying lobules are reported by Péraire and Cornil (Bull. et mém. Soc. d'Anat. de Paris, I907, 6 s., IX, 637), de Rouville (Bull. Soc. d'obstet. et de gynécologie, Paris, I914, iii, 532), Deniker (Bull. et mém. de la Soc. d'Anat. de Paris, I9I3, LXXXVIII, I25), Forbes (Medical News, Mar. 5, I892, LX, 269), Heitzmann (Medical Record, N. Y., I888, XXXIV, 2 I), Spencer (Trans. Path. Soc., London, I goo-or, LII, 70), and Stropeni (Tumori, Roma, I9I 5, IV, 509).

Supernumerary nipples may also require operative treatment and removal. The indication is usually clear when milk runs from the one nipple every time the baby nurses from the other. Supernumerary nipples may also be a disfigurement and operation desired for the restoration of normal symmetry of the breast.

The cases are so essentially different that each becomes a law unto itself. The small wart on the face, or of a larger "wart" on the neck, or a large pedunculated tumor of the vulva, as in Hartung's interesting case, have nothing in common, nor are their cases at all like what might be required should a large post-axillary tumor like that in Griffith's case require removal. Simple excision with incisions and skin flaps suitable to the particular locality is all that is required in most cases, and as the tissue to be removed 
will no doubt, at least, in most cases, be normal tissue, no following up of lymphatics will be necessary.

In the case of supernumerary nipples upon the otherwise normal breast, the excision of a wedge-shaped segment of the gland, varied according to the size of the area of breast tissue drained by the supernumerary nipple will be all that is necessary.

In the rare cases of double and triple nipple in the same areola, and in such cases as have been described in which there were three or five nipples distributed over the breast, nothing can be done, unless for some reason not apparent in an academic discussion of the matter, circumstances arise to indicate that the breast should be amputated.

A practical point deserving mention, in connection with the excision of troublesome axillary mammæ, has to do with the time of their removal. If they are to be removed the operation should be done during pregnancy or lactation, while they are large and troublesome, and not deferred until some future time. Von Brunn (Festschrift für Rindfleisch, r907, p. I55) had a patient who had several times suffered on account of an axillary "lump" that was very painful. She desired to have it removed, but the operation was deferred until four months after confinement and then attempted. The surgeon experienced much embarrassment and difficulty in finding the gland which had so diminished in size as to be no larger than a pea. It was embedded in the adipose tissue in close proximity to one of the vessels. During the period of lactation-hypertrophy this little gland was large and easily recognized on palpation.

\section{SUPPIEMENTARY REFERENCES}

Papers upon polymastia, that were not available for examination or verification either in the original or in the abstract, or that could not be found.

Albers.-Med, Correspondenzbl. für rhein. und westfäl. Aerzte, Bonn, r843, II, 400 .

Astrer.-Alger. médicale, I880, VIII, 72.

Brette.—“Multimammes," Dict. des Sciénces Médicale, Paris, I 913, IV, I5I.

Blanchard.-Coll. Phys. M. P., 2, 49.

Brouah.-Scapel, Leige, i 909, ro; LXII, ror.

D'tgostino.-Tomassi, Napoli, I907, II, 633 .

Fabre.-Echo méd. d. Cevennes. Mimes., I 906, VII, 88-92.

Falaschi.-Boll. d. soc. tra. i. cult. d. sc. med. in Siena, I883, I, I 5 .

FALk.-Centralblatt für Gynäkologie, I902, XXVI, 240.

Flandrin.-Dauphine méd., Grenoble, I896, XX, I60.

Frassi.-Arte Ostet. Milano, I9II, XXV, 227.

Funaioli.-Boll. de Soc. tra. i. cult. d. sc. med. in Siena, I886, IV, 23.

Candini.-Pensiero med. Milano, I9 I I, I, 805 .

GEYL.-Nederl. Tydschr. v. Geneek. Ams., I907, II, I3I3.

Godfrain.-Thèse de Paris, 1877. Blanchard says that he collected cases and added six to Peuch's list.

GoRIA.-Gazz. med. di. Torino, I895, XLVI, 737. This case is so frequently referred to and in such detail that it is introduced in our series of "dorsal mammæ."

Gotz-Oesterr. med. Jahrbücher, I 8 i 4 , p. 348 .

Hinbert.-Memorabilien, Heilbron, r892-93, n. F. I., XII, I 29.

Huber.-Med. Zeitschriftal Russlands, I844. p. 28.

IwaI.-Mitt. a. d. med. Gesellsch. zu Tokio, X, XIV.

Johnson:-Boston Med. Jour. and Archiv of Tocology, I887, p. I40.

Katayama.-Mitt. a. d. med. Gesellsch. zu Tokio, X.

Kuroiwa.-Koseikwan Med. Mag., I895, 1I, No. I I-I 2.

KyrkLUnd.-Duodecim. Helsinki, I889, V, i6.

LEE.-Inaug. Diss., Erlangen, 1872.

Martin, E.-Jahresberichte d. schless. Gesellschaft für vaterländische Kultur, I892, Breslau, I893, $\mathrm{LXX}, 43$. 
Mrnervivi.-Bull. Science Méd., X, 46I, ' 858 .

OTANI.-Mitt. a. d. med. Gesellsch. zu Tokio, III, No. 9; XIV, No. Io; and XIII, 9.

Perusinj.-Giornale di psichiat. Clin. et tech. manic. Ferrara, I903, XXXI, 5 I.

Sato.-Koseikwan Med. Mag., I895, Nos. II-I 2; IV, No. 6.

SAto.-Mitt. a. d. med. Gesellsch. zu Tokio, I904, XVIII, No. 20, p. 899.

ScalzI.-Commentario dell'Ostetrica in Italia della meta del sècolo dictiotesimo sècolo fino al presento, Bologna, I 874 .

SchMetzer.-Correspondenzbl. für Württemburgerischer Aerzte, VI, p. 33.

SELL.-Berichte d. naturf. Gesellschaft, Bd. IX, I-34.

Siraud.-La Province méd., I 897 , No. 26.

SteET.-Tr. Kentucky M. Soc. Louisville, I 892, N. S., I, 297.

Smrтh.-Louisville Medical News, 1880, X, 23 I.

Vulke.-Inaug. Diss., Bonn, I897.

Yoshinaga.-Zeitschrift d. med Gesellschaft zu Tokio, I899, XIII, 433.

Papers, cases and collections of cases that occur in the literature without references and to which no references appear in the Index Cotalogue or Index Medicus.

Ammon.-Said by Keibel to have studied numerous cases of polymastia and observed up to eight nipples.

BXLz.-Said by Hurinchi (vide Hug) to have observed I 20 cases of supernumerary mammæ among Japanese women.

FAYE.-Cited by Hartung as having seen a case witb four breasts.

HUGH.- Hofstätter says tbat in I908 he arranged Ioo cases of polymastia according to the "milchleisten."

Aberstaedt.-Cited by Hartung as having seen a small supernumerary breast on the left side about a handbreadth below the normal one.

RiNSig.-Also cited by Hartung as having seen a small supernumerary breast on the right side $\mathrm{r} 1 \%$ incbes below the normal right one.

VRöLIK.--Cited by Hartung as having seen a supernumerary breast with two nipples, below the left breast.

References in the literature that were erroneous and could not be verified.

AsHLey, W. H.-Lancet, London, I840, II, 227.

Davies, T. H.-London Med. Gazette, I 844 , I, 545 .

Grimm.-Centrajbl. für Gynäkologie, I 897 , No. I 2, p. 285 .

MARShall.-Brit. Med. Jour., I897, December-February, I898.

Rebatel.-Bull. d. Soc. d'Antbropologie. de Lyon, i88r, 2, p. I37.

\section{REFLECTIONS UPON AMÁSTIA, POLYMASTIA AND POLYTHELIA}

Amastia in its various forms is an exceedingly rare congenital malformation that is of no surgical interest or significance. It results from accidents of embryonal or fœetal life that cannot be recognized and against which it is impossible to defend the individual. There is no help for the condition, except that when rudimentary mammary glands are a source of annoyance to child-bearing women because of painful but useless enlargement it may be advantageous to remove them. No cases are on record where this appears to have been necessary.

Athelia is probably as rare as amastia but the references in the literature are not sufficiently numerous to enable us to judge. It incapacitates the patient from nursing her baby, though by the use of a shield and artificial nipple, some cases get along without undue discomfort. Mamillaplasty (q.v.) may be tried as a means of surgical correction of the deformity.

Polymastia is a common congenital malformation of which the literature shows the reported occurrence of upward of 10,000 cases. In the entire literature there are less than a dozen cases only that cannot be harmonized with the doctrine of atavism or reversion. Several of these cases are not above a suspicion of error in identification 
-as the cases of Holzt, on the back of the neck, Haug on the tragus of the ear, and Barth over the parotid gland. But including these as bonafide mammary glands, a proportion of a dozen cases against, and Io,00o cases for the theory, seem to establish the theory of reversion upon a very substantial foundation. There is no known explanation of the occurrence of "mammæ erratica."

Polymastia has few but definite surgical aspects. The supernumerary glands may be disfiguring, may be painful, may be annoying or may be the point of origin of morbid growths either benign or malignant. These are sufficient reasons for removing a certain number of them. The removal of all supernumerary glands so situated as to be subject to traumatic injury is strongly advised. There is ample evidence of the hereditary nature of the deformity, and the patients should be told that the chances are strongly in favor of their offspring being similarly affected.

There is some but not conclusive evidence that polymastic women are abnormally fecund and tend to have twins:

There is no support for Fournier's view that congenital syphilis predisposes to polymastia.

The evidence to show that polymastic men and women are predisposed to tuberculosis is inconclusive.

There is no reason for believing that neoplasm formation in supernumerary mammæ is more frequent than in normal mammæ.

Polythelia is much more rare than polymastia. It is of surgical interest and important because it is but rarely that there are more than two nipples, and the supernumerary nipple is usually small and drains a small area of the gland, making it easily possible to improve the gland by excision of the extra nipple and the tissue it drains. Such an operation ought always to be advised where a supernumerary nipple is a source of discomfort. The quantity of tissue to be removed is best determined during the period of lactation, though the operation may be deferred. 
CHAPTER IV

\section{THE ACQUIRED ANOMALIES OF THE BREAST}

I. Excessive growth

A. In the female

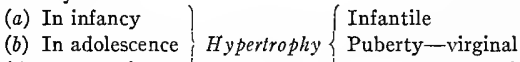

(c) In maturity (Pregnancy-gravidity-lactation-nondescript

B. In the male........ Gynecomastia

2. Recessive growth.......Atrophy

\section{MAMMARY HYPERTROPHY OR DIFFUSE MAMMARY HYPERTROPHY}

Infantile Hypertrophy or enlargement of the breasts of female children is a rare abnormality that is rather a manifestation of precocious sexual development, than of localized

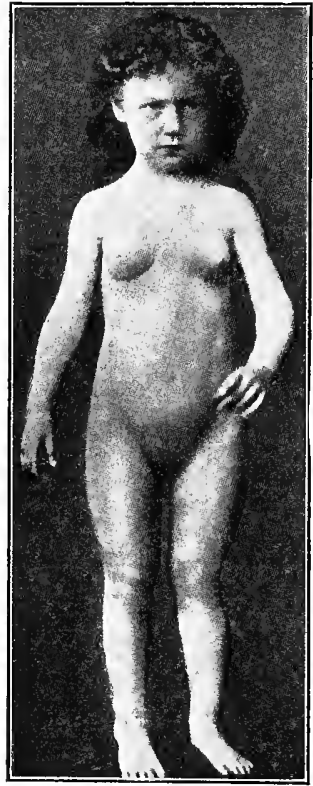

Fig. 64.-Infantile mammary hypertrophy. Precocious development in a child two years of age. (Marcy.) of an adult woman, and pubes covered with hair. Lebeau (Gaz. méd. de Paris, r832, III,"98),reports a still more remarkable case in which the baby when born had a hairy disturbance of the breasts. The breasts are not diseased, they are prematurely developed. A child of three may have a mammary development normal to a girl of fifteen. There is no parallelism between these cases and the virginal and gravidity hypertrophy-in the lātter cases, the breasts are distinctly abnormal.

A few cases of prenatal enlargement-i.e., hypertrophy -of the breasts are on record. Hahn (Amtlicher Bericht der deutscher Naturförscher und Aerzte zu Stuttgart, September, I834 (I835), p. I09; vide Schmidt's Jahrbücher, $V, I_{3} 8$ ) reported the case of a female infant, born with monstrous hands and a monstrous left breast. The child was three years old when shown at the society meeting. This case probably falls outside of the group under discussion, and is an example of real hypertrophy of the breast, in which it seems to be unique. Ramon de la Sagra (Julius and Gerson's Magazine, XX, 479) reports the case of a nergo slave girl belonging to Don Carlos Pedro of Havana, who was born July 6, I 821 , with welldeveloped breasts. Shortly after birth there was a flow of blood from the vagina, that was soon regularly repeated so that at the end of a year she was menstruating regularly. At 32 months of age, she was 3 feet, Io inches tall, and her breasts and sexual organs were as well developed as those of other Havana negresses of 13 years. Wilson (Gaz. des Hôp., I854, July 4) observed a baby girl whose breasts were as large as hens' eggs at the time of her birth; in five months they had advanced to the dimensions of those of an ordinary girl at puberty, and she began to menstruate; at six years of age she had breasts like those 
mons veneris and well-developed breasts, and began to menstruate in the third year. Malleat (Gaz. méd. de Paris, I832, p. 620) reports the case of a girl baby that had welldeveloped mammæ and genitals, and began to menstruate at $\mathrm{I}_{5}$ days old. Wall (Medio-Chirurgical Transactions, I8I 7 , II, I I6) saw a baby girl that began menstruating at nine months, and whose breasts were well-developed at i 8 months.

In regard to the past-natal infantile enlargement of the breasts it may be said that the earlier the sexual organs develop the earlier the breasts enlarge. The literature is not rich in bona-fide cases. The following references are in our collection.

Brttake (Prag. med. Wochenschrift, 1895, XX, 492; abstract Centr. f. Gynäk., I897, XXI, 832) observed a child whose breasts were like adult mammæ, with well-developed nipples, when the child was only six months of age.

Bourjot and Saint-Hitarre.-Gaz. méd. de Paris, 1832, p. 68 I. A little girl born of poor white parents in Louisiana, at three years of age had well-formed breasts and pubes covered with hair, like a girl of 13 or I4 years. At three years of age the catamenia appeared and continued regularly, lasting four days each time. Upon examination it turns out that this is the same case reported by Lebeau and cited above as prenatal infantile enlargement of the breast.

McGrllicuddy (Medical Record, New York, I891, XL, 446) speaks of having knowledge of enlargement of the mammary glands in a little girl who is menstruating.

MARCy.-Transactions of the American Medical Association, I876, XXVII, 237. The child was two years and seven months old when the photograph was taken. Pubic hair began to grow when she was nine months old. At the first month mammary development hegan.

MudD.-Dennis and Billings "American Practice of Surgery:" VI, 508. The child is four years and nine months old and began to menstruate at 5 months.

Bevern (Hufeland's Jour. der prakt. Heilkunde, Berlin, i 801 , XIV, part 3, p. 145) saw one of twin girls outgrow her sister in a remarkable manner. At three and a half years she had grown so large that she could no longer walk. She was very fat, and the belly hung in a pendulous position. The breasts were fully developed and the mons veneris

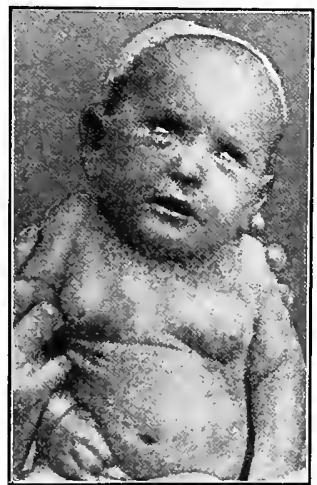

Fig. 65.-Infantile mammary hypertrophy: Six months' infant with previous development of the breasts. (Bittner.) was covered with long black hairs.

Bochut (Gaz. des Hôpitaux, Paris, I 878 ) saw a child whose breasts were as large as a man's fist, pyriform, with a rosy areolæ and well-developed nipples. The vulva was hirsute, and she was menstruating. At the begining of each period the precocious breasts increased in size.

Baudeloceue (Dictionaire des Sciences Médicale, Paris, 1818, article "Mamelle" by Murat et Patissier, XXX, 386) tells of a little negress eight years of age, who nursed an infant at her well-developed breasts. The original is as follows: "Une petite fille d'Alençon, agée de huit ans, appliquait souvent à son sein la bouche d'un enfant de quelque mois qui sa mère allaitait; il lui vint assez de lait pour le nourrir elle-meme pendent un mois, selon le temoignage de plusieurs personnes de la ville, la mère ne peuvant plus le faire par rapport aux gerçures de ses mamelons. Cette petite fille conservait encore beaucoup de lait d'une excellente qualité et l'exprimait aisèment par jets lorsque elle fut presentée à l' académie de chirurgie le 16 Oct., i $783 . "$

Dopd (Lancet, April 9, r88I, p. 60I) observed a female infant that commenced to menstruate at I2 months of age. This precocious child became pregnant at the age of nine years, when her breasts, that were like those of an adult, became engorged with milk.

Eurbing (Lancet, I 848, i, I37) observed a little girl three years old, who was menstruating and whose breasts were as well developed as those of most women of 20 years. There was hair upon the pubes. 
Grout (Archiv. gen. de méd. Paris, 1854 , i, $757,5 \mathrm{~s}$. , iii) saw a little girl three and a half years old both of whose mamme were developed like those of a fully developed woman, although in other respects she resembled children of her own age.

JAcoubowitsh (Nouvelles archives d'obst. et de gynécol., Suppl., June, I893, from Vratch, 1892) saw a little girl of three whose mammæ were the size of hens' eggs and discharged lactescent fluid, and who had some vaginal discharge. At six and a half years, she was regularly menstruating and the breasts were as large as small oranges. The genitalia were also somewhat developed.

KaUSSMAUL UND HeMPEL (Würzburger med. Zeitung, I862, iii, $32 \mathrm{r})$ report the case of Anna $S$., one year and seven months old, the child of healthy parents, whose size corresponded to her age, but whose teeth had nearly all developed, who had long hair upon the head, much hair upon the mons veneris, and both of whose breasts were well developed, rounded and surmounted with projecting nipples so that she looked like a miniature woman. She was suffering from ascites for which she was brought to the physicians.

Gedike (Horn's Archives, I825, September and Octoher, p. I 89) observed Charlotte L., aged seven years, overgrown and already menstruating. Both breasts were well developed and there was hair on the genitals. She died of peritonitis.

Tilesius (cited without reference by Kausmaul-vide supra) reported the case of J.F.G. who at four years of age was $27 \frac{1}{2}$ inches tall and weighed 84 pounds. She was sexually developed and had pendulous breasts

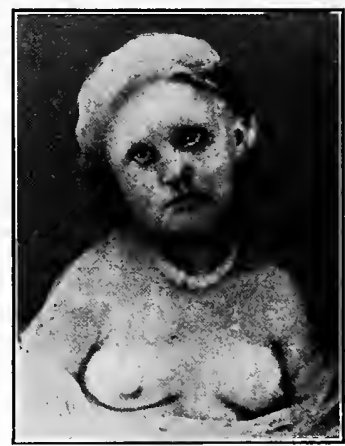

FIG. 66.-Infantile mammary hypertrophy. Precocious development of the breasts in a little girl of four years and nine months. (Mudd.) with distinct nipples surrounded by darkly pigmented areolæ.

Mandelsloh (Letter to Olearius-vide Weiterweben, Vierteljahresschrift f. d. prakt. Heilkunde, Prague $18_{47}$, XIII, 85) tells of a little girl who began to menstruate at three years of age, and whose breasts were as large as those of a nursing woman.

Descuret (Nouveau Jour. de Méd., I820, vii, roo) speaks of M.A.M., wife of Coquelin, born at Pouné, and living at Paris, who hegan menstruating at two and a half years, at eight years was 4 feet, $4^{1 / 2}$ inches tall, and whose bosom was extraordinarily well developed.

Von Leunossek' (Med. Jahrb. d. österr. Staates, vi, 3) saw a girl baby of ro months suddenly take on rapid precocious development. At two years of age she had well-developed breasts, pubic hair, and was menstruating.

PEAcock (London Medical Gazette, I839, XXV, 548) saw a little girl of five years whose breasts were like those of a woman, with erectile nipples and dark areolæ like those of pregnancy.

Puberty Hypertrophy, Virginal Hypertrophy or Hypertrophy of the Breast in Adolescence.-This is quite another matter, and is of great surgical interest. An effort has been made to collect and analyze all of the reported cases, and 98 have been found, and the references verified, or taken as correct when given by trustworthy writers.

Gravidity, Pregnancy, Lactation and Nondescript Hypertrophy of the Breast of Adults.-There seems to be little justification for separating the mammary hypertrophy of adolescence from that of maturity. Both conditions seem to be essentially the same and probably depend upon the same cause, for which reason they may be considered together.

Mammary hypertrophy may be defined as an excessive enlargement of the breast depending upon a fairly uniform and proportional enlargement of the structural components. There is scarcely any abnormality except the size. As Durston quaintly says of the enormous breast removed from his patient, "when opened nothing was found but 


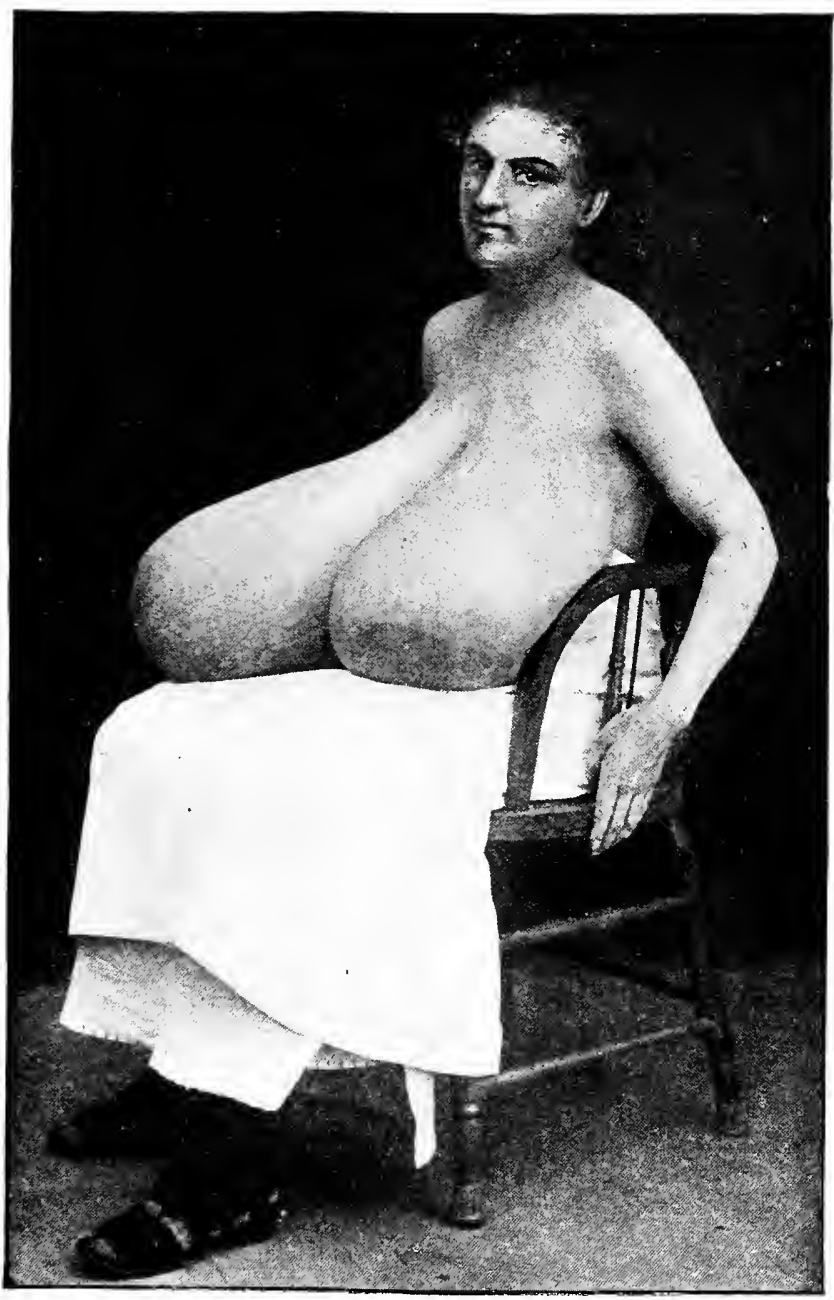

Fig. 67.-Hypertrophy of the breasts. (Porter.) 
prodigious bigness." The degree of enlargement varies greatly and it may be supposed that every surgeon of experience has had to deal with one or more cases of the milder grades of the affection. Probably the extreme cases that figure in the literature will be more rare in the future than they have been in the past because the public is so well informed upon medical and surgical questions and is being trained to be particularly solicitous about morbid conditions of the breasts.

There is striking uniformity in the case histories. A young girl before or at the beginning of menstruation observes that one or both of the breasts commences to enlarge. When the full size is reached, instead of the growth ceasing, it continues, usually in both breasts, but sometimes in one, until the size becomes so large that the patient is not only embarrassed on account of the alteration in personal appearance, but also because their weight makes it impossible to work, finally to walk, and perhaps, at length even to carry them about. The size that may be attained to is almost unbelievable. The

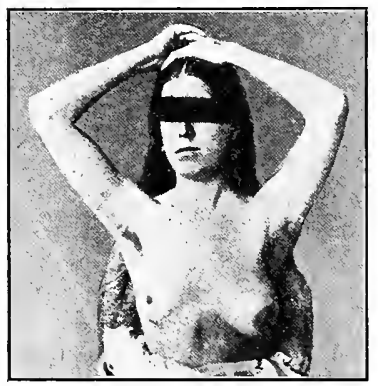

FIG. 68.-Inequality in the size of the breasts from hypertrophy of the left breast. (Fiaschi.) left breast of Durston's patient, when removed, weighed 64 pounds. During the period of growth that varies from a few months to several years there are rarely any symptoms, and the patients usually come under observation on account of the deformity and disability, being well in all other respects.

The disease is not infrequently described as "virginal hypertrophy," but aside from the fact that the greater number of cases commence to experience the enlargement shortly after the establishment of menstruation, at which time most young women are virgins, virginity has nothing to do with it and the expression is a misnomer. One-half of the bilateral cases reported occurred prior to the eighteenth year, the other half subsequent to it. The greatest number of cases occur-i.e., come under observation - in the sixteenth year. The enlargement may occur at any time up to the forty-eighth year.

The period of growth varies greatly. In Durston's case there seems to have been some misinformation about the inception of the disease. The case history as he gives it is as follows:

"Elizs Trevors, aged 23 or 24 years, went to bed July 3 d, 1669, and took good rest and sleep, but waked up in the morning with the breasts so swollen and heavy that she could not turn herself in bed or move, yet she had no pain or weakness either in her breasts or in any other part." .

Such a sudden onset is so remarkable, so inconceivable, and so unlike what happened in other cases as to make it appear either that the patient or the doctor was mistaken or misinformed.

Very rapid growth seems to have taken place in one of Zurakoff's patients, a woman, pregnant, and 22 years of age, whose breasts grew in two and one-half months to such a size that the greatest circumference of the right breast was $57 \mathrm{~cm}$., of the left $5^{8} \mathrm{~cm}$. It would seem as though the natural growth attending pregnancy might eventuate in a more rapid growth than would occur independently of pregnancy, but the cases show that the average time required for the breasts of young, pregnant women to undergo massive hypertrophy is ro months. 
For patients under $2 \mathrm{I}$ years of age, some virgins, some married, some pregnant, the average period of growth is 20 months. The longest period of development for a girl under $2 \mathrm{I}$ years of age is four years. The average duration of growth for women over $2 \mathrm{I}$ years of age is five years. For women over $2 \mathrm{I}$ years of age the shortest period of growth is two and one-half months in a woman of 22 years; the longest period of growth I6 years in a woman 48 years of age.

Among women over 30 years of age, the average duration of growth in cases of which data is available is five years.

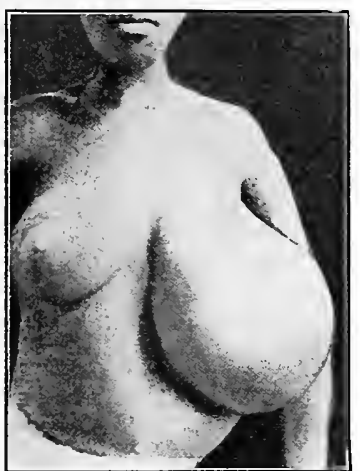

FIG. 69.- Hypertrophy of the breasts. Left unilateral hypertrophy. (DaCosta.)

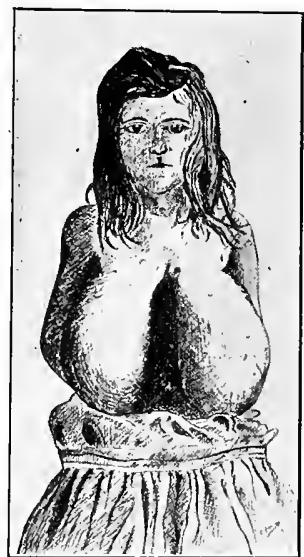

FIG. 70.-Hypertrophy of the breasts at puberty. (Cambet.)

The youngest patient with massive hypertrophy was I2 years old, the duration of the growth being one year. The oldest patient was 48 years, the duration of the growth being 16 years.

These data, however, are misleading because in nearly all of the cases the breasts of the patients had attained the maximum of growth and become stationary some time before they came under observation, and in few cases can it be made out when the passage from what might be called normal to what was certainly abnormal occurred.

In only four cases is it said that the patients suffered from pain. In one case, that of Ehrenhaus, the hypertrophied breasts were the seat of active secretory activitygalactorrhœe-and sometimes a quart of milk escaped from them in 24 hours. In one case, one of Zarukoff's, and in the case of Benoit and Monteils the enormously hypertrophied breasts secreted no milk after confinement.

In reading the account of many of the cases the impression is made that the women nursed their children with the hypertrophied organs, but it is difficult to understand how this could be accomplished as the nipple is usually flattened out upon the hypertrophied breasts.

Of 182 cases in which details are given, the hypertrophy affected both breasts in 142 ; one breast in 40 . Of the 25 unilateral cases, 8 were on the right, I 7 on the left side; in ${ }_{5} 5$ the side was not stated. 
The hypertrophy may progress uniformly, or rapidly for a time, then slowly, then perhaps cease for a time and begin again. In some cases the occurrence of menstruation seems to act as a stimulus to growth. In a number of cases when the breasts attained the maximum size, menstruation ceased. It is not always clear, from the case reports, however, whether, this was because the patients became pregnant, or whether it was due to some condition attending the disturbance of the breasts and inhibiting menstruation.

It is unfortunate that we are not better informed concerning the natural tendency of. the affection. The enormous size of the breasts so mortifies and incapacitates the patients that they apply for operative assistance which is apt to be afforded them without waiting to see what nature would do. There are, however, nine cases that suggest that the con-

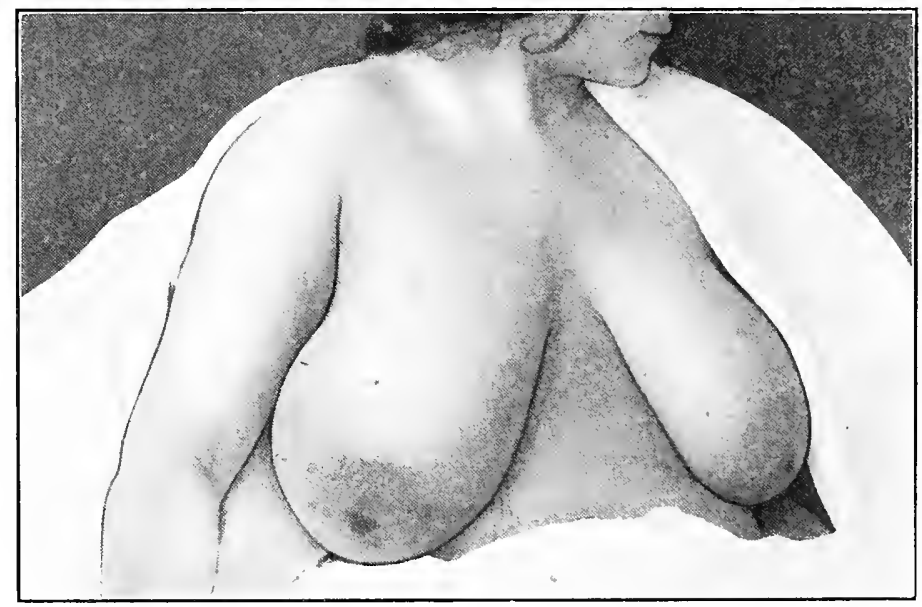

Fig. 7r.-Virginal hypertrophy of the breasts.

dition sometimes tends toward spontaneous amelioration or cure. Thus, in one of Billroth's cases, in which the breasts reached to the pubes, operation being refused, they diminished somewhat in size while the patient remained under observation. In the case reported by Delfiz, in which the breasts were still larger, the patient was kept under observation for some time during which she aborted a five months' fœtus. She refused operation and was treated by frictional applications of an ointment containing "hydriodate of potassium." After a few months, the breasts diminished to about twice the normal size. Hey, Hoy, Le Double, and Terrill removed one breast, after which the other was found to diminish in size. What would have happened to the removed breast if they had waited?

In the case reported by Benoit and Monteils, in which the breasts were of immense size, operation was strongly advised but refused. When the patient began to menstruate there was a marked diminution of size. Later the patient married and bore three children, the breasts continuing to grow smaller, until at the time of reporting the case, I 6 years after the time of advising the operation, the breasts were only a little larger than 
normal in size. Monod observed a patient who suffered from an enormous hypertrophy of the mammæ at each of three pregnancies, but always found them return to normal size after confinement. At the time of reporting the case the patient was in the fourth month of pregnancy and the breasts were enormous. The patient being extremely emaciated and in a somewhat cachectic condition, and treatment proving inefficacious, it was decided that operative removal was indicated.

Rosinski had a patient 28 years old in the sixth month of pregnancy with "colossal" hypertrophy of the mammæ. It was the fourth time that she had been pregnant and each time she had had a similar enlargement of the breasts which subsequently diminished at the puerperium. Zurakoff observed a case in which the breasts suddenly and rapidly grew to an enormous size, the patient being a young married woman, not pregnant.

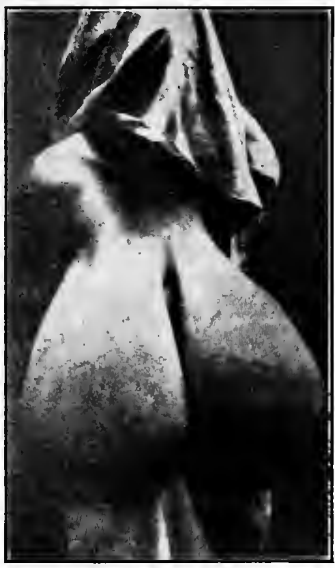

FIG. 72.-Virginal hypertrophy of the breasts. (Malone.)

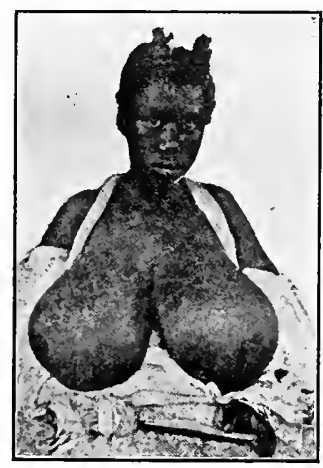

FIG. 73.--Virginal hypertrophy of the breasts in a negress I4 years of age. (Martin.)

Treatment with potassium iodide and compression of the breasts was tried, and in Io months they regained the normal size.

These short accounts of individual cases are introduced to show that the hypertrophy if mysterious in its origin is equally mysterious in its disappearance.

In the hypertrophied condition the breasts differ from the normal only in size. The general configuration is maintained until the breasts become so large and so heavy that the weight makes traction upon the natural attachments and gradually forms a kind of pedicle. Under these circumstances the breast becomes pyriform, the globe of the pear being down, the slender neck forming the attachment. The nipple might be said to correspond to the blossom of the pear, and is usually flattened out by the stretching of the skin about it. The skin over the breast is unchanged-not wrinkled, folded or velvety, as it is in elephantiasis. The tissue of the breast usually feels normal, that is, like the tissue of the normal breast, and it is evident that there is no tumor present. To this normality of the palpable structure of the breast there are few exceptions; Lozbeck says 
that the patient who came under his care first observed a lump like a "Welsh nut" on the inner side of the left breast. From this the enlargement spread uniformly to the entire breast. This makes the case more like a neoplasm-a fibro-epithelial tumorthan like simple hypertrophy, though the author does not regard it as a tumor but as a case of hypertrophy. Dumarquay found the enlargement in his case surrounded by a thin fibrous capsule. No other author describes such a structure, so that it is possible that this case was also a large fibro-epithelial tumor, though the author did not regard it as such but described the case as one of hypertrophy of the breast.

Microscopic studies of the tissue of hypertrophied breasts have been made in many of the cases, and all of the microscopists agree that the usual condition is hypertrophic increase of both the glandular parenchyma and of the inter-glandular stroma, the preponderance probably being in favor of the latter. The parenchyma is in some cases normal

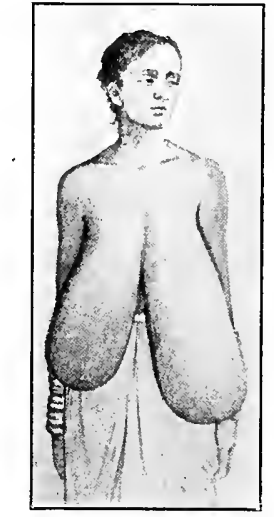

FIG. 74--Virginal hypertrophy of the breasts in a Hindu girl $r 7$ years old. (Maitland.)

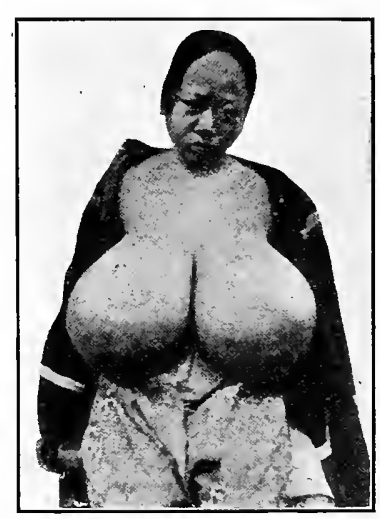

FIG. 75.--Hypertrophy of the breasts in a Chinese woman. (Tatchell.)

in appearance, in others has tubules that are dilated and lined with cuboidal cells. Albert found diminution of elastic tissue.

In a few cases there was preponderance of adipose tissue (cases of Rosenfeld and Guthrie and Albert). Guthrie and Albert have suggested that this is a different process from hypertrophy, and have suggested that it be called adiposity. In these cases there is relatively little glandular parenchyma, though what is found resembles that seen in the other cases.

It is interesting to note that the enlargement of the glandular tubules and the occurrence of spaces lined by cuboidal epithelium are not a little like the changes seen in cases of the disturbance known as "chronic cystic mastitis" or "abnormal involution."

The size attained by the hypertrophied breasts is almost beyond belief. In mild grades and in the early stages of the disease the breasts are described as being two or more times the normal size, and cases of this magnitude are so common that they do not attract much attention, are not commonly treated surgically and are rarely reported. As they increase in size they become more and more the source of embarrassment until 
the surgeon is consulted. Operative removal interrupts the further growth of many of the organs, so that it is only necessary to mention the cases in which a maximum growth has been attained. The most extreme enlargement on record is in Durston's remarkable case in which the removed left breast weighed 64 pounds, and the subsequently removed right breast 40 pounds. The combined weight of the breasts could have been little less than that of the patient after their removal. This patient did not survive the operations, which were performed before the period of anesthesia or asepsis. In Porter's case the right breast was so large that when the patient stood it reached midway down the thigh. The combined weight of the breasts was so great that the patient could no longer sustain them, and a frame was made to support them and give her comfort while in the hospital. The right breast when removed is said to have weighed 43 pounds, the smaller

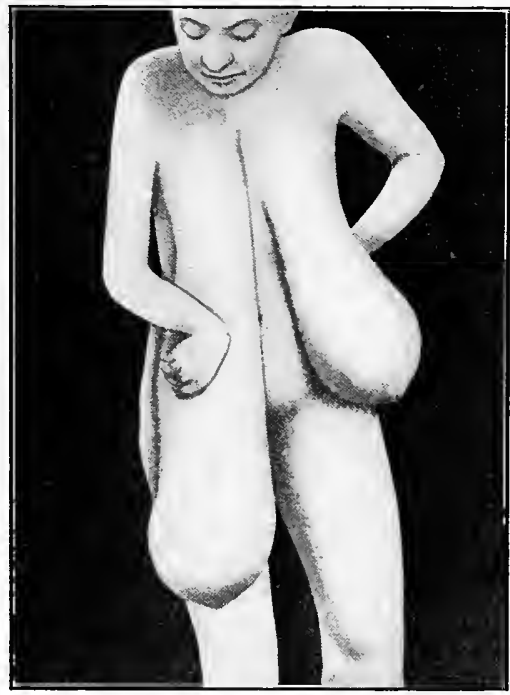

FIG. 76.-Enormous pendulous mammary glands simulating mammary hypertrophy, but caused by the pressure of fibro-epithelial tumors. (Muchanoff.)

left breast 17 pounds. The patient recovered from the operation. The breasts of the woman seen by Bartholinus reached to the patient's knees. Chassaignac and Richelot saw a breast that hung down to the patient's knees and weighed 30 pounds. Borellus also saw a case whose breast weighed 30 pounds and was carried in a sac. From these monstrous proportions, attained in but few cases, we pass to many in which the breasts reach to the pubes, and to a great many in which they reach to the neighborhood of the umbilicus.

Etiology.-No writer has done more than speculate upon the cause of the enlargement. There seem to be only two cases recorded in which hereditary tendencies are apparent. One of these, whose mother at one time suffered from enormous enlargement of the breasts, and whose brother was a gynecomastic, is reported by Pflanz. The other is that reported by Engländer, in which the breasts were so large that the circumference 
of the right was $52 \mathrm{~cm}$; of the left, $46 \mathrm{~cm}$. She was the daughter of a mother whose right breast was twice as large as the left.

Only one case seems to be recorded in which there was a suspicion that traumatism might play a rôle. It was one of Velpeau's cases, and the trauma concerned was "an unimportant blow on the breast with the elbow."

In only two of the cases in our list was mention made of associated disturbance of the sexual apparatus apart from menstruation and pregnancy. These were the case of Bartel, a I4-year-old girl with uterus infantilis and very small ovaries, but who had not yet menstruated, and the case of Grähs, who was ${ }_{5} 5$ years old and was suffering from pulmonary tuberculosis and ovarian disease.

It therefore seems quite clear that the abnormal and excessive growth of the breasts takes place in response to influences independent of heredity, of traumatism and of distinct lesions of the associated organs of reproduction.

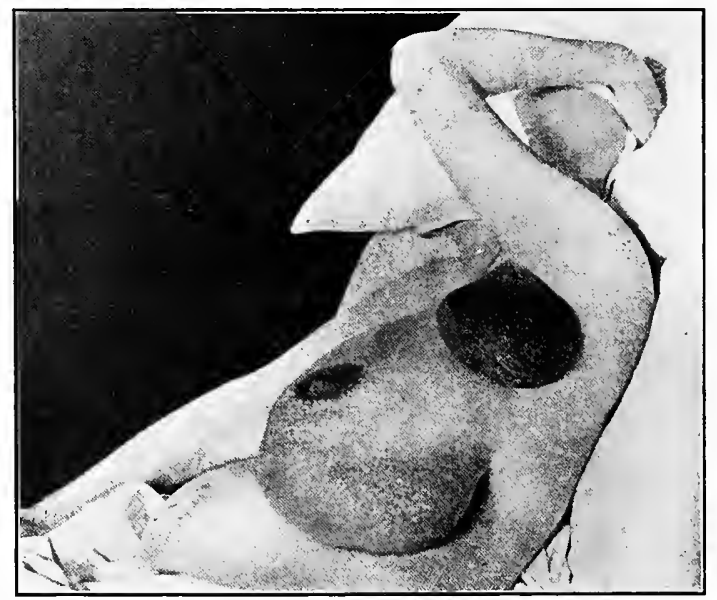

FIG. 77.-Diffuse hypertrophy of the breasts in a case of polymastia, showing how the polymastic structures participate in the hypertrophy. (Warren.)

Opposed to the theory that the enlargement depends upon the exciting influence of hormones or internal secretions brought to the mammary tissue in the blood, the hypothesis entertained by the authors of this book, is the fact that a small number of cases are unilateral in distribution. We are at a loss how to account for this, but it seems to be offset in importance by the behavior of supernumerary mammary glands when present. Of such we find three cases in the literature, reported by Foges, Herczel and Warren. In Foges' case with normal mammæ which, when removed weighed 6000 grams and 6500 grams respectively, there were two supernumerary axillary glands which experienced the same impulse to grow, and responded by enlarging to the size of cocoanuts, so that they too required amputation. In Herczel's case, in which the breasts enlarged so as to descend to the pubes, a supernumerary mamma in the left axilla enlarged to the size of the fist. In Warren's case there seems to have been a supernumerary mamma above one breast and one in the corresponding axilla of the same side, and a supernumerary 
mamma in the axilla of the other side, all of which underwent hypertrophy at the same time as the normal mammæ and in proportion.

Diagnosis.- The diagnosis of mammary hypertrophy should present few difficulties. The occurrence of the greater number of cases at puberty or during pregnancy, the rapid enlargement of both breasts, the painlessness, the uniformity and apparent normality of the breast tissue and the enormous size of the glands are characteristic.

That such enlargement occasionally occurs in one instead of both breasts, that it is sometimes painful, and that it sometimes occurs more slowly and later in life must be taken into account in a minority of the cases, but in cases with these peculiarities, the history of development and the uniformity of structure are usually sufficient to enable the diagnosis to be made with certainty.

Cases said to have begun as a lump, or as lumpiness of the breast, and cases in which circumscribed masses or fluctuating areas can be discovered should be ruled out as enlargements depending upon the presence of fibro-epithelial or other tumors and the presence of cysts. Cases of adiposity of the mammæ as differentiated from hypertrophy of the mammæ, as described by Guthrie and Albert, may be difficult to recognize before operation, but we are not well enough acquainted with adiposity to know whether it is an entirely separate process of rare occurrence or whether it is simply an excessive adiposity of a hypertrophied breast. At all events, the condition is a rare one, and so far as the treatment is concerned, it does not differ from that of hypertrophy.

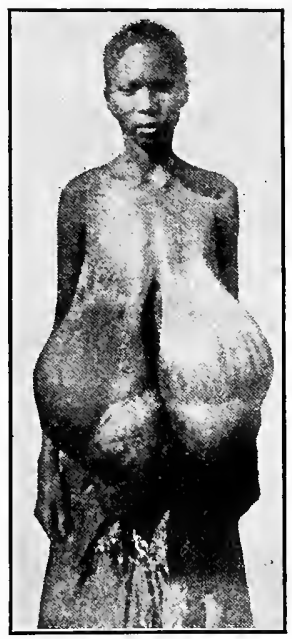

FIG. 78.-Lipoma of the mammæ. Symmetrical enormous lipomas. (Hoenigsberger.)

A few cases of bilateral enlargement occur, however, that may be mistaken for hypertrophy and must not be overlooked. Thus the remarkable case of enormous bilateral

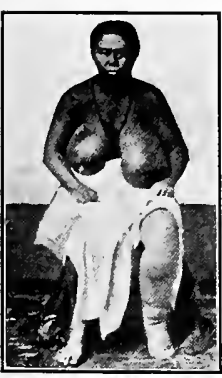

Fic. 79.-Elephantiasis of the breasts and left leg. Case of Davies of Samoa. (Journal of Tropical Medicine.) intra-mammary lipoma reported by Hoenigsberger (Münchener med. Wochenschrift, I905, LII, 222), of which we show an illustration, presents an appearance superficially very like mammary hypertrophy, and the case of bilateral enormous fibro-adenoma reported by Muchanoff (Chirurgia, I908; Centralbl. für Chirurgie, Igo8, XXXV, 1012), of which we also show an illustration, one even more like it. The patient was an insane woman in both of whose breasts fibro-epithelial tumors developed. They were rounded and nodular, and by their weight effected such traction that the breasts finally came to hang almost to the knees.

When only one breast is enlarged a careful examination should be made to determine that no tumor or cyst is present.

Elephantiasis of the breast is a very rare affection whose chief interest centers about the differential diagnosis between it and mammary hypertrophy.

Of undoubted cases, occurring in countries where other forms of elephantiasis are common, we have found the following: A Samoan woman, whose photograph, made by Dr. Davies, appears in Manson's "Trop- 
ical Diseases" (revised edition, London, I900, p. 53I, Fig. 72). Both breasts and the left leg were affected. Another Samoan woman, with an enormous enlargement of the right breast, is shown on plate VII of Vol. II of Kramer's "Die Samoa Inseln," Stuttgart, I903; and a third case is reported by Estienne (Bull. Acad. de Méd., Paris, I83839 , III, 560), as follows:

An Arabic woman, 28 years old, mother of seven children, when nursing the first child ro years ago suffered from acute pain in the right breast which soon began to increase in size, and continued to do so with each succeeding pregnancy, until at the time she came under the observation of Estienne the tumor, which was $r 8$ inches in diameter, hung down to the pubes, and was shaped like a vase with a long neck. It was amputated and the patient made a good recovery.

A case in the literature is referred to by Schreiber (Archivf. Schiffs und Tropenhygiene, Leipzig, I9II, XV, 366), but though we consulted the reference, we could not find any case of mammary elephantiasis in the article.

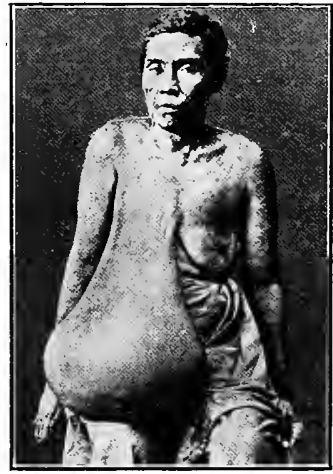

Fig. 8o.-Elephantiasis of the right breast in a Samoan woman. (Krämer.)

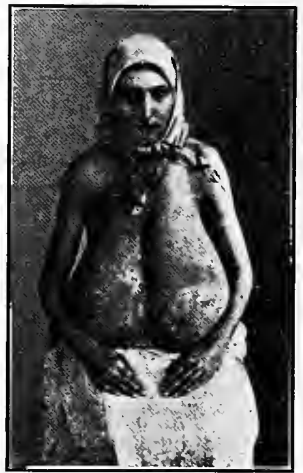

FIG. 8r.-Elephantiasis of the breasts (?). (Bogoluboff.)

The remaining cases are all recorded in the Russian literature, and are not above the suspicion of mistaken diagnosis. They are, however, peculiar in certain respects as will be seen from the following abstracts:

Bogoluboff (Russki Vrach, I907, No. I3) reports the following case:

E. E., a single woman aged I 8 years, was admitted to the clinic in January, r9oo, with enlargement of both breasts so great that their lower margins extended nearly "a quarter of a yard" below the umbilicus. The right breast had a circumference of $45 \mathrm{~cm}$. and a length of $3 \mathrm{I} \mathrm{cm}$.; the left breast, a circumference of $44 \mathrm{~cm}$. and a length of $37 \mathrm{~cm}$. The enlargement was uniform and the shape of the breasts was preserved. The skin of both was intensely pigmented, and in some places was reddened and swollen, in other places thickened. The nipples and surrounding structures appeared normal.

The illness began in the autumn of 1898 , when the patient had fever that lasted a few days, and the left breast reddened and swelled. A month later the right breast also became reddened, swollen and painful. From this time the breasts continued to increase in size and the patient suffered from three or four attacks of fever.

Soon after admission the patient developed erysipelas of the breast and was transferred to the hospital for contagious diseases, where she subsequently suffered from a relapse. Finally she was readmitted to the surgical clinic, and on March 27, rgoo, both breasts were amputated, a small portion of the glandular 
substance being left for "cosmetic" reasons. Subsequently the patient married and had an abortion, though her general bealth was fair.

The tissues of one breast were studied microscopically and showed marked increase in the connective tissue. The bulk of the glandular tissues was replaced by more or less dense connective tissue in which were scattered collections of atrophic glandular tissue. No mention is made of the state of the bloodvessels or of the lymphatics of the breast.

Firfaroff (Khirurgia, Mosk., rgrr, XXX, 33r) reports a unilateral case:

The patient was a woman ig years of age, whose first baby had been born eight months before she came under observation. The child nursed at the right breast only because of the deformed state of the left nipple. The left breast, without recognizable cause, had begun to enlarge and became firm in texture, two years before. It gave her no discomfort at first, and the skin was normal, though of late it became marked by bluish lines. The breast is now so large and heavy as to give the patient great discomfort, descending four fingerbreadths below the umbilicus and being several times the size of its fellow.

Amputation was performed. The tissues were examined microscopically and the condition was diagnosed elepbantiasis. The patient had always lived in central Great Russia (Tomsk) and had never been in the tropics.

\section{Lvoff (Russki Vrach, St. Petersburg, r892, XIII, 926) reports an interesting case:}

The patient, seen at the Kasan Hospital, was a well-developed healthy woman aged 20 years, who bad been recently married and borne a child. Toward the close of the seventh month of gestation the right breast began to enlarge, and the skin near the nipple began to thicken. Soon after, the malady attacked the right breast. and thereafter both breasts continued to enlarge, the skin especially becoming hypertrophied.

The breasts bung down to the umbilicus, and she was unable to nurse the baby. The general health was not good. The breasts were amputated and examined microscopically, the diagnosis of elephantiasis being made largely on account of the tbickened and wrinkled condition of the skin.

\section{Parin (Russki Vrach, St. Petersburg, r9r2, XI, r 292) reported the following case:}

The patient was a woman of Central Russia, 28 years of age, mother of one child still nursing at the left breast. A year ago, without discoverable cause, the right breast began to enlarge. There was no inflammation, no fever and no pain. In three months' time the breast became so large as to cause suffering and prevent her from working. It descended to the umbilicus, was firm-almost bard-and covered by soft skin, wrinkled about the nipple wbich was not retracted. Amputation was performed and the tissue microscopically studied. A diagnosis of elephantiasis was based upon the fact that much newly found connective tissue containing distended blood-vessels and dilated lymphatic vessels was found. About the vessels, and in the connective tissue, lymphocytes and plasma cells were found among the fibroblasts.

From these case reports it is evident that the patients were all of an age at which mammary hypertrophy is of common occurrence, and that in most of them the enlargement began under conditions of pregnancy and lactation, under which it is frequent.

The recurring "erysipelas" in Bogoluboff's case is suggestive of the usual history of elephantiasis. As wrinkling of the skin and subcutaneous thickening commonly occur in hypertrophy, they must not be given too much diagnostic significance. In no case was there associated filariasis.

The reports, however, show how difficult it may be to differentiate between mammary hypertrophy and elephantiasis in cases in which other parts of the body are not simultaneously and similarly affected, both in countries in which elephantiasis is common and in those in which it is rare, especially when the lesion is of too recent occurrence to show the usual hard, thickened, wrinkled, velvety and nodular appearances characteristic of elephantiasis.

Prognosis.-Enough cases of "spontaneous recovery," "marked improvement in the course of time," and "diminution in the size of one breast after the removal of the other" 
are on record to make it probable that the general tendency of the hypertrophy is to cease spontaneously and be followed by gradual diminution of size. Especially does this seem to be true of women who bear children, and in whom, on account of the occurrence or recurrence of pregnancy and lactation, the abnormal activity is interrupted by normal activities followed by normal results. This gives those patients who are not actually suffering from the effects of the enlargement the hope of spontaneous improvement if they are inclined to wait the necessary months or years that may be necessary.

It should not be forgotten that some of the largest breasts have eventually returned to a size approximating the normal. Thus in the case reported by Delfiz, in which the breasts were so large that they reached to the thighs, they returned after a few months to about twice the normal size. The return to normality may, however, be a matter of years.

Treatment.-The logical and scientific treatment for hypertrophy would be the inhibition of the stimulus to growth and the interruption and reversion of the process. This has been tried by Fraenkel, who used mammary extract and other glandular extracts, but without success. In the present state of knowledge this sort of effort is entirely empirical, for though it seems reasonable to refer the process of enlargement to a disturbance of production and to the effect of internal secretions, we are not certain what the secretions are, how they act, or how their effects can be overcome. No remedy of this kind is at present available.

The employment of potassium iodide has been recommended, but its use dates from a period when the drug was less well understood and more frequently employed than at present, and in most cases where it was tried the patients eventually came to operation, while some cases in which it was not employed recovered. There seems to be no reason for recommending it at present. The same obtains with reference to the injection of iodine into the breast. It has been tried a number of times, but there seem to be no real reasons for supposing it to have afforded the patient any benefit and no one employs it at present. A number of cases are said to have been much benefited by compression. This might be tried in appropriate cases, provided that it is not painful.

The remarkable case of recovery reported by Delfiz he was inclined to attribute to frictions with an ointment of hydriodate of potassium. No one. else ever used this remedy, or at least the literature is silent about it if he did, and results in one case are entirely neutralized by knowledge of the general tendency of certain cases to spontaneous recovery.

The remaining and most generally advised treatment is the operative removal of the offending organs. Whether or not all cases ought to be subjected to operative treatment is a question of surgical judgment. The operation is not a dangerous one, but it is a multilating one. Most of these patients, unlike cancer cases, for example, are young girls or women with their lives yet to live, and mutilation may, to them, be a serious matter. Fortunately, the question is often answered by the patient who demands the removal of the organs and leaves the surgeon free to act. In cases where the surgeon is called upon to exercise judgment, the conditions should be weighed somewhat as follows:

If the patient be very young and the enlargement of the breasts, though great, not physically injurious on account of size and weight, and where the patient can be persuaded to wait for a reasonable period, an attempt might be made to tide her over the period of sexual development with its various disturbances, in the hope that shortly afterward improvement or recovery might ensue.

On the other hand, if in such young patients the breasts are painful, or are a cause 
of mental distress, or of physical infirmity because of their weight and size, it may be best to operate.

If the patient be the victim of recurring enlargement and diminution, coinciding with each pregnancy and lactation, she may be left to decide for herself whether nature should take her course or whether the troublesome organs should be removed.

In older patients with slowly growing breasts gradually attaining to a great size, the disposition to spontaneous recovery seems to diminish and the patient should be advised to have the breast or breasts removed at once.

As a matter of fact, these patients more frequently apply to the surgeon because the period of patient expectation and physical and mental endurance is passed, and because they desire operation, than for purposes of diagnosis and advice.

Simple amputation of the breast is the appropriate operation. As there is no question of the benignancy of the condition, the opening of the axilla and the removal of the lymph nodes is entirely unnecessary. As the skin and superficial fasciæ are entirely normal, there is no question of flaps. As much tissue as is desirable can be retained

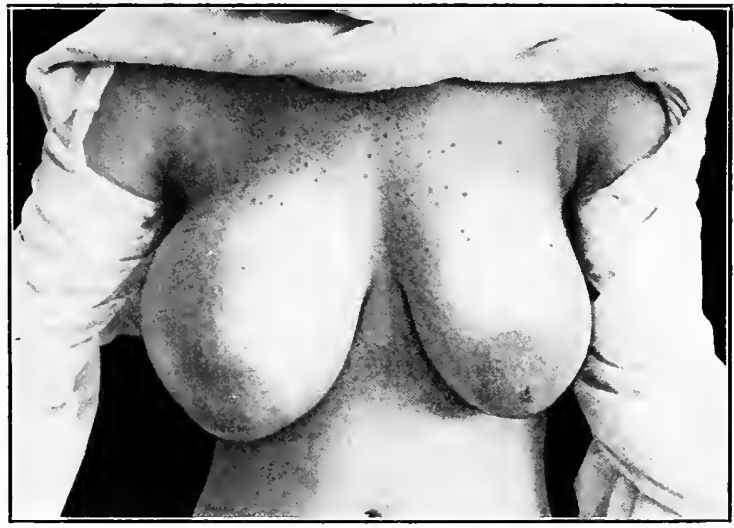

FlG. 82,-Lipomatosis of the breasts in a young girl simulating diffuse virginal hypertrophy.

and the approximation of the tissues effected in any manner that the surgeon deems expedient.

Some recommend plastic resection, and remove the superfluous tissue in such manner as to preserve the nipple and a part of the mammary tissue. Bunts seems to have accomplished this in one case with a fair result. "It might result in the preservation of enough mammary tissue to be subsequently useful for lactation, but it has not been tried out, and there are reasons why it cannot always be done. For example, how would one go about it when the nipple was at the level of the knees, or the thighs or the pubes? Such an operation would seem, therefore, to be limited to cases in which the breasts were only a few times the normal size.

In many cases the amputations have been performed at two successive operations. At the first, the larger, at the second, the smaller breast was removed. In a number of cases it has been unnecessary to do the second operation because, during the interval of about a month that is usually allowed to elapse between the operations, the remaining 
breast spontaneously diminished in volume to such an extent as to promise recovery. In these cases the surgeon might have asked himself whether precisely the same changes might not have occurred in both breasts had he not operated at all; this question cannot be definitely answered, of course, but it has embarrassing suggestions about it. At present it is customary to operate upon both breasts at the same time, when, of course, the question does not arise.

The existence of pregnancy is not a contra-indication to operation. At least four cases are on record in which the operations were performed during pregnancy, the patients subsequently going to term without accident. The condition of the patient should determine the advisability or inadvisability of operating at this time. If the patient be well, there is some hope that the coming establishment of lactation may favorably influence the course of the disease and even effect spontaneous recovery, and it might be well to wait; if the patient emaciates rapidly or shows other signs of serious disturbance, the operation should be performed at once.

Done according to modern methods and under modern precautions, the results of operation are perfect. The patients, unless in an otherwise morbid condition, all recover, the wounds heal kindly, and the cause of distress and disfigurement is gone forever. There are no complications or sequelæ peculiar to the condition and there is no aftertreatment to follow recovery.

\section{MASTOPEXY}

Various suspension operations have been devised for the correction of pendulous breasts (mastoptosis), but neither the deformity itself nor the annoying disturbances that it gives rise to in certain instances (hypostatic congestion, mastodynia, inflammatory change, submammary intertriginous eczema, etc.) justify operation except in the rarest instances, since relief may frequently be obtained by means of properly fitting bandages.

In the event that the latter cannot be worn, as may be true of opera singers and others who are obliged to dress décolleté, it becomes necessary to undertake operative correction of the deformity.

Various operative methods have been devised for the purpose, but the only ones worthy of detailed description are those in which an unsightly scar does not remain as a result of the operation; in other words, those in which the operation is done from below through a thoraco-mammary incision.

Excision of segments from the upper part of the gland with fixation of the remaining portion to the deep pectoral fascia or costal periosteum (Pousson, Michel, Dehner) is not to be recommended for the reasons already given. Verchère advises lateral displacement of the breast upward and outward, but the same objections apply here, besides which the displacement is not permanent.

In those cases in which the breasts are enormously hypertrophied, it is useless to attempt mastopexy, and subcutaneous excision of the breast through a Thomas incision promises little in the way of success; where the breasts are simply pendulous without being hypertrophied, submammary resection gives good results from both the cosmetic and functional standpoints. Kuttner describes the case of a young opera singer whose two breasts were so enlarged as to interfere with her vocation. She was obliged to bandage the breasts to her abdomen, which so hampered her breathing that her voice lost all its resonance. Kuttner.removed almost the entire body of the breasts through Thomas incisions, while with the skin and fatty tissue he fashioned organs that differed from the normal breast only in the somewhat lower position of the nipples. In this case 
the breasts were not only pendulous but "enormously hypertrophied," so that the results obtained are quite remarkable and wort hy to be remembered when similar cases present themselves with urgent necessity of saving the outline of the normal organ.

Mastopexy, as recommended by Girard, is suitable for cases in which the breasts are pendulous and only moderately hypertrophied.

He makes a semicircular incision around the lower part of the breast and dissects it away from the pectoral fascia until it can be turned up at an angle of at least 90 degrees, and after blunt dissection of the pectoral muscle, the second costal cartilage is exposed. The latter is then pierced vertically in the frontal plane with a very coarse, slightly bent needle and the coarsest catgut thread, or, better still, a finely braided silk thread is passed through. By means of a frontal mattress suture, the suture line is then carried through the upper pole of the crescent of the gland where, the thread being drawn together and tied, the margins of the gland can be pushed up as far as desired. The first suture should be made in the shape of a rather loose loop. Then with a small somewhat finer needle and using either catgut or silk thread, about four, separated, graduated frontal loop sutures are passed through the first large loop and, with the loop in the second costal cartilage as their first point of attachment, are carried over the whole width of the posterior surface of the gland from one margin to the other. As these loop sutures are tied the mammary gland assumes its normal shape. In addition to the above, a number of single up and down sutures are placed at intervals in order to attach the entire posterior surface of the breast to the pectoral fascia; a number of muscle fibers may be safely included in these sutures.

On account of the bleeding which is generally considerable in operations for hypertrophy of the breasts, it is useless, as a rule, to undertake such an operation for the relief of the condition, but if the preservation of the normal configuration of the organ is highly desirable, the attempt may be made after preliminary compression of the breast. This will not only effect a considerable reduction in the size of the organ, but also diminish the bleeding at the time of operation. The patient is confined to bed in the recumbent posture, the-breasts are elevated and a firm binder is applied; the treatment is continued for several weeks when it will usually be observed that the organs have diminished in size and that the congestion is much relieved.

Kutrner.-In Bier, Braun and Kümmel, Operationslehre, Leipzig, 1912, Vol. 2, p. 28.

GIRARD.-Verhandl. d. deutschen Gesellsch. f. Chir., I9I0.

DeHNER.-Muench. med. Wchn., Sept. 8, xg08, No. 36.

VERCHÈrE.-Méd. moderne, I $898, \mathrm{IX}, 540$.

Pousson.-Bull. de la Soc. de Chir., r897, XXIII, 507. 


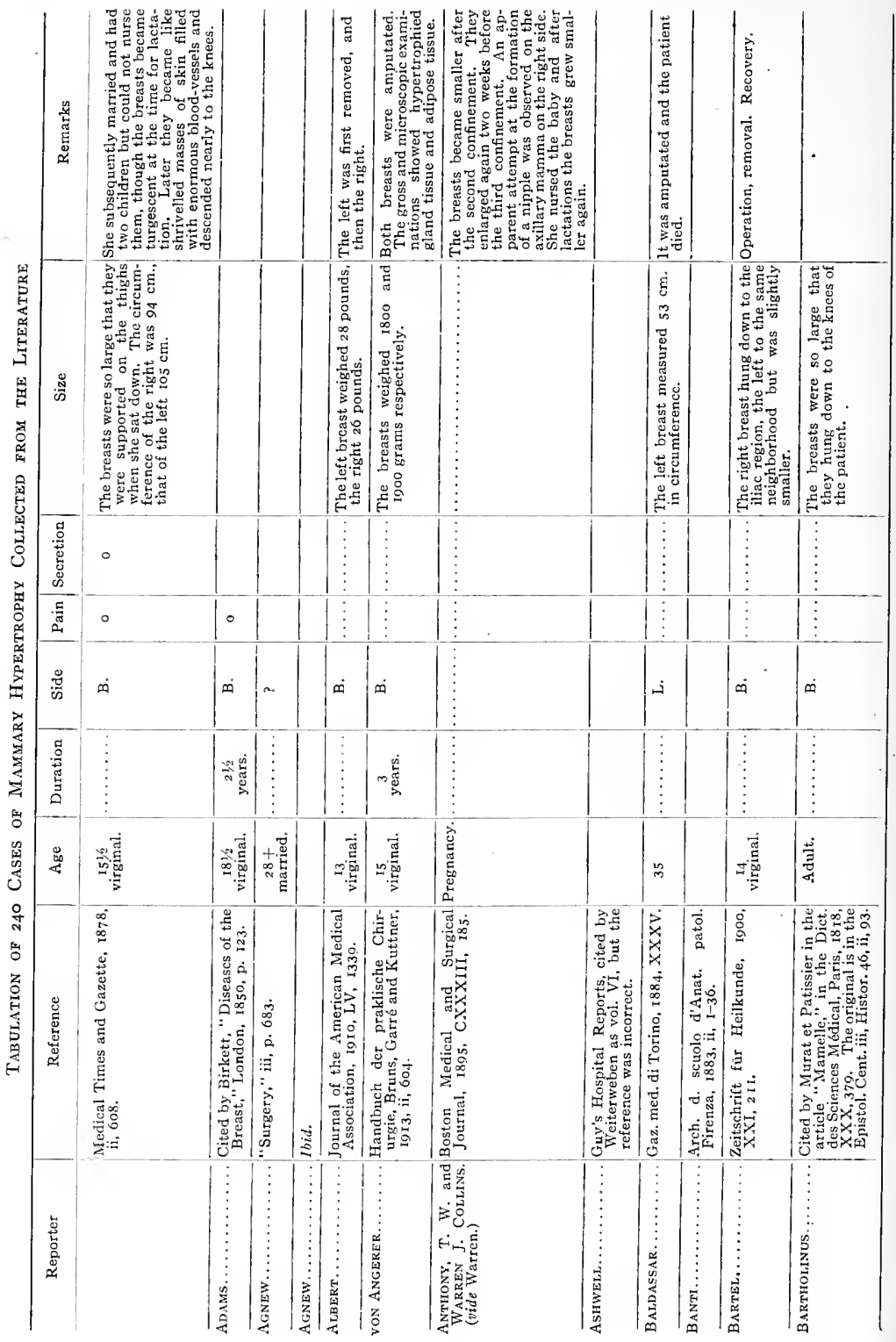




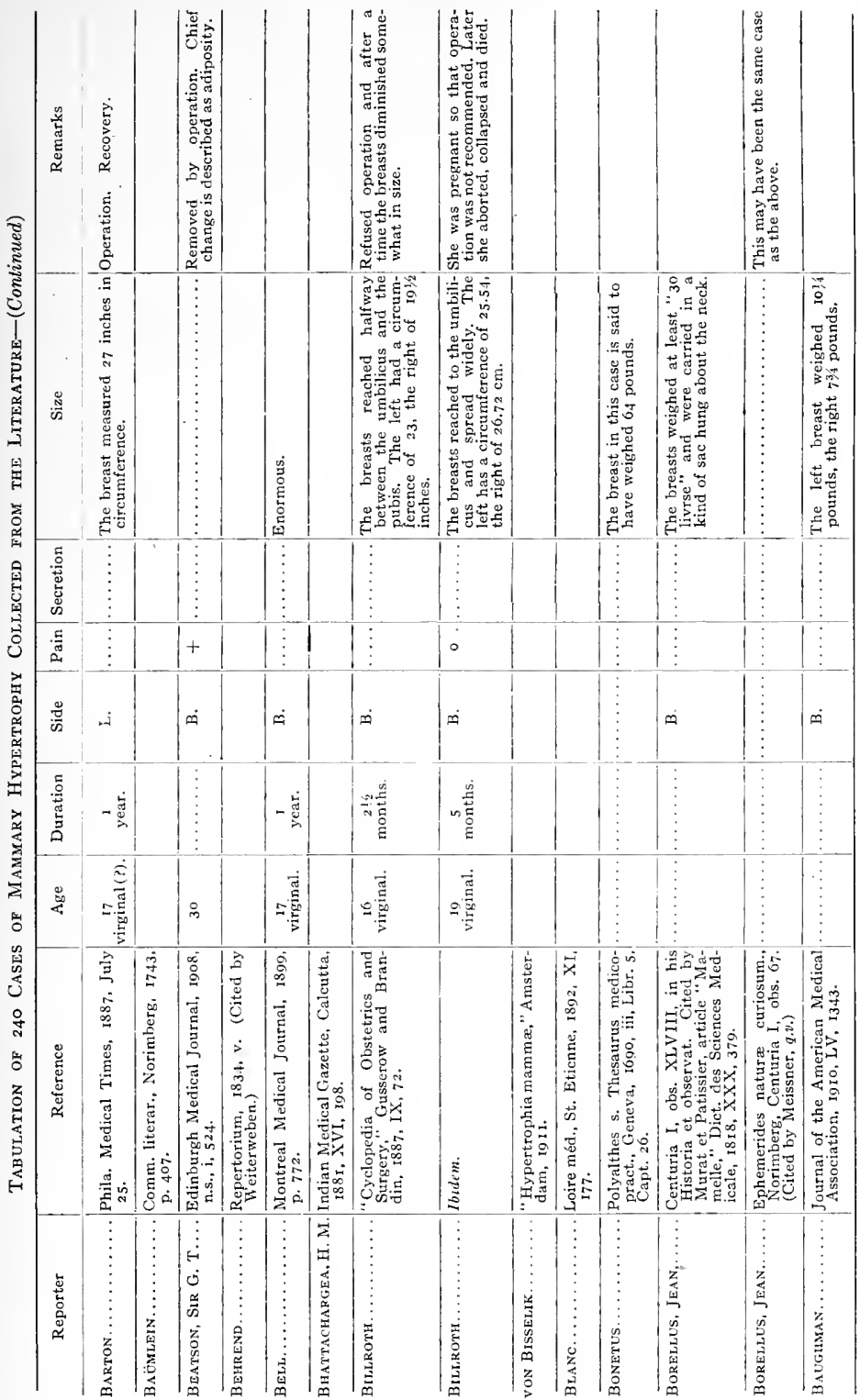




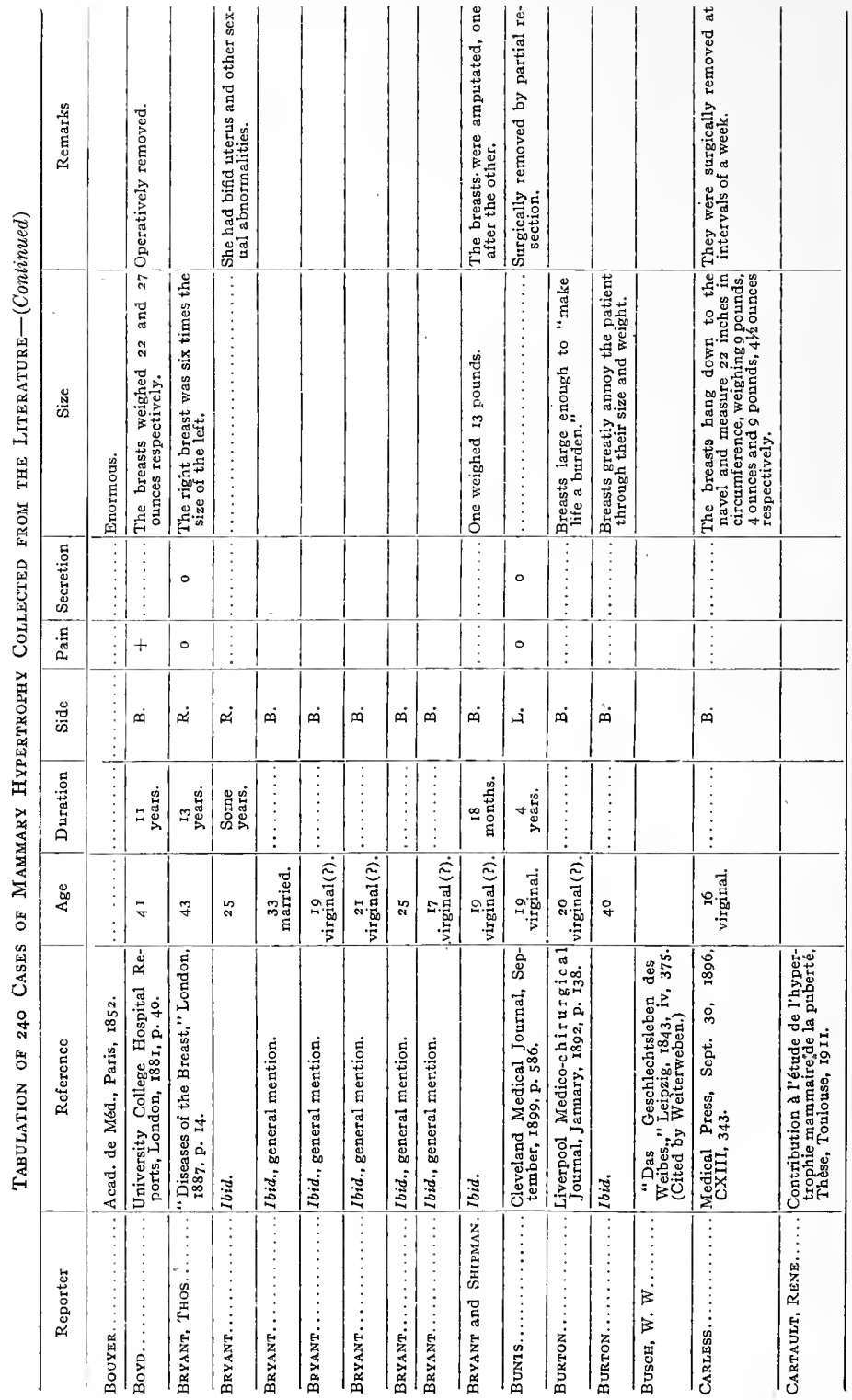


THE ACQUIRED ANOMALIES OF THE BREAST

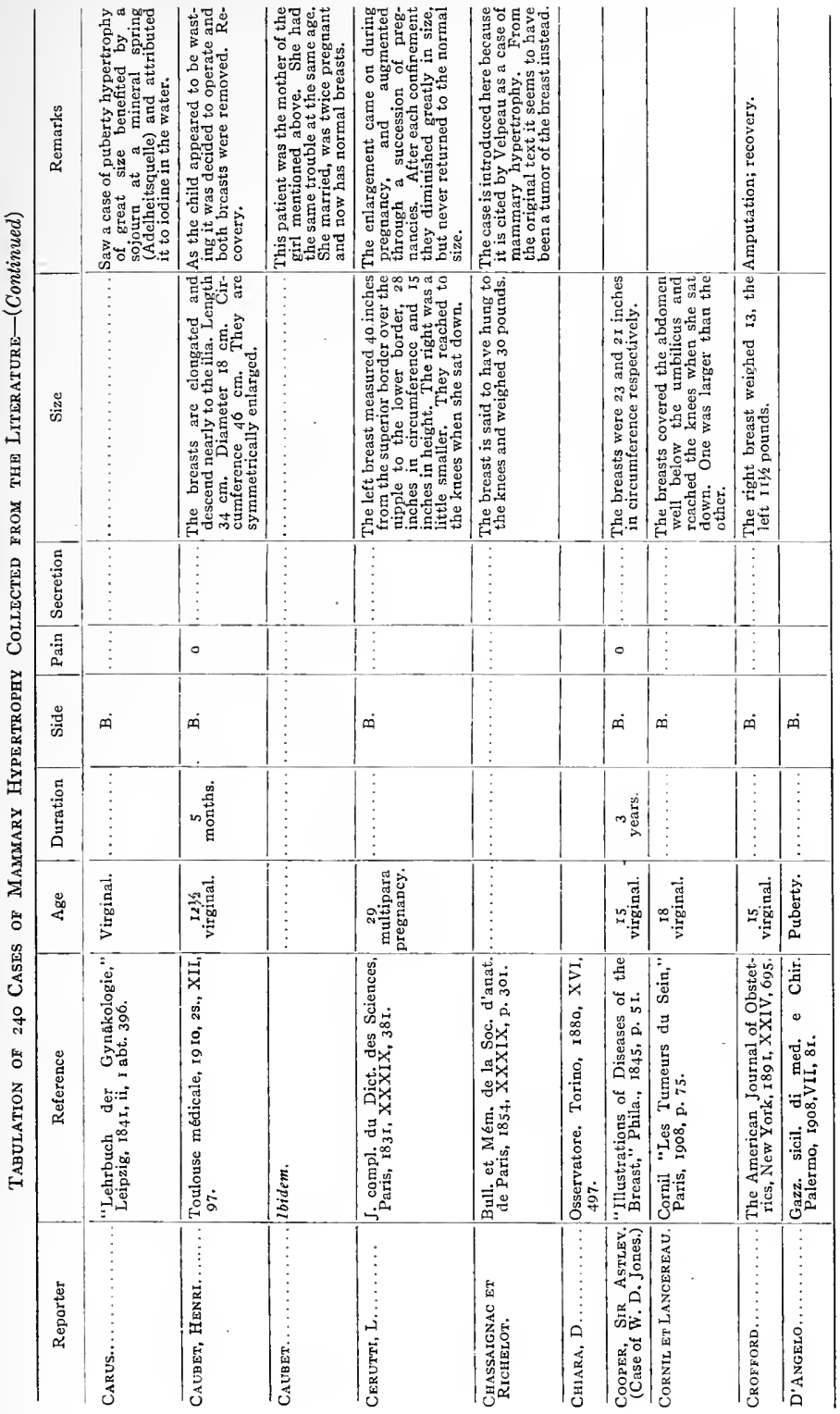




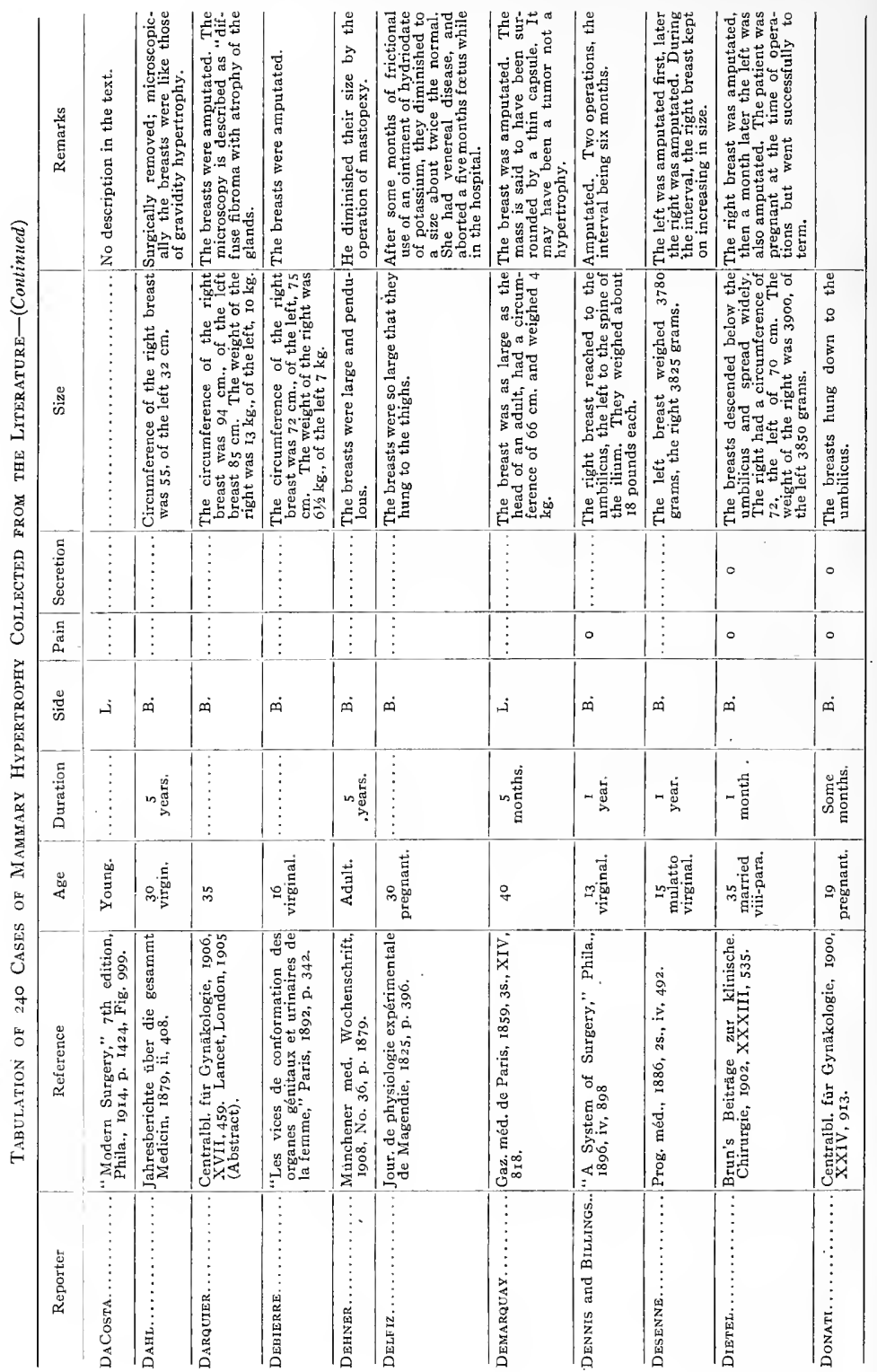




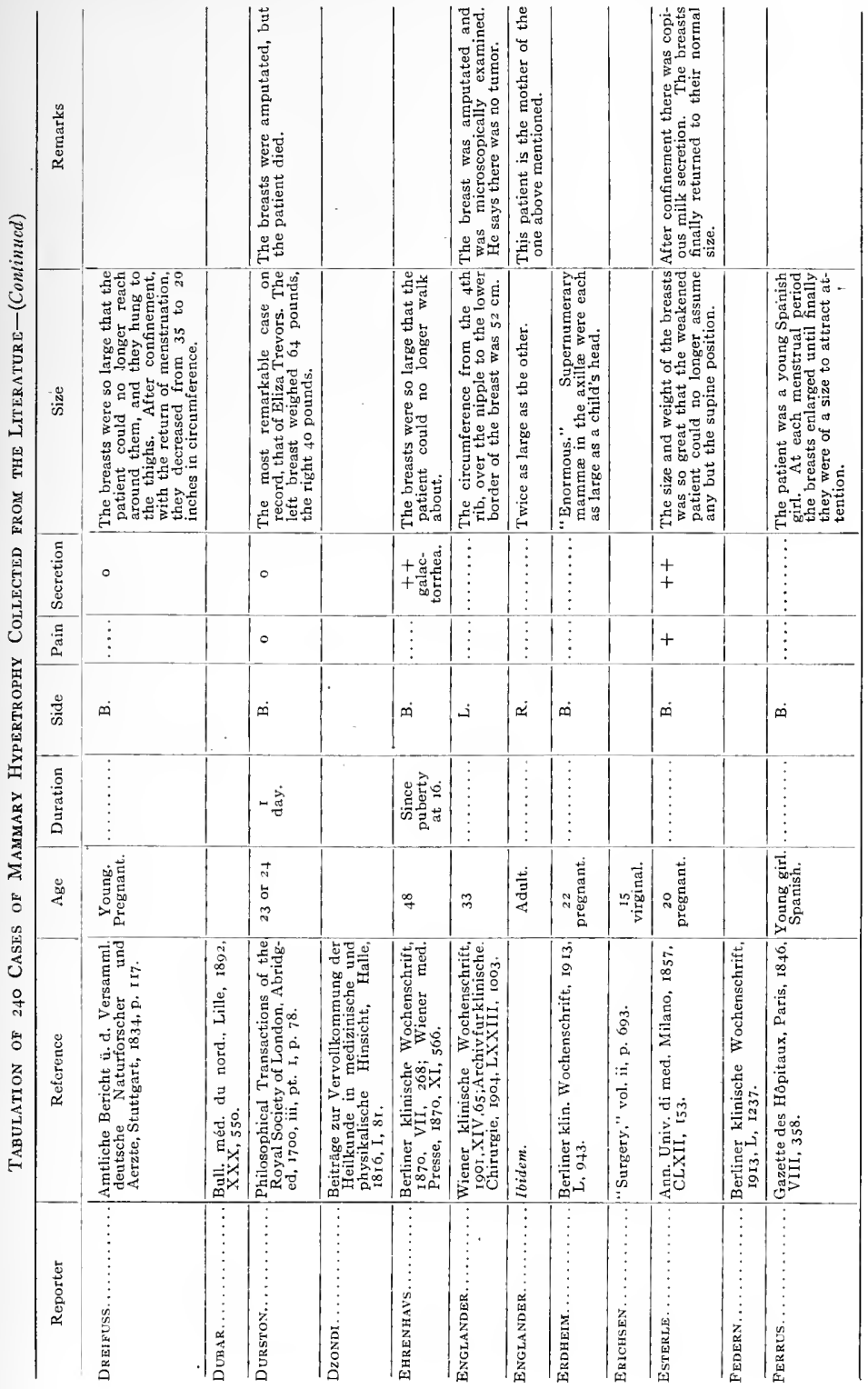




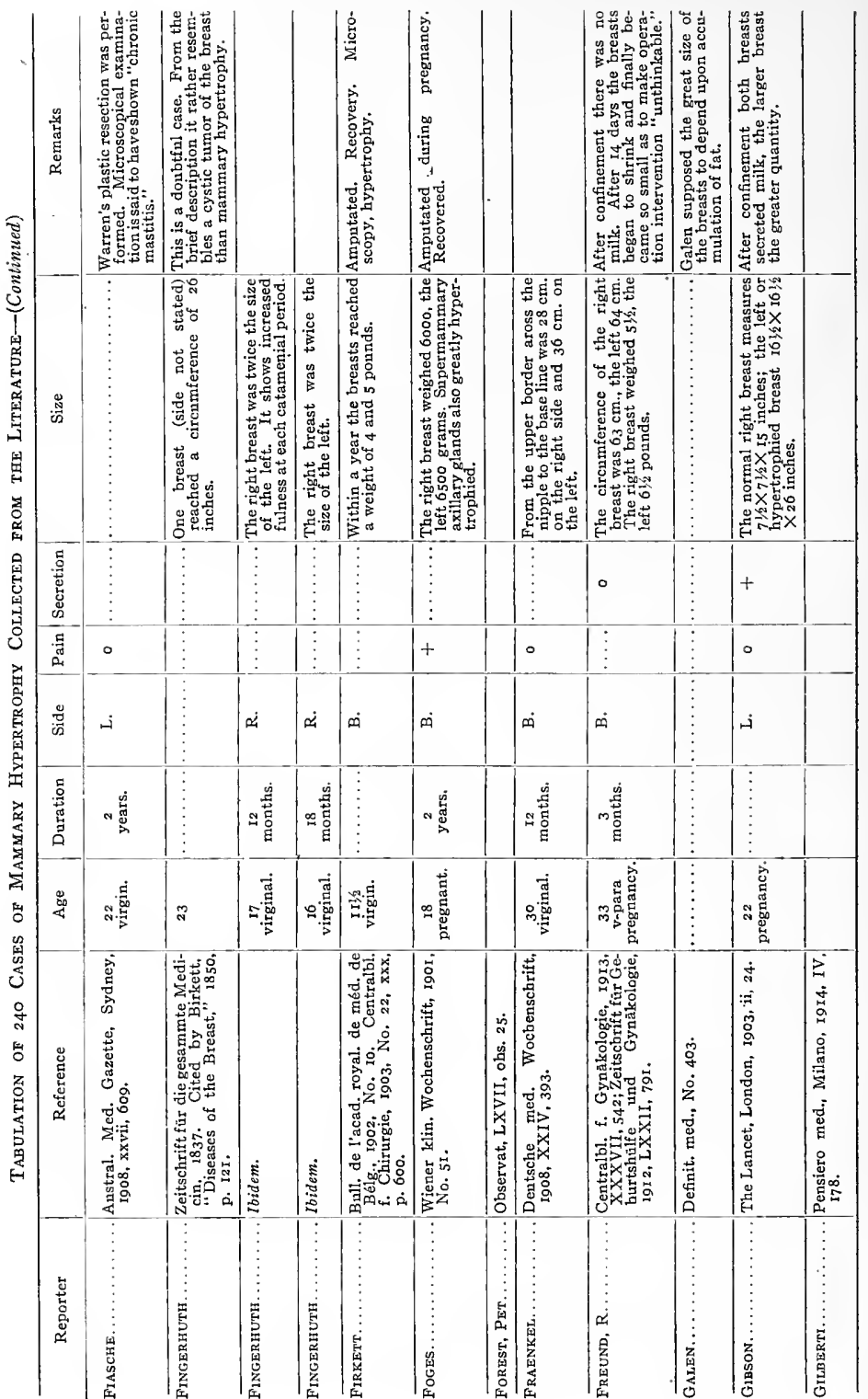




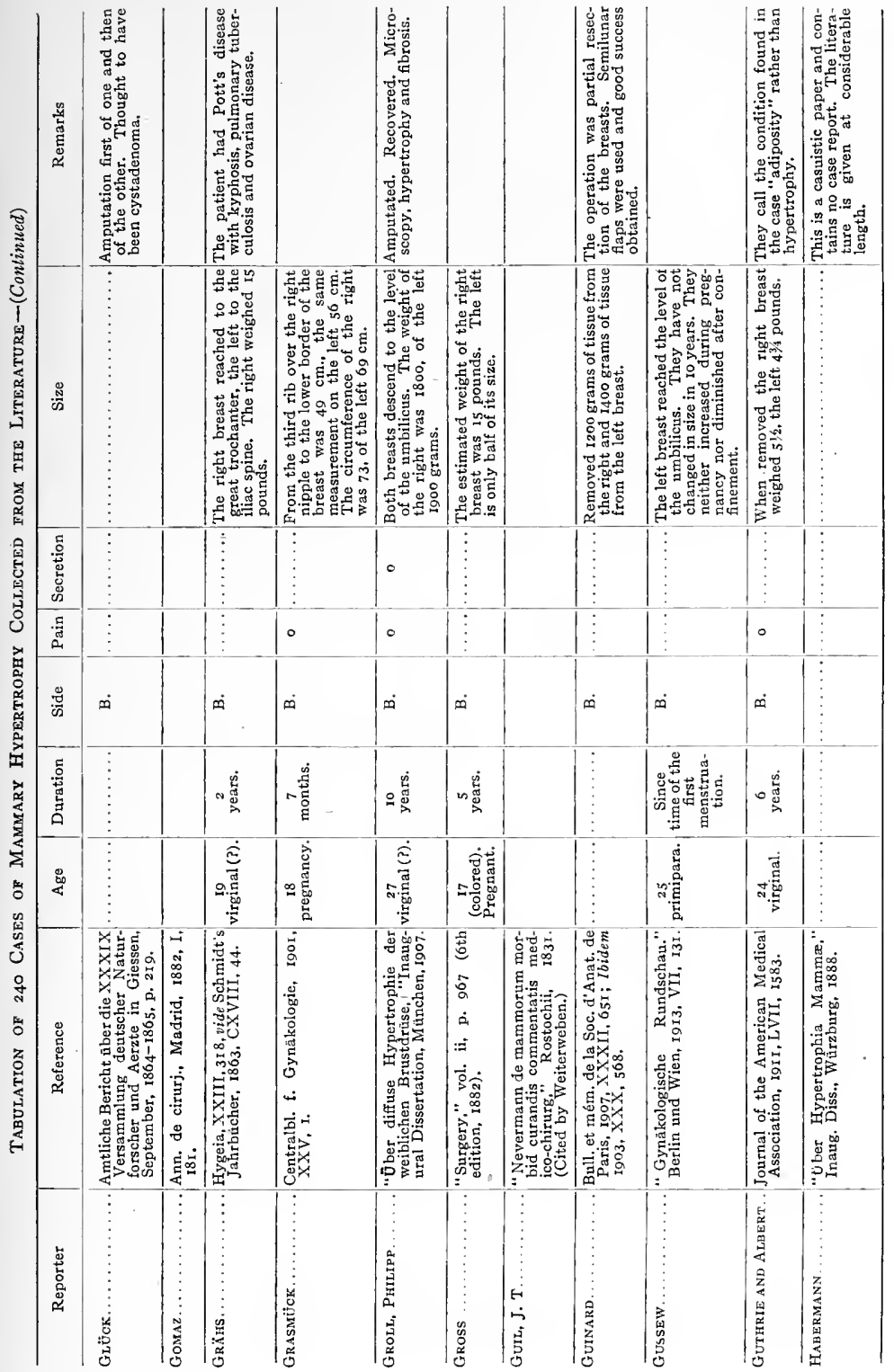




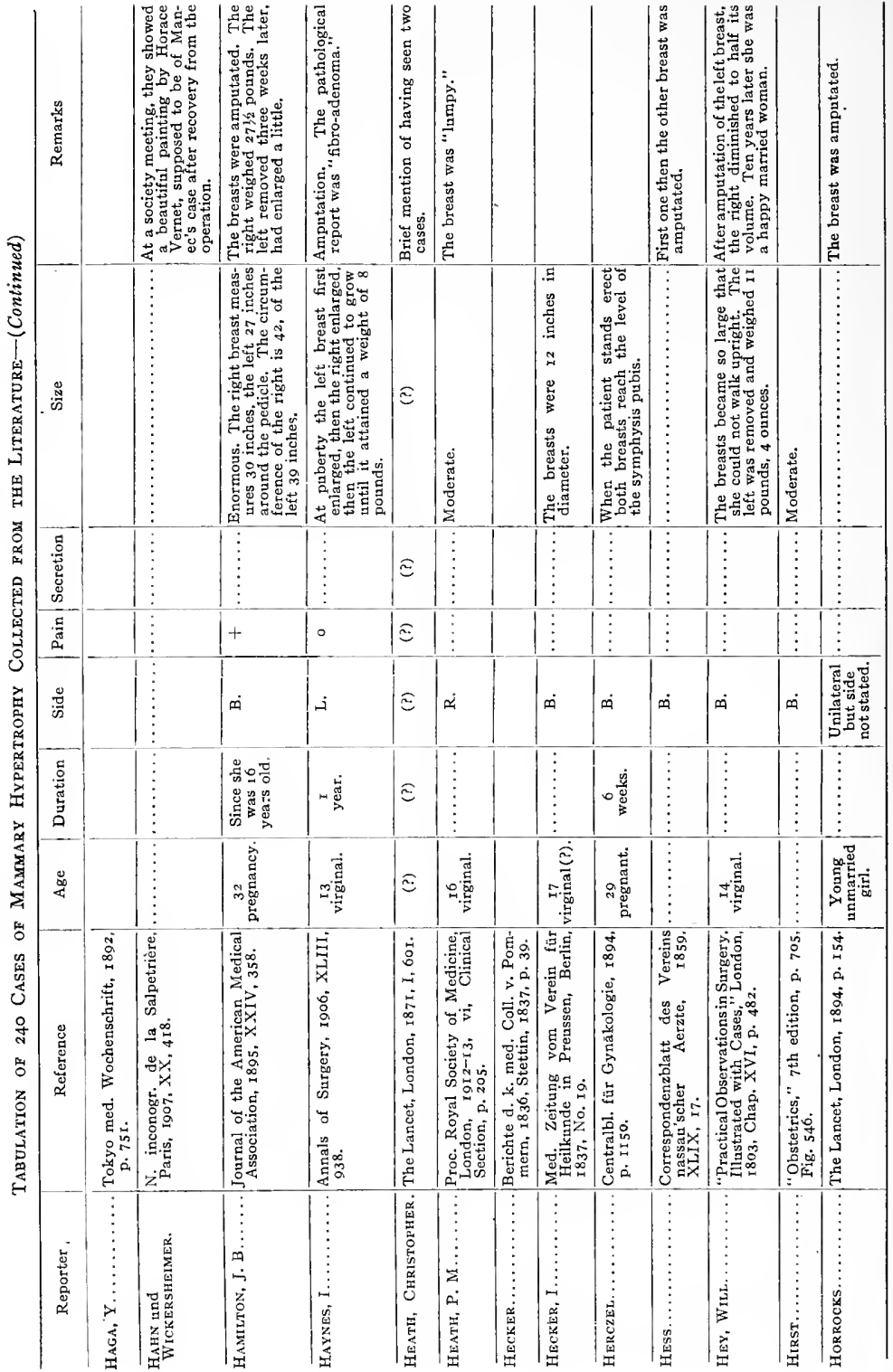


THE ACQUIRED ANOMALIES OF THE BREAST

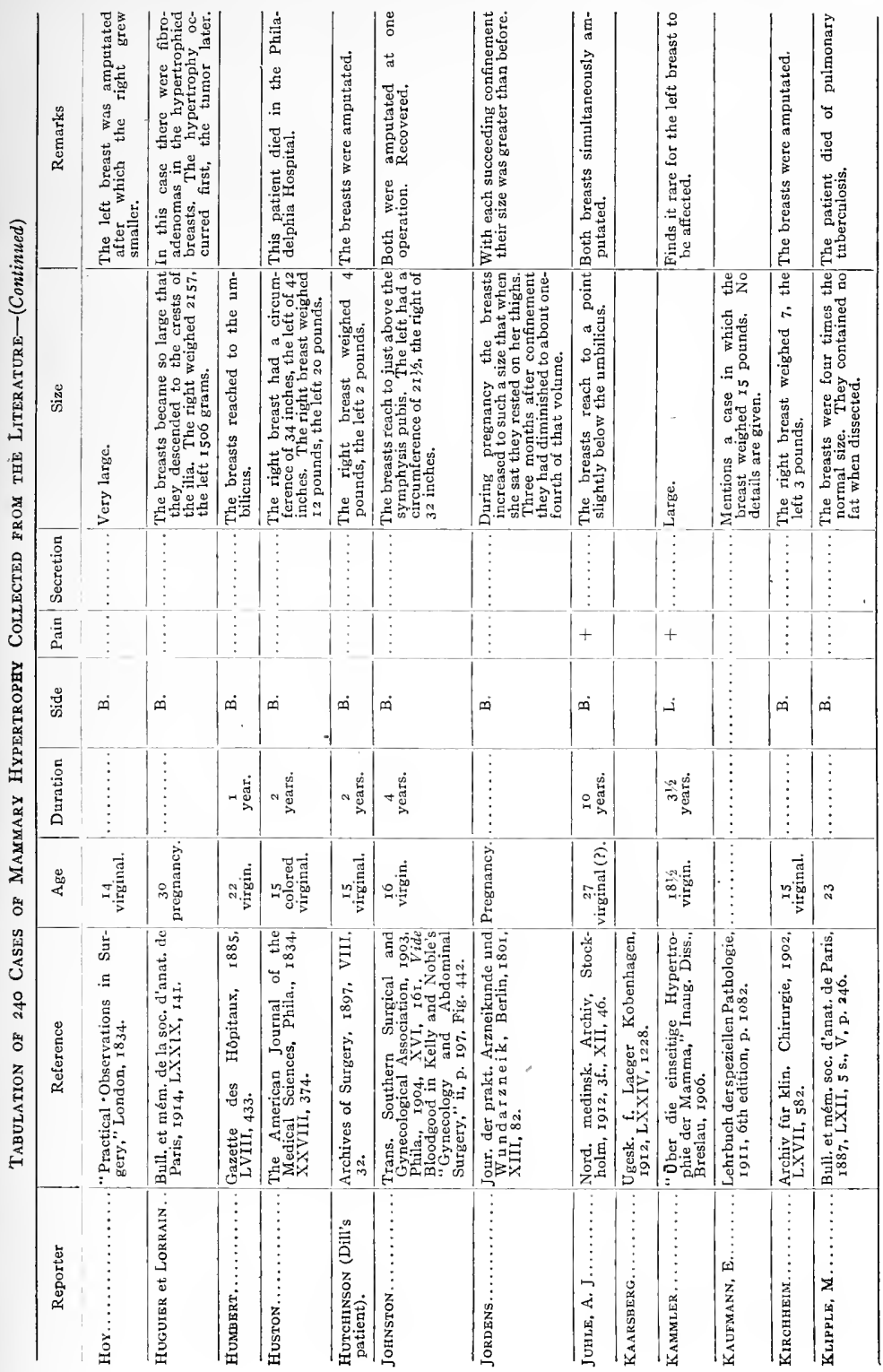




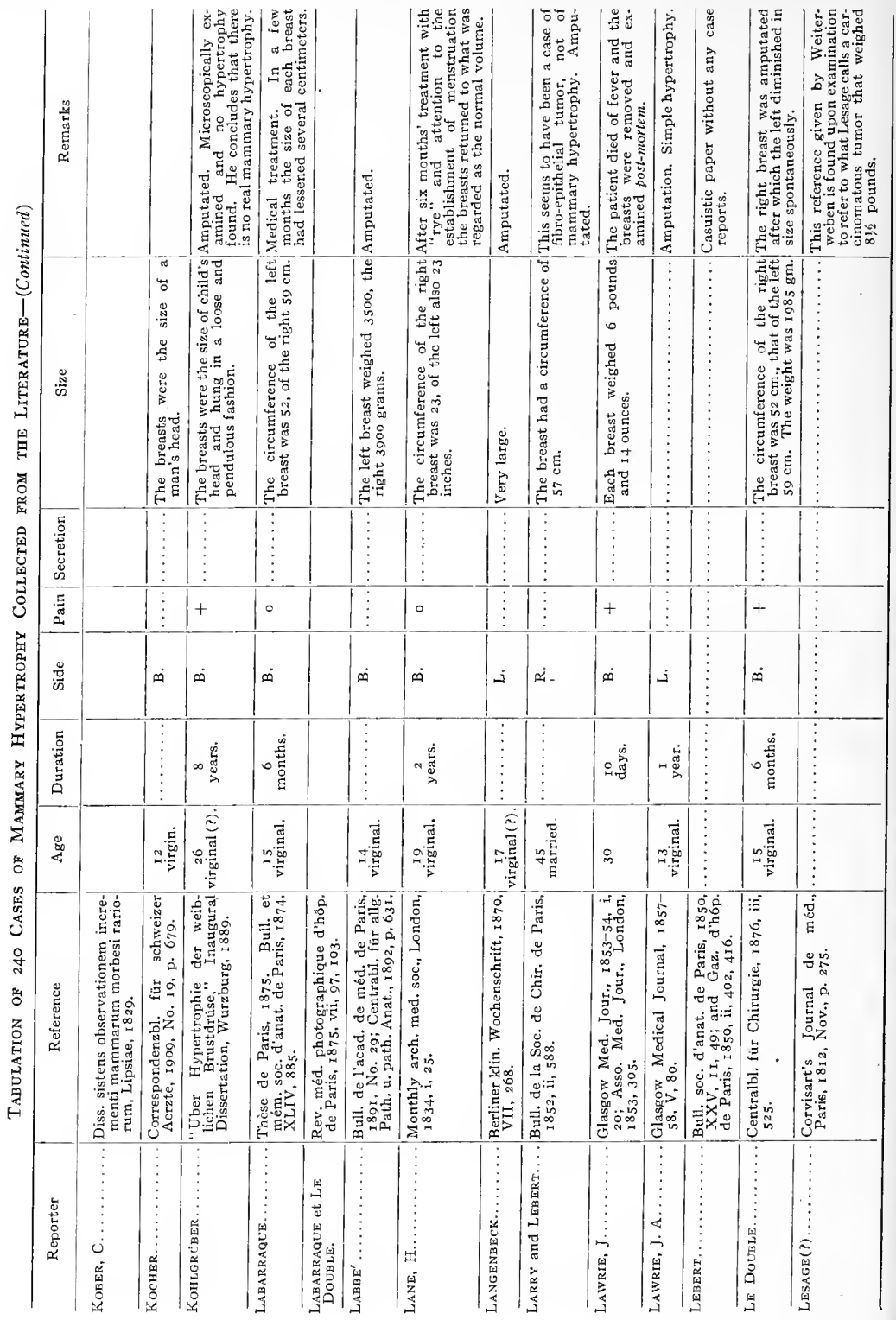


THE ACQUIRED ANOMALIES OF THE BREAST

\begin{tabular}{|c|c|c|c|c|c|c|c|c|c|c|c|c|c|}
\hline 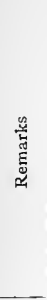 & 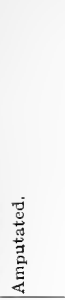 & 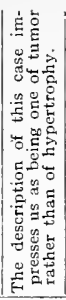 & 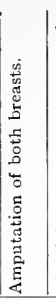 & 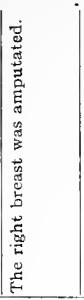 & & 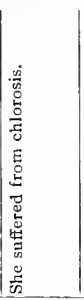 & 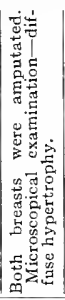 & 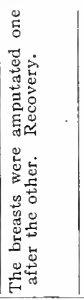 & 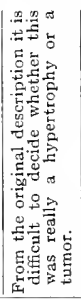 & & & 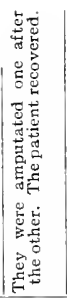 & \\
\hline 芯 & 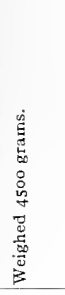 & 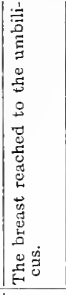 & 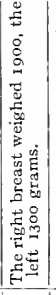 & 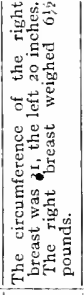 & & 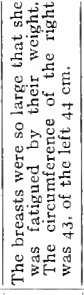 & 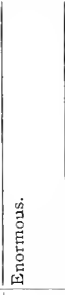 & 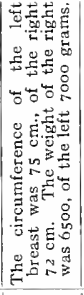 & 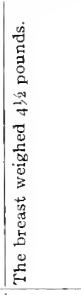 & & & 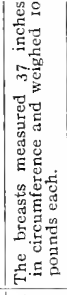 & 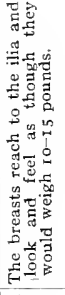 \\
\hline 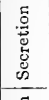 & $\begin{array}{l}\vdots \\
\vdots\end{array}$ & & & & & & & & & & . & & \\
\hline 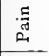 & $\vdots$ & & & 0 & & + & & & & & 10 & & 。 \\
\hline : & 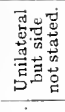 & i & $\infty$ & $\dot{n}$ & & $\dot{0}$ & $\dot{0}$ & m & $\simeq$ & & $\propto$ & $\dot{n}$ & $\dot{x}$ \\
\hline 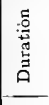 & $\vdots$ & 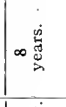 & m & - $-\underset{\mathrm{D}}{\mathrm{d}}$ & & $\vdots$ & m & - & $\stackrel{8}{m}$ & & & - - 离 & 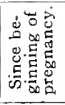 \\
\hline$\stackrel{0}{4}$ & $\stackrel{\circ}{\circ}$ & 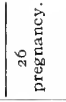 & 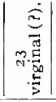 & 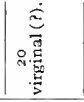 & & 离 & 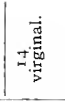 & 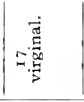 & 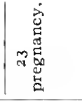 & & 要 & ( & 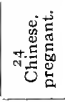 \\
\hline 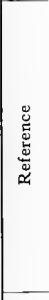 & 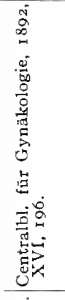 & 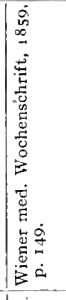 & 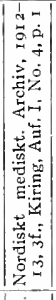 & 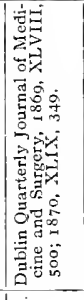 & 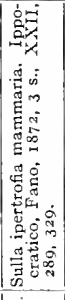 & 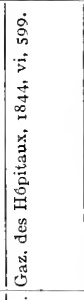 & 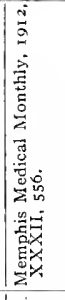 & 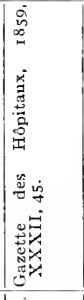 & 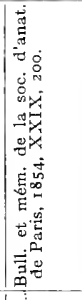 & 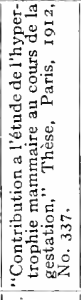 & 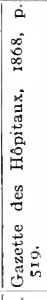 & 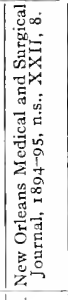 & 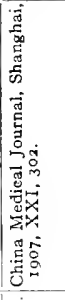 \\
\hline 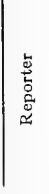 & 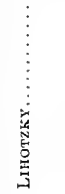 & 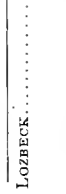 & 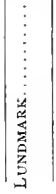 & 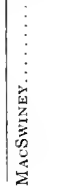 & 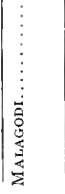 & 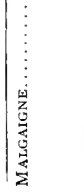 & 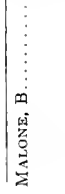 & 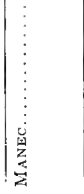 & 璃 & 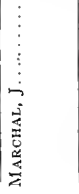 & 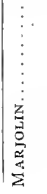 & 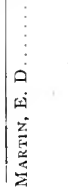 & 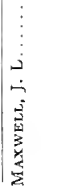 \\
\hline
\end{tabular}




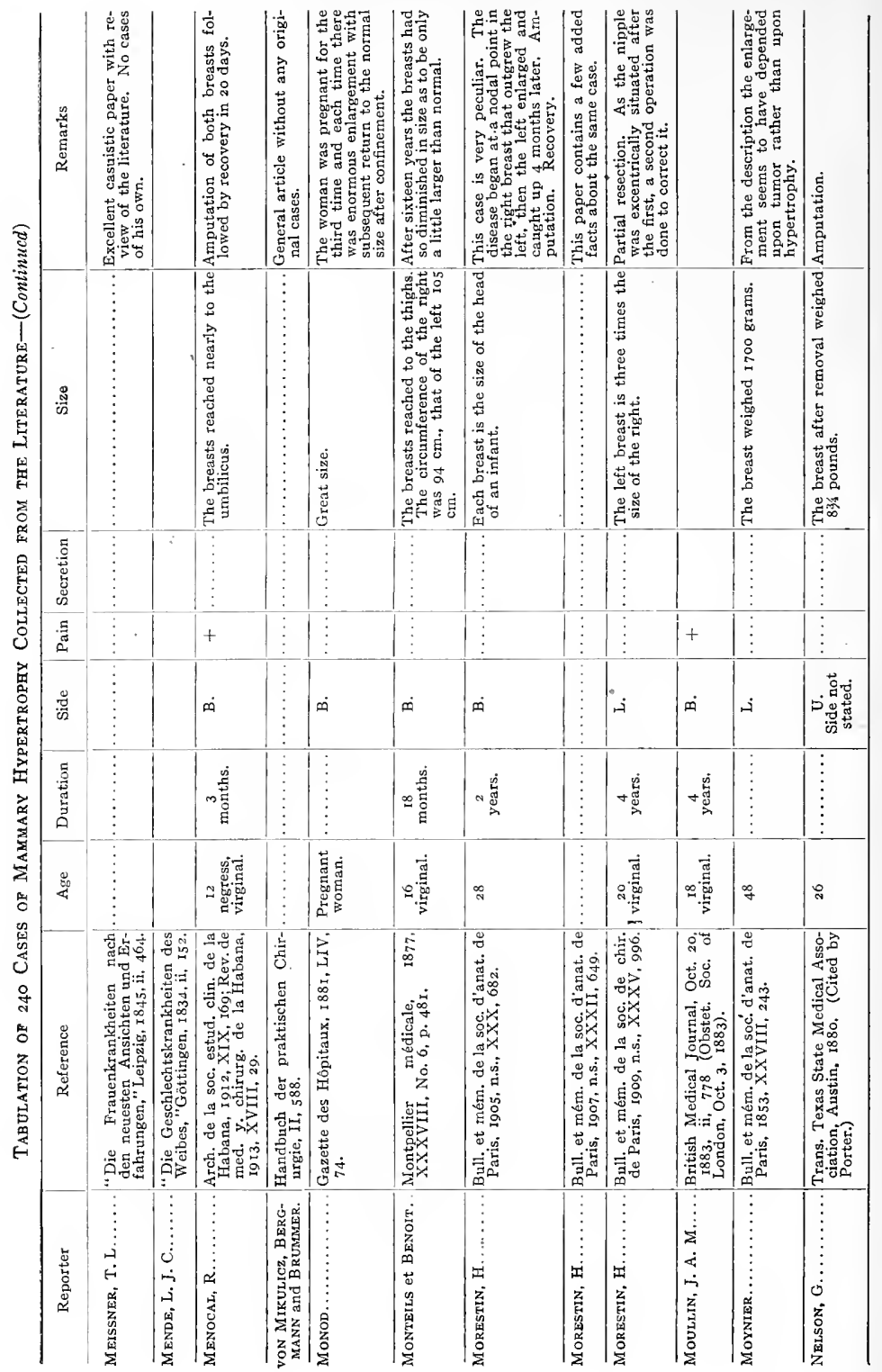


THE ACQUIRED ANOMALIES OF THE BREAST

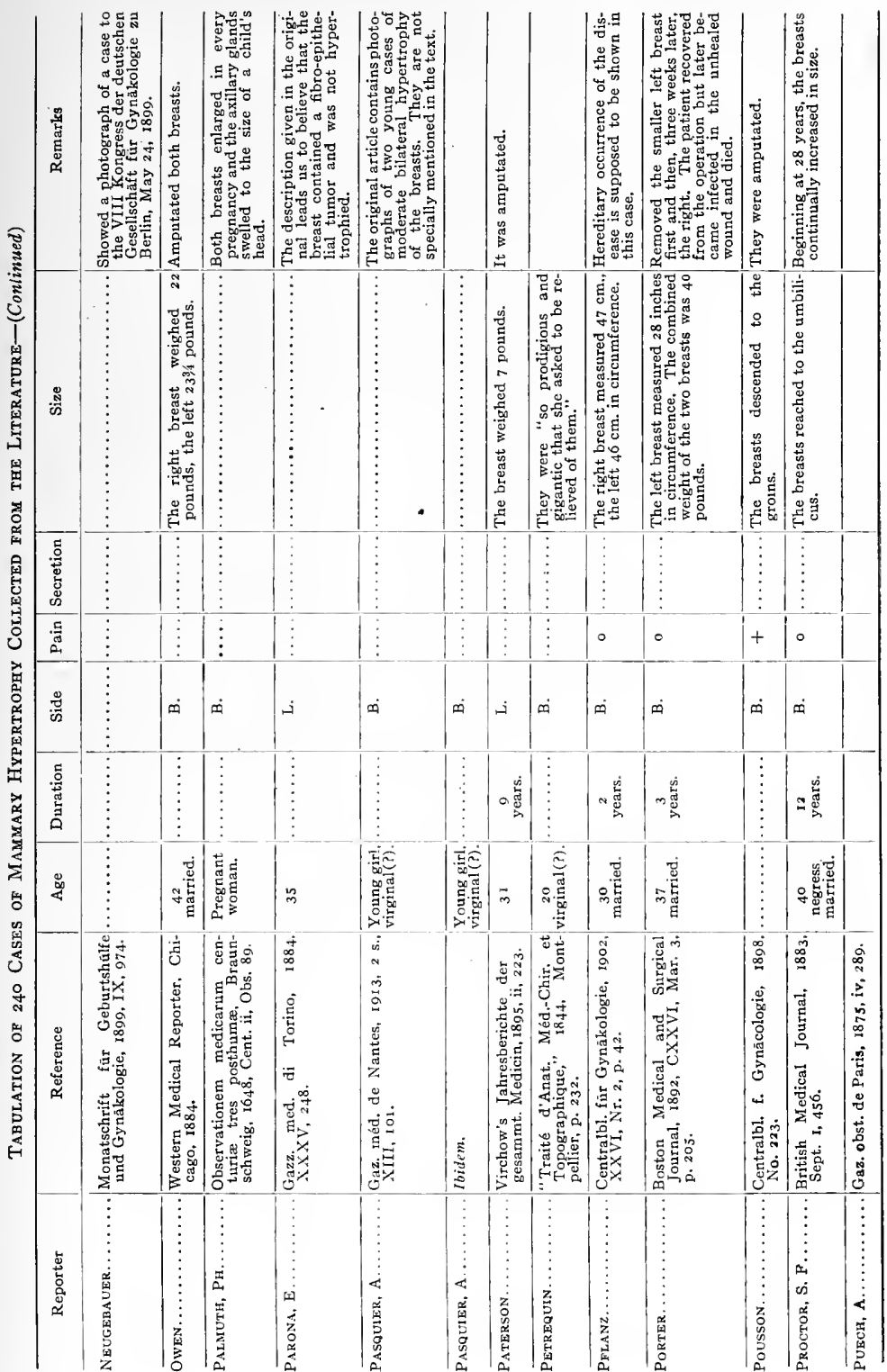




\begin{tabular}{|c|c|c|c|c|c|c|c|c|c|c|c|c|}
\hline 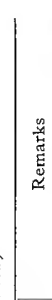 & 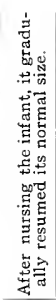 & & 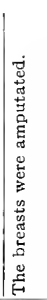 & & 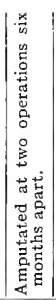 & & 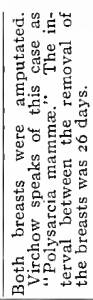 & 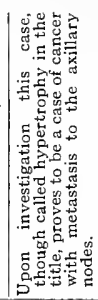 & 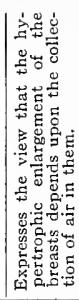 & 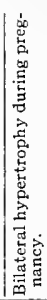 & 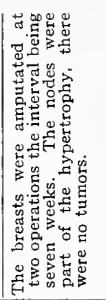 & \\
\hline 㫕 & 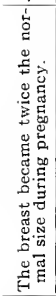 & 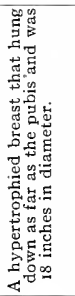 & 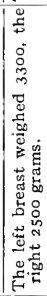 & 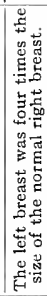 & 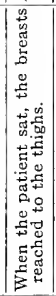 & & 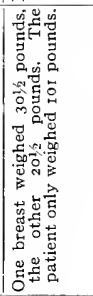 & & & & 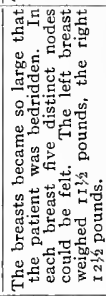 & \\
\hline 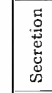 & & & & & & & & & & & & \\
\hline 点 & & $1:$ & & & $\vdots$ & & & & & & & \\
\hline 橧 & $\dot{\alpha}$ & is & $m$ & نـ & $\ddot{q}$ & & $m$ & & $\infty \dot{0}$ & $\dot{\varphi}$ & $\dot{\varphi}$ & \\
\hline 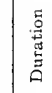 & & & 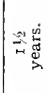 & 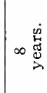 & & & m & & & & 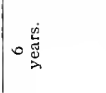 & \\
\hline$\frac{8}{0_{4}^{\circ}}$ & 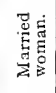 & 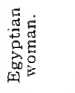 & 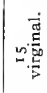 & 的总 & 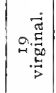 & & ). & & $\vdots$ & $\vdots$ & 弯 & \\
\hline 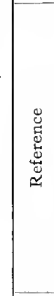 & 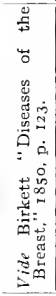 & 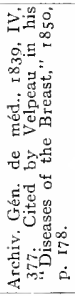 & 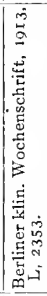 & 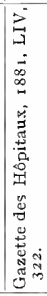 & 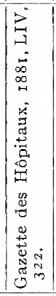 & 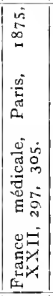 & 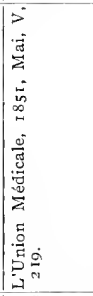 & 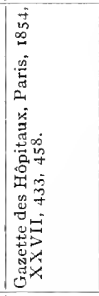 & 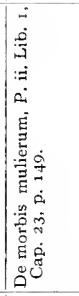 & 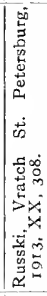 & 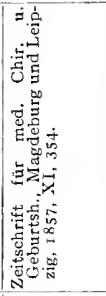 & 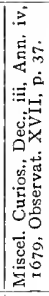 \\
\hline 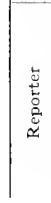 & 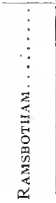 & 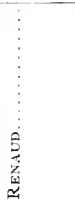 & 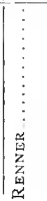 & 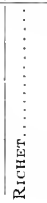 & 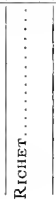 & 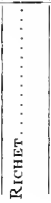 & 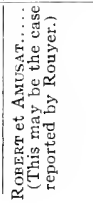 & 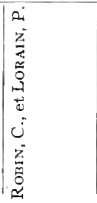 & 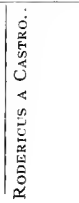 & 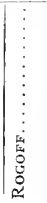 & & 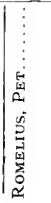 \\
\hline
\end{tabular}


THE ACQUIRED ANOMALIES OF THE BREAST

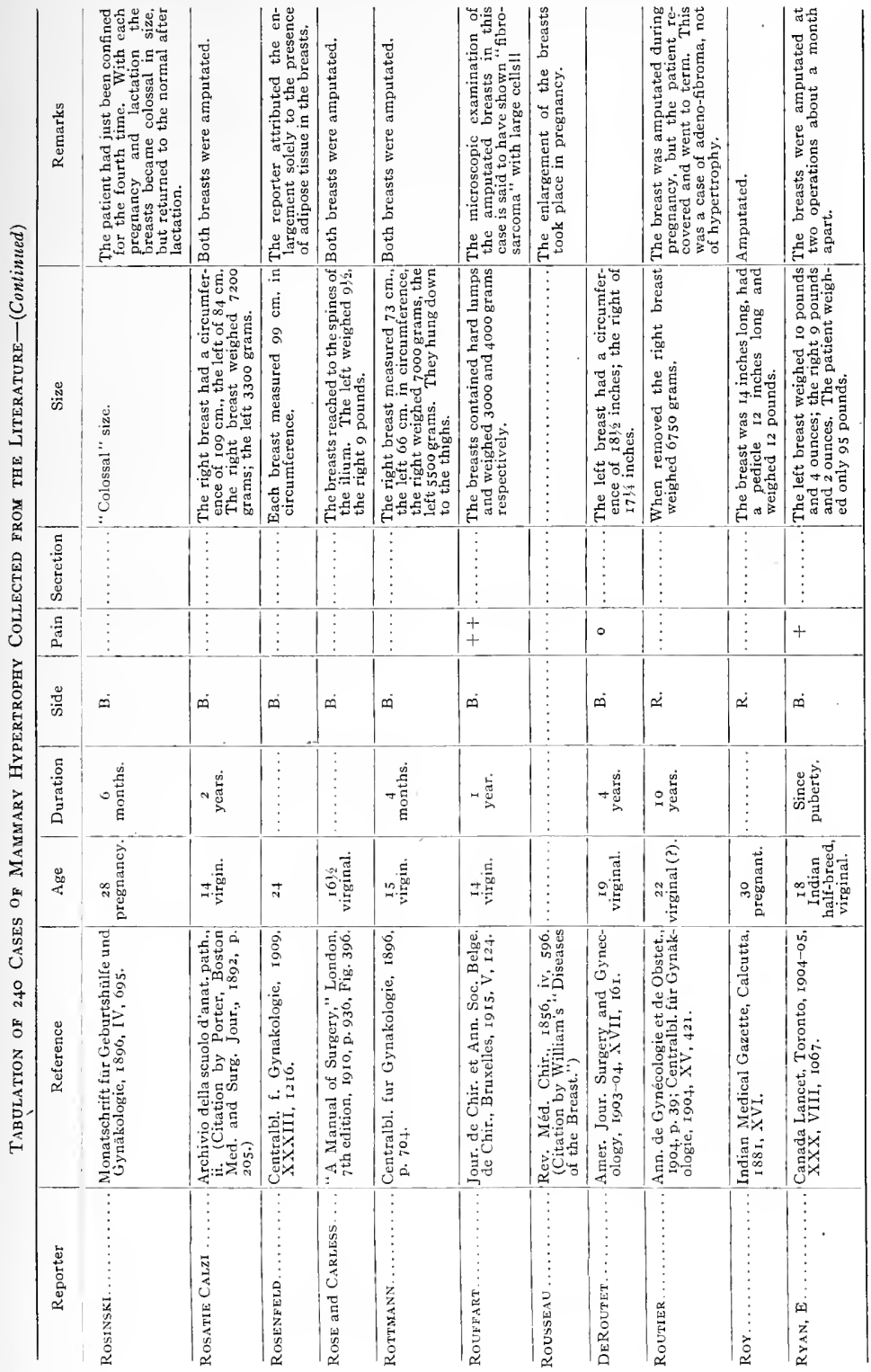




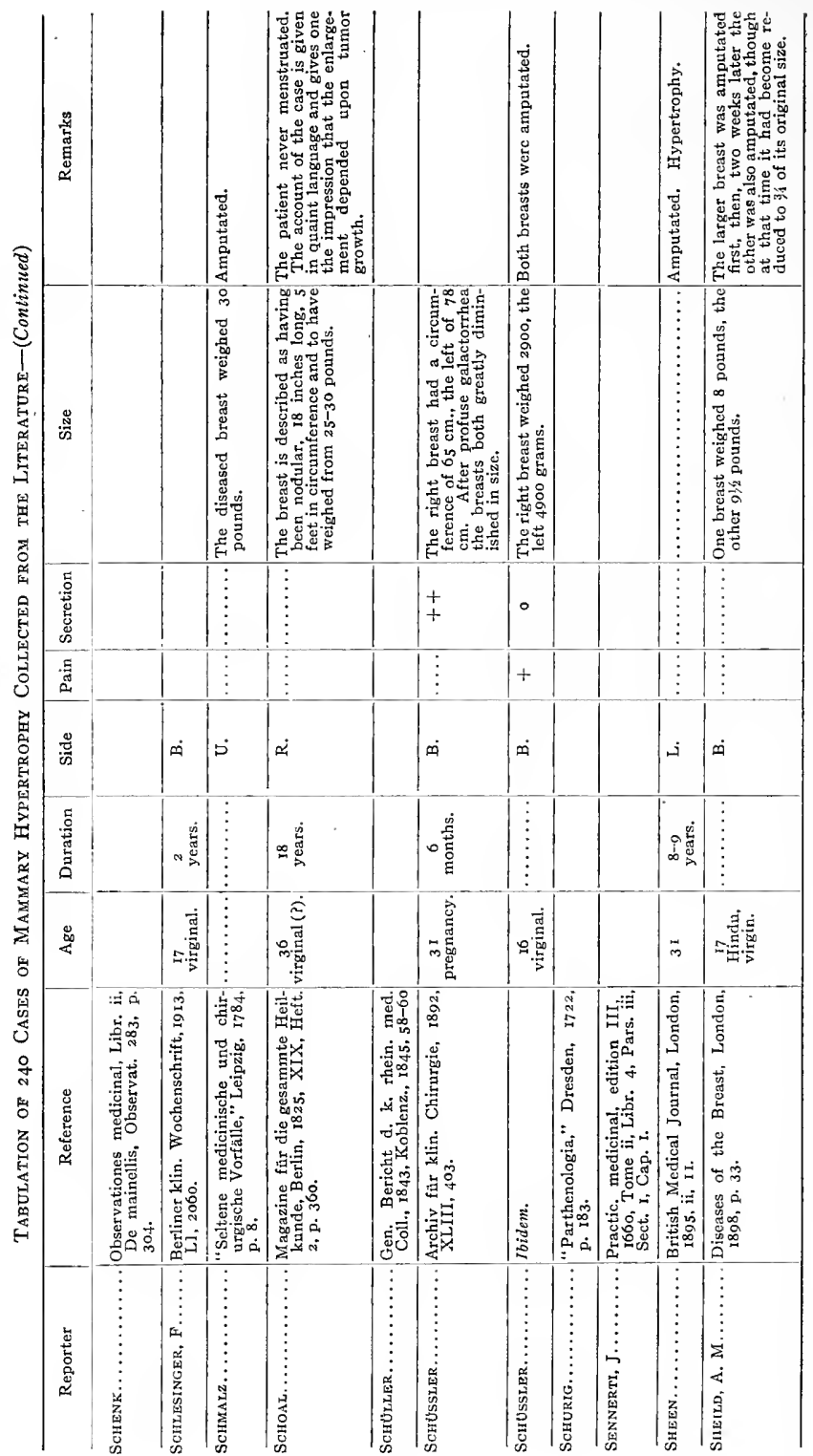


THE ACQUIRED ANOMALIES OF THE BREAST

\begin{tabular}{|c|c|c|c|c|c|c|c|c|c|c|c|c|c|c|}
\hline 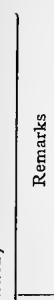 & 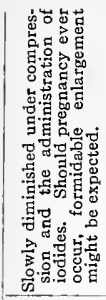 & 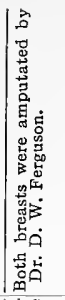 & & & & & 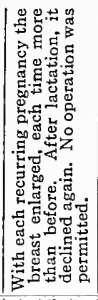 & 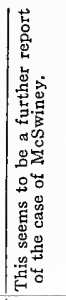 & 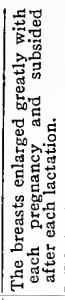 & & 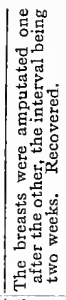 & 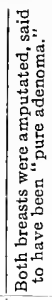 & 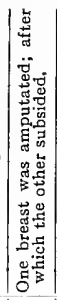 & 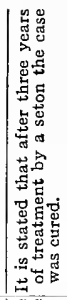 \\
\hline 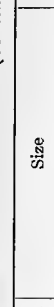 & 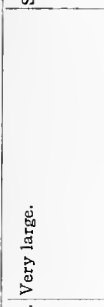 & 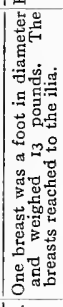 & 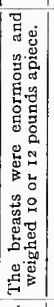 & 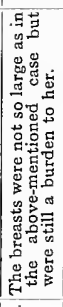 & 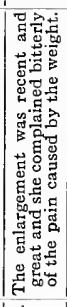 & & 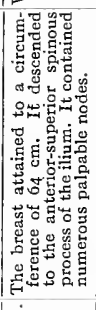 & & 总 & & 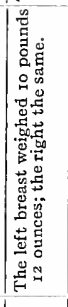 & $\vdots$ & 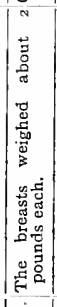 & 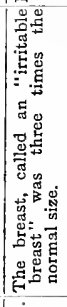 \\
\hline 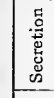 & & & \begin{tabular}{|c|}
$\vdots$ \\
$\vdots$ \\
$\vdots$ \\
\end{tabular} & & & & & & & & $\circ$ & & & \\
\hline 帛 & $\vdots$ & $\vdots$ & $\vdots$ & $\vdots$ & + & & + & & & & 0 & $\vdots$ & + & \\
\hline 苟 & $\dot{m}$ & வ & $\dot{n}$ & $\dot{m}$ & $\dot{n}$ & & نه & & & $\dot{\varphi}$ & $\dot{m}$ & $\dot{0}$ & $\dot{x}$ & 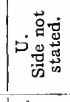 \\
\hline 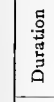 & 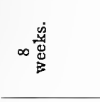 & $\vdots$ & $\begin{array}{l}\vdots \\
\vdots \\
\vdots\end{array}$ & $\begin{array}{l}\vdots \\
\vdots \\
\vdots\end{array}$ & $\begin{array}{l}\vdots \\
\vdots \\
\vdots\end{array}$ & & & & & & 竞 & & $\vdots$ & \\
\hline$\underset{4}{4}$ & 心离 & 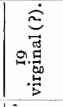 & 昜 & 우 & q & & 次苞 & $\stackrel{\circ}{\text { ㅇ }}$ & 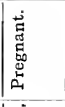 & & | & 蛋 & 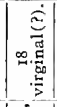 & 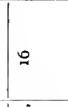 \\
\hline 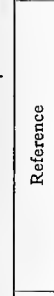 & $\begin{array}{c}\vdots \\
\vdots \\
\vdots \\
\vdots \\
\vdots \\
\vdots \\
\vdots \\
\vdots \\
\vdots \\
\vdots \\
\vdots\end{array}$ & 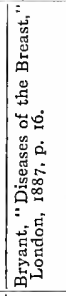 & 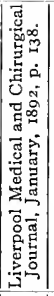 & 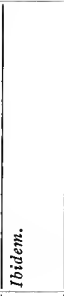 & 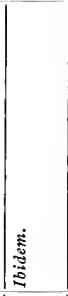 & 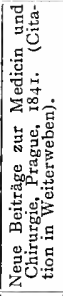 & 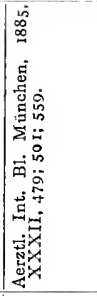 & 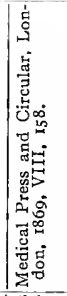 & 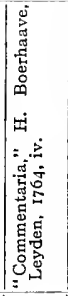 & 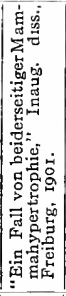 & 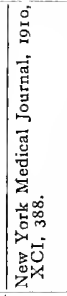 & 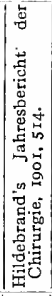 & 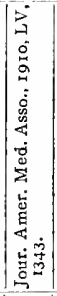 & 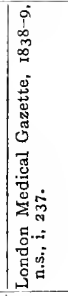 \\
\hline 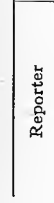 & 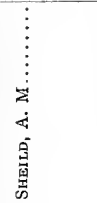 & 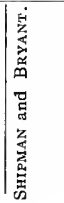 & \begin{tabular}{|c|}
$\vdots$ \\
$\vdots$ \\
$\vdots$ \\
$\vdots$ \\
$\vdots$ \\
$\vdots$ \\
$\vdots$ \\
$\vdots$ \\
$\vdots$ \\
$\vdots$ \\
0
\end{tabular} & 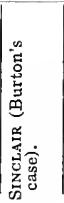 & 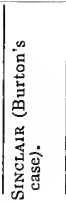 & 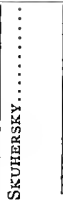 & 䔄 & 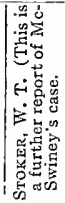 & 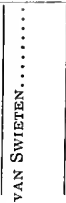 & \begin{tabular}{|c|}
$\vdots$ \\
$\vdots$ \\
$\vdots$ \\
$\vdots$ \\
$\vdots$ \\
$\vdots$ \\
$\vdots$ \\
$\vdots$ \\
$\vdots$ \\
$\vdots$ \\
$\vdots$
\end{tabular} & 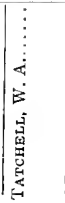 & 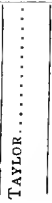 & 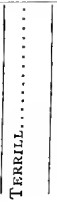 & 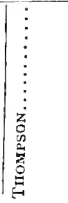 \\
\hline
\end{tabular}




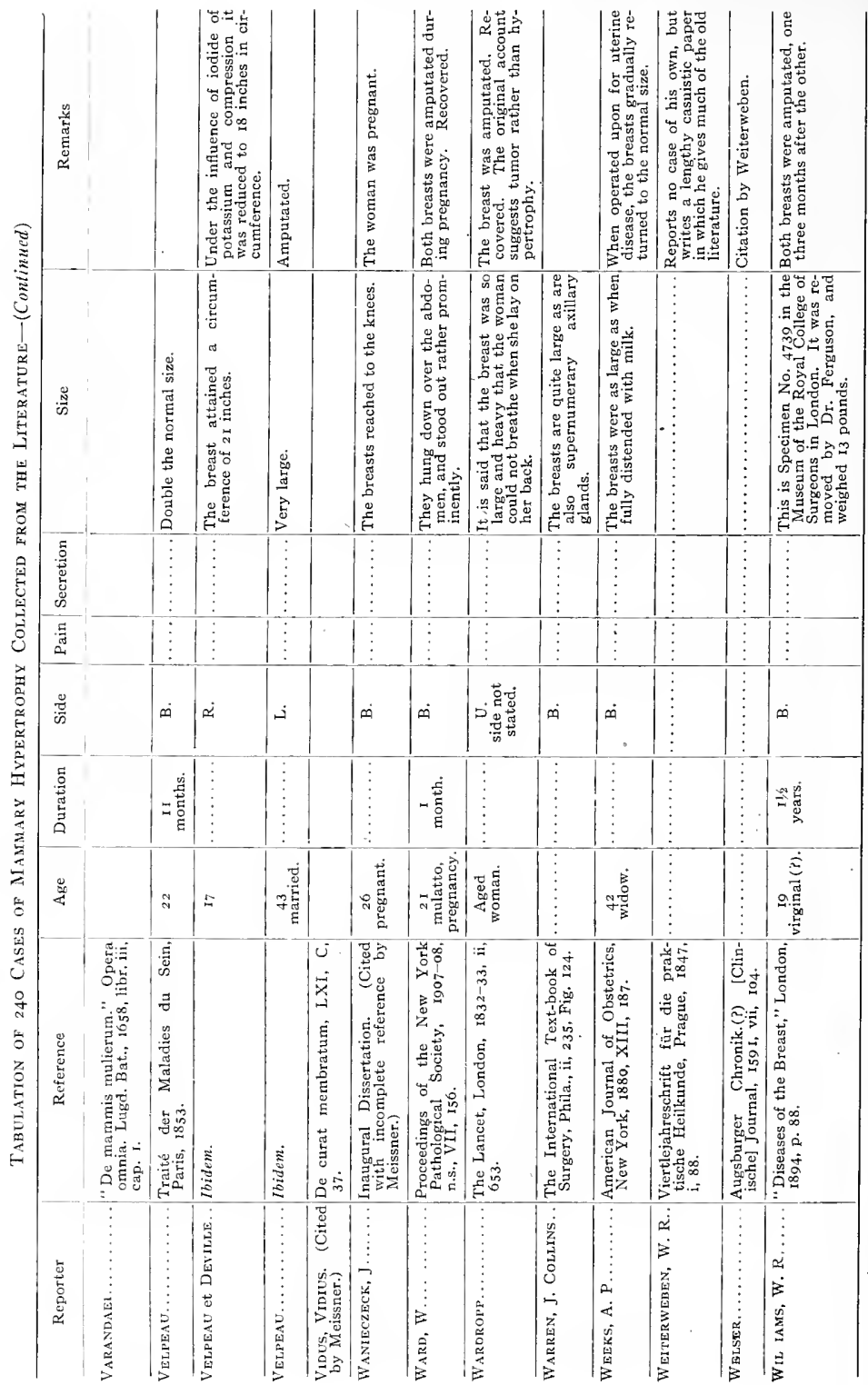




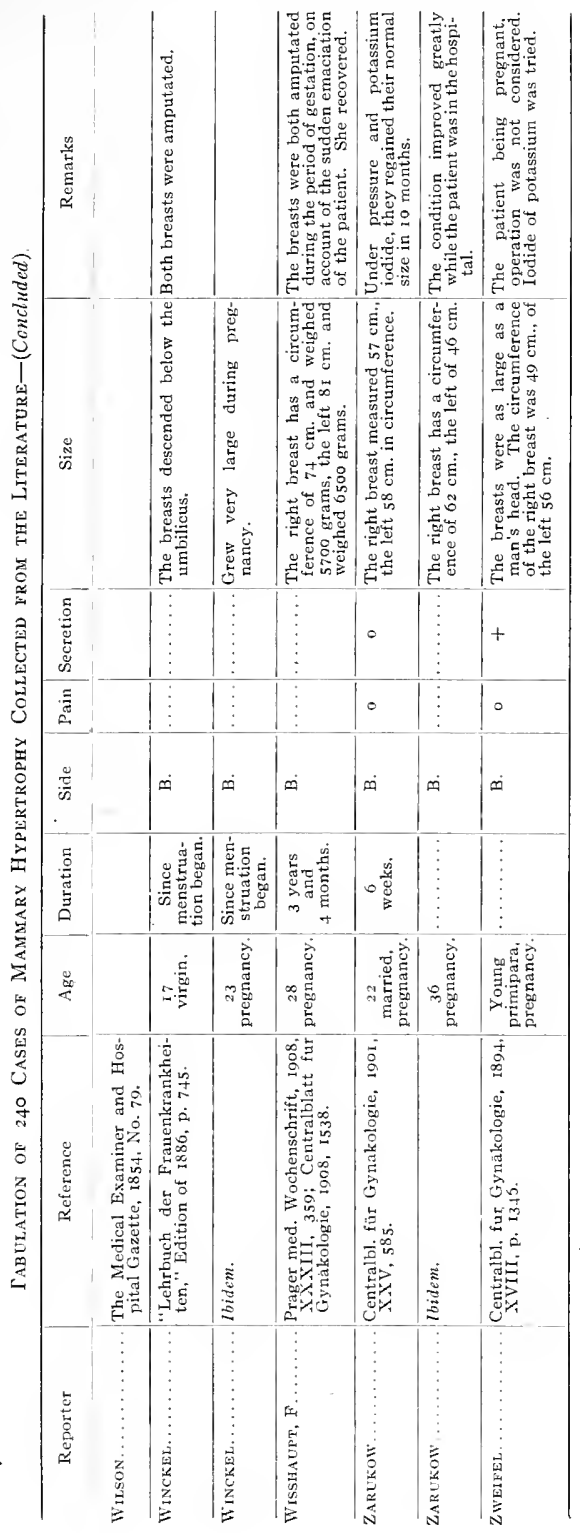




\section{B. EXCESSIVE GROWTH OF THE BREASTS IN THE MALE- GYNECOMASTIA}

Gynecomastia is an hypertrophy of the male breast that causes it to assume more or less the size and appearance of the female breast. Like the hypertrophy of the female breast it appears to be determined by disturbances of internal secretion attending the period of sexual development, or to be associated with disturbances of the sexual organs. A few cases are more or less definitely referable to traumatic disturbance. Many cases, especially those that are hereditary, cannot be explained. The following analysis of the subject is based upon the study of $\mathrm{I} 60$ cases collected from such literature as is appended to the end of this section, or made known to us through the kindness of friends.

In gynecomastia two factors are to be considered-secretion and enlargement. In the present writing gynecomastia will be treated from the morphological, not from the physiological point of view-we consider that the enlargement of the breast is the gynecomastia.

The chief writings upon the subject are by:

Gruber.-Mémoirs de l'Acad. Imp. des Sciences de St. Petersburg, I866-67, s. x., No. Io, p. I. LaUrent.- "Les Bisexués-Gynécomasties et Hermaphrodites," Paris, I 894.

Olphan.-Un mot sur la gynécomastie ou hypertrophie mammaire chez l'homme," Thèse de Paris, I880, No. 159 .

SChuchardT.-Archiv f. kl. Chirurgie, Berlin, $1885, \mathrm{XXXI}$, 59. This is a very important paper upon Mastitis pubescentium virilis and gynecomastia, and contains protocols of many cases. In references to this writing it is sometimes stated that the author collected 272 cases of gynecomastia, but this is a mistake, as the total number of ,cases collected by Schuchardt does not exceed 40.

\section{THEORIES OF GYNECOMASTIA}

I. The Theory that it is a Reversionary or Atavistic Phenomenon.-This theory is based upon Mr. Darwin's opinion ("The Descent of Man," 2d ed., pp. I84 and I85) that the existence of mammary glands in the male points to androgynous ancestors for all mammals including man, and that during the course of evolution the males have ceased to perform the function of lactation and so come to possess only rudimentary organs. This being the case, the appearance of mammary glands of the female type in men is a return to the androgynous type, or an example of reversion or atavism.

The adherents of the theory bring forward the following evidence in support of it: First, the males of the lower races of human beings have larger mammary glands than those of the higher races. Christopherson says that it is quite common among the members of the Firtitavi tribe of Sudanese. Cohen declares it to be normal among the Abysinian and Galla youths for the breasts to enlarge and to secrete a small quantity of milk when they are about I6 years of age. Johnson ("British Central Africa," p. 398) says that in all true negroes in whom virile development is otherwise well marked, there is a considerable development of the male breast so that he often had to ask himself the question "Is it a man or a woman?" Schufeldt has written an interesting account of the Zulu chief, Chengwayo, whose mammary glands were like a woman's in appearance, and who is said to have shared with his 40 wives the pleasure of nursing his children.

There are many other, mostly general statements, attributed to Livingstone and later travelers in support of the general fact that the breasts of men of lower races are larger and better developed than those of the higher races. This is, however, not true gynecomastia, which would imply that the mammary glands of the men developed 
like those of the women of their respective tribes, and when we come to consider the particular cases mentioned above, we find that one of the boys whose cases have been reported by Christopherson was so mortified by the real gynecomastia from which he suffered that he tried to disembarrass himself of the offending member by self-mutilation. We also find that Chengwayo was keenly alive to the fact that he was different from the common run of men and took great pride in it.

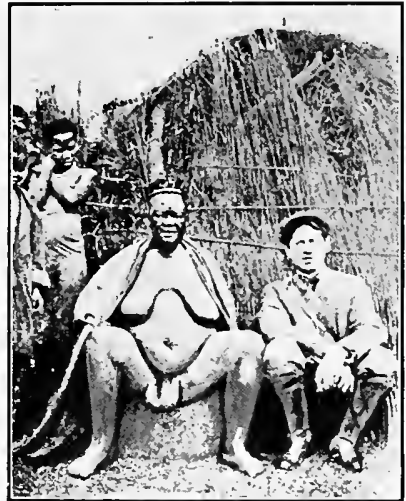

FIG. 83--Gynecomastia. The Zulu chief
Chengwayo. (Schufeldt.)

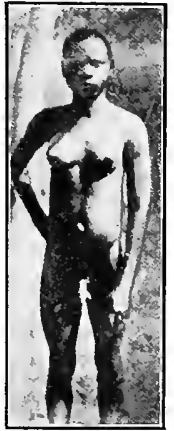

F I G. 84.-Gynecomastia. Rhodesian boy with bilateral gynecomastia. (Breeks.)

II. Gynecomastia is a Sign of Degeneration.-The gynecomastic is said to be a "degenerate," but when we inquire into the meaning and significance of "degenerate," we find it implies that the individual falls from the advanced position achieved by his kind, to assume the characteristics of lower types. Degeneration is therefore, more or less, an atavistic or reversionary phenomenon, and the theory is only a modification of the former one. The chief exponent of the theory is Laurent, whose studies were based upon experiences with and observations upon the criminal classes. Other criminologists, notably Havelock Ellis, support the same opinion, and the superintendents of reformatories usually find a high percentage of gynecomasts among the inmates of their institutions. The case reported by Carrara was a criminal and degenerate; one of Hutchinson's cases was an imbecile; Raggi's case suffered from delusional insanity, and Zilochi's case was insane and died in an asylum. Here are the chief evidences of degeneracy shown in our notes of the reported cases.

That gynecomastia is in many cases a hereditary condition is shown by Handyside, who records the history of a man, who, having large mammary glands himself, had five children, of whom three were gynecomasts; by Laurent, who gives the family history of six gynecomasts, and of Savitzky who observed a gynecomastic peasant, whose father, brother and a cousin were all gynecomasts.

The hereditary character of the condition is not necessarily a proof of its atavistic or reversionary nature, however, but may simply show that the members of certain families are peculiarly rich in the hormones that act upon the mammary glands. Thus in the family about which Pflanz has written, the mother at one time had enormous 
hypertrophy of a mammary gland, her daughter had at the time of writing enormous hypertrophy of both mammary glands, and her son was a gynecomast. If in this case the gynecomastia of the son were accepted as an evidence of degeneracy or atavism, what must we say about the women of the family.

That a greater number of gynecomasts do not exist to show the hereditary nature

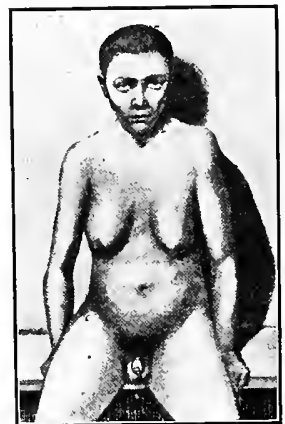

FIG. 85.-Gynecomastia. (Laurent.) of the affection is explained by Laurent as depending upon their inability to reproduce themselves for reasons shown in considering the next theory.

III. Gynecomastia is a Sign of Sexual Abnormality.There are at least 28 cases in the literature in which sexual abnormality (apart from hermaphroditism) and gynecomastia are associated. Some of these are of considerable interest. The subject divides itself into the following:

Gynecomastia occurs in association with and is probably referable to imperfect development of the sexual organs.-Where, as in the cases reported by Beau and Luke, the gynecomastia made its appearance before puberty, it may be difficult or impossible to work out a connection between the undeveloped state of the sexual organs and the overdeveloped state of the mammæ.

In Hassler's case the relationship was fairly plain. The patient was a boy of seven years who suffered from mumps and afterward from atrophy of the testes. When puberty should have arrived he failed to mature, and the left mamma became large. It is interesting to note that the left testis was the smaller.

In Luke's case, the boy being I 6 years old, it looked as though the occurrence of puberty had been delayed and as though the sexual organs were not going to mature perfectly. If such were true, then there is only one case, Beau's, in which the gynecomastia preceded puberty in time of occurrence.

In a great many cases examination of the sexual organs shows that the gynecomast is undeveloped to a greater or less extent. This is true of cases reported by Bedor, Carrara, Ansieux, Hutchinson, Laurent, Renauldin, Savitzky, Schaumann, Paulicky and Weber. The disturbances of the sexual organs vary from small size of the organs, to complete failure in the development of the secondary sexual characteristics. In a few cases like those of Laurent and Lieber the subjects of the deformity were decidedly of the female type of structure.

Gynecomastia Occurs in Psendohermaphroditism.-Here we have males, with sexual organs imperfectly developed and easily mistaken for female organs, whose secondary sexual characters develop along female lines. They are mistaken, either in childhood or at puberty, for females, because in addition to the female appearance of the sexual organs, the mammary glands develop, the body is short, often fat, the voice high-pitched and the face without a beard. Many such cases occur in the remarkable collection made by Neugebauer "Hermaphroditism beim Menschen," and cases are also reported by Laurent, Lieber, Dennis and Billings, Chambers, Kochenberger, and Polaillon.

Gynecomastia may Result from Disease or Removal of the Testes.-In these conditions the subjects of the malformation have been normal up to the time of the disease or operation, but afterward become abnormal as regards the mammary glands and in other particulars. It is particularly interesting to note that gynecomastia of this form may 
occur at almost any time. One of Galliet's cases aged only 20 years, suffered from a tumor of the epididymis of only five months' duration, yet had experienced enlargement of the mammæ. On the other hand the sailor, whose case has been described by both Gorham and Hare in different publications, was 57 years old when he met with the accident that caused his trouble. Here are abbreviated accounts of the case, given by the two authors mentioned:

Samuel Hare (The Lancet, London, I837-38, II, 878).

William Rogers, aged 60 years, a stout, muscular man, had pneumonia. At the same time it was observed that he presented extreme enlargement of the mammæ and wasting of the testes. At present the mammæ are very large, pendulous, heavy and knotty. Their circumference at the base is $I_{5}$ inches, the length vertically $6 \frac{1}{2}$ inches, transversely 8 inches. The nipples are very faintly pigmented and surrounded by an areola the breadth of an inch. They do not contain milk. The condition is said to have followed a blow simultaneously affecting the loins and back of the neck.

\section{J. Gorham (The Lancet, London, I840, II, 637).}

This is the case of William Rogers, a fisherman of Chatham, who was shot in the Queen's service, and suffered in various ways, among which was atrophy of the testes. His mammary glands began to grow three weeks after the accident until they were each as large as an orange, glandular to the touch and pendulous. The circumstance took place when he was 57 years of age. He experienced retarded growth of hair on the face, atrophy of the testes and enlargement of the breasts after the accident.

Concerning the nature of the disturbance of the sexual organs that may lead to gynecomastia, we find the following:

I. Cases of atrophy of the testes. Such are recorded by Boerhaave, Laurent, Schmitt, Lembert, and Hutchinson, no cause for the atrophy being given.

2. Cases of atrophy of the testes following mumps. Such are reported by Hassler and Lereboullet.

3. Cases of atrophy of the testes following varicocele. Such a case is reported by Martel.

4. Cases of atrophy following orchitis. Schmit has reported such a case. Gaillet.

5. Cases of tumor of the epididymis. Two such cases have been reported by

6. Cases of castration. One such has been reported by Zeleneff.

7. Cases of atrophy following injury to the testis, as in the case reported by Lacassagne.

8. Cases of traumatic injury followed by atrophy of the testes. In this group must be placed the case of William Rogers, reported by Hare and Gorham mentioned above, the case reported by Thompson, in which traumatic injury to the back was followed by atrophy of the testes and gynecomastia, and the case of Bouchereau.

Though these theories of gynecomastia are applicable to the cases cited, and perhaps to others that cannot be cited because of insufficient information, they cannot account for all cases. Thus the following groups present themselves:

IV. Gynecomastia Following Local Traumatic Injury to the Breast.-Léon's case was a sailor with enlargement of the left breast following a blow. Nélaton's case with a female-like mamma on the left side, referred the development of the breast to an injury received some time before. Peters' case was a soldier who was injured by being caught between the wall of a building and some machinery, and suffered contusions to the shoulder and side of the chest. Three years afterward he had hypertrophy and pendulousness. of the breast on that side. Wagner's patient, aged 2 I years, states that he was injured on the right breast by a rope, after which the breast enlarged. This case has certain 
circumstances that make it a little different from the others and might give it a different explanation. Thus, the patient had a deformity of the right hand, and the gynecomastia occurs on the deformed side, and at a critical age. However, the disturbance was attributed to the injury. Contagne's patient developed the gynecomastia three months after having received a blow on the breast. Kammler's patient was a shoemaker, and attributed his condition to the pressure of the shoe, upon which he worked, upon his breast. Ginsburg's patient, also a shoemaker, may have suffered similarly. In none of these cases is there a suspicion of heredity, degeneration or sexual defect. It is diffcult in the absence of exact information regarding the pathological changes of many of these cases, to decide whether they are true gynecomastia in the sense in which we employ the term, or are cases of chronic indurative mastitis closely resembling it.

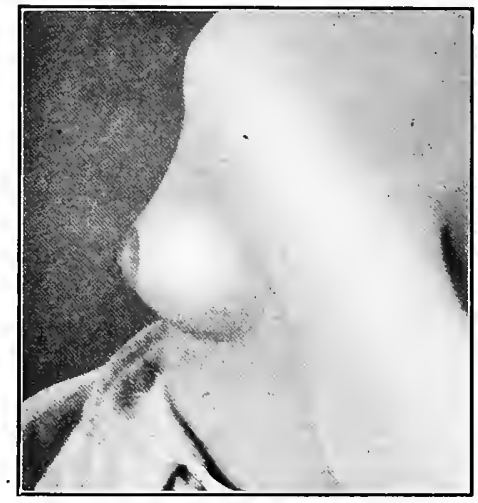

Fig. 86.-Case of true gynecomastia. Patient of Dr. Nathaniel Ginsburg.

V. Gynecomastia without explanation, that is, in cases in which there is no known inherited tendency, no sign of degeneration, no sexual disturbance, and no history of local injury to the part, or of injury to other parts that might lead to sexual disturbance indirectly. Such cases are said to be of unknown or indeterminate nature. The list of collected cases shows many of them, but only one group is particularly interesting, viz., that in which it is expressly stated by the reporter that there was no disturbance or defect of the sexual organs. Such cases are reported by Bertherand, by whom it is expressly stated that the sexual organs of his patient were abnormally large and well developed; Coe, whose patient was a precociously developed negro boy given to sexual excesses; Foot, Köster, Morgan, Paulicky, Scheiber, Tufnell and Wyeth, all of whom state there was no abnormality of the genitalia; Petrequin, whose patient with enormous mammæ is said not to have married because embarrassed by his excessive development, implying that there was no abnormality of the genital organs that prevented marriage or merited attention; Schufeldt, who relates the case of Chengwayo, the Zulu chief, a man of powerful physical development, who had 40 wives and over a hundred children, and concerning the development and functional activity of whose genitalia there can be no question, even though he had mammary glands as large as those of a woman and nursed some of his children; and by various others. 
Morphology.-Gynecomastia is frequently unilateral. A census of the cases of which we have notes gives the following:

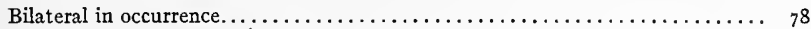

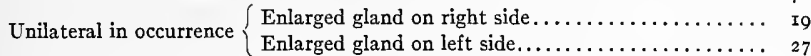

No data as to side or sides affected............................. 37

I6I

Thus in $7^{8}$ cases of which we have data, both glands were affected; in 46 cases only one gland was affected. In the latter the left gland suffered enlargement in 27 , the right in 19 cases.

Several of the cases of unilateral enlargement of the male breast associated with disturbance of the genital organs are of peculiar interest. Among these are Hassler's case, in which, after mumps, the left testis slowly atrophied and the left breast slowly enlarged, and Schmit's case of the soldier who suffered from orchitis and whose testes, especially the right, atrophied, while the right breast enlarged. These recall the interesting cases of amastia reported by Engström, in which a female patient minus the right ovary had no right breast, and another minus the left ovary had no left breast.

That there is any real connection between the testis of one side and the breast of the same side is, however, improbable, and is offset by Zeleneff's case in which after operative removal of the right testis, the left breast enlarged.

The age incidence of gynecomastia is difficult to determine. Many cases come under observation and are

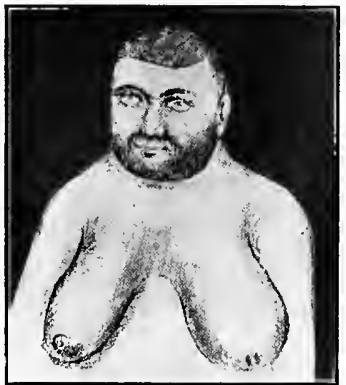

F1G. 87.-Gynecomastia. (Gruber.) reported years after the condition has developed, no mention being made of the time of first appearance. A few of the reports show that an attempt has been made to get at the actual time at which the abnormality first appeared.

The general appearance of the breasts in gynecomastia is usually described as being like the virginal mammæ of girls I $^{-1} 6$ years of age. The nipple and areola are usually enlarged in proportion, and the areola is sometimes pigmented. In a few cases, especially in men of advanced years, the breasts become as large as those of any normal woman and may be pendulous. Petréquin "saw in Pavia a remarkable case in a man 45 years old, tall, strong, and well built, whose mammæ were like long 'courge bouteille' (gourd bottles) hanging down like those of the Hottentots, reaching to the length of I5 and 18 inches ( $405-487 \mathrm{~mm}$.)." The man had never married because of this remarkable malformation. Between male breasts like those of virgin females, and monstrous mammæ like these, there seem to be all intermediate grades.

It not infrequently happens that the enlargement of the male breasts is attended by pains which vary from dull aching to severe lancinating or burning sensations. The cases of Beau, Cruveilhier, Nélaton, Schaumann, Stieda and Villeneuve were all troubled by pain of more or less severe character, usually in the early period of growth. The greater number of cases are, however, painless.

The tendency of the enlargement is to persist. This is to be expected, as gynecomastia may be looked upon as the abnormal occurrence of a female mamma upon a 
male subject. Having attained the female proportions it rests unchanged. Gynecomastia should not be thought of as running parallel with the hypertrophy of the female gland. The gynecomastic breast is in most cases a normal one, except that it does not correspond with the sex of the individual. It may be, therefore, either an active or a quiescent organ according to circumstances. Two cases are on record in which slight diminution in size was noted by the reporters, but both cases are peculiar in certain particulars that make them decided exceptions to the rule. The first is the case of Hiller, which is, briefly, as follows:

A merchant lost his first wife from scirrhus cancer of the breast. Three of his daughters suffered from various morbid conditions of the breast. Later he had much concern to find his own breasts, which had always been a little prominent because of congenital fatty deposits beneath them, were enlarging, and the areolæ becoming prominent. They eventually attained to the size of those of a 15 -year-old girl. They were $3 \frac{1}{2}$ inches in diameter and projected $1^{1 / 2}$ inches. Under treatment they diminished somewhat in size. The same condition obtained in his 17 -year-old son.

In this case we see a curious confusion of possibilities. First, the man always had prominent mammæ, secondly, his son seemed to have inherited the same condition. This looks like the unexplained hereditary cases of gynecomastia. But in middle life, under

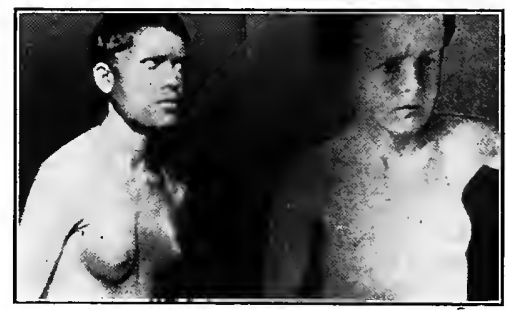

FIG. 88.-Gynecomastia. Bilateral in the left-hand figure; left unilateral in the right-hand figure (Lexer.)

the influence of the emotional disturbances attending disease of the breasts in four of the female members of his family, his breasts enlarged as through sympathetic or emotional disturbances and influences. Finally, under treatment the enlargement of the breasts subsided, as may be true in emotional disturbances.

The other case with diminution in the size of the breast is reported by Martel, and is briefly, as follows:

A man 23 years of age has always had a left breast somewhat larger than the right. He is vigorous and well developed, but has had varicocele a long time, and has had atrophy of the testes, especially the right. For two days he suffered from pain, and applied for relief. Upon inspection, a hemispherical mamma like that of a woman was observed. It was very tender on pressure, and from it a small quantity of fluid could be squeezed. He was placed under treatment and in a month the enlargement had gone down to such an extent that the left breast was but little larger than the right. Here with a mild grade of gynecomastia, a complication seems to have arisen and found expression in enlargement, pain and secretion. In a month the disturbance subsided and the breast returned to its quiescent state though not to its normal size.

The question naturally arises, can these female glands of the male, behave as their size suggests, and secrete milk? But do the glands of the female secrete milk under similar circumstances?

If the authors' views, be accepted, and it be granted that the gynecomastic gland is 
in most cases a female development of the mammary gland in the male, why should it behave differently from female glands in the female? Such glands are, as a rule, quiescent throughout the entire life of the woman except in those rare cases in which the recurrence of menstruation excites them, or in those common cases in which pregnancy excites them to the maximum of growth and activity. As it is impossible for either of these conditions to arise in the male, it should follow that his mammary glands ought to remain quiescent throughout his life.

But when we examine the data at hand we find that secretory activities sometimes do occur in gynecomastia.

Nélaton says of the enlarged left breast of his patient "it gave milk, which the other never did." Raggi states that the enlarged breast of his patient "furnished secretion, which stopped after several months." From the enlarged right breast of one of Schmit's patients, "fluid could be pressed out." The fact that the Zulu Chief Chengwayo nursed some of his children has already been pointed out. Wiltshire tells of an eminent naturalist, a gynecomast, who had a recurring period of lactation each spring, each time lasting about six weeks.

Here are enough cases to show that secretory activities leading to the presence of fluid and of milk may be present in the enlarged male breasts, but they are so few out of the total of the cases collected as to show that such activities are the exception and not the rule. The enlarged breast of the gynecomast is therefore a quiescent, not an active functional gland. What potentialities these breasts may possess it is very difficult to say since the normal stimuli to lactation must ever remain absent.

There is nothing abnormal discoverable to the naked eye in the gynecomastic breast. It appears like the normal breast of the opposite sex.

Microscopic examinations of these breasts have been made by Bartel, Christopherson, Hassler, Israel, Wyeth, Zillocchi and ourselves. They all agree that there is no abnormality. The breasts are hypertrophied, they consist of an increase of fibrillar and adipose tissue, with a marked increase in the number of ducts and tubules. In a few cases it is said that some acini were present. Their presence is interesting, but their absence signifies nothing, as they are never present in the normal male breast, nor should they be expected in the normal female breast until it has once undergone the stimulus to lactation.

Diagnosis presents few difficulties. The size, general appearance, female type and tactile sensation of the breast are usually sufficient evidence of the nature of the condition. Inflammatory disturbances, temporary secretory activities, sub-mammary lipomata and tumors of all kinds should be excluded without difficulty, though all of these have been present and accounted for mammary enlargements that have been reported as gynecomastia.

Prognosis based upon what has already been said, can lead the patient to expect no change in the enlarged breast. There is no danger of future trouble, and it is rather interesting to remark that in the notes of the long series of the cases upon which these studies are based, there is very rare mention of the development of a malignant tumor in a gynecomastic breast.

Treatment.-Few cases require treatment. The condition is an anatomico-physiological anomaly rather than a disease. There are cases, however, which require attention for particular reasons. First of all, there are the sensitive and emotional persons who feel themselves to be unsexed and therefore ridiculous when thus afflicted. Raggi tells us that his patient, for a time, was the victim of delusions, and fancied himself a woman, and he is inclined to refer the patient's insanity to his malformation. One of 
the gynecomastic boys observed by Christopherson was so mortified by his deformity that he could no longer endure it and was driven to self-mutilation. When discovered, he had amputated one breast and had partially succeeded with the other when both strength and courage failed. Again there was the middle-aged patient of whom Petrequin tells, whose enormous breasts had been the cause of bachelorhood. In such cases as these the patients need advice and treatment.

Another group of cases require attention-those who suffer pain in the breasts.

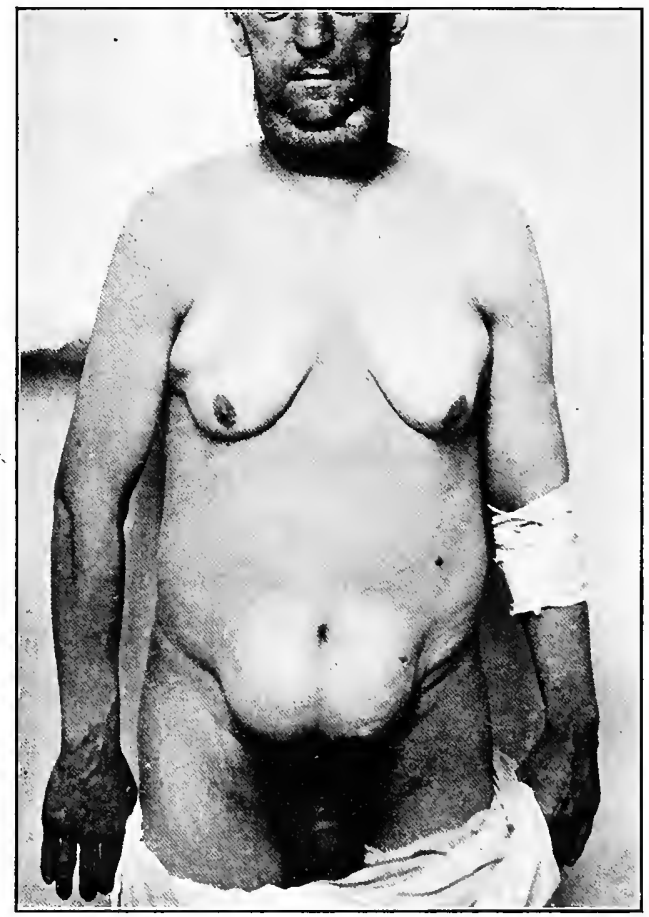

Fig. 89.-Gynecomastia, with bilateral symmetrical lipomas. (Sailer.)

When this is severe and does not disappear in time or yield to simple treatment, they too require particular advice and treatment.

The only treatment that will be of lasting benefit in all cases is the amputation of the offending breast or breasts. There is no need of hesitation in advising the operation in gynecomastia. The enlarged male breasts are both a disfigurement, and an encumbrance; and none of the feelings that foster conservatism in treating the female breast need be taken into consideration.

Simple amputation or preferably plastic resection of the breast is all that is required. The breasts are rarely very large, the tissues are normal, the axilla need never be touched, 
so that the operation is of the utmost simplicity. The wounds ought to heal perfectly and no complications should be expected or after-treatment required.

Such operations have been performed by Bartel, Christopherson, Eve, Hassler, Israel, Petrequin, Stieda, Wyeth and many others.

Reflections upon Gynecomastia.-Gynecomastia is an enlargement of the male breast analogous to the normal enlargement of the female breast, and consists of a simple hypertrophy corresponding to puberty hypertrophy. It is sometimes hereditary in occurrence, and accompanies a feminine habitus of the body that suggests reversion, atavism or "degeneration."

It is sometimes associated with genital malformations in such manner as to make it clear that they are its cause.

It may follow local injury to the breast. (Chronic indurative mastitis?)

Many cases cannot be accounted for.

It most frequently develops between the period of puberty and that of adolescence.

It is rarely attended by secretory activity.

It is commonly attended by pain, especially early in the period of growth.

The glands appear like female glands, usually like those of virgins just past puberty, sometimes like those of fully developed women.

The enlargement having occurred is permanent.

In most cases both glands are affected; when only one gland is enlarged, the left is more frequently affected than the right.

The majority of cases require no treatment, since they give no symptoms and excite no concern.

Some cases require treatment because of anxiety, mortification or pain.

The only treatment to be recommended is amputation or plastic resection, which are simple operations withoụt danger. 
List of i62 Cases of Gynecomastia Collected from the Literature, and Forming the Basis of the Precedieg Critical Studies of the Subject

\begin{tabular}{|c|c|c|c|c|c|c|c|}
\hline Reporter & Reference & Age & Duration & 苋 & Pain & 岕. & Remarks \\
\hline Ansieux. & $\begin{array}{l}\text { Jour. de méd. chir. pharm., } \\
\text { etc., Paris, 1807, XIV, } 262 .\end{array}$ & Adult. & $\begin{array}{c}\text { Since } \\
\text { puberty. }\end{array}$ & L. & & & $\begin{array}{l}\text { Sexual development was imper- } \\
\text { fect. }\end{array}$ \\
\hline BARTEL. & $\begin{array}{l}\text { Zeitschrift für Heilkunde, } \\
\text { 1900, XXI, 207. }\end{array}$ & 19 & $\begin{array}{c}3 \\
\text { years. }\end{array}$ & L. & & & $\begin{array}{l}\text { Breast measured-sagittal diame } \\
\text { ter } 26 \mathrm{~cm} \text {.; frontal diameter } 29 \\
\text { cm. Operative removal. His- } \\
\text { tological examination showed } \\
\text { excess of fibrous tissue. }\end{array}$ \\
\hline BARTEL. . & Ibid. & 17 & $\cdots \cdots$ & R. & + & o & $\begin{array}{l}\text { Surgically removed. Microscope } \\
\text { showed increase of fibrous tissue. }\end{array}$ \\
\hline BEAU...... & $\begin{array}{l}\text { Gazette des Hôpitaux, Paris, } \\
1849 \text {, p. } 563 \text {. }\end{array}$ & 16 & $\ldots \ldots$ & B. & + & $\cdots$ & $\begin{array}{l}\text { Each breast is } 6 \mathrm{~cm} \text {. in diameter } \\
\text { and elevated } 4-5 \mathrm{~cm} \text {. The geni- } \\
\text { tals are undeveloped. }\end{array}$ \\
\hline BEDOR........ & $\begin{array}{c}\text { Dict. des sciences médicale, } \\
\text { Paris, I8I7, XIX, 596. }\end{array}$ & 28 & & B. & & & Small and imperfect sexual organs \\
\hline BEDOR........... & Ibid. & & & & & & \\
\hline BEDOR........ & Ibid. & & & & & & . \\
\hline BELCHER, H. E... & $\begin{array}{l}\text { British Medical Journal, } \\
1890, i, 364 .\end{array}$ & 12 & $\begin{array}{c}5 \\
\text { months. }\end{array}$ & L. & $\ldots \ldots$ & $\cdots$ & $\begin{array}{l}\text { Looked like the mamma of } \\
\text { healthy girl at puberty. No ab- } \\
\text { normality of the genitals. }\end{array}$ \\
\hline BERNS.......... & Gazette hebđomađaire, I887. & 42 & Years. & B. & & & $\begin{array}{l}\text { Cancer developed in one of the } \\
\text { breasts, both of which had always } \\
\text { been large like those of a woman. } \\
\text { The breast was removed, the dis- } \\
\text { ease recurred and he died. }\end{array}$ \\
\hline BERTHERAND .... & $\begin{array}{l}\text { Gazette médicale, Paris, } \\
1857, \text { p. } 223 .\end{array}$ & I6 & $\begin{array}{c}4 \\
\text { years. }\end{array}$ & B. & $\cdots$ & $\ldots$ & $\begin{array}{l}\text { Genital organs large and ab- } \\
\text { normally well developed. Ad- } \\
\text { dicted to onanism. }\end{array}$ \\
\hline BIRKETT........ & $\begin{array}{l}\text { "Diseases of the Breast," } \\
\text { London, } 1850, \text { p. } 225 .\end{array}$ & 25 & $\cdots \cdots \cdots$ & $?$ & + & .. & Unilateral but side not stated. \\
\hline BIRKETT........ & Ibid. & $\cdots \cdots$ & $\ldots \ldots \ldots$ & B. & & & \\
\hline BoERHAAVE. . & $\begin{array}{l}\text { Tijdschrift van Geneesk, } \\
1838 .\end{array}$ & Adult. & $\cdots \ldots \ldots$ & B. & $\cdots \cdots \cdots$ & & $\begin{array}{l}\text { Patient was a soldier. He had } \\
\text { atrophy of the testicles. }\end{array}$ \\
\hline Bouchereau.... & $\begin{array}{l}\text { Ann. des maladies des or- } \\
\text { ganes génitourinaires, I909. } \\
\text { XXVII, I, p. } 625 .\end{array}$ & 23 & ....... & R. & & & $\begin{array}{l}\text { The disease began with the forma- } \\
\text { tion of a small nodule. The } \\
\text { breast finally grew to resemble a } \\
\text { female mamma and to have a di- } \\
\text { ameter of I I cm. He had atrophy } \\
\text { of a testis, otherwise was normal. } \\
\text { The breast was removed and ex- } \\
\text { a mined microscopically but } \\
\text { seemed to be a normal mamma. }\end{array}$ \\
\hline BouchereaU.... & Ibid. & 18 & $\begin{array}{c}4 \\
\text { years. }\end{array}$ & R. & $\ldots$ & $\cdots$ & $\begin{array}{l}\text { The appearance of the disease fol- } \\
\text { lowed injury to the scrotum. } \\
\text { Both testes are hypertrophied. }\end{array}$ \\
\hline BREEKS, C. W... & $\begin{array}{l}\text { Jour. Tropical Medicine, } \\
\text { 1904, VII, } 318 .\end{array}$ & Boy & . $\ldots \ldots$ & B. & & $\ldots$ & $\begin{array}{l}\text { An African boy of Rhodesia, } \\
\text { known to the white population as } \\
\text { "Mary Ann," Operative removal. }\end{array}$ \\
\hline BREEKS & Ibid. & & & & & & \\
\hline
\end{tabular}


List of 162 Cases of Gynecomastia Collected from the Literature, and Forming the Basis of the Preceding Critical Studies of the Subject-(Continucd).

\begin{tabular}{|c|c|c|c|c|c|c|c|}
\hline Reporter & Reference & Age & Duration & $\stackrel{0}{0}$ & Pain & 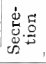 & Remarks \\
\hline BREEKS......... & Ibid. & & & & & & \\
\hline BRUANT. . & $\begin{array}{l}\text { Hôp. mil. de Lyon, I88a } \\
\text { (Cited by Olphan, } q . r^{\prime} \text { ) }\end{array}$ & 23 & $\begin{array}{c}3 \\
\text { months. }\end{array}$ & R. & + & & $\begin{array}{l}\text { The breast was the size of a hen's } \\
\text { egg and was tender on pressure. }\end{array}$ \\
\hline BRYANT. & $\begin{array}{l}\text { "Diseases of the Breast," } \\
\text { 1887, p. 15. }\end{array}$ & 25 & $\begin{array}{c}2 \\
\text { years. }\end{array}$ & L. & & $\therefore$ & $\begin{array}{l}\text { Breast was as large as that of a } \\
\text { "grown woman." }\end{array}$ \\
\hline BRYANT. & $\begin{array}{l}\text { "Diseases of the Breast, } \\
\text { 1887, p. I5. }\end{array}$ & $3 \mathrm{I}$ & $\begin{array}{c}6 \\
\text { years. }\end{array}$ & L. & & . & $\begin{array}{l}\text { The breast was as large as an } \\
\text { orange. }\end{array}$ \\
\hline BRYANT. & Ibid. & 20 & $\begin{array}{c}3 \\
\text { years. }\end{array}$ & $\mathrm{R}$. & . & $\ldots$ & The breast was the size of the fist. \\
\hline BRYANT.... & Ibid. & I8 & $\stackrel{2}{2}$ years. & B. & & & \\
\hline BURGI.. & $\begin{array}{l}\text { "Beitrag zur Kentniss der } \\
\text { Gynecomastie," Zürich, } \\
\text { I9oz. }\end{array}$ & I6 & $\begin{array}{c}6 \\
\text { months. }\end{array}$ & B. & o & $\cdots$ & $\begin{array}{l}\text { The breasts were like those of a } \\
\text { girl at puberty. The genitalia } \\
\text { were normal. }\end{array}$ \\
\hline Bush, E... & $\begin{array}{l}\text { Russk. Chir. Arch. St. } \\
\text { Petersburg, I905, XXI, } 55 .\end{array}$ & $\ldots$ & $\ldots \ldots$ & L. & & & \\
\hline Carrara.... & $\begin{array}{l}\text { Riforma medica, Napoli, } \\
\text { I896, XII, Ft. 3, p. } 387 .\end{array}$ & 29 & $\cdots \cdots$ & B. & $\begin{array}{c}+ \\
\text { when } \\
\text { pressed. }\end{array}$ & + & $\begin{array}{l}\text { The man was criminally insane. } \\
\text { His sexual development was im- } \\
\text { perfect, the testes being very } \\
\text { small. }\end{array}$ \\
\hline Chambers... & $\begin{array}{l}\text { Trans. Obstetrical Society of } \\
\text { London, 18.79. XXI, } 256 .\end{array}$ & 24 & & B. & & $\cdots$ & $\begin{array}{l}\text { The case was a female pseudoher- } \\
\text { maphrodite, with complete fem- } \\
\text { inine appearance and large } \\
\text { breasts, though they had no } \\
\text { nipples. The female-appearing } \\
\text { sexual organs were found to be } \\
\text { male organs. }\end{array}$ \\
\hline Christopherson. & $\begin{array}{l}\text { The Lancet, London, } 1904 \text {, } \\
\text { i, } 865 .\end{array}$ & 14 & $\cdots \cdots$ & B. & & $\cdots$ & $\begin{array}{l}\text { Surgically removed. Microscopical } \\
\text { examination showed hypertrophy } \\
\text { and fibrosis. }\end{array}$ \\
\hline Christopherson. & Ibid. & Boy. & $\ldots \ldots \cdots$ & B. & & $\cdots$ & $\begin{array}{l}\text { This African boy was so embar- } \\
\text { rassed by his large female breasts } \\
\text { that he amputated one with a } \\
\text { razor, and tried to do the same to } \\
\text { the other. }\end{array}$ \\
\hline Cloquet.... & $\begin{array}{l}\text { Nouv. Bibliothek. Med., } \\
\text { I828, I, 429. }\end{array}$ & Adult. & & B. & & & \\
\hline CoE......... & $\begin{array}{l}\text { Annals de Gynécologie, } 1889 \text {, } \\
\text { XXXI, } 456 .\end{array}$ & Boy. & & $?$ & & $\ldots$ & $\begin{array}{l}\text { Unilateral enlargement of the } \\
\text { breast in a negro boy. He was } \\
\text { sexually precocious and well de- } \\
\text { veloped. }\end{array}$ \\
\hline Collignon...... & $\begin{array}{l}\text { "Quelque cas de cancer du } \\
\text { sein chez l'homme," These, } \\
\text { Paris, IgI3. }\end{array}$ & $\cdots \cdots$ & & . & & $\cdots$ & $\begin{array}{l}\text { Mentions cases of cancer of the } \\
\text { male breast that have followed } \\
\text { gynecomastia. }\end{array}$ \\
\hline Contagne.. & $\begin{array}{l}\text { Gazettemédicale,Lyon, } 1867 \text {. } \\
\text { No. } 5 .\end{array}$ & Io & $\ldots \ldots$ & $?$ & & $\ldots$ & $\begin{array}{l}\text { Three months after being struck } \\
\text { by the fist, a gradual enlargement } \\
\text { of one breast occurred until it } \\
\text { came to resemble that of a girl at } \\
\text { puberty. }\end{array}$ \\
\hline
\end{tabular}


List of i62 Cases of Gynecomastia Collected from the Literature, and Forming the Basis of the Preceding Critical Studies of the Subject-(Continued)

\begin{tabular}{|c|c|c|c|c|c|c|c|}
\hline Reporter & Reference & Age & Duration & 串 & Pain & d. & Remarks \\
\hline CopLIN......... & $\begin{array}{l}\text { Keen's "Surgery, " article on } \\
\text { "The Breast" by Finney, } \\
\text { vol. iii, p. } 61 \text { r, Fig. } 348 .\end{array}$ & $14 ?$ & $\ldots \ldots \ldots$ & L. & & & \\
\hline Cowley...$\ldots \ldots$ & $\begin{array}{l}\text { Rev. de cien. méd. Habana. } \\
1895, \mathrm{X}, 176 .\end{array}$ & $\cdots \cdots$ & $\cdots \ldots \ldots$ & $\cdots$ & $\ldots \ldots$ & + & $\begin{array}{l}\text { Speaks of a wax model of a large } \\
\text { lactating male breast made by } \\
\text { Dr. Guiterrez from a man in the } \\
\text { neighborhood of Havana. }\end{array}$ \\
\hline Creasy........ & $\begin{array}{l}\text { Jour. Amer. Med. Asso., } \\
\text { IgI 2, LVIII, } 747 .\end{array}$ & 24 & $\cdots \cdots \cdots$ & L. & $\ldots \ldots$ & + & $\begin{array}{l}\text { The gland was materially larger } \\
\text { than its fellow and secreted milk } \\
\text { actively. }\end{array}$ \\
\hline CRISPIN........ & $\begin{array}{l}\text { The Lancet, London, 1904, i, } \\
1499 .\end{array}$ & $\cdots \cdots$ & $\ldots \ldots$ & B. & $\ldots \ldots$ & $\cdots$ & An African-a Soudanese. \\
\hline CRISPIN........ & Ibid. - & . & & , n & & & $\begin{array}{l}\text { A photograph taken by Dr. J. } \\
\text { Warnock of an Egyptian with ap- } \\
\text { parently female breasts due to } \\
\text { "excessive fat." }\end{array}$ \\
\hline CRISPIN....... & Ibid. & $\ldots \ldots$ & $\ldots \ldots \ldots$ & $\ldots$ & $\ldots$ & $\cdots$ & $\begin{array}{l}\text { Remembers having seen a case in } \\
\text { Egypt when engaged in examin- } \\
\text { ing conscripts. }\end{array}$ \\
\hline Cruveilhier..... & $\begin{array}{l}\text { Traité d'Anat. Descriptive, } \\
\text { Paris, 1852, iii, 3d Ed., p. } \\
730 .\end{array}$ & 25 & $\begin{array}{c}4 \\
\text { years. }\end{array}$ & R. & + & $\cdots$ & $\begin{array}{l}\text { The breast was so painful that the } \\
\text { patient desired to have it ampu- } \\
\text { tated. }\end{array}$ \\
\hline $\begin{array}{l}\text { DENN IS and } \\
\text { BILLINGS. }\end{array}$ & $\begin{array}{l}\text { "System of Surgery," Phila.. } \\
1896, \text { IV, } 942 \text {. }\end{array}$ & Adult. & $\ldots \ldots$ & R. & $\ldots \ldots$ & $\cdots$ & $\begin{array}{l}\text { The breast was the size of a func- } \\
\text { tionating female mamma. }\end{array}$ \\
\hline $\begin{array}{l}\text { DENN Is and } \\
\text { BILLINGS. }\end{array}$ & Ibid. & Boy. & $\ldots \ldots$ & B. & & & \\
\hline $\begin{array}{l}\text { DENNIS and } \\
\text { BILLINGS. }\end{array}$ & Ibid. & $\ldots \ldots$ & $\ldots \ldots$ & $\cdots$ & $\ldots \ldots$ & $\cdots$ & Hermaphrodite. \\
\hline $\begin{array}{l}\text { DENNIS and } \\
\text { BILLINGS. }\end{array}$ & Ibid. & $\cdots$ & $\ldots \ldots$ & $\cdots$ & $\ldots \ldots$ & $\ldots$ & Hermaphrodite. \\
\hline DETTLING........ & $\begin{array}{l}\text { Soc. de mil. med. franç. } \\
\text { Bull., Paris, 1912: VI, 394. }\end{array}$ & & & & & & These cases known through ci- \\
\hline DetTlling........ & Ibid. & . & $\ldots \ldots$ & $\cdots$ & $\cdots \cdots$ & $\cdots$ & $\begin{array}{l}\text { tations only. The original pa- } \\
\text { per could not be consulted. }\end{array}$ \\
\hline DeтtulNG........ & Ibid. & $\ldots \ldots$ & $\ldots \ldots \ldots$ & $\cdots$ & $\ldots \ldots$ & $\ldots$ & ) \\
\hline Durham........ & $\begin{array}{l}\text { Trans. Path. Soc. of London, } \\
1860, \text { XI, I63. }\end{array}$ & 25 & $\ldots \ldots$ & B. & $\ldots \ldots$ & $\cdots$ & $\begin{array}{l}\text { The breasts were large and promi- } \\
\text { nent like those of a young virgin. } \\
\text { The sexual organs were small and } \\
\text { imperfectly formed. }\end{array}$ \\
\hline Eve.......... & $\begin{array}{l}\text { Nashville Journal of Medi- } \\
\text { cine and Surgery, I854, VII, } \\
454 .\end{array}$ & 23 & $\begin{array}{c}8 \\
\text { years. }\end{array}$ & L. & o & $\cdots$ & $\begin{array}{l}\text { The breast was like that of a girl } \\
\text { of fifteen. It was surgically re- } \\
\text { moved. }\end{array}$ \\
\hline Finsterer...... & $\begin{array}{l}\text { Deutsche Zeitschrift für } \\
\text { Chirurgie, 1906, LXXXIV, } \\
\text { 20I. }\end{array}$ & $\ldots \ldots$ & $\ldots \ldots$ & $\cdots$ & $\ldots \ldots$ & $\cdots$ & $\begin{array}{l}\text { The breast was amputated and the } \\
\text { condition was referred to fibro- } \\
\text { adenoma. }\end{array}$ \\
\hline Foot.......... & $\begin{array}{l}\text { Dublin Quarterly Journal of } \\
\text { Medicine and Surgery, I } 866, \\
\text { XLI, } 451 \text {. }\end{array}$ & 14 & $\ldots \ldots$ & L. & o & $\cdots \cdots$ & $\begin{array}{l}\text { The sexual development was said } \\
\text { to be normal. }\end{array}$ \\
\hline
\end{tabular}


List of i62 Cases of Gynecomastia Collected from the Literature, and Forming the Basis of the Preceding Critical Studers of the Subject-(Continued)

\begin{tabular}{|c|c|c|c|c|c|c|c|}
\hline Reporter & Reference & Age & Duration & 总 & Pain & 离品 & Remarks \\
\hline Foor........... & Ibid. & $20-30$ & $|\cdots \cdots \cdots|$ & B. & $\ldots \ldots$ & + & $\begin{array}{l}\text { There was nothing effeminate in } \\
\text { the appearance of the patient ex- } \\
\text { cept that he had mammary glands } \\
\text { like those of a young virgin. }\end{array}$ \\
\hline Foor............ & Ibid. & 45 & $\ldots \ldots \ldots$ & B. & n.... & $\ldots$ & $\begin{array}{l}\text { The breasts were like those of a } \\
\text { young woman. Dr. Montgomery } \\
\text { made a plaster cast of them. }\end{array}$ \\
\hline Galliet........... & $\begin{array}{l}\text { Compt. rendu de la Soc. de } \\
\text { biologie de Paris. 1850, } 36 . \\
\text { Gazette méd. de Paris, } \\
1850,35 ., \mathrm{V}, 35 \mathrm{~T}\end{array}$ & 28 & $\begin{array}{c}1 \\
\text { year. }\end{array}$ & B. & $\ldots \ldots$ & $\cdots$ & $\begin{array}{l}\text { The patient was castrated for tu- } \\
\text { mor of the testis. A fungus hema- } \\
\text { todes formed in the wound, and } \\
\text { he died in about a year. His } \\
\text { breasts were beginning to project } \\
\text { like those of a girl at puberty. }\end{array}$ \\
\hline GaLLiet........ & Ibid. & 20 & $\begin{array}{c}5 \\
\text { months. }\end{array}$ & B. & $\ldots \ldots$ & $\cdots$ & $\begin{array}{l}\text { This patient also had a tumor of } \\
\text { the testis, and died two days after } \\
\text { its removal. His breasts in- } \\
\text { creased } 4 \text { cc. in diameter. }\end{array}$ \\
\hline GangItano...... & $\begin{array}{c}\text { Deutsche Zeitschrift für } \\
\text { Chirurgie, Ig09, CIII, I. }\end{array}$ & $\cdots \cdots$ & $\ldots \ldots$ & B. & & & \\
\hline GangItano...... & Ibid. & $\ldots \ldots$ & $\ldots \ldots$ & B. & & & \\
\hline GEORGIEFF...... & $\begin{array}{l}\text { Meditzinski Napredak, 190I, } \\
\text { No. 6-7. Hildebrand's } \\
\text { Jahresbericht für Chirur- } \\
\text { gie, I9oI, } 5 \text { I4. }\end{array}$ & 28 & $\ldots \ldots$ & B. & $\ldots \ldots$ & $\cdots$ & $\begin{array}{l}\text { The man had no beard or mus- } \\
\text { tache. His breasts were like those } \\
\text { of a nursing woman. }\end{array}$ \\
\hline GINSBURG........ & $\begin{array}{c}\text { Phitadelphia Academy of } \\
\text { Surgery, April 5, 1915. }\end{array}$ & 19 & $\begin{array}{c}6 \\
\text { months }\end{array}$ & L. & 0 & $\cdots$ & $\begin{array}{l}\text { Patient was a shoemaker. The } \\
\text { breast was like that of a girl at } \\
\text { puberty. The nipple was large } \\
\text { and surrounded by a faintly pig- } \\
\text { mented areola. He has hypo- } \\
\text { spadia. An uncle had bilateral } \\
\text { enlargement of the breasts. Am- } \\
\text { putation. }\end{array}$ \\
\hline $\begin{array}{l}\text { GoRHAM AND } \\
\text { HARE. }\end{array}$ & $\begin{array}{l}\text { The Lancet, London, } 1840 \text {, } \\
\text { ii, } 637 \text {. London Medical } \\
\text { Gazette, I840, ii, } 659 .\end{array}$ & 57 & $\begin{array}{c}3 \\
\text { weeks. }\end{array}$ & B. & $\ldots \ldots$ & $\cdots$ & $\begin{array}{l}\text { He was a fisherman, shot in the } \\
\text { Queen's service, who suffered } \\
\text { atrophy of the testes and enlarge- } \\
\text { ment of the mammæ to such an } \\
\text { extent that they measured } 8 \\
\text { inches transversely and is inches } \\
\text { vertically. }\end{array}$ \\
\hline Gorringe...... & $\begin{array}{l}\text { Prov. Med. and Surg. Jour., } \\
\text { Lond., 1846, 204. }\end{array}$ & 60 & $\cdots \cdots$ & $\ldots$ & $\ldots \ldots$ & 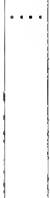 & $\begin{array}{l}\text { This is the famous case of } W \mathrm{~m} . \mathrm{R} \text {, } \\
\text { who was pursued by Don Carlos, } \\
\text { fell into a ditch, hurt his back, } \\
\text { suffered from atrophy of the testis } \\
\text { and gynecomastia. The circum- } \\
\text { ference of the mammæ was I4 } \\
\text { inches, the transverse diameter } \\
7 \text { inches, the vertical diameter } 6 \\
\text { inches. }\end{array}$ \\
\hline GREGORINI....... & $\begin{array}{l}\text { N. Raccoglitore med. Imola., } \\
\text { 1904, iii, 159. }\end{array}$ & & & & & & \\
\hline $\begin{array}{c}\text { GRUBER........ } \\
\cdot\end{array}$ & $\begin{array}{l}\text { Mémoirs de l'acad. imp. des } \\
\text { Sciences de St. Petersburg, } \\
\text { 1866, 7s., X, No. I, p. I. }\end{array}$ & 78 & $\cdots \cdots \cdots$ & B. & $\ldots \ldots$ & $\cdots$ & $\begin{array}{l}\text { The hreasts had a transverse diam- } \\
\text { eter of II.I and } 11.7 \mathrm{~cm} \text {. respect. } \\
\text { ively. They were removed. } \\
\text { Each weighed II } 0.5 \text { grams. }\end{array}$ \\
\hline
\end{tabular}


List of 162 Cases of Gynecomastia Collected from the Literature, and Forming the Basis of the Preceding Critical Studies of the Subject-(Continued)

\begin{tabular}{|c|c|c|c|c|c|c|c|}
\hline Reporter & Reference & Age & Duration & 壳 & Pain & 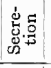 & Remarks \\
\hline HANDYSIDE... & $\begin{array}{l}\text { Jour. of Anat. and Physi- } \\
\text { ology, November, I870. }\end{array}$ & 50 & & B. & & $\cdots$ & \multirow{4}{*}{$\begin{array}{l}\text { These cases are a man and his } \\
\text { three sons, all of whom were } \\
\text { gynecomastics. }\end{array}$} \\
\hline HANDYSIDE ...... & Ibid. & $\ldots \ldots$ & $\cdots \cdots$ & B. & $\ldots \cdots$ & & \\
\hline HANDYSIDE.. & Ibid. & (...... & ......... & B. & $\ldots \ldots$ & & \\
\hline Handyside..... & Ibid. & $\ldots \ldots$ & $\ldots \ldots$ & B. & $\ldots \ldots$ & $\cdots$ & \\
\hline HARGENS......... & $\begin{array}{l}\text { Hufeland's Jour. der prakt. } \\
\text { Arzneikunde und Wundarz- } \\
\text { neikunde, I795, i, No. } 4 \text {. } \\
548 \text {. }\end{array}$ & & & $\cdots$ & ....... & $\cdots$ & Known by citations only. \\
\hline HARGENS...... & 1 bid. & $\cdots \cdots$ & & $\cdots$ & $\ldots \ldots \ldots$ & $\cdots$ & s \\
\hline HASSLER........ & $\begin{array}{l}\text { Archiv. der med. et pharm. } \\
\text { mil., Paris, I894, XXIII, } \\
531 .\end{array}$ & Adult. & $\ldots \ldots$ & L. & & 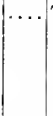 & $\begin{array}{l}\text { The patient had mumps followed } \\
\text { by atrophy of the testes. The } \\
\text { left mamma enlarged as the left } \\
\text { testis atrophied. It was ampu- } \\
\text { tated. }\end{array}$ \\
\hline Hiller... & $\begin{array}{l}\text { Schmidt's Jahrbücher, } 1845 . \\
\text { XLV, p. } 320 .\end{array}$ & Adult. & & B. & & $\cdots$ & $\begin{array}{l}\text { The breasts are } 315 \text { inches in diam- } \\
\text { eter and praject } 112 \text { inches. } \\
\text { They look like those of a young } \\
\text { girl. }\end{array}$ \\
\hline HiLler.... & Ibid. & 17 & ........ & B. & & $\cdots$ & $\begin{array}{l}\text { This is the son of the man whose } \\
\text { case is mentioned above. }\end{array}$ \\
\hline Hoffman........ & Inaugural Dissertation, 1855 . & Adult. & & $\cdots$ & & $\cdots$ & Known through citation only. \\
\hline $\begin{array}{l}\text { HOLLOPEAU ET } \\
\text { FrANCOIS-DAIN- } \\
\text { VILLE. }\end{array}$ & $\begin{array}{l}\text { Bulletin de l'acad. de méd. } \\
\text { de Paris, I9I4, No. II. 3s., } \\
\text { LXXI, 406. }\end{array}$ & 55 & & B. & $\cdots$ & $\cdots$ & $\begin{array}{l}\text { The man suffered from Dercum's } \\
\text { disease, adiposus dolorosa, and } \\
\text { had glands like those of a thin } \\
\text { woman. }\end{array}$ \\
\hline Horteloup...... & $\begin{array}{l}\text { Cited by Olphan, possibly } \\
\text { the same case was reported } \\
\text { by Gaillet. No reference is } \\
\text { given. }\end{array}$ & 20 & & & & & \\
\hline Hunter......... & $\begin{array}{l}\text { "Essays and Observations," } \\
\text { edited by Owen, vol. i, p. } \\
238 .\end{array}$ & & & & & & \\
\hline Hunter......... & Ibid. & & & & & & \\
\hline Hunter.......... & Ibid. & & & & & & \\
\hline Hunter......... & Ibid. & & & & & & \\
\hline Hunter......... & Ibid. & & & & & & \\
\hline Hutchinson..... & $\begin{array}{l}\text { Archives of Surgery, I895, } \\
\text { VI, 155, Plate II8. }\end{array}$ & Adult. & & B. & & 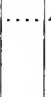 & $\begin{array}{l}\text { A man who applied to the hospital } \\
\text { to have his breasts removed be- } \\
\text { cause their large size made him a } \\
\text { subject of ridicule. }\end{array}$ \\
\hline HuTCHINSON. & Ibid., $189 \mathrm{I}-2$, iii, 327. & Adult. & 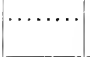 & B. & & $\cdots$ & $\begin{array}{l}\text { An ugly old fat man with breasts } \\
\text { like those of a woman. }\end{array}$ \\
\hline Hutchinson.... & Ibid. & Adult. & $\ldots \ldots$ & B. & & $\cdots$ & $\begin{array}{l}\text { A mentally and genitally defective } \\
\text { acromegalic young man brought } \\
\text { by his mother who said that his } \\
\text { breasts were as large as hers. }\end{array}$ \\
\hline
\end{tabular}


List of i62 Cases of Gynecomastia Collected from the Literature, and Forming the Basis of the Preceding Critical Studies of the Subject-(Continued)

\begin{tabular}{|c|c|c|c|c|c|c|c|}
\hline Reporter & Reference & Age & Duration & 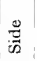 & Pain & 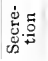 & Remarks \\
\hline HUTCHINSON..... & Ibid., 1889, i, 335 & Adult. & - & B. & & & $\begin{array}{l}\text { A young man who suffered from } \\
\text { a prolonged illness with high } \\
\text { temperature and severe nervous } \\
\text { and physical symptoms, whose } \\
\text { breasts became large and pen- } \\
\text { dulous. }\end{array}$ \\
\hline Hutchinson..... & $\begin{array}{l}\text { Annals of Surgery, London, } \\
1889, \mathrm{i}, 335 .\end{array}$ & 74 & $\cdots$ & B. & $\ldots \ldots$ & $\cdots$ & $\begin{array}{l}\text { An old man with large and pendu- } \\
\text { lous mammary glands like those } \\
\text { of a woman. }\end{array}$ \\
\hline HutchiNsoN.... & Ibid, I892-93, iv, p. 76 & 55 & $\cdots \cdots \cdots$ & B. & $\ldots$. & $\ldots$ & $\begin{array}{l}\text { A soldier with atrophy of one testis } \\
\text { and partial atrophy of the other, } \\
\text { loss of sexual characteristics and } \\
\text { power. Hemiplegic. Large pen- } \\
\text { dulous breasts. }\end{array}$ \\
\hline Hutchinson..... & Ibid., I897, VIII, 75. & 14 & $\begin{array}{c}2 \\
\text { years. }\end{array}$ & $\mathrm{R}$. & & & \\
\hline ISRAEL....... & $\begin{array}{l}\text { Inaugural Dissertation, Ber- } \\
\text { lin, I89.4. }\end{array}$ & 19 & $\begin{array}{l}18 \\
\text { months. }\end{array}$ & $\mathrm{L}$. & + & $\cdots$ & $\begin{array}{l}\text { Removed by surgical opera- } \\
\text { tion. Microscopical examination } \\
\text { showed increase of fibrous tissue } \\
\text { and distinct acinus formation. }\end{array}$ \\
\hline ISRAEL........ & Ibid. & 28 & $\begin{array}{c}3 \\
\text { years. }\end{array}$ & R. & + & $\cdots$ & $\begin{array}{l}\text { Breast was the size of the fist. } \\
\text { Amputated. Microscopically ex- } \\
\text { amined. Showed distinct acinus } \\
\text { formation. }\end{array}$ \\
\hline JANSSEN ........ & $\begin{array}{l}\text { "Boezems bij een soldaat." } \\
\text { Tijdschr.'v. prakt. verlosk. } \\
\text { Haarlem, Ig03, VII, } 250 .\end{array}$ & & & & & & \\
\hline KAMMLER...... & $\begin{array}{l}\text { Inaugural Dissertation, Bres- } \\
\text { lau, } 1906 .\end{array}$ & 23 & $\cdots \cdots \cdots$ & L. & + & $\cdots$ & $\begin{array}{l}\text { The enlargement of the left breast } \\
\text { attributed to the effect of his } \\
\text { occupation as a shoemaker. It } \\
\text { was as large as a fist. Genitals } \\
\text { normal. Surgically removed. }\end{array}$ \\
\hline KOCHENBERGER.. & $\begin{array}{l}\text { Zeitschritt für Geburtshülfe } \\
\text { und Gynākologie, I893. } \\
\text { XXVI, 73. (Cited by Wil- } \\
\text { liams. "Diseases of the } \\
\text { Breast," p. III.) }\end{array}$ & 33 & $\ldots \ldots$ & B. & $\ldots \ldots$ & $\cdots$ & $\begin{array}{l}\text { A female pseudo-hermaphrodite } \\
\text { that had been married, supposing } \\
\text { himself a woman on account of } \\
\text { the female mammæ, etc. }\end{array}$ \\
\hline Köster.......... & $\begin{array}{l}\text { Mūnchener med. Wochen- } \\
\text { schrift, I905, LII, } 725 \text {. }\end{array}$ & 16 & $\ldots \ldots \ldots$ & L. & $\ldots \ldots$ & 0 & $\begin{array}{l}\text { The left breast is like that of a girl. } \\
\text { The sexual organs were normal. }\end{array}$ \\
\hline KRIEG . . . . . . . & $\begin{array}{l}\text { Med. Correspondenzblatt } \\
\text { der Wurttemberger Aerzte, } \\
\text { Stuttgart, 1877, XLVII, 75. }\end{array}$ & & & & & & \\
\hline KRIEGER ...... & $\begin{array}{l}\text { London Medical Record, } \\
\text { I879, p. } 404 .\end{array}$ & $\begin{array}{c}7 \\
\text { years. }\end{array}$ & $\cdots \cdots$ & B. & $\ldots \ldots$ & + & $\begin{array}{l}\text { The breasts were like those of a } \\
\text { well-developed girl at puberty } \\
\text { and secreted a milky fluid micro- } \\
\text { scopically like colostrum. }\end{array}$ \\
\hline LABBÉ.. & $\begin{array}{l}\text { Gazette des Hôpitaux, I87o, } \\
\text { p. } 46 .\end{array}$ & 22 & $\ldots \ldots \ldots$ & R. & & + & $\begin{array}{l}\text { Suffered from a severe contusion of } \\
\text { the right shoulder and side of } \\
\text { chest. The right breast was like } \\
\text { a "bean" when he was five years } \\
\text { old, but it has now grown to the } \\
\text { size of a hen's egg. }\end{array}$ \\
\hline
\end{tabular}


List of i62 Cases of Gynecomastia Collected from the Literature, and Forming the Basis of the Preceding Critical Studies of the Subject-(Continued)

\begin{tabular}{|c|c|c|c|c|c|c|c|}
\hline Reporter & Reference & Age & Duration & $\stackrel{\oplus}{\mathscr{L}}$ & Pain & 总点 & Remarks \\
\hline LACASSAGNE..... & $\begin{array}{l}\text { Gazette hebdomadaire Paris, } \\
1877 \text {. }\end{array}$ & 22 & $\begin{array}{c}7 \\
\text { years. }\end{array}$ & B. & $\ldots \ldots$ & . & $\begin{array}{l}\text { Traumatic injury to the testes fol- } \\
\text { lowed by enlargement, then atro- } \\
\text { phy. The breasts are as large as } \\
\text { large oranges, and are firm like } \\
\text { those of a well-developed woman. } \\
\text { Brown areolæ surround the nip- } \\
\text { ples. }\end{array}$ \\
\hline LAURENT. . . . & $\begin{array}{l}\text { "Les Bisexués-Gynécomas- } \\
\text { ties et Hermaphrodites," } \\
\text { Paris, } 1894 .\end{array}$ & $\ldots \ldots$ & $\ldots \ldots \ldots$ & B. & $\ldots \ldots$ & $\cdots$ & $\begin{array}{l}\text { Five cases seen in the prisons of } \\
\text { Paris. They may be the same as } \\
\text { the following. }\end{array}$ \\
\hline LAURENT. . . . . & $\begin{array}{l}\text { Ann, d'hygiene, Paris, I890, } \\
\text { 3s., XXIV, p. } 43 \text {. }\end{array}$ & Adult. & $\ldots \ldots$ & B. & $\ldots \ldots$ & $\cdots$ & $\begin{array}{l}\text { This paper deals with heredity in } \\
\text { gynecomastia and describes six } \\
\text { cases. The first case was a man, } \\
\text { two of whose sons were mentally } \\
\text { defective and gynecomastic. }\end{array}$ \\
\hline LAURENT. . . . . . & Ibid. & $\ldots \ldots$ & $\ldots \ldots$ & B. & $\ldots \ldots$ & $\cdots$ & $\begin{array}{l}\text { This patient had some atrophy of } \\
\text { the testes. }\end{array}$ \\
\hline LAURENT $\ldots \ldots \ldots$ & Ibid. & 28 & $\begin{array}{c}13 \\
\text { years. }\end{array}$ & B. & $\ldots \ldots$ & $|\cdots|$ & $\begin{array}{l}\text { The breasts were the size of a fotal } \\
\text { head-circumference } 30 \mathrm{~cm} \text {.; dia- } \\
\text { meter r } 3 \mathrm{~cm} \text {. He was sexually } \\
\text { defective. }\end{array}$ \\
\hline LAURENT. . . . . & Ibid. & 20 & $\ldots \ldots \ldots$ & B. & $\ldots \ldots$ & $\cdots$ & $\begin{array}{l}\text { The breasts were as large as half } \\
\text { oranges. He had some cexual ab- } \\
\text { normality. }\end{array}$ \\
\hline LAURENT. . . . . & Ibid. & 26 & $\ldots \ldots \ldots$ & B. & $\ldots \ldots$ & $\cdots$ & $\begin{array}{l}\text { The breasts were as large as half } \\
\text { oranges. There was some sexual } \\
\text { abnormality. }\end{array}$ \\
\hline LAURENT . . . . . . & Ibid. & 35 & $\ldots \ldots \cdots$ & B. & $\cdots \ldots$ & $\cdots$ & $\begin{array}{l}\text { The breasts were as large as half } \\
\text { oranges. There was some sexual } \\
\text { abnormality. }\end{array}$ \\
\hline LeMtBert....... & $\begin{array}{l}\text { Thèse de Paris, 1878; Gaz. } \\
\text { bebdomadaire, Sept. 14. } \\
\text { 1877. }\end{array}$ & 28 & $\ldots \ldots$ & B. & $\cdots \cdots$ & $\cdots$ & $\begin{array}{l}\text { Atrophy of the testes. Hemispher- } \\
\text { ical mammz of good size. }\end{array}$ \\
\hline LEMBERT........ & $\begin{array}{l}\text { Ibid. (Tbis may be the same } \\
\text { case as that reported by } \\
\text { Robelin.) }\end{array}$ & 26 & $\begin{array}{c}\text { Io } \\
\text { years. }\end{array}$ & B. & $\ldots \ldots$ & + & $\begin{array}{l}\text { Has rudimentary genitals. Breasts } \\
\text { like those of a woman. }\end{array}$ \\
\hline LEON.......... & $\begin{array}{l}\text { Archiv de med. navale, } \\
\text { Paris, I879, XXXI, } 2 \mathrm{I}_{3} \text {. }\end{array}$ & 26 & $\ldots \ldots$ & L. & $\ldots \ldots$ & $\cdots$ & $\begin{array}{l}\text { The enlargement of the breast fol- } \\
\text { lowed a blow. The diameter of } \\
\text { the breast was ro } \mathrm{cm} \text {., and it } \\
\text { projected } 7 \mathrm{~cm} \text {. }\end{array}$ \\
\hline LEREBOULLET.... & $\begin{array}{l}\text { Gaz. hebd. de méd. et de } \\
\text { chirurgie, } 1877, \text { p. } 533 \text {. }\end{array}$ & 22 & $\ldots \ldots$ & B. & $\ldots \ldots$ & $\cdots$ & $\begin{array}{l}\text { Has complete atrophy of both tes- } \\
\text { tes following the mumps. The } \\
\text { breasts formerly normal are now } \\
\text { like those of a woman. }\end{array}$ \\
\hline LEXER........ & $\begin{array}{l}\text { Allgemeine Cbirurgie, rgro, } \\
\text { ii, } 228 \text {. }\end{array}$ & 18 & $\ldots \ldots$ & R. & & & \\
\hline LIEBER....... & $\begin{array}{l}\text { Cited without reference by } \\
\text { Hartung. }\end{array}$ & 40 & $\ldots \ldots$ & B. & $\ldots \ldots$ & $\cdots$ & $\begin{array}{l}\text { This patient was sexually under- } \\
\text { developed and higbly feminine in } \\
\text { appearance. }\end{array}$ \\
\hline LuKE. ......... & $\begin{array}{l}\text { Medical Times and Gazette, } \\
\text { London, I860, Jan, 7, I. p. } \\
\text { II. }\end{array}$ & 13 & $\begin{array}{c}6 \\
\text { months. }\end{array}$ & R. & 0 & $\cdots$ & $\begin{array}{l}\text { The boy is sexually undeveloped. } \\
\text { His right breast is the size of a } \\
\text { child's fist. }\end{array}$ \\
\hline
\end{tabular}


List of I $_{2}$ Cases of Gyneconastia Collected from the Literature, and Forming the Basis of the Preceding Critical Studies of the Subject.-(Continued)

\begin{tabular}{|c|c|c|c|c|c|c|c|}
\hline Reporter & Reference & Age & Duration & 苋 & Pain & 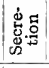 & Remarks \\
\hline McCoxisell. & $\begin{array}{l}\text { Personal communication to } \\
\text { the authors. }\end{array}$ & 17 & & $\mathrm{R}$. & & & $\begin{array}{l}\text { An applicant for admission to the } \\
\text { U. S. Marine Corps. The breast } \\
\text { was like that of a girl of the same } \\
\text { age. No genital defects. }\end{array}$ \\
\hline Martel. & $\begin{array}{l}\text { Archiv. de méd. navale, } \\
\text { Paris, 1893, LX, I52. }\end{array}$ & 23 & $\begin{array}{l}15 \\
\text { days. }\end{array}$ & L. & + & + & $\begin{array}{l}\text { Left breast always larger than the } \\
\text { right. Has had varicocele for a } \\
\text { long time on the right side and } \\
\text { the right testis is atrophied. }\end{array}$ \\
\hline MoIzard... & $\begin{array}{l}\text { Thèse de Paris, I88I, No. } \\
414 .\end{array}$ & & & . & & & $\begin{array}{l}\text { Known by citations in other writ- } \\
\text { ings only. }\end{array}$ \\
\hline MONTGOMERY... & $\begin{array}{l}\text { "Signs and Symptoms of } \\
\text { Pregnancy," p. 125. }\end{array}$ & +5 & & B. & & .. & $\begin{array}{l}\text { Had well-developed genitalia and } \\
\text { breasis like those of a woman. }\end{array}$ \\
\hline Morgax....... & Lancet, London, $1875, \mathrm{ii}, 767$, & $2 \mathrm{I}$ & $\begin{array}{c}5,5 \\
\text { years. }\end{array}$ & R. & .... & o & $\begin{array}{l}\text { External genitalia were normal } \\
\text { andfully developed. Breasts were } \\
\text { like those of a grown woman. }\end{array}$ \\
\hline MuRRAY......... & $\begin{array}{l}\text { Article on "The Breast," by } \\
\text { Finney in Keen's "Str. } \\
\text { 'gery," vol. iii, 611, Fig. } 347 .\end{array}$ & $17 ?$ & $\cdots \cdots \cdots$ & B. & & . & $\begin{array}{l}\text { The breasts are like those of a girl } \\
\text { at puberty. There is an illustra- } \\
\text { tion. but there is no description } \\
\text { in the text. }\end{array}$ \\
\hline Nelatox....... & $\begin{array}{l}\text { Gaz. des Hôpitaux, I856. } \\
\text { XXIX, p. 126. }\end{array}$ & 23 & $\ldots \ldots \ldots$ & L. & + & + & $\begin{array}{l}\text { This was a case of "irritable mam- } \\
\text { mary gland." It was very pain- } \\
\text { ful. }\end{array}$ \\
\hline NEUGEBAUER.... & $\begin{array}{l}\text { "Hermaphroditism beim } \\
\text { Mlenschen." }\end{array}$ & $\cdots$ & & .. & & & $\begin{array}{l}\text { Many cases of female pseudo-her- } \\
\text { maphrodites twith large female } \\
\text { mammæ are described. }\end{array}$ \\
\hline Ozphax........ & $\begin{array}{l}\text { Thèse de Paris, I880, No. } \\
\text { I59. }\end{array}$ & 15 & I8 & L. & o & $\cdots$ & $\begin{array}{l}\text { Breast the size of half an orange. } \\
\text { Genitalia normal. }\end{array}$ \\
\hline Olphax......... & Ibid. & 26 & $\begin{array}{c}\text { I I } \\
\text { years. }\end{array}$ & L. & .. & . . & $\begin{array}{l}\text { The genitalia were normal and he } \\
\text { was suffering from gonorrhœa. }\end{array}$ \\
\hline OtPHAS........ & Ibid. & 17 & $\begin{array}{c}8 \\
\text { months. }\end{array}$ & B. & o & a & Each breast is the size of at orange. \\
\hline PaUlickr..... & $\begin{array}{l}\text { Deutsche militārārztliche } \\
\text { Zeitschrift, I882, p. } 222 .\end{array}$ & $\ldots \ldots$ & & B. & . & . & Pooriy developed sexually. \\
\hline PaUlicky....... & Ibid. & $\cdots \cdots$ & $\cdots \cdots$ & $\mathrm{L}$. & & . . & Normal sexual organs. \\
\hline PeReLzWEIG... & $\begin{array}{l}\text { Med. Oborzr. Mosk., } 1890, \\
\text { XXXII, 6az. }\end{array}$ & I8 & & B. & & & \\
\hline Peters. . & $\begin{array}{l}\text { American Medical Times, } \\
\text { X. Y., I863. VI, } 196 .\end{array}$ & & $\begin{array}{c}3 \\
\text { months. }\end{array}$ & $\mathrm{L}$. & + & o & $\begin{array}{l}\text { Three years ago contused left } \\
\text { shoulder and side of chest. The } \\
\text { left breast subsequently became } \\
\text { large and pendulous. }\end{array}$ \\
\hline Petrequin.. & $\begin{array}{l}\text { Gazette médicale, Paris } \\
\text { 1837, No. } 42 .\end{array}$ & 45 & & B. & & & $\begin{array}{l}\text { The breasts were enormous and } \\
\text { pendulous, and hung down like } \\
\text { bottles } 13 \text { and is inches. He was } \\
\text { a strong healthy man without } \\
\text { sexuat abnormality. They were } \\
\text { amputated. }\end{array}$ \\
\hline Pflaiz.. & $\begin{array}{l}\text { Centralbl. f. Gynābologie. } \\
\text { I902, XXVI, p. } 42 .\end{array}$ & 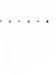 & & B. & & & $\begin{array}{l}\text { The mother and sister of this inan } \\
\text { both suffered from hypertrophy } \\
\text { of the breasts. }\end{array}$ \\
\hline
\end{tabular}


List of i62 Cases of Gynecomastia Collected from the Literature, and Forming the Basis of the Preceding Critical Studies of the Subject-(Continued)

\begin{tabular}{|c|c|c|c|c|c|c|c|}
\hline Reporter & Reference & Age & Duration & $\stackrel{\mathscr{N}}{\mathscr{n}}$ & Pain & 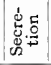 & Remarks \\
\hline Polaillon... & $\begin{array}{l}\text { Bull. de l'acad. de méd, de } \\
\text { Paris, I89I, XXV, 557. }\end{array}$ & 27 & $\cdots \cdots \cdots$ & B. & $\cdots \cdots$ & $\cdots$ & $\begin{array}{l}\text { A pseudo-hermaphrodite, passing } \\
\text { for a woman. }\end{array}$ \\
\hline RAGGI........ & $\begin{array}{l}\text { Ann. univ. de med, e chir. } \\
\text { Milano, I882, CLIX, } z 89 . \\
\text { Vide Schmidt's Jahrbücher, } \\
\text { I883, p. } 53 \text {. }\end{array}$ & 25 & $\ldots \ldots$ & B. & $\cdots \cdots \cdots$ & + & $\begin{array}{l}\text { This patient had delusional in- } \\
\text { sanity and at one time believed } \\
\text { himself to be a woman. }\end{array}$ \\
\hline RAYER. & $\begin{array}{l}\text { Vide "Anatomie" de Cru- } \\
\text { veilhier, p. 5r I. (Cited by } \\
\text { Olphan,) }\end{array}$ & & - & & & & \\
\hline RENAULDIN..... & $\begin{array}{l}\text { Article "Mamelle" by Mu- } \\
\text { rat et Patissier in the Dict. } \\
\text { des sciences médicale, Paris, } \\
\text { I } 8 \text { I } 8 \text {, XX, } 378 \text {. Original } \\
\text {--Mem. Soc, med, d'émnla- } \\
\text { tion. de Paris, I796-7, V. } \\
397 .\end{array}$ & 24 & $\ldots \ldots$ & B. & $\cdots \cdots \cdots$ & $\cdots$ & $\begin{array}{l}\text { Sexually imperfect, with breasts } \\
\text { like those of a woman. }\end{array}$ \\
\hline RICHTER........ & $\begin{array}{l}\text { Međ. u. chir. Beobachtungen, } \\
\text { Gottingen, I793, I, I3. }\end{array}$ & . & & $\cdots$ & $\ldots \ldots$ & $\cdots$ & $\begin{array}{l}\text { Known through citations by other } \\
\text { authors. }\end{array}$ \\
\hline ROBELIN........ & Thèse de Paris, I852, p. 32 . & & $\ldots \ldots$ & $\cdots$ & $\ldots \ldots$ & $\cdots$ & Cited by Velpean. \\
\hline SACASA........ & Thèse de Paris, $1867 \ldots . .$. & $\ldots \ldots$ & $\ldots \ldots$ & L. & $\ldots \ldots$ & + & $\begin{array}{l}\text { Only one testis had descended. } \\
\text { The breast was as large as that of } \\
\text { a nursing woman, and secreted } \\
\text { milk abundantly. }\end{array}$ \\
\hline SAILER . . . . . & $\begin{array}{l}\text { Personal communication to } \\
\text { the authors. }\end{array}$ & Adult. & $\ldots \ldots \ldots$ & B. & o & o & $\begin{array}{l}\text { The patient was a middle-aged } \\
\text { man with symmetrical mammary } \\
\text { lipomas and symmetrical supra- } \\
\text { pubic lipomas. His breasts were } \\
\text { large and like those of a moder- } \\
\text { ately well-developed woman, the } \\
\text { lipomas being situated in the } \\
\text { upper onter quadrant of each. }\end{array}$ \\
\hline SAVITZKY ( 4 cases) & $\begin{array}{l}\text { St. Louis Med. and Surg. } \\
\text { Journal, February, I894. }\end{array}$ & $2 \mathrm{I}$ & $\cdots \cdots$ & B. & $\ldots \ldots$ & $\cdots$ & $\begin{array}{l}\text { The father, brother and cousin of } \\
\text { this man were all gynecomasts. } \\
\text { His sexual organs were normal, } \\
\text { his breasts like those of a large } \\
\text { woman. }\end{array}$ \\
\hline Schauman..... & $\begin{array}{l}\text { Verhandl. đ. phys.-med. } \\
\text { Gesellschaft zu Wúrzburg, } \\
189+-5, \text { n.f., XXVIII, I. }\end{array}$ & 19 & $\begin{array}{c}3 \\
\text { years. }\end{array}$ & B. & + & + & Sexually imperfect. \\
\hline SCHEIBER....... & $\begin{array}{l}\text { Med. Jahrbücher. Wien, } \\
\text { I875, p. } 26 \mathrm{I} .\end{array}$ & 45 & $\ldots \ldots$ & B. & & $\ldots$ & Sexwally imperfect. \\
\hline Schmirt........ & $\begin{array}{l}\text { Cong. franç. di chir., etc., } \\
\text { Paris, I892, VI, } 284 .\end{array}$ & 20 & $\ldots \ldots$ & R. & $\ldots \ldots$ & + & $\begin{array}{l}\text { There was atrophy of the right } \\
\text { testis. The breast was the size of } \\
\text { a hen's egg. }\end{array}$ \\
\hline SchịitTt........ & $\begin{array}{l}\text { Rec. de mém. de méd. mil., } \\
\text { Paris, 1881, 3s., XXXVIII, } \\
690 .\end{array}$ & & & . & & & \\
\hline Schmitт. & lbid. & & & & & & \\
\hline
\end{tabular}


List of i62 Cases of Gynecomastia Collected from the Literature, and Forming the Basis of the Preceding Critical Studies of the Subject-(Continued)

\begin{tabular}{|c|c|c|c|c|c|c|c|}
\hline Reporter & Reference & Age & Duration & $\stackrel{\vec{U}}{\ddot{D}}$ & Pain & 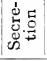 & Remarks \\
\hline SCHUCHARDT. . & $\begin{array}{l}\text { Archiv f, Klin. Chirurgie, } \\
\text { Berlin, I885, XXXI, } 59 .\end{array}$ & $\cdots \cdots$ & $\cdots \cdots$ & $\cdots$ & $\cdots \cdots$ & & $\begin{array}{l}\text { A long collection of cases with pro- } \\
\text { tocols, but no new ones of his own. } \\
\text { Perhaps the best synoptical } \\
\text { paper on the subject. }\end{array}$ \\
\hline SCHUFEIDT. . . . & $\begin{array}{l}\text { Medical Council, Phila., } \\
\text { I9I0, XV, 244. }\end{array}$ & 40 & $\cdots \cdots$ & B. & $\cdots$ & + & $\begin{array}{l}\text { This case was the Zulu chief Cheng- } \\
\text { wayo, who had } 40 \text { wives and over } \\
\text { Ioo children, many of whom he } \\
\text { nursed at his own breasts. }\end{array}$ \\
\hline Somirer. . . . . . & $\begin{array}{l}\text { Münchener med. Wochen- } \\
\text { schrift, I904, LI, 1;88. }\end{array}$ & I5 & & B. & + & o & $\begin{array}{l}\text { About the nipples there was a pig- } \\
\text { mented areola. }\end{array}$ \\
\hline StIEDA. . . . . . & $\begin{array}{l}\text { Beitrāge zur klin. Chirurgie, } \\
\text { 1895, XIV, I79. }\end{array}$ & 23 & $\cdots \ldots$ & L. & + & $\cdots$ & $\begin{array}{l}\text { The breast was as large as a man's } \\
\text { fist. It was amputated. Mlicro- } \\
\text { scopically examined, it was pro- } \\
\text { nounced hypertrophy. }\end{array}$ \\
\hline GTIEDA $\ldots \ldots \ldots$ & Ibid. & 23 & & B. & & & $\begin{array}{l}\text { The breasts were like those of a } \\
\text { female virgin. They were ampu- } \\
\text { tated when examined microscop- } \\
\text { ically, the condition was called } \\
\text { hypertrophy. }\end{array}$ \\
\hline TATCHELL....... & $\begin{array}{l}\text { New York Medical Journal, } \\
\text { February 19, I9I0, XCI, } \\
388 .\end{array}$ & 20 & $\begin{array}{c}4-5 \\
\text { years. }\end{array}$ & R. & o & $\cdots$ & $\begin{array}{l}\text { This patient was a Chinaman. } \\
\text { The nipple was large and sur- } \\
\text { rounded by a pigmented areola. } \\
\text { The breast was amputated. }\end{array}$ \\
\hline Thomson....... & Lancet, $1837, \mathrm{i}, 356$. & $\cdots \cdots$ & $\ldots \ldots$ & B. & $\cdots \cdots$ & $\cdots$ & $\begin{array}{l}\text { The enlargement of the breast fol- } \\
\text { lowed atrophy of the testes } \\
\text { brought on by an injury to the } \\
\text { back. }\end{array}$ \\
\hline TUFNELL. . . . . & $\begin{array}{l}\text { Dublin Quarterly Jour. Med. } \\
\text { and Surg., I855, XIX, 230. }\end{array}$ & $2 \mathrm{I}$ & $\ldots \ldots$ & L. & $\cdots \cdots$ & $\cdots$ & $\begin{array}{l}\text { There is no sexual abnormality. } \\
\text { The breast is like that of a girl at } \\
\text { puberty. }\end{array}$ \\
\hline VILLENEUTE..... & $\begin{array}{l}\text { Fournier's article "Gynéco- } \\
\text { mastie" in the Dict. des } \\
\text { sciences médicale, Paris, } \\
\text { I8I7, XIX, 5I9. }\end{array}$ & $\mathrm{I}_{7}$ & $\cdots \cdots \cdots$ & B. & $\ldots \ldots$ & $\cdots$ & $\begin{array}{l}\text { The breasts resembled those of a } \\
\text { young girl. }\end{array}$ \\
\hline Villeneure..... & Ibidem. & 60 & $\ldots \ldots$ & B. & + & $\cdots$ & $\begin{array}{l}\text { The breasts have been enlarged } \\
\text { since his youth. He is married } \\
\text { and is the father of a family. }\end{array}$ \\
\hline WAGNER ....... & $\begin{array}{l}\text { Schmidt's Jahrbücher, I8.42, } \\
\text { iii, supplementary volume, } \\
\text { p. } 66 \text {; Virchow's Archiv, } \\
\text { 1886. }\end{array}$ & $2 I$ & $\stackrel{4}{y e a r s .}$ & R. & o & + & $\begin{array}{l}\text { The enlargement of the breast fol- } \\
\text { lowed traumatic injury by a rope. } \\
\text { The genitals are rell-formed. }\end{array}$ \\
\hline WARREN.$\ldots \ldots$ & $\begin{array}{l}\text { International Textbook of } \\
\text { Surgery, ii, p. 27I, Fig. } 15 \text { I. }\end{array}$ & Adult. & $\ldots \ldots$ & R. & & & \\
\hline Weber......... & $\begin{array}{l}\text { Zeitschrift des deutschen } \\
\text { chirurgen Vereins f. Med. } \\
\text { Chir. u, Geburtshülfe, von } \\
\text { Vosges, 1852, v, 336. }\end{array}$ & 22 & & B. & & + & $\begin{array}{l}\text { A soldier with imperfect sexual } \\
\text { organs and breasts like those of a } \\
\text { woman. }\end{array}$ \\
\hline WILLIAMS....... & $\begin{array}{l}\text { "Diseases of the Breast," } \\
1894 . \text { p. } 108 .\end{array}$ & I3 & $\begin{array}{c}6 \\
\text { months. }\end{array}$ & R. & & $\cdots$ & $\begin{array}{l}\text { The breast was the size of the fist. } \\
\text { The boy showed no signs of } \\
\text { puberty. }\end{array}$ \\
\hline
\end{tabular}


List of r62 Cases of Gynecomastia Collected from the Literature, and Forming the Basis of the Preceding Critical Studies of the Subject-(Concluded)

\begin{tabular}{|c|c|c|c|c|c|c|c|}
\hline Reporter & Reference & Age & Duration & 苑 & Pain & 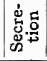 & Remarks \\
\hline Williams.... & Ibid. & 50 & & B. & + & & $\begin{array}{l}\text { Both breasts have been large since } \\
\text { youth. There are painful nodules, } \\
\text { thought to be gouty, in the right. } \\
\text { Similar nodules formerly were } \\
\text { present in the left but disap- } \\
\text { peared. }\end{array}$ \\
\hline Wiltshire.. & $\begin{array}{l}\text { British Medical Journal, } \\
\text { 1884, p. } 645 .\end{array}$ & Adult. & & B. & & + & $\begin{array}{l}\text { An elderly gentleman and eminent } \\
\text { naturalist with large breasts that } \\
\text { became active and secreted milk } \\
\text { for about six weeks each spring. }\end{array}$ \\
\hline Wyeth. & $\begin{array}{l}\text { Annals of Surgery, } 1894, \\
\text { XIX. }\end{array}$ & $I_{4}$ & & L. & & .. & $\begin{array}{l}\text { Normal genitals. Breast like that } \\
\text { of a I5-year-old girl. Amputated. } \\
\text { Examined microscopically and } \\
\text { called hypertrophy. }\end{array}$ \\
\hline$Z_{\text {ELENEFF }} \ldots$ & $\begin{array}{l}\text { Russk. J. Kozlen i yen Bo- } \\
\text { hiezn., Mosk., IgI 2, XXIII, } \\
230 .\end{array}$ & I8 & & L. & & .. & $\begin{array}{l}\text { Known by the title only "Dextro- } \\
\text { lateral castration with hyper- } \\
\text { trophy of the left breast in a } \\
\text { youth } 18 \text { years of age." }\end{array}$ \\
\hline 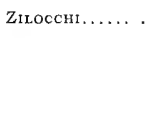 & $\begin{array}{l}\text { I1 Morgagni., Milano, I912, } \\
\text { LXXX, p. I7 I. }\end{array}$ & 34 & $\ldots$ & B & 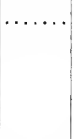 & 0 & $\begin{array}{l}\text { The patient was an insane man } \\
\text { who died in an asylum. His } \\
\text { breasts weighed } 52 \text { and } 53 \text { grams } \\
\text { respectively. Studied micro- } \\
\text { scopically they were called hyper- } \\
\text { trophy. }\end{array}$ \\
\hline$?$ & $\begin{array}{c}\text { Nouv. Bibl. med., 1818, p. } \\
420 . \text { (Cited by Olphan.) }\end{array}$ & Adult. & & B. & & & $\begin{array}{l}\text { An inmate of the St. Lonis Hospi- } \\
\text { tal in Paris, witb breasts nearly } \\
\text { like those of a woman. }\end{array}$ \\
\hline
\end{tabular}

\section{ATROPHY OF THE MAMMARY GLANDS}

The most common form of atrophy of the mammary glands is that already described in a former section of this work under the names Physiological and Senile InvoluTION. The former follows lactation and restores the gland to its normal size; the latter occurs in women whose organs are no longer functionally useful because they have passed the period of fecundity.

Apart from these, atrophic conditions are rare. Altmann (Archiv für path. Anatomie und Physiologie, I888, cxi, 318 ) has written a lengthy paper to show that it is possible for familial and provincial hereditary atrophy of the mammary glands to take place in consequence of habitual disuse of the organs. The theory is based upon the supposition that when a woman does not nurse her children, and brings about immediate involution of the mammæ, they undergo an excessive involution that results in loss of secreting tissue, the condition being transmitted to her daughters, who following the same custom, have a greater loss of secreting tissue to transmit to their daughters, until eventually the power of lactation is so far diminished that they become incapable of nourishing their offspring. He exemplifies the theory by citing the cases of the women of Upper Bavaria and Swabia, who, according to the researches of T. Escherich (Münchener med. Wochenschrift, I887, Nos. I3, I4, I8, I9, 36 and 38) and of Fritz Biller (Inaugural Dissertation, “Die Ursachen und Folgen des Nichtstillens bei der Bevölkerung 
Münchens," I888; Jahrbuch für Kinderheilkunde, I888), are largely incapable of lactation.

The theory is defective from the academic point of view in that it is based upon the supposed transmission of an acquired character. It would seem more probable that the true explanation would be found in the widely disseminated inheritance of a functional defect that had appeared spontaneously in the ancestral stock and made the milk secretion so inadequate in both ancestor and descendents that the attempt to nurse the offspring at the breast had come to be regarded as not worth while.

That some women have a remarkably deficient milk supply, and suffer from excessive involution with atrophy of the glands is shown by the cases cited under our consideration of the physiology of the mammary gland as agalactia (q.v.), as well as by the interesting case cited by Reynolds (Lancet, London, i, i884, p. $83 \mathrm{I}$ ).

The patient was a woman aged $2 \mathrm{r}$ years who was able to suckle her first child for a few weeks only. Compelled to cease, both breasts underwent such excessive involution that they almost entirely disappeared and not a vestige of them could be felt. Yet, when she became pregnant again, they enlarged to a fair size and gave milk, but as she neglected to suckle, the glands soon wasted away as before . . . and so after each pregnancy. Now, at 50 years of age, her chest is as smooth as that of any young girl.

In such cases it is easy to understand that all thought of nursing the baby would be abandoned after one or two abortive attempts. It is also not improbable that the condition might appear in female descendents, all of whom would similarly be obliged to abandon lactation.

It is said that atrophy of the mammary gland may follow the local application of certain medicaments, such a condition having followed the use of iodine in the experience of Drummond (Quarterly Journal of the Calcutta Medical and Physical Society, r843, i, 25).

Far more frequent, though naturally less important is local atrophy of the mammary gland. It results from the pressure of tumors (benign tumors) and cysts in the substance of the organ, and may vary from a moderate loss of substance, to the almost complete disappearance of the glandular tissue when the tumor is very large and the pressure exerted upon it excessive.

Some atrophy of the mammary tissue was also observed by Gruber (Münchener med. Wochenschrift, I9II, LVIII, 2328) in the remarkable case of mammary infarction that he observed to follow thrombosis of the mammary veins.

The body of this patient, aged 42 years, a scrub-woman, when examined at autopsy, showed a remarkable thrombosis of the veins extending from the right mamma to the axilla. The mamma itself was swollen and edematous, and contained numerous tiny and larger hemorrhagic points, especially in the outer quadrants. The glandular tissue was whitish in color and very firm. The microscope showed parenchymatous atrophy. The patient died of heart disease and had extensive venous thrombosis elsewhere. 


\section{CHAPTER V}

\section{WOUNDS AND INJURIES OF THE BREAST}

Contusions of the Breast are of frequent occurrence, are rarely serious so far as the immediate results are concerned, and are promptly recovered from, as a rule.

Injuries of this type are often associated with severe pain, and, depending upon the intensity and nature of the trauma; are followed either by simple ecchymosis or by hematomas.

Hematomas of the breast frequently become infected whereupon the condition becomes essentially the same, so far as its pathological features are concerned, as pyogenic mastitis of the puerperal period; the tendency to widespread involvement of the breast, however, which is a characteristic feature of many cases of puerperal mastitis, is absent in the traumatic types.

In the absence of complicating infection, mammary hematomas are absorbed in large part, a process that is hastened by the application of cold compresses and a tightly applied bandage.

Probably in every instance a variable amount of parenchymal tissue is destroyed, and at least a portion of the blood clot becomes organized into fibrous connective tissue, thus constituting one variety of chronic interstitial mastitis.

When the lactating breast suffers a severe contusion, one or more of the milk ducts may be injured and ultimately slough with the formation of a lactic fistula or fistulas. The latter are more likely to follow stab wounds than simple contusions, while the likelihood of their formation is always increased by complicating infection. With the arrest of lactation the discharge of milk will stop and the natural tendency of the fistulas is to close.

Frequently repeated, mild contusions may give rise to chronic mastitis and in our opinion predispose to carcinoma. More intense injuries are likely to be followed by sarcoma.

Incised and lacerated wounds of the breast heal promptly if infection does not occur. In closing such wounds it is advisable to insert a small drain. The hemorrhage following these wounds is rarely alarming unless they are deep and in the upper outer quadrant of the breast, when the long thoracic artery may be severed.

An interesting sequence of events attended the case of a woman and her child who came under our observation a few years ago. The child, a little girl of five years, was bitten on the cheek by a dog; the mother in attempting to protect the child had been bitten on the right breast.

The fangs of the animal tore through the breast tissues producing several ragged although comparatively superficial lacerations; the wounds in the case of the child were of the puncture type.

All of the wounds, with the possible exception of one that had perforated the lower left eyelid of the child, were cauterized with pure carbolic acid, notwithstanding which the child developed a fatal case of rabies; the mother was given the Pasteur treatment and recovered. 
These patients were first treated in the out-patient department of the German Hospital of Philadelphia; for the subsequent histories we are indebted to Dr. Bernard Mencke who attended them in consultation.

Stab wounds, puncture wounds, and gunshot wounds are not remarkable so far as the breast itself is concerned, but the likelihood of injury to the internal mammary aretry, the intercostal arteries and the intra-thoracic viscera must be borne in mind.

The intercostal vessels are rarely if ever injured unless a rib be fractured. The internal mammary artery has been repeatedly injured in stab and other penetrating wounds of the chest ( 52 cases reported by Zott), with the production of hemothorax or aneurism of the traumatic type. Exhaustive studies of injuries of this type have been made by Desgoutte and Lambert and by Vialle and Braun.

In cases where a reasonable doubt exists as to the presence or absence of injury to the artery it is advisable to explore the chest at the point of entrance of the penetrating object.

An abscess may follow a therapeutic puncture wound of the retro-mammary space in the operation of hypodermoclysis as happened in one of our cases. The patient, a woman aged 55 years, was admitted to the German Hospital of Philadelphia, 4-I4-I3. She had been operated on at another hospital for intestinal stasis, five months before the present admission. After the first operation a sub-mammary injection of saline solution had been given and an abscess followed in the retro-mammary space. This abscess had been incised promptly but a sinus persisted for the relief of which she entered the German Hospital. The sinus was found to lead into an abscess cavity which extended upward and outward from the lower inner quadrant of the breast to the anterior axillary line. Tuberculosis was suspected but examination of the thin pus that came from the sinus was negative except for the presence of a large Grampositive spore-bearing bacillus. The von Pirquet test was likewise negative; the general condition of the patient was excellent.

A wedge-shaped segment of the breast including the sinus tract was removed and a drainage tube was inserted. The wound failed to heal and several weeks later the breast was removed. The wound healed per primam, and after Io days the patient left the hospital and has since been well.

A somewhat similiar case was recorded by Angerer in I9I3. In this instance gangrene of the skin of both breasts followed the subcutaneous injection of salt solution in a young woman soon after childbirth. The author suggests either that the technic was at fault or that the salt solution used may have been too highly concentrated. The skin defects were covered with Thiersch grafts and a very satisfactory result was obtained.

Burns of the Breast usually occur in conjunction with burns of the thorax; they are especially serious in baby girls and not infrequently completely destroy the immature gland. In adult women, the nipple may be destroyed and the milk ducts obliterated as the result of scar formation. The breast may, but usually does not atrophy and is prone to give rise to serious disturbances in subsequent pregnancy, and may then necessitate amputation.

Foreign Bodies in the Breast.-Foreign bodies such as shot and small bullets occasionally become embedded in the breast as the result of accident. More rarely needles, etc., are inserted through design on the part of hysterical or insane patients.

Després repeats the case of a girl aged $2 \mathrm{I}$ with an abscess of the inner side of the left breast from which he removed a piece of match stick $2 \mathrm{~cm}$. in length.

In the chapter on tuberculosis of the breast we cite the case of Scott, in which the 
accidental insertion of a needle in the breast was followed by tuberculosis mammæ. Untiedt reports the remarkable case of an hysterical girl aged I9, who stuck a needle into her left breast. Soon after a pulsating tumor formed and the patient died of "marasmus." Post-nortem, an abscess was found which communicated with the pericardium. The abscess contained a pint of brown pus and a sewing needle $1 / 2$ inches in length.

Foreign bodies in the breast, uncomplicated by infection, need cause no concern: they should not be disturbed if symptomless.

Desgoutre and Lanbert.-Lyon méd., igr3, r2o, roo8.

Vialle and Braun. Lyon méd., 1904, 103, 873.

Lecene and Lennorant.-Précis de Path. Chirur., Paris, rgir, Vols. 3 and 4.

Angerer. Handbuch d. prakt. Chirur., v. Bruns, Garre and Kuttner, Editors, Stuttgart, rgr3, Vol. $2,5^{8} 7$.

Zotr.-Quoted by Vialle and Braun.

DesprEs.-Gaz. d. hop., r884, r43, xr37.

v. Bergmaxi, Bruns and Mikulicz.- System of Practical Surgery, Vol. 2, 563. (English Translation, Bull and Flint.) 


\section{CHAPTER VI}

\section{THE INFECTIOUS DISEASES OF THE BREAST}

\section{SUPPURATION-MASTITIS}

Mastitis occurs almost exclusively at one or the other of three periods of life: immediately after birth, mastitis neonatorum; at or about the time of puberty, mastitis adolescentium; and during lactation, mastitis post-parturium. Certain physiological activities of the glands manifest themselves at these periods and can be assumed to play an important rôle in the etiology of the disease. These have already been fully discussed in the chapter upon the "Evolution of the Breast" where reference has been made to the danger of supervening mammary infection during these periods. It is not, strictly speaking, correct to apply the terms mastitis neonatorum and mastitis adolescentium to the physiological swelling and congestion of the breasts in infants and in the pubescent. Nor should we refer to the congestion of the breasts incident to the establishment of lactation as mastitis. We reserve the term mastitis for those cases in which infection, with consequent true phenomena of inflammation, has taken place, independently of the physiological activities, or as is far more frequent, has been superimposed upon an organ whose increased functional activities have predisposed to it.

True acute mastitis may or may not lead to suppuration and the formation of an abscess. The pathogenesis of mammary infection will be discussed in the paragraphs devoted to the subject of mastitis post-parturium, and much that is there said will apply to mastitis in the quiescent breast as well. For the sake of completeness, however, the special features of mastitis in the new-born, in the pubescent, and in the quiescent breasts of adults, will be considered under separate headings, and the reader is urged to turn to the section on the Evolution of the Breast as it has such important bearings on the subjects about to be discussed.

I. Mastitis Neonatorum.-The term mastitis neonatorum is commonly used to denote any exaggeration in the physiological processes that normally manifest themselves in the breasts of infants of both sexes a few days after birth. The breasts of most infants, during this period, become congested, reddened and slightly tender to the touch, and a milky secretion (colostrum) appears in the breast about the fourth day after birth and slowly decreases in amount until by the twentieth day it has usually disappeared. As previously mentioned, however, the breasts of some children continue to secrete this fluid up to the end of the seventh month or even later. Thus far the activity is physiological. There is, however, predisposition to infection, that not infrequently occurs.

When true mastitis supervenes, each of the above symptoms becomes intensified. The breast or breasts-the disease may or may not be bilateral-enlarge, become rẹddened, shiny, and exquisitely tender. The secretion becomes more abundant and in some few cases is discharged from the nipple in a tiny constant stream. Some observers contend that true milk is secreted in a certain proportion of cases but this remains to be proved. 
Prognosis.-Mastitis in the new-born usually resolves completely, but in ill-treated and neglected cases suppuration is likely to follow. The immature parenchyma is then in grave danger of destruction. Many cases of so-called malformation of the breasts in adult women can be traced to attacks of mastitis neonatorum.

Treatment consists in cleanliness, the avoidance of handling of the inflamed breast and the local application of cooling lotions. Of the latter, cold boric acid compresses are most useful. If the tension of the skin is marked it is permissible to apply sterile olive oil or other emollient, but massage undertaken with the idea of emptying the engorged organ should never be attempted. When suppuration occurs incisions must be made to provide drainage.

II. Mastitis adolescentium is the term commonly applied either to the physiological activities of the breasts that manifest themselves at or about the time of puberty or to suppuration within the gland at this period. True suppurative mastitis of the pubescent breast is an extremely rare disease. The degree of normal enlargement of the breasts at the time of puberty varies to a considerable extent, not alone in the two sexes, but also in different individuals of the same sex so that the dividing line between physiological hyperemia and mastitis is not well defined. In a considerable proportion of children at puberty the breasts become considerably enlarged, slightly tender to the touch and exude a drop of milky fluid on pressure. This constitutes mastitis adolescentium, as it is generally understood. The condition is said to be more common in boys than it is in girls, although contradictory findings are reported by Zappert, who observed I 5 cases in girls and only two in boys.

In girls the disease begins earlier than in boys and persists for a longer time. All traces of it have disappeared as a rule by the time menstruation has become well established. The majority of boys with well-marked mastitis adolescentium are sexually mature; this is not true of girls. In both sexes the affection usually begins in one breast the other usually becoming involved three or four days later.

The initial symptom of true mastitis adolescentium in both sexes is a painful swelling of the breast. The pain is often severe and stabbing in character, but may be very slight and felt only when pressure is applied to the part. An indurated mass may be felt in the central part of the breast. The areola is sometimes discolored, but with the exception of tenderness and a slight local elevation of temperature the signs of true inflammation are wanting. Severe cases may be accompanied by a bloody discharge from the nipple. The disease usually lasts for about one week and terminates in resolution, the breasts of both sexes regaining their immature state. Mastitis adolescentium is not therefore the beginning of normal mammary development in girls, since the childish ontlines of the breasts are restored. It is only after the lapse of considerable time that the normal budding of the glandular tissues begins.

The diagnosis presents few difficulties if one bear in mind the normal evolutionary processes that take place in the breast and the predisposition to infection by which they are accompanied.

Treatment.-Prophylactic treatment in the form of cleanliness and a snugly fitting binder, together with the application of cold compresses is all that is required in cases of non-suppurative mastitis adolescentium. In the event of pus formation, incision and drainage become necessary. Suppuration rarely follows mastitis adolescentium.

III. Mastitis Puerperium, Puerperal Mastitis, Lactation Mastitis.-Inflammation of the lactating breast is a common complication of the puerperium. Its occurrence is predisposed to by the hyperemia and other physiological activities incidental to the establishment of lactation which takes place on the third day after delivery. 
Two theories have been offered to explain infection of the puerperal breasts, one teaching that the bacteria gain entrance to the breasts by way of the milk ducts; the other that they enter through the superficial lymphatics. It is probable that both portals may admit them, but the fact that primary lymphangitis is almost invariably associated with a fissure or crack of the nipple seems to favor the latter theory.

Boissard doubts if galactophoritis ever occurs without abrasions of the nipple or areola; while Sheild, in an attempt to prove the possibility of direct infection of the milk ducts, inoculated these structures in a lactating rabbit and cat, but with negative results.

Human milk in 98 per cent. or more of cases contains Staphylococcus albus or other microörganisms belonging to the pyogenic group, and "the same microörganisms are invariably present upon the superficial tissues of the nipple and areola, so that the sources from which the bacteria may come are evident.

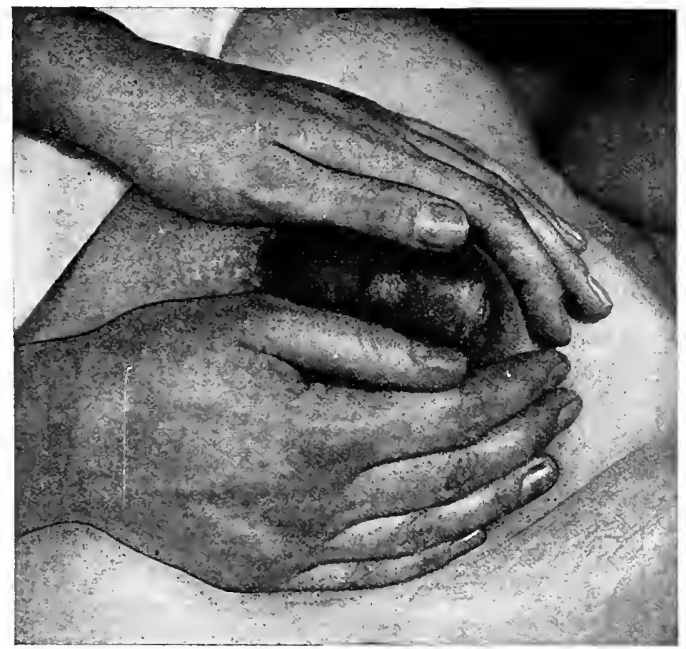

FIG. 90.--Massage of breast. Even compression of entire breast. First motion. (De Lee.)

From 90 to $9^{8}$ per cent. of all cases of true mastitis (not abscesses) occur during lactation, the majority occurring in the first and tenth months, the two months in which women most often stop nursing their infants. The time of onset of the disease in a series of $5^{8}$ cases reported by Nunn was as follows:

\section{TABle I. (NunN.)}

Ig in the first month.

$\mathrm{r}_{4}$ in the second month.

2 in the third month.

I in the fourth month.
2 in the sixth month.

I in the eighth month.

$I$ in the ninth month.

$I 7$ in the tenth month.

Both Velpeau and Nélaton emphasized the danger of abscess formation in the breasts of women who are compelled to cease nursing on account of fissures. Every precaution should be taken therefore to prevent stagnation in the breasts when the necessity of 
arresting lactation arises. Abrasions, excoriations eczematous patches, fissures and malformations of the nipple and areola undoubtedly serve as avenues of infection to the lactating breast, and explain the higher incidence of the disease among primiparæ whose tissues are less resistant to the trauma incident to nursing. In Winckel's experience, mastitis frequently appeared from eight to fourteen days after a lesion of the nipple had disappeared so that the danger of mammary inflammation does not end with the healing over of a crack or fissure of the nipple or areola. This is a practical point to remember when the question of resuming nursing arises.

Infantile stomatitis is also a frequent source of mammary infection in the mother. Puerperal septicemia and pyemia occasionally effect metastatic infection of the breasts.

Pathogenesis.- Infections of the breast may be grouped from the standpoint of the origin of the infecting microörganisms into the autogenous, exogenous and hematogenous varieties.

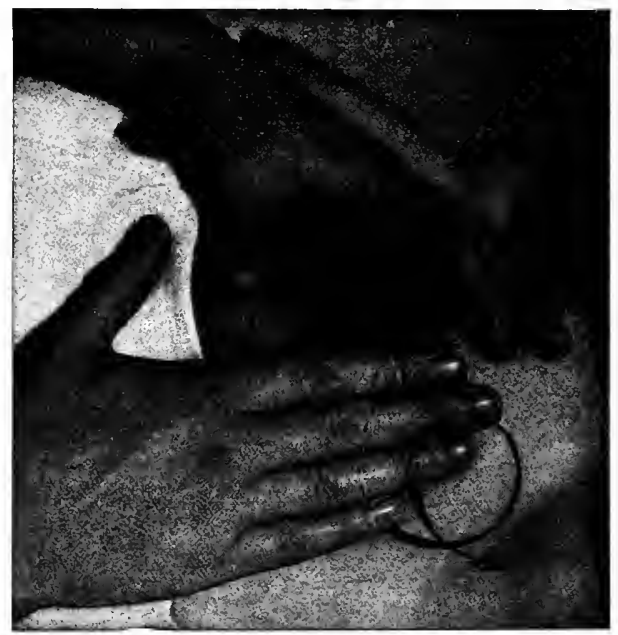

FIG. 9I.-Massage of breasts. Second motion. (De Lee.)

I. The great majority of cases are autogenous, i.e., the bacteria habitually present in the milk ducts and on the surface of the nipple and areola gain entrance to the congested (parenchyma) tissue and set up inflammation. Infection of the breast by contiguity as from a necrosed rib or sternum, from an empyema or from an infected axillary lymph node may be placed in this same group.

2. Exogenous infections of the breast include cases that result from contact with infective clothing, the unclean hands of a careless attendant, from infective salves or other applications, and finally from the saliva of an infant suffering from stomatitis. Infections of the breast arising in stab or puncture wounds are also to be looked upon as exogenous. The majority of exogenous infections of the breast are associated with lesions of the nipple. In the absence of such lesions, practically all cases of lactation mastitis may be attributed to the activities of bacteria resident in the milk ducts. 
3. Hematogenous infections usually occur in non-lactating breasts as complications of the infectious diseases. Gangrene of the breast is a not infrequent sequel of mastitis complicating scarlet fever, although this is not the only cause of this rare condition since a number of cases have been observed in parturient women. The pyemic or metastatic abscesses of the breast that follow puerperal pelvic infections are exceptions to the rule, in that they are hematogenous infections of the lactating breast.

Bacteriology.-Staphylococcus albus and aureus are the microörganisms most commonly found in the pus from abscesses of the breast. Isolated cases of infection with the Micrococcus tetragenus (Freund-Keim), gonococcus (Sarfert), pneumococcus, (Chirié-David), (Erdmann, Ann. Surg., I9II, 53, 727) and Bacillus pyocyaneus, associated with the Staphylococcus (Chassot), have been reported.

The typhoid and colon bacilli have also been recovered from the pus of mammary abscess in non-parturient women. Roger and Garnier found a facultative anærobic micrococcus in a case of puerperal gangrenous mastitis complicating scarlet fever. This particular microörganism was said to resemble one frequently found in the contagious mastitis of the cow and sheep.

Incidence of Mastitis.-According to Lecène and Lenmorant, mastitis occurs in 4 to 5 per cent. of all parturient women, and usually in the third or fourth week after accouchement. Wiebringhaus reports that the morbidity of puerperal mastitis among 4200 recently delivered women under his care was 2.02 per cent. These figures undoubtedly include a large number of cases of simple hyperemia and very mild cases of mastitis. Tarnier states that he saw.no cases of abscess of the breast in 4000 deliveries. Here we have to deal with the opposite

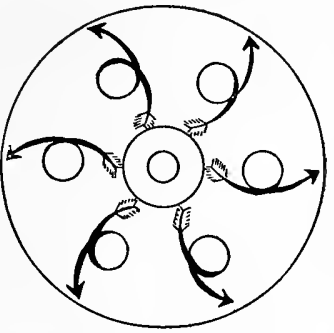

FIG. 92.-Diagram of outward strokings. (De Lee.) extreme and it is likely as Baumgartner suggests, that the unusual freedom from this complication in Tarnier's experience can be explained by the fact that careful prophylaxis was carried out and that his patients were not seen after the first few days following confinement. Again the term acute mastitis is used so carelessly that the frequency of the disease is difficult, if not impossible, to estimate correctly. One per cent. of abscesses in the lactating breast for all classes and conditions of women is, probably, a fair estimate.

The proportion of mastitis cases decreases with an increase in the number of pregnancies, primiparæ constituting the greater number of patients (Koehler, 57 per cent.; Deiss, $5 \mathrm{r}$ per cent.). In only 15 per cent. of Winckel's cases was there a history of more than three pregnancies, while 26 per cent. of Deiss's cases were among second paræ and only I.5 to 4 per cent. among women who had borne more than four children.

It is possible therefore for a patient to escape mastitis in several pregnancies, and to suffer with abscess formation in a subsequent one. Cases of this kind become infected through abrasions of the nipple rather than as a result of ascending infection of the milk ducts.

The comparative incidence of acute pyogenic mastitis among diseases of the breast varies in the statistics of different authors, but Winckel's estimate which places it as constituting $\mathrm{r}_{5}$ per cent. of all breast diseases we believe to be approximately correct.

Puerperal mastitis attacks the two breasts with equal frequency and is bilateral in from ${ }_{5}$ to 30 per cent. of the cases. In Winckel's series the right breast was affected in 
35 per cent., the left breast in 48 per cent. and both breasts in 16 per cent. of the cases. Simultaneous involvement of the breasts is uncommon, the inflammation in one organ following that in the other at varying intervals but usually before resolution has begun in the organ primarily diseased.

As regards the location of the inflammation, most cases belong to the intra-mammary variety. Non-glandular mastitis generally affects the sub-areolar or subcutaneous tissues, the retro-mammary form being comparatively rare. Intra-mammary mastitis may involve any part of the parenchyma, but in one-half or more of all cases the lower outer quadrant of the breast is affected. The entire breast may be involved, in neglected cases. In the primary diffuse gangrenous forms of mastitis the entire breast

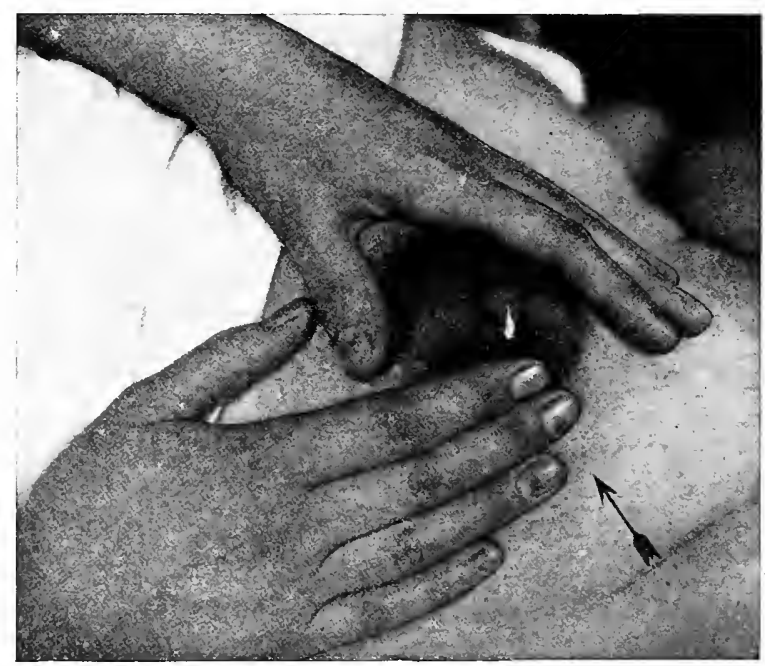

FIG. 93.-Massage of breasts. Third motion. (De Lee.)

may be involved from the onset of the disease. In streptococcic infection of the superficial mammary tissues it is possible to have attacks of true erysipelas.

It becomes evident from the foregoing statements that the location and extent of the mammary infections are largely dependent upon the varieties of the bacteria and their avenues of entrance into the breast together with the promptness with which appropriate treatment is begun.

Clinical Course, Symptoms and Diagnosis.-Inflammation resulting from the presence of pyogenic bacteria may involve the breast tissues proper, the subcutaneous tissues in front of the breast or the tissues behind the breast, thus giving rise to different clinical forms of mastitis.

I. Intra-mammary infection of the lactating breast occurs in three important clinical varieties all of which are prone to terminate in abscess formation: first, the ordinary type in which one segment of the breast is involved; second, the diffusing type in which 
different segments of the organ become successively involved; and third, the primary diffuse type in which the entire breast may be involved from the onset of the disease.

I. The ordinary type is characterized by slow evolution. There is no tendency to widespread extension of the infection, and abscesses develop late in the course of the disease, if at all. The foci of infection in these cases tend to coalesce and, in some instances, form one large abscess cavity.

This type of mastitis may be differentiated from simple hyperemia of the breast by the presence of more severe pain, of irregular fever, of a dusky red discoloration of the overlying skin and of more marked tenderness on pressure. In cases where the infection is deeply seated, the local signs are indistinct and great difficulty is of ten encountered in making the diagnosis of abscess. However, when the foregoing symptoms arise in

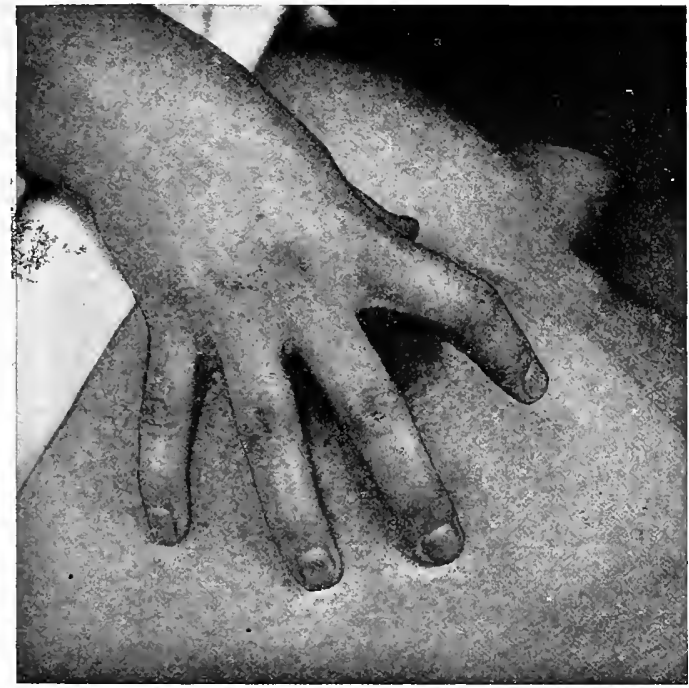

FIG. 94.-Stimulating massage. (De Lee.)

a patient who has been suffering with "caked breast" it should be taken for granted that an abscess is in the process of development, and treatment advised accordingly.

In many patients the disease pursues a subacute course, the local signs being indistinct, and the condition of the breast may be neglected under the misapprehension that the constitutional symptoms arise from puerperal septicemia.

2. Acute diffusing mastitis in the lactating breast begins like the preceding variety but shows no tendency to form well-circumscribed abscesses. The inflammation spreads rapidly, by degrees attacks the surrounding glandular tissues and eventually, if not treated, transforms the entire breast into a series of inter-communicating abscess cavities. The diagnosis of the diffusing types of mastitis is very simple, the symptoms being those of the foregoing variety in an aggravated form. There must be no delay in operating as the breast is in grave danger of total destruction. 
3. Primary diffuse mastitis (diffuse phlegmon) is a highly fatal but fortunately rare type of the disease, analogous to gangrenous cellulitis occurring elsewhere. It is easily distinguished from the diffusing type of the disease by the fact that all parts of the breast including the overlying skin are attacked from the time of onset. Necrosis or gangrene accompanied by grave constitutional symptoms may occur early in its course. The infection proceeds with extreme rapidity, sometimes terminating fatally within 48 hours. In other cases suppuration may continue for many weeks. Sheild quotes several interesting cases, the histories of which need not be repeated, and describes the disease as follows:

"Clinically, diffuse phlegmon is characterized by enormous swelling of the mamma, the skin becoming of a livid hue, and finally black and discolored in patches. Free incisions give vent to foul sloughs and

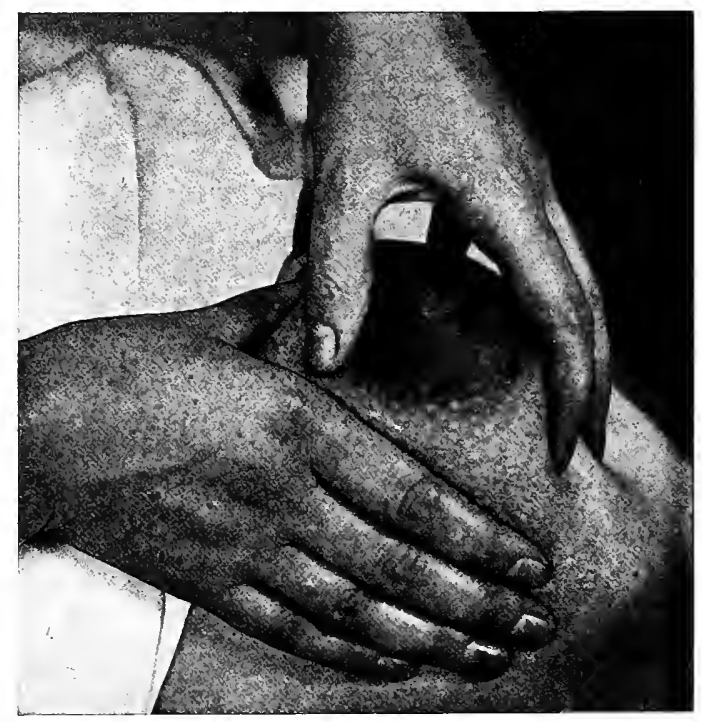

Fig. 95.-Stimulating massage. (De Lee.)

broken down tissue. The constitutional symptoms are at first fever of a high type, with delirium followed by exhaustion and a tendency to coma; the affection is comparable to the worst kinds of cellulocutaneous inflammations observed in the limbs, and its pathology is probably similar, the entrance of virulent organisms (Streptococcus and Staphylococcus or Bacillus septicus) into the tissues the normal resistance of which is lowered by renal disease, alcoholism, bad living and unhygienic surroundings."

In the cases reported by Durand and by Trillot and Latarget the. involved breasts were almost completely anæsthetic from the beginning of the disease.

Diffuse phlegmon of the breast may appear at any time during the lactation period, as is illustrated in the cases reported by Trillot and Latarget; in one of these the disease appeared on the fifth day after delivery, in the second it appeared one month afterward, and in the third it came on after five months of nursing. Two of the cases proved fatal, 
a termination which the reporters ascribe to massage to which the breasts had been subjected in the early stages of the inflammation.

II. Subcutaneous inflammation of the breast begins as a lymphangitis in the areola or adjacent tissues. The inflammation often remains localized as an ordinary cellulitis and terminates in abscess formation; the abscesses being situated in the subcutaneous tissue. Less frequently the inflammation extends into the breast.

Cases of this kind are usually preceded by a fissure or crack of the nipple that gives rise to pain on nursing long before the advent of the inflammatory symptoms. With the onset of the latter, the pain becomes spontaneous and throbbing in character, the tissues of the areola or the skin adjacent to it, become swollen and reddened, and, in certain instances, the nipple is displaced to one side. Swelling and tenderness of the axillary lymph nodes frequently appear soon after the onset of the inflammation and suppurative lymph-adenitis not uncommonly follows. This complication is comparatively rare in deepseated inflammations of the breast.

In cases that are primarily areolar, the skin is not extensively involved unless the disease assumes an erysipelatous character. In all superficial infections of the breast, the inflamed tissues become extremely tender to the touch and fluctuation can generally be demonstrated within three or four days from the time of onset. Subcutaneous abscesses often evacuate spontaneously on the surface of the breast, although there is always danger that the pus will

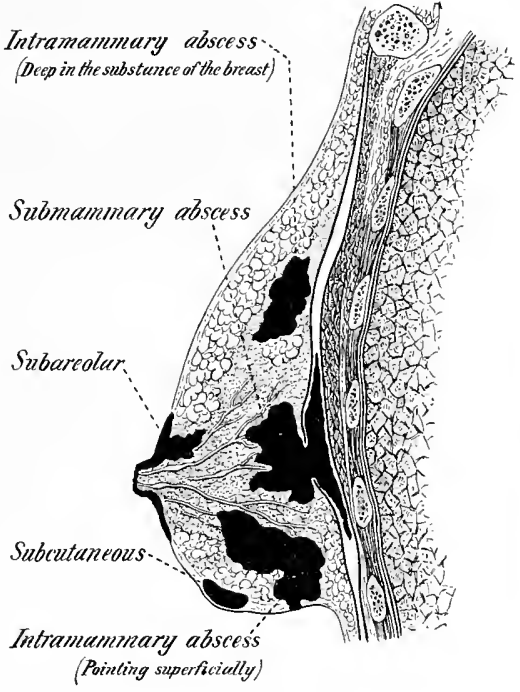

FIG. 96.-Diagram showing the various locations of mammary abscesses. burrow through the deep layers of the superficial fascia to involve the parenchymatous tissues. Constitutional symptoms are slight or absent in the ordinary well-localized and superficial types of mammary abscess.

Keyes groups abscesses of the nipple and areola with the true glandular forms of mastitis, but unless they arise in the para-ductal tissues it is probably better to look upon them as subcutaneous infections.

III. Retro-mammary infection of the lactating breast, almost without exception, results from the extension of glandular mastitis into the retro-mammary space. With the onset of this complication the already inflamed breast becomes more swollen and painful, and soon is pushed forward so that it projects from the chest wall more than its fellow of the opposite side. The evolution of the disease is rapid, and grave constitutional symptoms of sepsis, chills, fever of the hectic type, and sweats appear within several days from the onset. The breast is found, upon examination, to be spongy and boggy from edema, but lacking in the extent of glandular involvement that would account for the marked constitutional symptoms present. 
Diagnosis.-Certain rapidly growing tumors are the only conditions likely to be mistaken for puerperal mastitis.

In the majority of the reported instances of acute carcinomatous mastitis the breasts have been incised in the belief that the condition was due to pyogenic infection. Both diseases affect the breasts of comparatively young women in the lactating period, both are accompanied by the constitutional symptoms of sepsis, and in both the local signs of inflammation are present. We know of no pre-operative method of differentiating the two conditions in their early stages. This is equally true of small round-cell sarcomata in the lactating breast. An interesting example of this extremely rare condition is reported by Chaput and Souligoux: The patient presented herself soon after delivery with enlargement of both breasts. This subsided promptly with antiphlogistic treatment. One month later she returned with the tumors enlarged and adherent to the skin. At operation the condition was found to be a bilateral sarcoma of the roundcell type, from which she shortly died.

Prognosis.--Pyogenic mastitis is rarely fatal. It is, however, a painful complication of lactation and a menace to the health of both mother and child.

Retro-mammary abscesses may give rise to serious septic poisoning, or may invade the pleura, if not promptly incised.

The rare primary diffuse form of mastitis is sometimes fatal notwithstanding prompt recognition and treatment.

The duration of puerperal mastitis varies with the type of the disease. Superficial abscesses usually recover in one to three weeks; intraglandular and retro-mammary abscesses last from two weeks to several months, while the primary diffuse form, if not promptly fatal, consumes many months in the process of resolution. On this account. many cases of this latter kind require amputation of the breast, in order to spare the patient the painful and tedious convalescence that, after all, leads only to the retention of a useless mass of scar tissue in the place of the breast.

Chronic interstitial mastitis, chronic abscess, galactocele, simple retention cysts, malignant disease and perhaps abnormal involution, may occur as sequelæ of puerperal mastitis.

Treatment.-Prophylactic Treatment During Pregnancy.-During the latter half of pregnancy the nipple should be washed daily with tincture of green soap. Inverted nipples should be pulled out at regular intervals. Numerous antiseptic and astringent local applications have been recommended. Boericke saw a reduction in the mastitis cases, in his practice, from 2 I per cent. to I.6 per cent. follow the use of a tannin alcohol solution. Heck obtained equally good results by daily washing the nipples with plain water and pulling the poorly-developed nipple. Hirst advises, among other remedies, the daily application to the nipples of a mixture of glycerole of tannin and water, equal parts. Alcohol must be used sparingly if at all, since it favors the subsequent development of fissures.

Post-partum prophylaxis depends primarily upon the personal cleanliness of all concerned, and regular nursing of the child. When the secretion of milk is in excess of the needs of the child the breasts must be emptied by the use of the breast pump or massage. The proper manner of performing mammary massage is shown in figures 90-95, taken from De Lee's "Text Book of Obstetrics."

Bumm's compress method is a somewhat troublesome but highly efficient prophylactic measure against puerperal mastitis.

It consists in the constant application to the breast of a gauze square, dipped in 
four per cent. boric acid solution, during the entire lactation period. The gauze is covered with a large piece of rubber tissue which will adhere to the breast and the whole is covered with a clean cloth. It is said to act not only as a protective covering, but also to produce a hyperemia that serves as a palliative in case of a slight injury to the nipple. We do not favor the application of medicinal preparations to the nipples in the absence of fissuring or other lesions.

Inflammation of the Nipple (Thelitis) Treatment.-Nursing should be continued in cases of fissure of the nipple or areola unless the act gives rise to intolerable pain. A nipple shield should, however, be worn even if the act of nursing does not cause severe pain without its use. In the intervals between nursing, a lead shield should be worn to protect the abrasions from coming into contact with the clothing or mammary binder.

The nipple should be washed after each nursing,thoroughly dried and one of the following preparations applied to it: a powder containing powdered boracic acid, calomel, and tannin, equal parts; a powder containing powdered boracic acid and acetanalid, equal parts, or an ointment consisting of bismuth subnitrate and castor oil, equal parts (Hirst).

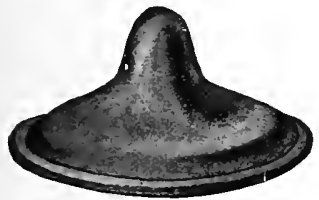

FIG. 97.- IVansbrough's lead nippleshield.

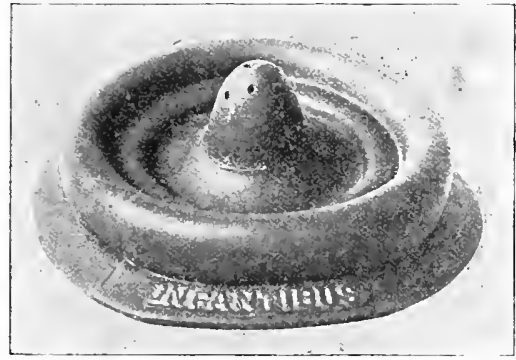

FIG. 98.-Soft-rubber nipple-shield called "Infantibus." Will be tolerated in cases of sensitive nipple when the "Phœnix" and others cannot be endured. (De Lee.)

The care of the infant's mouth would seem to be an important consideration in the prevention of mastitis, but the methods of treatment thus far proposed have been unavailing. The routine use of boracic acid solution in infantile stomatitis is advised against by Eicher on the ground that "it is apt to prove a snare for the deposit of thrush."

Deep fissures of the nipple are extremely difficult to heal and this is especially true of fissures located at the base of the nipple, because the act of nursing tends to separate its edges and thus extend the ulceration which has been known to penetrate a milk duct causing milk fistula or even to result in amputation of the nipple (Amer. Textbook of Obstetr., Phila., I902, 2, 272).

Deep fissures of the nipple and areola should be anæsthetized by applying a pledget of cotton soaked in 20 per cent. novocaine solution and then cauterized with the silver nitrate stick.

In incipient mastitis with or without an abrasion of the nipple, the treatment is designed to prevent suppuration.

The patient is put to bed, and ice-bags are applied to the inflamed organ which is supported in a suspensory bandage. Wet dressings, lead water and laudanum or lead water and alcohol are useful. Epsom or Rochelle salts are given until free catharsis is obtained. Only a liquid or soft diet is permitted. 
Schiller, among others, never resorts to weaning as a means of preventing suppuration in incipient mastitis cases. Instead, he applies a Biers cup for three-quarters of an hour once or twice daily and advises that the child shall continue to nurse after the application of the cup, so that the breasts are thoroughly emptied at least three times daily. In the intervals between cuppings, a salve is applied and the breasts are poulticed with a 50 per cent. alcohol or 2 per cent. aluminum acetate solution and "raised under moderate compression so that the nipple occupies the center of the breast." Schiller regards the nursing act as a healing process in itself through the production of active hyperemia. He advises that nursing be continued even if suppuration occur, provided,

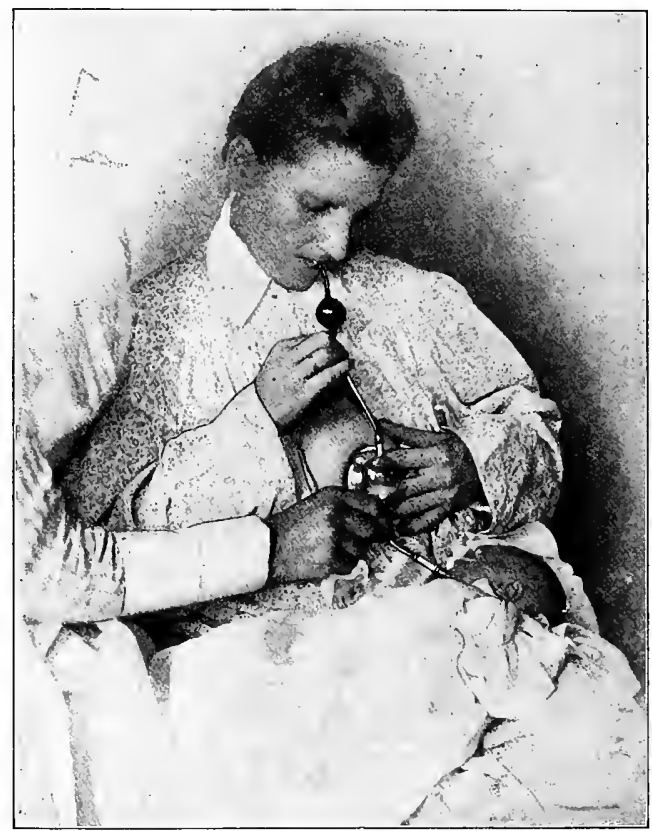

FIG. 99.--The teterelle in use. (De Lee.)

that the abscess be small and the incision to relieve it be made sufficiently remote from the nipple. Nursing at the healthy breast is seldom discontinued by his patients. Most European surgeons follow a similar line of treatment, but it is the custom among American surgeons to advise weaning the child when suppuration takes place in the mother's breast.

Gastro-intestinal disorders are common enough in infants suckled at infected breasts, but it is surprising to find that Damourette observed five fatal cases among a series of 27 infants who were suckled at breasts the milk ducts of which alone were affected. Great stress is laid upon this source of danger to the child by Baumgarten and 
Boissard, while numerous obstetricians hold that infantile marasmus is often due to the ingestion of bacteria-laden milk from a mother whose milk ducts alone are infected.

Dervaux and Salmon report the case of an infant in whom erysipelas and osteomyelitis followed nursing at an infected breast.

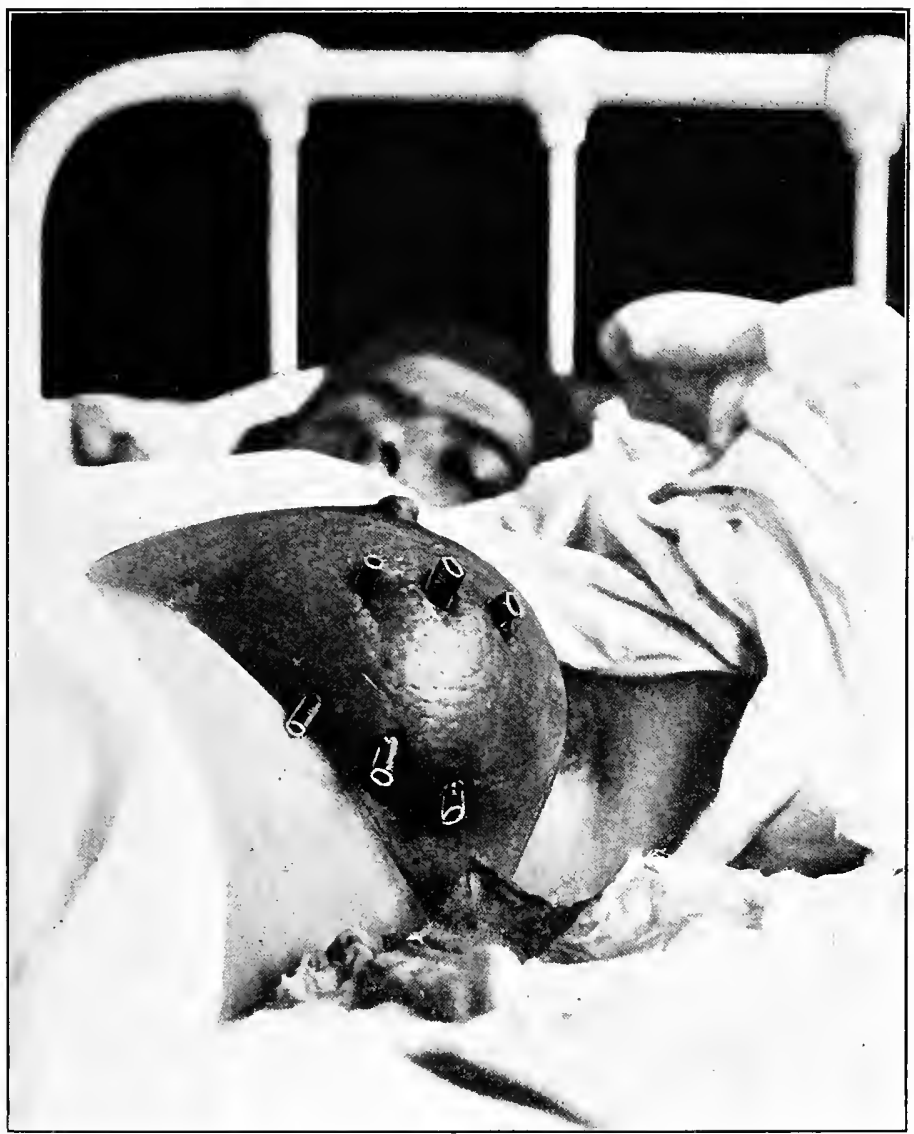

FiG. 10o.- Showing proper method of draining an intramammary abscess.

Infected milk other than mother's milk may also be a source of danger to the child, as is illustrated by the fatal cases of infantile purpura and melena reported by Gibbons, in which the source of the infection was traced to an abscess in the udder of a donkey.

Treatment of Mammary Abscesses.-The treatment of mammary abscesses consists of incision and drainage. Incisions into the breast may be made either inside or 
outside of the areola but must radiate from the nipple to avoid severing the milk ducts. They must be in sufficient number and so placed that free drainage is provided for every collection of pus.

I. Subcutaneous Abscesses.-A single incision usually suffices in the small superficial types of mammary abscess. In these cases it is unnecessary to explore the abscess cavity, and a small piece of rubber tissue is all that is required to secure adequate drainage. When a subcutaneous collection of pus communicates with an intra-mammary abscess, the treatment must be modified to conform to the requirements of the latter condition.

The after-treatment consists in frequent renewal of the dressings that should be kept moist for several days to facilitate drainage. Irrigation of the abscess cavity is usually unnecessary. The breasts should be supported in a suitable suspensory bandage.

2. Intra-mammary Abscesses.-Intra-mammary abscesses may require only one or two small incisions, or if the lesion have been neglected, so that a large part of the organ has become involved, or, as is frequently the case, if multiple sinuses have formed, multiple incisions, or even amputation- of the breast may be required.

The operation usually employed by us is as follows:

Wide radial incisions are made through the skin lying directly over the abscesses, which are then punctured with a pair of hemostatic forceps. The extent of the abscess cavity is then explored with the finger and its various pockets are brought into free communication with a central cavity. A counter-incision is made at the most dependent point of the cavity and a "through and through" drainage tube is inserted. This same procedure is repeated for each abscess. The ends of the drainage tubes are transfixed with large safety pins; a piece of sterile gauze is wrapped around each tube close to the pins and a sterile dressing applied. A firm binder is then adjusted to cover both breasts. Frequent dressing is required. The abscess cavities are irrigated daily through the drainage tubes. For the latter purpose a fountain syringe or an ordinary piston syringe answers. The solutions must be introduced very gently. The most efficacious are warm normal saline solution, a one to five thousand solution of potassium permanganate, or a one to four hundred solution of iodine. When the discharge begins to diminish, the gradual removal of the drainage tubes is commenced-a portion of each tube being removed at the time of each dressing.

In an ordinary case the drainage tubes are all out by the tenth day, after which the sinuses must be kept open by means of smaller tubes, or by pieces of rubber tissue, so that healing will take place from the bottom of the wounds.

A number of operations have been devised to insure a better cosmetic result than that which follows the method just described. The best of these are as follows:

Sheild's Operation.-Sheild advises that as soon as elasticity and deep fluctuation can be demonstrated in intra-mammary abscess, an incision be made, radiating from the nipple, and just large enough to admit the operator's index-finger. The opening is deepened until the pus flows, when the abscess cavity is explored with the finger, and all septæ are broken, thus bringing all outlying pockets into free communication with a central cavity. The success of the treatment largely depends upon the thoroughness with which this is carried out. The most dependent part of the common abscess cavity is then located, and in most instances it will be found that the end of the finger may be brought fairly near the surface at the thoraco-mammary junction. This, as Sheild points out, is the most desirable place for the scar since it is hidden from view when the breast is in its normal position. After making a counter-incision at this point, the 
Plate I

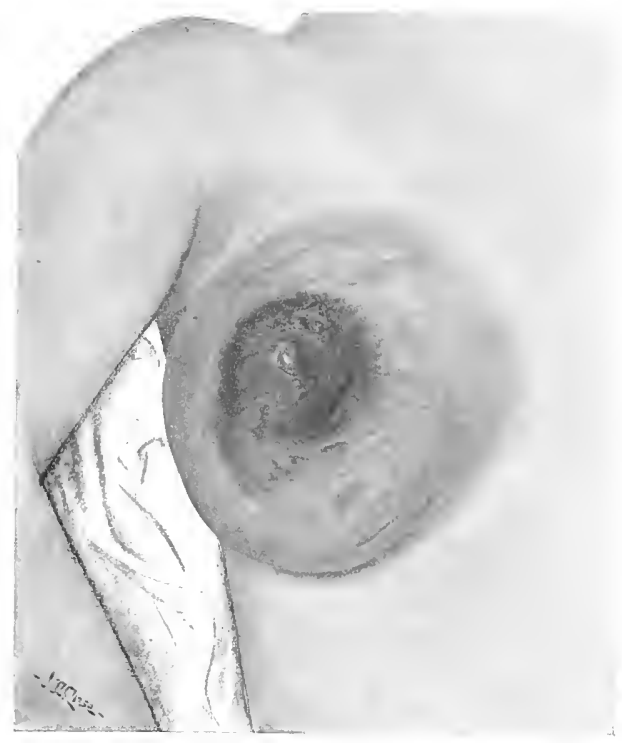

Mammary abscess. (IIirst.) 

abscess cavity is irrigated and a large fenestrated rubber drainage tube is inserted and anchored to the edges of the incision. The anterior incision is then closed with interrupted horse-hair sutures and covered with collodion. Primary union takes place, as a rule, and the scar that remains is almost invisible. The after-treatment of these cases, as given by Sheild, is similar in all essentials to that given above, although he disadvises flushing the cavity with antiseptic solutions. As soon as healing begins, he uses compression. A large flat soft Turkey sponge is wrung out of carbolized solution and placed upon the breast; an opening is made in the sponge through which the drainage tube is drawn and a firm binder is applied. The arm is bound to the chest wall to prevent traction by the pectoral muscles upon the walls of the abscess cavity or sinuses which is said to delay healing. The forearm is worn in a sling.
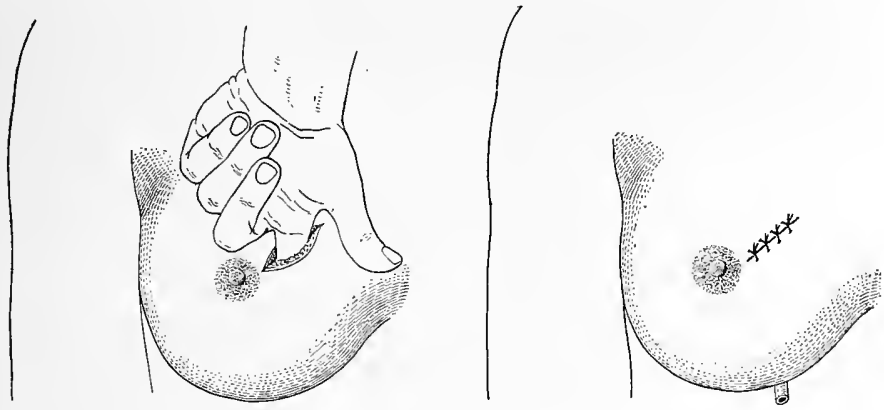

FIG. IOI.-Sheild's operation for suppurative mastitis.

Desmorest's Operation.--Thomas first suggested the method of incising mammary abscesses through the thoraco-mammary fold. This procedure, though advocated, has been modified to some extent by Bardenheuer and Eicher in Germany, and by Sheild in England. Desmorest has lately revived interest in the method and illustrates the steps in the operation with drawings. He calls attention, as did previous writers, to the fact that by means of a thoraco-mammary incision, multiple abscesses in the breast can be reached through a single opening, and given sufficient drainage in a manner that subsequently leaves a relatively inappreciable scar.

Under local anesthesia, a convex incision is traced around the base of the gland, and the skin and the adipose tissue incised. After clamping the superficial vessels, the cellular tissue which separates the breast from the aponeurosis of the external oblique muscle is reached. With a turn of the finger the gland is turned up so that its lower aspect is exposed, and the pus pockets are easily evacuated. The finger is introduced into the opening thus made and all of the cavities can be explored. Drainage tubes are introduced at the most dependent part of the abscess after which the breast is returned to its normal position and several sutures inserted. The after-treatment is the same as that for other forms of operative treatment.

Morestin's Areolar Skin Incision.-This operation is intended for the cure of mammary abscess with minimal subsequent deformity of the breast. According to Morestin, it is applicable to all cases except those in which the skin is deeply affected. We have employed it in the treatment of superficial abscesses within the areola, and the results obtained have been satisfactory, but we much prefer more free incision and drainage in 


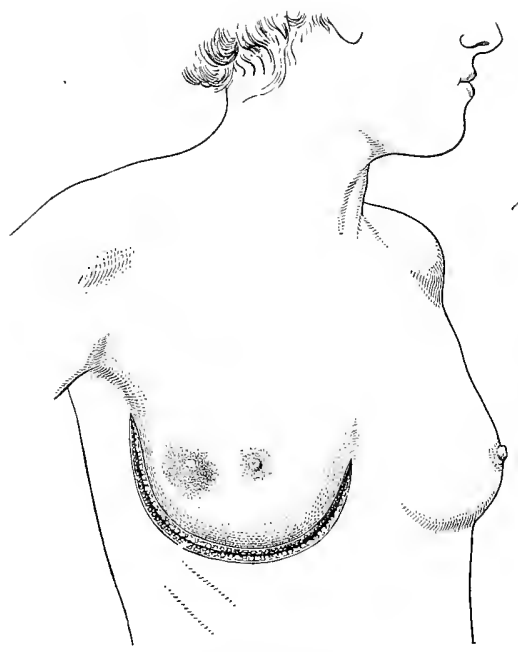

FIG. ro2.

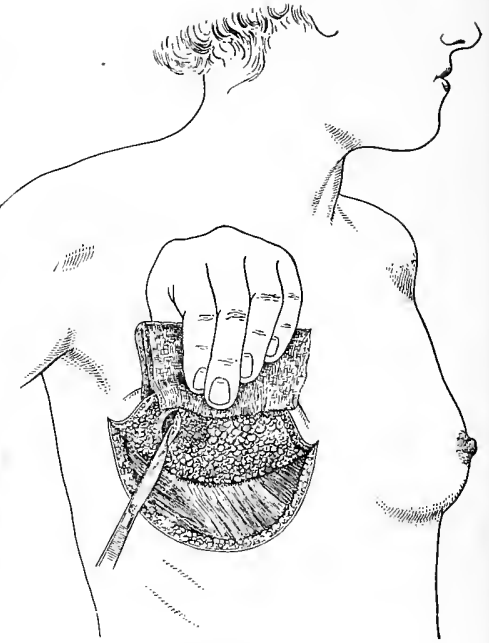

FIG. ro3.

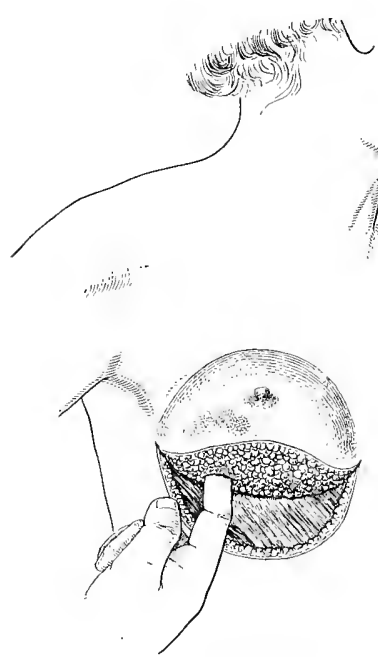

FIG. ro4.

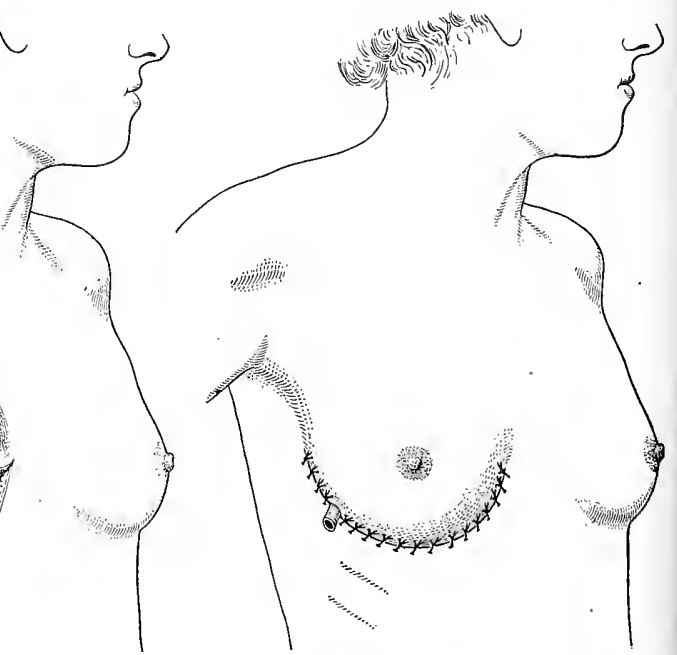

FIG. 105 .

FIGS. I02 To ro5.-Desmorest's operation for mammary abscess. 
the treatment of intra-glandular abscesses. In cases in which the cosmetic result must be given serious consideration, we believe that the operation recommended by Sheild, or that of Desmorest, will afford better drainage and for this reason give it preference.

The operation devised by Morestin is as follows:

Having located the abscess, an incision is traced around the areola, beginning at the base of the nipple and directed toward the abscess by the shortest way, stopping just within the limit of the areola (about $2 \mathrm{~cm}$.). The knife is carefully slipped under the skin toward the abscess and then turned down, the incision coming out toward the nipple. This will be accompanied and followed by pus coming from the wound. An explorator or a finger is then inserted into the wound to locate the root of the abscess which communicates with the deepest cavity, and the latter is freely opened.

After completely evacuating the cavity and cleaning it with iodine or formol, a rather large drain is put in place coming out at the areolar wound.

Hemorrhage is usually slight and ceases spontaneously in a few moments. The procedure is the same regardless of the position of the abscess, and should there be several, each can be treated at the same operation.

Drainage established in this manner proceeds most satisfactorily, as in mastitis during lactation, the breast is always more or less pendulous, and the areolar region comparatively low.

The results of the operation are usually most gratifying. The drainage tube can usually be removed on the fourth or fifth day, and healing is usually complete in from Io to 12 days.

3. Retro-mammary Abscesses. - In operating for retro-mammary abscesses, it is our practice to make the incision along the periphery of the breast in its lower outer quadrant. In the majority of these cases a "shirt stud abscess" is found, with one pocket within the parenchyma, the other in the retro-mammary space. The primary focus within the gland must be searched for with the finger and brought into free communication with the retro-mammary collection. A small counter-incision is then made along the edge of the breast at a point directly opposite the initial incision through which a fenestrated drainage tube is inserted and brought out through the former opening.

If no pus has been found behind the breast, the incision may be enlarged sufficiently to permit the posterior surface of the breast to be exposed so that abscesses may be searched for within its substance. If found, they may be evacuated through the incision as advised by Bardenheuer and Desmorest, but it is our practice to make a small counteropening in the skin overlying the abscess through which the drainage tube is drawn.

The best cosmetic results are obtained by omitting this second incision, or by closing it immediately, as Sheild advises, but there is danger of imperfect drainage without it. The after-treatment is the same as that already described for the intra-mammary type of abscess.

The Treatment of Mastitis by Means of Artificial Passive Hyperemia (Bier's Treatment).-As a Prophylactic.-Wiebringhaus reports that the incidence of suppuration among his cases has been reduced from I 6 per cent. to 8.3 per cent. since Bier's suction method has been employed as a prophylactic measure. In suppurative cases the average period of convalescence was reduced from 38 to 28 days. Both Jager and Schiller have had excellent results with the hyperemia method in the treatment of early cases of non-suppurative mastitis. Schiller states that during a period of five years not one of his early cases developed suppuration. The method is likewise warmly advocated by Biehler as a routine prophylatic measure in incipient mastitis. 
But all writers have not enjoyed the same success; thus, Zangmeister believed that Bier's treatment favored the development of suppuration in early mastitis cases. In 80 per cent. of his cases cures were obtained by antiphlogistic treatment; with Bier's treatment he saw three times as many cases of suppuration follow.

As a Substitute for Wide Radial Incisions.-The technic originally advised by Bier, which called for small multiple punctures followed by the application of the suction cup, has been practically abandoned. Some surgeons, however, including Bernheim, Schiller and Nohl, apply Bier's cups for the production of hyperemia, after the abscess has been widely incised.

Bier described the technic as follows (Hyperämie als Heilmittel, Leipzig, I907, 5th edition, p. 413-Ist edition ( $\mathrm{I}_{9} \mathrm{O}_{3}$ ) not available): "It is applicable to all stages of the disease for incipient inflammation as well as for fully developed abscesses and for old fistulas and cicatricial indurations.

"The suction cup should be smaller than the breast to be treated. While the rim of the cup may be round, it is better for it to follow the contour of the breast. The patient presses the apparatus against the breast herself and holds it throughout the treatment. As the air is pumped out of the cup through a syringe or a rubber ball, one can plainly see the breast being drawn into it. It assumes a bluish-red color,

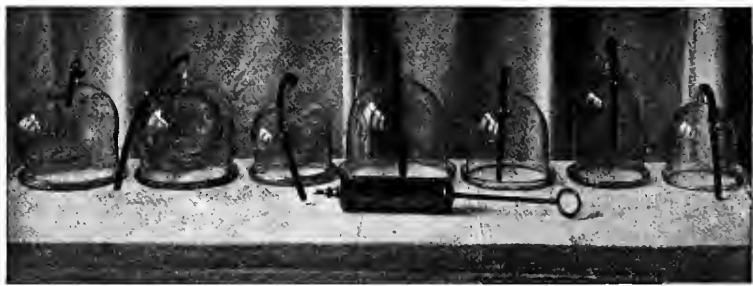

FIG. I06.-Various sizes and shapes of Bier's cups for the breast, with the syringe, to create a vacuum.

becomes filled with blood, the veins of the skin appear swollen, and the patient finally feels as if the breast were about to burst. The process should stop at this point. The whole procedure should be unattended by pain.

"About $30-60 \mathrm{cc}$. of milk are discharged in recent cases at one sitting, while from abscesses and fistulas blood and pus appear first followed by a bloody serous fluid.

"The milk should be thoroughly removed. If the cup does not do this thoroughly the ordinary small suction cup (pump) should be used in addition. A longer cup with a small diameter is best suited for the thorough withdrawal of the milk, the breast undergoing pressure against the side of the narrower vessel as it is drawn into it.

"Abscesses should always be incised under local anesthesia, the incision being $1 / 2-1$ $\mathrm{cm}$. long. The small incision is important in order to avoid extensive scars and loss of glandular tissue. The pus should be thoroughly withdrawn each time. It is sometimes well, in addition to the large suction cup, to use the ordinary dry cup in order to effect complete removal of the pus. As soon as the obstruction to the free flow of pus has been removed by this small and locally useful instrument, the large suction cup will at once produce an abundant flow of pus. This must be tried out for each individual case. At every treatment the operator should make sure that the previous puncture has not been occluded or displaced. Crusts covering the opening should be removed 
and more deep-seated obstructions treated with suitable instruments, or drainage tubes carefully introduced into the abscess cavity.

"The appearance of new abscesses should not lead to a premature abandonment of the treatment for operative intervention. Complete cures have been obtained without any disfigurement in cases where IO-I 2 abscesses have formed successively and been treated by small incisions. At first the suction cup should be applied daily for threequarters of an hour, five minutes at a time with intervals of three minutes. Shorter sittings can be used when the flow of pus is sparse and the pus serous. The breast should be treated with aseptic dressings between treatments.

"The suction treatment of mastitis fulfills all the requirements of an ideal method. It withdraws the pus and the milk and by its very effectual hyperemic action it alleviates the pain, softens the indurations and effects their resorption. Inasmuch as the breast invariably retains its natural appearance, it differs materially from the usual surgical treatment, so frequently followed by disfigurement and poor functional power. The long duration of the surgical method of treatment results in cicatrization of the gland, which not only unfavorably affects its function and spoils its appearance, but makes it more susceptible to future carcinomatous degeneration.

"Furthermore, it presents the advantage over the old method of treatment, with cataplasms and small incisions, in that its hyperemic action is much more thorough, reducing instead of increasing suppuration and providing for the complete withdrawal of the pus. To it may also be applied the dictum for our hyperemization method in general: the smallest possible amount of disfigurement with the smallest possible incision and least painful intervention.

"It is interesting to note that this method of treating mastitis has a forerunner in the folk medicine of some parts of southern Russia, where the women apply a large pot, in which there is some burning petroleum, over the affected breast and are fully convinced of the beneficial effects of this enormous dry-cup."

Klapp, Bier's associate, advises incision of the abscesses; his description of the technic is as follows:

"Every abscess should be opened at once. A small radial incision under local anesthesia is the choice, although it may be enlarged if required. The wound is neither drained nor treated with tamponage. The incisions must be made so as to allow of free flow of the pus. This frequently necessitates one or more small incisions after the extent of the cavity has been sounded. The treatment is specially designed to remove completely all infectious material, and success will follow only if the incisions are so made as to insure this. The incisions having been properly made, the suction is then applied, using either a large glass bell-large enough to take in the entire breastor a smaller one covering only the abscess site. The latter, however, should extend considerably beyond the inflamed part. The treatment is kept up intermittently for 2o minutes, five minutes of suction following a similar period of rest. Pressure should be so regulated as to insure a good suction without, however, going so far as to be painful. The subsequent dressing consists of a vaseline-coated cloth covered with absorbent cotton and a proper bandage. Drainage tubes are sometimes necessary. The child should be permitted to nurse regularly."

Bernheim advocates the use of a modified form of Bier's treatment. Wide exploration is made of all of the abscess pockets which are then loosely packed, the breast being allowed to hang free. The suction treatment is begun 24 hours after the operation. In $I_{5}$ cases in which this method was employed, the average duration of the infection was 
I9 $1 / 3$ days; the average number of cuppings was $7 \frac{1}{5}$. Thirteen of the patients were nursing mothers, four of whom were able to resume nursing at the affected breast. In one case a secondary collection required incision. Suppuration was prevented in two incipient cases. Bernheim claims, as the advantages of the treatment, "an almost absolute freedom from pain during the whole course of the disease, better conservation of glandular function for present and future function, minimum scar formation, shortening of the course of the disease and the prevention of abscess formation if the case be seen early enough."

Equally good results are reported by Biehler, who obtained cures in a series of I4 superficial cases in from 8 to ro days. In a series of 38 deep-seated infections, cures were obtained in from 20 to 30 days; 44 cases required incision, and in two cases erysipelas developed but subsided in one week under the influence of the suction treatment. In a group of 32 neglected cases with multiple fistulas, incision was necessary and the hyperemia was continued for a period of four or five weeks before the wounds closed. The immediate function of the breast was conserved in all but eight of these cases, although four of them were able to nurse their children after subsequent pregnancies. Biehler adheres to the original technic described by Bier. Graham found that suppuration in the breast was likely to recur after treatment by the original method. He therefore dispenses with small incisions, although the size of the latter varies according to the exigencies of the individual case, and states that diffused abscesses with brawny inflammation of the skin demand wide incisions.

Chronic suppurating sinuses of the breast, other than tuberculous, respond promptly to Bier's method of treatment. Bernheim recommends that they be laid open and packed and that the suction treatment be commenced 24 hours later. In Graham's series of seven cases, complete healing was obtained by Bier's hyperemia alone.

The Vaccine Treatment of Mastitis.-Vaccine therapy promotes healing after mammary abscesses have been incised and drained, and so shortens convalescence. It is also useful in the prevention of recurrent mammary inflammation. Autogenous vaccines are generally more useful than stock vaccines. The treatment is begun from 24 to 48 hours after operation, and the initial injection consists of a mixed stock preparation of staphylococci. Cultures are taken at the time of operation so that by the time a second injection is required the autogenous vaccine may have been prepared. The dosage is varied, according to the severity of the infection. Constitutional reactions are to be avoided. An initial dose of two hundred millions of the staphylococci is recommended, repeating the treatment at four-day intervals, with an increase at each dose equivalent to the amount of the first injection, until one thousand millions of the dead bacteria are given.

Benians, who has made extensive use of the vaccines in the treatment of acute mastitis, reports good results in the treatment of incipient cases. He recommends that cultures be made from fissures of the nipple and states that vaccines prepared from cultures obtained in this manner have apparently prevented suppuration in some of his cases. In the absence of fissures of the nipple he advises the injection of stock Staphylococcus aureus vaccines ("when suckling is to cease"). He also employs stock vaccines in the post-operative treatment of suppurative cases. In one series of 15 cases, injections of four to eight hundred millions of the bacteria were given immediately after operation and repeated in one week, which usually sufficed. He found that free incision and drainage of the abscesses are necessary, for, "when pus is pocketed, the condition is only aggravated by the administration of vaccines." In cases that did not respond well to 
the treatment it was found that secondary infection had occurred. Nine of the 15 cases in this series were cured in an average of $\mathrm{r} 2$ days, one became secondarily infected with streptococci and healing was delayed ro weeks, while the remaining five cases occurred in patients "who ceased to come after the first injection"-apparently not very sick individuals.

Thirteen patients with chronic suppurating sinuses were treated with stock vaccines where staphylococci were found, and autogenous vaccines were made in the streptococcic cases. Suppuration had been going on on an average of $\mathrm{I}_{4}$ weeks, and cures were obtained on an average of five weeks. Cure was delayed six months in a streptococcic case not included in this series, and in another similar case it was necessary to amputate the breast.

IV. Mastitis in Adults Occurring at Times Other than the Lactation Period.r. Typhoid Mastitis.-Slight swelling of the breasts sometimes makes its appearance during the febrile stage of typhoid fever, as part of the general glandular involvement characteristic of the disease. It is not true mastitis nor is it of any particular interest to the surgeon.

Metastatic colonization of typhoid bacilli may occur in the breast, however, and lead to suppuration that may become of surgical importance. This is, however, an extremely rare complication of typhoid fever of which Berg saw only four cases among r626 enteric fever patients-a percentage incidence of 0.02 . Even this must be considered a very high estimate as only 32 cases are recorded in the literature. Eighteen of these were collected by McCrea, in r902. In I9I3 Coste added five additional cases to the list. We now add six additional published ones that had apparently been overlooked, thus making a total of 32 cases in the literature. References to the writings and the number of cases reported are given in the following table:

Tabie II.-Mastitis as a Complication of Typhoid Fever: Cases Reported in the Literature to MAX I, IgI 5

Leudet: Clin. méd. de l'Hotel-Dieu de Rouen, I $873 \ldots \ldots \ldots \ldots \ldots \ldots, 4$ cases.

VallnN: Bull. de la Soc. Clin. de Par., I877, r, I $48 \ldots \ldots \ldots \ldots \ldots \ldots$ r case.

Delgrange: Jour. des. Sc. méd. de Lille, r88o.................. I case.

Berg: Deut. Archiv f. klin. Med., I895, $54,16 x \ldots \ldots \ldots \ldots \ldots \ldots \ldots \ldots$ cases.

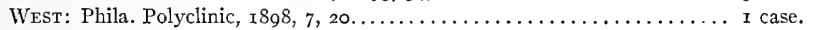

DestréE: Jour. de mèd. chir. et pharmacol., Brux, r 89 r, $449 \ldots \ldots \ldots \ldots 2$ cases.

Lichtheim: Reported by Tavel, in "Über die Etiologie der Strumitis,"

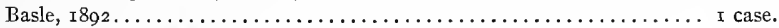

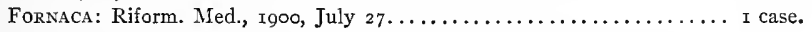

Capeilari: Corr. Sant. Milano, 1900, I1, $88 \ldots \ldots \ldots \ldots \ldots \ldots \ldots$ r case.

Curschmann: Encyclopædia of Practical Med, Translation I9oi, Phila., Pa.,

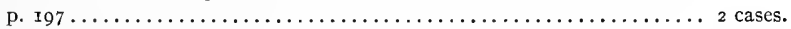

McCrea: Johns Hopkins Hosp. Bull., 1902, 13, $21 \ldots \ldots \ldots \ldots \ldots \ldots \ldots, 3$ cases.

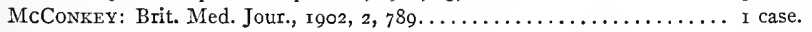

HANRIOT: Thèse de Nancy, Ig04 ......................... 2 cases.

Thayer: Johns Hopkins Hosp. Bull., 1906, I $7,60 \ldots \ldots \ldots \ldots \ldots \ldots \ldots$ case.

Guiraud: Montpel. méd., 1907, 24, II $4 \ldots \ldots \ldots \ldots \ldots \ldots \ldots \ldots \ldots \ldots$ r case.

SoulirR: Thèse de Montpellier, Ig07....................... I case.

(This case apparently reported previously by Roger-Montpel. méd.,

I907, 25, 35-as a personal observation.)

Roger et Margarot: Montpel. méd., I909, 29, $234 \ldots \ldots \ldots \ldots \ldots$. case.

Roger et SAPPEX: Montpel. méd., I IIo, $30,235 \ldots \ldots \ldots \ldots \ldots \ldots \ldots \ldots$ I case.

Garnitr et Roger: Montpel. méd, $1913,37,82 \ldots \ldots \ldots \ldots \ldots \ldots \ldots$ I case.

Davis, Patterson and Hewlitt: Amer. Jour. Med. Sc., cii, $778 \ldots \ldots \ldots \ldots$ I case. 
Sex.-Four cases of typhoid mastitis have been observed in men: two by Curschmann and two by Destrée. Curschmann's patients were comparatively young men and the inflammation was of very minor degree. Destrée's patients on the contrary suffered with abscesses of the breast, in both instances due to staphylococcic infection.

Age.-The average age of 22 cases of this series was 23.I years. The youngest patient was a girl aged I 5 years, under the care of Capellari; the oldest, a woman of 40 years, reported by Fornaca. Eleven of the patients were 25 years of age or younger, while only four were over 35 years of age.

Predisposing Causes.-Careful analysis of the reported cases fails to show an important predisposing cause for typhoid mastitis. Certainly the statement of Garnier and Roger, to the effect that "the disease occurs especially in multipara who have strained (overworked) the breasts," is without statistical foundation. Four of the reported cases occurred in men and the remaining ones are equally divided between nulliparous and multiparous women. Only two of the patients were lactating women (McCrea's case and Guiraud's case), and only one woman in the series was pregnant (Roger and Margarot's case). Traumatic injury is not mentioned as a possible cause, although in the cases reported by West and Thayer the complication followed the submammary injection of medicinal solutions and it is reasonable to attribute the infection to the treatment. Otherwise the only predisposing causes of any moment are age and sex, the majority of cases having occurred in young women.

Pathogenesis.-The clinical types of typhoid mastitis are two in number, viz. the suppurative and the non-suppurative. The latter is usually caused by the Bacillus typhosus; the former may be the result of a mixed infection (Thayer's case), although either the staphylococcus or the typhoid bacillus has been found alone in the majority of instances (Table III).

It is a well-known fact that the bacteria are contained in the various excretions and secretions of the body in typhoid fever, and this is generally believed to hold true for the milk, although Basch and Wileminsky maintain that typhoid bacilli are only excreted with the milk from diseased breasts. The basis of this opinion is their failure to find typhoid bacilli in the milk of experimental animals whose blood was surcharged with them.

The presence or absence of Bacillus typhosus in the milk of typhoid mastitis patients is of little practical moment, however, since only two of the reported cases occurred during the lactation period. It is of interest to recall in this connection that the child of one of McCrea's patients developed the premonitory symptoms of typhoid fever, but these were later found to be of gastro-intestinal origin.

We have included in the list of suppurative cases only those in. which abscesses that necessitated incision and drainage developed. The series includes ${ }_{3} 3$ suppurative and Ig non-suppurative cases.

Cultures were taken from the pus in eight of the 13 suppurative cases, and in one non-suppurative case the fluid obtained by aspiration was cultured and Bacillus typhosus found (Fornaca's case).

Table III.-List of the Cultivated Microörganisms:

Staphylococcus .................. case

Staphylococcus...................two cases

Staphylococcus and Bacillus typhosus......... one case

Bacillus typhosus.................. cane case

Bacillus typhosus..................... case

Bacillus typhosus................... cane

Bacillus typhosus.................. one case

Bacillus paratyphosus................. cane

$\begin{array}{ll}\text { female } & \text { McCrea } \\ \text { males } & \text { Destree } \\ \text { female } & \text { THAyER } \\ \text { female } & \text { ForNaCA } \\ \text { female } & \text { DAvis } \\ \text { female } & \text { McCoNkEy } \\ \text { female } & \text { HANRIOT } \\ \text { female } & \text { SoULIER (Roger) }\end{array}$


Symptoms.-Mastitis may occur at any time during the febrile state of typhoid fever, or during the stage of convalescence after the temperature has remained normal for days or even weeks. In a remarkable case reported by McConkey, an abscess developed in the breast of an unmarried woman aged 38 , six months after recovery from an attack of typhoid fever. The diagnosis cannot be questioned, in this instance, as the typhoid bacillus was found in pure culture in the pus and a positive Widal reaction was obtained for the diluted sero-purulent fluid contained in the abscess. Further to confirm the diagnosis, a 48-hour broth culture of the organism was injected into guineapigs with fatal results, and the same organisms were recovered from the spleens of the animals.

In contrast with the rare appearance of the mastitis as in the foregoing, the case reported by Roger and Margarot may be cited, in which the inflammation appeared on the sixth day of the fever. This patient, a woman aged 25 , was in the third month of pregnancy when the disease began, and it seems probable that the functional activity of the glandular epithelium predisposed it to infection.

In the majority of instances the mammary complication appears in the third or fourth week of the fever, in other words, during the stage of the decline of the disease. The average time of onset in the present series (excluding McConkey's case) was 25 days.

It is of interest to note that those cases of non-suppurative mastitis which occur during the primary course of typhoid fever may recur with each relapse of the disease (McCrea's second case), although we know of no instance where mastitis complicated relapse alone.

In some instances the acute symptoms subside but an induration remains that later undergoes softening with abscess formation. This happened in one of the cases reported by Hanriot. The time interval that elapsed between the subsidence of the acute inflammation and the development of the abscess was five weeks (the seventy-seventh day of the typhoid fever). The Bacillus typhosus was cultivated from the pus of this abscess.

The duration of the disease varies in different cases, but non-suppurative typhoid mastitis usually resolves completely within a week or ro days from its time of onset. Suppurative cases are of course slower to resolve, but there is not the tendency to widespread involvement of the breast, so characteristic of certain types of lactation mastitis, so that notwithstanding the debilitated condition of the patient, recovery from this complication may be expected within from ro days to three weeks.

When the disease attacks both breasts its course is prolonged because the involvement is rarely simultaneous.

In the ro bilateral cases in this series, simultaneous involvement of the- breasts was noted in only one instance (one of Leudet's cases). This was a non-suppurative case in which the inflammation appeared in the breasts on the twenty-second day of the fever. Caroline West's case is sometimes cited as an instance of bilateral suppurative mastitis occurring simultaneously, but this is a misquotation, for while the actual pus formation seemed to appear in both breasts about the same time, she distinctly states that the left breast was the first to become inflamed. The interval between the onset of the disease on the two sides in bilateral mastitis varies from one day (Davis's case) to ${ }_{7} 7$ days (Fornaca's case); the average being about four days. The inflammation in one breast may go on to suppuration, and that in the other subside.

Typhoid mastitis begins with pain followed shortly by a swelling or induration of the affected breast. The pain may be very severe, but is more often moderate and of a 
"sticking" character. The swelling or induration varies from the size of an almond to that of an orange. In 22 cases in which mention is made of the side involved, the right breast was affected four times, the left eight times, and both ten times. Typhoid mastitis may involve any part of the breast, but the outer half of the organ is the seat of predilection. The upper outer quadrant is as often diseased as is the lower outer quadrant. In two instances (Lichtheim's and Delgrange's cases) the inflammation was confined to the center of the breast. In Delgrange's patient, the areolar tissues became swollen to such an extent that the nipples were entirely hidden from view. The skin overlying the inflamed area becomes reddened, especially in the suppurative cases, and the breast is exquisitely tender at this point. The axillary lymph nodes were inflamed in only one instance.

With the onset of the mastitis, the fever usually assumes the septic type, but it is possible that the temperature curve will not be influenced, or, if the mastitis appear during the afebrile stage of convalescence, it may progress to pus formation without any temperature reaction.

Uterine hemorrhages occurred in two of Leudet's cases and nasal hemorrhage in a third, but these complications have not been observed by others.

Mastitis in typhoid fever does not materially alter the leucocyte count of the blood even in suppurative cases, as the following records of four cases show:

TABLE IV

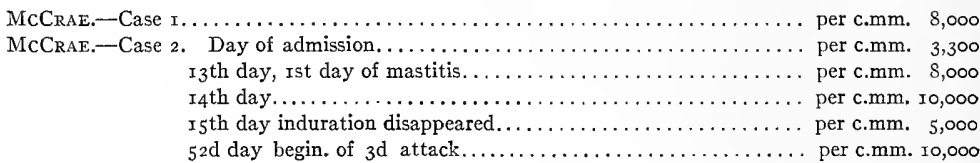

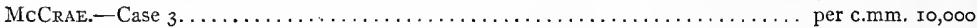

Davis.-Case 4. Mastitis began 39 th day of the fever. Leucocyte count on the 49 tb

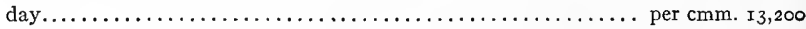

Prognosis.-Mastitis is not a serious complication of typhoid fever; it neither prolongs nor influences the course of the disease to any appreciable extent. One of the cases (Leudet's) terminated fatally on the twenty-ninth day of the fever, but the mastitis which had almost completely subsided at the time of death, contributed but little, if any, to the fatal issue. Mastitis occurring late in the disease may prolong convalescence. The great majority of cases terminate in complete resolution; in one instance the breast subsequently calcified. This patient was a girl, aged $x 6$ years, who was admitted to the Johns Hopkins Hospital in Thayer's service. Profuse hemorrhage from the bowels occurred on the nineteenth day of the disease, for which calcium lactate was prescribed. An infusion of $500 \mathrm{cc}$. of a $\mathrm{I}$ per cent. solution of calcium chloride was given under the left breast. On the thirty-fifth day of the disease a large abscess developed in the left breast, from the pus of which Staphylococcus aureus and the typhoid bacillus were recovered in culture. Eleven days after incision of the abscess had been made, "a sclerotic rim extending back at least $4 \mathrm{~cm}$. from the opening of the wound was noticed around the edges of the breast. Numerous white spots and streaks, stony to the touch, were seen in the pale granulation tissue. A probe introduced into the wound touched calcified tissue." This case was not tuberculous as was proved by microscopic examination. The calcified material was found to consist of phosphate of lime. 
Treatment.-The treatment of non-suppurative typhoid mastitis consists of the application of cold compresses and a firm mammary binder. When abscesses form they must be opened and drained.

2. Acute Pyogenic Mastitis in the Adult Male Breast.-Acute inflammation of the male breast is an exceedingly rare condition and is attributable, in the majority of instances, to traumatic injury, though it may arise as a complication of one of the infectious diseases. The inflammation, in either instance, seldom proceeds to abscess formation. The two cases outlined below are interesting, not only because pyogenic abscesses are rare in the male breast, but also because in one of them the disease arose without any apparent cause, and in the other the colon bacillus was obtained in pure culture from the abscess. The latter case is that of J. H. S. aet. 25, who had been under the care of one of the authors $(\mathrm{H}$.) for the treatment of prostatitis and epididymitis of gonorrheal origin. These conditions had practically disappeared when the trouble in the breast began, with a slight drawing sensation in the region of the left nipple. The next day he felt a lump "under the left nipple" and noticed that the breast was reddened

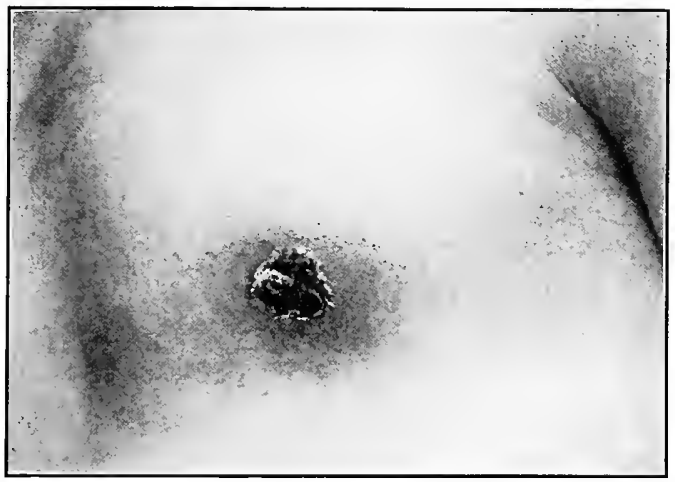

FIG. 107.- Suppurative mastitis of the male breast.

and tender. The lump gradually increased in size and four days from the time of its first appearance, the patient noticed stiffiness of the left side of his neck. He then presented himself for treatment. He had not had any chills or other general symptoms, and his temperature was found to be normal. Examination showed a reddened swelling to the upper outer side of the left areola where a painful nodule could be palpated though fluctuation could not be demonstrated and the axillary lymph nodes were not involved. Examination of the neck showed nothing abnormal. A diagnosis of mastitis was made and the breast treated with salves and compression. In the course of four days, fluctuation could be determined, an abscess was opened, and about one ounce of pus removed. The pus contained the colon bacillus in pure culture. The patient recovered promptly and remained well for a period of three months when a large carbuncle appeared on the back of the neck. This was excised. An autogenous vaccine was made from a culture of Staphylococcus aureus obtained from the pus and was administered. The patient quickly recovered and has since remained perfectly well. 
Griffith describes the following somewhat similar case:

- "The patient, aged 33 years, complained of a painful swelling in the left breast which had appeared about four days before coming for treatment. The breast was found to be swollen, resembling the gland of a well-developed female of $\mathrm{r} 6$ or 17 yearj. It was hard, tender, hot and its surface glazed and had an inflammatory blush. The nipple, occupying the center of the swelling, was somewhat retracted and imbedded in the inflammatory mass, a whitish liquid oozing from its surface. The axillary glands were enlarged and tender, the entire left arm and forearm were painful, tender and somewhat swollen.

Treatment with fomentations, leeches, etc., gave no relief. Incision was made, although there was no distinct fluctuation, the next day, and yielded a quantity of sero-purulent material. Bleeding was encouraged by fomentations and by the application of poultices. Relief was speedily obtained and the breast soon resumed its normal condition. The patient showed a tendency to develop boils in other parts of the body."

The reader will find similar cases reported in the theses of Moizard and Robelin.

The following case is an example of subacute mammary abscess of undetermined origin, in the male:

Solomon R., aet. 47, was admitted to the German Hospital of Philadelphia in July, rgrr, with a painful swelling in the right breast. This trouble began four weeks previously with a pricking pain in the region of the right nipple. The patient was at a loss to explain his condition and stated that he had not been injured nor had he suffered with an infectious disease.

Soon after the onset of the pain, a swelling appeared in the breast. "This slowly increased in size, was painful to the touch, and later became the seat of pain of moderate severity. Examination showed a small, hard, tender and nodular swelling behind the right nipple. The nipple itself was normal and no discharge could be obtained from it on pressure. The nodule was excised intact and on gross examination presented the appearance of a non-encapsuled mass of fibrous tissue. Section of the "tumor" revealed an abscess surrounded by dense fibrous tissue arranged in distinct lamina. The abscess contained a small quantity of thick purulent material. The microscopic diagnosis (pathological specimen 6595) was "acute and chronic suppurative mastitis."

3. Chronic Mastitis in the Adult Male Breast. - Chronic Hypertrophic Mastitis, Chronic Induration, Chronic Indurative Mastitis, Chronic Interstitial Mastitis, Chronic Diffuse Interstitial Mastitis, and Chronic Sclerosing Mastitis are terms given to chronic enlargements of the adult male breast, resulting from increase fibrous connective tissue supposed to be of inflammatory origin.

The condition is a distinct pathological entity, although difficult at times to distinguish clinically from certain forms of the benign mammary tumor and from chronic pyogenic mastitis. This condition, well-advanced examples of which are rarely met with, is characterized by an overgrowth of fibrous connective tissue, followed by induration and enlargement of the breast, so that the descriptive term, chronic hypertrophic mastitis seems to be the most appropriate. The newly formed connective tissue does not seem to share, with similar tissue occurring elsewhere, the tendency to atrophy and contraction. It is, strictly speaking, therefore, an example of fibromatoid formation, but differs from true tumors in structure as well as in its clinical course.

Incidence.-The first clinical description of the disease was written by Sédillot, in I 834, who had operated upon a patient in the belief that the condition was carcinomatous. Velpeau ( 1858 ) mentions the existence of chronic mastitis, in man, which he terms, "chronic induration." The condition was first studied histologically by Hassler in I894. Niclot and Massoulard have written the best account of it, basing their deductions upon an analysis of twenty collected cases. They, in common with others, express the belief

${ }^{1}$ See also Wounds and Injuries, Tuberculosis, Syphilis, Actinomycosis and Sporotrichosis. 
that the disease is more frequent than is commonly supposed; though it rarely attains clinical importance.

Etiology.-Much uncertainty exists as to the nature of chronic hypertrophic mastitis of the male breast. Many look upon the condition as infectious, but attempts on the part of Niclot and Massoulard and of Vaccari to prove this by bacteriological methods, failed. The disease is said to follow acute mastitis in one-third of all cases, and this, together with the fact that it sometimes follows parotitis or other infectious processes, argues against the aseptic theory of its origin. Undoubtedly, the majority of cases arise in the absence of a primary inflammatory focus, while in a considerable proportion of cases no etiological factor can be found. Traumatic injury is the most evident cause in a large percentage of cases, and so close is this relationship, in many instances, that the conclusion would seem to be inevitable that the trauma actually produced the disease. But traumatic influences can be denied on the grounds that in no other part of the body is injury followed by the production of a progressively increasing mass of scar tissue similar to that found in chronic hypertrophic mastitis. Nicaise answers this argument with the suggestion that the trauma may lower the resistance of the mammary tissues so that the microörganisms normally present in the milk ducts are enabled to induce a more or less continuous inflammatory reaction. Niclot and Massoulard maintain that an abnormal evolutionary process, similar to that exercised on the breasts of young girls during puberty is excited by the trauma. It is inconceivable that trauma alone would set up an inflammatory process continuing over a long period of time, yet, the fact remains that trauma is the primary etiological factor in the majority of cases of chronic hypertrophic mastitis in the male. According to Huguet and Péraire, indurative enlargement is the usual result of traumatic mastitis in men. A contusion of the male breast commonly causes acute mastitis, which usually subsides completely. It may, however, be the starting point of an abscess, or of a malignant tumor, usually a sarcoma, or, finally, after a longer or shorter period of time, indurative enlargement may appear.

Military life seems eminently to favor the development of the latter condition. Thus, I 3 of the 18 patients in the series collected by Niclot and Massoulard were soldiers, six belonging to the infantry, four to the cavalry and three to the marine branch of the service. Seven of these patients gave a history of some trauma incident to the service. The pressure of the straps of knapsacks apparently produced the disease in the case of the two infantrymen, a factor to which Barrey (Robelin) first drew attention. According to Niclot and Massoulard, the same holds true for the cavalrymen, whose rifle straps pass in front of the right breast. This was the side affected in all of the four cases included in their report. In a case reported by Düms, the patient was struck on the right breast by a bayonet; another patient; whose case is reported by Duguet, was struck on the breast by his horse's head.

The histories of Vaccari's four cases illustrate the uncertainty that attaches to any given etiological factor; two of these patients gave a clear history of severe trauma, another had had an attack of acute mastitis I 2 years previously which left a nodule which remained quiescent for a long period of time, and then became painful and increased in size; in the fourth case no apparent cause for the disease could be found.

Lévèque believes that the majority of the cases of chronic mastitis in adult men are infectious. His opinion is based on his experience with seven cases, all of which occurred in soldiers. The fact that influenza and bronchitis preceded the development of the 
mammary enlargement in several of these patients would not seem to warrant the conclusion of their infectious origin.

Clinical Course and Symptoms.-Chronic hypertrophic mastitis is a disease of adult life; the average age in the cases reported by Niclot and Massoulard was 26 years, the extremes, 18 and 50 years. In 3 I cases that we have collected from the literature, the right breast was affected ${ }_{7} 7$ times, the left breast to times and in the remaining four cases the disease was bilateral.

While in a few of the reported cases congenital anomalies of the sexual organs were noted, there is no reason for believing that men so afflicted are more susceptible to chronic hypertrophic mastitis than are normal men.

The principal symptoms of the disease are pain and tumor. Pain is not a constant symptom but one that usually accompanies the disease at some stage of its development. In traumatic cases the patient experiences pain of varying degrees of intensity immediately after the receipt of the injury but this disappears only to recur later with the appearance of the lump in the breast, which may not be appreciable for many months after the injury.

Spontaneous pain is less severe, as a rule, than that caused by pressure, but in exceptional instances the pain may be constant and so severe that the patient will demand operation on account of it. In other instances the pain disappears, entirely, after a time, while the swelling remains stationary or continues to increase. Sometimes the pain is slight but continuous throughout the course of the disease. The breast is invariably tender to the touch. The pain sometimes follows the appearance of the lump, as was the case with Düms' patient. In this instance the tumor was palpable several weeks after the receipt of an injury. It was three months before the first painful sensations were felt and they gradually increased in severity for two and one-half months, when it became necessary to remove the breast to give the patient relief. The breast in the meantime had continued to enlarge.

A breast that is the seat of a chronic hypertrophic mastitis appears uniformly enlarged and resembles the breast of a young girl about the age of puberty. This is due to the fact that the mass generally occupies the central part of the organ and is associated with a deposition of fat. The mammary skin is normal and shows the normal venation. The nipple is more prominent and the areola is likely to be more pigmented than normally, thereby increasing the resemblance to the young adult female breast. There is no deformity of these structures and there is no discharge from the nipple in uncomplicated cases. It is, therefore, very difficult to differentiate the condition from gynecomastia (q.v.) with which it may be confused, and of which it is no doubt an occasional cause.

On examination the entire breast may be found to be affected, a condition to which the term diffuse interstitial mastitis is sometimes given. More often, however, one or more hard nodules are found surrounded by normal glandular tissue and fat. These nodules are usually situated directly beneath the nipple and areola in the midst of the large duct terminals.

In other cases nothing is demonstrable on palpation except an increased density of one segment of the breast. Where no definite nodules are present, palpation gives the impression of one or more small foreign bodies imbedded in an otherwise normal breast. The nodules vary in size from that of a pecan nut to that of an orange. They are definitely outlined, smooth, hard and freely movable. They are not encapsulated but infiltrate the adipose tissue which surrounds them. Painful enlargement of the 
axillary lymph nodes which was associated with three of Niclot and Massoulard's 20 cases disappeared after excision of the diseased breast.

Diagnosis.- Chronic hypertrophic mastitis should be differentiated from gynecomastia, tuberculosis, and other specific inflammations, and from certain types of neoplasms. The breast in true gynecomastia is structurally identical with the normal breast of the young adult female and entirely lacks the indurated nodules characteristic of this disease.

The chronic sclerosing types of mammary tuberculosis and other specific inflammations of the breast cannot always be distinguished from chronic mastitis, indeed, not a few of the reported cases of indurative mastitis appear to have been either tuberculosis or syphilis. Malignant tumors may be differentiated by their more rapid growth and by their resistance to the therapeutic measures that usually bring about improvement in mastitis. Benign tumors of the male breast are usually well encapsulated and grow progressively despite treatment.

Prognosis.-Chronic hypertrophic mastitis usually resolves with proper treatment, although operation may become necessary for the relief of pain.

The results of operation are invariably satisfactory. There seems to be little or no danger of malignant transformation in cases treated palliatively.

Treatment.-Palliative treatment should be given a thorough trial in all cases before resorting to operation. It consists in the application of an ointment containing iodine, mercury or ichthyol and a firm binder and the internal administration of the iodides of sodium or potassium and mercury.

Lévèque recommends the injection of fibrolysine, but does not mention the results obtained with its use. When operation becomes necessary on account of pain or for cosmetic reasons, the method of plastic resection is most satisfactory.

4. Chronic Interstitial Mastitis.-Under this term we refer to two distinct clinical types of fibrosis: first, that in which a destroyed portion of the mammary parenchyma has been replaced by scar tissue; and second, that form of sclerosis described by Billroth, in which the entire breast is slowly transformed into a small, hard, shrivelled knotty mass of scar tissue. This latter type of the disease is extremely rare and is indistinguishable clinically from atrophic sclerosing carcinoma. We have had no opportunity to study the disease microscopically as all of the suspected cases that have come under our observation eventually turned out to be atrophic scirrhus cancer. It will be remembered that spontaneous cure of carcinoma in aged women sometimes results from excessive fibrosis, and it is possible that the disease to which Billroth refers is not, after all, uncomplicated sclerosis but in reality carcinoma undergoing fibrotic cure. Should the carcinoma be the underlying factor, the excessive formation of scar tissue may be looked upon as nature's attempt to overcome the malignant disease. It is, therefore, unwise, as will be stated elsewhere, to interfere with this natural process, especially in the case of very aged women. This equally applies to atrophic or sclerosing fibrosis of the breast in the absence of pain or other symptoms that might otherwise seem to indicate operation. So little mention has been made, in recent times, of the condition to which Billroth refers, that we are inclined to believe that the disease, in the majority of instances, certainly, is a malignant one associated with an excessive production of fibrous tissue. True examples of the disease have been known to follow widespread infections of the breast-panmastitis-in which practically the entire gland is replaced by a mass of scar tissue that continues to contract until the breast is finally replaced by a dense irregular mass indistinguishable from atrophic scirrhus cancer. Amputation 
of the breast is now practised in the acute stages of pyogenic panmastitis so that such terminal results are rarely met with.

Localized areas of fibrosis in the breast are identical in physical characteristics whatever cause underlies their development, and examination of the cut surface or even microscopic study may fail to show the etiological factor. If we exclude cases caused by the tubercle bacillus or other specific infection, the majority of the remaining cases will be found to comprise scars marking the seat of previous attacks of acute pyogenic mastitis. Many of the patients will recall having had acute mammary abscess during a previous lactation, a few will give a history of acute mastitis complicating an infectious disease, while others will recall a severe trauma of the breast that was followed immediately by a localized swelling and perhaps by discoloration of the overlying skin. The fibrosis in the latter cases is indicative of an organized hematoma. A few patients will state that the hard spot followed the removal of a mammary tumor; in this case the organization of the tumor bed has formed a fibroid nodule. A rare cause of chronic mastitis is inflammation with obliteration of a galactocele or simple cyst.

In speaking of chronic mammary abscesses we call attention to the recurrent or residual type which arises at the site of an acute abscess many years after apparent cure. This serves to illustrate the possible latency of pyogenic infection and it is conceivable that the microörganisms might continue to live within the tissues without producing abscesses, yet at the same time exerting enough irritation to excite connective tissue formation.

Diagnosis.-Countless numbers of women who are operated upon for acute mammary abscess and recover, remain perfectly well. Others notice nothing abnormal until about the time of the menopause when without apparent cause the breast or breasts become painful and tender. Examination may reveal one or more scars on the surface of the breast and an irregular area of tender induration underlying them. Excepting the tenderness, exactly the same condition will be found in women whose breasts have given them no trouble since a previous attack of acute mastitis. The surgeon will now seek to find if there be any demonstrable organic lesion present other than the fibrosis. An inexperienced man will have little difficulty in assuring himself that the breasts of any middle aged woman who complains of pain and tenderness are diseased, and recalling the advice of various authorities on the subject that these patients are in great danger of developing carcinoma, his course of action will very likely be radical. The advice of the one whose experience has taught him that the same physical characteristics are to be found in the breasts of women who have never had a symptom will be correspondingly conservative. In no other condition is the difficulty of formulating rules of practice greater, even for the most experienced surgeon. But there must be some practical method of separating the cases that should be operated upon from those that should be treated conservatively. Our course, in dealing with these cases is essentially the same as that recommended for abnormal involution (q.v.). In the first place, a detailed history of the case is taken so that an idea may be gained of the approximate amount of breast tissue that was destroyed at the time of the acute inflammation. An estimate is made of the probable nervous factor entering into the production of the symptoms, and it is surprising how often the onset of symptoms coincides with the time of the patient's discovery that an acquaintance or relative has a tumor of the breast - probably a cancer.

Examination of both breasts must be thorough and the physician must assure himself of the presence or absence of a definite nodule or tumor in the breast. Definite more 
or less circumscribed tumors are seldom-we would like to say never-found in uncomplicated cases of chronic interstitial mastitis or abnormal involution. 'Dimpling of the skin may result from the contraction of an incisional scar or arise as a result of organization of an abscess or hematoma that involves the deep layer of the skin. Localized dimpling, as frequently occurs after the healing of a chronic sinus of the breast. Broad attachment of the tumor to the suspensory ligaments of Cooper with the widespread dimpling of the skin so often seen in carcinoma of the breast is never associated with simple chronic mastitis. Retraction or displacement of the nipple commonly results from the contraction of an incisional scar following a sub-areolar abscess.

Palpation of the breast should always be made with the hand placed flat on the chest or with the flat of the fingers; the breasts of an adult woman who has borne children contain indurated areas that closely mimic tumors when "picked up" between the thumb and fingers, and especially in obese women the differentiation between these areas and neoformations may be most difficult. In cases of chronic mastitis a sense of increased density is imparted to the palpating hand, placed flat on the breast, but definite nodules can rarely be felt. The presence of the latter almost invariably denotes either carcinoma, a benign tumor, a small cyst or a chronic abscess. Enlargement of the axillary lymph nodes is rarely associated with chronic mastitis, although they frequently become enlarged and tender in cases of abnormal involution. In the absence of a history of injury or previous abscess formation, the diagnosis of the cause of chronic mastitis becomes exceedingly difficult and often impossible. Tuberculosis and syphilis must be ruled out by the various laboratory tests. If syphilis be suspected the administration of the iodide of mercury is indicated. If the Wassermann test of the blood shows a strong positive reaction, it is justifiable to administer neosalvarsan before resorting to any operative treatment even if there are good reasons for believing that the condition in the breast is due to some cause other than syphilis.

If the diagnosis cannot be made in spite of all examinations and tests and the patient is not suffering acutely, it is advisable to suggest palliative treatment for a time and keep her under close observation.

Treatment.-Patients with chronic mastitis come to the surgeon either because they fancy that a tumor is growing in the breast or because of pain and tenderness in a scar that had existed for some time without causing any trouble. If the physician find a nodule in the breast he should advise immediate operation. Nodule formation in the breast of middle-aged women is a matter of serious importance and the fact that the classical symptoms of carcinoma cannot be demonstrated is no justification for delay. If the individual be obese and the surgeon cannot assure himself that the breast is free of nodules it is a safer plan to advise operation. Whether the carcinoma, if present, has developed from the area of chronic mástitis, is not the question; the practical point of the matter is that the great majority of lumps or nodules in the breasts of middleaged women are cancers and the earlier the cases are operated upon the better is the prognosis.

The method of operation in chronic mastitis cases is exactly the same as that given for abnormal involution (q.v.), and need not be repeated here. Palliative treatment is indicated in cases in which definite nodules cannot be felt. The breast should be examined at frequent intervals for changes in the size, density and configuration of the indurated area.

Patients with chronic mastitis associated with marked sensitiveness of the breast, are benefited by mild counter-irritation in the form of tincture of iodine. Small 
blisters are sometimes useful in severe cases. The breasts should be supported by a suitable binder so adjusted that firm, even pressure is exerted, or wide strips of adhesive plaster may be applied for the same purpose, the breast itself being protected by a square of lint or gauze. Ointments containing mercury and belladonna or ichthyol give a measure of relief in some cases. It is important to look after the general health of the patients. The majority are anemic and neurasthenic, so that the administration of iron and arsenic or other tonic remedies is usually necessary. In many cases the subjective symptoms referable to the breast disappear when the general health improves and the climacteric becomes fully established. The routine internal use of mercury and the odides is recommended by some and can do no harm.

5. Chronic Pyogenic Abscesses of the Breast.-Chronic abscesses of the breast are usually tuberculous and are usually due to a mixed infection by the tubercle bacillus and staphylococcus. Simple, non-tuberculous chronic abscess is one of the rarest forms of mammary infection and is seldom met with. Its cause is very obscure. The onset is slow and insidious and it may clinically resemble carcinoma or other tumor, and be so diagnosed in many instances. Chronic abscesses not infrequently rupture externally with the production of a chronic sinus or sinuses, but may become organized, after a time, into a mass of fibrous tissue. A small collection of pus may lie above a large mass of scar tissue and not be recognized before operation. In many cases small abscess cavities are entirely surrounded by thickened and dense walls of connective tissue so that the presence of the pus cannot be clinically demonstrated. Such cases closely simulate scirrhus carcinoma. In still another group of cases, the pus is situated in the deep portions of the breast and is covered by a thick wall of scar tissue that makes the pre-operative diagnosis extremely difficult. Chronic abscesses in the breasts of young nulliparous women are almost without exception of tuberculous origin, the only other causes of the condition being syphilis, actinomycosis and in the rarest instances pyogenic infection or sporotrichosis. The majority of chronic abscesses other than those due to tuberculosis occur in older women, although the latter are not immune to tuberculous infection of the breasts. So the fact that the patient with a chronic abscess of the breast is 40 or more years of age, is no proof of the non-tuberculous nature of the infection.

The majority of cases of uncomplicated pyogenic abscesses are divisible into four groups, viz., (a) cases of lartation mastitis that are subacute or chronic from the beginning; (b) cases in which the onset is preceded by a blow, followed sooner or later by a lump that eventually undergoes softening with abscess formation; (c) recurrent or residual abscesses which occur in the breasts of women who have had an acute lactation abscess, often many years removed; and finally, $(d)$ chronic abscesses of the breast due to necrosis of an underlying rib. Other and rarer causes of chronic mammary abscesses are infection of simple cysts, carcinomatous and other tumors and galactoceles, and finally the invasion of the breast by the pus of a pointing empyema.

Subacute lactation mastitis often runs a slow insidious course with the formation of a mass of sclerotic tissue that surrounds an abscess cavity. These patients apparently improve after a time but a palpable mass remains or gradually contracts and disappears. Or the mass slowly increases in size to soften and spontaneously open, leaving behind a chronic sinus. In other instances the mass remains quiescent for months or even for years, and then, without apparent cause, or as is more often the case, during the course of a subsequent lactation, a large abscess develops. Residual abscesses, that result from recrudescence of the infection, in cases of acute mammary 
abscesses that had been opened and drained, are likely to point at the site of the incisional scar. In both of the foregoing groups of cases the pus is attributable to the activities of bacteria that had remained dormant within the breast tissues for long periods of time.

More uncertainty of diagnosis attaches to cases of chronic abscess in the breasts of women of middle age. These patients present themselves with hard lumps in the breast which they often attribute to blows received some time previously. The lump is usually irregular, an infiltrating mass of great density often underlying a retracted nipple. There may be a demonstrable point of softening in the center of the mass, but as a rule the physical characteristics of abscess are entirely absent. The axillary lymph nodes are rarely enlarged and pitting of the skin does not occur except in the rarest instances. In dealing with cases of this kind the surgeon is often chagrined to find that he has performed an unnecessary radical excision of the breast for a chronic abscess with much thickened walls. The only absolute method of pre-operative diagnosis in these cases is by means of a preliminary incision in to the mass or by the use of the aspirating needle which, however, is seldom entirely satisfactory.

Chronic suppurative mastitis occasionally arises as a result of ulceration of an inverted nipple as in the following case:

Mrs. B., aet. $7 \mathrm{I}$, was admitted to the German Hospital of Philadelphia, March ro, I9I0, complaining of a lump in the left breast and a "running sore" of the areola. The trouble was first noticed by the patient two weeks before admission. The nipples were congenitally inverted. The patient had never been pregnant. She stated that her attention was called to the disorder in her breast by a discharge of pus from an opening in the areola, whereupon she examined the breast and found a Iump under the areola. The breast was not painful.

Examination revealed a nodule 2 by $2.5 \mathrm{~cm}$. situated just below the left nipple, and a small area of ulceration, which discharged pus, in the lower margin of the areola. The skin overlying the nodule was smooth and reddened; the nodule itself was firm, movable and not tender. The axillary glands were palpably enlarged. Simple amputation was done. Pathological diagnosis "chronic suppurative mastitis with superficial ulceration." Specimen 5364.

Necrosis of the ribs underlying the breast is usually of tuberculous origin; the chronic mammary abscess succeeding this condition may be either retro-mammary or intraglandular in position, the latter often being connected with the primary focus by means of a long narrow fistula. The primary focus is rarely discovered before the breast is opened and even then may escape recognition until the fistula that usually follows the operation is probed and dead bone found. The following rules may be of service in differentiating chronic mammary abscesses from tumors and other diseases of the breast:

I. The majority of chronic abscesses of the breast are associated with more pain than the diseases for which they may be mistaken. Carcinoma especially is a painless disease in its early stages.

2. Fluctuation can rarely be demonstrated in chronic mammary abscesses, and the classical symptoms of acute inflammation, with the exception of localized tenderness, are wanting.

3. Chronic abscesses in the breasts of young unmarried or sterile women are usually tuberculous.

4. Chronic abscesses of the breast that have quickly formed sinuses are usually tuberculous.

5. A mass of fibrous tissue resulting from an acute lactation abscess, that remains quiescent for a time and then undergoes softening, usually indicates the presence of a residual abscess of the chronic pyogenic variety.

6. Masses that have existed in the breast for a long period of time without producing pitting of the skin, and which give rise to a great deal of pain, are most likely not carcinomas. 
7. In all doubtful cases the various laboratory tests for syphilis and tuberculosis should be made before resorting to operation.

8. If operation is decided upon and a reasonable doubt exists as to the nature of the affection, a preliminary incision should be made into the mass.

Treatment.- When the abscess is large, central in position, and surrounded by a thick wall of sclerotic tissue, simple amputation should be performed, especially if the patient is a middle-aged woman. In simpler cases, where peripheral areas of the breast are diseased, excision of the abscess bearing area suffices. Simple incision and drainage is all that is required in other cases.

6. Chronic Sinuses and Fistulas of the Breast.-These disturbances frequently follow acute pyogenic abscesses that have been improperly drained. Subacute or chronic pyogenic abscesses with thick and unyielding walls that open spontaneously, or that are incised, but allowed to heal too soon, so that healing does not take place from the bottom of the cavity, are often followed by a chronic sinus. These cases are often but not always attributable to an ancient lactation abscess. Chronic sinuses commonly form in the course of tuberculous mastitis, especially in the nodular variety of that disease. Tuberculous abscesses of the breast usually discharge spontaneously within one year from the time of the onset of the disease. This is not a common disease, however, so that the total number of cases is small. In our series of collected cases, fistulas were present in 3 I.I per cent. of the primary cases and in 44.7 per cent. of the secondary cases. Fistulas were associated with two of the five cases that we have personally observed. Scudder stated that they occurred in over 59 per cent. of cases and Scott found them present in 35 per cent. The disease in one of our own cases was apparently primary in one of the underlying ribs and the fistula did not occur until the breast had been operated upon. Notwithstanding the rarity of tuberculous mastitis the persistence of a chronic sinus in the breast of a young nulliparous woman after a chronic abscess had been opened, should excite grave suspicion of its tuberculous nature. If the nipple on the affected side is retracted and the axillary lymph nodes are enlarged, the disease is almost certainly tuberculosis. Infected foreign bodies in the breast give rise to chronic sinuses in rare instances.

Actinomyocosis (q.v.) is such a rare cause of mammary sinuses that its occurrence need only be mentioned. The diagnosis is not difficult if note be made of the characteristic "sulphur grains" in the discharge. Chronic sinuses have also been known to occur in carcinoma of the breast, but in such event a complicating infection is present and the sinus before long becomes replaced by fungoid vegetations of the malignant tumor. The true nature of the condition will have been recognized as a rule long before this is permitted to take place.

The diagnosis of the presence of a sinus in the breast is not difficult but it is essential that the cause of the condition be ascertained. The important question that arises in the majority of cases, is, are we dealing with a simple pyogenic infection or is the tubercle bacillus at the bottom of the trouble?

Many patients will state that an abscess appeared while they were nursing a child and that the sinus in the breast had been there since the doctor opened the abscess. This is suggestive but is not absolute evidence that the sinus is the remains of an imperfectly drained pyogenic abscess. But lactation mastitis is known to be a precursor of tuberculous processes in the breast, so that notwithstanding the history it is possible that the condition results from a mixed infection. If the patient has scrofulous tendencies and the nipple is retracted or the axillary lymph nodes enlarged, our suspicions that the 
disease is tuberculous should be greatly strengthened. The discharge from the sinus should be cultured and examined for the tubercle bacillus. If for any reason preservation of the breast tissue is highly desirable, every effort must be made to determine the presence or absence of the tubercle bacillus, through microscopic examination and by guinea-pig inoculations with the pus. In primary tuberculosis of the breast with or without sinus formation we would not countenance conservative treatment any more than we would consent to treat a case of primary unilateral tuberculosis of the kidney palliatively. Secondary cases with active disease of other organs are not so urgently in need of radical treatment. Chronic sinuses of tuberculous origin always become secondarily infected with staphylococci after a time. If it be impossible to determine the cause of a chronic mammary sinus and if the latter be surrounded by a good-sized mass of scar tissue, the safest plan is to treat the condition as if it were tuberculous and excise the involved segment of the breast. If the breast be honeycombed with intersecting fistulas it had better be amputated no matter what the underlying infection may happen to be. Small sinuses should be laid open, painted with tincture of iodine, and packed with gauze. A few mammary fistulas will heal if the indurated tissue that surrounds their openings be cut away, their walls scraped and the sinuses injected with a solution of silver nitrate (5 per cent. or stronger), balsam of Peru or other stimulating remedy. Injections of Beck's bismuth paste are of doubtful value in these cases. Vaccine therapy and Bier's hyperemia have proven of great value in certain instances and are worthy of trial. Sinuses that lead into good-sized cavities or intercommunicating fistulas will not respond to palliative measures, so that operation should be performed without delay. Patients with chronic mammary sinuses are usually in poor physical condition and the hygienic regimen suitable for a case of tuberculosis should be enjoined. Tonic medicines, of which iron is the most important, should be used routinely.

7. Mastitis and Parotitis.-Mastitis and parotitis may occur simultaneously as complications of general septicemia; parotitis may arise as a complication of septicemia caused by primary mastitis; or, as is more often the case, the mastitis may follow infectious parotitis (mumps). Acute mastitis is a rare complication of mumps and one which, so far as we know, never gives rise to mammary abscesses; it may, however, be the starting point of diffuse mammary hypertrophy. According to Maupin, the disease was mentioned by Trenel in I8r2, and we have not found any reference to the disease in the literature prior to this time. Maupin himself saw only one case among $23 \mathbf{I}$ patients during an epidemic in France. This patient, a soldier, presented himself with the classical symptoms of parotitis and at the same time complained of severe pain in the right mammary region. The breast appeared slightly swollen, was painful to pressure but was neither red nor inflamed. The condition disappeared after a few days. Rilliet saw a case, also in a soldier, which was accompanied by enlargement of Montgomery's glands and a discharge of serous fluid from the nipple. Sheild mentions two interesting cases observed during an epidemic of mumps in England. One of these patients was a nurse girl who had contracted the mumps from a child under her care and had complicating mastitis. Hennig mentions a case of parotitis which was followed by mastitis in the left breast of a woman aged 27 . This patient was suffering with typhoid fever that had appeared I I weeks after a premature birth, and the case shows that a double glandular infection may be due to typhoid fever. The occurrence of parotitis as a complication of primary acute mastitis is extremely rare but has been observed in lactating women. In Wenning's case, an abscess in the breast had been opened 
and drained, notwithstanding which pyemia with metastatic parotitis followed. Mastitis accompanying scarlet fever and influenza is so rare that it is unnecessary to do more than mention the possibility of its occurrence.

8. Acute traumatic pyogenic mastitis is an exceedingly rare condition if those, cases that arise during pregnancy and lactation and in which trauma seems to be the exciting factor in their development be excluded. Many cases of lactation mastitis are really due to injury and this, as Sheild states, is especially true of mastitis in patients suffering from eclampsia and in whom the probability of mammary contusions is increased. The common result of a blow upon the breast of a man or upon the quiescent breast of a woman is aseptic non-suppurating mastitis, or in other words a simple contusion, or, more rarely, a hematoma; the latter may of course become infected. Punctured wounds, on the contrary, are prone to be infected especially in cases in which foreign bodies become lodged in the breast. This rule, however, has its curious exceptions; thus, one of our patients, a woman aged 43 years, ran a piece of wood and a pin into her breast. The wound healed promptly, without infection, and the breast gave her no further trouble for many years. Shortly before coming to us a painful lump developed at the site of the ancient injury, and proved to be a localized area of chronic mastitis.

Després reports the following case of traumatic mastitis:

"A girl, unmarried, 2 I years of age, presented herself with an abscess in the right breast for which the only assignable cause was a fall which the patient had sustained, the breast striking the ground. The usual incision and bandaging was done, but a deep induration persisted and the patient complained of severe pain in the region of the tumefaction. The condition was diagnosed as abscess following a contusion, and a partial mammary adenitis was suspected. About I I days after the incision, while examining the breast Després extracted a piece of wood from the pus and by again pressing on the breast, he extracted two additional small pieces of match stick about $\mathrm{I} \mathrm{cm}$. long. (The patient remembered having had three or four matches in her hand when she fell.) Erysipelas appeared, a few days after, in both breasts, and after persisting for $\mathrm{I}_{2}$ days recovered. At the same time the patient menstruated.

At this time the patient complained of pain in the left iliac fossa and retention of urine. This was attributed to an hysterical condition and was treated by baths and medication. In spite of this, however, there appeared a contraction of the left foot-equinism and turning of the foot inward. This disappeared to some extent by bandaging, but the patient complained of pain in all the members.

The abscess failed to close and a counter-puncture with insertion of a drain tube was made.

The patient had a history of ganglionic enlargement in the neck and a felon of the little finger of the left hand which had suppurated for a long time, and then required removal of a joint of the finger. No hysterical manifestations followed this operation. The author calls attention to the old theory of hysteria following lesions of genitalia, and to the close relation of the breasts with these he attributes the phenomenon in this case.

Occasionally an abscess of the breast develops independently of lactation and in the absence of a history of trauma. These cases occur almost without exception in patients whose nipples and areolaæ are congenitally deformed. This suggests that there is some probability that similarly deformed breasts may become diseased when predisposed to infection through lactation or traumatism.

The following case histories of patients observed by Duvergey are typical examples:

The first case was that of a young girl, 22 years of age, with negative history as far as illnesses and traumatism are concerned. An abscess had appeared in the lower quadrant of the right breast about two weeks before coming for treatment. The umbilicated nipple was sunk in the areola. Enlarged and painful lymph nodes were present in the axilla. The abscess was incised at once and drained of a large quantity of thick yellowish pus having a fecal odor. The pus was found to contain streptococci and staphylococci. The patient recovered.

The second case was a married woman, 38 years of age. She never had been pregnant, and always 
enjoyed good health. A slightly painful swelling had appeared in the left breast about two weeks before. The nipple was umbilicated, and an abscess was situated in the lower part of the gland. There was no distinct fluctuation and after the application of hot compresses for $\mathrm{r} 2$ days an incision was made into the abscess. A considerable quantity of pus was discharged and also presented the fecal odor. Streptococci and staphylococci and some gram negative bacilli were found in the pus.

Duvergey attributed the phenomenon entirely to the malformation of the nipple. That being sunken would easily become the receptacle for dust and retain the secretions of the skin in which microörganisms are plentiful. The skin over such a nipple is also subject to a constant humidity which predisposes to the formation of "chaps," of fissures, and even of ulcerations. The organisms penetrating the cutaneous lesions produce infection of the lymphatics, the cellular tissue of the breast and eventually give rise to suppuration. The pathogenesis of these abscesses is thus comparable to those sometimes arising in the umbilical region.

Such abscesses of the breast have not yet received much attention and two cases cited are not sufficient for an accurate description of their characteristics. But Duvergey calls particular attention to the slow formation of pus, especially in the second case (I2 days) and the fecal odor of the pus, a fact probably indicating the presence of numerous associated microörganisms.

Pregnancy predisposes the breasts to infection but not to the same degree as lactation. In a series of 1000 cases of acute pyogenic mastitis that we have collected, 75.6 per cent. occurred during lactation and only Ix.I per cent. during pregnancy. According to J. T. Williams, 5.5 per cent. of all breast abscesses occur in the mammæ of pregnant women. There is nothing in the clinical course of the cases arising at this time to distinguish them from lactation mastitis. The treatment is the same.

\section{Bibliography of Mastitis}

Bardenheuer.-Quoted by Feinen, Deutsch. Zeitschr. f. Chirur., I9o8, 94.

Baumgartner.-Maladies de la Mammelle (in LeDentu and Delbet, Nouveau Traité de Chirur., Paris, I9I3).

Benians.-British Med. Jour., I9I I, I, 864 .

BerHhenr.-Jour. Amer. Med. Assn., 1910, $55,25$.

Biehler.- Wien. klin. Rundschau, I9II, 25, 805.

Birlroth.-Ency. Obstetr. and Gyn., vol. 9, r887, p. 3т.

BOERICKE.-Quoted by Eicher.

Boissard.-La Semaine médicale, Paris, I893, p. 499.

Bumr.-Quoted by Eicher.

Caddy.-British Med. Jour, I893, I, 457.

Chaput et Souligoux.-Bull. et Mém. Soc. Chirur., Paris, igo7, 33, to.

Coues.-Boston Med. and Surg. Jour., I91 I, I65, I32.

DAMOURETTE.-Quoted by Baumgartner.

Dearden.-Amer. Jour. of Surgery, 191 2, 26, 356, "Sponge Compression in the Treatment of Mammary Abscess."

Delrez.-Scalpel, 1912, 65, 105," Chronic Catarrhal Mastitis and Carcinoma."

Dervaux and Salmon.-Bull. Soc. d'Obstet. de Paris, i9io, I3, 157.

Desmarest.-Presse médicale, 1914, 505 .

Dubrisay.- Jour. de méd. de Paris, 1913, 33, 325.

Duguet.-Med. Week, Paris, r $895,3,439$.

Dums.-Monatschr. f. Unfallheil, $1896,3,328$.

Durand.-Lyon méd., 1907, 108, 605.

Eicher.-Beiträg, z. Geburtsh. u. Gynäk., I9 I I-I 2, I7, 208.

ERdmann.-Annals of Surgery, I9II, 53, 727

Grbbons.-Med. Times and Gazette, Jan. 3, I 885

Graham.-Edin. Med. Jour., I911, 3, 442 . 
Gross.-Amer. Jour. Med. Sci., r888, xcv, zrg, "Suppurative Mastitis as a Cause of Carcinoma of the Breast."

Hassler.-Arch. de méd. mil., r894, 23, 531.

HECK.-Quoted by Eicher.

Hennig.-Archiv f. Gynäk., r87r, 2, 33I.

Hirst.- "A Textbook of Obstetrics," W. B. Saunders \& Co., Phila., 1906.

Huguet and Pératre. - Gaz. Hebd. de Méd. et de Chirur., r895, 32, 5.

JAGER.--Deut. med. Wochenschr., rgo9, 25, 624 .

Keyes.-Surg. Gyn. and Obstet., r914, r9, 364, "Mastitis Lactantia."

KLAPP.-Therap. Rundschau, I908, 2, 726.

LÈcÈne and Lenormant.-Précis de Path. Chirur., Paris, rgrr, Chap. I; Maladies Chir. de la Glande Mammaire, p. 5 .

LÉvÈque.-Soc. de med. mil. franç, Bull. IgI 2, 6, I 77 .

MaUPin. $\rightarrow$ Soc. de med. mil, franç, Bull., I9I2, 6, 327 .

Mintz.-Centralbl. f. Chirur., Igrr, 38 , r87 " "Chronischer Catarrh der weiblichen Brustdrüse."

Morzard.-Thèse de Paris, r88r, "Mammite chez l'Homme."

Morestin.-Gaz. d'Hôp., r9r3, 86, 953, "Traitm. esthétique des abscés du sein."

NiCAISE.-Quoted by Niclot and Massoulard, loc. cit.

Niclot and Massoulard.-Arch. méd. exper. et d'Anat. Path., rgoo, ro, 788.

NoHL.-Med. Klin., rgr 2 (2), I862, "Zur Etiologie und Therapie der Mastitis Puerperalis."

Pirmie.-The Lancet, rgro, r, I69, "Septic Infection Due to Mastitis."

Pizetre.--Pathologica, rgr4, 6, 205, "Sopra un Caso di Mastite Suppurata con Gangrena della Cutı della Mammella."

Rilliet.-Houdel in "Nouveau Traité de Méd. et de Therap.," Brouardel and Gilbert, Paris, r905, 9, p. 97.

RobeIIN,-Thèse de Paris, $\mathrm{I}_{52}$.

ROGER and GARNIER.-Quoted by Baumgartner.

SARFERT.-Deutsch. Zeitschr. f. Chirur., r894, 38, 6I5.

Schiller.- "Zur Pathologie und Therapie der laktierenden Mamma," Aertzl. Mitteil. aus und für Baden, rgrr, 8 and 9.

ScHILIER.-Monatschr. f. Kinderheil, rgro-rr, 9, 6ra.

SÉDilıoт.-Quoted by Niclot and Massoulard, Arch. med. expér. et d'Anat. Path., r9oo, r 2, 788.

SHEILD.- "Diseases of the Breast," p. 72.

STIASSRX.-Gynäkol. Rundschau, I907, r, 5,

Theuveny.-Bull. Gén. de Therap., r9o9, I57, 85.

Tousey.-Post-graduate, rgr2, 27 , Ir 46 .

TRILlOT and Latarget.-Lyon méd., 1907, 108, 605 .

Tytgat.-Gaz. méd. de Paris, I9I3, 84, 389, "Traitm. esthétique des abscés du sein."

VACCARI.-Annal. di Med. Nav., Igri, I7 (r), 639.

VACHER.-Thèse de Paris, r882.

Velpead.— "Traité des maladies du sein et de la region mammaire," 2d ed., Paris, I 858.

WENNING.-Amer. Jour, Obstetr., 1889, 22, 942.

WrebringhaUs.-Der Frauenarzt, rgrr, 26, 246.

Winckel._-"Die Pathologie u. Therapie des Wochenbetts," Berlin, r878, p. 428.

ZAPPERT.-Festschr. f. Kassowitz, I9I2, $3^{89}$.

\section{TUBERCULOSIS OF THE BREAST}

Introduction.-The original observations of Sir Astley Cooper (ז829) undoubtedly placed the breast among organs subject to tuberculosis. It is rather remarkable, therefore, that Sir Astley's lucid description of the macroscopic features of "scrofulous swelling of the bosom" did not lead to a larger number of reported cases in the literature of the succeeding half century. But errors inherent to clinical observation preclude the unreserved acceptance of many of the cases reported before the advent of microscopic pathology. With the perfection of the latter, and the consequent separation of the 
Plate II

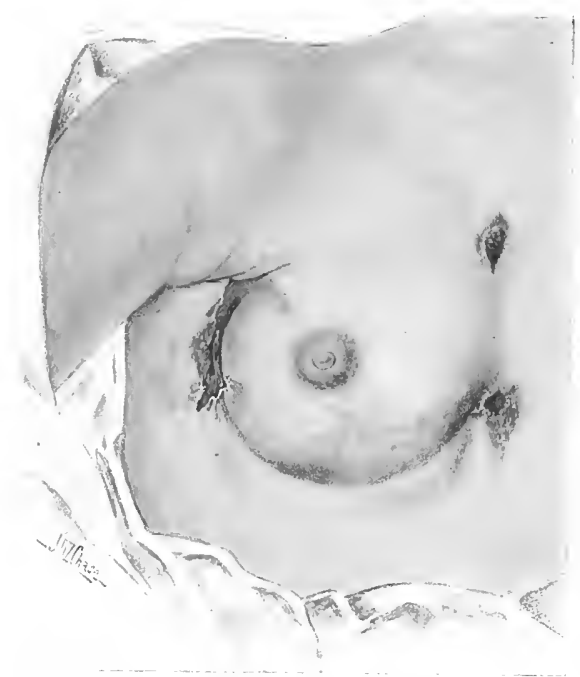

Tuberculosis of the breast. (Painted from a case in the Pennsylvania Hospital, through the courtesy of Dr. R. H. Harte.) (IIirst.) 

infectious granulomas from the tumor diseases, Dubar was enabled, in I88I, to prove the breast subject to tuberculosis on microscopic grounds.

His work, although somewhat belated in comparison with the microscopic recognition of other forms of surgical tuberculosis, marks the real beginning of our knowledge of its mammary form. Indeed, little has since been added to Dubar's description of the disease.

Subsequent writers have usually discussed the condition from the standpoint of primary and secondary involvement, a question that must fail of absolute solution in any given case, except post-mortem examination is made to say the final word. We must, however, classify all proved cases of mammary tuberculosis as primary-the solitary tuberculosis of Geissler-in which physical examination fails to prove the involvement of other organs.

A positive tuberculin reaction after resection of a supposed primary focus of the disease does not prove the presence of a hidden lesion, for, as Halsted has shown, these individuals react to the test as the result of bacillary products in the blood and not because of the presence of living organisms or their diseased tissue products.

The diagnosis of mammary tuberculosis can be made with absolute certainty only by means of bacteriological or pathological study. Chronic suppurative mastitis may pursue a clinical course to the formation of multiple fistulas that makes this condition indistinguishable from tuberculosis mammæ. The same difficulty is experienced in the absence of suppuration and fistula formation in the differentiation of tuberculosis, gummas, neoplasms, and cystic conditions of the breast. For this reason we have excluded from our series of collected cases all those in which the diagnosis is unsupported by laboratory confirmation, however typical the clinical history and physical findings. The diagnosis then depends upon microscopic recognition of the tubercle; the presence of the tubercle bacillus in stained smears of pus from an abscess, or discharge from the nipple or sinus, or in stained tissue sections; upon cultural demonstration of the organism, or finally upon the development of the disease in susceptible animals after inoculation. The tuberculin reaction is probably of the same uncertain diagnostic value in the mammary as in other forms of tuberculosis, although it has never, so far as we have found, been used in this connection. In a certain proportion of cases in which the tissue reaction to the tubercle bacillus results in an atypical sclerosis, a type to which Scott has drawn attention, the diagnosis, in the absence of the bacilli in tissue sections, must be problematical. Ohnacker, in the year $188_{3}$, following Koch's announcement of his discovery of the Bacillus tuberculosis, reported two cases of mammary infection, the first in which the identity of the disease was made by animal inoculation. Additional case reports followed, often with insufficient study to fix, without question, their pathogenesis, until ı90 , when Roux subjected the cases reported since Dubar's time to critical analysis. Roux accepted only $3 \mathrm{I}$ cases as authentic. This author reported three personally observed cases, in two of which the tubercle bacillus had been found. He added a third pathological type, the intraglandular cold abscess, to the confluent and nodular varieties first suggested by Velpeau and described in greater detail by Dubar. Since Roux's time the literature has been reviewed and cases reported, among others by Powers, I894; Scudder, I898; Bartsch, I90I; Anspach, I904. Since the appearance of Anspach's paper, Scott, Schley, Geissler, Braendle, Fuller, and Powers have contributed excellent papers on the subject, but the time has seemed opportune for a complete review of the cases reported since Anspach's studies in I904.

As mentioned above, we have disregarded all those cases reported in the literature that we find to be unsupported by microscopic diagnosis. The cases are divided into 
primary and secondary groups. We have accepted as primary only those cases in which the disease was confined to the breast and axillary nodes of the same side, but it is possible that the disease, in a number of instances, primarily attacked the lymph nodes and secondarily invaded the breast. The histories of five personally observed cases are added to the list.

Primary Mammary Tuberculosis.-The occurrence of primary tuberculosis of the breast is denied by many observers, including Klebs and Ribbert. It is evident that the cutaneous covering of the organ may become involved and constitute a local process in the same manner as lupus of other areas is produced, the pathogenesis of which was long since shown by Friedländer. Demme, Pluyette, Orthmann, and Kramer have reported cases of mammary tuberculosis in which the organism gained entrance to the tissues through abrasions of the skin and nipple. These observations refute the opinion of the

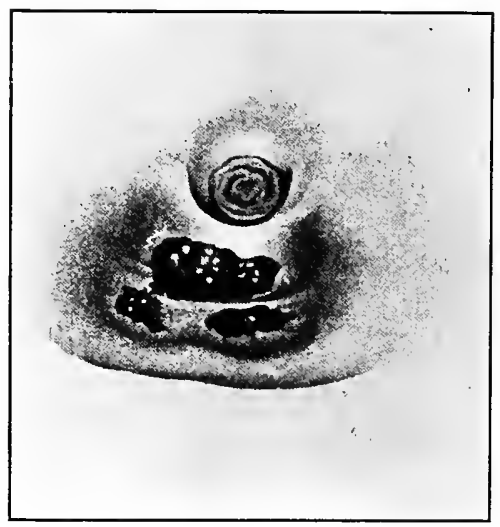

FIG. IOS.-Tuberculous ulcers of the breast. (Sheild.) writers quoted above, and more recently expressed by Spediacci, that all mammary tuberculosis is secondary. Babes has shown that the tubercle bacillus may gain entrance to the body through an apparently unbroken skin. That these organisms may pass through uninjured mucous membranes has been conclusively proved by Nicolas and Descos and by Ravenel, experimentally. The occurrence of infantile mesenteric tuberculosis in the presence of an intact bowel wall is a familiar clinical support of these views. Tuberculous infection via the lactiferous ducts may excite a primary focus of disease in the alveoli of the breast, but this avenue of infection must be extremely rare, and certainly one impossible to prove in the late stages of the infection when the interstitial tissues are involved. Instances of ductal infection have been reported by Verneuil and Verchère. Primary involvement of the breast with tuberculosis by blood or lymph-vascular infection presupposes the absence of the disease at the point of entry of the organisms. Blood dissemination is rare, and usually incites a rapid and generalized tuberculous process. Primary mammary tuberculosis through blood-vascular infection means that the bacilli have gained entrance to the blood-stream directly, have not caused disease at the point of entry, but have localized themselves in the breast tissues.

Secondary Mammary Tuberculosis. - With the few exceptions of directinoculation of the breast, through abraded surfaces of the nipples and skin and possibly through the milk ducts, all mammary tuberculosis may be looked upon as a secondary manifestation of the disease. In many cases the bacilli can be supposed to reach the breast through lymph channels, probably by retrograde embolic processes. The most important primary foci are located in the axillary, cervical, and retro-sternal lymph nodes, and the adjacent ribs, sternum, pleuræ, and lungs. The tubercle bacillus may perhaps reach the breast through ly mphatic channels in the absence of lymph-node involvement. We know that the urine and bile of tuberculous subjects may contain tubercle bacilli at times in 
the absence of renal or hepatic localization. Hirschberger produced tuberculosis in laboratory animals by inoculation with the milk of tuberculous cows, the udders of which were entirely free of disease.

Niepce observed a case of infantile infection in a child born of healthy parents, due to bacilli-laden milk from a wet-nurse. Rogers and Garnier report a case in which the milk was proved infectious by animal inoculation and the breast found normal at autopsy. No obviously tuberculous mother is of course allowed to nurse her infant, but we believe the restriction should be applied to all mothers who are suspected of harboring a tuberculous process, however latent.

Every case of tuberculous mastitis should be looked upon as harboring the disease after the removal of the involved breast, and should, therefore, be kept under strict regimen lest the disease remanifest itself. When the disease is limited to the upper outer quadrant of the breast and associated with enlarged nodes of the anterior pectoral subgroup of the axillary chain, in certain cases with a palpable band of neoformation joining the two foci, it is impossible to determine the primary area of disease. The breast in these instances is probably secondarily involved, but in the absence of a clear history. indicative of this sequence of events we have not excluded these cases from the series of primary infections. Infection of the breast tissues from a contiguous focus by direct extension is of comparatively common occurrence. Two of our cases illustrate this feature of the disease. The history of one of these is as follows:

M. H., aged 26 years; single; stenographer. Admitted to the German Hospital April 20, 19r2, complaining of a painful lump in the right breast, first noticed four months before admission. Her attention was drawn to the breast by pain on deep breathing at the site of the lump. The latter when first discovered was hard and tender, but later became soft and cystic.

Examination showed an encapsulated cystic tumor about the size of a hen's egg, in the lower inner quadrant of the right breast. The overlying skin was normal. General physical examination revealed notbing except a scar on the back at the site of a previous "gathering." A well-encapsulated cystic tumor was exposed after the plastic method of Warren. The sac, which was attached to the sixth rib, was excised and the rib carbolized. The wound was packed with gauze. The patient made an uneventful recovery.

In our second case the disease was of two years' standing. The mammary process was of the nodular type, although an area of softening was connected by a small sinus tract to the rib. There was no suggestion of an abscess, in this case "shirt-stud abscess," said to occur in this type of the disease, owing to the resistant deep pectoral fascia.

Parsons reports a similar case in a young Italian laborer.

Invasion of the breast from a primary osteitis of the sternum is exceedingly rare. An instance of this type of infection is included in the series of Hardouin and Marquis. This patient was operated upon in $189^{\circ}$ for osteitis of the lower end of the sternum. Two years later a tumor appeared in the lower inner quadrant of the right breast. This was found at operation to be connected by a fibrous cord with the site of the primary focus. The diagnosis was not confirmed pathologically, so the case is not included in our series.

Gautier and Péraire have reported a similar case.

Twenty-nine of our collected cases were looked upon as representative of the secondary type of the disease. The following table shows the site of additional foci of the disease in these cases. 


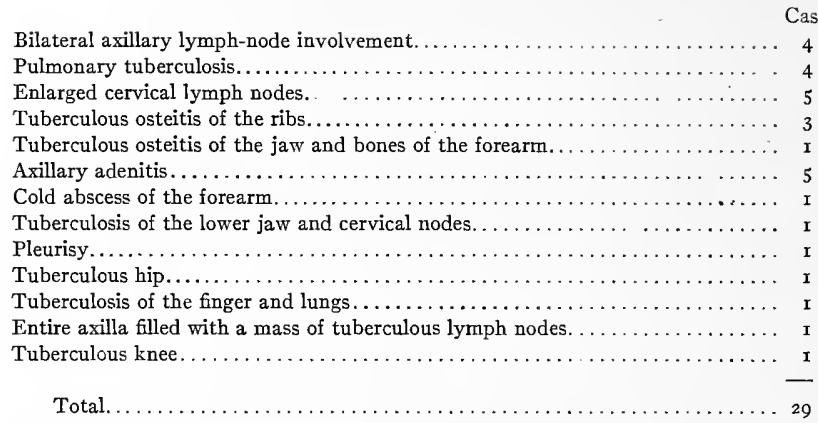

A most interesting case is reported by Duvergey, in which the evidence of a retrograde lymphvascular infection of the breast is almost irrefutable. The patient suffered a slight excoriation of one of the fingers of her left hand in September, rgro, while washing linens of tuberculous hospital patients. The wound suppurated for about two weeks and then healed completely. During the succeeding winter the patient noticed that she was steadily losing weight without any apparent cause. In April, Igrr, she noticed a painful swelling in the left axilla. This increased in size, and in May it was incised, with evacuation of a large amount of serous and granular material. The wound did not heal. In July she felt pain in the left breast, and a swelling appeared above the nipple. This was opened and a large quantity of sero-granular pus removed. Immediately two small abscesses appeared near the site of the incision. These opened spontaneously and the three sinuses increased in size, and, as a result of progressive ulceration, finally united. In the meantime another lump appeared in the subclavicular space and progressed to fistula formation. Other sinuses appeared from time to time and the axillary and upper mammary regions became united in one "vast ulceration." The apices of the lungs eventually became involved. Tubercle bacilli were found in the discharge from the sinuses.

Analogous cases are reported by Scott, Vignard and Pasquier, and Schmidt. This clear sequential order of events is lacking in the majority of cases, but it is probable that the bacilli reach the breast from the cervical lymph nodes in the same manner. In cases reported by Cignozzi, Bahaud, Scott, and Braendle the first manifestation of the disease appeared in the cervical lymph nodes. The fact that in these cases the axillary nodes escaped infection merely supports the well-known pathological fact that the lymphatic nodes may transmit infectious organisms without becoming involved in the disease process. It is impossible to chart the avenues of bacillary transmission from the lungs to the breast. The usual route is probably by way of the communicating trunks between the retro-sternal chain of lymph nodes and the breast. These branches follow the mammary branches of the internal mammary artery. Here again the process is a retrograde one. In the cases reported by Hardoüin and Marquis and Abraham and Khesin, in which there was antecedent joint tuberculosis, it would seem rational to look upon the blood stream as the medium of dissemination. We may therefore consider the breast subject to primary tuberculosis as the result of infection through abrasion of the mammary skin or nipple, through the milk ducts, and rarely as a result of lymphand blood-vascular infection.

Secondary mammary tuberculosis arises by direct extension from a contiguous area of infection or by blood- or lymph-vascular metastasis from a distant focus.

Incidence of Mammary Tuberculosis.-Ninety-five cases of mammary tuberculosis are reported in the literature since I904. To these we add five personally observed cases. Six of the 27 cases collected by Scott from the records of St. Bartholomew's 
Hospital lacked microscopic confirmation of the diagnosis. These together with three cases reported by St. Jacques, four cases reported by Braendle, three by Hardoiiin and Marquis, two by Fraenkel, two reported by Carr and three reported by Putzu are not included. Of the remaining 77 cases, 48 are classified as primary and 29 as secondary in type. Scott's series, notwithstanding the elimination, remains the largest as yet reported, while our experience (five cases) has not been exceeded by that of any individual operator. These five cases occurred among a series of approximately 600 operative cases of mammary disease ( 1898 to $19 \mathrm{I}_{4}$ ), and we do not recall having seen another instance of the disease in 35 years of surgical practice. This low ratio (less than I per cent. for all cases, or $\mathbf{2 . 5}$ per cent. for the benign lesions) is in decided contrast to the observations of Bloodgood, who found tuberculous mastitis in 6 per cent. of the cases of benign breast lesions admitted to the Johns Hopkins Hospital. The average relative frequency is more nearly approached in the list of cases collected by Sidney Scott, as follows:

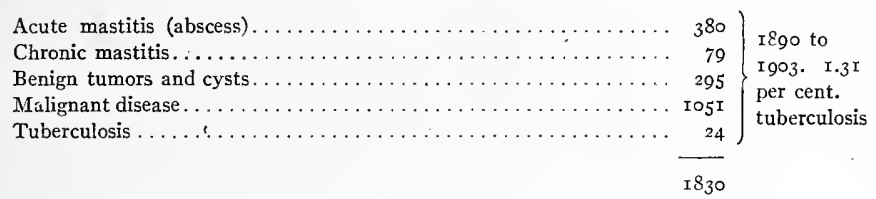

Anspach accepts the 30 cases considered by Bartsch as primary among the latter's series of 65 collected cases, and adds 12 cases from the literature of the succeeding three years, I90r to 1904 . Therefore, were it not for the uncertainty of determination of the primality of mammary tuberculosis, we would be surprised at the statement of von Eberts, who, in I 909 , accepted only 40 of the cases reported since Dubar's contribution. in $\mathrm{I} 88 \mathrm{I}$ as true examples of a primary manifestation of the disease. We accept the 42 cases collected by Anspach and add 48 additional cases, making a total of 90 cases of primary tuberculosis of the breast reported since $\mathrm{I} 88 \mathrm{I}$.

With the exception of cases of concurrent carcinoma and tuberculosis which are to be considered elsewhere, our review of the literature is complete.

The meager number of cases (48) reported over a period of ro years (Igo4 to I9I 5 ), when compared with the general morbidity of tuberculosis and a yearly mortality of $5,000,000$ people from this disease, proves the extreme rarity of tuberculous infection of the breast.

Predisposing Causes.-Sex.-Tuberculous mastitis almost invariably occurs in the female; only ro male cases are recorded. Heyfelder reported the first case occurring in the male, in $185 \mathrm{r}$. Since then Delbet, Ferguson, Ressiguié, Poirier, Hebb, Schede, Demme, Parsons, and Khesin have each observed a case.

We have included Ressiguié's case among the list of primary infections, while Parson's case is clearly secondary to tuberculous osteitis. The third case reported since I904, that of Khesin, was secondary to tuberculous infection of the knee-joint. Scudder rejects those cases in the male reported by Horteloup and Heyfelder.

Age.-The youngest patient in our series, a girl of $\mathrm{I} 4$, was operated upon by Abraham; the oldest, a widow, aged 64 years, by Ingier. Both Scudder and von Eberts remark that the patient of Remy and Noël, a woman, aged 54 years, is the oldest case on record. The cases of Geissler, Ingier, and Scott in our series exceed this age. No case of tuberculous mastitis in the female has been observed before the age of puberty, and 
the oldest case on record is that reported by Sheild, in a woman aged 73 years. Demme reports a case the result of direct inoculation in a male infant, four days old.

The following tables prove the correctness of von Eberts' statement that "the period of reproductive activity embraces the vast majority of cases."

Age InCIdence

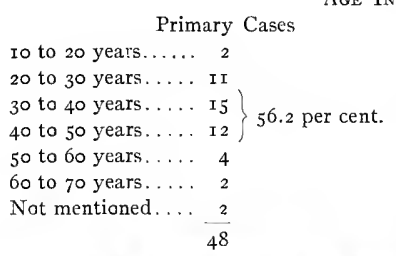

\section{Secondary $C_{\ddot{~}}$ ses}

Io to 20 years..... 4

20 to 30 years.... 9

30 to 40 years.... 8

40 to 50 years..... 44$\} 4 I .9$ per cent.

50 to 60 years.... 3

60 to 70 years..... I

29

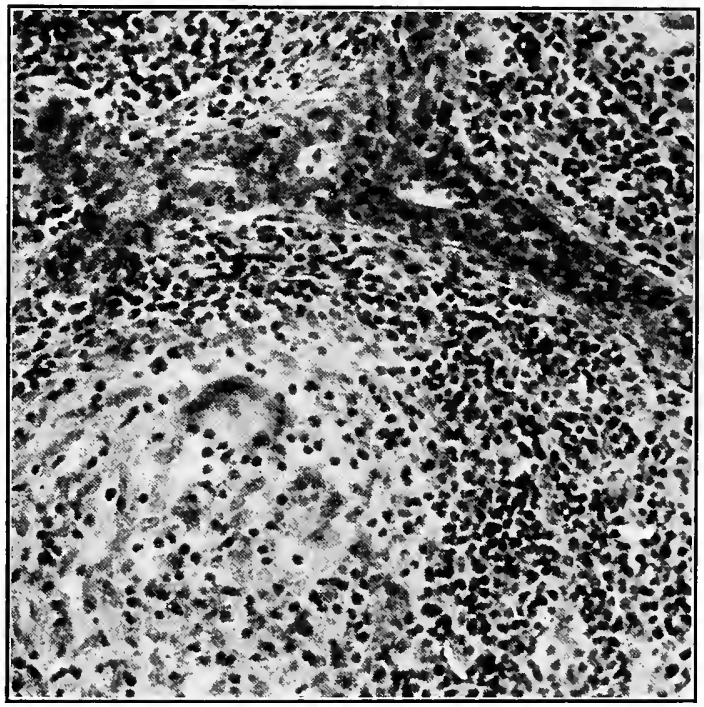

Fig. rog.-Tuberculosis of the breast showing a part of the following section under a higher power.

These tables also disprove the assertion of the older writers and of more recent observers, among others St. Jacques, that tuberculosis of the breast is a disease of adolescence and young womanhood.

\section{Socral Condirion}

\section{Primary Cases}

Single $\ldots \ldots \ldots \ldots 7$

$\left\{\begin{array}{l}\text { Married ..... } \\ \text { Widows..... } 29 \\ 2\end{array}\right\} 64.5$ per cent.

Males.......... I

Not mentioned.... 9
Parous........ 23 or 5 I.I per cent.

Nulliparous....... 2 I

Males.......... I 
Secondary Cases

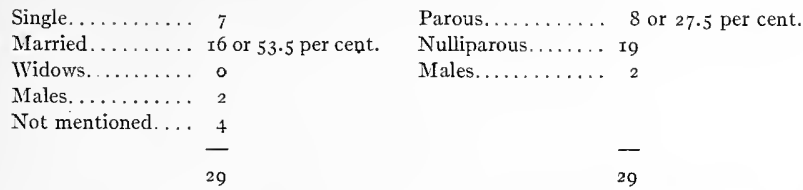

Whether the influence of fecundity as indicated by the above tables acts in the rôle of a real predisposing cause, or that it is merely coincidental to the age at which the disease

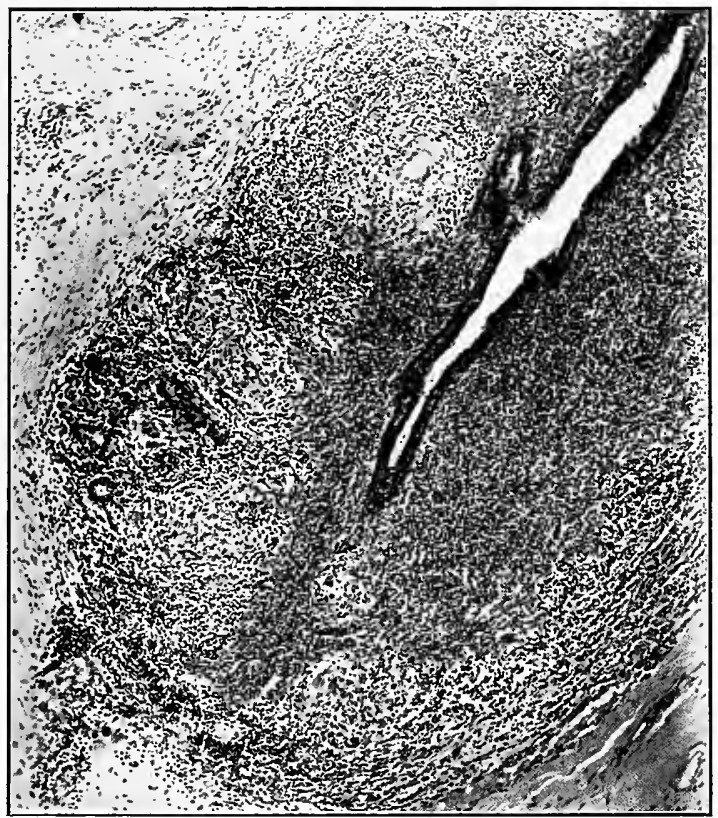

FIG. Iro.-Tuberculosis of the breast, showing a distinct tubercle with a characteristic giant-cell in the upper part of the field.

is more likely to occur, is difficult to answer. The statistics of Anspach's 40 primary cases are as follows:

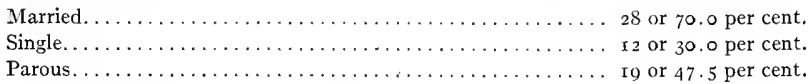

These figures, it will be observed, closely correspond with those in the list of prinary cases in our series. It is unjustifiable to draw conclusions from so small a number of cases, yet it would seem that the mammary changes incidental to pregnancy are not more predisposing to tuberculous involvement of the breast from a distant focus than 
to the so-called primary involvement. At least were such predisposition potent in the production of tuberculous mastitis, we would expect to find many more cases among the thousands of nulliparous women suffering with various forms of tuberculosis, active or latent. Von Eberts says that "lactation is possibly the most important predisposing cause of tuberculous mastitis." That many factors concur in reducing the tissue vitality to the point of tuberculous predisposition is true of the breast as of other tissues, and no one factor stands out prominently in this regard.

Heredity. - A tuberculous family history was elicited from four of our secondary cases and from three of the primary cases. The influence of heredity in the production of tuberculosis of the breast, as elsewhere, acts merely in the rôle of a contributing cause.

Trauma.-Traumatic injury to the breast is rarely followed by tuberculous infection. Schley quotes Poirier, Hebb, Sabrazès, and Binaud, who observed cases preceded by injury. In five of the primary cases of the present series trauma seemed influential in the tuberculous process. These cases have been observed by Wannienwenhuyse, Marangoni, Abraham, Scott and ourselves. In Marangoni's case a violent injury was received five years before the development of the tuberculosis, which was also preceded by suppurative mastitis. The latter occurred two years after receipt of the injury, which was looked upon as causal.

Scott's case is of particular interest: The patient, a woman, aged 34 years, accidentally pierced her left breast with a needle. Suppuration followed. The needle was removed, but a sinus persisted, with increasing induration around it, and involvement of the axillary glands. Tuberculosis was found on microscopic section of the involved area.

Demme noticed the development of tuberculosis in a pre-formed sinus, the latter a sequel of simple pyogenic mastitis.

Slight trauma is more likely to be followed by tuberculosis in susceptible persons than is violent injury. This view is of general application in surgical tuberculosis, especially of the bones and joints; but there is no reason for believing it true of mammary tuberculosis. Abraham, however, looked upon his cases as a result of slight injury. A latent focus of tuberculosis in the breast, as in other tissues, may be incited to activity by traumatism. If the traiuma is violent the overlying tissues suffer immediate ulceration in the absence of abscess formation, as illustrated in one of our secondary cases. The usual result, however, is the production of an active tuberculosis which eventuates in abscess formation, the residual abscess of Sir Stephen Paget.

Antecedent Mastitis. - Six (I 2.5 per cent.) of the primary cases gave a history of suppurative mastitis. This antedated the tuberculous process, one, two, two, five, eleven, and thirty-seven years respectively. Of those cases collected by von Eberts in which the gland had functionated, there was a history of inflammation complicating lactation in 42 per cent., with suppuration in 20 per cent. Scudder accepts 53 of the reported cases as primary tuberculous mastitis, and states that half of the patients had borne children and that Io (I8.8 per cent.) had previous attacks of mastitis. He remarks that mastitis (pyogenic) is more common during the puerperium in tuberculous individuals than in normal individuals. Schmidt's case, included in our list of secondary cases, illustrates the coincident appearance of tuberculous and acute pyogenic mastitis in the puerperium. The patient, aged 23 years, noticed a small nodule on the left forearm in the summer of I904. She was confined in November, I904, and a few days later developed acute mastitis on the right side. An abscess opened spontaneously, leaving fistulas, which failed to heal. She was admitted to Schmidt's clinic in March, I905. 
Examination showed a fluctuating swelling the size of an orange on the left forearm. The right breast was enlarged, hard, and nodular, and showed five fistulous openings in the areola. Both axillæ contained enlarged lymph nodes. Both the tumor of the forearm and the mastitis were proved to be tuberculous at operation. The possibility of local tuberculous infection of a preformed sinus is to be remembered.

\section{Symptomatology (Initial Symptoms)}

Primary Cases

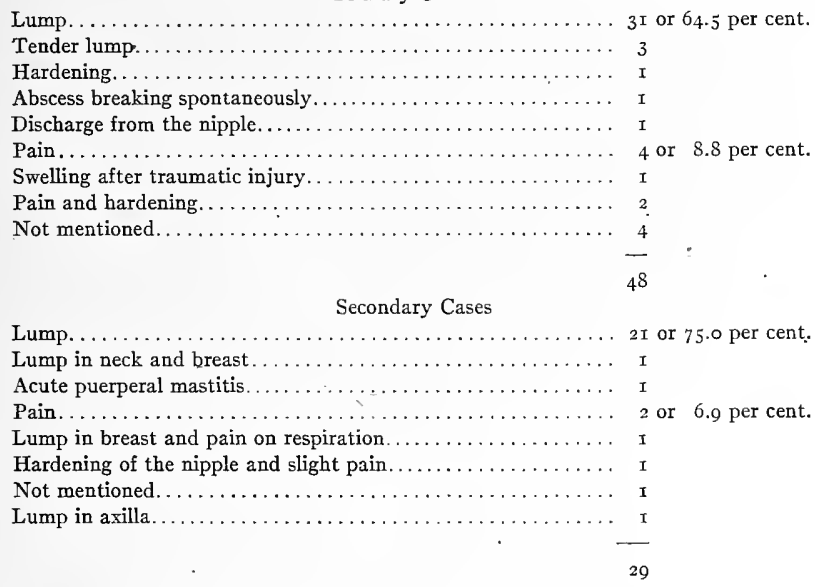

The most frequent initial symptom of tuberculous mastitis is a painless lump. In 78 per cent. of the malignant and 86 per cent. of the benign mammary neoplasms operated on by us this was likewise the first sign of the disease. Pain, it will be observed is an infrequent initiative sign, although it occurs more often during the course of the disease. Eighteen of our primary and nine of the secondary cases suffered with pain. But this was slight, rarely referred, and was especially noted during the stage of abscess formation and just prior to rupture. These figures refute the statement of Scudder that "pain is an early and constant symptom, often severe in type, and affecting 50 per cent. of cases." Any, patient presenting a lump in the breast and complaining of pain on respiration in the region of the tumor should be skiagraphed for osteitis of the underlying ribs. The difficulties of diagnosis of tuberculous mastitis resulting from contiguous bone disease should be in this wise eliminated. Beyond this, the value of pain as a differential diagnostic index is practically nil. Retraction of the nipple was rated by Dubreuil, Verneuil, and Warden as the first indication of tuberculosis of the breast occurring in their respective cases eleven months, two years, and five years before a mass was palpable.

Course of the Disease.-The average duration of the disease in the primary cases was ro.I months, in the secondary cases, II.2 months. Tuberculosis of the breast runs a much more rapid course than carcinoma of the breast. In our series of the latter condition, 30 months elapsed on the average from the time of onset to the date of operation. In one of Marangoni's cases the disease was of four years' duration. Geissler and our- 
selves have observed cases in which the patients came to operation less than a month from the time of the appearance of the initial symptoms. The rapidity of the disease process, changes in the size and consistence of the tumor mass, early fistula formation, early involvement of the axillary lymphatics, and, in a few instances, pain, bring the great majority of the subjects of tuberculous mastitis to the surgeon within the first year of the disease. Tenderness, usually slight, is noticed in the later stages, but like the other subjective symptoms offers little aid in differential diagnosis.

General Condition of the Patient.-It is surprising to find that the larger number of our primary cases occurred in robust women. In the secondary cases also, in spite of additional foci of tuberculosis, little mention is made of marked systemic effect. Tuberculous mastitis is not only compatible with but usually associated with excellent general health.

\section{Physical Signs (Location)}

\section{Primary Cases}

Under nipple. . . . . . . . . . . . . . . . . . . . . . . 4

Upper outer quadrant (only four associated with palpable axillary enlargement)... . ro

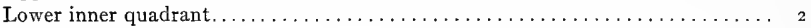

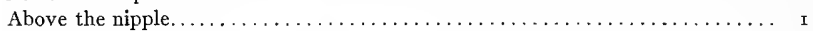

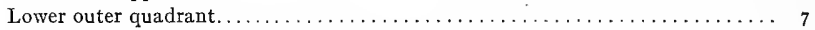

To the outer side of the nipple. $\ldots \ldots \ldots \ldots \ldots \ldots \ldots \ldots \ldots \ldots \ldots \ldots \ldots \ldots$

Upper outer and upper inner quadrant......................

Below the nipple.........................

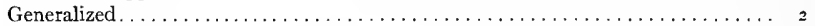

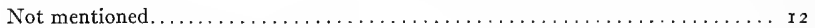

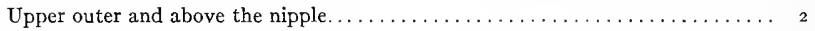

Near the nipple................................... 2

Above and below the nipple. . . . . . . . . . . . .

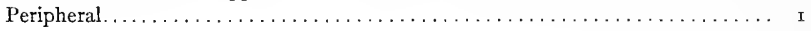

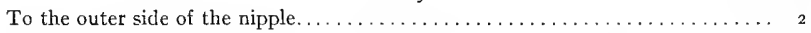

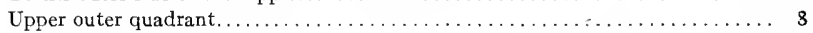

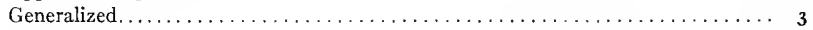

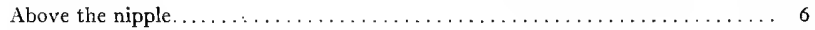

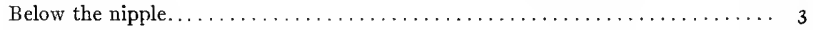

Under the nipple....................

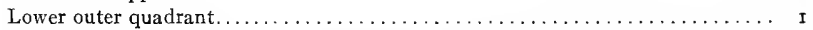

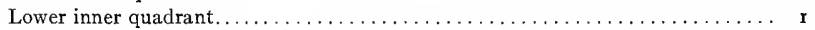

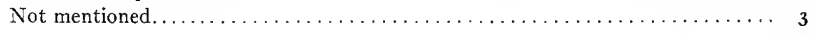

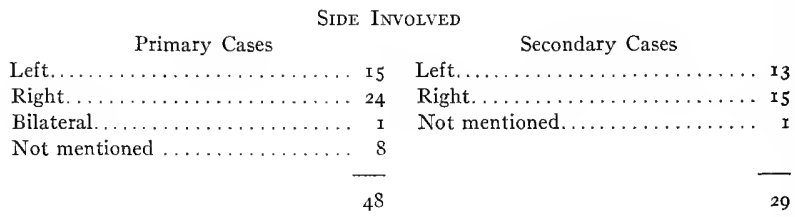


CoNdition OF THE SKIN

Involvement of the skin.

\section{Primary Cases}

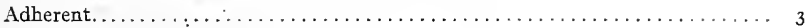

Red and tender. . . . . . . . .

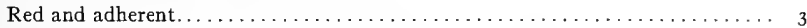

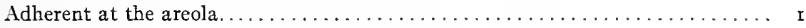

Darkened. . . . . . . . . . . . . . . .

Dimpled. . . . . . . . . . . . . . .

Adherent and discolored at site of fistula...................... ro

Normal. . . . . . . . . . . . . . . . . . . . . . . . ${ }_{2} 8$

Secondary Cases

Inolvement of the skin.

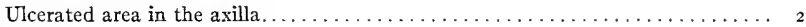

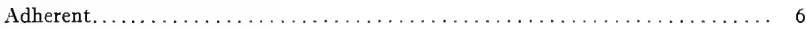

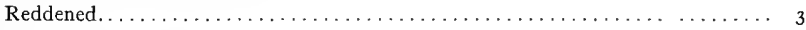

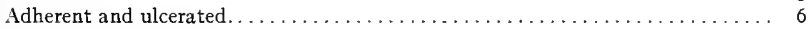

Hard and discolored $\ldots \ldots \ldots \ldots \ldots \ldots \ldots \ldots \ldots \ldots \ldots \ldots \ldots \ldots \ldots \ldots$

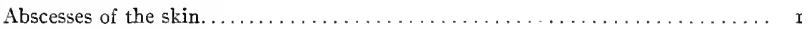

Normal...................................

Primary Cases

Present in $I_{5}$ cases ( $3 I_{.2}$ per cent.)

Multiple in 3 cases

Condition of the Nipple

Primary Cases

Retraction (one bilateral) ................... I9 or 39.5 per cent.

Ulcerated.............................. 3

Discharge from the nipple:

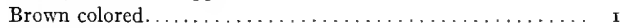

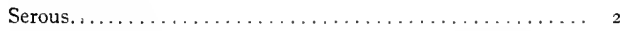

Not mentioned........................ r

Normal............................ 22

Normal............

Secondary Cases

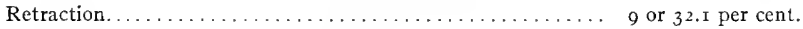

Discharge from the nipple (purulent) ............. r

Normal. .............................., 20

Palpable Enlargement of the Axillary Lymph Nodes Primary Cases

Secondary Cases

28 cases. 58.3 per cent.

2 I cases. .

6 bilateral.

In one case a palpable cord connected the tumor in the breast with the axillary nodes.

In two cases a palpable cord connected the breast tumor with the axillary lymph nodes.

The presence of fistulas, retraction of the nipple, and enlarged glands in the axilla is a triad strongly suggestive of tuberculous mastitis. Scudder found fistulas present in over $5^{\circ}$ per cent. of cases, and states that nearly all cases had axillary tuberculosis. The following statistics taken from Scott's series of 27 cases are given for their comparative value: 
Fistulas present in to cases, or 35 per cent.

Definite history of injury in one case.

Acute onset in two cases.

Skin adherent in two cases, or 70 per cent.

Nipple retracted in Io cases, or 30 per cent.

Axillary glands enlarged in 17 cases, or 60 per cent.

Lymph-node Involvement.-The lymph nodes of the side corresponding to the lesion were enlarged in 58.3 per cent. of the primary cases and in 75 per cent. of the secondary cases of our collected cases. Von Eberts estimates the frequency in primary cases at 75 per cent. The enlargement may depend upon simple hyperplastic adenitis, but microscopic examinations were too few to permit the proportion to be determined with accuracy.

Tuberculous axillary lymph adenitis of the opposite side may possibly occur by way of the lymph channel described by Poirier. This arises in the lower inner quadrant of one breast and passes to the opposite axilla in the plane of the deep fascia without traversing the breast of that side. Secondary infection of the tuberculous areas of the breast with pyogenic bacteria occasionally takes place, as a result of blood infection, from other pyogenic foci in the body, but usually results from extraneous infection after the spontaneous rupture of a tuberculous abscess, or the unclean surgical opening of such collection.

We know of no case in which septicemia followed secondary infection, as not infrequently occurs in tuberculous abscesses of other organs.

Pathological Types of Mammary Tuberculosis.-Tuberculosis of the breast may be classified as follows: (r) Acute miliary tuberculous mastitis. (2) Nodular (discrete, disseminated, confluent) tuberculous mastitis. (3) Sclerosing tuberculous mastitis (Scott) (comparable to fibroid phthisis). (4) Mastitis tuberculosa obliterans (Ingier). (5) Various atypical forms.

Acute miliary tuberculous mastitis occurs in conjunction with generalized miliary tuberculosis and has no special surgical significance.

Nodular Tuberculous Mastitis. - The great majority of cases of mammary tuberculosis are of the discrete, nodular variety. The tuberculous process is fundamentally the same in all organs, but in the breasts presents variations as the result of the histological peculiarities of these structures. The bacilli lodge in the mammary stroma rather than in the ductal or periductal tissues, and excite a localized tubercle formation. Daughter tubercles form at the periphery of the original focus and, in time, usually a matter of several months but sometimes longer, a palpable mass is formed. This varies in size, but rarely exceeds that of a hen's egg. As a rule, it remains unattached to the structures underlying the breast, and the overlying skin is not attacked until comparatively late in the course of the disease. The mass is of irregular contour, poorly defined, and slightly tender. It is of irregular consistence, and certain areas almost without exception show softening, often with fluctuation.

If the inflammatory reaction is marked, sclerotic tissue contraction causes retraction of the nipple, especially if the mass is centrally located. The clinical course varies, depending upon the secondary changes that take place in the nodule. In most cases the skin becomes adherent, often at the periphery of the areola; it assumes a dark red color, with final pointing and spontaneous rupture of the abscess or abscesses, and one or more sinuses remain, as a rule, around which the tuberculous tissue can be felt as a nodular column. Progression of the disease results in further abscess and sinus forma- 
tion. Frequently the disease remains quiescent or the sinuses may heal. It is in the former stage that the patient is often first seen by the surgeon. On the other hand, nature may wall off the primary nodule and cause its cicatrization, with permanent cure, or the process may remain latent for years, with ultimate remanifestation. Finally, the caseation and liquefaction of the focus may be quite complete, but so well walled off that rupture is impossible. In some instances this sclerotic wall may reach a thickness of $\mathrm{I} / 2$ inches or more. The result is an abscess in which we see no reason for differentiation from the intraglandular cold abscess of Roux; it is simply a terminal stage of the discrete nodular variety.

Disseminated Nodular Variety.-As illustrative of this type of the disease we can offer no better description than that given of Marangoni's case.

The patient, a woman aged 29 years, began having pain in her left breast soon after weaning her second child. The breast became enlarged and hard, and at the same time the axillary glands also enlarged. On examination the left hreast was found enlarged, diffusely nodular, and exquisitely tender. Marangoni's notes of the pathological features were as follows:

"The entire gland is covered with nodules. The lesion is very diffuse, so that only very few lobules are of normal structure for the most part; the less altered areas are situated near the periphery of the organ. Au advanced sclerosis of the connective tissue is present. The sudoriparous glands beneath the connective tissue are enlarged and cystic. Epithelial proliferation of both the ductal and acinous epithelium is marked." In this, the much rarer form of nodular tuberculosis of the breast, the disease is more rapid in development and rarely becomes quiescent.

As with Marangoni's case, this type of the disease is seen most frequently during lactation. In the confluent variety of mammary tuberculosis the nodules run a rapid course to caseation and liquefaction. The abscess is often centrally located and lacks the tendency of the discrete, nodular variety to peripheral spreading. Schley considers this the usual mode of formation of the "intraglandular cold abscess" of Roux.

Sclerosing Tuberculous Mastitis (Scott).--In Io of Scott's 27 cases the prominent pathological feature was a diffuse sclerosis. In three of these cases an overlying sclerosis hid deep abscesses, while in four others, superficial abscesses were found overlying areas of marked sclerosis. From the remaining three cases solid tumors were removed. These latter cases were considered carcinomatous until microscopic examination revealed tuberculosis. It is to cases of the latter type that we would limit the term sclerosing tuberculous mastitis. Sclerosis is a feature of almost every case of nodular tuberculosis, but, like fibroid phthisis, there is a pathological entity among tubercle infections of the breast in which, instead of tubercle formation, there occurs a diffuse epithelioid and embryonic connective tissue infiltration from which Langhans's giant cells are wanting and in which the process is essentially sclerotic.

As Scott remarks, this type is seen most often in patients advanced in years. The breast in the terminal stages of this condition is small, hard, and deformed. Differential diagnosis from scirrhus is impossible. Demonstration of the tubercle bacillus in stained tissue sections is the only absolute means of diagnosis.

Mastitis Tuberculosa Obliterans.-Ingier has recently described a case in which the inflammation was confined to the walls of the milk ducts and peri-acinous connective tissue, with slight involvement of the inter-lobular stroma. Granulation tissue involved the membrana propria of the finer ducts and acini from without. In the larger ducts the process seemed to arise within the duct walls. Detachment of the epithelium resulted, with final obliteration of the lumina of the ducts. Tubercle bacilli were found in fluid expressed from the cut surface of the tumor. The nipple had ulcerated away, and the cases seemed illustrative of primary ductal infection. 
Various Atypical Forms.-Cases, such as the one in our list, in which the disease began in a nodule resembling a sebaceous cyst, are to be considered atypical. Poirier describes a case in which two small cutaneous vesicles developed into indurated tuberculous nodules. In Orthmann's case a subcutaneous infection resembling a furuncle first appeared, with subsequent induration and extension of its base.

Edematous swelling of the breast sometimes occurs in patients suffering with pulmonary tuberculosis. This peculiar condition affects the breasts of both sexes. It is said to depend upon trophic or vasomotor disturbances resulting from a disturbance in the innervation of the breast, the latter being attributable to disease of the intercostal nerves. The phenomenon is prone to occur on the side where the pulmonary lesion is most advanced. In addition to the mammary enlargement, the patient suffers with pain, often severe in type, but suppuration and tubercle formation do not occur and the condition tends to disappear with improvement of the pulmonary lesions.

Concurrence of Tuberculosis and Neoplasms.-Klose has collected 17 cases in which carcinoma and tuberculosis of the breast occurred concomitantly; in a number of these cases, however, the diagnosis was not confirmed microscopically. The author gives the notes of a personally observed case in detail, and quotes Franco, who had the good fortune to see two cases. He further quotes Kellenberger, who saw secondary cancer in the tuberculous breast of a woman.

Scheidigger operated on a woman whose father, two sisters, and a brother died of tuberculosis, and whose mother died of cancer of the uterus. The tumor of the breast, which was about the size of a plum, was found to consist of adeno-carcinomatous tissue with inclusions of tubercles scattered throughout its substance; the axillary glands contained areas of tuberculosis but no carcinoma could be found.

We have recently had a patient with the not uncommon condition of carcinoma of the breast together with tuberculosis of the axillary glands on the same side.

Berger reports a similar case:

The woman, aged 47 years, noticed a hard, movable tumor in the upper, outer quadrant of the left breast which was connected to enlarged and tender nodes in the axilla by a hardened cord. The tumor in the breast proved to be scirrhus in character, while the axillary lymph nodes were found to be tuberculous.

The concurrence of carcinoma and tuberculosis mammæ has recently been the subject of papers by Rodman, Bauer, Bundschuh, Fricke and Massabuau, each of whom reports a case.

In Bundschuh's case, the carcinoma was the primary affection in the breast, although the patient had had an ancient pleuro-pulmonary tuberculosis.

The history of the patient is as follows:

Female, aged $5 \mathrm{x}$ years. Negative family history. Previous medical history negative except for enlargement of the neck which has been present for several years. Present illness dates from about nine months previous to her admission to the hospital, when a small, painless tumor appeared in the right breast. This grew slowly in size, was at first accompanied by a dull ache and during the few weeks prior to her admission to the hospital had given rise to considerable pain. The patient recently noticed a sweiling in the right axilla. Examination: The right mammary gland is enlarged in its lower portion, the nipple slightly retracted and covered with a few small crusts covering minute fissures. The lower half of the breast is the site of an indurated crust about the diameter of a two-cent piece; this scab covers a hard, irregular tumor occupying the outer, and a portion of the inner, lower quadrant, intimately connected with the mammary tissue and movable on the underlying fascia. The tumor is only slightly tender to the touch; the overlying skin appears shrunken. A few, thin, hard, movable cords extend from the tumor to the right axilla, the cords being studded with hard nodules up to the size of a lentil, these nodules merging in the axilla into a hard, nodular, painless swelling about the size of 
a plum. The left breast is normal. The breast was removed together with the pectoral fascia, and the axilla was cleansed. The patient contracted erysipelas two months after her dismissal from the bospital, from the effects of which she died.

Histology of the Tumor.- "Carcinoma solidium simplex, tubular structure." In a section of the carcinoma close to its transition into the fatty tissue between the gland and the pectoralis major muscle, a small nodule, visible only under the microscope, was found imbedded in the carcinomatous tissue, its structure differing from tbat of the carcinoma itself and proved to be a typical tubercle. A similar tubercle was also seen in a section taken from the lateral portion of the carcinoma, and one in the deeper portions of the same section. There were no tubercles to be found in the metastatic lymph vessel cords extending into the axilla.

In the smaller axillary lymph glands there were seen only old, large tuberculous foci undergoing caseation, and smaller tubercles surrounded by a fibrous capsule. In the large glands similar old tuberculous foci were seen and also a few fresh tubercles not yet presenting caseous degeneration.

The greater part of all of the lymph nodes is occupied by carcinomatous cells. Tubercle bacilli were found in the stained tissue sections of both the axillary nodes and the mamma. The report of the autopsy reads: old pleural adhesions, old calcified areas in the right, upper lobe of the lung; recent and old tuberculosis in the glands.

The carcinoma is thus seen to be the primary disease in this case as is indicated by the absence of old tuberculous areas in the mammary gland and by the few, very recent tubercles present.

In the cases reported by Fricke and by Massabuau, the carcinoma was the primary disease. In neither instance was the tuberculous processes diagnosed before operation nor were the tubercle bacilli found in stained sections of the tumors. There seems to be no doubt, however, of the dual nature of the disease in these cases.

At a meeting of the surgical society of Paris, December, 1906, Walther presented a specimen taken from the breast of a young woman, 30 years of age.

The pathological diagnosis was fibro-adenoma with epithelioma and tuberculosis. A growth had been present in the left breast for about so months, the patient describing the first appearance of the affected organ as being irregularly disseminated with minute grains of lead. Later a small nodule appeared on the outer periphery of the breast, rapidly growing to the size of a nut and then gradually increasing in size. Finally, during the past few months there had developed a small, prominent, rosecolored, indurated area to the right of the areola and toward the nipple. On palpating the gland it gave the impression of the hard granulations of chronic mastitis. Otherwise it was solt, mobile, and nonadberent to the skin.

The external portion of the breast was the site of a tumor the size of a lemon, slightly nodular, and at first gave the impression of an adenoma apparently non-adherent and freely movable. A hard, completely isolated nodule, resembling a scirrbus, was present to the inner side of the areola. Several ganglia of considerable size were found in the axilla. Diagnosis: Chronic mastitis and diffuse fibroma with epithelioma localized in two distinct points, the external portion of the breast, and to the inner side of the areola. Pathological report:

Macroscopy.-A series of very hard nodules the size of a small pea to that of a cherry were found throughout the skin, which was non-adherent to the tumor. On section, a layer of adipose tissue could be seen between the skin and the small nodular tumors. These nodules and the neoplasm, which occupied the greater portion of the breast, were indurated, compact and not cystic.

Microscopy.-Pure fibro-adenoma in parts, in others, in the midst of the cancerous area, glandular acini were found completely transformed into fibrous tissue. Some large acini were found, their cul-desacs and their excretory ducts dilated and filled with large cancer cells. Other parts of the section showed typical epitheliomatous and alveolar structure, the tubes and alveoli being filled with large cancer cells. In one series of sections a small but typical area of tuberculosis was found entirely separated from the cancerous tissues by a zone of round-celled infiltration. The axillary lymph nodes were entirely cancerous.

Bacteriologic Diagnosis. - Zironi and von Eberts have grown the tubercle bacillus in culture from breast lesions. Ingier and Schley have found the bacillus in stained smears. Fuller, Brandsburg, Hartwell, Spencer, and Stromberg have demonstrated the organism in stained tissue sections. The foregoing are included in our list of primary cases. Among the secondary cases is that of Duvergey, in which the diagnosis was con 
firmed by finding the tubercle bacillus in smears of pus. "Delfino and Mantelli report the only instances of positive animal inoculation from tuberculous breasts since I904. In Mantelli's case (No. 35, primary series) the diagnosis was made by guinea-pig inoculation with pus aspirated from a breast abscess. Davis found tubercle bacilli in the discharge from the nipple of a case of tuberculous mastitis.

Differential Diagnosis.-When tuberculous mastitis has progressed to the stage of fistula formation, the usual termination of all except the sclerotic varieties, it must be differentiated from simple pyogenic mastitis of a subacute or chronic form, broken-down gummas, and actinomycosis. The two latter conditions are exceedingly rare, although Shattock calls attention to the necessity of distinguishing between syphilis and tuberculosis. We have not met with a case in our studies in which either condition was suspected before or found at operation undertaken on the diagnosis of tuberculosis. When the history or the presence of another lesion raises the question of the gummatous nature of a breast lesion, the Wassermann reaction will prove or disprove the presence of the disease. In the event of a positive blood test, the effect of antileutic treatment will demonstrate the nature of the breast lesion. The discharge from a broken-down actinomycotic lesion may contain the ray fungus.

The differentiation of subacute or chronic pyogenic mastitis, either of the true chronic abscess type, or one in which fistulas have formed, from the similar varieties of primary tuberculosis is impossible, except by laboratory methods. Sclerosing tuberculosis of the breast, especially in the absence of areas of degeneration gives, in certain cases, all of the classical symptoms of carcinoma, from which it cannot be differentiated clinically.

The pre-operative diagnosis in this class of cases, in our list, was invariably cancer. These mistakes are unfortunate, since less radical measures than total excision effect a cure in mammary tuberculosis. Tumors of the breast giving the typical physical signs of fibro-epithelial tumors, simple cysts, and sarcomas will not excite suspicion of a tuberculous origin. Revel reports a case of cystic adeno-fibroma associated with tuberculosis. In these rare cases the presence of inflammatory signs arising in a preëxistent tumor and in the axillary nodes aids in the diagnosis. The tuberculin test should be of value in keeping with its diagnostic value in tuberculosis of other organs. Von Eberts insists upon its use for diagnostic purposes, but we can find no reference to its employment in mammary tuberculosis. Frozen section diagnosis of all doubtful tumors should be made at the time of operation. This may prevent unnecessary mutilation in mammary tuberculosis in young women, for we are assured that in the ordinary case less radical procedures than those employed in the past will serve to cure tuberculosis of the breast.

Reference has already been made to bacteriological methods of diagnosis. The use of the $x$-ray will, as mentioned above, serve to diagnose a primary focus in an adjacent rib.

Prognosis. - No reported case of mammary tuberculosis died as the result of operation. With one exception all of the cases in our series were operated upon, and all were discharged from the hospital apparently cured. The exception was a case operated upon by Mantelli, in which a sinus persisted. Stromberg and Robinson report recurrences. Braendle reports four cases alive and well I 3 years, I I years, nine years, and eight years, respectively, post operationem. In one of Schley's cases there was no return of the disease after four years, and Fuller observed cases three and eight years after operation with no sign of recurrence. Von Eberts' case was well six months after operation. Of Anspach's I 2 cases, four were well one year after operation, three not heard from, and one died at the end of three years (cause unknown), while the others remained well eight, four, three, and two years respectively. Few cases of recurrence have been reported. These cases 
presented pulmonary lesions, as a rule. In several instances tuberculous peritonitis, meningitis, or acute miliary tuberculosis manifested itself usually some years after operation. Operative treatment as carried out in the past offers, in the primary cases, almost complete assurance of permanent cure. The prognosis in the secondary form of mammary tuberculosis depends entirely upon the activity, location, and extent of the primary focus.

Treatment.-The treatment in all of the primary cases collected was operative. The methods being as follows:

\section{Primary Cases}

Simple amputation of the breast and curettage of the axilla $\ldots \ldots \ldots \ldots \ldots$ I I

Simple amputation of the breast. . . . . . . . . . . . . . .

Wet dressings for 15 days, with incision of the abscess $\ldots \ldots \ldots \ldots \ldots \ldots \ldots$

Exploratory incision (diagnosed cancer), with radical operation . . . . . . . . 4

Incision followed by excision of the mass . . . . . . . . . . . . . . . 5

Incision followed by excision of the mass and axillary nodes . . . . . . .

Excision of the tumor and a portion of the pectoralis major muscle ........ I

Simple amputation of the breast, with removal of a portion of the pectoralis major

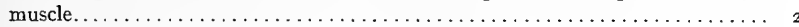

Excision of the mass in the left breast, incision and curettage of abscess in the

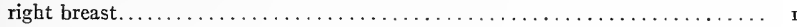

Simple amputation of the breast, followed by tuberculin, I to I $500 \mathrm{mg}$. every io

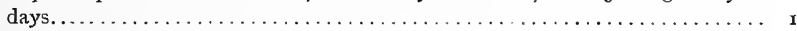

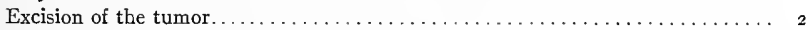

Radical amputation. .......................... 3

Simple amputation of the breast and removal of pectoral fascia and the axillary lymph nodes. . . . . . . . . . . .

\section{Secondary Cases}

Incision followed by excision of the involved quadrant. . . . . . . . . . . I

Excision of the involved quadrant and axillary nodes $\ldots \ldots \ldots \ldots \ldots \ldots \ldots$

Incision followed by radical excision of the breast $\ldots \ldots \ldots \ldots \ldots \ldots \ldots \ldots$

Simple amputation of the breast with excision of the axillary nodes........ I I

Radical excision of the breast (one by Tansini's method) $\ldots \ldots \ldots \ldots \ldots \ldots$

Simple amputation of the breast. . . . . . . . . . . . . . . . . . . . . .

Incision and curettage of the abscess. $\ldots \ldots \ldots \ldots \ldots \ldots \ldots \ldots \ldots \ldots$

Not operated. . . . . . . . . . . . . . . . . . . . . . . . .

Excision of mass in the breast and curettage of the ribs $\ldots \ldots \ldots \ldots \ldots \ldots \ldots$

Amputation of the breast and pectoralis major muscle. Scraping of rib. Serum

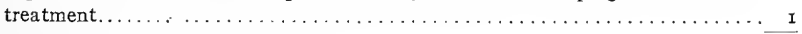

Von Eberts advises tuberculin therapy in early cases, in the absence of mixed infection, and when the probability of lactation can be safely ruled out. We know of no early case in which this form of treatment has been used. The details of the operation must depend upon the type and extent of the lesion. We are of the opinion that many of the operations were unnecessarily radical, and that equal good might have been accomplished by more simple means.

We advise the excision of a localized tuberculous mass in the breast of a young woman, with exploration of the axilla for the purpose of removing tuberculous lymph nodes. In older women, simple amputation with excision of the axillary lymph nodes, is the method of choice. In either case tuberculin should be given, since this in proper dosage and in properly selected cases can do no harm and may perhaps aid nature in overcoming any small focus of disease that might have escaped the knife. Conservatism had better be expressed in limiting the area of excision than in discarding operative treatment. 
Cases of Mammary Tuberculosis (Primary Type) Reported in the Literature

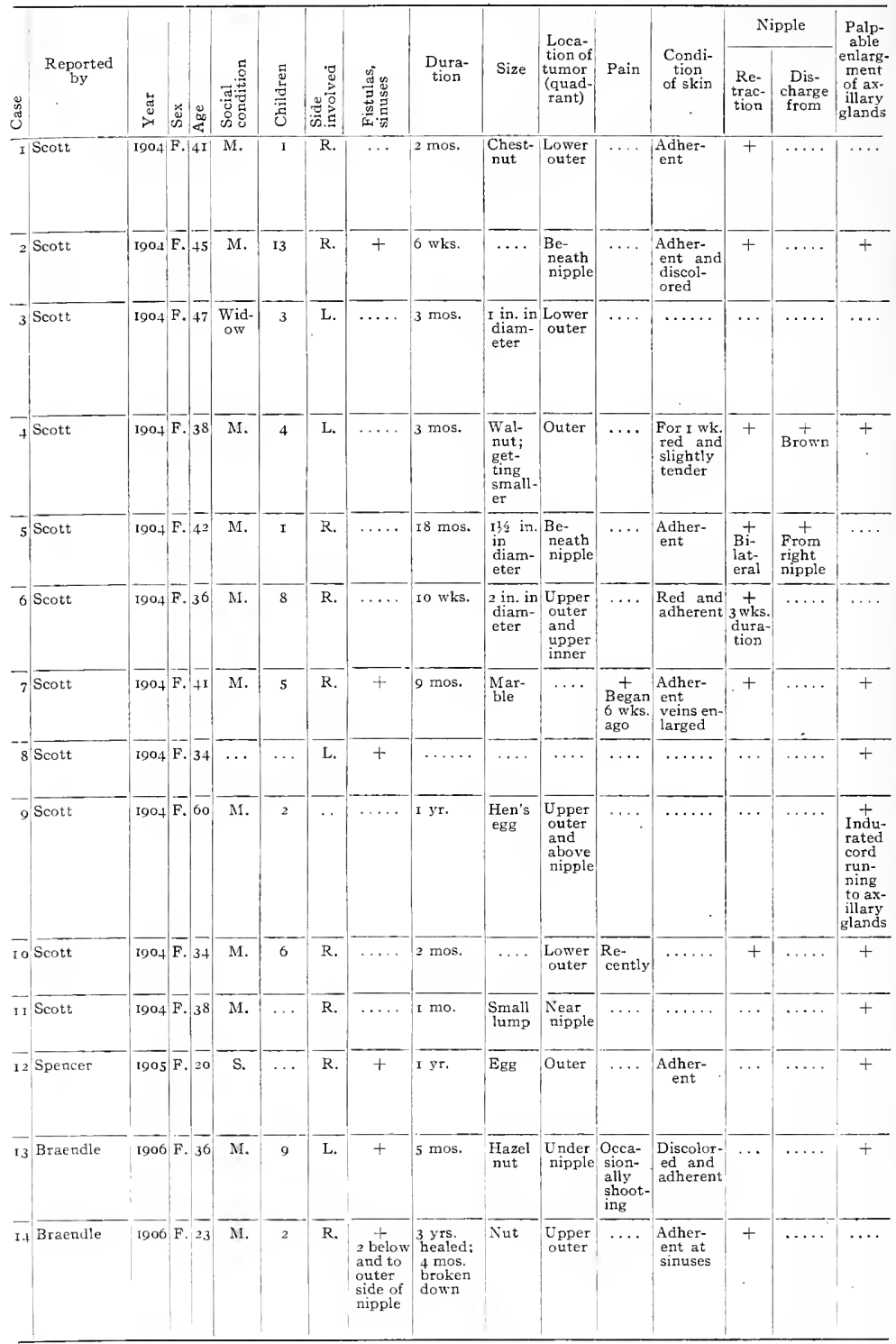


from igo to igi4, Including Two Personaliy Observed Cases-(Continued)

\begin{tabular}{|c|c|c|c|c|c|c|c|c|c|}
\hline $\begin{array}{l}\text { Initial } \\
\text { symp- } \\
\text { toms }\end{array}$ & $\begin{array}{l}\text { Hered- } \\
\text { ity }\end{array}$ & $\begin{array}{l}\text { Antecedent condi- } \\
\text { tion of breast }\end{array}$ & 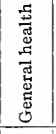 & $\begin{array}{l}\text { General } \\
\text { physical } \\
\text { exami- } \\
\text { nation }\end{array}$ & Treatment & Result & $\begin{array}{l}\text { Pathol- } \\
\text { ogy; } \\
\text { micro- } \\
\text { scopic }\end{array}$ & $\begin{array}{l}\text { Tuber- } \\
\text { cle } \\
\text { bacilli } \\
\text { found }\end{array}$ & $\begin{array}{l}\text { Animal } \\
\text { inocu- } \\
\text { lation }\end{array}$ \\
\hline Lump & $\begin{array}{l}\text { Mother } \\
\text { and I } \\
\text { child } \\
\text { died of } \\
\text { tuber- } \\
\text { culosis }\end{array}$ & $\cdots \cdots \cdots$ & $\cdots$ & Negative & $\begin{array}{l}\text { Exploratory incision; } \\
\text { diagnosed cancer. } \\
\text { Radical operation }\end{array}$ & $\cdots \cdots$ & $\begin{array}{l}\text { Tuber- } \\
\text { culosis }\end{array}$ & & \\
\hline Lump & $\cdots \cdots$ & $\begin{array}{l}\text { Suppurative masti- } \\
\text { tis twice }\end{array}$ & Fine & $\begin{array}{l}\text { Strong } \\
\text { obese } \\
\text { woman }\end{array}$ & $\begin{array}{l}\text { Diagnosed as suppu- } \\
\text { rative mastitis and } \\
\text { scirrhus; radical op- } \\
\text { eration }\end{array}$ & $\ldots$ & $\begin{array}{l}\text { Tuber- } \\
\text { culosis; } \\
\text { lymph } \\
\text { nodes }\end{array}$ & • & \\
\hline Lump & $\begin{array}{l}\text { Hus- } \\
\text { band } \\
\text { and } \\
\text { father } \\
\text { died of } \\
\text { tuber- } \\
\text { culosis }\end{array}$ & $\cdots \cdots \cdots \cdots$ & Fine & Negative & $\begin{array}{l}\text { Incision; pus evacu- } \\
\text { ated; } 5 \text { w elling ex- } \\
\text { cised }\end{array}$ & $\cdots \cdots$ & $\begin{array}{l}\text { Tuber- } \\
\text { culosis }\end{array}$ & & \\
\hline Lump & $\ldots \ldots$ & $\begin{array}{l}\text { Cough for several } \\
\text { weeks }\end{array}$ & Fine & Negative & $\begin{array}{l}\text { Incision; pus evacu- } \\
\text { ated; excision of in- } \\
\text { volved area }\end{array}$ & $\ldots \ldots$ & $\begin{array}{l}\text { Tuber- } \\
\text { culosis }\end{array}$ & & \\
\hline $\begin{array}{l}\text { Dis- } \\
\text { charge } \\
\text { from } \\
\text { nipple }\end{array}$ & $\cdots \cdots$ & $\cdots \cdots \cdots$ & $\cdots$ & Negative & $\begin{array}{l}\text { Incision, pus evacu- } \\
\text { ated; excision of in- } \\
\text { volved area }\end{array}$ & $\begin{array}{l}\text { Wound } \\
\text { healed } \\
\text { by first } \\
\text { intention }\end{array}$ & $\begin{array}{l}\text { Tuber- } \\
\text { culosis }\end{array}$ & & \\
\hline Lump & $\cdots \cdots$ & $\ldots \ldots \ldots$ & $\cdots$ & Negative & $\begin{array}{l}\text { Incision; I oz, of pus } \\
\text { evacuated; Io days } \\
\text { later excision of in- } \\
\text { volved area and ax- } \\
\text { illary glands }\end{array}$ & $\cdots \cdots$ & $\begin{array}{l}\text { Tuber- } \\
\text { tculosis }\end{array}$ & & \\
\hline Lump & $\begin{array}{l}\text { Brother } \\
\text { died of } \\
\text { tuber- } \\
\text { culosis }\end{array}$ & $\begin{array}{l}\text { Had poultices applied } \\
\text { and two . abscesses } \\
\text { burst }\end{array}$ & $\cdots$ & Negative & $\begin{array}{l}\text { Excision of a portion } \\
\text { for frozen section; } \\
\text { simple amputation }\end{array}$ & $\cdots \cdots$ & $\begin{array}{l}\text { Tuber- } \\
\text { culosis }\end{array}$ & & \\
\hline Lump & $\cdots$ & $\begin{array}{l}\text { Needle in breast fol- } \\
\text { lowed by infection } \\
\text { and persistent sinus }\end{array}$ & Good & Negative & Simple amputation & $\begin{array}{l}\text { Unevent- } \\
\text { ful re- } \\
\text { covery }\end{array}$ & $\begin{array}{l}\text { Tuber- } \\
\text { culosis }\end{array}$ & & \\
\hline Lump & $\cdots \cdots$ & $\begin{array}{l}\text { Acute mastitis at age } \\
\text { of } 33 \mathrm{yrs} \text {. }\end{array}$ & Good & Negative & $\left\{\begin{array}{l}\text { Excision of lump and } \\
\text { axillary glands }\end{array}\right.$ & $\begin{array}{l}\text { Unevent- } \\
\text { ful re- } \\
\text { covery }\end{array}$ & $\begin{array}{l}\text { Tuber- } \\
\text { culosis; } \\
\text { Jymph } \\
\text { nodes }\end{array}$ & & \\
\hline Lump & $\cdots \cdots$ & $\begin{array}{l}\text { Abscess of right breast } \\
\text { after birth of } 3 \mathrm{~d} \text { child; } \\
\text { retracted nipple since }\end{array}$ & Good & Negative & $\begin{array}{l}\text { Incision of abscess; } \\
\text { radical amputation }\end{array}$ & $\begin{array}{l}\text { Unevent- } \\
\text { ful re- } \\
\text { covery }\end{array}$ & $\begin{array}{l}\text { Tuber- } \\
\text { culosis }\end{array}$ & & \\
\hline Lump & $\cdots \cdots$ & $\ldots \ldots \ldots$ & Good & Negative & Radical incision & $\begin{array}{l}\text { Unevent- } \\
\text { ful re- } \\
\text { covery }\end{array}$ & $\begin{array}{l}\text { Tuber- } \\
\text { culosis }\end{array}$ & & \\
\hline Lump & $\ldots \ldots$ & Normal & Good & Negative & $\begin{array}{l}\text { First had incision of } \\
\text { the axilla then am- } \\
\text { putation of the breast } \\
\text { and cle a n s ing of } \\
\text { axilla }\end{array}$ & $\ldots \ldots$ & $\begin{array}{l}\text { Tuber- } \\
\text { culosis }\end{array}$ & + & \\
\hline Lump & $\ldots \ldots$ & $\begin{array}{l}\text { Left breast never } \\
\text { functionated }\end{array}$ & $\begin{array}{l}\text { Ro- } \\
\text { bust }\end{array}$ & Negative & $\begin{array}{l}\text { Simple amputation; } \\
\text { excision of axillary } \\
\text { nodes }\end{array}$ & $\begin{array}{l}\text { Alive and } \\
\text { well I3 } \\
\text { yrs. later }\end{array}$ & $\begin{array}{l}\text { Tuber- } \\
\text { culosis }\end{array}$ & & \\
\hline $\begin{array}{l}\text { Abscess } \\
\text { opened } \\
\text { sponta- } \\
\text { neously }\end{array}$ & $\ldots \ldots$ & $\begin{array}{l}\text { Nursed children at } \\
\text { left breast }\end{array}$ & Good & Negative & Simple amputation & $\begin{array}{l}\text { Alive and } \\
\text { well I } \\
\text { yrs. later }\end{array}$ & $\begin{array}{l}\text { Tuber- } \\
\text { culosis }\end{array}$ & & \\
\hline
\end{tabular}


Cases of Mammary Tuberculosis (Primary Type) Reported in the Literature

\begin{tabular}{|c|c|c|c|c|c|c|c|c|c|c|c|c|c|c|c|c|}
\hline \multirow[b]{2}{*}{ 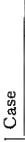 } & \multirow{2}{*}{$\begin{array}{c}\text { Reported } \\
\text { by }\end{array}$} & \multirow[b]{2}{*}{$\underset{\mathbb{N}}{5}$} & \multirow[b]{2}{*}{$\stackrel{4}{\infty}$} & \multirow[b]{2}{*}{ 足 } & \multirow{2}{*}{ 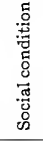 } & \multirow[b]{2}{*}{ 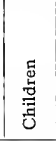 } & \multirow{2}{*}{ 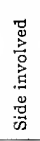 } & \multirow[b]{2}{*}{ 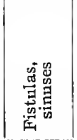 } & \multirow{2}{*}{$\underset{\text { tion }}{\text { Dura- }}$} & \multirow[b]{2}{*}{ Size } & \multirow{2}{*}{$\begin{array}{l}\text { Loca- } \\
\text { tion of } \\
\text { tumor } \\
\text { (quad- } \\
\text { rant) }\end{array}$} & \multirow[b]{2}{*}{ Pain } & \multirow{2}{*}{$\begin{array}{l}\text { Condi- } \\
\text { tion of } \\
\text { skin }\end{array}$} & \multicolumn{2}{|c|}{ Nipple } & \multirow{2}{*}{$\begin{array}{l}\text { Palp- } \\
\text { able } \\
\text { enlarg- } \\
\text { ment } \\
\text { of ax- } \\
\text { illary } \\
\text { glands }\end{array}$} \\
\hline & & & & & & & & & & & & & & $\begin{array}{c}\text { Re- } \\
\text { trac- } \\
\text { tion }\end{array}$ & $\begin{array}{c}\text { Dis- } \\
\text { charge } \\
\text { from }\end{array}$ & \\
\hline I 5 & Braendle & 1906 & F. & $3^{8}$ & M. & 2 & L. & $\begin{array}{l}+ \\
2\end{array}$ & 3 mos. & $\begin{array}{l}\text { Entire } \\
\text { breast } \\
\text { en- } \\
\text { larged }\end{array}$ & $\begin{array}{l}\text { Lower } \\
\text { inner }\end{array}$ & Lately & $\begin{array}{l}\text { Adher- } \\
\text { ent at } \\
\text { sinuses }\end{array}$ & + & $\cdots \cdots$ & + \\
\hline I6 & Braendle & 1906 & F. & 34 & M. & $\cdots$ & R. & $\underset{2}{+}$ & $\begin{array}{l}5 \text { wks.; } 3 \\
\text { wks. ago } \\
\text { opened; } \\
\text { lo days } \\
\text { ago } \\
\text { again } \\
\text { opened }\end{array}$ & $\begin{array}{l}\text { Entire } \\
\text { breast } \\
\text { en- } \\
\text { larged }\end{array}$ & $\begin{array}{l}\text { Fistu- } \\
\text { las } \\
\text { above } \\
\text { and } \\
\text { below } \\
\text { nipple }\end{array}$ & $\cdots$ & $\begin{array}{l}\text { Adher- } \\
\text { ent and } \\
\text { discol- } \\
\text { ored at } \\
\text { sinuses }\end{array}$ & $\cdots$ & $\cdots \cdots$ & + \\
\hline 17 & Geissler & 1906 & F. & 50 & $\cdots$ & $\cdots$ & R. & $\cdots \cdots$ & 4 mos. & $\cdots$ & $\cdots$ & $\cdots$ & $\cdots \cdots$ & $\cdots$ & $\cdots \cdots$ & $\cdots$ \\
\hline I 8 & Geissler & 1906 & F. & 56 & $\cdots$ & $\cdots$ & R. & $\ldots \ldots$ & 2 wks. & $\begin{array}{l}\text { Hen's } \\
\text { egg }\end{array}$ & $\begin{array}{l}\text { Upper } \\
\text { outer }\end{array}$ & $\cdots$ & $\cdots \cdots$ & $\cdots$ & $\cdots \cdots$ & + \\
\hline 19 & Berger & 1906 & F. & 47 & $\cdots$ & $\cdots$ & $\cdots$ & $\cdots \cdots$ & $\cdots \cdots$ & $\cdots$ & $\begin{array}{l}\text { Upper } \\
\text { outer }\end{array}$ & + & $\cdots \cdots$ & $\cdots$ & $\cdots \cdots$ & $\cdots$ \\
\hline 20 & Zironi & 1907 & F. & 23 & M. & $\begin{array}{l}2 \text { mis- } \\
\text { carri- } \\
\text { ages }\end{array}$ & L. & $\cdots \cdots$ & I yr. & $\ldots$ & $\begin{array}{l}\text { Upper } \\
\text { outer }\end{array}$ & $\begin{array}{l}\text { Ten- } \\
\text { derness }\end{array}$ & $\cdots \cdots$ & + & $\cdots \cdots$ & $\cdots$ \\
\hline $2 I$ & Marangoni & I907 & F. & $4 \mathrm{I}$ & M. & $\cdots$ & $\cdots$ & $\begin{array}{l}+ \\
\text { In lower } \\
\text { part of } \\
\text { areola }\end{array}$ & 5 yrs. & $\cdots$ & Lower & $\cdots$ & $\begin{array}{l}\text { Adher- } \\
\text { ent and } \\
\text { discol- } \\
\text { ored. }\end{array}$ & + & $\cdots \cdots$ & + \\
\hline 22 & Marangoni & 1907 & F. & 29 & M. & 6 & R. & $\ldots$ & $\cdots \cdots$ & $\begin{array}{l}\text { Large } \\
\text { lump }\end{array}$ & $\begin{array}{l}\text { Gener- } \\
\text { alized }\end{array}$ & + & $\ldots \ldots$ & $\cdots$ & $\cdots \cdots$ & + \\
\hline 23 & Hardoüin & 1907 & F. & 32 & M. & I & R. & $\cdots$ & 2 mos. & $\cdots$ & $\begin{array}{c}\text { Above } \\
\text { nipple }\end{array}$ & $\begin{array}{l}\text { Shoot- } \\
\text { ing } \\
\text { pain }\end{array}$ & $\begin{array}{l}\text { Tender- } \\
\text { ness }\end{array}$ & $\cdots$ & $\cdots \cdots$ & + \\
\hline 24 & Revel & I908 & F. & 45 & S. & 0 & L. & $\ldots$ & Few mos. & Nut & $\begin{array}{l}\text { Per- } \\
\text { iphery }\end{array}$ & $\cdots$ & $\cdots \cdots$ & $\cdots$ & $\cdots \cdots$ & + \\
\hline 25 & Brandsburg & 1908 & F. & 30 & M. & 0 & L. & $\cdots$ & 6 yrs. & $\begin{array}{l}\text { Hen's } \\
\text { egg. }\end{array}$ & $\cdots$ & $\cdots$ & $\cdots \cdots$ & + & $\begin{array}{l}+ \\
\text { Ulcer- } \\
\text { ated, } \\
\text { suppil- } \\
\text { rative }\end{array}$ & + \\
\hline 26 & Brandsburg & 1908 & F. & 34 & M. & 4 & R. & $\ldots$ & 2 mos. & $\begin{array}{l}\text { Hen's } \\
\text { egg }\end{array}$ & $\cdots$ & \begin{tabular}{l}
\multicolumn{1}{c}{+} \\
Espe- \\
cially \\
in \\
nipple
\end{tabular} & $\ldots \ldots$ & + & $\begin{array}{l}+ \\
\text { Ulcer- } \\
\text { ated }\end{array}$ & + \\
\hline 27 & Ressiguie & 1909 & M. & 40 & $\cdots$ & $\cdots$ & R. & $\cdots \cdots$ & 3 mos. & $\begin{array}{l}\text { Horse- } \\
\text { chest- } \\
\text { nut }\end{array}$ & $\begin{array}{l}\text { Near } \\
\text { nipple }\end{array}$ & At & $\ldots \ldots$ & $\cdots$ & $\cdots$ & $\cdots$ \\
\hline 28 & Fuller & 1909 & F. & 35 & M. & 3 & $\cdots$ & $\begin{array}{l}\text { Under } \\
\text { nipple }\end{array}$ & I yr. & Egg & $\begin{array}{l}\text { Upper } \\
\text { outer }\end{array}$ & $\ldots$ & $\begin{array}{l}\text { Adher- } \\
\text { ent and } \\
\text { discol- } \\
\text { ored }\end{array}$ & + & $\cdots \cdots$ & + \\
\hline 29 & Fuller & 1909 & F. & 50 & M. & 2 & $\begin{array}{l}\text { Bi- } \\
\text { lat- } \\
\text { eral }\end{array}$ & $\underset{\text { In left }}{+}$ & I yr. & $\ldots$ & $\begin{array}{l}\text { Upper } \\
\text { outer, } \\
\text { L.; } \\
\text { upper } \\
\text { inner, } \\
\text { R. }\end{array}$ & $\cdots$ & $\begin{array}{l}\text { Adher- } \\
\text { ent and } \\
\text { discol- } \\
\text { ored }\end{array}$ & $\cdots$ & $\cdots \cdots$ & $\cdots$ \\
\hline
\end{tabular}


from ig04 to 19i4, Including Two Personally Observed Cases-(Continued)

\begin{tabular}{|c|c|c|c|c|c|c|c|c|c|}
\hline $\begin{array}{l}\text { Initial } \\
\text { symp- } \\
\text { toms }\end{array}$ & $\begin{array}{l}\text { Hered- } \\
\text { ity }\end{array}$ & $\begin{array}{l}\text { Antecedent condi- } \\
\text { tion of breast }\end{array}$ & 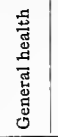 & $\begin{array}{l}\text { General } \\
\text { physical } \\
\text { exami- } \\
\text { nation }\end{array}$ & Treatment & Result & $\begin{array}{l}\text { Pathol- } \\
\text { ogy; } \\
\text { micro- } \\
\text { scopic }\end{array}$ & $\begin{array}{l}\text { Tuber- } \\
\text { cle } \\
\text { bacilli } \\
\text { found }\end{array}$ & $\begin{array}{l}\text { Animal } \\
\text { inocu- } \\
\text { lation }\end{array}$ \\
\hline Lump & $\cdots \cdots$ & $\ldots \ldots \ldots \ldots$ & Good & Negative: & Simple amputation & $\begin{array}{l}\text { Alive and } \\
\text { well g yrs. } \\
\text { later }\end{array}$ & $\begin{array}{l}\text { Tuber- } \\
\text { culosis }\end{array}$ & & \\
\hline $\begin{array}{l}\text { Harden- } \\
\text { ing of } \\
\text { breast }\end{array}$ & $\cdots \cdots$ & Mastitis 2 yrs. before & Good & Negative & Simple amputation & $\begin{array}{l}\text { Alive and } \\
\text { well } 8 \text { yIs. } \\
\text { later }\end{array}$ & $\begin{array}{l}\text { Tuber- } \\
\text { culosis }\end{array}$ & & \\
\hline Lump, & $\ldots \ldots$ & $\ldots \ldots \ldots$ & Good & Negative & Amputation & $\begin{array}{l}\text { Unevent- } \\
\text { ful re- } \\
\text { covery }\end{array}$ & $\begin{array}{l}\text { Tuber- } \\
\text { culosis }\end{array}$ & & \\
\hline Lump & $\ldots \ldots$ & $\ldots \cdots \cdots \cdots$ & Good & Negative & Amputation & $\begin{array}{l}\text { Unevent- } \\
\text { ful re- } \\
\text { covery }\end{array}$ & $\begin{array}{l}\text { Tuber- } \\
\text { culosis }\end{array}$ & & \\
\hline$\ldots \ldots$ & $\ldots \ldots$ & $\cdots \cdots \cdots \cdots$ & Good & Negative & Amputation & $\begin{array}{l}\text { Unevent- } \\
\text { ful re- } \\
\text { covery }\end{array}$ & $\begin{array}{l}\text { Tuber- } \\
\text { culosis; } \\
\text { sclerotic } \\
\text { lymph } \\
\text { nodes }\end{array}$ & & \\
\hline $\begin{array}{l}\text { Tender- } \\
\text { ness and } \\
\text { enlarge- } \\
\text { ment }\end{array}$ & $\ldots \ldots$ & $\ldots \ldots \ldots$ & Good & Negative & $\begin{array}{l}\text { Amputation of breast } \\
\text { and curettage of ax- } \\
\text { illa }\end{array}$ & $\begin{array}{l}\text { Alive and } \\
\text { well } 2 \text { yrs. } \\
\text { later }\end{array}$ & $\begin{array}{l}\text { Tuber- } \\
\text { culosis }\end{array}$ & $\begin{array}{l}\text { In cul- } \\
\text { ture }\end{array}$ & \\
\hline $\begin{array}{l}\text { Swelling } \\
\text { after } \\
\text { trauma: } \\
\text { abscess } \\
\text { opened } 3 \\
\text { yrs.later } \\
\end{array}$ & $\ldots \cdots$ & $\begin{array}{l}\text { Violent trauma } 5 \text { yrs. } \\
\text { ago, followed by suf:- } \\
\text { purative mastitis } 3 \\
\text { yrs. ago }\end{array}$ & Poor & Negative & $\begin{array}{l}\text { Simple amputation } \\
\text { and cleansing of ax- } \\
\text { illa }\end{array}$ & $\cdots \cdots$ & $\begin{array}{l}\text { Tuber- } \\
\text { culosis; } \\
\text { lymph } \\
\text { nodes }\end{array}$ & & \\
\hline $\begin{array}{l}\text { Piercing } \\
\text { pain in } \\
\text { breast }\end{array}$ & $\ldots$ & $\ldots \ldots \ldots$ & $\overline{\text { Good }}$ & Negative & $\begin{array}{l}\text { Simple amputation } \\
\text { and c leansing of } \\
\text { axilla }\end{array}$ & $\cdots \cdots$ & $\begin{array}{l}\text { Tuber- } \\
\text { culosis }\end{array}$ & & \\
\hline $\begin{array}{l}\text { Pain and } \\
\text { lump }\end{array}$ & $\ldots$ & $\ldots \ldots \ldots$ & Good & Negative & $\begin{array}{l}\text { Wet dressing for I5 } \\
\text { days; incision of ab- } \\
\text { scess }\end{array}$ & $\begin{array}{l}\text { Recovery } \\
\text { unevent- } \\
\text { ful }\end{array}$ & $\begin{array}{l}\text { Tubercu- } \\
\text { losis of a } \\
\text { portion } \\
\text { of ab- } \\
\text { scess } \\
\text { wall }\end{array}$ & & \\
\hline Lump & $\ldots \ldots$ & $\ldots \ldots \ldots$ & Ro- & Negative & $\begin{array}{l}\text { Simple amputation; } \\
\text { curettage of axilla }\end{array}$ & $\begin{array}{l}\text { Recovery } \\
\text { unevent- } \\
\text { ful }\end{array}$ & $\begin{array}{l}\text { Tuber- } \\
\text { culosis; } \\
\text { lymph } \\
\text { nodes }\end{array}$ & & \\
\hline Lump & $\ldots \ldots$ & $\ldots \ldots \ldots$ & $\overline{\text { Good }}$ & Negative & Simple a mputation & $\ldots \ldots$ & $\begin{array}{l}\text { Tuber- } \\
\text { culosis }\end{array}$ & $\begin{array}{l}\text { In } \\
\text { stained } \\
\text { tissue } \\
\text { sec- } \\
\text { tions }\end{array}$ & \\
\hline Lump & $\ldots \ldots$ & $\begin{array}{l}\text { I y yrs. ago suppura- } \\
\text { tive mastitis; } 2 \text { mos. } \\
\text { ago present conditior } \\
\text { began }\end{array}$ & Poor & Negative & Radical excision & $\ldots \ldots$ & $\begin{array}{l}\text { Tuber- } \\
\text { culosis }\end{array}$ & $\begin{array}{l}\text { In } \\
\text { stained } \\
\text { tissue } \\
\text { sec- } \\
\text { tions }\end{array}$ & \\
\hline Lump & $\ldots \ldots$ & $\ldots \ldots \ldots$ & $\overline{\text { Good }}$ & Negative & $\begin{array}{l}\text { Simple amputation } \\
\text { with removal of por- } \\
\text { tion of involved } \mathrm{P} \text {. } \\
\text { major muscle }\end{array}$ & $\ldots \ldots$ & $\begin{array}{l}\text { Tuber- } \\
\text { culosis }\end{array}$ & & \\
\hline Lump & $\ldots \ldots$ & $\begin{array}{l}\text { Abscess lanced } 2 \text { yrs. } \\
\text { ago }\end{array}$ & Good & Negative & $\begin{array}{l}\text { Ercision of involved } \\
\text { area }\end{array}$ & $\begin{array}{l}\text { Well } 3 \text { yrs. } \\
\text { afterop- } \\
\text { eration }\end{array}$ & $\begin{array}{l}\text { Tuber- } \\
\text { culosis; } \\
\text { frozen } \\
\text { section }\end{array}$ & & . \\
\hline Lump & $\ldots \ldots$ & $\ldots \ldots \ldots$ & $\overline{\text { Good }}$ & Negative & $\begin{array}{l}\text { Excision of mass in } \\
\text { left breast; incision } \\
\text { and curettage of ab- } \\
\text { scess in right breast }\end{array}$ & $\begin{array}{l}\text { Well s yrs. } \\
\text { after op- } \\
\text { eration }\end{array}$ & $\begin{array}{l}\text { Tuber- } \\
\text { culosis; } \\
\text { frozen } \\
\text { section }\end{array}$ & $\begin{array}{l}\text { In } \\
\text { stained } \\
\text { tissue } \\
\text { sec- } \\
\text { tions }\end{array}$ & \\
\hline
\end{tabular}


Cases of Mammary Tuberculosis (Primary Type) Reported in the Literature

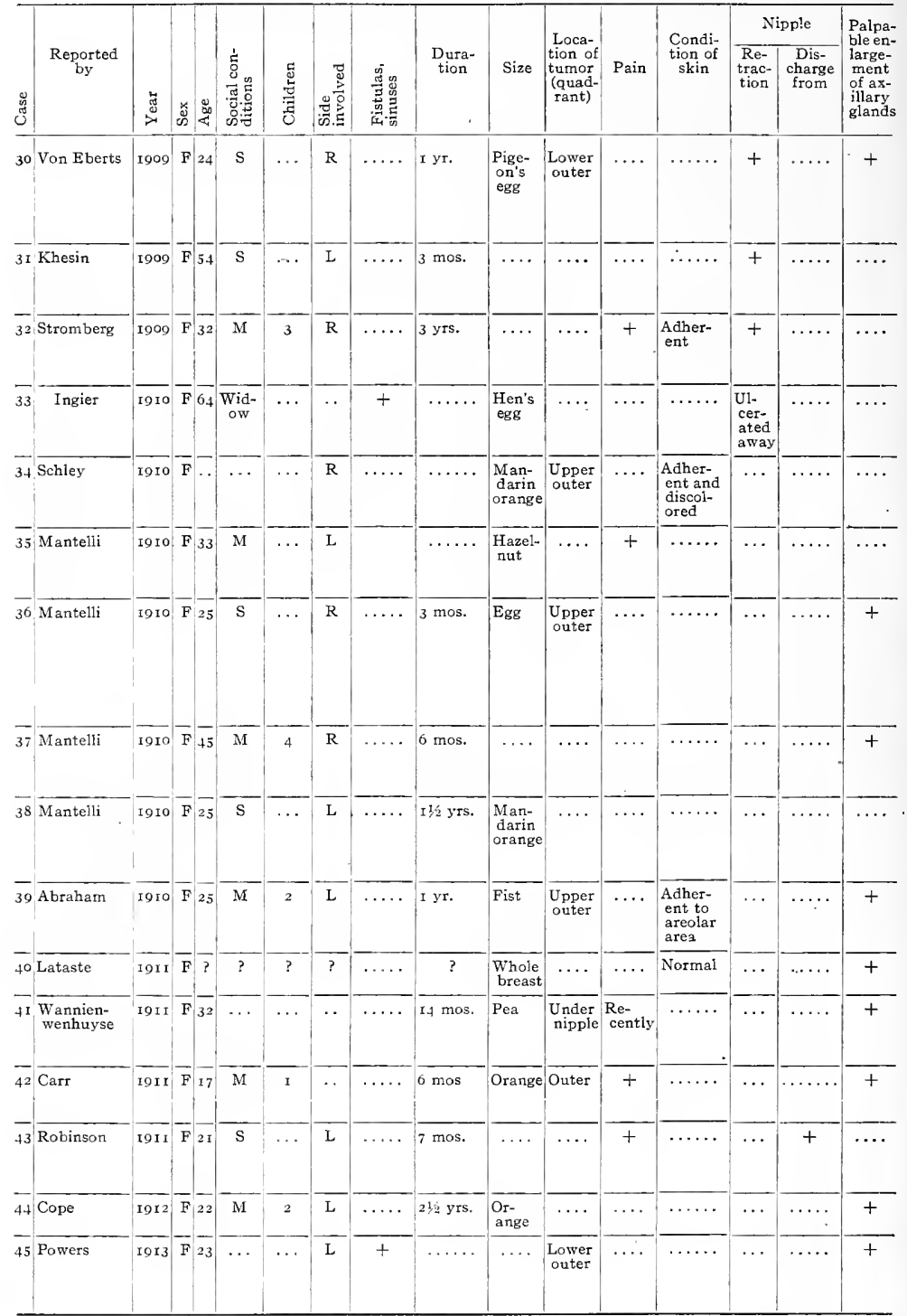

1 The following report of a case of the discrete nodular variety of primary mammary tuberculosis was sent to us mammary tuberculosis that is indistinguishable clinically from scirrhus carcinoma.

Mrs. C. B., aged 4I years, was admitted to the Kensington Hospital for Women of Philadelphia. I-9-16, comhealthy woman except for the lump in the breast, and is the mother of four healthy children. Fourteen years ago and gave rise to no further trouble until six weeks before her present admission when she struck the right breast where-

Physical examination was negative except for the presence of a hard mass about the size of an English walnut in the or retraction of the nipple. The axillary glands were not palpahle. The clinical diagnosis of carcinoma was made and noma, and it was so considered until the microscope revealed its true nature. 
from Igo4 to igi4, Including Two Personally Observed Cases-(Continued)

\begin{tabular}{|c|c|c|c|c|c|c|c|c|c|}
\hline $\begin{array}{l}\text { Initial } \\
\text { symp- } \\
\text { toms }\end{array}$ & $\begin{array}{l}\text { Hered- } \\
\text { ity }\end{array}$ & $\begin{array}{l}\text { Antecedent condi- } \\
\text { tion of breast }\end{array}$ & 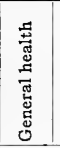 & $\begin{array}{l}\text { General } \\
\text { physical } \\
\text { exami- } \\
\text { nation }\end{array}$ & Treatment & Result & $\begin{array}{l}\text { Pathol- } \\
\text { ogy; } \\
\text { micro- } \\
\text { scopic }\end{array}$ & $\begin{array}{l}\text { Tuber- } \\
\text { cle } \\
\text { bacilli } \\
\text { found }\end{array}$ & $\begin{array}{l}\text { Animal } \\
\text { inocu- } \\
\text { lation }\end{array}$ \\
\hline Lump & $\ldots$ & $\begin{array}{l}\text { b yrs. ago abscess of } \\
\text { breast opened spon- } \\
\text { taneously and dis- } \\
\text { charged for } 4 \text { mos.. } \\
\text { since when bas been } \\
\text { closed }\end{array}$ & Good & Negative & $\begin{array}{l}\text { Simple a mputation; } \\
\text { tuberculin, } 1 / 1500 \mathrm{mg} \text {. } \\
\text { every ro days }\end{array}$ & $\begin{array}{l}\text { Well } 6 \\
\text { mos. after } \\
\text { operation }\end{array}$ & $\begin{array}{l}\text { Tuber- } \\
\text { culosis; } \\
\text { lymph } \\
\text { nodes }\end{array}$ & $\begin{array}{l}\text { Grown } \\
\text { in pure } \\
\text { culture } \\
\text { from } \\
\text { breast } \\
\text { lesion }\end{array}$ & \\
\hline Lump & $\cdots \cdots$ & $\ldots \ldots \ldots \ldots$ & Good & Negative & $\begin{array}{l}\text { Simple amputation } \\
\text { and cleansing of axilla }\end{array}$ & $\begin{array}{l}\text { Fistula } \\
\text { persisted } \\
\text { for some } \\
\text { months }\end{array}$ & $\begin{array}{l}\text { Tuber- } \\
\text { culosis }\end{array}$ & & \\
\hline $\begin{array}{l}\text { Pain and } \\
\text { indura- } \\
\text { tion }\end{array}$ & $\ldots \ldots$ & $\begin{array}{l}\text { Operated } 3 \text { yrs. ago } P \\
\text { for similar condition; } \\
\text { disease immediately } \\
\text { recurred. }\end{array}$ & Poot & Negative & $\begin{array}{l}\text { Simple amputation } \\
\text { and cleansing of } \\
\text { axilla }\end{array}$ & $\ldots$ & $\begin{array}{l}\text { Tuber- } \\
\text { culosis }\end{array}$ & $\begin{array}{l}\text { In } \\
\text { stained } \\
\text { tissue } \\
\text { sections }\end{array}$ & \\
\hline \multicolumn{4}{|c|}{$\begin{array}{l}\text { Ingier describes the pathology of this case and } \\
\text { calls it tuberculosa obliterans. He refers to } 2 \\
\text { similar cases. I a fibrosis mastitis of tubercu- } \\
\text { lous origin in a lactating breast. }\end{array}$} & Negative & Simple amputation & $\ldots$ & $\begin{array}{l}\text { Tuber- } \\
\text { culosis }\end{array}$ & $\begin{array}{l}\text { Found } \\
\text { in } \\
\text { smears } \\
\text { of pus }\end{array}$ & \\
\hline Lump & $\ldots \ldots$ &.$\quad \cdots \ldots \ldots$ & Fine & Negative & Simple amputation & $\begin{array}{l}\text { Well } 4 \\
\text { yrs. after } \\
\text { operation }\end{array}$ & $\begin{array}{l}\text { Tuber- } \\
\text { culosis }\end{array}$ & $\begin{array}{l}\text { Found } \\
\text { in } \\
\text { smears } \\
\text { of pus }\end{array}$ & \\
\hline $\begin{array}{l}\text { Pain and } \\
\text { lump }\end{array}$ & $\cdots \cdots$ & $\ldots \ldots \ldots$ & Good & Negative I & $\begin{array}{l}\text { Iodine locally follow- } \\
\text { ed by excision of } \\
\text { nodule }\end{array}$ & $\cdots \cdots$ & $\begin{array}{l}\text { Tuber- } \\
\text { cuiosis }\end{array}$ & $\cdots \cdots$ & $\begin{array}{l}\text { Guinea- } \\
\text { pig inoc- } \\
\text { ulation } \\
\text { positive }\end{array}$ \\
\hline Lump & $\ldots \ldots$ & $\ldots \ldots \ldots$ & Good & Negative & $\begin{array}{l}\text { Aspiration; guinea-pig } \\
\text { inoculation with pus } \\
\text { positive; simple am- } \\
\text { putation of breast } \\
\text { and cle ansing of } \\
\text { axilla }\end{array}$ & $\cdots$ & $\begin{array}{l}\text { Tuber- } \\
\text { culosis }\end{array}$ & $\cdots \cdots$ & $\begin{array}{l}\text { Diag- } \\
\text { nosed by } \\
\text { injecting } \\
\text { pus from } \\
\text { abscess } \\
\text { into } \\
\text { guinea- } \\
\text { pig }\end{array}$ \\
\hline Lump & $\cdots \cdots$ & $\cdots \cdots \cdots$ & Good & Negative & $\begin{array}{l}\text { Simple amputation } \\
\text { and cleansing of } \\
\text { axilla }\end{array}$ & $\ldots \ldots$ & $\begin{array}{l}\text { Tuber- } \\
\text { culosis }\end{array}$ & $\begin{array}{l}\text { Found } \\
\text { in } \\
\text { tissue } \\
\text { section }\end{array}$ & \\
\hline$\cdots \cdots$ & $\ldots \ldots$ & $\begin{array}{l}\text { Operated I } 1 / 2 \text { yrs. ago } \\
\text { for lumpin leftbreast; } \\
\text { fistula remained } 3 \\
\text { mos.; immediately } \\
\text { recurred }\end{array}$ & Good & Negative & Excision of lump & $\begin{array}{l}\text { Fistula } \\
\text { remained }\end{array}$ & $\begin{array}{l}\text { Tuber- } \\
\text { culosis }\end{array}$ & & \\
\hline Lump & $\ldots \ldots$ & Slight trauma & Good & Negative & $\begin{array}{l}\text { Simple amputation } \\
\text { and cleansing of } \\
\text { axilla }\end{array}$ & $\ldots \ldots$ & $\begin{array}{l}\text { Tuber- } \\
\text { cuiosis }\end{array}$ & & \\
\hline$\ldots \ldots$ & $\ldots \ldots$ & $\ldots \ldots \ldots$ & $\cdots$ & $\ldots$ & Simple amputation & $\ldots \ldots$ & $\begin{array}{l}\text { Tuber- } \\
\text { culosis }\end{array}$ & & \\
\hline Lump & $\ldots$ & Trauma & $\cdots$ & Negative & $\begin{array}{l}\text { Excision of the tumor } \\
\text { and a portion of the } \\
\mathrm{P} \text { major m s cle } \\
\text { wbich was involved }\end{array}$ & $\cdots \cdots$ & $\begin{array}{l}\text { Tuber- } \\
\text { culosis }\end{array}$ & & \\
\hline $\begin{array}{l}\text { Tender } \\
\text { lump }\end{array}$ & $\ldots \ldots$ & $\ldots \ldots \ldots \ldots$ & Good & Negative & $\begin{array}{l}\text { Simple amputation } \\
\text { and cleansing of } \\
\text { axilla }\end{array}$ & $\cdots \cdots$ & $\begin{array}{l}\text { Tuber- } \\
\text { culosis }\end{array}$ & & \\
\hline Pain & $\ldots \ldots$ & $\begin{array}{l}\text { Operated on Aprit, } \\
\text { I9Ir: tumor } 5 \mathrm{~cm} \text {. in } \\
\text { diameter } \mathrm{rem} \text { o ved } \\
\text { from left breast }\end{array}$ & Good & Negative & Radical excision & $\ldots \ldots$ & $\begin{array}{l}\text { Tuber- } \\
\text { culosis }\end{array}$ & & \\
\hline Lump & $\ldots \ldots$ & $\ldots \ldots \ldots$ & $\overline{\text { Good }}$ & Negative & Excision of tumor & $\ldots \ldots$ & $\begin{array}{l}\text { Tuber- } \\
\text { culosis }\end{array}$ & & \\
\hline Lamp & $\ldots \ldots$ & $\ldots \ldots \ldots$ & $\cdots$ & Negative & $\begin{array}{l}\text { Amputation of breast; } \\
\text { removal of deep pec- } \\
\text { toral fascia and axil- } \\
\text { lary lymph nodes }\end{array}$ & $\ldots \ldots$ & $\begin{array}{l}\text { Tuber- } \\
\text { calosis }\end{array}$ & & \\
\hline
\end{tabular}

by Dr. H. C. Deaver, but too late to include in the tabulation of cases. Tbis is a typical example of the type of plaining of a painful tumor in the right breast. The patient's family history is negative; she herself is a perfectly while nursing her last baby, sbe developed an abscess of the rigbt breast which subsided promptly after it was incised. upon sbe discovered a little tender mass in the upper inner quadrant.

upper inner quadrant of the right breast. This nodule was not freely movable but there was no dimpling of the skin a radicai amputation of the breast was performed. The gross appearance of the tumor was that of a scirrhus carci- 
Cases of Mammary Tuberculosis (Primary Type) Reported in the Literature

\begin{tabular}{|c|c|c|c|c|c|c|c|c|c|c|c|c|c|c|c|c|}
\hline \multirow[b]{2}{*}{ Uू } & \multirow[b]{2}{*}{$\begin{array}{c}\text { Reported } \\
\text { by }\end{array}$} & \multirow[b]{2}{*}{ 题 } & \multirow[b]{2}{*}{ ڤึ } & \multirow[b]{2}{*}{ is } & \multirow[b]{2}{*}{ 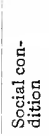 } & \multirow[b]{2}{*}{ 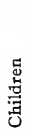 } & \multirow[b]{2}{*}{ 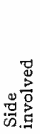 } & \multirow[b]{2}{*}{ 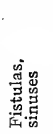 } & \multirow[b]{2}{*}{$\begin{array}{c}\text { Dura- } \\
\text { tion }\end{array}$} & \multirow[b]{2}{*}{ Size } & \multirow{2}{*}{$\begin{array}{l}\text { Loca- } \\
\text { tion of } \\
\text { tumor } \\
\text { (quad- } \\
\text { rant) }\end{array}$} & \multirow{2}{*}{ Pain } & \multirow[b]{2}{*}{$\begin{array}{l}\text { Condi- } \\
\text { tion of } \\
\text { skin }\end{array}$} & \multicolumn{2}{|c|}{ Nipple } & \multirow{2}{*}{$\begin{array}{l}\text { Palpa- } \\
\text { ble en- } \\
\text { large- } \\
\text { ment } \\
\text { of ax- } \\
\text { illary } \\
\text { glands }\end{array}$} \\
\hline & & & & & & & & & & & & & & $\begin{array}{l}\text { Re- } \\
\text { trac- } \\
\text { tion }\end{array}$ & $\begin{array}{c}\text { Dis- } \\
\text { charge } \\
\text { from }\end{array}$ & \\
\hline 46 & Deaver, J. B. & I9 I3 & $\mathbf{F}$ & 47 & M & $\cdots$ & $\mathrm{R}$ & $\cdots \cdots$ & 3 wks. & $\begin{array}{l}\text { Small } \\
\text { lump }\end{array}$ & $\begin{array}{l}\text { Upper } \\
\text { outer }\end{array}$ & + & ....... & + & $\underset{\text { serous }}{+}$ & $\ldots$ \\
\hline 47 & Deaver, J. B. & 1913 & $\mathrm{~F}$ & 44 & M & $\cdots$ & $\mathrm{R}$ & + & 3 yrs. & Egg & $\begin{array}{l}\text { Upper } \\
\text { outer }\end{array}$ & $\begin{array}{l}\text { + } \\
\text { When } \\
\text { ab- } \\
\text { scesses } \\
\text { formed }\end{array}$ & $\begin{array}{l}\text { Adher- } \\
\text { ent and } \\
\text { ulcer- } \\
\text { ated }\end{array}$ & + & $\cdots$ & $\cdots$ \\
\hline 48 & Hartwell & 1913 & $\mathrm{~F}$ & 23 & M & 3 & $\mathrm{R}$ & $\ldots \ldots$ & 6 wks. & $\begin{array}{l}\text { 10 } \times 15 \\
\mathrm{~cm} .\end{array}$ & Inner & + & $\begin{array}{l}\text { About to } \\
\text { ulcerate }\end{array}$ & $\cdots$ & $\ldots \ldots$ & + \\
\hline
\end{tabular}

Cases of Mammary Tuberculosis (Secondary Type) Reported in the Literature from igo4

\begin{tabular}{|c|c|c|c|c|c|c|c|c|c|c|c|c|c|c|c|}
\hline \multirow[b]{2}{*}{ 离 } & \multirow[b]{2}{*}{$\begin{array}{c}\text { Reported } \\
\text { by }\end{array}$} & \multirow[b]{2}{*}{ 永 } & \multirow[b]{2}{*}{ 惢 } & \multirow[b]{2}{*}{ 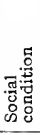 } & \multirow[b]{2}{*}{ 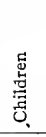 } & \multirow[b]{2}{*}{ 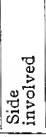 } & \multirow[b]{2}{*}{ 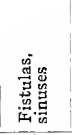 } & \multirow[b]{2}{*}{$\begin{array}{c}\text { Dura- } \\
\text { tion }\end{array}$} & \multirow[b]{2}{*}{ Size } & \multirow{2}{*}{$\begin{array}{l}\text { Loca- } \\
\text { tion of } \\
\text { tumor } \\
\text { (quad- } \\
\text { rant) }\end{array}$} & \multirow[b]{2}{*}{ Pain } & \multirow[b]{2}{*}{$\begin{array}{l}\text { Condi- } \\
\text { tion of } \\
\text { slin }\end{array}$} & \multicolumn{2}{|c|}{ Nipple } & \multirow{2}{*}{$\begin{array}{c}\text { Palpa- } \\
\text { ble } \\
\text { enlarge- } \\
\text { ment } \\
\text { of axi- } \\
\text { lasy } \\
\text { glands }\end{array}$} \\
\hline & & & & & & & & & & & & & $\begin{array}{l}\text { Re- } \\
\text { trac- } \\
\text { tion }\end{array}$ & $\begin{array}{l}\text { Dis- } \\
\text { charge } \\
\text { from }\end{array}$ & \\
\hline & Scott & 1904 & $\mathbf{F}+4$ & M & $\cdots$ & L & $\ldots$. & $6 \mathrm{wks}$. & $\begin{array}{l}11 / 2 \text { in. } \\
\text { in di- } \\
\text { ameter }\end{array}$ & Outer & $\cdots$ & $\ldots \ldots$ & + & $\ldots$ & $\begin{array}{l}\underset{\text { Bilat- }}{+} \\
\text { eral }\end{array}$ \\
\hline 2 & $S \cot t$ & 1904 & F 26 & M & I & $\mathrm{R}$ & $\cdots \cdots$ & 3 wks. & $\begin{array}{l}\text { I11- } \\
\text { de- } \\
\text { fined }\end{array}$ & $\begin{array}{l}\text { Upper } \\
\text { outer }\end{array}$ & $\cdots$ & $\begin{array}{l}\text { Ulcer- } \\
\text { ated } \\
\text { area in } \\
\text { right } \\
\text { axilla }\end{array}$ & $\cdots$ & $\cdots$ & $\begin{array}{l}\text { Bilater- } \\
\text { al. In } \\
\text { right } \\
\text { axilla } \\
\text { an ulcer } \\
\text { over- } \\
\text { lies the } \\
\text { en- } \\
\text { larged } \\
\text { gland }\end{array}$ \\
\hline & $S \cot t$ & 1904 & 4. F 37 & M & $\ldots$ & L & $\ldots$ & I yr. & $\ldots$ & $\begin{array}{l}\text { Entire } \\
\text { breast }\end{array}$ & $\ldots$ & $\begin{array}{l}\text { Adher- } \\
\text { ent }\end{array}$ & + & $\ldots$ & $\begin{array}{l}\text { Indur- } \\
\text { ated- } \\
\text { ated } \\
\text { cord } \\
\text { running } \\
\text { from } \\
\text { breast } \\
\text { to axilla }\end{array}$ \\
\hline & Scott & 1904 & $4 \mathrm{~F} 38$ & $M$ & $\cdots$ & $\mathrm{R}$ & $\ldots$ & 3 wks. & $\begin{array}{l}\text { Pige- } \\
\text { on's } \\
\text { egg }\end{array}$ & Upper & + & $\begin{array}{l}\text { Red and } \\
\text { inflamed }\end{array}$ & + & $\cdots$ & $\begin{array}{l}+ \\
\text { Bilat- } \\
\text { eral }\end{array}$ \\
\hline & Scott & 1904 & $4 \mathrm{~F} 38$ & $S$ & $\cdots$ & $\mathrm{R}$ & $\begin{array}{l}\text { Ulcer in } \\
\text { axilla }\end{array}$ & 6 wks. & $\cdots$ & $\begin{array}{l}\text { Upper } \\
\text { outer }\end{array}$ & + & $\begin{array}{l}\text { Adher- } \\
\text { ent and } \\
\text { ulcer- } \\
\text { ated in } \\
\text { axilla }\end{array}$ & $\cdots$ & $\cdots$ & + \\
\hline & Thurston & 1904 & ${ }^{4} \begin{array}{c}\mathrm{F} 36 \\
1\end{array}$ & . & $\ldots$ & $\mathrm{R}$ & + & 4 mos. & $\ldots$ & $\begin{array}{l}\text { Upper } \\
\text { outer }\end{array}$ & $\cdots$ & $\begin{array}{l}\text { Adher- } \\
\text { ent }\end{array}$ & $\cdots$ & $\cdots$ & $\begin{array}{l}\text { Bilat- } \\
\text { eral }\end{array}$ \\
\hline 7 & Schmidt & 1905 & F 23 & $3 \mathrm{M}$ & 2 & $\mathrm{R}$ & $+\frac{+}{5}$ & 5 mos. & $\cdots$ & $\begin{array}{l}\text { Gener- } \\
\text { alized }\end{array}$ & + & $\begin{array}{l}\text { Mlultiple } \\
\text { sinuses }\end{array}$ & + & $\cdots$ & $\begin{array}{l}\text { Bilat- } \\
\text { eral }\end{array}$ \\
\hline
\end{tabular}


from rgo4 to I9I4, Includng Two Personally Observed Cases-(Continued)

\begin{tabular}{|c|c|c|c|c|c|c|c|c|c|}
\hline $\begin{array}{l}\text { Initial } \\
\text { symp- } \\
\text { toms }\end{array}$ & $\begin{array}{l}\text { Hered- } \\
\text { ity }\end{array}$ & $\begin{array}{l}\text { Antecedent condi- } \\
\text { tion of breast }\end{array}$ & 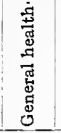 & $\begin{array}{c}\text { General } \\
\text { physical } \\
\text { exami- } \\
\text { nation }\end{array}$ & Treatment & Result & $\begin{array}{l}\text { Patbol- } \\
\text { ogy; } \\
\text { micro- } \\
\text { scopic }\end{array}$ & $\begin{array}{l}\text { Tuber- } \\
\text { cle } \\
\text { bacilli } \\
\text { found }\end{array}$ & $\begin{array}{l}\text { Animal } \\
\text { inocu- } \\
\text { lation }\end{array}$ \\
\hline Pain & $\ldots \ldots$ & Trauma I yr. ago & Fine & Negative & Simple amputation & $\ldots \ldots$ & $\begin{array}{l}\text { Tuber- } \\
\text { culosis }\end{array}$ & & \\
\hline Pain & $\ldots$ & $\ldots \ldots \ldots \ldots$ & $\overline{\text { Good }}$ & $\overline{\text { Negative }}$ & Simple amputation & $\cdots \cdots$ & $\begin{array}{l}\text { Tuber- } \\
\text { culosis }\end{array}$ & & \\
\hline Lump & $\ldots \ldots$ & Normal & Good & Negative & $\begin{array}{l}\text { Excision of diseased } \\
\text { area }\end{array}$ & Cured & $\begin{array}{l}\text { Tuber- } \\
\text { culosis }\end{array}$ & & \\
\hline
\end{tabular}

(Anspach's Paper) ro igi4 Including Three Personally Observed Cases-(Continued)

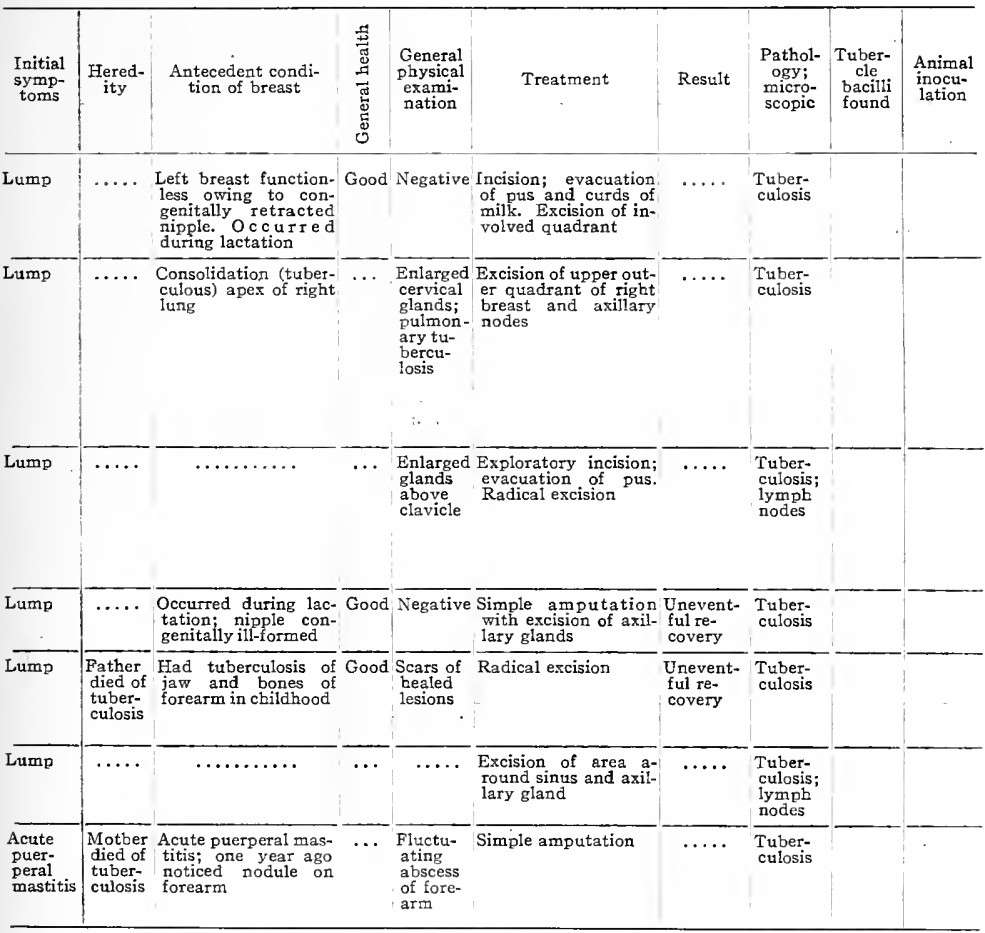


Cases of Mammary Tuberculosis (Secondary Type) Reported in the Literature from igo4

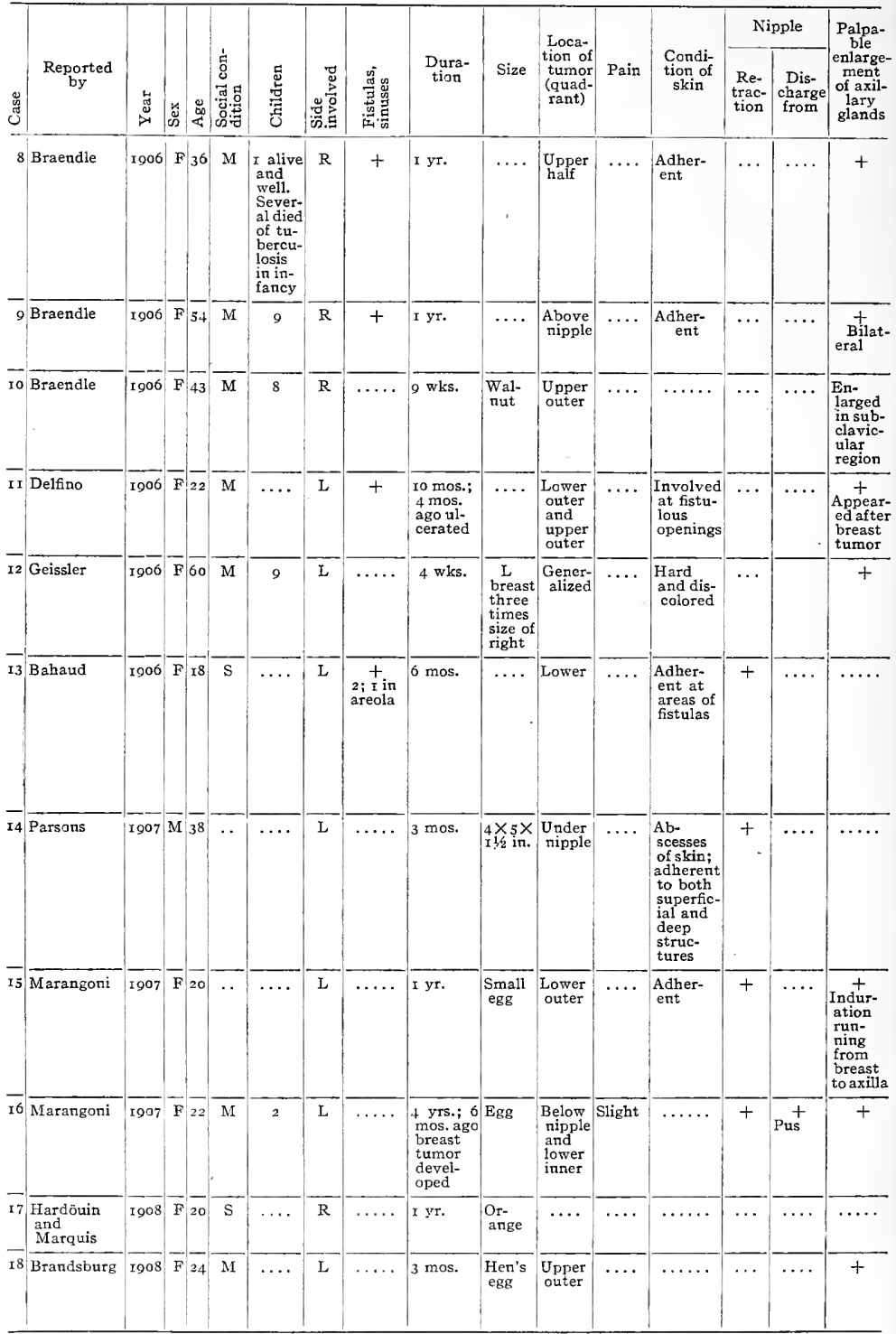


(Anspach's Paper) to igi 4 Including Three Personally Observed Cases-(Continued)

\begin{tabular}{|c|c|c|c|c|c|c|c|c|c|}
\hline $\begin{array}{l}\text { Initial } \\
\text { symp- } \\
\text { toms }\end{array}$ & $\begin{array}{l}\text { Hered- } \\
\text { ity }\end{array}$ & $\begin{array}{l}\text { Antecedent condi- } \\
\text { tion of breast }\end{array}$ & 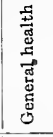 & $\begin{array}{c}\text { General } \\
\text { physical } \\
\text { exami- } \\
\text { nation }\end{array}$ & Treatment & Result & $\begin{array}{l}\text { Pathol- } \\
\text { ogy; } \\
\text { micro- } \\
\text { scopic }\end{array}$ & $\begin{array}{l}\text { Tuber- } \\
\text { cle } \\
\text { bacilli } \\
\text { found }\end{array}$ & $\begin{array}{l}\text { Animal } \\
\text { inocu- } \\
\text { lation }\end{array}$ \\
\hline Lump & $\cdots \cdots$ & $\cdots \ldots \ldots \ldots$ & Good & $\begin{array}{l}\text { Lump } \\
\text { size of } \\
\text { goose } \\
\text { egg in } \\
\text { left } \\
\text { cervical } \\
\text { region }\end{array}$ & $\begin{array}{l}\text { Amputation of breast } \\
\text { and cleansing of } \\
\text { axilla }\end{array}$ & $\begin{array}{l}\text { Alive and } \\
\text { well } \mathrm{r} \text { yr. } \\
\text { after } \\
\text { operation }\end{array}$ & $\begin{array}{l}\text { Tuber- } \\
\text { culosis }\end{array}$ & & . \\
\hline $\begin{array}{l}\text { Lump in } \\
\text { neck } \\
\text { and } \\
\text { breast }\end{array}$ & $\cdots \cdots$ & $\cdots \ldots \ldots$ & Fair & $\ldots$ & $\begin{array}{l}\text { Amputation of breast } \\
\text { and cleansing of } \\
\text { axilla }\end{array}$ & $\begin{array}{l}\text { Alive and } \\
\text { well } \mathrm{y} \text { yr. } \\
\text { after } \\
\text { operation }\end{array}$ & $\begin{array}{l}\text { Tuber- } \\
\text { culosis }\end{array}$ & & \\
\hline Lump & $\cdots \cdots$ & $\begin{array}{l}\text { Operated on } 6 \text { yrs. ago } \\
\text { for suppurative } \\
\text { glands in right axilla }\end{array}$ & Fair & $\cdots \cdots$ & $\begin{array}{l}\text { Amputation of breast } \\
\text { and cleansing of } \\
\text { axilla }\end{array}$ & $\begin{array}{l}\text { Alive and } \\
\text { well I yr. } \\
\text { after } \\
\text { operation }\end{array}$ & $\begin{array}{l}\text { Tuber- } \\
\text { culosis; } \\
\text { lymph } \\
\text { nodes }\end{array}$ & & \\
\hline Lump & $\cdots \cdots$ & $\begin{array}{l}\text { Pulmonary tuberculo- } \\
\text { sis }\end{array}$ & $\cdots$ & $\begin{array}{l}\text { Pulmon- } \\
\text { ary } \\
\text { tuber- } \\
\text { culosis }\end{array}$ & $\begin{array}{l}\text { Amputation of breast } \\
\text { and curettage of ax- } \\
\text { illa }\end{array}$ & $\begin{array}{l}\text { Unevent- } \\
\text { ful re- } \\
\text { covery }\end{array}$ & $\begin{array}{l}\text { Tuber- } \\
\text { culosis }\end{array}$ & $\cdots \cdots$ & $\begin{array}{l}\text { Guinea- } \\
\text { pig incc- } \\
\text { ulation } \\
\text { positive }\end{array}$ \\
\hline $\begin{array}{l}\text { Indura- } \\
\text { tion and } \\
\text { lump }\end{array}$ & $\cdots \cdots$ & $\begin{array}{l}\text { Pulmonary tubercu- } \\
\text { losis }\end{array}$ & $\cdots$ & $\begin{array}{l}\text { Pulmon- } \\
\text { ary } \\
\text { tuber- } \\
\text { culosis }\end{array}$ & Simple amputation & $\cdots \cdots$ & $\begin{array}{l}\text { Tuber- } \\
\text { culosis }\end{array}$ & & \\
\hline Pain & $\begin{array}{l}\text { Fatber, } \\
\text { mother, } \\
\text { I } \\
\text { brotber } \\
\text { and } \\
\text { several } \\
\text { sisters } \\
\text { died of } \\
\text { tuber- } \\
\text { culosis }\end{array}$ & $\begin{array}{l}\text { Tuberculosis of jaw } \\
\text { (lower) and cervical } \\
\text { nodes }\end{array}$ & $\cdots$ & $\begin{array}{l}\text { Pulmon- } \\
\text { ary } \\
\text { tuber- } \\
\text { culosis }\end{array}$ & $\begin{array}{l}\text { Simple amputation } \\
\text { and curettage of } \\
\text { axilla }\end{array}$ & $\cdots \cdots$ & $\begin{array}{l}\text { Tuber- } \\
\text { culosis }\end{array}$ & & \\
\hline $\begin{array}{l}\text { Lump } \\
\text { and pain } \\
\text { on } \\
\text { respira- } \\
\text { tion }\end{array}$ & $\cdots$ & $\cdots \cdots \cdots \cdots$ & $\cdots$ & $\cdots \cdots$ & $\begin{array}{l}\text { Amputation of breast } \\
\text { and F. major muscle; } \\
\text { scraping of ribs; ser- } \\
\text { um treatment }\end{array}$ & $\ldots$ & $\begin{array}{l}\text { Tuber- } \\
\text { culosis } \\
\text { in scrap- } \\
\text { ings } \\
\text { from } \\
\text { ribs }\end{array}$ & & \\
\hline $\begin{array}{l}\text { Lump in } \\
\text { left } \\
\text { axilla }\end{array}$ & $\cdots \cdots$ & Axillary tuberculosis & $\cdots$ & $\ldots \ldots$ & $\begin{array}{l}\text { Amputation of breast } \\
\text { and cleansing of } \\
\text { axilla }\end{array}$ & $\cdots \cdots$ & $\begin{array}{l}\text { Tuber- } \\
\text { culosis }\end{array}$ & & \\
\hline $\begin{array}{l}\text { Harden- } \\
\text { ing of } \\
\text { nipple } \\
\text { and } \\
\text { slight } \\
\text { pain }\end{array}$ & $\cdots \cdots$ & $\begin{array}{l}\text { Axillary adenitis; op- } \\
\text { erated on } 4 \text { yrs. ago }\end{array}$ & .. & $\cdots \cdots$ & $\begin{array}{l}\text { Simple amputation } \\
\text { and cleansing of } \\
\text { axilla }\end{array}$ & $\ldots$ & $\begin{array}{l}\text { Tuber- } \\
\text { culosis }\end{array}$ & & \\
\hline Limp & $\ldots \ldots$ & Pleurisy 4 yrs. ago & $\cdots$ & $\ldots \ldots$ & Simple amputation & $\begin{array}{l}\text { Unevent- } \\
\text { ful re- } \\
\text { covery }\end{array}$ & $\begin{array}{l}\text { Tuber- } \\
\text { culosis }\end{array}$ & & \\
\hline Lump & $\cdots \cdots$ & $\begin{array}{l}\text { Abscess for past } 3 \text { yrs. } \\
\text { in left axilla; opened } \\
\text { spontaneously, leav- } \\
\text { ing sinuses }\end{array}$ & Fair & $\begin{array}{l}\text { Axillary } \\
\text { adenitis }\end{array}$ & $\begin{array}{l}\text { Amputation of breast } \\
\text { and cleansing of } \\
\text { axilla }\end{array}$ & $\begin{array}{l}\text { Well } 316 \\
\text { yrs. after } \\
\text { operation }\end{array}$ & $\begin{array}{l}\text { Tuber- } \\
\text { culosis }\end{array}$ & $\begin{array}{l}\text { T. B. in } \\
\text { stained } \\
\text { tissue } \\
\text { sections }\end{array}$ & \\
\hline
\end{tabular}


Cases of Mammary Tuberculosis (Secondary Type) Reported in the Literature from I904

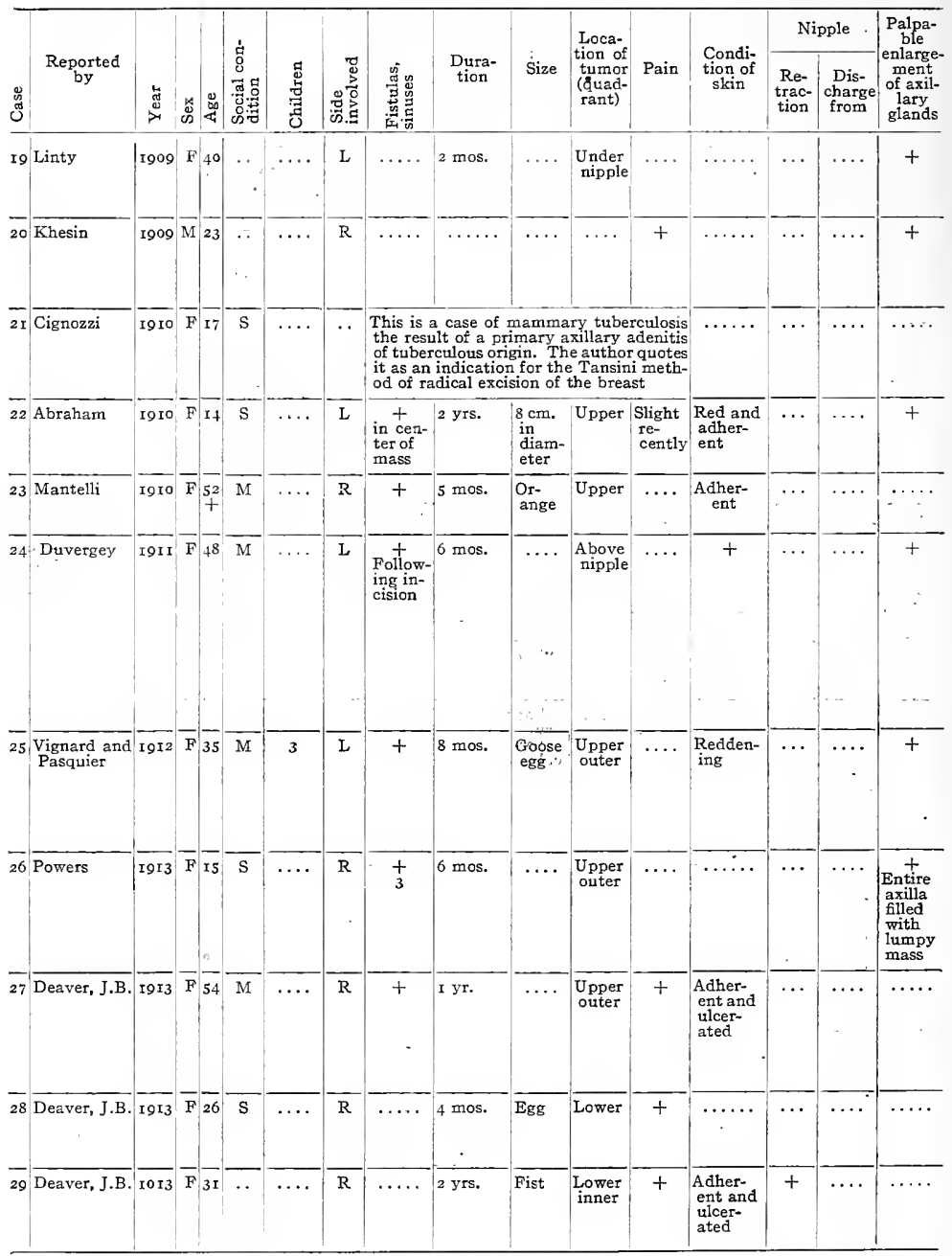


(Anspach's Paper) to igi4, Includng Three Personally Observed Cases-(Continued)

\begin{tabular}{|c|c|c|c|c|c|c|c|c|c|}
\hline $\begin{array}{l}\text { Initial } \\
\text { symp- } \\
\text { toms }\end{array}$ & $\begin{array}{l}\text { Hered- } \\
\text { ity }\end{array}$ & $\begin{array}{l}\text { Antecedent condi- } \\
\text { tion of breast }\end{array}$ & 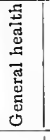 & $\begin{array}{c}\text { General } \\
\text { physical } \\
\text { exami- } \\
\text { nation }\end{array}$ & $\cdot$ & Result & $\begin{array}{l}\text { Patho1- } \\
\text { ogyr; } \\
\text { micro- } \\
\text { scopic }\end{array}$ & $\begin{array}{l}\text { Tuber- } \\
\text { cle } \\
\text { bacilli } \\
\text { found }\end{array}$ & $\begin{array}{l}\text { Animal } \\
\text { inocu- } \\
\text { lation }\end{array}$ \\
\hline Lump & $\because \cdots$ & $\begin{array}{l}\text { Pulmonary tubercu- } \\
\text { losis }\end{array}$ & $\cdots$ & $\begin{array}{l}\text { Pulmon- } \\
\text { ary } \\
\text { tuber- } \\
\text { culosis }\end{array}$ & Halsted amputation & $\cdots \cdots$ & $\begin{array}{l}\text { Tuber- } \\
\text { culosis }\end{array}$ & & \\
\hline Lump & $\ldots$ & $\begin{array}{l}\text { Leg amputated for } \\
\text { tuberculosis of knee; } \\
\text { ascribes trouble in } \\
\text { breast to trauma }\end{array}$ & $\cdots$ & $\begin{array}{l}\text { Antece- } \\
\text { dent } \\
\text { joint } \\
\text { tuber- } \\
\text { culosis }\end{array}$ & $\begin{array}{l}\text { Simple amputation } \\
\text { and cleansing of } \\
\text { axilla }\end{array}$ & $\cdots \cdots$ & $\begin{array}{l}\text { Tuber- } \\
\text { culosis }\end{array}$ & & \\
\hline$\cdots \cdots$ & $\cdots \cdots$ & $\begin{array}{l}\text { Enlarged cervical } \\
\text { glands since age of ro; } \\
2 \text { yrs. ago operated on } \\
\text { for enlarged glands in } \\
\text { left axilla }\end{array}$ & $\cdots$ & $\cdots \cdots$ & $\begin{array}{l}\text { Tansini's method of } \\
\text { radical excision }\end{array}$ & $\cdots \cdots$ & $\begin{array}{l}\text { Tuber- } \\
\text { culosis }\end{array}$ & & the \\
\hline Lump & $\cdots \cdots$ & $\begin{array}{l}\text { Pain in the hip for } 2 \\
\text { yrs. }\end{array}$ & $\cdots$ & Negative & $\begin{array}{l}\text { Incision along lower } \\
\text { margin of the breast; } \\
\text { curettage of tumor } \\
\text { mass }\end{array}$ & $\ldots \cdots$ & $\begin{array}{l}\text { Tuber- } \\
\text { culosis }\end{array}$ & & \\
\hline Lump & $\because \cdots$ & $\begin{array}{l}\text { Antecedent pleurisy; } \\
\text { purulent mastitis } \\
\text { years ago }\end{array}$ & $\cdots$ & Negative & Simple amputation & $\cdots \cdots$ & $\begin{array}{l}\text { Tuber- } \\
\text { culosis }\end{array}$ & & \\
\hline Pain & $\cdots \cdots$ & $\begin{array}{l}\text { Sept., roro, infected } \\
\text { (left hand) finger } \\
\text { while washing clothes } \\
\text { in tuberculosis hos- } \\
\text { pital; opened, drain- } \\
\text { ed and bealed. In } \\
\text { April, I g I bad lost } \\
\text { weight and developed } \\
\text { axillary a b c e s s } \\
\text { whicb opened in May } \\
\text { and left a sinus }\end{array}$ & . & $\begin{array}{l}\text { Pulmon- } \\
\text { ary } \\
\text { tuber- } \\
\text { culosis; } \\
2 \text { ulcers } \\
\text { of breast. } \\
\text { Ulcer in } \\
\text { subcla- } \\
\text { vicular } \\
\text { fossa; } \\
\text { multiple } \\
\text { fistulas }\end{array}$ & Not operated & $\cdots \cdots$ & $\ldots \ldots$ & $\begin{array}{l}\text { T. B. } \\
\text { found } \\
\text { in pus }\end{array}$ & \\
\hline Lump & $\cdots \cdots$ & $\begin{array}{l}\text { In June, I9 II, had tu- } \\
\text { berculous abscess of } \\
\text { palmar surface of left } \\
\text { tbumb, opened and } \\
\text { also had epitrochlear } \\
\text { and axillary node in- } \\
\text { volvement }\end{array}$ & $\cdots$ & $\cdots \cdots$ & $\begin{array}{l}\text { Partial excision of } \\
\text { breast and curettage } \\
\text { of axilla }\end{array}$ & $\cdots \cdots$ & $\begin{array}{l}\text { Tuber- } \\
\text { culosis }\end{array}$ & - & ; \\
\hline Lump & $\cdots \cdots$ & $\cdots \cdots \cdots \cdots$ & $\cdots$ & Negative, & $\begin{array}{l}\text { Upper outer quadrant } \\
\text { of breast excised; ax- } \\
\text { illa cleaned; glands } \\
\text { adherent to axillary } \\
\text { vein: tuberculin after } \\
\text { operation }\end{array}$ & $\begin{array}{l}\text { Well } \\
\text { several } \\
\text { months } \\
\text { later }\end{array}$ & $\begin{array}{l}\text { Areas of } \\
\text { tuber- } \\
\text { culosis } \\
\text { found in } \\
\text { over- } \\
\text { lying } \\
\text { skin }\end{array}$ & 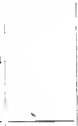 & \\
\hline Lump & $\ldots$ & $\begin{array}{l}\text { Trauma caused lump } \\
\text { to ulcerate }\end{array}$ & Good & $\begin{array}{l}\text { Enlarged } \\
\text { glands } \\
\text { in left } \\
\text { supra- } \\
\text { clavic- } \\
\text { ular } \\
\text { triangle }\end{array}$ & $\begin{array}{l}\text { Excision of involved } \\
\text { area of breast; exci- } \\
\text { sion of enlarged } \\
\text { glands }\end{array}$ & $\begin{array}{l}\text { Dis- } \\
\text { charged } \\
\text { in good } \\
\text { condition }\end{array}$ & $\begin{array}{l}\text { Tuber- } \\
\text { culosis }\end{array}$ & i & \\
\hline Lump & $\cdots \cdots$ & $\begin{array}{l}\text { Abscesses of ear, back; } \\
\text { etc.; pain on deep } \\
\text { breathing in breast }\end{array}$ & Good & $\cdots \cdots$ & $\begin{array}{l}\text { Excision of cyst in } \\
\text { breast; scraping of } \\
\text { ribs }\end{array}$ & $\begin{array}{l}\text { Dis- } \\
\text { charged } \\
\text { in good } \\
\text { condition }\end{array}$ & $\begin{array}{l}\text { Puber- } \\
\text { culosis }\end{array}$ & & \\
\hline Lump & $\begin{array}{l}\text { Father } \\
\text { died of } \\
\text { tuber- } \\
\text { culosis }\end{array}$ & $\ldots \ldots \ldots$ & Good & $\cdots \cdots$ & $\begin{array}{l}\text { Simple excision re- } \\
\text { vealing sinus leading } \\
\text { to rib; scraping of rib }\end{array}$ & $\begin{array}{l}\text { Dis- } \\
\text { charged } \\
\text { in good } \\
\text { condition }\end{array}$ & $\begin{array}{l}\text { Tubet- } \\
\text { culosis }\end{array}$ & & \\
\hline
\end{tabular}




\section{BIBLIOGRAPHY}

Abraham.-Thèse de Paris, igio.

ANSPach.-Am. J. M. Sc., r904, CXXVIII, 98.

BABEs.-Presse médicale, r907, XV, 377 .

Bahaud.-Gaz. méd. de Nantes, r9o6, XXIV, 317.

Bartsch.-Inaug. Dissert., Jena, rgor.

Bauer.- "Ùher Kombination von Carcinom und Tuberkulose in der Mamma," Göttingen, I9I 2.

Bender.-Rev. de gynéc. et de chir. abd., rgr4-15, XXIII, 265.

Berger.-Rev. gén. de clin.' et de therap., rgo6, XX, 22.

Billroth.-Deutsche Chir., r88o, XII, zo.

Bloodgood.-Kelly and Noble, Gynecology and Abdominal Surgery, Phila., 1908.

Braendle.-Beitr. 2. klin. Chir., 1906, L, 2:5.

Brandsburg.-Kharov. M. J., rgo8, VI, 25.

BundschuH.-Beitr. z. path. Anat. u. allg. Path., I913, LVII, 65.

CARR.-Physician and Surg., rgII, XXXIII, 26.

Chiavarelli.--Rev. veneta di sc. med., r907, XLVII, 424.

Cignozzi.-Policlin. Roma, I910, I7, sez. prat., 8Ir-8r3.

Cignozzi.-Riforma med., I910, XXVI, 965.

Cooper.--"Illustrations of Diseases of the Breast," London, r829.

Cope.-Australas. Med. Gaz., I9I2, XXXI, I86.

Cumston.-Albany Med. Ann., igro, XXXI, 295.

Davis.-Med. News, r897, LXX, 79I.

Deaver and Herman.-Am. J. M. Sc., I9I4, CXLVII, 157.

Delbert.-Cited by Schley, Ann. Surg., r9o3, XXXVI, 5 ro.

Delfino.-Gaz. mil., r9o6, XXVII, 977.

Demme.-Cited hy Schmidt.

Dubar.-Thèse de Paris, r $88 \mathrm{r}$.

Dubreuil.-Gaz. méd. de Par., r888, V, 198.

Dubreuil.-Gaz. hebd. d. sc. med., I 89o, XII, 325 .

Duvergey.-Jour. de méd. de Bordeaux, rgr r, XII, 84 r.

Ferguson.-J. Am. M. Assn., I 898, 30, I4I2.

Franco.- Virchow's Arch., I908, CXCIII, 370.

Fraenkel.-Jahrsber. f. Chirur., rgo8, XIV, x63.

Fricke.-Beitr. z. Klin. d. Tuberk., I907, VIII, 309.

FrIEDLÁNDER.-Notbnagel's Ency. of Pract. Med., "Tuberculosis," G. Cornet, p. 25.

Fuller.-N. York M. J., ıgo9, XLV, go.

Gaudier and Péraire.-Rev. de Chir. I895, XV, 768.

Gautier.-Thèse de Bordeaux, r 895 .

GeIssle R.-Deutsche med. Wchrschr, r9o6, XXXII, I780.

HabermaA9.-Cited by Mandry.

Halsted.-Trans. First Annual Meeting Nat. Assn. for the Study and Prevention of Tuberculosis, March rgo5.

Halsted and LeConte.-Ann. of Surg., r898, XXVIII, $68_{5}$.

Hardoüin.-Bull. et mém. soc. Anat. de Paris, I907, LXXXII, $5^{8}$.

HARDoüIN and MARQuis.-Rev. de Chir., r9o8, XXXVIII, 79.

HarTwell.-Ann. Surg., I9I3, LVIII, 396.

HeBb.-Trans. Path. Soc., London, I892-93, XIIV, I 23.

Heyfelder.-Deutsch. Klin., I85I, III, 590.

Hirschberger.-Cited by Anspach.

Hoeckel.-Arch. f. klin. Chir., I894, XLVII, 274.

Horteloup.- "Tumeurs du sein chez l'homme," Paris, I 892 .

Ingier.--Virchow's Arch., I910, CCII, 217.

Kaplan.-Khirurgia, Mosk., I9I3, XXXIII, 322.

Khesin.-Khirurgia, Mosk., I909, XXV, 552.

Klose.-Beitr, z. klin. Chir., I9ıo, LXVI, I.

KocH.-Berlin. klin. Wchnschr., I882, XIX, 221. 
Kramer.-Centralbl. f. Chir., I888, XV, 867 .

Lartigad.-Twentieth Century Practice of Medicine, XX, 94.

LinTy.-Long Island M. J., 1909, III, 286.

MANDRY.-Beitr. z. klin. Chir., I89r, VIII, I79.

Mantelli.-Morgagni, I9Io, LII, 96.

Marangoni.-Rev. veneta de sc. med., I907, XIVI, 49, IIo.

Massabdau.-Montpel. méd., I909, XXVIII, 608.

Mires.-Edinburgh M. J., I9I5, XIV, 205.

MüLrer.-Deutsche med. Wchnschr., I905, XXXI, 21.

NIEPCE. -Thèse de Paris, I886.

Nicolas and Descos.-Jour. de phys. et path gén., I902, IV, 9 Io.

Ohnacker.-Arch. f. klin. Chir., I88 $38_{3}$ XXVIII, 366.

ORTHMANn.-Virchow's Arch., I885, C, 365 .

OSTRowski.-Swow. tygodn. lek., r908, III, 203.

PARK.-Med. News, I896, LXIX, 524.

PARSons.-Brit. M. J., I907, II, 263.

Pirliet and Piatot.-Bull, et mém. soc. anat. de Paris, I897, LXXII, 424.

Potrier.-Thèse de Paris, $\mathrm{I}_{88} 3$.

Poncet.-Lỳon méd., 1906, CVI, 765.

Powers.-Ann. Surg., I894, XIX, I59.

Powers.-Ibid., $1897, \mathrm{XXV}, 86$.

Powers.-Ibid., I9I3, LVII, I 7 I.

Putzu.-Archiv Internat. de Chir., I9I3, VI, 247.

Rabinsonn.-Inaug. Dissert., Königsbr. in Pr., I9 I.

Ravener.-Proc. Path. Soc., Phila., I902, XXIV', I54.

Ravenex.-Jour. Med. Research, I903, X, 640.

REMY and NoËL.-Bull. et mém. soc., anat. de Paris, I893, LXVIII, 4I 2.

Rrssigrie.-Albany Med. Ann., 1909, XXX, 671 .

Revel.-Tribune Médicale, I908, VI, 74 I.

Rodman.-Proc. Sixth International Congress on Tuberculosis, October, 1908.

RoDMan.-Southern M. J.,.1909, II, 67 I.

Roger and GARNIER.-Comp. rend. soc. de biol., I900, LII, I75.

Roux.-Thèse de Genève, I 89 I.

SABRAZẼs and Binaud.-Arch. gen. de med., I896, CLXXVII, 586.

Schede.-Deutsche med. Wchnschr., I893, XIX, I3I6.

Scheidigger.- "Ein Fall von Carcinom und Tuberkulose der gleichen Mamma," Aarau, I 904 .

Scriey.-St. Luke's Hosp. Rep., I9Io, II, 47.

Schley.-Ann. Surg., I903, XXXVII, 5 Io.

SchMrd.-Inaug. Diss., Lübeck, Igo5.

Sсотт.-St. Bartholomew's Hosp. Rep., I905, XL, 97.

Scudder.-Am. J. M. Sc., I898, CXVI, 75 .

Shatтock.-Trans. Path. Soc., London, I889, XL, 39 I.

SHEILD.-Clin. Jour., I903, XXII, 55.

SPEDIACCI.-Schmidt's Jahrb., I895, CCXIVII, 148.

SPENCER.-Amer. Med., I905, IX, 432.

Stromberg and Kasgledov.- Russ. Archiv f. Chir., I 909 , XXV, 5 I 2.

St. JACQUES.-Med. Rec., I909, LXXV, 348.

Thurston.-Indian Med. Gaz., 1904, XXXIX, I5.

Venot and Lataste.-Jour. de méd. de Bordeaux, I9I I, XLI, I39.

VerCHÈre.-Thèse de Paris, I884.

Verneuil.-Prog. médicale, I882, $\mathrm{X}$, 580 .

Vignard and Pasquier.-Gaz. méd. de Nantes, I9I 2, XXX, 493.

Von EberTs.-Am. J. M. Sc., Igog, CXXXVIII, 70.

Walther.-Bull. et mém. soc. d'anat. de Paris, I906, XXXII, 1o76.

WannienwenhuYse.-J. d. sci. méd. de Lille, I9i I, I, 2 I.

WARTHIN.-Am. J. M. Sc., I899, CXVIII, 25.

ZIRONI.-Riforma med., I907, XXIII, 426. 


\section{ACTINOMYCOSIS OF THE BREAST}

For nearly a hundred years, a disease of herbivorous animals has been recognized under the names "big jaw," "lumpy jaw," "swelled head," "wooden tongue," etc. Bollinger (Deutsche Zeitschrift für Thiermedizen, I877) discovered that the disease is caused by a peculiar microörganism to which he gave the name actinomyces, a word

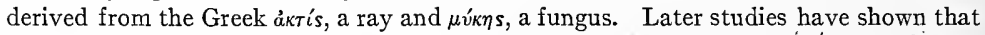
there are, in all probability, a number of actinomycetes, of which that discovered by Bollinger and called, by him Actinomyces bovis, is the most frequent in occurrence in both man and the lower animals, though other species undoubtedly occur in man. Langen-

beck, as early as 1845 , found that the disease could

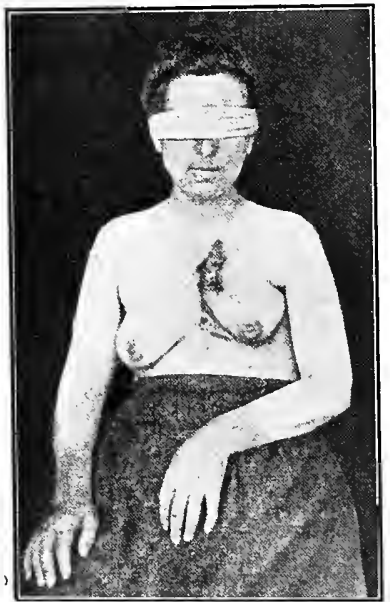

FIG. III.-Actinomycosis of the breast. (Nelaton.) be communicated to man, though his publication of the fact was delayed until 1878 , and between the time of his observation and that of its publication, many cases of human infection were reported.

The actinomyces is a member of a group of minute vegetable organisms, known as "higher bacteria," that differ from the bacteria proper in the formation of more or less definite mycelia, and in having certain cells specialized for reproductive purposes. The best known and most characteristic actinomyces is that to which it owes its name, the "ray fungus," the Actinomyces bovis. It can be found in the lesions of the disease, and in the puriform discharges from its softened areas as "sulphur grains," i.e., minute bright yellow granules, visible to the naked eye. When one of these in a section of a specific lesion, or in pus from such a lesion is crushed between a slide and cover-glass and exam. ined with a microscope, it can be resolved into a central somewhat granular or amorphous central mass, from which branching tangled filaments radiate in all directions, to terminate at the periphery in clavate or club-shaped extremities. The significance of the branching reticulum is clear; it is the mycelium, and finds its closest homology in the much coarser mycelia of the molds. That of the granular center is less certain; some interpret the granules, which resemble micrococci in size and general appearance, to be the spores of the parasite, others look upon them as degeneration products. The significance of the clubs is unknown. Many believe that they are the result of gelatinization of the filaments through contact with defensive substances in the juices of the host. The clubs are distinct and characteristic in Actinomyces bovis, but are not always seen in the human actinomyces, hence some doubt arises whether the fungi of the bovine and human lesions are the same. The actinomyces can be cultivated artificially, though there is usually considerable difficulty in getting it started, and the primary cultures rarely succeed except under anaërobic conditions. When once the growth is secured, sub-cultures are easily made, and can commonly be continued under aerobic conditions. Artificial cultures quickly lose virulence, and attempts to infect laboratory animals with them commonly fail. Instead of the characteristic lesions being produced by the parasite, it dies and is absorbed or becomes surrounded by cicatricial tissue and calcifies. 
The natural history of the actinomyces is very superficially known. We are acquainted with it as we find it in diseased animals, in cultures, and in lesions following successful inoculations; but of its habitat in nature and the form in which it occurs outside its animal host we know nothing. Some have supposed that the actinomyces has two cycles of development, one in an animal host, the other in a plant host. This is, however, only conjecture. The fact that it occurs almost entirely in herbivorous animals suggests that vegetation has something to do with the infection; that the usual primary disturbances are about the mouth, suggests that the food is the source; that defective teeth and sore gums seem to be common portals of entrance, that the source is in something that requires mastication. It is commonly believed that the source of infection is a cereal or grass and that those with sharp awns are most likely to convey it. Human beings may become infected through eating vegetable foods to which the infectious agent is attached, or through eating, raw, the flesh of animals suffering from the disease, or through the application of meal poultices not sufficiently heated to sterilize the components, or through undeterminate sources.

The microörganism may also be inhaled, when it is to be presumed that it was free in the atmosphere.

The primary lesions are usually not far from the portal of entrance, as in "big jaw," "lumpy jaw," "wooden tongue," etc. In human beings many cases center about the mouth, making their appearance about the roots of carious teeth. One case is recorded in which the perforation of the pharyngeal wall by a barley spikelet was followed by the primary appearance of the disease at that point. Pulmonary infection is not infrequent in human beings.

The lesions of actinomycosis vary according to the species of ray fungus, according to its virulence and according to the tissue in which it occurs. In human beings there is probably less variety than in lower animals. In most cases the presence of the developing fungi results in necrosis of the cells of the immediately surrounding tissue and in an inflammatory reaction beyond. As the extent of the necrosis gradually increases, the extent of the inflammatory reaction also gradually increases, and cavities are slowly formed in a subacutely inflamed and indurated tissue not unlike a tumor. Through some means and in some form not clearly known, but presumably lymphogenic transportation of some spore form or filamentous form of the parasite, the lesion spreads irregularly, and a succession of similar lesions is formed. The result is that by the time it has attained sufficient size to excite solicitation, the lesion is found to consist of an aggregation of smaller or larger communicating centers of necrosis and suppuration with external sinuses and fistulas from which a small quantity of thin serous or sanious material escapes. In this pus, the ray fungi may be present in great or small numbers, as "sulphur grains," or they may be absent from it if the destruction is not sufficiently far advanced to release them.

Actiomycosis of the breast may be either primary, that is, independent of similar disease elsewhere, or secondary, that is, consequent upon disease of other, usually adjacent tissues.

I. Primary Actinomycosis of the Breast.-It is not impossible, though it is scarcely consistent with what is known of the actinomyces fungi, that primary colonization in the breast should result from the actinomyces brought by the blood. It is difficult to understand how such a blood invasion by the parasite could take place. It is, therefore, wiser to examine the breast itself and endeavor to account for the disease through direct and immediate local infection. Two possibilities present themselves; the infection 
may take place through superficial abrasions or injuries, or it may take place through the milk ducts. As the latter are closed in the inactive breast, it would seem as though abrasions or injuries of the breast were the more probable avenues of infection. The injury may be so trivial as to be overlooked at the time or forgotten afterward, and as the progress of the disease is slow there is ample opportunity for this. To realize how trifling an accident may be followed by infection it is only necessary to recall the cases in which infection followed the puncture of the pharyngeal wall by a barley awn, to which reference has already been made.

The following cases of primary actinomycosis of the breast have been collected from the literature and are instructive.

I. MüLLER (Münchener med. Wochenschrift, I894; XLI, 1027) had a patient whose right breast was congenitally small, and who nursed two children from the left breast only. The hypoplastic right breast, however, was the seat of a traumatic injury and a small tumor subsequently made its appearance. It softened and later was opened when a small amount of pus was evacuated. Afterward a poultice of meal and honey was applied, and recovery took place. But two months later a painful swelling made its appearance, the nipple became retracted, and fistulas appeared about it. At operation a fistulous tract was traced to an abscess cavity which contained pus and actinomyces grains.

In this case the suspicion is raised that the primary abscess was a simple pyogenic infection that later became infected with actinomycosis through spores of the fungus contained in the meal and honey. Müller found, however, that his patient had carious teeth, in scrapings from which actinomyces and pseudo-actinomyces are said to have been found.

2. A second case is reported by the same author (loc. cit.). This patient suffered a blow upon the left breast. A few months later a tumor began to develop. It softened, was opened, and some pus was evacuated. This was also treated with similar poultices of meal and honey. The wound closed kindly but six weeks later a new abscess formed. When this was evacuated, actinomyces grains were found in the pus.

3. PARTSCH (Deutsche Zeitschrift für Chirurgie, I 884 , XXIII, 5 Io) observed a case of actinomycosis of the male breast. It was in a man 60 years of age operated upon for carcinoma of the breast, and a considerable denudation of tissue remaining, it was grafted with skin taken from a young and healthy subject. The patient subsequently suffered from actinomycosis of the scar. Fistulas formed and several abscesses developed beneath the pectoralis major muscle, opening along its anterior axillary margin. A considerable quantity of chocolate-colored pus was discharged, in which actinomyces were found.

If we can be sure that the primary trouble was uncomplicated carcinoma, then this case must be excluded from the cases of actinomycosis of the breast for the disease only appeared in the mammary region after the breast had been removed. It shows, however, that wounds afford an appropriate avenue of entrance, and probably also shows that the source of infection maly be upon the skin.

4. Ammentorp ("Om Aktimomykose." Kliniske Jagttagelser, paa Komm. hospitalet. Biblioth. f. Laeger., I893, 7r., Bd. IV, 433, Centralbl. f. Chirurgie, 1894, p. I074) reports the case of a peasant woman 35 years of age who was in the habit of working in the fields with the breasts exposed. Three weeks before coming under his observation she began to suffer from pain in the right breast. Examination showed a tumor in the upper, outer quadrant. Its greatest diameter was $7 \mathrm{~cm}$. and though it was well circumscribed, it was adherent to the skin near the nipple. The breast was removed and the axilla cleaned out. When the tumor was examined the yellow granules of actinomyces were found.

5. Reichel (" $Z$ wei Fälle von Aktinomykose der Mamma, Inaugural Dissertation, München, 1903) reports the following case: A woman 37 years of age, married for 13 years, has had nine children, five of whom are now living and well. She is a farmer's wife and takes care of the stable and works in the fields. She does not kinw of any disease among the cattle on the farm. She, herself, has always been healthy, except that she suffered from swelling of the left breast that subsided after the birth of her first child. Seven years ago a new swelling appeared in the same breast, but she paid very little attention to it until it finally eroded the skin. Two years ago her last child was born, and several months afterward she observed a red elevation on the under surface of the left breast which became painful. Ulceration took place and blood and pus exuded. Eighteen months later erosions appeared at two other places, and she consulted a physician who sent her to the hospital with the diagnosis of actinomycosis. During the latter period of her illness she was in the habit of working in the fields with the breast exposed to avoid painful friction of the eroded surface by the clothing. 
At the hospital no disturbance of internal organs could be found. When the breast was examined, a small bluish-green lesion was found, in the middle of which was a row of small fistulous openings some of which led into destroyed gland tissue. On pressure a serous liquid escaped from the fistulas, and in it small yellowish granules were suspended. Yellow fluid containing actinomyces could also be expressed from the nipple. The breast and pectoralis muscle were removed. The underlying tissues were normal.

6. BISEL-ZWICKAU (Verhandl. d. deutschen pathol. Gesellschaft, I909, 322) reports the following case: A woman 32 years of age, mother of three children, always well, and never having had any trouble with the breasts, observed about six months ago that there was a nodular formation in her left breast. A sinus soon developed and discharged bloody serum. The breast became reddened, increased in size and additional nodules formed. These were incised, thick yellowish pus evacuated and actinomyces found. The breast, fascia and pectoral muscles were subsequently removed.

7. McArthur (Amer. Gynecological and Obstetrical Journal, N. Y., r897, X, 364) reports the following case: A single woman, 22 years of age, discovered some eight weeks ago that she had a small mass in the upper portion of the left breast. It was soft in consistency and sensitive upon pressure. An incision was made and a portion of the mass removed for examination. It showed only glandular tissue. Three weeks later a fistula formed above the incision, and thick yellow pus exuded. An operation was performed and a brown mass containing many yellow "sulphur grains" was found behind the breast and under the pectoralis muscle. The disease recurred and at a second operation a more extensive area was excised. Later, numerous subcutaneous fistulas formed. These were cured through the application of carbolic acid.

8. SEHRT (Beiträge zur klin. Chirurgie, r907, LV, 522) reports the following case: A woman aged 34 years, with negative previous history, had one child that she nursed nine years ago. About one year ago a painful swelling appeared upon the outer súrface of the left breast. It seemed to attain its maximum development in the course of four or five days, then remained stationary for several weeks, when it subsided, the nipple retracted and pus escaped from it. When the patient was examined, the left breast was found to contain an irregular, freely movable, but not encapsulated, tumor-like mass on its lateral aspect. The nipple was retracted and from it a band extended to the tumor. When the mass was compressed, yellow pus issued from the nipple. The neighboring lymph nodes were not enlarged. A simple amputation of the breast was performed. When the specimen was examined, it was found that the tumor communicated with the nipple by a fistulous tract. The breast tissue about it showed infiltration and contained degenerated areas filled with yellowish substance which when examined proved to be granular matter rich in fat droplets (inspissated milk). Beneath the nipple, and connected with it by the fistula, was a cavity of the size of a small cherry, filled with yellowish pus and small yellow granules which are adherent to the walls. The tumor itself, when sectioned, showed two centrally situated abscess cavities, each as large as a hazelnut and apparently arising through dilation of galactophorous ducts. These cavities contained pns in which were great numbers of the yellow actinomyces granules.

9. Angerer (Handbuch der prakt. Chirurgie, r9r2, II, 586) reports the following case: A woman aged 24 years, the mother of five children, suffered from great pain and swelling of the right breast. Examination showed a fistulous opening in reddened and necrotic skin, on the inner side of the breast, from which thick yellow pus exudes upon pressure. At operation radial incisions were made and the necrotic tissue was remoyed with a curet. The inflammation continued and two weeks later actinomyces grains were demonstrated in the pus. About the same time a painful fluctuating swelling formed over the ensiform cartilage. A second operation was performed at which the mass was excised and the breast amputated. The perichondrium of the lower costal cartilages appeared to be involved, and though the patient recovered from the operation, she I ter died from internal actinomycosis. (It seems doubtful whether this was a primary actinomycotic lesion of the breast.) The author says that he has seen three cases in his clinic, but he gives no description of the others.

ro. Verse (Primäre Aktinomykose der Mamma," Verhandl. d. deutschen pathologischen Gesellschaft, Jena, rgo9, p. 326.) In the discussion following the paper by Bisel-Zwickau (vide supra), Verse remarked that he had amputated a mammary gland of a woman aged 42 years. The disease had existed for six months and indurations and fistulas had formed. Actinomyces were, at length, found in the pus, so the mamma w s amputated. The disease returned in six weeks when a second operation was performed and the pectoral muscle was removed. The thoracic wall and ribs were normal. The mamma contained typical lesions of actinomycosis. The nipple and ducts were free.

Ir. JACOBSTHAL (Verhandl. d. deutschen pathologischen Gesellschaft, rgog, p. 326) in discussing the case reported in the paper of Bisel-Zwickau remarked that he begged briefly to record a case of actinomycosis of the breast that was interesting because it was complicated by carcinoma of the same mamma. Presumably this was a case primary of actinomycosis as well as a primary cancer. 
From these protocols of all the cases that we have been able to trace out in the literature, it seems that no case of primary actinomycosis of the male breast is on record except that of Partsch, and doubt has already been expressed as to whether it is justifiable to consider this a case of mammary actinomycosis. If this be eliminated, all of the primary cases are in women. Of the ro women, we are told that five nursed children, nine were married, one was single. In the protocols of four of the married women no mention is made concerning children so we are not sure that they, too, may not have had and nursed them. Should such have been the case, it might be regarded as evidence in favor of the entrance of the parasite into the open milk ducts or into the fissures and abrasions so commonly incidental to suckling.

II. Secondary Actinomycosis of the Breast.-This form of mammary disease follows pleuro-pulmonary, thoracic or other forms of the disease and takes place either by continuity of tissue or by lymphatic extension from the primary focus. It is commonly preceded by disease of the ribs and costal cartilages and not infrequently invades the retro-mammary and mammary tissues by way of the intercostal spaces. Cases of this kind are, we have found, reported as follows:

I. ANGIer (Actinomycose de la region mammaire, Nord. méd., Lille, rgo3, IX, I54). The patient was a woman aged 52 years. The disease first made its appearance in the fourchette of the sternum, the invasion of the mammary gland occurring later. The nature of the disease was confirmed by microscopic examination. Potassium iodide was used in the treatment.

2. KaUffMan (Lehrbuch der speziellen pathologischen Anatomie, IgI r, 6th edition, p. I082) speaks of having seen a case of secondary actinomycosis of the mammary gland following disease of the pleura. The patient was an emaciated girl.

3. NÉLAton, C. ("Actinomycose mammaire gauche survennée dans le cours d'un phlegmon actinomycosique pleuro-lombaire du meme coté," Lyon méd., rgoo, XCIV, No. 18, p. 5). This case, reported by Poncet, was in the person of a woman aged 42 years, who first suffered from pleuritis followed by a large phlegmonous lesion in the left lumbar region for which she was treated by incision and drainage. When this had pretty well healed, and some months had passed, the lesion broke out afresh in the mammary gland and adjacent tissues. Actinomyces were found in the pus.

4. SNow (British Medical Journal, I89I, II, r24), reports an interesting case of combined tuberculosis and actinomycosis. The patient, 30 years of age, was the much abused wife of a hawker, and was suffering from pulmonary tuberculosis. A lump appeared in the right breast, and some suspicion was entertained that it was cancer, as the breast became adherent to the chest wall. Later it softened and discharged first at one and then at many points and widespread disease of the chest wall, lung and liver ensued. The patient died and Dr. Beadles found tuberculosis and actinomycosis of the lungs and actinomycosis of the breast. The actinomyces were found.

5. MileffF (Thèse de Lyon, I900, No. 67). A woman aged 26 years suffered from a furuncle-like lesion over the left mastoid process. When the pus discharged, actinomyces grains were found. The patient died in six days from the time of coming under observation. At autopsy a sinus was found extending from the mastoid process along the external jugular vein. Metastatic abscesses were also found in the liver and kidneys, and breast.

6. Reichel (Inaugural Dissertation, München, I903) reports the case of a woman aged 24 years whose right breast was greatly swollen, particularly the lower inner quadrant over which the skin was inflamed. In the diseased area there was a small opening through which pus exudes upon pressure. The nipple is greatly retracted. Before marriage she was enagaged in farm work, but was always sickly and has lately suffered from a violent cough and pain in the chest. She is the mother of five children, the youngest of whom is only five months old. None of the children were nursed at the breast. Three weeks ago she observed a swelling in the right breast, and experienced stinging pains. A small incision was made into the lesion before she entered the hospital, and considerable pus was evacuated. Upon admission to the hospital, examination showed limitation of respiratory motion on the right side of the chest. An area of percussion dulness was found below the fourth and fifth ribs on the right side. There was a small amount of expectoration in which nothing characteristic was found. The patient returned in ro days, when it was found that the incision had become converted into fistulas from which flowed a thin pus with yellow granules that proved to be actinomyces. Milk also exuded from a 
number of openings. The breast was amputated, and the lesion was found to be adherent to the fourth and fifth costal cartilages, so that it was necessary to remove a portion of the perichondrium. A few weeks after operation the pulmonary symptoms became more violent and a large number of deep intercommunicating fistulas formed. Death occurred about a year after the last operation. No autopsy was permitted.

In discussing the details of his own case Reichel cites the following case but unfortunately gives no references to the sources of information:

7. Ginsberg. A six-year-old boy with actinomycosis of the right thoracic wall and of the mamma, following the formation of an area of disease in the lung.

8. Adler (Berl. klin. Wochenschrift, I89o, XXVII, 549; Deutsche med. Wochenschrift, r89o, $\mathrm{XVI}, 596)$ reported the case of a woman of $5 \mathrm{I}$ years, the wife of a brushmaker, who had been ill with a cough and expectoration for five months. For two months an induration had been forming in the right breast, and at the time of examination the skin covering it was bluish. The induration softened and evacuated through numerous sinuses. Above the median half of the right breast and between the mammæ, the skin was soft and boggy and perforated in about a dozen places with little sinuses with fistulous communications. From these, pus containing yellow actinomyces "grains," was discharged. There was consolidation of the right lung, and in the muco-purulent expectoration, actinomyces grains were found. The patient died, and at autopsy there was found actinomycosis of the right lung, with extensive involvement of the lower lobe, and fistulation communication with the external surface through the lesions in and near the mamma.

9. Douglas, Powell, Godlee and Taylor (Medico-Chirurgical Transactions, r889, LXXII, r76; Lancet, rSS9, I, 328 ; Brit. Med. Journal, r $889, \mathrm{I}, 357)$. The patient was a little boy nine years old, the son of a dairyman. He had been ill four months when first seen, and suffered from a slight cough and a painful swelling under the right nipple. There was complete dulness over the lower third of the right side of the chest. The glands in the right axilla were swollen. There were no external sinuses. The lesion was shown by autopsy to be actinomycosis.

ro. HaNaU (Correspondenzblatt für schweizer Aerzte, r889, No. 6, I s., r65). The patient was a woman, a housewife, aged 39 years. She suffered from what was supposed to be phthisis pulmonalis with caries of the ribs. There was an abscess in the left axilla, and another below the left mamma, each of which evacuated through fistulous openings. Her cough and expectoration continued for a year during which the temperature was generally normal, with occasional evening exacerbations to $38.5^{\circ} \mathrm{C}$. At the autopsy she was found to have widespread actinomycotic disease of the left upper pulmonary lobe which was dense, cicatricial, slaty, indurated and almost tendinous in parts. There were pus cavities in the anterior and lateral thoracic walls below which were carious ribs. She also had carious teeth.

ri. Jamain ANd Terrier (Manuel de path. et de clin. chirurgie, r892). Sheild ("Diseases of the Breast," p. 70) cites these authors as describing a case of actinomycosis of the breast in a woman aged 32 years. It was associated with troublesome sinuses, the thoracic walls being permeated with fistulous tracts and abscesses.

r. Somner (Bollet tino delle cliniche, Milano, $1887, \mathrm{~V}, 393$ ). His patient was a woman 38 years old. The trouble began with bronchitis after six months of which she developed a pain in the right side of the chest, pleuritis, and hemoptysis. At the end of I I months an abscess formed below the right clavicle and opened in the neighborhood of the mamma, some of which was involved. From the opening a fungous mass projected externally and gradually the entire inner half of the right breast became involved. She died $201 / 2$ months from the beginning of the disease. The right lung and diaphragm were united by callous adhesions. The left lower pulmonary lobe contained a small lesion. Actinomyces grains were found.

13. SzÉNÁsy (Centralbl. f. chirurgie, r886, XIII, 705). The patient, the wife of a butcher, was 30 years of age. She had been ill for the last nine years but had become rapidly worse during the last two months. She had pain in the right side of the chest and severe cough, and was so weak that she could no longer walk without assistance. She was thin, pale, had a coated tongue, and carious teeth. In the lower part of the left mamma there is a hen's egg-sized fluctuating tumor over which the skin is hot and stretched though of normal color. Another similar lesion, twice as large as that in the manma was found between the fourth and fifth ribs. Puncture of the mammary lesion evacuated $\mathrm{r}_{50} \mathrm{cc}$. of thick yellow pus with actinomyces grains.

r4. WELjAMnNow (cited without reference by Illich "Beiträge zur Klinik der Aktinomycose," I"ien, r 892). The patient was 60 years old and suffered from retro-mammary abscess, fetid expectoration and chronic bronchitis. Incision was followed by the evacuation of fetid pus from the abscess and exposed 
a disease of the ribs that had to be resected. In operating upon the rib a walnut-sized pulmonary cavity filled with pus was exposed. It was scraped out, disinfected and packed.

I5. Israel O. (Berliner klin. Wochenschrift, 1884, No. 33, p. 360) and König ("Ein. Fall von Aktinomycose hominis," Inaug. Diss., Berlin, r884). The patient was a woman $3 \mathrm{r}$ years of age who in November, $188_{3}$, began to suffer from a painful swelling over the sternum. She died the next year, when, at autopsy it was discovered that there was primary actinomycosis of the lung with perforation of the chest wall, secondary disease over the sternum and small metastatic abscesses in both mammæ. This case is also cited by James Israel ("Beiträge zur Kenntniss der Aktinomykose des Menschen," 1885).

16. IsRael, J., and WolfF, M. ("Über Aktinomykose, mit Demonstration," Verbandl. der deutsch Gesellsch. für Chirurgie, I89r, p. r48). This patient was afflicted with pulmonary actinomycosis that secondarily involved the mamma.

Diagnosis.-The diagnosis of mammary actinomycosis, whether primary or secondary in origin is rarely possible in its early stages. During the period when nothing exists but a "lump" in the breast, it may be mistaken for cancer if not painful, for pyogenic mastitis if painful. The chronic form with sclerosis is difficult, if not impossible to differentiate from the sclerosing types of tuberculosis, syphilis, chronic pyogenic mastitis and scirrhus.

Primary mammary actinomycosis is rapid in its invasion of the breast and leads to an enlargement that is frequently painful and invariably sensitive to the touch. It spreads rapidly, the skin becomes adherent and discolored, and within a period of several months fistulous openings appear. The disease is infiltrating in character and its lesions are rarely circumscribed. Both tuberculosis and chronic pyogenic mastitis of the sclerosing types form fistulas, but in actinomycosis fistula-formation occurs more early and the openings are more numerous. The discharge from the openings may be thick and yellowish, thin and watery or bloody. The appearance of the yellow granules is pathognomonic of the disease.

Mammary actinomycosis is commonly associated with pronounced disposition toward invasion of the deeper tissues, especially the pectoral muscles, beneath which the pus may burrow to point at the anterior axillary margin. When there are no actinomyces grains, or when there are no openings through which they can escape, the diagnosis may sometimes be arrived at by exclusion. A Wassermann test of the patient's blood helps to exclude syphilis; exploratory puncture with bacterioscopic or bacteriological examination of the pus obtained, may rule out pyogenic mastitis, and are quite justifiable as well as useful measures to employ.

Prognosis.-The prognosis of mammary actinomycosis is favorable if proper treatment can be instituted early. Some kind of operation is indicated in all cases, but must be varied from excision of the entire area of diseased tissue, wherever possible, to simple opening and draining of abscesses where more drastic measures are impossible. The complete eradication of the diseased tissue removes the source of the trouble and may in itself be followed by cure, but the numerous prolongations and extensions that obtain when the disease is advanced, make the measure applicable to cases of moderate extent and severity only. Whatever is done, care should be taken so to treat the lesions as not to spread the disease by distribution and implantation of the actinomyces.

In the secondary cases, the lesion appearing late in the breast may show what the primary trouble is when its correction is impossible. About 50 per cent. of the secondary cases died.

Treatment.-In young women with well-developed areas of involvement, the diseased tissues should be excised. This is presumably the safest and most satisfactory treatment 
but when it is not permitted, the fistulous tracts should be treated by local applications of iodine or carbolic acid. Extensive involvement of the breast requires amputation and the complete removal of all the diseased tissues even to cleaning out the axilla when enlarged lymph nodes can be found. Whatever is done in the way of excision, eradication or local application, the patient should be given large doses of iodide of potassium as routine treatment, both during the period of local treatment and after it has been completed. Iodide of potassium is known to bring about a cure in many cases of actinomycosis whether in the breast or elsewhere, and is the only drug that is known to be of any benefit in the treatment of the disease.

\section{SYPHILIS OF THE BREAST}

Syphilis of the breast is a rare disease, is becoming more rare, and promises to be almost unknown in the future, because of the substitution of artificial infant feeding for the "wet nurse," and because of the improvement in the means of recognizing and treating syphilis in its early stages.

Manifestations of all three stages of the disease have been described as affecting the breast.

I. The Primary Lesion or Chancre.-This may occur upon the nipple, the areola, or the skin. It was formerly a rather frequent affection among wet nurses and resulted from the infection of "chapped," abraded, or fissured nipples by mucous patches in the mouths of congenitally syphilitic infants. Occasional epidemics of syphilis have been known to occur, a succession of wet nurses being infected by the same syphilitic infant, or a succession of infants by the same syphilitic wet nurse. Wet nursing having almost completely ceased as a vocation, this means of disease dissemination is fortunately at an end and the rare cases of chancre of the breast observed at the present time are almost exclusively the result of the infection of a female breast by mucous patches in the mouth of an adult of the opposite sex.

Fournier (Les Chancres Extra-génitaux, Paris, r897) found that 6.33 per cent. of all chancres were extra-genital in situation. Of 672 cases of this kind collected by him, ig were upon the
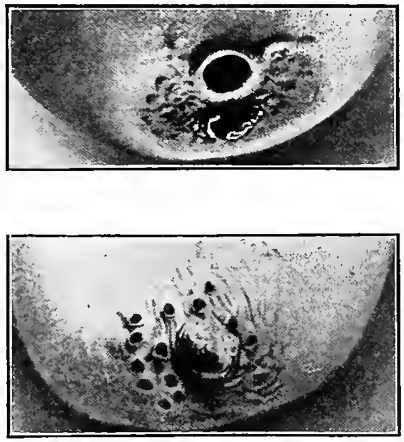
breast; of $48 \mathrm{I}$ cases, collected by his pupils, 40 were upon the breast. Of these 59 cases of mammary chancre only 3 occurred in men. In 39 of the cases they were multiple. They were usually confined to the nipple, sometimes occurred in the sulcus at the junction of the nipple and areola, and in rare cases were at the periphery of the areola or upon the skin beyond.

These chancres differed widely in size and configuration, though when they were fully developed they usually presented the typical characteristics of the Hunterian chancre. They may, however, lack any or all of these qualities and occur in the form of 
minute erosions or fissures at the base of the nipple the painless character of which is alone suspicious. They are not infrequently bilateral and multiple. Vennes (Montpellier méd., I905, XX, 549) saw a healthy woman infected through "wet nursing" who had one chancre on the right and eight on the left breast. Gravagna ("Syphilis," Paris, I905, III, 588) called attention to a specimen in the museum of the Saint Louis Hospital in Paris, that shows 28 separate chancres about the nipples of a wet nurse infected by a syphilitic infant. Sometimes the chancre is very large as in the case reported by Petges (Jour. de méd. de Bordeaux, I9I3, XLIII, 42I) in which the right breast of the patient showed a large rounded ulceration $10 \mathrm{~cm}$. in diameter, centering about the nipple. It was red, had clean borders, secreted abundant lymph, and had exuberant granulations over the surface projecting nearly $2 \mathrm{~cm}$. The entire nipple and areola were lost in the lesion. The axillary lymph nodes were enlarged and hard. The subsequent appearance of syphilitic roseola proved the diagnosis of the disease.

GoTrHeIL (Jour. Cutan. Diseases including Syphilis, New York, I908, XXVI, 280 ) observed a married woman aged 40 years, whose husband bit both of her nipples, not causing bleeding, but leaving the marks of his teeth upon the structures. The marks soon disappeared, and she forgot all about the circumstance until some weeks later when the nipples began to be "sore." Even then she attributed the soreness to irritation of the clothing, and recalled the injury only when carefully questioned as to antecedent accident. When she came under observation, there was, on the right breast, just above the nipple, and occupying the areolar area, an oval, inflamed elevated and eroded lesion measuring $3 / 4$ by $1 / 2$ inch. The margins were brownish red and angry looking, the center ulcerated and depressed, and the entire base, the seat of a very hard, painless, typical syphilitic induration. The skin around the lesion, and, in fact, that covering the entire gland is reddened, covered with vesiculo-papular eruption, and in an acutely inflamed condition.

On the left breast the entire nipple and areola are swollen, dusky red, and covered with a dark brown adherent crust. The nipple is four times the size of its fellow on the other side, and it and the areola about it are the seat of a large, painless induration. The skin covering this breast is also the seat of an acute exanthematous efflorescence. Besides these lesions the patient showed a macular general exanthem, with lesions of the palms of the hands, adenopathy and angina.

Later the large dark crust detached from the left nipple, leaving a half-dollar-sized typical sclerosis. The exanthematous lesions were attributed to some external application used by the patient.

In discussing the case Dr. Paroun gian remarked that he had, sometime before, seen a case with three chancres on one breast and two on the other, contracted by the patient from her own child that had been infected through the kisses of a servant in the house.

A somewhat rare form of the primary mammary lesion is the "incrusted chancre," mentioned by various writers and described as a well-circumscribed round or oval sore surmounted by a tightly adhering brown or dirty gray incrustation, removal of which reveals an ordinary Hunterian chancre, as soon as the oozing following the removal of the crust has been arrested.

Such a case has been reported by Gravagna ("Syphilis," Paris, I905, III, 588): A young woman having lost her third baby shortly after its birth, being in good health, and troubled by the painful distention of her breasts with milk, sought relief by nursing another baby in the hospital. She shortly observed that there were white patches in the baby's mouth. Later she developed two chancres on the left nipple and areola, and one on the right nipple. Those on the left were of the erosion type, but that on the right were of the rare "type crousteux." All of the lesions were indurated and painless.

Fournier has also described a "confluent chancre," in which a number of minute superficial and seemingly benign sores coalesce to form an erosive lesion of considerable extent.

The mammary chancres are at times destructive and may become phagedenic and destroy the mammary tissues to a considerable extent. Milk fistulas may result from - 
chancerous erosion and destruction of the milk ducts as in the case reported by MaretLavilli.

II. The Secondary Lesions.-The cutaneous eruptions of genital syphilis, or extragenital syphilis not mammary, being common to the skin generally and in no way peculiar. to the breast, can be dismissed without further mention.

Two remaining secondary manifestations merit attention.

1. The Mucous Patch or Condyloma Latum. - This lesion may occur upon the nipple, or upon the areola, or upon both, or it may occur in the sulcus between a pendulous breast and the chest wall. It occurs most frequently where the skin is soft and warm and moist, as a slightly elevated, glazed, red area, covered when moist, and comparatively undisturbed, with a grayish slime. It can scarcely be mistaken for any other lesion. Mucous patches are of an importance that can scarcely be overestimated, being the chief source by which the transmission of the disease from the syphilitic nurse to the healthy infant takes place.

2. Diffuse Syphilitic Mastitis.-This is a somewhat rare condition that makes its appearance later in the secondary stage. Attention was first attracted to it through the work of Ambrosoli (Di una mallati della glande mammæ, Gaz. med. clin. ital. Lombardia, I864) whose observations were confirmed by Lancereaux (Traité practique et historique de la syphilis, Paris, I874). Ambrosoli reports two cases; one a 19-year-old girl with papules upon the genitals, who in 37 days observed swelling and hardness of the right breast that increased by one-third of its original size. The skin was not discolored, the temperature was not elevated, the axillary nodes were not enlarged. In a few days the other breast became similarly affected. Mercurial treatment was promptly followed by return to the normal size and condition. The other case was a woman 24 years old, similar lesions of whose breasts promptly recovered after the employment of iodide of potassium following mercury.

Unlike the lesions previously mentioned, diffuse syphilitic mastitis frequently occurs in the male breast which swells and causes the patient to suffer from a sensation of increased tension, though there is little actual pain. When palpated, the breast feels nodular, not unlike the female breast in chronic interstitial mastitis or abnormal involution. There is but slight inflammatory reaction and the fibrotic process makes slow progress. Softening and ulceration of the diseased tissues sometimes but rarely occurs. Rouanet (Mercredi méd., Paris, I895, VI, 73) spent some time studying diffuse syphilitic mastitis and reports a case in a man. He believes that the condition may occur either in the secondary or tertiary stages. The lesions may become much like cancer but do not ulcerate.

III. The Tertiary Lesions. - Of these the most frequent is the gumma which may be either subcutaneous or intraparenchymatous. Gummasa of the breast are sometimes multiple and bilateral, but in the ordinary run of cases are single and unilateral. Traumatic injury seems to exert some predisposing influence in their formation. They occur in both men and women. Barthelemy (Bull. soc. franç. de dermatol. et syph., Paris, I896, VII, 38) reports a case of bilateral gummas of the breast in a man; Richter (Dermatologische Zeitschrift, Berlin, I903, X, 897) a very clear case of gumma in a young man of 22, two years after syphilitic infection. They make their appearance as hard, well-circumscribed, movable nodes of varying size, and increase slowly and without pain, to eventual softening, ulceration and cicatrization. During the open stage of the lesion a foul-smelling grumous, brownish fluid is discharged. It represents the products of necrosis and its escape continues until a deep ragged ulcer is formed and cicatrization 
begins. As the lesion is apt to be centrally situated, the nipple is not infrequently destroyed and in severe cases almost the entire breast may become slowly transformed into a malodorous slough closely simulating a broken-down malignant tumor as in the remarkable very destructive gumma reported by Bryant ("Diseases of the Breast," r867, p. 73).

He reports the case of a woman with an induration of the upper half of the left breast that had heen coming on for 8 or to months. In August, 1869 , the skin on the lesion was natural. In addition to the mammary induration she had a lesion over the frontal bone. In October, I869, the skin had become "bossy" and there were external signs of inflammation-heat, redness and fluctuation. In March, I870, the breast had become as large as a cocoanut, the skin over it was ulcerating, and the gland

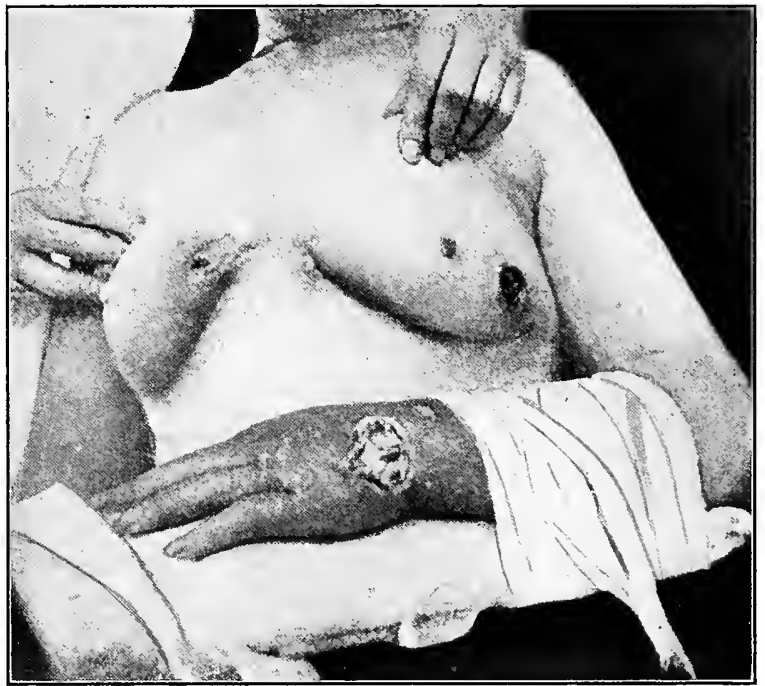

FIG. II3.-Gumma of the breasts with other tertiary lesions of syphilis. (Porter.)

tissue seen through the opening looked dead and presented a "yellow wash-leathern aspect so characteristic of syphilis." In September, I870, the whole mass sloughed and fell as a putrid mass into a basin leaving a clear granulating surface. On November ro, 1870 , the woman was well.

Actual gangrene may occur as in Robinson's case (Medical Times and Gazette' London, I 864, II, 26I). A less frequent manifestation of tertiary syphilis is diffuse syphilitic mastitis. Fundamentally the process is similar to gumma, but instead of the force of the infection concentrating at a single focus and effecting complete destruction, it occurs at many tiny scattered foci, and distributing its force over considerable tissue, loses its extremely destructive character. The result is a subacute inflammatory disturbance without resemblance to tumor, without ulceration, and terminating in more widespread sclerosis when the final stage is reached.

Congenital syphilis may also affect the breast, producing a chronic caseating lobular mastitis to which Billroth and Loeck first drew attention in $r 880$. It seems not to 
differ essentially from diffuse syphilitic mastitis of acquired syphilis, and is a late manifestation of congenital syphilis.

Gummas also occur in the breasts of congenitally syphilitic children. Mention of such is to be found in the writings of Birsch-Hirschfeld, Gay, Groma, Henning and Neumann.

Syphilitic disease of the breast sometimes takes place through continuity of tissue, as, for example, in cases with syphilitic osteoperiostitis of the underlying ribs.

Diagnosis. - It may be easy to make a clinical diagnosis of syphilis of the breast, or it may be impossible to do so. A typical Hunterian chancre of the nipple or areola, or a characteristic gumma in a person with a clear syphilitic history, ought not present difficulties, yet the rarity of syphilis of the breast is such as to cause them to be mistaken either for more simple or for more dangerous conditions.

Thus, chancres of the breast may be mistaken for fissures with simple infection and ulceration, for eczema, for herpes, which are less important, or for squamous-cell carcinoma or Paget's disease, which are more so.

Minute, atypical and harmless appearing sores about the nipple and areola may not arouse any suspicion of their true nature and the advent of the secondary eruption comes as an unpleasant surprise to both patient and physician. But even in cases in which the lesion is most typical in appearance, one should hesitate in the absence of confrontation -a rare possibility in such cases-to pronounce the lesion to be a chancre upon its physical characteristics alone. In every suspicious case the microscope should be called into requisition, and a drop of the lymph obtained after removal of crusts and abrading the surface examined for Treponema pallidum, either by the aid of a dark field illuminator or by staining methods. If such an examination cannot by made by the medical or surgical adviser of the patient, the coöperation of some competent laboratory worker can easily be secured, to whom a drop of the lymph, spread thinly upon one or two clean glass microscopic slides and simply dried in the air, may be sent for examination and diagnosis.

No matter how atypical the chancre, however, there are certain features that ought not be overlooked and that should be given careful consideration so soon as suspicion of syphilis is aroused. These are the absence of pain and the presence of enlarged lymphatic nodes, both of which point strongly toward syphilis.

Fissures of the nipple, eczema, herpes, squamous-cell carcinoma and Paget's disease are the conditions most often confused with chancre, and as the similarity between them is of ten too great to permit of correct differentiation by clinical means, the assistance of the laboratory becomes imperative.

The constitutional symptoms attending the period of primary incubation and the primary stage do not differ from those of chancre elsewhere. The first lymph nodes to show enlargement are those of the anterior pectoral chain which become easily palpable and sometimes visible.

Although it has been said that mammary syphilis is exceptionally malignant, we have been unable to find any evidence in support of that opinion.

Gumma of the breast is frequently mistaken for cancer. The "cancer verolique" of the "Nosologia Méthodique," published in the eighteenth century by de Sauvages, seems undoubtedly to have been gumma of the breast, as it disappeared under medical treatment.

When an ulcerating mass is found in the breast, the differential diagnosis requires the consideration of the following diseases, the order of frequency being about the same 
as the order in which they are named; cancer, sarcoma, chronic pyogenic mastitis, tuberculosis, syphilis, actinomycosis and sporotrichosis.

The differential diagnosis between chancre and gumma of the breast may present difficulties, as in a case recently observed in the out-patient department of the German Hospital of Philadelphia:

The patient was a woman 30 years of age, the mother of four healthy children, who had on one breast a rounded elevated encrusted sore with an indurated margin. It was approximately $2 \mathrm{~cm}$. in diameter and occupied the upper surface of the nipple and the adjacent surface of the areola. It was highly suggestive of chancre and the axillary lymphatic nodes were enlarged. The patient was treated for several weeks with bland ointment without improvement. Three separate examinations were made for Treponema, but none was found. Two Wassermann tests, made by two different serologists, were, however, strongly positive. After some days the ulcer developed a "punched-out" appearance that strongly resembled a gumma. The lesion quickly disappeared after an injection of neosalvarsan.

Rosenthal (Dermatologische Zeitschrift, Berlin, I903, X, 398) tells of a young girl that suffered from both gonorrhea and syphilis:

A year after first being seen she experienced marked swelling of one breast. A surgeon made a diag nosis of mastitis, and incision was recommended. Dissatisfied, she consulted a gynecologist, who told her that it was a cancer and that the breast should be amputated. She now returned to Rosenthal, who upon examination found the right breast as large as two fists and the seat of six or eight circumscribed hard nodes, some apparently in the breast, some behind it. On the skin surface two had softened. The diagnosis was now changed to syphilitic mastitis. The patient never came back, but Rosenthal heard that it was because she had recovered under antisyphilitic treatment.

Beer (Medical News, New York, I905, LXXXVII, 825) reported the following case:

A married woman 35 years of age who four months before coming under observation observed a mass in the left axilla and, a few weeks later, a similar mass in the upper half of the left breast. The latter was about 2 inches in one diameter by 3 inches in the other, not tender, freely movable and not attacbed to the skin. The nipple was normal. Soon a mass appeared below the left clavicle. Various doctors told the patient that the disease was cancer and advised operation. Careful questioning determined that the patient had been infected with syphilis by her first husband some years before. She was placed upon antisyphilitic treatment, and at the time the report was published was nearly well.

That unnecessary operations may sometimes be performed under these conditions is shown in the case reported by Bruc (Montpel. méd., I903, XVI, 244) of

an Italian woman who had had syphilis eight years before, all signs of which bad disappeared under treatment. A year before the paper was published she found a tumor in the breast which a surgeon removed. The operation was a failure and ulceration followed.

Heller (Münch. med. Wochenschrift, I903, L, 738) has reported the following interesting case:

A woman aged 62 years had previously suffered from a considerable number of soft and hard tumors of the skin that had been diagnosed gummas and improved under treatment. Jan. 27, 1902, the patient discovered a small tumor in the lower outer quadrant of the left breast. It was carefully examined and diagnosed scirrhus. In the right mamma there was another walnut-sized, bard, well-circumscribed node from which palpable strands radiated in all directions as in scirrhus. The general condition of the patient was bad, and the discovery of bilateral cancers was looked upon as sufficient explanation for it. The presence of syphilitic infection being in no way opposed to the occurrence of cancer, the diagnosis of cancer of both breasts was made. The bad general condition caused the postponement of operation for a time during which the patient should be given general treatment. She was, therefore, placed upon iodide of potassium. The tumors in the breasts soon changed, became round, and gave evidence that they were not cancerous. At length they softened, the skin purpled but they did not ulcerate. By the spring of 1902 they had entirely disappeared. In June, 1902 , a new tumor appeared in the upper outer quadrant 
of the left breast. The skin was unattached and unchanged. In spite of to or 50 gummas having healed in this patient, this one did not show any such tendency and persistently increased until it became as large as a large apple. It seemed to fluctuate, but an aspirating needle secured no pus. An operation was begun by opening the lesion, when $500 \mathrm{cc}$. of gummatous matter filled with flocculi were obtained. It was then clear that it, too, was a gumma and not a cancer, and further operation was regarded as both unnecessary and dangerous. Under antisyphilitic treatment it healed completely and there were no more tumors.

Gumma may also be mistaken for sarcoma as in Patterson's case (Proc. Roy. Soc., London, Ig09-Io, III, Clinical Section, 82):

A woman aged 26 suffered from a hard irregular nodular formation in the upper outer quadrant of the right breast. It was not adherent to the skin or deep fascia, and the axillary nodes were not enlarged. Explored under chloroform anæsthesia it was found to be hard and regarded as sarcoma, which opinion was confirmed by microscopic examination. It was removed. Two or three weeks later the suture holes ulcerated and small red nodules appeared in the surrounding skin along the line of incision which became brawny and infiltrated, and fnally ulcerated. The ulceration spread and the axillary and supra-clavicular nodes became enlarged. Fourteen weeks after operation a smooth hard swelling developed over the sixth rib in the axillary line. Mercury and iodide of potassium were administered and the lesions quickly healed. Three years subsequently she was in perfect health.

It thus becomes not only desirable, but absolutely imperative to make use of the assistance of the laboratory in all doubtful cases.

The process of ulceration is slower in cancer than in gumma, and the involvement of the axillary lymph nodes is much earlier in cancer. Ulcerated malignant tumors are usually painful, gummas painless. The ulcerating gumma is soft; the ulcerating cancer is surrounded by a dense induration.

Sarcoma usually occurs as a nodular rounded tumor that slowly reaches the surface causing atrophy and ulceration of the overlying tissue. The tumor mass can usually be felt and more or less definitely outlined: In tuberculosis, sinuses and fistulas are formed by the gradual extension of the disease to the surface, and the discharges are purulent and may contain tubercle bacilli. Actinomycosis of the mamma, which also causes abscesses with communicating fistulas and external sinuses, may be recognized by the occasional presence of the "actinomyces grains" or ray fungi in the pus of the discharges. Sporotrichosis, of which but few cases have been reported, may present greater difficulties of differential diagnosis, its true nature only being revealed through bacterioscopic and cultural methods.

It should be remembered if this examination is to be successful it must be made before the patient receives salvarsan or mercury, or before mercurial preparations are applied locally.

In tertiary syphilis this method of examination usually fails because of the very small number of specific microörganisms present. It is therefore necessary in such cases to pursue another method of study. To this end a needle is introduced into a vein in the arm, and blood withdrawn for making a Wassermann or Noguchi test. The most simple device known for securing the blood is that suggested by Keidel (Jour. Amer. Med. Asso., I9I 2, LVIII, I 579). It can be used by any one possessed of a small amount of skill, and the blood can be forwarded, without danger of contamination, to a distant laboratory in the same tube in which it is collected.

The positive Wassermann reaction is not in itself conclusive evidence that the lesions in the breast are syphilitic. A patient with a cancer or a sarcoma may be syphilitic as well as another, but the discovery by this method of examination that the patient has syphilis adds an important item to our data for diagnosis. With the 
knowledge that the patient has syphilis comes the indication for immediate antisyphilitic treatment, and through this final test the diagnosis of many difficult cases may be perfected. All cases with suspected cancer and known syphilis should await the effect of the antisyphilitic treatment, before being operated upon for the cancer.

Prognosis.-The prognosis of syphilis of the breast does not differ from that of other syphilitic lesions. Prompt treatment causes the rapid healing of the lesions. Deformity may follow in proportion to the extent of tissue destruction effected by the disease, which in turn will be in proportion to the promptness and efficiency of the treatment.

Treatment.-The treatment to be advised in the treatment of all forms of syphilis, including that of the breast, is the intravenous injection of neosalvarsan. The only exceptions are in cases that for any reason show distinct evidences of meningeal irritation from any cause, or suffer from marked impairment of the renal function from other causes than syphilis. The existence of cardiac lesions should not be looked upon as a contra-indication, although, it is perhaps advisable in such cases to decrease the dose somewhat.

In ordinary cases the biniodide of mercury, combined with one of the iodides and consisting of the so-called "mixed treatment," is given to supplement the effects of the neosalvarsan.

The efficacy of the treatment must be determined solely through blood examinations, made at occasional intervals. Injections of 0.9 gram of neosalvarsan repeated at intervals of about a month should be continued until the blood test (Wassermann reaction) is negative. Three or four injections are usually necessary to accomplish this effect, and after it the mixed treatment is continued for a varying number of years. During this time the arsenical preparations are held in reserve lest there should be a relapse and the blood again show a positive reaction. This treatment, carefully carried out, will bring about good results in mammary or other forms of syphilis.

Local treatment is indicated in all cases of open lesions of syphilis. For the chancrous ulcerations it is well to employ a powder consisting of equal parts of boracic acid, acetanilid and calomel. Many syphilitic ulcerations are benefited by applications of "black wash."

For tubercular syphilis, rupial lesions, and ulcerating gummas mercurial ointment is, perhaps, to be preferred.

In all cases attention is to be paid to the general hygienic and dietetic treatment of the patients who are apt to be anemic and debilitated.

\section{LTTERATURE UPON SyphiLIS OF THE Breast}

AMbrosolı.- "Di una mallatia della glande mammaria, etc.," Gazette med. clin. Ital., Lombardi, r864. BARThelemy.--"Gommes syphilitiques du sein," Bull. soc. franç. de dermat. et syph., Paris, r 896, VII, 38. BEER, E.- "Mammary Syphilis with Involvement of the Axillary and Supra-clavicular Glands, Simulating Cancer of the Breast," Medical News, New York, I905, LXXXVII, 825.

Besnier, M. E.- "Ulcération chancriforme du sein," Bull. soc. franç. de dermatol. et syphilis, Paris, I896, VII, 87; Ann. de dermat. et. syph., Paris, I896, 3s., VII, I93.

Bisselt, J. B.- "Syphilitic Tumors of the Breast," Medical Record, New York, July 6, I9o7, LXXII, r4. BROECK.- "Erfahrungen über Syphilis," Stuttgart, I875.

Bruc.-Mastite gommeuse du sein gauche," Montpellier méd., I903, XVI, 244.

BRYANT.- "Diseases of the Breast," I 877, p. 73.

Chavannez et Loubet.- "Gomme syphilitique du sein," Jour. de méd. de Bordeaux, I9I3, XLIII, 482.

Cheever.- "Syphilitic Tumor of the Breast," Bost. Med. Surg. Journal, i 879 , XXIII, $3^{8} 4$.

Cheminade, G.-Chancre induré du sein droit," Union méd. Paris, 1889, 3s., XIVIII, I57.

Claude.- "Etude sur la syphilis du sein," Thèse de Paris, I886. 
DANeL.- "Gommes syphilitiques multiples de la mamelle," Jour. de soc. méd. de Lille, rgo7, II, 529. DUPLAY and REcLus.- "System of Surgery," r892, chapter on "Syphilis of the Breast," by Pierre Delbet. EMERy.- "Gomme du sein," Bull. soc. franç. de dermat. et syph., Paris, I896, VII, 36.

Fournier.- "Chancres du sein," Paris, r896, p. 225.

Fournier, A.- "Extra-genital Chancres," Paris, 1897.

Fournier, E.-"Hereditary Syphilis in the Adult," rgr 2.

Gay, C. C. F.-Medical Record, New York, I883, II, I 9 .

Gotrhen, W. S.- "Sclerosis of Both Nipples," Jour. Cutan. Dis. Incl. Syphilis, N. Y., rgo8, XXXVI, 280.

Gravagna.- "Sifilomi primari della mamelle; sifilide da allattamento," Boll. d. mal. ven. sif. e. d. pelli., Roma, r 905, V, 96; and "Syphilis," Paris, r905, III, 588.

Groso, A.- "Contribution a l'étude des gommes du sein," Paris, 1878 .

Heller.- "Über Spätsyphilis der Mamma," Dermat. Zeitschr., Berlin, I903, X, 396.

Heller.- "Über gummöse Syphilis der Mamma," Münchener med. Woch., I903, L, 738.

Hennig.-Arch. f. Gynäkologie, 187 1.

ICARD, J._"Note sur un cas de tumeur syphilitique simulant un cancer du sein," Jour. de méd. de Lyon, r867, VII, 2 r.

Jullien, L.- "Sclérosis bilatérale du sein; guérison très rapide par le traitment mercurielle," Jour. d. mal. cutan. et syph., Paris, rgo8, XIX, 262.

Lancereux.--"Syphilis of the Breast," "Jour. Cutaneous Diseases Including Syphilis, New York, Igo8, XXVI, 372; 1909, XXVII, I25.

LAPOWSKI.- "Syphilis of the Breast," Jour. Cutaneous Diseases Including Syphilis, New York, rgo8, XXVI, 372; r909, XXVII, r25.

LAvilLI.-Quoted by LeDentu and Delbet.

Le Dentu et Dérbet.— "Traité de Chirurgie Clin. et Oper., r899, Vol. II, article on "Syphilis du Sein," by Binaud et Braquehaye.

Maisonneuve.-- "Leçons clinique sur les maladies cancéreuses," Paris, 1854 .

Modercin.-Contribution a l'étude des mastites syphilitiques," Paris, r go3.

Neumann.- "Über die syphilitische Erkrankung der Brustdrüse," Allg. Wien. med. Zeitung, r889, XXXIV, 593. Article "Syphilis," in Nothnagel, "specielle. Path. u. Therapie," r8g6, XXIII.

Ostermayer, N.-“"Ein Fall von gummöser Erkrankung der weiblichen Brustdrüse,” Arch. f. Dermat. u. Syphilis, Wein und Leipzig, I893, XXV, 940.

Patterson, H. J.- "Gumma of the Breast Simulating Malignant Disease," Proc. Royal Society of Medicine, London, rgog-ro, III, Clinical Section, 82 .

Petges.—“Chancre syphilitique géant du sein," Jour. de méd. de Bordeaux, 1913, XLIII, 42 r.

Richter.- "Gummöse Mastitis bei einem Manne," Dermatol. Zeitschrift, Berlin, I903, X, 397.

Robinson.- "Case of Syphilitic Gangrene of the Breasts," Medical Times and Gazette, London, I864, II, $26 \mathrm{I}$.

RosentHad.-“"Syphilitische Mastitis," Dermat. Zeitschr., Berlin, r903, X, 397.

Rouanet.- "De la mastite syphilitique diffuse chez l'homme," Mercredi méd., Paris, I895, VI, 73.

DE Roulet.- "Clinical Diagnosis of Surgical Diseases of the Breast," "Syphilis of the Breast," American Journal of Surgery and Gynecology, 1903-04, XVII, r62.

Sauvages.- "Nosologia methodica," r 768 , T., IV, 344.

VenNes, J.- "Chancre multiple du sein," Montpel. méd., rgo5, XX, 549.

voN ZEISsL, M.—“Über die Erkrankung der Brustdrüse in Folge von Syphilis," Allg. Wiener med. Zeitung, $1885, \mathrm{XXX}, 73,82$.

\section{SPOROTRICHOSIS OF THE BREAST}

Sporotrichosis is a rare form of human infection, the first occurrence seeming to have been observed and studied by B. R. Schenck ("Bulletin of the Johns Hopkins Hospital," December, 1898). A second case was studied by Hektoen and Perkins ("Journal of Experimental Medicine," 1900-0I, V, 77). Additional cases were studied and reported by de Beurmann and Gougerot (Ann. de dermatologie et syphiligraphie, r9o6, ${ }_{837}$ ), and by Lutz and Splendore (Centralblatt für Bakteriologie, etc., I907, XLV, Orig. 
632). By Aug. 8, 1908, the writer of an editorial in the Journal of the American Medical Association was able to give references to 14 cases of the infection, recorded in the world's literature. In I9I2 Ruediger (Journal of Infectious Diseases, 1912, XI, I93) published a collection of 57 cases that had occurred in the United States. In the same year de Beurmann (British Medical Journal, Aug. I6, I9I 2, II, 290) stated that more than 200 cases had been placed upon record since the beginning of his interest in the subject in r903. From this brief survey of the history and chronology of the subject it will be seen that sporotrichosis is an infection that has but recently received attention and presents itself somewhat in the light of a new disease.

As a disease of the breast sporotrichosis is exceedingly rare. In the most complete monograph upon the subject that has come to our attention, Quenu ("De la sporotrichose mammaire," Revue de chirurgie, Paris, I9I4, XLI, 585), has been able to collect only five cases. They are of sufficient interest, however, to merit attention because of the difficulty of making a correct diagnosis and thus possibly subjecting the patient to an unnecessary operation for a condition that is commonly amenable to other than surgical treatment.

Etiology.-The infection is caused by a fungus-sporotrichum-characterized by a delicate spore-bearing mycelium, the filaments of which are slender, partitioned, colorless, much branched and tangled and measure about $2 \mu$ in diameter. The chief characteristic is the occurrence of spores along the length of recumbent filaments either at the extremities or on branches, arranged in cylindrical cuffs about $10 \mu$ in size or in glomeruli, and readily isolated from one another. They arise, one by one, in variable numbers along the mycelium, but as a rule in large numbers on each segment of the thallus, there being no appearance of order in their arrangement. The spores are pearshaped, attached by a very delicate sterigima, from $\mathrm{I}-2 \mu$ in length and $\circ .5 \mu$ in breadth. The shed spores are ovoid and measure $3-6 \mu$ in length and $2-4 \mu$ in breadth.

These generic characters vary in the different species of which, according to de Beurmann, there are now known S. schencki, S. beurmanni, S. beurmanni var. asteroides, $\mathrm{S}$. beurmanni var. indicum, S. jeanselmei and S. gougerati.

It is not necessary to give the characters of these different species in a writing of this scope. The microörganism can be seen and examined in the fresh and living state in the pus from the lesions. It can also be examined stained, though this is less appropriate, for the manipulations incidental to staining modify its appearance through shrinking.

It can also be cultivated, and in all cases where sporotrichotic infection is suspected, the diagnosis should be assisted by sowing drops of pus upon various culture media, as well as by the examination of a drop of -the fresh pus with the microscope.

For purposes of culture, agar-agar, glycerine agar-agar and glycerinized potato are most appropriate. The colonies usually appear in from 24 to 72 hours. Their general appearance is like that of the little tufted colonies of the common moulds. Isolated colonies spread in circular form, smears form more coherent bands with wrinkled and folded appearance. The thick mycelial felt-work sooner or later assumes a brownish color, and when it becomes dark the culture medium itself becomes brown. Though the surface is fuzzy and the edges fringed, there are no aerial sporangia as in the moulds.

The sporotricha are pathogenic for men, horses, dogs, rats and white mice. Not every species is pathogenic for all these animals, nor is it true that a culture that is newly isolated from one of the animals is necessarily infectious for the others.

According to de Beurmann the fungus is widely distributed in nature. It has been found upon green vegetables, upon bark, thorns, potatoes, various implements in the 
soil and in infected insects. It usually enters the animal organism through a wound of the skin, and injuries about the fingers and hands are the common portals of admission.

Pathology. - The seat of primary infection is commonly spoken of by the French writers as the sporotrichotic chancre, the metastatic lesions as sporotrichotic gummas, but these terms have not become popular in English-speaking countries. The primary lesion, which is traumatic to begin with, usually forms a deep, well-defined, sharply circumscribed, undermined ulceration with a roughened base covered with a grayish shining pus. When this is wiped away a bright red surface is left. From such a lesion the infectious agent spreads by lymph and blood metastasis. In the greater number of reported cases lymphogenic metastasis seems to have predominated, so that the secondary lesions are in the neighborhood of the primary lesion along the lines of the lymphatic vessels. Such lesions are naturally for the most part superficial. Each lesion begins as an area of inflammation and spreads peripherally. In the center, at the oldest part, there soon forms an abscess containing polymorphonuclear leucocytes and large phagocytes; round about this is a zone of infiltrated but not colliquated inflamed tissue, densely invaded by leucocytes of all kinds, and containing many small giant cells and numerous tubercle-like formations; beyond this and fading away into the surrounding healthy tissue is a third zone of leukocytic infiltration, connective-tissue cell proliferation, with plasma cells, basophilic cells and fibroblasts. The lesion is thus shown to be a true specific inflammation, closely related to that of syphilis and tuberculosis.

In cases of blood metastasis, the portals of primary infection may remain undiscovered. Such is the case in the reported instances of spirotrichotic infections of the mammary gland. The lesion of the mamma was not the result of local infection but of metastatic infection from some unknown source. In one of the cases (that reported by Landouzy) the sporotrichium was found in the blood of the patient. No case of primary direct infection of the mammary gland is known to be on record.

General Description of the Disease.-Briefly abstracted protocols of the reported cases of mammary sporotrichosis, given below, will serve to show the clinical peculiarities of this interesting disease.

De Beurmann and Gougerot (Soc. franç, de derm. et de syph., I909, XX, 363 ).

The patient was a woman, a dishwasher 66 years old, emaciated and much bent with age. A sister died with pulmonary tuberculosis. She entered the Saint Louis Hospital covered with soft suppurating lesions with numerous external fistulas. The lesions not yet open were firm, movable beneath the skin and painless. There were also some large ganglia in the inguinal regions. The lesions never attracted attention themselves, and the patient always discovered them by accident. Among the lesions in this case was one of the right breast. After treatment with iodides for a short time the lesions all disappeared and the patient returned to a state of good health except that a hard tumor adhering to the skin remained in the breast. This was diagnosed as a scirrhus. Upon careful palpation of the breast three other smaller nodules could be made out, and it was suspected that the trouble might be sporotrichosis.

The breast was amputated. It was found to contain a cancer node at one side and sporotrichotic nodules elsewhere. Microscopic examination verified the diagnosis of cancer and sporotrichosis.

\section{Landouzy (Presse médicale, I909, XVII, 985).}

The patient was a woman, a housekeeper 66 years of age, apparently in good health, though she showed a positive cutaneous tuberculin reaction. The present illness began with the appearance of a nodule on one forearm. In the course of a month no less than 70 had made their appearance beneath the skin of all parts of the body. There was also a periosteal frontal lesion. Upon the right breast were cutaneous and subcutaneous ulcerated and incrusted lesions which about the areola and nipple assumed appearances resembling impetigo, pityriısis and eczema. There was also a large pemphiguslike bulla on the breast. The general condition of the patient remained good. Sporotricha were found 
in the blood of the patient. The treatment consisted in the employment of iodides by which the lesions all disappeared in eight days.

Rouslacroix and Wyse-Lauzun (Soc. franç. de dermatol. et de syphiligraphie, I909, $\mathrm{XX}, 363$.$) .$

The patient was a woman aged 57 years, a cook. She suffered from ulcerating lesions on the arms, wrists, calves, etc. Each began as a hard, indolent, painless node that rapidly enlarged and extended upward to the skin which took on a violet hue. The node then softened, fluctuated, became painful evacuated a small quantity of grayish-yellow pus striped with blood, after which it continued to ulcerate. At the time of entering the hospital she had three such lesions on the upper aspect of the right arm. On the outer inferior part of the right breast there was a tumor the size of a man's fist. It was hard and mobile and without ulceration. A di gnosis of sporotrichosis was made and the patient placed upon iodides. At the end of about eight days all of the cutaneous lesions had disappeared and the large mammary lesion had resolved itself into three small nodules the size of walnuts.

\section{Lerat (Presse médicale, Belge, I909).}

This patient was a man over 70 years of age, a lover of horses and dogs. He was pale, emaciated and weak. About six months ago he began to be troubled with a lump that appeared in the neck not far from the "Adam's apple." When first observed it was firm and the size of a pea, but it rapidly enlarged to the size of a nut. It softened and suppurated and was opened by a medical man who thought it a suppurating sebaceous cyst. Later, however, another similar nodule appeared below the hyoid bone. Detailed examination showed that the patient had also a pigeon's-egg-sized nodule in the right breast. This the patient thought resulted from a blow that he had experienced some time before. The nodule w as firm and was neither attached to the skin nor the deeper tissues. It was thought to be a cancer. There was a third nodule at the inner border of the biceps muscle of one arm. It was the size of a cherry, well circumscrihed, covered with violet skin. A fourth nodule was found about $2 \mathrm{~cm}$. above the crest of the ilium. It appeared as a subcutaneous swelling like a sebaceous cyst.

The patient was seen again in three weeks. The tracheal and mammary nodes had softened, evacuated and fistulated. The evolution and peculiar appearances of the lesions suggested sporotrichosis. Tubes were inoculated and cultures of the sporotricha were obtained.

Quénu (Rev. de chirurgie Paris, I9I4, XLIX, 585) reports a case that occurred in a woman $5^{8}$ years old.

She complained of a tumor that had been forming in the right breast for six months. It occupied the outer lower quadrant and formed a firm indolent swelling that already increased from the size of a nut to that of a hen's egg. It was irregular and nodular, the skin which was adherent to it had a violet color and the nipple was retracted. The tumor was not separate from the gland and was hard. There were no enlarged lymph nodes in the axilla. A diagnosis of scirrhus was made.

Upon more thoroughly examining the patient, however, it was found that she had a lesion at the right elbow, a little above the epitrochlear region. It was a small firm tumor, slightly elevated, and covered with violet skin that was adherent, and was slightly painful on pressure. This was thought to be gumma about a month old. Further examination revealed another nodule on the back of the level of the inferior angle of the left scapula, and finally, still another lesion on the left huttock, with a central ulceration the size of a dime, and appearing much like a tuberculous ulceration with fistulas.

The patient was very weak and thin. Nine years ago she had left-sided pleurisy that continued for six months and was attended with much pain along the intercostal muscles. Two years ago she spent five days in bed with symptoms of pulmonary congestion. Since recovery from that illness she has never had any pulmonary symptoms. At no time had she any hemoptysis. Physical examination of the lungs at present fails to discover any signs of disease. The family history was negative. Wassermann reaction negative. When the patient was next seen, the center of the mammary lesion had softened. On this account and because of the scattered nature of the lesions, the diagnosis was changed from neoplasm to mycosis, and the mammary lesion was punctured and grayish pus obtained. The cavity was then opened and curetted and a portion of its wall excised. Later the small nodules softened, umbilicated and evacuated.

The patient was treated with potassium iodide, and the smaller lesions all promptly healed and the larger one in the breast greatly improved. 
The pus obtained from the mammary lesion when planted upon glucose agar failed to give a growth of any kind, but a simultaneously made culture upon glycerinized potato gave a culture that corresponded with the description of Sporotricha beurmanii.

These five cases, one in a man, four in women, have in common, the occurrence of multiple lesions, of which some are mammary. They all occur in patients past middle life, and in none is the portal of original entry to be established. In three the mammary lesion was at first mistaken for cancer; in one it was associated with cancer. In all the disease was checked by appropriate treatment.

Diagnosis.-In cases of sporotrichosis with a dermal lesion that is the evident portal of entry, and with multiple secondary lesions appearing in succession and having the characteristic history of appearing as firm painless nodules that grow to a certain size, reach the skin surface, become attached, cause purplish discoloration of the skin followed by softening and ulceration, the diagnosis ought not to offer great difficulty. But in cases in which a considerable sized firm attached swelling appears in the breast without other lesions - which may be possible, though no case is reported-or with other lesions so trivial that the patient may say nothing about them, the diagnosis may present grave difficulties. Naturally the patient finding an increasing firm lump in the breast, fears carcinoma, and the medical adviser is very apt to share her opinion. With our present crude methods of diagnosis it may not be possible to arrive at the truth but a short delay may be followed by the characteristic changes. The node softens, and an exploratory puncture reveals the grayish or grayish-yellow pus in which the sporotricha may be found immediately with the microscope, or in a few days by culture.

In cases with multiple lesions the disease is most ap1 to be mistaken for syphilis but here the history of the case, a negative Wassermann reaction, and the examination of the pus for the sporotricha should enable the proper diagnosis to be made.

Prognosis.-The prognosis of sporotrichosis is good when the proper treatment is instituted. Fortunately, mistakes in diagnosis may not be a serious menace to the patient. If the disease be mistaken for cancer and the breast removed, the patient suffers a useless mutilation, and the disease may break out elsewhere or recur in the wound; if it be mistaken for syphilis and treated accordingly, little harm and much good may result if potassium iodide be employed. Salvarsan and other arsenical compounds may not be beneficial and mischief might follow their unnecessary employment.

Treatment.-In all the cases mentioned above, great benefit or permanent cure followed the use of iodides. The exposed lesions may be locally treated by the applications of Lugol's solution and potassium iodide should be given internally. The protocols of the cases cited show the promptness with which the drug acts, for in two of the cases the lesions entirely disappeared under this treatment in eight days. 


\section{CHAPTER VII}

\section{CYSTS OF THE BREAST}

Cysts are well circumscribed spaces filled with fluid or seml-fluid contents. They are divisible into two groups which Marchand has designated true and false cysts. The former have distinct walls; the latter no distinct walls. The former arise through accumulation of fluids in preformed spaces; the latter through the colliquation or liquefaction of morbid tissue.

The following classification outlines the chief characteristics of the principal forms of cysts:

I. True cysts, having definite circumscribing walls.

A. Arising from Antecedent Normal Structures.

(a) Lined with epithelial cells.

I. Retention cysts-formed through the retention of glandular products through obstruction of the normal outlets.

2. Exudation cysts - formed through the excessive collection of glandular products in ductless glands.

3. Teratoid cysts-formed through the collection of fluid through retention or exudation in abnormal or vestigial structures.

Dermoid cysts.

Tubulo cysts.

(b) Lined with endothelial cells.

I. Exudation cysts caused by excessive collection of fluid in normal serous cavitiesbursæ, etc.

2. Cysts following old hemorrhages and abscesses of the central nervous system, cavities of new formation becoming lined with endothelial cells as the result of regeneration and protection activities.

B. Arising through the Growth of Parasites in the Tissues.

(a) Echinococcus cyst or hydatid cyst.

(b) Cysticcrcus disease.

II. False cysts, having no circumscribing walls.

(a) Suppuration.cysts-old and coid abscess.

(b) Hemorrhagic cysts-following interstitial hemorrhages.

(c) Colliquation cysts resulting from tissue metamorphosis and necrosis.

The cysts of the breast may be of single or multiple occurrence, of varying size and of great diversity of contents, and may arise in various ways from various structures. For purposes of discussion the cysts of the breast may be grouped as follows:

r. Cysts arising from structures in the skin of the breast.

2. Cysts arising in the parenchyma of the breast.

3. Cysts occurring in the stroma of the breast.

4. Cysts occurring in tumors of the breast.

5. Cystic disease of the breast.

I. Cysts Arising from Structures in the Skin of the Breast.-Of these, two are of importance, though rare in occurrence; the sebaceous cyst and the dermoid cyst. In many textbooks, and according to most lecture room teaching, the sebaceous cyst is a retention cyst formed in consequence of the obstruction of the outlet of a sebaceous gland that becomes greatly distended with accumulated secretion, while a dermoid 
cyst is a teratoid inclusion of embryonal skin-forming elements, whose subsequent development results in the formation of a solid tissue that eventually becomes cystic through the collection of secreted and desquamated products of the dermal elements. Teleologically the two are without connection, are in no manner related to one another and should be quickly differentiated both theoretically and practically.

As a matter of fact, however, the relation of the two is so far otherwise as to make it a matter of doubt in the minds of many pathologists whether they are not the same thing-that is, whether the greater number of sebaceous cysts, or in fact all sebaceous cysts are not in reality, dermoids, or vice versa, whether such dermoids as occur in the skin, and sometimes make their appearance in the breast, are dermoids in the accepted sense, or are sebaceous cysts.

Aschoff (Lubarsch and Ostertags Ergebnisse der allg. Path. u. path. Anat., I895, 477) gives the following outline of the cystic diseases of the skin:

I. Simple Epithelial Cysts.-The walls are smooth and lined by a single or multiple layer of squamus epithelium without typical arrangement. They occur through:

(a) Retention of the contents of the normal glandular formations of the skin-hair follicles, sebaceous glands, sweat glands and comprise mileum, comedo, Chiari's follicular cyst, etc.

(b) Neoplasm of the glandular appendages of the skin-syringo-cyst, adenoma, etc.

(c) Embryonal displacement of the epithelium.

(d) Traumatic displacement of the Malpighian layer.

II. Epidermoid Cysts.-These are lined with epithelium usually showing a definite papillary structure and a typical stratum Malpighi. They occur:

(a) From the presence of embryonal germs in the skin, such comprising the greater number of atheromas [in this Aschoff follows Franke and Chiari].

(b) From traumatically displaced fragments of the skin.

III. Dermoid Cysts.-The walls of these are lined with epithelium upon a papillary layer beneath which or in which the appendages of the skin - sebaceous glands, sweat glands and hair follicles -are found. The whole cyst wall resembles the structure of the external skin, parts of it reproduce it. Such tumors originate only through dislocation and isolation of the embryonal germs of the skin.

Aschoff adds that the sharp separation of these groups is not always possible, especially with reference to groups II and III, and here he simply restates the difficulty experienced by Chiari in his endeavors to find out what the atheroma or sebaceous cyst really is.

Chiari (Zeitschrift für Heilkunde, I89ı, XII, r89) found it necessary to include the following under the term atheroma:

r. Retention cysts of the hair follicles and sebaceous glands that lie in the cutis and subcutis and have lost their connection with the surface.

2. Dermoid cysts of the most simple character, like the hair-forming skin dermoids that occur by preference in the fissural regions of the hody.

All this goes to show that it is difficult to determine the nature of such cysts as are termed sebaceous cysts or atheromas and dermoids. There is, in fact, no criterion. The presence of a papillary layer may be observed in each; hairs may occur in both.

Much stress was formerly laid upon the presence of the papillary layer but Aschoff agrees with Unna and Beneke that its presence or absence is no proof, as papillary bodies may appear and disappear, and are therefore very irregular in occurrence in the epidermoid cysts, though constant in dermoid cysts.

It is claimed that the dermoid cysts can be recognized because they begin to form as solid bodies and later become cystic, but the same is undoubtedly true of many 
atheromas, and is one of the arguments used by those desiring to prove that atheromas are in reality dermoids.

To say that the dermoids are congenital and the atheromas acquired affords no aid in their differentiation, for though undoubtedly congenital in occurrence, it is only later in life that the dermoids grow to a size attracting attention, and that the atheroma is not seen until middle life is no proof that its germs have not been present since embryonal life.

But not to prolong this academic discussion unduly, let it be supposed that the dermoid is congenital and does depend upon embryonal inclusion and that the atheroma is acquired through obstruction of glandular outlets.

It is a mistake to suppose the atheroma or sebaceous cyst to depend upon obstruction of the outlet of a sebaceous gland. Were that the case it should be lined with cells like those of the sebaceous glands and filled with sebum, but as a matter of fact both the cyst and its contents are far more complex.

It is well known that the sebaceous glands are in connection with hair follicles into which they open, the two having a common outlet. Should obstruction result from retention of inspissated or pathologically altered sebum, the effect would be to obstruct both the sebaceous gland and the hair follicle, and while dilatation of the former would certainly occur, a dilatation of the latter would also become inevitable and the resulting cyst would consist chiefly of a wall derived from the dilated upper part of the hair follicle. From this origin it is easy to account for th eotherwise difficultly explainable contents of the cyst. If it were formed through dilatation of the sebaceous gland it should contain sebaceous matter only and should be lined by sebaceous gland cells. But as a matter of fact, sebum forms only a small part of the mushy part of the cyst contents, in many of the atheromas is entirely absent, and the cyst wall consists of stratified epithelium. To conceive the cyst to be formed by dilation of the follicles, is to conceive it filled in large part with the lymph (serum) that might easily collect in the follicle, to which is added as much sebaceous and fatty element as the associated glands might furnish, as well as to account for the considerable quantity of squamous epithelium in scales or lamella that can arise from the lining membrane to which such epithelium is normal when derived from the wall of the hair follicle. The occurrence of hairs in the cyst contents, a matter of great surprise when the cyst is supposed to arise from the sebaceous glands, becomes a matter of great simplicity if the cyst arise from the dilated upper part of the follicle, for its wall is then certain to contain the root of at least one hair.

The formation of every cyst is, according to Ribbert, a two-fold process, and results from distention and growth. If he be correct, while the process of distention is in progress, growth is going on in the cyst wall which thus becomes more and more thick and better provided with the foundation areolar and vascular structure that shall nourish the epithelium and eventuate in a papillary layer. As the inner layers of the epithelium arrive at perfection, the cells are shed singly or in groups or layers, and mingle with the contents. Occasionally whole lamina hold together so that a concentric mass composed of concentric layers of epithelial cells is found. As is not uncommon where epithelial cells are thus accumulated, cholesterin platelets are also of ten found.

Such cysts must originate in the derm, and must be primarily superficial. Their subsequent position and appearance will be largely determined by the local conditions to which they are subjected. Thus, in the scalp where most frequent, their descent is quickly checked by the resisting bony cranium, and the enlarging cysts ele- 
vate the tissues and present themselves as hemispherical enlargements. How differently they behave when the subcutaneous tissue has behind it the soft mammary gland with its fatty stroma, is evidenced by their disappearance into its tissue where they are usually felt and not seen. If, however, one arise near the nipple, and have beneath it the fibro-muscular tissues of that vicinity, it may be more easy for it to ascend than to descend and it may make a visible appearance at the surface of the areola.

Great depths in the mammary tissue scarcely seems to be compatible with an origin from the skin, so that such cysts are by common consent regarded as dermoids, though there is no information as to how deeply situated a tumor derived from the derm may become.

Discussion of this subject should not be terminated without a reference to Delbet's explanation that the rarity of dermoid cysts of the breast is to be referred to the comparative lateness of embryonal life, at which the ingrowth of epidermis that is to form the mammary gland takes place.

Having thus shown the difficulty of differentiating between atheroma and dermoid and having failed to find any satisfactory criterion for separating the two, it is not surprising to find that the cases of atheroma and dermoid cyst of the mammary gland that have been recorded in the literature cannot be accurately assorted.

In reviewing the literature, however, one finds that the terms "atheroma" "steatoma," and even "dermoid" are occasionally employed with reference to cysts that have nothing to do with such formations except that they more or less closely resemble them.

In the section upon Cholesteatoma, in the chapter upon "Sarcoma of the Breast" in this book, much space has been devoted to the occurrence of cysts with squamous epithelial linings and concentrically laminated epithelial contents-pearls-suspended in more or less fatty fluid, in cystic tumors of the breast. Such cysts bear a not inconsiderable degree of resemblance to certain of the atheromas and dermoids, though their origin is entirely different. We have found the following cases reported in the literature:

\section{Sebaceous, Atheromatous or Steatomatous Cysts of the Breast}

\footnotetext{
"Balggeschwulst in der Brustdrüse," Med. Ann. Heidelberg, I 835, I, ro3.

Billroth.-Deutsche Chirurgie, XLI, go (reports 2 cases).

BirketT.-Holmes "System of Surgery," r883, III, 460.

BurgGraeVe.-Bull. de la soc. de méd. de Gand., I857, XXIV, 160.

Cruveilhier.-Traité d'anat. pathologique, III, 338 (2 cases).

Fredet.- "Kyste sébacée mammaire," Bull. et mém. de la soc. d'anat. Paris, r9o7, 5 s., IX, 643.

GERDY.- "Kyste sébacée de la mamelle," Bull. et mém. de la soc. d.'anat. de Paris, I852, p. 42.

GuYot.- "Kyste sébacée du sein," Thèse de Paris, 1853, No. rig.

HAEckel.-Beiträge zur Kentnniss der Brustdrüsengeschwülste," Archiv für klin. Chirurgie, r894, XIVIII, 299.

KIEBS.-Handbuch der path. Anatomie, I, 99.

LeBert. - Bull, et mém. de la. soc. d'anat. de Paris, I852, p. 42.

McGee.- "Case of Steatomatous Tumor of the Breast," Dublin Hospital Gazette, I856, III, 358.

Porta.-_"Dei tumori folliculi sebasei," Schmidt's Jahrbücher, r857, XCVI, r 27 (3 cases).

Rodman.--"Diseases of the Breast," Phila., I908, p. 82.

RUSSELL.-Cited by Winckell (Lehrbuch der Frauenkrankheiten, r886, p. 740) as baving seen a case of sebaceous cyst of the mammary areola.

SHeILD, M. A.- "Diseases of the Breast," r898, p. 146 (mentions 2 cases).

TYrRell.- "Sebaceous Tumors of the Breast," Proc. Pathological Society of Dublin, r $865-68$, n.s., iii, 347 .

Velpeat.—"Traité des maladies du sein," p. 3r4 (mentions the case of Guyot, vide supra).
} 


\section{Dermoid CYSTS OF THE BREAST}

ALbERs.-(Dermoid cyst of the breast) Atlas d. path. Anat., Erlaüterung, III, 589 .

Bloodgood.- "Benign and Malignant Cystic Tumors of the Female Breast," Bulletin of the Johns Hopkins Hospital, I907, XVIII, 139 (reports 6 cases).

Herrmann, K.- "Über einen Fall von Dermoidcyste in der rechten Mamma einer 66 jährige Frau," Prager med. Wochenschrift, $\mathrm{x} 890, \mathrm{XV}, 547$.

IsraEL, E.- "Demonstration einer Dermatoidcyste der Mamma," Berliner klinische Wochenschrift, rgO4, XLI, 289.

KaUfMann.- "Carcinomatöse entartete geschlossene Dermatoidcyste in der Mamma, neben Carcinoma der Mamma selbst," Jahresberichte der schlesigen Gesellschaft für vaterländischer Kultur, 1894, Breslau, I895, LXXII, Abt. med., Sect. 56.

Lannelongue et Achard.-Traité des Kystes Congénitaux."

LAUnAy ÉT FERRAN.—- "Kyste dermöid de la region mammaire," Bull. et mém. de la soc. d'anat. de Paris, rgrr, LXXXVI, 263.

MANLEy, T. H.-"Some Tumors of the Breast Which Were Not Carcinoma," American Journal of Surgery and Gynecology, Ig04, XVII, No. 8, p. 135 .

REVERdin et MAYER.-“"Tumeurs associées du sein; kyste dermöide et fibromes multiples; suppuration du kyste," Rev. méd. de la Suisse Romande. Genève, r887, VII, 96.

WALTHER.- "Kyste dermöide inclus dans un adèno-fibrome du sein droit," Bull. et mém. soc. de chirurgie de Paris, rgro, n.s., XXXVI, p. $\mathrm{r}_{55}$.

Williams.-Hunterian Museum. Pathological Catalogue, Appendix, r887, p. 5, No. 256 of the pathological series.

WiLliams.-Hunterian Museum Pathological Catalogue, Appendix, r887, No. 235 of the Pathological Series. See "Diseases of the Breast," p. 5r4.

These references have enabled us to examine in more or less detail 37 cysts, of which I9 were described as sebaceous cysts, atheromas, or steatomas, and I8 as dermoid cysts. Many of the writings were of no value for purposes of analysis or classification, thus Bloodgood, whose experience seems to have been unique, simply states:

"I have observed five benign and one malignant tumor of this cbaracter (dermoids) so situated subcutaneously in the breast that they had all the appearance of primary breast tumor. In the benign dermoids the wall was thin and was easily enucleated and the contents typical of dermoid. In the malignant tumor the wall was thick ( 3 by $5 \mathrm{~mm}$.), not easily separated from the surrounding tissue and on section it had the appearance of carcinoma. The contents, however, did not differ from that of benign tumor."

With six cases to study it is a pity that Bloodgood did not publish the details and explain why he regarded the tumors as dermoids.

Another unique experience was that of Manley who removed what he calls a dermoid cyst from each breast of a woman 47 years of age, and another from the left breast of a woman aged $4 \mathrm{r}$ years. He gives no description whatever of the tumors or cysts, but simply says "dermoid cysts."

Some publications with titles suggesting the presence of such cysts as are under discussion proved, upon examination, to deal with cysts or tumors of entirely different character, as, for example:

BRANDEIs.- "Évolution sebacée de l'acinus au cours de l'épithéliomatose intracanaliculaire du sein," Compt. rendu de la soc. de biol. de Paris, Igr2, LXXII, 47 r.

CRISPIN.- "Stratified Squamous Epithelium on a Cyst of the Breast," Bull. of the Ayer Clinical Laboratory of the Pennsylvania Hospital, Phila., r907, No. 4, p. 26.

ChrLius, N. J.- "Steatom der Brustdrüse," Heidelberger Klink., r828, V, 517.

SchUн.-"Steatoma utriusque mammæ," Allg. Wiener med. Zeitung, 1867, XII, 28. 
Burkitt's patient was a man. He says:

"We have seen a sebaceous cyst developed close to the nipple and elevating it, and so closely resembling the bluish tint of a tuber of cancer, just about to ulcerate, as to excite grave apprehension; but it was excised with the happiest result."

Both of the specimens mentioned by Williams as being preserved in the Hunterian Museum are also taken from the breasts of men. Concerning No. $256 \mathrm{~B}$. of the pathological series, the catalogue of the Museum says:

"A dermoid cyst measuring 3 inches in its long diameter, and flattened from side to side. The specimen was removed from the mammary region of a man aged 40 , where it was situated just above the left nipple. He had noticed the swelling there for 15 years. At the same time that the cyst was removed a smaller one of similar nature was also extirpated from the right infra-scapular region. About ro years previously other similar cysts, first noticed at the age of $\mathrm{I} 6$ and 20 had been removed, one from over the vertebra prominens, and another from the scalp."

Concerning No. 235 of the pathological series, Hunter has given the following:

"An encysted tumor taken from the breast, of Mr. Waters, filled with a flaky substance, which seemed to be a succession of cuticles, being the same with that which lines it."

To these cases collected from the literature, we add one of our own removed from a patient in the German Hospital of Philadelphia.

The patient was a woman aged 65 years who had a painful nodule in the right breast. It had been observed a year before as a cherry-stone sized formation situated close to the right sternal border, on the level of the nipple. The patient had experienced pain, sometimes of fulminating character, for about one month before coming under observation. At the time of operation, the growth, that had once become as large as a hickory nut, had diminished a little in size.

With these three exceptions, all of the collected cases were in the breasts of women. The youngest patient whose age is given was Cruveilhier's, aged 26 years, the oldest was Hermann's aged 66 years. The shortest period during which the presence of the cyst was recognized is stated as six months; the longest period I9 years. Of the reported cases, the side is stated in only nine. Of these the cyst was on the left side in eight, on the right side in one.

The largest uncomplicated cyst was in Herrmann's patient and is said to have been the size of a man's fist. The usual size seems to be about that of a walnut or a hen's egg. The greater number of the patients suffered from pain which is sometimes said to be "a sense of discomfort," sometimes to have been "lancinating." It was .on account of the pain that attention was usually called to the morbid growth. In some cases, the nodule was known to have been present in the breast for years before any pain was experienced.

The general symptomatology resembled that of benign tumors. The breast contained a somewhat superficially situated, more or less rounded, rather soft (occasionally plastic) movable, insensitive node; the axillary lymphatic nodes were not enlarged. In a few cases a dark point was observed on the surface, and as in Cruveilhier's case, was thought to be the obstructed outlet of the gland (sebaceous cyst). The skin was usually normal and free, but sometimes, as in the case of Launay and Ferran, it was red and adherent. In that case the cyst was mistaken for chronic mammary abscess. In Tyrrell's case the cyst was unattached to the skin, but firmly attached to the gland behind.

In a few cases the diagnosis was made before operation, by examination of the 
contents obtained by puncturing the growth with a hollow needle, but in most cases it was made subsequently through examination of the contents of the cysts.

The contents were most varied, and when arraigned in ascending series consist of serum, fatty matter, white of egg and cholesterin, serum containing fatty matter and crystals, "white serous fluid with grumous flakes," "great quantities of epithelium," "white flaky substance which seemed to be a succession of cuticles, being the same with that which lines it."

It is interesting to observe that there is not a single recorded mention of the presence of hairs of any kind in any one of these cysts, though hairs are commonly looked upon as characteristic of dermoid cysts, and numerous fine hairs are common in the greasy contents of sebaceous cysts on other parts of the body.

With the exception of the case reported by Launay and Ferran, which consisted of a central cyst surrounded by six smaller ones, two of the latter communicating with the former, and which is described as a "multilocular cyst," all of the described cysts were single and simple. The walls varied in thickness: if they were thin and transparent, the cysts were described as sebaceous; if thick and fibrous, they were more apt to be called dermoid.

Many of the cases were submitted to careful microscopic examination, but as the microscopy has been carefully dwelt upon in the general considerations, with which this section opened, it is unnecessary to give further details.

The treatment of these cysts varied with their size. When small, they were usually enucleated; when large, as in Herrmann's case, the breast was amputated. This seems to be good practice. When the diagnosis can be made before the time of the operation, the breast should be saved. There is no case reported in which subsequent trouble arose after the removal of either a sebaceous or a dermoid cyst.

II. Cysts Arising in the Parenchyma of the Breast.-For convenience of description and consideration these may be grouped as follows:

I. Cysts depending upon the accumulation and retention of the normal or modified products of secretion in the larger ducts (galactocele or lacteal cyst).

2. Cysts depending upon the accumulation of abnormal products, usually having nothing to do with secretion, in the larger ducts (simple cyst or serous cyst).

3. Cysts depending upon the accumulation of abnormal products, having nothing to do with secretion, in the smaller ducts and acini (cystic disease; chronic cystic mastitis; abnormal involution, etc.).

4. Papillary cysts.

I. Cysts Depending upon the Accumulation and Detention of the Normal or Modified Product of Secretion in the Larger Ducts of the Breast.-Galactocele.-Such comprise the group commonly known as galactoceles or lacteal cysts, and are true retention cysts. The introduction of the term galactocele is credited by Abell, who gives no reference to the original text, to De Lambell ( 1845 ) who defines galactocele as "a form of tumor which springs from one of the milk ducts forming a cyst." The two criteria for their formation are, that the gland shall have been secreting at the time of formation, and that a duct shall have become obstructed prior to or at the same time.

The best monograph upon the subject, and that which the interested reader should peruse is by Nordmann, "Über die Galactocele," Virchow's Archiv, I897, CXLVII, 475.

In our section describing the physiology of the breast it has been shown that milk secretion is possible in both male and female breasts, under a variety of conditions. 
Naturally as milk secretion is normal to the female breast only, and only during the period of lactation, it is to be expected that galactoceles shall be most frequent in the breasts of.women and shall appear sooner or later after lactation has begun, though the possibility of their occurrence under other circumstances is to be kept in mind.

According to the requirements of the accepted definition, the galactocele must contain milk, but the term milk, as here used, means mammary secretion, and one need only glance at a few of the published descriptions to find that the contents of galactoceles differ greatly in different cases. This is only to be expected if one considers what milk is, and what conditions obtain in galactoceles. Milk is water, containing casein, sugar, fat and some salts. Though the proportions of these ingredients maintains an average that is looked upon as the standard of normality, there are variations in different individuals and at different periods of activity. Thus, during pregnancy the process of secretion begins, and up to a day or two after confinement, consists of a moderate quantity of a thin and watery product known as colostrum. This is followed by an abundant quantity of rich milk that in the course of a period varying in different cases, increases in quantity but commonly declines in quality.

Considering galactoceles of early formation, it is conceivable that they may be filled with a thin fluid analogous to the

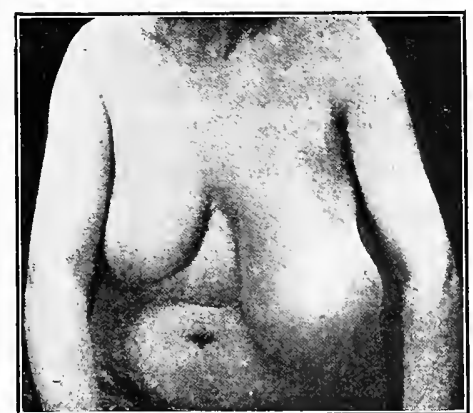

FIG. II 4.-Galactocele. (Rubesch.) colostrum, or with milk of varying richness.

Supposing such a cyst filled with normal milk-i.e., having the standard composition - can its contents remain indefinitely unchanged? In a few cases they appear to do so; thus in Scarpa's case, milk must have been added continuously for a long time in order that the ro pounds it contained could accumulate. In other cases, however, it seems clear that changes have taken place. One must not be too hasty, however, in concluding that the contents of a galactocele necessarily have undergone great change. Even during the period of its greatest activity pathological mammary tissue may not functionate normally, and the mammary tissue whose duct is closed can scarcely be regarded as normal. There may be, therefore, abnormalities and disproportions of the component ingredients of the secretion, of which the most frequent seems to be an excess of fat, or deficiency of water, by which the contents of the cyst become creamy or buttery. It has been suggested that the absorption of the water from the secretion is responsible for the creamy or buttery transformation of the contents, but should such absorption of water take place and the remaining fatty matter thereby become condensed, the loss of water should be accompanied by shrinking of the cyst, which has never been observed, all observed galactoceles tending to progressive increase in size. It is, therefore, probably nearer the truth to suppose that the creamy and buttery contents result from the primary secretion of an excess of fat and deficiency of water.

In case of reversal of the process and the secretion of water without the normal proportion of fat, the contents must be correspondingly watery. Under the conditions, casein may be present in solution, or may be coagulated into flakes, or perhaps through some modification be the source of the "white-of-egg"-like material that has 
been pointed out. When the formation of the galactocele takes place through secretory processes occurring under abnormal conditions, as in the male breasts, or in the breast of the aged, it is not surprising that the products of abnormal activity should differ materially from the normal secretion of the normal gland, the primary variation corresponding to the abnormality of the secretory function. But that changes occur in the cyst contents, after they have been collected seems patent from a knowledge of what goes on in the way of physico-chemical processes generally. It is, however, difficult to follow them in detail.

If the divisions into which Velpeau divides galactoceles,

r. Infiltrating galactoceles in which the milk diffuses into the mammary tissue;

2. Fluid galactoceles in which the milk in a fluid state is inclosed in a circumscribed space; and

3. Solid galactoceles in which a firm tissue is formed through collections of solid ingredients of the milk,

hold good, it is easy to imagine that in the first, the water of the diffused milk would be drained away through the lymphatics of the breast, leaving the solid to remain, and so explaining some of the tumors as grouped here.

By far the greater number of galactoceles are single cysts, a few of them, like those of Forget, Nordmann and Rubesch, however, were multilocular and consisted of a large cyst, about which were smaller ones, forming pockets, some of which had very slender communications with the major cyst, and which, in Forget's case, were entirely separate and independent.

The size of the cysts varied greatly; that described by Scarpa contained Io pounds and reached to the thigh of the seated patient; Da Costa's was the size of a cocoanut; Nordman's was the size of a child's head; Clutton's contained a pint of fluid; Diriat's was as large as a fetal head; Rubesh's cyst was as large as a man's head; the greater number were smaller and some no larger than a hen's egg.

The galactocele is a comparatively rare form of cyst. The references to the literature at the end of this section have enabled us to collect about $7 \circ$ cases for analysis and consideration. Of these the side on which the cyst occurred is given in only 42 cases, of which 27 were in the left, and ${ }_{5}$ in the right breast. The disease, therefore, seems to occur almost twice as frequently in the left breast, as in the right.

The youngest patient to suffer from galactocele was Cattani's, a child of I 4 months. Its breast contained a cyst out of which $30 \mathrm{cc}$. of milk were evacuated. The youngest adult patients were Gould's, aged i 8 years, and one of Perker's, aged 20 years; the oldest, Bouchacourt's, aged 5 r, unless we include Velpeau's somewhat doubtful case in a man of 75 years. In general, the period of formation corresponds with the reproductive age, as might be expected. The earliest to form after lactation set in seems to be Rubesch's case in which the cyst was discovered four days after lactation had begun. Sheild saw a case that had existed for I 8 years. Da Costa says that if the galactocele from which his patient suffered began during pregnancy or lactation, she never noticed it, but supposed that it began about six years later.

The general symptomatology of the disease is usually fairly definite. At some time, varying from a few days to many years, after the occurrence of lactation, an asymmetrical painless enlargement of the breast is observed. Upon investigation it usually is found to be a somewhat irregular, soft, fluctuating, semi-fluctuating or plastic formation. It is free of attachment to the skin above or to the fascia behind. The skin may show enlarged veins, as in solid tumors. There are no enlarged axillary lymphatic nodes. 
A needle or trocar introduced, enables the investigator to discover milk, cream, buttery matter, curdy fluid, or matter like "white-of-egg," and sometimes permits him to empty the cavity, after which the breast collapses. In many cases one or two tappings have resulted in the complete disappearance of the cyst. In other cases drainage was practised, with subsequent cure. Not infrequently the cyst has been dissected out, leaving the breast undisturbed; in a few cases it was deemed necessary to amputate the breast. In cases in which the cyst was opened under conditions that permitted careful observation, and the removal of the contents enabled the wall to be examined, it was usually found to be more or less regularly rounded in shape, lined with a smooth shining membrane, which is the reinforced duct of one of the lobes of the gland. Section of a healthy part shows columnar epithelium that may have undergone some modification of shape. In most cases the cyst is partly divided by trabeculæ that consist partly of the glandular, partly of the fibrillar tissue of the breast. In rare cases papillary formations have been found to grow from the cyst wall of the cavity. In some cases the effects of the pressure and other circumstances attending the disease have caused ulceration of the cyst walls with structural defects that may explain why the contents of the cyst should be bloodmixed (chocolate-colored fluid) and, also, how some of the contents may infiltrate the breast tissue. In these cases, as well as in cases associated with infection and in cases in which the cyst contents were chemically irritating, the walls may be infiltrated with lymphocytes and contain foreign-body giant cells in considerable areas. In some casesNordmann, Rubesch - there were tumor growths in proximity to the cysts. Attention to the importance of this will be given below.

The origin of the galactocele is obscure. From all that has been said it seems clear that the formation of the cyst follows closure or obliteration of the mouth of one or more milk ducts. Experimental proof of this, however, is lacking. Thus, when the milk ducts of the mammary gland of a bitch are ligated, no cystic distention occurs. However, this may depend upon some difference in the freedom of the lymphatic circulation in human and canine animals.

When we examine the reported cases for possible causes, some interesting facts bearing upon the etiology are brought to light, as are also some interesting theories. Both of Jewell's cases are of interest. In one the patient, having stopped nursing, applied a breast pump, when "something like a thread" came out of one of the ducts in the nipple. In the other case a lady, about two weeks after the birth of the second child, complained of pain in one breast, which upon examination was found to have one of the lactiferous ducts of the corresponding lobe of the gland distended and very hard to the touch. The nature of the case was apparent. The orifice of the duct which had become covered by a thin pellicle was distended by accumulated secretion. Upon rupturing the bleb with the point of a needle, creamy fluid could be pressed from the nipple at the duct orifice, and the pain promptly ceased and the swelling disappeared. In neither of these cases was true galactocele induced, but it is interesting to note that in the former "something like a thread" could be present in a duct, and in the latter that the epiderm could close the duct orifice. In the latter case, however, there was pain, which is rare in galactocele.

Scarpa looked upon the flaccidity of the milk ducts as predisposing to their rupture and the consequent formation of galactocele. It seems as though such rupture should be followed by extravasation of the milk into the breast tissue, not by collection of the milk in the ducts. Such would naturally correspond to Velpeau's "diffuse galactocele," but there seems to be no reported cases of this type of cyst. 
Cooper, Forget, Jewett, Saltzmann and others observed the occurrence of galactocele after mastitis, and it is self-evident that in recovering from that disease some of the ducts might be closed so that upon subsequent activity of the gland, the fluid must collect because of inability to escape. Traumatism was known to precede the formation of galactoceles in the cases reported by Velpeau, Bouchacourt, Puech, Gilette and Gould. How the trauma acts is not known, but it is easy to imagine that the organization processes that follow interstitial hemorrhage, or the rupture of the ducts that thereby become permanently closed when the breast is inactive, may be responsible for the later cystic change.

Reference has already been made to the associated presence of galactocele with fibro-epithelial tumors-Nordmann and Rubesch.

The examination of many portions cut from all the denser parts of many slightly diseased breasts has shown us that minute nodes of peri-ductal fibroma are of occasional occurrence in breasts in which they are not suspected. Such nodes, as well as larger tumors of similar kind, may be causes of galactocele formation by kinking and compressing the ducts, and perhaps serve to explain a number of the remaining cases.

The presence of galactocele is injurious to the breast in proportion to the size and density of the cyst, and the length of time it is present. Women with galactoceles rarely nurse their children from the breast of the affected side. However, there are exceptions, and if the cyst be removed or emptied, the normal function may continue. Thus Abell's patient, who suffered from a galactocele that began one week after confinement and in nine months attained the size of an orange, nursed her baby from both breasts, was able to continue the function without interruption, even though he operated, elevated the breast and dissected out the cyst from behind.- In the course of years the increasing size of the cyst and the compression of the tumor may result in the complete disappearance of the mammary tissue. Da Costa, whose patient suffered from a cyst as large as a cocoanut, filled with a grayish-yellow mass of the consistence of butter, says that "microscopically there was no breast tissue remaining." A rare form of galactocele occurs in the axilla. It is to be referred to secretory activity of axillary mammary glands without ducts or with closed ducts. Several such are described by Williams in his "Diseases of the Breast," p. 67-68.

Treatment.-Galactoceles of small or moderate size should be excised, preferably after the plastic resection method, as advised by Warren. Large galactoceles which have caused the major part of the mammary parenchyma to atrophy as the result of pressure demand simple amputation of the breast. Simple incision with evacuation of the contents and subsequent packing of the cyst cavity should not be employed. This is likewise true of the puncture method with the introduction into the cyst of irritating fluids, in the attempt to bring about obliteration of the sac through an inflammatory reaction. These methods are obsolete, and in every way inferior to a clean dissection with primary closure of the wound.

\section{Literature upon Galactocele}

ABELL.-_"Galactocele," American Practitioner and News, Louisville, I9Io, XLIV, 4I $z$. Alexandroff.- "Zur Casuistik der Milchcysten."

AtleE.-The American Journal of the Medical Sciences, I874, LXVII, 4 rg.

Barrier.-Gazette des Hôpitaux, 1850, No. 23.

BEAMish.- "Notes on a Case of Galactocele," British Medical Journal, I884, 7 ז 2. 
BIRKett, JohN.- "Diseases of the Breast," London, r850, p. r98. "Guy's Hospital Reports," I86r, 3s., VII, 344. "Holme's System of Surgery," 3d Edition, r883, III, 448.

Bouchacourt.- "Du galactocele et de son traitement," Gazette medicale de Lyon, 1857 .

Bryant.- "Diseases of the Breast," I887, p. 3 IO.

Cattani.-Annali di ostetrica, ii, Nos. 7 and 8 . Consult Virchow-Hirsch Jahresberichten, 1880 , ii, 569 .

CHADWICk.-American Journal of Obstetrics, I875, viii.

Ciurton, H. H.-“"Galactocèle," St. Thomas Hospital Reports (I879), r88o, n.s., X, 65-

COOPer, Sir Astiey.-Illustrations of "Diseases of the Breast," I 829 .

Cruveilhier. - "Traité d'ana tomie pathologique," Paris, I856, III, 376.

Da Costa, J. Chalmers.- "Lacteal Cyst of the Breast," Annals of Surgery, rgiz, LVIII, ${ }_{42} 8$.

Diriat.- "Galactocèle ou kyste laiteux," Bull. et.mém. de la Soc. d'Anat. de Paris, I895, LXX, 630.

Dupurtren.- "Diagnostic différentielle des tumeurs du sein," Berard, Thèse de Paris, 1842, Gazette hebdomadaire, I829, IV, 227.

FORGET.- "Considérations practiques sur le galactocèle mammaire ou tumeur laiteuse du sein et son traitement," Bulletin générale de thérapeutique, I844, p. 355 ; 1845, p. 34.

Gillette.-Kyste crémeux de la mamelle gauche, L'Union medicale, 1878, Nos. 7I, 72, 75.

Gross, S. W.- "Tumors of the Mammary Gland," p. I94.

Gould, Pearce.-The Lancet, London, I880, ii, 850.

Hasrmton. - "Lacteal Tumour," Dublin Hospital Gazette, I860.

Hugurer.-Bulletins et mémoirs de la Societé de Chirurgie de Paris, i $8_{5}$ I, i, r 19 I.

Jewetr, C.—"A Case of Galactocele," Proc. Med. Soc. County Kings, Brooklyn, N. Y., I883-84, viii, I5I.

JoBerT. 一Vide Forget.

KEHRER.- "Handbuch der Geburtshülfe," Stuttgart, I889, III, 487.

KLotz.-Archives für klin. Chir., r88o, XXV, 47 .

Korteweg.- "Galaktokele hei Mastitis," Nederl. tijdschr. v. Geneeskunde, I89o, No. ro; vide Centralbl. f. Gynäkologie, r89i, No. 49 .

Lroyd.-The Lancet, London, XV, p. 249.

MARSDen.-The Lancet, London, I872, ii, 335 .

Matrakowski.-Torbiel maslowa wsuter, Gazeta lekarska, No. x I, vide Virchow-Hirsch Jahreshericht, I886, II, 4I4.

von Mioorhor.-Vide Schmidt's Jahrbücher, 1877 , CLXXXVI, 194.

Morestin.- "Galactocèle," Bull. et mém. de la Soc. d'Anat. de Paris, r9o7, LXXXII, 40.

Nordmann, A.- "Über die Galactocele," Virchow's Archiv, r897, CXIVII, 475.

Pandurang.- "Milky Cyst or Galactocele," India Medical Gazette, r86g.

PARKer, R.--"Gal actocele; Puncture; Cure," Medical Times and Gazette, London, r882, ii, 2 rr.

PARKer, R.- "A Case of Galactocele," Brit. Med. Journal, I908, i, II 73.

Parker, Willard, - "Notes on Clinical Lectures," New York Medical Gazette, I842, ii, I8.

PEUCH.-Moniteur des Sciences médicales, 1860 .

Rodman.- "Diseases of the Breast," Phila., r 908, pp. 76 and 77 .

Rubesch, R.--"Zur Kenntniss der Galaktokele," Prager med. Wochenschrift, rgo5, XXX, 40.

Scanzont.- "Lehrbuch der Krankheiten der weiblichen Sexualorgane," Wien, I857, 53 I.

SCARPA.-Beohachtungen der K.K. medizinisch-chirurgischen Josephsacademie zu Wien, r8or, Bd. I; also "Opusculi di chirurgia, Pavia", I 825 , II, I 83 .

SaIxzmann.- "Ett fall'of galactocele," Linska läk handl., XXVI, 409 , vide Virchow-Hirsch Jahresberichten, i $885, \mathrm{ii}, 389$.

SCHREger.-Medicinisch-chirurgische Wahrnehmungen, in Horn's Archiv für medicinische Erfahrungen, I8ro, p. 217.

von Sreboid, C. Th_-Berliner medizinische Zeitung, г8 38 , vi.

Sheild, A. M.- "Cysts of the Breast," The Clinical Journal, London, Dec. 16, I896, p. r 24. " "Diseases of the Breast," I 898 , p. 294.

Sourt.-Translation of Chelin's "Fandbook of Surgery," London, 1846, ii, $789-790$.

TrIBES.-- "Tumeur butyreuse du sein," Montpellier med., r860.

Veipead.- "Tumeurs laiteuses ou galactocèles," Gazette hebdomadaire, 1853, pp. 72, 122. "Traité du Maladies du sein," 1858, p. 360; 693. Gazette medicale de Lyon, I850, p. 9.

Waldenström.-Upsala Läkaref. Förk., I 874-5, X, 425; Virchow-Hirsch Jahresberichte, I875, ii, 444.

Williams.- "Diseases of the Breast," I894, p. 496. University College Hospital Reports, I884, p. 5r; I888, p. $76 \pi$. 
2. Cysts Depending upon the Accumulation of Abnormal Products, Usually Having Nothing to do with Secretion, in the Larger Ducts.-Simple Cyst or Serous Cyst.These cysts are extremely perplexing and paradoxical. They make their appearance in breasts that are not, and sometimes never have been, called upon to perform secretory function, and in which no indication of secretory activity is apparent. For this reason it seems that the fluid accumulation is independent of secretory activity properly so called. They may also occur without obstruction of the ducts, so that they do not properly fall within the group of retention cysts. They occur in the breasts of both sexes, and at ages varying from infancy to 75 years. They are undoubtedly much more frequent in occurrence than the published records show, yet are doubtless rare. We have been unable to assemble more than two dozen reported cases for analysis. Of these it is interesting to note that the youngest (Parson's case) was a child of three years in whose left breast the formation of a morbid growth had been under observation for

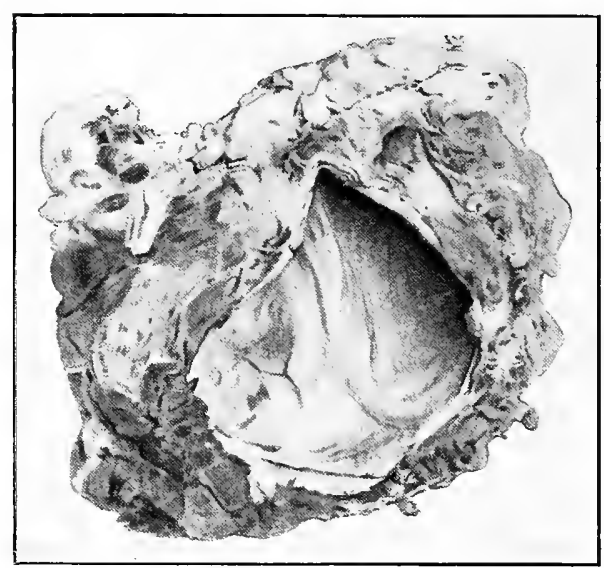

FIG. II 5.-Simple (benign) cyst of the breast. From a specimen in the Laboratory of Surgical Pathology, Medical School of the University of Pennsylvania. r 8 months. It grew slowly without pain or discharge from the nipple, until it became as large as a hen's egg. It was then removed and found to be a cyst filled with clear fluid and lined with a smooth membrane. The next youngest patient was a boy aged $\mathrm{r} 5$ years. It is also interesting to note that this was the largest cyst of the kind on record, being the size of a child's head. The youngest female patient was $r 8$ years of age, and had not yet menstruated when the cyst appeared; the oldest female patient was 67 years of age, unmarried, and had not observed the tumor until $\mathrm{I}_{4}$ months before, when she met with an injury. The average of $\mathrm{r} 7 \mathrm{pa}-$ tients whose ages were given was 44 years, and in not one of them was any connection between antecedent lactation or secretory activity and the formation of the cyst pointed out. Of $\mathrm{r}_{5}$ cases in which it was stated in which breast the cyst occurred, seven were in the right and eight in the left side.

The largest cyst in the female breast seems to be that of von Dumreicher, and contained $500 \mathrm{cc}$. of fluid. Bryant reports a cyst the size of a Tangerine orange, and Sheild one the size of a "small orange." Most 'of them were the size of hens' eggs or walnuts. The duration is usually stated to be "a few months." In one of Sheild's cases it is stated that there was a "tumor in the left breast for an indefinite time."

The cysts presented themselves as "lumps" in the breast. In one case the discovery was made "accidentally." In seven out of 20 cases there was tenderness, aching or pain to direct attention to the breast. Two of the cases were suppurating and may not have been previously painful, so that some kind of pain may have occurred only in onefourth of the uncomplicated cysts.

The "lumps" were usually rounded, sometimes nodular; they were sometimes very 
hard, sometimes soft and fluctuating. Fluctuation was naturally not easy to elicit in cysts that were neither large nor superficial. One large superficial cyst is said to have been "translucent like a hydrocele." The "]umps" were usually movable, unattached to the skin or deeper structures, but occasionally, through inflammatory disturbance, they became adherent. There was no discoloration of the skin as a rule; Williams observed reddening of the skin in one of his cases, but in this case there had been inflammation and the skin was adherent to the cyst. The nipples were normal except in the case of Williams, just mentioned, when they were congenitally retracted. The lymphatic nodes were never affected.

The clinical diagnosis was usually correctly made when the cysts were superficial or large, but when deeply situated they were frequently mistaken for benign tumors or for cancers. In a number of cases puncture of the cyst was performed for the purpose of diagnosis. In a number of other cases the diagnosis was made during the operation for removal of the tumor or after the removal of the breast.

The appearance of the cyst when opened varied according to existing and previous conditions. In the most simple forms the wall of the cyst was thin, smooth and shining. In other cases it was thick, tough and fibrous and intimately attached to the surrounding mammary tissue, to the skin above it or to the pectoral fascia below. In a few cases papillary excrescence grew from the walls into the cysts.

The contents varied somewhat. The $500 \mathrm{cc}$. of fluid removed from the cyst reported by von Dumreicher is said to have been "stringy yellow fluid." Among eight cases described by Sheild the contents are variously stated to have been "turbid fluid," "glairy mucoid fluid," "serous fluid," "clear fluid," "reddish fluid," and "yellowish fluid." In no case is the fluid milky, creamy, buttery or fatty as in the galactoceles. The presence of the cyst in otherwise normal breast tissue is less frequently noted than occurrence with other smaller cysts. In the case reported by Verneuil there were four large cysts beneath the nipple, which compressed and displaced the gland tissue. The largest of these was the size of an egg, the others the size of nuts; there were also numerous small cysts the size of peas around them. This case suggests "cystic disease," but it is particularly stated that the breast tissue elsewhere was normal.

The general tendency of these cysts seems to be to persist and increase, though in a few cases they behave differently. Thus Bryant has reported two cases in which the cysts, having been present for some months, entirely disappeared without treatment, and some have fluctuated in size from time to time.

One of the most interesting peculiarities of these cysts is that the ducts may undergo the dilatation without being obstructed. Prior to the formation and discovery of the cyst, the patient has been known to have had occasional serous discharge from the nipple. It is said by Sheild that "occasionally the obstruction of the duct seems to yield, and an escape of yellowish or brownish fluid takes place from the nipple; the cyst fills again, to be again emptied by the same process, and firm pressure upon such a mammary cyst may readily cause some exudation from the nipple. Indeed, cysts have been dissected out in which a bristle can be passed from one of the main ducts into the interior." He pictures such a bristle passing through the nipple and along one of the ducts into a cyst, from a specimen in the museum of St. George's Hospital.

The etiology of the simple serous cyst is difficult to understand. How can a cyst be formed where there is no obstruction of the duct to retain it, and no secretion to be retained? Such cysts cannot be retention cysts, but must be exudation cysts. They seem to have nothing to do with secretion, but to depend upon exudation, and are 
related to the cystic formations that take place in epithelial-lined vestigial structures, such as the thyro-lingual ducts, paroöphoron and urachus. Instead of embryonal vestigial structures, however, we are dealing with galactophorous ducts, that is all.

But to point out this analogy is of little value if the cause of the exudation cannot be found. What is it? Here it is necessary to depart from fact and enter upon theory in order to come to reasonable conclusions. An examination of the conditions under which exudation into joints, bursæ and other closed cavities takes place shows that traumatism and infection are the common causes. The conditions leading to cystic dilatation of closed epithelial cavities are less easy to determine. Vestiges of Pfliger's tubes are not infrequently discovered as a matter of surprise in normal appearing ovaries, and of the paroöphoron in normal appearing broad ligaments. They have undoubtedly been present and changed very little since embryonal life, yet in either case it is well known that such vestiges may form the starting point of large cysts or cystic tumors through exudation and growth.

It is well known that the mammary gland when active may eliminate bacteria from the blood; it is also known that bacteria may enter the galactophorous ducts from the surface of the skin.

Putting all this together, we may conclude that when the ducts of the mammary gland are chemically irritated through the presence of bacteria of feeble virulence derived from the blood of the patient or admitted from the skin, or when they are disturbed by mild traumatic injury, exudate may accumulate and distend them at a time when their walls lack the normal resisting force and yield to the pressure of the accumulating fluid. In this manner the cystic dilatation may take place whether the duct be open or closed and the retention or expression of the fluid may be a matter of balance between the pressure of the fluid upon the tissue or the tissue upon the fluid. Naturally, if the cause of irritation has previously closed the duct, as it commonly seems to do, the opportunity for cyst formation is greatly facilitated. The same irritant that provokes the fluid accumulation may also excite the growth of connective tissue round about the lining membrane of the duct and so form the fibrous layer of the cyst wall. When such reënforcement takes place, the further growth of the cyst is made increasingly difficult, and it is usually in the cysts with the toughest walls that the fluid is found to be under the greatest pressure.

The clinical irritant, whether microörganismal or otherwise (and we found no references to cysts of the mamma that had been bacteriologically examined), that excites the process varies in injurious property, hence the varying structure and contents of the cyst, whose walls vary in thickness and whose contents are sometimes puriform.

Treatment.-The majority of simple cysts can be excised; certain large ones demand amputation of the breast. Incision and drainage, as well as puncture with the instillation of irritating fluids, are obsolete methods that should not be employed.

Literature upon Simple Cyst or Serous Cyst

Bryant.--Medico-Chirurgical Transactions, XIX.

Bryant.- "On Cysts of the Breast, Their Relation, Frequency, Diagnosis and Treatment," The Lancet, London, Apr. 28, I900.

von Dumreicher.-Vide Fischer, Zeitschrift für Wundärzte und Geburtshülfer, I882; XXXIII 223. Kammerer, F. W.- "Cysts of the Mammæ in Males," Annals of Surgery, r894, XIX, 87.

MalHerbe.- "Note sur deux cas de kystes simples de la mamelle," Gaz. méd. de Nantes, i882-83, i, 779 . Parsons.-British Medical Journal, Apr. 29, I896.

Pilliet et Vaudremer.- "Kyste essentiel du sein," Bull. et mém. de la Soc. d'Anat. de Paris, is92, LXVII, 790. 
SHEILD, A. M.- "Disease of the Breast," r898, 227; 239 et seq.

SEeILd, A. M.-Clinical Journal, London, I896-97, IX, r9.

Velpeau.-Le Progres médical, March, r886.

WILliairs, J. A.-Cited by Williams, W. R., "Diseases of the Breast," r894, p. 513.

Williass, WV. R.- "Diseases of the Breast," r894, p. $494 ; 5$ r4.

To this collection of cases from the literature we add the following case operated upon by Dr. Deaver in the German Hospital of Philadelphia:

D. M., a woman aged 43 years, married 22 years and the mother of two children, accidentally dis. covered a "lump" in her right breast, a month before coming under observation. She had never suffered from any pain, nor had any difference in the size of the breasts been previously observed. Upon examination after admission to the hospital, a freely movable lump the size of a goose egg was found in the right breast above the nipple and toward the sternum. It proved to be a single cyst filled with a dirty greenish fluid, surrounded by adipose tissue.

\section{CANCER CYSTS OF THE BREAST}

Bloodgood (Jour. Amer. Med. Asso., I909, LIII, I475) has aroused considerable interest in what he describes as "cancer cysts." The name is scarcely justified pathologically, as no particular kind of cyst is indicated. Cancer and cysts may occur in relation to one another in two ways: First, both morbid conditions occurring in the same breast and in close juxtaposition to one another, the cancer invades the wall of the existing cyst and forms a projecting reddish, more or less polypoid excrescence from its wall. Second, a small cancer, by obstructing and irritating a duct, may occasion the formation of a cyst, in the wall of which it subsequently appears. Doubtless the latter was the explanation of the case reported by Nepveu, of "Epithéliom très petit compliquant un kyste volumineux de la mamelle" (Gaz. med. de Paris, r882, 6s., IV, 48). Cysts associated with cancer are recognized by Bloodgood through their sanious contents, and through the presence of the reddened excrescence that grows out from the wall. Simple cysts rarely have sanious contents and any papillary excrescences from the walls are usually devoid of hemorrhagic infiltration. Further information regarding these cysts can be found in writings by Speese (Annals of Surgery, February, I910, p. 51; New York Medical Journal, Feb. 22, 1908, p. 97).

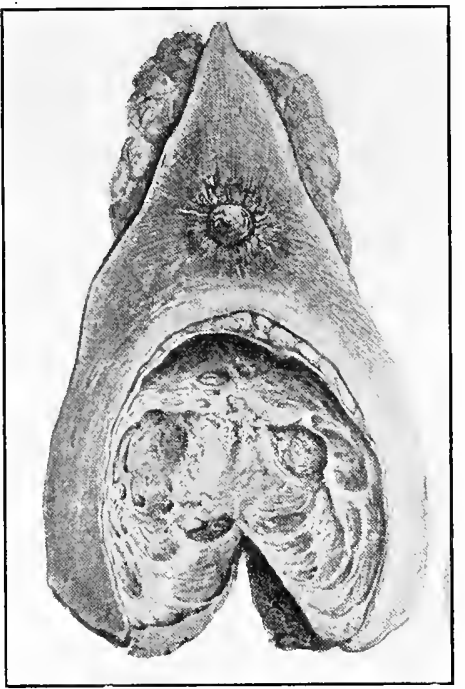

FIG. rr6-Carcinomatous cyst of the breast, showing the reticulated interior like a cardiac ventricle. From a specimen in the museum of St. George's Hospital. (Sheild.)

3. Cysts Depending upon the Accumulation of Abnormal Products, Usually Having Nothing to do with Secretion, in the Smaller Ducts and Acini.-Cystic Disease of the Breast; Cystic Mastitis; Chronic Cystic Mastitis; Maladie de Reclus; Brodie's Disease; Cystadenoma; Abnormal Involution, etc., etc. 


\section{CYSTIC DISEASE OF THE BREAST-ABNORMAL INVOLUTION; MALADIE DE RECLUS; CHRONIC CYSTIC MASTITIS; BRODIE'S DISEASE OR CYSTADENOMA}

If one read the older writings upon diseases of the breast he cannot fail to be astonished at the frequent mention of "hydatid cysts" and "echinococcus cysts" as compared with the writings of the present day. Abernethy, Bell, Cooper and other writers of their time supposed cysts of the breast to be "hydatids." Later writers, among whom are Brodie, Paget and Virchow, believed the cysts to be formed through obstruction of the ducts, and called them "retention cysts." After Leuckart showed the echinococcus or hydatid cysts to be embryo flat worms, they ceased to be mentioned among the diseases of the breast except as very rare occurrences. Still, though not "hydatids," cysts of the breast were of common occurrence, excited interest and had to be accounted for.

The first important studies of cystic diseases of the breast appear to have been made by Sir Benjamin Brodie, who in his "Lectures on Pathology and Surgery," London, I846, p. I37, writes as follows: "The disease of which I propose to treat on the present occasion, is an affection of the female breast. It is one of great interest in various ways, and among others in this: that in its more advanced stages, although it is not really of a malignant nature, it is liable to be confounded with carcinoma. I have not met with any description of it in books corresponding to what I have myself observed of its actual progress. You will presently see that this is easily to be explained by the disease assuming a wholly new character as it proceeds, so that if you were to look at two cases of it, one in an early, and the other in a more advanced stage, without having witnessed the intermediate changes which have taken place, you would be scarcely able to recognize their identity. Let me not, however, be misunderstood as representing that no notice whatever has been taken of this disease by surgical writers. The account which Sir Astley Cooper has given of the hydatid breast has been taken principally from cases of this kind, and there are also some allusions to it in the "Treatise on Disease of the Breast," lately published by M. Velpeau.

"The first perceptible indication of the disease is a globular tumour embedded in the glandular structure of the breast, and to a certain extent movable underneath the skin. Sometimes there is only one such tumor; at other times there are two or three or many more. The examination of the breast in the living person does not enable you to determine the exact number which exist, as it is only where they have attained a certain magnitude that they are perceptible through the skin. In most instances the disease is confined to one breast, though it is by no. means very uncommon for both breasts to be similarly affected.

"The globular form which the tumor invariably assumes in the first instance, is a sufficient proof that it is formed of fluid collected in a cyst, and of course pressing equally in every direction. If you puncture the tumor with a grooved needle, the fluid may be evacuated so as completely to empty the cyst, and the perfect subsidence of it afterwards proves how little space the cyst itself occupies. The fluid is always serous. When the tumor is small it seems to be serum, unmixed with anything else. In a more advanced stage of the disease, some coloring matter is generally blended with it, and it may be green, or brown, or so dark-colored as to be almost black. The quantity of fluid of course varies. In dissection, I have sometimes found the cyst to be so small 
as to contain scarcely a single drop. But in a more advanced stage it is capable of containing several ounces. In two cases, in each of which I had the opportunity of dissecting a breast affected with this disease, I found small cysts, composed of a thin membrane, and containing serum, pervading the whole of the glandular structure, the intermediate parts of the breast presenting a perfectly healthy and natural appearance; and I could discover nothing more. There seems to be little doubt that the cysts are originally formed by a dilatation of the lactiferous tubes. In one of the preparations now on the table, you will perceive a bristle introduced into the orifice of one of these tubes opening on the nipple, which has passed into a cyst immediately below; and it is not uncommon to find that by pressure on the tumor the fluid may be made to escape by the nipple, so that you may even expel the whole of it.

"To complete the history of the disease, as it first shows itself, I may add that the general health is unaffected, and that the patient complains of no pain, unless it be that, in some instances, there are those disagreeable nervous sensations that are apt to arise whenever the attention is anxiously directed to any one part of the body. I have never known the disease to occur previously to the age of puberty; it is rare after the middle period of life, and I am inclined to.believe it is more common in single than in married women."

Reclus (Gazette des Hôpitaux, 1887 , p. 673) came to the conclusion that the cysts were the result of epithelial proliferations similar to those occurring in carcinoma, followed by secondary degeneration of the accumulated cells and the conisequent formation of the cysts. He called the process intra-acinous cystic epithelioma, but later writers of his own nationality named it after him-_"Maladie de Reclus." The same disease has been made the subject of study in other countries, and from many publications we now derive a complicated nomenclature and an unfortunate confusion of ideas. Upon reviewing this literature, we find the following terminology to harmonize:

Chronic cirrhosing mastitis.-Billroth, "Deutsche Chirurgie," I880, XLI, "Krankheiten der Brustdrüse."

Polycystadenoma mammæ.-Brissaud, Archiv de Physiol. et Pathologie, 1884, III.

$\left.\begin{array}{l}\text { Intra-acinous cystic epithelioma } \\ \text { Maladie Kystique de la Mamelle }\end{array}\right\}$ Reclus, Gazette des Hôpitaux, r887, p. 637 .

Cystic disease of the breast

Chronic interstitial mastitis $\}$ Bryant, "Diseases of the Breast," London, I887.

Cystadenoma.-Schimmelbusch, Archiv für klinische Chirurgie, I892, XLIV, Ir 7 .

Chronic cystic mastitis.-König, Centralblatt für Chirurgie, 1893, 49.

Peri-ductal mastitis.-Delbet, Bull. soc. d'anat. Paris, January, 1893 .

Polycystoma

Polycystoma epithelial Sasse, Archiv für klin. Chirurgie, r897, LIV, i.

Plexiform fibroma.-Binaud et Braquehaye, "Traité de chirurgie," Le Dentu et Delbet, Paris, r899, VII.

Cystoma.-Tietze, Deutsche Zeitschrift für Chirurgie, rgoo, LVI, 5 r 2.

Maladie noueuse.-Phocas, Report of the XIV Congress of French Surgeons, Paris, rgor, p. 470.

Diffuse fibro-adenoma.-Wood, Medical News, 1904, p. 294.

Senile atypical parenchymatous hypertrophy.-Bloodgood, Surgery, Gynecology and Obstetrics, rgo6, III, 721; Journal of the American Medical Association, r904, XIIII, Aug. 6, p. 367 .

Fibrous and glandular hypertrophy with retention cysts.-Whitney (cited by Warren).

Abnormal involution.-Warren, Jour. Amer. Med. Asso., r905, XIV, r6o.

Cystic mamma.--Lichtenhahn, Deutsche Zeitschrift für Chirurgie, r907, XC, 507.

In addition the following names are also used, though it is difficult to determine the source from which they emanate: Maladie de Reclus; Maladie kystique; Schimmelbusch's disease; Involution cysts (Gross?).

So it appears that the literature contains at least two dozen complex technical terms, 
descriptive or eponymic in character, that have apparently been applied to the same condition, or to different stages or conditions of the same general process.

We prefer the name "abnormal involution" as that which most clearly expresses the origin and nature of the process. The term was introduced by Warren in his comprehensive paper, in the Journal of the American Medical Association, r905, XLV, r49, which gives an excellent synopsis of the literature and early views upon the subject.

When the above-given synonomy is examined it becomes clear that there are at least three theories of the nature of the disease to consider.

\section{Abnormal Involution is an Inflammatory Disturbance.-}

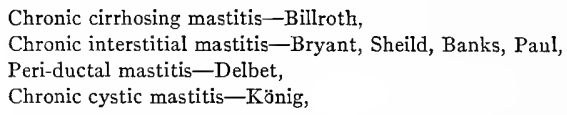

are terms that make it clear that the early writers supposed inflammatory disturbances to be at the foundation of the disturbance.

The evidences in support of this theory are partly clinical and partly pathological.

A. Clinical Evidences.-The breasts that are the seat of the disturbance are commonly painful and may show localized or generalized enlargement. The pain may be slight or severe. If the patient has not yet reached the climacteric, it may occur or augment with each recurrence of the menstrual flow. The breast may be slightly sensitive upon pressure, and serous fluid, sometimes with a milky, sometimes with a bloody quality, may escape from the nipple, either spontaneously or when the breast is compressed.

B. Pathological Evidences.-Examination of the breast with the naked eye shows, among other things, a varying degree of induration, and the presence of one or more small cysts.

Microscopic examination shows more or less lymphocytic infiltration of the periductal tissue, and disturbance of the inter-lobular stroma, which is of ten composed of dense collagenous fibers and is not infrequently hyaline.

The evidences against the theory are as follows:

A. Clinical Evidences.--Swelling, tenderness, pain and fluid upon pressure are not necessarily inflammatory phenomena, as they universally accompany those conditions of the mammary tissue characterized by growth and activity of the parenchymapuberty hypertrophy, lactation hypertrophy, etc.

B. Pathological Evidences.- The lymphocytic infiltration of the peri-ductal connective tissue is invariable in involution after lactation, and occurs to a moderate degree in senile involution. The dense inter-lobular tissue shows no increase of fibroblasts. The presence of real foci of inflammation, shown either by leucocytic collections when acute, or by fibroblastic proliferation when chronic, is rare and probably incidental.

It seems as though the supporters of the inflammatory theory of the origin and nature of the process had not made a very clear and convincing case.

\section{Abnormal Involution is a Neoplasmic Process.-}

Papillary epithelioma-Cornil,

Intra-acinous cystic epithelioma-Reclus,

Cystadenoma-Schimmelbusch, von Saar,

Polycystoma

$\begin{aligned} & \text { Polycystoma } \\ & \text { Polycystoma epitheliale }\end{aligned}$
Polycystadenoma mamma-Brissaud, 
Diffuse fibro-adenoma-Wood,

Cystoma-Tietze,

Plexiform fibroma-Binaud et Braquehaye,

Adeno-cystoma papilliferum mammæ epitheliale-Lesle,

Cystadenoma intra-canaliculare,

Intra-cystic epithelioma,

Cystadenoma papilliferum,

Cystosarcoma phyllodes,

are all names showing that many authors have looked upon the disturbance as a form of tumor.

There is no tumor in abnormal involution. If this statement be true, how can it have come about that men of such distinction as those whose names appear above can be found to support the neoplasmic nature of the process. The fundamental idea seems to be that the breast tissue behaves like tumor tissue and may become transformed into tumor. Thus, in the opinion of Reclus, the epithelium of the ductules of the breast assume a rapid growth, distend the duct, push aside the surrounding tissue and form a cellular mass of considerable size, to suffer subsequent retrogressive and degenerative changes by which the cells later disappear, leaving the space filled with the fluid products of the degeneration. Such changes occurring simultaneously or successively in many parts of the breast, soon riddle its tissue with cystic spaces of all sizes and in all stages of cell proliferation and degeneration. This appeared to Reclus to be a process more or less the counterpart of what takes place in cancer, and connected the two in his mind. That the cysts in abnormal involution are occasional seats of papillary excrescence doubtless led others to conclude that such processes were inherent in the morbid process, and again connected the disease with tumor, in their minds. Finally, the fact that abnormal involution and cancer commonly coexist in the same breast has led many to believe that the former is the beginning of the latter. But in the great majority of cases, regardless of the particular changes shown by the breast, there is no tumor and nothing distinctly like a tumor. The changes may be localized or widely distributed throughout the breast, or not infrequently throughout both breasts, and it seems an error to classify them as neoplasmic.

\section{Abnormal Involution is a Perversion of Involution.-}

Involution cysts-Gross,

Abnormal involution-Warren,

Fibrous and glandular hypertrophy with retention cysts-Whitney,

Senile atypical parenchymatous hypertrophy-Bloodgood,

These names suggest that the disease is referable to disturbances of evolution and involution in the mammary tissue, which theory accords with our own view of the subject. The breast tissue is restless; it is acted upon by a variety of agencies (hormones, etc.), is stimulated to grow or its growth inhibited according to circumstances known or unknown. The result is disturbance of structure and function, whose extreme departures from the normal constitute abnormal involution and are supposed to prepare the way for, if not directly lead into, the epithelial invasion of the malignant character that we know as cancer. There is no inflammation, or any coexisting inflammation is incidental and accidental. There is no tumor, or if there be, it is either incidental, papillary formations in the cysts, or consequential, cancer.

Symptomatology.- The patients come under observation either because they experience pain or find "lumps" in the breasts, or perhaps, more rarely, because there is a discharge of fluid, sometimes serous, sometimes milky, rarely bloody, from the nipple. 
The breast or breasts may be slightly but uniformly increased in size, or there may be a localized swelling in one or both. Sometimes the swollen part is slightly tender. Palpation sometimes reveals a vague lump or induration that may be felt only with the fingers, at other times with the flat of the hand. It is sometimes called a "vanishing tumor." When such a lump is large, it may be movable, elastic and even fluctuating, and can be recognized as a cyst. If the breast be compressed the larger cysts can sometimes be made to appear upon the surface as rounded eminences. They do not give the impression of being indurations of breast tissue, usually being more smooth, rounded and elastic. If, however, a differential diagnosis between the "lumps" resulting from the presence of cysts and the "lumps" of carcinoma could always be made, the diagnosis would be greatly simplified. It must frankly be admitted that it is not always possible to make the diagnosis, and many cases are operated upon with an erroneous diagnosis of cancer, to have the true nature of the process discovered later.

The lymph nodes in the axillæ are not infrequently enlarged so as to be palpable. Microscopic examination shows the enlargement to depend upon endothelial hyperplasia.

Morbid Anatomy.-Among the 575 breast cases forming the basis of our pathological studies, there were I 48 that were finally called "abnormal involution." They were gathered from various hospitals and from the clinics of various surgeons. Many of them were removed for suspected carcinoma, and subsequently found to be abnormal involution. They were examined in the laboratory either by making a series of parallel incisions from the posterior surface to the skin, and thus opening the organ like the leaves of a book, or, as has proven to be a rather better plan, by incisions radiating from the center of the organ. The microscopic examinations were at first made by excising and examining a single fragment of tissue from the least normal appearing area, but with increasing experience an increasing number of fragments was removed, until at present no breast is considered thoroughly examined, unless a half dozen blocks of tissue from as many different areas are sectioned and studied.

According to the gross appearance, breasts surgically removed in what is supposed to be the incipient stage of cancer or in pre-cancerous conditions may be grouped as follows:

A. Cases showing symmetrical arrangement of the mammary tissue, quite normal in appearance, without any distinct corpus mammæ. (Normal inactive breasts.)

B. Cases in which there was symmetrical arrangement of the mammary tissue, with a distinct corpus mammæ of uniform structure. From some of these cases, all parts of the mammary tissue yielded a creamy fluid when compressed. (Normal breasts in incomplete involution after lactation.)

C. Cases in which the mammary tissue, soft in consistency and white in color, formed a kind of symmetrical reticulum throughout a large amount of adipose tissue. Some of these cases showed nodular fatty deposits-lipomatoid in character. (Adipose or lipomatoid breasts, otherwise normal.)

D. Cases in which the breast is small and firm, without much adipose tissue, in which the mammary tissue is white, soft and elastic, symmetrically disposed, but in which there are single or multiple cysts no larger than a pin's head, with smooth shining walls and clear fluid contents. (Senile involution.)

E. Cases in which the tissue of the breast is of greater density, and lacking in uniformity. One or more localized areas, rather more dense than the remainder and having a mottled gray and pink color, may show a group of closely approximated cysts of pin-head size or a little larger. (Abnormal involution of ectatic type.)

F. Breasts of similar general appearance to those of Group E, but in which in addition to the tiny cysts there may be one or more cysts the size of peas or even of marbles, with smooth and shining walls, and clear or slightly turbid contents. (Abnormal involution of the ectatic type, more advanced in development.)

G. Cases in which a fairly normal appearing breast contains a single cyst, as large as a walnut, surrounded by a somewhat indurated area. Such a cyst has a smooth wall and its contents may be clear or clouded fluid. (Simple cyst.) 
H. Cases in which the breasts are firm, showing small cysts in a normally disposed parenchyma, but in addition a number of distributed shot- or pea-sized cysts filled with smoky, greenish or dark brown fluid or jelly-like material. (Schimmelbusch's disease.)

I. Cases in which at some part, usually the edge, of an otherwise slightly changed breast there is a firm mass of uncircumscribed character that is mottled white, pink, gray and yellow, in which is a cluster of tiny cysts with red or red-brown contents. (Abnormal involution with probable adeno-cystic change.)

J. Cases containing cysts, like those of $F$, from the walls of which papillary excrescences grow as little eminences, sometimes barely visible, sometimes larger, and sometimes large enough to fill the cyst. Such papillary formations may be found in only one cyst, or in every cyst. (Ectatic abnormal involution with early intra-cystic papilloma.)

$\mathrm{K}$. Cases with cysts, single or multiple, containing papillary excrescences, among which some are dark-colored and surrounded by bloody fluid. It may be possible to demonstrate twists or kinks in the pedicles of the papillæ. (Intra-cystic papilloma with passive hyperemia and hemorrhage.)

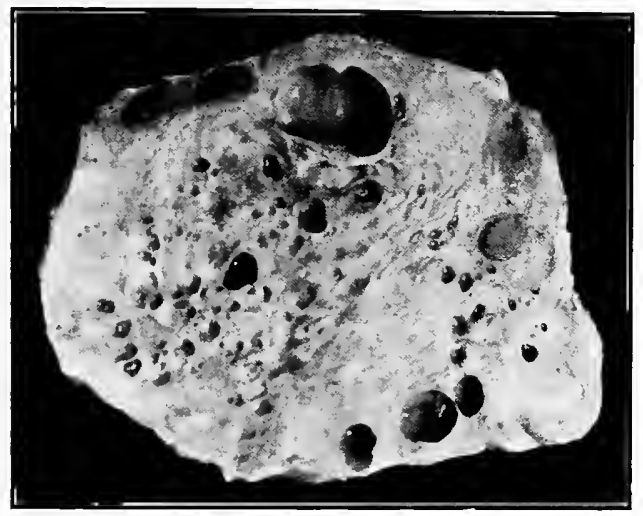

FIG. II7.-Section of a breast showing well-marked "cystic disease" or abnormal involution. This breast also contained a small cancer nodule, but it is not shown. The diameter of the upper and largest cyst was a little over one inch.

L. Cases like K, but in which the papillæ are adherent to the cyst wall, whose tissue is thick, firm, variegated in color, and distinctly abnormal. (Intra-cystic papilloma with carcinomatous invasion of the cyst wall.)

M. Cases in which the breast appears normal but upon section contains lobules of the parenchyma abnormally visible because of their large size, firm texture and peculiar light brown color. (The nature of this condition is not known. It is looked upon as an individual peculiarity.)

N. Cases of any type mentioned, in which are found a mass, sometimes no larger than a pea, sometimes as large as a walnut, in which the tissue is entirely unlike the normal, being firm and cicatricial in texture, slightly striated or radiated in the fibrillar arrangement, impressing one as having a "drawn" or contracted quality, and of a variegated white, gray and buff color. (Carcinoma.)

The microscope being requisitioned to aid us, we find the breasts in group A show every indication of being normal breasts; those of group B, normal lactating breasts; those of group $\mathrm{C}$, breasts in the normal senile involution, and group $\mathrm{N}$, breasts in which cancer is present. With the exception of group $\mathrm{M}$, all of the remaining breasts contain cysts as the chief evidence of disease. Abnormal involution is a cystic disease. It is important, therefore, to pay strict attention to the cysts.

When we consider the cysts, apart from other changes that may be present, we and it possible to arrange them in series in such manner as to indicate that they are 
probably but different stages of the same process or, at least, that they are very closely connected:

D. Pin-head-sized cysts, single or multiple, scattered through the breast.

E. Pin-head-sized cysts collected into groups.

F. Pea- or marble-sized cysts with smooth shining walls and clear or slightly turbid contents.

G. Single large cysts, sometimes as large as a ben's egg, with smooth walls and clear or slightly turbid contents.

H. Pea- or marble-sized cysts containing dark or chocolate-colored thick fluid.

I. Pin-head- or pea-sized cysts in groups, filled with red viscid fluid.

J. Cysts with excrescences growing from the wall.

$\mathrm{K}$. Cysts of large size with large excrescences whose kinked or twisted pedicles cause the fluid to become bloody and some of the excrescences themselves dark purple or brown.

L. Cysts with papillary excrescences that have adhered to the cyst wall, and whose substance is apparently invading the nearby tissue.

Microscopy.-Warren (Jour. Amer. Med. Assn., I905, XLV, I60) says that the changes of abnormal involution are cystic and proliferative. Of the proliferative group of changes he makes three subdivisions according to the degree and character of the epithelial growth:

r. Proliferation of the acini-an apparent increase of acini in the lobules.

2. Papillary outgrowths of epithelium into the cysts-epithelial cells beaped up and projecting into the cyst cavity, without a connective tissue pedicle or support.

3. Adenomatous proliferation of the epithelium in the cysts-a condition resulting from the meeting of papillary outgrowths from different parts of the cyst wall, which fuse together in such manner as to give a microscopic picture of a space filled with epithelial cells in which, here and there, an open gland lumen is observed. This change is of greatest interest because it is chiefly in its presence that the combination of abnormal involution and carcinoma is observed. Warren observed I5 cases among $5 \mathrm{I} 7$ cases of cancer of the breast.

Bloodgood (Surgery, Gynecology and Obstetrics, I906, III, 72I) gives three stages of the process as well-characterized:

I. The adenomatous, in which there is proliferation of acini, and which probably corresponds with Warren's first stage.

2. The ectatic stage, in which the ductules dilate more and more, and the epithelial lining disappears.

3. The adeno-cystic, in which the cysts are always small, and lined by modified epithelium that tends to proliferate, as in Warren's divisions 2 and 3.

- Microscopic examination of our sections from breasts from cases called "abnormal involution" reveals the following histological features:

\section{Changes in the Connective Tissues.-}

I. Atrophic.-A. Loss of the differentiation hetween the inter-lobular and peri-ductal tissues, by which the latter gradually disappear and the glandular elements come to lie in an undifferentiated connective tissue.

2. Hypertrophic.-A. Increase in the volume of peri-ductal tissue, in indefinitely circumscribed areas, which at certain foci may be so marked as to resemble peri-ductal fibroma except that it is not circumscribed or encapsulated. In some cases the peri-ductal tissue trespasses upon the ductules; resemblance to intra-canalicular fibroma may be observed.

B. Inequality in the arrangement and distribution of the elastica of the peri-ductal tissue, so that some ductules may entirely lack it while others may be surrounded by dense rinds of it. Victor Bonney thought loss of elastic tissue to he an important step in the inception of abnormal involution, but there is no regularity about it, and von Saar seems to have been the first to show that it is apt to be locally increased. It will be remembered that the elastica normally varies, and that it disappears during lactation hypertrophy.

C. Increase in quantity and alteration in quality of the inter-lohular connective tissue. The quality 
was altered either througb marked coarseness of the collagenous fibrillar tissue or througb its byaline transformation.

3. Inflammatory.-Iymphocytic infiltration of the peri-ductal tissue was not infrequent. It was most pronounced in those cases in which secretion was present in the alveoli or ducts, and the number of lymphocytes in the peri-ductal tissue is in proportion to the quantity of secretion they contained.

II. Changes in the Parenchyma or Epithelial Tissues.-

r. Atrophic.-The alveoli become smaller and smaller, the basement membrane and basket cells disappear or can no longer be defined, and the secreting cells after becoming unrecognizable, except by their position, slowly disappear. This atrophy is not uniform, but affects the alveoli of the lobules one after the other. If the atrophy of the parenchyma of a Iobule is fairly complete, before the peri-ductal tissue blends with the inter-lobular tissue, the waning lobule may appear as a small fibrous node.

2. Cystic.-In addition to cysts easily seen by the naked eye, there are minute cysts less than a millimeter in diameter. Many of these appear in process of formation, and it seems as though what is seen

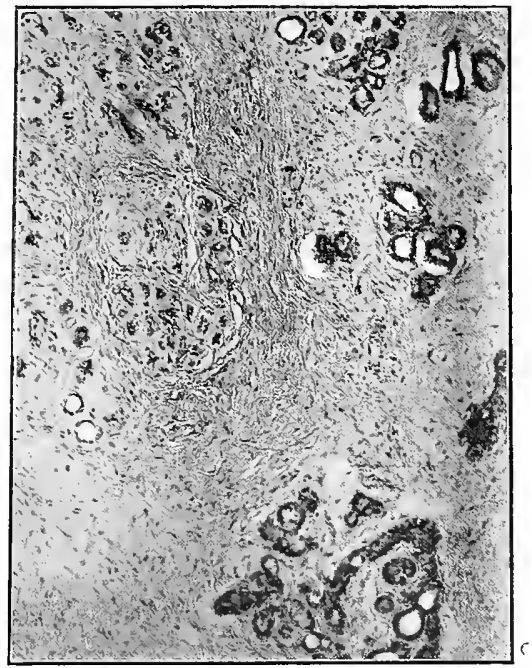

Fig. II 8.-Abnormal involution of the breast showing an atrophic lobule on the left, and dilated and proliferating acini on the rigbt. The lower right-band area suggests carcinomatous change, but there was no cancer.

with the aid of the microscope ought to explain the beginning and occurrence of the visible cysts. One receives the impression that distending influences descending from the larger tubules were impressing the ductules of the lobules, and effecting dilatation of the alveoli. In thick sections it is easy to see that the radicles of a dilated duct are dilating, and that as the dilatation reaches the alveoli, their distention causes traction on the walls, diminishes the inter-lobular partitions, and effects coalescence of closely connected alveoli until a space with a puckered wall is formed, the corrugations in which consist of the remains of inter-alveolar septæ. Later these disappear and a smooth-walled cyst is found. It seems probable that these occur in systems of ducts, as the dilatations are apt to occur in groups, otber lobules being undistended. Small cysts usually have smooth walls with a single layer of cuboidal epithelial cells. Large cysts, such as are readily visible to the naked eye, may lack any epithelial lining. The peri-ductal tissue suffers extinction by distention in cyst formation. Dense elastic tissue sometimes forms about distended ducts and may prevent cysts from forming.

3. Hypertrophic or Proliferative.-A. MacCarty's "primary epithelial hyperplasia." This is a peculiar separation of the epithelium of the alveoli and ductules into two layers. The inner, which is 
supposed to represent the true secretory cells, is composed of a single layer of crowded, compressed, small-sized cells with dark appearance because of the relative poverty of cytoplasm they show, and an outer layer of much larger cells with cytoplasm whose appearance suggests distention with large vacuoles. What this condition signifies is not known. It was not common in the breasts studied by us, but when present was usually widespread. Its presence seemed to be entirely irrespective of what other changes were present in the tissue. We are rather inclined to believe that it is a nutritive disturbance or an artefact, and not a part of involution or of abnormal involution.

B. The A ppearance of Pale Epithelium.- "Blasse Epithelzellen" were first pointed out by Borst and Wohlsecker, the former of whom looked upon them as true carcinoma cells. They appear to arise through multiplication of the lining cells of the minute cysts, and sooner or later completely fill and distend them. It may have been these cells that were seen by Creighton and led him to conclude that aberrant sweat glands were sometimes present in the breast and formed the common starting point of cancer ("Cancers and Other Tumors of the Breast; Researches Showing their True Seat and Cause,"

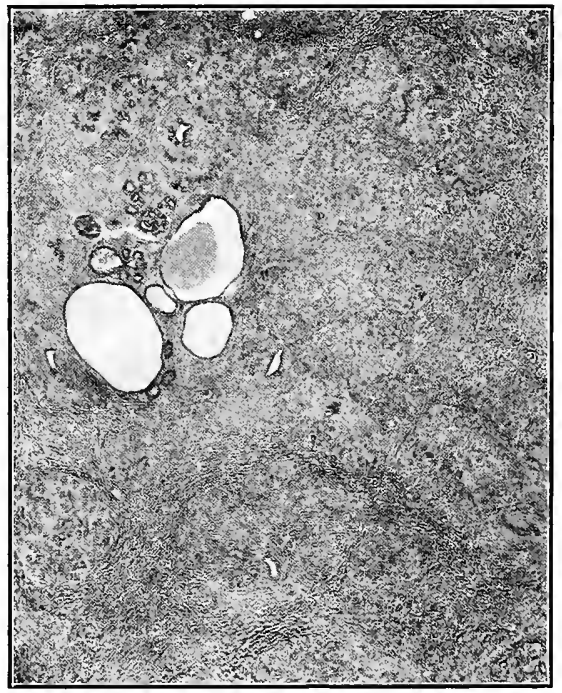

FIG. II 9.-Group of small cysts in an early case of abnormal involution. Shown under very low magnification.

London, I902); von Saar (Ergebnisse d. Chirurgie und Orthopædie, Igro, 4II) also pointed out an analogy between these cells and those of the sweat glands, and Krompecher (Verhandl. d. deutsch. path. Gesellschaft, Jena, I9I3, XVI, 365) holdly declared that sweat-gland cysts were present, at times, in the breast, proving it to his own satisfaction by demonstrating the presence of considerable unstriated muscle tissue beneath the epithelium. Anyone reading his contribution and examining the illustrations if at all familiar with the histology of the morbid breast, cannot fail to see the resemblance between what he describes and what is at present under discussion. Large collections of these cells sometimes, appear closely packed together in circumscribed spaces in certain areas of badly diseased breasts, each space perfectly circumscribed by connective tissue that can be regarded as the walls of previously formed cysts that the cells have filled, or the future walls of cysts that may be formed when the cells degenerate. The cells are unlike the normal cells of the breast parenchyma in being large, having abundant clear cytoplasm, vesicular nuclei, and columnar form. When packed closely in the dilated spaces they become polyhedral, the nuclei become small and shrunken, and they show a marked tendency to undergo colliquation. There is no demonstrable basement membrane where they occur, yet they are never found invading the tissue. They are totally different in appearance from carcinoma cells which have less cytoplasm, 
and larger, darker staining nuclei. These cells have been studied with particular attention by von Saar, Thiele, Kuru, Müller and others, all of whom vigorously oppose Borst's idea that they are the starting point of carcinoma, and point out, as we have done, that they differ essentially, in appearance, from carcinoma cells and that no intermediate steps between them and carcinoma cells can be found. Kuru recognized them in fibro-epithelial tumors, and frequently found them in the mammary glands of children. They have also been observed in sweat glands. von Saar thinks that they arise through simple benign proliferation and agrees with Thiele in believing that they differ from the normal epithelium only in having a greater vegetative activity and a shorter life duration. They probably comprise the greater number of cells with which the smaller cysts are filled in Schimmelbusch's disease or maladie de Reclus, but which later melt away to cause the turbid and dark-colored contents of the cysts. In our cases of associated abnormal involution and cancer, these cells were present to form numerous large or smaller

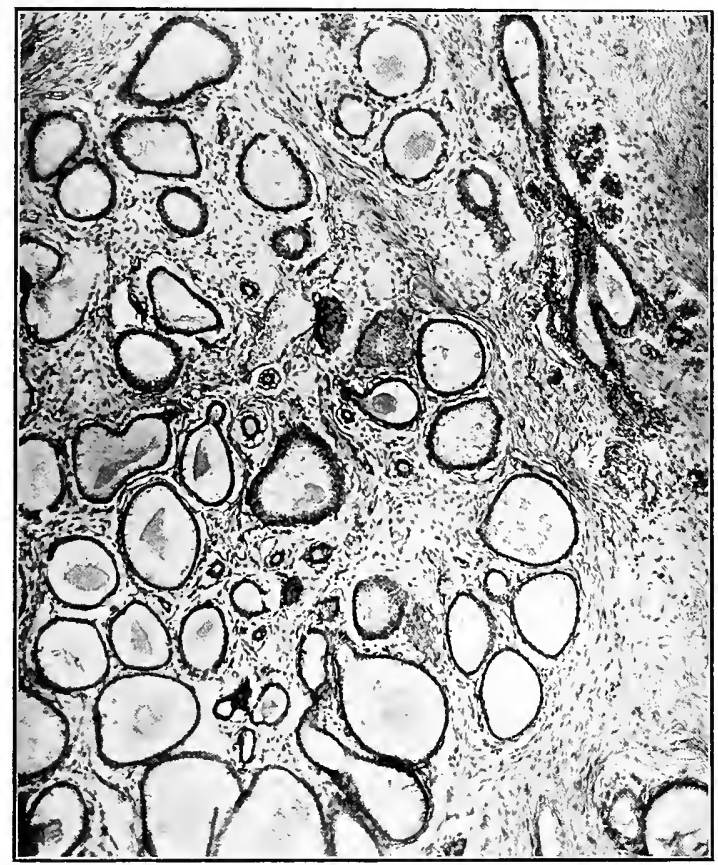

FIG. I 20.--A group of dilated alveoli in a case of well-marked "abnormal involution" of the breast.

rounded circumscribed masses some of which were in close juxtaposition to the carcinoma cells, or in some cases even invaded by them, but the difference between them and the carcinoma cells was usually striking.

C. Alveolar Sprouts and Buds.-Many of our sections showed appearances closely resembling evolutional or developmental processes such as are universal in the breast at puberty. They consist of groups of cells, forming striking objects that at once arrest the eye when the section is examined beneath the microscope. Each group is obviously a bud or sprout from the glandular tissue, and the groups occur in collections that suggest an effort at lobule formation. Each bud is a clavate or flask-shaped termination of parenchymatous tissue, formed of a solid mass of cells, the outer of which stand regularly upon the subjacent connective tissue, without any defnite basement membrane, the inner being massed together without a lumen. The close packing together of the cells makes the buds appear quite dark 
in ordinary stained specimens. In rare instances, large buds may have a small central lumen, and in more rare instances the center of the largest of such formations has so large a lumen as to justify the statement that it is cystic-prohably because of degeneration of the compressed internal cells. The cells have nothing in common with the "blasse Epithel" described above. We regard these huds and sprouts as a kind of regenerative process or perversion of mammary evolution, and do not connect them with other mammary disturbances. It is probable that Schimmelbusch saw them and interpreted their significance differently, for in his description, so far as we can harmonize what he describes with what is described above, he regarded them as indications of neoplasmic changes and saw in them the evidence of the tumor nature of the cystic disease, which he called "cystadenoma." But they cannot be of such nature. They certainly appear like normal evolutionary processes, and they occur in tuberculosis (von Saar) and other mammary diseases. Berka regarded their presence in senile breasts as normal.

D. Papillary and Adenomatous Proliferation.-This term applied by Warren, the equivalent of the adeno-cystic change of Bloodgood and of the "secondary epithelial hyperplasia" of MacCarty, has been observed in many cases. In its simplest forms it consists in multiplication of the layers of epithelial cells in the dilated parenchymatous spaces. With or without such stratification, cell processes next begin to extend in irregular prolongations into the fluid contents of the spaces. In some cases it is simply the super-position of cell on cell; in others there seems to be folding of the cellular lining and elevation of the cells. No supporting connective tissue appears, as in intra-cystic papilloma. As the number of such cell processes increases, they begin to interfere with one another or to attach to one another, and thus eventually the dilated space, whether large or small, becomes filled with the multiplied cells through which there are openings surrounded by cells, and contributing a pseudo-glandular structure to the mass. In some cases in which there were signs of degeneration in these areas, it seemed as though the strands of cells were the survivors of a cell mass in which most of the components had suffered dissolution. The cells that thus grow to form the "adeno-cystic areas," or to produce the "adenomatous stage," or to manifest the "secondary epithelial hyperplasia" are not" blasse Epithel," but cells descended from the normal glandular cells. The same may be true of the "blasse Epithel," but if so it becomes changed in some manner that permits it to be at once recognized.

E. Free Epithelial Cells in the Spaces of the Connective Tissues.-If we have seen these we probably regarded them as carcinoma as did Brissaud, Maly, Lichtenhahn and others; at all events, our notes contain no reference to them. The authors mentioned, however, paid particular attention to them, and report their frequent occurrence about epithelial-filled cysts. Kuru arrived at the conclusion that they were swollen "Wanderzellen" and believed them to be negligible. von Saar conceived them to be epithelial cells passively expressed through the cyst wall into the lymph spaces of the surrounding spaces because of the intra-cystic pressure. In support of his theory he calls attention to Maresch's observation of the expression of fat globules from dermoid cysts under similar circumstances. Whatever the sources and nature of the cells, they are productive of appearances so strikingly like cancer as to deceive almost any observer. That such deception is not infrequent is probably exemplified by Bloodgood's results in excising simple cysts of the breast. Though the surrounding condensed tissue sometimes closely resembles carcinoma when microscopically examined, it could scarcely have been such, for when it was excised there was no return, as is usual in cancer.

F. Appearances Resembling the Lactating Brcast.-These occasionally occurred as smaller or larger distributed areas for the most part in badly diseased breasts. Some were quite typical and gave one the impression that local areas of mammary tissue had responded to stimulation by acinus formation and the appearance of secretory epithelium. More interesting were atypical areas in which, in the presence of what appeared to be acinous structure and secretory activity, the lactating tissue was dilated so that all of the acini were considerable sized uniform spaces with their partitions lined with a low secretory epithelium. Most of the spaces appeared to be empty.

Pathology.-The chief macroscopic lesion of abnormal involution is the cyst. Can any of the explanations of cyst formation given in the earlier part of this chapter apply in this peculiar cystic disease of the breast?

Langhans suggested that inflammatory disturbances caused closure of ducts and led to cystic disturbances, as early as I 873 . Samelson-Kliwanski, Mintz, Referent and Ingier claim to have observed the closure of ducts by granulation tissue (peri-canaliculitis) and resulting formation of cysts. Von Saar, on the other hand, thinks that in all such cases no new cysts are formed, and that already existing cysts are destroyed. In the 
many cases from which we have studied sections, signs of inflammation with granulation tissue formation were as rare as the cysts were common. Occasional plugs of condensed secretion - or tubular contents-were sometimes found and may have acted as obstructions.

That the cysts are formed through dilatation of the tubules of the gland there can be no doubt. The only question is how it comes about, and though it is difficult to understand the nature of the obstruction, it seems certain that an obstruction must be present.

It is equally interesting to know what collects behind such an obstruction in breasts that are not secreting. It is certainly not milk, for the contents of the cysts never show any of the morphological components of milk, or show them rarely and in minute

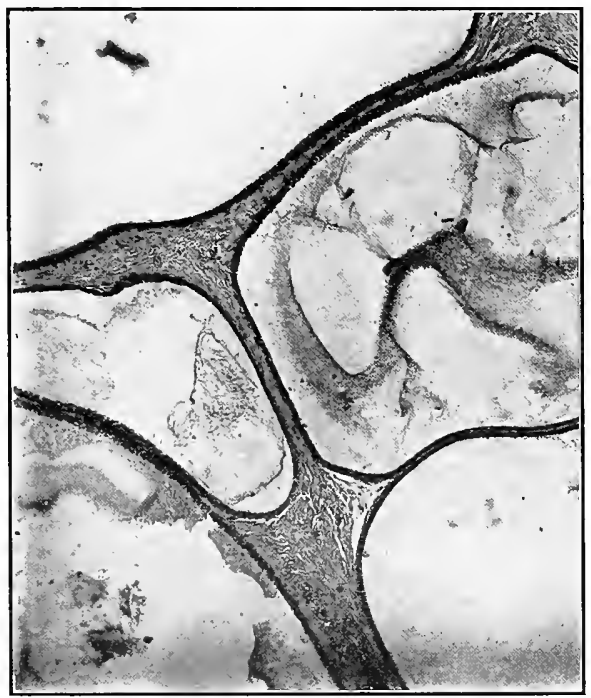

Fig. I21.-Parts of five small cyssts with epithelial linings, from a case of well-marked "abnormal involution" of the breast.

quantity. It is probable, therefore, that the fluid is not the product of secretion but of exudation. Exudation cysts usually result from the dilatation of preformed cavities into which the fluid exudes in increasing quantity because of altered chemical conditions. Can we suppose the ducts of the mammary glands sufficiently spacious to permit this to take place? That very minute spaces may permit of considerable accumulations and eventuate in cysts is shown by what frequently takes place in the thyroid gland, in whose normally small alveoli cystic dilatation is not uncommon. We may, therefore, suppose that should the smaller ducts of any portion of the mammary gland be obstructed, serous exudation and dilatation, eventuating in the formation of cysts varying in size, are possible. Thus may be explained the formation of cysts with clear fluid contents. Lastly, we know that the cells of the tubules not infrequently proliferate and form great aggregations in widely distended ducts and alveoli, to undergo 
subsequent degeneration or colliquation by which a cloudy fluid is formed. Whether this proliferation precedes the dilatation and is its cause, or whether the cells multiply because the space is already prepared to receive them, is not clear from what is seen, but we can imagine the factors of cell proliferation and colliquation as each playing a part, even though it be a subordinate part, in cyst production.

In closing the discussion of the origin of the cysts, mention must be made of one more possibility that bears some relation to Ribbert's ideas of cyst formation. It is not impossible that the modification of the peri-ductal tissue-loss of elastica in some places, increase of elastica in others; atrophy and blending with the inter-lobular tissue in

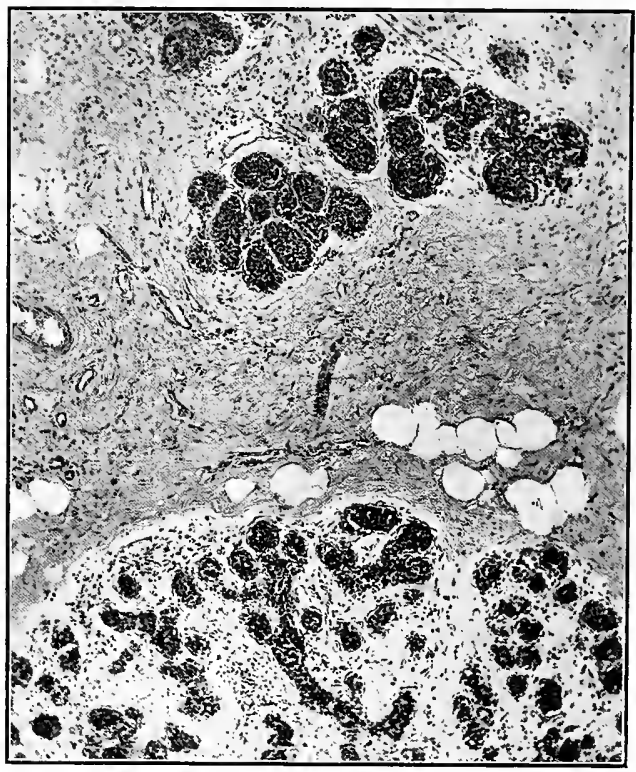

FrG. I22.- The lower part shows part of a lobule of normal breast tissue; the upper part, a collection of cell-filled dilated alveoli, not unlike the flask-shaped expansions at the ends of the tubules in the breast at puberty. These probably indicate growth of the parenchyma, but may be a mere survival of an early condition.

some places, multiplication in others-may cause tugging upon the walls of the tubules by which they are drawn apart and their lumen made to open widely. This may possibly explain those cases in which cyst formation takes place in the absence of all other causes.

The Chief Microscopic Lesion of Abnormal Involution is the Epithelial Proliferation. -If the breast be cystic but nowhere show epithelial herperplasia, it is doubtful whether it is correct to call it "abnormal involution," for the reason that cysts may occur in other conditions; if a breast show the epithelial hyperplasia, it is certainly correct to call it abnormal involution, because one theory of the disease is to the effect that the formation of cysts depends upon the epithelial hyperplasia. The epithelial hyperplasia is sometimes present to a very limited extent in otherwise healthy appearing breasts. It is 
not impossible that it may always have been present in some breasts, for we are not sure of its nature nor its beginning. Creighton, in his book upon "Cancers and Other Tumors of the Breast",London, I902, has built up a theory by which the origin of cancer is referred to aberrant sudoriparous glands in the breast tissue. It is not improbable that the objects which he saw in the mammary gland and thus interpreted are the same peculiar tubules, with apparently increasing epithelium, that we now regard as tubules in which abnormal involution is beginning.

In cases with so little epithelial hyperplasia that it is difficult to find, and without cysts, it is naturally difficult to come to a correct pathological diagnosis. Do these changes begin in senile and presenile involution or does the least suggestion of them constitute abnormal involution? If the former, when does the case become one of abnormal involution? The difficulty is not solely one for the pathologist to wrestle with; it seems to worry the surgeon quite as much.

Among our 148 cases called "abnormal involution" there are 45 breasts that have

The Microscopic Changes Observed in 45 Cases Called "Abnormal Involution" of the Breast, Studied with Reference to the Age of the Patients

I. Changes in the Larger Ducts.

I. The ducts are dilated and collapsed.

2. The ducts are dilated and distended

3. There are cysts less than $\mathrm{I} \mathrm{mm}$. in diameter.

4. There are cysts more than $\mathrm{I} \mathrm{mm}$. in diameter.

5. The cysts have translucent contents containing cells.

6. The cysts have smooth epithelial linings.......................

7. The cyst walls have columns of cells forming papillæ.

II. Changes in the Lobular Tissue.

I. The appearance is interpreted as suggesting recent lactation.

2. The acini are aggregated in large lobules.

3. The acini are in small lobules or some are atrophic..............

4. The acini are very few in the lobules.....................

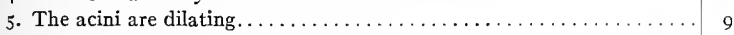

6. The acini are coalescing............................

7. MacCarty's primary epithelial hyperplasia.

8. MacCarty's secondary epithelial hyperplasia.......

9. Acini dilated, not distinguishable from ductules.

10. Acini solidly filled with cells.

III. Changes in the Peri-ductal Tissue.

I. The peri-ductal tissue is infiltrated with cells.

2. The cellular infiltration obscures the epithelium. .

3. The peri-ductal tissue is atrophic-difficult to see.

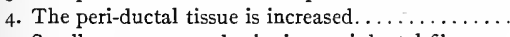

5. Small areas suggest beginning peri-ductal fibroma.

IV. Changes in the Stroma or Matrix of the Gland.

I. There are inflammatory infiltrations in the stroma.............. I I

2. The stroma shows more than usual adipose tissue.............. r 2

3. The stroma is fibrous............................ 5 . 3

Diagnosis.

I. Certainly benign .

2. Potentially malignant-danger remote

3. Potentially malignant-danger greater.

\begin{tabular}{|c|c|c|c|c|}
\hline 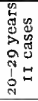 & 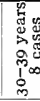 & 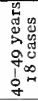 & 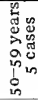 & 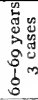 \\
\hline
\end{tabular}


been studied with particular care. They have been set aside because they seem to show how easily mistakes in diagnosis may be made. A few of them showed no cysts; most of them showed minute scattered cysts; a few showed a few larger cysts. All of the cysts were filled with clear fluid or jelly and had smooth shining walls. The gross examination failed to show any structural alterations that appeared in the least degree "suspicious." Nevertheless, the patients suffered from some symptom or symptoms, and the breasts showed some visible changes that were mistaken for abnormal involution or cancer. When these cases were examined microscopically so little was found that there seemed to be no reason for their amputation. The microscopic results are expressed upon the foregoing chart.

In looking over the chart it will be seen that it shows various unexpected things. Thus, instead of the supposed disease making its appearance at or about the fortieth year, it has the following age distribution:

$\begin{array}{lr}20-29 \text { years } & \text { I I cases } \\ 30-39 \text { years } & 8 \text { cases } \\ 40-49 \text { years } & \text { I } 8 \text { cases } \\ 50-59 \text { years } & 5 \text { cases } \\ 60-69 \text { years } & 3 \text { cases } \\ 70-+ \text { years } & 0 \text { cases }\end{array}$

Of the I 8 cases that occurred between the fortieth and the forty-ninth years, Io were between the forty-fourth and forty-seventh years, I 4 between the forty-fifth and fiftieth years. There were, therefore, a greater number of cases about the time of the menopause than at any other time. The second most frequent period is that between the twentieth and twenty-ninth years.

The average age for all these cases is 40 years. Of the patients, 28 were married, I 5 single, the social state of the others being unknown. The average age of the married women was 42 years; for the single women 35 years. There were four cases in the series in which both breasts were removed, one from whom they were removed simultaneously, three from whom they were removed consecutively.

The fact that almost one-half of the cases were below the usual age incidence, the fact that 32 of the 45 cases showed no microscopic signs of abnormal involution at all, and that of the I 2 cases that did show epithelial hyperplasia only four showed enough to be regarded as dangerous, are sufficient to indicate that there must be difficulty of diagnosis or undue apprehension regarding the disease.

Most surgeons now accept the opinion that abnormal involution is a primary disturbance that may lead to malignant (carcinomatous) disease, and there are reasons for so doing. For example, in Warren's collection of $5^{\mathrm{I}} 7$ cases of cancer of the breast there were 15 cases that showed associated carcinoma and abnormal involution, and in our own pathological series of 575 breasts removed for tumor, among which there were 335 cases of cancer, there were 23 in which both conditions were present in the same breast. It is commonly supposed that because the two coexist they must therefore be connected, and the final conclusion is drawn that the cancer evolves from the abnormal involution. We have seen a few cases in which extreme abnormal involution accompanying cancer, and the peculiar adenomatous type of the cancer, gave the almost irresistible impression that the cancer was developing from the abnormal involution with its active epithelial hyperplasia. Indeed, we said that such was the case, yet we are not really sure, there being no case known to us in which could be pointed out an unequivocal transformation of the involutional into the carcinomatous disease. We reviewed a 
considerable number of slides for the purpose of showing that this change did take place, but were obliged to admit that even in those cases in which it appeared to be most probable, the epithelium in the areas that we regarded as involutional was different in form, staining quality and other particulars from that which we knew to be carcinomatous.

The uncertainty of the transformation is further increased by several other facts not sufficiently dwelt upon. One of these is that abnormal involution may progress to an advanced stage and effect extensive changes in the breast without cancer development. Thus, in the type commonly known as Schimmelbusch's disease, which is very probably the same as that described by Reclus, the breast becomes small, dense, riddled

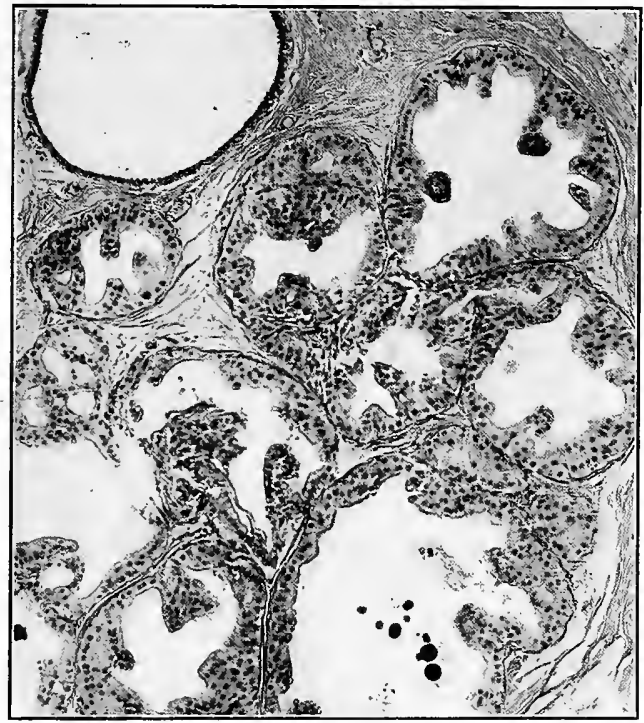

FIG. r23.-An area of abnormal involution exemplifying the structures looked upon by Creighton, Krompecher and others as aberrant sweat-glands; by Warren as the adenomatous from of abnormal involution; by Bloodgood as the adeno-cystic form of senile parenchymatous hypertrophy; and by MacCarty as secondary epithelial hypertrophy. Many believe these appearances to indicate beginning or impending malignant change, but they occur in otherwise normal breasts.

with small cysts filled with pale, dark or chocolate-colored material. Microscopic sections of these breasts show epithelial proliferation in the form of columns of cells or solid masses of cells in the cysts and atrophy of the parenchymatous structure, yet there is no epithelial invasion. In these cases the axillary lymph nodes may be enlarged and easily palpable, but when examined they show only endothelial hyperplasia. Such progress of the disease without malignancy is important to keep in mind. Another fact to remember is the common occurrence of malignant disease (cancer) where involutional changes are quite moderate.

The involutional changes are almost always more marked, the nearer a cancer focus is approached. Lastly, and this is one of the most important facts, abnormal 
involutional changes occur in the breasts of young patients suffering from such chronic infectious diseases as tuberculosis and (according to published statements) actinomycosis, as well as in cases of squamous-cell carcinoma which cannot possibly arise from it.

All of these considerations taken together make too ready an acceptance of the doctrine that abnormal involution is the "precancerous stage of cancer" a mistake. Instead of the abnormal involution being the cause of the cancer, may not cancer be the cause of the abnormal involution? Granting that abnormal involution is a disturbance of growth in the epithelial tissues of the breast, provoked by general or local stimuli, may not the presence of the cancer, like that of tuberculosis in the breast, be the local stimulus that leads to the abnormal involution? May it not be worse in cancer cases because there is a greater disturbance in such cases? May it not be most marked near the cancer because the greatest local disturbance is near the cancer?

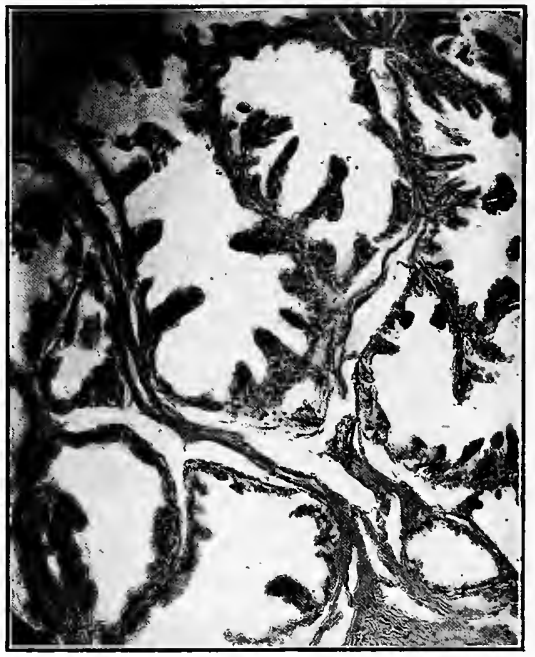

FIG. I24.-Dilated acini in a long quiescent breast, the seat of abnormal involution and carcinoma.

Finally, may not the differences that obtain between the appearance and arrangement of the cells of the abnormal involution lesions and the cells of the cancerous lesions depend upon the fact that they are not the same things and therefore ought to look different?

It is sometimes urged that both the conditions, cancer and abnormal involution, are most frequent at the same period of life, and that therefore they are probably connected with one another. We cannot see the necessity for supposing that two conditions that happen to coexist must be connected with one another in the relation of cause and effect. At a certain age the breast is subject to involution which sometimes becomes abnormal and peculiar, at the same age cancer develops in the breast, irrespective of any cause or condition known, but the involutional changes are apt to be numerous and diffused, the cancer quite as apt to be localized. Of course both may be the reverse; the involutional disturbance may be localized and the cancer diffused. 
In the present state of knowledge the questions cannot be answered. We cannot be certain of the relation of the one morbid process to the other. The case is "not proven." But the matter is of the utmost importance in its surgical application, for it is upon the theory that abnormal involution is the "precancerous stage" of eancer that many surgeons are now advising and treating their patients. Handley (Choyce and Beatties, "System of Surgery") who looks upon the condition as a mastitis, summarizes the evidence for and against abnormal involution as an exciting cause of cancer, as follows:

I. Clinical Evidence.-Bryant found that out of 360 cases of cancer, mastitis had occurred at some antecedent period in 8o. Gross found similar evidence in $7 \mathrm{I}$ out of 365 cases; Sheild found evidence of post-inflammatory trouble in only Io per cent. out of all the cases at St. George's Hospital, but he justly points out that a focus of chronic mastitis much too small to be clinically appreciated may yet form an adequate nidus for a carcinoma.

The clinical statistics, then, amount only to this-that there is evidence of past chronic mastitis in a large minority of cases of breast cancer.

II. Pathological Evidence.-Beadles, from the examination of the non-carcinomatous portions of 100 cancerous breasts at the Brompton Cancer Hospital, found without exception, in each of these breasts, such abnormal changes as undue proliferation of the acini and of the stroma, and cysts were of common occurrence.

Lenthal Cheatle has found similar changes post-mortem in apparently healthy breasts.

F. T. Paul, as the result of prolonged observation, recorded in rgor, his belief that evidence of mastitis is present in nearly every breast affected with carcinoma.

Victor Bonney found traces of chronic mastitis in all the mammæ removed for early carcinoma, which he had the opportunity of examining. Thus the pathological investigation shows chronic mastitis to be an almost universal precursor of carcinoma of the breast.

Is the closing statement of Handley a correct deduction? Would he not be better justified in stating that chronic mastitis is an almost universal accompaniment of carcinoma? Where is it shown to be a precursor? Surely not from the pathological evidence. It seems to be extremely doubtful whether Bryant, Gross and Sheild were considering the same conditions as Beadles, Cheatle, Paul and Bonney or whether they corresponded with the "abnormal involution" of Warren.

Diagnosis.--The patient usually seeks advice because she thinks she finds a painful "lump" in the breast. The patient being of the cancer age, her anxiety becomes transmitted at once to the surgeon. If examination of the breast reveal a definite "lump," an imbedded, immovable, uncircumscribed and hard "lump," he diagnoses cancer and knows what to do. If the "lump" be vague or "vanishing," or if he be able to recognize it as a cyst, or if the dense tissue and general lumpy texture of the breast suggest to him that the case is one of cystic disease or "abnormal involution," what shall he do to be sure? In answer to this question Warren is very definite. He says:

"Attention must again be called to the fact that the clinical symptoms of these proliferative types of abnormal involution are to be distinguished in no way from those of simple abnormal involution, and by no sign on physical examination can the degree of epithelial growth be determined. Microscopic examination is, therefore, absolutely necessary for the correct classification of the individual case, and in fact the variation between the different portions of the same gland is so great that microscopic examination of all of the tissues is necessary to a correct diagnosis. For these reasons and because of the liability to carcinoma which these cases present, $\mathbf{I}$ have no hesitation in recommending operative treatment for abnormal involution in every case. An induration in the breast gland at or about the time of the menopause, which is palpable with the flat of the hand against the chest wall, I consider sufficient indication for operation. For cases of this character I perform 'plastic resection of the mammary gland,' by means of which a thorough exploration of the gland may be obtained and portions of a suspicious nature may be removed for microscopic investigation without the mutilation of an amputation. This operation I would recommend for every case of abnormal involution in which the diagnosis can be established." 
The case is then to be made the subject of an operation by which an uncertain diagnosis can be made certain and the benignancy or malignancy of the case established by actual visual and microscopical examination of the tissues. This seems to us most sound doctrine. If the case with the diseased breast be thus treated, incision of the tissue in all of its suspicious parts can be made without injury, and the nature of localized disturbances determined. Every surgeon ought to be sufficiently skilful in pathological anatomy to recognize cancer tissue when he sees it. But it is not a question of cancer, it is one of the benign or potentially malignant character of abnormal involution, and Warren says, and we fully agree with him, that this cannot always be determined without the aid of the microscope.

This is not intended to apply to cases in which the breast when explored is found to be riddled with cysts, large and small, or to contain cysts with papillary excrescences, or to typical cases of Schimmelbusch's disease or the "maladie de Reclus," or where there is any other generalized or localized disturbance of such obviously destructive character as to suggest at once that the breast should be excised whether the question of benignancy or malignancy enters into the matter at all, but it is intended to apply to cases where little is found and the surgeon is therefore left in doubt.

The chief difficulty arises when diffused mild changes such as small cysts with clear contents, and occasional induration are found. What is the nature of these? Or in cases where there is an indurated area containing a congeries of little cysts close together, often filled with reddish jelly-like substance.

From such breasts the suspicious areas should be excised, together with other fragments from less suspicious areas, for future study. The breast can then be returned and sutured.

But there is a strong argument in favor of an immediate examination of the tissue by means of the frozen section. It takes but a short time, and if satisfactory evidence of the presence of active epithelial hyperplasia can be found, the distress and danger of a second operation is made unnecessary, for the surgeon may at once proceed to remove the breast.

There seems to be no valid objection to the use of the freezing microtome for this purpose, providing it can be done promptly so that the patient is not kept too long under ether, and providing that enough of the breast tissue be examined to give results as useful as the more time consuming method of celloidin or paraffine sectioning. We regard the method as a most important adjunct to the scientific success of the surgical clinic.

Prognosis.- Many authors agree that the abnormal involution in some stage is to be found in about 25 per cent. of senile breasts. It presents forms-the proliferative and ectatic - that may well be regarded as harmless and benign. Indeed, Bloodgood seems to be of the opinion that these cases, in which the epithelial activities appear striking, may recover through exhaustion of the proliferation activity, leaving simple cysts behind them. It presents the other form, the adenomatous or adeno-cystic, that may be dangerous. Of these Tietze, Warren and Bloodgood agree that about Io per cent. will probably develop cancer. When the abnormal involution reaches its maximum development, i.e., when the signs of proliferation are everywhere distinct, when the cysts are numerous and many filled with adenomatous epithelial cell aggregations, cancer is likely to be already present in the breast. Bloodgood states that in about 50 per cent. of the cases with bad adeno-cystic change, cancer was already present.

The prognostic problems are, how great is the danger of cancer in the particular 
case? How shall the patient be treated to prevent cancer? If treated otherwise than by radical operation, how great is the danger of subsequent return of the same disease or of the subsequent appearance of cancer?

The general malignant tendency of abnormal involution may be very real, but is neither immediate nor certain. If it be true that 25 per cent. of all old women show more or less of it, and that of those who show it only so per cent. are in danger of cancer and if it can be assumed as Bloodgood says, and we believe, that one-half at least of the very bad cases are already associated with cancer, by treating all of the bad cases as cancer, we ought to reduce the danger to say 5 per cent. A simple operation may suffice to save the cases comprising these 5 per cent. from future malignant disease.

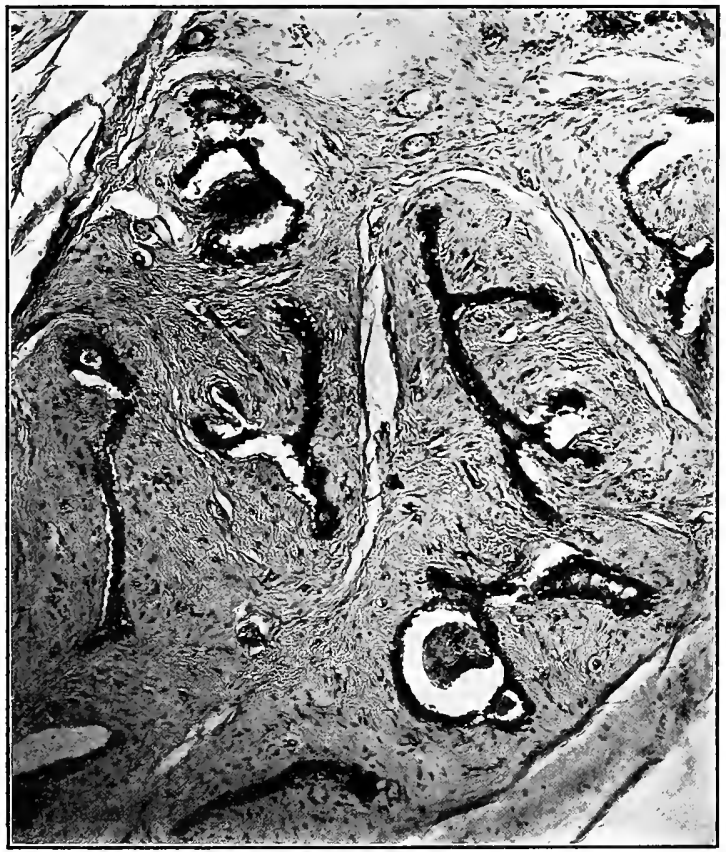

FIG. 125.-Badly circumscribed area of periductal fibroma (?) such as may often be found in the breasts with abnormal involution.

The fact that abnormal involution is a process that is apt to be distributed throughout the breast, and often throughout both breasts, and that it may be in different stages in different parts of the breast or breasts, makes it imperative to make exploration of the breast as thorough as possible, and the removal of the suspected areas from as many parts of the breast as possible.

It may be well to inquire what happens if the disease be treated conservatively according to this method. Bloodgood reports about roo cases in which the breasts were explored, cysts of simple character, and sometimes cysts of suspicious character 
removed. He says that the cysts were smooth-walled, contained clear or slightly cloudy fluid - no blood or chocolate-colored fluid-and that they were free from papillary excrescences. Sometimes the walls were indurated, and upon microscopic examination these indurations sometimes showed carcinoma-like structure. Nothing was done except to excise the cyst and the surrounding tissue, yet recovery took place without the subsequent development of cancer. About roo women were thus saved from unnecessary and undesirable mutilation.

Greenough and Simmons (Annals of Surgery, rgr4, LX, July, No. r, pp. I-r 36) performed excision of the diseased areas from 83 cases of "Cystic Disease of the Breast," in which the diagnosis was confirmed by microscopic examination. In $\mathrm{r}_{4}$ of the cases, both breasts were operated upon so that there was a total of 97 operations in 83 cases. In 59 cases, partial plastic resection was performed, and in 32 cases a local excision of the affected part of the breast was done. In two cases all of the gland tissue was subsequently removed by the plastic operation (subcutaneous amputation) and in four cases a later total amputation was done. The subsequent histories of these 83 cases have been investigated. The length of time which elapsed from the first operation varies in these cases from I to $r 7$ years - an average of over seven years for each case. Four of the 83 cases or 4.8 per cent. developed carcinoma of the breast-three after partial plastic resection and one after simple excision of the tumor. Four patients have died of other causes, without evidence of any disease of the breast. Sixty-two patients are alive and well, and these with the four dead without recurrence make 66 of the 83 cases, or 80 per cent. free from recurrence, and apparently up to the present time at least, cured of their disease by a partial operation. Thirteen cases (I5.6 per cent.) showed sooner or later a return of the disease. In five patients the disease returned in the other breast, and in eight patients it returned on the same side, in the gland tissue remaining after the first partial operation. One patient died ro years after operation, of a broken hip. Another died five years after operation with a cerebellar endothelioma. In neither case was there evidence of any malignant process in the breast, though both were reported to have had recurrence of cysts. Four patients refused operation and were reported living and well, but with cystic disease presentone, one year, and three, five years after operation. The other seven were operated upon again, by amputation of both breasts in the greater number of cases and reported well at intervals of ten, five, four, two, one and one and one-half years, seven months, and one month later.

Thus either the recurrence of cystic disease of the breast or carcinoma occurred in breasts treated by partial operation in $\mathrm{r} 2$ out of 83 cases, or in 14 per cent. In $\mathrm{r} 6$, or rg per cent., the patient failed to get permanent relief from the partial operation. From these results it seems clear that abnormal involution or cystic disease of the breast is not an affection that should unduly alarm the surgeon or his patient.

Somehow there is a sentiment abroad that tends to overemphasize the danger, and has no treatment for the disease except the radical operation.

There are no doubt serious difficulties in the way of an accurate diagnosis of the disease if it must depend upon clinical diagnosis alone, but there ought to be little difficulty in cases explored after the exposure of the tissue by the plastic resection.

Amputation of the breast in simple benign cases is bad treatment, founded upon faulty diagnosis and inadequate exploration of the breast, or upon a fear of the future development of malignant diseases, not borne out by surgical knowledge and experience.

Surgical science must be in a very inexact stage indeed when we are able to get to- 
gether and place before the reader the results of pathological examination of 45 breasts of which only four showed mild adeno-cystic change, and only seven epithelial proliferation into cystic spaces, while 34 were entirely benign cases of normal or senile involution.

Treatment.- If the symptoms are such as to arouse the suspicion that carcinoma may be present or impending, the upper half of the breast should always be explored by transcutaneous incision, the lower half by a Thomas' incision and plastic resection, reinforced by the microscopic examination of a frozen section.

If the smallest area of carcinoma be found, the case is no longer abnormal involution, but carcinoma and should be dealt with accordingly, and the radical amputation performed.

If there be no carcinoma, but the disease be widespread and the breast riddled with cysts of small size filled with grumous contents, and these cysts surrounded by

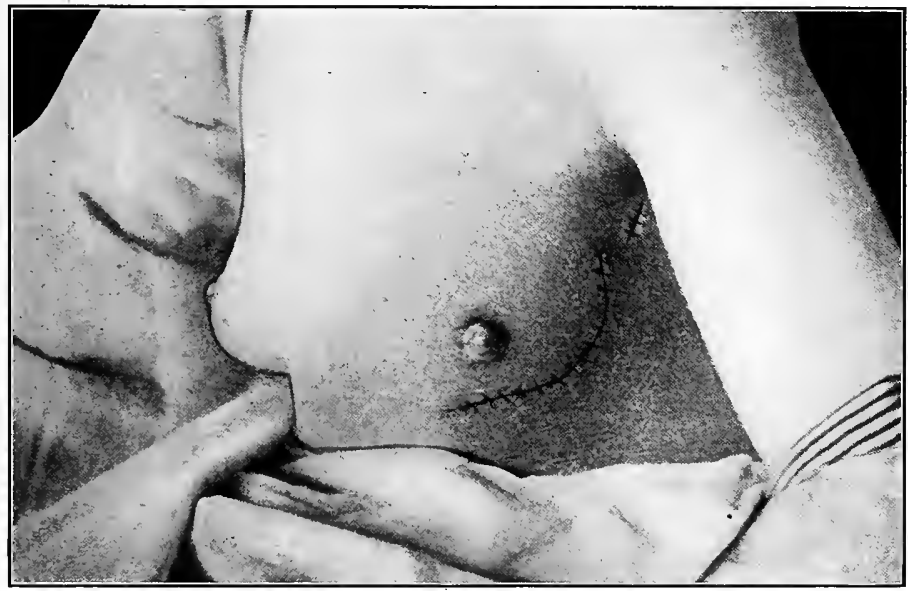

FIG. I 26.-Subcutaneous excision of the breast with excision of the anterior pectoral group of lymph nodes. Case of abnormal involution.

more or less indurated areas of doubtful character, there is enough justification for the removal of the breast by simple (conservative) amputation, no attention being paid to the fact that no carcinomatous disturbance has been found.

If the generalized disturbance be slight, but somewhere-usually at the periphery of the breast-there be an area of tissue condensation containing cysts, that area should be excised. If there should be several such areas with what seems to be healthy intervening tissue, each may be cut out, after which the breast may be replaced, sutured and dressed.

Reflections upon Abnormal Involution and Its Relation to Carcinoma.- $r$. We are not suffciently well informed concerning such changes in the mammary gland as may depend upon age and activity, to separate the normal from the abnormal with certainty.

2. Abnormal involution may be premature as excessive involution, but there is no fixed point at which the normal ceases and the abnormal begins.

3. Abnormal involution is probably a senile change, abnormal only when excessive.

4. Abnormal involution and cancer commonly coexist in the same breast. 
5. The age of occurrence is the same for both affections.

6. These facts lead to the conclusion that carcinoma may accompany or follow abnormal involution in about one case out of ten.

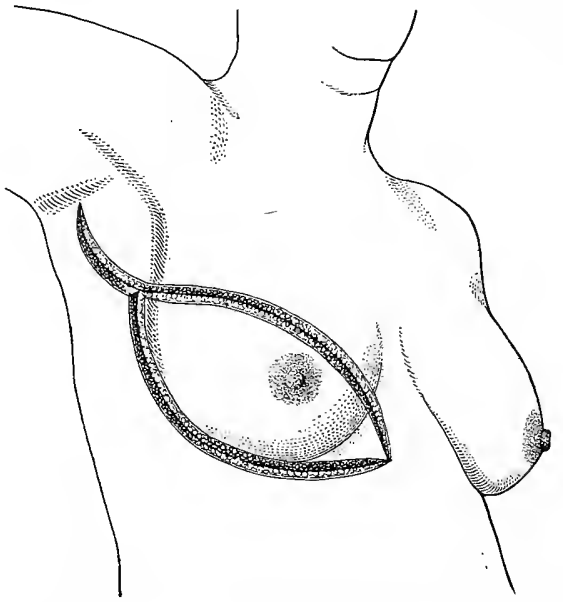

Fig. I 27.-Conservative amputation of the breast. Primary skin incision.

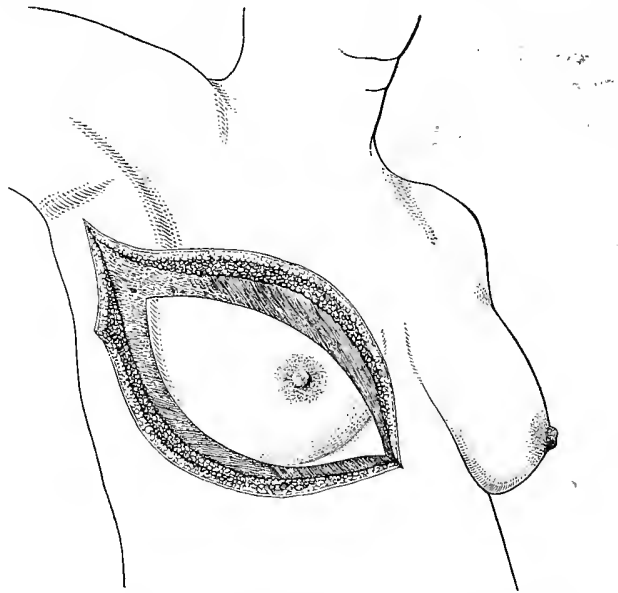

Fig. 1 28.-Conservative amputation of the breast. Skin flaps reflected.

7. The fact that abnormal involution occurs in squamous-cell carcinoma, in tuberculosis and in otber chronic diseases of the breast makes it possible that it is not infrequently a secondary process indicating that the breast is diseased.

8. The probability of this is increased by the fact that the involutional changes are severe in proportion to proximity to the local lesion. 
9. No one has seen the transmutation of abnormal involution into cancer.

ro. Exaggerated fear of the occurrence of carcinoma after abnormal involution has led to unnecessary mutilation of patients by the removal of many breasts that show no important disease.

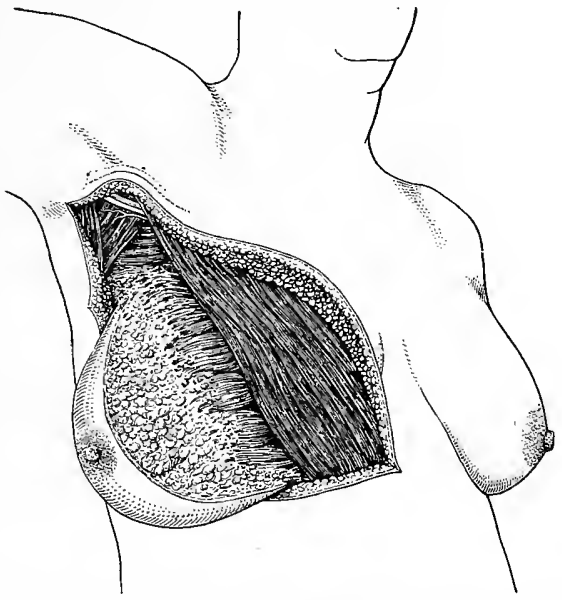

FIG. 129.-Conservative amputation of the breast. Axilla cleansed from above downward, deep pectoral fascia removed and breast attached only to the fascia covering the serratus magnus muscle.

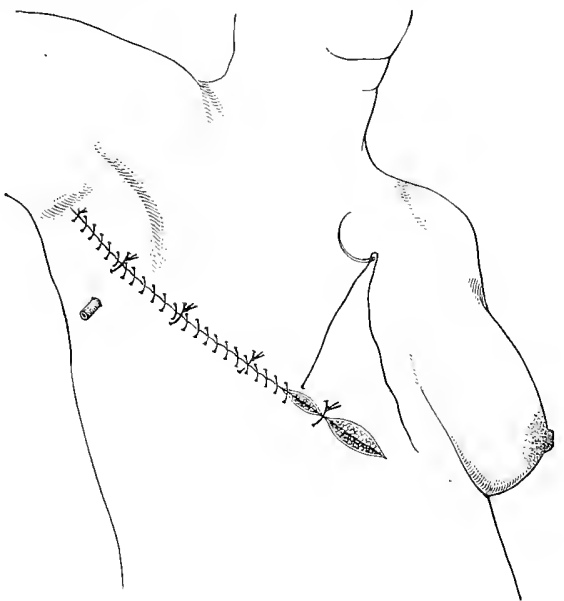

FIG. r30.-Conservative amputation of the breast. Operation completed.

rx. Instead of amputation without examination, the breasts should be investigated by plastic resection. If normal they should be let alone; if slightly and locally diseased, the diseased areas should be excised.

r2. In cases with badly diseased breasts, simple amputation is indicated. 
r. In cases with carcinoma, the breast is carcinomatous and radical amputation should be performed.

\section{Literature upon Cystic Disease of the Breast}

Albertin:- "Maladie kystique de la mamelle," Mém. Soc. de. sc. Méd. de Lyon (r886), r887, XXVI, 44.

Altmann, R.- "Über die Inactivitätsatrophic der weiblichen Brustdrüse," Archiv f. path. Anat. r888, CXI, 3 r8.

von ANGerer.- "Chirurgie der Brustdrüse," Handbuch der praktischen Chirurgie, von Bruns, Garre and Kuttner, Bd. II, p. 598, r9r3.

BERKA.-Beiträge $z$. path. Anat., r 912 , LIII, 284.

BERTELs.-Deutsche Zeitschr. f. Chir., rgr 3, p. r 24.

Besancon et Broca.- "Maladie kysteque de la mamelle," Bull. et. Mém. Soc. Anat. de Paris, 1886, LXI, 38. Progrés Med., Paris, I886, 28, III, 202.

BLoodgood.-Kelly and Noble, "Gynecology and Abdominal Surgery," II, p. r94. Surgery, Gynecology and Obstetrics, I906, III, 72 r.

BobBis.-Gior. della r. Accad. de Med. di Torino, rgo5.

BORST.- "Die Lehre von den Geschwülsten.".

BreaMr.-St. Petersburg med. Wochenschrift, rgo8, No. 2r. Zeitschrift f. Chirurgie, rgo8, 35 . Correspondenzbl. f. schweizer Aerzte, I910, 40.

BrisSAND.-Archiv d. Phys. et Path., r884, III.

BRODIE.- "Lectures in Pathology and Surgery," r846, p. 137 .

Brisse-\$atnT-MoCARY.—“De la maladie kystique de la mamelle," Paris, r883.

Cestan.- "Maladie kystique des mamelles," Toulouse Méd., rgo3, 2s., V, $2 \times 7$.

Clermont and Duening.- "Maladie de Reclus à forme douloureuse," Toulouse Méd., r9ro, XII, 429.

Creighton, Chardes.- "Cancers and other Tumors of the Breast," etc., London, rgo2, Williams" and Nougate, 307, p. 24, Pl. 80.

Delaet, P.- "Maladie kystique de la mamelle," Bull. Soc. d' Anat. de Paris, r893, LXVIII, 2-r6.

Dobrinoff, ThÈodon.- "Anatomie Pathologique et Pathogenie de la Maladie Kystique de la Mamelle," Montpellier, rgo8, 89, p. 6, Pl. 80.

Ellis, A. G.-Annals of Surgery, Sept., r903. Pub. Lab. Jeff. Med. Col. Hospital, Vol. L, Ig04.

Ferguson, G. B.-St. Barth. Hosp. Rep., London, r884, XX, 253.

Franks.-La Clinica Chirurgica, rgo6, No. 2.

FrEMICOURT.-Thèse de Lille, rgog.

Greenovgh and Simmons.-Ann. of Surgery, r9i4, LX, pp. r-r6.

Greenovgh and Simmons.-Ann. of Surgery, Phila., rgI4, LX, 42.

GREENOUGH, SimMons and BARNEY.-Ann. of Surgery, rgo7.

Handify.-Practitioner, London, r910, 84, 463. "Diseases of the Breast," London, rgro. Choyce and Beattie's "System of Surgery."

Hedringer. - "Presenile Involution of the Breast," Berliner klin. Wochenschrift, ror4, Mar. r6. Abst. J. A. M. A., r914, Apr. 25.

HEDRINGer, E.- "Bedeutung der präsenilen Involution der Brustdrüse," Berl. klin. Woch., rgra 4 , LI, 577.

Judd, E. S.-Refe. J. Mich. S. Med. Soc., rgr4, r3, 2.

KIEBEL.-Berl. klin. Wochenschrift, I904, No. 30.

KöNIG.- "Lehrbuch der spez. Chirurgie," I904-8. Aufl. 2, Centralbl. f. Chir., I893, No. 3, XX, 49.

KROMPECHER, E.-“Über Schweissdrüsenzysten der Brustdrüse und deren Krebse," Verhandl. d. deutsch. path. Gesellsch., Jena, I9I3, XVI, 365 .

KuRN.-Deutsche Zeitschr. f. Chirurgie, XCVIII, 4I5, rgog.

LERICHE.- "Tuberculose inflammative et maladie kystique du sein," Lyon Med., r9r4, CXXII, ro76.

L.etulle.-Bull. Acad. de Méd., rgrr, LXV, p. 287.

Lichtenholm.-Deutsche Zeitschr. f. Chirurgie, rgo7, XL (XC?), $5 \circ 7$.

MacCarty.-Wm. Carpenter, "The Histogenesis of Cancer (Carcinoma) of the Breast and Its Clinical Significance," Surgery, Gynecology and Obstetrics, rgr3, October, p. 44r.

MacCarty.-Surgery, Gynecology and Obstetrics, rgr 4, p. 284. Surgery, Gynecology and Obstetrics, r9r3, p. 44I. Collected papers by the staff of St. Mary's Hospital, I9rr.

MaLY.-Zeitschr. f. Heilkunde, I898, XIX. 
Mannoury, G.-" "Note sur la bilateralité dans la maladie kystique de la mamelle," Progres Mẹ́d., Paris, I888, 2s., VII, 3 .

Mathrev, F.- "Maladie kystique de la mamelle, son prognostic." Montpellier, I9I3, 40, No. 37, 80. MAYER.- "Maladie kystique de Reclus avec dégénérescence carcinomateuse," Presse Méd. belge. Brux., I9I3, LXV, 262.

Menière, P.- "Maladie de Reclus ou maladie kystique de la mamelle," Gaz. de Gyne., Paris, I888, III, 8I.

Mintz.-Centralbl. f. Chirurgie, rgr 5 , No.6. Berliner klin. Woch., I899, No. 47.

PAUL, F. T.- "Chronic Mastitis and Its Relation to Tumor Formation," Trans. Path. Soc. London, rgor, LII, 3 .

Poncet, A.- "Sur la maladie kystique des mamelles," Gaz. hebd. de méd., Paris, r886, 2c., XXIII, 244.

Porter, MI. F.- "Potential Cancer of the Breast," Am. J. Obst., N. Y., I9I2, LXVI, roo4.

RecLUs, P.- "Metastasis chronique et cancers du sein," Gaz. hebd. du Paris, 1887, 2s., XXIV, 193.

RECLUS, P.—"La maladie kystique de la mamelle," Tribune méd. Par., s 905 , n.s., XXXVII, 293.

Rectus, P.- "La maladie kystique des mamelles," Rev. de Chirurgie, ı883, No. I0, III, 76r. Prog. Med., No. ז9, Paris, r884, XII, 379. Gaz. d'Hôsp., r884, 1887, LX, 673, 769. Bull. Soc. Anat. de Paris, $\mathbf{1 8 8 3}, \mathrm{LX}, 673,769$. Bull. méd., Paris, r887, I, 147. Clin. Chir. de l'Hôtel Dieu. Paris, $1888,389-404$. Semain méd., Paris, 1893 , XIII, 353. Clin. Chir. de la Paris, $1894,183,178$.

Robrnson, H. B.- "Cystic Diseases of Breast in Young Women," Tr. Path. Soc. London, I890-91, XIII, 226.

von SAAR. - "Ergebnisse d. Chirurgie u. Orthopädie," Igro, 4 II.

SAsse.-Archiv. f. klin. Chirurgie, r897, LIV; 1907, LXXXIV.

Schimmelbusch.-Archiv f. klin. Chirurgie, I 892 , XILIV.

Scrmamelbusch.- "Das Cystadenom der Mamma," Langenbeck's Archiv, Bd. 44. Archiv f. klin. Chir., I802.

SICRE.-Thèse de Paris, r89o, No. 77, "Maladie kystique de la mamelle."

SiCRE, R.- "Contribution a l'étude de la maladie kystique de la mamelle (Maladie de Reclus)," Paris, I 887 .

Speese.-U. of P. Med. Bull., January, Igo8. Ann. of Surg., I9io, LI, No. 2, p. 213.

StILES.-Edinburgh Med. Jour., I892, XXXVIII.

TAILHEFEr.- "La maladie kystique du sein," Archiv Med. de Toulouse, I8g6, II, 347.

TAPPEY, E. T. - "Cystic Degeneration of the Mammary Gland," Physician and Surgeon, Detroit and Ann Arbor, I897, XIX, 69.

TAYLOR.-Annals of Surgery, LII, No. 2, p. 253.

TIETZE.- "Epithelial Changes in the Senile Female Breast," Deutsche Zeitschr. f. Chir., LXXV, I905, 5, II 7 .

TIETZE._- “Über Epithelveraenderungen in der senilen weiblichen Mamma," Deutsche Zeitschr. f. Chir., Leipzig, 1904, LXXV, II 7 .

TIEтZE, A.- "Über Epithelveränderungen in der senilen weiblichen Mamma," Deutsche. Zeitschr. f. Chir., Bd. 75, x905, S., xr7; Abstract, Centralblatt f. allgemeine pathologie u. pathologische Anatomie, Mar. 5, 1905, p. 188.

Thene.-Archiv f. klin. Chirurgie, rgog, LXXXVIII, $26 \mathrm{r}$.

Touper.- "Trois cas de maladie kystique des mamelles considerées au point de vue anatomique," Semaine Med., Paris, r89o, X, 370.

Toupet and Glantenay.- "Observation du maladie kystique des mamelles," Bull. Soc. d'Anat. de Paris, I89r, LXVI, 575 .

Verga.-Il Polyclinico, Igo7.

Vernedil.- "Maladie kystique des mamelles," Gaz. d'Hôsp., I 884, LVII, 250.

Vorturiez.- "La maladie kystique des mamelles (Maladie de Reclus)," Bull. Soc. Anat. Clin. de Lille, I89r, VI, 373. J. d. sc. Méd. de Lille, r89r, I, 3r3, 337, 385 .

WARREN.-Jour. Amer. Med. Asso., rgo5, II, p. I49.

WARREN, J. C.- "Abnormal Involution of the Mammary Gland, with Its Treatment by Operation," Am. J. M. Sci. Phila. and N. Y., s907, n.s., CXXXIII, 521 . 


\section{INTRA-CYSTIC PAPILLOMA}

Adeno-cystoma papilliferum.

Duct papilloma.

Cystoma mammæ papilliferum.

Cystadenoma papilliare.

Intra-canalicular cystadenoma.

Involution cyst.

Papillary cystoma.
Papillary cystadenoma.

Polycystoma proliferum.

Proliferating cystadenoma.

Proliferous cyst.

Epithelioma intra-canaliculaire.

Villous papilloma.

Epitheliome dendritique du sein.

All of these names are applied to a peculiar neoplasmic disease of the breast characterized by the growth of papillomas into the ducts or into pre-formed cystic expansions of the ducts.

The name intra-cystic papilloma appeals most strongly to us because it seems clear to us that the fundamental structure is in most cases the papilloma, and that it may make its appearance in any duct or cystic distention of a duct. From this point of view the terms duct papilloma-cystoma mammæ papilliferum; proliferous cyst-papillary cys-

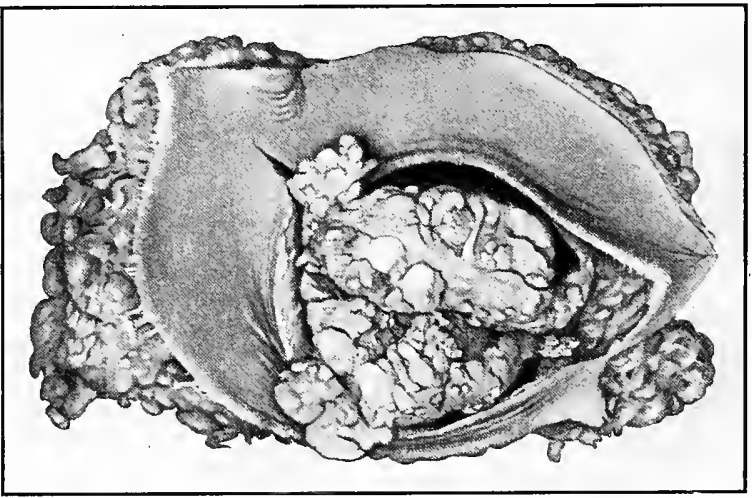

FIG. r3r.-Intra-cystic papilloma of the breast. From a specimen in the Laboratory of Surgical Pathology, Medical School of the University of Pennsylvania.

toma, polycystoma papilliferum; villous papilloma-proliferous cyst are all correct. But as it is not clear that there is any connection with adenoma other than the false impresssion resulting from erroneous deductions following microscopic examination of certain types of the tumor, we look upon all other terms as misnomers and encumbrances. We do so with full knowledge that many pathologists will differ from us in this opinion.

Source.-There is no satisfactory explanation for the origin of the papillary tumors. Presumably they are brought about through the presence of an irritant that may be localized in the duct or in a cyst, or diffused throughout the breast. It is not impossible that it enters the breast through the nipple, as the papillæ usually grow in the large ducts just below the nipple, but it is equally possible that it may arise in the breast itself.

There are two distributions of the papillary excrescences-ducts and cysts. Those occurring in the former are large, and constitute the clinically important group.

I. Duct Papillomas.-These occur in the large ducts of the breast, which dilate as the papillomas grow. They lead to the occurrence of a tumor-like mass that is usually 
centrally situated in the breast, behind the nipple. The papillomas grow first and the duct expands to accommodate them, the tumor mass lying in the cyst. One or sometimes several ducts may be affected simultaneously or consecutively as one or more papillomas are present. The papillomas appear to be independent of one another. The duct may remain open or be closed by the tumor or through secondary galactophoritis. The resulting tumor, usually single, forms a rounded nodular, or usually well-circumscribed, encapsulated mass of any size up to a man's fist. The capsule is the expanded wall of the dilated duct; the mass, within, the papilloma. In the tumors of this kind, there having been no cyst prior to the formation of the papilloma, there is rarely any space between the growing tumor and its surrounding duct, so that it has the general appearance of a solid tumor.

2. Cyst Papilloma.-In this more rare form of the disease the papillomas grow from the walls of pre-formed cysts, which may be large or small and full of fluid. In an early

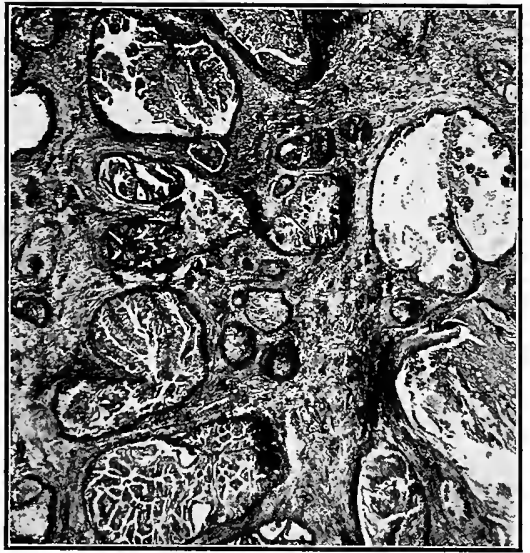

Frg. 132.-Cystic disease of the breast, each cyst containing numerous intra-cystic papillomas.

stage the papilloma may appear as a tiny papilla projecting into and bathed on all sides by the fluid collection in a relatively large space.

Pathology.-Naked-eye Appearance.-The papilloma seems to begin as the result of localized vegetative activity of the epithelial lining of the duct or cyst, by which it outgrows its substratum and becomes thrown into folds carrying with it the basement membrane and a few fibers of the subjacent connective tissue. Soon the folded or wrinkled condition gives place to what appears to be a complexly branched system of processes, and the growth becomes polypoid, fungoid, arborescent or dendritic. When the dendrons hang together fairly well, naked-eye inspection usually reveals one or more rounded polyps with velvety surfaces springing from the walls of the ducts or cysts. In more rare cases the villi spread out and the papilloma has an arborescent or villous appearance. The papillomas are usually pinkish gray in color, but some cases show passive hyperemia from compression or torsion of the pedicles and appear dark red, the fluid in the cyst becoming red or brown from recent or old admixture of blood. Under these conditions the patient's attention is sometimes directed to the breast because a 
small amount of bloody discharge may take place from the nipple should the ducts be open. As the papillomas grow they distend the ducts or fill the cysts with what seems to be a solid mass, but which is in reality a confused mass of inter-digitating, more or less confluent and adhering papillary masses.

Microscopic Appearance.-The tumor is beautiful, interesting and characteristic, when sections are viewed through a low power of the microscope. The appearance will vary according to the size, complexity and compactness of the mass. Thus, a tiny papillary formation springing from the wall of a large cyst may show a dendritic epithelial formation, each of whose branchings is composed of a double layer of cuboidal or columnar epithelium separated by the delicate fibrillar tissue. Larger, more compact masses may appear adenomatous, i.e., appear to have a gland-like structure because of the complexity of the branchings which interlock and frequently coalesce. This is the source of the erroneous idea of the adenomatous nature of the lesion. No matter how large, how compact or how complicated the formation becomes, the same general arrangement obtains. There are always portions that show branched processes of delicate connective tissue covered with the single layer of cuboidal or columnar epithelium.

Historical.-In its mature state, the intra-cystic papilloma is subject to wide anatomical variations, and the essential unity of these apparently different forms escaped the attention of surgeons and pathologists alike for many years, indeed until recent times. Thus in one instance the chief feature of the disease is the cyst; in another, the solid mass of papillomatous tissue, while in a third the invasive character of the epithelium justifies a diagnosis of carcinoma.

The first clear description of the clinical and pathological features of the disease was given by Sir Benjamin Brodie in his "Lectures," in 1846 , in which he called them "sero-cystic tumors." He called the attention of his students to the fact that pressure over the tumor caused the appearance of secretion at the nipple, in explanation of which he passed a bristle through the milk duct into the cyst cavity. This particular tumor consisted of a cyst "with one-fourth of its cavity occupied by an irregular-shaped excrescence attached to one portion of its internal surface."

Rogeau, in 1874 , seems to have been the first to give a correct, clinical account of the disease: "a conical tumor, fluctuating, starting under or beside the nipple and radiating outward like a hardened cord; alternately filling and emptying its contents by a flow of sero-sanguineous fluid from the nipple; the absence of adhesions to the skin or the deeper structures; no general metastases, and little or no pain."

Rogeau looked upon the tumor as "a special variety of retention cyst of the mammary gland."

In 1876 Labbe and Coyne described a typical case of intra-cystic papilloma, but in keeping with the current opinion of the French school, looked upon the disease as a primary cancer of the milk ducts, and for this reason suggested the term "épithélioma intra-canaliculaire."

Cornil and Ranvier about this same time proposed the name "carcinome villeux," but there seems to be little doubt but that these writers were confounding the nonmalignant papilloma with adeno-carcinoma.

The term "true adenoma" was suggested by Gross, in I880.

Butlin was of the opinion that cyst formation is the primary step in the development of the growth and that the papillary excrescences and the fluid contents of the sac owe their origin to a common irritative cause. The interest of Bowlby in the subject 
began with his examination of the specimen removed by Butlin which led to the presentation of a paper describing seven cases and with the following deductions: ${ }^{1}$

"The microscopical appearances presented by the growths removed in all the above cases were practically identical. The tumors were all papillary in nature, and in those cases where there was a definite cyst wall, the papillæ grew directly from its epithelial lining, and were of the arborescent or foliaceous type. The base of each papilla was formed of very delicate connective tissue, which in some cases was almost myxomatous in texture, and on this grew several layers of short columnar epithelial cells. The papillæ branched in all directions, giving off numerous offshoots of various forms and sizes. Many of these coalesced, and by so doing formed an irregular network enclosing spaces of different sizes and shapes. In all parts of the sections more or less infiltration of blood had taken place, red blood cells in various stages of disintegration stained all parts of the sections and fully accounted for the pigmented appearance presented to the naked eye. Up the center of each papilla ran a large and very thin-walled blood-vessel, whose branches followed the ramifications of the growth. In some of the sections cysts without any papillary ingrowths could be seen, and in others the ingrowth was only commencing."

This is undoubtedly an excellent description of intra-cystic papilloma, but that which follows indicates that the writer confounded the tumor with abnormal involution.

"The disease appeared to affect different parts of the breast at one and the same time, and in some parts of the mamma near to the tumor, where the naked eye could not detect any definite tumor formation, the microscope yet revealed the early development of cysts. In many sections it could be seen that the cell growth was not entirely confined by the cyst wall, but that in places the cells had extended through the lining membrane into the subjacent connective tissue of the gland, and had formed cysts of new formation as apart from the mere dilatation of preëxistent ducts or acini. It is by this extension of cell growth that those tumors situated outside the breast tissues are to be accounted for. In Case 4, in addition to the above appearance, there was found in the more dense parts of the tumor already mentioned a very definite growth of alveolar carcinoma, differing in no way from the common scirrhus type except in the comparatively small amount of its fibrous stroma."

At a meeting of the Philadelphia County Medical Society held in I889, Dr. George E. Shoemaker presented a specimen of malignant papillary cystadenoma of the breast, and the discussion that followed this presentation indicates the differences of opinion among surgeons at that time relative to the true nature of this variety of mammary neoplasm. The familiarity of the senior author with the incorrect observations of Brodie, and the similarity that exists between papillomatous cysts and fibro-cystic sarcomata as pointed out later by Bowlby, led him to remark: "this tumor is most likely a cystic sarcoma-what is known as "Brodie's tumor."

The honor of having clearly differentiated the benign intra-cystic papilloma from malignant tumors belongs to the English surgeons, and in the writings of Williams, Sheild, Bryant and others we first meet with the terms "duct papilloma," nonmalignant villous papilloma," etc. Williams remarks "under the term villous cancer as hitherto commonly employed, at least two perfectly distinct kinds of neoplasms are included, viz., the non-malignant villous papilloma and the malignant tubular cancer" (adeno-carcinoma).

Contemporary writers of the German school, including Sasse, Tietze, and Schimmelbusch, defined the disease as "cystadenoma papillare," "intra-canalicular cystadenoma," or "papillary cystoma," but looked upon this condition together with abnormal involution and carcinoma as steps in the progress of one disease.

The investigations of Warren and Ill in I905 finally settled the classsification of these tumors both pathologically and clinically. It is an interesting fact that Ill arrived

${ }^{1}$ Bowlby.- "The Clinical Course and Structure of Duct Cancer or Villous Carcinoma of the Breast" (St. Bartholomew's Hospital Reports, r888, V, 24). 
at correct deductions notwithstanding an almost complete ignorance of the work of previous investigators. Warren, Greenough and Simmons, Bloodgood and others have made intra-cystic papilloma a definite clinical entity.

Incidence (General).-The intra-cystic papilloma, according to the figures of Warren, comprise 0.015 per cent. of all mammary tumors (I 2 cases among $75^{8}$ breast tumors) and 0.049 per cent. of benign mammary tumors (I 2 cases among $24 \mathrm{I}$ breast tumors). Greenough and Simmons collected 20 cases including the 12 cases reported by Warren. Our own personal experience with this particular variety of tumor, in keeping with that of most other surgeons, is meager, only one case having come to our notice among a consecutive series of 100 cases of benign mammary growths admitted to the wards of the German Hospital. It was an atypical case, recognized only after excision.

The following discussion is based upon an analysis of 40 cases collected from the literature.

Sex Incidence.-Intra-cystic papilloma is essentially a tumor of the female breast. There are, however, a few recorded cases in which tumors identical in structure and giving rise to the classical symptom complex of the growth as it occurs in the female were removed from the breasts of men. In several of these, the tumor had undergone malignant transformation. An instance of this is reported by Peachell (Lancet, I906, Dec. I5, p. I660).

Male, aged 58. Mammary tumor of two years' duration. Small and irregular in outline. Soft in consistency and non-adherent to the skin or underlying tissues. Axilla not involved. Bloody discharge from the nipple. Diagnosis: Duct papilloma. One year later the patient again presented himself, when the growth had become hard and adherent to the skin and pectoral fascia. The patient died nine months after operation of intercurrent disease. There was no recurrence of the cancer.

At a meeting of the Pathological Society of London in 1892 , Shattock (Trans. Path. Soc., London, Vol. 43 , I892, p. II9) presented a male breast containing columnarcelled (duct) cancer which was similar in many respects to the foregoing.

"The breast was removed from a man 57 years of age by Mr. Mackellar. The tumor was of three years' duration; it was spheroidal in outline $(2.5-\mathrm{I} .5 \mathrm{~cm}$.) and was situated immediately beneath and in close relationship with the nipple. The growth was enclosed in a capsule which is firmly adherent to the surrounding tissues. In consistence it is moderately firm and to the naked eye presents a distinctly alveolar structure. Histologically the tumor consists of mutually adapted channels, all of which are lined with a single layer of well-formed columnar epithelium. The channels have a distinct lumen, though this is mostly occupied with secretion. Whether the tumor has arisen from the ducts by outgrowth into the surrounding tissues or has been preceded by the formation of a cyst, is now beyond determination."

The following typical case of intra-cystic papilloma of the male breast is described by Russell. Note the absence of the characteristic clinical signs.

Man, aged $5^{6}$ years. Four months ago the patient noticed a small, hard, painless lump in the left breast. The tumor gradually grew until it had reached the size of an orange and had involved the entire breast. It was tender and fluctuating in the region of the nipple, but there was no discharge from the latter. The tumor was of dense consistency in its periphery. The axilla was normal. No etiological factor was determinable. Simple amputation. Diagnosis: Papillary cystadenoma.

Strasser (The Post-Graduate, I909, 24, 57I) assisted in the removal of a typical intra-cystic papilloma from the breast of a man aged 63 . The tumor was of four years' duration and during the last half year of its existence had been associated with a serosanguineous discharge from the nipple. 
In Spencer's case (Westminster Hospital Reports, I895, No. 3, 9I-92), which was probably not a true intra-cystic papilloma, the tumor had been present since birth. Rapid enlargement began when the boy was four years old and reached the size of an egg in three weeks. It consisted of multiple cysts with bloody fluid.

Williams quotes from the Pathological Catalogue of the Hunterian Museum as follows: Specimen No. 4752a, Path. Series, Path. Catalogue, Appx. 5, I89I.

"A male breast showing two oval cysts beneath the nipple and areola, separated by a thin fibrout septum, the larger one measuring $x$ inch in the longest diameter. Each cyst is filled with blood clos. The specimen was removed from the mammary region of a man aged 49 years, who $r 5$ years previously first noticed a few drops of brownish discharge escaping from his left nipple. This continued for many years. About four years before operation the discharge ceased, and the tumor then appeared."

The following case history is taken from the series reported by Greenough and Simmons:

No. 21 I, I905. Dr. Wm. M. Conant. Man, aged 5r. Four months' duration. Tumor size of a walnut. Upper outer quadrant. Pain not marked. Bloody discharge from the nipple on pressure. Amputation with dissection of the axilla. Papillary cystadenoma. Examination 16 months later, no trouble.

Additional cases in the male are reported by De Morgan (British Med. Jour., Vol. 2, I863, p. 542), Hewett (Lancet, Vol. 2, I863, p. 482), and Worbs (Inaugural Dissertation, Bonn, I902; this is probably a large fibro-cyst adenoma).

Age Incidence.-The age incidence of intra-cystic papilloma of the female breast is shown in the following tables:

Table I.-Age Incidence in Our Series of 40 Collected Cases
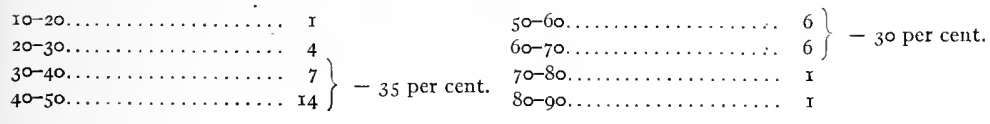

40

The average age incidence in this series was 46.6 years; according to Warren it is 52 years; Williams found it to be 43 years, and Greenough and Simmons estimate it to be 49.5 years. The youngest and oldest patients are reported by Greenough and Simmons, their ages being I9 and 8I years respectively.

Table II.-Age Incidence in Collected Series of Fifteen Cases (Williams, P. 372)
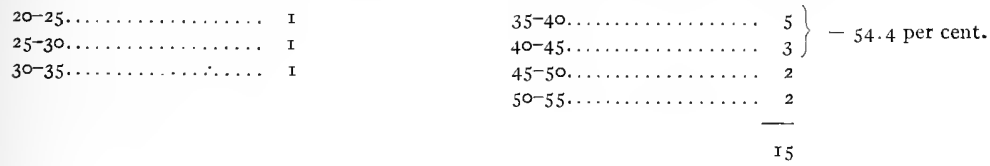

Predisposing Factors.-Trauma, child-bearing and lactation are of some practical interest in the general pathology of intra-cystic papilloma. Trauma seems to have been of predisposing influence in five of the I7 cases of the benign form reported by Greenough and Simmons, and in two of Williams' I8 cases. In one of the latter. 
the nipple had been severely bitten 22 years previously to the development of the tumor; in the other instance the disease was first noticed four months after the receipt of a blow on the breast. One of Ill's cases gave a history similar to that of the latter case of Williams.

Several of our collected cases had had previous attacks of mastitis or galactophoritis, but the evidence does not justify the conclusion that this has any etiological significance.

All authorities seem to be agreed that intra-cystic papilloma is a tumor of the breasts of prolific women, and conclude that pronounced functional activity of the gland predisposes it to this particular form of neoplasm. On close analysis, however, this relationship becomes more apparent than real, for while a definite percentage of the women are multiparous, the disease is by no means uncommon in those who have never conceived. Thus in our collected series of 40 cases only 20 (5० per cent.) of the patients were parous women and the average number of children borne by them was 4.8 . If we now take into consideration the fact that the majority of women between the ages of 40 and 60 are married women, the influence of child-bearing loses much of its significance as an etiological factor in the development of this tumor.

The question of heredity may be dismissed as being unimportant.

Symptoms and Diagnosis.-Discharge from the Nipple.-The most important symptoms of intra-cystic papilloma of the breast are discharge-often bloody-from the nipple and the presence of a rounded tumor situated beneath or close to the nipple. These signs are not invariably present, however, the discharge being present in only 75 per cent. of cases, while the tumor is not always central in position. Again, a centrally located tumor is not always of this variety and, to complicate matters still further, discharge from the nipple, bloody or otherwise, sometimes occurs from other causes. It is incorrect therefore to speak of any one symptom as being pathognomonic of this particular type of tumor. The fact remains, nevertheless, that spontaneous bleeding from the nipple, either continuous or intermittent in type, or a bloody mammillary discharge following pressure when applied to the breast are due in the vast majority of instances to intra-cystic papilloma, and the presence of a slow-growing tumor in the center of the organ, together with a bloody discharge from the nipple, is practically diagnostic of it. Discharge from the nipple, either bloody, lactescent, mucoid, thick brownish, serous, or purulent, may occur in association with other benign tumor diseases, with malignant tumors, either carcinoma or sarcoma, in cases of duct cancer, cancer cysts, chronic galactophoritis, certain granulomas, after traumatic injury, and finally it may perhaps be an indication of vicarious menstruation.

In our experience, discharges from the nipple are rarely associated with benign mammary tumors; they occur very commonly in advanced cases of carcinoma, and are only occasionally seen in cases of peri-ductal sarcomas. In tumors other than the intra-cystic papilloma, the discharge is prone to be serous rather than bloody in character, or thick brownish in character if mixed with blood. According to Gross, mammary carcinoma is associated with discharge from the nipple in 7 per cent. of instances. Discharges caused by cancer are irritating and frequently cause an eczematoid excoriation of the nipple and areolar coverings, a condition rarely if ever present in other conditions.

Inflammation of the milk ducts is associated with a muco-purulent or sometimes frankly purulent discharge from the nipple; this may or may not be streaked with blood.

Four of our patients with primary tuberculosis of the mamma complained of discharge from the nipple, in one instance bloody in character (Scott, St. Bartholomew's Hosp. Reports, I9०5, Vol. 40). 
There is nothing of particular interest ordinarily in the occurrence of mammillary bleeding after traumatic injury to the breast, but in the case of one of our patients this symptom immediately followed the receipt of a blow and continued for one year, when a scirrhus cancer made its appearance. In the following exceptional case symptomless bleeding took place from the nipple of an apparently healthy breast.

Mrs. S., aged 70 years. (German Hospital of Philadelphia) Para 3. Menopause at 50. For about Io years the patient had noticed intermittent bleeding from the right nipple. The bleeding stopped two years ago, and examination of the breast showed nothing abnormal to account for this unusual occurrence. Four years ago she noticed a small lump in the left breast which has grown progressively larger. There is no history of injury. The growth is neither painful nor tender. Her general physical condition is excellent except for the presence of a small superficial epithelioma of the right cheek, of one year's duration. The left breast is swollen to the size of a small grape fruit. A fluctuating, freely movable mass occupies practically the entire breast. The overlying skin is bluish gray in color, but it is not adherent to the tumor mass. The nipple is inverted; the axillary glands are not palpable. Simple amputation. Diagnosis: Benign cyst.

The specimen was found to consist of a large tense cyst occupying practically the entire breast with atrophy of the normal breast tissue. It was filled with brown grumous material and its walls were smooth and free of papillary excrescences. Certain reddish brown spots in the lining of the cyst wall denoting areas of superficial necrosis explained the bloody character of the contents of the cyst.

Microscopic examination of various sections taken from the thickened areas of the cyst walls showed the presence of many minute cysts together with an adenomatous arrangement of the enclosed epithelial elements. This strongly suggested the probability that this is not a simple cyst but an area of abnormal involution in which the unusual development of one cyst is the dominant feature of the disease.

The rarest cause of bleeding from the nipple is vicarious menstruation, an interesting example of which has recently been described by Hirschberg (Centralbl. f. Gyn., I9I4, 38 , p. 939) who states that the condition has been described only twice before. The history of the case is as follows:

An apparently healthy young woman, puberty at the age of Ir. Menses always regular and profuse. At 15 the breast began to secrete a watery fluid at each period but at 17 this became bloody. For the following ro years the patient had at each period a day or two before the uterine bleeding and for six or seven days after its cessation, a discharge of blood from both breasts-more profuse from the right-at times spontaneously, at others only on pressure. Drawing pain. Two miscarriages, one at the fifth month, one at the fourth month. During the pregnancies bleeding from both the uterus and breasts ceased, but came on again after the discharge of the ovum the first time. Since the second pregnancy in Ig10, the bleeding from the nipple has never reappeared.

Hirschberg attributes the condition either to some disturbance in the glands of internal secretion or to a blood-vessel neurosis.

Frank bleeding from the nipple occurs in only about one-half the cases of intracystic papilloma, but an additional 25 per cent. of cases are associated with serous discharge. The latter usually contains blood in microscopic amounts.

The circumstances attending the bleeding are in certain instances almost diagnostic of this particular type of tumor. Thus the bleeding may continue for a time and suddenly stop with the appearance of a centrally located cystic tumor, or coincident with the sudden enlargement of a tumor that has been existent for some time. The latter was the course of events in Williams' case which is quoted in full above. A similar history was given by one of Murphy's patients. (Surgical Clinics, Vol. 3, No. 4, August, I9I4.)

Woman, aged 46 years. Twelve years ago, in r 902 , first noticed a slight milky discharge from the nipple of the left breast. This discharge came, she says, just as milk would come when she was nursing her children, and amounted to about $1 / 2$ dram per day. The discharge continued and became bloody in char- 
acter during the following year. In the year I9I 2 , she first noticed a small hard nodule about $1 / 2$ inch in diameter directly above the left nipple. About the same time the discharge from the breast gradually disappeared. The tumor has gradually grown until it is now about the size and shape of a hen's egg and is freely movable on the deep structure and the skin is freely movable over it. The growth, situated just behind the nipple, is wooden in consistency but not tender. The patient says she often has sharp shooting pains in the breast. She can recall no injury or infection of the breast. The axillary glands are not palpable. She has lost no weight since the tumor was discovered two years ago.

\section{The following notes are abstracted from Murphy's comments up on the case:}

"When the patient presented herself she had a large nodular mass just above the nipple which was diagnosed as cystic on account of a difference in the resistance detected in different areas of the mass. The cyst was thought to be multilocular because bloody fluid was aspirated from one part of it and clear fluid from another part. Withdrawal of the fluid caused most of the tumor to disappear but a hard mass was left above the nipple. The excised breast was opened and a villous growth presented itself arising from an otherwise smooth cyst wall. The cut surface of the solid portion of the tumor was encapsulated and apparently situated on the side of the cyst wall whence the papilloma sprang. The condition was suggestive of malignancy and the axilla was therefore dissected. The pathologist's report was as follows: The specimen removed from the breast at operation gives the gross and microscopic appearance of a chronic cystic mastitis, a single large cyst near the nipple contains a cystadenoma papilliferum, probably malignant.".

In a case reported by Lerat, "Tumeur du Sein" (Épithélioma et adénome kystique avec proliferation épithéliomateuse, Gaz. méd. de Nantes, I9г2, 30, p. 293), bleeding from the nipple preceded the development of the lump by seven years, and continued in the presence of the tumor; the latter it will be noted was in an unusual situation and was fluctuant.

Woman, aged 39 years, two children, second at the age of 3 r. After weaning the second child (seven years ago), she noticed a sero-sanguineous discharge from the left nipple and at the same time felt some pain in the lower part of that breast. No tumor was to be found and seven months ago the breast became acutely painful, and a small nodule appeared in the lower part of the breast. The breast was not enlarged and the skin was normal. A small irregular horseshoe-shaped mass is palpable in the lower part. The skin above the growth does not suggest orange skin to the touch nor is it supple nor soft. A mass as large as a walnut was palpable toward the axilla and seemed separated from the tumor itself by a ridge about the width of the finger. Distinct fluctuation could be elicited. Clinical diagnosis-malignant tumor. Radical amputation. Microscopic diagnosis-cystadenoma-cylindrical-cell-and epithelioma.

A case similar in many respects to the foregoing was presented by Vignard at a meeting of the Pathological Society of Nantes in November, I9x.

Woman, aged 6I years. Four years before operation, she noticed a bloody discharge from the nipple. This continued until about one year ago; a tumor about the size of an almond then appeared external to and below the nipple. It was hard, lobular and non-adherent to the skin. Subcutaneously it seemed to be prolonged by a tract extending toward the nipple which was slightly retracted. The growth was slightly painful; axillary involvement doubtful. Physical examination showed a "bilobate pouch" in the lower external portion of the breast; this proved to be a cyst with intra-cystic projections. The diagnosis was "intra-canalicular epithelioma."

Bloody discharge from the nipple is rarely associated with adeno-fibromata; the following case is therefore exceptional. (Vignard, Gaz. méd. de Nantes, I9 1 2, 30, 35).

Delicate girl, 24 years old. Since puberty had a painless tumor in the lower inner quadrant of the left breast. About two months ago noticed a slight bloody discharge from the nipple, one or two drops. The tumor is lobular, mobile, consistency that of an adenomatous cyst. The microscope showed an ordinary adeno-fibroma in connection with the milk ducts. 
Pain.--Intra-cystic papillomas are painful in 32.5 per cent. of instances but the suffering is rarely complained of as being intense. There are curious exceptions to this rule however, when very severe pain is attributable to sudden distention of the cyst as the result of profuse intra-cystic bleeding. The tumor under these circumstances may become exceedingly tender to the touch. In at least two-thirds of the cases, the disease pursues a painless course throughout, and in the absence of a discharge from the nipple, the tumor is usually discovered accidentally.

Duration.-The intra-cystic papilloma is a slow-growing tumor, the average duration in our collected series having been 25.67 months. The average duration of the other forms of benign fibro-epithelial tumors in our experience is 5.9 months.

One of the patients in Ill's series presented herself in the third year of the disease and was kept under observation for a period of nine years before the growth was removed.

Mrs. E. G., colored, domestic, married, no children, was sent by her mistress in May, 1893 , because of a discharge from the left breast. The woman was 43 years old, menstruated regularly, and was in good general health. Several years previously had a large, bleeding fibro-polypus removed from the uterus. There was a discharge from the left breast copious enough during the day to produce several spots, as large as a silver dollar, on a handkerchief. Menstruation had no effect on the discharge. The discharge was yellowish, transparent fluid, which, under the microscope, showed a few red blood corpuscles and lencocytes. An oblong mass about $2 \mathrm{~cm}$. in diameter and $\mathrm{x} \mathrm{cm}$, wide was discovered running from a little beyond the nipple inwardly. Gentle pressure on this mass showed that the discharge came from that source.

By June, 1900, the mass had grown somewhat larger and the discharge more copious. In 1903 it was noticed that the tumor had become multinodular, with a greatly increased quantity of flow from the nipple. These masses had a doughy and slightly fluctuating feel. On Mar. x $_{3}, 1_{905}$ ( 12 years after the onset), the breast was removed. The tumor proved to be an intra-cystic papilloma.

The Tumor.-The size has in a general way a definite relationship with its duration, but this is not an inflexible rule by any means since intra-cystic papillomas of long duration may remain very small. They rarely become larger than an orange, however long their existence, their average size being about that of an English walnut.

Location.-These growths, in contra-distinction to the other members of the fibroepithelial group of mammary neoplasms, are seldom multiple or bilateral. Both breasts are equally affected. In $\mathrm{r} 2$ of our collected series of cases the tumor mass was central in position; in 18 cases it was spoken of as being "near the nipple;" in nine instances it was not mentioned as having any relationship with the nipple. The majority of this group occupied the upper outer quadrant of the breast; multiple tumors were noted in only one case. Other types of mammary tumors may occupy the central area of the breast, especially the peri-ductal fibromas, so that the location of the tumor in itself has only a relative diagnostic value.

W. S. Forbes (Medical News, 60, r, r892, p. 269) describes the unique case that occurred in an aberrant breast nodule.

Mrs. S., aged 48 years. Weight 385 pounds. Never pregnant. When examined Dec. 18 , 191 r, a tumor was found in the left upper quadrant of the left breast. Both breasts were huge and pendulous. The patient had observed a lump in the left breast for 10 years but only in the last 12 months had it begun to enlarge. The tumor was freely movable. It appeared to be fibroma lodged in a mass of fat, having no bands binding it either to the pectoral wall or to the mammary gland. Simple excision. Microscopic examination by Dr. Coplin who pronounced it a papiliferous fibro-cystadenoma (solid).

General Physical Characteristics.-Intra-cystic papillomas of the breast are usually oval or rounded tumors or elongated rounded swellings situated near the nipple with their long axes running from it in a radial manner, parallel to the main milk ducts. 
In outline they are generally irregular and lobular or lumpy, and rarely do they form a single rounded smooth tumor that resembles a simple or benign cyst. Their consistency depends more upon the nature of the contents of the cyst than upon the structure of the cyst wall. The majority of them give the impression of solid growths to the palpating finger. A feeling of elasticity is imparted to the examining finger when the contents of the cyst are largely fluid, however great the tension under which this is held. In cases where the cyst is packed full of papillomatous tissue, the tumor is virtually a solid growth and feels like one. Many of these tumors vary in consistency in different areas, one portion being hard and nodular, another, often small area, being elastic or even fluctuating. In cases of this kind, the possibility of carcinoma must be taken into consideration, and it is advisable to aspirate the fluid when a better opportunity will be afforded for a more thorough examination of the solid portion of the mass.

The tumors are usually well circumscribed and freely movable, being unattached to the skin or pectoral fascia. They rarely project beyond the normal level of the mammary skin, and the latter is in every way normal in the average case. Retraction of the nipple is usually indicative of carcinomatous change in the tumor but to all of these rules there are interesting exceptions. The following case history is illustrative of several of these exceptions.

J. B. Sutton (Trans. Path. Soc., London, Vol. 43, I892, p. II7).

Tall, stout woman, aged 68 years. Thirteen children. Tumor of left breast. Two years' duration. Slowly increased in size. No pain. During the past six months free discharge of blood from the nipple. On examination, a tumor the size of a Tangerine orange was found in the left breast immediately to the outer side of the nipple which was retracted. The tumor stood above the level of the surrounding skin which was deep red in color. A small soft tuft of granulation-like tissue, resembling a small ripe mulberry, projected into the bay formed by the retracted nipple, and from this the bloody fluid appeared to ooze. The skin over the tumor was smooth and tense. There were no enlarged glands. The breast was removed. ít contained an encapsulated cyst lying immediately beneath the skin and encroaching upon the nipple. The whole of the cyst was filled with a mass of soft tissue of a deep mahogany color. When carefully hardened and subsequently examined, the intra-cystic mass was found to grow from a broad base attached to the portion of the cyst wall nearest the skin. Near the nipple some of the warty growth had made its way through the cyst wall into the recess formed by the nipple, and appeared to be the source of the blood-stained fluid. Microscopic diagnosispapillomatous cyst.

The fact that intra-cystic papillomas rarely involve the skin makes the following case exceptionally interesting. (BowLBY, Case 4, p. 205.)

Mary A., aged 67 years. Admitted in r887. Married, no children. Lump in the inner half of the left breast. Four years' duration. Quiescent for three years. Past year painful and discharging dark red fluid from the nipple. A fortnight ago the breast became suddenly inflamed and swollen and has continued so ever since. Inner half swollen and the overlying skin red. Firm, irregular, lumpy in consistence. Fluctuation at two points. Nipple normal. One enlarged gland in axilla. Poulticed until Aug. 3r (admitted Aug. 25) when the tumor burst and discharged a small amount of reddish fluid. On Sept. 2 , the cavity which had burst was opened and a little pus and a good deal of blood-stained fluid escaped. Amputation Sept. 15. Most of the breast healthy. The walls of the cyst were found to be smooth, and no solid portions were found. On the inner side of the nipple another cyst was found. It contained blood-stained fluid and a soft papilloma. The latter was granular, friable and dark red in color. This was continuous with a very hard, dense and nodular tumor, situated partly in the wall of the cyst, and partly in the surrounding breast tissue, and looking on section like a scirrhus cancer. " No microscopic examination.

Retraction of the nipple does not occur in uncomplicated cases, but the papillomas have been known to project from the milk ducts and appear on the summit of the nipple 
as warty excrescences. A beautiful illustration of this is shown in Plate I, Fig. 3 of an article by J. Howell Evans in The Practicioner, London, 19r3, 9I.

A similar case is described by Pollard (Trans. Path. Soc., London, 1886, 37, 483, Plate I 7 , Figs. 2-3).

Female, aged 50 years. Six children. Twelve years ago when six months pregnant first noticed a slight bloody discharge from the nipple; this continued for three years then a soft warty growth the size of a pea projected from the nipple. This was ligatured and removed but it soon grew again. It was next burnt off but it still grew and the bloody discharge continued. Patient first seen by Mr. Farnell two and a half years ago; at that time there was a hard lump in the breast around the nipple and extending 2 inches to its outer side. Blood-stained discbarge from the nipple continued and was increased by pressure over the tumor. Skin not adherent. No axillary involvement. October, 1885, simple amputation of the breast by Mr. Farnell. Encapsulated tumor, friable, typical arborescent papilloma.

Axillary gland involvement if present in uncomplicated papillary cystadenoma is merely incidental and bears no relationship to the tumor itself.

Differential Diagnosis.- Intra-cystic papillomas are likely to be confounded with simple cysts, cancer cysts, primary duct cancer, peri-ductal fibromas or fibro-cystadenomas, with other forms of benign tumors, or with malignant tumors.

Slow-growing tumors situated in the center of the breast and attended by a bloody discharge from the nipple are almost invariably intra-cystic papillomas. In the absence of one or more of these important symptoms, the diagnosis can rarely be made with any degree of positiveness, and as shown above, each one of these symptoms may occur in certain other tumor diseases so that the diagnosis can only be made with certainty when the typical symptom complex is present.

Benign cysts and cancer cysts are rarely associated with discharge from the nipple. The clear contents of the former obtained by aspiration may assist in the differentiation from papillomatous cysts, the contents of the latter being bloody in the majority of instances. Cancer cysts if existing for some time will most likely show some of the characteristic signs of malignancy, in the absence of which the diagnosis will be impossible. The common varieties of carcinomatous tumors, scirrhus, adenocarcinoma, etc., will resemble papillomatous cysts only when they occupy the central areas of the breast or when they are associated with a bloody.discharge from the nipple, both of which are rare occurrences.

Cysts in association with abnormal involution may be situated in the central portion of the mamma; they sometimes contain papillary excrescences which may give rise to bleeding from the nipple. It is a question whether some of the reported cases are not really localized areas of abnormal involution with marked cyst formation. The pathology of the two conditions may be dissimilar but the clinical signs are absolutely identical in certain instances. In the great majority of cases, however, abnormal involution affects the peripheral areas of the breast, involves a large part of the organ, and produces an irregular lumpy condition that should not be mistaken for the intra-cystic papilloma.

Fibro-cystic sarcomas are rapid in evolution, occur in younger persons, are rarely associated with bloody discharge from the nipple, and soon produce a large lobulated mass that can scarcely be mistaken for intra-cystic papilloma.

The other benign mammary tumors that occur in the breasts of young women, are frequently multiple, seldom give rise to mamillary bleeding or other discharges from the nipple, are centrally located in only 7 per cent. of cases, and seldom contain cysts of 
demonstrable size at the time at which they are subjected to operation. The chief clinical features of intra-cystic papilloma may be summarized as follows:

It is a tumor that usually occurs in the breasts of women who have passed the menopause. It may occur at any age, and is independent of trauma, lactation or pregnancy.

Males are sometimes affected.

The tumor is almost invariably unilateral and single. It is is irregular in outline.

It is often found in the center of the breast but may be situated in the peripheral portions of the organ.

It is a slow-growing tumor, rarely attains great size, and is not subject to sudden and capricious increases in size, except as the result of trauma-to the same extent as are other cystic tumor diseases of the breast.

Its consistency varies not only in different tumors but in different parts of the same tumor; as a rule, an area of elastic consistence can be demonstrated.

The tumor varies in size from that of a filbert to that of an orange.

Pain occurs in one-third of all cases but the suffering is rarely intense.

The nipple is never inverted in uncomplicated cases.

Enlargement of the lymph nodes in the axilla, if present, is coincidental and is never caused by uncomplicated papillary cystadenoma.

Bloody discharge from the nipple is the most characteristic clinical sign but is not pathognomonic of the disease; it occurs in 50 per cent. of the cases. Discharge unmixed with blood takes place in 25 per cent. of the cases.

The tumors are associated with caricinoma in a definite proportion of the cases, but it seems probable that duct cancer is a clinical entity sometimes wrongly attributed to the carcinomatous transformation of intra-cystic papilloma.

Prognosis.-Spontaneous cures have been reported by Bowlby, but there is certainly no justification for believing that this will take place in any given case or for awaiting its occurrence.

This variety of tumor is believed to be particularly susceptible to malignant transformation but in at least some of the cases quoted to prove this relationship, it seems likely to us that the disease was carcinomatous from its onset. According to Bloodgood, carcinoma supervenes in 50 per cent. of the cases; Greenough and Simmons estimate that I 5 per cent. of the tumors become cancerous. The particular type of cancer that succeeds these growths is said to be of a low grade of malignancy, but this is not an argument for delaying operation, inasmuch as excision of an uncomplicated benign tumor will result in Ioo per cent. of cures, when with the advent of carcinoma, not only does the radical operation become necessary, but the chances of permanently curing the patient are materially lessened.

Interesting examples of local recurrences following the removal of papillomatous cysts have been reported, from time to time. The specimen which, according to Shattock first established the local recurrence of "villous papilloma," was shown by him before the Pathological Society of London in I882. (Specimen C, 216, St. Thomas Hospital Museum, Tr. Path. Soc., London, I882, 8, 39, 324).

The specimen consisted of portions of two ribs from the left side, each of which was the seat of a secondary new growth. These bones were taken from a woman, aged 60 years, whose left breast had been amputated a few weeks before her death.

\section{Repeated local recurrences were observed by Bowlby (Case 5).}

Woman, aged 43 years. Single. Admitted Sept. 16, r883. Lump in the left breast of five months' duration. Several small rounded swellings. Axilla normal. Nodules excised. Returned in May, I 887 with recurrence of one year's duration. An irregular, lobulated tumor situated on the inner side of the nipple, with a bossy outline and a feeling of elasticity, or almost of fluctuation, in parts. Skin 
normal, no discharge from the nipple. May 5, 1887, simple amputation. Tumor consisted of multiple cysts containing dark red, very soft, friable solid growth, and blood-stained serum. Some of the growths were in the fat around the gland. March, 1888 , the inner end of the scar contained a small nodule, the size of a hazelnut, similar to the others but not so pigmented.

The question of recurrence of villous papillomas or duct cancers as they were then called, was discussed by Charles. A. Morton in 1894 , with the report of an unusual case.

Woman, aged 53, admitted to the Bristol General Hospital in November, I 892, with a large recurrent tumor of the breast. Primary operation; simple amputation three years before. The breast was reèxamined after her return; it contained a multicystic tumor each cyst being filled with papillomatous friable tissue. The growth began to recur two years after its removal. Examination showed a hard irregular mass the size of a cocoanut under the old scar. It was adherent to the scar but not to the muscle. Axilla normal. The tumor measured $5^{\frac{1}{2}}$ by 4 inches after its removal. On cutting into the tumor, dark red blood in quantity poured out. A number of cysts was found each containing either soft, white papillomatous growths or altered blood clots. The tumor was similar to the parent growth only not so solid.

Of the I7 cases of non-malignant intra-cystic papillomas in Greenough and Simmons' series, "seven had an amputation of the breast, eight had the tumor excised by a plastic or direct incision, and two by the areolar incision. In one of the amputation cases, the axilla was also dissected." The results were as follows:

"Of the seven amputation cases, one patient could not be traced, five were free from the disease at periods of one, one and a half, two, three and eight years after operation, and one died of senility three years after operation without recurrence. Of the ten excision cases, three were untraced, one showed a local recurrence of the tumor six months after operation; this had persisted for one and a half years without further increase; another showed a local recurrence $I 8$ months after operation, which was removed and the patient has not since reported; the other five cases are free from the disease from one and one half months to four years after operation. Of the two cases of recurrence, one was proved by microscopic examination to be similar to the original tumor and non-malignant, and the other had existed without change for the three and a half years, so that the presumption is fair that complete removal of the original tumor was not obtained at the first excision."

The results just quoted would seem to justify the conclusion that complete excision of papillary cystadenomas effects a permanent cure; the one point of great importance is the determination of the presence or absence of carcinoma at the time of operation.

Treatment.-Small intra-cystic papillomas can sometimes be removed satisfactorily through an areolar incision. This method is applicable only to cases in which the tumor is small; it is especially useful where the breast is very large, otherwise the method of plastic reaction is preferable. The incision is made to follow the periphery of the areola through one-third or more of its extent and is placed directly over the tumor. Its edges are retracted and the tumor is dissected out, but in so doing the knife must be carried parallel with the milk ducts to avoid injuring them.

Eccles (Med. Press and Circ., I905, 6, p. 543) advises that the nipple be split into two exact halves and the growth traced to its final limits and dissected out. The two halves of the breast tissue and nipple are then approximated by four silk sutures, two of them buried and two inserted in the superficial tissues. Eccles states that the wound heals rapidly without deformity of the nipple and that the scar in the areola and mammary skin is practically invisible after a time.

Large intra-cystic papillomas necessitate simple amputation of the breast. In all cases, whether the tumor be large or small, and whatever method of operation be employed, the presence or absence of carcinoma must be determined at the time of operation.

Preliminary incision into themass is contra-indicated; the tumor if small should be excised and immediately examined for carcinoma; in the case of large tumors, the 
breast should be removed and the same examination made. If the suspicion of malignancy exists, it is better to err on the side of safety and do a radical amputation at once.

III. Cysts Occurring in the Stroma of the Breast.-These may be divided for convenience of discussion into the following:

r. Lymphatic cysts.

2. Hemorrhagic cysts.

3. Parasitic cysts.

I. Lymphatic Cysts.- In their "Traité des tumeurs benignes du sein," ı876, p. $9 \circ$, Labbe and Coyne describe the lymphatics of the breast, with minuteness and point out the existence of "lacunæ" or lymph spaces lined by endothelial cells in the fibrillar tissue of the stroma. These spaces have been supposed by a few writers to be the starting points of certain small cysts, and a small amount of apparent confirmation of the theory was collected as will be shown below, but it is highly probable that the idea is erroneous, and that the confirmation depends upon errors of technic or of interpretation, as no one has added to the knowledge of the subject since 1885 . It is, therefore, very doubtful whether lymphatic cysts, in the sense in which the term was originally employed, ever occur.

Marshall and Gadsby (Lancet, London, 1878, I, 234) observed:

A woman aged 46 years, in whose right breast there was a mild inflammatory disturbance of six months' duration. No lump or tumor was discovered until two months before admission to the University College Hospital, London. At the time of admission the right breast contained a hard but painless nodule, as large as a "wood-nut," on the outer side of the nipple. The breast was removed. It was found to be small and fibrous. The nodule turned out to be a cyst filled with brownish-mucoid contents, and to be one of a number of small cysts scattered throughout the substance of the breast, filled with contents, varying from brownish fluid, to cheesy semi-solid matter. The inner walls of the cysts were smooth and bright, the outer walls connected with the structure around. A piece of the cyst wall was torn off and stained with 0.5 per cent. solution of nitrate of silver, and found to be made up of endothelial cells exactly like those of the serous surfaces. The areolar tissue was in intimate contact with the walls of the cyst, there being no new growth.

In his interesting paper on "Cysts and Cystic Tumors of the Breast" (Lancet, London, $\mathrm{r} 884, \mathrm{I}, 748$ ) Butlin mentions four cases of cysts of the breast that he places in the group of lymphatic cysts. The one described in detail is as follows:

A woman between 40 and 50 years of age suffered from a blow, following which a tumor grew. At the end of three months it was thought wise to remove the breast, the tumor being regarded as cancer though there were no adenopathies. The operation was performed. When the tumor, which seemed to be about the size of a tennis ball, was incised, there was a spurt of fluid, and the whole thing collapsed. The tumor proved to be a smooth-walled cyst the size of a walnut. When the wall of the cyst was examined, it was found to be fibrous, and to be lined with endothelium instead of epithelium.

About a year later, Pollard (Univ. College Hospital Reports, r885, p. 76, r48) reported another case.

The patient was a woman aged 44 years, who two months before coming under observation, accidentally discovered a lump in her breast. No cause for its presence could be assigned. Upon examination, a tumor the size of a marble was found in the midst of an indurated lobule. As the lymph nodes were normal, the mass was dissected out, together with some of the indurated tissue. Upon examination the tumor proved to be a tense cyst, containing clear, straw-colored fluid. When the cyst wall was stained with nitrate of silver solution, a simple layer of epithelial cells some of which had wavy margins, was demonstrated.

In the paper already quoted Butlin endeavors to identify these cysts with the "simple cyst of the breast containing serous fluid" described by Birkett in his "Disease of the 
Breast," London, 1850 , and thereby to attract interest in them, though, so far as the subsequent literature is concerned, without success.

The explanation is very simple: There is no real evidence that there are such things as "lymphatic cysts" as differentiated from the common cysts of the breast. The ages of the patients coincide with the ages of those with other cysts; the contents of the cysts, so far as described are not peculiar. Gadsby's case undoubtedly falls into the class of cases now classified as abnormal involution, chronic cystic mastitis, cystic diseases, etc., so that the sole criterion upon which the question of the existence or nonexistence of lymphatic cysts depends, is the absence of an epithelial and the presence of an endothelial lining. To those superficially acquainted with pathology this may seem to be a matter of considerable significance, but to those better informed it is of no significance whatever. When a small epithelial-lined space undergoes cystic distention, the behavior of the epithelium is interesting to observe. It may be able to grow fast enough, through multiplication of its cells, to keep pace with the distention. But if it cannot do so, the traction of the enlarging walls first changes the cells from cylindrical to cuboidal and then from cuboidal to flattened, pavement-like cells. In other cases, the pressure and abnormal conditions incidental to the cyst formation may effect the destruction of the epithelial lining of the space through compression, etc. Thus it comes about that some cysts arising from epithelial-lined structures may be partly or entirely devoid of epithelial lining. Now when unlined cystic spaces endure a certain length of time, nature provides a modification of the regeneration processes that results in the covering of the wall of the space with endothelium, some of which may be derived from the endothelium of the basement membrane, or may be derived from the endothelial cells of the lymphatics of the tissue effected.

The absence of epithelium and the presence of endothelium, therefore, are of no importance in assisting in the discovery of the origin of a cyst once formed.

2. Hemorrhagic Cysts.-Michaux (Bull. et mém. de la soc. de chirurgie de Paris, I907, n. s., XXXIII, 52I, 560) published a paper entitled, "Kyste hématique du sein." Upon examination it proved to be the report of a case of a woman 74 years old, with hemorrhagic intra-cystic papilloma of the left breast. Pons (Marseille médicale, I908, $\mathrm{XLV}, 43$ ) also published a paper with the same title, "Kyste hématique du sein." The perusal of this paper also resulted in the discovery that the name was misleading. The patient was a woman of 40 years of age with a rounded tumor in the right breast. When removed and examined, it proved to be a cystic fibro-adenoma with hemorrhagic fluid in the cysts.

The only case answering the requirement that a space in the matrix of the breast shall be filled with blood-a true blood cyst-that has come under our observation is that reported by G. W. Gay- "Hæmatoma of the Breast," Boston Medical and Surgical Journal, I878, XCVIII, 90 (n. s., XXI, p. 90).

The patient was a negress aged 22 years, who, when eight years old, while playing on the ice, broke through and sustained a severe blow upon the right breast. Ever since that accident she has known that a hard lump existed in the right breast just below the nipple. Seven months before she was seen by Gay, it began to enlarge steadily, become painful, and finally became as large as a goose egg. There were no signs of inflammation, no heat, and little tenderness. It was movable over the muscles. An incision was made over the tumor, and by gentle pressure, a mass, resembling very much the kidney in appearance and texture, was squeezed from its sac; the sac, being firmly adherent, was left to slough away. Suppuration was very slight through the whole process of healing. The tumor was submitted to Dr. Bolles for microscopic examination, who reported it as "hæmatoma." 
IV. Cysts Occurring in Tumors of the Breast.-With the exception of colliquation cysts, the cysts that make their appearance in tumors of the breast, are the homologues of the cysts that make their appearance in the breast itself.

This statement is easy to appreciate in lieu of our interpretation of the histogenesis, behavior and transformations of the tumors.

The cystic tumors of the breast are almost without exception either fibro-epithelial or sarcomatous. In the chapter upon the former, the theory has been expressed that the tumors begin through abnormal vegetative activities on the part of minute focilobules of the breast parenchyma-that by growth push aside the adjacent structures, the atrophy and disappearance of some of which they occasion, and surround themselves by a capsule partly derived from the fibrillar tissue residum of the compressed tissue. As they increase in size, they sever their connection with the mother tissue through traction of the ducts which finally rupture, after which they remain isolated, slowly growing entities enclosed in the mother breast, of which they are overgrown parts, but with which they are no longer functionally connected. The same stimuli to activity that act upon the breast act upon them; the same products of secretion that are furnished by the breast occur in them; the same morbid changes to which the breast is susceptible threaten them.

In the chapter upon sarcoma, it has been shown by a great number of examples that the greater number of sarcomas, and practically all of the cysto-sarcomas originated through abnormal activities in already existing fibro-epithelial tumors. Thus, these tumors all have anatomical and physiological relationships sufficient to explain our preliminary statement that the cysts of the tumors are the same as the cysts of the breast. But cysts in tumors are immensely more frequent than in breasts because the first prerequisite of cyst formation, the closure of the ducts, is invariable in the tumors and rare in the breast, and because the conditions obtaining in tumors are abnormal as contrasted with the breast.

I. Retention and Exudation Cysts in Tumors.-The cysts, met with in tumors, contain fluid corresponding more or less perfectly with that found in the simple or serous cysts of the breast. It is commonly thin, and straw colored, but may vary through reddish to chocolate color, and from watery to gelatinous, according to conditions corresponding with those obtaining in cysts of the breast. Such are exudation cysts.

When the secretory stimulation associated with pregnancy and following parturition makes its appearance in the breast, it also commonly appears in the tumor. The result in secretion with outflow from the breast, secretion with retention in the tumor, and the exudation cysts may become transformed into modified retention cysts. The tumors vary in their secretory power, according to the degree of lactation hypertrophy that they have undergone.

In a few cases lactation occasions no change in a fibro-epithelial tumor but in the great majority of cases, the formation of acini takes place simultaneously in both breasts and tumor, hence, as the breast grows to prepare for lactation, the tumor grows and often astonishes or frightens the patient. Then lactation begins in the breast which suddenly enlarges with secretion, and the tumor either fails to participate or it suddenly grows immensely from the secretion and retention of milk.

Dr. Deaver operated upon such a case in the German Hospital of Philadelphia in rgr4. The patient. was a woman, S. R., aged 22 years, in whose left breast the tumor appeared shortly after the birth of a child and grew to the size of the fist in five weeks. The growth of the tumor was so rapid, the cystic dilatation of its ducts and spaces became so enormous, its tissue was so soft and fluctuating, that it was 
regarded as a galactocele, and carefully dissected out without opening. When examined in the laboratory, it was found to be a solid fibro-epithelial tumor, but with such distention of ducts and cystic spaces, and such edematous saturation of its stroma, that it was soft, gelatinous, translucent, and easy to mistake for a cyst.

The tumor, having no means of emptying its cavities, at once falls into the state of the unused lactating breast, the useless activity is soon checked and involution of the tissue and absorption of the fluid begins. We now see in the cyst of the tumor, what has been described as taking place in galactocele. The watery part of the secretion is commonly absorbed, but the proteins and fats of the secretion, whether the activity has occurred as the result of the patients lactating, or has occurred through some local stimulus independently of it, are to be found in the cysts in the form of milky, creamy or buttery collections. Both the simple serous cysts and the retention cysts may occur in the same tumor, either because of local differences in secretory activity in the different parts of the tumor, or because of the formation of new simple cysts by additional growth of the tumor subsequent to the cessation of the functional activity that has induced the formation of the milk and butter cysts.

2. Cysts by Softening or Colliquation Cysts in Tumors.- These are badly circumscribed spaces in the solid tissues of tumors, formed through the softening or liquefaction of dead or diseased tissue. Their exact appearance depends upon the length of time they have existed. When the colliquation has recently begun, areas of tissue may be so soft as to permit the finger tips to enter and displace a pulpy substance, where no visible cyst or actual cavity previously obtained, the softened and degenerated tissue gradually fading away into the more healthy tumor tissue round about it. When older, the incised surface may show a space, a group of spaces, or be honeycombed with spaces of varying size, varying in circumscription, the contents being slimy or mucilaginous, or blood-stained and grumous, and the ill-defined walls soft and necrotic. When very old, which is a condition not likely to present itself in tumors, they become filled with a more slimy or gelatinous material, surrounded by a thin layer of connective tissue or immediately by the cellular tissue of the tumor.

Such cysts occur in myxoma, myxo-sarcoma, sarcoma, and rarely in carcinoma of the breast. Compared with the other forms of cysts that occur in tumors of the breast, they are rare and of little importance.

\section{PARASITIC CYSTS OF THE BREAST}

Echinococcus or Hydatid Disease of the Breast.-In the older writings upon the diseases of the breast, there is frequent mention of the occurrence of "hydatid cysts," whereas in recent writings the condition is either ignored or dismissed with brief and casual mention as being exceedingly rare.

The explanation is simple: the older writers used the term in its general etymological sense, and looked upon any cyst as a "hydatid," that was filled with watery fluid (the word hydatid being derived from the Greek, í $\delta \alpha \tau$ is, through the Latin, hydatis, meaning a watery vesicle); the recent writers use the term in its modern, restricted parasitological significance, for the cystic embryo of a cestode worm, the Tænia echinococcus.

The latter, which is now universally regarded as the only legitimate usage of the word, made its appearance in the literature of surgery somewhat slowly, as the facts concerning hydatids were being discovered and published. 
The determination of the nature and life history of the echinococcus is interesting and may be summarized as follows: In I 760 Pallas seems to have been the first to recognize that the hydatids were independent creatures related to the bladder-worms. Göze recognized the "moleculas singulas ex atomis, innumeris oblongis compactas," described by Pallas, as the heads of tapeworms and described the suckers and circlet of hooklets. Brenser in I82I gave the first exact description of the echinococcus of man. In I853 von Siebold in Breslau and Küchenmeister in Zittau fed the contents of echinococcus or hydatid cysts of cattle, to dogs and observed the development of Tænia echinococcus in the dog intestines. In I 862 Naunyn and later Krabbe and Finsen fed the contents of human hydatid cysts to dogs and observed the development of Tænia echinococcus in their intestines.

It thus gradually came to be understood that the true hydatid cyst was the embryo or larval stage of the Tænia echinococcus of the dog.

It also became clear that only a certain few of the cysts formerly included among the hydatids were of this nature. The difference beween the true hydatid and other cysts will become clear below:

Etiology.-The Tænia echincoccus is a minute tapeworm that lives in the small intestines of dogs, wolves, foxes, jackals, dingos and, more rarely, cats. It is from 3-6 $\mathrm{mm}$. in length, and consists of a head and neck, and three segments. The head is small, not more than $0.33 \mathrm{~mm}$. in breadth, and ends in a projecting rostellum provided with a double row of $25-50$ hooklets, there being about the same number in each. There are also four lateral suckers upon the sides of the head. The neck is short. Of the three segments or proglottides, the first is small, the second larger, the third as large as all the rest of the worm put together.

As is true of all cestode worms, the animal is a hermaphrodite, each segment being provided with male and female reproductive organs. As in all Tænias, the sexual openings are placed laterally at and alternately about the middle of one edge of the segment.

The last proglottid is alone gravid and may contain from 400 to 800 eggs, which are slightly ovoid and measure from $32-36 \mu$ in length by $21-30 \mu$ in breadth. Each contains a hexacanth embryo about $25 \mu$ in length.

There may be a single worm in the dog's intestine or there may be hundreds of them. From the gravid segment of each the eggs are expelled and leave the intestine in the feces. As the feces are broken up the eggs are set free and become mixed with the earth or may be blown about by the dust. By thus reaching articles of food and drink the eggs are occasionally taken into the human body.

The eggs may develop in any of a large number of mammals-man, monkey, dogs, bears, panthers, sheep, goats, cattle, camels, dromedaries, giraffes, elands, antilopes, hares, rabbits, mice, tapirs, zebras, horses, asses, hogs, kangaroos and even in a few birds such as peacocks.

It seems quite clear that the eggs must be swallowed as it is only by the gastric juice that their capsules are digested and the little larvæ set free.

The latter, in some unknown manner, penetrate the wall of the stomach or upper part of the intestine, and enter the lymphatics or the capillaries. In the former case they are carried to the thoracic duct, to the sub-clavian vein, to the right heart and to the lungs, where they may be caught in the capillaries, or failing to be caught may pass on to the left heart and then to the systemic circulation. In the latter case they are carried through the portal vessels to the liver in whose capillaries they may be caught or through which they may pass to the hepatic veins, vena cava, right heart and 
lungs, where a second capillary plexus may detain them. Again failing to be caught in the pulmonary capillaries, they may return to the left heart and be driven into the systemic arterial circulation to catch as accident may determine in the peripheral capillaries. Thus the greater number of embryos come to rest in the liver, and the next greater number in the lung, though it is possible for them to reach and remain anywhere in the peripheral capillaries, so that no part of the body is exempt from their occurrence. It is not known how many of the embryos survive in the tissues but, as it is a rare thing for the echinococcus cysts to be multiple in the same case, many of them doubtless die.

The embryo parasite, when favorably lodged, is very slow in developing. Leuckart studied it in the livers of artificially infected sucking pigs and found that in four weeks it had grown to be no more than $\mathrm{I} \mathrm{mm}$. in diameter. At this time it was always found

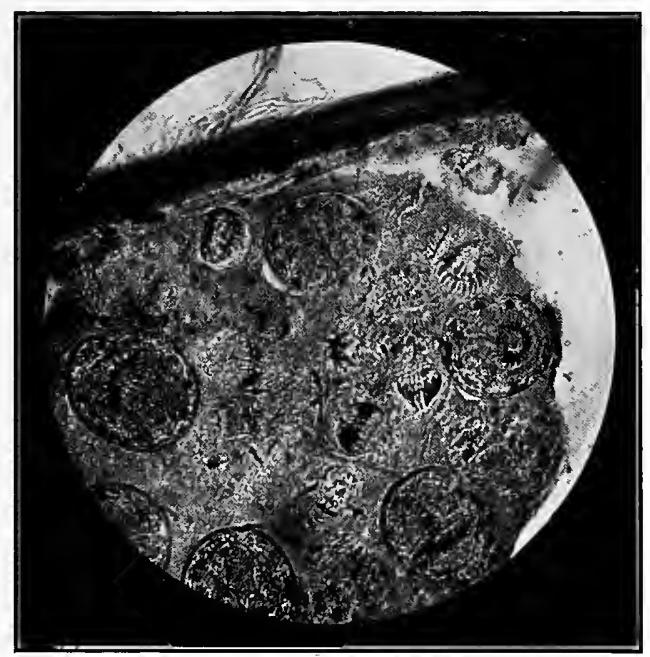

FIG. 133.-Groups of echinococcus embryos from the inner wall of an echinococcus cyst, showing the circles of hooklets.

upon the surface of the organ, and seen through its capsule, appeared to the naked eye much like a little miliary tubercle. Upon microscopic examination it was found to consist of a spherical or vesicular body not unlike a mammalian egg. A thick homogeneous capsule enclosed a somewhat coarsely granular highly refracting contents; the outer surface of the capsule showed a cellular texture; the whole thing was surrounded by a capsule of connective tissue of moderate thickness. In the course of eight weeks the parasites had doubled in size and appeared as small cysts with clear contents, when seen through the capsule of the liver. In the course of 19 weeks 30 to 40 nut-sized vesicles were found beneath the capsule of the liver. The walls of these were thick and firm and could be readily enucleated from the liver substance. The diameter of the cysts ranged from ro to $18 \mathrm{~mm}$., the thickness of the capsules was about $0.2 \mathrm{~mm}$. for each I $\mathrm{cm}$. of diameter. The parenchymatous layer, between the cysts wall and fluid contents- 
the actual living substance of the parasite-was only about $0.12 \mathrm{~mm}$. in thickness. Its inner surface which was sharply defined showed clear drops of highly refracting granules and distinct calchospheres were present. This stage of development is known as the acephalocyst.

As the cyst increases in size warty eminences appear upon the inner surface of the parenchymatous layer. In the interior of these a rounded space filled with clear fluid soon makes its appearance, elevating the eminence above the parenchymatous layer of the cyst wall, and gradually distending it into a daughter cyst. In some cases this daughter cyst continues to enlarge and similar eminences forming cysts arise from its inner wall, while other similar cysts keep forming from the parenchymatous layer of the primitive cyst wall. In other cases the daughter cyst becomes elongated, and develops the four lateral suckers and double circlet of hooklets that enable it to be recognized as a scolex or secondary larvæ of the tapeworm itself. The head of the scolex commonly invaginates itself into the space of the daugher cyst and enters upon a resting stage. Both mother and daughter cysts continue to form new cysts and new scolices, until the original or mother cyst may be entirely filled with smaller cysts free and unattached, and these in turn with smaller similar free and independent cyts, and so on, cyst within cyst of many generations.

It is through the scolices thus formed in the intermediate host that the life of the parasite is maintained. The echinococcus cysts or embryos occur for the most part in herbivora as intermediate hosts; the Tænia echinococcus strobila, or adults, live in carnivorous animals as definitive hosts. Thus we find the occurrence of these scolices in large number preparing the way for the infestation of the carnivorous animal by which the cyst may at some future time be devoured.

The duration of the life of a hydatid or echinococcus cyst varies in different cases, the circumstances governing it not being understood. It may die at any time or it may live for 30 or more years. The rapidity of growth and the size attained also vary in different cases. If the parasite occur in bony tissue, where there is firm resistance to be overcome on all sides, it may not be able to develop so rapidly as in yielding tissues or in body cavities. If the parasite occurs in the cranial cavity, compression of the brain may destroy the patient before the parasite attain either age or size.

Great damage may be effected by the progressive growth of the hydatid cyst, whose size sometimes becomes enormous - the weight of 44 pounds is said to have been attained in one case - and may occasion great distress and even cause death by displacing, compressing, obstructing and destroying the viscera. It is rarely that the cysts reach the size of a cocoanut, however, though the size is commonly sufficient to effect much suffering. The greater number probably do not exceed the volume of an orange. Small cysts in the internal organs are commonly discovered at autopsy in cases where their presence has never been suspected.

The parasite may die at any time. Under such circumstances the cyst contents becomes turbid, and not infrequently it suppurates. Whether the suppuration is primary and destroys the life of the parasite, or whether it occurs because the parasite has already died and the presence of its necrotic structure affords a nidus for the pyogenic bacteria is not known. It is supposed that the wall of the living cyst is impervious to bacteria. The sùppuration may subside or may serve to open the superficial tissues so that the cyst, piecemeal or intact may be evacuated, after which the patient recovers. In cases in which the parasite dies without suppuration, the scolices die off and disintegrate, the fluid clouds, the cyst shrinks, its contents insipissate, and eventually the parasite is 
represented by a circumscribed area of putty-like material surrounded by a membranous wall that may still show some of the characteristics of the hydatid cyst.

If the cysts rupture either spontaneously or through accident, the result depends upon a variety of conditions. Thus, in case of the acephalocyst, the injury may result in the escape and absorption of the fluid and an inflammatory reaction that destroys the membrane. Or in case of proliferous cysts, the rupture may permit the escape of the scolices that may be distributed and set up a new multiple infection. The scolices, it must be remembered, are in an appropriate animal host, and if they are liberated from the brood capsule, may attach themselves locally, or be carried mechanically or by the blood to new and suitable situations, where they may become transformed into new hydatid cysts. That they are well able to do this has been shown both clinically and

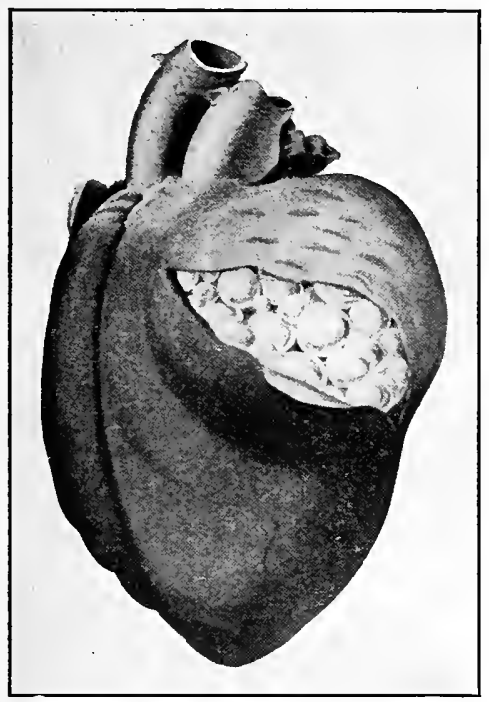

FIG. 134.-Hydatid cysts (echinococcus cysts) of the heart. (Graham.)

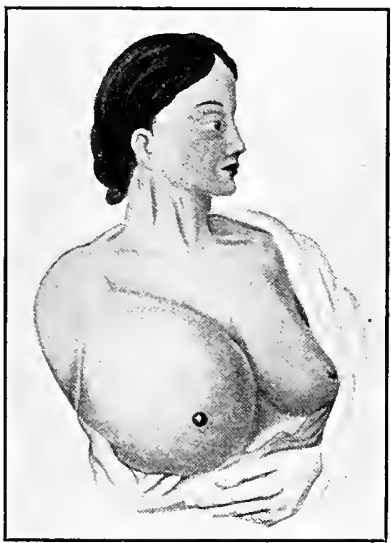

FIG. 135.-Hydatid cyst of the breast. (Graham.)

experimentally. Von Volkmann, at the VI Berliner Chirurgencongress showed that the scolices that escaped into the peritoneal cavity from a cyst of the abdomen, punctured for diagnostic purposes, had developed into cysts in the peritoneum. Heuter and Peau made similar observations. Lihotzky and Gratia found a similar result follow spontaneous rupture. Lebedeff and Andrejew found that if the scolices from a hydatid cyst were introduced into the abdominal cavity of a rabbit, they grew and developed into the proliferous cysts. It is thus possible that spontaneous rupture, accident or careless manipulation may scatter the minute scolices and effect metastatic secondary infestation. This is quite a different matter from the perfect development of the parasite. It is a mere continuance of the larval stage in the intermediate host or some other intermediate host. So far as is known, it is only in carnivora or closely related animals, and only in the intestines that the strobile or adult parasite ever develops. 
In the breast, therefore, no other stage of the parasite is possible than the embryo, or echinococcus cyst, and the only species to be expected is the Echinococcus unilocularis, characterized by the occurrence of a single mother cyst. Only one case of Echinococcus multilocularis of the breast has been recorded, that of Goinard and Sergent (q.v.).

The cyst itself will vary in appearance according to its age and condition. Thus, when small or sometimes when large, and in the form already described as the acephalocyst, it appears as a larger or smaller vesicle, filled with clear, colorless, watery fluid, and having a distinctly laminated wall of brittle, hyaline, bluish-white, chitinous material, easily broken into irregular fragments that immediately begin to curl up inside out. This, which is the integument of the parasite itself, is surrounded by a thin sac of connective tissue formed by the host.

When the cyst is larger and in active reproduction it is most interesting, for though it has the same brittle bluish-white homogeneous, partly chitinous membranous wall, it is found to contain smaller or larger vesicles in varying numbers. Each of these is in a certain sense a diminutive of the mother cyst but has thinner and more distinctly membranous walls. The mother cyst may be so filled with them that they trespass upon one another and flatten on the surfaces of contact, or there may be fewer so that the form of each is spherical. They are suspended in clear aqueous fluid, and each contains similar fluid in which may be still smaller cysts filled with still smaller cysts, and so on until the tiny scolices themselves are reached. When the contents of a goodsized hydatid cyst are collected in a conical glass and permitted to sediment, the cysts and scolices fall to the bottom as a deposit to which Dévé has given the name "sable hydatique." He calculated that in I cc. of this deposit there might be as many as 400,000 scolices. The fertility of the pedogenetic embryo is thus shown to be enormous. Many of the scolices in the mother and daughter cysts seem to die, without developing the cyst, and undergo dissolution in the fluid contents, into which their indestructible hooklets fall. The discovery of hooklets in any clear fluid withdrawn, by aspiration, from any cyst, is pathognomonic of echinococcus cyst.

When the cyst dies its appearance changes either through the suppuration or the inspissation of the contents. In the former case the hydatic nature of the lesion may disappear until through rupture and evacuation or through operative interference the wall of the cyst is brought to light. In the latter case the absorption of the fluid, the contraction of the cyst, and the reactive cicatricial formations round about the lesion may make it increasingly difficult to recognize. The contents at first turbid fluid, becomes mushy, then putty-like and finally may calcify. The probability of finding hooklets disappears with the opacity and condensation of the contents which consist of an increasing quantity of acids, leucin tyrosin, calchospheres, amorphous phosphates and carbonates and cholesterin.

Echinococcus or hydatid disease of the breast is rare. In I 901 when LeConte wrote the report upon the first case indigenous in America, he was able to collect only 33 cases of the disease from the world's literature. To his collection other cases must now be added. It is not impossible that some cases reported in the older literature as "hydatid cysts" were actually such, though LeConte refused to include them because the evidence of their true nature was inadequate to meet the modern requirements of the discovery of daughter cysts, scolices, hooklets, or laminated chitinous membrane.

At least 50 cases of true echinococcus disease of the breast are now recorded in medical literature. Of these, all but one have occurred in women, the single exception being Lilienthal's case (Medical Record, I $899, \mathrm{LV}, 26$ ) of suppurating cyst in the left 
breast of a young man, thought at the time of operation to be a tuberculous abscess but upon subsequent examination shown to be an echinococcus cyst. The patient stated that he had had a similar tumor in the right breast some time previously, but that it had disappeared spontaneously. As such a history is not incompatible with the behavior of echinococcus, as has been shown above, and as it is very unusual in regard to tumors, it may be accepted as probable.

The smallest cyst whose size is known is said to have been as large as a pigeon's egg; the largest the size of a cocoanut. The duration from the time of discovery to the time of observation and treatment, varies, the shortest interval being six months, the longest $2 \mathrm{I}$ years.

Symptoms.-The patient usually discovers, by accident, a small, hard, movable, non-adherent lump in the breast. It is not painful, or is slightly or intermittently painful, and grows slowly and steadily, or intermittently, for varying lengths of time. If the patient suffer from traumatic injury, or if she lactate, the tumor may grow more rapidly. It is pain or enlargement that usually causes the patient to consult the physician. His examination usually discovers little beyond what has been described except that in a few cases instead of being round or ovoid and smooth the growth has been nodular, lobulated or irregular. In those cases in which it was adherent to the skin, inflammation and ulceration soon followed. It is unusual for the axillary nodes to be enlarged, though associated inflammation may quickly be followed by such change. When the cyst is not too deeply imbedded in too large a breast, fluctuation may be detected. The symptomatology of the disease is well shown in the following protocol of the case reported by LeConte (American Journal of the Medical Sciences, Igor, CXXII, 272).

A well-nourished mulatto, aged 27 years, was admitted to the Pennsylvania Hospital in Philadelphia, on Mar. 13, r899. She was "born in Philadelphia, and has spent the whole of her life in this city or in the neighboring one of Camden. Menstruation hegan at the age of 14 , and was normal and regular. At 16 years she was married, and later was the mother of two children, the first born at 18 years and the second $\mathrm{I}_{5}$ months later. At $2 \mathrm{r}$ she had a miscarriage. Shortly after the birth of the first child she noticed an enlargement, with pain, of the right cervical glands near the angle of the jaw; the enlargement slowly spread down the neck, without suppuration. A little more than four years ago the right axillary glands also became prominent, with slight pain. Shortly after the axillary enlargement, say four years ago, she noticed a tumor the size of a chestnut, in the right breast, about 2 inches above the nipple. This tumor was hard, painless, not adherent to the skin, and freely movable. It preserved these characteristics for two years, during which time it did not increase perceptibly in size, until one day she struck it with the handle of a shovel while working. Rapid enlargement then began, and it was at times quite painful, particularly after a hard day's work. The tumor continued firm and hard until one month previous to admission, when it seemed to decrease a little in size and become soft. The right cervical glands suppurated and were incised six weeks before admission. On admission, a round, slightly tender, fluctuating tumor, the size of a small cocoanut, occupied the position of the right breast. The skin was normal in appearance and movable over the tumor, except for about an inch surrounding the nipple, where it was adherent, edematous, and slightly inflamed. The growth could easily be moved over the pectoral muscle. But little breast tissue could be made out surrounding the growth. A small mass of tender and enlarged glands were felt in the right axilla. In addition there was a suppurating sinus on the right side of the neck, which looked tuberculous.

He had the following facts on which to base a diagnosis: A hard, painless, freely movable tumor in a young multiparous mulatto woman, appearing two years after a miscarriage and five years after a chronic enlargement of the right cervical glands. The tumor remained quiescent until subjected to a trauma, when it underwent rapid growth, but still retained its hardness. The cervical glands broke down and suppurated, 
followed by a softening of the tumor, adhesion to the skin in the region of the nipple, and fluctuation. Three conditions were considered: (I) adenoma, which had undergone cystic change; (2) tuberculous abscess, and (3) echinococcus cyst. The latter was immediately dismissed on account of its extreme rarity and also because he knew nothing of its clinical symptoms. As the cervical glands were so evidently the seat of tuberculous abscesses, the possibility of the breast being the seat of a cold abscess was worthy of consideration. But this diagnosis was also dismissed on account of the long duration of the tumor (four years), its mode of growth, and the absence of sinus formation. A diagnosis was, therefore, made of adenocele or cystic adenoma, because adenoma is so common in young women, grows slowly and generally painlessly, causes atrophy of the gland from pressure, and sometimes attains large size, even to ro or 12 pounds in weight. The patient was etherized and a curved incision made over the tumor to the outer side of the nipple. The sac immediately presented. In attempting to dissect this from the adhesions about the nipple it was ruptured and from $\mathrm{r}_{2}$ to $\mathrm{r}_{5}$ ounces of pus escaped. Some of this fluid was immediately placed under a microscope and echinococcus hooklets were found in large numbers. As scarcely any glandular tissue of the breast remained, it was amputated together with the enlarged axillary glands. The wound was readily closed with silkworm-gut sutures without drainage, and healed by primary union. The recovery was uneventful.

Diagnosis.- Correct diagnosis has rarely been made before operation.

Damen's case was supposed to be the victim of cancer and it was at the time of operation that the discovery of a cyst containing "bladders" gave the first intimation of the mistake.

Darbefeuille removed a "tumor" from the breast and then found that it was a cyst containing numerous "bladders."

de Haen operated for supposed scirrhus and was probably surprised when the breast collapsed, under manipulation, and emitted a considerable quantity of water and four little bladders.

Gerdy thought that he was opening a cold abscess in the breast of a child three years old, who suffered from a swelling of the right thoracic region that extended from the xiphoid cartilage to the axilla and angle of the scapula. With the first gush of fluid came three or four little hydatids looking like "fish roe." When the incision was enlarged a retro-mammary cavity full of vesicles was opened.

Kablukoff thought that his patient had a cystadenoma. At operation he found a retro-mammary hydatid.

LeConte, who considered that his patient might be suffering from hydatid disease, ruled it out, because of its rarity, and made a diagnosis of cystic adenoma. The true diagnosis was made after operation.

Lehmann supposed that he was opening a retro-mammary cold abscess and found a hydatid cyst.

Lilienthal supposed his young man patient to have a tuberculous abscess when he began operation.

Michaelis supposed his patient to have cancer, but as there was a central soft area, he punctured it, obtained aqueous fluid and changed the diagnosis.

Pelander and Santy diagnosed their case as cystadenoma.

Roux removed a tumor from the breast and then found a cyst containing several small bladders.

Here is surely enough evidence to show that the diagnosis is by no means an easy one to make. 
In all of these cases there was a nodule of rounded form and firm consistence-freely movable in the breast. When deeply situated, and therefore somewhat obscure, it was easily mistaken for cancer; when superficially situated so that it can be easily outlined by palpation, it was as easily mistaken for a benign tumor. If fluctuation could be elicited, as is nearly always the case with the larger cysts, the situation is not much improved, for then confusion arises between the hydatid cyst and cystic adenoma and cold abscess.

Certain classic signs of hydatid such as erythema or urticaria of the skin have not been noted in mammary hydatids after puncture, and no one has reported crepitation or hydatid thrill upon the palpation of mammary echinococcus.

When the cyst is very superficial or when it becomes very large, the suprajacent tissues atrophy and finally ulcerate, and then, as in Buiko's case, the cyst wall may be seen and recognized through the openings.

The discovery of fluctuation ought to be a matter of considerable moment, and should suggest that an exploratory puncture be made and the fluid examined before operation. The fluid should be carefully collected, centrifugated and the sediment carefully examined for the characteristic hooklets. These are, however, not present in acephalocysts, so that though their discovery makes the diagnosis certain, their absence is of less importance. In cases with ulceration and spontaneous or accidental rupture, the discovery of vesicles is perfectly characteristic. In incision for supposed abscesses the same objects may be brought to light and prove the diagnosis.

The most serious error arises in cases when a small parasite is mistaken for cancer and amputation of the breast performed for a disease that is so simple and so benign. At the present time when the best advice seems to be early and radical operation for cancer the moment its existence is suspected, it may be difficult to overcome accidents of this kind, especially as the parasite occurs almost exclusively during the cancer period of life; but where there is the least doubt, and in cases where a suspicion of echinococcus might be entertained, there are certain adjuncts to diagnosis that may be called upon. The first and most simple is the examination of the blood, when the occurrence of otherwise unexplained eosinophilia is very significant. Too much reliance must not be placed upon it, however, as when the parasite has been present for many years no eosinophilia is, as a rule, to be found.

The second is the serological examination for fixation of the compliment. This has been studied by Weinberg and Parvu (Compt. rendu de la soc. de biol. de Paris, Igo8, Oct. I7), Weinberg and Veillard (Soc. centrale de méd. vétérinaire, I909, Jan. 2I) and Weinberg (Compt. rendu de la soc. de biol. de Paris, I909, Jan. 23), who found that when the hydatid fluid from a cyst, the diluted serum of a patient suffering from hydatid cyst, and diluted guinea-pig serum are mixed in proper proportions and allowed to stand together at $37^{\circ} \mathrm{C}$. for an hour, the complement in the guinea-pig serum becomes anchored by the amboceptors in the patient's blood, to the antigen in the hydatid fluid. If after this union is effected, the mixture receive proper proportions of washed erythrocytes of the sheep, suspended in physiological salt solution, and of anti-sheeperythrocyte hemolytic serum of the rabbit, no hemolysis results because of the previous fixation of the complement. If the control be made with normal human serum instead of echinococcus infested human serum, hemolysis at once occurs.

Unfortunately, this test is not readily applicable because cases requiring it are so rare that few laboratories are provided with the essential factor, the hydatid fluid that is to act as the antigen, and the cases of hydatid disease in this country so few that it is rarely procurable. 
Prognosis.-Though the deaths from echinococcus disease in general commonly reach about $\mathrm{I}_{3}$ in roo cases, no deaths from echinococcus disease of the breast are recorded. The fatal cases occur in disease of the internal organs where the lesion is not discovered until great damage has been effected. The breast being external and superficial, the parasite may be discovered when no larger than a pea or a pigeon's egg, and its discovery is apt to be followed by treatment that is as prompt as it is is effective. Even if un. treated it is probable that many of the cases would recover spontaneously through ulceration, spontaneous evacuation, suppuration and the emission of the cyst.

Confusion of hydatid disease with tumor is unfortunate when it leads to the unnecessary sacrifice of the breast, but in general it is not serious as it results in the immediate and complete removal of the parasite and the certain recovery of the patient.

Treatment.-The recommendations of LeConte are so clear that it seems hard to improve upon the treatment he suggests, which is as follows:

I. "When the cyst is young and not very adherent to the surrounding breast tissue, dissect it out and close the wound without drainage.

2. "When the cyst is old and larger and so intimately connected to the breast that excision would involve a considerable mutilation of the glandular tissue of the mamma, incise the growth freely and evaucate the contents, then pack and drain so that granulation may take place from the bottom.

3. "When the cyst is quite large, thick-walled and firmly adherent, but is still surrounded by a considerable portion of the breast tissue, make a partial amputation of the breast.

4. "When the cyst is so large that most of the breast has disappeared through atrophy or when the nipple is involved and adherent to the growth, a complete amputation should be done."

\section{Literature upon Hy datid Disease of the Breast}

\section{Cáses of True Echinococcus Diseases of the Mamma}

BANSI.- "Zusammenstellung der bis jetzt bekannten Fälle von Echinococcus der Brustdrüse, nebst Mitteilung eines neuen Falles aus der Chirurgischen Klinik zu Greifswald," Inaug. Diss., Greifswald, 1893 .

BERARD.- "Diagnostic différential des tumeurs du sein, Thèse, Paris, I842.

BERMOND.- "Tumeur hydatide du sein; ponction; accident fébrile; séton; énucléation de l'acephalocyst; guérison," Gazette des hôpitaux, Paris, I86o, p. 270.

Birketr.- "Clinical Lecture on True Hydatid Disease Developed in the Mammary Gland," Lancet, London, I867, I, 263; Guy's Hospital Reports, I872-73, XVIII, 4I3.

Bryant.- "Echinococcus of the Breast," Trans. Path. Soc. of London, I866, XVII, 276. MedicaI Times and Gazette, London, I865, II, I599.

BuIxo.- "Echinococcus Disease of the Mammary Gland," Proceedings of the Society of Physicians of Astrachan, I9IO, III, 53 .

COOPER.- "Illustrations of the Diseases of the Breast," London, I829, part I, p. 49, Pl. 29.

COREY.- "A Case of Hydatid Cyst of the Left Mammary Gland," Rev. med. de Chile, I9I3, XII, No. Io. (This journal was not available for examination.)

DAMEN.-Geneeskund Pröven von het Genoetech in Edinhurgh, Deil. I, I34.

Darbefeuille.--Journal générale de médicine, I8I2, XLIII, 145 .

DeHAEN.- "Rations Medendi," I763, VII, 285.

Dubourg.- " "Un cas de kyste hydatique de la mamelle," Gaz. hehdom d. sc. méd. de Bordeaux, I894, $\mathrm{XV}, 79$.

Dubreurl.- “Kyste hydatique de la mamelle," Bull. et. mém. de la soc. de Chir. de Paris, I8go.n.s., XVI, 265. 
DUPUYTren.- "Hydatides developpées dans la mamelle gauche," Revue médicale, franç. et étranges, Paris, I829, I, 359.

Finsen.- "Les échinocoques en Islande." Archives gén. de méd., Paris, I869, I, 23; r9I.

FISCHER, E.- "Ein Fall von Echinococcus in der Brustdrüse," Deutsche Zeitschrift für Chir., I880-I 88 I, XIV, 366 .

Franceschr.- "Due casi di cisti d'echinococco della mamella," Bull. d. sc. med. di Bologna, $188_{3}, 6$ s., XII, I68.

GraHaM.- "Hydatid Disease," r8gr, p. I38.

GoINARD Et Sergent. - "Kyste hydatique de la mamelle," Archiv. provinciales, r897, No. ri; Hildebrand's Jahresberichte der gesammt. Chirurgie, 1897 , iii, 474 . (This is the only reported case of echinococcus multilocularis.)

Gross, S. D.- "Hydatid of the Breast," "System of Surgery," I862, 2d edition, II, 96.

Hawkrns.-Removed an echinococcus of the breast preserved in the Museum of St. George's Hospital, London. (Sheild, "Disease of the Breast," London, r898, p. 254.

HeNRy, Mrtchell.- "True hydatid cysts developed in the left breast of a woman who, as a child, was subject to tapeworm; removed," Lancet, London, I86r, II, 497.

HöppeNER, J.- "Ein Fall von Echinokokken in der weiblichen Brustdrüse," St. Petersburg med. Wochenschrift, r88r, VI, No. 5 r, p. 449.

JONASSEN.- “Ekenoloksygdommen Beloct ved Islandske Legers Enfaring." (Sheild says that out of 35 cases of echinococcus disease collected by Jonassen, two were in the mamma. The original paper was not available for verification.)

KEATER.-Removed an echinococcus of the breast now preserved in the Museum of the St. George's Hospital, London. (Sheild, "Disease of the Breast," London, r898, p. 254).

KREBEL.- "Echinococcus in the Breast," Med. Zeit. Rusland, St. Petersburg, 1855, XII, 32I. (Paper not available for verification.)

Lauenstein, C.-“ “Über des Vorkommen von Echinococcus in der Mamma," Inaug. Diss., Göttingen, I874.

LeConte, R. G.- "Echinococcus Disease of the Breast," American Journal of the Medical Sciences, I90I, CXXII, 272.

LeDentu.- "Kyste hydatique de la mamelle," Gazette med. de Paris, 1873, XLIV, p. r7.

LENZI, A.- "Due casi di cisti d'Echinococco nelle parotide e nella glandula mammaria." Lo Sperimentale, $1885, \mathrm{LV}, 52$.

Lillienthal.- "Echinococcus in the Male Breast," Medical Record, r899, LV, 26.

Luigr, A.- "Hydatid of the Breast," Abstracted-Annals of Surgery, r885, II, I 57.

MacGullivray, P. H.- "Hydatid Disease," Australian Medical Journal, r865, X, 243.

Malgaigne. - "Hydatide du sein," Gazette des Hôpitaux, Paris, r853, XXV, 356; Revue méd. chir. de Paris, I 853 , XIV, 55 .

MichaEIIs, H. S.- "Ein Hydatidinbalg in der Brustdrüse," Jour. der Chir. Augenheilkunde, Berlin, $188_{3}, \mathrm{XX}, 500$. (This might have been a case of cysticercus disease.)

Modtex.- " Mémoir sur les hydatides du sein," Ann. clin. de Montpellier, r8 $85^{6-57}$, IV, 24; see Schmidt's Jahrbücher der gesammt. med., I859, CII, 265.

PaCKard, F. A.-Personal communication to Iyon, recorded in his monograph upon "Echinococcus Disease in America," American Journal of the Medical Sciences, I902, CXXIII, I24. It is no doubt Le Conte's case (vide supra).

Paton.-Geneeskund Pröven von het Genoetech in Edinburgh, Deil. I, I34. (This may also have been a case of cysticercus disease.)

Pelianda and Santy.--"Kyste hydatique du sein," "Lyon méd., rgr2, CXIX, 77.

Roux.-Froriep's Notizen aus dem Gebiete der Natur und Heilkunde, I828, XX, 35I.

Savelis.- "Un caso di cisti d'echinococco della mamella," Practica d. Med. Napoli, I9०7-08, rog. (Known only by citation, the journal not being available for verification.)

Sick.-Jahrbücher d. Hamburger Staatskrankenanstalt, I906, II, r 7. (Mentions without any details, one case of echinococcus of the breast that occurred in the institution and one that he saw in private practice.)

ScHMIDT.- "Über Echinococcusgeschwülste in der weiblichen Brust," Inaug. Diss., Rostock, I892.

Symonds, C. J.- "Hydatid of the Breast," Trans. Path. Soc., London, r 887 , XXXIII, 448. (This seems to be a case of cysticercus disease.)

Thomas, J. D.-"Hydatid Disease in Australia," Adelaide, I884, p. I2I. (Mentions without details two occurrences of echinococcus of the breast in Victoria, and one in South Australia.) 
Toca, M. S.- "Quiste hidatides situado en la parte superior esterna de la mama," etc., etc., La Cron. de les Hospitales, Madrid, I $857, \mathrm{~V}, 369$.

WhITE.- "Echinococcus in the Breast," Lancet, London, I838-39, May 4, 2 I6.

\section{Cases of Echinococcus Disease of Retro-mammary or Para-mammary Location}

Foster COOPER.-- Cited by Sheild ("Diseases of the Breast," London, 1898, p. 254) as having removed an echinococcus of the breast that is described in the old catalogue of the Guy's Hospital Museum in London.

Gardner, W.- "Echinococcus in the Breast," Lancet, London, I878, I, $85 \mathrm{I}$.

GERDY.- "Cas d' un enfant portant au sein gauche une tumeur étendue de la clavicule an nivean de l'appendice xiphoïde," Bull. acad. de méd., Paris, I $844-45, X, 517$.

Graef and Walther.--Jour. der Chir. u. Augenheilkunde, $1827, \mathrm{X}, 376$.

Kablukoff.- "Beitrag zur Casuistik der Echinococcus der verschiedenen Organe und Gewebe des menschlichen Körpers," Archiv. f. klin. Chirurgie, 1906, LXXIX, 576 .

Landau, L.-Zur Casuistik der Echinococcus an und in der weiblichen Brustdrüse," Archiv für Gynäk., Berlin, I875, VIII, $35^{\circ}$.

Lemmanx, O.- "Ein Fall von Echinococcus mit retromammärem Sitz.," Prakt. Arzt. Wetzlar, 1886, XXVII, 97 .

von Lesser.-- "Linkseitiger peripleuritischer Echinococcus mit retromamärem Durchbruch." Deutsche med. Wochenschrift, I88I, VII, 5 .

Schnepr.- "Über eine uniloculäre Echinococcusgeschwulst," Pester med. chir., Prsse., i 875, Nos. 33-34. Centralbl. f. Chirurgie, May I3, I876, p. 304 .

Sheild, A. MI.-" Diseases of the Breast," London, I 898 , p. 254 (two cases).

III. Cases of Supposed Echinococcus Disease of the Breast or Occurring near the Breast, but in Which the Nature of the Lesion is Strject to Some Question

vON DER HAAR. - "Echinococcus der Brust," Sammlung auserlesenen Abhandlungen für praktische Aerzte, 1799 , XVIII, 247. (This case was accepted as an echinococcus by Haussmann,

"Die Parasiten der Brustdrüse," Berlin, r874.)

Verdexin AND Leurs.- "Von dem Krebs," Ibidem, I799, XVIII, 247.

WharRen, John C.- "Surgical Observations on Tumors," 1839 , p. 205.

WIND, P.-Richter's Chirurgische Bibliothek," Göttingen, I775, III, 630.

\section{CYSTICERCUS DISEASE OF THE BREAST}

The Tænia echinococcus is not the only cestode worm whose embryos occurring in man may occasionally be found in the breast. It is, however, the only one whose presence is attended by danger, for it is the only one whose embryo is endowed with the properties of unlimited growth, unlimited multiplication, extension, tissue destruction and possible metastatic distribution.

Cysticercus cellulosa, the embryo of Tænia solium of the hog, and Cysticercus bovis, that of Tænia saginata of the ox, are the most frequent cysticerci of man; Cysticercus tenuicollis, the embryo of Tænia marginata, of the dog, Cysticercus fasciolaris, the embryo of Tænia crassicollis of the cat, and Cystercus pisiformis, the embryo of Tænia serrata of the dog, have also been found.

Of the two species of more frequent occurrence the life histories are similar. The strobile or adult or sexually perfect worms live in the small intestines of human beings and are not known to occur in any other hosts. They are both large worms, Tænia solium varying from $2 \sim 8$ meters, Tænia saginata 4 -1o meters. Like all cestodes or tapeworms they are elongate and flattened, like tape, and consist of a small head with a slender neck, followed by a series of segments increasing in size to the end and numbering from 700 to 2000 . The unripe segments are broader than long, the ripe or gravid segments longer than broad. Each proglottid or segment is a complete hermaphroditic 
reproductive animal. The sexual openings are at the middle of one lateral edge of the segment, usually alternating on the two sides; and usually visible to the naked eye. In these segments the eggs are produced, fertilized and provided with leathery shells that are capable of resisting external agencies for a long time. The segments detach one by one or in chains of three or four from time to time and pass out with the dejecta. Sometimes they still contain many eggs, though the eggs more commonly escape into and mix with the intestinal contents in numbers that run into millions.

It is possible to recognize the eggs, the segments, or the worms of each species. It is most easy to identify the worms by examining the heads. The head of Tænia solium is the size of a small pin. It terminates in a rostellum surrounded by a circle of $25-50$ hooklets, and is provided with four suckers on the four sides; that of Tænia saginata has no rostellum and no hooklets, has a pigmented center, is flattened, and is also provided with four suckers which are obliquely placed at the corners of the quadrilateral head.

The eggs from these worms, scattered upon the soil, and attached to vegetation, or disseminated through water, find their way into the stomachs of the respective intermediate hosts, the hog for Tænia solium, the ox for Tænia saginata. It is in the stomach alone that the shell of the egg can be destroyed and the embryo liberated.

It so happens that man, the definitive host of these worms, can also act as the intermediate host of each as well. If, therefore, the eggs enter the human stomach, development is possible. Two means of entrance are observed; first, the casual taking of the eggs with articles of food and drink; second, and probably less frequently, the regurgitation of the eggs from the intestine into the stomach when the worms or remedies taken to destroy them greatly excite intestinal peristalsis. In either case the result may be the same. The shells are dissolved and a tiny hexacanth larva-an embryo provided with six chitinous spines or teeth-is liberated. It bores its way through the wall of the stomach or intestine, enters the lymphatic or blood capillaries, becomes an embolus and lodges in some part of the peripheral capillary system, where it attaches itself, holds on, and undergoes a series of transformations resulting in the development of a head (scolex) precisely like that of the adult of its kind, and the formation of a cyst by vesiculation and distention of its body or tail. When the cyst becomes sufficiently large to permit it to do so, the head is withdrawn into the cyst by a process of partial invagination. The cyst is the cysticercus. Its purpose seems to be to provide the scolex with food during the long period of quiescence that it must endure, for there is nofurther vital change unless the cyst be broken and the scolex eaten by the appropriate definitive host (man). If the scolex escape comminution by the teeth in mastication, it passes uninjured through the stomach, attaches itself by means of hooklets or suckers to the intestinal mucosa and proceeds to grow the endless succession of proglottides, to provide the innumerable eggs by which future generations can be maintained.

In European countries, the common cysticercus found in man is Cysticercus cellulosa, in America it is Cysticercus bovis. The cysticerci are small cystic formations measuring about $I_{5} \mathrm{~mm}$. in length and about $8 \mathrm{~mm}$. in breadth. They are ovoid when free from compression but may be peculiarly flattened or laminated, or transformed into spindles or clubs through the pressure of surrounding tissue elements. Each has a double wall, the outer which is a very thin membrane is composed of the connective tissue of the host; the inner which is still thinner, and more transparent, is the integument of the parasite. The cyst contains transparent or yellowish fluid in which is suspended a small somewhat opaque polypoid body, the scolex or head of the future worm. If the inner cyst be cautiously removed from its outer membrane and placed in warmed physiological salt 
solution, the live parasite evaginates its head in a few moments and shows its true nature.

In small viscera like the eye, or important ones like the brain or spinal cord, the presence of a cysticercus may be a matter of profound concern or even of fatal injury to the host. In less important structures its presence may never be suspected. As in the case with hydatid cysts, cysticerci may die, inspissate and partly calcify, or may suppurate. In the latter event they may make themselves known through the inflammatory reaction. No case of cysticercus disease has been diagnosticated before operative treatment was instituted.

Allessandri (Bull. d. r. Accad. Med. di Roma, I906, XXXII, 3 I6) tells of the following case:

C. E., 49 years of age, noticed two years ago, that there was a small hard swelling in the upper external portion of the left breast. It remained stationary in size, but she suffered from occasional shooting pains. Upon palpation a small nodule the size and shape of a nut was found. It was hard, movable, fibrous, irregular, indistinctly limited and painless on pressure. Two enlarged lymph nodes were felt in the axilla.

A diagnosis of carcinoma with extension to the axilla was made and a radical operation was performed.

Upon subsequent examination he found a nodule of connective tissue that crushed under the knife. The center showed a softened area with a cystic cavity and turbid contents, from which escaped a bubble the size of a cherry. Under the microscope it was shown to be a typical Cysticercus cellulosa with the complete circle of hooklets.

\section{Another case is reported by Guermonprez (Lyon médicale, I883, XLIV, 73).}

The patient was a woman 29 years of age who in June, $\mathrm{r} 88 \mathrm{r}$, found a small node in the upper inner part of the left breast. It slightly elevated the skin. It was not painful and though it grew a little, caused no trouble or anxiety until she became pregnant in $188_{3}$, when it suppurated and caused widespread disturbance in the breast tissue. A prick with a bistoury enabled three things to be discovered; pus, serous fluid and a cyst that contained $6 \mathrm{cc}$. of a yellowish-green, opalescent fluid. The patient was given a tæniafuge which killed the scolex, and the whole was expelled shortly afterward. Examination with the microscope showed the parasite to be cysticercus cellulosa.

In the literature appended to the section upon echinococcus or hydatid disease of the breast, there are three references-Michaelson, Paton and Symonds-to cases that may just as well be regarded as cysticercus disease as echinococcus disease of the breast. As the essential details are wanting in these case reports, it does not seem worth while to quote them in detail.

\section{SPARGANUM DISEASE OF THE BREAST}

Not all cestodes or tapeworms have encysted embryos comparable to echinococci or cysticerci. Some have very simple vermicular embryos, others larger better developed larvæ not unlike the worms themselves except that they are much smaller, much less distinctly segmented, and never provided with sexually ripe segments. Worms of this class probably all belong in the family Bothriocephalidæ.

The larvæ of Dibothriocephalus latus, the fish tapeworm, the strobila or adult of which lives in man and the embryos in numerous kinds of fresh-water fishes, are simple and vermicular, and have not been found in man.

There have been found, however, in a dozen or more instances, human beings in whose tissues were tapeworm larvæ of good size and advanced development, but whose strobila or adults are still undetermined. Manson, who was the first to study these, gave them the provisional generic name Sparganum. Nothing is known of the life history of these parasites; their discovery has always been in the nature of a surprise. 
The following cases, both indigenous in America, have found their way into the literature. The first to be described certainly affected the breast, and was observed by Moore (The American Journal of Tropical Diseases and Preventive Medicine, I9I5, II, 518).

The patient a man aged 47 , a barber, married, always bas lived in Florida, where he was born, and in Texas. When 20 years of age $(\mathbf{r} 8 \mathrm{gr})$ he suffered for two years with a malady that was thought to be malaria, but was attended with digestive disorder in which diarrhea alternated with constipation, and the abdomen became bloated. He had fever at first, but none later. He lost much flesh, became very weak and spent a year in bed. Two months after this illness began, a lump, ahout the size of a small hen's egg, appeared at the margin of the ribs to the left of the sternum. It was tender on pressure and gave the patient much pain when he bent forward, but it was not red nor did it soften and it disappeared after about a year leaving some tenderness at that point. He has had "stomach trouble" for a number of years. Three years ago a small ischio-rectal abscess developed. It was opened and took six or eight months to get well, during which time the patient's weight ran down to Irg pounds.

About six months ago he noticed a mass in his left breast, and below and to the outer side was another smaller one. The latter was tender to the touch. He complained of dull pain along the left costal margin, and occasionally had sharp needle-like pains. These have continued ever since his illness 20 years ago.

When he came under examination he was rather a thin man ( 130 pounds) somewhat pale with a muddy complexion. The following were noted: Just beneath, or rather behind the left nipple was a firm mass the size of a small hen's egg. One conld not be certain whether it is in the muscle or lying

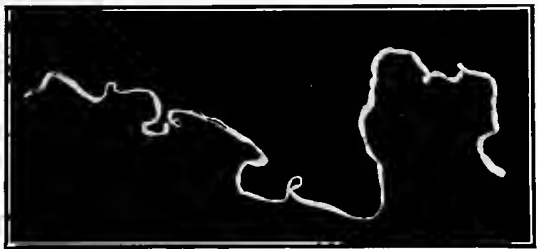

FIG. I36.-Sparganum mansoni from the human breast.

between the nipple and the muscle; there was a second but smaller mass just below and to the outer side of the nipple; the glands in the axilla were distinctly palpable. There was marked abdominal tenderness in the regions of the appendix and gall-bladder.

In December, rgrr, he was operated upon. Adhesions between the gall-bladder and omentum were freed, and the breast, muscle and glands in the axilla were removed. When the tissues were examined a mass was found in the pectoralis major muscle, behind and a little above the nipple. It was $2-4 \mathrm{~cm}$. in diameter. A section through it disclosed a white tape-like parasite coiled directly in and between the muscle fibers. It showed rather active movements in the form of frequent extension and retractionmovements of a peristaltic character. When at rest it measured $21.5 \mathrm{~cm}$. in length. It had a breadth that varied with its movements. The head end for about $4 \mathrm{~cm}$. was rounded. Close examination enabled cross lines suggesting the segments of a tapeworm to be made out anteriorly. A delicate line ran from the head backward for about $6 \mathrm{~cm}$. The worm lay in an irregular crevice in the muscle, without any surrounding cyst. The surface of this space was dark colored and granular and showed no increased density of structure. The smaller mass near the nipple when sectioned showed only dense fibrous tissue. Microscopic study of the muscle where the worm lay showed many breaks in the continuity of the fibers, the spaces being filled with eosinophils and endothelial leucocytes. Some bits of muscle tissue are entirely enclosed by this cellular infiltration and show varying degrees of degeneration.

The worm was examined by B. H. Ransom, of the Bureau of Animal Industry of the U. S. Department of Agriculture, who found it more closely corresponding to Sparganum mansoni than to any other recorded parasite of man.

The patient subsequently died, presumably of pellagra and a continuation of the tuberculous process that was the cause of and dated from the occurrence of the ischio-rectal abscess. No autopsy was permitted. 
Another case, in which if the worms were not in the mammary gland they were in the mammary region was seen by Dr. H. Gates of Manatel, Florida, and reported by Stiles (Public Health Marine Hospital Service, Hygienic Laboratory Bulletin No. 40, I908):

This patient was a man aged 48 years, who came with his father from Minnesota and settled in Florida in 1872 , at a point on the Manatel River now known as Mann's Point. When 23 years old, and hunting in the woods about a mile and a half from the coast, he noticed a small pimple on his shoulder that attracted his attention because of its itching. He thought the skin had been punctured by a thorn. $\mathrm{He}$ squeezed the lump, from which came a small flat worm about $1 / 16$ inch in diameter and $5 / 8$ inch long. One year after the first appearance on the shoulder he noticed four or five small itching lumps on the chest; these he opened with a knife and picked out the same kind of worms. An accompanying photograph shows the enlargement of the left breast and shoulder; also of the left groin and lumbar region. In a letter written by Dr. Gates, it is stated that the patient has thousands of these worms. There were sometimes as many as three worms in a cyst. Studies by Ijima, of similar worms in the subcutaneous tissue of the leg of a Japanese woman, showed that they multiplied by budding and the formation of supernumerary heads which later detach themselves, migrate through the tissue and become encysted to grow into new worms. The patient eventually died of the infection.

\section{NEMATODE PARASITES OF THE BREAST. FILARIASIS MAMMÆ}

The occurrence of worms in the breast was noted by the older writers whose accounts sometimes written in a perfervid vein fill us with wonder though not with conviction. Truth no doubt lies at the bottom of their stories, but lack of scientific methods of observation and description have stood in the way of convincing record. A careful examination of these records has been made by Haussman (Die Parasiten der Brustdrüsen, Berlin, I 874) who tells in his interesting monograph that there is not a single recorded case that can be given credence upon careful scrutiny.

The only nematode worm that is known to locate itself in or near the breast, is the Filaria medinensis, the guinea-worm, and only one case of such localization of this worm seems to have found its way into print. It is the case to which Cezilly ("Observations sur le dragonneau," Thèse de Paris, I 858 ) refers in these terms:

“J'ai presents à la mémoire, dit M. . . . , chirurgien de marine qui est resté trois ans au Sénégal, deux dragonneaux qui séjournèrent longtèmps sous un des glandes mammaires, et amenèrent quelques accidents. Le sujet eut de la fièvere, de l'anxiété, etc."

This case is cited by Davaine in his "Traité des Entozoaires," Paris, I877, p. 722. The worms occupied a retro-mammary position. Only the adults of Filaria medinensis infest human beings, and of them the female alone is known. The worms vary in length up to $100 \mathrm{~cm}$., but are very slender. Their presence in the subcutaneous tissue, where they usually take up their habitat, is soon attended by painful inflammatory reactions. Gradually the worm matures and works its way to the surface where vesicles and then pustules form, and finally open, leaving sinuses that refuse to heal.

Careful examination sometimes reveals one end of the worm at the opening. If touched this is quickly withdrawn. If a proper stimulation be applied a few drops of milky fluid appear, which when examined with the microscope is found to consist of fluid containing large numbers of tiny embryo-worms. The ulceration of the tissues and the appearance of the worm's extremity usually take place in a lower extremity and is supposed to be adaptive to the future requirements of the embryo-worms that find their intermediate host in water. It is presumably on this account that, even in tropical countries where guinea-worms abound, they do not occur in the mammary gland more frequently. 
The worm produces, viviparously, enormous numbers of tiny vermicular embryos, which finding their way into water, attack and enter into a small crustacean, the cyclops, where they undergo a further development. Whether the embryo-worm finally escapes from the cyclops and is free in water or whether it remains in the body, of the cyclops is not known. Man is supposed to become infected by drinking water containing infected cyclopides.

The diagnosis of the disease might be impossible in the early stages, even if it were clear that the patient had other guinea-worms elsewhere. After the ulcerations occur the diagnosis becomes more easy if the patient be in a guinea-worm section and the medical attendant be accustomed to dealing with them. The milky fluid filled with embryo-worms, obtained from the ulceration is characteristic.

The prognosis is good when the treatment is successfully carried out.

The treatment consists in catching the extremity of the worm with forceps, drawing it down gently until it ceases to come any more, then fastening the delivered portion to a match stick or other small object upon which the worm is wound as it is gently drawn out more and more from time to time. The success depends upon not breaking the worm by too rapid delivery. When it breaks it is lost from view and proceeds to regenerate, in the meantime keeping the sinuses open and the inflammation active. When the worm has been successfully delivered, the cause of irritation having been removed, the lesion heals kindly without special treatment. 


\section{CHAPTER VIII}

\section{THE GENERAL PATHOLOGY OF TUMORS}

Until the eighteenth century the humoral theory dominated medicine. All "swellings" were called tumors and any that could not be attributed to physiological enlargement or the displacement of normal organs were considered, by Galen and his followers, to arise as the result of accumulation of one or other of the several humors. The latter included the neoplasms as we now understand them, infectious granulomas and cysts, together with various other diseased tissue conditions associated with tumor (swelling) formation. The humoral theory continued to be evoked in explanation of neo-formations long after the discovery of the circulation of blood and lymph. Boerhaave voiced a note of dissension from the prevalent views and ascribed tumors to chemical changes in the newly discovered lymph. These theories, purely philosophical in origin, are interesting as history but are without scientific value. They continued in esteem, however, until the dawn of modern pathology. The work of John Hunter marked a new departure in pathology, especially as regards the significance of neoplasms. Hunter erred in the belief that tumors arise from "coagulable lymph," but he, at the same time, laid the foundation of anatomic-pathological study by demonstrating the resemblance between normal tissues and the constituent tissues of tumors. Tumors, he maintained, arose through modifications of the developmental processes, and in the years that have since elapsed, no evidence, conclusive of the fallacy of this theory, has been advanced. This is the first suggestion of the truth according to the modern belief. The masters in this early era of pathology concurred with Hunter in his views, and his principles went unchallenged until Broussais startled the scientific world with the statement that chronic inflammation consequent upon organic irritation is the underlying cause of all tumor diseases. The effect of this idea, so much at variance with prevalent theories, was to change, completely, the trend of thought, but as future events proved, for a very short time. The etiological rôle of chronic inflammation in neoplastic processes was entirely forgotten with the introduction of the cell doctrine in 1838 by Schwann, the biologist, and Schleiden, the botanist. This monumental contribution to science was a gift of the lately perfected microscope, and the Broussasian system fell into disrepute with the disclosure of its lenses. In the same year Müller discovered the cellular character of neoplasms and attributed them to aberrations of the force inherent in a primordial undifferentiated substance whence they grew-a substance comparable to Hunter's coagulable lymph. Müller taught that the degree of ultimate evolution attained by a cell was its only important characteristic and that cells leading a normal, orderly useful existence differ in no wise, either morphologically or in origin, from the essential elements of the most malignant tumors. The error of believing in the existence of an undifferentiated substance as the basis of the origin of the cells robbed Müller of the glory which came to Virchow 20 years later. Virchow supplemented his famous dictum "omnes cellula e cellula" with the adoption of the Müllerian teachings and the addition of the resurrected theory of Broussasian inflammation depending upon organic irritation.

Indeed, the succeeding years have added but little to our knowledge of the etiology 
of tumors and time serves only to strengthen the underlying principles of Virchow's belief. The important exception is discredence of certain metaplastic processes in tumor development. Virchow strongly advocates the possibility of transformation of connective tissue into epithelial cells and vice versa - a view which is not tenable in the light of modern histologic findings.

At first thought it may seem as though an academic consideration of the cause, nature, structure and behavior of tumors ought rather find its place in a work upon general pathology than in a monograph upon the diseases of the breast, but upon more mature consideration, one familiar with the facts of the case cannot but appreciate that there is much to be said upon the subject that is eminently appropriate to the present occasion.

Thus, there is probably no organ of the body in which so much uncertainty arises as to whether such or such condition ought to be considered a tumor or regarded as a manifestation of some other type of morbid change. Where is this problem better illustrated than in connection with that most perplexing process, "chronic cystic mastitis," "abnormal involution," "maladie de Reclus," "Schimmelbusch's disease" or "cystadenoma?" Is this a tumorous affection or is it of some other nature? If a tumor, is it a connective-tissue tumor or an epithelial tumor? Is it benign or malignant?

If tumors are to be satisfactorily discussed, certain premises must be established as points of departure, the first and most important of which ought to be a definition that would state in precise terms what a tumor is. At this point the first difficulty presents itself, for exactly what a tumor is, is not known. Well, then, if we do not know exactly what it is, we certainly do know what is ordinarily meant by tumor. No, here again we are placed in the position of greatest uncertainty, for we understand many and highly diversified formations to be tumors, and find that they have so little in common that none but the most liberal definition can be made to hold them together.

The following definition seems to comprehend as many features as tumors are known to have in common, and is therefore capable of serving as the foundation stone of the discussion that is to follow:

A tumor is a congenital or acquired anatomical defect, characterized by an excess of some tissue or tissues, fairly well circumscribed in distribution, atypical in structure or arrangement, subserving no useful purpose and tending to persist and increase without respect to those influences by which the organic economy is maintained.

Tumors May be Heredutary.-This is doubtless true of a number of tumors, though not yet so well established as to permit the introduction of the fact into a definition in which scientific accuracy is essential. Being perhaps hereditary or if not so, sometimes being congenital, and at other times acquired, a tumor may make its appearance at any period of embryonal, pre-natal or post-natal life.

That every tumor is an anatomical defect is quite clear. It is always an excess of some tissue or tissues causing the enlargement through which the name "tumor," a swelling, originated. The excess of tissue or tissues may be at the expense of some other tissue or tissues, in which case there may be no enlargement, or there may be simultaneous or subsequent destruction of the tissue that is or has been excessive, through degeneration, ulceration or necrosis by which an apparent loss of tissue may result and outweigh the visible increase of tissue. Persistent slow growth of a tumor accompanied by persistent associated destruction of the tissue involved, may cause the structures in which a tumor is growing to wither away and become small, as in "withering scirrhus of the breast." Persistent necrosis and ulceration of the tissue of the tumor 
itself may eat away the tissues affected as in "extensive rodent ulcers." In each case persistent increase of tissue lies at the bottom of the process.

When a growing and increasing tissue diffuses itself among other tissues or throughout the organ or viscus in which it occurs it is described as hyperplasia; when it localizes, as tumor. Between diffusion and circumscription of growth, and consequently between hyperplasia and tumor there is no sharp line of distinction. One blends into the other and there is no certain point at which it ceases to be correct to employ the one term and becomes correct to use the other. In the etymological sense of the word hyperplasia, overgrowth, all tumors are hyperplasias. It is commonly stated that tumors differ from other hyperplasias by their circumscription, but what degree of circumscription is required to make a tumor of any hyperplasia is not stated.

The tissue or tissues of which the tumor consists are atypical in structure or arrangement. Here, again, there is wide latitude of meaning.

The tissue of the tumor is atypical because of its structural imperfection. Instead of adult tissue, embryonal tissue commonly appears. It may be possible to account for the embryonal character of the new growth, through rapidity of growth with prosoplasia, or return to the embryonal tissue type. Thus, if fibrillar tissue be in process of rapid growth, the multiplication of its cells may take place more rapidly than they can from fibers. A cellular or embryonal tissue thus appears, and the greater the rapidity of growth, the more cellular the tissue becomes, the more widely it diverges from its normal type and the more embryonal it appears. If the epithelial elements of any tissue take on rapid multiplication, confusion of structure commonly results from crowding of the cells which under normal conditions always bear some definite relationship to one another, to some membrana propria, or to blood-vessels. Thus, there come into being successive generations of superfluous cells unable to assume their natural specialization through the unnatural environment in which they are found; such cells appear to revert, through prosoplasia, to the embryonal (spherical) type of cells.

When the processes, growth and development, are natural and harmonious, they are characterized by proportional adjustments that commonly fail in morbid processes, especially tumors. Thus, as the normal tissues grow, the blood-vessels extend in proportion to their needs; but as tumors grow the blood-vessels may fail to keep pace with them or grow excessively or atypically-i.e., without proper capillary distribution or with imperfectly developed walls. The effect of such imperfection and maladjustment is that parts of the tumor may be overwhelmed with nourishment while other parts are starving; that certain parts may grow while others are dying, or that hemorrhages from the bursting of the imperfect blood-vessel walls may pervade the tumor tissue.

Tumors Subserve No Useful Purpose.-In a general way it may be said, almost without reservation, that every tumor is a source of injury and detriment, never a source of benefit. The damage done may be slight like the disfigurement occasioned by a wart on the nose, or it may be fatal, but the rule holds that in the long run every tumor is disadvantageous to its victim.

Some questions of interest arise in this connection. Thus, certain so-called "adenomas" or fibro-epithelial tumors of the breast undoubtedly participate in the function of lactation as is shown by their rapid growth during the lactation hypertrophy and their subsequent subsidence. This shows that such tumors consist of tissue anatomically and physiologically like that of the breast, and are subject to the stimulating influences that excite the breast. But this function even though it eventuate in the 
secretion of milk is useless and harmful because there being no means by which the secretion can leave the ducts, it is retained to cause cystic distention and further increase the size of the tumor; but the fact that this inability to rid itself of its secretion places the secreting tissue of the tumor in a state comparable to that of the unused lactating breast that must at once begin involution, seeing that the purpose of its evolution has failed. The collected products of secretion impede the process of involution in the tumor because they are difficult to get rid of by absorption and throughout the period of its useless enlargement, the tumor crowds the breast tissue proper making its activity attended with difficulty and sometimes with danger. Here, then, is an example of the most gland-like tumor not only failing to subserve normal function but behaving normally to the injury and prejudice of the normal tissues. In one case it is stated that the milk secreted by such a tumor escaped from the ducts, so that the tumor actually participated in the function of the breast. If this were actually the case, the mass in the breast was not really a tumor, but a hypertrophy. It is excluded as a tumor by the terms of our definition.

A few tumors of the organs of internal secretion, such as the thyroid gland, are sometimes so similar in structure to the organs in which they occur as to be able to carry on more or less function, no ducts being needed to convey the secretion from the glandular tissue. There is always some doubt as to whether such formations are real tumors, but in such cases the patient usually becomes the sufferer either because the excessive tumor tissue provides an excess of the secretion, because it yields it to the blood abnormally or, should neither of these conditions obtain, because the tumor crowds compresses and destroys the organ proper and so inhibits the formation of the normal secretion.

Tumors are Structures that Tend to Persist and Increase.-Exceptions to this theorem are few. Warts or skin papillomas are notorious examples. They sometimes appear singly or multiple, grow rapidly to a considerable size, remain unchanged for varying periods, then disappear never to return. In all other known respects they conform to the requirement of the definition of tumor, and some of them remain and slowly but persistently grow. With regard to the persistent increase in size each tumor is a kind of law unto itself, thus proving the final requirement of the definition that the tumor is not dominated by those influences by which the organic economy is maintained.

Many tumors come into being so unobtrusively, grow so slowly, and occasion so little disfigurement or annoyance that the patient is surprised to discover them and still more surprised to know that they are tumors. This is true of many of the little tumors of the skin-soft moles, little lipomas, and single fibromatous formations related to the fibrous molluscum. Many of the tumors of the breast, especially the benign tumors, are discovered by accident, the size at the time of discovery varying from that of a pea, when they are fairly superficial, to that of a pigeon's egg or a walnut, when more deeply seated. They may grow very slowly, occasion no pain and excite no solicitation until their increasing size, or a suggestion of danger made by a friend, or through reading, brings the patient for medical advice.

Other tumors grow rapidly, and quickly arouse the apprehension of the patient.

There is a certain correspondence between the structure of a tumor and the rapidity of its growth. Thus, a microscopic examination of a rapidly growing tumor usually shows it to consist of cells of embryonal character with many karyokinetic figures; a slowly growing tumor, on the other hand, usually consists of adult tissue whose cells have perfected their specialization. This is not, however, invariably the case for the 
soft moles of the skin that grow so slowly that no change may be apparent in many years are purely cellular new formations.

Tumors that have remained small for years, whose growth has been very slow and whose unobtrusive character has lulled the patient into a sense of security sometimes takes on an unexpected and rapid growth. This is thoroughly consistent with the statement that they are not controlled by those influences by which the organic economy is maintained. What determines such misbehavior has not been discovered. In many cases it may depend upon the same or similar influences to those that determine the primitive appearance of the tumor; in other cases other factors, such as traumatic injury appear to be responsible for it.

Inability to predict exactly what any given tumor may do, has justly caused every tumor to be regarded with suspicion and is the source of that wise surgical opinion that counsels that every tumor be removed before it has time or opportunity to misbehave.

It can easily be understood that rapidly growing tumors are apt to be most injurious and require the most prompt action.

Etiology.-There is no tumor whose cause is definitely known. In the few cases in which the cause of a tumor-like lesion has become known, the lesion has at once ceased to be a tumor because it then became necessary to transfer it from the class of tumors to some other group of morbid affections. To illustrate what is meant the lymphoma may be used. In the writings of half a century ago lymphoma was a fairly frequent tumor, but when it was discovered that tuberculous infection was the cause of the greater number of lymphomas, all such cases were at once transferred from the class of tumors to that of infectious diseases. The tumor-like enlargements of Hodgkin's disease remain as lymphomas, but if it be shown that Rosenow is correct, and that certain diphtheroid bacilli are the cause of the disease, its lesions must cease to be regarded as tumors and also be transferred to the group of infectious diseases. If a microörganism were, tomorrow, shown to be the cause of cancer, cancer would no longer be thought of as a tumor, but as an infectious disease.

The diversified character of tumors, which if not already familiar to the reader, will certainly become so through the perusal of this chapter, is so striking that it is increditable that there can be any one cause of tumors.

There must be various causes for the different tumors, though not necessarily a separate cause for each.

So obscure a subject as the etiology of tumors has proved a source of fascination for a great number of thinkers and writers, and the literature of medical biology contains many interesting and ingenious theories. None has yet succeeded in explaining tumors, and no success can attend any theory that pretends to explain the origin of the whole group. Better success promises in cases in which the attempt is made to explain the occurrence of some particular kind of tumor.

For each kind of tumor two etiological factors may be presupposed: first, those that pave the way for its occurrence; and second, those that actually bring it about. The first are the predisposing or predetermining factors (not causes); the second the exciting or determining causes. Of the first a good deal is to be said; of the second very little. Much that is commonly said, and that may here be said, about both is probably untrue, though it appears to be true in the present state of knowledge.

\section{Predetermining Factors.-}

Phylogenetic Influences. - It is beyond the power of the cells of any living creature to surpass certain physiological limitations, and evolve products unknown to its class. 
For example, tumors are common to plant and animal organisms, and have certain marked resemblances as well as dissimilarities in common. Among the latter are the cell products. The cells of plant tumors produce lignin, suberin, cellulose, chlorophyll, etc. They are essentially plant products and never appear in tumors of animals because it is beyond the physiological capacity of animal cells to manufacture them. Being an animal, therefore, predetermines that one shall have animal tumors composed of animal tissue only. Not to carry out the argument in too great minutiæ it is evident that being a vertebrate, an animal is predisposed to those tumors from which vertebrates suffer, rather than any peculiar to invertebrates; being human, one is prediposed to tumors that are most frequent in human beings.

Race.-Continuing along precisely the same lines we find it true that being Caucasian or Mongolian or African, carries with it any special predisposition to tumors that may be peculiar to the Caucasians, Mongolians or Africans. Scientific accuracy is sadly lacking in regard to this predetermining factor, but it may be conceded as correct that Caucasians are more predisposed to tumors than the other races, and biological authority for differences in racial tumor incidence can be found in the fact that there are other physiological racial differences, such as variation in the quantity of pigment in the skin and eyes, the color, texture and shape of the hairs, etc. As there has been but little statistical study of disease incidence among the yellow, red, brown and black races, knowledge of the matter is insufficient for numerical comparison with disease incidence among the whites, and is casual rather than actual. Minor differences in tumor and other disease incidence are also said to obtain among different branches of the same race. Thus, among Europeans, it is said that there are variations between the northern and southern peoples. If this be true, it may be considered with the physiological differences between them shown by the greater stature, fair hair and blue eyes of the northern people, and the shorter stature, dark hair and dark eyes of the south.

Heredity. - That there is sometimes a family predisposition to tumor incidence has long been a common observation among clinicians and surgeons, and every writing upon tumors contains as much evidence of it as the author has been able to get together. The facts collected are, however, very imperfect because the observations have been made almost exclusively along the line of direct inheritance and without regard to the laws discovered by Mendel. When future evidence is collected and tabulated according to Mendelian principles it may be shown that when once tumors make their appearance, they descend through subsequent generations of the family as unfailing as polydactylism, color blindness, albinism and other heritable conditions. Positive evidence of this is found in Maude Slye's studies of the "Incidence and Inheritability of Spontaneous Cancer in Mice" (Journal of Medical Research, I9I5, XXVII, p. I59). Miss Slye found it possible, by careful breeding, to produce strains in which no spontaneous cancer occurred, and other strains in which spontaneous cancer made its appearance in 58. per cent. of the individuals. These investigations have to do with but one kind of tumor but they are remarkably interesting and suggestive and will undoubtedly pave the way for more accurate observation and study of the heredity of tumors.

Sex.-Sex is a predisposing factor in disease and in tumor incidence through the anatomical differences that obtain. Thus, tumors of the uterus and ovaries are very common in women, but cannot occur in men. Tumors of the testes and prostate are frequent in men but cannot occur in women. When organs are common to both sexes there may or may not be differences in tumor incidence. Thus, both sexes have mammary glands but while those of males are diminutive and inactive, those of females 
are developed and active. The larger active glands of women are as many times more predisposed to disease and tumors as they exceed those of men in size and activity.

Age.-At different periods of life, different activities are in progress. At its very beginning is the period of undifferentiated embryonal cells which quickly separate into blastodermic layers and differentiate into tissues and organs. During the first few months cell multiplication and differentiation progress rapidly, hand in hand. Then follows a period in which, the differentiation having been effected, growth preponderates and continues throughout pre-natal life and during post-natal life until the maximum size is attained. This is next followed by a period when growth having been attained, special activities, largely centering about the reproductive organs, becomes frequent. Then following the decline of the reproductive powers, come general vegetation inactivity, condensation and integration of the tissues and disproportionate preponderance of inter-cellular substance throughout the connective tissues.

The incidence of tumors bears some correspondence with this succession of events. During the period of growth, the vegetative activities are immensely greater in the connective tissues than in others, and during this period the simple tumors of the connective tissues are most common. When growth has ceased and these tissues become quiescent, reproductive activities begin and the tumor incidence in a general way shifts to the reproductive organs, and tumors of complex structure, the "organoid tumors" of Virchow, occur in breast, ovary and uterus. When the period of their activity terminates, the special organs of reproduction undergo atrophic changes -involution-and at about the same time the general decline of the tissues begin. This senile period sees loss of the integrity of the connective tissues through the dying out of the cells and the condensation of the inter-cellular substance, so that they are not so apt to engage in the morbid processes and tumors as the epithelial tissues that continue active for a longer time.

The tumors of youth are thus apt to arise from the connective tissues; those of old age from the epithelial tissues. Exceptions to the rule are, however, of frequent occurrence.

Diet.-Evidence is collecting to show that diet and the state of the individual's nutrition may have much to do with the growth of tumors. Miss Slye found that vigorous growth processes are necessary for cancer growth; reduction of feeding lowered cancer incidence among the mice; mice with poor growth had slow tumor growth; reproductive activity (pregnancy) retarded tumor growth. At a meeting of the Philadelphia County Medical Society, held June 9, I9I5, Saxon showed that the growth of mouse cancer was greatly accelerated by the administration of cholesterol. Knowledge of the relation of the diet or the requirement of the individual and the state of his nutrition may become of importance in the future clinical management of tumors.

Occupation.--The relation of occupation to tumor incidence is important, but is a vast subject because of the diversity of occupations and the multiplicity of tumors. That there is definite connection between the two cannot be doubted. When the subject is reduced to its simplest form it may be summed up in the statement that occupations of various kinds are attended with injury to the tissues, the reaction following which may express itself in the form of a tumor. The occupation effects the injury-mechanical, thermal, chemical, electrical, photic or radiant-and the tumor follows the injury.

The tumors more or less definitely referable to occupation are fibrous, sarcornatous and cancerous.

Habit.-Habit has precisely the same bearing upon tumor that occupation has, and it is scarcely possible to separate the two. Habits that result in injury to the tissues 
may pave the way to tumor formation. The classical example is the clay pipe by which the lip of the smoker is injured, and the use of which may therefore lead to cancer.

Defective Embryonal Development.-Cohnheim urged that every tumor found its beginning in "embryonal vestiges"-i.e., groups of embryonal cells, which at the time of embryonal development, became accidentally separated from their normal situation and were caught and sequestered in neighboring tissues. Such cells, prevented from fulfilling their normal functions, Cohnheim supposed to remain indefinitely in their sequestered positions, retaining a latent vegetative capacity that might, at any time, find expression in rapid multiplication and result in tumor formation. That such sequestrated and dislocated cell groups sometimes occur cannot be doubted. Cells supposed to be derived from the "anlage" of the adrenal body have been found in groups in the liver, the kidney and upon the spermatic cord; pancreatic tissue has been found in the wall of the stomach, beneath the capsule of the spleen and beneath the capsule of the left kidney. Thyroid gland tissue has been found in the bones (though whether sequestered in the bones or subsequently carried to them is uncertain). In all these cases, however, the cells have no longer been embryonal cells, but adult cells. Though in an abnormal environment, they have perfected their development, so far as local conditions permitted, so that instead of undifferentiated and unrecognizable embryonal cells, tissues easily recognizable and assignable to their kind were found. It must, however, be admitted that when one of these sequestered bits of tissue takes on a tumorous growth, as for example in hypernephroma of the kidney, a cause for the abnormal growth must be looked for, precisely as though it were normal tissue in the normal environment that had unexpectedly grown into a tumor.

II. Exciting Causes.-The growth of every tumor must be looked upon as a perversion of vegetative activity depending upon a localized and abnormal growth stimulus. This stimulus is the exciting cause of the tumor. If it should be shown by future studies that tumors are the result of inherited impulses, it will be comforting to many who have exercised their brains in trying to find the nature of the impulse and failed, for all attempts to discover the nature of hereditary impulses have also failed. But the chances are that it is not so much the tumor, as the predisposition to its occurrence that is inherited and that even in those families with the most marked predisposition and furnishing the greatest number of tumors, an exciting cause must be present to arouse the tissues abnormally prone to respond. What is the nature of the exciting cause? To Virchow it was irritation. Tumors were brought into being through the effects of injury. A half century of reflection and experimentation upon the aspect of the problem has brought about no great advance of knowledge. The precise nature of the irritant is not specified; it may be mechanical, chemical, thermal, photic, radiant-all or any, at times, provoke neoplasm formation. But how, cannot be said, nor can any one of them or any combination of them be employed with success for the experimental production of tumors. If a few rare cases in which tumors of unusual kind have been produced at special times by exceptional means-as for example such cases as those of Leo Loeb who by mechanically injurying the endometrium of gravid guinea-pigs obtained nodular formations (deciduoma benignum)--be excepted, it may be truthfully stated that it is beyond the power of man to provoke the formation of tumors at will. It would certainly seem that if the traumatism were the essential thing, experimental traumatism ought to act as accidental traumatism and provoke tumor formation. The literature is full of examples of tumors occurring after injury; the life of every individual is full of injuries that are not followed by tumors. 
The events that take place in injured tissues are fairly well known and comprise reactions included under the general terms "inflammation" and "regeneration." The phenomena are reparative. Vegetative activity is the exception and is commonly confined to the repair or reinforcement of the connective tissues. When the reparative function becomes excessive and too much new tissue is formed, as in keloid, we see at once that there has been a mistake, that something has gone wrong, that a new condition has arisen, and that condition is tumor. But the injury was not then the cause of the tumor in the strict sense; the tumor was something exceptional engrafted upon and subsequent to the injury, whose only rôle may have been to permit the true cause to act, just as abrasion of the skin is not the cause of infection though it serves to open the deeper tissues to the infectious microörganisms.

With the discovery of the relation of microörganisms to disease and the brilliant work of Pasteur, Lister, Koch and their followers, it was only natural that the suspicion should be aroused that microörganisms are the causes of tumors and that tumors are infectious diseases. The subject is full of fascination for every experimental investigator and seemed, and still seems, to hold out so many inducements that it cannot be abandoned. It has come to be regarded, however, more as a "will-o-the-wisp" than an illuminating principle, for those that have pursued it thus far have been the victims of disappointment. However, the idea that infectious agents may be the cause of tumors, or at least of some tumors, ought not be abandoned because tumors are such vague and diversified things that what is true of one is by no means necessarily true of all. Some tumors may be infectious diseases, and if so, the fact ought to be known. The two tumors for which an infectious origin strikes one as being most probable are sarcoma and carcinoma. Each resembles an infectious disease in arising at a primary focus, invading the tissues through continuity, distributing the essential cause through the blood and lymph circulations, effecting colonization and secondary formations of like kind in remote parts of the body and by recurring in loco after excision as though the essential cause diffused throughout the tissues had not been effectually eradicated. Opposed to their infectious nature is the fact that in practically all known infectious diseases the essential reactions take place in the connective tissues which behave according to fairly fixed rules, while in tumors and especially in carcinoma the essential reactions are independent of such participation of the connective tissue and consist essentially in persistent vegetative activity of the cells comprising the tumor.

When interest centered chiefly about bacteria as causes of disease, tumors were studied for bacteria which were sometimes found and heralded as the cause, to be later abandoned when it was shown that no bacteria were found whose presence could not be adequately explained as accidental; only a few cling to the bacterial origin of tumorsDoyen with his Bacillus neoformans. When interest was transferred to protozoa as causes of disease, a large literature grew up about protoza-like objects that were found in tumors; later this was all swept aside under the impression that the supposed protozoa were either misobservations, artefacts or accidentally present organisms. A few still cling to the theory, however, Clarke in England, Metchnikoff in France, and Calkins and Gaylord in America probably being among them. When later, blastomycetes became objects of interest, the Plimmer bodies were discovered (if they are not the same objects that had previously been regarded as protozoa) and claims were made for them, but at present it is difficult to find adherents of the blastomycetic theory. When spirochetes were newly discovered and were being subjected to close scrutiny and investigation, they were found in a mouse cancer, and the conjecture was at once made that the mouse 
cancer in general was caused by spirochetes. Later it was shown that the spirochetes found in the mouse cancer had nothing to do with the cancer per se, but simply showed that the mouse with the cancer suffered from spiriochetosis, frequent among mice. No spirochetes were found in cancer of mice not suffering from spiriochetosis nor in human cancer. A little later Borrel, Gastinel and Gorescu (Annales de l' Inst. Pasteur, I909) observed acari or mites (Demodex folliculorum) in the tissues of skin and mammary cancers and drew the conclusion that these arthropods were the causal agents. Saul, (Centralbl. für Bakt. etc., Orig., I9ıо, LV, I5) seems to have found acari in deeply seated carcinomas where their occurrence would seem to be impossible, as for example in carcinomas of the stomach, ovary and uterus. Saul did not find Demodex folliculorum, but another mite, belonging to an entirely different group, to which he gave the name Tarsomena hominis. But as such arthropods cannot be found in all carcinomas, it is doubtful whether all of those described were really acari, and the theory seems so extravagant that it has not been accepted. However, it is quite certain that acari have been found in cancers, though their presence may have been as accidental as that of bacteria and protozoa.

Febiger found a mouse with carcinomas of the stomach in which there were nematode worms. By introducing the worms into other mice he claimed to have produced carcinoma. It is not clear, however, whether the lesions were actually carcinoma, and it is certainly not true that nematode worms are present in the generality of cancers, hence they cannot be the cause of cancer.

The interest of the moment centers about "invisible microörganisms" and "filtrable viruses," and it is with great expectancy that the adherents of the infectious theory of tumors await the future investigation of the subject. So far as carcinoma is concerned no progress has been made. With sarcoma, however, the condition is somewhat different for there is evidence that at least certain forms of this tumor may be infectious. Rous (Journal of Experimental Medicine, I9I4, XIX, 52) has succeeded in producing a certain form of transplantable spindle-cell sarcoma of chickens by injecting them with the filtrate of comminuted tumor tissue. The filtrate must thus contain the essential irritant, though that irritant, whatever it may be, is not able, by itself, to originate the tumor. He found that it was necessary to effect some mechanical injury or excitation by which the virus could be brought to play. To this end he injected the tissues of the fowls with a suspension of diatomaceous earth and the virus, whereupon the tumor developed. Here we may discover a possible explanation of the relation of traumatism to tumor. If the essential cause of tumor be present, the trauma may enable it to develop and the injury results in tumor. If none of the essential causes be present the effect of the traumatism passes off ordinarily and the patient recovers without tumor. Thus we may be compelled to conclude that traumatism is not a cause of tumor any more than of suppuration, but only acts as a means of permitting the essential agent to enter and operate in the tissues, when it subsequently provokes the tumor.

Ross and Cropper ("Researches into Induced Cell-reproduction and Cancer," III, No. IV, p. $7 \mathrm{I}$ ) who have devoted considerable time and energy to the study of the effects of certain chemical agents--auxeties and augmentors-upon the multiplication of cells, claim to have induced the formation of small benign fibro-adenomatous nodules in the udder of a goat, by introducing them into the milk ducts. Their results as yet lack confirmation, though suggestive and interesting. However, no one doubts that there must be a stimulus to tumor growth, nor is it doubted that the stimulus is chemical. The question is, what is the nature and source of this irritant? 
If phylogenetic influences determine that no tissues can occur in animals that do not belong to them, ontogenetic influences seem to determine that it shall be rare for tumors to contain tissues entirely foreign to the organs or tissues in which they occur. The chief tumors of every viscus arise from the tissues of that viscus. Embryomas and embryoblastomas-mixed tumors-arise through heterotopia or displacements and confusions during embryonal development, but are so rare that they scarcely need be mentioned in connection with the general facts concerning tumors.

In so far as organs have structural resemblances their tumors resemble one another, in so far as they are dissimilar, their tumors are dissimilar. The salivary glands and the pancreas are much alike and their tumors are much the same; the uterus and the breast are totally dissimilar and the tumor that is most common in the uterus-the fibroid-is unknown in the breast. The more complex the structure of an organ is, the greater the variety of tumors that may arise from it. The skin is one of the most complicated organs and from it a great variety of tumors develop-from the epidermal cells, from the cuticular fibrillar tissue, from the blood- and lymph-vessels, from the nerves, from sebaceous glands, from sweat glands, from hair follicles, from the muscle fibers of the erectores pili and from the adipose tissue.

The mammary gland is complex. It consists of parenchyma with epithelial and fibrillar tissues supplied with blood vessels, supported by a connective tissue framework distended with adipose deposits and penetrated by blood-vessels, its surface is covered with skin of which that portion known as the areola is specialized and pigmented and supplied with glands of Montgomery, from the center of which the nipple projects through a basal ring of muscle cells. From any of these tissues tumors may arise. All such tumors, however, are native to the gland in the sense that they arise from structures normal to the gland. One does not expect to find tumors of kidney-like or of liver-like structure in the breast.

When a tumor arises from tissue of its own kind, it is called homoplastic or homologous; when it differs from the tissue from which it arises, heteroplastic or heterologous. The great majority of tumors including the great majority of those of the mammary gland are homoplastic or homologous.

Given the stimulus of growth, it is easy to understand how a homoplastic tumor may arise, but how can such a stimulus result in the occurrence of a heteroplastic tumor? How, for example, can it account for the occurrence of a bony or cartilaginous tumor in the mammary gland where no such tissues are? Heteroplasia of this kind is usually referred by pathologists to metaplasia or the transformation of one tissue into another. To the ill-informed this statement offers no particular difficulties, but to those familiar with the almost ironclad limitations of tissue behavior the transformation of one tissue into another of a different kind, is fraught with difficulties that make it seem almost impossible. Once the inherited ontogenetic impulses set embryological development into motion, the blastodermic layers map out the position of future organs and tissues according to fixed laws. Epithelium never transforms into connective tissue nor connective tissue into epithelium. The limits of metaplasia quickly define themselves. Epithelium remains epithelium, but the character of its cells may become modified according to circumstance. It may be in the power of one epithelial cell to do anything that other epithelial cells can do. How far this modifiability extends is not known, but it is certainly in the power of some epithelial cells to assume some of the appearances and accomplish some of the purposes belonging to other epithelial cells. In certain lesions of the lung we see the ciliated cylindrical epithelium of the bronchioles losing the cilia 
and flattening into squamous-like cells as it extends into and lines the abnormal cavities. The cylindrical epithelium covering hemorrhoids flattens out and assumes a squamous appearance when the hemorrhoids descend and are subject to frictional contact"with external agencies.

But it is in the connective tissues that the greatest latitude of modification is observed. It appears as though with less marked specialization there is greater modifiability. The cells of connective tissue form collagen, fibroglia, elastin, chondrin and ossein. They lay down frameworks that may be fibrillar, homogeneous or calcareous. How each of these is produced or what determines that one and not another shall be produced is not known, but seeing that all these various products result from the activity of cells of supposedly much the same kind and of much the same embryological derivation, it seems that the formation of cartilage where fibrillar tissue was expected, though an undoubted perversion, is quite within the range of probability and gives us at least a partial understanding of the process of metaplasia by which we account for heterologous tumors. To this must be added the fact that the whole matter of tumor formation is a perversion of growth, when the particular metaplastic perversion becomes simply an incident of neoplasia. The occurrence of a cartilaginous or an osseous tumor in the mammary gland, therefore, does not imply the admission of something from without; it is a perversion of growth within.

Is this tumor dangerous? This is among the first and most important questions concerning tumors of the breast, and it is well justified by the fact that about four out of five tumors of the breast are dangerous.

Tumors are divided in the minds of clinicians and surgeons into two classes, first suggested in the beginning of the last century by Sir Astley Cooper, the benign and the malignant. The former are harmless, the latter dangerous. The tendency of each tumor bears a certain correspondence with its structure. Tumors of certain types having certain structure, are constantly harmless; those of other types, having another structure, 'are persistently invasive, destructive, and commonly fatal. Unfortunately these are the extremes of a series between which lie many tumors that may or not be harmful, or whose structures may fail to give a clue to their true disposition.

When we consider malignancy and benignancy from the clinical point of view, we are able to form definitions that are accurate enough for practical purposes.

A benign tumor tends to separate itself from the surrounding tissue through the formation of a capsule, thus developing as an independent entity whose injurious effects result from compression, and traction followed by obstruction, occlusion, atrophy, necrosis ulceration, etc., as position may determine. Through their secondary effects benign tumors may cause suffering and even death, but their rôle in the matter is passive, and resembles the ill effects produced by foreign bodies, concrements and calculi.

A malignant tumor is one whose growth is usually fairly rapid; is attended by the destruction of the organ or tissue in which it grows; that usually returns when excised; that occasions secondary metastatic growths by which other and remote structures may be destroyed; that perverts the nutrition of the patient, and commonly tends to destroy life.

Malignant tumors are largely cellular tumors with little differentiation; benign tumors are commonly composed of clear cut, well-differentiated tissues. The former grow rapidly in most cases because all of the vegetative activity is expended in cell multiplication; the latter grow slowly because of the time necessary for tissue differentiation. In both the cells multiply throughout the tumor, causing a form of enlargement that is described as interstitial expansion, as each additional structure unit thus added must 
displace others to make room for itself. As soon as the size of the tumor becomes such as to make this impossible, growth continues chiefly at or near the surface. In the malignant growths capsules are usually lacking and as the cells grow, those at the periphery mingle with or insinuate themselves between and among the structural elements of the organ or tissue in which the tumor grows. Such growth is known as peripheral infiltration. The extent to which the infiltration occurs varies. In sarcoma it is limited to the immediate neighborhood of the tumor which forms a fairly well-circumscribed and rounded node. In carcinoma the cellular extensions or prolongations following the crevices and fissures and lymphatic spaces, form a kind of irregular fringe surrounding the tumor. Some threads of the fringe are quite short, others very long.

As the benign tumor grows it forces the normal tissues out of the way and causes them to atrophy through pressure; as the malignant tumor grows and especially as it infiltrates, it disorganizes the tissue by dissociating the elements, compressing and destroying them. The extent of destruction is far greater in the latter case. Benign tumors when superficial may project from the surface, and even become pendulous through a pedicle formed by the distention and traction of the coverings of the body. Malignant tumors rarely do this. Benign tumors reaching the surface may exert so marked a distending effect, especially when they grow rapidly, that there is not time enough for the superjacent tissues to stretch, may so press upon the surface coverings as to destroy them by ulceration, and thus actually make their visible appearance upon the surface.

The infiltrating tumors block up the lymphatic vessels, compress and invade the bloodvessels, destroy the tissue parenchyma, and bring about a confusion of morbid changes in their own tissue as well as in the invaded tissue, each of which may be explained by disturbances of mechanical and chemical nature attending the growth.

As soon as either a benign or malignant tumor effects destruction of the superficial tissues and ulcerates, it opens the way for secondary infection by which further mischief is done. In the case of malignant tumors it also facilitates the occurrence of hemorrhages. Infection and hemorrhage are common fatal terminations of malignant tumors.

Metastasis or the dissemination of the tumor cells by which secondary colonizations are formed and new tumors started in other viscera, and permeation by continuous growth, along the lymphatics, to distant points, are characteristic of malignant tumors; such secondary growths frequently bring about destruction of essential organs and constitute another and common cause of the death of the patient. Cachexia, a peculiar malnutrition incidental to malignant tumors, especially carcinoma, is understood, but is looked upon as a form of intoxication for which the products of protein changes taking place in the tumor, or the tissues it is destroying, may be held responsible.

No satisfying scientific classification of tumors has yet been invented. Many have been offered, some simple, some complicated. As tumors are not understood failure of classification becomes inevitable. The etiology is not known, therefore, the system employed should exclude reference to it; the disposition of many tumors is uncertain, therefore there should be no mention of it; the histogenesis of many is obscure, so that it is not wise to introduce it. The most successful systems of the past have been based upon histological resemblances between the tumor tissues and the normal tissues; most of them suffered because of confusion of histological structure with embryological descent.

Tumors are vague things. To classify anything correctly one must first determine exactly what it is-whales were classified as fishes until it became known exactly what whales were. It is impossible to tell exactly what some tumors are. They are assigned 
a place in this or that group arbitrarily. One microscopist calls a tumor $\mathrm{X}$, another $\mathrm{Y}$, a third $Z$.

But the classification of tumors in general does not concern the reader of this work so much as that of the tumors of the mammary gland in particular. Nor does their scientific classification interest him so much as a practical working arrangement. The best of these is to be found in the following tabulation of Warren, and is adapted as the general scheme to be followed in this text, though strict adherence to it is not promised.

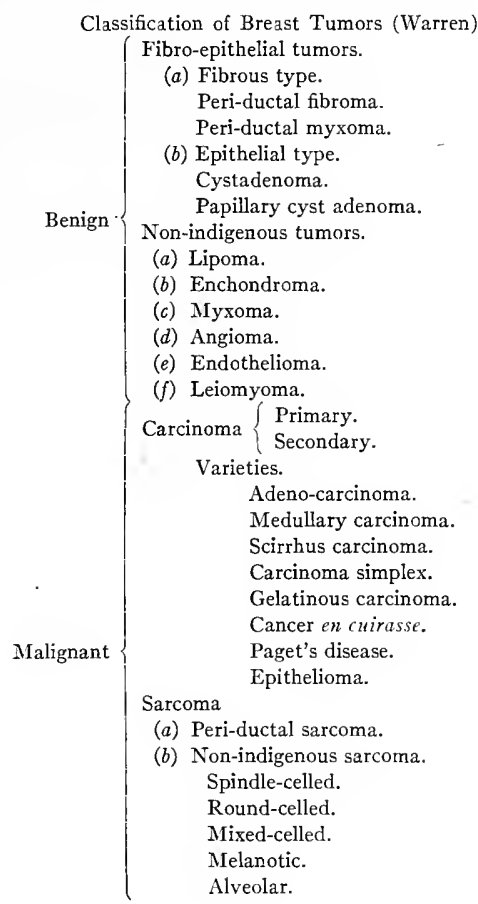




\section{CHAPTER IX}

\section{THE NON-INDIGENOUS TUMORS OF THE MAMMARY GLAND}

The tumors in this group are in no sense peculiar to the mammary gland. They consist of the different varieties of connective tissue, and presumably arise through perversions of growth in the connective tissues of the gland that might arise through the same means and from the same elements in any other gland, or, indeed, in any other tissue. They are clinically interesting because accurate diagnosis is difficult before operation, and because they are rare in occurrence. With the single exception of the sarcoma they are benign. They all form rounded, more or less nodular, well-circumscribed, usually well-encapsulated, movable nodules, commonly discovered by accident. They may first be detected when no larger than a pea, if superficially situated in a small breast, or when the size of a walnut when more deeply situated in a large breast. With the exception of sarcoma, they grow slowly, without pain as a rule, and without enlargement of the axillary nodes or disturbance of the general health of the patient. As they grow, the breast tissue is crowded aside and subjected to more or less pressure atrophy. Deformity results according to the size the tumor eventually attains, and usually takes the form of asymmetry of the breast, though if the size of the tumor be great, the nipple may become flattened through stretching of the skin.

Microscopic examination is commonly required in order that the tumor, after removal, be properly named and classified.

\section{FIBROMA}

This is a tumor whose structure corresponds to that of the adult fibrillar connective tissue. It is one of the rarest of the mammary tumors, and only one case of true fibroma seems to be recorded in the literature. It is the case of Beadles (Trans. Path. Soc. of London, I892-93, XIIV, I24).

W. H. (a white man) aged 34 years, has had a tumor of the left breast for four months. It arose without antecedent injury or irritation. It was the size of a small walnut and was situated above and a little to the outside of the left nipple. It was somewhat movable and not fixed to the skin. It was extremely hard and not painful or tender.

No enlarged glands were found in the axilla. It sprang from the back of the gland and lay partly embedded in the pectoral muscle, part of which was removed with it. It was round and distinctly delimited and quite free of muscle fibers. On section it presented a hard whitish surface. Microscopically it was composed of dense fibrous tissue, in the central part almost hyaline or myxomatous in appearance with only a few nuclei or cells, but at the periphery the growth had a more embryonic character. No trace of gland acini was present throughout the whole tumor. It was thought before operation to be either a scirrhus or a gumma.

In his contribution to Choyce and Beattie's "System of Surgery" Handley disposes of "Fibroma" with the statement that it is probably a fibro-adenoma from which the epithelium has disappeared, an opinion scarcely justified by the description given above.

A review of the literature of "fibroma of the breast," shows many references in which such tumors are mentioned, but in reading the descriptions of the tumors, and especially 
in studying the reports of their microscopy, one finds that they are almost without exception fibro-epithelial tumors of the variety now known as peri-ductal fibromas.

There has been and still is much confusion between fibroma and fibromatoid tumors and conditions. This is well illustrated by Virchow's teaching upon the matter ("Die krankhaften Geschwülste," I 863, I, 328). He describes three forms of fibroma of the breast.

I. Fibroma diffusum in which hard connective tissue forms in the stroma of the gland. The glandular elements are unaltered or become contracted, obstructed and dilated.

II. Fibroma Tuberosum.-Circumscribed hard nodes supposed to result from interstitial mastitis. Glandular tissue may accidentally be caught in the connective tissue.

III. Fibroma intra-canaliculare papillare, undoubtedly the peri-ductal fibroma of our present nomenclature.

To these Nordmann (Archiv f. path., I892, CXXVII, 338) thinks should be added

IV.-Fibroma Plexiforme.-A tumor observed by himself, in which the newly formed connective tissue follows and surrounds the ducts of the gland in a plexiform manner.

Confusion of cause with effect, of inflammatory new formations with tumors, and of fibroma and fibro-epithelial tumors is here apparent. Fibroma diffusum, and fibroma tuberosum are fibromatoid conditions not certainly tumors, but more in the nature of cicatricial formations and fibrosis comparable to cirrhosis of the liver; fibroma intracanaliculare papillare is certainly peri-ductal fibroma; fibroma plexiforme is a rare condition, not mentioned except by Nordmann, the nature of which is not clear. It may not be a true tumor.

We are thus left with but one case of true fibroma of the breast, unless the tumors reported by Jones (Lancet, I902, Jan. I8) of a slowly growing recently painful tumor in the left breast of an Egyptian soldier aged 35 years, and by Krawtschenks (vide Hildebrand's Jahresberichte für Chirurgie, I897, p. 475) of a fist-sized fibrous tumor extirpated, after I 5 years' duration, from the right breast of a man aged 42 years, concerning which we have no adequate description, ought to be so designated. The former was called a fibroma, the latter a fibroma durum in the original case reports.

Molluscum Fibrosum.-Among the fibromatoid conditions that sometimes make their appearance upon the breast, though they have nothing to do with the gland or any of the structures connected with it, the fibroma molluscum, molluscum fibrosum and dermatolysis must be mentioned.

In his paper upon "Pendulous tumors," MacSwiney (Dublin Medical Journal, I875, LIX, p. 484) gives several illustrations of small pedunculated tumors of the skin of the breast that can be recognized, at a glance, as belonging to the formations of this class. They are the size of peas or small beans, hang by slender, short pedicles, and are familiar and unimportant tumors of the skin. As is well known, molluscum fibrosum commonly occurs in the form of multiple tumors, enormous numbers of which, of varying size, may be widely distributed on the skin surface of the body. Under such circumstances, one or several may be found upon one or both of the mammary glands. When the disease presents itself in its most exaggerated form, the skin in certain areas seems to loosen, hypertrophy and undergo a fibromatoid change that results in the formation of folds or pendulous formation that sometimes attain to a great size.

Two such cases, curiously enough both in men, have had lesions in the mammary region, that were of such size as to become particularly noteworthy.

One of these, reported by Abbatucci (Ann. d'hyg. et de méd. Colon., Paris, Igo8, 
$\mathrm{XI}, 444$ ) was in a Chinaman aged 44 years, with many small tumors, and from whose left mammary region a mass the size of a child's head and weighing $2 \mathrm{~kg}$., sprang. It was removed, affording the patient great satisfaction.

The other was reported by Perkins (New York Medical Record, 1907, LXXII, 567). The patient was a man aged 65 years, with large numbers of small tumors, but who had in addition, an enormous mass forming a pendulous tumor that sprang from the left mammary region and hung down nearly to the knees. It weighed between 25 and 30 pounds and was of 40 years' duration.

The tumors are benign and harmless. The smaller ones rarely require any attention, the larger may require removal to afford the patient comfort. They are dermal tumors and can be removed by dermal incisions. If they occur upon the breast, they may be removed without in any way disturbing its tissues.

Keloid.-The peculiar fibromatoid tumor now known to us by this name, appears to have first been noted by Jean Paul Alibert, who gives a very good illustration of it in his "Description des maladies de la peau observés a l'hôpital Saint Louis," Paris, I 806 (Pl. 28). In this work the lesion is called "cancroide ovalaire." In a later edition of the work, the title page of which bears the words "Clinique de l'hôpital Saint Louis ou traité complet des maladies de la peau," Paris, I833 (p. 209), the lesion is described under the new name of "keloïde," and as synonyms are given "kelas, cheloide, cancroïde tubercules durs, cancelli, cancre blanc and la crabe." The derivation of "keloïde" is $\chi \eta \lambda \dot{\eta}$, a claw, and is the source of the preferred English spelling "Cheloid."

A thorough description of the lesion is given in the 1833 edition of the work mentioned, and a previous interesting and thorough description is found in Alibert's "Note sur la keloïde" (Jour. univers. de sc. méd., Paris, I816, ii, 207).

From the illustrations on Alibert's plates, and from his descriptions, there can be no doubt but that what he saw and described as keloide is identical with what we now know as keloid. It consists of a red, elevated, elastic new formation, not sharply circumscribed, though usually for the most part well-defined and abruptly rising from the healthy skin to a thickness of $1 / 4$ inch or more, the edges usually being thicker than the center.

It is reddish in color, variable in shape, sometimes oval or disk-like, sometimes rodlike or nodular, and almost always somewhere gives off irregular extensive "clawlike process" that are the source of the name- $\chi \eta \lambda \hat{\eta}$, a claw. Its occurrence is sometimes sudden and apparently spontaneous, sometimes gradual through increase in the growing connective tissue of a scar. The appearance and continued growth are commonly attended by itching, smarting or burning pain that may be trifling or may be extremely distressing.

Alibert saw such a formation upon the lower surface of the left breast, and one of his female patients with a similar tumor, who suffered greatly wrote to him that she had "au sein l'aspic de Cleopâtre."

The formations sometimes increase slowly and persistently, sometimes diminish and cicatrize after a time. When excised they return repeatedly, though they never become invasive or metastatic.

Alibert recognized two classes of keloids:

A. Vraie keloïde (kelodes genuina) or true keloids or spontaneous keloids.

B. Fausse keloïde (kelodes spuria) or false keloids that were the result of excessive inflammatory cicatrization. These constitute the familar keloids common in the experience of all surgeons. 
It would not have been necessary to particularize at such length upon the precise etymology and origin of the conception of keloid, had it not been for the accidental confusion injected into the subject through the mistake of Addison. This talented writer observed several cases in which whitish patches formed in the skin and bore a remarkable resemblance to the scars that follow burns and brands. Conceiving that Alibert derived the word from the Greek $\kappa \eta \lambda \iota s$, a brand or scar, and thinking that the lesions seen by him were strikingly more like scars than the hyperplasia of tissue seen by Alibert, he came to the conclusion that they were the real thing and thus made a distinction between the "keloid of Alibert" and the "true keloid."

This confusion of ideas continued for some time, and it was not until after the subject had been carefully reviewed in the writings of Dieberg (Deutsche Klinik, $8_{52}$, IV,

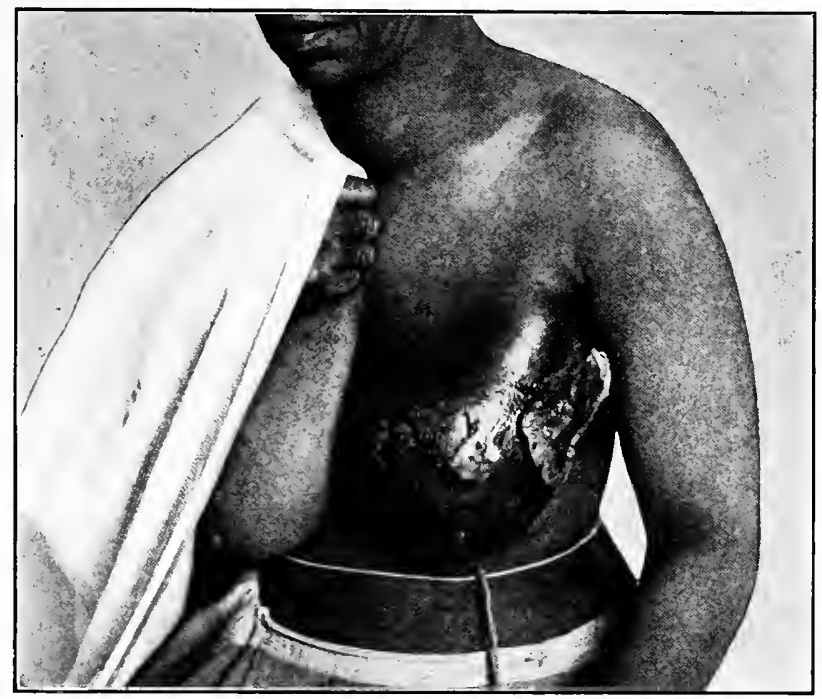

FIG. 137.-Keloid of the breast following chronic suppurative mastitis.

369, 387, 463) and Fagge (Guy's Hospital Reports, London, I868, 3s., XIII, 255), and others that it became finally cleared up. As now understood, the true keloid is the morbid growth described by Alibert; the scar-like formation observed and described by Addison is not keloid at all, but is a localized scleroderma, scleriasis, or scleroma better known among dermatologists as "morphea."

I. The Keloid of Alibert.-I. Spontaneons Keloid (Alibert's "Keloïde vraie.")Several cases in which these lesions occurred upon the breast are briefly mentioned by Alibert in the writings to which reference has been made. Crocker ("Diseases of the Skin," Phila., I903, p. 937) gives the following description of an interesting case:

"I saw a very peculiar case with Mr. Cursham Coover in a woman aged 67. Twenty-eight years before, the disease began in the right breast, 'like the sting of a wasp;' it was not very red, and in five years was only the size of a shilling; then another began in the left breast, and both increased together, 
and during the last year more rapidly. When seen, each lesion formed a ring about 5 inches in diameter, the border varying from $1 / 2$ to $\mathrm{I}$ inch or more. The patches as a whole were flat, thin and indurated, and could be pinched up like a plaque in the skin, $1 / 8$ inch thick and quite cutaneous and not at all adherent to the subjacent tissues. The patches itched and burned 'dreadfully' and sometimes they smarted or she had cutting pains. On the right side there was a third oval patch 3 inches by $2 \frac{1}{2}$, which had grown a third larger in 18 months. It was flatly convex, thicker than the others, and nearly uniform, but near the center the skin was pale yellow and becoming cicatricial, and there were three large comedones upon it As no histological examination could be made, the diagnosis is open to dispute, but its hardness, slow growth, appearance and symptoms agreed with keloid better than anything else."

Hutchinson (Archives of Surgery, I89I, p. 129) observed a case that probably belongs in this class: 2

"A widow, 50 years of age, had a purple-red, raised, indurated, horseshoe-shaped patch, rather larger than a crown-piece, on the inner side of the left breast. Unlike ordinary keloid, it had a shelving edge that merged gradually into the surrounding integument; moreover, its surface, instead of being smooth and glossy as in ordinary keloid, was rough, showing the orifices of hair follicles. The disease began about 20 years ago and it has ever since been spreading very slowly, but there has never been the least ulceration."

Velpeau (Maladies du sein, Paris, 1858, p. 467 ) mentions the following case that seems to belong in this class:

"A young lady of great beauty consulted . . . . for a small reddish growth projecting from the skin of the inner side of the left breast. It caused no pain. It was excised, but six months later another of larger size took its place. A second operation was followed by a similar result. When Velpeau saw her some months after the second operation, there was a smooth, ovoid, reddish plaque in the scar ( 3 by $21 \frac{1}{2} \mathrm{~cm}$.). A third excision was performed, but recurrence soon took place again and she gave up in despair. Some time afterward it spontaneously diminished."

2. Cicatrix Keloid (Alibert's "Keloide fausse.")-This is the well-recognized, somewhat frequent form of the tumor. It was first given the name adopted by Dieberg (Deutsche Klinik, Berlin, I852, IV). What determines its occurrence is difficult to say as its.appearance in wounds is occasional and peculiar. Negroes are more frequently affected than whites, and some individuals are far more predisposed to it than others. In those thus predisposed it is commonly multiple, and no lesion of the skin may be so trifling as not to cause it. Burns are supposed to lead to its appearance with greater frequency than other lesions, though we know of no satisfactory statistical evidence on the subject. When the tumor once forms it persists for a long time, sometimes continuously increasing, sometimes increasing for a time and then retrogressing by fiber formation, so that it may eventually form a large, hard, white cicatrix in the place of the previously red, somewhat softer tissue. Excised keloids usually return.

Cases affecting the breast have been reported by Bryant ("Diseases of the Breast," London, 1887, p. 3 ) in a cicatrix on the left breast of a woman aged 34 years, eight years after the excision of a fibro-epithelial tumor; it was excised and recurred after five years.

Howard (cited by Sheild, "Diseases of the Breast," London, I898, p. 419) observed the following interesting case:

"At consultation at St. Georges' Hospital on the 27 th of January, r897, Mr. Howard showed a woman aged 45, with carcinoma of the left mamma. There were two pinkish, hard nodules in the skin which, at first sight, looked like deposits of carcinoma. The woman assured us that they had grown in the scars of two burns which she had upon the part many years before. They were certainly keloid, and their recognition had an important bearing on the operative treatment of the case."

Lanphear (Reg. Med. Visitor, St. Louis, I905, V, I93) reports a case with a fine illustration of a keloid upon an amputated breast. It is a very large linear keloid following 
operation performed II years before for pyogenic mastitis. The lesion was about Io inches long and an inch broad, and was divided into three processes at the bottom.

Painter (American Journal of Clinical Medicine, I907, XIV, 55) observed the following case:

"A woman aged 25 years, the mother of three children, suffered from infection, pyogenic mastitis and sinus formation, at the time of her last lactation. It was treated with 'home remedies' and she finally recovered. Three months later the scars began to take on a dusky reddish-purple color and the case coming under observation, a diagnosis of keloid was made and amputation of the breast was advised. The patient refused to permit the operation, however. When heard from six months later, the growth had extended to at least one-third of the breast and was very painful."

Phillips (cited by Sheild, "Diseases of the Breast," I898, p. I49) also saw a case:

"In the days when 'tartar emetic' ointment was applied for chest affections, keloid would sometimes attack the resulting skin scars over the breasts. Thus a case is related by Phillips, where a woman had seven of these tumors on one mamma, and five on the other."

Sheild ("Diseases of the Breast," I898, p. I49) observed the following case:

"Some years ago, at St. Georges' Hospital, a mother and daughter were out-patients under my care with keloid growths over the skin of the breasts, which had followed the application of strong acetic acid liniment. The daughter had three keloidal discs over the skin of the left mamma, which were the size of a shilling. They were very unsightly, and only slowly lessened in size."

He also (p. 432) observed the following:

"The scars of the wounds made by removal of the breast sometimes become reddened and greatly thickened. - I have known this appearance, which is really keloid in nature, mistaken for recurrence of growth. Small red nodules also appear in the sites of the 'stitch apertures,' and their appearance is exactly like recurrent cancer for which they have often been mistaken. It is curious how of ten a certain amount of keloid change occurs about the scars of mammary operations, not only for the removal of the entire breast, but also after the extirpation of fibro-adenomatous tumors, or the opening of abscesses. Sometimes the growth is excessive and serious alarm at the supposed return of the tumor is readily created. When once the diagnosis of keloid is clear no operative treatment should be attempted."

Williams (Medical Chronicle, Manchester, I893-94, XIX, 370) mentions the following case:

"A woman aged $5 \mathrm{r}$ years, mother of five children, had, $\mathrm{r}_{4}$ years before, suffered from a boil at the upper part of the left breast. She now has a hard red nodule the size of a pea projecting slightly from the skin at that point. There was no enlargement of the axillary lymph nodes. It was excised and examined. It showed thickening of the derm, which on section was dense and yellow-white. On microscopic examination a fibrous network containing numerous nuclei with a few round and spindle cells imbedded in it was seen."

Histology.-The keloid consists of scar tissue, the exact appearance of which varies somewhat according to its age and activity. The chief structural compound is coarse collagenous fibrillar tissue, containing comparatively many spindle and plasma cells and capillary blood-vessels when it is actively growing, or comparatively few when it has stopped growing. Occasional foreign-body giant cells may be present but are not peculiar to the tumor. The cellular quality of the young growths sometimes suggests sarcoma, though the excess of the fibrillar tissue is opposed to it. In old dense cicatricial keloids all cells and capillaries may have become extinguished. The collagenous fibers form into parallel bundles usually coinciding in direction with the long diameter of the lesion. The relation of the derm to the epiderm is destroyed and a papillary layer can rarely be found. The epiderm is usually thin but rarely ulcerates. 
Diagnosis.- The history and general appearance of the keloid are usually sufficient to make the diagnosis. In cases in which keloid can. be mistaken for recurrent cancer in the operation wound, great care must be exercised, for the recurrent cancer may require immediate removal and the keloid should not be touched. In some cases it may not be possible to come to a definite conclusion as to the nature of the disturbance in the wound, but ordinarily a careful examination, by showing that the lesion is definitely connected with the wound, is superficial, and extends irregularly at certain points, will point to keloid. A microscopic examination is the final court of appeal and should at once settle the diagnosis.

Prognosis.-Keloids grow slowly, as a rule, for an indefinite period, then tend to undergo a complete structural differentiation that results in pallor, diminished size and firmer texture. They rarely ulcerate. They never give metastasis. When excised, they commonly return, either because the patient is particularly susceptible to them or harbors the essential cause on the skin or in the tissues.

Treatment.-Keloids usually require no treatment, but if they grow rapidly or become painful, local applications may be useful. Williams (Medical Chronicle, Manchester, I893-94, p. 370) recommends covering the lesion with "belladonna, salicylic acid, or ammonium cum hydrargyro plaster." Crocker had best results with hypodermic injections of Io per cent. thiosinamin solution, warmed just before using, 20 minims being injected along the lesion.

The most satisfactory results, however, seem to follow a few treatments with the $x$-rays or radium.

Morphea, Circumscribed Scleroderma, Scleriasis, Scleroma or the Keloid of Addison.-This peculiar form of skin disease occasionally makes its appearance upon the breast. It is a fibromatoid condition whose external appearance and microscopic structure much resemble cicatrices, and hence led to its confusion with keloid (q.v.). It is of unknown cause and spontaneous occurrence, having no connection with antecedent accident or injury.

Addison (Medico-Chirurgical Transactions, London, I854, XXXVII, 27) reports two cases affecting the female breast, and others in the same situation have been reported by Heath (The Lancet, London, I87 I, i, 603), Hutchinson (Archives of Surgery, I89o, p. $32 ;$ I 89 I, p. 32) and others.

The lesions are hard, whitish or yellowish white, irregular indurations, feeling somewhat like parchment, but easily pinched up from the subjacent tissues. The surface is dry, quite smooth, is without hairs, as a rule, shows minute radiating corrugations and occasional cracks. It may last a long time, varying about to years then fade away, leaving the skin normal again.

The chief histological feature is increase in the connective tissue in the cutis, accompanying cell proliferation and accumulation about the blood-vessels with partial closure and subsequent atrophy of the structures to which the vessels distribute. Unna found some hyperkeratosis of the epiderm.

The disease has no surgical interest, and is not a disease of the breast but only of the skin covering it.

\section{LIPOMA}

A lipoma is a tumor composed of adipose tissue. Adipose tissue differs from other connective tissues in the presence of large numbers of cells (lipoblasts) whose specialization adapts them for storing fats. Among the lower animals such cells are so restricted 
in distribution that definite fat depots are located with the same anatomical definiteness that characterizes the organs of higher animals. In man they are widely scattered throughout the subscutaneous, the subserous, the intra-muscular and other tissues. Many such cells are present in the stroma of the breast, and to the fat stored in them it owes much of its roundness and softness. The lipoma is a common tumor wherever adipose tissue is common, but it is a rare tumor elsewhere, as in the membranes of the spinal cord and in joints. In the mammary gland it arises from the adipose tissue and corresponds to it in distribution. Thus, there is no fat in the peri-ductal connective tissue of the breast, and peri-ductal lipoma is, therefore, practically unknown.

Lipomas of the mammary gland have been grouped by Zesas (Archiv gen. de chir., rgr 2, VIII, 924) as follows:

I. Intra-glandular lipomas.

II. Extra-glandular lipomas $\left\{\begin{array}{l}\text { Retro-mammary lipoma. } \\ \text { Subcutaneous lipoma. }\end{array}\right.$

I. Intra-mammary Lipoma of the Mamma.-A number of cases are recorded in the literature, but, upon examination, some prove to be retro-mammary lipomas by which the breast has been elevated, and in others there is insufficient information to enable us to be sure of their exact nature. They occur in both sexes and may attain to an enormous size. They are commonly unilateral, but may be bilateral and symmetrical.

A. Bilateral and Symmetrical Lipoma of the Breast.-

I. In the Female.-The most remarkable case of this kind of which we have knowledge is reported by Hoenigsberger (Münchener med. Wochenschrift, I905, LII, 222):

$\therefore \therefore$

The patient was a I2-year-old Kaffir girl whose breasts were so large and so pendulous as to resemble the most exaggerated cases of mammary hypertrophy, reaching down to the pubes when she stood. Her general appearance, her age, the bilateral character of the lesions and their enormous size suggest mammary hypertrophy, but the author says they were lipomas, and as he successfully removed them and has so recorded them, his report must be accepted unless he subsequently corrects it.

2. In the Male.-Baker and Bowlby (Medico-Chirurgical

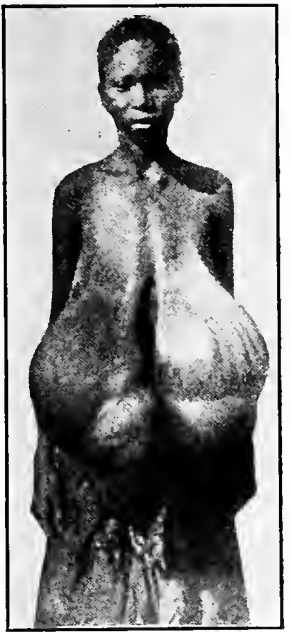

FIG. 138.-Bilateral enormous lipomas of the mammæ. (Hoenigsberger.) Transactions, I886, LXIX, p. 4I) report an interesting case:

A man who had in each pectoral region "a mass" as big as a full-sized female breast, with a nipple in its center. There were other diffuse fatty growths in the scrotum, on the abdomen, over the mastoids and elsewhere.

A similar case of bilateral symmetrical lipomas in the breasts as well as elsewhere came under the observation of Dr. Joseph Sailer, in the Philadelphia General Hospital, early in ${ }^{2}{ }^{1} 5$, and to him we are indebted for an interesting photograph of the patient who had gynecomastia as well as mammary lipomas. (Fig. 89, p. I48.)

It is not stated in these cases whether the lipomas were true intra-glandular tumors or not. Hoenigsberger says nothing about it, and though Sailer's case died of heart disease, no autopsy was permitted. The general appearance of the latter suggests subcutaneous tumors, but when palpated they appeared to be deeply seated in the greatly enlarged mammæ. 
B. Unilateral Lipoma of the Breast.-Enormous tumors of this kind are on record. Thus, Atkins (India Medical Record, Calcutta, r893, V, 4I) reports the following case:

A native Indian girl, Mussumal Budhri, aged $\mathbf{r} 6$ years, in whose left breast a tumor was first noticed when she was four years old. It grew slowly until she was 12 , and then rapidly until the present time. It is now enormous and pendulous, extending upward to the clavicle and axilla and downward into the hypochondrium. In walking the girl is obliged to support the tumor with both hands. The skin over

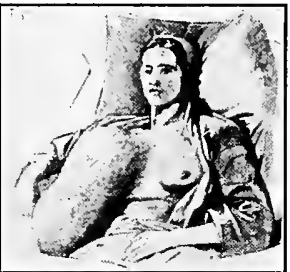

Frg. r39.-Enormous lipoma of the breast. (Billroth.) the proximal half is smooth, over the distal half is full of excrescences. The tumor is freely movable and feels firm, elastic and lobulated. There is no trace of a nipple. The other breast is normal. The tumor was removed by operation and measured 24 inches in length, 36 inches in circumference and weighed 25 pounds. The patient recovered. In this case it is not stated by the author whether the tumor was intra-glandular or not.

Warren ("Surgical Observations on Tumors," London, I837, p. 228) speaks of a woman, 28 years of age, whose left breast became so large that it was necessary to amputate it. When it was examined nothing was found but an increase in the fat. Later, the doctor informed him that "there was a tendency toward the same thing on the other side." This leads us to infer that the condition was not lipoma, but hypertrophy.

Other large mammary lipomas are on record. Sir Astley Cooper ("Illustrations of Diseases of the Breast," I 845 , pp. 48-49) reports one weighing I4 pounds, another weighing I4 pounds Io ounces, and a third of "great size." Brodie also reports one of large

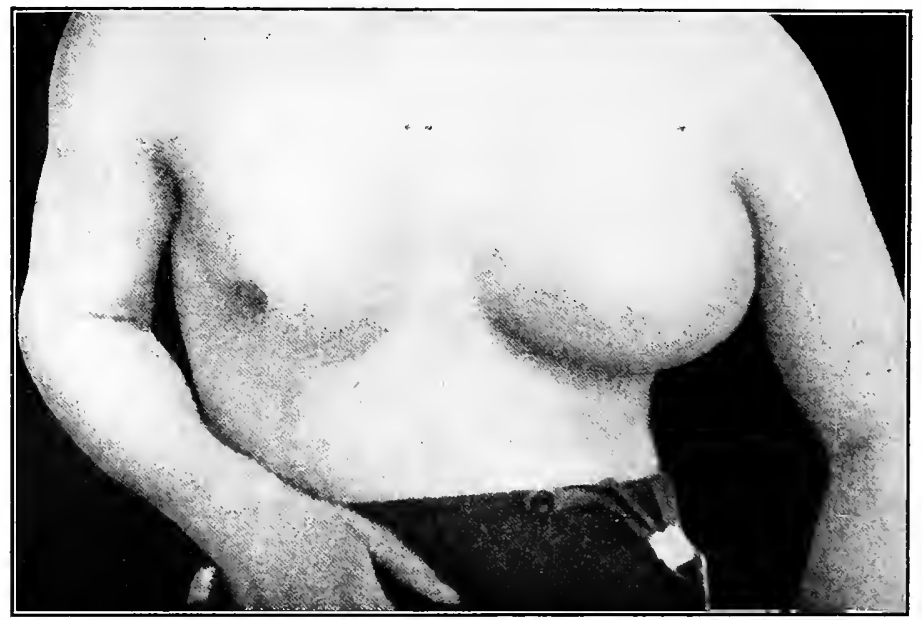

FIG. I40.-Lipoma of the male breast. (Warren and Gould.)

size. Dudley (Post-Graduate, N. Y., I89I-2, XVII, I57) removed one that weighed nearly 4 pounds, from the breast of a woman aged 50 years. Queirel (Rev. de. Chir., I889, IX, 923) removed a lipoma the size of a child's head from the left breast 'of a woman aged 64 years. It was soft and freely movable. She had lipomas in other regions of 
the body. Queirel (Thèse de Paris, I 897-98) aIso removed a lipoma from the male breast. Smith (Med. Times and Gazette, London, I 876, I, 333) removed a lipoma from the right mammary region (exact location not stated) of a man, aged 47 years. The tumor was on the level of the nipple, its long axis extending outward for about 6 inches, and measured $2 \frac{1}{2}$ inches across. Its surface was irregular. It was soft and elastic, the skin freely movable over it. The nipple was not adherent or depressed. There were no enlarged axillary nodes. The patient recovered from the operation. The tumor is described as "fibro-fatty." Masse (Thèse de Paris, I 897-98) removed a congenital lipoma from the breast of a male infant. It had attained to the size of an orange in nine months.

True intra-glandular lipomas of the breast seem to be few in number.

Bégouin (Jour. de méd. de Bordeaux, 1892 , XXII, ro9) cites such a case. It occurred in the upper outer quadrant of the breast of a woman aged 47 years. It had been discovered by accident two years before, and was the size of a nut. When removed and microscopically examined, it was found to consist of islets of glandular tissue that had lost themselves in the adipose tissue. There were stellate crystals of margarine and stearine scattered through it. Another strikingly similar case was reported by Haeckel (Archiv für klinische Chirurgie, I894, XLVII, 276). The patient was an unmarried woman aged 40 years, with a soft sharply circumscribed encapsulated node $3 \frac{1}{2}$ by $7 \mathrm{~cm}$. in size close under the skin of the lower outer quadrant of the right breast. Upon microscopic examination after removal it was found to be a lipoma with localized areas of glandular tissue in the tumor.

The remarkable feature of these cases was the presence of the "islets of glandular tissue," which are rare in lipoma.

Meldon (Dublin Jour. Med. Science, 1872 , LIII, $30 r)$ removed a lipoma that in one month grew from the size of a nut to that of an orange.

Velpeau ("Maladies du sein," I858, pp. 200 and

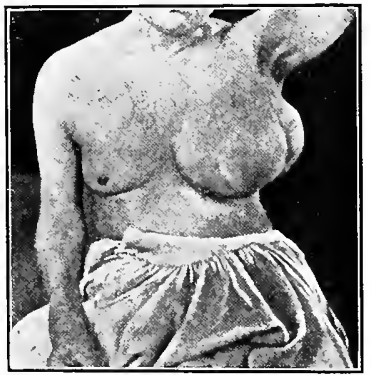

FIG. I4I.-Para-mammary lipoma of large size. (Sheild.) 20I) mentions two somewhat questionable cases of lipoma of the breast that followed injury.

The first was a woman aged 42 years, married and the mother of five children, who received an injury of the left breast I 2 years before coming under observation. Six months later she observed $t$ wo little nodules below the nipple to which she paid little attention because they gave her very little pain. With each of the five subsequent lactations they grew larger, finally coalesced and became painful, and attained to the size of two fists, forming a soft nodular tumor covered by thin red skin. The second was a woman of $3 \circ$ years who met with an injury that was followed by the appearance of a tumor in the lower outer quadrant of the breast which was soft, vaguely nodular and covered by freely movable skin. It was at first thought to be a cyst and punctured. As no fluid escaped, the diagnosis was changed to tumor and it was excised, proving to be a lipoma.

II. Subcutaneous mammary lipomas are also rare. Burrow (Mitt. a. d. chir. Privatklinik, Leipzig ( $1875-77)$, I880; r 33 ) removed a subcutaneous lipoma the size of a child's head and weighing $2 \frac{1}{2}$ pounds from the breast of a man aged 57 years.

III. Retro-mammary Lipomas Seem to be Comparatively Frequent.-Such cases are reported by Billroth (Deutsche Chirurgie), whose illustration showing a large lipoma of the right breast has been much copied in textbooks of surgery. 
Bryk (Archiv f. klin. Chirurgie, I874, XVI, 555 (from Marloth) reports the following case:

The patient was a working woman 47 years of age. The tumor made its first appearance just above and to the outer side of the nipple of the right breast, eight years before the operation. It is described as a large fibro-cystic lipoma and weighed 12 pounds. It was behind the breast and was easily removed. The patient, however, subsequently died of infection.

Rathmann (Zur Kentniss der Geschwülste der männlichen Brustdrüse, Inaug. Diss., Jena, I 89o,

reported a large retro-mammary lipoma in a man 42 years. It followed an injury received some years before and was attached to the scar. This does not seem to have been a simple lipoma, for after the tumor had been removed for some time, the patient returned with an enlarged and painful breast that had to be removed, and although said to be lipoma, its histological structure is described as heing "gland tissue with increase of adipose."

\section{Löbker (Wiener med. Presse, I883, No. 43) reports the case of}

a male infant whose left breast was as large as that of an adult woman. During the second year it rapidly increased in size and operative removal was performed. The enlargement was found to depend upon a lipoma loosely attached to the pectoral fascia.

Puyhaubert (Jour. de méd. de Bordeaux, I907, XXXVII, 3I4) reports the following case:

A woman aged 40 years, a III-para, who observed at the close of her last period of lactation that a small painful tumor was situated in the external aspect of the right breast. Six months after discovery it had grown considerably and formed a loose, nodular, non-fluctuating, painless mass behind the external half of the gland. It was excised and found to be a lipoma.

Retro-mammary lipomas are sometimes situated between the pectoral muscles as in the case reported by Marloth ("Subpectoral Lipoma in der Gegend der Mamma bei einem Manne," Inaug. Diss., Leipzig, I9I0).

The patient, a man of 56 years, a stonemason, suffered from an enlargement of the left breast that has now reached the size of a child's head. It depends upon the presence of a tumor of eight years' duration, that has grown slowly and without pain. The patient died of heart disease two days after coming under observation. At autopsy it was found that a large lipoma was situated behind the left pectoralis major muscle. It had the form of a circular disk, flattened behind, and weighed 400 grams. The mamma itself was not enlarged.

From these citations it becomes clear that lipomas begin as small rounded nodes in or behind the breast. They grow with varying rapidity. In Atkins' case a weight of 25 pounds was reached in $12 \frac{1}{2}$ years; in Bryk's case, of 12 pounds in eight years; in Marloth's case, the size of a child's head was attained in eight years; in Löbker's case the breast of the two-year-old infant had attained to a size much larger than that of an adult female; in Meldon's case the tumor grew from the size of a nut to that of an orange in one month; in Smith's case the tumor grew to measure 6 by $2 \frac{1}{2}$ inches in four months.

In general, it seems that the rapidity of growth bears some correspondence to the age of the patient-rapid growth being most frequent in the young.

Of the cases that have been chosen for citation, the youngest was only nine months, another only a year old, when the tumor was already large; the oldest woman was $5^{2}$, the oldest man 64 years. 
As has been shown, the tumors may be bilateral. In the case of Baker and Bowlby and in that of Sailer, the lipomas in the breast were but part of lipomatous disease in many regions; Queirel says that his patient had "lipomas in other regions."

The tumors may also be multiple in the same breast. In the case of Delage and Massabiau to be described below, the enlarged breast contained five nodules of unequal volume, and the patient described the breast as being like "a bag full of oranges."

The gross morbid anatomy of lipoma is simple. The tumors are rounded, nodular, single or multiple, circumscribed and movable, and are painless, as a rule. In the case reported by Puyhaubert, when the patient first discovered the little tumor it was "slightly painful:" as it grew larger the pain disappeared. The tumors are usually encapsulated, and their removal is easy because of the looseness of the attachments. When removed they are usually soft and fluctuating. The yellow fatty tissue is often divided by delicate fibrillar tissue partitions, showing through the translucent tissue of the capsule. When cut, the knife and fingers become covered with liquid fat that exudes.

Under ordinary conditions there is no mistaking the adipose tissue, but in some cases there is admixture of other elements, when the yellowish color may be much less evident and the texture as well as the oily quality of the tissue marked. In the case of Delage and Massabiau (Rev. de Chir., Paris, I904, XXX, 484) the tumor, which weighed I 700 grams, was a rounded, lobulated, encapsulated yellow tissue, like a large lipoma, but was found on microscopic examination to be "myxo-lipoma." The tumor in Smith's case was described as "fibro-fatty."

The histology of lipoma corresponds fully with that of adipose tissue, and is so simple and so characteristic that should any doubt arise concerning the naked-eye appearance, a glance at a microscopic section ought to clear up the diagnosis in a moment. But a word of caution.ought to be uttered at this point. Lipoma is regarded as a tumor of adult tissue and is expected to behave as adult tissue, which in most cases it does. It is a benign tumor, yet in a few cases it recurs. Thus the patient whose case is reported by Delage and Massabiau, a woman aged 52 years with a tumor of the left breast, had the following history:

Ten years ago she had a lipoma the size of an orange removed from the left breast; four years ago a swelling appeared below the cicatrix outside and on the level with the nipple. It was painless but grew rapidly. Later it was found that there were five nodules of unequal size in the breast, nicely separated from one another and freely movable beneath the skin. The patient described the breast as being like a "bag full of oranges." When the breast was removed and the tumors examined micrcscopically, a diagnosis of myxo-lipoma was made.

This is a very interesting case and the following questions must arise: Was the original tumor a lipoma? If so, was it a simple lipoma? Did the subsequent development of five tumors in the breast take place because of the presence of the antecedent tumor? Were all six tumors independent of one another? What is "myxo-lipoma?" Is it a simple combination of adipose and gelatinous tissues or does it possess a sarcomatous character? It would be interesting to know whether in the course of years there were other recurrences in this case.

There is also the case reported by Rathmann to be considered: Years after an injury to the left mammary region, a retro-mammary lipoma develops and is removed. Later the patient returns with pain and enlargement and a second operation is performed. The tissue obtained, when examined with the microscope showed "gland tissue with increase of adipose." Was this lipoma? Probably not; but if not, what was its 
relation to the primitive tumor? Was that a lipoma? Was there any relation between the two?

In these cases a more careful histological study might afford some indication of what was going on. Ordinary lipoma, like adipose tissue, consists of cells so distended with fat deposits that the cytoplasm is reduced to a mere surrounding envelope, and so closely packed together as to be polyhedral in outline through mutual compression. All this presupposes that the tissue has grown slowly and that its cells have not increased in number faster than the supply of fat antecedents were brought to them and transformed to the stored fat. But what would be the appearance of the tumor if the fat-storing cells increased in number faster than the fat could be formed for storage? Would it not then be a cellular tumor? Would it, as such, be a benign tumor?

An interesting tumor concerning which such inquiry is justifiable has been reported by Merkel as a "Pseudolipoma of the Mamma" (Beiträge z. path. Anat. u. zur allg. Path., Jena, I906, XXIX, I52).

It occurred in a woman aged 26 years, as a flattened, rounded, lobulated encapsulated tumor about Io $\mathrm{cm}$. in diameter, at the outer border of the right breast, where it grew slowly without pain. As the patient was in a very bad physical condition a suspicion of malignancy was aroused, and it was removed. Physical examination of the tumor, after removal, was followed by the diagnosis of lipoma, but when microscopic examination was made it was found to have a most unusual structure, for it was composed of cells, whose general appearance suggested those of the sebaceous glands, filled with molecular fat. Merkel could not make up his mind whether the cells were epithelial or endothelial, nor could he account for their peculiar appearance.

There seem to be no studies of lipomas in emaciating subjects, so that it cannot be known whether the peculiar cells in this case were cells in which the fat was changing from the globular to the molecular form prior to absorption or not. It is stated in some textbooks that lipomas continue to grow regardless of the health or emaciation of the patient, though there seems to be no authority for the statement which has simply been copied from book to book without verification.

Cases in which the adipose tissue of what would otherwise constitute lipoma has occurred in association with considerable numbers of round or spindle cells, and cases that have recurred and shown themselves to be malignant when previously thought to be benignant, are spoken of as liposarcoma. The myxo-lipoma of Delage and Massabiau, which was recurrent, may have been a sarcomatous tumor.

Retrogressive changes not infrequently take place in lipomas. It is in this manner that they become edematous, myxomatous or calcareous. The most frequent change is crystallization of the fatty acids. If these combine with calcium to form soaps, gradual replacement of the soap by added calcium and magnesium leads to the calcification of scattered foci. This change is, however, of infrequent occurrence in lipomas of the breast.

In considering fibroma it was found that confusion resulted from inattention to the circumscription by which fibroma is differentiated from other fibro-connective tissue hyperplasias for which we prefer the term fibromatoid. In dealing with lipoma a similar confusion presents itself. There are diffuse lipomas-lipomatoid conditions. These are of frequent occurrence about the neck, about the abdominal walls, and in the breasts. Some large and pendulous breasts, when examined, are found to be composed largely, sometimes almost entirely, of adipose tissue. Guthrie and Albert found such a condition where mammary hypertrophy was expected, and a large breast removed by Dr. J. B. Deaver in the German Hospital, Philadelphia, supposed to be mammary 
hypertrophy, when examined, was found to be a similar case of lipomatoid condition. Lipomatoid deposits are excessive adipose formations, which, though sufficiently localized to destroy the symmetry of the body or member, lack the circumscribing and capsulating membrane of the true lipoma.

\section{MYXOMA}

The myxoma is a tumor composed of mucous tissue. This is a fibro-cellular connective tissue containing more or less slimy or mucilaginous substance rich in mucin. It is supposed to find its prototype in the "mucous tissue" of the embryo, and particularly in the "jelly of Wharton" of the umbilical cord, but it must be admitted that there is more fancied than real resemblance between this tissue and that of any myxoma.

Upon academic principles the mucous tissue of myxoma may be such per se, that is, from the time of its first appearance the tumor may consist of tissue that is characterized by the slimy change in the stroma, or a fibrillar tissue of ordinary quality may become myxomatous through a local or general retrogressive change.

It is difficult to determine how frequently myxoma of the breast occurs. It is undoubtedly a very rare tumor, in which it resembles fibroma; it is also one about which there is much of the same lack of agreement as is the case with fibroma. Careful reading of the published case reports shows that a variety of different tumors appear under the name myxoma. Among these it is possible to recognize edematous or myxomatous peri-ductal fibroma, and myxomatous peri-ductal sarcoma.

True myxoma of the breast should occur as a rounded, sharply circumscribed encapsulated, movable, soft and sometimes fluctuating, painless tumor of fairly rapid growth, easy to enucleate and not tending to recur. Upon section it should be grayish or pinkish, slimy and soft.

Such a case is reported by Mauté and Daniel (Bull. et. mém. soc. d'anat. de Paris, I904, LXXIX, 609).

The patient was a man 37 years of age, a tailor, who had a slowly growing tumor in the left breast recognized seven months before operation. It was firm, regularly rounded, painless, freely movable and the size of a pigeon's egg. The clinical diagnosis was sebaceous cyst. After operation the microscopic examination showed it to be a myxoma.

Myxoma is supposed to be a benign tumor, and as such, is not expected to recur. When recurrence is observed it may be suspected that there has been some mistake in the diagnosis. Such is the probable explanation of the case reported by Barton (Phila. Med. Times, I882, X, I57).

The patient was an unmarried woman, aged 59 years, in whose right breast a small tumor grew, slowly for five years, before it reached the size of a walnut. It is distinctly encapsulated, developed from the cellular rather than from the gland tissue and fluctuated. When removed it was found to be a cystic formation with a thin wall easily mistaken for a simple cyst, but filled with black and tarry fluid blood.

At the time of reporting there was a second tumor twice the size of its predecessor, that had been recognized for about a year. It grew slowly for about six weeks before operation, since when it had doubled in size. It caused occasional sharp lancinating pains. It fluctuated, and was immediately beneath the skin, to which it was adherent, thongh it encroached decidedly upon the mammary gland. It was purplish in color, irregular in outline and grew at the situation of the first tumor. The entire gland was removed. Upon dissection the new tumor was found to resemble its predecessor. It is difficult to imagine what the nature of this tumor could have been. It was referred to the "Committee on Morbid Growths" of the Philadelphia Pathological Society (see Trans. Phila. Path. Soc. (I879-8I), I882, X, I57) who called it a "hematoid myxoma." 


\section{CHONDROMA, OSTEOMA AND OSTEO-CHONDROMA}

The occurrence of cartilaginous tumors of the breast was noted by Cooper, Nélaton, Velpeau, Cruveilhier and Leser, but they seemed so rare that doubt came to be felt as to whether they really existed. Billroth, in $\mathrm{I} 889$, in his monograph, "Die Krankheiten der Brustdrüsen," stated that he had never seen anything like cartilage in the breast tumors of human beings. Gross also doubted its occurrence and did not regard the cases of Cooper and Cruveilhier as "beyond doubt." In looking over the literature, however, one finds about two dozen reported cases of mammary tumors of which cartilage and sometimes bone were important constituents. They form a varied group and are diffcult to discuss collectively even after every effort has been made to eliminate condrifying and ossifying sarcomas.

A chondroma is a tumor composed of cartilaginous tissue; an osteoma, a tumor composed of osseous tissue; an osteo-chondroma a tumor composed of both cartilaginous and

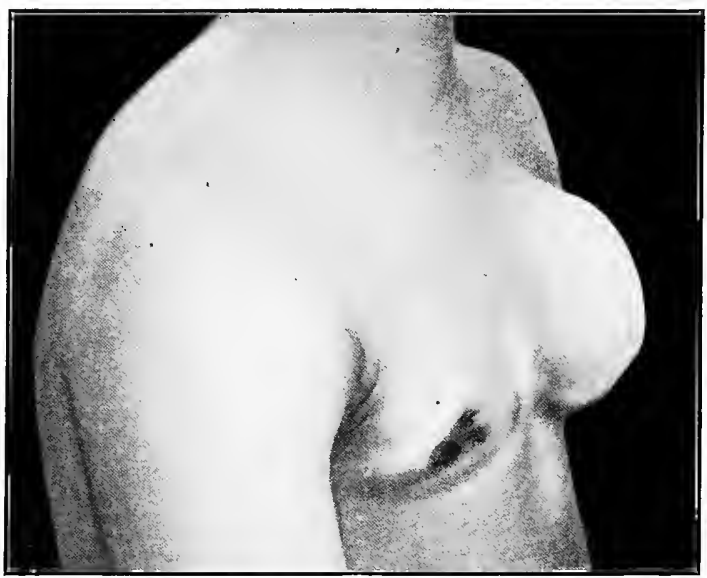

FIG. 142.-Chondroma of the ribs in a man. (Riedinger u. Henschen.)

osseous tissues. These tissues find their prototypes in the normal tissue of the skeletal system, from which they commonly arise as homologous tumors.

Tumors of cartilage or bone in the mammary gland are always heterologous and as such are conceived to arise through metaplastic transformation of connective tissue. When homologous and in the skeletal system, the tumors are usually uniformly composed of cartilage or bone but when occurring elsewhere through metaplasia, the cartilage or bone is apt to appear as an incident of structure, and to present itself in the form of distributed islands, though it is possible for the greater part of the tumor to be formed of the metaplastic products.

Such tumors are supposed first to show the chondroid formations which, through ossification, may subsequently become more or less bony. They occur in human beings and in the lower animals. Cornil and Petit (Bull. et. mém. de la soc. d'anat. de Paris, I905, LXXX, 23) describe a large, hard, nodular tumor, containing cartilaginous and osseous islets, that was removed from the mammary gland of a bitch. 
The tumors occur in human beings at ages varying from 25 to 72 years, the greater number being in patients past middle life:

All of the cases, in our collection from the literature, were in women except that of Foucher (Union. méd., Paris, 1859, 2 s., III, 403) which should not be included among the breast tumors. His patient was a man 35 years old, from the peri-chondrium of whose fifth costal cartilage, and the periosteum of whose fifth rib, a chondroma grew for five years, projecting anteriorly and appearing in the right breast near the nipple. It was removed, and the patient died of pleurisy on the third day. This case is a homologous tumor of the rib and cartilage, had nothing to do with the mamma, and does not belong to the series of cases under discussion. As the cartilage seems to be the tissue most essential to the tumor, as the calcification or ossification is a subsequent uncertain change in it, and as no true bony tumor of the breast is known to exist, in the further discussion, the tumors of our group will be collectively spoken of as chondroma.

The chondroma of the breast occurs as a hard, rounded nodule that increases in size very slowly. In Lange's case it required 13 years for the size to increase from that of a berry to that of a nutmeg. In Stefanini's case the tumor had reached the size of a hen's egg in 25 years. In Happel's case the tumor grew to the size of a goose egg in one year, remained unchanged for nine years, and then grew again until it reached the size of a child's head.

Tumors of small size not infrequently are discovered by accident ater having existed for a long time. Carelessness in recording may lead to entirely wrong conclusions as to the antecedent duration of tumors under such circumstances. Thus, Chevrier and Delval (Bull. et mém. soc. d'anat. de Paris, I 9 ro, LXXXV, 586) speak of a woman $5^{6}$ years of age, with a cartilaginous tumor the size of a walnut, situated behind the nipple of one breast. Its recognized duration was two months-it may have been there for ro years, having prèviously been too small to attract attention. In no case is it stated that the growth of the tumor was at all rapid.

Chondromas may or may not be encapsulated. Davidsohn (Centralbl. f. Gynäk., I 909, XXXIII, 1357) saw a woman 57

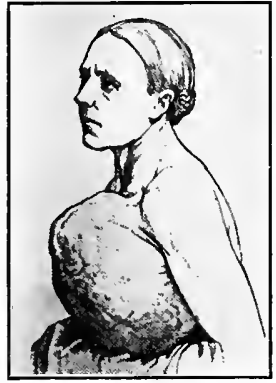

FIG. I43.-Osteo-chondroma of the breast. (Koloezek.) years old, in whose right breast there was a little cherry-sized tumor, well encapsulated, "like a nut in a shell," and of cartilaginous hardness. It proved to be a chondroma; more will be said about it below. Chevrier and Delval's (Bull. et mém. soc. d'anat. de Paris, I910, LXXXV, 586) case of chondroma, mentioned above, is said to have been nicely delimited, mobile, slightly adherent, not connected with the skin or deeper tissues, to have consisted of three nuclei in coalescence, the largest the size of a walnut, the others the size of peas. It was not encapsulated.

The tissue of the tumor is mixed. Chevrier and Delval's case consisted of different varieties of connective tissue, with adipose and glandular tissue. The connective tissue was rich in cells. This tumor contained both cartilage and bone. They may also be calcified as in the case reported by Warren ("Surgical Observations on Tumors," London, I 837 , p. $2 I_{3}$ ) of a tumor of two years' duration that was removed from the breast of a woman 45 years of age, and which is described as an osseous and cartilaginous tumor that contained three separate calcareous nodules.

The occurrence of glandular tissue in chondroma is also reported by Davidsohn who describes the microscopy of the tumor as follows: 
In a matrix poor in nuclei are numerous clusters and strands of cells whose peculiarity is well brought out by simple staining with hematoxylin. Beside glandular remnants whose lobules are, in part, dilated, and lined with a flattened epithelium, are cells in columns of $2,3,4$ or more, surrounded by a capsule. They have rounded or ovoid nuclei, distinct chromatin threads, suggesting cartilage cells. Staining with kresylviolette, an anilin color well adapted to the demonstration of chondrin, gives a brilliant color to the capsule borders while the surrounding tissue takes a pale red hue. He believes this tumor to have been a chondroma that developed between the glandular lobules, and not a "mixed tumor."

The tumor removed by Happel (loc. cit.) was the size of a child's head at the time of operation. When microscopically examined it consisted in part of spindle cells, in part of cartilage, and in part of glandular tissue "caught in." $\mathrm{He}$ is in some doubt whether this may not have been sarcoma.

In Lange's case no mention is made of glandular tissue; the tumor consisted of osseous and cartilaginous tissues. One division of the cartilaginous part contained a large bony nucleus. In Rey's case (Lyon méd., I903, C, 259) it is stated that some of the cartilaginous islets were calcified.

When so striking and so rare a substance as bone or cartilage presents itself, insufficient attention is apt to be paid to other and what are really more important elements of the tumor structure, that is, the matrix substance in which the cartilage and bone are contained. No doubt some of the chondrous tumors already cited belong in reality to the condrifying and ossifying sarcomas, the sarcomatous elements being eclipsed in importance by the more rare tissue elements. Thus Sehrt (Beiträge zur klin. Chirurgie, I907, LV, 589) describes:

"a tumor of fist size that grew in the right breast of a woman 44 years of age, where its presence had been recognized for six months. It was a painful tumor, rounded in shape, not adherent to the skin, smooth on the surface, movable and not adherent. It was removed together with the entire breast and axillary tissues. When subjected to microscopic study it was found to consist of miscellaneous and giant cells rich in chromatin, cartilage, calcification, and in certain areas bone formation. Such a structure ought to arouse the suspicion that the fundamental structure was sarcoma."

It would be interesting to know the subsequent history of the reported cases of chondroma of the breast, but it commonly happens that the published account of the case ends with the report of the first operation and the description of the primary tumor.

Morțon (Trans. Path. Soc., London, 1904, LV, 327) removed a small tumor from the breast of a patient, a woman, aged 64 years.

It had been accidently discovered only a month before, and was hard, heavy, somewhat lobulated, lay in the lower outer quadrant of the breast, just extending to the nipple that was not retracted. The tumor was about $\mathrm{I} 3 / 4$ inches in diameter. The whole breast, the fat and axillary nodes were removed. When examined after removal the tumor was as hard as cartilage and creaked under the knife like a scirrhus. Its cut surface did not glisten and it contained many areas of calcification. It was not definitely encapsulated and one small node was almost separate from the general mass. There was no softening or degeneration. Microscopically it proved to be a spindle-celi sarcoma with areas of cartilage some of which was calcified. Fifteen months after the removal of the breast a similar mass had to be removed from the left gluteal region, and later another grew upon a finger. The patient later died, but the cause of death was not determined. Morton states that his was the fifth case of the kind to be shown to the society, the others being by Bowlby ( 1882 , XXXIII, 306), Durham ( 1884, XXXV, 378), Bottle (I886, XXXVII, 473) and Clarke (I890, XII, 229).

Breast tumors containing cartilage undergo retrogressive changes and show areas of softening and sometimes cyst formation. Such change is said to have been present in the cases reported by Sehrt, Happel (large cyst in the middle), and Lange.

The association of cartilage and adipose tissue in the same tumor is reported by Sick (Jahrbücher d. Hamb. Staatskrankenanstalt, I906, XI, Abt. a. I7). 
The patient was a woman aged 72 years, who never had any children and never lactated. She had had no traumatic injury and no mastitis. The tumor had been present for a long time in the left breast, but only recently began to grow rapidly and became tender upon pressure. Upon examination, the left breast was found to resemble a virginal breast, while the other was shrunken and flaccid. The difference was caused by the presence in the left breast of a smooth round tumor without nodulations or cysts. There was no enlargement of the axillary glands. A diagnosis of sarcoma was made and the breast was amputated. Examination of the tumor showed it to be encapsulated like an adenoma. On section it was found to consist of a firm, yellow, fatty tissue with little hard points scattered through it. Upon microscopic examination the latter proved to be tiny cartilaginous formations varying from the size of millet seeds to that of grains of wheat. When the finger was rubbed on the tumor these little islets of cartilage could be distinctly felt. Each was surrounded by a small amount of fibrillar tissue. The matrix was adipose tissue. For this unique formation he suggested the name "chondrilipoma."

Uncomplicated cartilaginous and osseous tumors of the breast are benign. In studying them, however, great care ought to be taken to make sure that the presence of the cartilage and bone are not expressions of the cellular activity of sarcoma. If the fundamental structure be sarcoma, the tumor is sarcoma, with the general tendencies of sarcoma, no matter how much cartilage or bone be present.

\section{ANGIOMA}

An angioma is a tumor composed of vascular tissue. Two types occur, the hemangioma which is composed of blood-vessels and the lymphangioma composed of lymphvessels. When the term is used without qualification it may be assumed that hemangioma is meant. The vessels composing this tumor are chiefly of new formation. They arise through the same activity of angioblasts that may be observed in granulation tissue, in the process of regeneration, and as an accompaniment of the growth of most tumors. Presumably the angioblasts are the endothelial cells of the capillaries that first form delicate filamentous offshoots that subsequently become tubular through increase in the number of the cells engaged, and the admission of blood. As the number of capillaries is thus increased, the vessels by which they are supplied hypertrophy to meet the new requirement. Under conditions of normal growth, in granulation tissue, and in most tumors, the vascular increase is commensurate with the needs of the tissue to be nourished but it is sometimes in excess of it when the tissue is said to become telangiectatic or cavernous. In angioma the perversion of growth, like the stimulus to grow, seems to effect the vascular tissue only, the result being a new formation or "neoplasm" whose essential, or sometimes only tissue, is vascular.

The vascular new formations follow one or the other of two chief plans of structure, and are thus divided by the general pathologist into two varieties that have been described as simple or cavernous and racemose or plexiform.

I. Angioma simplex or cavernous angioma or cavernoma is most common and occurs most frequently in the skin, in the form of vascular nævus, and in the liver. It forms a fairly well-circumscribed area of purplish color, whose section shows a spongy texture, and which is found upon microscopic examination to be composed of atypically formed and more or less dilated vessels closely packed and held together by a small amount of areolar tissue. There is no differentiation of arterial and venous vessels. If the blood in the vessels be largely arterial, the color is red and the tumor may pulsate; if it be largely venous, the color is bluish and there is no pulsation. Not infrequently the tumors are erectile, i.e., swell up when they receive an accession of blood. As the tumors grow, the blood-vessels tend to communicate with one another more and more through atrophy of 
their walls and spaces of considerable size may be formed. In these thrombi may form. Whole areas may become obstructed by thrombosis and through necrotic or degenerative changes eventuate in cystic cavities containing chocolate-colored bloody fluid or even a straw-colored serous fluid. When such tumors are near a surface, the subjacent tissues may become thinned, yield and permit the escape of blood externally or into a cavity.

\section{Angioma Arteriale Racemosum.}

2. Racemose Angioma, or Hemartoma.-This is not, in the strict sense a tumor, but rather a congenital defect in vascular formation by which some part of the body becomes provided with an excessive number of vessels of abnormal magnitude. It is a diffuse vascular formation easily divisible into arterial and venous trunks with intervening capillaries. It is always congenital, is not progressive and is not subject to change except in case of accident. It is only by its congenital occurrence and indisposition to undergo change that it can be differentiated from telangiectasia or localized dilatation of systems of vessels.

Racemose angiomas are rare; telangiectasia more frequent; both are rare in comparison with the cavernous angiomas or cavernomas.

In the breast there is reason to believe that both forms of angioma and telangiectasia occur. The conditions of occurrence are not always such as to enable them to be easily separated or clearly defined. To classify them scientificially with the information at hand is impossible, hence the arrangement given below is anatomical and clinical rather than etiological and pathological.

We have been able to assemble 38 cases, from references given at the end of this section, of tumors of angiomatous-i.e., highly vascular-character. A few of them are of doubtful character and scarcely permit of classification, as those of Althrop (Lancet, I901, Oct. 5), Audebert (Compt. rendu soc. d'obst. de gynéc. et de pédiat. de Paris, I9I0, XII, I3I), Verrier (Lyon méd., I9I3, CXX, I180), Pariot et Villard (Congrès de méd. de Bordeaux, ı895; Prov. méd., r896), Richard (Gazette des Hôpitaux, 186ı, p. 9r) and Williams (Middlesex Hospital Reports, I887).

Of the cases' susceptible of analysis we have found six to have occurred in males and nineteen in females. Thirteen of the cases were in children; fourteen in adults.

Two methods of grouping the tumors have been devised; that of Màlapert and Morichau-Beauchaut-in which there are three divisions, cutaneous, subcutaneous and glandular, and that of Klebs in which there are also three, the mamillary, the paramammary and the intra-mammary.

Of these we prefer the latter with a slight amplification. This permits us to group the cases studied as follows:

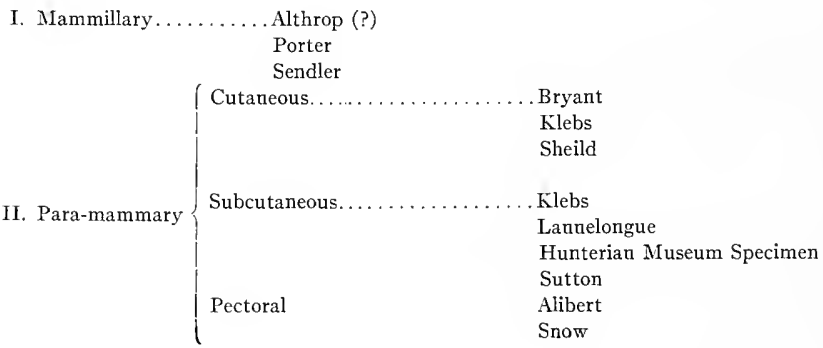


III. Intra-mammary $\ldots \ldots \ldots \ldots \ldots \ldots \ldots \ldots \ldots$ Asmus

Audebert (?)

Bejardi

Bryant

Carl

Colzi

Hoffmann (?)

Image

Langenbeck

Malapert and Morichau-Beauchaut

Taddei

Warren

Wullstein

IV. Undetermined

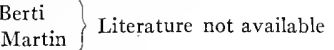

Sheild

Verrier

Pariot et Villard \{probably telangiestatic tumors of other kinds.

\section{THE MAMILLARY ANGIOMAS}

With the exception of Althorp's case which is doubtfully placed among the angiomas, being described as composed of smooth muscular, mucous and cavernous tissue, and which was a sessile tumor, entirely mammillary, these tumors are of an appearance that sometimes leads to their being grouped with the "pedunculated tumors of the nipple. For the description of these tumors see our chapter upon the Diseases of the Nipple and Areola.

\section{THE PARA-MAMMARY ANGIOMAS}

I. The Cutaneous Angiomas.-These constitute the nevi of the skin of the breast and are of trifling interest. A small tumor of this kind was removed from the right breast of a woman aged 24 years, at the German Hospital of Philadelphia, Mar. 20, 1909 (specimen 4630), by Dr. Deaver.

Bryant ("Diseases of the Breast," I 887 , p. 345) describes one in these words:

" Many years ago I saw a female child who had a raised florid nævus the size of a shilling, situated upon the breast and half of the nipple. I destroyed it with a galvanic cautery, after two or three applications."

Klebs (Handbuch der pathologischen Anatomie, 1876, I, Abt. 2, P. II94) observed an old man who had a rounded tumor $5 \mathrm{~cm}$. in diameter on the level of the nipple. Its surface was nodular, bluish and contained kinky hairs. It was traversed by galactophorus ducts that were unchanged, and it extended into the cellular tissue below the surface.

Sheild ("Diseases of the Breast," I 898, p. I43) observed

a healthy woman 42 years of age in the Waterloo Hospital who had a small red tumor, the size of a nut on the left mamma. It was obviously cutaneous and had been growing for two years. It was excised and proved to be a cavernous angioma. He adds, however, that in some areas the structure suggested sarcoma and he and Mr. Rolleston were inclined to regard it as an example of angio-sarcoma of the skin.

2. The Subcutaneous Angiomas.-Klebs (Handbuch der patli. Anat., i 876, I, Abt. 2, p. I I94) observed one in 
a man aged 22 years who had died of tuberculosis. It was on the inner, lower aspect of the right nipple and formed a circumscribed discoid growth $4 \mathrm{~cm}$. high by $4 \frac{1}{2} \mathrm{~cm}$. broad and $1 \frac{1}{2} \mathrm{~cm}$. thick. It was smooth, covered with healthy skin, and was mobile. It lay in the subcutaneous tissue between the nipple and the gland. Microscopic examination showed it to be cavernous angioma.

\section{Lannelongue (Centralbl. für Chirurgie, I889, p. 52) had under his care}

a little girl of seven years, who had a movable lobulated, discoidal tumor about $4 \mathrm{~cm}$. in. diameter above the right nipple. The skin was purplish near the center where it was also slightly adherent. It had only been observed for three months. After excision it was found to be composed of some half dozen small cystic cavities surrounding one large cyst. All were filled with a brownish fluid. It was regarded as a "degenerated subcutaneous nævus."

\section{Sutton (Trans. Clinical Society of London, I888-89, XXII, I89) observed}

a lad of 17 years, who at birth had a little nævus just above the right nipple. At ro years of age the breasts swelled and became painful, after which the pain disappeared but the swelling slowly increased. Hemorrhage occurred and caused him to apply for advice. Upon examination the right breast was found to contain a discoid tumor $3 \frac{1}{2}$ inches in diameter and adherent to the skin which had a purplish color, especially about the nipple which was also adherent to the tumor. The breast was amputated and a cavernous angioma found.

According to Williams ("Diseases of the Breast," 1894, p. 489) there is a specimen of subcutaneous angioma in the Hunterian Museum (No. 409 of the pathological series). It is thus described in the catalogue:

"A flattened, lobulated, oval, erectile tumor or nævus, removed from under the skin of the left side of the breast of a child nine months old. A small portion of the overlying skin is involved in the disease. The tumor consists of lobules of fibrous tissue and fat, with numerous large vessels coursing through it."

3. The Pectoral Angiomas.--These lie below the breast, between it and the pectoral muscle.

Alibert (cited by Williams, Nosol. Nat., p. 337) "mentions having met with a tumor of this kind situated over the pectoralis major muscle, in the vicinity of the breast of a child I3 months old."

The most interesting case is that reported by Snow (Lancet, I809, I, 240).

The patient was a woman $2 \mathrm{r}$ years old, who entered the Cancer Hospital in London for a tumor of the breast that had been known to exist since she was four years old and had since grown persistently. On the level of the pectoralis major muscle there was a round fluctuating tumor as large as a nut, mobile, and accompanied by enlargement of the axillary lymph nodes. It was excised independently of any glandular tissue, with which it was not connected. Upon microscopical examination it was found to consist of fibrillar tissue full of dilated vessels.

\section{THE INTRA-MAMMARY ANGIOMAS}

These occur in the tissue of the breast, and sometimes present themselves in a circumscribed though more frequently in a diffuse form.

I. Circumscribed Intra-manmary Angioma.-Bajardi (Lo Sperimentale, I892, XLVI, 250) tells of

a female child two years old whose parent first observed, when she was five to six months old, that her right hreast was larger and more prominent than the left. It continued to augment in volume until the second year and finally attained the size of a manderin orange. The skin that had long been normal in appearance now became purplish for a distance of $\mathrm{I} \mathrm{cm}$. in all directions about the nipple. The tumor was never painful. Upon examination a circumscribed, movable, hemispherical swelling, not adherent to the skin, 
was found to lie close under the nipple which was retracted. The tumor was soft and elastic and could be notably reduced in size, by compression, though it quickly regained its original volume when released. It also increased in size when the patient cried. After being removed by elliptical incisions the breast was examined and was found to contain an irregularly hemispherical nodular tumor covered with a resistant fibjous membrane that formed a kind of capsule but was continuous with the adipose and subcutaneous tissue. Microscopic examination showed typical angiomatous structure. Remnants of mammary gland tissue in a state of atrophy were found in the tissue of the tumor.

\section{Carl (Deutsche Zeitschrift für Chirurgie, Leipzig, I9I I, CXI, 308)}

reports that a woman aged 22 years bad had a tumor of the left mamma ever since she was a child, but had not been annoyed by it as it had not changed at all until she was $r 9$ when it became painful. It lay in the fold under the mamma and was thought to be either a cyst or a fibro-adenoma. Operation was performed, when it was found that the tumor could not be enucleated and that it was soft. After it was finally removed, a thin-walled sac remained. When the tumor was incised a chocolate-colored fluid escaped. Microscopic examination showed a thick connective-tissue capsule inside of which was a rich plexus of blood-vessels most of which had only endothelial walls, though some possessed a thin muscularis. Three years after the operation the patient had no recurrence.

From these tumors that were not only circumscribed but also encapsulated, one passes to others that were circumscribed but not encapsulated.

Bryant ("Diseases of the Breast," I887, p. 345) tells of such a case in a female infant $r_{5}$ weeks old, seen by him at Guy's Hospital, Oct. I4, I869.

She had a nævus that involved the whole of the right breast and the skin over it. The nipple was retracted. The tumor measured 2 inches in diameter and was like half of a globe. It was spongy to the feel and prominent. Large veins converged toward the surface and through the skin. At the margin of the gland the purple substance of the nævoid structure was visible. The whole swelling could easily be reduced by pressure.

We have some hesitation about placing this case of nævus among the intra-mammary angiomas, but it is difficult to classify, and we.have done so because of Bryant's statement that it "involved the whole of the right breast."

Taddei (Riforma medica, I904, XX, 989) reports the case of

a female infant $r$ months old, otherwise well, whose mother observed that she had a discoloration of the right mammary areola. It was characterized by red and blue strix ramifying over the surface in a tortuous fashion. It gradually enlarged to the size of a franc piece $(2 \mathrm{~cm}$.). Simultaneously with the occurrence of the discoloration tumefaction had been observed and had conformed in extent to the former. Gradually the tumor grew to the size of half a maderin orange. It was soft, indolent, vascular and reducible.

It was diagnosed angioma, and removed, and the patient recovered. Upon gross examination the tumor was found to be hemispherical, $5 \mathrm{~cm}$. in diameter, $x \mathrm{~cm}$. thick, its periphery which was without a capsule, adhering to the lobular adipose structure below. Histologically the tumor was "lipo-angioma." The vascular formations surrounded the ducts of the mammary tissue and extended among the fatty lobules in all directions.

\section{Malapert and Morichau-Beauchaut (Rev, de Chirurgie, Paris, XXIX, 200) observed}

a little girl I 2 years of age who had had an enlargement of the right breast since she was six months old. During the past five or six years it had grown steadily, without pain or tension until it formed a considerable sized tumor smooth, globularly rounded, at the center of which the nipple was situated. The nipple was not retracted, the skin of the breast was not discolored, there were no dilated veius on the surface. There was no increase of size when the child cried or exercised, nor could the tumor be reduced in size by 
pressure. There were no enlarged lymph nodes in the corresponding axilla. The formation was diagnosed a cyst, and operation for its removal performed. The knife entered a cavity as large as a manderine orange from which a quantity of bloody fluid escaped. Beside this were two other smaller cavities also filled with bloody fluid. None of the cavities communicated. As the entire breast was diseased it was amputated together with some of the overlying skin. There was abundant hemorrhage, and the tumor was found to be unencapsulated and to send out prolongation in all directions so that it had to be dissected from the pectoralis major muscle.

Microscopic examination of the tissue showed a fibro-adipose stroma filled with cavities containing bloody serum. Part of the tissue was like hemorrhagic infarction. There was no trace of a mammary gland. The pathological diagnosis was angioma cavernosum,

Williams ("Diseases of the Breast," I894, p. 513) describes a somewhat similar case.

The patient was a little boy seven years old who had a discoidal swelling the size of "half-a-crown" situated an inch ahove the right nipple and rather internal to it that had first been noticed five months previously.

It lay nearly over the intercostal space and adhered to the surrounding parts. The nipple and areola were well formed. The tumor was believed to be congenital in origin. It was dissected out; a thinwalled cyst, containing grumous yellowish-brown fluid, internally smooth, externally blended with adjacent structures. Beneath it the intercostal muscles were deficient; a process of the cyst seemed to have projected in this direction toward the pleura, but apparently did not join it. The cyst seemed to have originated from a degenerated angioma.

Wullstein (Arbeiten a.d. path. Inst. in Göttingen, I 893,253 ) studied a tumor removed from the breast of a child four months old.

After its birth, the baby's breast swelled and secreted milk as usual, then returned to the normal size and appearance. Four weeks ago the parents observed that the right breast was enlarged from the presence of a tumor whose skin covering showed numerous dilated vessels. The tumor was removed when it was found'to he unusually vascular, easily separable from the pectoral fascia, of a flattened hemispherical form, the size of a walnut, and everywhere surrounded by adipose tissue. On section it had a pale red color and it and the surrounding adipose tissue had a pronouncedly lobular texture. Each lobule was from millet-seed to pea size, and each was separated from the other by strands of connective tissue in which many vessels could be seen. When examined with a lens the tumor had a fairly spongy texture and each lobule was divided into many smaller lobules. Upon microscopic examination each lobule was composed of capillaries closely packed together.

2. The Diffuse Mammary Angiomas.-These form a series that begin in the unencapsulated but fairly well-localized tumors and terminate in morbid conditions characterized by such complete lack of circumscription as to leave one in doubt whether he is dealing with a tumor or with simple telangiectasis.

Warren ("Surgical Observations on Tumors," London, 1837, p. 213) reports the case of

"a healthy woman" 47 years of age with a small, hard, painless lump in the right breast near the nipple. After dissecting through the skin and adipose tissue a mass of dilated veins was exposed. The rest of the tumor was then carefully dissected out and found to be of erective character, occupying the entire gland,"

Langenbeck ("Nosology and Therap. der chirug. Krankheiten," Göttingen, II, 83), observed

a woman 18 to 20 years of age with a tumor of the breast. The breast was very large and its surface was marked by many veins. It was not tender, and diminished in size upon pressure. Upon palpation large pulsating vessels could be felt coursing through the parenchyma. Dissection showed veins some of which were as large as the finger; and a vascular tissue like that of vascular goiter.

Image, Hake and Liston (Medico-Chirurgical Transactions, I847, XXX, I05) reports the case of 
a woman 2 I years of age who had a red mark on the left breast for two years after having suffered from a traumatic injury. The breast increased in volume but was neither painful nor tender. Compression reduced it to half its size which was quickly regained when the pressure was relieved. Finally the skin of the breast assumed a livid color, and the breast came to measure i I by i 5 inches. Operative removal by strangulation was attempted, but the hemorrhage was so profuse that the patient died the same evening. The tumor was an angioma, and its vessels were large.

\section{Hoffman S. ("Prakt. Arzt, Wetzlar," I880, XXI, I45) observed}

a woman 32 years of age who had a soft tumor occupying a broad space between the left nipple and the sternal border and causing an elevation the size of an apple. It was immovable and had numerous outlying appendages. The skin was purplish in color and marked by dilated vessels some with pin-head sized openings plugged with coagulated blood. The tumor had grown rapidly for two months and had given rise to repeated hemorrhages. Removal by means of elastic ligature was followed by death from tetanus.

\section{Colzi ("Contributo di clinica operativa," Firenza, I89I, I43) described}

a little tumor in the right breast of a child (boy?) aged ro years, that involved the entire gland and became the size of a cberry. It was removed. When subsequently examined microscopically it was found to consist of newly formed vessels among which were the atrophic glandular structures of the mamma.

Asmus (Caspar's Wochenschrift, 1838 , No. 46) reports an interesting case that Klebs regards as an angioma of the breast.

The patient was a woman nursing her first baby, who complained that the left breast supplied blood instead of milk. Examination showed the right breast to be normal, well-developed and actively secreting, but the left to be composed of a coil of vessels that pulsated when touched and thumped as soon as the baby was applied to the nipple.

Audebert (Compt. rendu de la soc. d'obstét., de gynéc., et de pédiat. de Paris, I9IO, XII, II3) reports a most interesting case that may have been angioma or may have been telangiectasia.

The patient was a girl i 8 years of age. At puberty the breast began to enlarge and menstruation began at $I_{5}$, when the enlargement of the breast stopped. In the hope of increasing the size of her breasts the patient practised manipulation of the organs and titillation of the nipples. In the course of a couple of years she observed that the tip of the left breast-the one most frequently manipulated as she most frequently used the right hand-sometimes grew larger and projected as a kind of pulsating firm swelling that could be made to disappear by pressure. Later the same condition, but to a less marked degree, was observed on the right side. The size varied at different times; at the moment of turgescence the skin was violet colored and there was a sense of pain. When Audebert examined the patient he found her breasts well developed but containing very little adipose tissue. The left nipple was small but well formed and supported upon a well-formed conical areola. He says "the nipple seemed to be like the metal plug of a large top represented by the areolar region-the swelling is limited to the areola." No conclusion as to the nature of the peculiar condition was arrived at, nor was any operation performed.

Five cases reported by Pariot and Villard (Congrès de méd. de Bordeaux, I895; Prov. méd., I896) and by Verrier (Lyon méd., I9I3, CXX, I I80) are sometimes enumerated among the angiomas, but after having read the published descriptions we believe them to have been telangiectic tumors of other species. Four of them, described by Pariot and Villard are called "tumeur sudoripares naviformes" in the original text. The other case is difficult to name or classify.

We found a single reference to lymphangioma of the breast in our examination of the literature. 


\section{MYOMA}

Muscular tissue in the mammary gland occurs, first, in the form of bands of unstriated muscle cells surrounding the base of the nipple, second, in the basket cells or outer layer of cells of the milk ducts, and third in the walls of the blood-vessels. These may, "then, be looked upon as three starting points for the development of muscle tumors. It is quite certain that tumors do spring from the former, very doubtful whether they spring from the latter. Tumors arising from the unstriated muscle of the nipple, usually remain localized as tumors of the nipple, and in our chapter upon the Diseases of the Nipple and Areola (q.v.) a number of such cases receive consideration.

But as will shortly be seen, not all of the occurrences of muscle tissue in the breast, and especially in tumors of the breast can be referred to antecedent muscle tissue, but must be otherwise explained. For such occurrence two theories merit consideration, first, that the tumors are "mixed tumors," i.e., referable to embryonal displacement and consequent tissue confusion; second, that the muscle tissue develops through prosoplasia and subsequent metaplasia of the cells of the connective tissue.

Our examination of the literature shows the following cases in which muscle tissue has entered into the composition of breast tumors other than tumors of the nipple.

Billroth (Cyclopedia of Obstetrics and Surgery, Gussero and Grandin, I887, IX, 56) describes a completely encapsulated cysto-sarcoma that occurred deeply situated in the left breast of a girl $\mathrm{r} 6$ years of age. It was removed and recurred in four months. Microscopic studies showed the tumor to be a spindle-cell adeno-cysto-sarcoma. The remarkable feature of the case was the occurrence of striped muscle cells among the sarcoma cells.

Abramow, S. S. (Centralblatt für allg. Path. u. path. Anat., Igor, XII, 926) removed a tumor the size of a walnut from the subcutaneous adipose tissue of the left breast of a patient 45 years of age. It was known to have been present for about one month only. It was sharply circumscribed, movable and painless. At the operation it was found to be perfectly encapsulated and easy to enucleate. Microscopic examination made from the various parts of the tumor showed that it had a glandular structure variously distributed in a matrix of connective tissue in which were numerous fasciculi of unstriated muscle cells. These stained yellow by van Gieson's stain, and were typical in appearance. In certain parts of the tumor they were so numerous that the glandular elements were almost excluded and the tumor appeared as a leiomyoma.

Strong. L. W. (American Journal of Obstetrics, I9I3, LXVIII, 53) reports the following case, which he is quite correct in believing to be "unique in the literature of breast tumors."

The patient was a married woman aged 46 years, who had bad for about four years a deeply seated tumor of the right breast. Two years before coming under observation it began to enlarge, and during the last six months had caused some discomfort. Upon examination, a firm, uniform tumor was found in the upper outer quadrant of the breast. It was freely movable under the skin and over the muscles. There was no retraction of the nipple, no ulceration nor fluctuation. The tumor lacked sharp circumscription and seemed to merge into the breast tissue.

At operation the tumor was found to be well encapsulated, to be entirely separated from the nipple, and located to its outer side. It measured 6 by $3 \mathrm{~cm}$., and had pushed the breast tissue aside in its growth.

Upon microscopic examination it was found to consist of hyaline connective tissue with few nuclei, and to contain irregular bundles of smooth muscle fibers, generally circular in outline and of varying size, as well as single fibers and small bundles of muscle cells. The nuclei were long and straight with square ends, and occupied the centers of the fibers. There were few blood-vessels. The muscle bundles surrounded the blood-vessels in a circular manner and the central opening was often without endothelium. 


\section{NEUROMA}

Tripier ("Dictionaire Encyclopédique des sciences médicale," article "Mamelle," Paris, 1876 , 2S., iv, 37I) studied two cases of what he regarded as fibrillar neuromas of the mammary gland. They occurred as pea-sized nodules of hard structure, that lie in the subcutaneous tissue or more deeply in the tissue of the breast. By staining with chloride of gold, it was thought that non-medullated nerve fibers entered into their formation and explained the neuralgic and other painful symptoms that were found in association with them. Tripier says that to confirm the view that the tumors are neuromas, and are of importance, it will be necessary to examine a large number of cases. No confirmation of the observation has appeared during the 40 years that have elapsed since his publication, so that it is evident that some mistake must have been made.

We have not been able to discover any other mention of neuromas of the mammary gland in the literature.

\section{Literature upon Fibroma of the Breast}

Ballete.- "Fibrome diffus du sein chez l'homme," Bull. et mém. soc. d'anat. de Paris, I89o, LXV, 532. Beadies, C. F.- "Fibroma of the Male Breast;" Trans. Path. Soc., London, 1892-93, XLIV, 124. BULL.- "Fibroma of the Breast," Quarterly Medical and Surgical Journal, N. Y., I882, i, $8 \mathbf{r}$.

Gangolph.- "Fibroma douloureux du sein chez un homme," Lyon méd., I896, No. 30; Hildebrand's Jahresberichte f. Chirurgie, $x 896$, p. 577 .

Heurtadx.- "Tumeur du sein (fibrome)," Bull. soc. d'anat. de Nantes, 1876-78; Paris, 1879, i, 86. Hedrtadx.- "Fibrome végétant énorme de la mamelle," Bull. soc. d'anat. de Nantes, I88I, IV, 59. Jones. - "Note on a Case of Fibroma of the Male Breast," The Lancet, London, I goz, Jan. I 8. Jopson, Speise And White.- "Breast Tumors in Childhood," Annals of Surgery, 1908, ii, XLVIII, 662. Joüon.- "Fibrome de la mamelle," Bull. soc. d'anat. de Nantes, I880; Paris, r88ı, iv, 10.

KRAWTSCHENko.- "Ein Fall von Fibroma durum mammæ beim Manne," vide Hildebrand's Jahresberichte f. Chirurgie, 1897 , p. 475 .

MaLherbe, A.-“Fibrome végétant de la mamelle avec parties myxomateuses," J. de med. de l'ouest, Nantes, 1885 , XIX, 309 .

Nordmann, A.-“Über das plexiform Fibrom der Mamma," Archiv f. path. Anat., Berlin, 1892, CXXVII, 338 .

Raingeard.- “Tumeur du sein (fibrome myxomateux), Bull. soc. d' anat. de Nantes, I880; Paris, I88I, IV, 47 .

\section{Literature upon Molluscum Fibrosum of the Breast}

AbBatucc1.- “Obsérvation sur un enorme molluscum pendulum du sein gauche," etc., Ann. d'hyg. et de méd. Colon, Paris, I908, XI, 444.

MacSwiney.- "Pendulous Tumors," Dublin Medical Journal, I875, LIX, 484.

Perins.- "Fibroma Molluscum and Pendulous Tumors of the Breast," Medical Record, N. Y., I907, LXXII, $5^{6} 7$.

\section{Literature upon Lipoma of the Breast}

Axkins, C. J.- “Enormous Lipoma of the Breast in a Young Girl," Indian Medical Record, Calcutta, $1893, \mathrm{~V}, 4 \mathrm{I}$.

BAKER, W. M. and Bowlby A. A.- "Diffuse Lipoma," Medico-Chirurgical Transactions, I886, LXIX, 4I.

Begourn.-“Lipome interglandulaire du sein," Jour. de méd. de Bordeaux, I892, XXII, No. 9, p. Iog.

BRYK.- "Zu Kasuistik der Geschwülste; Retroglanduläres fibröses cystoid Lipom der rechten Brustseite," Arch für klin. Chirurgie, 1874, XVII, 555.

Cooper, Sir Astley.- "Diseases of the Breast," p. 48; 49.

Delage and Massabiat.- "Les lipomes du sein et de la région mammaire," Rev. de chir., Paris, I904, $\mathrm{XXX}, 484$. 
Dudley, A. P.- "Lipoma of the Breast, Removed without Mutilation of the Breast," "Postgraduate," New York, I89i-29, VII, I 57.

Etievant, R.- "Lipome de la région mammaire," Proc. méd. Lyon, r896, X, 593.

Gurlt.- "Solitare Lipom der Brust," Archiv f. klin. Chir., XXV, 430.

Hegetschwerler C.— "Über das Lipom der Mamma," Zurich, r 865.

Hoenigsberger, L.- "Ein Fall von beiderseitigen Lipoma Mammæ," Münchener med. Wochenschrift., I $90_{5}, \mathrm{LII}, 222$.

KLENTSINSKI, Ch.- "Epithelioma sebaceum (pseudolipoma mammæ Merkel; sarcoma lipoblasticum Borst)," Kharkov. M. J., I908; V, II6.

MARLoth, K- "Subpectoral Lipom in der Gegend der Mamma bei einem Manne," Leipzig, rgro.

Masse- "Lipome du sein chez l'homme," Thèse de Paris, I879.

MELDON.- "Rapid Growth of Fatty Tumor of the Breast," Dublin J. Med. Sci., i872, LIII, 301.

Merkel, H.- "Über ein Pseudolipcm der Mamma," Beiträge zur path. Anat. u. z. allg. Path., I $9 \circ 6$ XXXIX, I52.

PÉraire.- “ Àpropos des lipomes difius du sein," Paris, Chirurg., igi i, ii, II4.

Puyhaubert.- "Lipome retromammaire," Jour. de. méd. a Bordeaux, r9o7, XXXVII, 3 I 4.

QUE⿰REL.- "Lipome volumineux de la région mammaire chez l'homme," Rev. de Chir. Paris, I889, IX, 923.

Rouvray.- "Contribution à l'étude du lipome de la glande et de la région mammaire, "Thèse de Bordeaux, I9II, No. 56 .

Smyth, H.- "Fatty Tumor of Right Mammary Region in a Male; Removal; Recovery," Medical Times and Gazette, London, I876, i, 333.

Socın, A.- "Submammäres Lipom." Jahresberichte ü. d. chir. Abt. d. Spital zu Basel, I872, VII, 206.

Velpeau.- "Maladies du sein," Paris, I858, pp. 200 and 201.

Warren, J. C.- "Surgical Observations on Tumors," London, r837, p. 228.

Zesas, G.- "Les lipomes du sein," Archiv gén. de méd., Paris, rgr 2, viii, 924.

\section{Literature upon Myxoma of the Breast}

Barton, J. M.- "Hematoid Myxoma of the Breast," Trans. Path. Soc. of Phila. (I879-81), I882, X, I57; . Medical Times, June 5, I880, X, 464.

Hartmann, H.- "Myxo-fibrome du sein," Bull. Soc. d'anat. de Paris, i 884, LIX, 334 .

Mauté, A. and Daniel C.- "Myxome du sein chez l'homme," Bull. et mém. de la Soc. d'anat. de Paris, I904, LXXIX, 609.

MorrIs.-"Myxoma of the Breast; Recurrence; Death," Trans. Path. Soc., London, XXIII, 274. This case seems upon investigation to have been myxo-sarcoma.

\section{Literature upon Chondroma, Osteoma, Etc., of the Breast}

Amans, J. J. "Über eine complexe Bindegewebsneubildung der Mamma (Gallertenchondrom mit derbem und verkalktem Fibrom," Beiträge zur Geburtshülfe und Gynäkologie, Würtzb, I $860, \mathrm{IV}, 57$.

Cambria, A.- "Sull' enchondroma della mamella," Riv. veneta di soc. med. Venezia, I887, VI, 340.

Chevrier et Delval.- "Fibro-myxo-chondro-ostéome du sein chez la femme," Bull. et mém. de la soc. d'anat. de Paris, I9ıo, LXXXV, 586.

Connil et Petit.- "Chondromes ossifiées de la mamelle chez la chienne," Bull. et mém. de la soc. d'anat. de Paris, I905, LXXX, 23.

Cornil et Soulignoux.- "Osteo-chondrome du sein," Bull. et mém. de la soc. d'anat. de Paris, I907, 6 s., I4, 424 .

Davidsohn, C.- "Ưber ein Chondrom der Mamma," Centralbl. f. Gynäkologie, ıgo9, XXXIII, I357.

Desorl, P.- "Du chondrome et de l'ostéochondrome dans les tumeurs du sein," Thèse de Lille, I 895 .

Foucher._- "Enchondrome de la région mammaire chez l'homme, etc.," L'Union méd., Paris, r859, 2s., iii, 403 .

HAPPEL, SR.- “Ein Fall von Chondrom der Mamma," Beiträge zur klin. Chir., I895, XIY, No. 3, p. 721 .

LANGE.- "Osteo-chondroma of the Female Breast," Medical Record, New York, ז88I, XX, г6г.

Leeson.- "Semi-osseous Tumour of the Breast," Medic. Phys. Jour., London, I803, X, I62; I804, XII, 456.

Morton, C. A.- "Calcifying Chondro-sarcoma of the Breast," Trans. Path. Soc. London, I904, LV, 327 . 
PIED._-"Enchondrome kystique du sein chez une jeune fille; opération; guérison," Bull. soc. méd. de l'Yonne, 1879; Auxerre, I88c, XX, 50.

REY.- "Fibrochondromes multiples du sein chez une Kabyle," Lyon méd., I903, C, 259.

Le Sauvage.- "Mémoire sur les tumeurs eburnées du sein," Rev. méd. franç, et étrang., Paris, 1852. ii, 64r.

SEHRT, E.- "Beiträge zur Pathologie der Milchdrüse," Beiträge zur klin. Chirurgie, I907, LV, 589.

Sick.-Zwei seltene Tumoren der Mamma (Chondrolipoma und Blutcyste,") Jahrbücher d. Hamb. Staatskrankenanstalt, Igo6, XI, abt. I 7 .

SouliER.- "Chondrome à la région mammaire; avec généralization au maxillaire supèrieur et a l'omoplate," Dauphin méd., Grenoble, I891, XV, 260.

Stefanini.-“"Enchondroma mammæ," Soc. Med.-Chir., Pavia, July I4, is88; British Medical Journal Sept. I 5, I 888 .

WARren, J. C.- "Surgical Observations on Tumours," London, I837, p. 213.

\section{Literature Upon MYOMA OF THE Breast}

AвRAmofF, S. S.- “Ein Fall von Adenomyom der Brustdrüse," Centralbl. f. allg. Path. u. f. path. Anat., I90I, XII, 926.

BILLRoth.- "Rhabdomyosarcoma of the Breast" Cyclopedia of Obstetrics and Surgery, Gussero and Grandin, $1887, \mathrm{IX}, 56$.

Strong, L. W.- "Myoma Mammæ," American Journal of Obstetrics, I9r3, LXVIII, 53.

\section{Literature upon NeUroma of the Breast}

TripIER.-Dictionaire Encyclopædique des sciences mèdicale, article "Namelle," Paris, 1876, 2s., iv, 371 .

\section{LiteratURe UPON ANgionia OF THE BREAST}

Alibert.-Nosol. Nat., p. 337 (cited by Williams, "Diseases of the Breast," I894, p. 489).

Althore. - "A Case of Angioma of the Mamma," Lancet, London, igor, ii, Oct. 5.

Assus.- "Blutung durch die Brustwarzen einer nährenden Frau," Caspar's Wochenschrift, r 838 , No. 46; Schmidt's Jahrbücher, I839, XXV, 73.

Audebert. - "Angiome oủ angiecstaşe sous aréolaire," Compt. rendu Soc. d'obstet., de gynécol. et de pédiat. de Paris, I9ıо, XII, II3.

BAJARDI.- "Contributo allo studio dei tumori rari della mamella," Lo Sperimentale, 1892 , XLVI, 250.

BerTi.- "Angioma della ghiandolo mammario," Cesalpino Arezzo, igri, VII, I6r.

BRYANT.-"Nævi and Vascular Tumors of the Breast," "Diseases of the Breast," 1.887, p. 345.

CARL.- "Angioma Mammæ," Deutsche Zeitschrift für Chirurgie, Leipzig, Igıг, CXI, 308.

ColzI.-(Cited by Taddei.) "Contributo di clinica operativa, Firenza," ז 87 I, tt., I 43 .

Hoffmann.- "Cavernoma regionis mammalis," etc., Prakt. Aerzt. Wetzlar, x880, XXI, I 45.

Image, Hake and Liston.- "Case of Enlargement of the Left Namma," Medico-Chirurgical Transactions, $1847, \mathrm{XXX}, 105$.

KLeBS, E.- "Handbuch der pathologischeu Anatomie, 1876, I, Abt. 2, p. Ir94.

LangenBeCk.- "Angioma der Brustdrüse," Nosolog. u. Therap. der chirurg. Krankheiten, Göttingen, II, 83 .

Lannelongue.-(Cited by Williams, "Diseases of the Breast," i 894, p. 52 .) Centralbl. f. Chirurgie, 1889 , p. 52.

Malapert, Morichau-Beavchaut.- "Des Angiomes du Sein," Rev. de Chirurgie, 1904, XXIX, 200.

MaRTINI.- "Angioma cavernoso multiplo della mamella," Morgagni, Milano, XLVII, 739.

Porter, F. T. - "Erectile Tumor of the Nipple (from the Apex)," Irish Hospital Gazette, Dublin, I $873, \mathrm{i}, 30$.

RICHARD.- “Tumeur du sein fort curieuse," Gazette des Hôpitaux, r 86r, p. gr.

Sendeter, P.- "Demonstration eines Angioma cavernosum pendulum der Mamilla," Centralbl. f. Chirurgie, I889; supplement to No. 29, containing the Beticht über die Verhandlungen der deutsch. Gesellschaft für Chirurgie, XVIII Kongress, Apr. 24-27, I889, p. 52.

SHEILD, M.- "Diseases of the Breast," ז898, pp. ז43, ז84.

Snow, H.- "Angioma of the Breast," The Lancet, London, I89o, I, 240.

Sutron, J. B.- "A Case of Erectile Tumour of the Male Breast," Trans. Clinical Society London, r 888-89, XXII, 187 . 
TADDEI, D.-“Angioma della ghiandola mammaria," Riforma med., rgo4, XX, 989.

VERRIER.- "Tumeurs de la région mammaire chez une filette de 7 mois," Lyon. méd., rgra, CXX, rr8o. WARREN.- "Surgical Observations on Tumors," Boston, r837, p. 213.

Willyams, W. R.-Middlesex Hospital Reports, I887. "Diseases of the Breast," I894, p. 489, Ibid, p. 5 r.

Wullstein, L.- "Ein Geschwulst der Brustdrüse eines Kindes (congenitales Angioma simplex hyperplasticum)," Arbeiten a. d. path. Institut in Göttingen, 1893, p. 253.

\section{SARCOMA OF THE BREAST}

On account of its rarity as compared with carcinoma, sarcoma of the breast has been made the subject of numerous casuistical, analytical and statistical studies, of such thoroughness and excellence that he who now enters the field must indeed be well armed with facts and theories if he is to add anything new.

From the sources referred to in the literature appended to this chapter, the writer who has dealt with the problem of the pathology of the disease has assembled the largest collection of cases that appears to have thus far been subjected to scientific analysis, and has arranged them into such groups as the names given by the reporters or the detailed histological structure made possible. It is a woefully inadequate and inaccurate grouping, for many tumors placed in one class quite as correctly belong in one or even several of the others. The taxonomic difficulties, however, are only to be appreciated by those who have actually wrestled with the problem. The following tabulation, therefore, is simply the best that could be done. under the difficulties that beset the path of the systematist. If no other result follow its publication, it is hoped that the reader will be impressed that future accuracy of denomination is essential for future scientific work. We find the following cases of sarcoma of the breast in the literature:

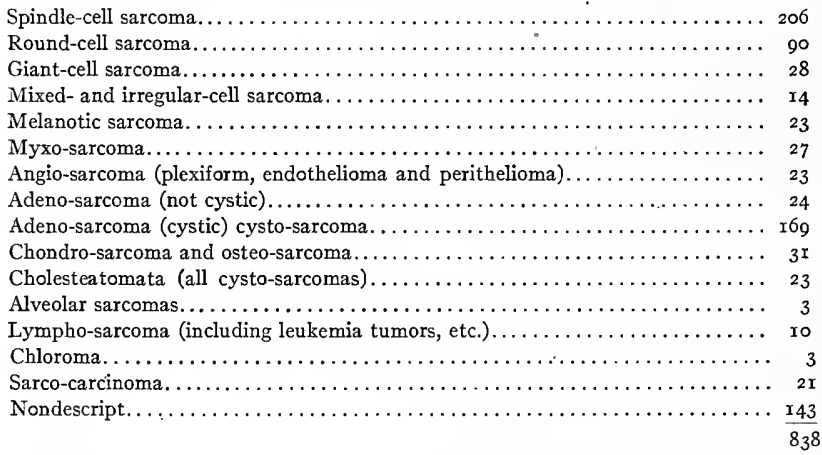

For readers interested in the statistical and analytical studies of the subject the following papers will be found to contain a vast fund of useful information:

Finsterer, J.- “'ther das Sarkom der weiblichen Brustdrüse," Deutsche Zeit. für Chirurgie, rgo7, LXXXVI, 352. An excellent statistical and analytical review of 23 cases, fully tabulated, followed by many references to the literature.

Gebele, H.-Zur Statistik der Brustdrüsengeschwülste," Beiträge zur klin. Chirurgie, rgor, XXIV, r67. This analysis is based upon 306 cases of carcinoma, 33 cases of sarcoma and ro benign tumors of the breast. 
GeIst, S. H., and WriEnSEy, A. C.- "Sarcoma of the Breast," Annals of Surgery, 1915, LXII, p. rr. The studies are made upon 22 original cases and 435 cases collected from the literature.

Gross, S. W.- "Sarcoma of the Female Breast; Based upon a Study of $\mathrm{r}_{5} 6$ Cases," American Journal of the Medical Sciences, $r 887$, n. s., XCIV, $\mathrm{r} 7$. This is one of the most important monographs on the subject and must be regarded as one of the great classical contributions to surgery and pathology.

Gross, S. W.- "Tumors of the Breast," American System of Gynæcology, r888, II, 247. This contains a different analysis of 92 cases of mammary sarcoma.

HorNer.- " "Uber die Endresultate von $\mathbf{r} 72$ operirten Fälle von maligner Tumoren," Beiträge zur klin. Chirurgie, r894, XII, 6rg. Although Horner has only $\mathrm{r}_{5}$ cases of sarcoma of the breast, his analysis is complete and interesting.

Poulsen._- "Die Geschwülste der Mamma," Archiv für klin. Chirurgie, I89r, XLII, 593. Among 355 operations for breast tumors there were 33 cases of sarcoma, which are carefully and systematically studied.

SchMrdT- - "Die Geschwülste der Brustdrüse," Beiträge zur klinischen Chirurgie, r888, IV, 40. This paper contains an analysis of 150 breast tumors from Prof. Czerny's clinic in Heidelburg, between the years $1877-1886$, among which there were 13 various sarcomas of the breast.

SCHUOLER.- "Beiträge zum klinischen Bilde des Brustdrüsensarkoms," Correspondenzblatt für schweizer Aerzte, $r 890$, p. 283. An analysis of the clinical and pathological peculiarities of $4 \mathrm{r}$ cases of mammary sarcoma from the clinics of Prof. Courvoisier, Prof. Socin and Prof. Billroth.

Wriliams, W. R.- "Sarcoma of the Breast," "The Medical Chronicle," Manchester, r893-94, XIX, 289, $36 \mathrm{r}$. This paper analyzes the study of 2397 consecutive neoplasms of the female breast of which 94 were sarcomas. It probably ranks next to Gross' monograph in excellence and comprehensiveness, and has the advantage of being later in time and more in accord with the modern views regarding tumors in general and sarcoma in particular.

Other valuable contributions whose scope is not limited to sarcoma of the breast are as follows:

CoLEy.- "Injury as a Causation Factor in Carcinoma and Sarcoma," The Annals of Surgery, Igrr, I, 449,6 6 5. This paper contains data regarding 970 cases of sarcoma of which $\mathrm{r} r$ were in the breast.

Finsterer.- "Zur Pathologie der männlichen Brustdrüse mit besonderer Rücksicht der Tumoren," Deutsche Zeitschrift für Chirurgie, r9o6, LXXXIV, 2or. This paper deals only with disturbances and tumors of the male breast.

Schuchardt. - "Zur Kasuistik und Statistik der Neubildungen in der männlichen Brust," Archiv für klin. Chirurgie, r885, XXXI, I; 1886, XXXII, 277. The studies are based upon 384 tumors of the male breast of which 14 were sarcomas.

Pathology.-A sarcoma is a tumor that arises through abnormal vegetative activity of the connective tissues, and is characterized by rapidity of cellular multiplication in excess of cellular differentiation. The result is a tissue mass or neoplasm in which preponderance of cells is the most striking feature. When the vegetation activity is at the maximum, the neoplasmic formation will be found to consist exclusively of cells that through prosoplasia, or return to the embryonal type, have assumed a spherical shape and uniform appearance; when near the maximum, of cells that preserve part of this normal differentiation, and are of spindle shape or of various shapes; when but slightly in excess of the normal, of cells in excessive numbers in a tissue that otherwise approximates the normal type. The ease with which the sarcomatous nature of the tumor is recognizable is in proportion to the number of cellular elements it contains. There may be cases in which the proportion of cells over inter-cellular and differentiated products is so slight as to make it difficult, if not impossible, to determine that the neoplasmic formation is not of adult tissue and therefore not sarcoma at all.

Such border-line cases comprise a small group concerning which the microscopist may give the surgeon erroneous information. 
The importance of any tumor, from the surgical and clinical points of view of recurrence and metastasis, is in proportion to its cellular structure. The more cellular it is, the more rapidly it grows, the more prone it is to return and the more apt it is to metastasize. Conversely, the more differentiated it is, the less likely it is to return and the less likely to disseminate. This general law neutralizes the occasional errors of the microscopist, for when the structure of the tumor is such as to make him hesitate whether it be sarcomatous or not, and misleads him into believing it to be other than sarcoma, the chances of return or of metastasis are always at the minimum.

As connective tissue is of almost universal distribution, those tumors that arise from it, whether of the adult or embryonal type, may also be of almost universal distribution throughout the organs and tissues of the body. Furthermore, as connective tissue is a component of most tumors and as conditions in tumors are already abnormal, it may be possible for abnormal growth of connective tissue in tumors to complicate their structure, either by giving them a superadded fibromatoid or a sarcomatous character. As a matter of fact, both of these conditions occur, though the former merits and receives but little attention because it effects no important modification in the disposition and behavior of the tumor, while the latter arouses interest because it transforms a benign into a malignant tumor.

The development of sarcoma has not been followed, nor is it known how the disease begins. In most cases it seems as though the cell proliferation begins as a focal lesion and extends centrifugally and centripetally in all directions. In support of this idea is the common experience that sarcomas begin as tiny tumors, and gradually grow larger and remain circumscribed. But sometimes the sarcomatous change seems to pervade an organ or a preëxisting tumor, transforming its entire structure into sarcoma through what is frequently described as "sarcomatous degeneration," a bad term as the change is in no way related to those morbid processes known to the general pathologist as "degenerations." "Sarcomatous transformation" better expresses the idea and is a preferable term. A number of pathologists deny that sarcomatous transformations of tissue, viscera or tumors can take place, but their opinion seems to be based upon a misconception of what sarcoma is. If it be granted that the tumor arises through abnormal and excessive vegetative activity of the connective-tissue cells that increase in number more rapidly than they can differentiate, and if, as there is every reason to suppose, this depends upon some abnormal stimulus applied to the connective tissue, it is in no way incompatible either with the facts or the theory to suppose that sometimes the source of stimulation is localized and therefore produces a focal and circumscribed lesion, while at other times it is diffused and produces a more widespread disturbance, the "sarcomatous transformation."

In the breast both forms of sarcomatous change may occur. Primitive sarcoma of the breast tissue is very rare; complicating sarcoma of breast tumors is relatively common. The primitive sarcomas usually arise from focal lesions, are small and nodular and increase slowly or rapidly about the original focus. But there are a few cases on record in which sarcomatous transformation of the whole breast or at least a large part of it can be supposed to have occurred and quickly transformed the entire organ into tumor.

The great majority of mammary sarcomas are complicating. They may make their appearance many years after other tumors - peri-ductal fibromas, fibro-adenomas, and sometimes carcinomas-have existed. Under such circumstances the clinical picture becomes transformed through increased rapidity of growth, or some other change 
incidental to the sarcomatous element. It is possible for the original tumor structure to become extinguished by the sarcomatous process through compression, displacement, atrophy or infiltration with tumor cells, but, as a rule, enough of it remains to make it easy to determine upon what condition the new neoplasmic process was engrafted.

The structure of the sarcoma tissue varies greatly for reasons not yet understood. One tumor is composed entirely of small round cells resembling lymphocytes but with more cytoplasm than lymphocytes ordinarily possess; another is made up entirely of spindle cells, sometimes small, sometimes large; a third seems to be composed of cells of both round and spindle shape; other tumors have cells of no particular shape. It some round-cell tumors, and in more spindle-cell tumors, giant cells are numerous. Ordinarily the type of the cells of which the tumor is composed is used to define its species. Thus, round-cell sarcoma, spindle-cell sarcoma and giant-cell sarcoma are the three chief types. Tumors occur in which the cells are both round and spindle in shape and others in which they are of no particular shape. It is a question why there

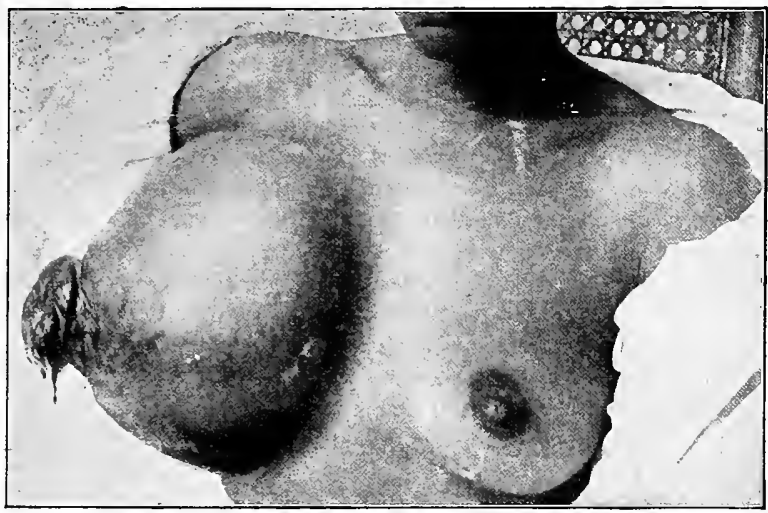

FIG. I45.-Round-cell sarcoma of the breast which had broken through the skin and given rise to repeated hemorrhages. (Stewart, Jefferson Hospital.)

should be a special group of giant-cell sarcomas, seeing that though such contain large numbers of giant cells, they are really and chiefly composed either of round or spindle cells.

It has also been found necessary to supplement these main groups by others that provide for other structural peculiarities. Thus, when a tumor has pigmented cells it is usually known as melanotic sarcoma, regardless of the morphology of the cells; if a sarcoma contain cartilage or bone, it may be described as chondro-sarcoma or osteosarcoma, chondrifying sarcoma or ossifying sarcoma, regardless of its cells and other morphological peculiarities.

To endeavor to overcome taxonomic difficulties by the use of compound terms has been tried, with scant success, and specific denomination has often been lost in cumbersome nomenclature.

To exemplify this difficulty, let it be supposed that a pathologist after thorough examination and intimate knowledge of the microscopic structure of a tumor decides to call it a "myxo-osteo-chondro-fibro-cyst-adeno-giant-cell sarcoma; can it be that this represents a distinct species of tumor? Surely not; such excessively descriptive 
names have no taxonomic value and are confusing. Such a tumor usually turns out to be a spindle-cell sarcoma, and as in spindle-cell sarcomas giant cells are of frequent occurrence, and cartilage and bone are frequently found, and as in all sarcomas a myxedematous degeneration is frequent, there is nothing further peculiar about it, except that it occurs as a complication in "adenoma" (peri-ductal fibroma) which is also the most frequent mode of sarcoma occurrence in the breast, and that the glandular units of the "adenoma" were dilated to form the cysts.

Sarcomas grow with varying rapidity and form nodes, commonly single, though sometimes multiple and amalgamated. They are usually well-defined, though rarely limited by capsules such as commonly surround the benign tumors. Mammary sarcomas that are well-encapsulated usually arise through sarcomatous transformation of benign tumors, in which case the capsule does not belong to the sarcoma, but to the preëxisting tumor.

Pure sarcoma as its name implies is usually a fleshy tumor of tissue that is fairly uniform throughout, though this uniformity must always be in proportion to its simplicity or complexity of structure. Thus, a purely cellular sarcoma is of fairly uniform appearance, except that dissolved areas may result from hemorrhagic extravasation or softened areas from retrogressive metamorphosis of the cells. Sarcomas containing bone or cartilage show differences of density and appearance between the cellular, the osseous and the cartilaginous areas. Sarcomas engrafted upon adenomas or other preëxisting tumors may appear as uniform nodes in the tumors or as distributed uniform areas and bands extending through their substance. It may not be possible to determine by naked-eye inspection that a given tumor is sarcoma or sarcomatous.

The growing tissue of the sarcoma always contains blood-vessels, many of which may have preëxisted in the tissue in which the tumor grows, but the greater number of which are newly formed to meet its requirements. In some cases the number of vessels is inadequate to meet the demands of the growing cells; in others it seems to be greatly in excess of them. The cells of the growing tumors are injurious to preëxisting blood-vessels, invading their coats, weakening them and causing frequent interstitial and sometimes external hemorrhages or penetrating and blockading them. Its own newly formed vessels rarely attain a perfect development. One can look on large areas of sarcoma tissue in microscopic sections, without finding a single vessel with more than capillary structure. Sometimes the vessels are of little more than capillary diameter and composed of endothelial cells only, sometimes they are large spaces or sinuses still composed of endothelium only. Not infrequently the endothelium appears to be defective so that the blood circulates in spaces or sinuses between the tissue cells without even the endothelium to confine it. It is largely to these vascular peculiarities that the metastatic behavior of sarcoma is to be referred.

When the cells of the tumors invade the wall and effect penetration of a vein, masses of them may become included in parietal thrombi that are sooner or later carried away, as emboli, to lodge and colonize in the lungs or liver. When the blood circulates through the tumor cells, it may gather them up and carry them into the veins and so to the pulmonary or hepatic capillary filters where they may meet destruction or grow and produce metastatic tumors. It is possible for tumor cells to pass these filters, enter the systemic circulation, find final lodgment in the peripheral capillaries, and occasion systemic peripheral metastatic tumors. Thus may be explained the most frequent form of metastasis-blood metastasis-observed in sarcoma.

No true lymphatics have been observed in the simple forms of sarcoma, hence 
there is no ready means by which the cells of the tumor can enter the lymphatic system and be carried to the lymph nodes. For this reason it is easy to understand that lymphatic metastasis with the formation of metastatic secondary growths in the lymph nodes is of rare occurrence in sarcoma. The only form in which lymphatic metastasis is frequent is melanotic sarcoma.

The inequality and imperfection of the blood-vessels also explains the frequency with which retrogressive changes take place in the sarcoma structure-when the cells outgrow the vascular supply, or what is more likely, when a formerly adequate nutrient supply becomes diminished through obstruction or other change in the imperfect vessels, the cells cease to multiply and rapidly degenerate. Mucinoid degeneration, necrosis, cystic change or calcification following necrosis then quickly supervenes.

Calcification in sarcoma, as in tissues generally, probably goes hand in hand with necrosis. As the cells and cell areas die, lime salts are deposited, and then arise amorphous calcareous deposits, or more rarely, spheroidal and spicular deposits such as form the calchospheres of psammosarcoma. Bone may also be formed.

It is a law, first stated by Marchand, that bone may be formed in any connective tissue provided that sufficient lime salts be present for the purpose.

The essentials to the formation of cartilage and bone in sarcomas-chondrifying and ossifying sarcomas - have not been fully determined. The formation of collagen, fibroglia, elastin, chondrin and ossein are all functions of connective tissue, but how interchangeable they may become through prosoplasia and metaplasia is unknown.

In tumors that consist exclusively of cells, amorphous calcareous deposits or calchospheres are found. It is chiefly in tumors with fibro-cellular structure, that cartilage appears, and as a rule it is only in those in which giant cells are present that bone is found. There are many round- and spindle-cell sarcomas with multitudes of giant cells disseminated throughout their substance, in which no chondrification or ossification occurs. The relation of the giant cells to the bone-forming property is, therefore, uncertain. The source of the giant cells is also uncertain. They are properly described as myeloplaxies, but surely not in the sense of referring them to antecedent bone marrow. Their presence, together with cartilage and bone, in the encapsulated mammary sarcomas that develop from fibro-adenomas, has led many to conclude that such tumors arise, as taught by Cohnheim, through embryonal sequestration, and that they are "mixed," i.e., teratoid tumors.

Certain tumors, sarcoma-like in other particulars, are characterized by an interesting relation of the cells to the vessels. When such can be shown, the tumor, regardless of its other qualities, is described as an angio-sarcoma. In the best characterized of these, the cells are so disposed as to surround the vessels with a many-layered investment that follows them throughout their entire course and is hence distinctly plexiform. Between the irregularly cylindrical cellular formations there is an indifferent or amorphous groundwork that seems to consist largely of disintegrated cells. In stained specimens the excellence of the nuclear staining of the cells in juxtaposition to the blood-vessels, contrasts with the colorless amorphous intermediate cells so as to intensify the vascular relationship that becomes distinctly perithelial. Such tumors are called perithelial sarcomas or peritheliomas, because one theory of their origin teaches that the cells of the tumor arise from the somewhat hypothetical perithelium of the blood-vessels. In cases in which the generality of the cells is better preserved, the perithelial arrangement may be indistinct, though the cells still show marked and definite relationship to the bloodvessels by which they are separated into ill-defined groups. 
An alveolar arrangement thus arising justifies the term alveolar sarcoma.

In some cases the vessels of the sarcoma are separated from the cells by homogeneous, mucinoid or hyaline deposits, by which they are transformed into homogeneous thick cylinders. Such appearance is characteristic of cylindroma.

The cells of certain tumors, by many included among the sarcomas, appear to arise from the endothelium of the blood- and lymph-vessels. These are endotheliomas and are divided into hamangioendotheliomas and lymphangioendotheliomas, respectively. The cells can be traced to the endothelia of the capillaries, rarely of larger vessels, in which they multiply and which they distend. As the number of cells increases the channels become obstructed and form the plexiform collections with which the process seems to start, and the cells extend into the surrounding tissue in which they fade away or are lost. The cellular character of the tumor is in proportion to the original number of vascular elements. If they are few, there will be few, but often large ramifying collections of cells; if many, the cell masses may be so closely approximated that the entire tissue becomes cellular and the derivation of the cells difficult to determine.

Of the degenerative conditions that occur in sarcoma, there are two that modify the terminology - mucoid degeneration and pigmentation of the cells.

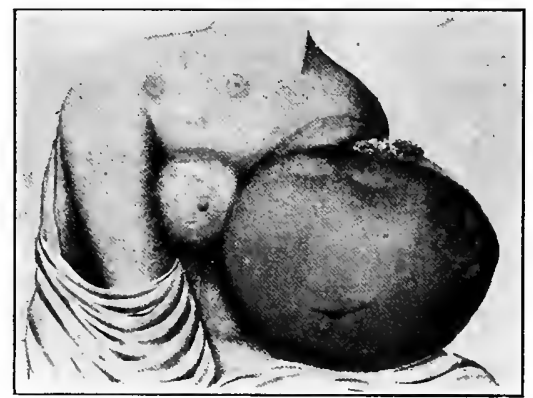

FIG. I46.--Enormous cysto-sarcoma of the breast. (Graefe.)

Mucoid or myx-edematous change in sarcoma is very common and presents itself in two different forms: First, in localized areas of the tumor tissue that melt away into a liquid jelly, forming colliquation cysts without well-defined walls; second, in the form of a mucoid change of the cells that seems to be common to them all, and to have nothing to do with nutrition. The first is an accidental circumstance, the second a fundamental characteristic of the cells. The first can occur in any kind of sarcoma or other connective-tissue tumor; the second can only obtain when the cells themselves are or have become myxoblasts. In the first the cells die and the mucinoid substance seems to be a product of their autolysis; in the second the cells produce the mucinoid substance while alive and multiplying. The second alone is the true myxo-sarcoma.

Every modern writing upon the subject contains more or less discussion as to the validity of the name sarcoma applied to the pigmented or melanotic sacoma tumor, and one need not read far before it becomes clear that the tumor has a different origin, different appearance and different clinical course from other sarcomas. Thus sarcoma, as has been shown, originates from mesoblastic connective tissues and can occur in any part of the body, but the distribution of melanotic sarcoma is restricted to 
the skin, the eye, and the nervous system, and probably originates from epiblastic and epithelial tissues. Sarcoma but rarely forms secondary tumors in lymphatic nodes, though melanotic sarcoma commonly does so.

Unna, Gilchrist and others, whose studies have chiefly concerned the melanotic tumors of the skin, are of the opinion that the cells of the tumor are of epithelial origin; Ribbert and others think that they are of connective-tissue origin and arise from the chromatoblasts or pigmented ameboid cells that control the pigmentation of the skin. If the former be correct, the melanotic skin tumors are pigmented carcinomas and should be considered among the tumors of that genus. But as the pigmented tumors of the eye and of the nervous system and its associated ganglia, differ in appearance and structure from those of the skin, and have cells of spindle shape or of irregular and branched shape, it is quite possible that there are various forms of pigmented tumors in no other way related to one another except in the pigmentation of the cells. The melanotic tumors of the skin always arise from congenital navi pigmentosi, through multiplication, invasion, and distribution of the pigmented cells which occur in alveolus-like groups in the center and form the mass of the nevus. For these cells Ribbert has suggested the name chromatophores and to the nevus he gives the name of chromatophoroma. This denomination is based upon his belief that the chromatophores are derivatives of the connective tissues and that the nævus pigmentosus is a chromatophoroma. Such being the case, the melanotic sarcomas of the skin are chromatophoro-sarcomas.

Very few pigmented tumors of the breast are on record, whose origin is not traceable to antecedent pigmented moles of the skin. As the result of injury these moles or pigmented nævi increase in size, their cells invade the subjacent tissues, penetrate between the lobules of the breast tissue, and soon show by secondary growths that they have found their way to the lymphatic nodes. Such tumors are highly malignant, recur quickly when excised and soon determine the occurrence of so many secondary tumors in the vital organs of the body that the patient succumbs.

Warren makes two groups of the mammary sarcomas, the indigenous and the nonindigenous. The former are relatively frequent, the latter extremely rare. The latter are supposed to arise from the connective tissue of the breast, precisely like sarcomas of other tissues and organs; the former, solely from the peri-ductal connective tissue, which is peculiar to the breast, and almost always arise in peri-ductal fibroma as a complicating change.

The literature of sarcoma though very extensive is sadly lacking in precision. The pathological details of the case records are so fragmentary as to be the despair of those who review them in the hope of effecting either a systematic arrangement or a scientific analysis.

Inattention to other than the surgical aspects of the case, makes it impossible to say how frequently non-indigenous mammary sarcoma occurs.

A few cases are on record in which it seems beyond doubt that the growth of the sarcoma took place independently of antecedent tumor growth. The greater number of these were spindle-cell tumors; a few were round-cell tumors. In none was there distinct encapsulation; in none were epithelial glandular elements in the sarcoma tissue.

The common form of sarcoma of the breast is the indigenous sarcoma, and while this may arise occasionally from the peri-ductal tissue of the breast, without antecedent tumor formation, it seems as though the greater number of cases result from sarcomatous change in benign tumors - peri-ductal fibromas. There are three chief arguments in support of this theory: 
I. A small tumor exists in the breast for a long time, then takes on a rapidity of growth out of all proportion to what has gone before. This is well exemplified by several of our cases of which the most characteristic is the following:

Anna C., aged 59 years, was admitted to the German Hospital of Pbiladelpbia, Jan. 29, 1908, with the history that I4 years previously she had struck her left breast against a piece of furniture whereupon a lump developed at the site of the injury. The lump did not increase in size until six months before her admission to the hospital when she again injured the left breast, and the tumor immediately began to grow with great rapidity. The affected breast when we first saw her was about twice the size of the normal breast, and gave rise to considerable pain. A simple amputation was done; the tumor proved to be a peri-ductal sarcoma.

Similar cases are reported as follows:

Anderson (Trans. Path. Soc. of London, 1872, XXIII, 254) whose patient aged 55 years had in one of her breasts a painless movable lump, the size of a walnut, for 25 years. It suddenly began to grow, in three more years attained a measurement of $\mathrm{I} 8$ by $14 \frac{1}{2}$ inches. Monod (Méd. moderne, I898, IX, p. I $_{52}$ ) also had a patient of $5^{6}$ years who had a small tumor for 25 years that later grew rapidly until at the time of

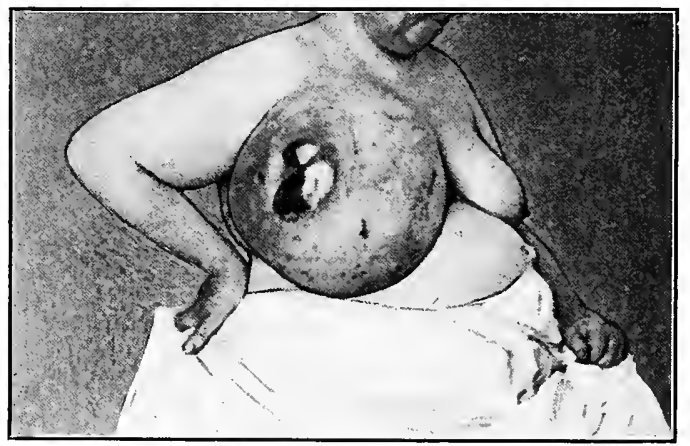

FIG. 147.-Periductal sarcoma of the breast with ulceration of the overlying skin.

removal it weighed ro pounds. Hutchinson (Path. Soc.,London) is said to have observed a soldier $4^{8}$ years old in whose right breast, close to the nipple, a small tumor had been known to be present for 2I years; when removed it was pronounced a "fibro-nucleated tumor," presumably a spindle-cell sarcoma. Gross cites Pick (Trans. Path. Soc., London, $\mathrm{XX}, 347$ ) as having observed a tumor that required I 8 years to grow as large as a fotal head. Tillaux (Cordier, Thèse de Paris, I880, No. 494, p. I6) observed a sarcoma of the breast that had been the size of an egg for 18 years, and then grew to be as large as an adult's head in the course of a few months. He also observed a tumor that grew from the size of a filbert to that of an egg in three years, remained unchanged for four years and then grew to be as large as an adult's head in six months. Vignard (Gaz. méd. de Nantes, x906, 2s., XXIV, 370) saw a woman aged 52 years in whose left breast a small hard nodule had been observed without change for $3 \mathrm{I}$ years. In six more years it grew to the size of an orange and when removed was found to be adeno-sarcoma. Cabot (Boston Medical and Surgical Journal, I867, LXXVII, $3 \mathrm{I}_{3}$ ) tells of a woman aged 48 years from whose breast a tumor of 20 years' duration was removed. It weighed $7 \frac{1}{2}$ pounds. Unfortunately, it is not certain that this was a sarcoma as no histological examination was made. However, that it was such is made probable by the fact that in 
two years there was a recurrent tumor the size of an orange. Leser (Beiträge zur path. Anat. und Physiolog., 1888, II) observed a woman of 67 years in whose breast a tumor the size of a hazelnut existed for 16 years. When removed it was the size of a man's fist. It was largely osseous but probably was an ossifying sarcoma.

A dozen additional cases of tumors of upward of ro years' duration are in our notes, but it does not seem necessary to add to this already long list.

2. The Tumors are Encapsulated.-Sarcomas are in general well-circumscribed tumors, but they are rarely surrounded by definite membranous capsules. Mammary sarcomas are, however, well encapsulated and freely movable during all of the early part of their existence. As the capsule is not peculiar to the sarcoma, it is reasonable to suppose that sarcomas of the mammary gland derive their capsules from the benign, antecedent tumors from which they grow.

3. Mammary sarcomas are commonly described as adeno-sarcomas, adeno-cystic sarcomas, etc., and the occurrence of the epithelial glandular element in their structure is most easily accounted for by supposing that they develop in tumors of glandular structure, many of whose elements persist in spite of the sarcomatous change of the connective tissue.

It is impossible to determine the time at which the sarcoma makes its appearance in an existing tumor. It is usually more a matter of guess than of certainty that the sarcomatous change has occurred. Rapid increase of growth in an inactive tumor is the common criterion, but may depend upon rapid growth or cyst-formation in the periductal fibroma without associated sarcoma.

The usual story told by the patient is that she met with an accident, weeks, months or years before, that the breast swelled and became livid, and that shortly after its return to normal a small lump was noted. For a long time this remained unchanged or grew slowly. This lump was usually painless, insensitive, freely movable, well circumscribed and encapsulated. So rarely were the patients themselves or their medical advisers concerned with these "lumps," in past decades that they have rarely been removed and examined.

Of small tumors of this kind that come under our observation, nearly all have proved to be peri-ductal fibromas, but a few have been peri-ductal sarcomas, or peri-ductal fibromas with spindle-cell proliferation, to a sarcomatous extent, in the stroma. What might have been the ultimate fate of these peri-ductal fibromas had they not been removed it is difficult to imagine. Judging by what has been said, above, of the duration of the "lumps" in the breast prior to the appearance of sarcoma, it may be supposed that some would have shown no change before the patient died; that some might have become sarcomatous after many years, and some in a short time. Of those that already showed the sarcomatous change it may be supposed that continuous sarcoma growth and development was to be expected. It has been impossible to follow these cases, and how many of them suffered from subsequent return of the tumor we do not know.

After a varying length of time, the patient observes that the node in the breast is increasing in size. If she is solicitous and early seeks surgical advice, the tumor usually meets with extirpation before it becomes larger than a mandarin orange. Fortunately, few cases are, at present, permitted to wait so long as this, and we believe that it is sound surgery not to wait at all, but to persuade the patient to submit to the removal of the tumor as soon as it is discovered, even though it be no larger than a pea. The earlier it is removed, the less is the damage done at the operation, the more likely it will be that the operation precedes any pending sarcomatous change, or in case this 
sarcomatous change has already supervened, the greater is the chance of escape from subsequent recurrence or metastasis.

A generation ago, when operations were attended with greater pain and danger such cases were permitted to go untreated, and from the literature of that time we can glean hundreds of cases, as among conservative surgeons and timid patients we can still collect dozens of cases, in which the further progress of the disease follows a fairly definite course.

The growing tumor, increasing in size, remains localized, circumscribed and painless. It forms a rounded, nodular movable mass that glides easily over the muscles below and beneath the skin above. How long it shall so continue depends somewhat upon its position in the breast; if near the surface, the changes next to be described make their appearance earlier than if deeply seated; if the breast be large and contain much adipose tissue, more slowly than if the breast be small and chiefly glandular.

The growing tumor, pushing aside the breast tissue, sooner or later appears as an

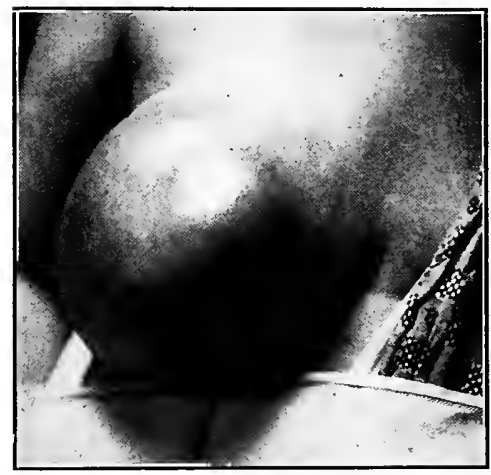

FrG. I48.-Periductal (complicating) sarcoma. eminence upon the surface, producing increasing deformity as it becomes more and more superficial. The skin over it becomes tense, more or less discolored-sometimes livid-and marked by large superficial veins. As the upward pressure of the tumor continues, the skin undergoes atrophy, suffers more or less inflammatory disturbance and becomes adherent, first at a limited focus, then over a broader and broader extent. At this time pain is apt to be experienced. The adherence of the skin is sometimes followed by necrosis, ulceration and infection, and an opening appears, at the base of which the capsule of the tumor may be seen. The opening in the skin is usually sharply defined. It may grow larger and larger or other necroses and ulcerations may form. If the tissue of the tumor escape the confines of the capsule or if the tumor be of the non-indigenous variety of sarcoma which is unprovided with a capsule, or if an existing capsule be injured by puncture or incision, the tumor tissue may project through the opening as a fungous bleeding mass (fungus hematodes) that becomes infected, and soon gives off a fetid hemorrhagic discharge. Such a mass may become as large as a man's head, or in rare cases even larger. Until the ulceration and necrosis become extensive there is no change in the axillary lymph nodes, and in the great majority of cases there is no other change at this time than a slight enlargement resulting from the bacterial infection. The patient may be in excellent general health, and may continue so in spite of the large ulcerated and fetid tumor, though extensive ulceration is apt to be accompanied by absorption of necrotic tissue juices and of saprophytic bacteria that may produce fever and depression. As the cause of the ulceration, the tumor continues to increase in size and to distend the skin more and more, there is no tendency for the ulcers to heal; they rather tend to progressive increase. Ashhurst has, however, seen one remarkable case in which such an ulceration did heal (Trans. Path. Soc. of Phila., r874-5, V, 230). 
Plate III

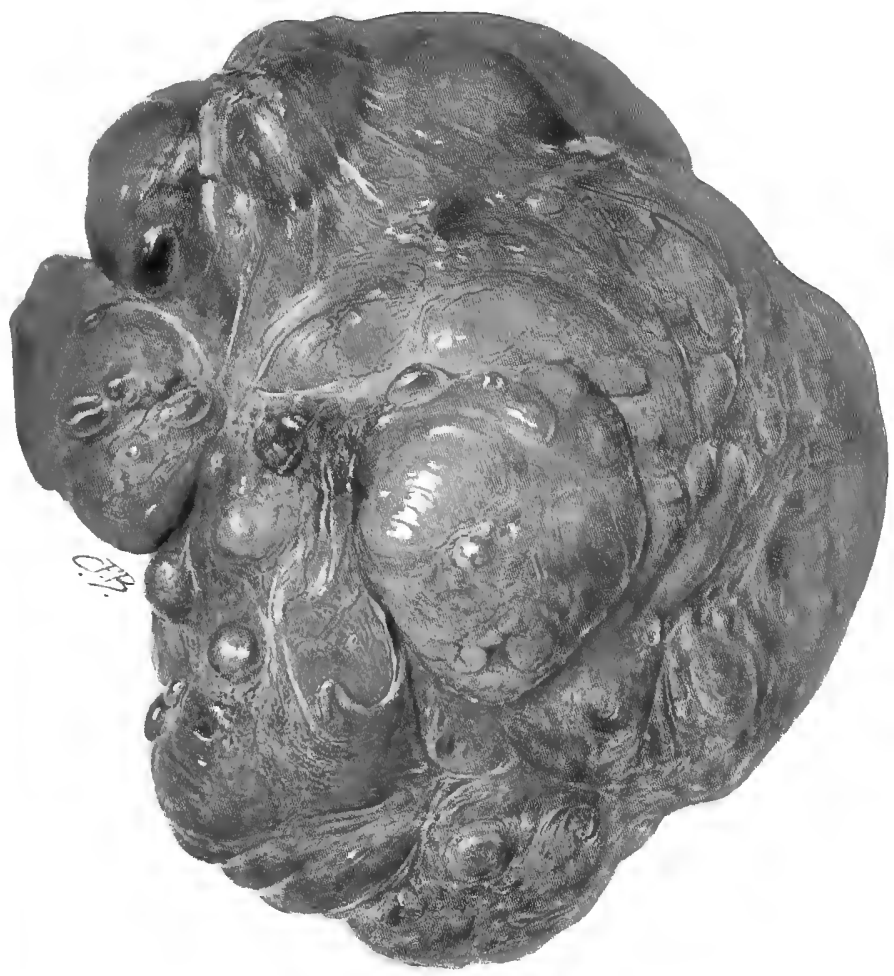

Periductal (complicating) sarcoma of the breast.

Deaver and MeFariand. 

This picture is so frequently repeated in the published case histories and in the experience of s'urgeons of large practice that it is unmistakable. But there is nothing in the picture that is characteristic of sarcoma. Any large tumor of circumscribed character, occurring in the breast may do the same. The conditions arise through the mechanical disturbances effected by the enlarging tumor. Nor does further examination of the breast itself assist in the diagnosis. The breast tissue may be stretched over or around the tumor but show no change. The nipple and areola may be stretched and flattened, but there is no retraction. Even further examination of the tumor fails to give any definite information as to its sarcomatous nature. It may be solid, but as it grows larger usually becomes cystic - but so do the many benign tumors.

There are cases of sarcomas of the breast, however, that present an entirely different history and clinical course, as can be well exemplified by some of the cases reported by Coley (Annals of Surgery, 1898, XXVII, 260).

Cases XIV and XV in his series were sisters. At the age of 31 years each received an injury to the right breast. In each a sarcoma began to grow immediately. In case XIV operative removal was undertaken in five months but was followed by immediate recurrence for which a second operation was performed. In $\mathrm{I}_{3}$ months five operations were performed for recurrences, and at the end of that period, $\mathrm{i} 8$ months after the injury, the patient died, presumably from cerebral metastasis. Case XV was not operated upon although at the end of six months her breast contained a tumor the size of a cocoanut, and was markedly protuberant and slightly fixed to the chest wall. The tumor grew with enormous rapidity and soon began to slough. The patient died seven months after receiving the injury. Presumably these were cases in which the sarcomas were primary and not complicating, and may have been non-indigenous in type.

In this paper Coley reports three other cases of rapidly growing sarcomas following injury, all probably being non-indigenous sarcomas of the breast. In a second paper upon "Injury as a causative factor in carcinoma and sarcoma," Coley (Annals of Surgery, I III, I, 449) mentions nine other cases in which sarcomas of the breast appeared, after injury, at times stated as "immediately," a "few days," a week, one month, three months and one year. Here again the tumors may be supposed to have been non-indigenous sarcomas of primary occurrence.

An interesting case, the nature of which is by no means clear, is reported by Lardennois and Moure (Bull et. mém. de la soc. d'anat. de Paris, r9r 4, LXXXIX, 94) and if it can be grouped with the sarcomas of the breast, presents a picture of unique character.

The patient was a woman of $3^{6}$ years, who in February, I9II, when ro weeks' pregnant, observed three nut-sized nodes in the upper part of the left breast. In May, Igi I, she miscarried with twins. After this she observed that the left breast increased rapidly, the right slowly, in size. The enlargements continued in spite of the use of a breast pump, purgation, etc. The breasts were painful and she was unable to sleep, had no appetite and had insatiable thirst. The breasts appeared as two red and violet globes with prominent nipples in pigmented areolæ. Pressure brought forth serous fluid. The right breast had a vertical diameter of $33 \mathrm{~cm}$., a horizontal diameter of $34 \mathrm{~cm}$.; the left breast a vertical diameter of $37 \mathrm{~cm}$. and a borizontal diameter of $39 \mathrm{~cm}$. The circumference of the left breast was $69 \mathrm{~cm}$. Serpentine veins were visible tbrough the thinned skin. The breasts were hard and resisting, the skin fixed. In the upper inner quadrant of the left breast one could feel a bosselated indurated area the size of the palm of the hand, over which the skin was adherent. Both breasts were movable upon the thoracic walls. Blood examination was negative. The patient died Aug. 25, I9II, with a temperature of $4 \mathrm{I} .5^{\circ} \mathrm{C}$. Secondary (?) tumors were found in the uterus and ovaries. The description of the breasts is interesting; they consisted almost entirely of a compact white tissue with red-brown points. Microscopic examination showed the chief cells to be lymphocytes. Cultures made from the tissue were negative.

The diagnosis was "acute neoplasmic mastitis of Volkmann." They do not attempt 
to explain the extraordinary features of the case, which may have been one of leukemia, or of acute mammary carcinoma, which latter possibility they express in the title of their paper, and this might be the conclusion with which the case could be dismissed from further consideration, were it not for the following:

Vignard (Gaz. méd. de Nantes, I909, XXVII, 256) observed

a woman 49 years of age, married but without children, who in April, r908 (about one year before a report of the case was published), suffered from boils. At that time her left breast began to increase in volume and caused much pain. After about eight days, and under appropriate treatment for mastitis, the pain entirely disappeared, but the breast remained two or three times as large as its fellow, the chief tumefaction being in the upper inner quadrant. The color was red violet, the consistence soft. At the center it appeared ready to ulcerate. The tissue was tender when pressed. There was no enlargement of the axillary lymph nodes. The skin became adherent to the tumor, but the latter continued to be mobile upon the chest wall. A diagnosis of chronic mastitis was made. An exploratory puncture secured reddish-brown fluid, and the diagnosis was changed to "blood cyst." The breast was amputated. Upon section it was found to contain a solid tumor with a softened necrotic center and sarcomatous-looking periphery. Microscopic examination of the latter tumor showed "sarcoma."

It, therefore, seems quite possible for sarcoma of the breast to make its appearance with symptoms suggesting mastitis, and grow and spread with great rapidity.

It is usually by examination of the tumor after removal, and frequently only after microscopic examination of various portions of the tumor that the correct pathological diagnosis can be made.

There are no variations in appearance that enable one to recognize any particular form of indigenous sarcoma - except, of course, the presence of bone and cartilage.

This inability to make a positive clinical diagnosis of sarcoma before operation, or a positive pathological diagnosis after operation without the use of the microscope, is the source of much of the confusion experienced in attempting to classify the case reports. Many tumors, undoubtedly benign, have been called sarcomas because it was thought that the clinical picture indicated sarcoma; some sarcomas escaped detection because benign tumors behave in the same manner and appear similarly.

Recurrence in mammary sarcoma is extremely common, and may be frequently repeated. S. D. Gross operated 22 times, Bryant 12 times, Hoffman $I 2$ times, Riedel 6 times, Erichsen 6 times, Heath 6 times, Gay 6 times, Billroth 4 times and Howard 4 times, each upon a single patient in attempting to prolong life and finally extirpate the disease.

It is not so easy to explain recurrence in sarcoma as in carcinoma. In the latter disease we deal with a tumor whose cellular offshoots permeate long distances into the lymphatic channels in all directions, making it impossible for the operator ever to be certain that the eradication has been thorough. The best that he can do is to remove every thing that is removable. But in sarcoma he commonly deals with a disease that is well localized, sharply circumscribed, very often encapsulated and concerning which he feels certain that the eradication is complete. Something, however, is left behind, for there are few exceptions to the rule that the recurrent tumor repeats the structure of the growth that has been removed.

In non-indigenous and non-encapsulated sarcomas there is no certainty that the circumscription of the tumor is as sharp as the macroscopic appearance suggests, and as histological studies of these tumors show that their cells grow for considerable disiances along the walls of blood-vessels, invading and destroying their walls, the conditions bear some correspondence with those attending carcinoma. But recurrence of encapsulated indigenous sarcoma takes place, and it may take place in sarcomatous peri- 
ductal fibromas where the disease is so limited in extent and so inconsiderable in degree that the malignant tendency of the tumor may be questioned by the microscopist.

An explanation may be found in the intra-vascular condition. If the capillaries of the tumor be imperfect, and if the blood circulate among the tumor cells with a tendency to detach and transport them, manipulation of the tumor can be expected to facilitate both. The disturbances attending operation may therefore be accompanied by the passage of an unusual number of the tumor cells into the veins. At the same time the operation results in venous obstructions, venous thrombosis, various compressions and ligations, and the cells in the small veins may be retained locally instead of being disseminated.

The considerable or inconsiderable number of cells at any point probably has much to do with secondary tumor growth. As a certain number of bacteria seem to be required to produce infection, so it may be that a certain number of tumor cells are essential to the growth of a secondary tumor. Single, dissociated cells entering the circula-

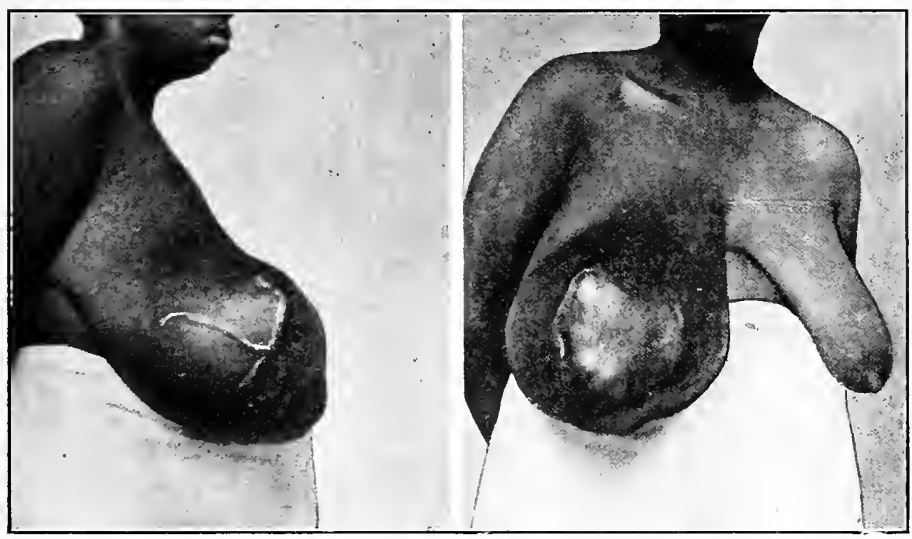

FIG. I49--Peri-ductal (complicating) sarcoma.

tion may be dealt with as a foreign element and destroyed by the body defences; groups of cells capable of acting as emboli may contain some able to survive and multiply. It may not be impossible that the greater number of cells retained in the coagulated blood of the veins or escaped from them into the wound determines that local return shall take place, while the smaller number that enter the circulation is not adequate to determine metastasis. Though recurrence may be prompt and frequent, metastasis may not take place at all. Thus in S. D. Gross' case, the patient was operated upon 22 times for $5 \mathbf{I}$ recurrent tumors, during four years, after which she was living and well, without any further recurrences, and with no metastasis for ten years and nine months.

The type of tumor has much to do with the early or late occurrence of metastasis. Unfortunately, it is difficult to obtain accurate data upon the subject. Presumably the order of frequency is round-cell sarcoma, melanotic sarcoma, myxo-sarcoma, spindlecell sarcoma, giant-cell sarcoma and lastly osteo-sarcoma and chondro-sarcoma. The unexpected is apt to occur both with regard to recurrence and metastasis. 
I. Round-cell Sarcoma.-These are indigenous or non-indigenous tumors of the breast of both sexes and of almost all ages. The youngest case of which we can find a record is that of Chambers (Univ. Med. Mag., I899, II, 376), a little girl of only four months. The tumor had been observed in the right breast when she was but five weeks old and had grown to the size of a hen's egg in eleven weeks.

They commonly follow injury to the breast, two of the cases reported by Coley (Annals of Surgery, I9I I, I, 449) having followed an injury after an interval of a "few days."

Of 44 cases of sarcoma of the male breast collected from the literature 8 or i 8 per cent. are said to have been of this form.

The tumors grow rapidly, form rounded, nodular, firm, movable masses that may ulcerate and fungate. Of the unpigmented sarcomas of the breast, they are most prone to give metastasis to the axillary nodes. In the case reported by Banks (Clinical Notes, I 884 , p. 69)

the man suffered from round-cell sarcoma of the right breast and had enlargement of the corresponding axillary nodes. The diseased breast was removed and the axilla cleaned out, but five months later he came under observation with a recurrence, bigh up in the axilla and in the glands at the root of the neck. The disease had spread with terrible rapidity, and in trying to clear the axilla of the recurrent growth, it was found that the great blood-vessels were completely surrounded. He died six months later with metastasis in both lungs.

In Morton's case (Trans. Path. Soc. of London, I892, XLIV, I 26)

the patient, a woman 50 years of age, bad received a blow in the left breast, 1o months before coming under observation. The breast swelled, and after recovery from the swelling a little node was found. In the months since, this node had grown to the size of an orange, when she fell and struck the breast again. The growth of the node then became rapid, and it increased until at the time of reporting it was as large as an infant's head. The breast was firm and "bossed." Tbere were two distinct nodes in its axillary aspect, one hard, the other fluctuating. On the anterior inner surface there was a black slough the size of the palm of the hand around which the skin was hardened and edematous. The veins about the base of tbe growth were much enlarged. The nipple was retracted, not simply buried in the tumor mass as there was no growth about it. The skin about the nipple was loose, though stretched elsewhere over the tumor. In the axilla a firm mass the size of a duck's egg was present. It was firm, rounded and insensitive. When the breast was examined after removal, it was found to contain a fairly well-circumscribed tumor of white soft appearance, and without cysts. The axillary tumor presented the same appearance. Microscopic examination showed the tumor to be a small round-cell sarcoma but the axillary mass contained both round and spindle cells. This patient died after a month. Examination at post-mortem showed the glands at the lower part of the neck to be invaded by the round-cell growth. There was no metastasis to internal organs.

\section{In the case reported by Putzu (Riforma Medica, I9I2, XXVIII, I380)}

a man of 30 was found to have a round-cell sarcoma the size of a mandarin orange in the right breast. It had only been observed for four months but had already caused mestatasis to glands in the axilla:

We have not found widespread metastasis frequently reported in these cases. The lymph nodes and the lungs are mentioned as a rule. Houzel (Archiv Prov. de Chir. Paris, I9I0, XIX, 88) has reported an interesting case in

a woman 45 , who had the left breast amputated and the axilla cleaned out for round-cell sarcoma, who, three months later, observed a small tumor on the hairy scalp of the left parietal bone. As it was not painful she paid no attention to it, but as it rapidly grew to the size of a hen's egg she consulted the doctor who incised it with a bistoury. It bled so freely that he had to send for assistance and to suture the wound in order to stop the hemorrhage. Twelve days later the tumor was like balf an orange applied to 
the parietal bone, was covered with hairy scalp, crepitated a little, like parchment, and gave the same sense of false fluctuation one finds in lipoma. A diagnosis of secondary sarcoma was made. An operation was performed a little later, when it was found that the tumor sprang from the dura mater and had eroded its way through the parietal bone, elevating the scalp. It was removed and the patient recovered from the operation. What subsequently befell the patient is not stated. The tumor, upon examination, proved to be round-cell sarcoma.

These tumors sometimes spring from multiple foci, which may be in both breasts. Such may be exemplified by the case reported by Elsberg (Annals of Surgery, Phila., I9I $4, \mathrm{XL}, 767$ ).

"The patient had been nursing a child for eight months, and six months before multiple tumors appeared in both breasts. These enlarged rapidly so that when the patient first entered the hospital, both breasts were much enlarged and filled with tumors of various sizes. The operation consisted of subcutaneous extirpation of both breasts, and the patient was presented (before the New York Academy of Medicine, May I3, I 1914) to show how small a deformity was left after such subcutaneous breast extirpation. The glands in the axilla were not enlarged. The pathological report was round-cell sarcoma."

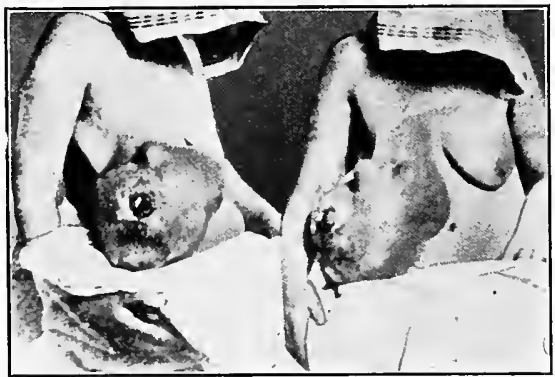

FIG. 150.-Sarcoma in a huge intra-canalicular myxoma of the breast. (Bloodgood.)

The microscopic structure of these tumors is most simple, consisting of round cells, sometimes resembling lymphosytes, but sometimes very large and with considerably more cytoplasm. The cells of each tumor are usually strikingly uniform, though sometimes, especially where nutritive disturbances occur, they may vary, some being much larger than others and possessing large deformed nuclei. Occasionally, a giant cell is seen in such areas though none can be found in healthy parts of the tumor. Between the cells there is an almost negligible quantity of inter-cellular substance of amorphous character. At the periphery of the tumor the cells extend but a short distance between the structural components of the tissues with which the tumors are continuous. This tumor as it grows partly pushes the tissues aside, partly disorganizes and destroys them. The greatest extensions from the tumor masses usually follow the vessels into the adjacent tissues.

One remarkable round-cell sarcoma reported by Billroth ("Handbuch der Frauenkrankheiten," "Krankheiten der weiblichen Brustdrüsen," I880, p. 53) is unique in its histological structure because it is stated to have contained striped muscle cells.

II. Spindle-cell Sarcoma.-Uncomplicating spindle-cell sarcomas of the mammary glands seem to be uncommon. Most of them seem to belong in the group to which the term adeno-sarcoma is applicable and which arise through changes in the stroma of peri-ductal fibromas. One writer has ventured the opinion that pure spindle-cell sar- 
comas arise through the extinction of the glandular elements in sarcomatous peri-ductal fibromas, but has offered no satisfactory proof of it. A case presented as a card specimen to the Pathological Society of Philadelphia, by Kennedy and Case (Apr. 8, rgr5), contained a tumor that presented all of the appearances of a non-indigenous non-complicating sarcoma. The breast contained a carcinoma at one edge of which, and well differentiated from it, there was a well-circumscribed, unencapsulated whitish tumor of homogenous appearance the size of a filbert. Microscopic sections showed pure small spindlecell structure.

The cases reported in the literature can with difficulty be separated from the complicating adeno-sarcomas. The cases that seem to be fairly well-defined non-indigenous sarcoma have the following features in common. They begin as small tumors that grow steadily and rapidly and call for surgical intervention in about $\mathrm{I} 2 \mathrm{months}$ 'time. They appear as firm, movable, nodular, painless tumors that never involve the lymph nodes. They rarely attain to a great size - the size of a fist is about the maximum-they cause ulceration of the skin rather early and sometimes fungate rapidly. When removed they usually recur and in many cases the recurrence is frequently repeated and calis for many operations. We find no reported case of uncomplicating non-indigenous spindlecell sarcoma in which death with metastasis to internal organs is mentioned. Persistent excision of the recurrent growths is sometimes followed by apparent cure, as in Gay's case (Trans. Path. Soc. of London, r879-80, XXXI, 272) in which a spindle-cell sarcoma of the breast, that may have belonged to this group, was excised six times in six years, the patient in the meantime greatly improving in physical condition.

Still more remarkable is the case reported by Hoffman (Archiv für klin. Chirurgie, XLVIII, 93).

The patient was a woman aged 50 years, who in the night of Sept. 29-30, 1886, first detected nodules in the left breast. The growth of these was so rapid that they soon formed a mass the size of two fists, which was sensitive and painful. No enlarged axillary nodes were palpable. The condition was regarded as inflammatory and the lesion supposed to be an abscess. It was therefore punctured for the purpose of evacuation, when only blood escaped and the lesion was found to be a solid tumor. As it continued to grow, the entire left breast was a mputated on Oct. 10, I 886. The tumor, which was as large as two fists, easily shelled out, was nodular on the surface, grayish white in color, fasciculated and marked by numerous interstitial hemorrbagic spots. Upon microscopic examination it proved to be a spindle-cell sarcoma with mucoid changes. On Dec. 22 of the same year, 1886 , she suffered from a recurrence in the scar, and between Jan. 6, r887, and Sept. 26, 1889, she was operated upon twelve times for the removal of recurrent tumors. From Sept. 26, 1889, until Dec. 22, 1892, she was treated with Fowler's solution, and had no recurrence, but after that date the disease came back and she suffered from recurrences and troubles incidental thereto until she died Sept. 16, 1893 .

The microscopic structure of these tumors is also very simple. They consist of uniform cells of elongate shape. Some are short like rice or oat grains; some are more elongate, some are much larger and much longer. The cells in the same tumor are usually all alike. As a rule they are arranged in strands or bundles, their long diameters parallel, the different bundles twisting and twining about one another and about the blood-vessels of the tumor.

If the tumor become edematous and undergo partial autolysis, the cells may loosen and cease to show this arrangement, but this is rare. The nuclei of the cells are vesicular and stain well. Between the cells is a negligible quantity of inter-cellular substance that is amorphous in the pure sarcomas, but becomes increasingly fibrillar by the formation of fibroglia and collagen. How much of this is required to necessitate the change of the name to the tumor of "fibro-sarcoma" is not anywhere stated and it is confusing 
to find purely cellular tumors sometimes described in fibro-sarcomas, and partly fibrillar tumors as spindle-cell sarcomas.

In a few rare cases, as in the one reported by Stone (Surgery, Gynecology and Obstetrics, 1905 , I, 400) of spindle-cell sarcoma from the breast of a man aged 25 years, striated muscle fibers are said to have been found among the sarcoma cells.

III. The Mixed-cell Sarcomas (Round- and Spindle-cell Sarcoma).-These tumors seem to have no peculiarities, apart from their microscopy, by which they can be differentiated from the unmixed forms, one or the other of which they may resemble. None seems to have been reported in which metastasis to the lymph nodes took place.

In a case reported by Powers (Colorado Medical Journal, Denver, I912, X, 203)

a woman aged 30 years was observed to have a large fungoid ulcerating mass involving the entire left breast, and firmly attached to the chest wall. It was of six months' duration, had already occasioned pulmonary metastasis, and caused the death of the patient five weeks after coming under observation.

A case reported by Clarke (Lancet, I879, II, 200) is entirely different.

The patient was a woman 58 years old, who, nine months before the date of publication, found a small painless enlargement in the left breast. Three months before the time of operation the tumor, which had been growing rapidly, ruptured and discharged a quantity of bloody fluid, some of which has been escaping ever since.

The tumor extended from the mid-line of the body to the axilla and vertically from 2 inches below the clavicle to 3 inches above the lower border of the ribs. Its circumference was $24 \% 4$ inches, its size laterally $\mathbf{x} 7$ inches, vertically $I_{3}$ inches. It looked about as large as an adult's head.

The breast itself was situated on the outer aspect of the growth, and just above the nipple, which was nearly in the axilla, there was normal breast tissue; the remainder was nodular and irregular, varying in consistency-hard in some parts, soft and fluctuating in others-and in the upper part was a sinus from which sanious fluid was exuding. It was freely movable upon the subjacent tissues, but the skin was adherent to it in many places, particularly at the upper part. The lymphatic glands in the axilla were slightly enlarged. The breast and tumor were removed. The tumor weighed $\mathrm{r} 7$ pounds $12 \frac{1}{2}$ ounces. It was solid except at the upper part where there were several large cysts. The microscope showed the tumor to be a spindle-celled sarcoma.

Here the tumor attained a large size without metastasis, and was still operable. What became of the patient subsequently is not known.

Microscopic studies of the tumors show them to be compounded of round and spindle cells. Sometimes the round and spindle cells are components of different parts of the tumor, all of the cells in such parts being similar, sometimes bundles of spindle cells pervade the round-cell structures everywhere, rarely the cells are more or less commingled. The latter peculiarity probably has something to do with edema and autolysis.

IV. Irregular-cell Sarcoma.-There are sarcomas whose cells cannot be classified because they are of no particular shape. The significance of this peculiarity is unknown. It is usually common to all parts of the tumor, and is not attended by inter-cellular mucinoid deposit or intra-cellular mucoid collection.

It is probable that the term "irregular cell" is employed in several different meanings. We believe that it should be restricted to cases where the cells are without classifiable shape. It should not be used as synonymous with "mixed-cell sarcoma.".

Few tumors of the breast are described under this name. What the primary condition was is not told, but Beatson (Edinburgh Med. Jour., I909, n.s., II, 23) pictures and gives an account of sarcoma of the breast that upon microscopic examination was described as "irregular-cell sarcoma." After two recurrences the patient died, the recurrent tumor having perforated the chest wall, and there being metastatic secondary tumors in the internal organs. 
V. Giant-cell Sarcoma of the Breast.-A sarcoma of any kind, in whose substance many giant cells occur, is apt to be called giant-cell sarcoma. There is, therefore, lack of precision in the employment of the term, and it is not always descriptive of the same condition.

Giant cells usually appear among the cells of spindle-cell sarcoma, and so far as our researches go, invariably do so in breast tumors. For this reason all of the giantcell sarcomas of the breast are fundamentally spindle-cell sarcomas or rarely, mixedcell sarcomas. In the latter the giant cells appear among the spindle cells.

The giant cells occur in sarcomas under two different conditions in which they may mean two different things:

I. The Giant Cells are Irregularly Distributed Throughout Unhealthy Parts of the Tumor Tissue, as part of a retrogressive or abnormal condition characterized by great inequality in the size, shape and proportions of the cells. In such areas the structure becomes confused. There are some irregular cells, some spindle cells large and small, some very large round cells with immense diseased nuclei, some gigantic spindle cells with equally immense and equally diseased nuclei, and finally few or many giant cells of all sizes with from two to a dozen nuclei in various stages of health or disease. Under these circumstances one cannot be sure that the giant cells are of other than accidental occurrence, whose formation has resulted from nuclear multiplication without associated cytoplasmic cleavage. Whether it is justifiable to call tumors with circumscribed or widespread areas showing such appearance "giant-cell sarcoma," is a question that merits serious consideration.

2. The Giant Cells are Uniformly Distributed Throughout the Healthy Tissue of the Tumor.-Under these circumstances the giant cells share in the general good health of the tumor tissue and are of uniform or fairly uniform size and appearance, have a fairly uniform number of nuclei, and give the tissue a character that suggests close relationship to bone-forming tissue and justifies the appellation of the term "myeloplaxes" so frequently employed by French writers.

That the giant cells of sarcoma are in some way concerned with bone formation is shown by the fact that giant cells occur in practically all osteo-sarcomas and ossifying sarcomas, but at this point they are to be considered without reference to bone formation, in tumors in which no bone has formed.

Billroth (Deutsche Chirurgie, Lieferung $4 \mathrm{I}$, p. $5^{8}$ ) seems to have been the first to record a case of giant-cell sarcoma of the breast, describing it as an "alveolar giant-cell sarcoma." Its histological structure is figured in his text and is peculiar as was the tumor itself, which when excised, reappeared in the axillary lymph nodes as well as in the wound. What would have been, the ultimate fate of the patient is unknown as she died of erysipelas.

A review of the reported cases shows that the giant-cell sarcomas of the breast are usually recognized, as such, only after removal and microscopic examination. There is no way by which to foretell that giant cells are present. The tumors are usually described as rounded, nodular, firm, well-circumscribed, and encapsulated growths, that develop slowly, ulcerate and behave like other sarcomas and benign tumors of nodular character. In none of the cases of uncomplicating and uncomplicated giantcell sarcoma, did invasion of the lymph nodes occur. On the other hand, when the tumors are complicated like that of Billroth, Malloizel, Autefage and Bornait-Legueule (Bull. et mém. de la soc. d'anat de Paris, I904, LXXIX, 674), the unexpected may happen. 
This patient was a woman aged 48 years who in 1902 discovered at the base of the left nipple a nodule the size of a pea. In four or five days it grew to the size of an egg after which it remained stationary for about a year, then began to enlarge rapidly, and to ulcerate. Irradiation with $x$-rays was practised without distinct effect and the tumor hecame as large as an adult's head, was hard, nodular, superimposed by thin skin with dilated veins and surmounted by an ulceration the size of the palm of the hand. No enlarged lymphatic nodes were found in the axilla. The tumor was removed. Upon microscopic examination it proved to be an adeno-sarcoma with complicating spindle-cell sarcoma of the stroma, many giant cells being found in the tissue. Later, however, there was a return of the disease, but in the form of adeno-carcinoma, in the lymph nodes.

Adeno-sarcomas containing giant cells commonly return and may also cause metastasis. The frequency with which they sometimes return is opposed to the frequently made statement that they are "benign" forms of sarcoma. Riedel (Centralblatt $f$. Chirurgie, I88I, VIII, 636) removed six recurrences in 20 years following an operation for giant-cell sarcoma. The patient finally died but seemed to have no metastatic tumors.

Uncomplicating sarcomas with giant cells may also be metastatic though the distribution is not extensive. The case of Moure and deJong (Bull. et. mem. soc. d'anat. de Paris, I9I4, LXXXIX, p. 32) may exemplify this:

A woman aged 67 . Ten years before coming under observation, found a nodule the size of a nut in the right breast below the nipple. It enlarged to such an extent that the left breast was twice the size of the right and contained a wooden induration forming a compact mass, well defined and sharply circumscribed. It was painless, not tender, and movable. There was one palpable lymph node in the axilla. The breast was amputated. Microscopic examination showed the tumor to be made up of large spindle cells with giant cells here and there. The patient died of pulmonary disturbance two months later and was found to have metastatic tumors in both lungs.

A peculiar and interesting case, the exact nature of which is open to some doubt, is reported by Lorrain and Ménard (Bull. et mém. soc. d'anat. de

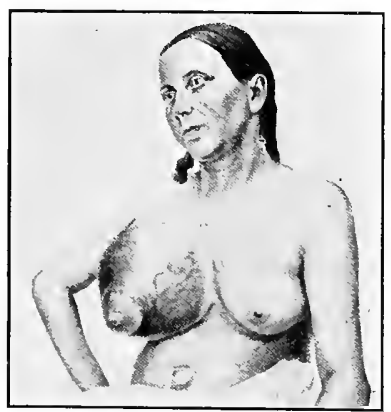

Fig. I5x-Giant-cell sarcoma of the breast. (Lixer.) Paris, I909, XXXIV, 103).

The tumor occurred in the left breast of a man aged 86 years, and in the course of a year grew to the size of a child's head. It was irregularly nodular, slightly sensitive, painless, and unattended by enlargement of the axillary lymph nodes. It was removed and the aged patient died seven days later.

The presence of giant cells in other forms of sarcoma will be discussed under other and appropriate headings.

VI. Myxo-sarcoma.-As has been said, this term should be reserved for those forms of the tumor in which the mucinoid change goes hand in hand with the growth of the tumor cells, which can justly be termed myxoblasts, and in which it gives the entire structure a uniform quality.

Unfortunately it has been applied to tumors in which circumscribed or widespread mucinoid change has occurred in the tissue of the tumor as the result of nutritive disturbance. What is worse has also sometimes been done, that is, an edematous state of the tissue has been mistaken for a myxedematous condition and the tumor misnamed in consequence.

It is not easy to assemble reports of uncomplicating myxo-sarcomas of the breast from the literature as many of the cases that have been described under suggestive names 
commonly prove, when carefully reviewed, to be something else or to have no adequate description of the microscopy accompanying them. Fortunately the matter is of little importance as the tumors are without clinical characters that enable their nature to be recognized prior to the pathological examination, and do not seem to differ from others either in course or in progress.

These tumors may appear very early in life, Sheild ("Diseases of the Breast," London, 1898) having removed a myxo-sarcoma from the breast of an infant aged six months.

It also occurs after middle life. Vignerat (Bull. et mém. de la soc. d'anat de Paris, r889, LXIV, 485) observed

a woman aged 54 years who since 28 yea rs of age had a tumor the size of a nut in the left breast. By February, 1886, it had grown to the size of a plum, but between that time and July, 1889, it grew to weigh 55 grams and have a circumference of $74 \mathrm{~cm}$., when examined microscopically after removal it was called myxo-sarcoma.

This case shows that the tumor may attain a great size, as does also the case of Boddaert and Vercoullie (Bull, et mém. de la soc. d'anat. de Paris, I907, LXXIV, 226)

a woman of 57 years, who had a distinct tumor in the right breast for several months. It was rounded, nodular, covered with skin showing large veins. There were no enlarged axillary nodes. When removed at operation the tumor weighed 3350 grams, was of a grayish-white color, divided by yellowish bands and was histologically diagnosed a "fibro-sarcoma myxomatoides."

Moore (Proc. Path. Soc. of Dublin, I875-77, n.s., VII, 2 I6) saw

a woman 35 years of age who, in the seventh month of pregnancy noticed that her left breast was getting hard and black and giving her a greal deal of pain now and then. The condition continued for six years, when it broke and she nearly bled to death.

Immediately after this accident the breast began to grow and has continued ever since. The mass was removed at operation and weighed 5 pounds $4 \frac{1}{2}$ ounces and presented a peculiar appearance, there being a large cavity in the breast in which the tumor lay imbedded. There were two small abscesses but no enlarged lymph nodes in the axilla. A microscopic examination of the tumor was made, and it was called myxo-sarcoma.

\section{Lilienthal (Ann. of Surgery, r905, XLII, 455) observed}

a woman aged 29 years, who six years before found a small painless nodule, the size of a marble, in the right breast. It grew rapidly especially during the last year and involved the entire breast which is as large as an adult's head. The tumor is nodular and cystic and adherent to the skin which is purplish and shows numerous blue veins. The whole mass was attached to the breast by a flat pedicle 6 inches wide by $3 / 4$ inch thick. A few soft glands could be felt in the axilla. Radical operation was performed. Dr. Mandelbaum reported that the tumor was myxo-sarcoma with cystic degeneration.

The myxo-sarcoma should be recognized without difficulty in most cases. The presence of the mucinoid substance should give it a soft quality and the cut surface a shining quality. Pressure should cause the gelatinous substance to exude. In true myxosarcoma the tissue should be uniform. In the spurious varieties with local mucoid metamorphosis, there may be cysts of varying size caused by complete mucinoid transformation of the tissue.

The microscopy usually reveals the peculiar multipolar and stellate cells of the socalled mucoid tissue. Specific stains are required in all doubtful cases, to show the presence of the mucin by microchemic reaction.

The difficulty of recognizing myxo-sarcomas is greatest when it occurs as a complication in peri-ductal fibroma or peri-ductal myxoma. This, however, will be discussed elsewhere. 
VII. Melanotic Sarcoma of the Breast.-We have been able to assemble 22 cases, from the literature, and from our own experience we add one, making 23 cases upon which to generalize regarding this tumor. The cases, from the literature, are reported by Betagh, Billroth, Bryant, Buff, Butlin, Coley, Cornil and Ranvier, Credé, Fioriani, Horteloup, Langenbeck, Marcano, Nunn, Stone, Vieregge, Velpeau, Wacker, Williams, and Winckel. Five of the reported cases, those of Betagh, Butlin, Credé, Langenbeck and Marcano, were in men.

Full particulars are not available in all cases. Some that have been included being specimens in the museums of Guy's and St. Bartholomew's Hospitals, introduced to make the collections as complete as possible. Winckel's case is known to us only from the drawing from the microscope that appears in his "Lehrbuch der Frauenkrankheiten," r886, p. 756, about which nothing is said in the text.

The earliest occurrence of the disease seems to have been recorded by Vieregge (Northwestern Lancet, St. Paul, r89r, X, 28) but the bound copy of the journal which we obtained was imperfect and the number containing this paper was missing. The title is, however, sufficient-" Melano-sarcoma of the Breast of an Infant"-to show that the tumor may occur in early childhood. The oldest male patient was observed by Buff (Inaug. Diss., München, r9०4), and was 63 years of age. The oldest female patients was seen by Nunn (see Williams' "Diseases of the Breast," London, r882, p. 105) and by Hourteloup (Bull. acad. de méd. de Paris, r870, XXX, 787 ) and were 73 and 75 years of age, respectively.

Most of the tumors are traceable to pigmented "moles" or "warts" upon the skin, and fall in the group concerning the true sarcomatous nature of which doubts have been raised by Unna and Gilchrist. As examples of such Buff's case, already cited, may be described:

The patient, a man aged 63 years, had for six years observed a pea-sized node beside his right nipple. In three years it increased to the size of a hen's egg and developed a painful ulceration. It was extirpated and upon micro-

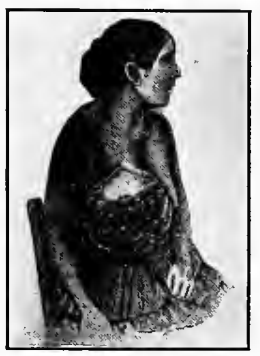

FiG. I 52.-Adeno-sarcoma of the right breast. (Whitson.)

scopic examination proved to be melano-sarcoma. In two years and six months there was recurrence and a radical operation was performed.

For the other sex Nunn's case, already mentioned, may be given:

The patient, a woman aged 73 years had a group of melanotic "warts" of the skin of the right breast toward the lower border. They enlarged, the axillary nodes became invaded, and five months later she died of hemiplegia.

The case reported by Hourteloup (Bull. acad. de méd., Paris, I870, XXX, V, 789 ) may also be cited.

The patient was a woman aged 75 years. When 56 years old she observed several fissures about the right nipple and a slight oozing of blood. About two years after this she noticed a little node the size of a nut, that increased and indented at the center, and found a slightly nodular tumor $5 \mathrm{~cm}$. high and 7 $\mathrm{cm}$. across. It caused lancinating pain, and continued to enlarge until it was the size of an orange. A sero-sanguinolent discharge occurred, followed by a dark bloody fluid. Amputation of the breast was performed, and the tumor was found to be "melanotic sarcoma."

But not all cases originate from the skin. Thus the tumor reported by Fioriani (La Clinica Chirurgia, rgo2, No. 9-see Jahresbrichte für Chirurgie, I912, p. 580) began a year before coming under observation with dripping of a whitish disagreeably 
smelling fluid from the nipple and a decrease in the size of the gland which became but one-half the size of its fellow. The upper outer quadrant contained a pigeon's eggsized encapsulated tumor and the axillary nodes were enlarged. Upon removal and microscopic examination the tumor was pronounced to be a melanotic lymphangiosarcoma. Haeckel (Archiv f. klin. Chirurgie, I894, XLVII, 275) reports from Prof. Reidell's clinic at Jena, a melanotic sarcoma as large as a clinched fist, that occurred as a sharply circumscribed tumor deeply situated in the substance of the breast.

Billroth (Deutsche Chirurgie, Lieferung, XLI, p. 56) has described an alveolar melanotic sarcoma.

It occurred in a woman aged 68 years, had made its first appearance three years before, and when observed was the size of a child's head, hard,-nodular, adherent to the skin, and accompanied by palpable axillary lymphatic nodes. A radical operation was performed but when she was discharged from the hospital, there was already a secondary metastatic tumor on the back. She died in eight months, the total duration of the disease being four years.

The melanotic sarcoma of the breast may be secondary. Thus Bryant ("Diseases of the Breast," p. 456) observed

a married woman, the mother of one child, who came under observation with the right breast covered and filled with meianotic lumps the size of nuts. There were similar lumps over the sternum, abdomen and back. The axillary lymphatic nodes were much enlarged. Ten months previously she had had a black tumor the size of a walnut removed from the left forearm, where it had originated from a mole.

He also ohserved a second woman, aged 55 years who came under his observation four months after having had a melanotic tumor the size of a duck's egg removed from the skin over the sternum where it originated from a mole. Upon examining the patient, many melanotic growths were found disseminated over the sternum, hoth breasts and the abdomen. The axillary lymphatic nodes were enlarged.

Velpeau ("Traité du Maladies du Sein," I 858 , p. 432) observed two cases of "pigmented cancer" of the breast. In one the disease was in the right breast and consisted of a tumor the diameter of a silver dollar, situated exclusively in the skin and about I $\mathrm{cm}$. in thickness. It was ulcerated at two points and discharged a black juice. The other patient had a tumor the size of a nut situated just outside of the nipple of the left breast. It was nodular and concrete. Both women died without operation, with numerous small black tumors of the skin, in the lymphatic nodes of the neck and in the internal organs.

The wide dissemination of the secondary metastatic tumors is well shown in the case reported by Wacker (Inaug. Diss., Rostock, I884) in which there were nodes in both breasts, in the lymphatic nodes of the left axilla, the spleen, the mesenteric nodes and the brain.

The tumors described as melanotic sarcoma, are therefore, various in origin, in course and disposition. Some arise from the skin; some apparently not. Some grow to a large size before becoming metastatic; others are metastatic quite early. Some are metastatic to the lymph nodes, others chiefly through the blood.

They all have in common a blackish pigmentation of the cells and a high degree of malignancy.

The recognition of the tumor may be difficult or impossible, before operation, if the pigmented character of the tumor tissue cannot be seen. Ordinarily the tissue is so deeply pigmented as to be described as black. Section of the tumor shows a uniform structure and a uniform black color. If the sarcoma tissue be penetrated by vessels or strands of connective tissue, and if it contain some adipose tissue it may lack uniformity and be somewhat variegated. In some cases the pigment is insufficient in quantity to produce blackness, when the color may be brown. 
When histologically examined, the tumor is found to be composed of cells that vary in appearance and in size in different cases. When it is possible to trace the cells from the seat of origin to the deeper tissues they may be large, epithelial in appearance, and extend in prolongations that branch and ramify as in squamous-cell carcinoma, but differing in being pigmented and showing no tendency to cornify.

The nearer the surface the cells are, the larger they are, and the more distinctly epithelial they appear; the deeper into the tumor one extends the examination, the more regular, more numerous and more sarcoma-like they become. In the secondary tumors the cells occur in uniform masses like sarcoma, but commonly deeply pigmented. It is not impossible for the secondary metastatic tumors to be lacking in pigment.

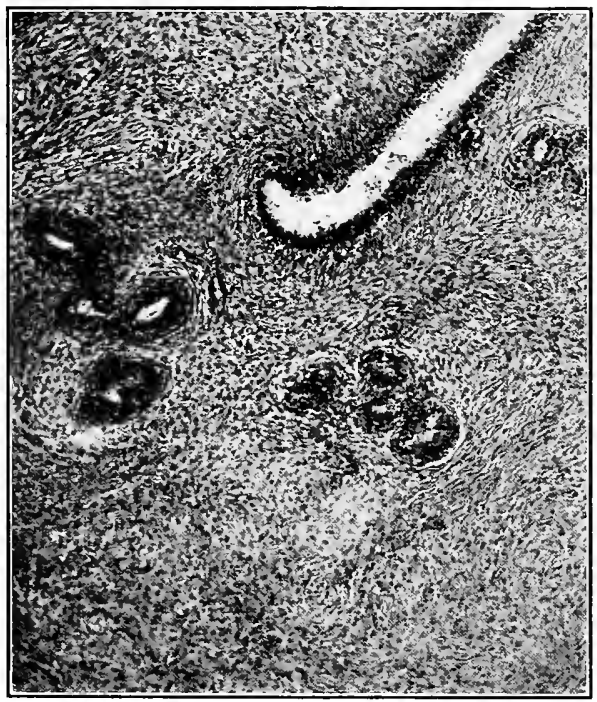

FIG. 153.-Adeno-sarcoma of the breast. The usual loose periductal fibrillar tissue has become purely cellular in type.

In most cases the cells are round in shape, but occasionally one finds spindle cells also deeply pigmented. We have found no references to the occurrence of such tumors in the breast, however.

The pigment is melanin. Cornil and Ranvier ("Manuel d'Hist. Path.," I, 33 I) in describing a case observed by them, state that "the melanotic substance was contained, not in the connective tissue, but in the epithelial cells of the glandular acini. Here the pigment had evidently been secreted by the cells themselves." It is to be supposed that "glandular acini" as used here means nests of tumor cells, and not acini of mammary tissue.

VIII. Chloroma.-This peculiar and rare tumor is like sarcoma in being purely cellular, and is characterized by the presence of certain lipochromes that give its tissue a bright green color on fresh section. Its true nature not being understood, it seems not illogical to mention it with the sarcomas, and since it is colored, not far from the pig- 
mented sarcomas. It has two modes of occurrence, one, the more frequent, in connection with the flat, short and irregular bones, which has given rise to the supposition that it is a tumor of the bone marrow composed of pre-myelocytes; another, independently of the bones that seems somewhat to controvert the theory. The former is commonly accompaned by the appearance of the Bence-Jones protein in the urine, the latter without it. In some of the cases of chloroma that seem to occur independently of any connection with the bones or bone marrow there are blood changes that have given rise to the opinion that the disease may be related to leukemia. Cases occur, however, without these blood changes, so that the explanations thus far given for the occurrence of the tumor are all unsatisfying.

Seven occurrences of the various forms of chloroma of the breast have been found in the literature. One of these, mentioned by Sheild ("Diseases of the Breast") is a specimen in the Museum of St. Bartholomew's Hospital. It was taken from a boy ro years of age, and was called a round-cell sarcoma of the breast. The lad also had orbital and cranial tumors, all of a bright green color.

Lawrence (Medico-Chirurgical Transactions, III, 72) observed

a case, in an Italian, a man aged 53 years, who suffered for a year with an ulcerating tumor of the right breast. The skin and adjacent tissues were extensively infiltrated and the axillary and clavicular lymphatic nodes were invaded by what was thought to be scirrhus cancer, and he suffered from edema of the upper arm. At the necropsy the whole of the soft parts of the right side of the chest were found to be infiltrated by hard, quasi-fibrous growths of bright yellowish-green color.

The thoracic muscles, anterior mediastinal glands, spleen and diaphragm were invaded by growths of similar nature, evidently by extension. There was hydrothorax with collapse of the lung. All of the metastatic growths were firm and of a bright green color.

Huber (Archiv der Heilkunde, I878, XIX, I29) reported a case in which tumors in the mammary gland were first observed, and followed by others in the orbit, nasopharynx and over the parietal bones. The blood was not examined until after death, but showed a considerable increase of leucocytes that bear correspondence with the cells found in the tumors.

Trinithek (The Lancet, London, $\mathrm{r}_{9} 0_{3}, \mathrm{II}, \mathrm{r}_{5} 8$ ) observed a similar case, the tumorswere in the mamma, orbits and lymph nodes. The blood picture was that of acute lymphatic leukemia.

Weinberger (Zeitschrift fïr Heilkunde, I907, XXVIII, i) observed a case of chloroma effecting the left mamma, the liver, spleen and lymphatic nodes. The blood picture was that of acute lymphatic leukemia.

Simon (Berliner klin.Wochenschrift, I9r2, XIIX, 893) reports a case of mammary tumor that occurred in Kuttner's clinic, and was mistaken for carcinoma. At the operation, the tumor was found to have a green color. Examination of the blood showed 47.6 per cent. of myeloblasts and a smear from the tumor showed numerous myeloblasts and myelocytes.

Ried (Beiträge zur klinischen Chirurgie, $\mathrm{I}_{9} \mathrm{r}_{5}, \mathrm{XCV}, 47$ (reports:

The case of a woman 30 years of age, married but without children, who five and a half months before, observed a lump in her left breast. In the course of two or three weeks it attained the size of a lemon, when she discovered that there were little tumors in her right breast. Three weeks of $X$-ray treatment caused the tumor in her left breast to diminish almost to disappearance but later it began renewed growth in spite of the continued treatment. The tumors in the right breast were not influenced by the irradiation. Five months after coming under observation enlarged lymphatic nodes were observed in both axillæ. 
In addition to the breast tumor the patient suffered from jaundice and had two uterine fibroids (?). At the first operation choledochostomy was performed and the right breast with a small portion of skin was removed. The patient recovered with a biliary fistula, but complete relief from the jaundice. Four weeks later, at a second operation, the left breast was amputated. The patient left the hospital with the biliary fistula and without improvement in her general condition. Blood examination showed $\mathrm{r}_{3}, 620$ white blood corpuscles at one time, and $r 4,750$ at a second count, bemoglobin 82 per cent. Differential count normal. No Bence-Jones protein in the urine: In five weeks she died. As she lived several hundred of miles from the hospital, and died at her home, little could be found. The local doctor stated, however, that before her death she developed a tumor of the rectum that he regagrded as a sarcoma.

The pathological examination of the amputated breasts showed that each contained a tumor of precisely similar character. That in the right breast occupied the greater part of the gland, conforming to its size and shape, and extending into the neighboring adipose tissue. Only a small portion of the normal breast tissue could be seen with the naked eye between the tumor and the skin. The section through the tumor showed a striking green color with red and purple spots sprinkled upon it. After fading in formaldehyde solution, in which it was preserved, the bright green color could be brought back in $\mathrm{H}_{2} \mathrm{O}_{2}$. The tumor in the left breast was smaller but showed the same kind of tissue. The axillary lymphatic lymph nodes were about $2 \mathrm{~cm}$. in diameter, were firmer than normal, and showed the same green color of the breast tumors. The neoplasm was not confined to the nodes but spread from them into peri-glandular tissue.

When examined with the microscope the tumor was found to be composed of cells whose general appearance conformed to those of large round-cell sarcoma, but upon careful study was found to belong to the myeloblastic tissues. They were very irregular in shape, approximately oval except in places where they were compressed, contained much cytoplasm in which were eosinophilic granules, and single, large, vascular, oval nuclei with considerable variation in the quantity and arrangement of the chromatin. Mitotic figures were frequent, and occasional deformed double nuclei suggested amitotic cell division.

This tumor belongs to the group of rare chloromas that arise independently of the periosteum or bony structures, and is peculiar in that it lacked the accompanying leukemia.

In four out of the seven cases of chloroma a diagnosis was possible by blood examination; in three it was made only after operation and examination of the tumor. Reid thinks that in all but his own case it ought to have been made before operation by blood examination.

There is much discussion as to whether the leukemia is the primary trouble and the occurrence of the tumors secondary or the tumors primary and the leukemia secondary. Dock, Butterworth, Fabian and others adhere to the former theory, Borst to the latter.

XI. Leukemic Tumors of the Breast.-Closely related to chloroma but without any color, and usually mistaken for sarcoma, are a few tumors of the breasts that have made their appearance during the course of leukemia.

Such have been reported by McWilliams (Annals of Surgery, Phila., rgr 2, LV, 439; Am. Jour. Med. Sciences, I9r2, CLXIII, 5I8).

The patient was a woman aged 33 years, mother of one child, who two weeks before coming under observation, had noticed a movable lump in the upper outer quadrant of the right breast. A piece was removed for examination, and the pathologist reported "benign lymphoma." Later other nodes appeared in both breasts, the axillary lymphatic nodes enlarged and the diagnosis was changed to "lympho-sarcoma." Both breasts were removed. Later it was discovered that the patient suffered from leukemia, the only objective sign of which was the disturbance in the breasts.

Dencker (Jour. Amer. Med. Ass., I9II, LVI, 4I7) has reported a case of extensive leukemia infiltration of the mammary gland and skin.

The patient was a woman aged 47 years, mother of four healthy children. The trouble dated from about nine months before, when she suffered from redness and itching of the nose soon followed by swelling of the nose and lips. She was treated by several physicians for eczema, etc. The lower eyelids 
became edematous, she was hoarse, short of breath and had pain on swallowing. Her teeth were in bad condition. The pinna of the right ear was enlarged to almost double its normal size and was of a reddish color. All of the superficial lymph nodes of the hody were enlarged, the largest being those of the axilla. The breasts were symmetrically enlarged, firm and infiltrated. They were movable. The skin over them was tense and shining but not fixed. The nipples were not retracted. No separate nodules could be felt. An abdominal tumor could he felt in the left hypochondrium. A tumor the size of a walnut was present in the skin in the posterior axillary fold of the right side of the thorax but it later disappeared.

The blood count showed I ro, 000 white corpuscles, 82 per cent. being small and 6 per cent. large lymphocytes. The urine contained albumin and a few casts.

The patient died and a careful autopsy was performed. The mammary glands were found to have been replaced by a mass of lymphoid tissue of uniform consistence resembling sarcoma tissue in gross appearance, and such a mass dissected away from the skin and adipose tissue measured I 2 by I 2 by 4 inches and weighed 350 grams. Microscopic examination showed that the proper structure of the mammary glands had almost entirely disappeared, only occasional isolated tubules being found here and there in the mass of large and small round cells that made up the new growth. These cells infiltrated the connective tissue of the nipple and areolas, up to, but not into the epithelium, accounting for the swollen condition of the areolas.

Some of the peculiarities of this case recall the extraordinary cases of acute mammary sarcoma described by Lardennois and Moure and by Vignard, already described. In the former of these, careful blood examination showed no leukemia; in the latter no blood examination seems to have been made.

X. Angio-sarcoma.-As it has long been customary to group the sarcomas according to the type of cells preponderating in their structure, the fact that those cells frequently bear a definite relation to the vessels of the tumor has often been overlooked, except when strikingly distinct. This probably explains why the species "angio-sarcoma" fails to appear in the excellent synoptical and statistical papers of Beckton, Finsterer, Gebele, Gross, Horner, Poulsen, Schroeder and others.

From our researches in the literature we have been able to assemble 30 cases of sarcomas falling in this group, and variously called angio-sarcoma, hemangio-sarcoma, lymphangio-sarcoma, perithelioma, endothelioma, plexiform sarcoma and cylindroma. Some appear as mere mention of the occurrence of cases into statistical complications, some as case reports or collected cases in monographs. They present as great diversity of microscopic structure and origin as the various names suggest, and comprise three or four distinct sub-species of tumor of interest to the general pathologist.

In reading the case histories one finds that the peculiar histological structure of these tumors in no way modifies their clinical occurrence or their naked -eye appearance. The recognition of the true nature has apparently always followed microscopic examination.

In the case reported by Licini (Riforma Medica, Napoli, I9II, XXVII, I3Ig) the patient,

a woman aged 73 years, first observed a small nodule, the size of a nut, beneath the nipple of the left breast. It was freely movable and painless. In the course of three years it was the size of a pigeon's egg, in four years the size of a duck's egg. The rounded form, movability and freedom from adbesion to the skin continued. It was removed and upon microscopic examination proved to be "hemangio-sarcoma."

Schmidt (Archiv für klin. Chirurgie, I887, XXXVI, 42I) has given us the largest collection of cases of angio-sarcoma-eight from Prof. Czerny's clinic at Heidelberg, two from Prof. Lassen's clinic and one from Dr. Antoni, making eleven cases in all. The patients varied from 26 to 75 years of age. Seven were married, six had had children. Seven occurred in the right and four in the left breast. The size varied from a hen's egg up to a child's head. The tumor always formed a single node-multiple nodes were 
never found. The consistence of the tumors was usually soft, elastic and sometimes semi-fluctuating. They were all freely movable in the breast, and sharply differentiated from it. In every case they were widely adherent to the skin that was usually reddened, and once perforated. There never was invasion of the axillary nodes, and in only four cases could the lymph nodes be palpated.

Rapid recurrence in the scar usually followed operation.

His description of the microscopy of these tumors stated that they showed a reticulated or alveolar arrangement of the cells which were in close relation to a network of fine capillaries. New capillaries are found, the intermediate tissues are compressed, then drawn into the sarcomatous degeneration. Thus is formed a tumor whose fine capillrry framework encloses a conglomerate of proliferated perithelium. With subsequent destruction of the capillaries necrosis of the cells occurs. The destruction may be hyaline, beginning in the capillary remnants and extending to the approximated cells and resulting in the formation of Meckel's tubes-cylindroma-or mucoid change beginning in the cell masses themselves and extending outward.

From this description it is clear that perithelioma and cylindroma comprised the greater number of the tumors studied by Schmidt.

We have found three occurrences of endotheliomas of the breast with sufficient information to be useful. These were all in women between $2 \mathrm{I}$ and $3 \mathrm{I}$ years of age, and are reported by DaCosta, Simpson and Robinson. We were unable to secure access to the journal containing the case of Bossi (N. Ercolani, Pisa, I905, X, 427 et seq.).

DaCosta (American Medicine, I903, V, ro24) observed

a woman aged $3 \mathrm{I}$ years who three months before coming under operation observed a nodule the size of a pea in the upper outer quadrant of the left breast. It caused a dull aching pain. In the three months following the discovery of the tumor it increased to the size of an English walnut, and became irregular, hard, movable, covered by healthy skin, and unaccompanied by enlarged axillary glands. Fearing carcinoma, a radical Halsted operation was performed. Prof. Coplin examined the tumor microscopically and found a curiously fibrillated connective-tissue stroma with nests of endothelial cells of various shapes and sizes, but most of them round or oblong. Within these nests were many sinuses without distinct walls but marked hy closely packed cells of the type already mentioned. Many of the sinuses were empty; some contained blood. Near the center of many of the large cellular collections was found a detritus composed of red blood corpuscles and fragmented endothelial cells. Within the stroma were quantities of blood-vessels filled with mattered blood as well as many collections of pure blood. The tumor was not encapsulated.

Simpson (Jour. Michigan Med. Society, Detroit, I907, VI, 285) observed

a woman, II-para, aged 30 years who $\mathrm{r}_{3}$ months before had ohserved a small lump in the right breast. It increased slowly in size and gave no pain. Its physical qualities caused it to be regarded as a cyst, but when punctured it yielded only bloody serum. At operation no cyst was found, but a cavity separated from the normal tissue by a wall of necrotic and broken-down tissue was found. There was no distinct tumor mass. The diseased tissue was all carefully removed. In two months there was recurrence, the new growth also quickly breaking down. A second operation was performed and a mass as large as a man's fist was removed. The microscopic examination showed proliferating cells much resembling endothelial cells arranged in alveolar form. The microscopic diagnosis was endothelioma. Later the entire breast, the pectoral fascia and muscles and the contents of the axilla were removed. An enlarged lymph node was found.

Robinson (Proc. of the Surgical Section of the Royal Society of Medicine, London, I9I3-14, VII, I08) observed

a woman aged 25 years who had discovered a painless tumor in her right breast four months before. When examined, two hard nodular swellings were found in the right breast just above the nipple, one in 
the outer, one in the inner quadrant. They were firm, nodular and movable. The skin was not attached. Three hard nodules were found in the axilla. Radical amputation was performed. The tumor upon examination by Dr. Lazarus-Barlow was said to be peri-endothelioma.

$\mathrm{He}$ also observed a woman $3^{8}$ years of age, a nullipara, who four months before had accidentally discovered a lump in the right breast. It was nodular, the size of a hen's egg, well defined, movable, and unattached to the skin. Upon operative removal, the tumor was found to consist of reddish tissue and was diagnosed perithelioma.

Endothelioma also occurs in the male breast, cases having been reported by Romer and Rothmann ("Ein Fall von Cystischeendotheliom der männlichen Brustdrüse," Inaug. Diss., Würzburg, I89r).

XI. Chondro-sarcoma and Osteo-sarcoma of the Breast.-The first description of a tumor of the breast containing bone and cartilage seems to have been given by Theoph. Bonet ("Sepulchretum anatomicum, seu anatome practice ex cadaveribus morbus denatis," etc., Lugdinni, r 700, II, 522) in the following words:

"Die Brustdrüsen einer Nonne, welche an beständigen Respirationsbeschwerden gelitten hatte, erschienen stein hart; die Haut über dieselben war ausserordentlich gespannt. Die von Körper abgelöste Mamma stellte eine halbkugelige durchaus verknocherte und so feste Masse dar, dass sie mit einem scharfen Messer nicht durchgeschmitten werden konnte (Globum hemisphaeralum sed totum osseum et tam durum, ut cultro meo quantumvis acuto discindi nequivirit). Mit der umgebenden Cutis war dieselbe untrennbar verwachsen. Daneben fand sich ein beiderseiter hochgradiger Hydrothorax."

In spite of the clearness of this description, and of the reports of other cases by Morgani, in 1779 , and Sir Astley Cooper, in 1836 , some doubt as to the verity of the statement that bone and cartilage could occur in tumors of the breast lingered in the minds of many.

In our researches into the literature of the subject, it has been possible to assemble 28 cases in which bone, cartilage, or both have occurred as complications in the structure of mammary sarcomas. In addition to the writers mentioned above, the following may be given as the authorities from whose contributions the cases were collected, the references being given in the "literature" at the end of this chapter: Arnold, Battle, Beckton, Bowlby, Clarke, Cook-Bruce, Durham, Gross, Guilbaud, von Hacker, Heurtaux, Holder, Horner, Heuter and Karrenstein, von Leser, Morton, Sehrt, Schroeder, Stilling, Sutton and Watson. It does not seem justifiable to endeavor to make a special species of either chondro-sarcoma or osteo-sarcoma. Reasons for this have already been given under our general consideration of the subject of sarcoma, and Marchand's law, which seems to offer the best explanation of the occurrence of the bone and cartilage has been quoted. The wiser plan seems to be to accept the presence of calcification, of chondrification and of ossification as complications of structure, common to those forms of sarcoma whose cells show some power of differentiation and specialization. Nearly all of these tumors are fundamentally spindle-cell sarcomas or fibro-sarcomas. Those that contain bone usually contain many giant cells. Their mode of origin and their clinical course stamp many of them as sarcomas resulting from changes in fibro-adenomas. Nearly all of the cases occur in persons past middle life, a notable exception being the case of Holder (Memphis Medical Monthly, I886, XVI, 66) which occurred in

a colored girl aged $r 2$ years. Nine months before coming under observation the left breast began to enlarge and at the time of observation had a circumference of $r_{4}$ inches, caused by the presence oi a lobular tumor over which the skin was freely movable. There were no enlarged axillary lymphatic nodes. The examination of the tumor after operative removal showed it to be an "intra-canalicular sarcoma," containing patches of coarse spindle cells and some cartilaginous tissue that in places surrounded the tubules. The diagnosis was "fibro-myxo-sarcoma." 
Presumably ossification is preceded by chondrification or calcification or by both. The process may end with chondrification in the absence of sufficient lime salts to ossify the cartilage. Apparently bone may. at times be formed without antecedent cartilage.

Clarke (British Medical Journal, I89o, I., II92) (Trans. of the Path. Soc. of London, I89o, XLI, 229) observed

a woman aged 46 years with a tumor of three years' duration involving the whole of one breast and the size of a small cocoanut, dense and hard, without involvement of the axillary nodes. At the time of operation a saw had to be employed to detach it from the subjacent tissues. The cut surface was hard and gritty like bone. The tumor was found to consist almost entirely of fibrous tissue which was partly calcified.

Velpeau (Traité des Maladies du Sein, I858, p. 434) describes two cases of "chondroid" tumors of the breast.

The first occurred in a woman of 50 years who at the age of 34 years had had a small tumor in the left breast. It was uneven on the surface and hard in substance and was removed by A. Dubois. Eight years later a similar tumor appeared in the right breast. It was painless, hard, nodular and adherent to the skin. She died with metastatic cartilaginous tumors in various organs. An account of the case is published in the Rev. méd., I825, II, I77.

The second case also occurred in a woman aged 50 years. The tumor had a known duration of sir months during which it had grown to the size of an infant's head. It was removed but soon returned. The patient died, and at autopsy it was found that she had more than 200 partly cartilaginous tumors in the body.

Watson (Catalogue of the Museum of the Royal College of Surgeons, Igog) reports the case of

a woman 60 years of age, who observed a tumor in the breast two months before. It was extremely hard, and measured $6.5 \mathrm{~cm}$. in diameter. It was removed, but it was necessary to operate for recurrence within three months. This proved to be a sarcoma undergoing chondrification. "The tracts of cartilage contained trabeculæ of calcified substance."

Beckton (Archives of the Middlesex Hospital, London, I9I2, XXVII, 2 I5) operated upon

a married woman 52 years of age and removed a hard lobulated tumor that involved practically the entire left breast, without invading the axillary lymphatic nodes. It was of five months' duration. When examined histologically it proved to be composed of dense fibrillar tissue for the most part, and of cells without alveolar arrangement, containing numerous spicules of bone.

Durham (Trans. Path. Soc., London, I883, XXXV, 378) removed

an encapsulated, lobulated, partly hard, partly soft, partly friable tumor from the breast of a woman aged 27 years. The largest mass contained a bony plate which the microscope showed to consist of close trabeculæ of osseous tissue. The tumor was a sarcoma and contained many scattered masses of cartilage. At the periphery it showed adenoid tissue with intra-cystic growths.

von Hacker (Archiv für klin. Chirurgie, ı88ı, XXVII, 6r 4 ) operated upon a

woman of 50 years and removed a tumor of the left breast. For 20 years the tumor had been scarcely larger than a pea, but during the last year a yellowish fluid discharged from the nipple and the tumor, which became painful, enlarged so as to involve two-thirds of the entire gland. It was everywhere surrounded by adipose tissue, was well encapsulated, and on section proved to be fibro-cartilaginous with occasional cysts. Upon microscopic examination the fibrous parts were found to be adenomatous 
or fibro-cartilaginous. The little cysts showed transformation into carcinoma. The cartilage was, for the most part in little islets, mostly hyaline, some osteoid.

Sehrt (Beiträge zur klin. Chirurgie, I907, LV, 574) described a tumor of six months duration that was removed from the right breast of a woman 44 years old, mother of I I children. When studied histologically, it proved to be an osteo-chondro-sarcoma.

Stilling (Deutsche Zeitschrift für Chirurgie, $188 \mathrm{I}, \mathrm{XV}, 247$ ) reports three cases of osteoid-sarcoma of the breast.

I. A woman aged ${ }_{5} 6$ years, married, I-para. The tumor was rounded, nodular, confined to one-half of the breast, and $6.5 \mathrm{~cm}$. in diameter. When removed it was found to consist of what gave the impression of being porous, crumbly, bony tissue. When examined histologically it was found to be composed of firm connective tissue rich in spindle cells, with numerous giant cells, many vessels, and radiating fine bony trabeculæ.

II. A woman of 53 years, married, VIII-para. Eighteen months ago a disturbance in the breast began with hardening of the nipple that gradually spread to other parts of the breast. It caused her much trouble because of the ulceration of the nipple. The tumor grew to the size of a child's head and became adherent to the skin, though freely movable upon the deeper tissues. The ulcer grew large and became fetid, and from it a fungous mass grew out. The axillary nodes were not enlarged. The breast was amputated but the patient shortly died with pyotborax and at the autopsy was found to have metastatic tumors in both lungs.

The histological examination of the tumor showed it to be largely composed of spindle and giant cells with osseous masses and trabeculæ.

III. A woman 59 years of age, married, IX-para, had a tumor of ro years' duration in the breast. It was large, nodular, hard in parts, fluctuating in parts, and in general rather soft. It was freely movable and covered by thinned skin. The lymphatic nodes in the axilla were not enlarged. The breast was amputated, but an operation for recurrence was necessary in one month and Io days, after which she died. The autopsy showed metastasis to the right ventricle of the heart. The microscopy of the breast tumors and of the cardiac metastasis fully correspond; all were composed of rounded spindle cells, giant cells and masses and trabeculæ of bone.

\section{Sutton (Archives of the Middlesex Hospital, I9Io, XIX, 98) reports}

the case of a married woman aged 73 years who had had a hard lump in the breast for nine months It felt hard and was mistaken for cancer, so a radical operation was performed. When the examination of the tumor was undertaken a saw was necessary to cut it in half. It proved to be an ossifying sarcoma. The peripheral parts of the tumor were most cellular, the central part most ossified. The cells were for the most part spindle shaped or angular. Few blood-vessels were observed.

\section{Adeno-sarcoma ; Adeno-cysto-sarcoma ; Cyst-adeno-sarcoma ; Cysto-sarcoma ;} Cysto-sarcoma Phyllodes.-This section is prepared with some doubt as to whether its. logical position should be as a supplement to the section upon fibro-adenoma, or a prelude to the section upon sarcoma, and it was only after some hesitation that it is given its present position.

Sarcoma may arise in the matrix of any tumor, and hence in the fibro-adenoma, at any time. We have specimens of small tumors $-2 \mathrm{~cm}$. in diameter-in which the inter-glandular tissue is completely and uniformly sarcomatous and of the spindle-cell variety, and we have records of many small tumors in which sudden augmentation in size took place after years of inactive existence. On the other hand, the benign growths may slowly increase during months and years and then manifest the change. In endeavoring to determine possible malignant development in benign tumors one must ordinarily be guided by the change in the rapidity of growth, but in so doing, should rule out cases in which the fibro-adenoma participates in pregnancy hypertrophy and 
lactation enlargement of the breast, which seems to be accompanied, in almost all cases, by associated proportionate or disproportionate enlargement of the tumor.

Though the difficulty of diagnosis is great it ought not have much practical bearing in the treatment of the case, for the advice that we believe ought to be followed is the immediate removal of every tumor, whether benign or malignant, so soon as it is discovered.

The literature of adeno-sarcoma, cysto-sarcoma and cyst-adeno-sarcoma is very large, many cases having been reported. Unfortunately, many are probably errors of diagnosis based upon faulty nomenclature. Thus, all cases of cysto-sarcoma phyllodes ought immediately to be ruled out because this tumor is in no way related to sarcoma. There are only three criteria for the recognition of the sarcomatous nature of these tumors; first, in cases not operated upon they most commonly cause death through the occurrence of metastatic tumors in the internal organs, with rare invasion of the lymphatic nodes; second, when operated upon they may return again and again at the original focus, without invading the axillary nodes; third, they prove to have a sarcoma structure when examined microscopically.

Any variety of sarcoma may make its appearance in the benign tumors of the mammary gland. If small and fairly solid, the sarcoma is usually described as round-cell, spindle-cell, etc., according to the prevailing type of cell, or as giant-cell, if giant cells are present, and though the presence of glandular elements is sometimes noted, their significance is neglected in naming the tumor. If the tumor be large and if cysts have formed in it, all else is apt to be lost sight of and the sarcoma is called cysto-sarcoma, cystic sarcoma, cyst-adeno-sarcoma, adeno-cystic-sarcoma. Or, if cartilage or bone be found, the tumor is called chondro-sarcoma or osteo-sarcoma; chondrifying sarcoma or ossifying sarcoma, or osteo-chondro sarcoma, regardless of everything else. It must occur to the reader that this is a very defective system of nomenclature and of no taxonomic value.

The sarcomatous change begins when the tumor is small; it seems to outgrow the slowly increasing benign formation in which it originated to such an extent that the epithelial glandular elements are crowded out of existence. As the result there may come under observation pure sarcomas of round- or spindle-cell types, whose mode of origin is no longer discoverable, and which may be mistaken for non-indigenous sarcoma. When the change begins in adenomatous tumors already well-grown, and containing cystic dilatation of the ducts, it may effect the tumor tissue locally causing an included uncircumscribed node, or extend in this direction and that throughout the tumor tissue diffusely.

The cystic formations in these tumors may be entirely independent of the presence of sarcoma as in cystic adenomas, or the cysts may depend upon the sarcoma.

There seem to be two ways in which sarcoma leads to the formation of cysts: First, by changing local conditions by compression, obstruction, alteration of circulation, etc., facilitating the collection, retention and local accumulation of fluid in the preëxisting epithelial-lined spaces of the tumor; second, by effecting colliquative changes in the substance of the tissue. Cysts formed as first suggested commonly retain their epithelial linings, have smooth walls and contain fluid that may be watery, serous, slightly turbid, milky or bloody; cysts formed by colliquation usually occur as indefinitely defined cavities, without linings and contain viscid, mucilaginous, turbid or grumous material resulting from the tissue destruction. Both forms of cyst may occur in the same tumor.

A very large tumor, primarily a cystic fibro-adenoma, whose connective tissue 
undergoes partial sarcomatous change may become exceedingly complicated in structure. There is the glandular structure that constitutes the formation of the whole process, parts of which are unaltered, parts of which show cystic distention in various degrees. Between the cysts of all sizes the stroma and peri-ductal tissue may have the normal appearance, or areas may be exclusively cellular, the cells sometimes round, sometimes spindle shaped. Densely fibrous areas may be found, or one may discover a fibro-cellular structure containing large numbers of giant cells. In the dense parts of the tissue calcification may occur in the form of a morphous deposition of lime salts; nearby are bony spicules and trabeculæ, or lamina, or masses of bone with well-developed Haversian systems. Cartilaginous deposits, either hyaline or fibrous, some calcifying, some ossifying, may occur in considerable masses or in scattered foci. Billroth (Cyclopedia of Obstetrics and Surgery, Guserow and Grandin, I887, IX, 56) reports that striated muscle cells were found in a cysto-sarcoma of the breast, though as this tumor was removed from a girl of 16 years, it may have been an entirely different kind of tumor (teratoma). Some of the cysts, probably the majority, have smooth walls, others show papillary projections. Other cysts are ill-defined and filled with degeneration products. Now and again a cyst is filled with a yellowish plastic fatty material. Rarely, and most interesting are occasional large or numerous small cysts containing laminated concentric "epithelial pearls" varying in size from visibility to a couple of centimeters in diameter.

Not one of these changes can be looked upon as being of taxonomic importance, not one or any combination of them gives the tumor a specific character. They are all incidents and accidents of growth.

These tumors behave precisely as all circumscribed nodular tumors do, that is they enlarge slowly or rapidly, according to the activity of their tissues or the distention of their substance by the cysts, sooner or later distend the skin at some part of the surface of the breast, effect attachment to the degenerating and reacting integument, cause superficial ulceration and then pave the way for hemorrhage or infection from which the patient may ultimately die if metastasis to the internal organs or some intercurrent affection does not intervene.

There can be no doubt but that cyst formation causing rapid enlargement in size, and calcification, chondrification and ossification of the stroma causing great density, may occur in fibro-adenomas of benign character, and entirely free of sarcomatous change. Indeed, we strongly suspect this to be the truth with respect to many of the tumors to which the name sarcoma has been applied, but which haveattained to a great size without metastatic distribution. Calling a tumor sarcoma does not make it one, and in the presence of behavior strikingly unlike that of sarcoma, one should hesitate to accept a name not well supported by pathological and histological evidence.

As an example of this Graefe's remarkable case may be cited (Jour. der Chirurgie und Augenheilkunde, Berlin, I838, XXVII, 576).

The patient was a woman aged 38 years, the mother of five children. In 1826 , when she weaned one of her babies, she discovered a nodule the size of a hazelnut in the right breast. In I $83_{3} 6$ a nodule appeared in the left breast, took on a rapid growth and ulcerated. After long delays caused by the fear of operation in the days when anæsthetics were not used, the breast was finally removed. It weighed 22 pounds and 8 ounces. The tumor was called "cysto-sarcoma." Five months afterward the patient was living and well.

Is one justified in supposing that a tumor that grows to a weight of 22 pounds without metastatic distribution and does not reappear locally in five months is sarcoma?

But worse than that is the extraordinary case pictured by Velpeau (Traite des Mala- 
dies du Sein," I 858 , p. 260) to which he, indeed, applied the term "tumeur adenoïde," but which is quoted by Billroth (Deutsche Chirurgie, Lieferung XII, p. 67) as a cystosarcoma.

This tumor in the right breast of a woman aged 54 years grew in four years, to an enormous size, and when removed at autopsy weighed $20 \mathrm{~kg}$. (about $4 \circ$ pounds). It seemed to bave about the same general structure and appearance as Graefe's tumor and like it grew to this enormous size without metastasis. No attempt to remove it surgically was made because of the feebleness of the patient.

The answer to our question as to whether tumors of such size without metastasis can be sarcomas seems to be yes, for we find a recent case that seems to prove it, and thus makes us quite uncertain as to the others. Thus, Tremearne (Austral. Med. Jour., Melbourne, I 883, n.s., V, 302) observed

a stout plethoric body in whose left breast there was a tumor that weighed 12 pounds, that be had to remove piecemeal, that had the naked-eye appearance of soft sarcoma, and which when examined microscopically by Dr. Allen was found to be "a sarcoma, chiefly composed of medium-sized spindle cells."

The size attained has, therefore, little to do with the actual nature of the tumor. Metastasis may take place sooner or later according to peculiarities of minute structure, as above described.

Tumors of such magnitude have always been very rare but the tumors of the group under discussion have commonly attained to the size of an adult's head, an infant's head or a cocoanut. Fortunately the progress of modern surgery that is changing the many conditions in pathology is making such tumors still more rare by bringing the patients early under observation and removing them while still small.

The literature upon this subject is so large and the case histories are so similar that it seems scarcely worth while to burden the reader with such citations as have been introduced to make the sections upon the rarer tumors complete.

The subject must not be dismissed, however, without a brief mention of another and somewhat popular theory of the etiology of these tumors. Many writers, notably, Lecène (Rev. de Chirurgie, Paris, I906, XXXIII, 434) are of the opinion that the mixture and confusion of tissues that enter into the formation of these tumors is evidence of origin from embryonal inclusions. The possibility of this is difficult to deny, but it is not a theory with which we can express much sympathy. Billroth's observations of striated muscle cells in a cysto-sarcoma might be difficult to explain on other grounds, but in mentioning that case, care was taken to point out that it differed from other cases in growing rapidly in the breast of a very young woman ( 16 years). To most of the writers adhering to Cohnheim's theory the presence of the epithelial pearls in the cysts seems to be a strong argument. It is, therefore, necessary for us to devote some space to the consideration of these bodies, which can best be done by collecting the cases in which they have been found and discussing them under the heading "cholesteatoma."

XII. Cholesteatoma.-A cholesteatoma is a tumor which is largely composed of, or contains numerous rounded, laminated, concentric masses of flattened cells, at the center of which crystals of cholesterin may be present. There is much latitude in the employment of the term. A tumor of the middle ear may be composed of a single such mass; small tumors of the central nervous system may contain innumerable minute masses.

For the present purpose all mammary tumors in which a laminated concentric cellular mass is found, or in which many such can be found, will be called cholesteatoma 
regardless of their general structure, because it seems most easy to arrive at an intelligent understanding of the origin, the occurrence, and the significance of the formations by bringing them all together and examining their similarities and dissimilarities.

The reader having particular interest in the problem will find the following authors to have deait with it at considerable length: Bauchet et Gaillet, Billroth, Bruch, Cooper, Dor, Gorham, Grohe, Haeckel, Klob, Kürstein, Lecène, Model, Müller, Neumann, Porter, Prym, Schmidt and Virchow (q.v., literature at the end of the chapter). Cruveilhier (Anatomie pathological, II, p. 6) described a "tumeur perlée" from the brain of a girl 18 years of age, and thus probably made the first observation upon cholesteatoma. Craigie (Elements of General Pathology and Pathological Anatomy, 2d edition, p. 345) called such tumors "margaroid."

Johanns Müller (Ửber den finern Bau der krankhaften Geschwülste, r838, p. 53) who was the first to describe cysto-sarcoma phyllodes, was also the first to point out that the cysts might contain onion-like concentric epithelial pearly formations, and was the first to use the name cholesteatoma.

Virchow (Virchow's Archiv, I853, VIII, 37 r) states that he repeatedly saw pearllike masses in the cysts of cysto-sarcoma of the mamma.

In the "Illustrations of Diseases of the Breast" by Sir Astley Cooper, an onion-like, stratified, concentric mass is shown in a cystic tumor of the breast. Haeckel (Archiv f. klin. Chirurgie, 1894 , XLVII, 274) has published a beautiful steel engraving of a similar formation in one of the cysts of a so-called cysto-sarcoma of the breast. Other cases with similar formations under similar circumstances are published. Thus, Gorham (Strassburger med. Zeitung, I9I I, VIII, I2I) observed

a woman $6_{3}$ years of age, who had for several months a small tumor in the breast that rapidly increased in size. Radical operation was performed. The breast contained a small circumscribed tumor of grayish-red color and glandular aspect. Microscopic examination showed it to be an intra-canalicular peri-ductal myxoma. The ducts were for the most part lined with unstratified epithelium except in certain parts where there was pleuri-stratified epithelium of cuboidal shape. 'A pea-sized whitisb area in the center of the tumor was of special interest because it contained islets of epithelium showing cornification. The stroma was, in parts, abnormally rich in rounded, elongated and stellate cells and was undoubtedly sarcomatous. He comes to the conclusion that as the stroma was sarcomatous and that as cysts with cornifying epithelium were present, the growth must be a "mixed tumor" of the breast.

Grohe (Deutsche Zeitschrift für Chirurgie, I900, March) removed a tumor of five years' duration from the right breast of a primipara aged 27 years.

It was as large as a man's fist, rounded, soft, and had fluctuating nodular eminences upon its surface. It was not adherent either to the skin or to the subjacent tissues. There were no enlarged axillary lymph nodes. Upon section this tumor presented a variegated appearance and contained large and small cysts in many of which were sessile or pedunculated excrescences that nearly filled them. A number of the cysts were without the excrescences, but contained white, glistening hairy masses usually showing a concentric arrangement.

These formations vary in size from the tiniest dots to hazelnuts, and the larger ones have caused the disappearance of the connective tissue through atrophy, and have begun to coalesce. The larger ones sometimes show that they have originated from varions centers. Some of them lie between the intracystic papillary growths. Microscopic examination showed that the papillary excrescences were covered with a single layer of cylindrical epithelium which in certain areas passed into squamous epithelium.

Grohe was fortunate to observe a second tumor of similar structure that occurred in Prof. Bungner's clinic.

Kürsteiner (Virchow's Archiv, 1894, CXXXVI, 302) observed

a woman 46 years of age, whose right breast had contained a tumor for six years. It was supposed to be referable to a blow received when she was is years of age. The tumor had grown slowly to the 
size of a child's head, was painless, movable and without enlargement of the lymphatic lymp nodes, and occupied the lower outer quadrant of the breast. When removed it was rounded, slightly flattened, and lobulated. On section it was generally like "adenoma phyllodes" or "papilloma intra-canaliculare." In many of the cysts concentric epithelial masses were found.

Lecène (Bull. et. mém. de la soc. d'anat. de Paris, I904, XXXIV, 698) studied

a hen's egg sized tumor removed from the right breast of a woman aged $5+$ years. It was of two months' known duration and had rapidly increased in size during the last eight days. It had the general appearance of such tumors as have been described, but upon microscopic examination proved to be a giant-cell sarcoma. Scattered through it were islands of squamous epithelium of the Malpighian type with cornification. He thought it to be a "mixed tumor."

Prym (Frankfurter Zeitschr. f. Path., Wiesbaden, I9I2, X, 60) examined at autopsy the body of

a woman 50 years of age whose right breast had sometime before been removed because of tumor growths. A movable cherry-sized recurrence was present in the scar. The left lung was partly adherent to the chest wall, and the entire costal and pulmonary pleura were covered with numerous walnut-sized gelatinous soft tumor nodes so loosely attached as to be easily torn loose, when they floated as glass-clear formations in the pleural fluid. Similor nodes but harder and more opaque and more flattened in shape, sometimes as large as a silver dollar, occurred upon the left pleura and diaphragm. These striking features of recurrence led to a renewed examination of the original tumor which had been looked upon as a benign intra-canalicular cysto-fibroma. It was found to consist of solid and softer portions, the latter of which were myxo-sarcoma. There were also cysts in which were numerous cholesteatomatous nodules. These he supposed indicated that the growth was a "mixed tumor" which view he thought supported by the discovery of some adipose tissue in the central portion of the tumor-a rare circumstance.

Schmidt (Archiv f. Gynäkologie, Berlin, I884, XXIII, 93) observed a tumor of about I 8 months' duration in an unmarried woman 72 years of age. It was diagnosed as cystosarcoma but upon histological examination showed a stroma of spindle and giant cells, and cysts, some of which contained concentric masses of cornified squamous epithelium.

Beneke (Festschrift für Orth, I903) saw a melon-sized cystic tumor of the breast in which there were numerous cholesteatomatous-i.e., pearly-formations: Dor and Poncet (Rev. de Chirurgie, I902, Nov. I) examined a soft cystic tumor the size of a mandarin orange, removed from a woman 48 years of age. The cysts were of particular interest because of their peculiar contents, which were composed of homogeneous material with crystals of fatty acids, some cholesterin platelets and some cholesteatomas or pearly masses of epithelium.

Konjetzny (Berlin. klin. Wochenschrift, I9I2, XLIX, I558) examined a tumor removed from the right breast of a woman 34 years of age. It was called cysto-sarcoma, and was indeed cystic containing villous excrescences between which were epithelial pearls of varying size.

Lahn (Monatsschrift für Geburtshülfe u. Gynäkologie, I9I4, XXXIV, 496) studied a cystic tumor removed from a nulliparous woman 34 years of age. It was the size of a hen's egg, soft, freely movable, and unattended by enlargement of the axillary nodes. After removal, the cysts were found to be filled with a kind of mush, the solid part of which consisted of concentric epithelial pearly formations arising from the epithelium of the cysts. No cholesterin could be found either by microscopic or chemic examinations.

Newmann (Archiv für Heilkunde, I868, IX, 480) found concentric squamous epithelial formations in the spaces of a fibro-myxo-adeno-sarcoma the size of a child's head, removed from the breast of a woman 25 years of age. Cholesterin crystals were found in the centers of the concentric formations. 
Wilms (Die Mischgeschwülste, I902, III hft.) is cited by Stoerk and Erdheim as having studied an adeno-sarcoma of the breast in which were yellowish masses and epithelial pearls.

Stoerk, O. and Erdheim (Wiener klin. Wochenschrift, I904, XVII, 358) report upon the pathology of three cases of cysto-sarcoma phyllodes studied by them, in each of which cholesteatomatous formations were to be found in some of the cysts.

A most interesting case is credited to Bauchet et Gaillet (Gaz. des Hôpitaux, r86r, No. 79) by Haeckel, by Stoerk and Erdheim and others, but the reference as given is not correct and we could not find the original report. It is, however, stated that they found a "large number of little cysts varying in size from a rice grain to a pea, each containing a solid white formation that reminded one of a crystalline lens hardened by crystallization, and concentric in structure." From the available citations it could not be determined whether these were in the breast or only in a tumor of the breast.

Bruch (Bull. et mém. de la soc. de chirurgie de Paris, I885, 887, ob. XVI) describes a circumscribed tumor removed from the right breast of a man aged 44 years. It was movable, painless, and covered with violet-colored skin. It was removed and when examined proved to be an unusual form of squamous-cell carcinoma with numerous microscopic epithelial pearls such as usually accompany that tumor. It is frequently mentioned as a case of cholesteatoma, but we agree with Stoerk and Erdheim that there is no ground for this in the original description. Similarly, the case reported by Hiebaum (Prager med. Wochenschrift, 1895, p. 304) is often included among the cholesteatomas of the breast, because squamous epithelial-lined cysts were present, and microscopic pearls were found, but here again there is no evidence that the case was true cholesteatoma.

Klob (Path. Anat. der weiblichen Sexorgane, I864) saw epithelial pearls in a mammary carcinoma. This also was not true cholesteatoma.

There are, then, about 20 recorded observations of the occurrence, in adenomas, fibro-adenomas, cysto-sarcomas and cysto-sarcoma phyllodes, of macroscopically, recognizable, concentrically laminated squamous epithelial, onion-like "pearls," whose presence has caused these tumors to be called cholesteatoma or has served to connect the tumors with cholesteatoma in the minds of those who observed them. In addition there are a number of other tumors, carcinomas for the most part, in which smallerusually microscopic-formations of similar kind have been described.

The matter is of considerable pathological interest from the point of origin. By a number of the reporters the presence of the squamous epithelium where on theoretical grounds no such cells ought to be, and for whose presence no ready explanation was forthcoming, has seemed sufficient to cause the tumors of this class to be grouped as "mixed tumors" or "embryoblastomas," and to accord support to the Cohnheim theory of tumor origin.

From our studies of the published case reports, and from the circumstances attending the tumors of the class in which the pearls occur, we find it difficult to arrive at the same conclusion. The regularity with which the formations make their appearances in tumors descending from the fibro-epithelial type; the prevalence of their occurrence in the adeno-cystic sarcomas; the facility with which the abnormal connective tissues of such tumors undergo metaplasia resulting in cartilaginous or osseous formations, impress us as indicating that metaplasia of the epithelium may be easily possible. That squamous epithelium may arise, through metaplasia, from columnar epithelium is well known to all pathologists who see it in cavities in the lungs, and in 
the rectum. It seems to us more rational to suppose that the squamous epithelium whose collected and compressed cells form the pearly bodies of cholesteatoma of the breast, arise through metaplasia of the epithelium of the cyst walls than to endeavor to account for their presence through Cohnheim's theory of dislocated and sequestered embryonal cells. In this view of the situation we find ourselves supported by Lahn, Stoerk and Erdheim, and Grohe, but opposed by Graham, Konjetzny, Lecène, Prym and Wilms.

XIII. Sarco-carcinoma, Carcinoma Sarcomatodes or Carcino-sarccma.-The literature contains references to at least 20 cases in which sarcoma and carcinoma occur in the same breast or in which both are mixed together in the same tumor. Such are reported by Barton, Benmosch(?), Coenen, Dorsch, Hedren, Hencke, Herxheimer, Kaufmann, Kerbirion and Danel, Kettle, Krompecher, Kennedy and Case, Morales(?) Orth, Perrier, Pfeiffer, Schlagenhaufer, Schwarz, Sécousse, Takano and Wehner, the references to each case being found under the authors' names in the literature upon sarcoma.

These tumors naturally arouse particular interest because of the taxonomic difficulties that they provoke. Shall they be regarded as sarcomas or carcinomas or as both?

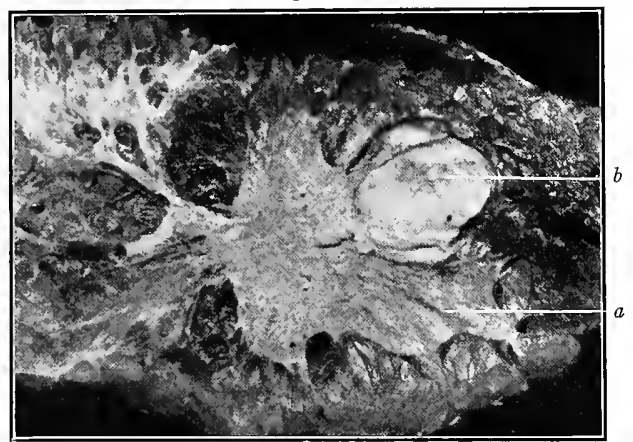

FIG. $154 .-$ Carcinoma and sarcoma in the same breast. $a$, the carcinoma; $b$, the sarcoma. (Kennedy and Case.)

Takano (Archiv für klin. Chirurgie, I9I3, CIII, I 55) differentiates between carcinoma sarcomatodes in which there is carcinomatous parenchyma and sarcomatous stroma, and carcino-sarcoma which is a combination of carcinoma and sarcoma in one tumor with such intimate relationships that one might as correctly say sarco-carcinoma or carcino-sarcoma. He thinks, however, that carcino-sarcoma is a general, broad and indefinite concept, while carcinoma sarcomatodes is a special, restricted, definite concept. Carcino-sarcoma is a very rare tumor anywhere, but makes its most frequent appearance in the mammary gland where it is more frequent than carcinoma sarcomatodes.

Borst uses the name carcino-sarcoma for tumors of several differing forms: (a) a carcinoma and sarcoma arise in different portions of the same organ and may grow in such manner as to terminate by mutally penetrating one another; $(b)$ when carcinomatous parenchyma and sarcomatous stroma occur in the same tumor, either through sarcomatous transformation of the stroma of a carcinoma or through carcinomatous transformation of the epithelium in a benign tumor, and $(c)$ when in certain tumorsendotheliomas, etc.-substantially sarcomas, nests of cells occur in such manner as to appear like carcinoma-false carcino-sarcoma. 
Tumors of double structure of the kind indicated are not infrequently called "mixed tumors," and are thought by some pathologists to arise through defective embryonal development.

The discovery of their duplex nature is usually made by microscopic examination of the tumors; sometimes both tumors are clearly visible as separate entities.

In most cases the tumor was clinically diagnosticated carcinoma; in a few cases it was diagnosticated sarcoma. There can be no doubt but that the tumors arise in different ways. Thus in the case described by Coenen (Beiträge zur klinischen Chirurgie, r910, LXVIII, 6c5).

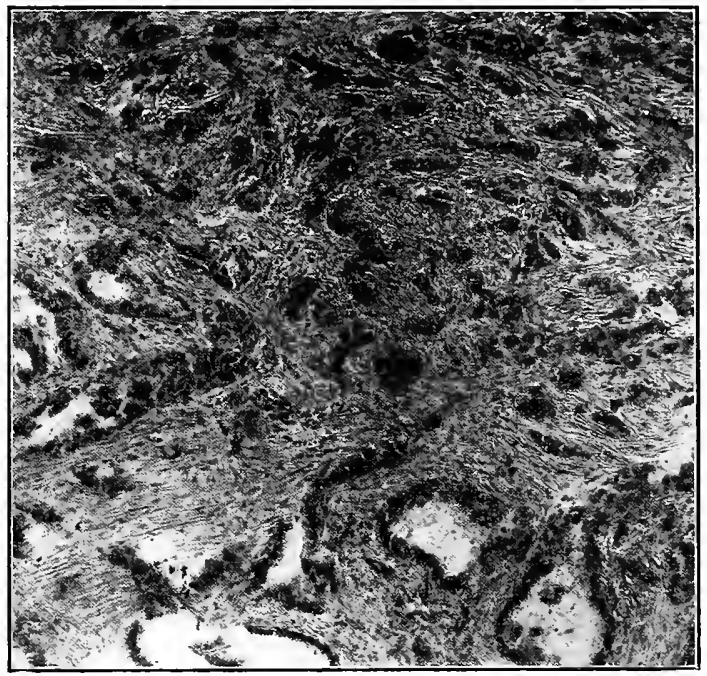

Fig. I55.-The carcinomatous part of the breast reported by Kennedy and Case.

The tumor which occurred in the right breast of a woman 43 years of age, was known to have existed for $\mathrm{I}_{4}$ years. It finally attained to the size of two fists. When examined microscopically, the greater part of it was found to be largely composed of spindle cells without inter-cellular substance; some portions contained many giant cells, others were myxomatous. Scattered through it were nests of carcinoma cells. The axillary lymphatic nodes were enlarged, and when examined showed metastasis of carcinoma only. Five months subsequently other metastatic formations showed sarcoma only.

A tumor of 14 years' duration, with spindle- and giant-cell structure ought to fall among the sarcomas arising from benign fibro-epithelial structure. According to the views that we entertain, both the sarcomatous change of the stroma and the carcinomatous change in the epithelium ought to be secondary and complicating transformations. It is evident that such a tumor has doubly malignant possibilities. There may be invasion and lymphatic metastasis on the part of the carcinoma or there may be blood metastasis to internal organs from the sarcoma. The order in which they occur or the occurrence of the one and the failure of occurrence of the other may be referred to local conditions in the tumor.

Kerbirion and Danel (Jour. de soc. méd. de Lille, I897, I, I75) observed 
a woman 55 years of age, who a year before had found a date-stone-sized tumor in the right hreast. It was painless and movable, and remained unchanged for some months after which it grew rapidly and became painful and tender. Finally it became as large as two fists and ulcerated. The axillary nodes were slightly enlarged. When removed it was found to he as large as two fists, movable, well rounded, encapsulated. It proved to be a combination of sarcoma and carcinoma.

The authors think the sarcoma was primary. The history and physical qualities of this tumor seem to make it fall among the cases of sarcoma arising from fibro-adenoma, and we agree that the sarcoma may have been the primary change, and the carcinomatous change of the epithelium secondary.

Sécousse (Jour. de méd. de Bordeaux, I9I2, XLII, 79I) reports

a tumor the size of a child's head, removed from the left breast of a woman aged 67 years, that had all the general clinical, pathological and microscopical appearances of cysto-sarcoma except that it contained carcinoma areas.

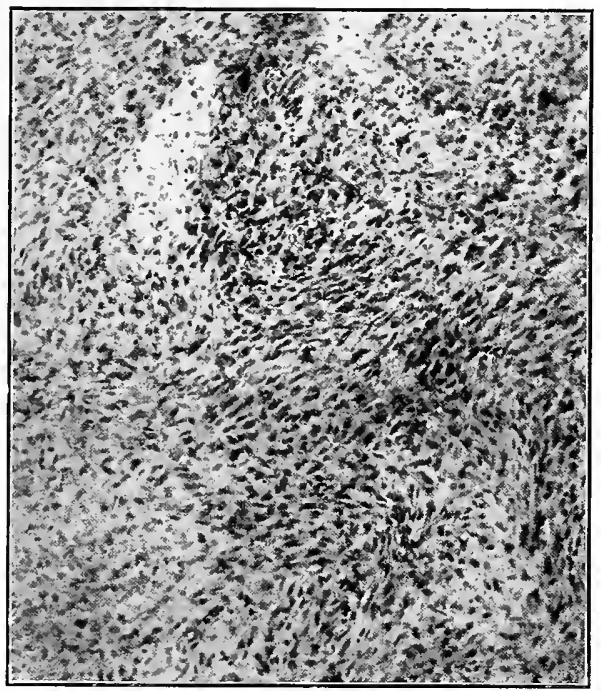

FIG. I 56.- Spindle-cell sarcoma, from the case reported by Kennedy and Case.

The most confused structure was found by Wehner (Frankfurter Zeitschrift für Path., Weisbaden, I9I4, XVI, I67).

It was a tumor the size of a child's head removed from the hreast of a woman aged $4 \mathrm{r}$ years. Parts of it were composed of pure spindle cells, parts were myxomatous, parts contained squamous epithelium with cornification of cells-all of which might present themselves in transformed fibro-epithelial tumorshut parts were like malignant adenoma and other parts more like scirrhus carcinoma.

A small tumor with a definite encapsulation was studied by Pfeiffer (Proc. Path. Soc. of Philadelphia, I910, n.s., XIII, 267).

It was taken from the breast of a woman aged $7 \mathrm{r}$ years, and formed a movahle rounded node $5 \mathrm{~cm}$. in diameter. The cut surface was fairly uniform, hut finely striated like fibro-sarcoma. Histological examination showed it to consist of a spindle-cell stroma with carcinoma nests. The metastasis from this tumor were carcinoma only. 
Schwarz (Amer. Jour. of Obstetrics, I9r3, LXVIII, 752) reports a tumor of similar structure, except that the stroma consisted of spindle and giant cells. Metastasis to the lymph nodes showed carcinoma structure only, while metastasis to the right shoulder and abdominal wall showed spindle-cell sarcoma only.

Dorsch's case (Inaug. Diss., Würzburg, r896) was similar in that the carcinoma and sarcoma elements were intimately mixed.

The tumor occurred in the left breast of a woman aged 43 years, was the size of a fist, was without circumscription, and perhaps was of entirely different origin. The reporter believed that the carcinoma was the original tumor and the sarcoma a secondary complication arising through vegetative activity of the stroma. Takano classed this tumor as a carcinoma sarcomatodes.

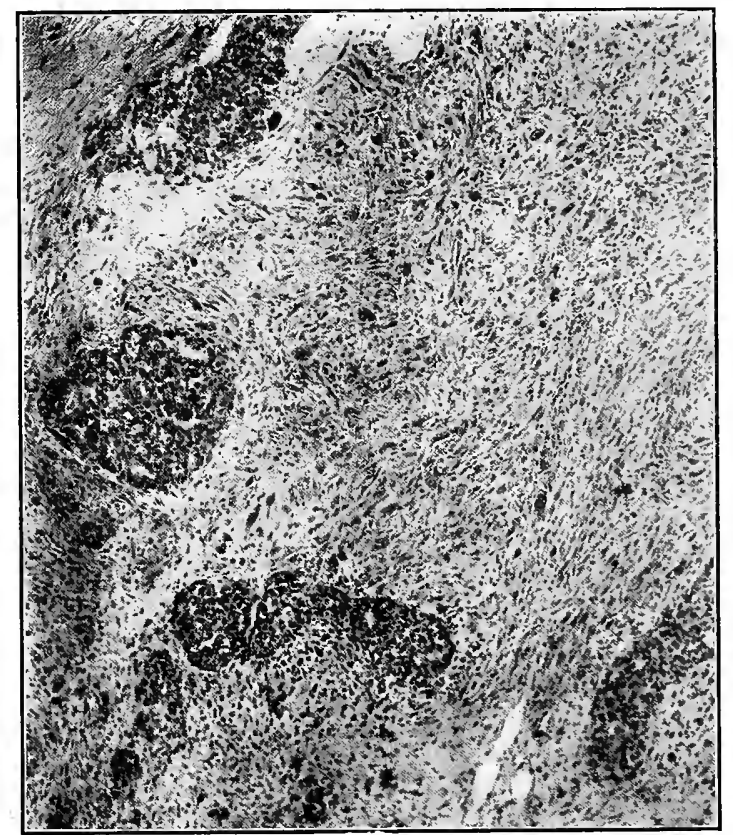

Fig. I 57.-Carcinoma of the breast with sarcoma of the stroma. (McFarland.)

Hedrén (Centralbl. f. allg. Path. u. path. Anat., I9r5, XXVI, 266) described a tumor that may have had a third mode of development.

It was a cherry-sized movable tumor in the right breast of a woman 42 years of age. It was associated with a pea-sized enlargement of the axillary nodes. When the tumor was examined microscopically it was found to consist of spindle- and giant-cell stroma with carcinoma cell nests throughout. The lymph nodes showed only hyperplastic enlargement, no neoplasm. In this case both tissue elements may have begun simultaneous malignant growths. It is not impossible that it arose through double transformation of the elements of a fibro-epithelial tumor, but its small size and the absence of any histological evidence are opposed to such a view. 
The presence of metaplastic products of the connective tissue has been observed in these duplex tumors, but does not assist in explaining their origin as they also occur in simple tumors of the same type as those from which compounded tumors arise. Thus Orth (Charité Annalen, I9I0, XXXIV, 2I) studied recurrent and metastatic tumors in the dead body of a woman of 40 years, from whose breast a myxo-chondro-cysto-sarcoma had previously been removed. From this we might infer that the primary growth had descended from a fibro-epithelial tumor. The recurrence was pure sarcoma with here and there scirrhus carcinoma nests but the metastases, which were for the most part highly necrotic, were mostly carcinoma.

Kaufmann (Virchow's Archiv, I898, CLIV) observed two cases of carcino-sarcoma of the breast, one the size of a man's head, in a woman, 63 years old.

There remains a group of these cases, in which the tumors appear to arise independently of one another. Thus, Kettle (Lancet, London, I912, II, 750) studied the left breast of a woman 46 years of age, from which a cocoanut-sized fibro-sarcoma, had been removed. Just below the nipple there was a small carcinoma. The patient died two months after operation and the axillary lymphatic nodes, the thoracic and abdominal organs and the brain all showed metastatic carcinoma.

Schlagenhaufer (Centrabl. f. allg. Path. u. path. Anat., I906, XVII, 385 ) examined a tumor the size of a small apple removed from the breast of a woman aged $5^{\mathrm{I}}$ years. The greater part of it was carcinoma, but a part of it, that was microscopically different in appearance, proved to be composed of spindle and giant cells and was sarcoma. $\mathrm{It}$ is interesting that in this case in which there was fairly well-marked separation of the structures composing the primary tumor, there should be confusion of them in the secondary tumors. In the metastatic growths both sarcoma and carcinoma occurred in combination.

Kennedy and Case. (Trans. Path. Soc. of Phila., Apr. 8, I9I5) observed a case of carcinoma of the breast with a sharply circumscribed walnut-sized sarcoma at one edge of the carcinomatous tumor. The sarcoma was a spindle-cell tumor and there was no admixture of the tissues of the two tumors.

That tumors of these or other kinds may occur simultaneously or successively, but quite independently of one another, in the same breast is no more remarkable than that they should occur in opposite breasts, which circumstance has frequently been reported. Thus, DeMorgan (Trans. Path. Soc. of London, XIX, 394) observed an adeno-sarcoma of the left breast, with scirrhus carcinoma of the right breast; Billroth (Chirurgische Klinik, I868, p. 68) a cystic sarcoma of the left breast with carcinoma of the right breast; and Bryant ("Diseases of the Breast," p. 335) a mixed cell sarcoma of the right breast and an atrophic scirrhus of the left.

\section{GENERAL INCIDENCE OF MAMMARY SARCOMA}

Sarcoma is a rare breast tumor. The $I_{5}$ cases of sarcoma of the breast operated upon in the German Hospital during the past I6 years represent approximately 2 per cent. of the total number of breast tumors that came under our observation during this time, and approximately $5 \frac{1}{2}$ per cent. of the total number of sarcoma cases admitted to the hospital.

The following tables show the relative frequency of neoplasms of the female breast and the comparative incidence of sarcomatous tumors in the various parts of the body. 
Table I.-Series of 534 Con'secutive Cases of Mammary Tumors Operated upon in the German Hospital of Philadelphia

\begin{tabular}{|c|c|c|}
\hline & & 69.1 per \\
\hline tumors....... & & 23.03 per \\
\hline$\ldots \ldots \ldots$ & 24 & 4.5 per \\
\hline Sarc & II & 2.0 \\
\hline Tuberculosis. & 6 & I. I \\
\hline
\end{tabular}

Table II.-Series of 192 Consecutive Cases of Sarcoma Operated upon in the German Hospital of Philadelphia

Lower extremity.................... 40 Prostate............. I

Upper extremity..................... 23 Spleen................ 2

Superficial tissues of the Retro-peritoneal tissues....... 5

(a) Face........................ 6 Lymph nodes............ 6

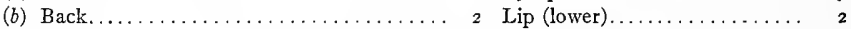

(c) Chest......................... I Jaw................... I

(d) Neck......................... I4 Carotid body......... r

(e) Scalp......................... 2 Cecum............... I

(f) Muscle........................ I Liver.............. I

(Biceps) Appendix.............. r

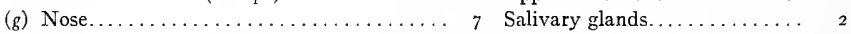

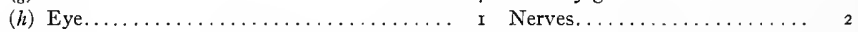

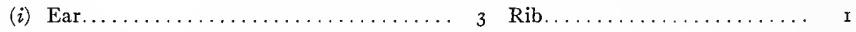

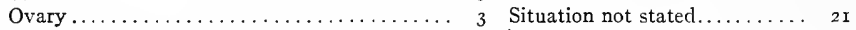

Parovarian cyst....................... 2 Breast............... II 5.5 per cent.

Uterus ............................. 7

Testicle .......................... r2

Total I92

Sarcoma of the breast occurs one time to every $171 / 2$ sarcomas occurring elsewhere. On the other hand sarcoma occurs with greater comparative frequency in the breast than in organs, the stomach or uterus which, like the breast, are the frequent seats of primary carcinoma. Indeed, if exception be made of the superficial tissues including the lymph nodes, the breast is as frequently the seat of primary sarcoma as any other organ of the body.

According to Williams the ratio of incidence of sarcoma among neoplasms in general is 9.4 per cent.; the following table shows the relative frequency of neoplasms in general and of female breast tumors.

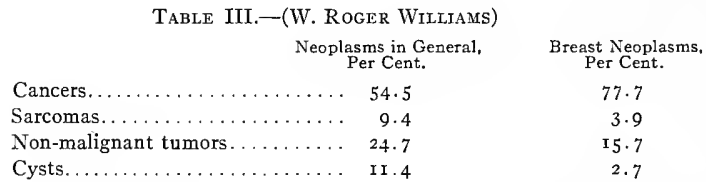

The ratio of incidence of sarcoma (3.9 per cent.) among female breast tumors as given in the preceding table is based on an analysis of 2397 consecutive tumors, $\mathrm{x} 863$ (77.7 per cent.) of which proved to be carcinoma and 94 (3.9 per cent.) sarcoma. In a further analysis of $1_{3}, 824$ primary tumors, Williams found I08 1 sarcomas and of the latter only 99 occurred in the breast; or stated in terms of percentage, 7.8 per cent. of all tumors are sarcomas and $0.07 \mathrm{I}$ per cent. of all tumors are sarcomas of the breast. See a final group of 2422 cases of breast tumors as given in Table IV, among which Williams found 3.5 per cent. of sarcomas. 


\begin{tabular}{|c|c|c|c|c|}
\hline & & E IV & & \\
\hline & Male & Female & & Total \\
\hline Cancer............ & I6 & I 836 & & I 879 \\
\hline Sarcoma.......... : & 3 & 92 & & 953.5 per cent. \\
\hline Myxoma........... & 2 & 2 & & 4 \\
\hline Fihro-adenoma....... & I & 372 & & 373 \\
\hline Papilloma.......... & o & I & & I \\
\hline Lipoma. . . . . . . . . & I & $\circ$ & - & I \\
\hline Chondroma......... & $\circ$ & I & & $\mathbf{I}$ \\
\hline Angioma........... & I & 0 & & $\mathrm{I}$ \\
\hline Cystoma........... & I & 63 & & 64 \\
\hline & 25 & 2397 & & 2422 \\
\hline
\end{tabular}

Among the recent references to the comparative incidence of sarcoma among breast tumors the lowest figures are given by Warren, who found only four examples of the periductal variety among $75^{8}$ breast tumors operated upon in the Massachusetts General Hospital. Randolph and Winslow state that they have had three sarcoma cases among roo cases of breast tumors.

If we now turn to the older authorities we find without exception a higher relative proportion of malignant connective-tissue growths. Schmidt states that sarcomata comprised 7.03 per cent. of the breast cases operated on in Czerny's clinic in the years $\mathrm{r} 877-1886$ inclusive. Of the 363 breast tumors removed in the Kommunne Hospital of Copenhagen from $\mathbf{r} 870$ to 1888 , cancer was found 208 times, sarcoma 33 times (9.r per cent.) and benign tumors 50 times. Hoover and Von Bergmann, contemporary with the surgeons just mentioned, gave 8.8 per cent. and 9.4 per cent. respectively as the relative frequency of sarcoma among breast tumors. This decided difference between the statistics as given by the preceding and present generations of surgical authorities is possibly to be explained by the more refined microscopic diagnostic technic in use at the present time.

Sex Incidence.-The great majority of sarcomas of the breast occur in women; only 34 male cases were recorded up to 1907 (Connell). Our own series of cases mentioned above contains only two instances of sarcoma arising from the mammary tissues of the male. The first patient, a man, 60 years of age, struck his right breast against a newel post several months before presenting himself. He had apparently recovered from the immediate effects of the injury which was described as having been moderately severe.

About six months before coming under observation he noticed a small hard and slightly painful nodule "in the nipple." On examination it was found to be about the size of a bean, slightly tender and situated below the right nipple. It was not adherent to the skin or to the deep fascia. The axillary lymph nodes were not palpably enlarged. The nodule proved to be a fibro-sarcoma. It has been estimated that only 5 per cent. of all tumors of the male occur in the breast and all writers are agreed that carcinoma is by far the most common variety of new growth of the male breast.

In the second male case in our series the tumor, a multilobular fibro-sarcoma, prob. ably arose in the subcutaneous tissues of the chest wall near the breast rather than from the stroma of the organ, many of the nodules, as is well shown in the accompanying illustration, being situated at some distance from the breast.

This patient, a man, aged 6o years, was admitted to the German Hospital of Philadelphia, Nov. 6, I9I4. He stated that he had first noticed a small lump above and to the inner side of the right nipple 
four years before. The lump increased in size, but very slowly, until six months before presenting himself, since when the growth has been rapid, and multiple nodules have appeared in the vicinity of the original tumor. The disease has not given rise to any pain. The patient is a farmer, has always enjoyed good health, and cannot recall having received an injury to the breast.

The growth consists of a number of firm, elastic, more or less well-circumscribed nodules varying in size from a pea to an English walnut. It is not adherent to the chest wall. The breast contains an irregular mass which has elevated the areola and pushed the nipple to one side. Operation: simple amputation. Patholoigcal report: mass of tissue with skin surface measuring $15 \mathrm{~cm}$. by $8 \mathrm{~cm}$. by $5 \mathrm{~cm}$. On section the tumor is seen to consist of discrete nodules composed of firm homogenous fibroid tissue. Microscopy: fibro-sarcoma:

It is commonly stated that sarcoma is next in frequency after carcinoma among male breast tumors, but the figures of Schuchardt refute this assertion since the author found $34 \mathrm{r}$ malignant growths among a collected series of 406 tumors of the male breast of which 334 were carcinoma, i4 sarcoma and the remaining $5^{8}$ various benign growths. Williams, on the other hand, found r 6 cancers, 3 sarcomas, and 6 benign growths in a series of 25 cases of tumor of the breast in men. As regards the relative frequency of mammary sarcoma in the two sexes, women are affected approximately thirty times as often as men.

Sarcoma of the breast in the latter sex is of interest chiefly because of its rarity. It will not be amiss however, to review the main facts in some of the recently reported cases. Particular interest attaches to Collignons' case of bilateral adeno-sarcoma of the breast of a boy 15 years of age, not only because of the youth of the patient, but also because it illustrates the extremely rare condition of bilateralism of mammary sarcoma.

Axillary glandular metastasis in association with a multiple round-cell sarcoma in the breast of a man aged 30 years has been reported by Putzu. The enormous size of the tumor and the extreme old age of the patient are points of exceptional interest in the case of Lorrain and Ménard.

The patient was a man aged 86 years, who first noticed a tumor in the left breast one year before presenting bimself. On admission to the hospital a growth the size of an adult's head was found to occupy the upper outer thoracic region on the left side, extending upward to the level of the clavicle and outward almost to the posterior axillary fold.

The tumor was irregularly nodular and movable, hard areas alternating with areas of liquid consistency.

Many other interesting and important features of sarcoma, of the male breast are found in cases reported by Finsterer, Schmidt, Connell and others, but the detailed consideration of these points has already been given in the section on Pathology.

Age Incidence.-Sarcoma of the breast has been observed in all decades of life; the extremes of age, however, offer comparative immunity to the disease. This is true of mammary sarcoma in both sexes. In by far the great majority of instances the disease begins between the ages of 40 and 60 as is shown in the following table.

Table V.-Age Incidence of Sarcoma of the Breast in the German Hospital of Philadelphia

$\left.\begin{array}{lll}\text { I5 } & 20 & \\ 2 \mathrm{I} & 30 & \\ 3 \mathrm{r} & & 0 \\ 4 \mathrm{I} & 40 & 4 \\ 5 \mathrm{I} & 50 & 6\end{array}\right\} 66.6$ per cent. $\} 86.6$ per cent.


For comparative purposes we have estimated the age incidence by decades in a series of 240 collected cases. The results are shown in the following table.

Table VI.-Age Incidence by Decades

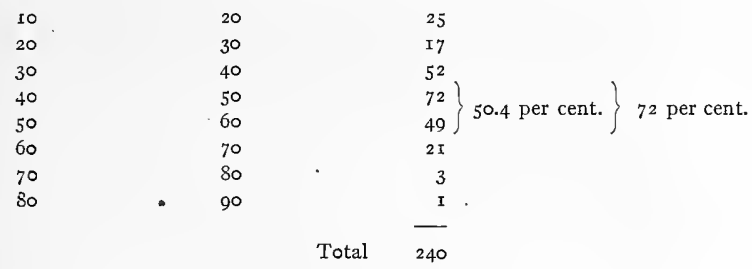

The average incidence of sarcoma of the breast in men slightly exceeds that in women; fewer cases are recorded as occurring in either extreme of life in men than in women, so that the higher average age in men must obviously be due to the greater proportionate incidence of mammary sarcoma in women of younger years. That this is actually true is evident if comparison be made between the following table of male cases and the preceding table which is based on statistics of mammary sarcoma in women.

Table VII.-Collected Series of Cases of Mammary Sarcoma in Men

$\begin{array}{ccc}\text { I0 } & 20 & 0 \\ 20 & 30 & 5 \\ 30 & 40 & 6 \\ 40 & 50 & 7 \\ 50 & 60 & \text { II } \\ 2 & \text { Total } 30\end{array}$

The average age incidence in our collected series of sarcoma in men is 45.5 years; according to Finsterer it is 45.6 years; Williams gives 44.8 years as the average age of women with sarcoma of the breast. As compared with carcinoma, sarcoma of the breast begins, on the average, about ten years earlier in men and approximately five years earlier in women. These figures are slightly at variance with the frequently quoted statistics of Gross whose experience led him to remark that sarcoma of the breast occurs most often during the period when the gland exhibits the greatest functional activity. In 66.66 per cent. of his cases the disease began between the ages of I6 and 40 . Gross states that the average age of patients with the spindle-celled variety of sarcoma was 32.6 years; in patients with round-cell tumors it was 42.4 years. In explanation of this decided difference he offers the suggestion that "spindle-celled and cystic sarcomata are the results of metaplasia of the functionally perfect gland, and that round-celled and solid sarcomata are due to metaplasia in the declining gland."

A further discussion of the incidence of the various types of mammary sarcoma at different ages will be found in the section on the pathology of mammary sarcoma.

The greater number of all malignant tumors of the breast occurring before the age of puberty are sarcomatous in nature. Mammary sarcoma is exceedingly rare during the first decade of life, however, and with the exception of the few cases mentioned by Sheild we know of no authentic examples. One of Sheild's patients was an infant six months old, from whose breast a typical myxo-sarcoma was removed. In a second case-that of an infant of four months-the growth was of the small round-cell variety that in 
five weeks had reached the size of a hen's egg. This tumor was excised and after five months the disease showed no evidence of recurrence. Gross mentions the case of a boy nine years of age whose breast contained a typical sarcoma. In searching for additional examples of sarcoma of the breast, in the very young, we have been surprised to find the recent literature is lacking in case reports with the exception of one mentioned by Rodman. The breast of this girl, II years of age, contained a tumor which was diagnosed on the gross appearance of its cut surface.

Instances of mammary sarcoma occurring in the opposite extreme of life are not uncommonly met with, but the comparative incidence of sarcoma of the breast after the age of 60 is much less than is the case with carcinoma; this is especially true of sarcoma of the male breast. One of our patients was a woman, aged $7 \mathrm{I}$ years, from whose breast we removed a rapidly growing sarcoma in I909. The patient died within one year after operation with axillary and internal metastases.

Gross mentions a typical sarcoma in the breast of a woman aged 75 years; Williams' oldest patient was 59.2 years of age. Sheild states that a tumor is listed in the Museum of the London Hospital as being a sarcoma that was removed from the breast of a woman aged 84 years. He gives the case history of a woman said to have been Io2 years of age with a complicating sarcoma of the breast.

Race.-There is no reason for believing that racial influence plays any part in the genesis of sarcomatous tumors other than that already mentioned in connection with carcinomatous growths in the breast.

Heredity.-The general discussion of heredity as a predetermining factor in tumor formation is given elsewhere, suffice it to say that not one of our patients with mammary sarcoma had relatives die of the disease, and only two of Poulsen's 33 patients gave a family history of sarcoma.

Trauma.-The etiological rôle of traumatic injury in sarcoma generally is much disputed although it must be conceded that in a large number of instances the appearance of tumors of this nature so closely follows the receipt of an injury that the etiological significance of the latter seems apparent. Not infrequently a long existent though quiescent tumor suddenly takes on rapid growth almost immediately after the receipt of an injury, while in another group of cases sarcomatous tumors seem to develop without apparent reason from or in the vicinity of a mass which was noticed by the patient many years before and attributed by her to an injury.

As an example of sarcoma of the breast immediately following an injury is that of Emma U., a girl is years of age who came to the German Hospital of Philadelphia in July, Igr4, with the history of a severe injury to the breast some four months previously.

The breast which had been perfectly normal so far as she knew before this time, became indurated and swollen; one week before admission to the hospital she accidentally stuck a needle into her breast close to the nipple, after which the swelling seemed to increase more rapidly. The mass was neither painful nor tender at any time. The organ is diffusely enlarged, the nipple is not retracted but is stretched over the tumor, and the superficial veins are dilated. The tumor in this case was of the peri-ductal variety of sarcoma.

An illustration of the remote as well as the immediate effect of trauma in the de-. velopment of mammary sarcoma is shown in the history of Anna C.:

A married woman 59 years of age received an injury to the breast about I 4 years before the onset of serious trouble. A second injury to the breast about six months before coming to the German Hospital 
of Philadelphia seemed to excite rapid growth in a small nodule which had been present since the time of the initial injury. During the last six months of the patient's illness, the diseased organ, with its contained tumor, became as large as an adult's head. Severe pain and tenderness characterized the disease in this instance.

Germatz studied a series of I 906 different tumors and found that 20 per cent. of sarcomas had a history of antecedent trauma. Dehrnean in a study of $33 \mathrm{I}$ sarcomas noted I 3 per cent. as the result of trauma, and it is an interesting fact, in this connection, that I 3 per cent. of our carcinomas of the breast were preceded by injury.

Coley states that of $\mathrm{I} 70$ of his personal cases of sarcoma, 46 (27 per cent.) gave a history of trauma. Among the latter there were five breast cases and four of these gave a clear history of injury immediately antedating the onset of the tumor. In the first instance the patient, a woman aged 55 years, noticed a contraction of the tissues over the breast at the site of an injury which she had sustained one week before by falling against the sharp end of an umbrella. This patient eventually died with visceral metastasis after six operations for local recurrence had been done.

Two other cases are of even greater interest.

The patients are sisters. Each was operated upon at the age of $3 \mathrm{I}$; in each instance the tumor followed, immediately, a severe injury to the breast, and in both cases the disease proved fatal. In one of these patients, the breast became swollen immediately after striking it against an iron bracket; the tumor grew progressively for five months, when it was removed. Recurrence promptly took place and a second operation was done four months later. Death ensued 8 months after the injury from a supposed recurrence in the internal organs. The sister of this patient sustained an injury (blow) to the right breast in August, I 896 , which was immediately followed by a swelling at the site of the blow. This patient was not operated upon and died seven months after the receipt of the injury. The family history of these patients was negative for malignancy.

Another case reported by Coley was that of a young woman 27 years of age, who sustained a severe carbolic acid burn on the breast which was followed after three months by the appearance of a round-cell sarcoma. In view of the definite history of trauma preceding the onset of the disease in the foregoing cases-and they are by no means exceptional instances-it would seem that traumatic injury has a decided influence in the production of sarcoma of the breast, and though the outbreak of the disease is apparently spontaneous in the majority of instances and not traceable to the action of any extrinsic cause, we believe that cases like those mentioned above are due to the injury. On the other hand, we cannot agree with Collignon, who, in speaking of trauma in relation to sarcoma of the male breast says: "This is the particular kind of tumor resulting from trauma." As a matter of fact, the danger of malignant tumor formation after traumatic injury varies with the type of the injury; it also depends, as we have stated elsewhere, to a large extent, upon the age and sex of the patient, upon the organ or tissue involved, etc., while the variety of the tumor is also dependent, to a certain extent, upon the foregoing factors.

Thus an intensive injury to the breast of a young woman is more likely to be followed by sarcoma than by carcinoma; the reverse is true after the thirty-fifth year of life. All degrees of traumatic injury are apparently productive of mammary carcinoma; in fact it has been estimated that 93 per cent. of all traumatic tumors of the breast are carcinoma. The truth of this statement is confirmed by Speese, who in speaking of tumors of the male breast says that trauma does not play as important a rôle in the production of mammary sarcoma as it does in the production of mammary carcinoma. For all 
practical purposes the relationship detween traumatic injury and malignant tumors of the breast may be summed up as follows:

A nodule remaining at the site of a traumatic injury to the breast is potentially malignant; in the event of subsequent malignant tumor formation in such a nodule the disease will be carcinoma in the vast majority of instances; if after remaining quiescent for many years, however, the nodule shows sudden and rapid increase in size, the probabilities are that we have to deal with a sarcoma-usually of the peri-ductal type; or given the history of a severe injury to the non-lactating breast of a young woman succeeded immediately by the appearance of a rapidly growing tumor, the probabilities are that we are dealing with a sarcoma. ${ }^{1}$

Child-bearing, Lactation, and Pyogenic Mastitis.-Owing to insufficient statistical data, definite conclusions cannot be drawn relative to the etiological significance of child-bearing, lactation and pyogenic mastitis in sarcoma of the breast. The few data at hand, however, seem to indicate that in sarcoma as in carcinoma the physiological changes incident to the menopause are more important as predisposing factors than are the changes associated with lactation or pyogenic mastitis. We have shown elsewhere that the marital state does not offer any particular predisposition to carcinoma mammæ, and the same apparently holds true in the case of sarcoma mammæ; indeed, the number of married women with sarcoma of the breast is said to be comparatively less than with carcinoma of this organ. This does not hold true in our own experience, since the disease in twelve of our female patients occurred in married women. Only four of these patients had borne children, however, and some few of them had had attacks of pyogenic mastitis. It is equally true of sarcoma and carcinoma of the breast that lactation is prone to excite a preëxistent and apparently simple tumor to marked activity. This effect of lactation in the case of sarcoma is well shown in the history of Anna T., a married woman 38 years of age who came to the German Hospital of Philadelphia in July, Igo6, with a myxosarcoma of the left breast which measured $10 \mathrm{~cm}$. in diameter.

She stated that a small nodule had been discovered accidentally in the region of the present tumor in I89g; that the nodule had remained stationary in size until the birth of her first child one year later, whereupon it began to grow; two years later an operation was done and the patient remained well for a period of two years, when with the onset of a second lactation the tumor reappeared and in the succeeding two years gradually increased in size until at the time when she came to the hospital it had reached the size of a large orange. The relationship between lactation and the growth of the tumor seems selfevident in this case.

In one of Poulsen's series of 33 cases of mammary sarcoma, the tumor appeared two months after weaning the child; 39.3 per cent. of the patients in this series had borne children, but only in five instances as late as one or two years before the appearance of the tumor; two of the patients gave a history of pyogenic mastitis, and in one instance a hard mass remained in the breast after the inflammation had subsided. Of Williams' I 7 cases of cysto-sarcoma seven lived in wedlock - two were barren-one had had two miscarriages, and the other four were prolific. Of seven non-cystic adeno-sarcomas four of the women were married and all were fertile. Five of Schmidt's seven cases of angio-sarcoma were married women-four had borne children-three had nursed their children and one gave a history of mastitis in the affected breast.

Prognosis-Operative-Primary Mortality.-The operative mortality in sarcoma and carcinoma of the breast is practically the same, namely I per cent., notwithstand-

1 The reader is requested to consult the paragraph dealing with the relationship between injury and carcinoma of the breast, 519 et seq. 
ing the more extensive operation performed in cases of carcinoma; the causes of death after operation, which are likewise the same in the two conditions, are in their order of frequency as follows: pneumonia, uræmia, sepsis, shock and hemorrhage. For a more detailed discussion of the immediate complications following operations for malignant tumors of the breast, the reader is referred to the chapter on carcinoma.

General Consideration of Prognosis. - The ultimate fate of a patient with sarcoma of the breast depends, in the main, upon the same set of factors that determine the prognosis of mammary carcinoma. As a class the sarcomas are less malignant than the carcinomas. If the length of life of the average patient be the only factor taken into account in estimating the malignant attributes of the two neoplasms, the prognosis is dcidedly more favorable in sarcoma than in carcinoma, for Gross estimated the average

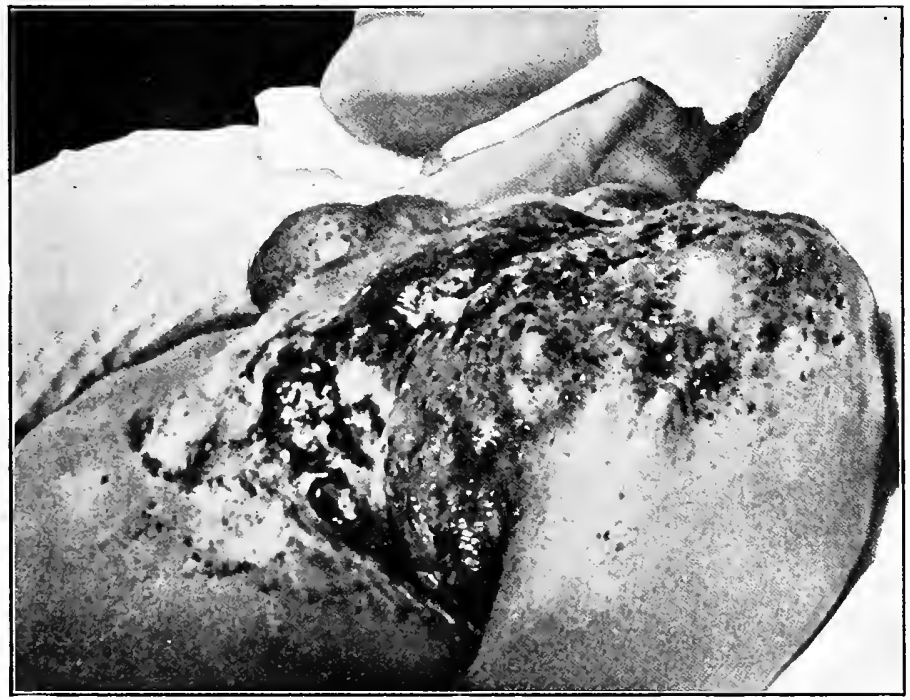

FIG. 158 .- Recurrent alveolar sarcoma of the breast showing outgrowths, local infiltration, and ulceration in the final stages of the disease. Patient aged $7 x$ years. (Grieg: Edinb. M. J., I9r 3, i, r48.)

duration of life of a patient with mammary sarcoma to be seven years as contrasted with an average duration of 37 months for the carcinoma. The probability of cure is likewise greater, according to Gross, in sarcoma than in carcinoma, 13.8 per cent. of his sarcoma cases having been cured by operation, while only 10.4 per cent. of the carcinoma cases in his series remained free of recurrences. The operative results in malignant diseases of the breast have materially improved since Gross' time, nevertheless we believe that the figures quoted above come nearer to expressing the real prognostic truth for the average results obtained by operation at the present time than do the higher percentage of cases reported by some other writers. We are inclined to agree with Sheild that an attempt to give the prognosis of sarcoma of the breast in percentage is futile on account of the inaccuracy of much of the statistical data; no attempt has been made in recent years to collect a large series of cases of mammary sarcoma 
with the view of ascertaining the results after operation and our efforts in this direction were fruitless, owing to the incompleteness of the majority of case histories contained in the recent literature. We are dependent, therefore, to a great extent, upon the statistics of past generations and of these the most valuable are included in the reports of Gross and Poulsen which, as will become evident later, differ to a marked degree.

In a series of $9 \mathrm{I}$ primary operations for sarcoma of the breast, Gross found that 32 (35.I per cent.) of the patients were free from recurrences from one month to ten years and nine months after the operation. The average post-operative period of freedom from recurrence was 49 months, the mean duration of life since the onset of the disease was to years. In the 32 favorable cases, the freedom from recurrence lasted:

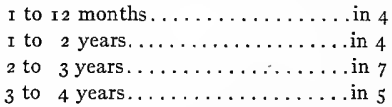

4 to 5 years.............. in 5

7 to ro years.............. in 4

Io to ro years and 9 months...... in 3

Poulsen's figures show that 66.5 per cent. of the 33 patients operated upon in the Kommunne Hospital of Copenhagen during the period of I870-1888 remained free from recurrence five or more years after operation. These figures justify the statement that sarcoma offers a better prognosis in general than carcinoma of the breast.

The probability of permanently relieving a patient of sarcomatous disease of the breast, by operation, differs widely in the individual case, for while in a few instances the tumor 'may exhibit the most malignant tendencies, in the majority of cases the disease is much less malignant than the least malignant variety of carcinoma. The most important single factor of prognostic significance, therefore, is the type of tumor with which we have to deal. This does not always coincide with the rapidity of the growth of the neoplasm for though very malignant tumors, as a rule, grow with great rapidity, this is by no means peculiar to them; in fact, the comparatively benign varieties of mammary sarcoma may attain to a size equivalent to or even greater than the most malignant types in as short a period of time.

Sarcomas of the breast may be grouped for the purpose of prognosis according to their minute structures-round-cell, spindle-cell, etc.-or they may be divided into the cystic and non-cystic or solid variety, the latter method being preferable from the clinical standpoint.

The small round-cell sarcoma in the breast or elsewhere is the most malignant variety of the disease; it is likewise the most malignant of all mammary neoplasms with the single exception of medullary carcinoma in the lactating breast--the so-called.acute carcinoma. Fortunately this is the rarest of all mammary sarcomas, it grows with frightful rapidity, as a rule, metastasizes both by way of the lymphatic and bloodstreams, is prone to early and widespread dissemination and in no reported instance, as far as we know, has a permanent cure been obtained by operation where the malignant cells had escaped the immediate confines of the breast itself. Thus, of the patients operated upon by Gross, only two were free from recurrences and in these the time interval was not long enough to insure the permanancy of the result. Notwithstanding the rapidity of growth and the tendency to local and internal recurrences after operation for round-cell sarcoma of the breast, the average duration of post-operative life in these cases is said to be four years. The prognosis in the round-cell variety of mammary sarcoma is very grave, therefore, as regards permanent cure but even in the most 
malignant type of sarcoma, life is more prolonged by operation than it is in the average case of mammary cancer where operation fails to cure the patient.

The small spindle-cell sarcomas, as a class, are less malignant than the small round-cell sarcomas. The intermediate types; the large round-cell and the large spindle-cell sarcomas, are less malignant than the small round-cell type but decidedly more malignant than the small spindle-cell variety.

The remaining histological varieties of sarcoma including the mixed types in which both round and spindle cells occur in association, or in other instances giant cells (the myeloid sarcomas) exhibit malignant tendencies in direct ratio with the immaturity of their constituent cells--that is to say, the nearer the sarcoma cells approach the embryonal type of connective tissue the greater the degree of malignancy exhibited by the tumor. This explains the comparative benignancy of fibro-chondro or ossifying sarcoma of the breast. The histological classification of sarcoma of the breast for purposes of prognosis is by no means ideal and the same is true of the grouping of cystic and non-cystic varieties, but of the two the latter has the decided advantage of more practical clinical application. True cysto-sarcomas of the breast, sarcomas containing dilated lactiferous ducts and acini, are decidedly less malignant than the solid tumors ; in Poulsens' series of 33 cases, of which I 5 were of the cystic and I 8 of the solid varieties, 75 per cent. of patients in the former group and $5^{8}$ per cent. in the latter group were free from recurrence five or more years after operation. The data relative to the II ( $5^{8}$ per cent.) patients with solid tumors, who were apparently cured by operation are as follows:

TABLE VIII

\begin{tabular}{|c|c|c|c|c|c|}
\hline No. & Microscopy & Size & $\begin{array}{l}\text { Time under } \\
\text { observation }\end{array}$ & Operation & Time of freedom \\
\hline I & Sarcoma & Nut & I4 days & Excised tumor & $4 \frac{1}{2}$ years \\
\hline 2 & Fibro-sarcoma & Hen's egg & I year & Excised tumor & I61/2 years \\
\hline 3 & Fibro-sarcoma & Large egg & I month & $\begin{array}{l}\text { Simple amputa- } \\
\text { tion }\end{array}$ & 8 years \\
\hline 4 & Fibro-sarcoma & Nut & 3 years & $\begin{array}{l}\text { Excision of } \\
\text { tumor }\end{array}$ & $71 / 2$ years \\
\hline 5 & Spindle-cell & Child's head & I month & Amputation & I $3 \frac{1}{2}$ years \\
\hline 6 & Spindle-cell & Head & 9 years & Amputation & 6 years \\
\hline 7 & Round and spindle-cell & Large egg & 2 months & Excised tumor & 7 years \\
\hline 8 & Round and spindle-cell & Entire breast & 2 months & Amputation & 612 years \\
\hline 9 & Adeno-sarcoma & Pigeon's cgg & I 8 months & Excision & I 312 years \\
\hline ro & Adeno-sarcoma & Hen's egg & 6 months & Excision & ro 12 years \\
\hline I I & Adeno-sarcoma & Large egg & I year & Amputation & 4 years \\
\hline
\end{tabular}

Too much importance must not be attached to the cystic or non-cystic characters of the tumor, however, in prognosing the individual case for in certain instances an excessively malignant small round-cell or large spindle-cell sarcoma will contain either true cysts or cystoid cavities resulting from liquefaction necrosis within the body of the tumor, while in other instances a small fibroid and fleshy tumor will pursue a comparatively benign course; it is only true in a general way, therefore, that the cystic type of mammary sarcoma offers a better prognosis than the solid variety.

The duration of the disease is of some prognostic significance, since, other things being equal, the longer a sarcoma of the breast has been in existence the greater the likelihood of metastatic dissemination. The duration of the disease in itself is not, therefore, of great importance in the prognostic sense. The local condition of the sarcomatous growth in the breast aids us in the prognosis to a limited extent. In the case of carcinoma 
we are justified in looking upon retraction of the nipple, dimpling of the skin, fixation of the tumor, ulceration, etc., as grave symptoms because experience has taught that these are indications of an advanced state of the disease and in the majority of instances mean widespread dissemination of the malignant cells; with sarcoma, however, neither ulceration of the skin enveloping the tumor nor fixation of the tissue are always significant of a serious condition, but here again we must seek to find the histological type of the tumor before exhausting the probabilities of operative cure. Ulceration in mammary sarcoma is invariably found in association with large tumors and is due, not to infiltration of the tissues overlying the tumor, but to actual pressure necrosis, and the symptom is therefore indicative of a tumor of long standing, as a rule.

Fixation of the tumor to the chest wall raises the question whether the disease may not have originated from the tissue underlying the breast, especially from the periosteum or perichondrium of the ribs and costal cartilages, with secondary invasion of the breast; but if the tumor is known to be of mammary origin and has become fixed to the chest wall secondarily, it is highly important from the prognostic standpoint to remember that the malignant cells have probably invaded the anterior mediastinum by way of the intercostal spaces. Fixation of the mass to the deeper structures should not discourage us in the attempt to cure the disease by operation to the same extent as in carcinoma, although the prognosis is decidedly more grave in cases of this kind than it is where the tumor is freely movable within the breast.

The Axillary Nodes.-The presence of axillary metastasis in mammary sarcoma is very rare and makes the prognosis grave; only very malignant sarcomas invade the axillary lymph nodes; it was formerly believed that only the round-cell type invades the axilla, but Poulsen found axillary involvement in two cysto-sarcomas and two fibro-sarcomas in his series of 33 patients. The palpable enlargement of the axillary nodes in sarcoma of the breast is not always caused by metastasis, however, for in a few instances Schmidt found the enlargement to be inflammatory. Nor is the absence of palpable enlargement proof that the tumor cells have not invaded the axilla, for in at least several instances tumor cells have been found in microscopic sections of apparently normal nodes.

Age.- It is an interesting fact that age, which plays such an important part in the prognosis of mammary carcinoma, has little bearing on the prognosis of sarcoma of the breast, and any influence that it may have is directly opposite to that shown in carcinoma mammæ. Generally speaking, the younger the patient the more fatal the prognosis in carcinoma; in the case of sarcoma, on the other hand, the probability of operative cure diminishes with increasing age.

The most malignant among the mammary sarcomas occur after the thirtieth year of life, and after this age the chances of operative cure diminish with increasing years, regardless of the type of sarcoma. This fact justifies the opinion expressed by Gross that the more malignant tumors are products of the declining gland. The average age incidence for spindle-cell and cystic, the least malignant varieties of mammary sarcoma, was 32.6 years in Gross' series; for the solid and round-cell varieties or most malignant forms it was 42.4 years. The vast majority of sarcomas of the breast arising before the age of puberty are of the spindle-cell type (seven-eighths of all cases appearing before the age of 16, (Gross)) and pursue a comparatively benign course.

Sex.-According to Finsterer the prognosis in sarcoma of the male breast is extremely grave; the literature, he states, contains only one case in which operative cure was obtained-this patient, who was operated upon by Horteloup, was free from recurrence 
II years after the operation. The great possibility of error in statistical data is evidenced by the fact that a year after the appearance of Finsterer's report (rgo6) Connell collected a series of 34 sarcomas of the male breast with only II (32.4 per cent.) recurrences. Of the cured cases one was free from recurrence for a period of two years after a fourth operation. A second patient developed keloids, but was otherwise well; another patient who developed erysipelas after the operation remained perfectly well for a period of II years, and a fourth case was cured of an inoperable recurrence by the use of Coley's toxins. We have no means of proving but are inclined to believe that the figures given by Connell are approximately correct, and that the case reported by Horteloup is not, as Finsterer maintains, the only known instance of operative cure in sarcoma of the male breast. In either event, however, there can be no question but that sarcoma is a more fatal disease in men than in women.

Personal Experience.-The outcome of the disease in seven of our sarcoma cases is known to us; four of the patients are alive and well, and three have died as the direct result of recurrence of the disease. The histories of these cases follow:

Patients Who are Alive and Well.-Case I.-Edith G., aged 45 years, was admitted to the German Hospital of Philadelphia Sept. 9, I9r3. The patient had been aware of the presence of a symptomless, stationary lump in the right breast for a period of two years. Two months before her present admission it began to increase rapidly, and when the patient presented herself to us it had grown to the size of an orange, but had given rise to no pain. There was no history of traumatic injury. The tumor occupied the outer half of the right breast; it was irregular, nodular, hard, freely movable, and non-sensitive to pressure. The axillary glands were normal to palpation. The tumor alone was removed.

Pathological Report.-Specimen consists of a rounded mass measuring 5 by $8.5 \mathrm{~cm}$. It is surrounded by a well-formed capsule, is bard and nodular. Section reveals many small cysts.

Microscopy.-Fibro-cystic sarcoma.

Case 2.-Josephine B., aged 46 years, was admitted to the German Hospital in April, rgog. A small tumor was excised from the left breast; this was diagnosed as myxo-fibro-adenoma by the pathologist. In $19 \mathrm{I}_{2}$ the patient noticed a swelling in the breast from which the tumor had been removed; tbis disappeared under treatment, but reappeared in March, $\mathrm{r}_{9 \mathrm{r}} 3$, whereupon she returned to the hospital. Examination at the time of this, her second admission, showed a tender, diffuse mass beneath the scar of the first operation. Two masses, one the size of an orange, the other the size of a plum, were enucleated from the left breast.

Pathological Report.--Specimen consists of tumor mass measuring 8 by 4.5 by $3.5 \mathrm{~cm}$., surrounded by a thick capsule, and composed of firm fleshy tissue. Section shows fibro-fatty tissue with numerous hemorrhagic areas. A second, smaller mass is essentially the same as the above.

- Microscopy.-Adeno-myxo-sarcoma.

The pathologist made the following comment after careful reexamination of microscopic sections from the tumor removed at the time of the first operation: "This growth was diagnosed originally as myxofibro-adenoma. The appearance of the present growth is very similar to that of the original; it must be regarded as a recurrence of the latter. In view of the cellular character of the stroma and its tendency to recurreuce, I prefer to change its nomenclature as above."

The patient returned to the hospital Apr. 5, I9r4, with another tumor at the site of the previous ones. This was excised and found to be a typical myxo-sarcoma, thus confirming the opinion of the pathologist, which we have just quoted. The patient wrote us June I, I9I5, that she has been perfectly. well since the last operation.

Case 3.-Rev. S., aged 53, came to the German Hospital in October, r goo. Several months previous to this he had struck his right breast against a newel post, but the effects of the injury were slight; and be imagined himself well until six weeks prior to his present admission when he roticed a hard, slightly painful nodule under the right nipple. Examination was negative except for the presence of a freely movable bean-sized nodule under the right nipple. The breast was removed; the little nodule proved to be a fibro-sarcoma. This patient wrote to us, June 1,1915 , that he has had no further trouble that might be attributed to the tumor in the breast.

Case 4.-Frances A., aged 49 years, came to the German Hospital in March, rgo8, on account of an enormous enlargement of the left breast. The patient stated that she had discovered, by accident, 
a small nodule in the hreast, 20 years before, and that her present condition is the result of a gradual and progressive growth of this nodule. During the latter two years of its presence, the tumor has given rise to considerable pain. The left breast was found to contain a large globular mass, about the size of a child's head; it was cystic in some parts, hard and nodular in others. The skin was thinned and contained many large veins. A peculiar bluish translucency was noted in the skin overlying the cystic parts of the tumor. The breast containing the tumor was removed. Pathological report: Specimen consists of a female breast with skin surface measuring $16-12 \mathrm{~cm}$., containing a tumor measuring ${ }^{2} 2-13-10 \mathrm{~cm}$. The growth contains many cysts containing yellowish-brown gelatinous material. $\mathrm{Mi}$ croscopy: Myxo-sarcoma (peri-ductal). This patient when last heard from, in 1913, was alive and well.

Patients who have Died as the Result of Recurrence.-Case I.-Lucy A., aged 50 years, was admitted to the German Hospital, Dec. 12, 1913, complaining of an enlargement of her right breast of only ro weeks' duration. The patient first noticed a lump the size of a large walnut in the lower, outer quadrant of the right breast. She is of the opinion that the lump itself has increased in size, and that the hreast as a whole has become enlarged. One week before coming under observation, she began to apply a salve to the breast with the result that a slight ulceration has appeared on the nipple. The breast was found to contain a movable, hard, slightly irregular, sensitive mass, the size of an orange, in the lower portion of the hreast. The lymph nodes in the axilla were palpably enlarged. The opposite breast is normal. A radical amputation was performed Dec. I3, I913.

Pathological report: Specimen consists of breast with skin surface measuring $30-16 \mathrm{~cm}$. Skin normal; nipple slightly ulcerated. On section, a tumor mass measuring $6-4-4 \mathrm{~cm}$. is seen in the lower part of the breast. The tumor is fairly well encapsulated, lobulated, soft in consistency, and cream like in color. Small hemorrhagic areas are scattered throughout the specimen. No enlarged glands were found among the axillary tissues.

Microscopy: Tumor: Small round-cell sarcoma. Breast: Ahnormal involution. Axillary glands: Endothelial hyperplasia.

This patient was operated elsewhere for a recurrence in the opposite breast in July, 19I4, and died Sept. $I 6,1914$. We are unable to obtain any detailed information regarding the appearance time of the recurrence or exact cause of death, although it may be taken for granted that internal metastasis occurred.

Case 2.-Fredericka B., aged $7 \mathrm{I}$ years, was operated upon in the German Hospital by Dr. A. D. Whiting, July 21, Ig09 (simple amputation of the left breast). The patient dated the beginning of the trouble in the breast from the time of discovery of a small painful lump one year before presenting herself. When first noticed the mass was ahout the size of a marble, and this the patient thought was the result of a blow which she had received some time previously. The tumor soon began to increase with great rapidity so that at the time of our examination, it had reached the size of an orange. The skin over the tumor was found to be slightly adherent, and discolored in one spot, where the tumor itself is soft in consistency, being moderately hard elsewhere. The nipple and axillary glands are normal.

Pathological report: Specimen consists of a breast which contains an encapsulated tumor, the entire mass measuring $7.2-6.5-5.9 \mathrm{~cm}$. The tumor is fleshy in consistence but contains several small cystr. Microscopy: Sarcoma (peri-ductal).

This patient had a recurrence on the axilla five months after operation and died ten months after operation with symptoms suggestive of internal metastases.

Case 3.-Margaret F., aged 43 years, was operated upon in the German Hospital, of Philadelphia, Apr. 12, I913; an orange-sized tumor was enucleated from the outer portion of the right breast. The frozen section diagnosis was fibro-adenoma hut grossly the tumor looked like a sarcoma which it later proved to be, and the breast and a portion of the pectoralis major muscle were removed.

The disease, which was of one year's duration, hegan as a small painless nodule situated near the nipple. This grew very slowly until two months before her admission to the hospital when it suddenly and without apparent cause, began to increase in size. When the patient presented herself the right breast was about the size of a large cocoanut. The skin although dusky red in hue and containing large venations, was not adherent to the tumor. The latter is multilobulated, apparently a solid structure, and is non-sensitive to pressure. There is no adhesion between the tumor and the chest wall. The axilla is normal.

Pathological report: Specimen consists of hrcast with skin surface measuring $20-7.5 \mathrm{~cm}$.; nipple normal, and a tumor mass measuring $\mathrm{r}^{8-1} \mathrm{r}^{-14} \mathrm{~cm}$. surrounded by a thick capsule. On section it is seen to be composed of solid fibro-fatty and very vascular tissue. Microscopy: Peri-ductal sarcoma.

The patient returned to the hospital, Mar. 30, 1915, stating that for two months a hard lump had been forming in the old scar and a small round tumor in the upper inner quadrant of the left breast. 
Examination showed a hard firm mass in the scar on the right chest wall and a marble-sized nodule in the left breast. The axillie were negative. Fluoroscopic examination of the chest revealed mediastinal and peri-bronchial metastases. The nodules described above were removed for psychic reasons and both were found to be myxo-sarcoma.. The patient died soon after leaving the hospital.

No one will question the malignancy of this particular peri-ductal sarcoma.

Differential Diagnosis.-In dealing with tumors of the breast in their early stages, the diagnosis has so often failed us, that we would only lead the reader astray in an attempt to formulate rules for a differentiation that we ourselves have found it impossible to make. The diagnosis must be made at the time of operation. Even in advanced cases of mammary sarcoma, the diagnosis is by no means an easy one to make in every instance, but a precise knowledge of the clinical features of the several varieties of the disease will lead to a correct opinion in the majority of instances. It is impossible to use the histological structure of the tumors as the basis of clinical classification because the clinical features differ entirely in different tumors that may be composed of the same types of cells. Thus, though the cells may be morphologically identical in two sarcomas of the breast, the presence of an excess of fibrous stroma, or the presence of cysts, etc., in one of them may so modify their clinical behavior as to make them appear to be entirely different varieties.

Billroth divided sarcoma of the breast into adeno-sarcoma and the pure sarcoma. The former, as the name implies, comprises tumors containing glandular elements, the latter consisting entirely of sarcoma cells together with the intercellular matrix.

This classification which is the one accepted by Williams has certain advantages in that the cystic sarcomas, which comprises at least 60 per cent. of all mammary sarcoma, belong to the adenomatous group; it likewise has decided disadvantages since a proportion of adeno-sarcomas fail to undergo cystic change in which case the tumor is of smaller size and is indistinguishable from a pure sarcoma.

Furthermore, the latter not infrequently undergoes degeneration with cystic changes in which event they closely simulate cystic-adeno-sarcoma.

Following the suggestion of Gross, many divide sarcomas of the breast into the solid and cystic varieties. But here again obvious objections arise because it is probable that cystic tumors will be mistaken for solid ones when the cysts are small, deeply placed, or when their contents are under great tension, while cystic changes in an originally solid tumor are difficult to differentiate at times from true cysts. Warren called attention to the fact that primary sarcoma of the breast takes origin either from the hyaline connective tissue that surrounds the milk ducts (peri-ductal sarcoma) or from the connectivetissue stroma of the organ (non-indigenous sarcomas). Representatives of the latter group may, but usually do not, contain glandular inclusions; they are solid, as a rule, and with the exception of the round-cell variety are slow in development and closely resemble the benign fibro-adenomas. Inasmuch as the highly malignant round-cell sarcoma may arise from the stroma of the breast, the term non-indigenous is applicable to very different types of tumors. An equal diversity is shown in the clinical courses of tumors originating in the peri-ductal tissues.

It seems to us that a more practical classification of these growths from the standpoint of differential diagnosis is based upon their rapidity of growth.

The variability in the rate of growth of a mammary sarcoma does not in itself enable the surgeon to differentiate the several pathological varieties; it merely serves as a convenient means of calling his attention to the types which are slow or rapid in development, as the case may be.

A convenient clinical classification of sarcoma of the breast is as follows: 


Rapidly growing
mammary sarcomas $\begin{cases}\text { Round-cell } & \begin{array}{l}\text { Small } \\ \text { Large } \\ \text { Mixed } \\ \text { Myeloid }\end{array} \\ \text { Spindle-cell } & \left\{\begin{array}{l}\text { Peri-ductal } \\ \text { Myxomatous } \\ \text { Large spindle-cell }\end{array}\right. \\ \text { Angio-sarcoma } & \left\{\begin{array}{l}\text { Round-cell. } \\ \text { Spindle-cell. }\end{array}\right.\end{cases}$

Slow growing mammary sarcomas Non-indigenous and Non-cystic, as a rule
Fibro-sarcoma

Chondro-sarcoma

Osteo-sarcoma

It now remains to consider those clinical features of the various mammary sarcomas that distinguish them not only from each other but from other types of mammary tumors as well.

Rapidly growing sarcomas of the breast usually attain considerable size before the patient presents herself. This does not preclude the possibility of the future rapid growth of a tumor that has grown slowly up to the time of the first examination. As a rule, however, the rapidly growing sarcomas will have reached considerable size when the patient is first seen by the surgeon.

The rapidity of growth depends upon entirely different causes in the various types of mammary sarcoma; how then may we distinguish them one from another?

Let us assume that a rapidly growing tumor in the breast is sarcomatous; according to the above classification, growths of this kind will consist of round cells, spindle cells or a mixture of the two types of cells, while they may or may not be excessively vascular. If the tumor be composed entirely of either round cells or large spindle cells, or even in certain instances of a mixture of the two, the marked rapidity of growth is often dependent entirely upon an actual increase in the number of cellular elements in the tumor; if, on the other hand, the tumor be made up of small spindle cells the rapidity of growth will be found to depend either upon the presence of dilated lactiferous ducts, or upon myxomatous degeneration of the tumor in the absence of cysts, while in either instance, the presence of enormous blood-vessels may contribute to the size of the mass.

Members of the first group including the round-cell and large spindle-cell sarcomas grow with frightful rapidity and give rise in a percentage of cases to early metastasis to adjacent lymph nodes; metastasis is especially common in melanotic round-cell sarcomas. The tumor mass is large and irregularly rounded, but less well defined than other types of mammary sarcomas.

Softened and fluctuating areas are not infrequent but they are found on palpation to lack the definite wall so characteristic of true cysts. Finally tumors of this kind usually occur later in life than the true cystic sarcomas, and unlike the latter are rarely associated with a discharge from the nipple.

Mammary sarcomas that simulate the varieties just described arise from the periductal tissues; they consist of round cells or spindle cells and are slightly malignant but attain a large size on account of the formation of large cysts within their substance, or as a result of myxomatous degeneration of the stroma. These tumors (the peri-ductal sarcoma), as a rule, follow a characteristic clinical course; they first appear as a small 
freely movable mass usually in the center of the breast; not infrequently the tumor remains stationary for a considerable period of time and then of ten without any apparent cause it suddenly takes on active growth. Tumors of this variety may double their size in the course of a few hours as the result of intra-cystic hemorrhage. Periductal sarcomas are globular in outline and definitely lobulated; each lobe is surrounded by a distinct wall while the entire tumor, if not too large, is manifestly encapsulated and sharply defined from the mammary tissue that surrounds it.

In the case of very large tumors, the entire breast hangs from the chest wall suspended by a pedicle of skin. The septæ between the cysts and lobes of a peri-ductal sarcoma are easily demonstrable and the intervening portions are soft or even fluctuating unless the cavity of the cyst has been obliterated by an intra-cystic growth, and in the absence of marked tension of the cyst contents.

The presence of blood clots within one or more of the cysts imparts a doughy sensation on palpation. These tumors do not metastasize to the axilla except in the rarest instance. A serous or bloody discharge from the nipple is commonly associated witb peri-ductal sarcoma.

The term angio-sarcoma is applied in the clinical sense to any excessively vascular sarcoma. Where the rapidity of growth of a mammary sarcoma is due to the presence of an unusual number of blood-vessels or blood spaces, the tumor often pulsates. This is an extremely rare but pathognomonic sign of sarcoma .

From what other varieties of mammary neoplasm must each of the above types of sarcomas be differentiated and how may such differentiation be made? Practically speaking the small round-cell sarcoma must be distinguished only from medullary carcinoma, the peri-ductal (spindle-cell) sarcoma only from rapidly growing cystic adeno-fibroma.

The chief points of similarity between medullary carcinoma and round-cell sarcoma of the breast are their rapidity of growth and early invasion of the axillary lymphatics. As a rule, however, the ordinary medullary carcinoma is not only less rapid in development than a round-celled sarcoma, but soon gives rise to signs characteristic of cancer. Thus the carcinoma invades. the breast tissues irregularly, infiltrates the skin which becomes dimpled, attaches itself to the deep fascia and frequently causes retraction of the nipple. These signs are wanting in the vast majority of mammary sarcomas. In the event of ulceration the deeply infiltrated, indurated and undermined edges of the cancerous ulcer is in decided contrast with the necrotic skin surrounding an ulcerating sarcoma.

The rapid growth of an acute carcinoma of the breast arising during lactation will at first suggest the possibility of sarcoma but the carcinomatous growth soon comes to resemble an inflammatory process; in the majority of reported cases of acute cancer of the breast a pre-operative diagnosis of acute mastitis has been made. This fact suggests the appearance of the organ in this disease.

Large fibro-cystic adenomas resemble cystic sarcomas, but the benign growth rarely attains the enormous proportions of the typical cystic sarcoma, exceptions to this rule are, however, not unknown. The tumor in one of our patients appeared during lactation and grew with great rapidity. It presented the characteristic features of a peri-ductal sarcoma, and was so considered by us and all others who examined the patient. The tumor proved to be fibro-cystic adenoma with lactation hyperplasia of the epithelium. (Fig. I62). 
Myxo-sarcomas (spindle-cell) and benign fibro-myxomas resemble one another very closely. The benign tumor is usually firmer in consistence and slower in development than the sarcoma, but in the early stage differentiation is extremely difficult.

Large intra-mammary gummas mimic the myxo-sarcomas, but the smooth and regular outline of the former, their general firmness to the touch, and the customary central softening, are important differential points.

In doubtful cases the concomitant signs of syphilis must be sought for and recourse be had to the Wassermann test.

The slow-growing sarcomas remain for consideration. Most of the members of this group are representatives of the pure variety of sarcoma; they do not contain glandular elements but are solid growths and usually arise in the periphery of the breast. Slowgrowing mammary sarcomas almost invariably consist of small spindle cells and an intercellular matrix that is subject to variation both in quantity and quality. This latter characteristic is the basis of the histological classification into fibro-sarcomas, osseoussarcomas, etc. Chondro-sarcomas and osseous-sarcomas of the breast are exceedingly rare; they are described elsewhere.

Fibro-sarcoma, the common type of slow-growing sarcoma of the breast resembles non-cystic fibro-epithelial growths (benign), early carcinomas, areas of chronic inflammation (tuberculous, pyogenic, etc.), abnormal involution and gummas.

The clinical differentiation between a fibro-sarcoma and a fibro-epithelial tumor in their initial stage is impossible, but as time goes on, the sarcoma becomes less freely movable within the breast tissue; the benign growth is more perfectly encapsulated and remains freely movable in all instances. The sarcoma grows steadily and usually progressively, is more regular in outline and softer in consistance, as a rule, than the benign tumor. The fibro-sarcomas are rarely multiple in comparison with the frequent multiplication of fibro-epithelial tumors of the breast.

The chronic inflammatory diseases, especially mammary tuberculosis, usually present multiple foci, and the diffuse character of the condition, localized tenderness and early tendency to softening and fistula formation will give a clue to the diagnosis; chronic solitary pyogenic abscesses with greatly thickened walls are mistaken for carcinoma rather than sarcoma on account of their marked density. Mistakes will be avoided by elicitıng a careful history and by the use of the aspirating needle in doubtful casses.

Treatment.-Patients with sarcoma of the breast should be operated upon whenever possible. The contra-indications to operation in this disease are essentially the same as those applying to carcinoma mammæ. It is more justifiable, however, to advise operation in cases of sarcoma in which the disease has a widespread superficial distribution than in similar cases of carcinoma. Recent experience with the therapeutic use of the $X$-rays and radium in malignant tumors of the breast shows that sarcomatous growths are more amenable to these agents than are carcinomatous growths. In the latter disease, as we have shown elsewhere, partial operations are either futile or actually hasten the course of the malignant process. This is not the case with sarcoma in which the same plan of treatment has met with success. An extension dissemination of sarcoma cells in the superficial tissue does not in itself contra-indicate operation.

The results obtained by the operative treatment of mammary sarcoma are uniformly better than in carcinoma of the breast. In both conditions, however, there is a decided need of improvement. The fact that local recurrence of mammary sarcoma promptly follows a large percentage of operations and that death from internal metastasis is by no means rare, indicates either that many patients are subjected to operation at a time when 
Plate IV

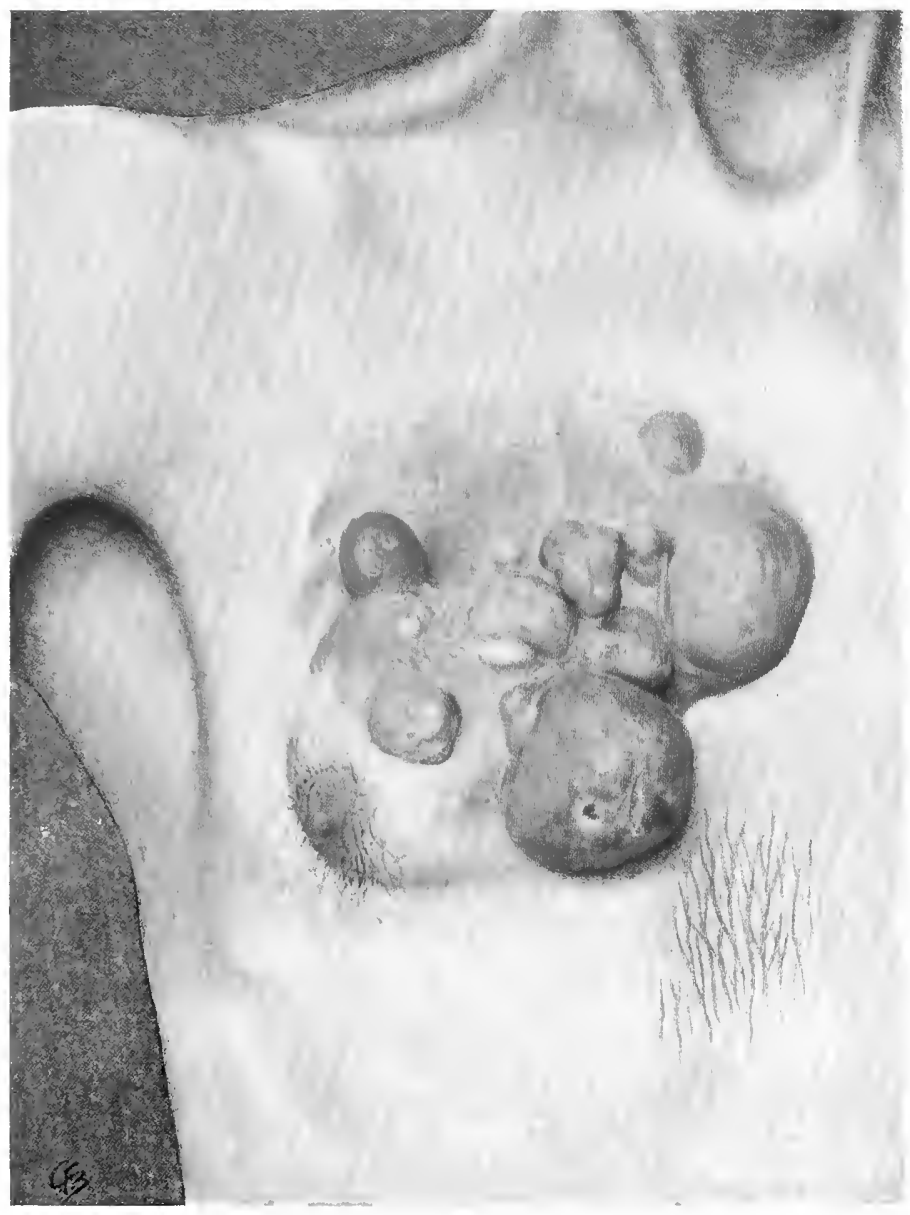

Fibro-sarcoma of the male breast.

DEAYER AND MCFARLAND. 

widespread dissemination of the disease has already taken place, that the operations are incomplete, or that the wound becomes "infected" with sarcoma cells at the time of operation.

The clinical demonstration of early internal metastasis is often impossible, so that there is no way of preventing unnecessary operations in cases of this kind. Local recurrences are due in the vast majority of instances, we believe, to incompleteness of the operation.

It is the common practice among surgeons in dealing with mammary sarcoma either, to excise the tumor or to perform simple amputation of the diseased breast together, in certain instances, with removal of the underlying deep pectoral fascia. Cleansing of the axilla is either omitted or is reserved for use in cases where the axillary lymph nodes are palpably enlarged. Inasmuch as sarcomas as a class rarely metastasize by way of the lymphatics, it would seem, at first thought, irrational to remove the regional lymph nodes; indeed it is difficult to take exception to conservative practice in dealing with mammary sarcoma with the hope of proving one's contention on statistical grounds, but our own experience convinces us that the general adoption of a radical procedure in the treatment of this form of tumor will lessen the percentage of local recurrences. The latter are due, we believe, in the great majority of instances, to the retention of sarcoma cells in the small venules leading from the breast.

If this be true, the principle of block dissection is as applicable to sarcoma as to carcinoma; in one case we endeavor to remove in one mass the tumor-bearing organ and regional lymphatics; in the second case, the tumor-bearing organ with the veins leading from it. The danger of traumatic dissemination of sarcoma cells by way of the veins is certainly as great as the danger of disseminating carcinoma cells through the lymphatics, and for this reason it is equally important in operating for sarcoma and carcinoma of the breast to begin the dissection in the axilla.

A glance at Table VIII will show that Poulsen was guided in his choice of operation for mammary sarcoma by the size of the tumor and furthermore that of the eleven cured cases of solid sarcomas, seven had had simple excision of the growth. Almost all other surgeons including ourselves have been content in the past to practice simple excision in the case of small sarcomas reserving simple amputation of the breast for very large tumors; in only one of our own cases, that of a round-cell sarcoma with metastasis to the axillary nodes, was a radical operation done. Later studies of the subject convince us that radical amputation is the better practice regardless of the variety of the tumor. If, on the other hand, we would continue in the older practice let us be guided by the constitution of the growth rather than by its size.

Every effort should be made to determine the variety of tumor with which we are dealing at the operating table, especially by examination of its cut surface and also by immediate microscopic examination of a frozen section of the tumor. In young women it is advisable to expose small tumors after the method of plastic resection, but at all events opportunity must be had to make a detailed examination of the mass. If the latter proves to be a sarcoma, and, apparently, a malignant one, of the large spindle-cell or roundcell varieties, radical amputation should be done regardless of the age of the patient, the size of the tumor, or the presence or absence of enlarged lymph nodes.

If the tumor be small and represent a less malignant type of the disease than the foregoing and the axilla is apparently uninvolved, and finally if the patient be a young woman, it is justifiable perhaps to simply excise the tumor wide of its capsule and to keep watch over the patient for evidence of recurrence for a period of at least three years.

This, let us repeat, is justifiable only in exceptional instances, and the safest plan of 
procedure, and that which we propose to adopt in future cases, is to advise radical amputation in every instance.

Non-operative Treatment.-The $X$-ray, radium and Coley's fluid have been successfully used in the treatment of sarcoma of the breast. The field of application of irradiation in sarcoma of the breast is essentially the same as in carcinoma. According to Kienböck, this treatment is indicated primarily in those pre-operative cases in which the tumor will not assume an inoperable character in the meantime. We are not told how to differentiate the cases which will not become inoperable in the meantime, and as every surgeon experienced in the treatment of malignant neoplasms knows, this is impossible and can lead only to grave error.

Kienböck further advises the use of the $X$-ray in inoperable cases and we fully agree with him. Pfahler speaks of the results of $X$-ray therapy in inoperable and rapidly recurrent mammary sarcomas as "wonderful." He recommends the use of the $X$-ray in all inoperable cases and states that certain cases may be rendered operable with its use by destruction of underlying foci of the disease. Peterson has made a recent study of the results in cases of sarcoma treated by irradiation and concludes that while a permanent cure is possible under the treatment it is actually a rare occurrence. Comparatively little is written of Rœntgen therapy in breast sarcoma, but since the method of treatment is particularly efficacious in rapid, superficial, soft growths proceeding from the superficial tissues, it would seem that sarcoma of the breast, if not too extensive though inoperable, would be a very suitable form of the disease for this method of treatment. The effect of the Rœntgen rays on sarcoma was observed by Favvey in the case of a patient in whom a fibro-sarcoma of the left breast disappeared under $X$-ray treatment; this individual subsequently died of typhoid fever, and nothing was found at the previous site of the sarcoma except normal skin and scar tissue.

Judd states that the action of the $X$-ray in sarcoma as well as in carcinoma is primarily stimulative and causes "a changing over of the embryonic type of connective tissue into the adult type, a change from preponderant cells to a tumor mostly composed of fibers, and the final result is a fibroma with possibly latent sarcoma cells included in the mass." This satisfactorily accounts for the local recurrences of sarcoma, which have disappeared under $X$-ray treatment.

The present status of irradiation in the treatment of sarcoma of the breast may be summed up as follows:

The $X$-ray or radium and perhaps a combination of the two should be used in the treatment of inoperable mammary sarcoma. The prognosis is good in the absence of visceral metastases as regards prolongation of life but not as regards permanent cure of the disease. In certain instances, inoperable cases may in this wise be rendered operable by the destruction of nests of malignant cells situated beyond the reach of the knife.

Neither $X$-rays nor radium should be used in the treatment of operable sarcoma of the breast. As post-operative measures, these agents, especially the $X$-rays, should be routinely employed for prophylaxis.

The Use of the Mixed Toxins of Erysipelas and Bacillus Prodigiosus-Coley-in the Treatment of Inoperable Sarcoma of the Breast.

Coley has observed $\mathrm{r}_{7}$ cases of sarcoma of the breast in patients whose age varied between 16 and 55 years.

There was a history of antecedent trauma in 33 per cent. of the cases. In some instances the tumor developed so shortly after a local trauma, that there can be no question as to the causative influence of the injury in these cases. 
The duration of the tumors before operation varied between four weeks and three years.

As regards the histological types of the tumors, round-cell sarcoma was found in $\mathrm{I}_{3}$, spindle-cell in I, round-cell melanotic in I.

With regard to the total duration of life after operation, one case remained well five years after the first operation which was followed by three further operations during this period; the toxins were used after the last operation. Three cases lived one year after operation; one, one and one-fourth years; two, one and one-half years; one, a melanotic sarcoma, lived two years; one is well at present, two years after operation. (Toxins were used in this case.) In one case the entire duration of the disease, from the time the tumor was first noticed until death, was only four months. One case showed the other extreme: The patient was first operated upon in I882; she remained well until I889, when a recurrence took place, for which a second operation was done; in 1895 she was referred to Dr. Coley with an entirely inoperable recurrence and in bad general health, and recovered under the mixed erysipelas and bacillus prodigiosus toxins, remained well eight years and then died of an injury. Careful examination at the time of her death, in I 903 , showed no recurrence of her old trouble. The total duration of life in this case from the first operation was 2 I years.

One case is well and free from recurrence at the present time, nine years after the first operation. She had four operations in all plus four months' toxin treatment. One case was well ig years after disappearance under the toxins.

Three cases of the foregoing list must be regarded as permanent cures:

Case I.-E. F. Spindle-cell sarcoma, well ig years. This case was entirely inoperable and the diagnosis was confirmed by Dr. Wm. H. Welch of Johns Hopkins. The disease disappeared under the mixed toxin treatment.

Case 2.-Mrs. A. C. Adeno-sarcoma; recurrent case entirely inoperable; diagnosis confirmed by Prof. T. M. Prudden, professor of pathology of the College of Physicians and Surgeons of N. Y. She remained well eight years and then died of the results of an injury.

Case 3.-H. R. Well at present, nine years; had four operations and four months' toxin treatment.

In the last case it is impossible to estimate the exact part the toxins played in the cure, inasmuch as one operation was performed after the toxins were begun; however, as a rapid recurrence had followed each of the preceding operations, it would seem reasonable to assume that the toxins played some part in the cure.

The toxins were used in I 4 of Dr. Coley's I 7 cases; 3 of these cases should probably be excluded, inasmuch as the toxins were given only for two weeks, as the condition of the patients made it seem unwise to continue longer. In all of the cases the disease was inoperable at the time the toxins were begun, with exception of the three cases in which they were used as a prophylactic. In one of these, a rapidly growing tumor which had appeared immediately after a local trauma, the use of the toxins after operation apparently had little influence in preventing a recurrence. In the two other cases in which the toxins were used as a prophylactic, the patients were well when last heard from, one, one year, the other, two years later.

Glandular involvement was present in I I cases; in three there was no enlargement and in three no notes regarding this point were made.

\section{Literature upon Sarcoma of the Breast}

ALLIX.- "Cystosarcome du sein droit; ablation; trois recidives sur place; trois nouvelles opérations," Ann. soc. d'anat. path. de Bruxelles, I86o, iii, 22. 
Allrx.- "Quatrième recidives sur place d'un sarcome de la région mammaire; cinquième opération; mort," Ann. soc. d'anat. path. de Bruxelles, 1862, vi, I8. A

Amado.- "Adeno-cystic Sarcoma of the Male Breast," Correio Med. de Lishon, I87 r-72, i, 2 ro.

Amaya, R. and Garcia, A. P.- "Sarcoma mieloidea" (of breast), Rev. Med. Bogota, I883-84, viii, I31. Anderson, W.- "Recurrent Sarcoma of the Breast," Trans. Path. Soc. London, r872, XXIII, 254.

Armstrong, G. E.- "Sarcoma of the Breast," Montreal Medical Journal, I903, XXXII, 39 r.

ARNOLD.- "Üher einer Knorpel und Knochenhaltigen Tumor der Brustdrüse," Virchow's Archiv, I897, CXLVIII, 449.

Asheurst, John, JR.- "Cystic Mammary Tumor," Trans. Phila. Path. Soc., I883, v, 230.

Ashrurst, John, JR.--"Sarcoma of the Breast," Trans. Phila. Path. Soc., I88r, iii, r77.

AvLandr.-Osp. Mag., Igr 3, i, 5 rg.

Banks.-"Round-cell Sarcoma of the Male Breast," Clinical Notes, r884, p. 69.

Bantock.- "Cystic Sarcoma of the Breast; Extirpation," The Lancet, London, r880, i, 68r.

BatTLE.- "Osteochondrosarcoma of the Breast," Trans. Path. Soc. London, I886, XXXVIII, 473.

Battle.- "Two Cases of Sarcoma of the Breast," The Lancet, London, rgor, i, r77.

BaUchet et Gailret.-Gaz. des Hôpitaux, r86r, No. 79.

BAUR.-“Cystosarcoma phyllodes," Archiv f. anat. Phys. u. für wiss. Med., Leipz., i862, p. r69.

BeArson.- "Sarcoma of Female Mamma," Edinburgh Medical Journal, rgog, n.s., ii, 23.

Beckton.- "Note on a Sarcoma of the Breast Showing Early Ossification, Archives Middlesex Hospital, London, I9I 2, XXVII, 215.

Beckton.-- "Malignant Disease of the Breast; A Statistical Study Based on the Records of the Middlesex Hospital from rg04 to r908," Archives of the Middlesex Hospital, I909, XV, 74.

Beneke.- "Zur Histologie der fœetalen Mamma und der gutartigen Mammatumoren," Festschrift für Orth., I903.

Bennett.- "Cancerous and Cancroid Growths."

BerRÈze.- "Tumeur fibro-plastique du sein," Bull. de la soc. d'anat. de Paris, r866, XLI, 94.

von Bergatann, Bruns and von Mikulicz.-"System of Practical Surgery," translated into English, Bull and Flint, 1904, ii, 58r.

Betagh. - "Contributo allo conoscenza dei tumori maligni della mamella dell' uomo," Il Policlinico, Supplement, rgor, vii, 760 .

Billroth, Th.--"Die Krankheiten der weiblichen Brustdrüsen," Handbuch der Frauenkrankheiten, I 880 , p. 53 .

Billroth, TH.- "Tumors of the Mammary Gland," "Cyclopedia of Obstetrics and Surgery," Gussero and Grandin, $1887, \mathrm{IX}, 56$.

Brllroth, Th.--"Alveolares Melanosarcom der Brustdrüse," Klin. Chirurgie, Wien, I869-70, pp. 56 and $\mathrm{I} 42$.

Billroth, Th.-Archiv f. path. Anat., XVIII, 68.

BIRKETT.- "Adeno-cystic Sarcoma of the Male Breast," "Diseases of the Breast," I850, p. 257.

BockeNhemer.- " Uher die Tumoren der Brustdrüse und ihre chirurgische Bedeutung," Therapeutische Monatshefte, r909, XXIII, 463.

BODdaERT and VercouthliE.- "Note sur un cas de fibro-sarcome myxomatode du sein," Bull. Soc. de med. de Gaud., 1907, LXXIX, 226.

BONET.- "Sepulchretum," etc., Lugduni, r700, ii, 522.

BorChMEYER, M.- "Über Sarcoma Mammæ," Würzburg, r889, 80.

Bossi.- "Contributo allo studio dell'endothelioma mammario della cagna," N. Ercolani, Pisa, rgo5, X, $427,444,46 \mathrm{r}$.

BowlBy.- "Chondrosarcoma of the Female Breast," Trans. Path. Soc. London, I88r-82, XXXIII, 306 BRUCH.- "Épithéliome pavimenteux lobulée, cornée, d'apparence calcificée chez un homme," Bull. et. Mém. Soc. de Chirurgie de Paris, I885, XI, 887 , Obs. XVI.

Bryant.- "Secondary Melanotic Sarcoma of the Breast," "Diseases of the Breast," p. 456 .

Bryant.-Trans. Path. Soc. London, XIX, 387 .

BuFF.- - "Über eine melanotische Geschwulst der männlichen Brustdrüse," Inaug. Diss., München, r 904.

BulL.- "Spindle-celled Sarcoma of the Breast," Quarterly Medical and Surgical Journal, New York, I $882, i, 8$.

BuRcr.- "Di un emangiosarcoma endotheliale della mammella," Bull. Soc. Med. Pisana, r894-95, i, 28.

Butlin.- "Recurrent(?) Melanotic Sarcoma of the Breast," Trans. Path. Soc. London, 1886-87, XXXVIII, 343, Lancet, London, Jan. 8, r887, p. 72.

Савот, A. T.- "Sarcoma of the Breast," Boston Medical and Surgical Journal, $1876, \mathrm{XCV},{ }_{7} \mathbf{x}$. 
CABOt, S.- "Recurrent Sarcoma of the Breast," Boston Medical and Surgical Journal, r867, LXXVII, 313.

Canto.- "Sarcoma ulcerado de la mamma, etc.," Gaz. de l'hop. Valencia, r 882, i, 205.

Cartledge, A. M.- "Sarcoma of the Breast at the Age of Sixteen," Medical and Surgical Reporter, I 839 , LXVIII, 88.

Chambers. J. P.- "A Case of Sarcoma of the Breast in a Child of Four Months," University Medical Magazine, 1889 , ii, 376 .

Chretien.- "Sarcoma du sein; extirpation; exâmen histologique," Bull. soc. d'anat., Paris, t89r, LXVI, 367 .

Clark, A.- "Sarcoma of the Breast; Hemorrhage; Recovery," The Lancet, London, I879, ii, 200.

Clarke, Bruce.- "Calcifying Sarcoma of the Breast," Brit. Med. Jour., May 24, I89o, p. I I92.

CoËN, E.- "Chondro-osteo-carcinoma della mamella mulièbre," Bull. d. Sc. med. di Bologna, I8gr , 7s., ii, 302.

Coley, W. B.- "Development of Sarcoma after Injury," Annals of Surgery, I898, XXVII, 260.

Cotex, W. B.- "Injury as a Causative Factor in Carcinoma and Sarcoma," Annals of Surgery, IgII, i, 449 .

Collignon, P.—“Quelques cas de cancer du sein chez l'homme," Thèse de Paris, I9I3.

Conneli, F. G.-"Sarcoma of the Male Breast," Surgery, Gynecology and Obstetrics," r9o7, iv, I3.

COOPER, SIr Astrex.- "Illustrations of Diseases of the Breast," Phila., I845.

CORDIER.- "Contribution à l'étude des sarcomes kystiques de la mamelle, Paris, 1895 .

Cornic et Ranvier.-Manuel d'Hist. Path., i, 33r.

CoYNE:- "Sarcome endocanaliculaire et péricanaliculaire de la mamelle," Bull. Soc. d'anat. et de phys. de Bordeaux, $188_{5}, \mathrm{VI}, 210$.

CREDÉ.-Archiv f. klin. Chirurgie, I 885, XXXII, 308.

CROrT.-Archiv f. klin. Chirurgie, 1876 , p. 45 .

Cushing, H.-Bulletin of the Johns Hopkins Hospital, 1905, p. I 79 .

DA Costa.- "A Case of Endothelioma of the Mammary Gland," American Medicine, 1903, V, 1024.

Deaver, J. B.-Journal of the American Medical Association, I9 13, LX, 795.

Decomps et Murer._-"Tumeur du sein; adenosarcoma," Bull. et. mém. Soc. d'Anat., Paris, r903, LXXVIII, 392.

DE Roulet.- "Clinical Diagnosis of Surgical Diseases of the Breast," American Journal of Surgery and Gynecology, I903-04, XVII, I62.

DeSchwernitz, G. E.- "Sarcoma of the Breast," Trans. Phila. Path. Soc., I886, XII, 233; also p. 232.

DeSchwernitz, G. E.- "Sarcoma of the Breast," St. Louis Medical and Surgical Journal, r884, XLVI, 73.

DeSchwernitz, G. E.- "Spindle-celled Sarcoma of the Breast," Trans. Phila. Path. Soc., I886, XII, $229,233$.

Desmarest et Masson.-_"Sarcome à myeloplaxes du sein," Bull. et mém. soc. d'anat., Paris, I912, LXXXVII, 28 I.

Dor et PoNCET.- "Le cholestéatome du sein," Rev. de chirurgie, r902, XXV, 68.

Dubar, G.-- "Essai sur la sarcomatose osteoĩde," Thèse de Paris, I 888, No. 231.

-Duplax, S.-See Holmes" "System of Surgery," V.

Durham.- "Two Cases of Ossification of Tumors not Connected with Bone," Trans. Path. Soc. London, I883, XXXV, 378 .

Erliotт, J.- "Sarcomatous Tumor of the Breast Successfully Removed," Med. and Phys. Journal, London, I 822, XLVIII, 305 .

ElsBerG, C. A.-“Multiple Lymphosarcoma of Both Breasts," Annals of Surgery, Phila., Ig I 4, XL, 767

Englisch.-- "Cystosarcom der linken Brustdrüse; Extirpation; Heilung," Ber. aus der k. k. Krankenanst, Rudolph Stiftung in Wien, 1878 , p. 3 r 5 .

ENTz, J. J.- “Sarcoma of the Breast," International Journal of Surgery, N. Y., I8g6, IX, too.

FINDLAX, P.- "Sarcoma of the Breast," Chicago Medical Recorder, I879, XII, I86.

Finsterer, J.-_Zur Pathologie der männlichen Brustdrüse mit besondere Rücksicht der Tumoren," Deutsche Zeitschrift für Chirurgie, I9o6, LXXXIV, 201.

Finsterer, J.-“"Uber das Sarkom der weiblichen Brustdrüse," Deutsche Zeitschrift für Chirurgie, I 907. LXXXVI $35^{2}$. 
Froranı.- "Sopra un neoplasma raro della mammella; linfangiosarcoma melanotico," La Clinica Chirurgica, I902, X, 772 .

Frscher.- "Cystosarcom der rechten Mamma; Extirpation; Heilung," Zeitschrift f. Wundärzte und Geburtshülfer, I882, XXXIII, 223.

FRANK, L.- "Sarcoma of the Breast," Louisville Monthly Journal of Medicine and Surgery, I905-06, XII, I89.

FRIEND, E.- "Intracanalicular Fibroma of the Breast Undergoing Sarcomatous Change," Jour. Amer. Med. Asso., I909, LIII, I485.

Garciá, S.- "Examen microscopico de un sarcomixoma de la mamma," Prensa med. di Grenada, 1880, ii, 209 .

Gay.--"Adenoid or Spindle-shaped Sarcoma of the Breast," Trans. Path. Soc. London, 1874, XXV, 233. Gay, J.- "Recurrent Mammary Tumor; Spindle-celled Sarcoma; (?) Sixth Removal," Trans. Path. Soc. Lond., I 879-80, XXXI, 272, Lancet, London, I 88I, ii, 626.

Gebele, H.- "Zur Statistik der Brustdrüsengeschwülste," Beiträge zur klin. Chirurgie, I gor, XXIX, I67. GeIst and WrLensky.- "Sarcoma of the Breast," Annals of Surgery, July, I9I5, LXII, II.

GLuCK.-Archiv f. klin. Chir., I867, viii, 599 .

GoRHAm, W.- "Adenomyxofibroma papillare intra-canaliculare mammæ mit Sarkom und Epidermiszellen," Strasshurger med. Zeitung, rgr I, viii, I21.

GRAEFE, E.- "Heilung eines ungewöhnlich grossen Cysto-sarcoma der weihlichen Brustdrüse," Jour. de Chir. u. Augenheilk., Berl., I838, XXVII, 576 .

GREenovgh and Srmmons.- "Fibro-epithelial Tumors of the Breast," Annals of Surgery, rgII, V, 517.

GROHE.- "Cystische Fibrosarkom der Mamma mit epidermoïd Metaplasie," Deutsche Zeitschrift für Chirurgie, March, Igoo.

Gross, S. W.- "Sarcoma of the Female Breast; Based upon a Study of One Hundred and Fifty-six Cases," Amer. Journal of the Medical Sciences, I887, n.s., XCIV, I7.

GRoss, S. W.- "Sarcoma of the Breast," American System of Gynecology, r888, Vol. ii, 247.

Gross, S. W.- "Recurrent Round-cell Sarcoma of the Breast," Phila. Medical Times, 1879, IX, 383.

Groszbreckes.- "Ein Fall von Rundzellensarkom der weiblichen Brustdrüse," Inaug. Diss., Würzhurg, I 898 .

GRuget.- "Tumeur du sein (sarcome à glandes cellules)," Bull. de la soc. d'anat. de Nantes, I882; Paris, 1884, vi, 13; Jour. de med. de l'ouest, Nantes, I883, XVII, 215.

Guilbaud.-Gaz. méd. de Nantes, Igo6, 2 s., XXIV, 372.

HAECKEL, H.- "Beiträge zur Kenntiss der Brustdrüsengeschwülste," Archiv f. klin. Chirurgie, I894, XLVII, 275 .

Haslam, W. F.- "Sarcoma of the Male Breast," Birmingham Medical Review, r889, XXV, 286.

Heurtaux.-Mém. de la Soc. de Chirurgie, Paris, vii, I.

Heurtaux.- "Tumeur du sein (sarcome avec dilation glandulaire)," Bull. Soc. d'Anat. Nantes, r 876-8; Paris, $1879, \mathrm{i}, \mathbf{I}_{5}$.

Heurteloup.- "Tumeur mélanique du sein droit datant de neuf années; amputation; guérison depuis onze mois," Bull. Acad. de Med. de Paris, 1870, XXXV, 787.

Heurteloup et Duplay.-Vide Schuchardt's Archiv f. klin. Chirurgie, I869, XXXI, 33.

Hewson.-Gross "System of Surgery," 6th Edition, Vol. ii, p. 974.

Hrebaum, A.- "Zur Casuistik der multiplen Cystenbildung in der weiblichen Brustdrüse," Prager med. Wochenschrift, $1895, \mathrm{XX}, 304$.

Hirt, W.- "Sarcomatous Tumor of the Mamma," etc., Transylv. Jour. Med., Lexington, Ky., I $8_{3}$ I, IV, 508. Western Jour. Med. and Phys. Sci., Cincin., O., I832, V, 350; Baltimore Medical and Surgical Journal and Review, I833, i, 505 .

vaN Hocker.- " "Über das Vorkommen von Knorpel und Knochen in einer Geschwulst der weiblichen Brustdrïse," Archiv f. klin. Chirurgie, I88I, XXVII, 614.

Hofmann, A.- "Ein durch die grosse Zahl der Recidive, sowie durch einen ausnahmsweise langdauernden recidivfreien Intervall bemerkenswerther Fall von Mammasarkom," Archiv f. klin. Chirurgie, I894, XLVIII, 93.

Holder, A. B.- "Sarcoma of the Mamma," Memphis Medical Journal, I896, XVI, 66.

HoRner.- "Über die Endresultate von 172 operirten Fälle von malignen Tumoren," Beiträge zur klin. Chirurgie, I894, XII, 6I9.

Houzer, G.- "Sarcome du sein gauche; amputation; guérison, trois mois aprés apparition d'un sarcome de la dure-mère chez la même malade. Ablation; recidive rapide sur place," Arch. prov. de Chir., Paris, Igro, XIX, 88. 
HUBER.-Archiv für Heilkunde, I878, XIX, r29.

Hubert.-Bull. et mém. soc. d'anat. de Paris, XLVIII, 690.

Hueter und Karrenstein.- "Eine Mischgeschwulst (Osteoidsarkom) der weiblichen Brustdrüse," Virchow's Archiv, 1906, CLXXXIII, 495.

Jackson, V.- "Very Large Sarcomatous Tumor of the Right Breast of a Female; Successful Removal," British Medical Journal, r888, i, 957 .

JACOBI, A.—“Fibro-sarcoma of the Breast," Bull. New York Pathological Society, I88I, 2s., i, 9 r.

JAcOBORICr.-"Fibroma of the Breast," Spitalul. Bucuresci, I9I 2, XXXII, 473.

JACOBSON, N.-Medical News, Jan. 20, I897.

JoHnson.-University College Hospital Report, I889.

JoHnson, C. P.- "Medullary Sarcoma of the Breast," Stethoscope and Virginia Medical Gazette, Richmond, 185 I, i, r39.

Jopson, SpEese and Wirte.- "Tumors of the Breast in Childhood," Annals of Surgery, I908, II, 668.

JuDD.- "The $X$-rays in the Surgery of Sarcoma," Medical Record, I906, LXX, I020.

KAREWSKI.- "Surgical Diseases of Children."

KaUtSCH.-Deutsche Klinik, I905, viii, 9 I6.

Keenan.-Montreal Medical Journal, I903, XXXII, 392.

Kennedy and CASE.- "Carcinoma and Sarcoma of the Same Breast," Trans. Path. Soc. of Phila., Apr. 8 , I9I5.

KesSeL.- "De sarcomatis cystici mammae muliebris specil nova, Bonn, I839, Inaug. Diss.

Ketrle.-"Sarcoma of the Breast," The Lancet, London, r9r 2, ii, 750.

KLOB.- "Anomálien der Brustdrüse," Path. Anat. der weiblichen Sexorgane, I864, p. 480 et seq.

Konjetznx.- "Das Cholesteatom der Brustdrüse," Berliner klin. Wochenschrift, I9I 2, XLIX, I585.

KüRSTEINER.- "Adenom der Milchdrüse mit cylindrischem und geschichtetem, zum Theil verhorntem

Epithel," Virchow's Archiv, I894, CXXXVI, 302.

KüsTER.-Archiv f. klin. Chirurgie, I88I, 307.

LaHm.- "Ein Cholesteatoma carcinomatosum der Mamma," Monatschrift für Geburtshülfe und Gynäkologie, 1914, XXXIX, 496.

LANCEREaUX.- "Une tumeur du sein constituées par une trame fibreuse avec myéloplaxes et de quelque cellules pigmentaires," Bull. de la soc. d'anat. de Paris, I860, XXV, 292.

LANDaU.-_"Krebs und Sarkom am gleichen Menschen,". Münchener med. Wochenschrift, I905, LII, 650.

LANGENBECK.-MIed. Centralzeitung, XVIII, 3.

LARDENors et MOURE.- "Lymphocytome du sein; mastite carcinomateuse aiguë de Volkmann," Bull. et mém. de la soc. d'anat. de Paris, Igr4, LXXXIX, 94.

LAURIE.--"Case of Sarcoma of the Breast," Intercol. Med. Jour. Australas, Melbourne, r907, XII, 406.

LAWRENCE.-Medico-Chirurgical Transactions, iii, 72.

LECÈNE.- "Tumeurs mixtes du sein," Rev. de Chirurgie, Paris, Igo6, XXXIII, 434.

LECÈNE, P.- "Tumeur mixte du sein chez la femme (sarcome a myeloplaxes et epithelioma pavimentaux)," Bull. et mém. de la soc. d'anat. de Paris, I904, LXXIX, 698.

Legrain.- "Sarcome du sein chez une femme Kabyle," Bull. Soc. franç., de dermat. et syph., Paris, I906, XVII, 36; Ann. de dermat. et syph., Paris, rgo6, 4s., VII, 69.

Legrange et Duret.-Bull. et mém. de la soc. d'anat. de Paris, XIVIII, 5 I6.

LESER.- "Beiträge zur pathologischen Anatomie der Geschwülste der Brustdrüse," Beiträge zur path. Anat. u. Physiologie, I888, ii.

Licinr.- "Contributo allo studio dei tumori della mamella; un caso di emangiosarcoma," Riforma Medica., Napoli, I9I I, XXVII, I319.

LIELI, E. S.- "Sarcoma of the Breast," Virginia Medical Semi-Monthly, Richmond, I904-05, IX, 83; Southern Med. Jour., Nashville, I908, i, 392.

Lilienthal, H.- "Enormous Sarcoma of the Breast," Annals of Surgery, I905, XIII, 455.

Lippens, A.- "Operation de Handley pour sarcoma du sein chez une jeune fille de I6 ans," Gazette de Gynécologie, Paris, I9ro, XXV, I45.

Lorrain et MÉNARD. - Bull. de la soc. d'anat. de Paris, r909, XXXIV, ro3.

McGraw.- "Sarcoma of the Breast Weighing I2 Pounds," Tr. Med. Soc. of Michigan, Lansing, I869, iii, 59 .

McJunkin.- "A Case of So-called Adeno-sarcoma of the Mammary Gland," Physician and Surgeon, Ig07, XXIX, 21.

McWilliams, C. A.- "Bilateral Lympho-sarcoma of the Breasts," Annals of Surgery, I912, LV, 439. 
MaNz, OтTо.- "Über Riesenzellensarkome der weiblichen Brustdrüse," Beiträge zur klin. Chirurgie, I895, XIII, 66.

Mallotzel, Autefage et Bornait Legueule.,"-Adeno-sarcome à myélopIaxes du sein, etc.," Bull. et mém. de la soc. d'anat. de Paris, x 904 , LXXIX, 674 .

Manson, J. S.- "Hereditary Transmission of Sarcoma," British Medical Journal, 1913, ii, II35.

Marchand.-Gaz. des Hôpitaux, 1869, p. I96.

Marignac.-Bull. et mém. de la soc. d'anat. de Paris, LII, 428.

Markoe, T. M.- "Clinical Remarks on Sarcoma of the Breast," Medical Gazette, New York, I883, X, 318.

Mauclarre.- "Sarcome mixte du sein," Gazette des Hôpitaux, Paris, I903, LXXVI, 925.

Mazzoni.- "Sarcoma parvocellulare al disopra di un enorme sarcoma magnocellulare della mammella sinistra," Clin. Chir. (Mazzoni) Roma, I876, iii, I59.

Mermet, P.- "Cystosarcoma hematode du sein," Büll. et mém. de la soc. d'anat. de Paris, 1895, LxX, 348.

MEUNTER, H.- "Sarcome du sein; regréssion d'un noyau secondaire de l'autre sein," Archives générale de Med., Paris, I896, i, 725; ii, 9 I.

Mres, G. W.- "Mammary Sarcoma," Denver Medical Times, rgo7, XXVI, зга.

MODEL. - "Ein Fall von glandulärem Cystosarcome mit autogenem Atherom," Inaug. Diss., Erlangen 1858 .

Monod.- "Tumeur volumineuse du sein," Med. Moderne, I898, IX, No. 20, p. 152.

Monski.- "Untersuchung über nicht carcinomatöse Geschwülste der weiblichen Brustdrüse," Inaug. Diss., Freiburg i. Bađen, I894.

Moore, J. W.- "Myxo-sarcoma of Breast," Proc. Path. Soc., Dublin, $1875-77$, n.s., vii, 2 I6.

MORELLI.- "Vasto fibro-sarcoma della mamella destro," Morgagni, Napoli, I879, XXI, 284.

MoRNARd et MASSON.--"Un volumineux sarcome du sein succedant à une tumeur benigne," Bull. et mém. de la soc. d'auat. de Paris, I909, XXXIV, 67.

Morris.- "Myxoma of the Mamma, Recurrence, Death," Trans. Path. Soc. London, XXIII, 274.

Morton.- "Sarcoma of the Male Breast," Glasgow Medical Journal, I88o, XIV, I57.

MorTon, C. A.- "Calcifying Chondro-sarcoma of the Breast," Trans. Path. Soc. London, I904, LV, 327.

Morton, C. A.- "Pure Sarcoma of the Breast with Marked Gland Infection," Trans. Path. Soc. of London, I892-93, XLIV, I 26.

von Mosetig.-Archiv f. klin. Chirurgie, 1877 , p. 300.

Movcher, A.- "Sarcome pur fasciculé de la mamelle," Bull. et mém. de la soc. d'anat. de Paris, r893, LXVIII, 545 .

MOURE et DE JONG.- "Sarcome massif du sein," Bull. et mém. de la soc. d'anat. de Paris, 19r4, LXXXIX, 32.

MÜLLER, E.—" Úber ein Sarkom in der Gegend der männlichen Brust," Inaug. Diss., Würzburg, I895.

Müller, JoHAnNes. - "Über den feinern Bau der krankhaften Geschwülste," I 838, p. 53.

NANCREDE.- "Case of Large Spindle-celled Sarcoma of the Mammary Gland,". Phila. Medical Times, I879-80, X, 359; Trans. Path. Soc. Phila., I882, X, I93.

NeUMaNN.- "Fibromyxom der Mamma mit übergang in sarcomatöse Wucherung," Archiv für Heilkunde, I868, IX, 480 .

"Zur Kasuistik der Myxome und Cylindrome," Archiv für Heilkunde, I868, IX, 480.

von Nussbaum.-Archiv f. klin. Chirurgie, I872, XXXII, 297.

PAGET. - "Lectures on Surgical Pathology," 1876, p. 543.

PAGEr.- "Lectures on Surgical Pathology," I 854, p. 260.

Poulsen.- "Die Geschwülste der Mamma," Archiv für klin. Chirurgie, I 89 I, XIIII, 593, 634.

PEAU.- "Fibro-sarcoma du sein; recidive à une opération fait vingt-cinq ans avant," Leçons de klin. chir., I 892 , p. 960 .

Petit, G.- "Les sarcomes de la mamelle en pathologie comparée (.12 observations)," Bull. de l'asso. franç. pour l'étude du cancer, Paris, I $9 \times 2, \mathrm{~V}, \mathrm{x} 35-162$.

Peterson, O. H.- "Zur Frage der Dauerheilungen von Sarkomen durch Röntgenstrahlen," Strahlentherapie, I913, iii, 420 .

Pilliet, A. H.- "Cystosarcome papillare du sein," Bull. et mém. de la soc. d'anat. de Paris, I893, VII, $5 \circ 6$.

Pick.-Trans. Path. Soc. London, XX, 347 . 
Pierre-Nadal et Lacouture.-Tumor mixte du sein à formation malpighiennes," Bull. et mém. de

la soc. d'anat. de Paris, rgro, XXXV, 6r6.

PrTHA.--Langenbeck's Archives, VIII, 599.

PorTA.-Schmidt's Jahrbücher, I857, XCII.

Post.- "Fibro-sarcomatous Tumor Removed from the Left Breast," Medical Record, N. Y., I872, VII, II2.

Powers.- "Sarcoma of the Breast," Colorado Medical Journal, Denver, I9I 2, IX, 203.

Powers, D'Arcy.- "Sero-cystic Disease of the Breast," British Medical Journal, July 28, I883, p. I66.

PrYM, P.- "Fibro-cystadenoma sarkomatosum der mamma mit Metastasen," Frankfurter Zeitschrift f. Pathologie, Wieshaden, I9 $2, \mathrm{X}, 60$.

Purcell._" "Sarcoma of the Right Breast," British Gynaecological Journal, I888-89, IV, 442.

Purzo.- "Sopra un caso de sarcoma della mamella maschile," Riforma Medica, December, Igr2, XXVIII, ${ }_{3} 38$.

RandolPH and Wnssow. - "Breast Affections; a Series of roo Cases," Maryland Medical Journal, rgir, LIV, 335 .

Reverdin.-Bull. et mém. de la soc. d'anat. de Paris, XLII, jo8; XLIV, 285.

Rheinoff.- "Uber Riesenzellensarkome der weiblichen Brustdrüse," rgo3, C. Lehman, Freiburg i. Boden, 3r, p. 80 .

RICHARDSON,- "Round-cell Sarcoma of the Male Breast," Trans. Southern Surgical and Gynaecological Asso., I903, XVI.

Richeцот, L. G.- "Des tumeurs kystiques de la mamelle," Thèse d'Agra, 1878 .

Richer, M.- “Tumeur rare du sein; sarcome kystique," Gazette des Hôpitaux, Paris, June r7, r880, LIII, 553 .

RICher, M._- "Kysto-sarcome du sein," Gazette des Hôpitaux, Paris, r88o, LIII, i I6 I.

RIED, Mont.- "Über ein doppelseitiges myeloides Chlorom der Mamma," Beiträge zur klin. Chirurgie, Tüingen, $\mathrm{r}_{9} \mathrm{I} 4 \mathrm{XCV}, 47-55$.

RoBIN.-Bull. et. mém. de la soc. d'anat. de Paris, XLVIII, 8I 7.

Robertson.- "Endothelioma of the Breast," Proc. Roy. Soc. Med. Surgical Section, Lond., I9I3-I4, VII, I08.

Rodman, IV. L.- "Sarcoma of the Breast in a Little Girl of Eleven Years," Annals of Surgery, I $9 \circ 6$, XIIII, $3 \circ 8$ :

Rörer, A.— "Ein Fall von cystischem Endotheliom der männlichen Brust," Inaug. Diss., Würzburg, I89r.

Rosenstein.- "Ein statisticher Beitrag zur operativen Behandlung der bösartigen Brustdrüsengeschwülste," Archiv für klin. Chirurgie, rgor, LXIII, 555 .

Rothurann,-- "Ein Fall von cystischem Endotheliom der männlichen Brust," Würzburg, x $89 \mathrm{r}$.

Satterthwait, T. E.- "Sarcoma of the Breast," Trans. N. Y., Path. Soc. N. Y., I881, 2 s., i, 223.

Schadel.-See Schuchardt, Archiv f. klin. Chirurgie, r885, XXXII.

Schmmelbusch.- "Das Cystadenom der Mamma," Archiv für klinische Chirurgie, I89i, XIIV, ir 7.

Schmid, G. B.- "Ein Fall von Cystosarcom mit Epithelperlenbildung in der Mamma," Archiv für Gynäkologie, Berlin, r884, XXIII, 93.

Scrumr.- "Über das Angiosarkom der Mamma," Archiv für klin. Chirurgie, I887, XXXVI, 42 I.

Schмто. - "Die Geschwülstè der Brustdrüse," Beiträge zur klin. Chirurgie, I888, IV, 40.

Schmockert, K.- "Adeno-fibrom der Mamma übergehend in Adeno-sarkom," Inaug. Diss., Munchen, Wolf und Sohn, r904.

Schró́per, E. O. H.- "Über das Sarkom der Mamma," Berlin, I9r2, H. Blanke.

Schuchard.- "Zur Kasuistik und Statistik der Neubildungen in der männlichen Brust," Archiv f. klin. Chirurgie, I 885, XXXI, I.

Schuoler. - "Beiträge zum klinischen Bilde des Brustdrüsensarcoms," Correspondenzblatt für schweizer Aerzte, $1890,283$.

Schwartz.- "Three Unusual Tumors: Carcinoma and Sarcoma Mammæ," American Journal of Obstetrics, rgr 3 , LXVIII, : $5^{2}$.

Secousse. - "Sur un cas de fibro-sarcome kystique de la mamelle s'accompagnant de points carcinomateux et à contenu gélatineux," Jour. de méd. de Bordeaux, I9I2, XLII, 79 I.

Segond et Renadd.- "Histoire d'une sarcome du sein," Bull. d. l'assos. franç. pour l'étude du Cancer, Paris, rgro, iii, ro4.

SeHrt.— Beiträge zur Pathologie der Milchdrüse," Beiträge zur klin. Chirurgie, I907, LV, 574. 
SIEBERT, E.- "Das Sarcom, insbesondere seine Lokalisation in der Mamma," München, I903, G. Hoffmann.

SEll.- “Mammary Tumor," The Medical Record, N. Y., r877, XII, 360; Trans. New York Path. Soc., Apr. 22, I875.

Sheild, M.- "Unusual Tumor of the Breast, British Medical Journal, 1883 , iv, 965 .

SHEILD, M.- "Remarks on a Case of Recurrent Sarcoma of the Mammary Gland Treated by Coley's Fluid, with Fatal Result," British Medical Journal, I879, i, I94.

Sheild, M.-“Diseases of the Breast," London, 1898.

Shere.- "Sarcoma of the Breast," Colorado Medical Journal, Denver, I9 I4, ii, 49.

Simon.-Berliner klin. Wochenschrift, I9I2, XLIX, No. 9.

Simpson, C. E.- "Endothelioma of the Breast with Report of a Case," Journal of the Michigan Medical Society, Detroit, I907, VI, 285.

Speese, J.- "Sarcoma of the Breast," Annals of Surgery, Phila., I909, XLIX, 428.

SpeEse, J.- "Tumors of the Male Breast," Annals of Surgery, Phila., I9 I 2, LV, 536 .

STEXNBERGER, I.-- "Ein Fall von Sarcoma fusocellulare der Brustdrüse," Wiener med., Presse, r889, XXX, I84I, I90I.

Stilling.- "Uber Osteoidsarkome der weiblichen Brustdrüse," Deutsche Zeitschrift für Chirurgie, I $88 \mathrm{r}, \mathrm{XV}, 247$.

Stoerk and ERDheim.- "Uber cholestea tomhaltige Mammaadenom," Weiner klinische Wochenschrift, I904, XVII, 358.

Stokes.- "Mammary Sarcoma," Proc. Path. Society of Dublin, I880-82, n.s., IX, I47.

Stone, W. J.- "The Surgical Pathology of roo Mammary Tumors," Surgery, Gynecology and Obstetrics; I905, i, 400 .

Studsgaard.-See Schuchardt, Archiv f. klin. Chirurgie, I885, XXXII, ז.

Sutron, J. B.-_Tumors, Innocent and Malignant."

Sutron, J. B.--"Keen's Surgery," Vol. i, 750.

Sutron, J. B.- "An Ossifying Sarcoma of the Female Breast," Archives of the Middlesex Hospital, r9ıo, XIX, 98 .

Swann, A.- "Cystic Tumor of the Breast; Removal; Recovery," The Lancet, London, I880, i, 9 I5.

Theilmaber.- "Die Beziehungen von chronischer Entzündung, Narbe und Trauma und die Fortpflangungsorgangen zu der Entstehung von Tumoren," Deutsche med. Wochenschrift, rgr2, i, 264 .

Thompson, R.- "A Case of Sarcoma of the Breast; Operation; No Recurrence at the End of Five Years," Medical Press and Circular, London, r9o8, n.s., LXXXVI, 722.

Thiriar.- "Cysto-sarcome volumineux du sein droit; ablation," Presse med. belge., Bruxelles, r88o, XXXII, I 29.

Tiesze.- "Hautsarkom in der Mammagegend einen Mammatumor vortäuschend," Zentralbl. f. Chirurgie, I900, 50 (Appendix).

Tillaux,-Thèse de Cordier, Paris, i880, No. 494, p. I6.

Trllaux.- "Sarcome du sein," Méd. moderne, I894, V, I557.

TRELAT, M.-Fibro-sarcome lacunaire d̦e la mamelle," Gazette des Hôpitaux, Paris, r889, LXII, 679.

TRINITHEk.-The Lancet, London, r9o3, ii, I58.

VALUDE, M. E.- "Adenome sarcomateux kystique de la mamelle," Bull. et mém. de la soc. d'anat. de Paris, I884, LIX, 269; Prog. Med., Paris, I884, XII, I Ioo.

Ver.Peau.- - "Traitê des Maladies du Sein," 1858, pp. 432, 434.

VENOT.- "Récidive de sarcome du sein," Jour. de méd. de Bordeaux, r903, XXXIII, 673.

Vieregge, J. A.- "Melano-sarcoma of the Breast in an Infant," Northwestern Lancet, St. Paul, I8gr, $\mathrm{XI}, 28$.

VIGNARD.— "Fibrome du sein transformé en adéno-sarcome," Gazette méd. de Nantes, Igo6, 2s., XXIV, 370.

VIGNARD.- "Sarcome du sein simulant une mammite," Gaz. med. de Nantes, I909, 2 s., XXVII, 256.

VIRCHOw, R.-“Über Perlgeschwülste," Virchow's Archiv, I855, VIII, 37I; "Die Krankhaften Geschwülste," Berlin, r863.

Vignerat.- "Myxo-sarcome du sein extrémement volumineux; ablation de la tumeur," Bull. et. mém. de la soc. d'anat de Paris, I889, LXIV, 485 .

von Volkmann.- "Sarkom der weiblichen Brustdrüse" (?), Beiträge zur. klin. Chirurgie, i875, p. 3Ir. - WARD.--"Sarcoma of the Male Breast," Trans. Path. Soc. London, I860, XI, 268. 
Watson, C. G.- "Chondro-sarcoma of the Breast," Catalogue of the Museum of the Royal College of Surgeons, London, xgog.

Weigandt.- "Ein Fall von Riesenzellensarkom der Mamma," St. Petersburger med. Wochenschrift, I 877 , ii, 406 .

WEINBERGER.-Zeitschrift für Heilkunde, I907, XXVIII, I.

Weinlechner.- "Zwei Fälle von Cystosarcom phyllodes in der weiblichen Brust, etc.," Berichte der k. k. Krankenanstalt, Rudolph Stiftung in Wien, 1876, 349.

Wharton, H. R.- "Recurrent Sarcoma of the Breast," Trans. Phila. Path. Society (1887-89), I89r, XIV, 2 Io.

Wharton, H. R.- "Tumors of the Breast; Two Specimens," Trans. Path. Soc. of Phila., 1887-89, - XIV, 2 II.

Whitson.- "Case of Adeno-sarcoma of Mamma; Removal of Growth; Recovery," The Lancet, London, I883, $\mathrm{i}, \mathrm{I} I 22$.

Wirliams, W. R.- "Melanotic Sarcoma of the Breast," Medical Chronicle, I 893-94, XIX, 366.

Willians, W. R.- "Sarcoma of the Breast," Medical Chronicle, MIanchester, I 893-94, XIX, $289 ; 361$.

Williams, W. R.- "The Varieties of the Mammary Neoplasms and Their Relative Frequency," British Medical Journal, Sept. 10, 1892, 576 .

Williass, W. R.- "Diseases of the Breast," "Twentieth Century Practice of Medicine," XVII, 542. WILMs.- "Die Mischgeschwülste," I902, iii, heft.

WINCKEL.- "Lehrbuch der Frauenkrankheiten," 1 886, p. 756.

WinfIELd.- "Report of a Case of Cutaneous Angio-sarcoma," Jour. of Cutaneous and Genito-urinary Diseases, I9oo, VIII, I I 3.

Winsiow, R.-- "Specimen of Spindle-celled Sarcoma of the Breast Removed from a Woman 73 Years of Age," Maryland Medical Journal, Baltimore, $1884-85$, XII, 243.

Zambianchi.-Bull. et mém. de la soc. d'anat. de Paris, XIVI, 314.

Zerenin.- "Bilateral Sarcoma of the Mammary Gland," Med. obozr. Moskow, LXX, I39.

\section{Literature upon Sarcoma and Carcinoma Combined in the Same Breast}

Barton, J. M.- "Sarcomatous carcinoma of the Mamma," Trans. Path. Soc. of Phila. (r88I-83), I884, $\mathrm{XI}, 2$ ro.

Benmosche.- "A Case of Primary Double Growth in One Breast," Archives of the Middlesex Hospital, London, I9II, XXIII, 97.

Coenen.- "Über Mutationsgeschwülste und ihre Stellung im onkologischen System",·Beiträge zur klin. Chirurgie, I910, LXVIII, 605.

DoRsch.—“Über Carcinom und Sarkom derselben Mamma,” Inaug. Diss., Würzburg, I896.

Hedren.- "Sarkocarcinom der Mamma," Centralbl f. allg. Path. u. path. Anat., I9I5, XXVI, No. Io. p. I9.

HENCKE.—“Mikroskopischen Geschwulstdiagnostik," 1906.

HerXhermer.- “Das Carcinoma Sarcomatodes," Zeigler's Beiträge zur path. Anat., I9o\&, XIIV.

KaUfmann.- "Lehrbuch der speziellen pathologischen Anatomie," I9I I, 6th Ed., p. 605; Virchow's Archives, 1898 , CLIV.

Kennedy and Case.-Trans. Path. Soc. Phila. Ap. 8, I9I 5.

KeRBirion et Danel.- "Sarco-epithéliom kystique du sein," Jour. d. Sc. med. de Lille, ז879, i, I 75.

Kettle, E. H.--"Carcinoma and Sarcoma in the Same Breast," The Lancet, London, x9 1 2, ii, 750.

KRAVEhenko.- "[Mixed Tumors of the Breast]", Khirurgia, Moskau, I9I2, XXXII, 50I.

Krompecher.-Ziegler's Beiträge zur path. Anatomie, I908, XLIV, 88.

LIPPMANN.- " Das Carcinoma Sarcomatodes," Inaug. Diss., Berlin, I907.

Morales, A.- "Mastitis; sarcomas y carcinomas mammarios," Rev. de med. y cirug. pract. Madrid, I9I 2, XCVI, 201.

Nebesky.- "Über das gleichzeitige Vorkommen von Sarkom und Carcinom im Uterus," Archiv f. Gynäkologie, I904, LXXIII, 653.

ORTH.-Charité Annalen, 19 ro, XXXIV, 2 I.

Perrier, H.- "Les Sarco-carcinomes du sein," Rev. méd. de la Suisse Romande, Geneva, I9I 2, XXXII, 447.

Pfeifrer, D. B.-_"Mixed Tumors of the Breast with Malignant Changes Both in the Connective Tissue and in the Epithelium," Trans. of the Path. Soc. of Phila., I9ro, n.s., XII, 267. 
Schlagenhaufer.- “Carcinom und Riesenzellsarkom derselben” Mamma," Centralb1. f. allg. Path. u. f. path. Anat., I906, XVII, 385 .

Schwarz, E. - "Carcinoma and Sarcoma Mammæ," Amer. Jour. Obstetrics, New York, rgra, LXVIII, 752.

Tokano, K.- "Über das Carcinoma sarcomatodes der Mamma," Archiv k. klin. Chirurgie, I9I3, CIII, $\mathrm{I}_{55}$.

WeHNer._ "Ein Beitray zur Frage der Karzinosarkome unter Mitteilung eines Mammatumors," Frankfurter Zeitschrift f. Path., Wiesbaden, I9r4, XVI, r67.

Younc, R. A.--"On Multiple Primary Malignant Growths," Archives of Middlesex Hospital, iii, I65.

\section{THE FIBRO-EPITHELIAL TUMORS OF THE MAMMARY GLAND}

Pathology. - The fibro-epithelial tumors form a group to which the generic name fibro-adenoma is commonly applied. The term "pure adenoma" refers to a morbid grow $\mathrm{h}$ completely isolated from the surrounding breast tissue by a well-marked capsule; and composed entirely of the glandular or parenchymatous tissue. It usually turns out to be a fibro-adenoma in a state of lactation hypertrophy. By "fibro-adenoma" is understood a similarly circumscribed and encapsulated tumor whose structure, like that of the breast itself, consists of glandular or parenchymatous tissue, embedded in a fibrillar or cellular matrix. In neither of the tumors is the normal structure of the inactive breast perfectly repeated. When a small circumscribed node of tumor-like appearance, removed from the breast, is found to have a structure exactly corresponding in arrangement and appearance with that of the breast itself, it may generally be concluded that it is not a tumor, but a lobule of the breast.

To come to an understanding of the origin of tumors of this class it is important to keep in mind the restless character of the mammary tissues, and their variations in structure.

The gland grows slowly from year to year during childhood, then at puberty takes on a sudden and rapid enlargement to many times its previous size. What it next does depends upon the individual. In the great majority of cases it seems to remain quiescent almost indefinitely, but in not a few cases it is roused to secretory activity, or manifests hyperemia, or shows some other disturbed effect at each monthly period. During pregnancy it experiences a growth that replaces the adipose deposits, more or less completely according to the individual responses to the stimuli, with acini of newly formed glandular parenchyma. When lactation is ended, involution removes this same acinous tissue, and fatty deposits again take its place. Each time pregnancy and lactation occur the same phenomena are repeated. When the climacteric is reached, retrogressive changes in both parenchyma and stroma continue to make slow progress indefinitely.

From this it is clear that the mammary tissues are quick to respond to stimuli, and that there must be many stimuli capable of exciting the glands. In another chapter it is shown that the responses manifested by different glands and even by different parts of the same gland not infrequently lack uniformity. As some indolent lobules of a lactating breast may fail to grow or to functionate, so peculiarly sensitive portions of a quiescent gland may respond, by growth or by functional activity, to stimuli not intended to produce such effects and not sufficient to affect the entire gland. Under such circumstances, local growth of either matrix or parenchyma or both takes place, and a mass is formed that may constitute the foundation of a tumor. This is entirely in keeping with our theory that the growth and functional activity of the mammary glands, whether general or local, is regulated by the effects of hormones or internal secretions, and yet is in no sense 
opposed to the hypothesis that local growth and local activity may arise through local disturbances arising in the breast itself. In that most varied of the disturbed activities of the breast known as "abnormal involution," there are to be found in nearly all cases areas that show just such evidences of localized growth as have been under consideration and may eventuate in tumors. We regard the fibro-epithelial tumor, therefore, as the result of some kind of stimulation of breast tissue followed by localized growth.

In senile breasts, and especially in those in which "abnormal involution" is present, occasional circumscribed growths of the peri-ductal connective tissue can be found. The fibrillar tissue becomes increased out of proportion to the parenchymatous tissue which it transforms by compression, dislocation or distention, until a strong resemblance to "peri-ductal fibroma" is presented. There is, however, this difference: the true peri-

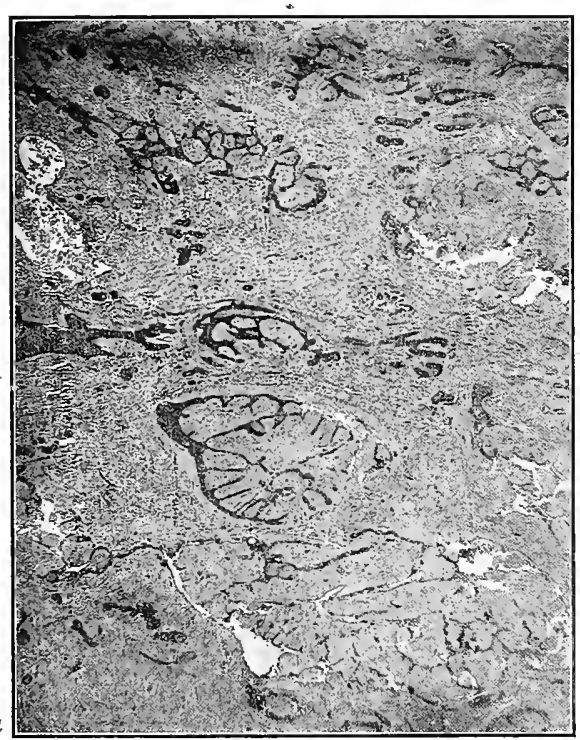

FIG. I59--Intra-canalicular periductal fibroma of the breast seen under a very low magnification.

ductal fibroma is surrounded by a capsule that separates it from the surrounding healthy breast tissue, which these tumor-like formations of abnormal involution lack. None has been observed with a capsule.

Our purpose in calling attention to these disturbances of growth as an introduction to the fibro-epithelial tumors is to show that hyperplastic disturbances of connective tissue in the breast are frequent in occurrence, and that they form a series of which only the extreme forms a distinct tumor.

Pathological Histology.-The fibro-epithelial tumors consist of both fibrillar-periductal-and parenchymatous-epithelial-tissues. In some cases the parenchyma appears to be passive, the vegetative activity manifesting itself in the connective tissue which proliferates rapidly or slowly, draws upon, crowds, compresses and deforms the 
parenchyma. In other cases it is clear that the parenchyma is itself under stimulation and grows as the connective tissues grow, the combined product of the two crowding aside the surrounding mammary tissue, compressing and destroying it. In still other cases the activities in the parenchymatous tissue exceed those in the connective tissue and the resulting tumor appears more glandular than fibrillar. But in all cases the relations of the tissues to one another are disturbed. The true fibro-epithelial tumor, though easily resolved into epithelial elements derived from the gland and connective tissue of periductal origin, shows loss of the normal relationships, and a more or less radical departure from the typical structure of the breast. The epithelial tubules sprout and extend in all directions with the formation of new tubules like those of the developing breast, but without the formation of lobules, and the peri-ductal tissue ceases to be peri-ductal, and

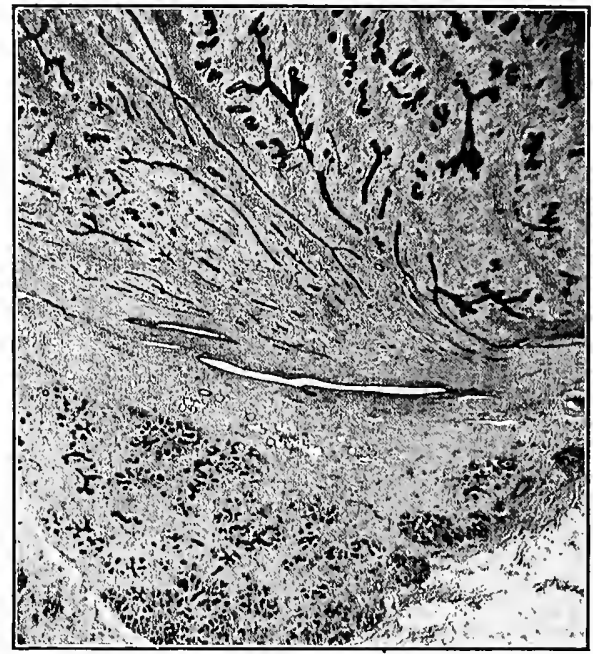

Fig. I60.-Edge of a fibro-adenoma, showing the tumor above and the breast below. The separation of the tumor from the breast through traction upon the ducts, and the formation of the connective tissue capsule by compression are foreshadowed.

forms a more uniform matrix into which the developing parenchyma extends. The result is complete loss of lobular structure in the parenchyma and of peri-ductal distribution of the connective tissue. Such local excesses of growth may arise at one or many foci, in one or both breasts, but wherever they occur, the result is a tumor.

As the mass grows, it occupies space at the expense of the breast, compresses it, provokes atrophy of the neighboring parenchyma, and soon becomes surrounded by a zone of condensed connective tissue that forms its future capsule. While the tumor is growing and the type of its structure changing, traction is made upon the ducts at its periphery, which sometimes become enormously elongated and compressed and at length rupture, so that before the growing mass is much larger than a pea it may have separated itself from the breast proper, and its stroma of growing tissue abuts against a thinned zone of atrophic surrounding connective tissue from which it readily escapes when 
incised. Accumulated secretion or exuded lymph sometimes collects in and distends the tubules of the parenchyma-cystadeno-fibroma.

Closely similar in external appearance to these fibro-adenomas are certain other fibro-epithelial tumors to which Warren has applied the name "peri-ductal fibromas." That there is any essential difference between the fibro-adenoma and the peri-ductal fibroma is improbable, as not a few tumors show the typical appearance of the former in certain areas and of the latter in other areas of their tissue. The chief peculiarities of the peri-ductal fibroma depend upon the fact that the vegetative activity in the peri-ductal tissue outweighs that of the parenchymatous tissue. The result is a tumor in which the peri-ductal tissue becomes a striking and important component that justifies the

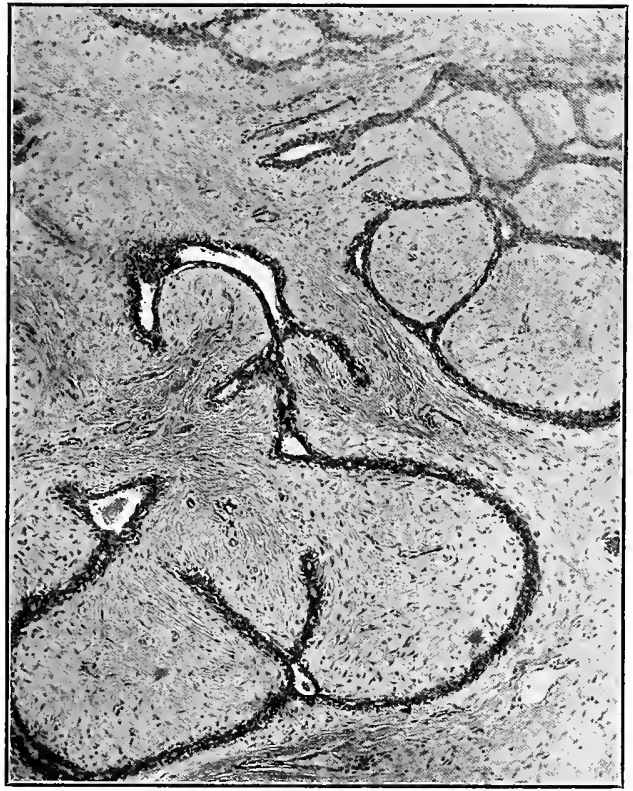

Fig. I6I.-Intracanalicular periductal fibroma, showing the typical appearance.

name fibroma, though the term is misleading, as the tumor is really fibro-adenoma. Two forms of this fibromatoid condition are described-peri-canalicular peri-ductal fibroma and intra-canalicular peri-ductal fibroma. These are not different species of tumor, nor is either a different tumor from fibro-adnoma, as is easily proven by an examination of a series of slides from a large number of tumors, which shows that all three appearances not infrequently coexist, and that two commonly coexist in the same tumor. If our theory of origin be correct, and the tumor is primarily a lobule of the breast tissue aroused to growth through unknown stimuli, and the separation of the growing lobule takes place through compression and traction of ducts and connective tissue, it is easy to conceive that the ordinary fibro-adenoma results from uniform growth of both paren- 
chymatous and peri-ductal tissue; that pure adenoma and adeno-fibroma (the latter characterized by preponderance of parenchymatous over peri-ductal tissue) result from rapid growth of the parenchyma as contrasted with the peri-ductal tissue, and that periductal fibroma results from the preponderance of the growth of the peri-ductal tissue over the parenchymatous tissue. When the increased peri-ductal tissue surrounds the tubule concentrically, the tumor may be called peri-canalicular fibroma; when it grows more rapidly close to the tubules and less rapidly away from them, so that the inner (subepithelial) layers are thrown into folds, making traction and compression upon the tubules, into which rounded masses or processes of the peri-ductal tissue seem to be forced, with the axis of the fibres radiating from the tubules-intra-canalicular fibroma.

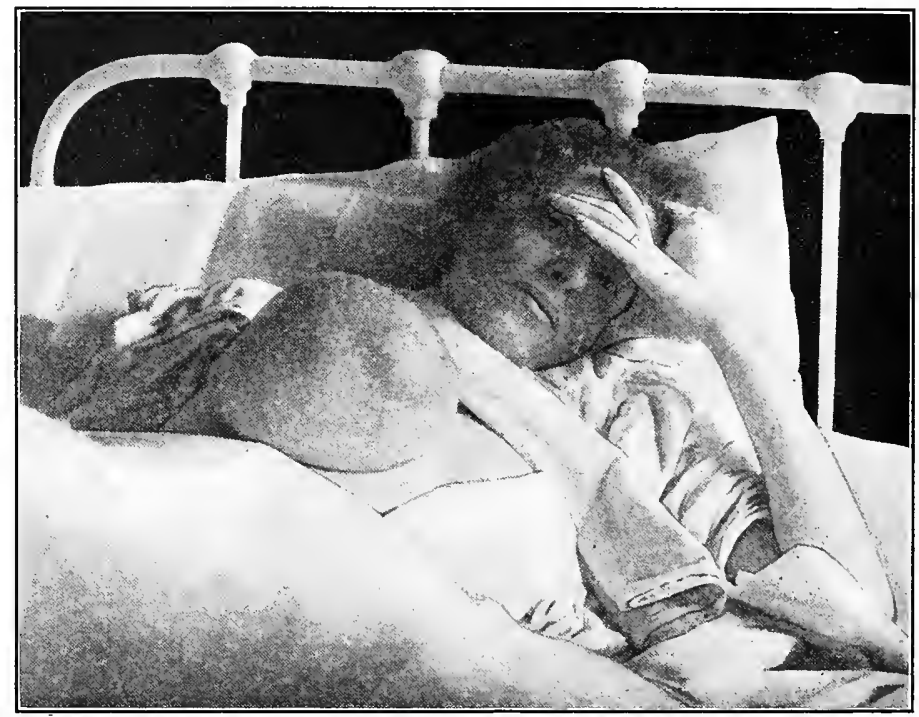

FrG. 162.-Lactating periductal fibroma simulating sarcoma. The nipple is obliterated as the result of stretching of the tissues.

In either variety, the peri-ductal tissue may maintain the normal type and vary but slightly from that seen in normal breast tissue, or may be changed to an extent that destroys all resemblance. Thus, it is commonly edematous, and frequently mucoid in character. In the latter case it is desirable to modify the names and call the tumors peri-ductal myxoma, or if it be desirable to use terms expressing the relationship of the peri-ductal tissue to the tubules, to canalicular, peri-canalicular and intra-canalicular myxoma respectively. Through what seems to have been some misapprehension of the true nature of the change, large tumors of the intra-canalicular myxomatous type, in which tubules become distended into cysts and the intra-canalicular formations become large enough to be easily seen by the naked eye, so that in a section of the fresh tumor they can be seen to project in the form of teat-like or finger-like eminences, have been described as cysto-sarcoma phyllodes. Such tumors are not sarcomas, and the name 
cysto-sarcoma phyllodes ought to be abandoned. Fibro-epithelial tumors of all the kinds thus far described are perfectly benign in disposition. They are recognizable when small, as rounded, freely movable tumors that usually occur in the breasts of young women. The size of those most commonly removed in the clinic is about that of a peach kernel. There may be one or several, in one or both breasts. When neglected they may grow to a large size, and most surgeons have met with cases in which the tumors were the size of a hen's egg, a man's fist, or even as large as a cocoanut. A generation ago it was not unusual to see them of great size.

Thus, Ashwell (vide Sheild, "Diseases of the Breast," London, $\mathrm{x} 898$, p. 202) saw one that weighed upward of 20 pounds; Barton (Proc. Path. Soc. of Phila., I885-87, XIII, r65), one 27 inches in circumference in the breast of a r7-year-old colored girl; Finsterer (Deutsche Zeitschrift für Chirurgie, rgo6, LXXXIV, 557) speaks of a very large one; Gross (Medical and Surgical Reporter, 1887 , LVII, 3) speaks of a cystic fibro-adenoma that weighed 29 pounds, and Velpeau ("Traité du Maladies du Sein," Paris, r 858 , p. 260 , Fig. 2) figures what probably was one of these tumors that weighed 40 pounds, though he called it "tumeur adenöide" and Billroth regarded it as a cysto-sarcoma.

The large tumors are nodular in appearance, and are usually composed of congeries of small tumors forming a composite mass, in which the parenchyma of one lobule seems to be independent of that in others. Different lobules of the same large tumors may show different forms of arrangement of the peri-ductal and parenchymatous tissues. Very large tumors are always cystic.

Although the conditions attending its growth cause the parenchyma of the fibroepithelial tumor to sever its connections with that of the breast proper, and have changed its structural arrangements so that they may no longer resemble the breast lobules, the fibro-epithelial tumor is still, physiologically, a mammary gland to all intents and purposes, as is shown by the manner in which it comports itself during the mammary hypertrophy of pregnancy and lactation. As the breast tissue under these circumstances enlarges and transforms its tubular to racemose structure through the formation of acini, the parenchyma of the tumor does the same. For this reason many cases of fibro-epithelial tumors first come under the surgeon's observation during pregnancy and lactation because of the sudden appearance of tumors in the breast where they had not previously been noted, or because of the rapid and sometimes painful enlargement of small tumors known to have been present in the breast. The tumor tissue engaging in secreting activity but being deprived of outlets, swells and becomes very firm and tense so as to be felt with ease in the flaccid breast after the baby is nursed. Under the misapprehension that the sudden enlargement of these tumors is indicative of some change in their nature and tendency, and in the fear that they might prove to be malignant if neglected, not a few are operatively removed. There is no advantage in operating under such circumstances as in reality the only change in the tumor is that common to aII the mammary tissues, whether in the normal breasts, or in supernumerary breasts, or in fibro-epithelial tumors.

Such behavior of a fibro-adenoma during pregnancy and lactation is shown by the history of a patient operated upon in the German Hospital of Philadelphia.

The patient, D.G., was a woman, aged 24 years. Six months before coming under observation, when six weeks pregnant she first observed enlargement of the right breast that had always been a trifle larger than the left. There was no pain, but the breast continued to enlarge rapidly and after three months the nipple retracted and the breast became bluish in color. After her baby was born the right breast enlarged rapidly until it became the size of a grape fruit and was very heavy. It was hard and nodular, and showed large pigmented areas about the nipple which was retracted and dislocated toward the inner side of the breast. Superficial veins were visible and distended. She complained of pain about the 
areola, but there was no tenderness upon manipulation, nor could any fluctuation be detected, though some parts of the tumor were soft. A small amount of yellow fluid could be expressed from the nipple. There were no enlarged axiliary nodes. The left breast was normal and lactating.

Under the conviction that the tumor was a sarcoma, amputation was performed. Upon pathological examination the tumor (Pathological Collection, No. 9205) was found to be an adeno-fibroma with secondary cbanges and enlargement due to pregnancy and lactation. These consisted of marked epithelial hyperplasia and an accumulation of milk. In consequence of its encapsulation, its rapid increase in size during the periods of pregnancy and lactation, the tumor was regarded as benign. Some areas were found to have undergone anemic necrosis, but there was nothing about it to suggest malignancy.

A most interesting tumor of this class supposed to be a galactocele (Plate, $\mathrm{V}$, ) was removed from the breast of a lactating woman, in the German Hospital of Philadelphia. It was a soft fluctuating translucent formation about the size of a duck's egg, enclosed in a thin membranous envelope supposedly the sac. When examined pathologically, it proved to be a fibro-epithelial tumor, in lactation hypertrophy, its ducts distended with milk, and its. interstitial tissue highly edematous in appearance and extremely soft in texture.

When fibro-epithelial tumors are removed at the time of the lactation hypertrophy, interesting and pardonable errors may be made as to their nature. The fibro-adenoma that has undergone lactation hypertrophy is no longer a fibro-adenoma, it is a pure adenoma. It now has alveolar and acinar structure like the breast itself.

Dr. B. C. Hirst brought one of us, in the year I894, a rounded, encapsulated soft tumor as large as a hen's egg, just removed from the breast of one of his patients. Microscopic examination showed it to consist entirely of alveolar glandular tissue, and it was thought to be one of the rare cases of "pure adenoma," described and published as such. Years passed before experience with other cases raised a doubt as to the true nature of the growth, when an inquiry not previously made, showed that the tumor had suddenly appeared in the breast of a woman just beginning to nurse her baby. It seems clear that the tumor was not a "pure adenoma," but a fibro-adenoma participating in the lactation hypertrophy and activity. Recently Speese (University of Pennsylvania Medical Bulletin, April, 1909) has published a description of a "pure adenoma of the breast," that has precisely the same history, even to the tumor having been brought to him by Dr. B. C. Hirst, and precisely the same appearance. That it was known to have been present for several years and to have suddenly grown large with the establishment of lactation, is sufficient explanation of its "pure adenoma" appearance. The writer knows of another precisely similar case, in which the same diagnosis was made under the same conditions by a surgical pathologist of large experience.

The enlargement of the tumor during lactation is in all probability always followed by subsequent diminution in size, with the termination of lactation, and sometimes long before lactation terminates when left to take its normal course. Its tissue can be supposed to undergo involution like that of the breast tissue itself, and to do so more rapidly than the breast tissue, seeing that there can be no escape for its secretory products. It behaves like an unused breast. Here may be found one explanation of the fact that tumors of the breast in young women have been reported to have diminished in size, spontaneously.

Morbid Anatomy.- To the naked eye the fibro-adenomas are usually easily recognizable. They form small or larger, solid or cystic tumors, completely surrounded by a thin fibrous capsule. They are easily enucleated as a rule. Small tumors are usually rounded and smooth, larger ones nodular and cystic. Upon section the color is commonly uniformly grayish pink, and slightly granular. Upon close inspection it may be 
Plate V

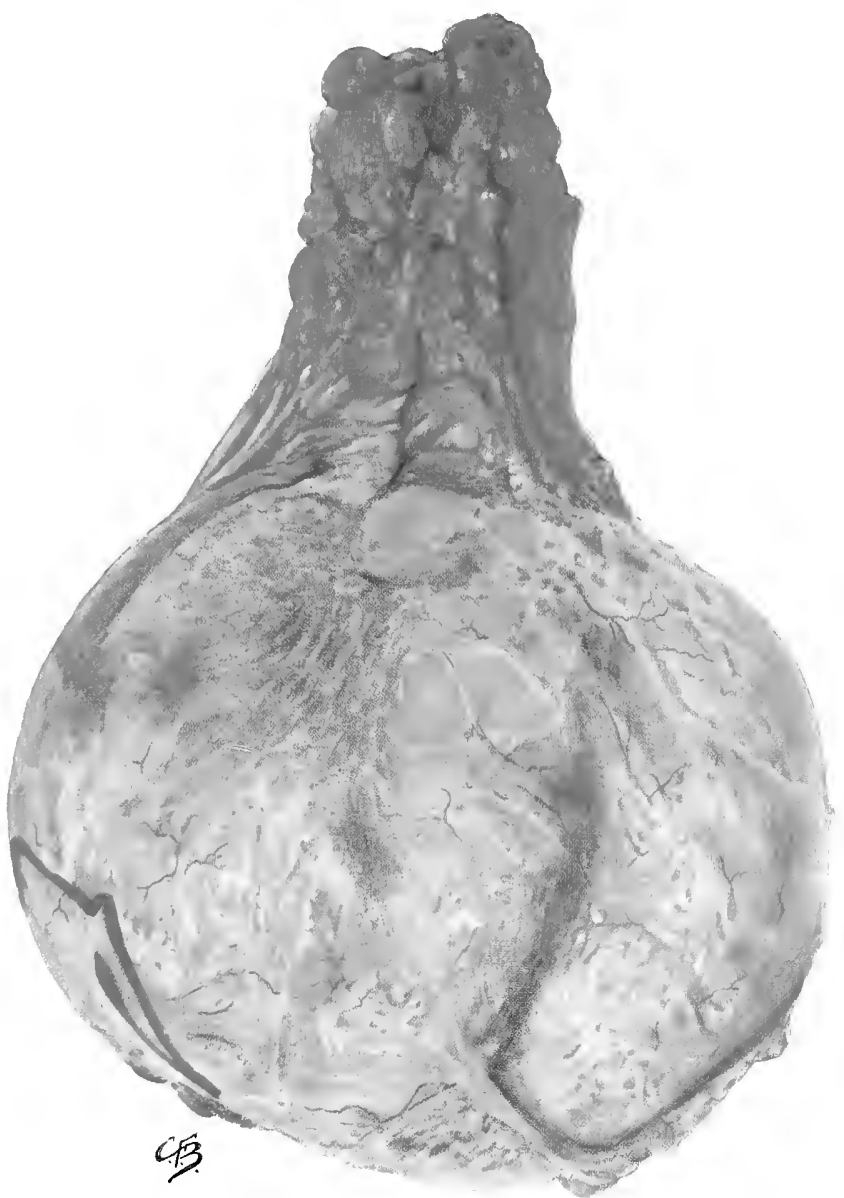

Lactating adeno-fibroma simulating galactocele. Natural size.

Deaver and McFartand. 

possible to make out a delicately fasciculated groundwork, in which the granules are imbedded. The groundwork is the fibromatoid structure, the granules the epithelial tubules. In large tumors growth from numerous centers can be seen, and the tumor is compounded by amalgamated nodules. The color is occasionally varied through peculiar circumstances. Thus when the tubules dilate into cysts, or when extravasations of blood, or necrotic change in the stroma are present, the color and texture may be modified accordingly.

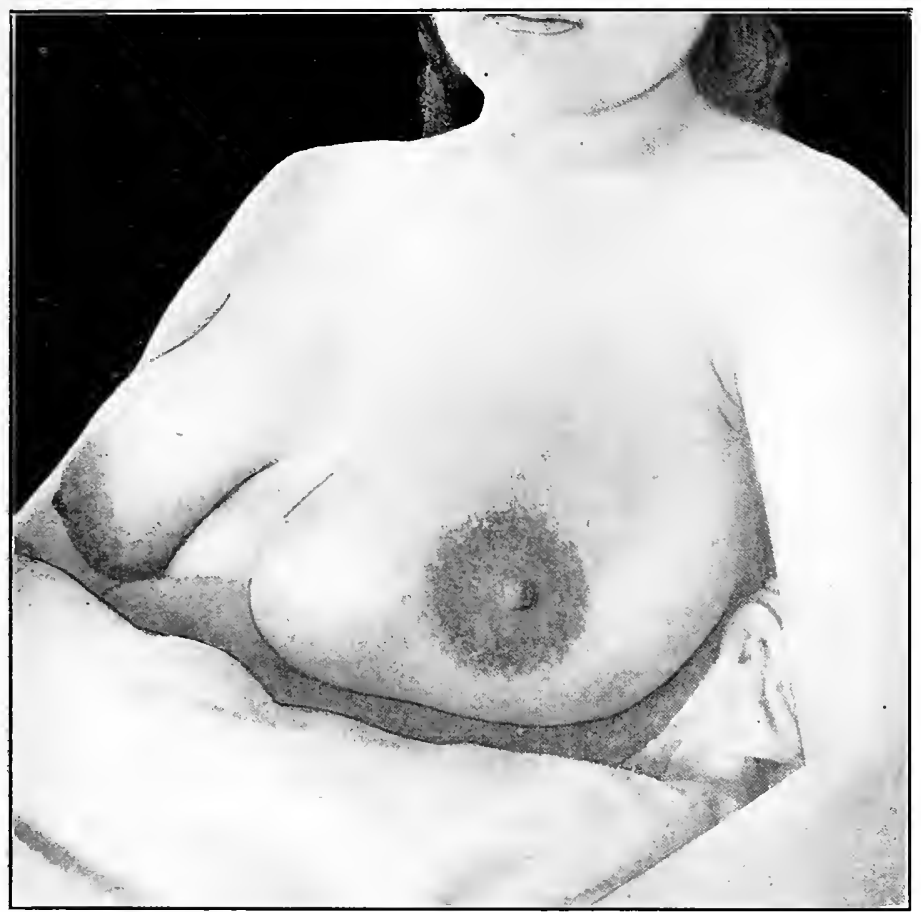

FIG. I63.-Lactating adeno-fibroma simulating galactocele. Appearance of the tumor shown in Plate V.

When the tumors are not removed, and continue to grow, they push aside the surrounding mammary tissue, causing it to atrophy and eventually to disappear. At the same time superficially situated tumors become non-superficial and appear beneath the skin which becomes thinned, often shows veins as in sarcoma, and becomes atrophic. At this time inflammation and necrosis of the skin set in, and the capsule of the tumor may become visible through the ulceration. Deeply situated tumors do not ulcerate but remain as movable nodular, firm, insensitive masses in the breast.

Cystic Change.-This is the most common complication of the fibro-epithelial tumors, and at once changes the name to cystadenoma or cystic adenoma. In the chapter upon 
"Cysts of the Breast," the section upon "Cysts in Tumors of the Breast' gives a full explanation of the occurrence of these cysts.

They sometimes make their appearance rather suddenly and grow rapidly, giving the tumor a somewhat modified character that arouses suspicion of malignancy. Their presence can be detected clinically through bosselation of the surface of the tumor and sometimes by fluctuation of the fluid in the cysts.

Pathologically they appear as circumscribed spaces filled with lymph serous-fluid of a straw color. Sometimes the fluid escapes under pressure when the cyst is incised; sometimes it becomes gelatinous through admixture of tissue colloid and remains like jelly; sometimes it is dissolved through admixture of blood. The spaces occupied by the fluid are rounded and have smooth shining walls, usually lined by a single layer of columnar or cuboidal epithelium. Sometimes the lining is lacking.

In cystic "intra-canalicular peri-ductal fibromas" the cysts are sometimes quite large and nearly filled by the rounded nodular fibromatoid formation. This is the character of the erroneously so-called cysto-sarcoma phyllodes of Johannus Müller.

Calcareous change may take place in the stroma of any of the fibro-epithelial tumors, either in the form of scattered and amorphous deposits, massive localized deposit, or there may be true ossification. As such changes occur more frequently in sarcomas, the reader is referred to the chapter upon "Sarcoma of the Breast" for an explanation of the phenomenon.

Malignant Change in Fibro-epithelial Tumors.-I. Sarcoma.-In certain cases the peri-ductal tissue forming the matrix of the fibro-epithelial tumors loses its normal loose fibrillar and sparsely cellular structure, and becomes highly cellular in part or in the whole. The cause of the cellular multiplication and the failure of cell differentiation is not known. The excessively cellular character of the stroma, however, gives a new microscopic appearance to the tumor, and necessitates the introduction of new names as we shall see. But first let us inquire into the nature of this cellular change. We have no precise information and no exact knowledge to work upon, but it is well known that when tumors of the connective tissues undergo active cell multiplication and change from the largely fibrillar to the purely cellular type of structure, they simultaneously change from a benign to a malignant disposition. When they change from the largely fibrillar to a more cellular type of structure, they arouse our suspicions, but we have almost no positive knowledge that they have certainly changed in disposition. We are then in this interesting but unfortunate dilemma; we know that fibrillar tumors are benignant and that cellular tumors are malignant, but we have no certain way of telling whether a tumor composed of both fibers and cells is one or the other. We cannot tell where benignancy ends and malignancy begins. It is entirely a matter of opinion whether the general character of a tissue be sufficiently cellular to be declared malignant or not. And when, as in the fibro-epithelial tumors of the breast some parts are largely fibrillar and other parts highly cellular, the amount of personal equation that enters into the judgment is very large.

Cellular tumors arising from the connective tissues are termed sarcoma. When the cells arise from the peri-ductal tissues of a fibro-epithelial tumor, the tumor becomes known as a peri-ductal sarcoma, being descriptive of the nature and origin of the tumor. Such sarcomas, since they arise in a tissue peculiar to the breast are also known as indigenous sarcoma. They usually are of the spindle-cell variety.

- Peri-ductal sarcoma may bear so close an external and clinical resemblance to periductal fibroma or myxoma as to make it impossible to differentiate them. In such cases a microscopic examination becomes essential, when the former will show a cellular, the 
latter a fibrillar or myxomatous tissue growing about and pressing into the ducts. The similarity of arrangement is sufficient to indicate that the sarcoma develops from the fibroma, and not independently of it, and to justify the terms peri-canalicular sarcoma and intra-canalicular sarcoma.

As usually conceived, sarcoma is a largely or purely cellular tumor but in these indigenous sarcomas of the breast, there are more or less conspicuous glandular elements in the form of more or less altered tubules. Must they be taken into serious account when the tumor becomes sarcoma? Is it wise to introduce descriptive terms such as adeno-sarcoma to apply to them? It seems as though this might be regarded as a supererogation, for if the tumor be described as peri-ductal sarcoma, it ought to be inferred that it grew among or about the glandular ductules which may be found in its substance.

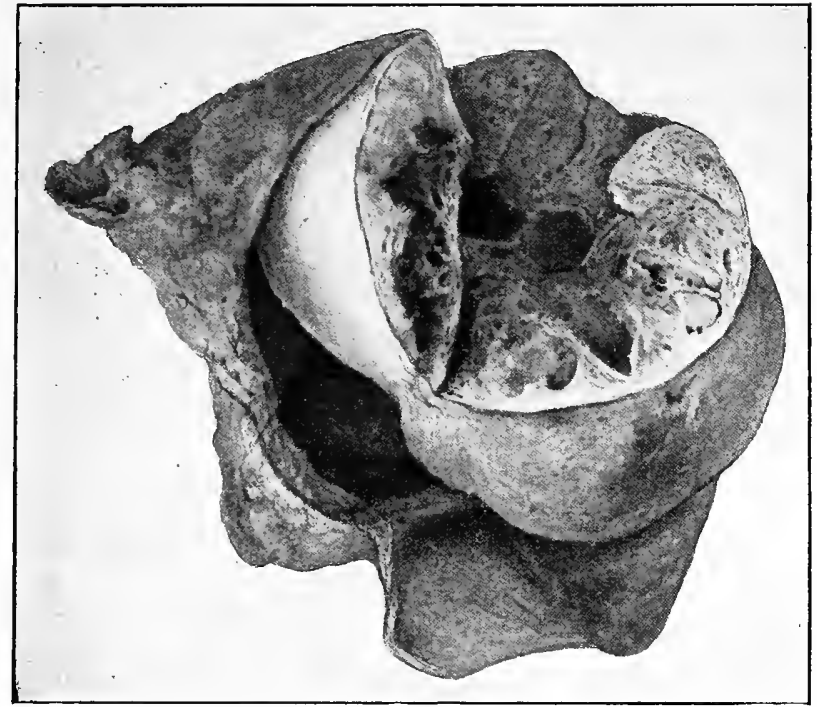

FIG. I64.-Periductal fibroma (cystic).

As the sarcoma tissue increases more rapidly than the fibrillar tissue possibly can, the growth of the tumor advances more rapidly after the sarcomatous change sets in, and in the cases that we have studied, it seems as though the rapidly growing cells of the sarcoma soon begin the effacement of the parenchymatous elements by compression and perhaps by starvation until they become relatively few in numbers, fall into obscurity and eventually may disappear.

Non-indigenous sarcomas of all varieties-round-cell, spindle-cell, giant-cell-may grow in the fibro-epithelial tumors, just as in the breast itself. Full particulars in regard to them, and in regard to adeno-sarcoma, cysto-sarcoma, and the sarcomatous transformations of the benign tumors will be found in the chapter upon "Sarcoma of the Breast" (q.v.).

2. Carcinoma.-The fibro-epithelial tumors result from activities of growth shared 
by both the ductal and peri-ductal tissues. In the ordinary development of the tumor the ductules sprout, extend, bifurcate, and penetrate in all directions ints the growing stroma, gradually losing the characteristic lobular arrangement of the normal breast. If, as has been shown, excessive reproductive cellular activity and transformation to a cellular type of structure on the part of the peri-ductal tissue leads to sarcoma, excessive reproductive cellular activity of the parenchymatous and epithelial tissue may lead to carcinoma. The fibro-adenoma is to all intents and purposes a gland. It contains not only the essential glandular tissue from which carcinoma is supposed to grow, but contains it under conditions of disturbed growth and activity that might be regarded as especially favorable to carcinoma growth. It is true that the fibro-epithelial tumors are neoplasms of early life, and carcinomas, for the most part, of later life, but with such

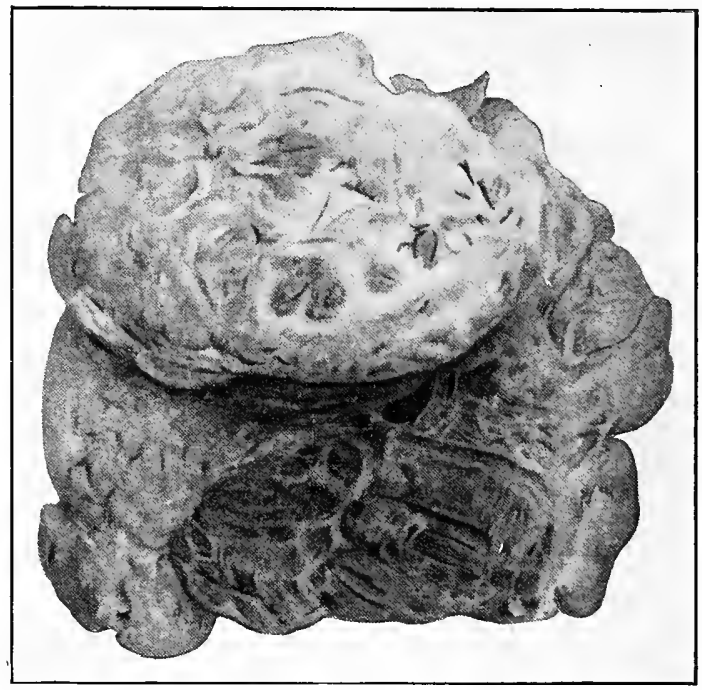

Frg. 165.-Periductal fibroma (section surface). From a specimen in the Laboratory of Surgical Pathology, Medical School of the University of Pennsylvania.

conditions as have been outlined it would seem not only possible but probable that such change can and does occur. But experience shows that fibro-epithelial tumors rarely change to carcinoma. Sarcoma is the more frequent malignant change in fibro-epithelial tumors, and outnumbers carcinoma change many times. That it does occur cannot be gainsaid. Cases are reported by Quervain (Correspondenzbl. für schweizer Aerzte, I 9 Io, No. 28) by Speese (Amer. Jour. of the Med. Sciences, I9Io, LI, 2 I3), and by others, but few are on record. Even in tumors of great size such as have been reported by Barton (Proc. Path. Soc. of Phila., I $885^{-7}$, XIII, I65) in which in the breast of a I 7 -yearold colored girl, such a tumor grew so large as to measure 27 inches in cricumference; or the perhaps still larger tumor pictured by Binaud et Braquehaye ("Maladies de les Mamelles," Traité de chirurgie, etc., Le Dentu et Delbet, Paris, I899, VII, I 5 I, Fig. I8) showed no sign of malignant transformation. 
Clinical Consideration.-The clinical diagnosis of benign mammary tumors was a much simpler task in the past, when they were permitted to attain to enormous proportions and to undergo various degenerations before the patients sought their removal, than now when they are brought to the attention of the surgeon while so small as to be, as a rule, symptomless.

The average recognized duration of roo consecutive cases of fibro-adenomata operated on in the German Hospital of Philadelphia, was 5.9 months. This estimation was made from the time that the patients first discovered the lump in the breast. Eighteen of the patients in this series presented themselves within one month from the time of the discovery of the tumor; in $7^{6}$ cases the tumor had been known to be present less than one year; eight patients had known of a lump in the breast for five or more years, and in I 3 instances the disease was of less than five, but of more than one year's duration. This is quite different from our carcinoma cases in which an average of 30 months passed between the discovery of the lump in the breast and the request for advise.

Occasionally we meet with an exceptionally large tumor that has developed within a comparatively short period of time, and in rare instances, with a very small growth that has remained stationary, in size, for many years. These are exceptional cases, however, for the discovery of the tumor is usually made while it is still very small and the patient promptly presents herself for treatment. Again we find this differing from what happens in the case of the malignant tumors, which are usually much larger when brought to the notice of the surgeon.

Women of the better classes are keenly alive to the danger that may arise from the presence of lumps in the breast, and it is with the thought of possible malignant disease uppermost in their minds that they present themselves for examination and advice. The skilled examiner may easily be able to satisfy himself of the malignancy or benignancy of a growth in the breast yet find it impossible to assign it to the special variety of benign tumors to which it belongs. This is, however, a matter of small practical importance from the clinical point of view.

Predetermining Factors.-General Incidence.-According to clinical statistics gathered from the records of the German Hospital of Philadelphia, the fibro-epithelial tumors constitute 23.7 per cent. of all mammary neoplasms. McFarland found the incidence of these growths among mammary neoplasms received in his laboratory to be I2.I 7 per cent. ( 70 benign tumors among 575 tumors of the breast).

Rodman estimates that $\mathrm{I} 7$ per cent. of all mammary tumors are fibro-epithelial in structure and benign in nature. Williams, in a collected series of 2422 cases, found I 5.I per cent. of the benign tumors.

Age and Sex Incidence.-All tumor diseases of the breast are rare in the aged and in the very young. A tumor in the breast of an aged person is more likely to be malignant (carcinoma), than benign in nature, while the reverse is true in the case of a young person.

Solid fibro-adenomas usually occur in the young and active mamma; cystic tumors of similar kind in the mature and decadent glands. This was, long ago, pointed out by Gross.

Fibro-epithelial tumors are rare in the breasts of men and very young girls, but are comparatively common in the breasts of adolescent girls. Thus six (I 2 per cent.) of the 50 patients in Gross' series were under 16 years of age, the majority of them being between the ages of 14 and I6. Only 6 per cent. of our patients were under 20 years of age and all of them had passed the age of puberty. These figures are of no value, however, in estimating the age incidence of tumors occurring in the breasts of the young since no 
patients are admitted to the German Hospital of Philadelphia less than I $_{5}$ years of age.

In their paper upon "Tumors of the Breast in Childhood," Jopson, Speese and White report 2 I cases of benign tumors, I I of which were classified as fibro-adenomas. Speaking of the latter group they say: "They constitute the most numerous type of tumor of the breast occurring in childhood and their proportion to the total number of benign breast tumors is higher in children than in adults." We are unable to agree with this statement as in our experience fibro-adenomata comprise more than $5 \mathbf{2 . 4}$ per cent. of this group of mammary tumors in childhood. In the adult the proportion of fibroadenomata to other benign tumors, in our experience, is about nine to one.

Both Woodyatt and Speese attribute some etiological influence to mastitis adolescentium in the development of benign tumors of the adolescent breast, especially of boys. The incidence of fibro-epithelial tumors shows a sudden increase coinciding with the establishment of puberty, in both sexes.

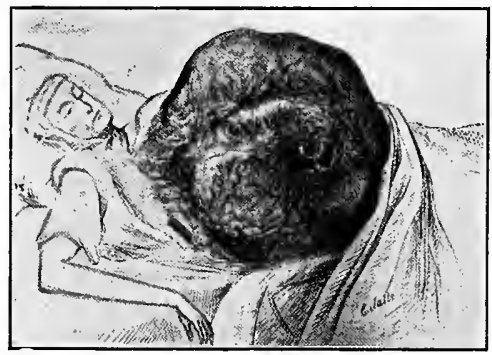

FIG. I66.-Enormous fibro-adenoma of the breast. (Velpean.)

Women between the ages of 30 and 40 years are especially liable to benign tumors of the breast, while approximately the same number of cases occurs in women between 20 and 30 years, and 40 and 50 years of age; the same is true of patients between the ages of 10 and 20 years and 50 and 60 years of age. The following tabulation shows the age incidence in our own cases:

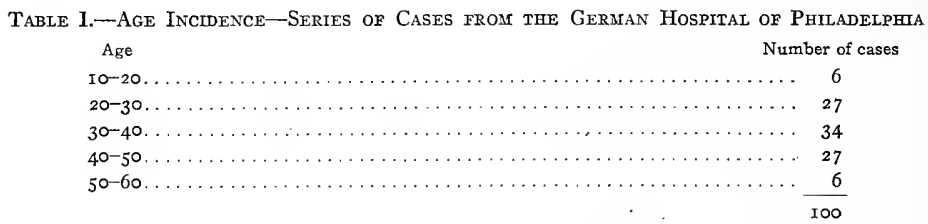

Recent papers by Warren, and by Greenough and Simmons give a lower age incidence for the benign tumors than that shown in the preceding table. Thus Warren states that most of his 54 patients with peri-ductal fibromas were between the ages of 29 and 38 , and that the average age for patients with fibro-cystadenomas was only 32 years. Forty-five per cent. of the 27 cases of peri-ductal fibroma in the series reported by Greenough and Simmons occurred in women between the ages of 20 and 30 ; the average age of these patients being 28.8 years. Their patients with fibro-cystadenomar averaged 
30.5 years; the youngest patient was $1_{5}$, the oldest 54 years of age. Of our patients under 40 years of age 33.6 per cent. were suffering from carcinoma, but only 18.5 per cent. of the total number of cases of carcinoma of the breast occurred in women under the age of 40 . One in every seven women under 30 years of age, with a tumor of the breast, was found to be suffering with carcinoma. The average age of the patients with benign tumors was 34.5 years as contrasted with 49.6 years for the cancer patients.

The statistics of Primrose, which are quoted in connection with the age incidence of carcinoma, are invalidated so far as the benign tumors are concerned because no distinction is made between fibro-epithelial tumors and chronic mastitis.

Sheild states that the youngest patient with a benign tumor of the breast admitted to St. George's Hospital in 35 years, was 14 years of age; the oldest was $5^{6}$ years of age. The average age of Gross' patients with the solid type of benign mammary neoplasms was 23.9 years as contrasted with 36.9 years for patients with cystic tumors. Gross maintained that the only tumors occurring in the breast before the age of 16 are fibromas and sarcomas, and that "solid tumors at that period of life are fibromas (fibroepithelial tumor) and nothing else." This is not strictly speaking true since angiomas which are benign tumors, occur in the breasts of children.

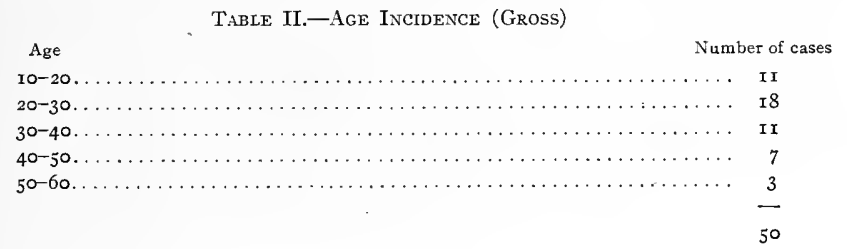

The youngest patient in Williams series of $5^{2}$ cases was $\mathrm{I}_{5}$ years old; the oldest 63 years of age; the mean age was 30.4 years. The number of Williams' cases occurring in each quinquennial age period is given in the following table:

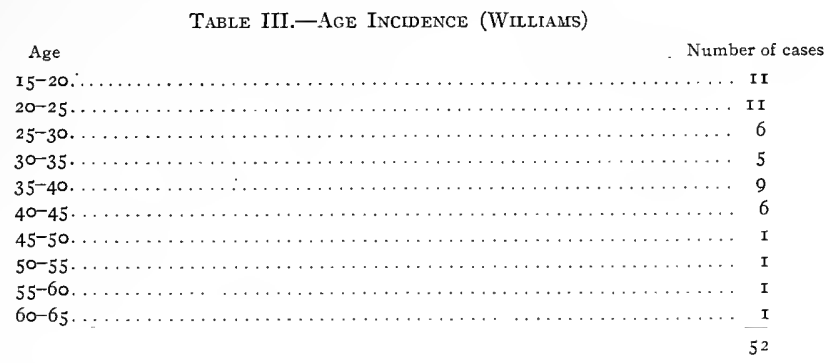

Benign tumors of the breasts of very aged women have been reported by many writers, including Velpeau ( 85 years), Gross ( 74 years), and Sheild (102 years).

Notwithstanding the frequency with which benign tumors occur in the breasts of young women and the comparative rarity of malignant tumors in the young, the physician should never forget the possibility of the occurrence of carcinoma in the breast of any woman who has passed the age of puberty. 
The time of tumor development in the breast in relation to the menopause has very little diagnostic significance. As shown in the following table, the greater majority of benign mammary tumors occur before the climacteric but the same is true of a not inconsiderable proportion of carcinomas.

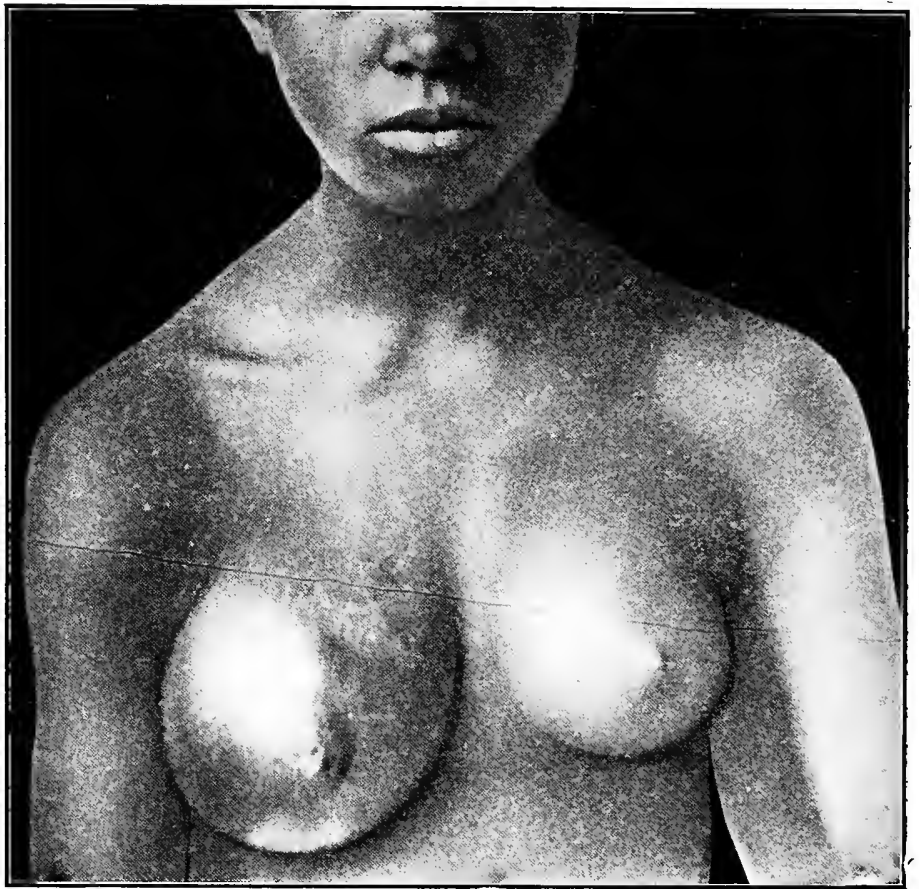

FIG. I67.-Diffuse fibroma of the breast of a young colored girl. (Jopson, Speese and White.)

Table IV.-The Thare Incidence of Mammary Tumors in Relation with the Mexopause Fibro-epithelial Tumors

$\begin{array}{rr}\text { Number of cases } & \text { Per cent. } \\ 91 & 91 \\ 7 & 7 \\ 2 & 2 \\ 100 & 100\end{array}$

\section{Carcinoma}

Number of cases

Before the menopause...............

After the menopause................

Males........................

No record.

$\begin{array}{r}95 \\ 75 \\ 3 \\ 27 \\ \hline 200\end{array}$

Per cent.

$47 \cdot 5$

$36 \cdot 5$

I. 5

$\frac{14.5}{I 00.0}$ 
A certain proportion of benign fibro-epithelial tumors occur in the breasts of young, neurotic, unmarried women who also suffer from disordered or even arrested menstruation. Too much attention must not be paid to this sta tement, however, as another group is composed of otherwise perfectly healthy women. Menstrual disorders, therefore, seem to have no etiological influence in mammary tumor formation; the single or the marriage state, as well as pregnancy and lactation, can be dismissed as causal factors.

Table V.-German Hospital Cases

Fibro-epithelial Tumors

\begin{tabular}{|c|c|c|}
\hline- & Number of cases & Per cent. \\
\hline Single $\ldots \ldots \ldots \ldots \ldots \ldots \ldots \ldots$ & 49 & 49 \\
\hline 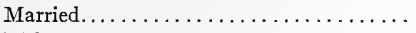 & 49 & 49 \\
\hline \multirow[t]{2}{*}{ 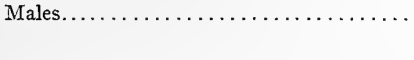 } & 2 & 2 \\
\hline & IOO & 100 \\
\hline 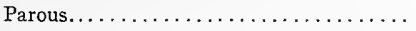 & 24 & 24 \\
\hline Nulliparous.................... & 76 & 76 \\
\hline
\end{tabular}

Carcinoma Cases

\begin{tabular}{|c|c|c|}
\hline 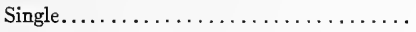 & 34 & 17.0 \\
\hline 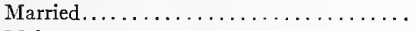 & 163 & $81 \cdot 5$ \\
\hline 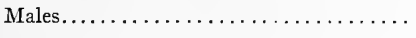 & 3 & I. 5 \\
\hline 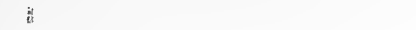 & 200 & 100.0 \\
\hline 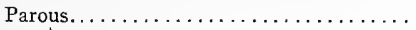 & I IO & 55 \\
\hline Nulliparous................... & 90 & 45 \\
\hline & 200 & IOO \\
\hline
\end{tabular}

Trauma.- Ten per cent. of our patients with benign mammary neoplasms gave a history of having injured the breast, but in only a few instances could the injury be ascribed a definite causal relationship. After reviewing the operative findings in cases of this kind, we have come to the conclusion that in the majority of instances trauma of the female breast results in inflammatory rather than neoplastic disturbances, and is in nature analogous to the hypertrophic mastitis that frequently occurs after injury to the male breast. Benign cystic tumors have been known to undergo sudden enlargement after the receipt of an injury; this is spurious, however, and is due to intra-cystic bleeding.

Heredity.- "Tumor diathesis" and "familial types" are expressions commonly but often unscientifically employed in oncologic writings. There are at present no recorded statistical data to justify the conclusion that heredity plays any considerable part in the genesis of fibro-adenomata of the breast.

Among our own series of roo consecutive cases of fibro-epithelial growths of the breast, we found only two instances in which sisters of the patients were similarly affected and only two in which the mothers of the patients had had benign tumors of the breast.

Twenty-four of the relatives of these patients had cancer; the disease involved the mamma in seven instances. This makes a total of 28 relatives of 100 patients who suffered with tumors, I of which were mammary.

These figures differ slightly from those given by Deaver (Jour. of the Amer. Med. Ass., I9r3, LX, 795). The older statistics were computed from roo cases of fibroadenomata and 200 cases of carcinoma. Thirty-seven of the relatives of the carcinoma patients and 22 of the relatives of the benign-tumor patients died of cancer, I3 
per cent. of each group having had cancer of the breast. Neither of these groups of figures is disproportionate to the general incidence of tumor diseases, and do not, as might readily be inferred, indicate a hereditary predisposition to tumor.

Williams believes in a hereditary tendency in both the benign and malignant forms of mammary tumors, but also believes that instances of the transmission of the fibroepithelial tumors are relatively less frequent than of cancer. In his series of $3^{8}$ cases of benign mammary tumors, there was a history of the direct transmission of the tumor from mother to daughter in only one instance ( 2.6 per cent.), while in I3.I per cent. of the 38 fibro-adenoma cases there was a family history of cancer, but in only one instance was the breast affected.

Puls records the cases of a mother and her daughter each of whom had a fibro-cystic adenoma of the left breast. Mammary fibro-adenomas in three generations, complicated with scirrhus carcinoma in one of them, is reported by Hutchinson.

Occasionally an instance of apparent inheritance of a benign mammary neoplasm in the male is met with. Gangitano has recorded two such cases. We are inclined to look upon his experience as unique rather than as indicative of the hereditary transmission of mammary fibro-adenomata.

Symptoms.-Pain.-The larger the tumor and the more rapid its growth, the greater the associated pain, owing to stretching of the matricial tissues. The amount of pain associated with a benign mammary tumor is in direct proportion to its content of fibrous tissue so that a very small or even clinically undemonstrable nodule may give rise to great suffering. Cases of this kind are often erroneously diagnosed as "mastodynia." Benign fibro-epithelial tumors in the breasts of young women sometimes give rise to marked suffering; more often painful sensations are absent or very slight, and experienced only at the menstrual periods.

Pain unrelated with menstruation was experienced by only 7 per cent. of our patients. Slight discomfort in the breast is, however, a frequent symptom of benign tumor. The pain may be intermittent, the patient having no abnormal sensation in the breast for a number of months or years, then without any demonstrable change in the size or density of the nodule, and without traumatic injury or other exciting cause, the breast becomes extremely painful.

Greenough and Simmons state that one-third of their patients had pain of varying degrees of intensity, while Sheild observed that the greater number of his patients suffered from referred pains down the arms and over the chest wall. Sometimes the patients complain of aching or burning sensations and in a considerable proportion of cases, the affected breast becomes sensitive, especially at the time of menstruation.

Pain is unusual in early carcinoma so that its occurrence in small freely movable and otherwise benign mammary tumors is of some diagnostic importance.

General Symptoms.-A tumor in the breast of a young woman with psychopathic tendencies may be the determining factor in exciting a latent neurosis, but neurosis per se has no known relation with the development or growth of the tumor. The presence of a benign tumor of the breast is not incompatible with otherwise perfect health.

Location.-We have observed no difference in the incidence of tumors in the two breasts. The majority of mammary tumors of all kinds with the exception of the intra-cystic papilloma arise in the upper outer quadrant of the breast. Benign tumors are prone to involve the periphery of the organ (intra-cystic papilloma excepted), although in I I per cent. of our cases the tumor was centrally located. The diagram Fig. I97 shows the position of the tumor in roo cases of fibro-adenomas. 
Two or more tumors of the breast or breasts were present in 20 per cent., of our patients. A tabulation of 20 cases of this kind occurring among roo consecutive cases shows the following distribution:

Multiple tumors in one breast. .................... 3 cases. Multiple tumors in one breast with a single tumor in the opposite breast. I case. Multiple tumors in both breasts...................... I case. Recurrent tumor in the breast....................... 3 cases. Benign tumor in one breast followed after operation by a benign tumor of

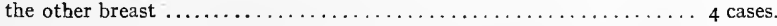
Bilateral benign tumors.

(a) those arising simultaneously.................... 2 cases.

(b) those not arising simultaneously.................. 3 cases.

Carcinoma of one breast followed by benign tumor in the otber breast..... 3 cases.

Relation to Para-mammary and Supernumerary Mammary Structures.-We must refer the reader to the chapters on "The Surgical Anatomy of the Breast" and "Polymastia" for the general consideration of aberrant breast tissue; that which concerns us at this time is the occurrence of benign neoplasms in such tissues.

Personally we have always looked upon tumors occurring in juxtaposition to the breast and composed of cells representative of the normal mammary tissues, as originating in outlying but otherwise normal lobules of the breast. In certain instances tumors do, undoubtedly, arise in true polymastic organs but these, as we have already pointed out, are most exceptional.

Fibro-adenomas are occasionally found to lie between the mammary skin and the deep layer of the superficial fascia that covers the breast. These comparatively rare and superficial tumors project beyond the normal level of the skin; they are perfectly encapsulated and are without demonstrable connection with the normal glandular tissues of the breast. Schimmelbusch's interest in this particular variety of tumor led him to collect the 37 cases from von Bergmann's clinic. Similar cases have been reported by Dowd and others. Tumors in this situation can easily be removed through a simple incision.

Critical consideration was first given to the clinical importance of para-mammary structures by Williams, who believed in the comparative frequency of these structures as well as in the frequency with which "neoplasms identical in structure with mammary neoplasms arise from them."

An unusually large sequestration of this nature may in itself invite apprehension on the part of the patient, who believes that she is harboring a tumor. These useless and possibly dangerous structures should be removed although Martin maintains that since the danger of malignancy is no greater than that of the normal breast, they should not be disturbed. Petgès and Bonin, like ourselves, take the opposite point of view. When a tumor is present in one of them there can be no question of the advisability of its removal.

Para-mammary tumors occur at all points in the circumference of the breast, the majority of them arising in the line of the anterior axillary fold. Ollier, who was one of the first to call attention to the fact that tumors may arise in isolated encapsulated masses of mammary tissue, reported the case of a young girl who had a growth of this nature which was situated between the third and fourth costal cartilages on the right side and was entirely unrelated with the mammary gland.

Williams has studied the subject of para-mammary tumors most carefully and 
finds that fibro-adenomas arise in para-mammary sequestrations very frequently. In 7 instances among 50 cases ( 44 per cent.), the benign form of tumor was found beyond the margins of the normal breast. The situation of the tumor, in these cases was as follows:

Just above and external to the right breast-size of a bantam's egg.

Just above the right breast-size of a walnut.

Just above the left breast-size of a walnut.

Axillary side of the left breast-two small tumors.

Edge of the sternum-left side, size of a walnut.

Edge of the sternum-right side-size of a hazelnut.

Below and outside the left breast-size of a walnut.

Pitzorno is said to have seen five cases of polymastia in one year with neoplasms in two of them. An encapsulated fibro-adenoma the size of a cricket ball was removed by Cameron from the right axilla. The tumor in this instance undoubtedly originated from a supernumerary mamma.

Size of the Tumor and Its Rate of Growth.-The size of the average fibro-adenoma of the breast when it is first seen by the surgeon is about that of a peach kernel or an English walnut. In some instances the tumors are no larger than a pea, in other more rare instances they may attain to an enormous size. Tumors of the enormous proportions described by the older writers are fortunately rare at the present time. Occasionally, however, an unusually large tumor arises in the lactating breast. Such enlargement, which usually takes place with great rapidity, is due to hyperplasia and functional hypertrophy of the glandular epithelium within the tumor together with the distention caused by the accumulation of milk within its ducts and acini.

A small benign tumor of the breast may enlarge to the size of a goose-egg during lactation and yet the patient remain ignorant of its presence until with the subsidence of lactation the tumor becomes visible or palpable in the flaccid organ. The retained milk within a growth of this kind gives it a soft or even fluctuant feel, so that the neoplasmic nature of the condition may be overlooked in the belief that we have to deal with galatocele.

Occasionally an enormous benign fibro-epithelial tumor is met with in the non-lactating breast, but these cases are so rare at the present time that it is worth while to quote the history of a case of this kind observed by Finsterer.

M., aged 45 years, was admitted to the hospital, Mar. 20, Igo6. Four years before her admission, shortly after having carried a heavy box against her breast, she noticed a small, hard, movable nodule in the lower part of the left breast. A few weeks later she noticed a second entirely independent movable tumor in the same breast. In one year the two had attained the size of a child's bead. In the next two years they had attained the size of a man's head. Ahout one year before presenting herself ulceration appeared in the upper outer part of the tumor. This followed the application of a plaster, and sometime later a second ulceration appeared in the lower part of the breast. Except for an occasional burning sensation there was no pain, nor was there any discharge from the nipple. Difficulty in breathing, persisting during the past four years was the major symptom complained of by the patient. The patient is small, poorly developed, and anemic but not cachectic. Weight, 45 kilos. Physical examination revealed a retro-clavicular goiter. The right breast was atrophied. The site of the left breast was occupied by a triangular tumor, the size of a man's head. The tumor extended to the level of the umbilicus, with the patient in the upright position. The largest circumference is $70 \mathrm{~cm}$.; the circumference at the base of the tumor is $40 \mathrm{~cm}$. The surface of the growth is nodular, some of the nodes being as large as a pigeon's egg; distinct furrows are seen between the nodes.

The integument is thin, shiny, and movable over the tumor. Venous interlacings are visible with thickened cords extending over the middle of the sternum to the left clavicle; a distinct venous hum is 
audible over this region. The nipple is seen in the lower median region of the tumor. It is completely flattened, is enlarged to the size of a 25 -cent piece, and is recognized only by the tough wart-like skin with its pigmented areola and Montgomery's glands. No secretion could be expressed from the nipple. Toward the lower part, the skin is adherent and ulcerated. The general consistency of the growth is tough with some points of fluctuation. A movable gland can be felt in the axilla but there is no demonstrable supra-clavicular involvement nor metastasis to the lungs or liver.

Operation.-Amputation of the breast and removal of the axillary glands, together with the sternal portions of the pectoralis major muscle down to the ribs. Thyroidectomy. Uneventful recovery. The extirpated tumor was found to weigh $4 \frac{1}{2} \mathrm{~kg}$., one-tenth of the entire body weight. Its histology was that of a typical fibro-adenoma with mucous degeneration of its stroma and secondary inflammation at the site of ulceration.

Physical State of The Tumor.-The ordinary fibro-adenoma is a small, apparently solid, rounded, lobulated and perfectly encapsulated mass that is freely movable within the breast tissue. It forms no attachment to the skin or pectoral fascia in uncomplicated cases and under ordinary circumstances gives rise to no characteristic symptoms. The tumor is frm in consistency but somewhat elastic, and may or may not be sensitive to pressure. The cystic nature of a small fibro-cystic adenoma may be difficult to demonstrate, although careful examination will usually reveal a slight difference in the consistency of different parts of the tumor; in doubtful cases the aspirating needle 'will prove the presence or absence of fluid.

Fibrowadenomas are not associated, as a rule, with any abnormality of the nipple, of the mammary skin overlying them, or of the axillary lymph nodes, but certain changes may be noted, under exceptional circumstances, in any of these structures.

In 6 per cent. of our cases the skin was found to be firmly adherent to the tumor but in all of these cases, there was a complicating inflammation which was caused either by trauma, the application of irritating salves, by pyogenic infection or by chronic cystic mastitis (abnormal involution). Large fibro-adenomas either of the cystic or myxomatous varieties resemble peri-ductal sarcomas not only in rapidity of growth, but also in the physical characteristics of the tumors. These large growths are lobulated and cystic. The overlying skin is thinned and shiny and contains a network of prominent veins. The nipple often becomes obliterated as the result of stretching though free mobility of the breast on the chest wall is retained. In uncomplicated cases, the axillary lymph nodes are not enlarged.

Ulceration of the skin rarely occurs in association with benign mammary neoplasms. We have not had a complication of this kind in our last soo cases although it sometimes does occur as the result of pressure in very large tumors.

As an illustration of the extensive destruction of the soft tissues that a benign tumor of the breast is capable of causing if left to run its course, the extraordinary case of Foerster is most instructive. A solid tumor, $\mathrm{II}$ inches long, 8 inches broad, $4 \frac{1}{2}$ inches thick, caused absorption of a portion of the seventh rib and penetration of the thorax, where, covered by the pleura, it formed a mass 7 inches in length, 5 inches in breadth, and $31 / 2$ inches in thickness. This mass rested on the diaphragm, pushed upward and compressed completely the lower lobe of the lung, dislocated the heart to the right and curved the vertebral column to the opposite side.

The Nipple.--Retraction of the nipple was noted in 8 per cent. of our cases. In two instances the inversion was bilateral and of congenital origin; one patient stated that the nipple of the affected breast had always been retracted; in three instances the deformity was acquired and was associated with a centrally located tumor, while in the three remaining cases the retraction accompanied tumors situated near to but not directly beneath the nipple. Obliteration of the nipple occurred in one case. 
Benign tumors of the solid variety rarely if ever cause retraction of the nipple unless they are situated directly beneath this structure while the intra-cystic papillomas which are usually found in this situation seldom cause the deformity.

Discharge from the nipple is associated with one-half or more of the latter class of tumors and in the majority of instances the discharge is bloody. Solid tumors practically never give rise to this symptom, although in one of our cases a mucoid secretion could be expressed from the nipple. Upcotts nipple line is a physical sign of some importance in the differentiation of cancer from other forms of mammary tumors. This sign is based on the fact that a carcinomatous tumor exerts traction on the adjacent tissues so that the nipple becomes displaced in the direction of the tumor if not actually inverted. The line is drawn horizontally through the nipple of the unaffected breast. A tumor situated in the upper quadrant of the.breast that has drawn the nipple above the level of this line is most likely a carcinoma, while a tumor that has pushed the nipple downward is most likely non-malignant in nature. Obviously the test has a very limited field of application, yet Van-den-Berg who has again drawn attention to it shows by means of several good illustrations that it is not without value. Enlargement of the axillary lymph nodes occurred in 9 per cent. of our cases of benign mammary tumors, in each instance due to a complicating lymph-adenitis.

Prognosis.-Does a benign tumor of the breast ever disappear spontaneously; if not, what are the dangers associated with its presence in the breast, as compared with the dangers of operation for its removal? A few conditions that simulate neoplasms sometimes disappear without treatment and so delude the patient into the belief that spontaneous cure of the tumor is to be hoped for. Genuine new growths never go away of themselves.

For reasons given in the sections on the pathology and prognosis of malignant growths every benign mammary tumor should be removed. What about the chance of permanent operative cure of benign mammary tumors; is the operative procedure a safe one; will the tumor recur; is there a possibility that the other breast will ultimately become diseased? These are questions that must be taken into consideration in advising patients with simple tumors of the breast.

Our experience with $24 \mathrm{r}$ operations for benign diseases of the breast, without a death, indicates the safety of the operative forms of treatment. The post-operative histories of 130 of these patients, of whom 70 had benign fibro-epithelial tumors, are available for statistical study. One patient died of pneumonia several years after leaving the hospital; r 29 patients are living but not all of them are in perfect health. Of the 7o patients with benign fibro-epithelial tumors, 17 have either returned to us for a second operation or have written us that they have had further trouble with the breasts. The post-operative complications were as follows:

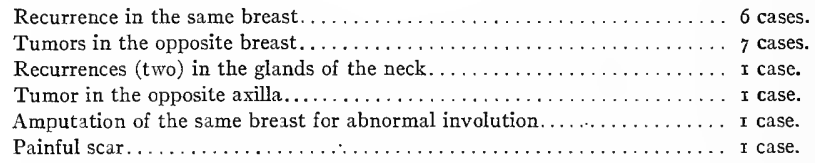

The histories of the patients follow:

E. N., 39 years. I-8-'02. Fibroma; excision. I-30-'I5, has had two subsequent operations on same breast making three operations in seven years. Last operation five years ago. No trouble since then.

C. D., 32 years. Adeno-fibroma left breast. Excision of tumor, 2-25-'06. Second tumor removed 
from left breast, II-20-'06. 2-4-' $I_{5}$, both breasts amputa ted elsewhere two years after second operation. In good health since then.

E. M., I9 years. Adeno-fibroma removed from the right breast 8-22-'o6, simple excision. 6-r-'r5, living, nodule recurred about six months after operation. Has shooting pains at times.

A. M., 2 I years. Adeno-fibroma excised from the left breast, ro-23-'o6. Second tumor removed by simple excision, 5-I 7-'Ir. I-30-'r5, living, suffered from mastitis during last confinement. Still has shooting pains in the breast; no lumps present.

W. M., 2; years. Simple excision of fibro-adenoma from left breast, 2-r4-'r3. 6-I-' I5, has an enlarged gland back of nipple in left breast.

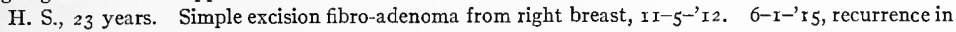
the same breast two and one-half years later.

"Recurrences" in the Opposite Breast.-

N. J., 42 years. Amputation of right breast, 4-6-'04 for cystic adenoma. 6-I-'15, living and well. Had lump removed from the other breast in r907. Microscopic diagnosis - "benign tumor."

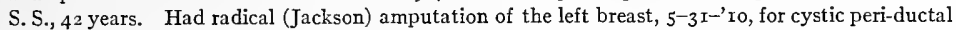
fibroma. 7-2-'12, had radical amputation of right breast for cystic adeno-fibroma. $1-30{ }^{-}{ }^{\prime} 5$, living and well.

E. L., 33 years. Radical amputation of right breast, 5-29-'ro, for fibro-adenoma. 12-6-'ro, radical removal of left breast for cystic fibro-adenoma. $\mathrm{x}_{-1} \mathrm{r}_{5} \mathrm{x}_{5}$, living and well.

Robert B., ig years. Simple excision of peri-ductal fibroma from right breast, 7-14-'ro. Reports, I-6-' I5, "living and in the best of health. A growth appeared in the opposite breast shortly after leaving the hospital, but disappeared spontaneously in a short time."

M. W., 36 years. Simple amputation of right breast, 9-8-'r 3 , for adeno-fibroma. Reports, 6-r-'r 5 , "a tumor is present in the left breast; the right breast gives no trouble."

A. N., 38 years. Simple excision of fibro-adenoma from left breast, 6-25-'02. Simple excision of a

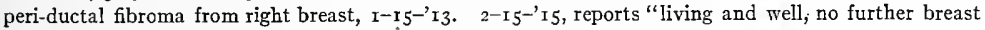
trouble."

E. F., 35 years. Radical amputation or right breast for cysțic adeno-fibroma, ro-1 7-'o3. Simple amputation of left breast for similar tumor, ro-3-'09. 6-r-'r5, reports "living and well."

"Recurrence" in Glands of the Neck.-

M. C., 30 years. Simple excision of fibro-adenoma from right breast, 3-I6-'ro. 6-1-'r5, reports. Two recurrences in the glands of the neck. Operations performed. (This was undoubtedly a case of carcinoma although sections of the tumor removed by us failed to show malignancy and the probabilities are that the carcinoma originated in another area of the breast.)

Tumor in the Other Axilla.-

E. S. 26 years. Simple tumor excised from the right breast, $2-14-$ 'oo. $x-6-' x 5$, reports "living, have developed tumor in the other axilla."

Amputation of the Breast for Abnormal Involution.-

L. V., 27 years. Simple excision of a fibro-adenoma, 4-20-'I3. 5-2I-'13, breast amputated elsewhere for condition that was said to be abnormal involution. 6-r-'r5, reports "living and well."

Post-operative complications occurred therefore in 24.3 per cent. of our patients with benign fibro-epithelial tumors of the breast.

The six cases in which similar benign tumors appeared in another part of the same breast, occurred among a series of 47 cases (I 2.8 per cent.).

This is a significant fact to which little attention has been paid and serves as a sound basis of argument for more radical treatment of benign mammary tumors especially in women who are approaching the end of the child-bearing period.

Our results justify the statement that when a tumor appears in the breast it is an indication of the susceptibility of the entire breast tissue to the formation of neoplasms and if simple excision is performed the patient should be kept under observation for an indefinite period of time.

Treatment.- It is good surgical practice to remove all benign tumors when such removal does not endanger the life of the patient. This applies to benign tumors of the breasts, first, because one can seldom be absolutely sure of the diagnosis, secondly, be- 
cause the simple excision of a small benign tumor of the breast is a minor operation and one practically devoid of danger, and, finally, because though the growth when first discovered, may in nowise jeopardize the health of the patient, no one can foretell the time when it may become a serious menace to life as a result of malignant transformation.

The presence of a growth in the breast is, in our judgment, an indication for operation in the absence of grave systemic disease. If the patient with a small benign mammary tumor elects to await some change in the tumor before submitting to operation, she should be told that continued growth of the tumor may later necessitate amputation of the breast, or, if the patient is a young married woman who has not borne children, she should be told that a rapid and sometimes painful enlargement of the tumor often takes place as the result of hypertrophy incident to pregnancy and lactation. If opera-

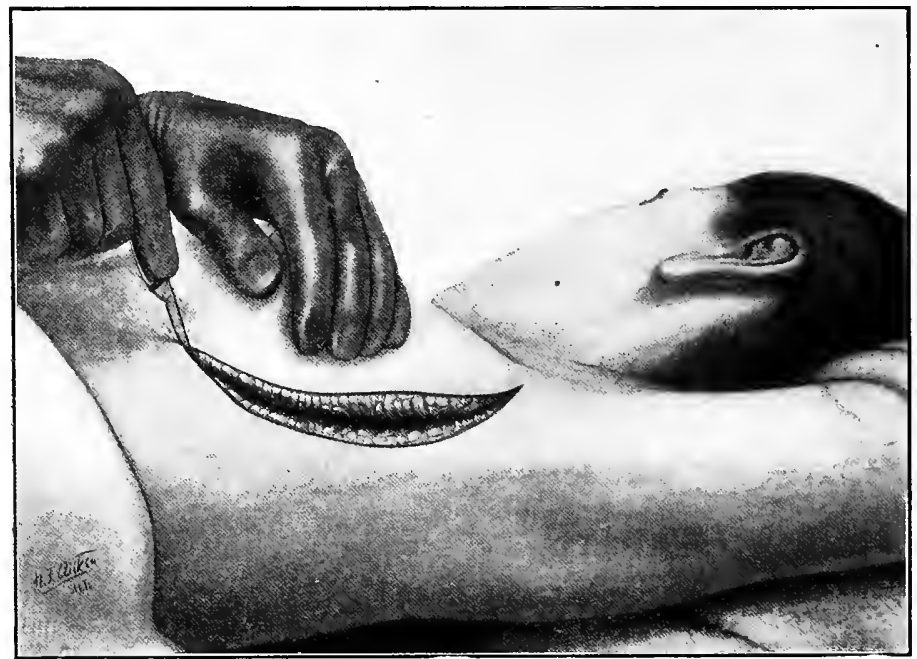

FIG. I68.-Illustrating the Warren operation of plastic resection of the mammary gland. Primary incision.

tion is still refused, she should be advised to report to her physician at regular intervals for examination.

Small, benign, well-encapsulated tumors, situated near the surface of the breast, or in the deeper portions of the upper inner quadrant of the breast, should be removed through an incision made directly over them. The Warren method of plastic resection is applicable to tumors situated in the deeper portions of the lower half of the breast or in its upper outer quadrant, but has not proved satisfactory, in our hands, for the removal of tumors occupying the upper inner quadrant of the organ. The benignancy of the tumor must be confirmed or disproved, in all cases, at the time of the operation by microscopic and macroscopic examination. In the treatment of women past the age of 35 , our practice is more radical in some instances than the structure of the tumor would seem to warrant. In I I instances among 70 cases, radical amputation was done 
and the sacrifice of the pectoral muscles was an unwarranted procedure in these cases. These patients are alive and well, however. Simple amputation was performed in i 2 of the 70 cases. This operation should be given a more prominent place in the treatment of benign mammary tumors. It is indicated especially when the patients are approaching the menopause when the tumors are multiple, when they are associated with abnormal involution of the breast, where the growth is of the so-called diffuse type, and finally in cases of large tumors.

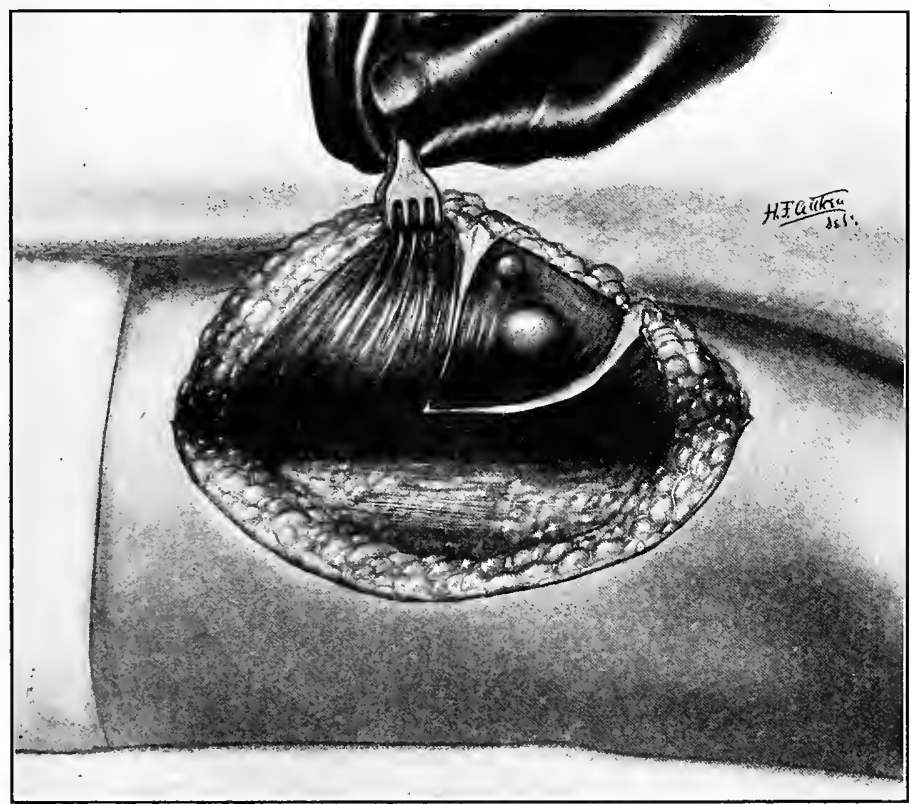

FIG. I69.-The breast has been elevated and displaced inward; its posterior surface exposed. A V-shaped segment of tumor-bearing tissue has been outlined preparatory to its removal. (Warren.)

Plastic Resection (Warren).--The removal of the majority of small or medium-sized benign tumors, of localized areas of abnormal involution or interstitial mastitis; "the drainage of certain forms of mammary abscesses; the excision of segments of breast tissue containing chronic abscesses, foci of tuberculosis or other granulomata, and the subcutaneous resection of male breasts that are the seat of chronic indurations (so-called diffuse fibro-epithelial tumors), or hypertrophy (gynecomastia), can be most satisfactorily accomplished through an incision made along the lower and outer margins of the organ.

This method of approach to the posterior aspects of the breast, first described by T. Gaillard Thomas, is now universally used in the modified and improved form devised by Warren. The term plastic resection is used to denote the excision of the tumor-bearing segment of the breast with subsequent plastic repair of the organ; the primary incision is essentially the same as that originally described by Thomas. 
Warren has performed the operation in a considerable number of cases with excellent results, and we have found it a useful and satisfactory method in selected cases. Warren warns against its employment for the removal of large tumors, and calls attention to the necessity of a thorough and painstaking examination of all parts of the breast in doubtful cases where cancer is suspected; this especially applies to cases of abnormal involution in which the greater part of the breast is involved.

As regards the use of the method in advanced cases of abnormal involution, we cannot agree with Warren in the safety of the radiating incisions, however numerous, to expose all of the diseased areas, and to eliminate the possibility of overlooking a small area of cancer. There is no alternative, however, in cases of this kind if the breast is to be pre-

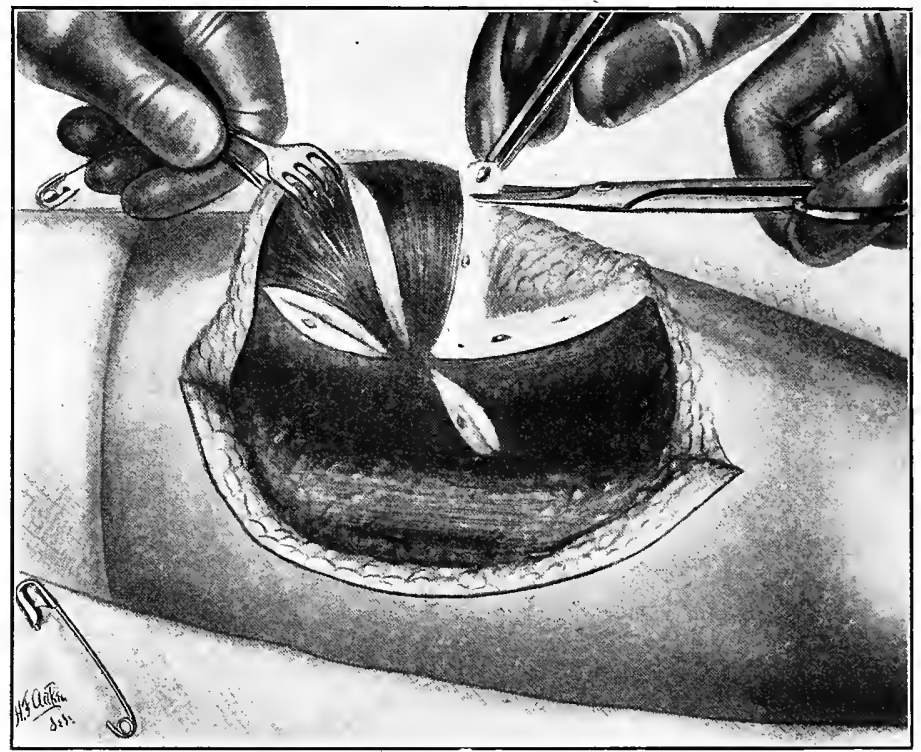

FIG. I70.-A segment of tumor- or cyst-bearing tissue has been removed from the breast, and the several remaining cysts will be excised in the manner shown in the illustration. Additional radiating incisions have been made for purposes of exploration. (Warren.)

served, except subcutaneous removal of the organ, and when the patient absolutely refuses to submit to amputation, this is the method used in cases of advanced abnormal involution. The advisability of amputation increases as the patient approaches the end of the child-bearing period.

We have not found it necessary to perform plastic resection in every case of simple tumor because in a considerable proportion of the cases the growth is so well encapsulated that it shells out readily, and it is unnecessary to sacrifice normal breast tissue. Cases do occur, however, and in considerable numbers, in which the stroma of the breast is firmly adherent to the tumor, in which event, it is better practice to make a clean cut excision of a segment of breast tissue, than to attempt the difficult and mutilating task 
of separating the tumor from the surrounding tissue to which it has become firmly adherent.

Plastic resection is not the most satisfactory method to be employed for the removal of benign tumors situated near the surface of the breast or in its upper inner quadrant. The removal of tumors in these situations through an incision placed directly over them is a much simpler matter than when the approach is made through a Thomas incision, so that unless the cosmetic result has to be seriously considered, we much prefer the former method. Real objections to the plastic method are, however, few in number, and with the exception of its application to cases of abnormal involution, of minor importance.

The technic of the operation as given by its author is as follows:

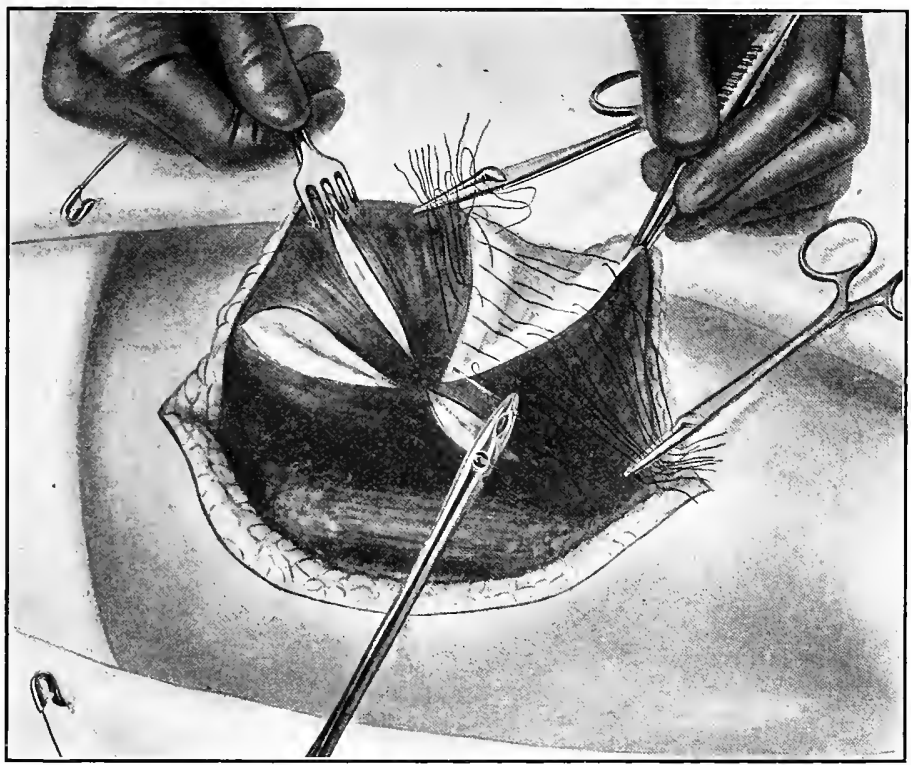

FIG. I 7I.-The V-shaped wound is closed with interrupted sutures. (Warren.)

"The patient standing erect and the mamma being completely exposed, a semicircular line is drawn with pen and ink exactly in the fold which is created by the fall of the organ upon the thorax. This line encircles the lower half of the breast at its junction with the trunk. As soon as it has dried the patient is anæsthetized, and with the bistoury the skin and areolar tissue are cut through, the knife exactly following the ink line just mentioned until the thoracic muscles are reached. From these the mamma is now dissected away until the line of dissection represents the chord of an arc extending from extremity to extremity of the semicircular incision. The lower half of the mamma which is now dissected off is, after ligation of all bleeding points, turned upward by an assistant and laid upon the chest wall just below the clavicle.

"An incision is then made upon the tumor from underneath by the bistoury, a pair of short vulsellum forceps firmly fixed into it, and while traction is made by these, its connections are snipped by scissors, the body of the tumor being closely adhered to this process, and the growth is removed. All hemorrhage is then checked and the breast is put back into its original position. 
"Its outer or cutaneous surface is entirely uninjured, and the only alteration which has been effected in the organ is the leaving of a cavity which was formerly occupied by the tumor. A glass tube with small holes at its upper extremity and along its sides, about 3 inches in length, and of about the size of a No. ro urethral sound, is then passed into the cavity between the lips of the incision, and its lower extremity is fixed to the thoracic walls by adhesive plaster. The incision is closed with silk and covered with collodion. The tube is removed in nine days."

Warren (Annals of Surgery, Vol. 45, No. 6, June, I907, p. 810) gives the following elaboration of the operation first described in his paper "The Surgeon and the Pathologist" (J.A. M. A., July I5, I905).

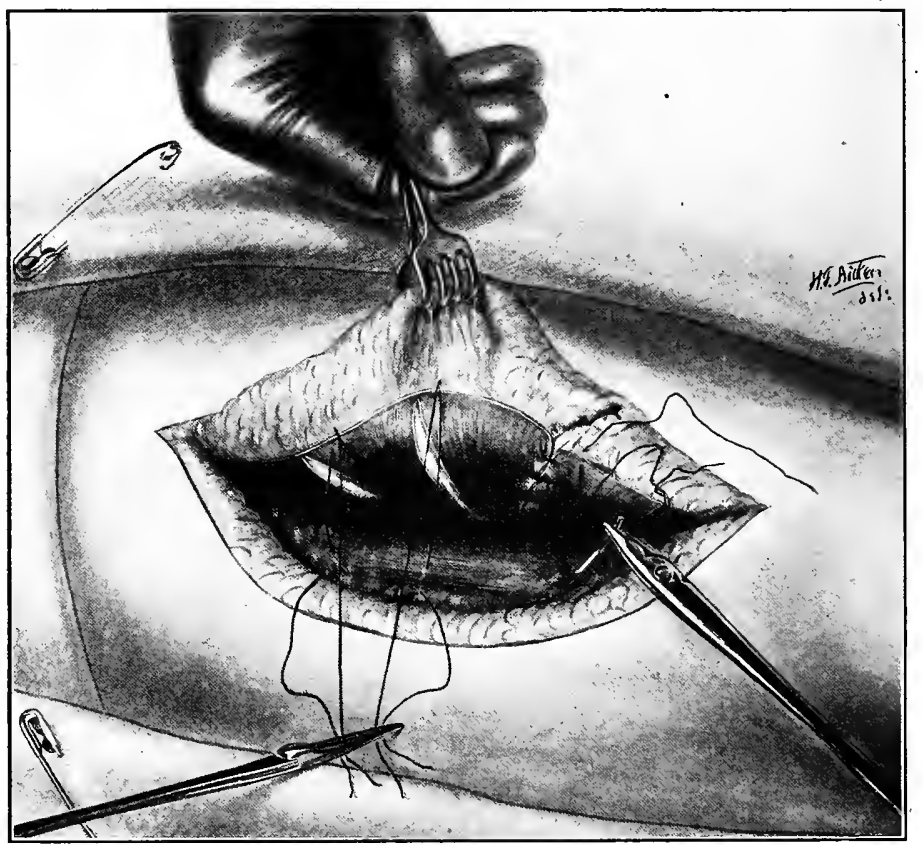

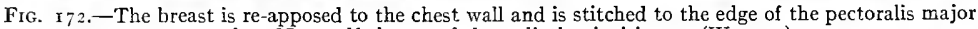
muscle. Note self-closure of the radiating incisions. (Warren.)

"The operation is designed to take the place of those exploratory incisions which are often inadequate for the purpose, or are so situated as to leave a cicatrix in a part of the integument frequently exposed to view. It is also so planned as to expose freely every part of the gland, and, therefore, to accomplish all that an amputation would in doubtful cases. An operation that can relieve the mind of the patient from all uncertainity as to diagnosis, produces no subsequent deformity and entails but little discomfort and sacrifice of time, seems well indicated as a substitute for the various forms of treatment which have from time to time been suggested-such as puncture, aspiration or small exploratory incisions. It is also well adapted to overcome the fears of those who shrink from any operative interference whatsoever.

"In early operations I began with an incision similiar to that described by Thomas, but have changed it to coincide with the edge of the outer hemisphere, as this incision gives a freer access to the upper 
hemisphere and at the same time to the outer hemisphere of the gland, regions more frequently the seat of tumors than the inner quzdrants.

"By prolonging the incision slightly along the anterior axillary border, the breast can be thrown over toward the sternum, and the most remote regions of the gland freely exposed. As the breast falls not only downward but outward, when the patient is in the upright position, this incision is concealed from view.

"The dissection should be carried down to the outer edge of the pectoralis major muscle; when fibers of this muscle have been exposed the knife will have passed through the deep layer of the superficial pectoral fascia, a fascia which covers the posterior surface of the gland. This layer is separated from the deep pectoral fascia covering the pectoralis major muscle by a loose layer of connective tissue. The loose connective tissue enables the dissection to be carried easily between the gland and the muscle, so that they are quickly separated from one another. The left hand of the operator can now manipulate the breast so as to expose the entire posterior surface of the gland. The gland tissue is covered by the posterior layer of the pectoral fascia, but is readily recognized beneath it, as are also any cysts or tumors that may be present.

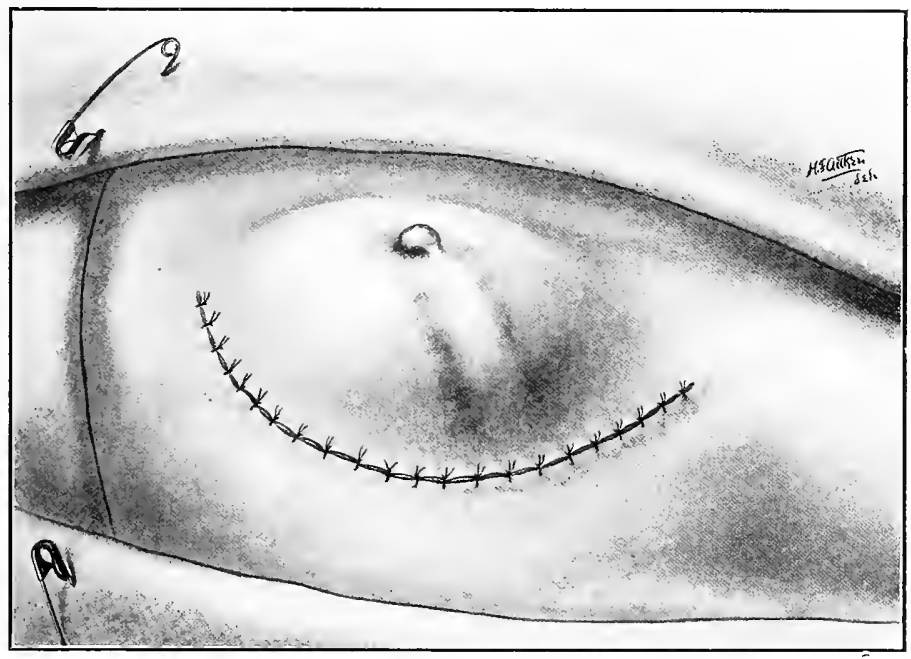

FIG. I73.-Appearance of the breast at the conclusion of the operation. (Warren.)

"An incision radiating from the center to the periphery of the gland should be made through the fascia, to expose the subjacent growth. The segment of the gland containing the tumor should now be removed by two radiating incisions which, meeting at the center of the gland, include a $\mathrm{V}$-shaped portion of its tissue.

"The knife should make a clean cut through the gland tissue down to the loose adipose tissue which lies in front of the gland. This adipose layer should not be removed, as its presence is important in preventing a subsequent depression at this point. No attempt should be made to dissect out the tumor, whether it be solid or cystic. Solid tumors, such as the peri-ductal fibroma, or a cystadenoma, are so intimately associated with the gland tissue that they cannot be 'shelled out.' The fibers of the capsule seem to be continuous with those of the stroma of the gland. Any attempt, therefore, at a dissection of the tumor is followed by a considerable laceration of the surrounding tissues. It is desirable to avoid cutting into the cyst cavity, one or two of which are usually found in the same quadrant.

"In the case of a single solid tumor, the V-shaped wound should be carefully approximated with a double row of sutures, one adjusting the anterior edges of the wound and the other its posterior lips. 
The full thickness of the gland at each side will thus be brought into contact, and no gap left to cause a depression on the surface of the breast.

"In the case of the presence of cysts (in abnormal involution of the breast) a further exploration of the gland tissue is necessary, for although the group of larger cysts forming the tumor, for which the operation has been performed, are usually clustered together in one quadrant, there are also numerous minute cysts in other parts of the gland which have escaped detection. If these are left undisturbed, they may grow later and involve a second operation.

"After the removal of the cluster of large cysts by the V-incision, the remaining segments of the gland can be explored by a series of radiating incisions. In this way all the smaller cysts are laid open, a procedure which is sufficient to insure their permament disappearance. Cysts the size of a pea can be snipped out with scissors. Smaller cysts can be left after being laid open. The number of these radiating incisions may vary from three or four to double that number. It depends largely upon the amount of gland tissue present. Many breasts consist of but little else than adipose tissue interspersed with bands of connective tissue. Usually two or three such incisions suffice to satisfy one that the gland has been thoroughly explored.

"In case an operation has been performed for the purpose of settling a doubtful diagnosis of malignant disease, the breast may be sliced as freely as a brain is at autopsy, provided the radiating method is adopted, without danger of interfering with its vitality.

"It is usually unnecessary to close these incisions with sutures, as their lips drop together naturally when the organ is folded back on to the pectoral muscle. If, however, any tissue has been dissected out from the sides of one of these incisions it is well to catch the edges together with a single suture. In some operations a very large amount of tissue has to be removed, as in the case of larger cysts, and then it is difficult, if not impossible, to adhere to the radiating system of cutting. Keeping, however, in mind that nothing must be removed except acinous tissue, a great deal of the cortical portion of the gland can be saved and considerable portions of the stroma, and all the surrounding adipose tissue of the breast. The somewhat jumbled mass of tissue which remains behind may be so brought together by buried sutures, by the quilting or purse-string methods of sewing, that a well-formed breast may be built up from what is left behind.

"A second V-shaped incision is occasionally necessary for large cysts in other quadrants, but I have rarely been obliged to resort to it. All hemorrhage should now be arrested. This can be done partly by pressure and partly by ligature. Catgut is the only material that should be used for this purpose, as silk leaves a more or less permanent knot behind which may act as a source of irritation.

"The V-shaped openings should next be sutured in the way above described, and the gland is now released from the hand of the operator, and dropped back on the pectoral muscle.

"It will be found that the various incised portions of the gland resume their natural positions, and fit accurately together.

"The gland should next be anchored to the outer edge of the fascia of the pectoral muscle. This holds the muscle firmly in its place. A second row of sutures should be taken through the deep layer of the superficial fascia before closing the outer edges of the wound with silkworm-gut. This last row of buried sutures is useful in removing strain from the surface sutures. It is not an uncommon occurrence to find a folding in or inversion of the nipple, particularly in a case of abnormal involution. This condition should be distinguished from retraction of the nipple as observed in carcinoma.

"This deformity can easily be remedied during the operation by dissection from behind, so as to lay bare the base of the nipple, where a purse-string suture can be applied in such a way as to force the nipple outward.

"In cases of doubtful tumor, where cancer is suspected, the disease can be approached through the incision made for plastic resection. It is well, however, to carry the incision so as to separate the primary nodule from the Iymphatic circulation by extending it a little farther along the axillary border. When the breast is freed from the pectoral muscle, all danger of forcing cancerous juices through the lymphatic channels is averted. If the nodule proves to be cancer, the small cut which has laid it open should be immediately closed by a suture, and the major operation proceeded with immediately.

"The dressing (after plastic resection) should be applied so as to produce lateral compression of the lower and upper hemispheres, as the ordinary swathe tends to flatten out the gland and put a strain upon the buried sutures. For this purpose I have devised the "empire" bandage. The material of the bandage should be of compress cloth or cheviot ahout 5 inches wide, and long enough to encircle the chest and cross diagonally in front. At the point of crossing it should be caught with a safety pin, and pinned like a diaper. The ends which cross each other at right angles are then folded longitudinally so as to form a "box plait" and are attached to suspenders crossing over the shoulders." 


\section{FIBRO-EPITHELIAL TUMORS OF THE MALE BREAST}

Every tumor of the female breast has its counterpart in the male breast.

In the breasts of both sexes, the fibro-epithelial tumor is the common type of benign neoplasm; it is proportionately less common, however, in men than in women.

Among a series of 100 consecutive cases of fibro-epithelial tumors of the breast operated on in the German Hospital of Philadelphia, four were in the male. As will be shown later, not all of these cases are true neoplasms notwithstanding the microscopic diagnosis as such, but belong to the "chronic indurations" which we have described elsewhere as inflammatory fibroses. The latter condition, like hypertrophy of the male breast (gynecomastia), is fibro-epithelial in structure, but neither of these conditions is a true tumor formation.

Carcinoma is by far the most frequent new growth of the male breast, and next in frequency of occurrence come the fibro-epithelial tumors and cysts. Sarcomas are very rare. Fibromas, myxomas, chondromas, angiomas, and myomas of the male breast are pathological curiosities.

According to Bonzani, the benign tumors and carcinomas of the male breast occur in the proportion of $\mathrm{I}$ of the former to 28 of the latter. It is practically impossible, however, to ascertain the true relative incidence of these tumors since the breast is subject to a number of tumors or tumor-like diseases, all of which are fibro-epithelial in structure but concerning the nature of which a decided degree of opinional difference exists.

Confusion arises in the differentiation of true fibro-adenomas, chronic indurations (indurative mastitis), gynecomastia, and mastitis adolescentium. The error commonly made is that of mistaking chronic indurative mastitis resulting from traumatic injury for benign tumors of the fibro-epithelial type.

Chronic induration is considered by some writers to represent a diffuse type of fibroadenoma so that while these cases are spoken of as tumors it is with full knowledge that they differ from the typical rounded, circumscribed growths. It will be noted that several of our cases reported herewith belong to the scleroses although the pathologist has preferred to call them fibro-adenomas.

Woodyatt recognized the physical differences that exist between these conditions but advocated the retention of the generic term fibro-adenoma with separation of the members of the group into two classes, which he described as follows:

Group A.- "Sharply circumscribed, firm, dense tumors, which arise without traumatism in the breasts of young men, run a painful clinical course and show under the microscope little or no evidence of inflammation but all the characteristics of ordinary fibro-adenoma, such as may occur in the breasts of young women, and to which they are here looked upon as analagous." (Two of the seven cases in Woodyatt's series were of this type.)

Group B.- "Diffuse or ill-defined growths which may occur at any time as a result of traumatism. Microscopically these enlargements have virtually the same structure as those of group A. Signs of inflammation are more in evidence however, so that their differentiation from chronic inflammation may not be easy. They are here called adeno-fibroma because of their progressive growth and microscopic structure. This group corresponds to the 'traumatic induration' of some writers." (Four of Woodyall's seven cases belonged to this group.)

The majority of the reported cases of fibro-adenomas of the male breast belong to group B; they are not neoplasms in the true sense of the term and we prefer to limit the use of the name fibro-adenoma to tumors corresponding to the members of group A in the above classification. The following case history is typical of chronic indurative mastitis except for the absence of trauma as an exciting factor. The microscopic diagnosis was fibro-adenoma. 
H. C., aged 3 r, male, was admitted to the German Hospital of Philad elphia in May, rgo8, complaining of a lump in the left breast. This he said had been present for many years but gave rise to no disturbance until six years ago since when it has been slightly sensitive to pressure. The general physical condition of the patient was excellent. A firm nodule the size of a waln ut was found below the nipple of the left breast. The nipple itself was normal as was the skin overl ying the growth. The tumor was attached to the nipple and areola, but not to the pectoral fascia. The axilla was negative to palpation. The breast was removed. It was found to contain an ill-defined, non-encapsulated mass of white sclerotic tissue which the pathologist reported to be fibro-adeno ma.

The pathological diagnosis of the second case was "cystic adenoma," but this too corresponds to the typical chronic induration.

Carl B., aged 23 was admitted to the German Hospital of Philadelphia, July 4, 1902. One year before admission he noticed that the left breast was hard and that it contained a mass. He stated that he had probably injured the breast while boxing. There were no subjective symptoms except tenderness which was slight. The lump remained stationary until about four months ago when it began to increase in size and became more tender.

Examination revealed a firm tumor involving the left mamma, but without retraction of the nipple or skin involvement. The axillary glands were not enlarged, and except for the mammary affection the patient was in perfect health. The history states that "the mass is probably inflammatory although movable within the hreast." At operation the mass was found to be adherent to the pectoral fascia at one point. The tumor itself was similar to that found in the foregoing case. The patient reports, July, I9I5, that he has had no further trouble with the breast.

The third case is probably an instance of gynecomastia, although our notes are so incomplete that, in the absence of microscopic slides for reëxamination, this diagnosis cannot be made unreservedly. The original diagnosis was peri-ductal fibroma.

Lawrence, L., aged 23, was admitted to the German Hospital of Philadelphia in April, rgrr, suffering with a goiter, hypertrophy of the breasts and inguinal hernia. The right breast was more enlarged than its fellow, and this he said was of only three months' duration. Burning pain was the sole subjective symptom complained of by the patient. The notes of the case merely state that the right breast which was enlarged and soft in consistency, was dissected out subcutaneously.

The fourth case has already been reported by Speese. The history of this patient who was also operated on in the German Hospital of Philadelphia is as follows:

Male, aged 68, noted a lump three months ago in the left breast. Little attention was paid to it until two months later, when it became slightly painful and enlarged progressively. The mass was situated under the nipple and felt as large as a goose egg. It was not tender and the axillary lymph nodes were not enlarged. The growth was excised. It was made up of fairly dense white tissue which was not encapsulated as is the ordinary fibro-adenoma. Microscopically a fibro-adenomatous process was seen. The peri-ductal tissue showed proliferation, was fairly cellular and contained many round cells. The acini were more numerous than normal. The lining cells were cylindrical and occurred in several layers. Slight dilatation of the ducts were seen and in some of the cystic cavities small papillæ were present. Diagnosis: adeno-fibroma.

Many of the cases reported as benign tumors and accepted as such by modern writers are not tumors at all but entirely different conditions, such as gynecomastia.

Whelan reported in I 909 a case of mammary enlargement in a young man that both from the clinical and pathological findings corresponds to gynecomastia. This case has been repeatedly quoted as an instance of fibro-adenoma. The breast or breasts of the gynecomast are to all outward appearances identical with the normal breasts of the virginal pubescent female and contain nothing that would even suggest the presence of a true tumor.

Woodyatt states that "nearly all cases of sharply circumscribed adeno-fibromas of the 
male breast heretofore described have developed in youths in the course of what appeared to be adolescent mastitis."

Speese, too, looks upon adolescent mastitis as an important etiological factor in the benign tumor diseases of the male breast. The nature of this relationship is most obscure but the fact remains that at variable periods of time after the subsidence of mastitis adolescentium, nodules frequently make their appearance in the breast. Tumors arising in this manner are prone to be bilateral; they grow very slowly and seldom reach a size larger than that of a walnut.

The following case reported by Fiaschi embraces both pubescent hypertrophy and traumatism as etiological factors in the tumor formation.

Male, aged 25, admitted Jan. 4, I9r2. Eleven years hefore the patient was struck on the left hreast in a football game. Soon after this a mass made its appearance in the breast under the nipple. This increased in size very slowly. Three years ago, he noticed that a smaller mass had formed to the outer side of the original growth and that they had become confluent. From the outset, the tumor had been tender and painful if touched. The examination showed a well-developed atheletic young man whose left hreast was markedly enlarged. The enlargement involved the two lower quadrants and consisted of a fairly well circumscribed mass $2 \frac{1}{2}$ inches in the transverse direction and ' 1 inch vertically. There were no changes in the nipple, in the skin or in the glands indicative of malignancy.

The mass felt hard, hut there were numerous small areas which on feeling through the skin gave the sensation of feeling shot or rice grains through a linen bag. The long duration of the growths, i I years, suggested a slow-growing benign tumor. Plastic resection; entire breast removed. Microscopic examination showed the tumor to be a fibro-adenoma with a preponderance of fihrous tissue.

Bilateralism or occurrence in the second breast after excision of a tumor from its fellow of the opposite side is commonly encountered in benign tumors of the male breast arising at or about the time of puberty. This is illustrated in a case reported by Denenholtz.

I. W., male, aged I5, was horn in the United States, occupation, school boy. Previous history negative except for persistent hronchitis.

Present illness: about the latter part of January, I909, patient noticed a swelling of the left breast after having played a game of haseball. Examination showed a hulging of the left breast which was found to contain a somewhat fattened mass. This mass was ahout $2 \frac{1}{2}$ inches in diameter; a hard circumscribed, rounded, lobular tumor presented itself heneath the nipple. This was freely movable on the underlying parts, except in the vicinity of the nipple where it was slightly adherent. There were tenderness, no dilated veins, and no secretion on pressure. The axillary glands were enlarged hut not painful. The right hreast was normal to inspection and palpation. The tumor was in intimate relationship with the nipple. The breast was removed by plastic resection. Pathological report: fibroadenoma.

The patient remained well until May, I909 (was operated on in February, I909), when he noticed an enlargement of the right hreast. The latter was then found to contain a diffusely enlarged soft mass with some serous secretion oozing, on pressure, from the nipple. The overlying skin was normal in color and movable upon the underlying parts but not so at the nipple. The axillary glands were enlarged.

The mass grew rapidly and in two weeks had invaded the entire breast. It had become extremely hard; the skin was normal, the nipple adherent, and slightly retracted. Simple amputation was done. Pathological diagnosis: fibro-cystadenoma.

The majority of benign tumors of the male breast occur in adolescence, or in young adults. Male children are practically exempt from this variety of new growth.

Bryant's case of fibro-adenoma in the breast of a three-month-old child is now generally considered to have been a case of mastitis. The tumor in this instance contained fat and inasmuch as fat is never a part of true fibro-epithelial tumors the condition was most likely an inflammatory one.

Benign tumors of the mixed variety are seldom encountered in the breasts of men beyond the age of 30 . The following cases reported by Gangitano are extremely inter- 
esting not only because they occurred in men well advanced in years, but because in one instance the tumors were bilateral and in the other the tumor was recurrent. Gangitano looked upon these cases as instances of family types.

Case I.-Man, aged 57 years. Grandfather died of cancer of the rectum. Mother and father died of unknown causes. Sister operated on at the age of 34 for a small tumor in each breast. The growths were benign, and simple excision was done. There has been no recurrence.

The patient gave a history of the removal of a small, slow-growing benign and painless tumor which had been removed from the breast $\mathrm{r} 6$ years hefore. History otherwise negative, no syphilis or tuherculosis, no trauma past or present.

Physical Examination.-Healthy, strong individual. Scar in the left hreast from previous operation. Left hreast uniformly enlarged (this enlargement had been noticed by the patient for about four years). Skin and nipple normal. Palpation revealed an irregularly lobed, painless tumor, movable in the suhcutaneous tissue, suggesting fibro-adenoma. Two enlarged glands, the size of a pea in the axilla. Operation, Fehruary, Igo6, excision of the tumor and axillary glands. The excised tumor was ahout the size of a large nut. In the center of a layer of fat there was a grayish lobular tumor of firm consistence. The cut surface of a section showed the same consistency and grayish appearance, and also some pinkish cavities here and there. Histology showed the neoplasm to be composed mostly of masses of connective tissue crossed with canalicular or distinct adenomatous formation. The epithelial lining is cubical, usually without stratification. The axillary glands showed simple hyperplasia. No indication of recurrence for three years. Recently the patient hegan to complain of pain in the liver, which seemed somewhat enlarged.

Case 2.-Patient, aged 66. Mother died of cancer of the breast. Brother died of cerebral hemorrhage, had had enlargement of one breast. No history of trauma in the patient. Present trouble began about seven years ago with itching in both breasts whereupon the patient noticed a small tumor in each breast. These growths developed slowly, the right heing somewhat larger than the left. Palpation shows the growths to be movable and of fibrous consistency. They were not painful.

No axillary involvement on either side. The tumor in the right breast is about the size of an apple; that in the left hreast is about the size of a walnut. The patient would consent to the removal of the growth in the right breast only. The histology of this was similar to that in the first case. No recurrence after two years. The tumor in the left breast has increased in size, but the patient will not consent to its removal.

Fibro-adenomas of the male breast vary in size and in the rapidity with which they grow. The majority of them are slow in development and rarely attain a size larger than that of an orange. The case reported by Griffin is therefore exceptional; since in this instance the tumor grew to a large size in a short space of time.

Pain is a more frequent symptom of tumors of the fibro-epithelial type in the breasts of men than of women.

These tumors when occurring in the male breast have rarely been known to undergo malignant change. The case of carcinoma in the breast of a I 5 -year-old boy, reported by Bryan, is said to have developed in a benign growth and stands as an exception to the above rule; the case reported by Owens and Eisendrath is undoubtedly an instance of carcinomatous transformation of a benign neoplasm of the male breast.

The patient, aged 56 , noticed a slight depression of the nipple and a nodule the size of a pea in the right breast 36 years before coming for treatment. The condition remained unchanged until shortly before the patient presented himself when a small scab formed on the nipple which would bleed slightly when the scah was removed. The nodule began to enlarge one year before and formed a hard tumor $\mathrm{r}$ inch in diameter, sharply circumscribed from the surrounding skin. The overlying skin was atrophic, hluish in color and immovable. The microscopic examination after extirpation of the tumor showed a scirrhus carcinoma which undoubtedly arose in the benign tumor described.

Treatment.-The treatment of benign tumors of the male breast is the same in principle as that for similar tumors in the female breast. In the case of the male breast, it frequently becomes necessary to sacrifice the nipple owing to the attachment of the 
growth to this structure. Simple excision and plastic resection are less applicable therefore to benign tumors of the male breast.

\section{BIBLIOGRAPHY}

Ashwell.-Cited by Sheild, "Diseases of the Breast," London, 1898 .

Benton.-Trans. Path. Soc. Phila., r885-87, xiii, r65.

Binaud and Braquehaye.-In "Traité de chir.," Le Dentu et Delbet, vii, I5I, Paris.

Bonzant.-Riform. med., $\mathrm{rg} 9 \mathrm{~g}, \mathrm{xxv}$, $\mathrm{I} 75$.

BRYAN.-Surg., Gynec. and Obstet., rgr4, xviii, 545 .

BRYANT. - "Diseases of the Breast," London, r887, p. 90.

BRyant.- "Diseases of the Breast," in Wood's Med. and Surg. Monographs, New York, r8g9.

Cameron.-Jour. Anat. and Physiol., I879, xiii, I49.

Davis.-Ann. Surg., I90r, xxxiv, 308.

Deniker.-Bull. et mém. soc. d'anat. de Paris, r9r 3 , xv, r 25.

Denenholz.-New York. M. J., rgog, xc, 548.

Fiaschi.-Austral. Med. Gaz., Igr 2, xxxii, 508.

Finsterer.-Deutsche Ztschr. f. Chir., rgo6, lxxxiv, 557.

Foerster.-Handb. d. Anat., Leipzig, 1863 , ii, 482 .

Gangrtano.-Deutsche Ztschr. f. Chir., rgog-10, ciii, I.

GiUck.-Berl. klin. Wchnschr., I885, xx, 292.

Greenough and Simmons.-Ann. Surg., rgr $4, \mathrm{~lx}, 42$.

GREenOUGH and StMmons.-Ann. Surg., I9I r, liv, 517.

Gross.- "Tumors of the Mammary Gland," New York, 1880.

Gross.-Med. and Surg. Reporter, I887, Ivii, 3 .

GRIFFIN.-Bull. Johns Hopkins Hosp., rgog, xx, 218.

Hutchinson.-Arch. of Surg., I890-9r, II, Pl. xxiv.

Jopson, SPEESE and White.-Ann. Surg., Ig08, xlviii, i62.

Martin.-In Le Dentu and Delbet, l.c.

MAURE.-Bull. et mém. soc. d'anat. de Paris, $\mathrm{rgr}_{4}$, xvi, II 5 .

OWens and Eisendrath.-Chicago Med. Rec., I898, xv, I49.

OlLIER.-Gaz. méd. de Lyon, 1855, I44.

PéraIRE.-Bull. ét mém. soc. d'anat. de Paris, r9o7, ix, 637 .

Petges and Bonne.-Jour. méd. de Bordeaux, rgr r, lxi, 7 ro.

Pitzorno.-Riforma med., r896, xii, $65 \mathrm{r}$.

PrimRose.-Am. J. M. Sc., rgI3, cxlv, roo.

Putzo.-Arch. f. patb. Anat., r883, xciv, 455.

DEQUERVAIN.-Correspondenzbl. f. schweiz. Aerzte, rgro, xl, 785 .

DE Rouville.-Bull. soc. obstet. et de gyn. de Paris, rgi 4, iii, 552.

Schmomelbusch.-Arch. f. klin. Chir., r892, lxiv, ro2.

SHEILD.—"Diseases of the Breast." London, 1898 .

SPEESE.-University of Pa. Med. Bull., rgog-ro, xii, 55.

SPEESE.-Ann. Surg., rgro, li, 212.

Speese. - Tr. Phila. Acad. Surg., I $9{ }^{2} 3, x v, 9$.

THomas.-N. Y. M. J., I882, xxv, 337.

Uрсотт.-Practitioner, I9I3, xci, I 4 .

VAN DEN BERG.-J. Michigan State Med. Soc., r904, xiï, 367.

Velpead.- "Traité des maladies du sein," p. 250 , Paris, 1858 .

WARREN.-J. Am. M. Ass., I905, xlv, 149 .

WARREN.-Ann. Surg., 1907, XLV, 80I.

WHELAN.-Brit. M. J., I909, i, roo6.

WHITEFORD.-Brit. M. J., rgo8, i, r 359 .

Williams.-Jour. Anat. and Physiol., I89o-gr, xxv, 245.

Wrrifams.—"Diseases of the Breast," London, I894.

Woodyat.-Am. J. M. Sc., rgog, cxxxviii, 244. 


\section{CHAPTER XII}

\section{CARCINOMA}

Pathology.- The nature of carcinoma is unknown. Most pathologists claim to have abandoned the idea that it is an infectious disease, but many still think that it may be. All agree that the carcinoma cells are the lawless descendants of the cells of the parenchyma of the organ in which the tumor occurs, but it is not impossible that this may be an error.

We define carcinoma as a tumor that results from an invasive hyperplasia of epithelial cells. Having done this, we recall that there is more in carcinoma than the invasive cells, for these lie in the interstices of a stroma that, though we trace it to the antecedent connective tissue of the organ in which the tumor grows, shows no more inclination to follow the laws of growth and proportion than do the epithelial cells.

Textbooks and monographs have pages of information concerning the racial, familial and individual factors that predispose to the occurrence of cancer, and other pages filled with information concerning its determining or exciting causes, all of which form interesting reading but in the end are found to contain little knowledge of the real cause of the disease.

In spite of a great amount of experimental research upon the subject, no one has yet devised a method by which carcinoma of any organ, in any known animal, can be induced at will.

Thousands of transplantation experiments.were performed, in every way except the right way, and failed, and it was almost universally conceded that carcinoma was not transplantable, when Hanau successfully transplanted a rat carcinoma to other rats, and Jensen a mouse carcinoma to other mice, and the mystery of transplantation was solved by the discovery that to be successful it must always be homologous-i.e., from animal to animal of the same kind. With this addition to the knowledge of the subject seemed to come the ability to cause cancer at will, and the discovery was enthusiastically welcome as opening the door to a knowledge of the true nature of the disease, to be later abandoned as it became clear that one was no more causing cancer by the implantation of a cancer graft, than he was creating a willow tree by planting a slip from another tree in the ground.

With the invention of methods for cultivating tissue in vitro, by Harrison and Carrel, the study of the subject received a new impetus, and cancer tissue cultures were started everywhere, but disappointment resulted from the fact that when growth took place, it was the wrong tissue - the connective tissue - that grew, while the epithelial cells, the chief factors, soon died out.

Thus a generation of workers have labored with great industry, intelligence and patience, and a mass of information has been collected, but when it is carefully sifted, we find ourselves very much where our forefathers were so far as any clear idea of the cause and nature of cancer are concerned. But what is most disappointing, we are precisely where they were so far as the treatment of the disease is concerned. All that they knew, was, that the proper thing to do for cancer of the breast was to remove it. All that we 
know, is to remove it. We do it with less pain than they, thanks to anæsthetics; we do it with greater safety than they, thanks to antiseptics and asepsis; we do it with less probability of return than they, thanks to better technique, but we still do nothing to cure it.

If there be a disheartening subject to think about or to write about, in connection with the much vaunted progress of modern medicine and surgery, it is our inability to penetrate into the mystery of this disease.

Most surgeons and pathologists are of the opinion that injury by external violence or internal disease is the chief cause of cancer. Quite a collection of cases of cancer following injury and disease can be gathered together in support of this theory but when carefully sifted they are not entirely convincing. Thus, concerning external cancers, we have squamous-cell carcinoma following lupus; squamous-cell carcinoma in chimney sweeps, squamous-cell carcinoma in paraffine and coal-tar workers; squamous-cell carcinoma in $\mathrm{x}$-ray operators; squamous-cell carcinoma following burns by the "kangri" or pot of coals with which the highlanders of central Asia warm themselves. Of mucous membrane cancers, we have the classical example of the clay pipe, and the cancer of the lip; ulcer of the stomach and cancer following it; gallstones, cholecystitis and cancer of the bile ducts and gall-bladder; diverticulitis and cancer of the colon; traumatic injury of the cervix uteri and subsequent cancer. It seems like a long list, and doubtless numerous others might be added, but what is the actual connection between the conditions mentioned and the occurrence of the cancer? In some cases it is so close as to scarcely leave any room for doubt as in the cutaneous cancers in the chimney sweeps and in the paraffine and coal-tar workers. In the case of kangri burns, the clay pipes, and the gallstones there is some room to suspect that the cancers may be coincidental and not consequential. In the case of the gastric ulcer and diverticulitis, we have an attractive hypothesis but still less certainty, because of the difficulty of obtaining accurate information of the precise course, progress and order of the lesions concerned.

But conceding the general facts to be true, how can they be connected with the occurrence of cancer of the breast? The breast is an external organ and therefore subject to traumatism, but although there may be more cases of cancer among those that have met with a traumatic injury, there are great numbers that have no recollection of such, and if the traumatism were a factor of great importance, how about them? Again the breast is one of the most frequently diseased viscera, pyogenic inflammation during lactation being very common and very destructive, but cancer is not strikingly more frequent among those that have thus suffered than among others. The hypertrophy and involution before and afte $r$ lactation are striking examp es of epithelial modifications and might serve as starting-points for epithelial misbehavior, but the percentage of incidence is not much if any more frequent among women that have borne and nursed children than among those that have not. We are, therefore, obliged to admit that mechanical and chemical injuries, whether by external violence or internal disease have not yet been shown to be very potent factors in the occurrence of cancer of the breast.

With regard to abnormal involution and its relation to cancer much has already been said. That it may and sometimes does eventuate in cancer seems probable, but that it is the predetermining cause and constitutes the "pre-cancerous" stage of cancer, it seems hard to believe when we remember that cancer is not always a disease of the period of involution, but sometimes occurs very early in life. We have cases in our collection from girls of I 6 and 17 years of age. It seems impossible to connect the younger cases with a disease that is supposed to represent a decline in the integrity of the breast tissues. 
We are therefore led to the conclusion that there must be numerous predetermining and exciting conditions that lead to cancer, which is about the same as saying that we do not know what conditions do so.

One of the interesting things about cancer is that it begins as a local disturbance, at a minute focus, and spreads. The breast does not become cancer by transforming into cancer; the cancer begins somehow at a minute point, and invades the breast as cancer. The final result may be that the breast is all cancer, but that is because the growth of the cancer into the breast tissue has caused it to disappear until none is left and only the cancer tissue remains. In the small tumors for which the breast is now commonly amputated, it is easy to demonstrate the extending cancer driving its masses of cells between and among the contiguous mammary structures in all directions, and also to observe the injurious effects sustained by the mammary tissue in consequence.

It is comparatively easy to explain the destruction of the organ in which the cancer grows, once the tumor has begun; the difficulty is in accounting for its beginning. The process is usually conceived as the "breaking of the epithelium through the basement

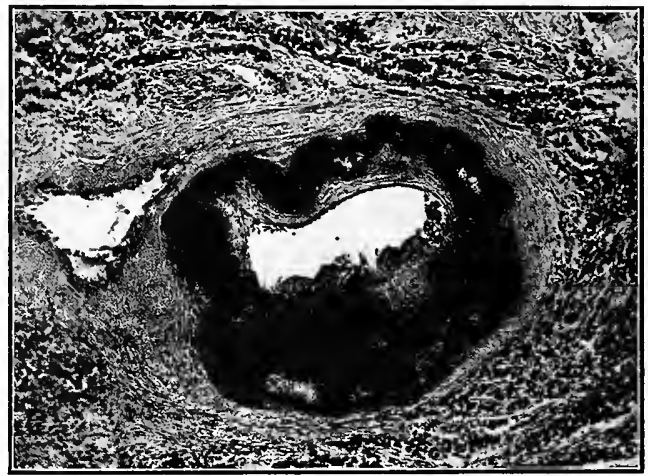

FIG. I 74.--Calcified artery from a scirrhus carcinoma of the breast.

membrane" by which it is normally held within bounds, but more than that is necessary. A basement membrane cannot always be demonstrated as circumscribing the parenchyma of the breast, and innumerable occasions arise through accident, disease and design, by which the epithelium is dislocated from its customary relation to basement membrane in the breast and in other organs, yet no cancer develops. Knowledge of this has led some (Ribbert) to conclude that the primary disturbance is not in the epithelium, but in the connective tissue; that it is not because the epithelium, through activities of its own, escapes and invades, but because the connective tissue weakens and permits it to invade. Both theories seem to be faulty, for there are occasional disturbed conditions in which dislocated epithelium is passively expressed from cysts of the breast into the surrounding connective tissue so as to appear like cancer, yet, no invasive growth of active character follows.

It would seem as though the barrier that prevents the invasion of other tissues by the epithelium must be chemical rather than mechanical. Should such be the case, it is comparatively easy to understand why dislocated epithelium in the interstices of the 
connective tissue does not grow to form cancer, and why the epithelium in its normal environment may become invasive if the barriers be destroyed.

However it begins, the invasive growth once having started, the foundation of cancer is laid. Whether invasion may begin and later be checked through general or local activities by which the growing cells are overcome, we do not know. All that we know refers to those cases in which the invasion succeeds and the disturbance is continuous and progressive.

The rapidity of growth as well as the direction of growth, depend upon conditions that may be both local and general. We know that when cancer occurs in the breast of young lactating women, it progresses so rapidly as to resemble an acute infectious process, and destroys the patient in the course of a few weeks; we also know of cases where elderly women with quiescent breasts have suffered from cancer for many years without extensive destruction of the breast or apparent danger to life.

Associated pyogenic infection sometimes appears to have a favorable influence upon the growth of cancer which progresses rapidly in and about the infected tissue. A few cases in which the two lesions-cancer and suppuration-were so intimately associated that the cancerous and purulent infiltrations occurred together and masses of cancer cells occurred in the pus, have been called by von Volkmann "mastitis carcinosa" and later, by Schuman, "carcinoma mastitoides." Such cases are usually rapidly destructive, metastatic and fatal.

It is to be supposed that under such conditions as ordinarily obtain, the growth of the cancer cells follows the line of least resistance. The dislocated cells are in the interstices or crevices of the tissue which are the beginnings of the lymphatic system. Supposedly, they grow along these spaces, following their intricate communications. Their numbers are soon sufficient to effect obstruction here or there, with resulting distention of the radicles of the lymphatic system, by which new or enlarged spaces are furnished for the extending cellular growth. Accident seems to determine where the process starts, and such accidents as follow lymphatic obstruction and progressive invasion, determine what direction the growing tumor shall take. Thus may be explained the circumstance that some of the tumors remain a long time as "Iumps" in the breast; that others rapidly extend to the surface, invade and destroy the skin, escape as fungating masses upon the surface and pave the way for infection, hemorrhage and other evils, and that still other cases show invasion of the lymphatic nodes while the primary tumor in the breast is still very small.

The growing and invading cells usually form a localized mass that can be plainly felt in the breast tissue. It is, however, a mass within definite circumscription, and instead of being movable like the circumscribed and encapsulated fibro-epithelial tumors, is apparently, a part of the breast itself. This is indeed, true, for the growing tumor mass is much like a rounded fungus whose mycelial threads form a fringe that extends and branches in all directions from a common center that ever becomes larger and denser. The invasion of the breast itself certainly takes place through the continuous growth of these branching fringes.

The growth of cancer cells is quickly seconded by a change in the connective tissues. contiguous to them. The cancer cells seem to stimulate this tissue to slow multiplication and are, therefore, soon found to occupy the spaces of a connective tissue of modified appearance and texture. It is not only excessively fibrillar through the development of coarse collagen and fibroglia, but considerable elastica may develop in it. That such tissue is not preëxistent in the part affected and brought into view through crowding and 
compression, is shown by a study of cancer growths in the lymph nodes and liver where very little connective tissue is normally present but where great quantities appear in most cases of cancerous invasion. There seems to be no uniformity in the proportion of newly formed connective tissue to epithelial tissue; in some cases there is comparatively little, in other cases much.

The quantity formed, however, has much to do with the general character of the cancer itself. If the cancer grow without much proliferative change in the connective tissue, there is apt to be a great preponderance of epithelial cellular tissue so that the tumor may be large and soft; when the connective-tissue reaction is marked and much new fibrillar tissue with a cicatricial quality develops, the cancer is apt to be small and hard.

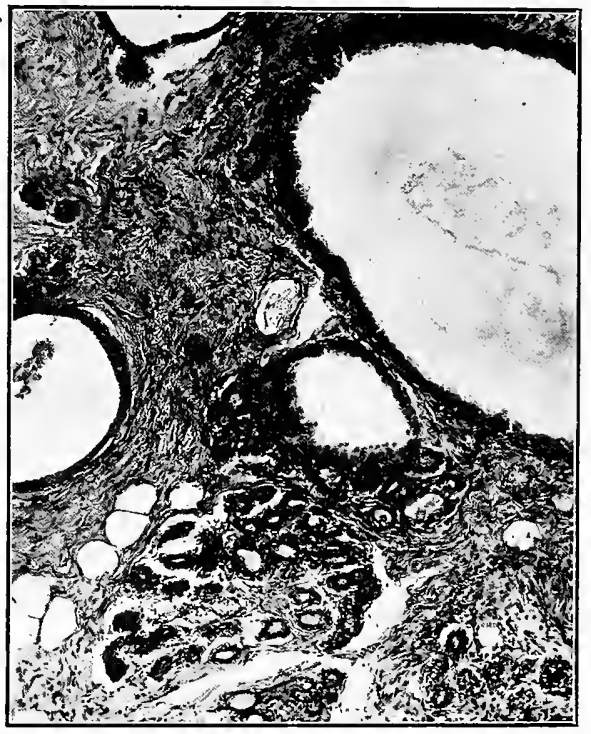

FIG. 175 . -Non-carcinomatous portion of a carcinomatous breast showing dilated ducts.

Thus arises the two chief clinical types-the encephaloid or soft and the scirrhus or hard cancers.

As the primary cancer grows and its outlying cellular extensions invade the tissue, the normal parenchyma of the breast shows marked disturbance. Every breast that is the seat of cancer shows marked changes of the kind described as "a bnormal involution." We interpret these changes to mean that the presence of the cancer effects stimulation of the mammary parenchyma, not that the mammary parenchyma, being primarily disturbed, evolves the cancer. In proof of this it may be pointed out that cancer is not alone in effecting these abnormal involutional changes. They occur just as regularly in squamous-cell carcinoma, in tuberculosis, actinomycosis and other forms of localized disturbances, as in cancer. Further examination of cancerous breasts shows that the greater the proximity to the cancer the more marked are the involutional changes, though 
they are by no means such as may, supposedly, most easily eventuate in cancer. For example, near a cancerous area of the breast, the ductules may show considerable dilatation and hyperplasia of the epithelium of the type known as "blasse epithel," though the cancer may be squamous or scirrhus, its cells of an entirely different type and its structure entirely different in arrangement.

The invading cancer respects no structure, provided the way is open to its progress, and soon the breast tissue shows changes of other kinds-edema, interstitial hemorrhage, malnutrition, pyogenic infection, necrosis, etc.; to which must shortly be added the effects of compression and connective-tissue modification. Thus the cancer destroys the organ as a slow fire transforms fuel into ashes and cinders. In the meantime the induced morbid conditions react upon the tissues, both parenchyma and stroma, of the cancer itself, which show a variety of changes that vary greatly in different tumors and in different parts of the same tumor. The tissue is sometimes edematous, sometimes hemorrhagic, sometimes necrotic; the stroma sometimes hyaline, sometimes gelatinous, sometimes calcareous. The prevalence of one or another of these conditions has sometimes given the impression that one has to deal with some specific variety of cancer, and in the long list of descriptive and specific names that have accumulated, one easily sees how this or that appearance, though it may be most accidental, has impressed some observer with undue force.

It would be a great gain to the clinician, at least, if we could disabuse ourselves of the complicated terminology of cancer, and call it by the one name-cancer or carcinomawithout reservation or qualification, but though we approve a method of treatment that would make the subject appear as simple as possible, we realize that there are objections to it. However the subject be treated, we feel that the matter of nomenclature has been much abused and that simplification is earnestly called for. Why, for example, should we be burdened with the following?

Acinal carcinoma.

Acinar carcinoma.

Acinous carcinoma.

Adeno-carcinoma.

Adeno-carcinoma of Halsted.

Adeno-carcinoma cylindromatosum.

Acute miliary carcinosis.

Cancer en cuirass.

Cancer atrophicans.

Carcinoma adenomatosum.

Carcino-chondrosarcoma.

Carcinoma chondrosarcomatosum.

Carcinoma colloides.

Carcinoma cylindromatosum.

Carcinoma cysticum.

Carcinoma gelatinosum.

Carcinoma mastitoides.

Carcinoma melanoides.

Carcinoma medullare.

Carcinoma simplex.

Carcinoma solidum.

Carcinoma solidum simplex.

Carcinoma solidum medullare.

Carcinoma solidum scirrhus.

Carcinoma scirrhosum.

Chondro-sarco-carcinoma.

Colloid cancer.
Columnar-cell carcinoria.

Comedo-carcinoma.

Cysto-adeno-carcinoma.

Cysto-carcinoma mammæ papilliferum.

Cysto-carcinoma papillare.

Cysto-carcinoma simplex.

Duct cancer.

Duct carcinoma.

Epithelioma.

Encephaloid cancer.

Gelatinous cancer.

Hard cancer.

Mastitis carcinosa.

Medullary cancer.

Melanoid cancer.

Melanotic cancer.

Paget's disease.

Papillary cysto-carcinoma.

Pigmented cancer.

Psammo-carcinoma.

Scirrhus carcinoma.

Sarco-carcinoma.

Soft cancer.

Spheroidal carcinoma.

Squamous epithelioma.

Tubular carcinoma.

Tubular scirrhus carcinoma. 
When this formidable list of names, some of which we have not been able to interpret and the source of which we have been unable to trace, is carefully scrutinized, it appears possible to dispose of it according to the following plan:

I. Scirrhus or hard cancer in which the prevailing cell nests are small and the quantity of connective tissue between them considerable, and in which the tumor usually appears small and hard. Into this group fall the following:

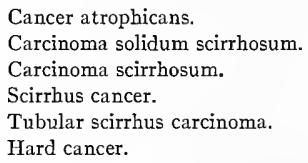

II. Encephaloid, medullary or soft cancer in which the prevailing cell nests are large, and the quantity of connective tissue between them relatively small, and in which the tumor tends to be large and soft. Into this group fall the following:

Carcinoma medullare.

Carcinoma solidum medullare.

Encephaloid carcinoma.

Medullary carcinoma.

Soft cancer.

III. Carcinoma simplex, an intermediate form characterized by cells packed together in more or less solid masses without enough connective tissue to correspond to scirrhus or enough cellular element to correspond to encephaloid. It embraces:

Carcinoma solidum.

Carcinoma solidum simplex.

IV. Adeno-carcinonia.-By this term is meant those forms of cancer in which the growing and extending cancer nests and extensions, maintain a more or less distinctly glandular appearance, through an arrangement of the cells by which hollow cylinders are continually formed. The arrangement obtains in both the primary tumors and their metastatic secondaries. It is unfortunate that the term adeno-carcinoma has been used by many to signify that the carcinoma has developed from glandular tissue, and not from surface epithelium. Such is not the usage of the term as employed here. We consider that the following should fall into this class:

Acinal carcinoma.

Acinar carcinoma.

Acinous carcinoma.

Adeno-carcinoma.

Adeno-carcinoma of Halsted.

Adeno-carcinoma cylindromatosum.
Carcinoma adenomatosum.

Carcinoma cylindromatosum.

Carcinoma cysticum.

Columnar cell carcinoma.

Comedo-carcinoma.

Cyst-adeno-carcinoma.

V. Gelatinous Carcinoma.-This is any form of carcinoma, in which the stroma or matrix together with the cancer cells, is transformed, with great regularity, into a mucous jelly. The conditions are common to the primary tumor and to its secondaries as well. This group includes the following:

Carcinoma colloides.

Carcinoma gelatinosum.

Colloid cancer.
Gelatinous cancer.

Myxomatous carcinoma.

Mucoid carcinoma. 
Plate VI

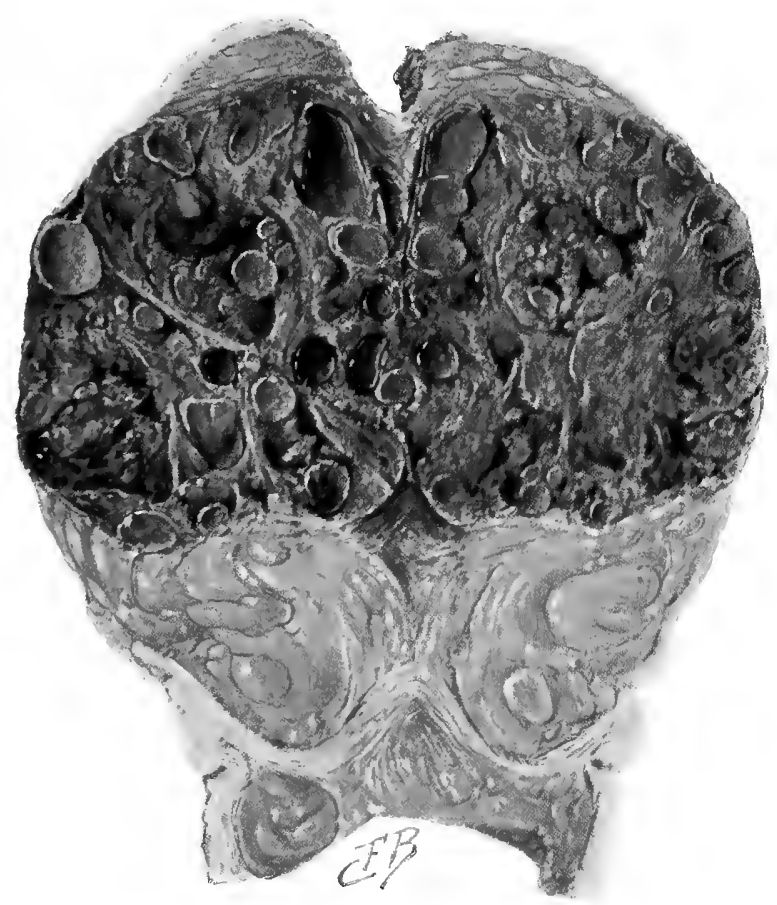

Gelatinous (colloid) carcinoma of the breast.

Deaver and McFarLand. 

VI. The Squamous-cell Carcinoma.-A form of cancer that may arise from the squamous epithelium of the skin of the nipple, areola or surface of the breast, or from the squamous epithelium of the terminations of the larger milk ducts in the nipple. It is sometimes pigmented, when the tissue from which it springs contains pigmented cells. It is also called:

\section{Squamous epithelioma.}

Carcinoma melanoides.

\section{Melanoid cancer. \\ Melanotic cancer.}

When carcinoma follows the invasive growth of the intra-cystic papilloma, it is in no way peculiar except that it is associated with its parent lesion. It scarcely seems neces-

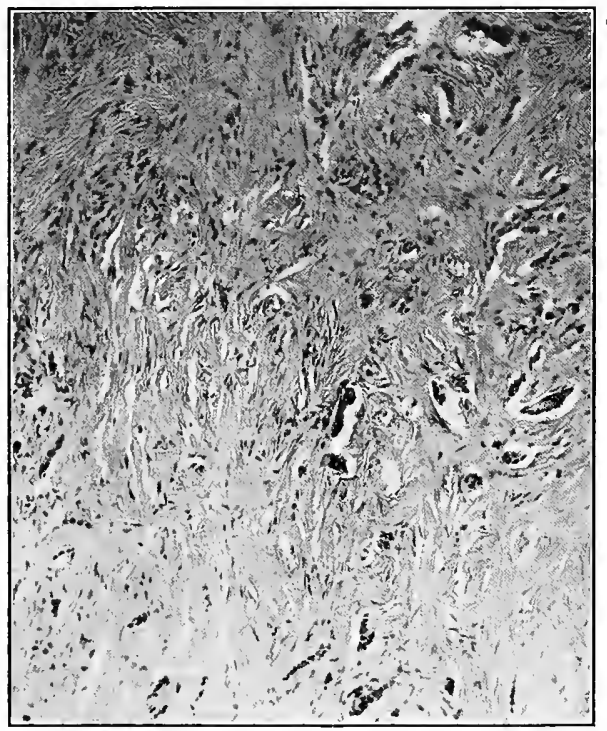

Fig. 176.-Atrophic scirrhus of the breast, showing the small cell nests in the dense stroma.

sary or justifiable under such circumstances to burden the terminology of cancer with the following:

Cysto-carcinoma papillare.

Cysto-carcinoma mammæ papillare.

Duct carcinoma.
Duct cancer.

Papillary cysto-carcinoma.

Cysto-carcinoma simplex (?).

The following are composite tumors in which two neoplasmic types coexist:

Carcinoma chondrosarcomatosum.

Carcino-chondrosarcoma.
Chondro-sarco-carcinoma.

Sarco-carcinoma.

The mastitis carcinosa or carcinoma mastitoides is carcinoma growing rapidly into a purulent infiltration. It is but an accident of carcinoma growth. The true type of structure must be looked for in the non-suppurating tissue.

The psammo-carcinoma is one in whose tissues small spherules and cylinders of cal- 
careous material are deposited. Such deposits in no way affect the true type of the carcinoma as indicated by its cellular structure.

The term "acute miliary carcinosis" was used by Adami and Nicholls to describe a peculiar carcinomatous invasion of the breast which everywhere showed pinhead-sized distributed carcinoma nodules.

"Cancer en cuirass" is a clinical condition depending, supposedly, upon disturbances in the superficial lymphatics and attended by edema, which enables the carcinomatous invasion to affect extensive areas of the integument of the thoracic wall, shoulder and arm. It is in no sense a pathological entity in itself.

"Paget's disease," like the above seems to be a clinical rather than a pathological entity. Exactly what it is, is not known. The disease appears as a chronic eczema of the areola and nipple and eventually effects the destruction or obliteration of the latter. It was at first regarded as an inflammatory disturbance of the skin which, in the course of time, became carcinomatous and invasive, much as squamous-cell carcinoma of the skin follows lupus vulgaris. Further discussion of the subject will be found in the chapter upon "Diseases of the Nipple and Areola."

The varieties of mammary carcinoma that are sufficiently well characterized pathologically, by which is meant histological structure and the repetition of the parent type in the secondary tumors, to form distinct species, are the following:

Carcinoma simplex.

Scirrhus carcinoma.

Miedullary carcinoma.
Adeno-carcinoma.

Gelatinous carcinoma.

Squamous-cell carcinoma.

I. Carcinoma Simplex.-When no qualifying term is used, any case of mammary carcinoma should be referred to this most common class. Each observer no doubt has his own method of classifying his specimens so that there cannot be perfect correspondence between his work and that of others, especially when the confusion of nomenclature above discussed is taken into account.

Among the series of 575 breast cases forming the foundation of the pathological studies made by us, in the preparation of this chapter, the following were found:

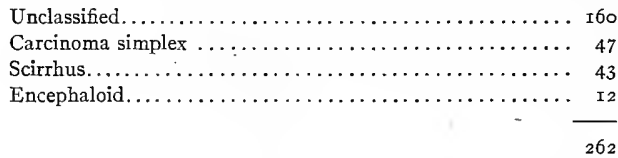

27.82 per cent.

8. 17 per cent.

$7.4^{8}$ per cent.

2.08 per cent.

$45 \cdot 55$ per cent.

The 160 unclassified cases probably fall with more or less correctness into the class of carcinoma simplex. It is said "with more or less correctness" because these cases were unaccompanied by clinical data, did not fall into any easily recognized class and the labels simply say "carcinoma."

As a matter of fact, the above given four groups are not to be looked upon as clearcut microscopic varieties. It is often more easy to classify a tumor clinically than microscopically. Experience has shown us that one must be very guarded about assigning a tumor to either the group of "scirrhus" or "encephaloid" upon the microscopic examination of a single slide. We have seen numerous cases in which a section from one block of tissue showed the typical appearance of scirrhus, while, another block taken a short distance away showed equally typical encephaloid.

Many of the slides "unclassified" were so treated because their tissues showed neither 
Plate VII

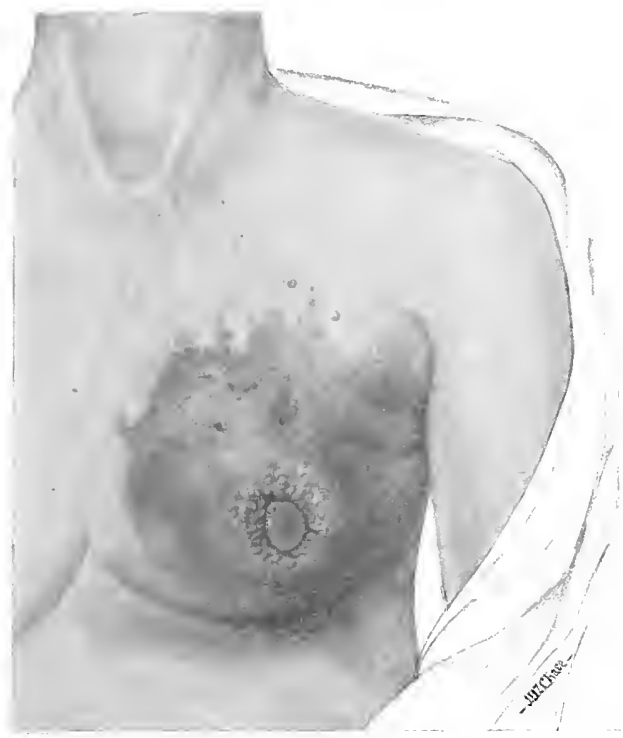

Mastitis carcinosa. VIII. para; eight months after childbirth. Inoperable. Began in second week of puerperium. Treated at first as abscess. (IIirst.) 
all scirrhus nor all encephaloid in the same section. To know nothing of the tumor itself, and to call it scirrhus because the section shows small cell nests and much connective tissue, or to call it encephaloid because it shows the reverse, is to fall into egregious blunders, for both of these terms are clinical rather than pathological, and though the microscope may explain why the one tumor was small and hard or the other large and soft, why the one might last for years without effecting great destruction, and why the other is more likely to be invasive and quickly ulcerate, it cannot tell the general structure of a large tumor when it only shows that of a small fragment.

II. Adeno-carcinoma.- In our pathological series of 575 cases there were 35 , or 6.08 per cent., that were specifically designated by this name. All forms of the adeno-carcinoma were recognized though they have not been separately enumerated. Some showed small cell nests and might be called acinous; others were tubular; still others were characterized by the presence of large masses of cells with necrotic centers, which when the fresh cancer tissue is incised can be squeezed out in the form of tiny cylinders, and have led Bloodgood to call them "comedo-carcinoma."

We have found the adeno-carcinoma rare compared with the sirrhus, medullary and the carcinoma simplex. It might be said that our collection embraces 23 cases of carcinoma associated with abnormal involution, some of which might be classified as adenocarcinomas, but which have not been included because experience has shown that the adenomatous changes that first strike the eye in this combination are commonly accompanied by appearances like carcinoma simplex elsewhere. We look upon such tumors as too mixed in

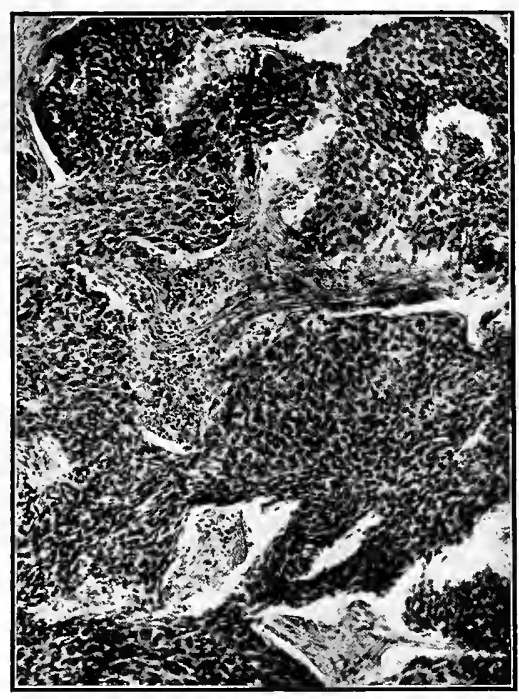

Frg. I 77.- Large cell nests with small amount of stroma, such as appear in encephaloid or soft cancer. character to be included in these well-characterized forms of carcinoma. If this is not reason enough, it may be added that we have found that the metastatic tumors in such cases rarely show any gland-like structure.

III. Gelatinous Carcinoma.-In the 575 cases in our pathological series, only to or I.73 per cent. were of this variety. The gelatinous carcinoma is, therefore, a rare tumor. It is quickly recognized the moment it is incised, because of its gelatinous consistency and pale color. The extent of the degenerative destruction of the tissues, for it affects both epithelium and connective tissues, varies in different cases, so that some tumors are softer than others. In advanced cases of the gelatinous degeneration the greater number of the cells are destroyed. The metastatic growths show the same tendency to mucoid metamorphosis as the primary tumor. When excessive destruction of tissue has taken place, the mucous product may be collected in pockets in the tissue, where it forms more or less clear, viscid, yellowish or colorless jelly-like collections that can be pressed out, 
and has a dense, though slimy rather than sticky quality. The microscope usually shows the cell nests degenerating from the periphery toward the center. The peri-ductal tissue is attacked before the inter-lobular tissue. The gelatinous carcinoma was formerly called "colloid cancer," but it is now universally recognized that there is no true colloid cancer of the breast, and that the name should be abandoned.

The cause of the mucoid change is not known. It might be ascribed to some local nutritional disturbance did it not occur equally in the secondaries. On this account it has to be regarded as a specific quality of the tumor.

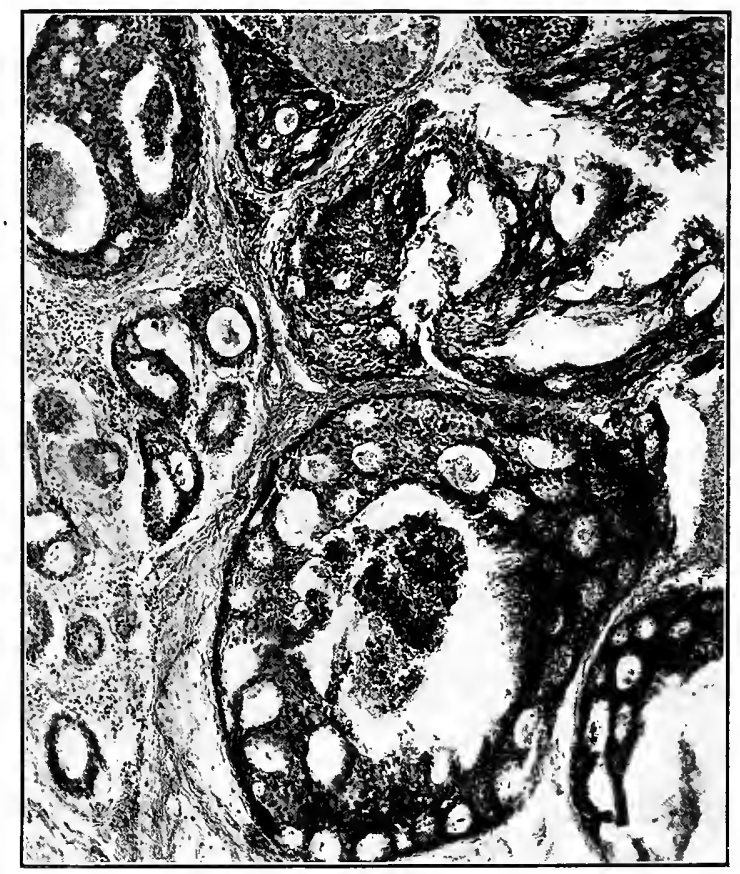

Fig. I78.-Adeno-carcinoma of the breast.

IV. Squamous-cell Carcinoma.-This form of tumor is only indigenous and properly regarded as a true tumor of the breast when it arises from the nipple and areola, or from the extensions of the squamous epithelium from the surface of the former into the milk ducts. It is a very rare tumor of which our pathological series of 575 cases contains but 4 or 0.695 per cent. It is so unusual that one is scarcely sufficiently well acquainted with it to recognize it by gross examination. It is apt to be a centrally and superficially situated tumor of the breast, but that is not sufficient to enable the diagnosis to be made without a microscopic examination. That examination usually at once settles the matter, for the branching and extending squamous epithelium is not easily mistaken. 
When the dermal epithelium invades the breast, no mistake is possible for the "epithelial pearls" with their distinct keratinization cannot be overlooked.

One peculiar case of squamous-cell carinoma of the breast in our collection came to. operation in the German Hospital of Philadelphia. The patient had long had a pigmented wart at the margin of the areola, which finally ulcerated and invaded the surrounding skin and subjacent tissues. The tumor extended throughout the neighboring breast tissue as a rodent ulcer, but its cell nests being small and closely packed together, and all of its cells being more or less deeply pigmented with melanin, it was, at first, mistaken for a melanotic sarcoma, and under this diagnosis was removed.

A complete tabulation of the cancer cases in our pathological series of 575 breast cases shows the following:

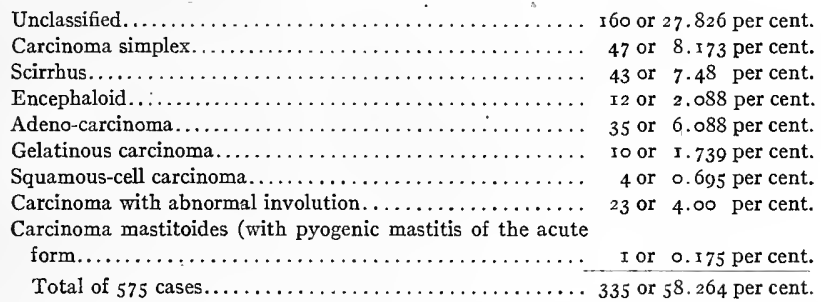

These figures which represent the results of microscopic study of the breast tumors do not correspond with those that result from combined clinical and microscopic studies, and show the importance of always combining the two. This is well brought out by comparing the work of others with our own. Thus Warren (Annals of Surgery, rgo4, II, 805) gives roo cases distributed as follows:

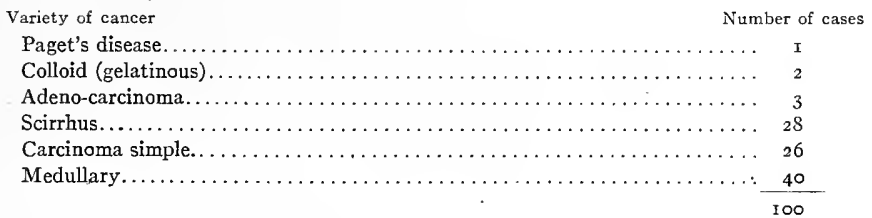

and Halsted gives the following list:

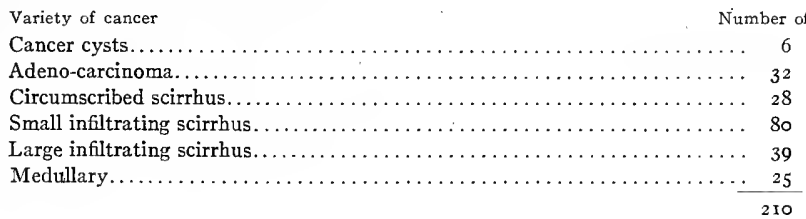

These tables show differences in terminology that are somewhat difficult to harmonize satisfactorily, but there is enough correspondence to show how different are the experiences of different men. Thus, we have $\mathrm{r} 2$ or $3.5^{8}$ per cent.; Warren 40 per cent. and Halsted I 2 per cent. of medullary cancers.

Differences in diagnoses have practical bearings upon prognosis. Thus, in Warren's hands.only 7 per cent. of the cases of medullary carcinoma operated upon recovered, but 
in Halsted's hands $4^{8}$ per cent. recovered. Why this difference? Could it be because the same things were not called "medullary cancer?" In Warren's experience only 3 per cent. of the cases were called adeno-carcinoma, and 66 per cent. of them recovered after operation, but in Halsted's experience, I5.23 per cent. of the cases were called adenocarcinoma, and 75 per cent. recovered.

If we are to make deductions concerning future eventualities from the type of tumor that is removed, there ought to be simplification of the nomenclature, a general agreement as to what things should be called, and established criteria by which the different species of carcinoma can be recognized and assigned to their respective classes.

The best that can be done at the present time is to say that the order of malignancy

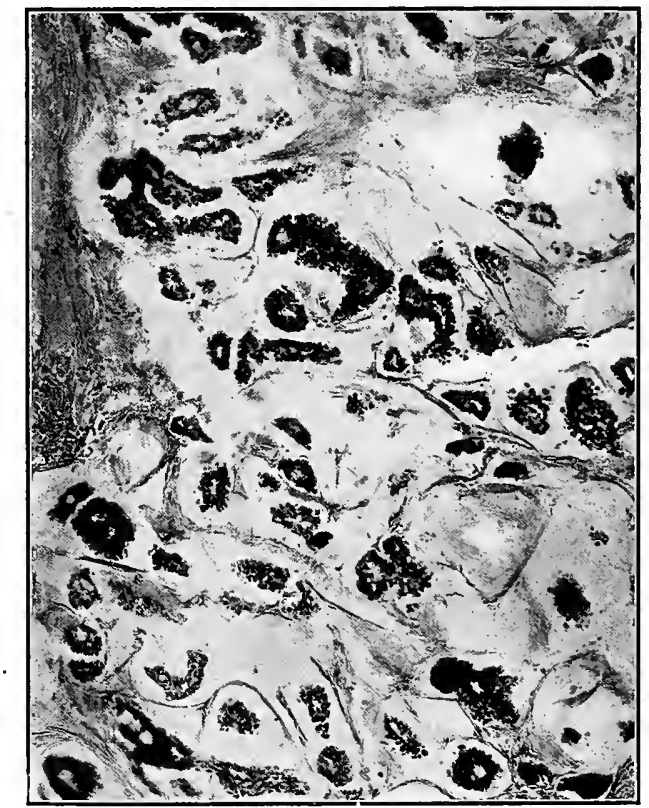

FIG. I79.-Gelatinous (colloid) carcinoma of the breast.

of carcinoma is encephaloid or medullary, carcinoma simplex, scirrhus, adeno-carcinoma, Paget's disease and gelatinous, the first being most, the last least malignant.

Associated Sarcoma and Carcinoma.-This subject has been exhaustively treated in the chapter upon "Sarcoma of the Breast" (q.v.), but a brief mention will not be out of place at this point.

The tumors can coexist in the same breast as independent tumors, or as what appear to be cause and effect. A few cases are on record in which a carcinomatous breast, when incised for examination, was found not only to contain the typical carcinoma but also an equally typical, fairly well-circumscribed non-indigenous sarcoma. Under such circumstances the patient suffers danger of malignant manifestations through lymphatic 
metastasis and permeation as regards the carcinoma and blood metastasis as regards the sarcoma. Each is a menace independently of the other, and it is difficult to see how either could influence the other.

In addition to the small number of cases in which such accidental association of malignant tumors occurs, there is another small number of cases in which the development of the sarcoma occurs because of the presence of the carcinoma, through changes in the actively stimulated stroma. In such cases the inter-alveolar tissue-the matrix or stroma - of the carcinoma takes on a rapid multiplication of cells that may progress until nothing but spindle cells can be seen between the carcinoma cell nests. This has all of the appearances of fibro-sarcoma, and experiences with several of such tumors show that they may behave like fibro-sarcomas in taking on a mucoid change. The sarcomatous change may not be uniform, some areas are purely cellular, some partly cellular, some not yet changed by cell multiplication. The relation of the fibro-cellular to the epithelial constituents closely resembles that seen in the fibro-epithelial tumors,

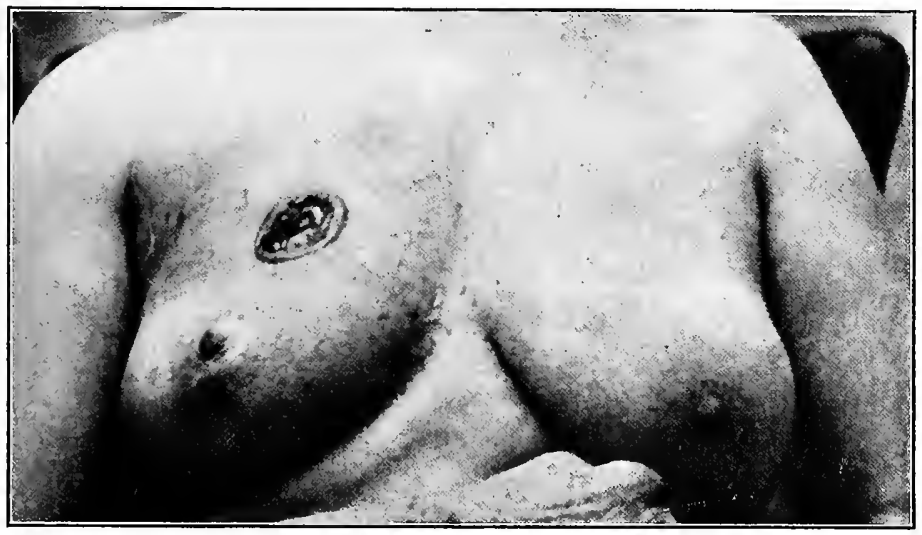

FIG. 180.-Squamous-cell carcinoma of the mammary skin.

and already described. This sarcomatous change in carcinoma of the breast, may find an analogy in what is sometimes observed in transplantation experiments with carcinomas of the lower animals. When frequently transplanted, the tissues sometimes lose the epithelial cell components, though a highly cellular connective tissue arising from the stroma, continues to be transplantable and to all intents and purposes behaves as sarcoma.

Morbid Anatomy.-The gross appearance of the incised breast containing cancer is usually such as to enable the diagnosis to be made without difficulty. As has been pointed out in the section upon Pathology, the disease begins at a focus and spreads. In cases in which the tumor is still very small the first difficulty may be to find it. This can usually be done by making many parallel incisions and carefully feeling the tissue for indurations. The normal white mammary tissue is soft and yielding to the fingers, cancer tissue is usually firm and hard: In the routine examination of a breast every area of dense texture should be carefully incised and examined. It has been a rare happening 
in our experience for cancer tissue to be discovered by microscopic examination without previously having been detected by the finger or the eye.

The cut surface of the denser cancer tissue usually presents an appearance, which, varying somewhat in the different varieties of cancer, is sufficiently different from the normal to attract the eye. In general, it may be said to present a drawn and variegated appearance. The area may be fairly well defined, but is rarely sharply circumscribed and never encapsulated. As a rule, it tends to fade away on all sides by irregular extensions into the surrounding healthy tissue. The more localized the lesion is, the more it

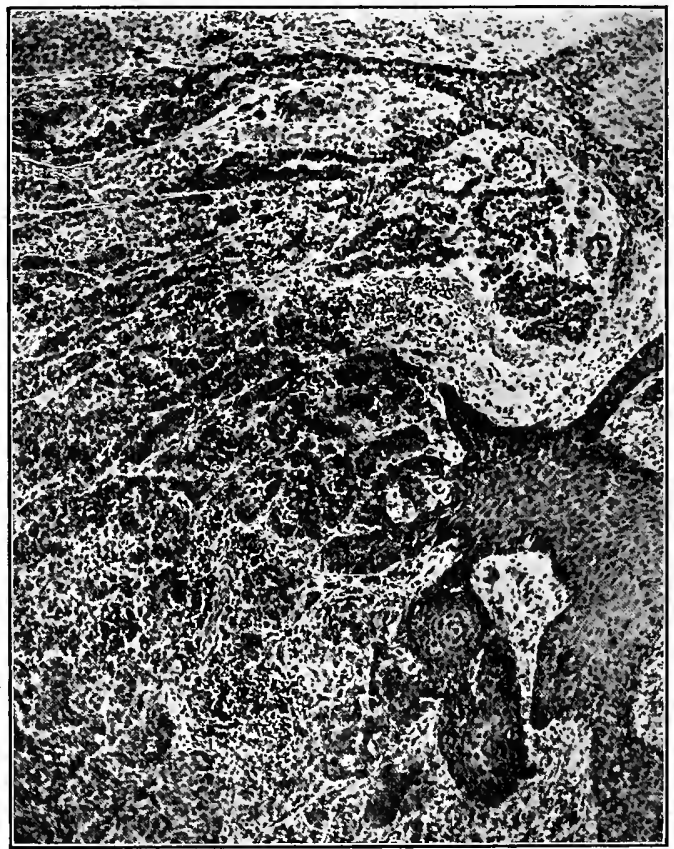

FIG. I8I.-Pigmented squamous-cell carcinoma, mistaken clinically for melanotic sarcoma. (Low magnification.)

tends to exhibit an appearance of radiation from a vague center; the more diffused it is, the more it shows linear striation and prolonged extensions that draw upon the adjacent glandular tissue. This "drawn" appearance, for which the interstitial connective tissue or stroma is responsible is sometimes secondary in importance to the color change though it may exceed it. The tissue frequently looks somewhat porous, the "pores" being the spaces in the stroma, and is variegated, being finely mottled with pink and tan, the general effect being to darken the tissue and make it contrast with the normal white of the mammary tissue. The degree of mottling and variegation depends in large measure upon the varying proportions of cellular and intercellular components in the cancer. In scirrhus, 
where the connective tissue stroma preponderates, it is far less marked than in encephaloid or adeno-carcinoma in which the cellular structure preponderates.

The analysis of the variegated appearance resolves it into the whitish or grayish stroma, the pinkish healthy cellular tissue, the tan color of necrotic cells and the red dots of gaping transversely cut blood-vessels.

When the tumor is larger and can at once be felt and found when the breast is handled, the same general description applies, though now the growth may have progressed to a point when it takes on one of the forms sufficiently well characterized to constitute a variety.

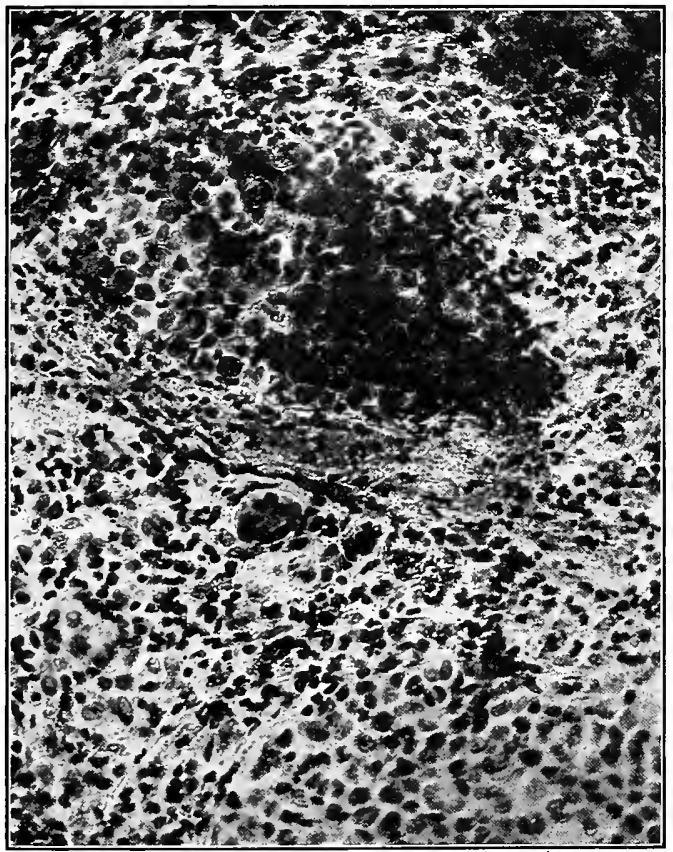

FIG. 182.-Pigmented squamous-cell carcinoma, mistaken clinically for melanotic sarcoma. (High power.)

Scirrhus.-In typical cases of scirrhus carcinoma, the breast is small and hard, or if it be large because it contains much adipose tissue, it presents a hard body of indefinite shape. When incised, the tissue is tough and dense almost like leather, the cut surface presenting an appearance like a dense scar. The confines of the cancer are usually not delimited. The scar-like tumor tissue usually extends irregularly in this direction and that, and as it contains comparatively little cellular tissue, is but slightly variegated in appearance, and little darker in color than the breast tissue itself. In some cases more or less distinct nodules with fairly clear separation from the white mammary tissue, and much more sharp separation from the yellow fat show a pinkish color. In such the type 
of the tumor is much less clearly shown upon microscopic examination than in the denser more cicatricial portions. When ulceration forms upon the surface of breasts containing scirrhus, the margins are dense, and the ulceration without deep excavation.

Encephaloid and adeno-carcinoma probably cannot be differentiated from one another with any certainty by naked-eye inspection. The tumors are usually apparent before the breast is incised. They may attain a large size, be entirely in the breast tissue or, having extended to the surface have become somewhat excavated through ulceration, or through the ulceration the tumor may extend as a smaller or larger fungoid mass. The incised tumor is at once apparent through its grayish-pink color and its fine sprinkling of tan-colored points and dots.

It usually forms a fairly well-localized sometimes quite well-circumscribed mass, with suggestions of radiations from the center, and sometimes of indefinite lobulations about the center. The edges are in parts finely fringed in appearance, but may be defined with some sharpness, especially where they abut against the intra-mammary or subcutaneous fat. There never is any real encapsulation. Extensions project from the tumor mass in this or that direction sometimes connecting with other nodes elsewhere, and sometimes at considerable distances away in the breast tissue. The substance of the tumor is soft and may sometimes be broken up by the finger, and it cuts easily. When necrosis is active in the tumor tissue, the yellowish-tan color may occur in larger foci sprinkled through the node, or may even embrace the entire central part of a lobule. In adeno-carcinoma, the central portions of the glandular areas undergo necrosis in such manner as to be soft enough to escape, when the tumor tissue is compressed, in a cylindrical form suggestive of the comedones popping out of the sebaceous ducts or the epithelial plugs being expressed from a squamous-cell carcinoma of the lip. Bloodgood has applied the term comedo-carcinoma to adeno-carcinomas having this peculiarity.

Carcinoma Simplex.-When the naked-eye appearances conform neither to the description of scirrhus nor to that of encephaloid, yet do not correspond with any of the varieties yet to be described, the surgeon usually calls it carcinoma simplex. Being a group of non-descript tumors, no satisfactory description is possible.

Gelatinous Carcinoma.-The mucinoid (erroneously called colloid) change sometimes makes its appearance in the carcinoma tissue when the tumor is still minute. It is, however, more frequently observed in larger tumors, perhaps because they more frequently come under observation.

The chief characteristic is gelatinous consistency and a more or less pronounced tendency to cyst formation in the cancer tissue. The firmness of texture so characteristic of most forms of cancer is lost through the mucinoid change in the stroma, the cells melt away into jelly and the entire quality of the tumor becomes changed. The color of the jelly varies. In some cases the tissue is whitish or grayish, in others it is yellowish, in still others it is reddish and in rare cases so red as to appear almost hemorrhagic. The tissue is soft and translucent, the contents of the cysts sometimes transparent. The circumscription of the tumor is commonly more distinct than is usual with carcinoma, and the cysts which vary in size from a pinhead to a centimeter or more in diameter, usually appear to have smooth walls.

In general, the gelatinous change pervades the entire tumor, with all of its extensions, and also occurs in the secondaries. In exceptional cases it is localized to certain areas.

Squamous-cell Carcinoma.-This is a superficial form of tumor that usually makes its appearance about the nipple and areola, forming a fairly well-circumscribed superficia] node that soon ulcerates and forms a shallow excavation with dense infiltrated and ele- 
vated edges of almost cicatricial density. When a vertical incision is made through the tumor into the breast tissue, the tumor is usually found to be superficial and fairly well localized. Few extensions penetrate deeply into the breast tissue.

When such tumors arise from pigmented warts, they may be pigmented and mistaken for melanotic sarcoma.

Carcinoma mastitoides or mastitis carcinosa usually "manifests itself as a general painful and rapid enlargement of the entire breast or of both breasts, without the presence of any previously noted mass or area of induration. The gland becomes reddened, hot, edematous and may present a sense of fluctuation. Appearing, as it most frequently does, shortly after parturition, the similarity to acute mastitis is marked, and many patients have been persistently treated on this basis. The skin shortly becomes in-

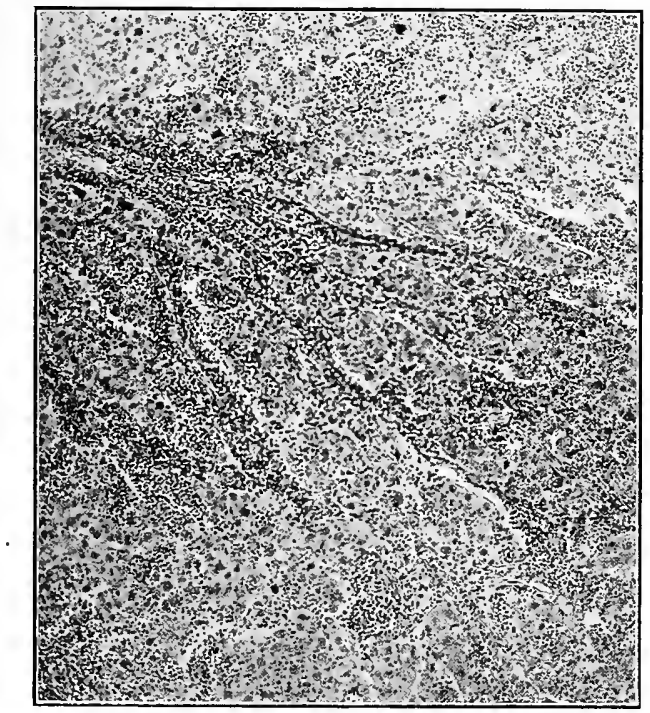

FIG. I $83 .-$ Carcinoma mastitoides. A combination of purulent infiltration and carcinomatous change in which the carcinoma cells seem to be diffused in the puriform collection.

filtrated and brawny and small areas of necrosis may appear. The nipple may or may not be retracted, and the axillary and supra-clavicular glands are early enlarged in the majority of instances. The skin of the thorax immediately surrounding the breast may become indurated and reddened; there is usually some elevation of temperature and locally the part may be hot. A point of interest is, that though small abscesses are occasionally noted, in no case did the breast tissue break down en masse. Cachexia is profound and metastasis rapid, death transpiring from toxæmia."

"On incising such a tumor there will be found a fairly firm tissue, which may or may not present small abscess cavities. The substance of the growth is usually firm and fibrous, of a purplish-red color, and frequently exhibits small isolated areas of hemorrhage. There are usually scattered throughout the gland small necrotic spots, sometimes ab- 
scesses of considerable size. The contiguous skin is markedly indurated and edematous, the induration extending in the writer's experience, beyond the middle line anteriorly and to the post-axillary line, posteriorly" (Schumann, Annals of Surgery, July, I9Ir, p. 69).

Psammo-carcinoma, characterized by the formation of chalcospheres in the tissue, but by no other fixed characteristics, can usually be recognized by the grittiness of the tissue felt by the knife in cutting it, or by the fingers in palpating it.

Cancer en cuirasse is a widespread carcinomatous infiltration of the skin of the thoracic wall, sometimes extending from the sternum anteriorly to the scapula posteriorly and even covering the shoulders and extending down the upper arm. How much or how little dermal invasion justifies the use of the term is a matter of judgment, but it was the evident intention of the originators of the term that it should be reserved for cases sufficiently widespread to suggest a "breastplate," and not applied to ordinary cases in which the skin is infiltrated for a short distance only.

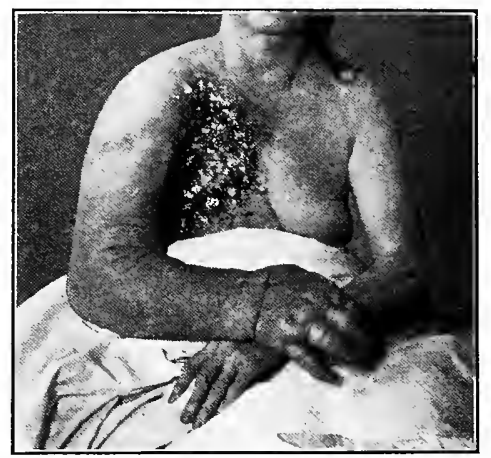

FIG. I84.-Cancer en cuirasse (recurrent). with lymphœdema of the arm. Suitable case for lymphangioplasty.

\section{METASTASIS}

Malignant disease is transferred to distant structures by conveyance of tumor cells which have become detached from the parent growth. Undoubtedly, the most important avenue of dissemination in the early stages of carcinoma is furnished by the larger lymphatic vessels which join the affected organ with its regional lymph nodes, and, however distant the cancer cells may be in the later stages of the disease, it is to the lymph nodes adjacent to the primary growth that we must look for the first clinical evidence of metastasis in the great majority of instances. Thus, the axillary lymph nodes are the most frequently involved structures in the early stages of metastasis of cancer from the breast; indeed, complete freedom from such involvement is most exceptional in cases referred for operation.

The comparative rarity of metastatic cancerous involvement of the pectoral muscles is well known, yet in one of our recent cases, that of a young woman with a small scirrhus nodule in the outer portion of the breast, the pectoral muscles were studded with cancer nodules ranging in size from a pea to a pigeon's egg, while the axillary lymph nodes 
had entirely escaped. As we shall show in our description of the modern operation for mammary cancer, the subject of muscle invasion in cancer of the breast has been recently discussed by Speese, who concludes from careful microscopic studies, that this is not of rare occurrence, and that it is unwise practice to preserve the muscles in operations for malignant disease. Primary cancer arising in aberrant mammary tissue situated in the substance of the pectoralis major muscle must not be mistaken for metastatic growth.

In some instances the lymph nodes escape metastatic involvement while the abdominal or other internal viscera become involved at a comparatively early stage of the disease, and not infrequently patients with widespread metastasis to one or other of the abdominal organs present a small and symptomless lump of which they have possibly been unaware. Examples might be multiplied at great length to illustrate the lack of uniformity in the distribution of both parietal and visceral metastases arising from cancer of the breast. We must be prepared therefore to expect decided variations in the localization of metastatic foci in patients suffering from carcinoma of the same, as well as of different organs. On the other hand, carcinoma of each organ has, in a general way, its own metastatic geography, so that the surgeon is enabled to search for secondary deposits of the disease in question, in certain areas, with a reasonable degree of assurance that, if metastases have taken place, the cancer cells will have lodged in these structures. This is especially true of mammary carcinoma which in the great majority of instances disseminates itself to certain well-defined locations. These will be considered in detail later.

The Mechanism of Metastasis.-Unfortunately, the process of cancer dissemination is an exceedingly complicated one, and while embolic invasion of adjacent lymph nodes regularly occurs, the further progress of the metastatic cells presents many problems that are far from satisfactory solution.

The local dissemination of mammary cancer undoubtedly begins in the very early stages of the disease. This varies with the different types of tumor and early metastasis is more likely to occur in young and fat women owing to the greater richness of lymphatic vessels in such patients. Traumatic injury of the tumor likewise increases the probability of early metastasis, and finally, the greater the rapidity of growth of a carcinoma, the greater the likelihood of early dissemination of its constituent cells, a characteristic that is in direct contrast with that obtaining in the case of certain sarcomata of the breast, the peri-ductal type of which, while usually of very rapid development, rarely metastasizes until a comparatively late stage of the disease.

According to Fink, the axillary lymph nodes become involved in carcinoma of the breast as early as the sixth month of the disease and after the thirteenth month are invariably invaded. These nodes harbor cancer cells for a considerable period of time before they become palpably enlarged so that the clinical findings are by no means a true index of the pre-metastatic time interval, which latter, in the case of human cancer at least, seems to vary considerably in different cases. Tyzzer, on the other hand, claims that the interval of time that elapses between the appearance of the tumor and the occurrence of metastasis, is quite constant for certain tumor diseases of the lower animals, an observation which Murphy considers the most important contribution to the pathology of malignant disease since Virchow's introduction of the cellular theory. If this observation proves applicable to cancer in man it will undoubtedly become of the greatest practical value. Williams states that general dissemination of cancer of the breast occurs from one to three years after the onset of the disease, and about ${ }_{5}$ months after invasion of the axillary lymph nodes. It is well to remember, however, that 


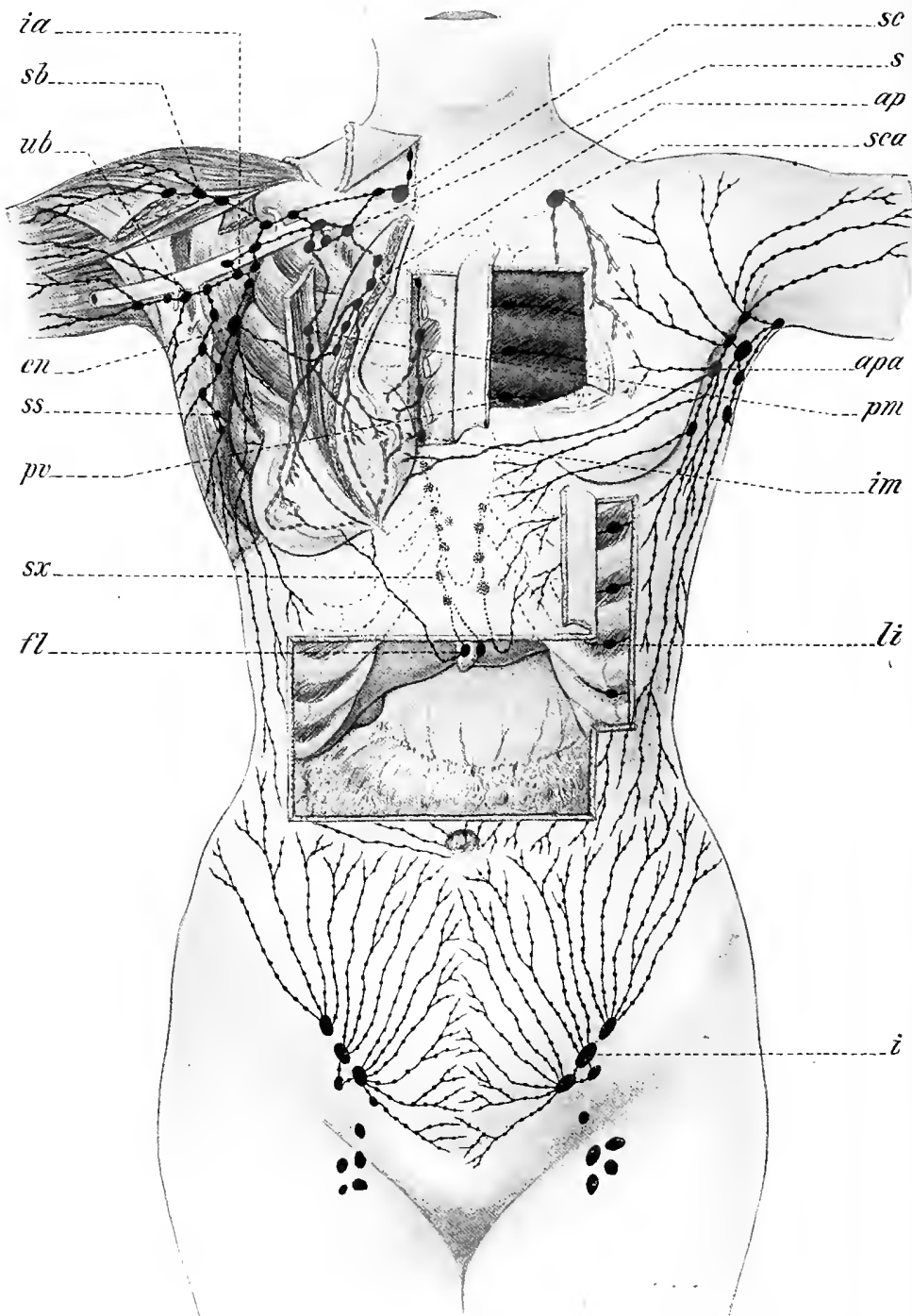

F1G. I 85,-Diagram showing the lymphatics of the breast and the iymphatic systems with which they communicate. (For Explanation of diagram see foot note, page 497.) 
visceral metastases may be present in the entire absence of palpable lymph-node involvement, so that a negative axilla is not incompatible with widespread internal metastasis.

Not only is the exact time at which metastasis takes place in the individual case unknown, but we are likewise ignorant of the factors that actually cause cancerous dissemination. It is likely, however, that a number of factors combine to cause metastasis and that a different set of factors is effective in different cases. It is a well-known fact that organs or even parts of organs which frequently give rise to primary cancer rarely lodge metastatic cancer cells from distant organs. The frequent invasion of one breast from cancer of its fellow of the opposite side is explained by the distribution of the lymphatics of the chest wall, while true secondary carcinoma of the breast from a distant organ is a pathological rarity. Thus while certain organs are "immune" to metastatic cancer, other organs, especially the liver, are equally susceptible. Again, some tissues are frequent seats of metastases of malignant connective-tissue tumors (sarcoma), others of malignant epithelial tumors (carcinoma). Metastatic carcinoma of the eye-a rare condition-is practically always secondary to cancer of the breast (Bland-Sutton). Cartilage is rarely if ever invaded by carcinomatous metastases. The blood is most resistant to malignant cells of epithelial origin, and for this reason, as will be shown later, rarely serves as the avenue of carcinomatous dissemination. On the other hand, it is a well-known fact that sarcoma metastasizes in the great majority of instances is by way of the blood stream. This is true of sarcoma occurring in the lower animals as well as in the human subject. We do not believe these phenomena to be due to the circumstance that the rich blood supply of sarcomatous tumors invites blood metastasis, but we suppose that the sarcoma cells are not destroyed, as is the case with carcinoma cells, by the phagocytic action of the blood. Tyzzer concludes from the results of his experiments with mouse cancer, that the production of metastasis is dependent upon certain demonstrable factors - the biologic character of the tumor, the duration of its growth, the size of the primary mass, possibly peculiar conditions furnished by the tissues of the host and, under artificial conditions, forcible manipulations. He explains the rapid growth of metastases after excision of the primary tumor, to an increase in the amount of specific food substance made available by removal of the parent growth (Ehrlich's athrepsia theory). While a number of steps in the progress of dissemination of malignant tumors need further investigation, metastasis may for all practical purposes, be attributed either to embolism (blood or lymph vascular) or to the process which Handley terms "permeation."

Embolism.- As a malignant tumor increases in size and invades the surrounding tissues, it sooner or later involves the lymphatic vessels and the small blood-vessels, especially the venules, in proximity to it. Practically all observers agree that embolism of the lymphatic trunks commonly occurs in malignant epithelial tumors and that the cells thus transported to the adjacent lymph nodes give rise to metastases. Goldman

The red lines indicate lymphatic trunks that drain the breast; the red dots indicate the position of the lymph nodes that serve as terminals for the lymphatic trunks drawn in red. The black lines and dots constitute lymphatic systems that are more or less directly related to the mammary system of lymphatics. The terminal lymph nodes (indicated hy red dots) comprise the following: sc. Suprascapular group. sca. Suprascapular group. apa. Anterior pectoral group of the opposite side: im. Internal mammary group. $a p$. Anterior pectoral group of the same side. s. Subclavian group. $p m$. Rotter's nodes between the two pectoral muscles. The associated lymph nodes (indicated by black dots) comprise the following: $i a$. MIid-axillary group. $s b$. Delto-pectoral group. $u b$. Upper brachial group. en. Central axillary group. ss. Subscapular group. pv. Para-vertebral group. $s x$. Supra-xiphoid group. $f l$. Falciform ligament group. li. Lateral intercostal group. $i$. Inguinal group. 
maintains that the blood-vessels as well as the lymphatics are primary agents in the dissemination of cancer. He has proved by microscopic study that, in both sarcoma and carcinoma, there is an extensive invasion of the coats of the arteries and veins in association with the tumor. The pathway of this invasion is furnished, according to Goldman,

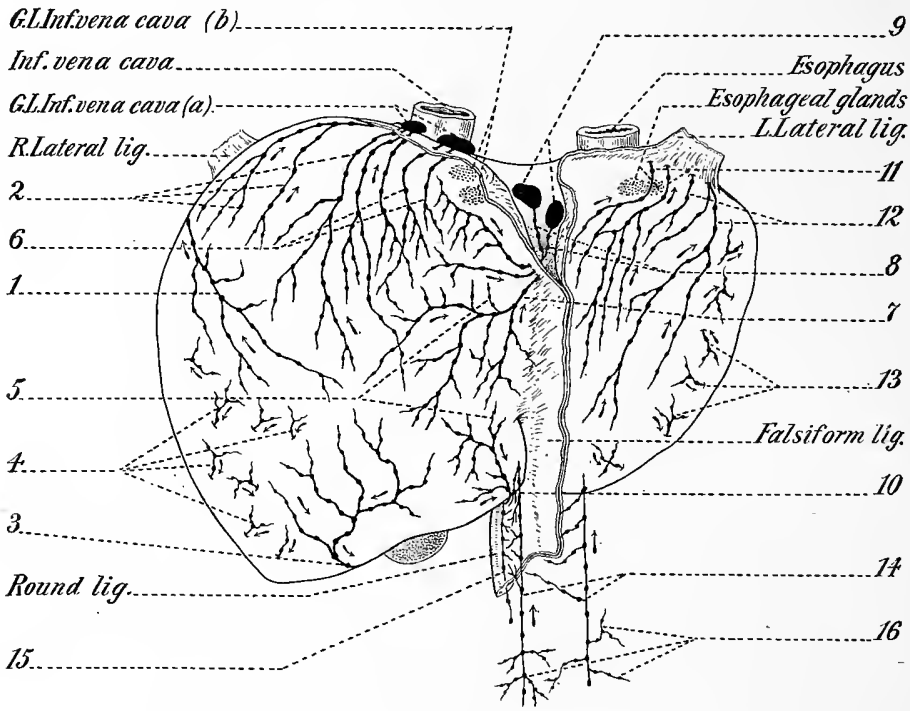

Fig. r86.-Lymphatics on the upper surface of the liver. (Leaf.)

1. Large lymphatic trunk situated on the right border of the right lobe; this trunk descends on to the concavity of the diaphragm and passes into one of the glands which lie on the head of the pancreas. 2. Smaller and shorter trunks which turn round the uppèr border of the liver and terminate in some small glands (gl. Inf. Ven. Cav. (a)) situated in front of the inferior vena cava, immediately above the diaphragm. 3. A trunk which turns round the inferior border of the liver and runs towards the glands of the hilum. 4. Trunklets which plunge almost at once into the hepatic tissue and then run in the channels of Glisson's capsule. 5. A net work which corresponds to the adherent border of the suspensory ligament (represented as a dotted line). 6. Trunks in which some of the branches of this network (5) end. 7. A group of convergent trunks which start from the same vessels and run obliquely between the two layers of the suspensory ligament. 8. Trunks formed by the fusion of the preceding trunks. 9. Glands in which its branches end. ro. Another trunk situated in the suspensory ligament, which passes into the longitudinal fisșure of the liver and ends in one of the glands of the hilum. rr. Trunks which ascend towards the superior border of the left lobe where they turn and run towards some glands situated round the inferior vena cava (gl. Inf. Ven. Cav. (b)). r2. Another group which traverses the left triangular ligament and ends in glands placed round the cardiac end of œsophagus (gl. cesoph.). I3. Trunks which disappear by penetrating Glisson's capsule. 14. Internal mammary chain receiving tributaries from branches in the triangular ligament which communicates with branches running round into: 15. Lymphatic trunk accompanying obliterated hypogastric. 16. Lymphatics from upper part of rectus abdominus and its sheath passing into the internal mammary chain.

by the nutrient arteries of the vessel walls, which latter he states are without lymphatics; the distribution of the cancer cells within the outer coat of the arteries and beneath the intima of the veins corresponding to the distribution of the vasa-vasorum. This location of the cancer cells beneath the intima serves to explain the greater incidence of cancer emboli within the veins. Handley believes that cancer cells reach the blood stream in very few instances and as rarely_give rise to metastasis by this avenue of dissemination. 
Schmidt, on the other hand, believes that while the blood-vessels of the primary tumor or of the regional lymph nodes are rarely involved, cancer emboli frequently reach the pulmonary circulation by way of the main lymphatic trunks. He conclusively proves this to be the case in a series of cases of carcinoma of the abdominal organs in which he found positive evidence of embolic dissemination in the lungs in $I_{5}$ instances. Moreover, the pulmonary arterioles were involved in every instance. These findings led Schmidt to the conclusion that while embolic dissemination of the cancer cells occurs by way of the pulmonary circulation "with unexpected frequency and often repeatedly," they rarely give rise to metastatic tumors on account of organization of the thrombi which form around them.

It seems rational to believe that cancer cells reach the pulmonary circulation by way of the large lymphatic ducts in the majority of cases of breast cancer, and it seems likewise rational to attribute the small percentage of metastatic growths in the lungs following mammary cancer to this same process of organization which Schmidt has shown to occur in metastases from abdominal cancer. Williams, who strongly advocates the embolic (blood) theory, expresses the belief that cancer emboli may be carried either by way of the blood-vessels or by way of the lymphatics. He calls attention, as did Goldman, to the fact that mammary cancer cells usually invade the veins of the primary growth, and that cancer cells have frequently been found within the veins between the tumor and its derivatives and the right side of the heart. Williams, on the other hand, states that other than the mere mechanical factors involved must be taken into consideration in the disseminative process of cancer. He calls attention to the rarity of uncomplicated lung metastases secondary to breast cancer in comparison with the unusual frequency of liver metastases, notwithstanding the fact that cancer cells owing to their large size would necessarily become arrested in the terminals of the pulmonary vessels, and systemic invasion could occur, therefore, only as the result of a secondary metastasis from nodules in the lungs. Schmidt says that this has never occurred although he proved the possibility of it by demonstrating that the cells of an embolus in the lung may push forward through an ensheathing thrombus into the capillary blood-vessels, and in this wise give rise to secondary tumors, of ten microscopic in size, along the vessels of the systemic circulation. The localization of secondary metastatic cancer nodules arising in any particular organ can only be explained by the advocates of the embolic theory on the grounds, entirely unproved as yet, that though every organ is equally susceptible to embolic invasion, certain organs possess peculiar resisting powers that prevent the development of the tumor cells into clinically demonstrable growths. Paget was one of the first to point out the discrepancies of the embolic theory in association with bone metastases. This observer called attention to the fact that if we accept the embolic theory in its entirety we must attribute to certain parts of the body an almost selective affinity for cancer emboli. It is rational to believe that cancer cells which reach the systemic circulation are equally distributed throughout the body. The unequal distribution of metastases, on the other hand, leads to the inevitable conclusion, either that other than mere mechanical factors determine the localization of the metastatic foci, or that the different tissues have properties which prevent or invite the development of carcinoma, as the case may be. If, for instance, metastasis to the skeletal system were dependent upon the embolic process alone, we should expect to find the distal bones of the extremities involved as often or even more often than the femur or humerus. On the contrary as Handley points out, "the liability of a bone to cancerous involvement increases with the proximity of its site to the primary growth." This is true in general of mammary 
cancer. Again, the actual site of the metastatic foci in bone is not, according to Handley, that which would be expected if embolism was the process at work, since the cancer "does not develop in the area of distribution of the nutrient arteries," an assertion which is disputed by v. Recklinghausen and others.

What contributions has experimental pathology made to the solution of the problem of malignant metastasis? In answer to this question it is entirely fair to say that the results of cancer research have merely confirmed clinical observations. Spontaneous cancer in laboratory animals rarely gives rise to metastases. This is attributed to the fact that the lymphatics are rarely involved and that the blood destroys the cancer emboli in animals as it does in human cancer. Intra-vascular injections (jugular vein) of emulsions of tumor material have been productive of interesting results but have failed to elucidate the problems of metastasis. Sarcomas of the lower animals, as well as

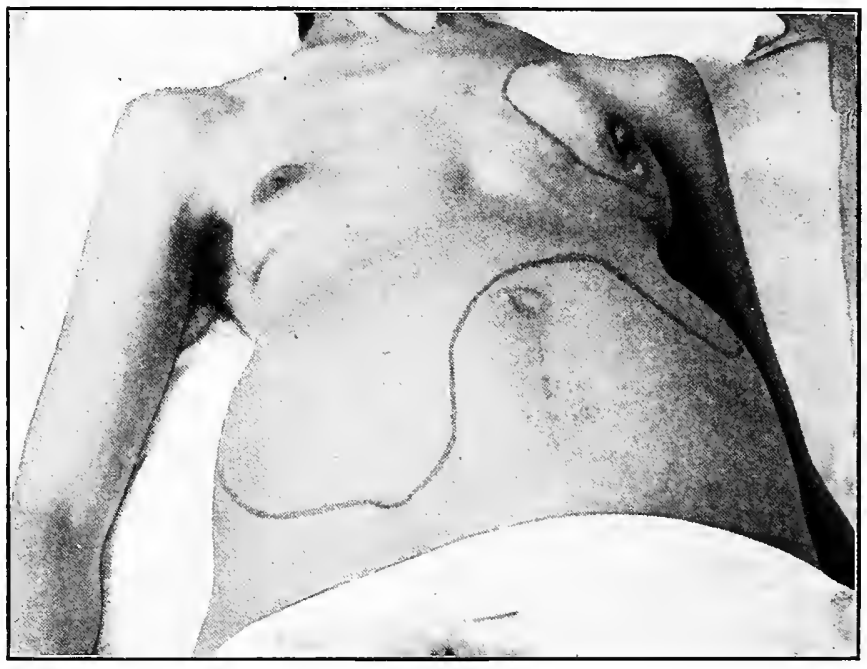

FIG. I87.- Scirrhus carcinoma of the left breast with metastasis to the liver.

human sarcomas, metastasize by way of the blood stream in the majority of instances. Weil reports that the results of intra-vascular and subcutaneous implantation of sarcoma and carcinoma (Flexner-Jobling type) in the rat confirm the clinical and pathological findings in man. This observer found that pulmonary growths commonly occurred after intra-vascular (jugular vein) injections of sarcoma cells and rarely after the injection of carcinoma cells; carcinoma commonly developed at the site of subcutaneous injections-sarcoma rarely. These experiments indicate that the blood of rats is highly resistant to carcinoma and slightly so to sarcoma, a feature equally characteristic of human blood. Carl Lewin likewise attributes the rarity of cancer metastasis in laboratory animals to the fact that the emboli are destroyed by the blood. A series of experiments performed by Levin and Sittenfield confirm the observations of Weil with the important difference that in a number of instances, growths appeared in the liver after 
injections of adeno-carcinoma (Flexner-Jobling type) into the jugular vein, which as the authors state would seem to indicate a specific affinity of certain organs for metastatic growths. This is the most significant experimental evidence in support of the possibility of embolic dissemination of cancer with predilection of the cancer cells for certain parts, and goes far to explain the discrepancies of the embolic theory when governed solely by the laws of circulatory mechanics. The sum total of evidence leads one to the conclusion that while invasion of the pulmonary circulation usually occurs in cancer of the breast, and of the systemic circulation less often, the cells thus transported rarely give rise to secondary tumors for the reason that their activity is destroyed by the blood. Again the varying evidence of embolic metastases in various organs is to be explained not by difference in the morphology of the several tissues, but rather on the grounds of difference in resistance or susceptibility of the tissues. We can assume for all practical purposes that while blood embolism is the cause of metastatic growth in a small percentage of cases of cancer, there remain a large number in which other factors must be taken into consideration. By far the most important substitute for the embolic theory is that one proposed by Handley, and which he terms "permeation."

One of our illustrations shows a carcinomatous nodule in the subcutaneous tissues on the dorsum of the middle finger of the right hand, from a case presenting many. unusual features, for the account of which we are indebted to Drs. Hutchinson and Baldwin. The patient, Mary K., aged $7 \circ$, was admitted to Dr. Hutchinson's service in the Methodist Hospital of Philadelphia, June I6, I9I4, complaining of a painful lump in the right breast. The left breast had been removed I 8 years before at the Jefferson Medical College Hospital for what the patient states was cancer. The trouble in the right breast, which is of eight years' duration, began soon after the receipt of a blow, with the appearance of a small painless lump just to the right of the nipple. This lump gradually increased in size but was painless until three years ago since when she has suffered with pains referred down the right arm.

Two years ago she noticed a hard, painful lump in the right axilla. Thus far the history is not extraordinary, but about nine years ago, i.e., nine years before her admission to the Methodist Hospital and nine years after her discharge from the Jefferson Hospital, a lump appeared just below the left ear and slowly increased in size until five years ago when a diagnosis of sebaceous cyst was made, and it was removed. Three years later the lump returned and has since been gradually growing larger but has not given rise to any pain. The nodule on her finger appeared I 8 years ago and was caused, she says, "by a cut."

The nodule in the neck is about the size of a hen's egg; it is situated just below and behind the lobe of the left ear, and is cystic, slightly adherent to the skin, and tender. The lymph nodes are palpable along the posterior edge of the sterno-cleido-mastoid muscles on both sides. The left breast is absent but the pectoral muscles remain.

The right breast contains a dense mass which is attached to and dimples the skin. It is situated I inch above and external to the nipple which is not retracted.

Several enlarged nodes are palpable along the anterior axillary fold and at the lower part of the axillary space there is a tender mass, I inch in diameter, which is firmly adherent to the skin and to the deep tissues. The nodule on the finger is freely movable.

A radical amputation of the breast was performed and the patient recovered without complications. A few weeks later the nodules on the finger and neck were excised.

Dr. Lyon, pathologist to the Methodist Hospital, examined microscopic sections of 
the tissues of the breast, axillary nodes, and of the nodules from the finger and neck, all of which showed adeno-carcinoma.

Attempts to trace the sequence of events in this unusual case bring one to an interesting speculation. Was there a primary mammary cancer in the left breast followed by late multiple recurrences? Was there a primary cancer of the right breast, the tumor in the left breast having been benign, and metastases to the finger and neck; or finally, was it a case of multiple primary cancers? The fact that the nodule on the finger existed for a period of 18 years or more, and that it was undoubtedly adeno-carcinoma is difficult to explain.

Lymphatic Permeation (Handley).-The process of permeation implies regional dissemination of cancer cells from a primary focus along the lymphatics in the plane of the deep fascia; the dissemination is said to take place in a centrifugal manner with approximately equal distribution in all directions. Handley recognizes the frequent occurrence of lymph embolism of the regional lymph nodes and the less frequent invasion of the blood stream, but he denies that the latter is productive of metastases, basing his opinion largely on the work of Schmidt, which has been quoted above. $\mathrm{He}$ maintains that lymph emboli cannot explain the general dissemination of carcinoma, and in support of his claim calls attention to the fact that the lymphatics of the body wall have a segmental distribution, the different systems anastomosing with adjacent systems by means of very fine lymphatic radicles, which on account of their minute size and the presence of valves, would prevent the passage of cancer emboli from one system to another; retrograde embolism in the lymphatics is therefore not considered possible. The lymph nodes serve as central filters for cancer emboli so that the lymph stream becomes effective as a means of dissemination of cancer "only within the limits of the lymphatic area where the primary focus is situated." In order to follow Handley's arguments it is necessary to understand his conception of the distribution of the parietal lymphatics which differs from our description of the mammary lymphatics, which is taken in large part from the writings of Sappey. Thus Handley denies that the major portion of the lymph from the breast drains into the sub-areolar plexus (Sappey) and is carried thence by two large lymphatics to the anterior pectoral nodes. It is Handley's behef that the lymphatics of the skin arise in the papilla of the skin and join at the base of the latter to form a sub-papillary plexus; that lymphatics from the subpapillary plexus pierce the skin at right angles to enter the plexus of the deep fascia, the latter also receiving the lymph from the subjacent tissues, including the muscles, bone, etc. He believes, furthermore, that the lymph from the breast is carried to the deep fascia and that all of the lymph of the pectoral region, including the breast, is poured into the lymphatics which run in the plane of the deep fascia, and finally, that this fascia and not the skin is the plane along which cancer dissemination takes place.

The Process of Permeation as Applied to Cancerous Dissemination from the Breast. Handley maintains that cancer of the breast spreads from the primary tumor centrifugally in all directions along the plane of the deep pectoral fascia, with extensions upward into the skin and downward into the subjacent tissues. The outermost limits of this circle of dissemination is represented by "a microscopic growing edge of carcinoma cells." The shape of the involved tissues he compares to that of a biconvex lens. Permeation is said to take place along the medium-sized lymphatics; the minute vessels mechanically preventing permeation, the larger vessels transporting the cancer cells as emboli to adjacent nodes. Handley makes no mention of the actual process of extension, 
but leaves us to infer that the constant multiplication of cancer cells within the lymphatics forces the cells onward. Lambert and Hanes have lately shown that cancer cells growing in vitro exhibit ameboid movements which would serve as a rational explanation for the occurrence of the permeative process. According to Handley permeation does not proceed in the complete absence of tissue resistance for an inflammatory reaction, "peri-lymphatic fibrosis" is said to take place which either destroys the cancerfilled lymphatics completely, transforming them into fibrous cords, or partially destroys them, leaving isolated islets of cancer cells which may remain dormant or multiply, with the formation of cancer nodules at some future time. These cancer nodules are usually subcutaneous in position but they have also been found beneath the deep fascia. Skin nodules are said to arise from cells which have extended upward along the lymphatic tributaries from the skin to the deep fascia. These nodules in cancer of the breast

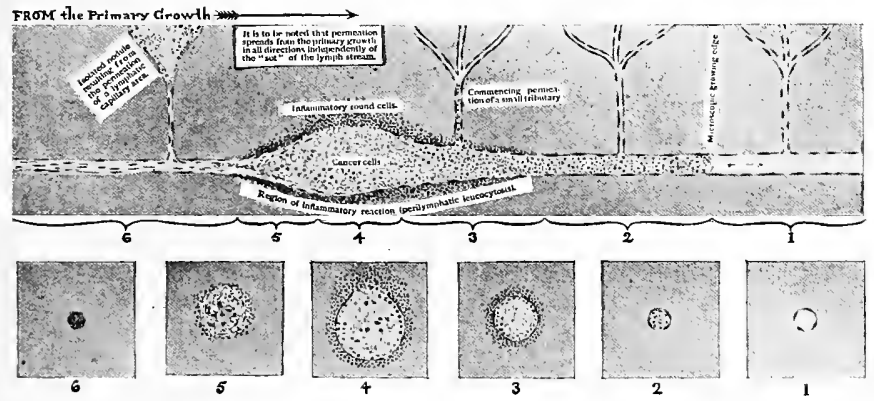

FIG. 188.- Scheme to illustrate the advance of permeation along a small lymphatic, seen in the upper figure in longitudinal section, and in the lower figure as a series of transverse sections. The lymphatic is inally destroyed by peri-lymphatic fibrosis. (Handley. Choyce and Beattie, "System of Surgery".)

r. Normal lymphatic shortly to be invaded by the advance along it of permeation. 2. Lymphatic permeated by cancer cells, but not yet distended. Note the absence of inflammatory reaction in this region. 3. The lymphatic distended by the growing cancer.cells. The central cancer cells are becoming degenerate. 4. The lymphatic ruptured by the growing cancer cells: an event followed by vigorous inflammatory reaction. 5. The mass of degenerate cancer cells enclosed in a false capsule of newly formed fibrous tissue. 6. The cancer cells are finally strangled by contraction of the fibrous capsule. The original lymphatic is now represented simply by a thread of fibrous tissue, the cancer cells having been destroyed.

are found equidistant from the site of the primary tumor, a strong argument in support of the permeation theory. Several photographs similar to the one shown, which is taken from a photograph in the laboratory of surgical pathology in the University of Pennsylvania, are reproduced in Handley's book to illustrate the distribution of skin nodules in cancer of the breast. The most convincing argument offered by Handley is, in our opinion, that cancer en cuirasse (cancerous pachydermia) is primarily a non-cancerous condition and identical with the pachydermia associated with elephantiasis and also seen in some long-standing eczemas, in both instances being dependent upon the same cause: obstruction to the return flow of lymph from the skin. The cancer nodules associated with cancer en cuirasse occur at a later stage of the disease than the lymphedema, which latter is the primary and essential factor in the production of brawny skin. Those cases in which lymphedema of the pectoral region is an early symptom of breast cancer, almost invariably result fatally within a short period of time 
and this symptom is usually a positive contra-indication against operation since it denotes widespread cancerous involvement of the deep fascia.

It would be impracticable to repeat in detail the arguments advanced by Handley in support of his theory; suffice it so say that it commends itself as a rational explanation for regional dissemination in cancer of the breast and for a large percentage of local post-operative recurrences, and at the same time serves as a rational theory for planning the radical removal of a carcinomatous breast.

Parietal Dissemination. Lymph Nodes.-Metastasis to the regional lymph nodes almost invariably occurs in untreated cases of mammary carcinoma. Bull estimated that 65 per cent. of cases when first seen by the surgeon have palpable axillary nodes. Enlargement of the axillary nodes in association with a mammary growth is not necessarily carcinomatous since in chronic mastitis, abnormal involution and other benign conditions, as well as in the early stages of cancer, these nodes undergo structural changes affecting especially their germinal centers and leading to a hyper-

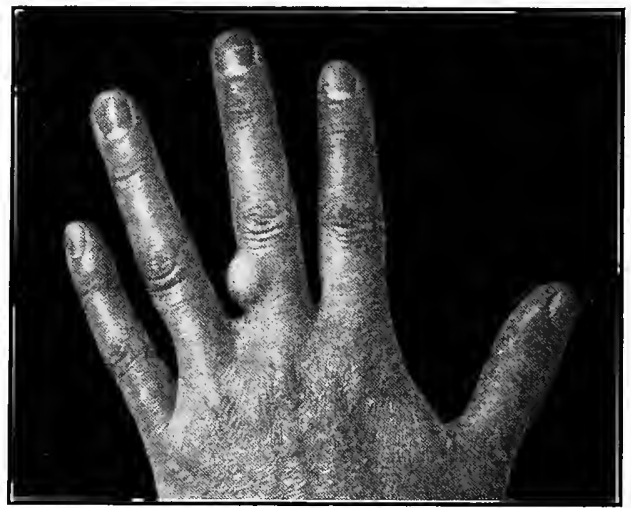

FIG. I89.-Nodule of carcinoma metastatic from the breast. Patient of Drs. Hutchinson and Baldwin in the Methodist Hospital of Philadelphia.

trophy that has been styled the "pre-cancerous adenopathy." Thus, in 6.5 per cent. of 37 per cent. of our malignant cases in which the axillary nodes were palpably enlarged, the microscope proved the absence of cancer cells. In 9 of a series of roo of our benign tumor cases, enlarged axillary glands were found and proved free of cancer by microscopic examination. Finsterer found the same condition 7 times in 64 cases of benign neoplasms. Enlargement of these nodes is commonly associated with abnormal involution of the breast and in a large percentage of cases the enlargement is bilateral. Halsted has reported two cases of mammary carcinoma in which the axillary enlargement in one instance prece ded the development of, and in the other progressed in the entire absence of, any de monstrable mammary neoplasm. In the latter instance, the disease probably originated in an accessory mamma. Snow reports a primary schirrus cancer of the axilla which arose, he believes, from a gland of the skin and not from an axillary breast. Tumor in the axilla was the first symptom noticed by the patient in two of our cases although in each instance the breast contained a growth of which the patient had 
been unaware. Quénu has likewise had two cases in which adenopathy preceded demonstrable mammary involvement. The latter cases are highly instructive; in both of them enlarged glands were removed from the axilla and found to be carcinomatous. In one patient the breast was apparently normal to clinical examination, while the breast of the second patient had a point of tenderness in the upper outer quadrant. Radical amputation was done in each instance and cancer was found in the breast of each patient. These cases further serve to illustrate the variability in the length of the premetastatic time interval in different cases of cancer of the breast.

Enlargement of the axillary lymph nodes, as we have stated, is not always caused by metastasis from a coexistent cancer of the breast, nor does the absence of palpable enlargement prove the freedom of these glands from metastases. Thus, though only 3 I.5

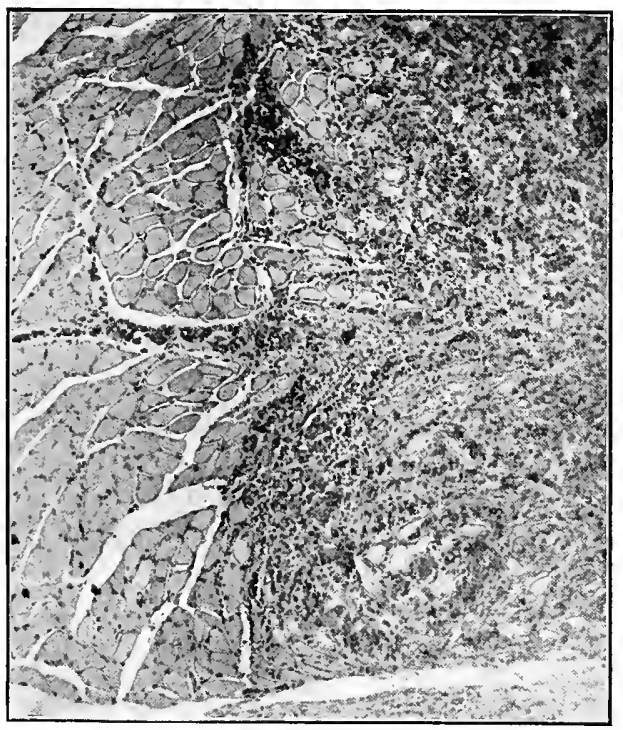

FIG. I90.-Carcinomatous invasion of the pectoral muscle. The muscle on the left, the invading tumor on the right.

per cent. of our cases presented palpable cancerous nodes, 62 per cent. had microscopic involvement of these structures. Küster found only 2 among II 7 cases in which radical amputation of the breast, had been done, that were entirely free of axillary metastases. Those nodes situated high in the axilla may reach a considerable size before they become palpable though the lower axillary nodes remain perfectly normal. The cancer cells in a certain proportion of cases of this kind are probably transported along the lymphatics that run between the two pectoral muscles, directly to the infraclavicular space. It is evident, therefore, that the absence of palpable enlargement of the axillary nodes is of questionable value as an index of the progress of the case. Bilateral axillary involvement is a rare complication of breast cancer. Invasion of the opposite axilla is said by Handley to result from permeation along the lymphatics of the 
deep fascia. It is a positve contra-indication to operation. Some surgeons believe that embolic invasion of the nodes of the opposite axilla takes place in a small percentage of cases. A lymphatic trunk which arises in the lower inner quadrant of the breast (see diagram) is said to serve as the means of transportation of the cancer cells. Handley found bilateral axillary involvement in 6 per cent. of a series of 422 late cases.

The lower cervical lymph nodes were not involved in any of our cases in which the tumor occupied the upper inner quadrant of the breast. This leads us to the conclusion that the lymph channel described by Poirier and Cuneo which is said to proceed directly to these nodules from this area of the breast, rarely transports cancer cells, and furthermore that supra-clavicular involvement is ordinarily sequential to axillary metastasis. This is well supported by Handley who found supra-clavicular metastasis in 18 per cent.

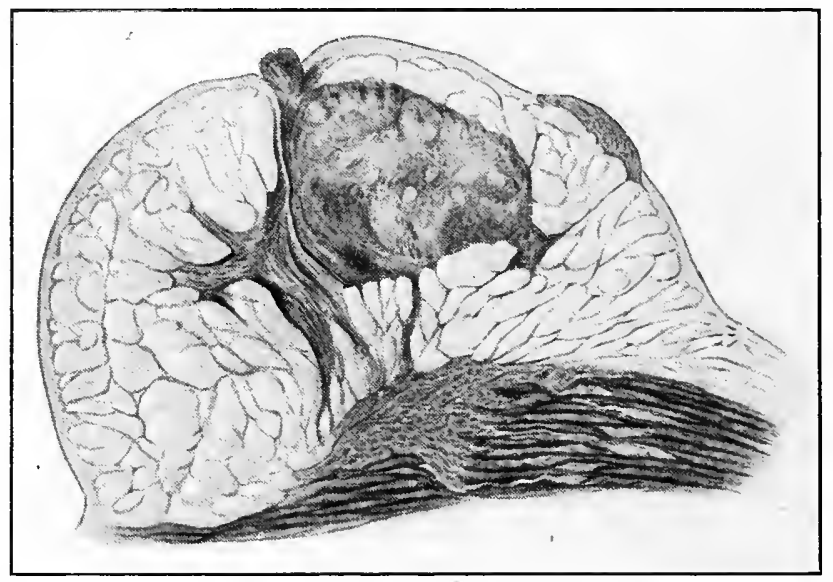

FIG. Igr.-Carcinoma (medullary) of the breast showing retraction of the nipple and invasion of the pectoral muscles. (From a specimen in the Laboratory of Surgical Pathology, Medical School of the University of Pennsylvania.)

of 229 cases in the records of the Middlesex Hospital records (late cases) and in only 13 per cent. of 93 Guy's Hospital (early) cases.

The anterior mediastinal chain of lymph nodes constitute the final group that receives afferents directly from the breast, and which are therefore susceptible to embolic invasion. Fortunately, these inaccessible structures are rarely invaded in the early stages of breast cancer and far less frequently than might be expected in its late stages. Török and Wittelshofer found cancer cells in the mediastinal nodes in only 6.5 per cent. of 366 autopsies. This low percentage in a series of terminal cases is said by Handley to depend upon the fact that the small calibre of the afferent lymphatics opposes the passage of cancer emboli. Poirier attributes the rarity of metastases to these nodes, to the fact that the intercostal lymphatics undergo early senile atrophy.

Cancerous involvement of lymph nodes belonging to lymphatic systems not in direct communication with the breast is a late manifestation of the disease and is the result of permeation (Handley) or retrograde embolism (Nagle and others). The upper brachial, the sub-scapular and the inguinal nodes are the principal members of 
the accessory parietal systems which may become involved in cancer of the breast. Late in the course of the disease they should never be overlooked in the routine examination of an apparently operable case.

Other Parietal Metastases.-Cancer of the breast becomes rapidly disseminative in the tissues adjacent to the primary growth owing to the rich lymphatic supply of these parts. The breast itself becomes diffusely infiltrated at an early stage of the disease, and every particle of the organ must be removed if our operations are to be radical in the true sense of the word. According to Handley, the parietal tissues are susceptible to metastasis in direct proportion to their proximity to the primary tumor. Stiles,

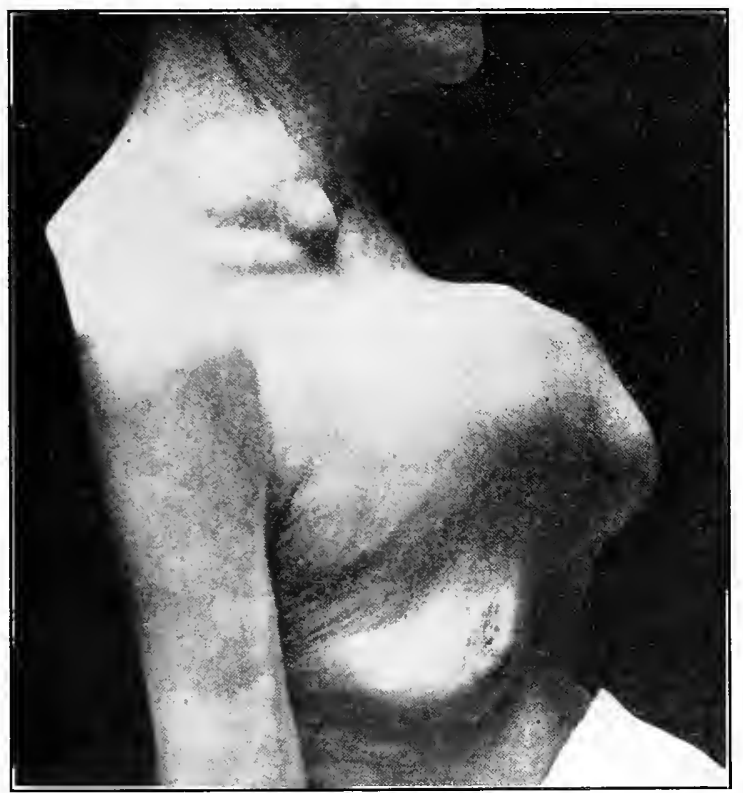

FIG. I92.--Huge inoperable carcinoma of the breast with a large metastatic mass in the supraclavicular region.

on the other hand, states that metastasis to the skin results from embolic invasion of the small arterioles of the breast. This is a rational explanation for the occurrence of isolated nodules which appear at a considerable distance from the primary focus, an occurrence which Handley maintains is due to permeation with destruction of the lymphatics intervening between the nodule and the primary growth.

The muscles are rarely involved in cancer of the breast notwithstanding the proximity of the cancer-laden lymphatics of the deep fascia. Murphy preserves the pectoral muscles in his operation believing in his ability to separate the overlying pectoral fascia together with its intra-muscular extensions from the substance of the muscles themselves. 
In advanced cases the intercostal muscles often become diseased and in some instances the pleura is involved as the result of extension of the cancer cells through one or other of the intercostal spaces. The digitations of the serratus magnus muscle arising from the fifth and sixth ribs and the fascia overlying them are subject to cancerous invasion especially in cases where the tumor occupies the lower outer quadrant of the breast. Henderson failed to prove this relationship, however, and there are no other studies available; nevertheless, we believe that the digitations of the serratus magnus muscle should be removed when the tumor overlies them as it does in 9.2 per cent. of cases.

Bone Metastases.-Cancer of the breast and of the pyloric end of the stomach become the most widely disseminative of all cancers and yet bone metastasis though exceedingly rare in the latter is common in the former. There must therefore be some essential difference either in the disease processes themselves or in the mechanism of metastasis. Spontaneous or painless fracture of the long bones is caused in the great majority of

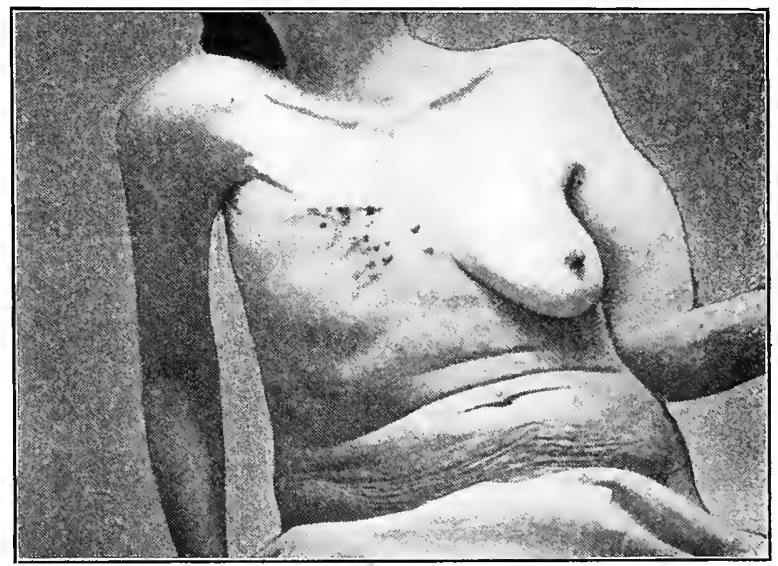

FIG. 193.-Pathological fracture of the lefthumerus below the point of insertion of the pectoralis major muscle. Recurrent carcinoma of the right breast.

instances either by syphilis or metastatic cancer from the breast. The latter is the usual cause of spontaneous fracture of the femur or humerus in aged women, so that the breasts should never be omitted in the examination of a patient with spontaneous fracture of either of these bones, since the tumor in the breast may have been symptomless and so small that it escaped attention. In cancer of the breast the ribs and sternum are often involved as a result of direct extension from the primary tumor. This would seem to confirm Handley's assertion that "the liability of a bone to cancerous involvement increases with its proximity to the site of the primary growth." The clavicle is, on the other hand, rarely diseased in mammary cancer and stands as an exception to the foregoing rule; an exception for which no satisfactory explanation has been given. Of the remaining bones in the cancerous involvement of which embolism would naturally be expected to play a part, the femur and humerus are most frequently affected. In a study of $65^{\circ}$ post-mortem records in cases of breast cancer, Paget found that the cranial bones 
were involved 36 times, the femur 18 times and the humerus so times. These findings led Paget to conclude that in cancer of the breast " the bones suffer in a special way which cannot be explained by any theory of embolism alone." The figures reported by Nunn likewise show that the cranial bones are the most frequent site of metastases to the skeleton in cases of cancer of the breast. Metastasis to the femur occurred four times in Williams' series of 44 autopsies, to the humerus twice, among a total of nine cases in which skeletal metastases were noted. In the following table, Handley gives the incidence of bone metastases in 329 autopsies on cases of breast cancer. Excluding contiguous bone involvement-ribs and sternum-there were 37 cases with spontaneous fractures or secondary bony involvement, but without fracture.

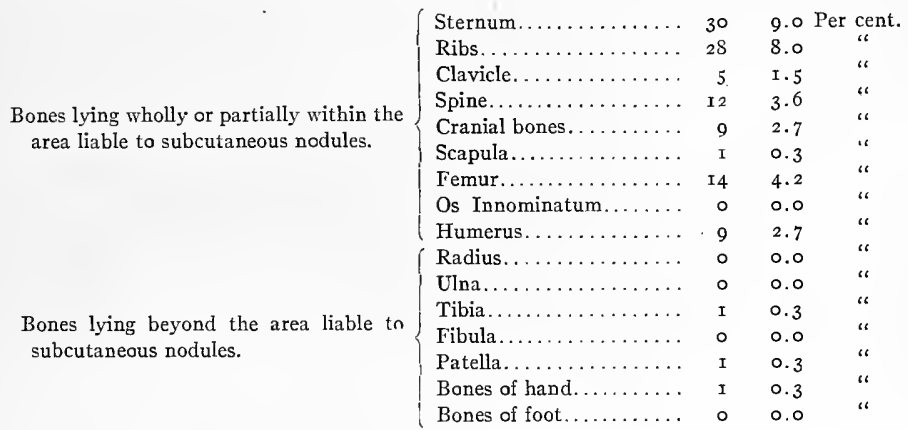

Metastatic cancer of the distal bones of the extremities is exceedingly rare. Hubbard has recently reported a case in which cancerous involvement of the head of the tibia became clinically demonstrable one year after the amputation of a cancerous breast. The peculiarities in the distribution of bony metastases are attributed by some to specific resistance of certain bones against cancerous invasion, whereas Handley says that the reason the distal bones rarely become involved is because the patients die before the cancer cells have had time to reach them by the process of permeation along the deep fascia. We must admit that it takes some stretching of the imagination to attribute the bone metastasis to lymphatic permeation in cases similar to that reported by Hubbard. Goldman entirely rejects Handley's theory; he quotes von Recklinghausen, whose microscopic studies showed that the cancerous metastases to bones occur in the marrow in the line of distribution of the nutrient arteries, observations which were later confirmed by Bamberger and Paltauf. Handley, on the contrary, maintains that the femur is first involved in metastatic cancer from the breast at the base of the great trochanter, the humerus at the point of insertion of the deltoid muscle-areas which correspond to the subcutaneous portions of the bones nearest the primary focus of disease. Spontaneous fractures of the humerus, caused by cancer of the breast, occur, as a rule, in the thinnest portion of the bone-the lower third. Fracture of the middle third likewise occurs, although rarely. The humeral fragments frequently unite with the formation of an excess of callus; spontaneous fractures of the femur are less likely to unite.

If we attribute the disproportionate incidence of metastatic cancer from the breast in the thoracic and abdominal viscera to embolism, we must assume with Williams that the ultimate fate of the cancer embolus "depends mainly upon whether the inherent vital activity of its constituent cells is strong enough to resist successfully the phago- 


\begin{tabular}{|c|c|c|c|}
\hline \multicolumn{4}{|c|}{ Visceral Metastasis } \\
\hline \multirow[b]{2}{*}{ Liver. . . . . . . . . . . . } & $\begin{array}{l}\text { Guy's Hospital } \\
\text { (early) cases }\end{array}$ & $\begin{array}{l}\text { Middlesex Hospital } \\
\text { (late) cases }\end{array}$ & Total \\
\hline & r3 & 77 & $9 \circ$ \\
\hline Portal glands............ & I & I & 2 \\
\hline Ovaries............... & I & 2 & 3 \\
\hline Uterus............... & $\circ$ & I & I \\
\hline Pelvic peritoneum......... & ○ & I & I \\
\hline Peritoneum............. & $\circ$ & I & I \\
\hline Mesentery..$\ldots \ldots \ldots \ldots$ & $\mathbf{I}$ & I & 2 \\
\hline Intestines. . . . . . . . . . . . & I & I & 2 \\
\hline Spleen. . . . . . . . . . . . & $\circ$ & I & I \\
\hline Right kidney............ & $\circ$ & 4 & 4 \\
\hline Left kidney............. & 0 & I & I \\
\hline Both kidneys............. & $\circ$ & $\mathrm{I}$ & I \\
\hline Right adrenal. .......... & $\circ$ & I & I \\
\hline Lumbar glands............ & 0 & I & I \\
\hline \multirow[t]{3}{*}{ Lumbar vertebræ........... } & o & 2 & 2 \\
\hline & 17 & 98 & 215 \\
\hline & $\begin{array}{l}\text { out of I } 93 \text { cases } \\
=\text { I } 8 \text { per cent. }\end{array}$ & $\begin{array}{l}98 \text { out of } 329 \text { cases } \\
\quad=29 \text { per cent. }\end{array}$ & $\begin{array}{l}\text { I I } 5 \text { out of } 422 \text { cases } \\
\quad=27 \text { per cent. }\end{array}$ \\
\hline
\end{tabular}

cytic action of the part of the body in which it has lodged or not." The fact that cancer of the breast so commonly becomes disseminative within the body cavities is explained by Handley by the close anatomical relationship that exists between the lymphatics of the parietes and those of the subcutaneous tissues, the arrangement serving to convey cancer cells by the process of permeation to the internal organs. Thus the frequent involvement of the liver is attributed to cancerous permeation along the deep fascial lymphatics of the thoracic wall to the epigastrium and to the umbilicus, whence these cells follow the subserous lymphatics to become deposited either on the surface of the liver, or are conveyed along the lymphatics of the falciform ligament to the portal glands (see chapter upon the Surgical Anatomy of the Breast). The less frequent involvement of the other intraperitoneal organs is attributed to the fact that metastasis to these organs represents a very advanced stage of the permeation process. Pelvic metastases, which are found in 6.5 per cent. of fatal cases arise, according to Handley, from cells that have gained entrance to the upper abdomen and reach the pelvis by gravity.

Thoracic and retro-peritoneal metastasis is explained on the hypothesis that permeation of the chest wall takes place and is followed by transpleural implantation, the cancer cells gravitating to the lower posterior portion of the pleural cavity whence they become disseminated to the vertebræ and retro-serous tissues.

The most powerful arguments in favor of the theory of epigastric invasion are, first: The fact that Handley has demonstrated, microscopically, the presence of cancer-bearing lymphatics in the deep fascia overlying this area; secondly: the frequency of hepatic metastases in the absence of pulmonary or other internal metastases; thirdly: the frequent localization of cancer nodules on the upper surface of the right lobe of the liver; and, finally: the absence of splenic involvement. Handley's operation is based on the theory that local recurrences after removal of a cancerous breast are due to incomplete removal of the deep pectoral fascia, and that internal recurrences are in large part due to preservation of the deep fascia overlying the epigastric triangle.

The comparative incidence of metastases in the internal organs in a series of 44 autopsies reported by Williams was as follows: 


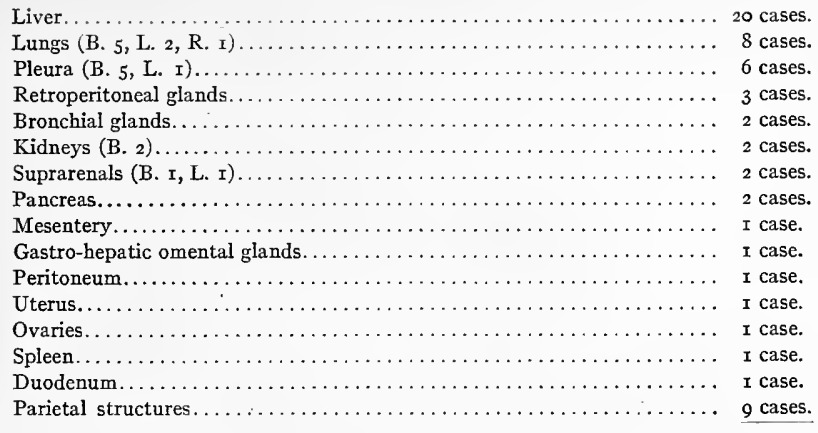

44 cases.

As the above table shows, the liver is the most frequent site of visceral metastases in cancer of the breast. Handley states that this organ was involved in 77 per cent. of the 229 autopsies performed on patients who died of mammary cancer in the Middlesex Hospital. In many of these cases the liver became involved in the comparatively early stages of cancer of the breast; it is therefore advisable to examine this organ before advising operation, however recent the development of the growth in the breast. The metastatic nodules usually develop on the upper surface of the right lobe of the liver, or in the portal glands. When in the latter situation, obstructive jaundice frequently follows. Metastases within the substance of the liver are secondary, as a rule, to superficial nodules, although it is believed by many that cancer emboli may be carried to the interior of the organ and give rise to metastatic growths. The more important symptoms suggestive of hepatic involvement are irregular enlargement of the organ, palpable nodules on its surface, epigastric tenderness, pain in the upper right abdomen and jaundice.

Next in the order of frequency of involvement in metastatic cancer from the breast, are the pleura and lungs, the latter being invaded, as a rule, as the result of extension from the former. Pleural involvement usually results from direct extension of the cancer cells from the primary growth through the intercostal spaces, from the anterior mediastinal lymph nodes, or from the supra-clavicular lymph nodes, where the latter come into relationship with the apical portion of the parietal pleura. Invasion of the thorax from the abdomen by way of the diaphragmatic lymphatics sometimes occurs.

The pelvic viscera were involved in 4.8 per cent. of late cases and in 8.6 per cent. of early cases reported by Handley. These paradoxical findings he attributes to the comparative youth of the patients comprising the early series, youth predisposing the generative organs to metastatic cancer.

Metastasis to the brain and spinal cord and their membranes occurs in approximately 5 per cent. of fatal cases. These structures may become indirectly involved from a focus in one of the bones of the cerebro-spinal axis, while in other instances the only rational explanation for their presence would seem to be the lodgment and development of a cancer embolus.

From clinical data alone the location of metastases in 59 cases of recurrent mammary carcinoma as determined by ourselves, or as given by the patients' attending physicians, were as follows: 


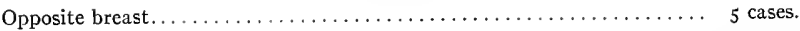

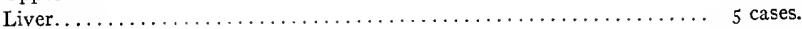

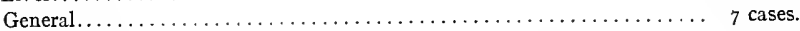

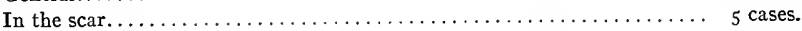

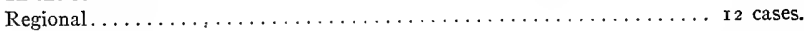

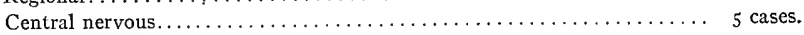

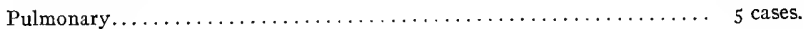

Neck. . . . . . . . . . . . . . . . . . . . . .

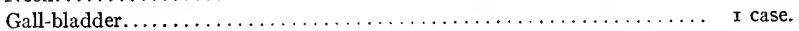

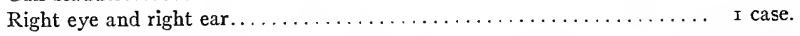

Skeletal, visceral, etc. ............................

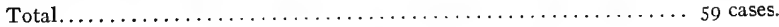

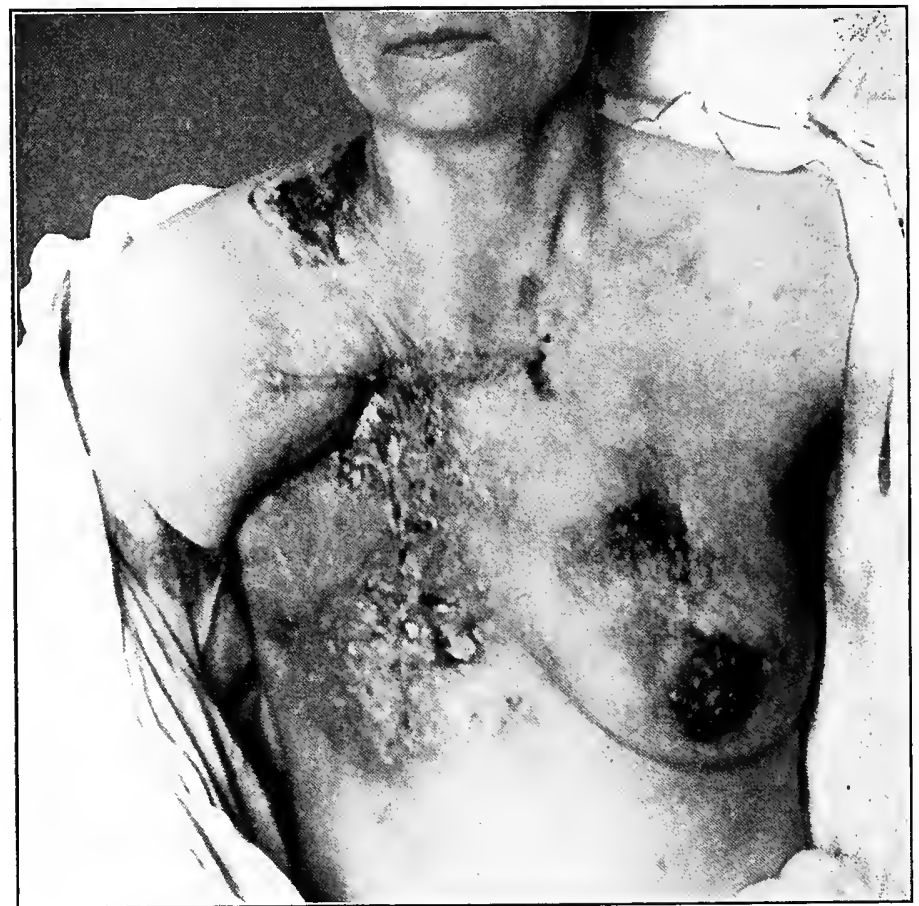

Fig. r94.-Widespread recurrent carcinoma. Note the involvement of the areola of the breast.

Mielecke made an exhaustive study of the autopsies performed in the RudolphVirchow Krankenhaus, Berlin, from October, rgo6 to September, Igr2. The material comprised $7 \mathrm{I}, 860$ subjects, among which were 560 cases of malignant tumors including 30 cases of cancer of the breast. The study of metastasis in these cases showed that breast cancers metastasize in the following proportions in the different organs: 


\begin{tabular}{|c|c|c|}
\hline Organ & Times & Per cent. \\
\hline 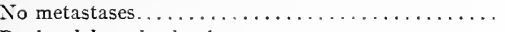 & I & $3 \cdot 3$ \\
\hline 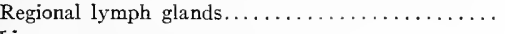 & 13 & $43 \cdot 3$ \\
\hline Liver. . . . . . . . . . . . . . . . . . . . . . . & I3 & $43 \cdot 3$ \\
\hline Peritoneum............................... & 6 & 20. I \\
\hline 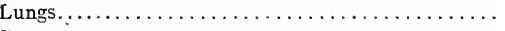 & I $\mathbf{I}$ & 36.6 \\
\hline 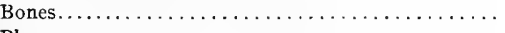 & I 7 & 56.6 \\
\hline 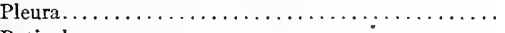 & II & 36.6 \\
\hline 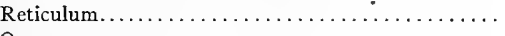 & I & $3 \cdot 3$ \\
\hline 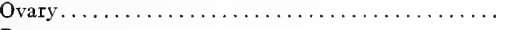 & I & $3 \cdot 3$ \\
\hline Bone marrow $\ldots \ldots \ldots \ldots \ldots \ldots \ldots \ldots \ldots \ldots$ & 6 & 20.0 \\
\hline 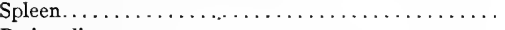 & 2 & 6.6 \\
\hline Pericardium $\ldots \ldots \ldots \ldots \ldots \ldots \ldots \ldots \ldots \ldots$ & 5 & I 6.6 \\
\hline 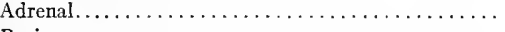 & I & $3 \cdot 3$ \\
\hline 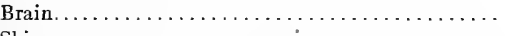 & I & $3 \cdot 3$ \\
\hline 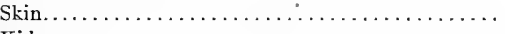 & 3 & 10.0 \\
\hline 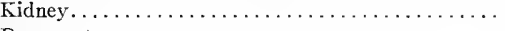 & 2 & 6.6 \\
\hline 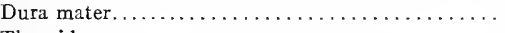 & I & $3 \cdot 3$ \\
\hline 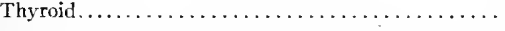 & I & $3 \cdot 3$ \\
\hline
\end{tabular}

There are many phases of the problem of metastasis that cannot be considered in a treatise of this kind but they are of little practical moment. Clinically demonstrable metastasis in cases of breast cancer means an advanced stage of the disease, however much confined to the superficial tissues this dissemination may seem to be, for certainly no one can foretell how far "the microscopic growing edge" of cancer has extended.

We believe that the operative treatment of mammary cancer should be carried out, not with a preconceived idea of how far the disease has advanced in each instance, but with the determination to remove in every case, however early, all those tissues that we know to be subject to metastatic breast cancer and that experience has taught can be excised with no deleterious after-effects.

\section{BibLIOGRAPHY}

Arsiuroles and Legrand.-L'Echo méd. du Nord., r913, xvii, 305.

Bamberger and Paltauf.-Wien. klin. Wchnschr., I899, xii, i Ioo.

Bernard and Cann.-Bull. assoc. franç. pour l'étude du cancer, r912, v, 233.

Bramwell. - Edinburgh, M. J., I894, xl, 5 I.

Bogart.-Amer. Practitioner, 1914, xlviii, 336.

Cheyne.-Lancet, I904, i, $70 \mathrm{r}$.

Fink.-Zeitschr. f. Heilk., I 888, ix, 453.

Frexner and Jobling.-Monographs. Rockefeller Inst. for Med. Research, 1910, i, I.

Halsted.-Tr. Am. Surg. Ass., 1907, xxv, 61.

Heidenhain.-Arch. f. klin. Chir., I889, xxxix, 97.

HUBBard.-Boston M. \& S. J., rgI2, clxvii, I.

JudD.-N. Jork M. J., I912, xcv, 867 .

Kuster.- Terhandl, d, deutsch. Gesellsch. f. Chir., I883, xii, 2 te Teil, 288.

Lambert and Hanes.-J. Am. M. Ass., I9I I, lvi, 79 r.

Langhaxs.-Arch. f. Gyn., I875, viii, I8I.

Levin, I.-Jour. Exper. Med., I913, xviii, 397.

Levin and Sittenfield.-Jour. Exper. Med., igi I, xiv, I48.

LEwIN, C.- "Die bösartigen Geschwülste," p. 46, Leipzig. I909.

Montigel.-Inaug. Dissert., Tübingen, r 907 .

Mielecke. - Zeitschr. f. Krebsf., I913, xiii, 505.

Murphy.-N. York M. J., I906, Jxxxiii, I.

Nadal. - Bull, et mém. soc. anat. de Par., igr3, lxxxviii, 353.

Nunn.- "Cancer of the Breast," p. 130, Londor, I882. 
Pager.-Lancet, $1889, \mathrm{i}, 57 \mathrm{I}$.

PAUl.-Proc. Roy. Soc. Med., vii, Surg. Sect., 276.

Primrose.-Am. J. M. Sc., I913, cxlv, 100.

Qù̀NU.-Bull, méd., I913, xxvii, 1039.

v. Reckimghausen.-Festschr. f. Virchow, I89i, p. 22.

RIBBERr.- “Das Karzinom des Menschen," Bonn, rgrr.

SAPPEY.- "Des vaisseux lymphatiques," p. 48 et seq., Paris, 1885 .

Schmid, M. B.- “Die Verbreitungswege d. Karzinome u. d. Beziehung generalisierter Sarkome zu d. leukämischen Neubildungen," Jena, I9०3.

Schwarzkopf.-Beitr. z. klin. Chir., I912, 1xxx, 317 .

SterLd.- "Diseases of the Breast," p. 348 , London, 1898 .

THORNE.-Brit. M. J., I912, ii, I745.

TöRöK and WrTrelshöFER.-Arch. f. klin. Chir., I88I, xxv, 873.

Tyzzer.-Jour. Med. Research, I913, xxiii, 309 .

WEIL.-Ibid., 497.

Wiltiams, W. R.-“Diseases of the Breast," London, r894.

\section{PREDETERMINING FACTORS}

Age.-Mammary carcinoma occurs at all ages, but it is most exceptional to find it in patients under 20 years of age. Carmichael and Everhard Home have reported bilateral cases in patients 12 and ${ }_{5} 5$ years of age.

The city pathologist of Bradford, England, made the microscopic diagnosis of adenocarcinoma from sections of a tumor removed by Thompson from the left breast of an I I-year-old girl. The existence of the growth had been known for a period of three years but it had not increased in size until shortly before her admission to the hospital, when rapid enlargement took place. This, in the opinion of the parents of the child, was due to traumatic injury. Thompson describes the tumor as being very hard, about the size of a plover's egg, and involving the nipple which had practically disappeared.

This case together with that of Battle and Maybury, the latter an epithelioma of the nipple, also in a girl of II years, are the youngest patients of which we have records. Rand, in reporting a case of carcinoma mamma in a girl of 19 , quotes Paget to the effect that "scirrhus of the breast has been known before puberty." Brewer, of New York, removed from the breast, near the areola, of a 16 -year-old negress an intra-canalicular adeno-papilloma undergoing malignant transformation.

The foregoing cases prove beyond a doubt that carcinoma mammæ does occur in the breasts of young girls.

The percentage incidence of the disease increases as age increases, up to a certain point which varies according to different observers. The percentage of cases that occur in early life is not inconsiderable, however, and we should never dismiss the possibility of cancer when dealing with a neoplasm of the male or female breast until the true nature of the growth is absolutely proved by microscopic examination.

There is a remarkable similarity in the age incidence in cases of mammary cancer in the two sexes. Table I (Bryan) gives the percentage incidence of the disease in men and women at different ages. According to this table, the average age at which the disease occurs in men is two years later than in women. Bryan's figures show furthermore that cancer of the breast occurs more frequently after the age of 70 in men than in women. The oldest male case, that of a man aged $9 \mathrm{I}$, is reported by Lunn. Blodgett reported the youngest male case, that of a boy aged $\mathrm{r} 2$. The age incidence for mammary carcinoma among men under 35 years of age is slightly greater than it is for women under this age. Bryan's paper records the successful removal of a carcinomatous breast from a boy aged 14 years and $8 \cdot$ months. 
The uncertainty of the diagnosis of malignant tumors reported as occurring in childhood was shown by Phillip who collected 300 cases of which number only 87 (22.3 per cent.) withstood critical examination for malignancy. Phillip found no cases of breast cancer under I5. Jopson, Speese and White succeeded in finding three cases of carcinoma of the breast in children, but the diagnosis is spoken of in these cases as being doubtful.

Table I.-(Bryan.) Age Inctdence of Mammary Cancer in the Two Sexes

$\begin{array}{ccc}\text { Total number of cases } & \begin{array}{c}\text { Males } \\ 90\end{array} & \begin{array}{c}\text { Females } \\ \text { Males, } \\ \text { per cent. }\end{array} \\ \text { Age } & 2 & \begin{array}{c}\text { Females, } \\ \text { per cent. }\end{array} \\ 20-25 & 2 & 0.6 \\ 25-30 & 9 & 4.0 \\ 30-35 & 12 & 6.0 \\ 35-40 & \text { II } & 14.0 \\ 40-45 & \text { I7 } & 16.0 \\ 45-50 & 15 & 20.0 \\ 50-55 & 12 & 15.0 \\ 55-60 & 7 & 10.0 \\ 60-65 & 3 & 9.0 \\ 65-70 & \text { I0 } & 3.2 \\ \text { Over 70 } & - & 3.2 \\ & \text { I00 } & 100.0\end{array}$

When tumors of the breast appear before the age of 40 the probabilities are that they are benign. To believe, on the other hand, as is common among physicians, that cancer of the breast is rare before this age, is a mistake-cancer of the breast is a common disease in women under 40 years of age.

Table II.-Age Incidence in Cases of Cancer and Fibro-epitheltoma at the Cinic of the German Hospital of Philadelphia

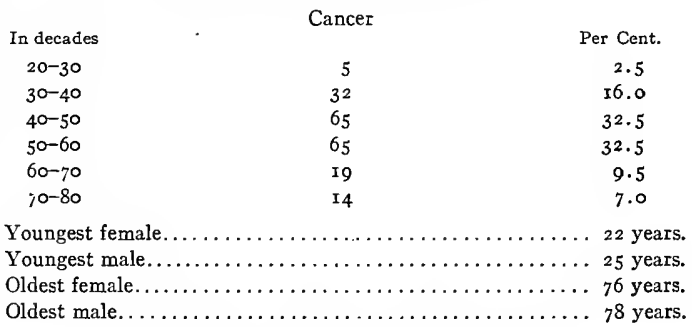

Average age.................

Fibro-epithelial Tumors

$\begin{array}{ccc} & \text { Per Cent. } \\ \text { IO-20 } & 6 & 6 \\ 20-30 & 25 & 25 \\ 30-40 & 32 & 32 \\ 40-50 & 25 & 25 \\ 50-60 & 6 & 6\end{array}$

Youngest female...................... I4 years.

Youngest male......................... Ig years.

Oldest female......................... 6r years.

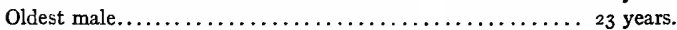

Average age................. 
In 13 per cent. of our patients with tumors of the breast, under 30 years of age the growths were cancerous in nature. Cancer occurring at this time is highly malignant in character; it is doubly important to remember, therefore, that one out of every seven women under 38 years of age with a breast tumor is suffering from cancer. In 33.6 per cent. of our patients under 40 years of age, the tumor was malignant. One out of every three women under 40 years of age with a tumor of the breast, therefore, is suffering from cancer. Warren gives approximately the same figures. He found that 76 per

TABLe III.--(Warren), ioo Consecutive Cases

Age Incidence

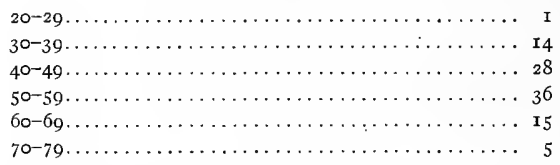

cent. of tumors occurring in the breasts of patients past 30 years of age were cancers: in cases in patients under that age, less than ro per cent. were cancers. Sixty per cent. of mammary tumors appearing between the ages of 30 and 40 are malignant according to Warren. The age incidence of cancer of the breast estimated in decades leads to the impression that the disease is rare in early life; this is true only in proportion to the number of cases occurring in later years. The comparative frequency of malignant mammary growths in relation with the sum total of tumors of the breast is such that the only safe rule of practice is to consider every tumor of the breast malignant until it is proven otherwise by operation and microscopic examination. In Rodman's collected series of 5000 cases, 9 per cent. occurred between the ages of 20 and 30 . In our own series $21 / 2$ per cent. occurred in patients under 30 years of age. The latter figures represent the approximate average for this decade. According to our statistics, cancer of the breast occurs more often between the ages of 70 and 80 than between the ages of 20 and 30 (2.5 per cent.). After 80 , the disease is extremely rare.

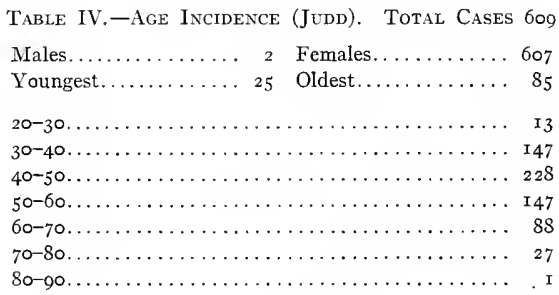

In Judd's series of 609 cases only one patient was over 80 years of age. Primrose reported 5.6 per cent. of cases in patients over 70 years of age. The majority (in our series 65 per cent.) of mammary carcinomas occur between the ages of 40 and 60 . The comparative proportion of cases occurring in these two decades and of cases occurring before the fortieth year and after the sixtieth year of life, so nearly approach each other, that the average age incidence becomes 50 years. The average age incidence in $a$ total of the largest series of cases reported during the past $5 \circ$ years by ${ }_{5}$ surgeons, is 50.I years. The lowest age incidence is reported by Winiwarter ( 45.3 years); the highest by Schwarzkopf (Schlosser's cases) ( 54.4 years). In our series it is 49.6 years. 
Table V.-Age Incidence (Primrose). Total Cases 323

Malignant cases.................... $2 \mathrm{r} 6$

\begin{tabular}{|c|c|c|c|c|}
\hline Average age & Oldest & Youngest & Male & IFemale \\
\hline 49.2 years & 77 years & 28 years & 5 & $2 \mathrm{II}$ \\
\hline $\begin{array}{r}3.4 \\
\times 7.5 \\
40.9 \\
19.0 \\
\text { r } 4.0 \\
5.6\end{array}$ & $\begin{array}{c}\ldots \ldots \ldots \ldots \\
\cdots \ldots \ldots \ldots \\
\cdots \ldots \ldots \ldots \\
\cdots \ldots \ldots \ldots \\
\cdots \ldots \ldots \ldots \\
\cdots \ldots \ldots \ldots\end{array}$ & $\begin{array}{l}\ldots \ldots \ldots \ldots \\
\cdots \ldots \ldots \ldots \\
\ldots \ldots \ldots \ldots \\
\cdots \ldots \ldots \ldots \\
\cdots \ldots \ldots \ldots \\
\ldots \ldots \ldots \ldots\end{array}$ & $\begin{array}{l}\ldots \cdots \\
\cdots \cdots \\
\cdots \cdots \\
\cdots \cdots \\
\cdots \cdots \\
\cdots \cdots\end{array}$ & $\begin{array}{l}\text { der. } \\
\text { usive. } \\
\text { usive. } \\
\text { lusive. } \\
\text { lusive. }\end{array}$ \\
\hline \multicolumn{5}{|c|}{ Benign cases.. } \\
\hline Average age & Oldest & Youngest & Male & Female \\
\hline 37 years & 6 r years & I9 years & ${ }^{\prime} 2$ & 105 \\
\hline $\begin{array}{r}3.0 \\
23.0 \\
38.5 \\
27.5 \\
6.0 \\
1.5\end{array}$ & $\begin{array}{c}\cdots \ldots \ldots \\
\cdots \ldots \ldots \\
\cdots \ldots \ldots \ldots \\
\ldots \ldots \ldots \ldots \\
\ldots \ldots \ldots \ldots\end{array}$ & $\begin{array}{c}\ldots \ldots \\
\ldots \ldots \ldots \\
\ldots \ldots \ldots\end{array}$ & $\begin{array}{l}\cdots \cdots \\
\cdots \cdots \\
\ldots \ldots \\
\ldots \ldots\end{array}$ & $\begin{array}{l}\text { nder. } \\
\text { lusive. } \\
\text { lusive. } \\
\text { lusive. } \\
\text { lusive. }\end{array}$ \\
\hline
\end{tabular}

The majority of the cancers of the breast appear within five years after the beginning of the menopause. Our figures seem to contradict this statement, however, because those cases occurring before complete establishment of the menopause were included in the previous group.

\section{Table Vi.-Age Incidence (German Hospital of Philadelphia)}

In relation to the menopause

Cancer

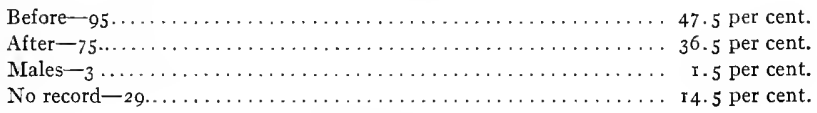

Fibro-epithelial tumors

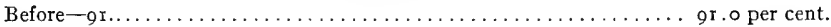

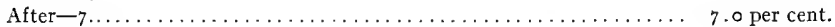

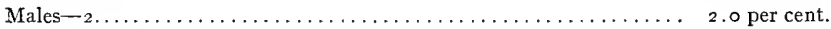

The favored time for the development of cancer of the breast is within one or two years after the establishment of the menopause. Cases are on record, however, in which the appearance of the neoplasm succeeded this physiologic event by 35 years. Seventy ( 8 per cent.) of Schwarzkopf's 300 cases began before the climateric. Rodman states that $2 \mathrm{I} .5$ per cent. of cases occur in women past 60 . He believes that this comparatively low percentage is due to the fact that there are fewer women over 60 alive than there are between the ages of 40 and 60 . There can be no doubt, however, that the majority of cases develop within the latter period. Middle age and its associated period, the menopause, would therefore seem to be important contributing factors to the development of cancer of the breast.

Sex.--One and one-half per cent. of the malignant and 2 per cent. of the benign tumors in our series occurred in men. Schuchardt states that of all neoplasms in the 
breast, about 2 per cent. occur in men. His series comprises a total of 406 cases, 58 of which were non-carcinomatous and 348 carcinomatous. These figures refute the recently expressed opinion of Bryan that "I per cent. of all tumors of the breast occur in the male and 2 per cent. of this number are malignant." Carcinoma or the scirrhus carcinoma is the most common variety of malignant tumor that affects the male breast; it is also the most common of all types of mammary neoplasm found in man. Approximately 20 per cent. of all tumors of the male breast are benign. The vast majority of the remaining 80 per cent. are carcinomas; sarcomas are exceptionally rare. Primrose had 4 male patients among 2 I6 (I.8 per cent.) of cases of mammary cancer. Judd's series consisted of 607 women and 2 men ( 0.032 per cent.). The average per cent. in the series reported by Primrose, Judd and ourselves is 0.088 per cent. These figures show that approximately I per cent. of cases of mammary cancer occur in men. According to the statistics given in the eleventh census of this country carcinoma affects the male breast in 3.8 per cent. of instances. The proportionate incidence of cancer among men and women serves, we believe, to indicate the influence of functional activity in the genesis of the disease. In England, according to Syms, eight women die of cancer to every man. Mr. Hoffman, Statistician of the Prudential Insurance Company of America, in a paper read before the Clinical Congress of Surgeons of North America at Chicago, Nov. I3, I9 I3, shows that while the comparative incidence of cancer is much higher among women than among men, the disproportion is less marked in the United States than that given by Syms for England. Hoffman's estimations were made by decades, according to the ages of the patients, and the proportionate mortality was much higher throughout among insured women than among insured men.

In the latter, at the ages 45 and over, 7.7 per cent. of the mortality from all causes was due to cancer, in women of corresponding ages it was I3.3 per cent. These same figures hold true for all ages, with slight variations. In a table giving an estimate of the mortality from cancer in the Continental United States during I9I2, Hoffman shows that in 24.9 per cent. of the total number of cancer deaths during this period, the disease involved either the female breast or the female organs of generation. The international . classification of the cause of death (I907) attributes 8.5 per cent. of all deaths from cancer to primary mammary involvement. Furthermore, 9.7 per cent. of 70,990 cancer deaths in the United States during I9I3 were due to primary disease of the breast. This indicates not only an increase in the incidence of mammary cancer during this period (I907 to I9 I 2), but also an increase in the incidence of fatal cancer of the breast. Eliminating cases of cancer of the female breast and generative organs, the proportionate incidence of the disease is somewhat greater among men. As regards the rare occurrence of cancer of the male breast, this is in keeping with the general rule that malignancy rarely affects vestigial structures. It is entirely rational to conclude that the many abnormal functional disturbances to which the breast and pelvic organs are subjected during the sexual life of women, have an important bearing on the disproportionate incidence of cancer of these particular organs in the female.

Since mammary hypertrophy is considered an etiological factor in certain cases of cancer of the breast, it is natural to believe that a similiar condition (gynecomastia) of the male breast would likewise predispose to the disease. Collignon gives some credit to this hypothesis, and Pigot, Schuchardt, and Berns have met with six cases showing concurrent cancer and gynecomastia.

Heredity.--From the practical standpoint, the problem of hereditary influence in cancer is at the present time of little moment. It resolves itself into determining in each 
case how many members of the patient's family have suffered with cancer. Where there is apparently a decided familial predisposition we are justified in adding one link to our chain of suspicion that the individual in question is suffering with cancer. The problem has been studied most carefully by Levin. His attempts to apply the laws of Mendel and Galton to the hereditary transmission of cancer while productive of extremely interesting data are not conclusive. Miss Slye's experiments upon the heritability of cancer in mice are far more convincing than statistics based upon the study of human cancer. These are considered elsewhere.

The advocates of the parasitic theory of cancer genesis, maintain that heredity must be effective only in creating a developmental predisposition as is the case with tuberculosis. We have already alluded to the theory that cancer is a biological problem in which not only a local change in the tissues is a necessary etiological factor, but also one in which a constitutional susceptibility plays an important rôle. It is conceivable that the latter may be a true inheritance but beyond this the adherents of this theory cannot go. Levin states that "only when an individual formed from a diseased germ cell which in its turn develops into a similarly diseased individual of a next generation can the disease be said to have been transmitted through inheritance." That this occurs in human cancer is most unlikely. The results of Levin's studies lead him to conclude that, "the resistance to cancer is a dominant character whose absence creates the susceptibility to cancer" and, "that this susceptibility is specific in different families for different organs." The value of Levin's observations consists in the fact that they show the possibility of an inherited resistance to cancer development. It has already been proposed that special study be made of the blood of those patients who recover spontaneously from carcinoma. It would likewise be valuable to investigate the physical peculiarities of families that have been free of malignant disease for several generations. The average frequency of an apparent hereditary influence in cases of mammary cancer as given by 18 authors whose writings we have consulted relative to this point, is 8.3 per cent. Thirty-seven of the relatives of 200 of our cancer patients, and 22 relatives of 100 of our patients with benign tumors of the breast died of cancer; I 3 per cent. of each type affecting the breast. The history of hereditary predisposition to cancer is more often given by women than by men suffering with the mammary form of the disease.

It would seem to be a significant fact that heredity is looked upon as an important factor in the causation of cancer by the medical directors of the large insurance companies, not only of America, but also of most foreign countries. The majority of writers on insurance medicine, especially Hall and Ramsey, attribute much importance to the theory of hereditary transmission of cancer. Hoffman, however, advises, in a recent article, that attention be paid rather to the means of diagnosing pre-cancerous lesions, than in seeking for a cancerous ancestry of the individual applicant for life insurance. That insurance companies are beginning to recognize the importance of such lesions is a very good indication that this, rather than heredity, or other so-called predisposing factors, is the problem of real practical importance in malignant disease at this time.

Trauma.-The influence of trauma as a cause of malignant tumors of the breast is much disputed. Of II 5 authors writing in the years I 9 or to I 909 inclusive, 30 did not assign trauma as a cause of cancer. Phelps states that only 9 per cent. of authors since the middle of the last century believed that transient injury might be a cause of malignant disease. In an analysis of a large number of cases reported by 22 writers, we find that on the average 9.5 per cent. of patients gave a history of injury antedating the develop- 
ment of the tumor. Most recent authorities are agreed that traumatic injury has some infience in the development of carcinoma of the breast in certain individuals. Those cases in which trauma seems to be a predisposing factor may be divided in three distinct groups: viz., (a) those appearing at variable intervals after the receipt of an intensive injury; (b) those immediately following an injury, acute mammary carcinoma: and. (c) those apparently due to long-continued irritation.

$A$ severe blow upon the breast may be followed by a malignant tumor at the seat of injury. the tumor, in these cases, may make its appearance, soon after the receipt of the injury. Or the trauma may be merely a factor leading to the rapid growth of a preëristent "latent" tumor, as in cases of acute carcinoma following injury of the lactating breast, in which a preëxistent slow-growing tumor may suddenly take on such rapid growth that the process resembles an acute pyogenic infection. Indeed, it is diffifult if not impossible to differentiate the two conditions. Cases of this kind occur, as a rule. in young women.

The predisposing intluence of trauma is more clear in those cases in which the cancer follows the injury aiter a number of years, under which circumstances, a precancerous change in the tissues is undoubtedly induced by the trauma. The fact that the cancer process does not manifest itself for many years after the injury is in keeping with the late development of cancer in scars following burns, ulcers and other chronic lesions of the supericial tissues. Several of our patients stated that a small nodule in the breast followed a blow received many years before, in one instance 20 years, and that the nodule remained stationary and symptomless until the receipt of a second injury when rapid growth occurred. Cases of this kind illustrate the twofold influence of severe trauma in the genesis of mammary carcinoma; in the former instances serving as a predisposing iactor, in the latter as an exciting cause of rapid growth. In many instances an injury to the breast merely serves to draw the patient's attention to the breast and a lump is accidentlaly discovered which had existed for some months. It is important to determine this point in cases in which legal complications are likely to arise. The law recognizes trauma as a cause of cancer in those cases in which the tumor develops "within a reasonable length of time after the injury."

Frequently repeated minor injuries, such as may be exerted by a corset-stay, the pressure of tools used in rarious trades, as, for instances, the shoemaker's awl, are sometimes mentioned by patients with mammary carcinoma as the causes of their trouble. While apparently causative in certain instances, it is estremely doubtiul whether these factors play a large part in the general incidence of the disease.

The danger of malignant tumor after traumatic injury varies with the type of the injury: it also depends to a large extent upon the organ or tissue inrolved, and the age and ses of the patient. The type of the tumor also depends, to a certain extent, upon the foregoing factors. Thus an intensive injury to the extremity of a young person is more likely to be followed by a sarcomatous tumor than is an intensive injury to the breast of a young woman. On the other hand, an intensive injury to the breast of a young moman is more likely to be followed by sarcoma than by carcinoma. After the thirtytifth year of life. the reverse is true. Theilhaber especially calls attention to this specificity of the neoplasm for certain parts after distinct types of injury. He states that 9.3 per cent. of all traumatic tumors of the breast are carcinoma, while about the same percentage holds good for sarcomas following injuries to the extremities. In discussing a case oî cystadenoma oî the breast due to trauma. Murphy says, " the breast is the one place in which a single trauma oi moderate severity produces a carcinoma and besides, 
is the only place in which we have carcinoma also due to chronic irritation as well." In I3 per cent. of our cases a definite history of injury, usually transient in nature, was given. In one of these cases, bleeding from the nipple, said to be of traumatic origin, recurred at irregular intervals for a period of one year before the clinical evidence of malignancy appeared. As a general rule, however, from three to four years elapsed from the time of receipt of the injury to the time of onset of symptoms suggesting malignancy. Williams states that 25 per cent. of 137 cases gave a history of trauma and that in rooo cases of cancer of the breast, the disease immediately followed the receipt of the injury. Coley mentions 52 cases of carcinoma of the breast which gave the history of a single antecedent injury. Röpke in a study of 800 cases in which cancer apparently developed from irritation, shows that only ig were caused by a single trauma. McWilliams gives statistics of too cases of cancer of the breast with reference to trauma as a causative factor; he says, "In our list of cases there is record on this point in 65 per cent. of the patients of which number, 29 ( 44.6 per cent.) gave a history of distinct antecedent injury." Collignon believed that both chronic irritation and acute trauma have an important place in the etiology of cancer of the male breast, although he adds that here as elsewhere, sarcoma is the particular type of tumor resulting from intensive injury. According to Williams, 53 per cent. of cases of cancer in the male breast give the history of an antecedent injury to the affected organ. Bryan gives the percentage incidence of trauma as a predisposing factor in 50 per cent. of cases in men. On the other hand, in only 25 of Schuchardt's 406 cases was trauma influential in causing the disease. It is evident, therefore, that trauma is generally considered more important as an etiological factor in cancer of the breast in men than in women. These observations leave little room for doubt of the predisposing influence of trauma in the development of mammary carcinoma. With increased knowledge of the pre-cancerous tissue states, the ascribed influence of bacterial and traumatic inflammation has a more rational basis, nor can the frequent occurrence of the disease in the absence of such influence render it equirocal, for in the light of modern knomledge we must consider trauma with other causes of inflammation as a factor predisposing to cancer through the destruction of the normal fibro-epithelial relationship. The prophylaxis of cancer of the breast clearly demands avoidance of all forms of irritation and trauma.

Race. - The apparent racial influence in the development of malignant neoplasms proves on critical analysis to depend more on national customs and habits than upon a racial resistance or susceptibility to cancer, as the case may be. This is best illustrated by the comparative incidence of cancer among the several negroid races. Thus. cancer is undoubtedly a rare disease among the native African negroes; it is, as we shall show later, quite common among the American negroes. Cancer is likewise rare among the negro population of the Panama canal zone. Dr. Noland of the Colon Hospital, Cristobal, Canal Zone, states that only 35 cases of cancer were found among 54.240 patients treated at the hospital during the past five years. He attributes this small percentage to the large proportion (three-quarters of the population) of negroes in the population. He fails, however, to give the relative number of men and women treated. which should of course be taken into consideration. since the most trequent sites of malignant disease in the colored race are the uterus and breast. If we now turn to the latest census reports of the United States. we find that while there is a greater incidence of cancer among native whites. there is also a relatively greater incidence for the disease among blacks in this country than in the Canal Zone. This is especially true for mammary cancer in which the death rate as given in the eleventh census report was prac- 
tically the same in whites and blacks, being 4.77 in the former and 4.19 in the latter. Rodman quotes statistics from reports of the Louisville City Hospital for 20 years, which show that three-fifths of cases of cancer of the breast were in whites and twofifths in blacks, the latter representing only one-third of the hospital population. Our own records relative to this point are without value owing to the overwhelming majority of whites who apply for admission to the wards of the German Hospital of Philadelphia. The disease, in the greater number of our cancer cases in colored patients, attacks the uterus or breast in women and the stomach in men. Racial differences we believe have absolutely no diagnostic significance in patients coming to Philadelphia hospitals for the treatment of mammary neoplasms. This does not apply to those sections of this country in which the native Indian population becomes a factor since the American Indian retains that immunity to cancer which characterized his primitive state. According to Levin, only 29 cases of cancer were encountered among a population of

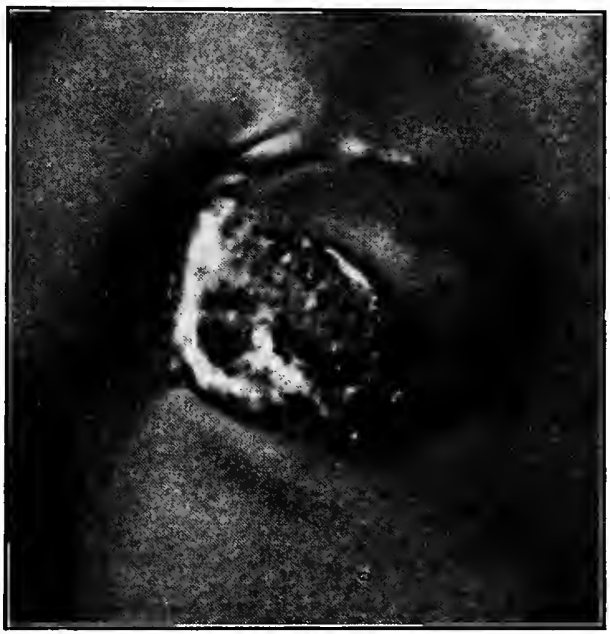

FIG. I95.-Carcinoma (ulcerating) of the breast of a native East African. (Welch.)

I 15,455 by 107 physicians in the Indian Field Service, whose practices ranged from a few months to 29 years. His studies also show "that cancer is just as frequent among the whites of the states in which the Indian Reservations are located, as in other states.

Cancer is generally considered to be rare among oriental races. Levin states that the proportion of deaths from cancer in Hongkong, China, is 0.65 per rooo deaths, as contrasted with 38 per I000 of all deaths in England. Here again there seems to be a marked difference in the relative incidence of the mammary form of the disease. According to W. Roger Williams (Rodman) carcinoma of the breast is relatively common in certain districts of China.

We are unable to quote figures illustrating the relative frequency of the mammary or other forms of cancer among the immigrant classes of the United States. It has been our personal experience that the Russian Jewess is more susceptible to cancer of the 
breast than the women of other European races who make up a large proportion of our immigrant population. Here again the racial variations in cancer incidence are so small that they can for all practical purposes be disregarded.

Child-bearing, lactation and pyogenic mastitis are generally looked upon as having a causal relationship with cancer of the breast. If these conditions are influential in the production of mammary carcinoma, it is obvious that the disease will occur with comparatively greater frequency among married women. Most statistics, including our own (Table VII) apparently prove this to be the case.

Table Vil.-German Hospital Clintc (Philadelphia)

\begin{tabular}{|c|c|c|c|c|c|}
\hline Cancer & & & Fibro-epithelioma & & \\
\hline & Cases & $\begin{array}{l}\text { Per cent. } \\
I z .0\end{array}$ & & Cases & $\begin{array}{c}\text { Per cent } \\
49.0\end{array}$ \\
\hline Married.... & $\begin{aligned} x+4 \\
x 63\end{aligned}$ & $8 \mathrm{I} .5$ & Married........... & 49 & 49.0 \\
\hline Males.................. & 3 & I. 5 & Males............ & 2 & 2.0 \\
\hline & IIO & 55.0 & & 24 & 24.0 \\
\hline Tulliparous............ & go & 45.0 & Nulliparous.............. & 76 & 76.0 \\
\hline
\end{tabular}

We have consulted the writings of 20 authorities on this subject and find that an average of 82.5 per cent. of cases occur in married women. The lowest percentage mentioned is 68.6 per cent.; the highest, 90 per cent. It has been shown recently, however, that this difference in the ratio of cancer incidence among married and single women is only an apparent one, since there are more married than single women living between the ages of 30 and 45-"the cancer age." In a series of $6 \mathrm{I}_{3}$ cases of cancer of the uterus and female breast, Levin found that the disease occurred in virgins in 6.6 per cent. and I 7 per cent. respectively. He also calls attention to the fact that the ratio of deaths

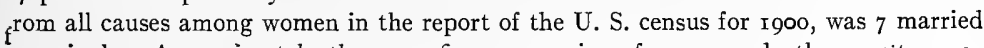
${ }^{\prime}$ I single. Approximately the same figures are given for cancer deaths $-7.5^{\circ}$ to $\mathrm{I}$, or

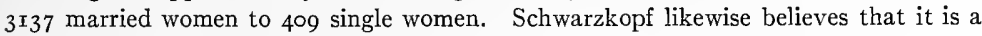
fallacy to consider the disease proportionately more common among married women. The ratio between the married and single women in our collected series was 4.5 married to I single. Granting that the figures ( 7.5 married to I single) given in the U. S. census report are correct and express the true ratio of incidence of cancer as it affects the female, it is evident from our figures ( 4.5 married to I single) that the comparative frequency of cancer of the breast is proportionately much higlier among single women.

Statistics relative to the percentage number of patients with cancer of the breast who have borne children differ widely; 55 per cent. of our own cases were parous women. The average percentage of women with cancer of the breast who have borne children in the series of cases reported by $\mathrm{I}_{7}$ different writers is 70.3 per cent., the lowest 39.5 per cent., the highest, 90 per cent. Statistics reufte the generally accepted belief that child-bearing and lactation predispose womankind to mammary cancer. Table VII shows that the breasts of 55 per cent. of women who suffered with this disease had functionated. It will be observed that in one series of cases, only 12.5 per cent. of the patients had lactated. These figures are computed on the basis of the total number of cases; if we now apply the fact that there is a disproportionately large number of married women alive at the cancer age, it will be seen that pregnancy and lactation are less influential as predisposing factors to mammary carcinoma than is generally believed. Most writers maintain that the marital state per se has little or no bearing on the incidence of cancer of the breast. Our figures show in addition, that the functional activities to which 
the marital state predisposes the breast have no real causal relationship to the disease. It has been our belief for many years that married women were not only comparatively but also absolutely more prone to cancer of the breast than their single sisters; if the statistics given above are correct, as we believe they are, the conclusion is inevitable that married women are proportionately less liable to develop cancer of the breast than are unmarried women. It is, therefore, not illogical to believe that the changes in the breast incidental to menstruation and the menopause are more influential in cancer production in these organs than is actual functional activity of their glandular tissues. On the other hand, the majority of young women who suffer from cancer of the breast are married. We, however, have had several unmarried women under 30 years of age with mammary cancer. Fourteen of I 5 patients under 30 years of age reported by Schwarzkopf were married women. The predisposing influence of the marital state in mammary cancer would seem, therefore, to be in inverse ratio to the age of the patient.

Pyogenic mastitis seems to serve as a predisposing factor to cancer of the breast in a small percentage of cases. Statistics bearing on this relationship are meager. This is due to the fact that the various types of mastitis are grouped together and their influence estimated collectively by many writers. An average of I 4.6 per cent. of antecedent mastitis is given in the reports of 2I authors whose writings we have consulted. In rare instances, the malignant process appears in conjunction with or soon after the subsidence of a pyogenic infection. In the former instance the infection is usually superimposed on a preëxistant tumor. In the latter group of cases, the infection probably serves as an excitant to a growth that had existed prior to the time of bacterial invasion of the heart. The remote influence of pyogenic mastitis in cancer genesis is by no means clear. In some cases a nodule of scar tissue remains at the site of an abscess and appears to form the nidus for cancer development. For this reason women who have had abscesses of the breast, and especially those with nodules of scar tissue remaining at the site of such abscesses, should be examined at regular intervals for changes in the size, consistence, etc., of the lump. This is especially indicated during the several years preceding and succeeding the menopause. Immediate excision is, of course, the safest procedure regardless of the physical state of the nodule.

\section{BIBLIOGRAPHY}

AвBE, T.-Surg., Gynec. and Obstet., I9I3, XVI, I85.

BASHFord.-Niederl. Tijdschr. v. Geneesk., I9I 2, I, I69o.

BASHFORD.-Lancet, I9I I, i, I 596 .

BASHFORD.--Practitioner, I9II, LXXXVI, 337 .

Battle and Maybury.-Lancet, I9I3, i, I52I.

BEHLA.-Cited by Park.

v. Bergmann.-Cited by v. Hansemann.

Bertels.-St. Petersb. med. Ztschr., I9I 2, xxxvii, 2 I.

Bertels.-Deutsch. Ztschr. f. Chir., I913, CXXIV, 9.

Billroth.-Cyclop. Obstr. and Gynec., IX, New York, I 887.

Bloodgood.-Surg., Gynec. and Obstet., I906, iii, 72 I.

Bloodgood.-Progressive Med., I9r 2, December, 242.

Bonney.-Practitioner, I909, lxxxii, 737 .

Borrell.-Trav. II Confer, pour l'étude du cancer, Paris, I91 I, I9.3.

BORST. - Ibid.

Brewer.-Ann. Surg., I907, xlvii, 755.

Bristol.-Med. Rec., I9 I3, lxxxiii, 787.

Butuin.-Brit. M. J., I9I I, ii, I393.

Cheatle.-Brit. M. J., I909, i, I4rI. 
Coley.-Ann. Surg., I9II, LIV, 449.

Deaver.-West Virginia, M. J., I913, I4, viii, I43.

v. Dungern.-Centralbl. f. Bakteriol. u. Parasitenk., Igr 2, LIV, Ref., Beiheft, 84.

FinNey.-Keen's Surgery, vi, Phila., 1908.

Grefiough, Simmons and Barney.-Ann. Surg., Igo7, XLVI, 20.

HANDLEY.—"Diseases of the Breast," London, Igog.

Handley.-Practitioner, I910, lxxxiv, 463.

v. Hansemanv.-Ztschr. f. Geburtsh. u. Gynäk., 19I3, LXXIV, 149

Jopson, Speese and White. -Ann. Surg., 1908, xlviii, 662.

JUDD. -N. York M. J., 1912, xcv, 867 .

Levin.-Studies in Cancer, George Crocker Cancer Research Funf, rgr 2, ii, 15, 29

Lockwood.-Lancet, 1910, i, 285.

LOEB, LeO.-Interstate M. J., I912, xlv.

MacCarty. - Tr. South. Surg. and Gyn. Ass., 1910, XXIII, 262.

Martin.-Lyon Med., 1912, cxviii, 34 .

MclVilliass.-Med. News, Igoo, LXXVI, 644.

MAYo, C.-J. Am. Med. Ass., I910, LV, 1605.

Mayo, W. J.-Boston M. \& S. J., I912, CLXVII, $75^{1}$.

Mayo, W. J.-Collected Papers, I9Ir, I37.

MaYo, W. J.-Ibid., 95.

MURPHY.-Surgical Clinics, Igr2, I, 28r.

Neve.-Brit. M. J., 1910, ii, 58 g.

Nutt, Beatrie and Sarith.-Lancet, I913, ii, 210.

Park.-Tr. South. Surg. and Gynec. Ass., IgII, xxiii, 346 .

Phillip.-Ztschr. f. Krebsf., I907, v, 326.

Poncet and Leriche.-Rev. de Chir., IgI2, XLV, I53.

Porter.-Tr. Am. Ass. Obstet, and Gynec., 1913, xxv, 217.

Rand.-Brooklyn M. J., r893, vii, 753.

RöPKE.-Arch. f. klin. Chir., rgo5, LXXVIII, 201.

SPEESE.-N. York M. J., IgO8, LXXVII, 357.

Speese.-Univ. of Penna. Med. Bull., I909-io, XXII, 55.

SPEESE.-Ann. Surg., Igro, li, 2 I 2.

Steadraxi:-Internat. Cong. Med., London, I9r3, August.

Syms.-Med. Rec., I9I3, LXXXIII, 88r.

Syrs.-Ann. Surg., I9I3, LVIII, 399.

Theilhaber.-Deutsche med. Wchnschr., IgI 2, XXXVIII, 264.

Thompson.-Brit. M. J., 1908, ii, 502.

WARREX.-Ann. Surg., 1904, XL, 805.

WERNER. -München. med. Wchnschr., I9ri, 2235.

WERNER.-Cancer Internat., I9I I, III, I46.

WILE.-N. York M. J., IgII, XCIV, Ir69.

Williams. - "Diseases of the Breast," London, 1894 .

Wilson.-Collected Papers Mayo Clinics, I9I 2, 721.

Wilsox and MacCarthy.-Am. J. M. Sc., igo9, cxxxviii, 946.

Symptoms and Diagnosis.-In the diagnosis of tumors of the breast the factors predisposing to cancer of this organ must be given due consideration. These factors have been dealt with elsewhere. It now remains to consider the symptoms and signs that are associated with carcinomatous growths, and especially with those which serve to differentiate them from the several tumor diseases of the breast for which they may be mistaken. It should never be forgotten in attempting the diagnosis of a mammary tumor that the vast majority are carcinomatous. The percentage occurrence of mammary cancer according to different authors is as follows: Billroth 82 per cent., Bryant 83.I per cent., Schmidt 82.6 per cent., Gross 82.4 per cent., Poulsen 78 per cent., Schwarzkopf 83 . I5 per cent. Every growth in the breast should, therefore, be considered malignant until it is proven to be otherwise; in no case are we justified in 
awaiting clinical developments when the diagnosis is impossible. It would at first thought seem unnecessary to deal at length in a diagnostic way with the symptoms and signs associated with the advanced stages of cancer of the breast, but contrary to expectations, we find that mistakes in the clinical diagnosis are not infrequent in far advanced cases. We have likewise found that the limitations of surgery in the advanced stages of the disease are little understood. Hort has shown that mistakes in the clinical diagnosis of mammary carcinoma are most frequently made in young subjects, which is not surprising in view of the common error of believing that cancer rarely occurs before the age of 40 . In a series of 300 cases of mammary cancer occurring before the twenty-fifth year of life, Hort found that I 28 were not diagnosed clinically, and further, that $5^{82}$ of $353^{2}$ cases at all ages were sent to London hospitals with wrong diagnoses.

The general misunderstanding of the surgical limitations in the treatment of far advanced cases of mammary cancer is shown by the fact that 3 I (I 5.5 per cent.) of a series of 200 cases in our German Hospital clinic, had extensive ulceration of the tumor and widespread metastases. Mayo states that the disease is inoperable in 25 per cent. of patients presenting themselves for treatment at St. Mary's Hospital, Rochester, Minn. The import of these figures is appalling, for they show without question, that in a definite proportion of cases, the patients are permitted to go untreated until symptoms appear that have long been considered classical. That these symptoms are classical remains a fact, but that they do not appear until the case is inoperable is another fact, the great importance of which the profession does not fully appreciate.

Subjective symptoms are seldom prominent in the early stages of mammary carcinoma. In a small minority of cases, the disease progresses insidiously to the point of extensive dissemination in the entire absence of symptoms. One of our patients was sent to the hospital on account of severe upper abdominal symptoms including the characteristic pain which is commonly associated with gallstones. Examination showed widespread cancerous involvement of the liver, metastatic from a small nodule in the right breast. This patient was entirely unaware of the existence of a tumor in the breast.

initial Symptoms in Cases of Cancer and Fibro-epithelioma at the Clinic of the German Hospital of Philadelphia

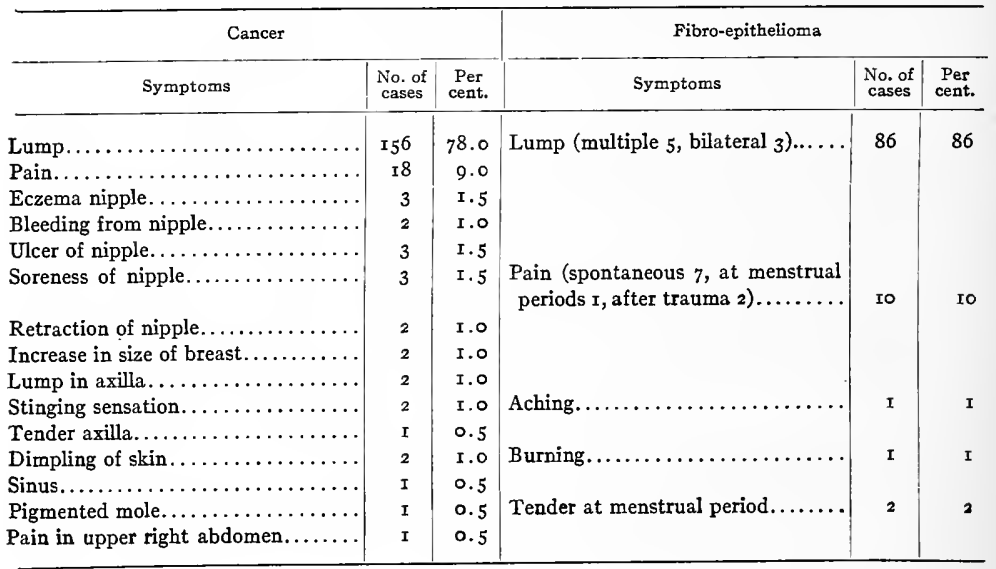


Two patients in our series first noticed nodules in the axilla and had not suspected any trouble with the breast, while similar cases were observed by Halsted and Quénu. In the great majority of instances cancer of the breast runs a symptomless course in its early stages and the first. suggestion of trouble comes with the accidental discovery of a lump in the breast.

The initial symptoms in our series are given in the foregoing table:

Pain.-Pain as the initial symptom of cancer is rare when compared with the frequent occurrence of a symptomless lump in the breast as the first indication of the disease. On the other hand, among symptoms other than the lump itself, pain was the first symptom in as many instances in our series as were all other symptoms taken together. In a very small percentage of cases, pain of a severe and lancinating character precedes the appearance of a palpable induration by several months. In a still smaller number of cases, the patient gives a history of a painful and tender condition of the affected breast for a period of several years before any gross change is discovered in the organ. The probabilities are, that in cases of this latter group, undemonstrable benign lesions precede the development of the cancer. When a patient complains of persistent pain in the breast she should be examined at regular intervals and not be assured that the condition is an innocent one (mastodynia) in the absence of a palpable induration at the time of the first examination. Carcinoma of the breast in its earliest stages is less frequently associated with pain than almost any other disease affecting this organ. In a small minority of cases, the disease reaches an advanced stage without causing the slightest pain. This is especially true of rapidly growing medullary tumors which cause very slight pressure upon the nerves. The disease in one of the cases in our series proceeded to extensive ulceration in the entire absence of pain. This is exceptional, however, pain being rarely absent in the late stages of cancer of the breast. In 65 per cent. of our malignant cases, the patients suffered no pain until several months, and in some instances until several years after the discovery of the lump.

The pain associated with cancer of the breast may be localized, referred or generalized.

Localized pain is caused by cancerous involvement of the subcutaneous tissues and skin; of the connective-tissue stroma of the organ, or of the pectoral fascia; it is most common in the scirrhus variety of the disease.

Referred pain arising from a carcinomatous nodule in the breast is usually felt in the arm on the affected side; less often in the axilla, back, shoulder and neck. When the pain is referred to the arm it is due to involvement of the intercostal humeral nerve, a branch of the lateral cutaneous of the second intercostal nerve which communicates with the lesser internal cutaneous nerve of the arm. Pain referred to the back is due to involvement of the lateral cutaneous branches of the third, fourth and fifth intercostal nerves, and when to the neck, to involvement of the descending branches of the cervical plexus. The area of reference is dependent to some extent upon the location of the tumor. Pain referred down the arm is usually associated with a tumor involving the upper outer quadrant of the breast, or upon secondary involvement of the anterior pectoral chain of lymph nodes. Tumors involving the lower quadrant of the breast are sometimes associated with pain in the lower thoracic and upper abdominal regions. Pain felt in the mediastinal and thoracic cavities is usually, but not always, caused by metastatic involvement of the organs in the thorax, or of the pleural membrane. The possibility that pain due to metastatic foci may simulate referred pain must not be forgotten; this is especially important when the operability of a given case depends upon the determination of the presence or absence of distant metastases. Pain 
referred along the intercostal nerves is not infrequently felt in the region of the lower thoracic and upper lumbar vertebræ; it must be differentiated from that caused by metastases in the vertebral bodies. General pain, by which we mean pain which is experienced in areas remote from the breast and due neither to metastasis nor to direct reference from the primary tumor, is a symptom of the advanced stages of the disease. It is especially frequent in cases where ulceration has taken place and is due to the effect of toxines absorbed from the necrotic tissues. In deciding for or against operation, this symptom should have no weight until the actual cause of the pain is conclusively proven by $X$-ray and other examinations. The pain associated with mammary carcinoma has been described by our patients as slight, moderately severe, or excessive; of a sticking drawing character, or knife-like and shooting into the arm, axilla, neck, abdomen or chest, and in several instances was complained of as affecting only the axilla and abdomen. Trauma, infectious diseases, the menstrual periods and damp weather were all given as influential in its production.

Diseases of the breast other than carcinoma are frequently associated with pain in their early stages; thus abnormal involution causes slight degrees of pain in its earliest

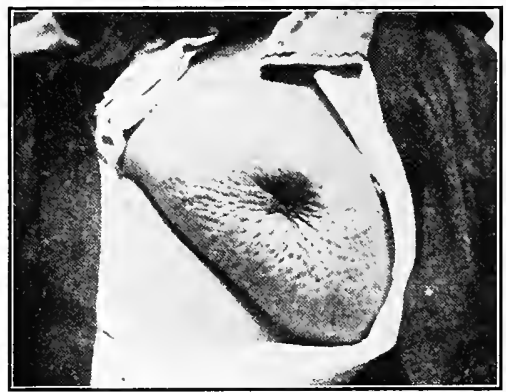

FIG. I96.- "Peau d'orange" or "pig-skin" appearance of the breast in a well-characterized case of carcinoma. (Handley.)

stages in the majority of instances. The specific granulomas are rarely unassociated with this symptom. The fibro-epithelial tumors in the breasts of young women sometimes cause marked degrees of pain; more often these patients merely complain of painful sensations at the time of the menstrual periods, when the tumors also seem to increase in size. Greenough and Simmons state that one-third of their patients with the fibroadenomatous type of tumors complain of pain of varying degrees of intensity, while only Io per cent. of our own patients with benign tumors gave the history of this symptom, and in only seven instances was the pain spontaneous and unrelated with the menses. Sarcoma, of the peri-ductal type, usually pursues a painless course until the tumor attains an enormous size. The non-indigenous variety of mammary sarcoma, on the other hand, is more frequently painful in its early stages.

Tenderness is not characteristic of uncomplicated cancerous tumors until the overlying skin becomes involved when the tenderness may be exquisite.

Patients are prone to ascribe benignancy to a lump in the breast which causes no discomfort. It is extremely difficult to convince them of the very serious nature of a condition which gives rise to no discomfort whatsoever. In many instances, patients 
with carcinoma of the breast await the appearance of some change in the lump before consulting a physician. There would indeed seem to be little hope of improving the operative results in mammary carcinoma until women in general can be made acquainted with the seriousness of painless lumps in the breast.

The Tumor.-The most frequent sign of carcinoma of the breast is the presence of a tumor. This is likewise, as we have already stated, by far the most frequent initial symptom. The clinical manifestations in a series of 216 cases of mammary carcinoma reported by Primrose were, in the order of their frequency, as follows:

Tumor present in all cases.

Glandular involvement.

Axillary glands not involved....................... 6 per cent.

Axillary glands involved and palpable.....................

Subclavicular glands involved and palpable................. I per cent.

Supraclavicular glands involved and palpable................. 2 per cent.

Pain present......................................

Skin involved...................................... 23 per cent.

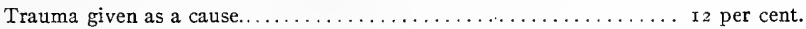

Ulceration...........................................

Retracted nipple............................... 6 per cent.

Discharge from the nipple: bloody in one-half the cases, not noted in the others........................................

Sore nipple in previous history, usually described as cracked nipple.... 3 per cent.

Size of the Tumor.-In the majority of instances a cancerous tumor appears as a small induration which gradually enlarges, involving more and more of the breast tissue, and finally the skin, subcutaneous tissue and the pectoral fascia. In other cases the patient first notices a gradual shrinking of the breast-a characteristic feature of the atrophic schirrus variety of carcinoma. In a small minority of cases, the entire organ seems to swell and become indurated. This is most frequently seen in the socalled acute carcinomas occurring during lactation and in the rapidly growing medullary types of tumor, although this same feature may be noted in other varieties of tumor of the breast, notably in the peri-ductal sarcomas. Untreated cancerous tumors of the breast rarely attain the enormous proportions so of ten met with in cases of peri-ductal sarcoma. This is due either to the fact that skin involvement with ulceration occurs early in the course of the disease, or, as is the case with the scirrhus type of cancer, tumor formation is never a prominent feature of the disease. Again, patients are usually referred for operation before the growth has attained its full development because of other symptoms. The size of the tumor at the time of operation in Schwarzkopf's series of cases was as follows:

TABLE VIII.-SIZE OF THE TUMOR

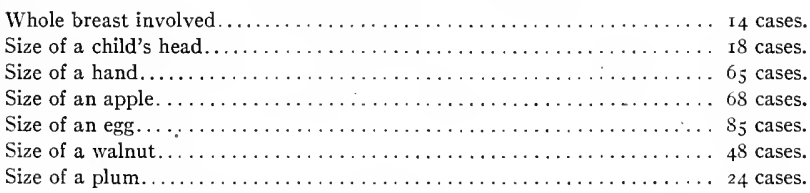

In rare cases the nodule in the breast becomes no larger than a filbert and yet gives rise to early and fatal metastases. As a rule, however, the growth reaches much larger proportions before widespread dissemination takes place. 
Location of the Tumor.-The most common site for both malignant and benign tumors is the upper outer quadrant of the breast. Many writers claim that the benign tumors are usually located in the sternal half of the organ, but in our experience this portion of the breast is rarely involved in either benign or malignant tumors. When tumors do occur in the sternal half of the breast, however, the malignant forms are twice as numerous as the benign.

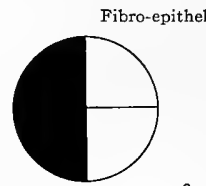

Axillary half $54 \%$
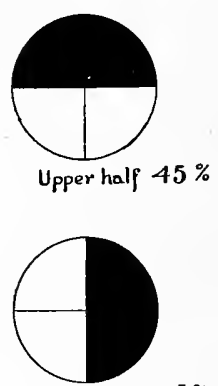

sternal half $5 \%$

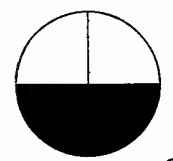

Lower half $29 \%$

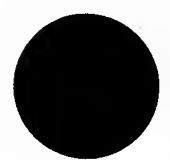

Generalized 3\%

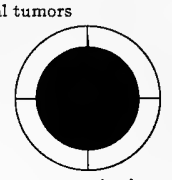

Central $11 \%$

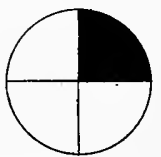

Upperinner $4 \%$

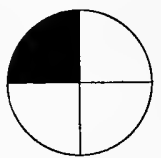

Upper ouler 28\%

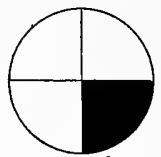

Lower inner $0 . \%$

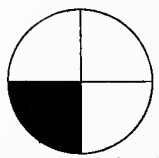

Lower outer $17 \%$

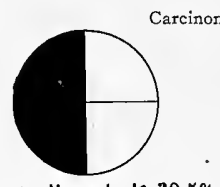

Axillary half $38.7 \%$

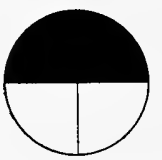

Upper half $38.7 \%$

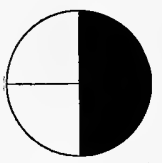

Sternal half $10.2 \%$

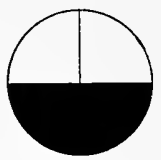

Lower half $12.2 \%$

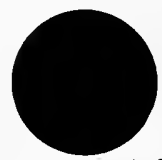

Generalized 9.2\%

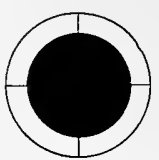

Central $19.7 \%$

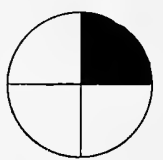

Upper inner 5\%

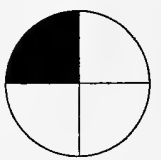

Upper ouler 29.2\%

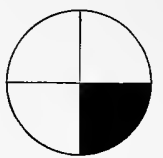

Lower inner $2.7 \%$

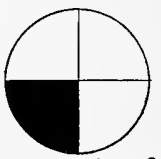

Lower ouler $9.2 \%$

F/G. 197.-Diagram showing the location of tumors in the breast. (Note the much higher percentage of involvement of the axillary half of the breast.)

It will be observed that in 9.2 per cent. of our malignant cases, the disease was generalized throughout the breast, and in 19.7 per cent. the tumor was centrally located.

The right and left breasts are affected with equal frequency in both the benign and malignant tumors. It has been stated that the right breast is more prone to cancer than is the left breast. That this is a fallacy is demonstrated by the fact that in a 
Table IX.-Location of the Tumor (Schwarzkropf)

Upper outer quadrant 83 cases Upper inner quadrant 28 cases Lower inner quadrant $I_{7}$ cases
49.80 per cent.

r 4.82 per cent.

9.6 per cent.
Outer half............. 74.57 per cent.

Lower outer quadrant 49 cases 27.12 per cent.

Inner half............. 25.42 per cent.

Note the much higher percentage of involvement of the axillary half of the breast.

series of 595 collected cases including our own, the left breast was involved in 292 instances, the right breast in 287 , while in 16 cases the disease involved both organs. Bilateralism is not uncommonly met with but in the great majority of instances the process in one breast is secondary to a primary nodule in its fellow of the opposite side Simultaneous involvement of both organs is extremely rare. Poulsen had I I bilateral cases among his 355 patients; Schwarzkopf had 5 among 322 ; and we have had $\mathrm{x}$ I among 200 patients. According to our own statistics, if tumors arising both simultaneously and subsequently are taken together, bilateralism is more frequently met with in the benign than in the malignant forms of mammary tumors. We cannot agree with Primrose, however, in the statement that "bilateral tumors are usually benign." In not one of our Ix cases of bilateral cancer did the case history indicate simultaneous involvement of the two organs.

The concurrence of cancer and benign tumors arising independently in the same breast is not as uncommon as is the occurrence of cancer in one breast and a benign growth in the other breast. We have had four patients with benign tumors of the breast who have had previous operations on the other breast for carcinoma. In a case recently seen by one of us, both breasts contained a dozen or more nodules which were apparently fibroadenomatous in nature. One of these nodules was excised and on microscopic examination a small area of carcinoma was found. The breasts were then amputated but careful examination failed to show any evidence of malignancy in the remaining nodules. Our experience leads us to the conclusion that bilateralism is of little practical importance in the differential diagnosis between benign and malignant tumors of the breast. When two or more tumors are found in one breast, however, the chances are in favor of benignancy, but multiplicity of the tumors in itself should not carry a great deal of diagnostic weight since as mentioned above, benign and malignant tumors may occur in association, or as is frequently the case, one of the benign nodules may be undergoing undemonstrable malignant change. Patients with multiple nodules in the breast should be operated upon promptly, and tissue removed from each nodule and examined for malignancy.

In well-advanced cases of mammary carcinoma the tumor has certain physical characteristics which at once reveal the true nature of the disease. This does not apply, however, to its very early stages in which the cancerous growths closely simulate benign growths. Thus in the incipient stages of mammary carcinoma, the tumor presents itself as a rounded discreet nodule situated in the glandular tissues of the organ and is freely movable with the breast tissue in all directions and, therefore, unattached to the subcutaneous tissue or to the pectoral fascia. The tumor may feel encapsulated in certain instances although this is only apparent and due to the fact that the invasion of the glandular tissue which has already occurred in the vast majority of cases, however recent the development of the cancer, cannot be felt.

In very obese subjects with deeply placed tumors, or in cases with very small tumors occupying the deeper planes of the breast, and finally in cases in which primarily benign tumors have recently undergone the initial chang es of malignancy, clinical differentiation 
is, in our experience, impossible. Such cases are, however, rare, and when first seen by the physician commonly show one or more signs suggestive of malignancy, the most important of which are extreme hardness, the irregular infiltrating nature of the growth and the shortening of the fibrous trabeculæ of the breast. Halsted says relative to this point of differentiation: "It is important to note most carefully the relative amount of uninvolved mammary gland remaining, relative to the amount in the other breast and to the size of the new growth. If the tumor has grown little or not at all at the expense of the breast, it is quite surely a definite adenomatous type and not a scirrhus."

One of the earliest signs of mammary carcinoma is shortening of the fibrous trabeculæ which soon manifests itself clinically in the production of a visible pitting of the overlying skin (orange skin, "peau d'orange," pig skin).

Before this pitting becomes visible, the shortening of the trabeculæ may be demonstrated by fixing the skin to one side of the breast with one hand, at the same time making

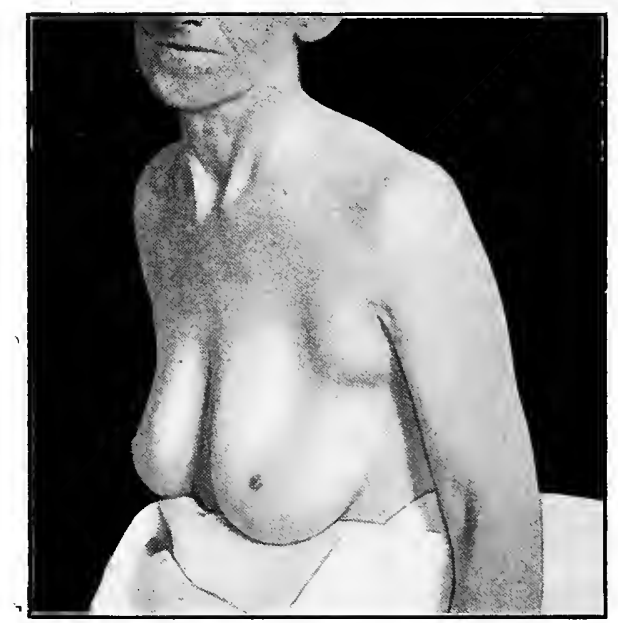

FIG. 198.-Carcinoma originating in the axillary tail of the breast. The breast proper was normal.

pressure on the tumor in an opposite direction when typical pitting will be observed to occur in the skin directly overlying the tumor mass. This sign is more easily elicited in patients with superficially placed tumors, but will usually be found in cases with deeply placed tumors, as well. Dimpling of the skin may be demonstrated, therefore, in many cases where the disease has not progressed to that stage where permanent dimpling results, but in either instance this symptom must be considered a late one from the prognostic standpoint, although it is one of the earliest positive signs of malignancy. In two of our cases the first symptom noted was dimpling of the skin. This symptom is never seen in association with benign tumors unless they have become infected. It is uncommonly seen in its typical form in the infectious granulomas or pyogenic mastitis; it may occur in association with the non-indigenous varieties of sarcoma, but rarely if ever in the peri-ductal types. 
Actual fixation of a cancerous tumor of the breast to the chest wall is caused by infiltration of the deeper layer of the superficial fascia, which, it will be remembered, covers the posterior surface of the organ, and with secondary involvement of the layer of deep fascia covering and enveloping the pectoral muscle. In advanced cases the pectoral muscle also becomes involved together with the periosteum of the ribs and costal cartilages, and sometimes the intercostal muscles and finally the parietal pleura. When the latter structures are involved the tumor is absolutely fixed. When only the pectoral fascia and muscles are involved a small degree of lateral mobility may be demonstrated; if we now put the muscles and fascia on the stretch by abducting the arm, the tumor cannot be moved, even to the slightest extent, in the direction of their fibers. The pectoral muscles may, of course, contain metastatic nodules in the presence of a freely movable cancerous mass in the breast. Fixation of the tumor to the structures underlying the breast has already taken place in a large number of patients when they first seek advice, notwithstanding the fact that this is a late symptom. Marked fixation was noted in 43 of a series of 200 of our cases, while in I4I of these cases, the tumor was adherent to the skin although ulceration had taken place in only 3 I (I5.4 per cent.) instances.

Ulceration.-Ulceration usually occurs about one year from the time of the appearance of the lump. $\dot{\text { It }}$ not infrequently occurs much later in the scirrhus type. In medullary and adeno-carcinomatous tumors, and especially in those primarily situated near the skin surface, ulceration takes place early in the course of the disease. Gelatinous cancer of the breast is less likely to undergo early ulceration. Ulceration almost invariably begins in the area of skin directly overlying the growth. The skin becomes puckered, atrophied and bluish purple in color; the veins are dilated. Frequently there is a brawny induration of the skin at the periphery of the involved area. A fissure eventually appears in the skin and progressively increases in extent until finally a crateriform cavity is formed which in certain instances is very extensive. The edges of the cavity are indurated and undermined and entirely lacking in that clean-cut appearance which is so characteristic of gumma. The base of a cancerous ulceration presents a sloughing mass which is greenish or brownish in color and gives off a malodorous sanious discharge. White plugs of necrotic material can be expressed from the mass by gentle pressure, especially in cases with the adeno-carcinomatous type of tumor (comedo-carcinoma of Bloodgood). Complicating infection takes place promptly and the destruction of the breast tissue continues until, in certain instances, the pectoral muscles and even the ribs are exposed. Blood-vessels are eroded, but the resulting hemorrhage is not alarming unless the axillary artery or its larger branches are involved. In a small number of cases metastatic nodules in the skin of the pectoral region, the back, or axilla ulcerate.

Benign tumors rarely ulcerate. The few cases in which ulceration is seen depend upon the pressure of an enormous growth, or result from complicating infection.

The encapsulation of the tumor, the absence of infiltration of the skin and surrounding tissues together with the lobulated condition of the mass and absence of metastases usually serve to differentiate a benign tumor which has undergone ulceration from a malignant one.

Ulcerated sarcomas of the peri-ductal type appear as rapidly growing distinctly encapsulated fungoid masses, lobulated and of soft consistence. They are not likely to be mistaken for carcinoma, while their rapid development serves to differentiate them from benign tumors, although the latter may, in certain instances, grow with great rapidity. 
Retraction of the nipple is another sign of carcinoma which is directly dependent upon the physical state of the tumor. It is a late symptom of mammary carcinoma from the prognostic standpoint, notwithstanding which it was noted ro7 times among 200 of our cases. Retraction of the nipple is by no means characteristic of carcinoma of the breast. It is caused by any neoplastic or inflammatory disease of this organ which tends to cause shortening of the milk ducts and peri-ductal connective tissue. This explains why the nipples are more often retracted in cases of scirrhus carcinoma, abnormal involution and the infectious granulomas than in other diseases of the breast. Carcinoma is the most frequent cause of inversion of the nipple because this is the most frequently occurring disease which causes inversion of this structure; the symptom is relatively more frequent, however, in tuberculosis ( 72 per cent.) than in carcinoma. It must be differentiated from congenital inversion which is not uncommonly met with and is usually bilateral. Sarcoma of the peri-ductal type sometimes causes retraction of the nipple though the non-indigenous sarcomas are frequently associated with this symptom. According to our own figures 5 per cent. of benign growths in the breast cause the nipple to retract because of inflammatory complications. Tumors centrally located are more

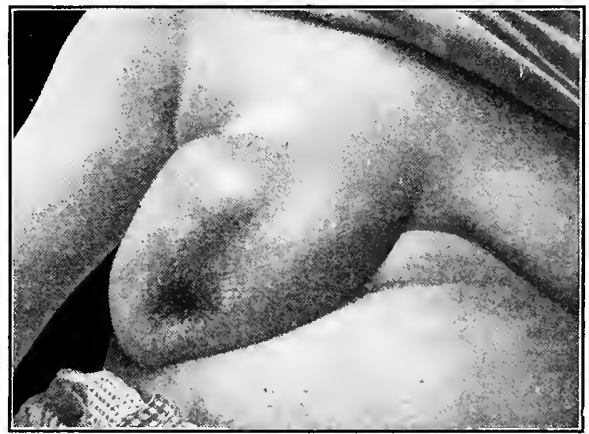

FIG. I99.-Large carcinomatous tumor of the breast with total inversion of the nipple.

likely to cause retraction than those that occupy the periphery of the breast. Tumors in the latter situation not infrequently draw the nipple to one side and at the same time cause a certain degree of inversion. As a diagnostic symptom inversion of the nipple is of the greatest value in very obese subjects with centrally located and deeply placed tumors and in which other signs of carcinoma are wanting. This may be the first symptom noted by the patient with a well-advanced cancer of the breast.

Discharge from the nipple occurs in from 3 to 5 per cent. of the cases of carcinoma of the breast. It is usually due to cancerous involvement of the milk ducts, but according to some authorities, may be caused by inflammaory changes of a catarrhal nature in the milk ducts in association with the malignant process in the breast tissue proper. Bloody discharges from the nipple are due in the great majority of instances to primary papillary epitheliomas of the milk ducts or to benign intracystic papilloma. Cancer of the milk ducts often arises secondarily either as a result of malignant invasion from a contiguous focus in the glandular tissue proper, or from malignant transformation of a simple intracystic papilloma. In rare instances a dilated milk duct in an area of abnormal involution, which may or may 
not have undergone malignant change, is the source of a bloody or serous discharge from the nipple. The discharge may consist of bright red blood, it may be brown in color when the blood has become degenerated, not infrequently it is muco-purulent or sero-purulent and in the presence of an active infection it becomes frankly purulent. The discharge may be continuous or intermittent. More often it appears only on pressure. Bloody discharges from the nipple should excite the suspicion of malignancy in every case notwithstanding the absence of other signs of the disease. The discharge should be examined microscopically for detached tumor cells, for by this means the diagnosis may sometimes be confirmed in otherwise obscure cases, as illustrated in a case recently reported by Nathan.

Condition of the Associated Lymph Nodes (see also metastasis and prognosis).-The diagnostic value of palpably enlarged lymph nodes has been much overrated. Palpably enlarged axillary nodes in association with a carcinomatous tumor of the breast may have been caused by an antecedent infection of the arm or breast. The nodes of ten become enlarged in diseases of the breast other than cancer. This occurs not only in mastitis of all varieties but also in certain cases of abnormal involution and benign tumors. When these nodes are enlarged as a result of metastatic mammary cancer, the disease is in a far advanced state, and if we hope to cure our cases we should operate on them long before the cancer cells have been transported to the regional lymph nodes. And finally metastasis to the axillary and even to the supra-clavicular glands may occur without causing palpable enlargement. It becomes evident, therefore, how valueless this symptom is from a practical diagnostic standpoint. In $\mathbf{I} 3$ out of 74 of our cases of mammary carcinoma with palpably enlarged axillary lymph nodes, the enlargement proved to be non-cancerous, but to have depended upon endothelial hyperplasia. Palpably enlarged glands were noted in 9 out of Ioo clinically benign cases; these also proved to be non-cancerous and to depend upon the same cause when examined microscopically. In no case in our series were thc lymph nodes of the opposite axilla palpably enlarged. Enlargement of the supra-clavicular group of lymph nodes occurs late in the disease, as a rule. In tumors occupying the upper inner quadrant of the breast these nodes may become involved while the axillary nodes escape. Such enlargement is, however, of very little practical diagnostic value.

General Symptomatology.-Carcinoma is primarily a local disease. It does not give rise, as a general rule, to systemic symptoms until far advanced. This is especially true of mammary and other forms of superficial cancer. Patients in the early stages of mam. mary cancer not infrequently show a decided gain in weight incidental to the metabolic changes of the menopause. As the disease progresses, however, it causes impairment of the general health, and symptoms arising from metastatic foci are added to the general and local symptoms caused by degenerative changes in the primary"growth. The patient gradually loses in health and strength. Absorption of the necrotic products of the tumor and of toxins produced by bacterial infection of the growth in cases where ulceration has occurred, the loss of blood in cases with advanced ulceration, together with the actual suffering, which is rarely absent, and often intense, late in the disease, soon saps the vitality of the unfortunate individuals. To this general symptomatology, must be added symptoms arising from metastatic involvement of the various organs and tissues. In a few cases (from 3 to Io per cent.) compression of the axillary vein, together with obliteration of the axillary lymphatic trunks, results in edema of the arm. The member becomes useless, extremely burdensome if not actually painful and at all times adds greatly to the discomfort of the patient. Metastases to the skeletal system, the abdominal and pelvic organs and the central nervous system give rise to symptoms refer- 
able to the area involved. The practical importance of these latter symptoms is chiefly concerned with determining the operability of the individual case, for the clinical diagnosis is usually possible long before this widespread involvement has occurred.

Differential Diagnosis.- Carcinoma of the breast must be differentiated from abnormal involution, benign fibro-epithelial tumors, sarcoma, tuberculosis, syphilis, and in certain instances, from chronic pyogenic mastitis and actinomycosis.

Sarcoma.-The peri-ductal variety of sarcoma is a rapidly growing tumor, encapsulated, multilobular, of soft consistence, and frequently cystic in places. The skin is not attached to the tumor except in instances of incipient ulceration, so that the tumor is freely movable. These features alone will serve to differentiate the condition from carcinoma. Dilatation of the veins overlying the growth and the absence of palpably enlarged axillary lymph nodes are characteristic features of sarcoma and usually wanting in carcinoma. Sarcoma arising from the connective-tissue stroma of the breast (nonindigenous variety of Warren) is difficult or impossible to differentiate from carcinoma in its earliest stages. The sarcomatous tumor is very rapid in its development and usually occurs in young women, and this together with the absence of lymphatic involvement will suggest its true nature.

Abnormal Involution.-It may be impossible to differentiate a small area of abnormal involution from a beginning carcinoma. It may likewise be impossible to determine the early stages of malignant change associated with abnormal involution. The diffuse nature of well-advanced cases of abnormal involution, its frequent bilateral occurrence, the presence of cysts, the absence of dimpling of the skin and attachment to the pectoral fascia together with its greater sensitiveness on pressure are clinical signs that serve to differentiate the disease from carcinoma. Pain, which is usually present in abnormal involution and often absent in carcinoma, is an important differential point between these conditions.

Fibro-epithelial Tumors.-Fibro-epithelial tumors, as a rule, occur in younger subjects than do carcinomas. In the absence of infection the tumors are freely movable and without attachment to the skin or pectoral fascia. They are well defined, encapsulated, rounded, and lobulated. Benign tumors usually have an even, firm consistence and are not sensitive to pressure. The presence of cysts in the cystic fibro-adenomas may, however, modify the physical findings. The foregoing features together with the usual absence of retraction of the nipple, axillary lymph-node enlargement and other late signs of carcinoma will serve to differentiate the two conditions. The peri-ductal myxomas closely resemble sarcoma of the peri-ductal type. The more rapid development of the latter is the most important point of differentiation between the two tumors, although the growth of the benign variety may become so much accelerated during pregnancy that malignancy cannot be excluded except at the time of operation. Neither is likely to be mistaken for carcinoma. Intra-cystic papilloma so frequently undergoes malignant change that even in cases where the signs of malignancy are entirely wanting, operation should be done immediately and the tumor subjected to microscopic examination. These growths are centrally placed, as a rule, often bilateral, and in the majority of instances are associated with a discharge from the nipple which is bloody in one-half the cases. The cystic nature of the tumor is demonstrable in the majority of instances; in doubtful cases aspiration may settle the question but we rarely employ this diagnostic practice in diseases of the breast. It is our invariable practice to operate on these cases at once; only by this means is it possible to avoid mistakes in the diagnosis and treatment of breast tumors in their early stages. 
Tuberculosis.- Tuberculosis of the breast runs a much more rapid course than carcinoma. The average duration of the disease in our series, from its time of onset to the time of operation, was less than one year, while the average duration of the disease in our carcinoma cases was 30 months. The rapid change in the size and consistence of tuberculous masses in the breast, early fistula formation, early involvement of the lymphatics together with localized tenderness and pain serve to distinguish the condition from carcinoma. Tubercle bacilli may be discovered in the discharges from fistulas and the diagnosis thus confirmed. Extensive ulceration sometimes results from the coalescence of several fistulas; the process lacks the indurated and undermined edges of a cancerous ulceration. The acute disseminated nodular variety of tuberculous mastitis that sometimes occurs during lactation at times closely resembles acute carcinoma, but in tuberculosis the nodules are scattered throughout the breast. Coalescence and softening of several of the tuberculous nodules followed by fistula formation is an early point of differentiation from carcinoma. The incipient stages of the two conditions are indistinguishable. Sclerosing tuberculous mastitis is characterized by the development of a mass which in the absence of abscess formation is difficult to differentiate from carcinoma. The pre-operative diagnosis in cases of this nature included in our collected series of cases was invariably carcinoma. In cases in which the sclerosis is progressive and in which degenerative changes are absent, the breast becomes small, hard and deformed. The clinical picture is typical of scirrhus carcinoma. Demonstration of the tubercle bacilli in stained tissue sections may be the only means of differentiating this condition from sclerosis caused by chronic forms of pyogenic infection. Tuberculosis of the breast is usually a secondary manifestation of the disease. The demonstration of an active primary focus of the disease will aid in the diagnosis. Finally, the occasional association of tuberculosis and carcinoma of the breast must not be forgotten although the diagnosis of the dual nature of such a process has never, so far as we know, been made before operation.

Syphilis,-Chancres, tubercular syphilides and gummas resemble carcinoma. The Wassermann reaction is of prime importance in eliminating the probability (not the possibility) of lues. Syphilis and carcinoma of the breast may coexist. For all practical purposes, however, entire dependence should be placed on a negative blood test in cases clinically suggestive of mammary syphilis, with the exception of chancre-like lesions. The patient must not have taken anti-syphilitic treatment for a period of time before the test is made. Lesions of the breast suggestive of chancre should be examined for Treponema pallidum. If this test, as well as the Wassermann reaction, is negative and doubt still exists as to the true nature of the condition, it is permissible to await the development of secondary manifestations of syphilis before resorting to operation. Tubercular syphilides, which rarely localize themselves upon the breast, are not likely to be mistaken for epithelioma. In doubtful cases, the presence of lesions elsewhere, the history of the case, the blood findings, together with the effect of antileutic treatment, will serve to differentiate the two conditions.

In Paterson's case, about to be described, the diagnosis of sarcoma was made and a radical amputation of the breast done, but this was unjustified since the subsequent course of the disease was that of syphilis.

Female, aged 26, was admitted to the hospital for a swelling of the right breast in November, I9or. The swelling had been noticed for three months but had given rise to little or no pain. The patient was thin and anemic, looked very ill and had apparently lost a great deal of weight.

The upper outer quadrant of the breast was hard and irregular, not adherent to the skin or deep fascia, 
and was not associated with axillary adenopathy. A complete Halsted operation was done after exploratory incision into the mass. Two weeks after operation, the suture holes ulcerated and small red nodules appeared in the surrounding skin. Gradually the skin bordering on the line of incision became brawny and infiltrated, and the scar itself became ulcerated. The ulcerated area slowly spread and the axillary and supra-clavicular glands became enlarged. Fourteen weeks after operation a smooth, hard swelling developed on the sixth rib in the axillary line. Mercury and potassium iodide were administered and the mischief quickly cleared up. Three years after operation she was in excellent health. Further investigation of the breast demonstrated the inflammatory nature of the swelling and corroborated the opinion as to the gummatous nature of the tumor.

Syphilitic mastitis sometimes closely resembles carcinoma. This is especially true of the discrete gummatous variety before breaking down has occurred, and in cases where sclerosis is a prominent pathologic feature of the disease. Indeed, differentiation from scirrhus is impossible in the absence of the therapeutic test. The latter should be tried only in cases presenting positive blood findings for syphilis. We cannot agree with Meyer that it is advisable to administer mercury and the iodides in all cases of tumor of the breast in which the diagnosis is doubtful, before resorting to operation. We would limit the use of anti-syphilitic remedies to doubtful cases which give a positive blood test. Nor is it justifiable to persist in the use of anti-leutic treatment; if partial resolution of the tumor does not take place after the injection (intra-venous) of neosalvarsan or after two weeks administration of mercury and potassium iodide, operation should be done. Broken-down gummas of the breast resemble tuberculosis and actinomycosis; they will rarely be mistaken for carcinoma. The cavity resulting from gummatous ulceration is sharply defined from the surrounding tissues and the infiltration characteristic of carcinoma is entirely wanting. The syphilitic ulcer has clean-cut edges and is deeply excavated. Actinomycosis of the breast is so rare that its true nature will not be suspected until ulceration or fistula formation has taken place, when the characteristic discharge containing "sulphur granules" will suggest the nature of the disease which can be easily confirmed, as a rule, by microscopic search for the ray-fungus.

Chronic Pyogenic Mastitis.-Circumscribed areas of chronic mastitis, the remainl of an antecedent acute pyogenic infection or the result of such an infection as has been essentially chronic from its onset, sometimes mimic carcinoma in many of its clinicas features. If areas of softening and tenderness are wanting, as is not infrequently the case where sclerosis is the predominating feature of this variety of mastitis, and in cases where the nipple is retracted, the skin adherent, and the axillary nodes enlarged, differentiation from scirrhus by clinical methods alone is entirely out of the question. It is usually possible, however, to elicit the history of a more or less acute stage of the disease which will give a clue to the diagnosis.

Cysts.-We have already discussed the differential points between the cystadenomas, and cysts associated with areas of abnormal involution and carcinoma.

There remain for consideration, the single-retention cysts, and galactoceles or milk cysts, which result from dilatation of the milk ducts and are, therefore, found in the vicinity of the areola. The retention cyst, like most other cysts of the breast, imparts an elastic feel on palpation. It is rounded, smooth, and freely movable, being unattached to the skin or pectoral fascia in uncomplicated cases. It is slightly if at all tender. The absence of infiltrating tendencies, retraction of the nipple or adhesion to the skin or pectoral fascia are points which serve to distinguish it from carcinoma. Excision should be advised lest undemonstrable malignant change may have occurred in its walls. Galactoceles appear as a rule during or soon after lactation. The description given above for the single-retention cyst applies to this variety, with the exception that galactoceles 
often impart a doughy feeling on palpation and in certain instances, especially in cases where the mass is superficial in position, pitting on pressure is said to occur.

The Sero-diagnosis of Carcinoma.-The sero-diagnosis of carcinoma is in the formative stage. No method has been discovered as yet that gives uniform results, nor does the experience up to this time in the use of the various methods seem to indicate that the value of any one method greatly surpasses that of the other methods that have been employed. On the other hand, our scientific knowledge of the biochemistry of the blood in tumor diseases has materially increased as a result of these investigations, and it is by no means unlikely that technical refinements of one or other of the methods already proposed, will furnish us with a test for carcinoma as simple and practical as is the Wassermann reaction in the diagnosis of syphilis.

"An ideal serological diagnostic method for carcinoma," says Wolfsohn, "would be a method which is absolutely specific both clinically and biologically. One that would indicate the presence of malignancy in its earliest stages and would react with a carcinomatous antigen which would be easily obtainable and stable." Abderhalden's test, the demonstration of anti-ferments in carcinomatous patients, seems to come closest to this ideal in the author's opinion. He further states that all hemolytic tests, complement fixation methods, allergic reaction, and antitrypsin tests lack specificity, and that other methods, including agglutination, precipitation and coagulation, while probably specific in a biological sense are impracticable on account of technical difficulties. In so far as we are able to judge from the recent publications of serologists, there are four serodiagnostic methods which give promise of practical usefulness in the future. These are the meiostagmin reaction of Ascoli and Izar, the skin reaction (a hemolytic test), $v$. Dungern's tumor reaction, and the dialyzation process proposed by Abderhalden.

The meiostagmin reaction is based on the law of surface tension. It is a reaction between an antigen obtained from the tumor by alcohol-ether extraction, and an immune serum furnished by the blood of the patient. The normal surface tension is determined by counting the number of drops contained in a measured quantity of this mixture of antigen and serum. The mixture is then incubated for one hour at $50^{\circ} \mathrm{C}$, or at $37^{\circ} \mathrm{C}$. for two hours, when the surface tension is again estimated. It is said that in the presence of cancer, certain physico-chemical changes take place during the incubation which reduces the surface tension as indicated by an increase of from 3 to 8 drops. This same reaction is obtained with any type of antigen. Ascoli and Izar applied the test in a series of 203 cases with positive results in 93 per cent. of 100 malignant cases, including seven mammary carcinomas, and negative results in 102 of IO3 non-malignant cases. In conclusion they say: "We wish to state emphatically that we are not in a position to state whether the meiostagmin positive reaction in malignant growths presents an actual immunity reaction, or whether we are dealing with antigen and antibody in the accepted sense of these terms."

v. Dungern's test is, in principle, a complement fixation reaction but, according to the author, the nature of the reaction is dependent upon abnormal products of metabolism and not upon antibodies. The original investigations were made upon a series of 244 patients. In 102 of these, the sera were taken from proven cases of carcinoma, and while all of the other cases were clinically carcinoma this fact was not substantiated by microscopic examination. The series included 22 cases of mammary carcinoma, all of which gave positive results. v. Dungern claimed a high degree of specificity for the test, a claim which is disputed by Halpern, who remarks that "the results prove that while v. Dungern's test is not an infallible indication of malignancy, it is without doubt a valu- 
able aid to the clinical symptoms in the diagnosis of malignant growths." This opinion is based on an experience of 300 examinations. Positive results were obtained in 89 per cent. of the carcinoma cases in Halpern's series while the sera of the 56 non-tumorbearing individuals gave 92.8 per cent. of negative reactions. Eleven of $I_{3}$ cases of mammary carcinoma gave positive tests.

Abderhalden, in his "Handbuch der biochemischen Arbeitsmethoden," Vol. 6, p. 228 (Berlin, I9I 2), first suggested the use of the dialyzation test, which he had elaborated for the sero-diagnosis of pregnancy, in the diagnosis of carcinoma. Since then a number of articles have appeared, notably those of Frank and Herman, Wolfsohn, andLudke. Frank and Herman obtained positive results with the test when using both carcinoma and placental extracts which fact led them to conclude that the differentiation of the two processes was impossible. Later Abderhalden modified the technic somewhat and claimed to have clearly differentiated 20 cases of carcinoma from pregnancy. Frank and Herman obtained identically the same results in the use of this later method as they had obtained previously with the use of the original technic. The material examined consisted of nine cases of carcinoma and ten cases of pregnancy. They therefore regard the specificity of the test as doubtful even with the modification suggested by Abderhalden. All told, these investigators obtained 98.2 per cent. of positive reactions for carcinoma- 53 out of 54 cases. Ludke also claims that the test is positive in certain non-cancerous individuals and that it is therfore not a specific reaction. Wolfsohn offers the following as the theoretical and practical conclusions of his experience with the Abderhalden test:

"(a) The more slowly a tumor develops the more benign the growth, probably the greater the tendency to the production of anti-ferments.

" $(b)$ It is possible that, as in pregnancy, specific anti-ferment formation takes place very early in tumor development.

" $(c)$ The more independent the development of the carcinoma cells (rapid growth, metastasis, etc.), the less will be the probability of the presence of an anti-ferment.

"(d) Vigorous individuals will probably react more powerfully.

"The formation of anti-ferments may be wanting in progressive cachexia. The reaction is highly specific inasmuch as it only indicates anti-ferment derivatives of carcinomatous albuminoid substance.

"Should future investigations confirm to a great extent the above observations, the test would be of immeasurable importance in the realm of diagnosis-a procedure for accurately diagnosing cancer in its earliest stages."

There are good reasons for believing that this test will prove to be of great value not only in the diagnosis of carcinoma, but also in the prognosis of the disease. At the present time, however, there seems to be some question of its specificity especially in relationship with pregnancy.

The antitrypsin reaction of Brieger and Triebig is looked upon by Pinkuss as an important clinical aid in the diagnosis of cancer. This author, who obtained positive reactions in 95 per cent. of cases, considers the test of prognostic value and as an aid indetermining the final cure after operation. The technic used in the test is given in detail in Pinkuss' article.

The hemolytic reaction proposed by Kelling seems to have met with little favor, and according to the latest reports, has been practically abandoned. Williams, horvever, states that this test may serve for the accurate diagnosis of malignant abdominal tumors in their initial stages. He also believes that the test will serve to prevent unnecessary operations in hopeless cases of intra-abdominal cancer when the condition cannot be 
differentiated clinically from necrotic cysts or other non-malignant conditions. Williams goes so far as to state the belief that, with a perfected technic, this test will be of the highest practical value and will be used as a routine laboratory method. As stated above, Williams stands practically alone in his advocacy of the test. The various other proposed methods of sero-diagnosis in vitro, have not proved of real value nor do they give promise of greater applicability in the future.

A test differing somewhat from the Kelling reaction and at the same time dependent upon hemolytic processes, is the skin reaction. This test was originated by Elsberg, Neuhof and Geist, who first described it in Igro. In principle, it depends upon the destruction of human red blood cells injected subcutaneously-by hemolysins contained in the blood of the cancer patient. This test is, therefore, a reaction in vivo in contradistinction to the Kelling reaction which is a test in vitro, although in principle the reactions are probably exactly the same. The technic of the skin reaction is very simple. A suspension of washed red blood corpuscles taken from a healthy individual is introduced beneath the skin. In 89.9 per cent. of cancer patients a characteristic reaction occurs at the site of injection. This reaction did not occur in 94.3 per cent. of non-cancerous patients. All of the cases of mammary carcinoma, six in number, gave negative reactions. Positive reactions were not obtained in advanced cases with visceral metastases nor in miliary carcinoma. The original report is based on an experience with 684 injections in $43^{2}$ patients. The reaction is described as follows: "It makes its first appearance about five hours after the injection, reaches its height in about six to eight hours and may remain stationary for several hours, and disappears gradually, or very quickly. At its height the lesion produced is a somewhat irregular oval area with a welldefined margin measuring from $\mathrm{I}^{-2}$ to $3-5 \mathrm{~cm}$. The margin varies from a brownish red to a maroon, with rarely a bluish tinge. The lesion is distinctly raised from the surrounding skin surface. At times this elevation is so slight that careful examination in good daylight is necessary to recognize it. The raised area has a slightly boggy feeling, as if there were a subcutaneous exudation, and it is often somewhat tender."

The prognostic value of the test after operation is problematical although it has been found to diminish and gradually disappear after the radical operation, while in cases in which only partial operations were done the test remained positive.

In performing the test, it is advised that blood be taken from perfectly normal individuals, preferably children. Blood taken from tuberculous or syphilitic persons, or, in fact, from any diseased individual must not be used. Recent anesthetizations or operations are said to destroy the test. Elsberg and his co-workers call attention to the fact that Crile was one of the first to point out the hemolytic action of the sera of the hosts of malignant tumors in their earliest stages with gradual disappearance of this property as tl e disease advances. They also call attention to the fact that many diseased conditions are productive of hemolysins and that all attempts to diagnose carcinoma by examination for hemolytic properties of the blood serum have been futile. On the other hand, they express the belief, that while perhaps not specific in the true sense of the word, the skin reaction in carcinoma is sufficiently characteristic to be of diagnosticimportance. Risley, on the other hand, speaks of a lack of specificity and states that while the test is highly significant, "it requires further study or a more refined technic before it can be of value." One of the most exhaustive recent articles on the subject is that of Gorham and Lisser. In the work of these investigators, the problems of hemolysis in carcinoma were studied by employing both the skin reaction and the test-tube reaction (Kelling). Their tabulated results comprise I $23_{3}$ cases, I $_{5}$ of which were various types of carcinoma 
in which the diagnosis was verified by operation, autopsy or microscopic examinations; one unverified case of carcinoma; 3 of sarcoma and 103 of normal individuals suffering with various ailments. The figures show 60 per cent. positive reactions in carcinoma; 13 per cent. doubtful; and 27 per cent. negative. Of the ro3 cases in patients suffering with diseases other than cancer and of a minor nature, ro per cent. were positive, 2 per cent. doubtful, and 88 per cent. negative. Commenting on these results, the authors say: "Many problems in connection with this reaction bearing upon its aid in the diagnosis of malignant disease are now open for solution. Whether the test can be utilized as an index of cure after complete radical operations; and how soon the reaction disappears after operation provided it has been positive before. Whether a positive reaction can be obtained in early cases, and clinically doubtful cases, thus insuring early eradication.

"Whether the reappearance of a positive reaction two or three years post-operationem would indicate recurrence." In conclusion they say: "The test is certainly not specific for carcinoma. A positive reaction is of much greater significance than a negative one. If the reaction is positive, the patient very probably suffers from cancer; if, however, it be negative, cancer cannot be excluded."

In summing up the clinical value of the various diagnostic tests for carcinoma, Halpern says: "None of the reactions at our command today are of sufficient value that a corresponding result alone would justify surgical intervention or abstaining from the same if the clinical findings do not agree with the serological examinations or perhaps contradict the latter."

\section{BIBLIOGRAPHY}

ABderhatden.-Handb. d. Biochem. Arbeitsmethod., vi, 228, Berlin, I9 12.

Ascoli AND Izar.-München. med. Wchnschr., tgro, lvii, 62.

BRÜGGeMan.-Mitt. a. d. Grenzgeb. d. Med. u. Chir., I9I3, xxv, 879.

v. DUngern.-München. med. Wchnschr., I9I2, lix, 2854.

Ersberg.-J. Am. M. Ass., rgog, lii, 1036.

Ersberg Neuhof and Geist.-Am. J. M. Sc., igio, cxxxix, 264.

Frank and Herman.-Berl. klin. Wchnschr., I9I3, 1, 63 I.

FreOND AND KaAmNer.-Wien. klin. Wchnschr., I910, xxiï, 378, 1271.

FreUnd and Kaminer.-Ibid., I9I I, xxiv, I759.

Gorham AND Lisser.-Am. J. M. Sc., IgI 2, clxiv, I03.

Greenough and Sinmons.-Ann. Surg., IgII, liv, 517.

GREENOUGH AND Simmons.-Ibid., $1914,1 \mathrm{x}, 42$.

HALPER N.-München. med. Wchnschr., I9I3, Ix, 9I4.

HaLPERn.-Mitt. a. d. Grenzgeb. d. Med. u. Chir., I9r3, xxvii, 340.

Halsted.-Tr. Am. Surg. Ass., I907, xxv, 6r.

HORT.-BRIT. M. J., I909, ii, 966.

Lisser and Bloomrneld.-Bull. Johns Hopkins Hosp., I91 2, xxiii, 356.

LUdKe.-Gaz. d'Hôp., I9I3, Ixxxvi, I064.

Paterson.-Proc. Roy. Soc. Lond., Igog-Io, iii, Clin. Sect., 82.

Pinkuss.-Trav. II Confér. Internat. pour l'étude du cancer, I9Io, p. 665.

Podlsen.-Arch. f. klin. Chir., I891, xlii, 593.

Prinrrose.-Am. J. M. Sc., I9I3, clxv, I00.

QUর́no.—Bull. méd., I913, xxvii, I039.

Risley.-Boston M. \& S. J., I9II, CLXV, I 27.

SAXL.-Wien. med. Wchnschr., I913, lxiii, I730.

SCHWARzKOPF.-Beitr. z. klin. Chir., IgI 2, lxxx, 317.

VAN DEN BeRg.-J. Mich. State Mied. Soc., I9r4, xiii, 367 .

WeINBERg.-Trav. II Confér. Internat. pour l'étude du cancer, Igro, p. 37 I.

Williams.-Arch. f. Diag., I9I 2, v, 362 .

WiLson.-St. Paul. M. J., I 913 , xv, 274 -

Wolfsohn.-Arch. f. klin. Chir., I9r3, cif, 247. 
Prognosis.-It is impossible to gîve an accurate prognosis in any individual case of carcinoma of the breast after operation. We know, on the other hand that, with very few exceptions, patients afflicted with the disease die within a few years if not operated upon. A large number of factors contribute to the possibility, or impossibility, of operative cure of mammary carcinoma in any given case. It is our purpose in this chapter to consider, in detail, each one of these factors, hoping to give to each its proper value in so far as we are able to judge of this from our own personal experience as well as from that of other surgeons. The influence of many of these factors is determinable in a given case only with the lapse of months or years after operation, for, not infrequently, recurrence takes place promptly in cases apparently favorable at the time of operation, while in other seemingly unfavorable cases the results are surprisingly good. We can never be sure that every malignant cell has been removed, however early and well-localized the disease seemed to be at the time of operation, nor do the most complete operative procedures in such cases insure freedom from recurrence. Thus when the disease is localized to a small area of the breast, and the case is in other respects a suitable one for operation, we may be led to hold out the hope of surgical cure only to have the patient die of early metastatic involvement of the viscera. The metastatic foci in the majority of such instances have been present at the time of operation but escaped clinical demonstration. In other instances, the lymph nodes at the apex of the axilla or in the supra-clavicular triangle contain cancerous emboli in the absence of palpable enlargement. The presence of metastases in these structures decreases the chances of operative cure by at lest 60 per cent. If, under the above circumstances, there is a small and freely movable nodule in the breast, we would naturally be led to believe that complete eradication of the disease is possible, a mistake which often becomes evident only after the operation is undertaken, indeed, in many instances only with the lapse of months after operation. Therefore, the apparently favorable local condition of the disease must not lead us to undue optimism in advising the individual patient. We should confine ourselves in prognosing any given case of carcinoma of the breast to the average result obtained in that class of patients to which we believe, from the results of our physical examination, the one under consideration belongs. It has been demonstrated that 80 per cent. of patients in whom the disease is confined to the breast as proved by both macroscopic and microscopic examinations of the tissues adjacent to this organ, are permanently "cured" of their disease by the radical operation. Therefore, a patient presenting a small movable mass localized to the breast, can be assured that four out of five cases of a similar nature are cured by operation. When the axillary lymph nodes are palpably enlarged as the result of metastases, the chances of operative cure are at once diminished to one in five. It is our first duty to determine as accurately as is possible, the state of the disease from the standpoint of its complete operative removal. We must then weigh in the balance other factors which contribute to a correct prognosis, including, the age of the patient, the duration of the disease, the degree of the malignancy of the growth, the presence or absence of lactation, etc.

In this manner we are enabled to give in a general way the chances of cure in that particular class in which our patient is properly grouped. When the question of palliative operation arises, it is necessary to determine whether the patient will live longer and more comfortably after the operative, or non-operative, methods of treatment. We have expressed elsewhere our general dissatisfaction with operations of a palliative nature in the treatment of carcinoma of the breast. In certain instances the disease is excited to greater activity by an incomplete operation, and the life of the patient is considerably 
shortened. In other groups of cases, as will be showh later, the radical operation increases the span of life when complete removal of the malignant process is impossible. We shall attempt in the succeeding paragraphs to consider the many factors which enter into the prognosis of mammary carcinoma in such manner that we hope the reader will be able to apply them practically.

\section{Table I.-Prognosis of Carcinoma of the Breast}

(Based an Statistics Collected from the Records of the German Hospital of Philadelphia)

Number of operations $1898-$ IgI $_{3}$ (inclusive)............ 506

Operative deaths, per cent....................... 5

Number of letters sent......................... $4{ }_{45} 6$

Number of patients traced..................... 175

0.98 per cent.

Results-

Primary deaths.

(All of the primary deaths are included as the outcome of such cases is known to us.)

Living without recurrence but with some minor complication.......... 4

Living and well, three years or more....................... $5^{\mathrm{I}}$

Living and well, less than three years........................ 25

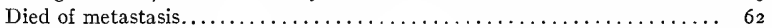

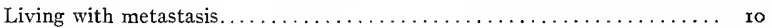

Deaths from intercurrent disease....................... r8

The 25 cases that are living and well less than three years from the date of operation must be subtracted from the total number leaving 150 cases upon which our figures are based.

(a) Living and well three or more years after operation, $5 \mathrm{x}$ cases, 34 per cent. or if estimated on 175 cases, 29.1 per cent.

(b) Living and well five years or more after operation, 39 cases, 26 per cent. or if estimated on 175 cases, 22.4 per cent.

NotE.--There is a difference of 8 per cent. in those living and well between the three-year limit and the five-year limit.

\section{Patients that Lived Three or More Years after the Operation}

\begin{tabular}{|c|c|c|}
\hline Class $(a)$ those that are now well. & & per cent. \\
\hline Class $(b)$ those dead of cancer..... & r8 & \\
\hline Class $(c)$ those living with metastases $\ldots \ldots \ldots \ldots \ldots$ & ro & \\
\hline Class $(d)$ those dead of intercurrent diseases............... & II & 7.3 per cent. \\
\hline Class (e) those living with minor, non-cancerous complications & 4 & 2.3 per cent. \\
\hline & 94 & \\
\hline
\end{tabular}

Total living after three years, 43.3 per cent. or those that lived three years or more without cancer, 44 per cent.

\section{Patients that Lived Five Years or More after Operation}
Class $(a)$ those that are now well.................. 39
Class $(b)$ those dead of cancer..................... 7
Class $(c)$ those living with metastases.............. 7
Class $(d)$ those dead of intercurrent disease............ ro
Class $(e)$ those living with minor, non-cancerous complications $\frac{3}{66}$
20. 0 per cent.
6.6 per cent.
2. 0 per cent.

Total that lived five years or more without cancer, 34.6 per cent.

Note.-There is a difference of 9.4 per cent. between the total number of those that lived three, and those that lived five years without cancer. This does not refer to patients who remained alive and well, but includes all cases that remained free of cancer thrce or five yeurs; some of them died of intercurrent disease. 
Post-operative period

LIVING AND WELI

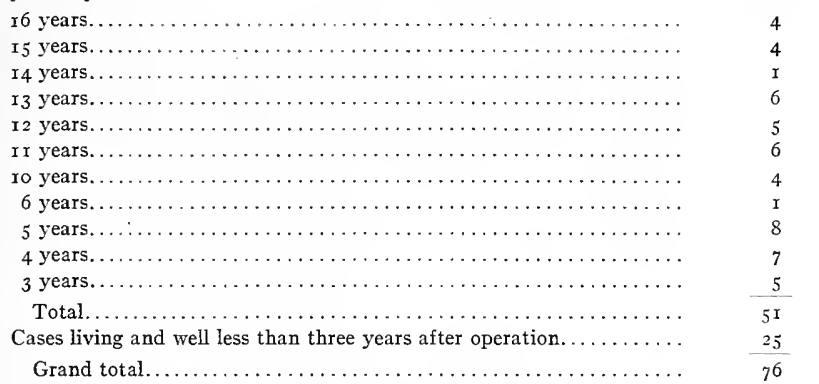

\section{Dead of Intercurrent Diseases}

Post-operative period

17 years.

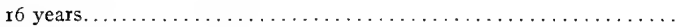

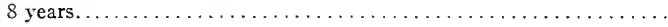

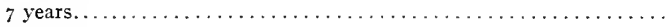

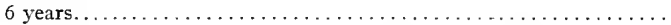

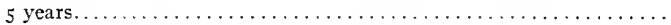

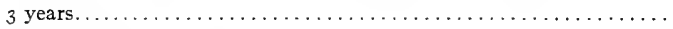

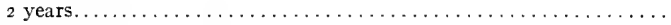

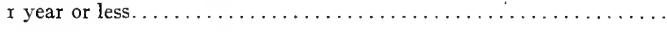

Total.

Living with Minor CoMplications

Post-operative period

No. of cases

\begin{tabular}{c} 
I \\
I \\
3 \\
I \\
3 \\
I \\
I \\
2 \\
4 \\
\hline I8
\end{tabular}

No. of cases

ro years.

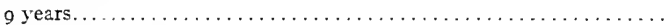

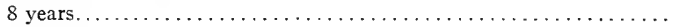

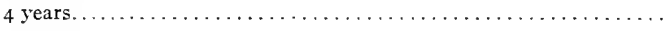

Total.

Post-operative period

Living with Metastases

8 years 7 months.

7 years $I$ month.

6 years 4 months

5 years 3 months

I

I

I

I

4

4 years 8 months.

3 years 4 months

2 years.

Total.

No. of cases

$\begin{array}{r}\text { I } \\ \text { I } \\ \text { I } \\ 4 \\ \text { I } \\ \text { I } \\ \text { I } \\ \hline \text { IO }\end{array}$

Note.-Some of these cases are remarkable, having been kept alive for years by X-ray therapy.

Post-operative period

Deaths from Recurrent Cancer

Less than one year.

No. of cases

One to two years.......

22

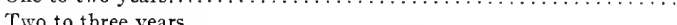

18

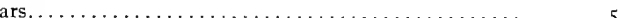

Three to five years. . . . . .

Over five years. 
Note.--None of the late recurrences in this series was over eight years.

We have observed that the majority of patients that died within one year from the date of operation had internal metastasis--and in the majority of cases the course of the disease indicated that the metastasis existed at the time of operation. These patients should not have been operated upon, but there does not seem to be any way of predetermining the presence of internal cancer in all cases.

The primary mortality following the radical operation for carcinoma of the breast at the present time, and in the hands of experienced operators, is approximately r per cent. A small minority of deaths that occur after operation are avoidable, but the great majority are entirely accidental and due to post-operative complications of which the most important are cerebral and pulmonary embolism, cardiac dilatation and pneumonia. In using the term avoidable we, of course, refer to a lack of conservatism in accepting cases for operation in which organic disease of the kidneys or other organs makes any operation hazardous. On the other hand, it is justifiable to take a greater surgical risk in dealing with a malignant process than with a chronic condition, such, for instance, as hernia. In view of the extensive operation performed at the present time, the advanced age and concomitant organic defects of many of the patients, a mortality rate of I per cent. is extremely low. In Billroth's first series of cases the primary mortality rate was 23.I per cent. and only 4.7 per cent. of his patients were alive and apparently well three or more years after the operation. The patients included in this series were operated upon in preantiseptic days, and the high mortality rate is, of course, attributable to infection. Incompleteness of the operation explains the small percentage of cures obtained. With the introduction of asepsis and antisepsis, there was an immediate and decided improvement, not only in the primary mortality rate, but also.in the number of cures reported. This is well shown in Tables II and III. It will be observed that Hildebrand reported a mortality rate of 7.2 per cent. for patients operated upon in the decade $1875^{-1885}$, a rate practically one-third of that obtained prior to his time. In the succeeding decade ( $\left.1885^{-1} 895\right)$ this rate was reduced approximately 50 per cent. In Halsted's first series, reported in $\mathrm{r} 894,76$ consecutive cases were subjected to the radical operation without a single death. The fact that a more extensive operation was performed in this series makes the result all the more remarkable for this early stage in the development of the modern technic of breast amputation. Rotter, who was an early exponent of the radical operation, had the low mortality rate of 3.5 per cent. Since I 890 the radical operation has come into more general use. The operation devised by Halsted has been performed most frequently by American surgeons, and the lowest mortality rates following its use have likewise been obtained in this country. An average mortality rate of $2.6 \mathrm{r}$ per cent. has been obtained by the foreign and American surgeons whose reports appeared after 1890 . These reports are included in Table II. This estimate is based on the results obtained in thousands of cases. It expresses the results as regards primary mortality after 25 years' experience with the radical operation in its various forms. At the present time there can be no doubt that the above figures would be too high if only the work of the most experienced operators was taken into consideration. As an index of the results obtained by the average surgeon throughout the world, we believe it is approximately correct. Rodman states that less than I per cent. of 2133 patients operated upon in the years I893-I903, by 21 American surgeons, died as a direct result of the operation. In 1904 Warren reported a series of roo consecutive cases without a death. In larger series the lowest death rate has been obtained by Judd (Mayo clinic) and by ourselves. Of 609 patients subjected to the radical operation, I902-1912, by Judd and his associates, 3 deaths occurred as a direct result of the operation, a mortality rate of 0.049 per cent. We had 2 deaths in a series of 370 consecutive cases 
(reported in the Jour. Am. Med. Assn., I9I3), giving a mortality rate of 0.054 per cent.; in our present series of 506 cases there were 5 primary deaths, a mortality rate of 0.98 per cent. Fatalities following the radical operation for carcinoma of the breast, as we have previously stated, are usually due to complications which may follow any major operative procedure. One of our patients died of post-operative pneumonia. The second fatality in our series was due to uremia; another was due to sepsis; while two died of endocarditis. A patient of Judd's died as the result of pulmonary embolism, another of

Table II.-Primary Mortality Rate

\begin{tabular}{|c|c|c|c|}
\hline Investigator, name and date & Number of cases & $\begin{array}{l}\text { Primary mor- } \\
\text { tality, per cent. }\end{array}$ & Cause of death \\
\hline v. WINIWARTER (Billioth) I $867-$ I $875 \ldots \ldots$ & .... & $23 . I$ & \\
\hline OLDEKOPF, $1850-1878 \ldots \ldots \ldots \ldots \ldots \ldots$ & $\ldots$ & I0. 2 & \\
\hline Tietze, $1878 \ldots \ldots \ldots \ldots \ldots \ldots \ldots$ & $\ldots$. & $23 . I$ & . \\
\hline 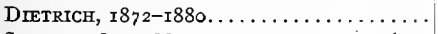 & $\ldots$ & 20.4 & \\
\hline ScHMm, $1871-188_{5} \ldots \ldots \ldots \ldots \ldots \ldots$ & $\ldots$ & 14.4 & \\
\hline HIIDEBRAND, I875-I885 $\ldots \ldots \ldots \ldots \ldots \ldots$ & $\ldots$. & $7 \cdot 2$ & \\
\hline Schмтd, G. B., I877-I886............. & $\cdots$ & $4 \cdot 4$ & \\
\hline RotTer, $1882-1887 \ldots \ldots \ldots \ldots \ldots \ldots$ & $\ldots$ & $3 \cdot 5$ & \\
\hline Poulsen, $1870-1888 \ldots \ldots \ldots \ldots \ldots \ldots$ & $\cdots$ & I. 7 & \\
\hline 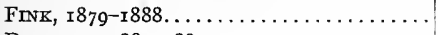 & $\cdots$ & 3.2 & \\
\hline DIETRICH, I880-I889................. & $\cdots$ & 7.6 & \\
\hline HORNER, I88I-1893 $\ldots \ldots \ldots \ldots \ldots \ldots \ldots \ldots$ & $\cdots$ & $4.2^{*}$ & \\
\hline & 76 & 0.0 & \\
\hline $\begin{array}{l}\text { MAHLER, } I 887-1897 \ldots \ldots \ldots \ldots \ldots \ldots \ldots \ldots \\
\text { GULEKE, I } 882-1899 \ldots \ldots \ldots \ldots \ldots \ldots \ldots \ldots\end{array}$ & $\cdots$ & $\begin{array}{l}\text { I. } 3 \\
3.1\end{array}$ & \\
\hline 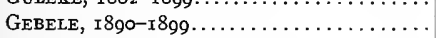 & $\cdots$ & 2.6 & \\
\hline 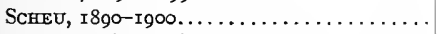 & $\ldots$ & 2.7 & \\
\hline SCHRÖDER (Ehrich), I875-I9OI........... & $\therefore$. & 4.6 & \\
\hline Sснмтдт, $1884-1902 \ldots \ldots \ldots \ldots \ldots \ldots$ & $\cdots$ & I.O & \\
\hline FINSTERER, I $877-1903 \ldots \ldots \ldots \ldots \ldots \ldots$ & $\cdots$ & 5.2 & \\
\hline TпEтZE, I897-I903 $\ldots \ldots \ldots \ldots \ldots \ldots \ldots$ & $\cdots$ & $\mathrm{I}, 2$ & \\
\hline SteINTHAL, I892-I904............... & $\ldots$ & $3 \cdot 5$ & \\
\hline ScHWARZ, I896-1904 $\ldots \ldots \ldots \ldots \ldots \ldots$ & $\ldots$ & 6.9 & \\
\hline 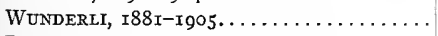 & $\ldots$ & 2.1 & \\
\hline 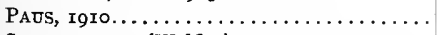 & $\cdots$ & I.० & \\
\hline SCHWARZKOPF (Wölfler), r895-r910.......... & $\cdots$ & 4.6 & \\
\hline SCHLOFFER (Innsbruch) 1904-I9I I Schwarz- & $\ldots$ & 3.8 & (All private patients.) \\
\hline SCHLOFFER (Zahlstock) I9O4-I9II / kopf & $\ldots$ & $5 \cdot 5$ & (All hospital cases.) \\
\hline 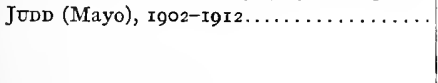 & 609 & 0.049 & $\begin{array}{l}\text { One pulmonary embolus. } \\
\text { One sepsis. } \\
\text { One diabetes. }\end{array}$ \\
\hline RodMAN, $1893-1903 \ldots \ldots \ldots \ldots \ldots \ldots$ & $\begin{array}{c}2133 \\
\text { (2I American } \\
\text { surgeons) }\end{array}$ & $\begin{array}{l}\text { Less than } \\
\text { I per cent. }\end{array}$ & \\
\hline HaLSTED, $_{\text {I }} 907 \ldots \ldots \ldots \ldots \ldots \ldots \ldots \ldots \ldots \ldots$ & $23 \dot{2}$ & 2.5 & \\
\hline WARREN, IgO4...................... & 100 & 0.0 & \\
\hline GreENotgh, SmMMONS and BaRNEY, I907 ... & 416 & 3.6 & \\
\hline DeAVER, I898-19I3 (inclusive)............. & 506 & 0.098 & $\begin{array}{l}\text { One of endocarditis. } \\
\text { One of endocarditis. } \\
\text { One of uræmia. } \\
\text { One of pneumonia. } \\
\text { One of sepsis. }\end{array}$ \\
\hline
\end{tabular}

*Note.-Since Horner's report, an average mortality rate of $2.6 \mathrm{I}$ per cent. has been reported. 
diabetes, coma coming on immediately after operation. We have been unable to find the report of a patient dying of shock either during or following operation. No patient appears to have died as a result of hemorrhage, although this complication occurs soon after operation in a very small number of cases as the result of the slipping of a ligature, and sometimes necessitates opening of the wound. Sepsis rarely occurs, although it is the most frequent local cause of death after the radical operation. A low-grade septic infection, however, proved fatal in a recent case of our own. It was necessary in this case to resect a large segment of the axillary vein because of extensive carcinomatous involvement of the summit of the axilla. The skin flaps became necrotic, and a low-grade sepsis set in, and despite free incision and drainage, proved fatal. A similar case is included in Judd's statistics. The high mortality rate recently reported by Schwarzkopf from the clinics of Wölfler and Schloffer well illustrates the influence of organic disease in raising the percentage of deaths following operation. The author excuses the disproportionately high death rate of 4.26 per cent. with the statement, "The material necessitated operations on rather aged and weak women." In Schwarzkopf's series of 321 patients, there were eight cases of pulmonary tuberculosis, three of organic heart disease, eleven were arterio-sclerotic, three were pregnant, eight of the patients had goiters, in one instance due to metastatic adeno-carcinoma, one patient was diabetic and another had recently been operated on for uterine polyp. Complications of this nature together with the advanced age of many of the patients satisfactorily explains Schwarzkopf's mortality rate which seems, at first sight, very high.

Percentage of Cures.-Even if a patient remain free of carcinoma for a period of three or more years after operation, we cannot be sure that recurrence will not still take place. The longer this period of freedom, however, the less likely is it that the disease will remanifest itself. It is unjustifiable to fix an arbitrary time limit and to pronounce that patient forever free of the danger of recurrence of the disease whose post-operative life has extended beyond this limit of time and in whom no evidence of carcinoma can be found. It is necessary, on the other hand, to know the shortest time after operation when the danger of recurrence is minimal. The fifth year after operation is generally accepted as the time when it is safe to give a positive opinion of the permanency of an apparent cure in carcinoma of the breast. Recurrences after this time, while exceptional, cannot be disregarded in prognosing the individual case. Volkmann's three-year limit has been found insufficient, for in a large number of patients, recurrence, usually metastatic in type, manifests itself between the third and fifth years after operation, and in our own series of cases there is a difference of 8 per cent. between the number of patients living after the three- and five-year limits. Local recurrences during this same period are exceptional. Barker has estimated that 30 per cent. of patients who are apparently well three years after operation for carcinoma of the breast die of carcinoma. This estimate is confirmed by Schwarzkopf, 29.4 per cent. of whose patients were alive and well, as far as could be determined by physical examination, three years after operation, while only 2I per cent. were alive and free of recurrence at the end of the fifth year after operation. The reader will note the remarkable similarity between these figures and our own (Table I). The patients who-died in the interval all showed unmistakable evidence of recurrent carcinoma. Smith (quoted by Finney) found only 17 per cent. of his patients free from carcinoma five years after operation in a series in which 43 per cent. had been apparently well at the end of the third post-operative year. This disproportion is decidedly less marked in Judd's experience. Bloodgood suggests that eight years be accepted as the limit of time of recurrence for practical purposes. His reasons for 
offering this suggestion are as follows: "In 2 r 3 complete operations, recurrences not in the region of the wound have occurred from three to eight years after operation; the average duration of life has been 6.9 years. These figures show that freedom from evidence of carcinoma after operation for eight years may be considered a permanent cure." Steinthal has studied the subject most carefully in a series of cases which he reported at intervals of three years on three successive occasions. In the milder cases, he claimed 78.5 per cent. of "cures" in $\mathrm{I}_{905}$; in Ig08, $7 \mathrm{r} .4$ per cent., and in $\mathrm{r} 9 \mathrm{rr}, 64.2$ per cent. For the more severe cases, the figures for the three reports are, in order, as follows: 29.4 per cent., 26.4 per cent. and 23.5 per cent. The foregoing statistics prove beyond a doubt that three years of freedom from recurrence after the radical operation for mammary carcinoma does not insure a permanent cure. Steinthal's figures, on the other hand, indicate that as many recurrences take place between the sixth and the ninth years after operation as between the third and sixth years, thus confirming Bloodgood's observations. The greatest danger of recurrence is undoubtedly during the first three years after operation. The probability of recurrence in a patient who has shown no evidence of the disease during the first three post-operative years, is in inverse ratio to the length of time that has elapsed beyond this limit. Steinthal's figures seem to contradict this statement, which expresses, however, the belief of the great majority of surgeons at the present time. In Table III we have given the comparative statistics of various operators relative to the percentages of operative cures obtained. These figures are based on the three-year limit of recurrence. It will be observed that the first marked increase in the percentage of operative cures was reported by Küster, who it will be remembered, was the first surgeon to practice the routine exploration and cleansing of the axillary space. It will also be noted that since the time of Halsted's introduction of the radical operation there has been a steady increase in the percentage number of operative cures obtained. His figures ( 38.3 per cent.) may be accepted at this time to express the chances of operative cure in the average operable case of carcinoma of the breast, when operated upon by an experienced surgeon. This, of course, does not take into account any one of the many factors that influence the prognosis of the individual case. It merely expresses the average result obtained in operable cases under ideal conditions of treatment. There can be no doubt but that the average percentage of cures obtained by surgeons throughout the world is much lower than that obtained by Halsted. In rgr 3 Deaver reported a series of 370 cases of mammary carcinoma of which the end results were known in 75 . Of these, $x 6(2 \mathrm{r} .3$ per cent.) were alive and well three or more years after operation, on an average of seven years after operation. In the present series there are 506 cases and of these the end results are known in $5_{50}$. All of the latter cases were operated upon three or more years ago. As is shown in Table I, 34 per cent. of these $r_{50}$ patients are living and well three or more years after operation, and 26 per cent. are living and well five or more years after operation. Since 1895 the results of the operative treatment of carcinoma of the breast, while encouraging when compared with those obtained in previous decades, fail to show that decided improvement which the high perfection of modern operative technic would seem to warrant. On the other hand, there has been a steady, though small, increase in the percentage of cures obtained during the past 20 years. These results are due we believe to the fact that patients come for operation at an earlier stage of their disease than formerly, but not early enough to insure any decided and sudden improvement in the results of operation. The operation itself, we believe, has about reached the limit of perfection. In prognosing the individual case of carcinoma of the breast, the following facts must be taken into consideration: 
(a) Age of the patient.

(b) Sex of the patient.

(c) The malignity of the tumor.

(d) The duration of the disease.

(e) The local condition of the disease. (f) The comparative probability of local, regional and metastatic recurrence.

(g) The method of treatment employed.

(h) Complications that increase the malignity of the tumor-lactation, etc.

Table IIT.-Comparative Operative Statistics. Number of Cases "Cured"

\begin{tabular}{|c|c|c|c|}
\hline Investigator, name and date & $\begin{array}{l}\text { Number } \\
\text { of cases }\end{array}$ & $\begin{array}{l}\text { Cured three-year } \\
\text { limit, per cent. }\end{array}$ & $\begin{array}{l}\text { Cured, five-year } \\
\text { limit, per cent. }\end{array}$ \\
\hline V. WINIWARTER (Billioth) I $867-$ I $875 \ldots \ldots \ldots \ldots \ldots \ldots$ & $\cdots \cdots$ & $4 \cdot 7$ & \\
\hline 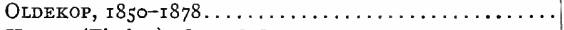 & $\ldots \ldots$ & II +7 & \\
\hline HENRY (Fischer) I 87 I $-\mathrm{r} 878 \ldots \ldots \ldots \ldots \ldots \ldots \ldots \ldots$ & $\ldots$. & 9.0 & \\
\hline SPRENGEI (Volkmann) $1874-1878 \ldots \ldots \ldots \ldots \ldots \ldots$ & $\cdots \cdots$ & II.O & . \\
\hline ScHMID, H. (Küster) I87 I-I $885 \ldots \ldots \ldots \ldots \ldots \ldots \ldots$ & $\cdots \cdots$ & $2 \mathrm{I} .5$ & \\
\hline HILDEBRAND (König), I875-1885 $\ldots \ldots \ldots \ldots \ldots \ldots$ & $\cdots \cdots$ & 22.5 & \\
\hline 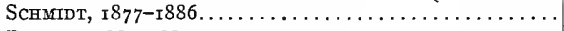 & $\cdots \cdots$ & 18.8 & \\
\hline 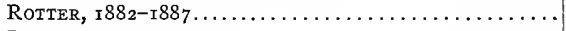 & $\cdots \cdots$ & I 2.0 & \\
\hline 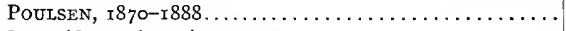 & $\ldots \ldots$ & 20.0 & \\
\hline 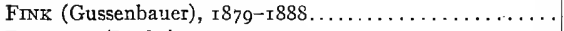 & $\cdots \cdots$ & 16.0 & \\
\hline DIETRICH (Lucke) r $880-$ r $889 \ldots \ldots \ldots \ldots \ldots \ldots \ldots$ & $\cdots$ & $\mathrm{I} 6.2$ & \\
\hline HORNER, I88I-I $893 \ldots \ldots \ldots \ldots \ldots \ldots \ldots \ldots \ldots \ldots \ldots \ldots$ & $\cdots \cdots$ & 19.4 & \\
\hline JoERss, $1885^{-1893} \ldots \ldots \ldots \ldots \ldots \ldots \ldots \ldots \ldots \ldots$ & $\cdots \cdots$ & 28.5 & \\
\hline 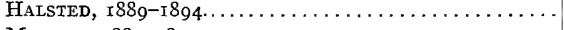 & 76 & 45.0 & \\
\hline 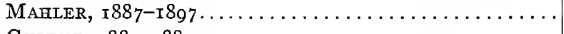 & $\cdots \cdots$ & 21.0 & \\
\hline 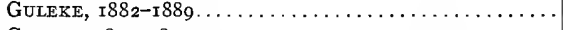 & $\cdots \cdots$ & 28.7 & \\
\hline 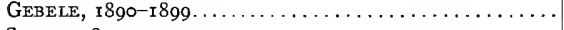 & $\cdots \cdots$ & 16.9 & \\
\hline SCHEU, I8go-rgoo $\ldots \ldots \ldots \ldots \ldots \ldots \ldots \ldots \ldots \ldots$ & $\cdots \cdots$ & 20.2 & \\
\hline Rosenstein, r8g6-igoo $\ldots \ldots \ldots \ldots \ldots \ldots \ldots \ldots \ldots \ldots$ & $\cdots \cdots$ & $22 \cdot 7$ & \\
\hline 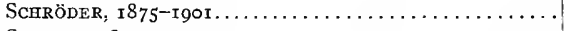 & $\cdots \cdots$ & $2 \mathrm{I} . \mathrm{I}$ & \\
\hline SteINER, I897-I90I $\ldots \ldots \ldots \ldots \ldots \ldots \ldots \ldots \ldots \ldots \ldots \ldots \ldots \ldots$ & $\cdots \cdots$ & I6.0 & \\
\hline SCHMIDT, $188_{4}-\mathrm{rg} 92 \ldots \ldots \ldots \ldots \ldots \ldots \ldots \ldots \ldots \ldots$ & $\ldots$. & 28.3 & \\
\hline 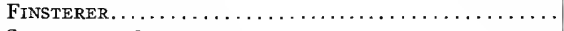 & $\ldots \ldots$ & 26.0 & $\cdot$ \\
\hline 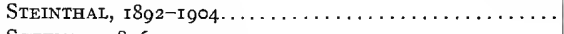 & $\ldots \ldots$ & $33 \cdot 3$ & \\
\hline 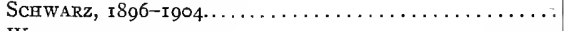 & $\cdots \cdots$ & I6.6 & \\
\hline 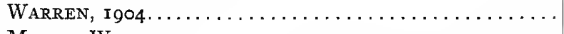 & I00 & $33 \cdot 3$ & \\
\hline 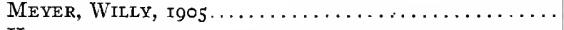 & ;0 & 35.8 & \\
\hline 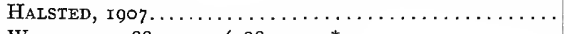 & 232 & 38.3 & \\
\hline WUNDERLI, I88I-I905 (I88I-I905* $\ldots \ldots \ldots \ldots \ldots \ldots \ldots$ & $\cdots \cdots$ & 20.0 & \\
\hline 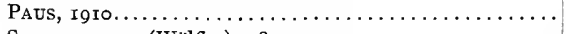 & $\cdots \cdots$ & $3 \mathrm{I} \cdot 4$ & \\
\hline 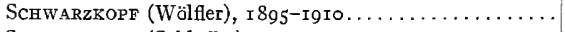 & $\cdots \cdots$ & 29.4 & $2 I .0$ \\
\hline SCHWARZKOPF (Schloffer), IgO4-I9II. $\ldots \ldots \ldots \ldots \ldots$ & $\cdots \cdots$ & $\begin{array}{l}27 \cdot 7 \\
\text { Hospital cases }\end{array}$ & \\
\hline SCHWARzKOPF (Schloffer), rgo4-I9II.......... & $\cdots \cdots$ & $\begin{array}{l}42.8 \\
\text { Private cases }\end{array}$ & \\
\hline JUDD AND Sistrunk (Mayo clinic), I902-I9I2*........ & $5^{\text {IO }}$ & $44 \cdot 7$ & 29.8 \\
\hline 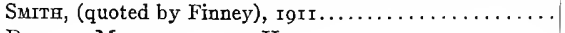 & & 43.0 & 17.0 \\
\hline Deaver, Mcfarland and Herdian $\ldots \ldots \ldots \ldots \ldots \ldots$ & $\begin{array}{c}(506) \\
\text { No. traced } \\
\text { I50 }\end{array}$ & 34.0 & 26.0 \\
\hline
\end{tabular}

* These figures are based on the cases which they were able to trace, and not on the total number of cases.

Age and Sex.-Carcinoma of the breast is said to be especially fatal in young subjects. The degree of malignancy of mammary carcinoma is said to be in inverse ratio to the age of the patient. In certain instances we find a very malignant neoplasm in the 
breast of an aged person, but this is exceptional, and while marked degrees of malignancy are manifest in tumors growing at all ages before the menopause, as a general rule, the most marked examples occur in women under 35 years of age. It is likewise exceptional to find a low grade of malignancy in a carcinoma of the breast occurring in a woman under 30 years of age. Judd and Sistrunk, however, have five patients under 30 years of age upon whom they have performed the radical operation for mammary carcinoma, and who were alive and apparently well from two to nine years later. In young patients the malignant nature of the disease is more likely to be mistaken, and the patient allowed to go untreated until the disease advances to the inoperable stage. Schwarzkopf reports ${ }_{5}$ cases in patients under thirty years of age all of which were rapidly fatal, notwithstanding comparatively early and radical treatment.

As the following tables show, our experience regarding the prognostic significance of age in cases of mammary carcinoma is, in some respects, unique. We have separated the cases of which we have complete records, into three groups: one group comprises all who were 60 years of age or over at the time of operation; another those under 35 years of age; while the third group comprises all of the remaining cases. The prognostic significance of age in the last group, that is, patients between the ages of 35 and 60 , is of relatively slight importance and we have therefore omitted these figures. Forty-one of the 175 cases, of which we have complete records, were women under 35 years of age or over 60 years of age. These patients are divided as follows: (a) Those living and well; (b) those who have died as the result of metastatic cancer; $(c)$ those alive but with evidence of metastatic cancer; $(d)$ nine cases that occurred in women who were operated upon after the age of 70 .

Group (a) Patients Living and Well.-The noteworthy feature of this group is that I I in whom the disease appeared before the age of 35 years are now living and well, and as the next table shows, only two patients who were operated upon before this age have died as the result of recurrent or metastatic cancer. These figures are at variance with

Table IV.-Patients Living and Well

Group (a), patients over 60 years

\begin{tabular}{|c|c|c|}
\hline Post-operative time interval & Age at time of operation & Operation \\
\hline I 2 years $\ldots \ldots \ldots \ldots \ldots$ & 7o & Simple \\
\hline I 2 years $\ldots \ldots \ldots \ldots \ldots$ & 64 & Radical \\
\hline In years $\ldots \ldots \ldots \ldots \ldots$ & 62 & Radical \\
\hline 3 years.$\ldots \ldots \ldots \ldots$ & 62 & Radical \\
\hline 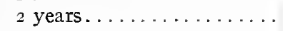 & $7 x$ & Radical \\
\hline 2 years $\ldots \ldots \ldots \ldots \ldots$ & 64 & Radical \\
\hline
\end{tabular}

Group (b), patients under 35 years

\begin{tabular}{|c|c|c|c|c|c|}
\hline $\begin{array}{l}\text { Post-operative } \\
\text { time interval }\end{array}$ & $\begin{array}{l}\text { Age at time of } \\
\text { operation }\end{array}$ & Operation & $\begin{array}{c}\text { Post-operative time } \\
\text { interval }\end{array}$ & $\begin{array}{l}\text { Age at time of } \\
\text { operation }\end{array}$ & Operation \\
\hline r6 years... . . . . & 22 & Radical & Ir years........ & 34 & Radical \\
\hline is years....... & 32 & Radical & 9 years....... & 34 & Radical \\
\hline I 4 years....... & 34 & Radical & 8 years......... & $3 r$ & Radical \\
\hline I3 years....... & 22 & Radical & 3 years....... & 30 & Radical \\
\hline I3 years....... & 26 & Radical & 5 years....... & $3 I$ & Radical \\
\hline I I years...... & 32 & Radical & & & \\
\hline
\end{tabular}


those given by Schwarzkopf and would seem to refute the generally accepted opinion that cancer of the breast is a very fatal disease in young women. The series is toosmall, however, to warrant any final conclusions being drawn, but we have not met with any large series of cases that occurred in young women and in which the disease was rapidly fatal.

One of the patients in this group, a woman aged 34 , had carcinoma of both breasts; radical amputation was done double II years ago and the patient has since been in excellent health. Another patient, a woman aged $3 \mathrm{I}$ years, was operated on eight years ago (Jan. 30, 1907) for carcinoma of the left breast; about one year later the right breast was removed for what was thought to be a metastatic carcinoma but which proved to be an adeno-fibroma. This patient writes us (Jan. 30, I9I5) that she has borne a child since the last operation and that she has perfect use of her arms.

\section{Table V.-Patients Dead of Metastasts}

\begin{tabular}{|c|c|c|}
\hline \multicolumn{3}{|c|}{ Group $(a)$, patients under 35 years } \\
\hline $\begin{array}{l}\text { Post-operative } \\
\text { time interval }\end{array}$ & $\begin{array}{l}\text { Age at time } \\
\text { of operation }\end{array}$ & Operation \\
\hline I4 months & 22 & Radical \\
\hline
\end{tabular}

This patient had a radical amputation of the right breast May 28, r905. Radical removal of the left breast and excision of recurrence on right side of chest Nov. 28, rgo5; died, July 22, rgo6. Recurrence on chest wall six months after last operation.

Group (b), patients over 60 years

\begin{tabular}{|c|c|c|c|c|c|}
\hline $\begin{array}{l}\text { Post-operative } \\
\text { time interval }\end{array}$ & $\begin{array}{c}\text { Age at time of } \\
\text { operation }\end{array}$ & Operation & $\begin{array}{l}\text { Post-operative time } \\
\text { interval }\end{array}$ & $\begin{array}{c}\text { Age at time of } \\
\text { operation }\end{array}$ & Operation \\
\hline 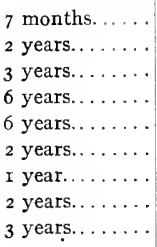 & $\begin{array}{l}69 \\
60 \\
62 \\
66 \\
6 r \\
70 \\
6 r \\
86 \\
65\end{array}$ & $\begin{array}{l}\text { Radical } \\
\text { Radical } \\
\text { Radical } \\
\text { Radical } \\
\text { Radical } \\
\text { Radical } \\
\text { Radical } \\
\text { Radical } \\
\text { Radical }\end{array}$ & 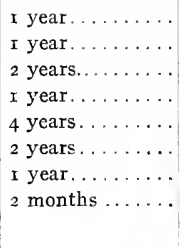 & $\begin{array}{l}67 \\
64 \\
68 \\
66 \\
72 \\
79 \\
62 \\
62 \\
\end{array}$ & $\begin{array}{l}\text { Radical } \\
\text { Radical } \\
\text { Radical } \\
\text { Radical } \\
\text { Radical } \\
\text { Radical } \\
\text { Radical } \\
\text { Radical }\end{array}$ \\
\hline
\end{tabular}

Table VI.-Patients Living but wrth Metastasis

Group (a), patients under 35 years of age

$\begin{array}{lcc}\begin{array}{l}\text { Post-operative } \\ \text { time interval }\end{array} & \begin{array}{c}\text { Age at the time } \\ \text { of operation }\end{array} & \text { Operation } \\ 5 \text { years } & 3^{\mathrm{r}} & \text { Radical } \\ 5 \text { years } & 27 & \text { Radical }\end{array}$

Both of these cases are remarkable in that they have lived so long after the cancer remanifested itself.

The first case, a woman aged $3 \mathrm{r}$, was first operated on in August, rgro; a small tumor was excised. In March, rgrr, the patient returned with the characteristic signs of carcinoma in the same breast. Radical amputation was then performed. Unfortunately, the microscopic diagnosis of the tumor removed at the first operation, cannot be found. After the second operation, the patient had no further trouble for a time, then the scar began to pain her and her suffering became so severe that in April, rgr2, she returned to the hospital and the scar was excised.

Cancer shortly appeared in both axillæ, in the opposite breast, both supra-clavicular regions, in the 
lungs and in the vertebræ. She was immediately placed under the care of Dr. Pfahler who has since treated her with the $X$-rays. The patient reports (June $r, r_{9} r_{5}$ ) that she has gained in weight, is feeling well and is able to do ber own housework.

The second case was a woman aged 27 years. The right breast was removed in September, I9ro. Recurrence took place in the axilla and in August, I913, the axilla was cleansed and the pectoral muscles were removed. (The radical operation should have been performed at the time of the first admission to the hospital.) This patient reports (June $\mathbf{r}, \mathrm{rgr}_{5}$ ) that the growth has recurred on the chest wall and that she is bedridden most of the time.

Group (b), patients over 60 years

$\begin{array}{ccc}\begin{array}{c}\text { Post-operative } \\ \text { time interval }\end{array} & \begin{array}{c}\text { Age at time } \\ \text { of operation }\end{array} & \text { Operation } \\ 6 \text { years } & 74 & \text { Radical }\end{array}$

(Recurrence in the opposite breast two years ago-increasing in size.)
2 years
66
Radical

Table VII.-Patients Dead of Intercurrent Disease

Group (a), under 35 years of age

There are no cases to be included in this group.

Group (b), over 60 years of age

\begin{tabular}{|c|c|c|}
\hline Time interval since operation & Age at time of operation & Operation \\
\hline Io years $\ldots \ldots \ldots \ldots \ldots$ & 72 & Radical \\
\hline 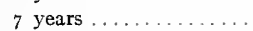 & 70 & Radical \\
\hline 3 years $\ldots \ldots \ldots \ldots$ & 74 & Radical \\
\hline 5 years $\ldots \ldots \ldots \ldots \ldots$ & 62 & Radical \\
\hline I year $\ldots \ldots \ldots \ldots \ldots$ & 60 & Radical \\
\hline r year $\ldots \ldots \ldots \ldots \ldots$ & $7 \mathrm{I}$ & Radical \\
\hline
\end{tabular}

The following table shows the results obtained in radical operations for mammary cancer in patients beyond the age of 70 years. The average age of the nine cases in the series was 73.3 years; the average duration of life after the operation was six years. Two of the patients are alive and well; three have died of intercurrent disease. No patient of this age died as a direct result of the operation.

Evidently old age is not a contra-indication to radical amputation of the breast, and the post-operative period of life is as great on the average in aged as in young persons.

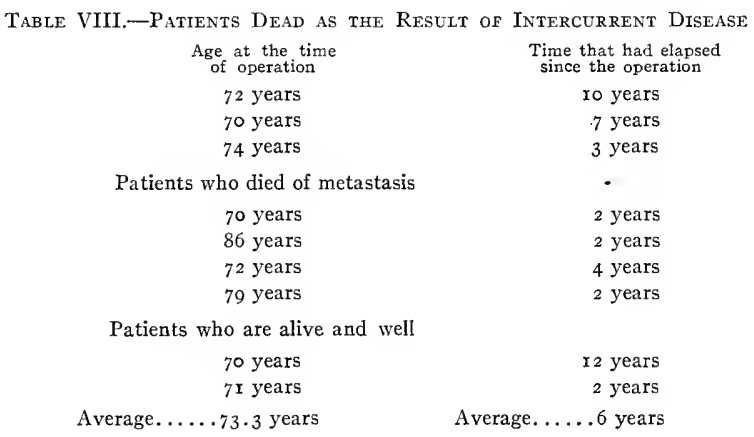


The age of the patient, therefore, is most important as a prognostic index in mammary carcinoma in youth and old age. In the intermediate decades, it is of slight significance. The percentage of deaths according to ages in the series reported by Judd is given in the following table:

Table IX.-Percentage of Deaths According to Ages

\begin{tabular}{|c|c|c|c|c|c|c|}
\hline & Ages & $\begin{array}{l}\text { Died within } \\
\text { one year, } \\
\text { per cent. }\end{array}$ & $\begin{array}{c}\text { Died within } \\
\text { three years, } \\
\text { per cent. }\end{array}$ & $\begin{array}{l}\text { Died within } \\
\text { five years, } \\
\text { per cent. }\end{array}$ & $\begin{array}{l}\text { Died after } \\
\text { five years, } \\
\text { per cent. }\end{array}$ & $\begin{array}{l}\text { Alive } 2 \text { to Io } \\
\text { years, } \\
\text { per cent. }\end{array}$ \\
\hline Total; pre-climacteric period. & $\begin{array}{l}20-30 \\
30-40 \\
\cdots \cdots\end{array}$ & $\begin{array}{r}0 \\
20 \\
19\end{array}$ & $\begin{array}{r}0 \\
46 \\
43\end{array}$ & $\begin{array}{r}\circ \\
55 \\
52\end{array}$ & $\begin{array}{l}0.0 \\
1.0 \\
1.0\end{array}$ & $\begin{array}{c}5 \text { patients } \\
43 \\
47\end{array}$ \\
\hline Total, climacteric period..... & $\begin{array}{l}40-50 \\
50-60 \\
\cdots \ldots\end{array}$ & $\begin{array}{l}20 \\
15 \\
19\end{array}$ & $\begin{array}{r}45 \\
45 \\
\cdot \quad 45\end{array}$ & $\begin{array}{l}50 \\
57 \\
53\end{array}$ & $\begin{array}{l}5.0 \\
1.8 \\
4.0\end{array}$ & $\begin{array}{l}43 \\
4 I \\
42\end{array}$ \\
\hline Total, post-climacteric period & $\begin{array}{l}60-70 \\
70-80 \\
80-90 \\
\ldots \ldots\end{array}$ & $\begin{array}{r}x 6 \\
7 \\
0 \\
13\end{array}$ & $\begin{array}{r}37 \\
50 \\
0 \\
39\end{array}$ & $\begin{array}{r}44 \\
50 \\
0 \\
45\end{array}$ & $\begin{array}{l}7.0 \\
7.0 \\
0.0 \\
7.0\end{array}$ & $\begin{array}{cc}43 \\
43 \\
\text { I patient } \\
\quad \quad 48\end{array}$ \\
\hline
\end{tabular}

Sex has very slight influence in the prognosis and mortality rate of carcinoma of the breast. The disease, however, is generally more advanced in men when subjected to operation than it is in women. In prognosing a case in the male the same factors must be taken into consideration that apply to carcinoma occurring in the female breast.

One of the most important prognostic factors in mammary carcinoma is the degree of malignancy of the tumor. Gelatinous carcinoma and Paget's disease are the least malignant types. The most malignant variety is the medullary, especially the so-called acute cases which occur during lactation, and which seem to be dependent for the marked malignancy on cellular activities incident to this function. Adeno-carcinoma is relatively less malignant than either carcinoma simplex or scirrhus carcinoma, while the latter is less malignant by far than the medullary form. The various varieties of mammary carcinoma are most favorable for operation in the following order: Gelatinous, Paget's disease, adeno-carcinoma, schirrus, carcinoma simplex, medullary, and finally carcinoma mastitoides, which is a type of medullary cancer. This is the order given with percentages, in the following list of roo cases reported by Warren.

\begin{tabular}{|c|c|c|}
\hline \multicolumn{3}{|c|}{ TABLE $\mathrm{X}$} \\
\hline & Number of cases & Cured, per cent. \\
\hline Colloid (gelatinous) ............ & 2 & 100 \\
\hline Pagets.................. & $\mathrm{I}$ & Ioo \\
\hline Adeno-carcinoma.$\ldots \ldots \ldots \ldots \ldots$ & 3 & 66 \\
\hline Scirrhus................. & 28 & 43 \\
\hline 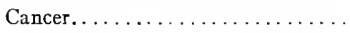 & 26 & 23 \\
\hline Medullary ................. & 40 & 7 \\
\hline Total $\ldots \ldots \ldots \ldots \ldots \ldots$ & 100 & \\
\hline
\end{tabular}

In the analysis of larger series of cases, the order of frequency for the least malignant type is reversed. Thus, Finney considers Paget's disease a more malignant variety than adeno-carcinoma. All writers agree that the gelatinous is the least malignant variety of the disease. Halsted adopts a somewhat different classification, and the gelatin- 
ous and Paget's types are not included in his list. It will be observed that 48 per cent. of the patients who had tumors of the medullary type are reported as cured of the disease. This experience is at variance with that of the great majority of surgeons.

TABLE XI.-HALSTED

\begin{tabular}{|c|c|c|c|}
\hline Type of the disease & Number of cases & Number of "cures" & Percentage number of "cures" \\
\hline Cancer cysts..... & 6 & 2 & $33 \cdot 3$ \\
\hline Adeno-carcinoma............ & 32 & 24 & 75.0 \\
\hline Medullary $\ldots \ldots \ldots \ldots \ldots \ldots \ldots \ldots$ & 25 & I 2 & 48.0 \\
\hline Circumscribed scirrhus............. & 28 & & \\
\hline Small infiltrating scirrhus............ & So & 3 & 35.0 \\
\hline Large infiltrating scirrhus $\ldots \ldots \ldots \ldots \ldots$ & 39 & 8 & 20.5 \\
\hline
\end{tabular}

In the large series reported by Schwarzkopf from Wölfler's clinic in Prague, 44.7 per cent. of the cases of scirrhus carcinoma, and I8.9 per cent. of those with the simplex variety were cured by radical amputation. All of the patients with the medullary type of the disease were dead as the result of recurrence or showed evidence of recurrence within three years after operation.

The duration of the disease is the most important factor to be taken into consideration in determining the curability of mammary carcinoma. Metastasis almost invariably occurs, and while the period elapsing between the onset of the disease and the involvement of other organs and tissues varies considerably, the fact remains, that the chances of operative cure decrease with each day's neglect of surgical interference. A few exceptions to this general rule are found in cases of the fibrosing type of the disease occurring in aged women. This variety of mammary carcinoma is essentially chronic and shows little tendency to metastasize. It runs a protracted course, the patients frequently surviving $\mathrm{I} O, 20$ or even more years from the time of onset. In a definite proportion of these cases, the patients will live longer if palliative treatment is employed rather than operation. We do not refer to the early stages of carcinoma of the breast in aged women in which the future course of the disease cannot be foretold, but of those cases in which the patient is first brought to our attention several years after the onset of the trouble, and with the breast presenting the typical picture of a "withering, atrophic or scirrhus breast." Surgical interference not infrequently excites a greater rapidity of growth in malignant processes of this type and materially shortens the life of the patient. Even in the absence of all evidence of metastases and in cases otherwise suitable for operation, we are inclined, in dealing with cases of this kind, to advise against operation. The duration of the disease under these circumstances has obviously a different influence on the prognosis than is the case with the ordinary operable form of carcinoma of the breast. Before entering upon a detailed study of this latter phase of the subject, let us consider, in an abstract way, the attitude of the profession relative to the operative treatment of tumors in general, basing our opinion on the duration of malignant disease in patients referred for operation. In reviewing any series of cases of carcinoma affecting any organ we find that a much longer period of time has elapsed between the time of onset of the disease and the time of operation, than is justifiable in the light of our present knowledge of the evil effects of procrastination in advising operation. This fault is, of ocurse, not attributable entirely to the physician. The fact remains, however, that malignant disease is subjected to operation at a comparatively late date. The average length of time the disease had existed in our series was 30 months. Several of these 
patients had noticed a lump in the affected breast many years, in one instance 20 years, before the clinical evidence of malignancy became manifest. In our cases giving a family history of carcinoma, 22.9 months on the average had elapsed between the time of onset of the disease and the time of operation. In cases well three or more years after operation, only I6 months had elapsed. Ulceration and local metastasis had occurred in $3 \mathrm{I}$ per cent. of a series of 200 patients referred to us for operation. These are late symptoms and of exceedingly evil prognostic significance. At least 25 per cent. of all cancer patients referred to us for operation are found to be inoperable. Among the cases of superficial malignancy seen by the surgeons of Pennsylvania in I9I I 32 per cent. were found to be inoperable. It is a safe prediction to make, that an even greater proportion of inoperable cases was found among those occurring in the internal organs. In the operable cases reported by Schwarzkopf, I4.4 months on the average had elapsed from the onset of the disease to the time of operation. In the inoperable cases, the disease was of 16.9 months' duration. Primrose states that 14.37 months is the average duration of mammary carcinoma at the time of operation. His tabulation of cases relative to the duration of the disease is as follows:

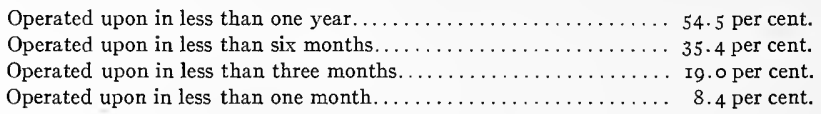

According to our figures, the duration of the disease exceeds that given above, but this can probably be explained by the fact that many of our patients gave the history of a symptomless lump in the breast of several or more years duration, and this was looked upon as the initial symptom of the disease. These figures show without question, that malignant disease of the breast is subjected to operation at a comparatively late stage of the disease. In treating specifically of the duration of the disease as a prognostic factor, it must be considered both from the standpoint of its local and metastatic effects. Regardless of the duration of the disease, the prognosis is bad in a patient whose breast is deeply ulcerated, and in whom metastatic nodules are palpable in the supra-clavicular space. The prognosis is obviously better in a patient whose disease has existed for three years but is localized to the breast, than in one whose disease while of only two months' duration has already involved the liver or other internal viscera. These are self-evident facts, but they must be remembered in order that we may avoid laying too much stress on the duration of the disease in prognosing carcinoma, which in exceptional cases fails to follow any definite law as regards the time of dissemination. As a general rule, however, there is a more or less constant relationship between the physical state of the tumor and its duration. The local condition rather than the duration of the disease is of the greatest prognostic value.

The significance of the local condition in determining the probability of surgical cure in carcinoma of the breast is well shown in the following table which is taken from Greenough's studies of a series of cases operated upon in the Massachusetts General Hospital.

Ulceration of the skin overlying the tumor, and adhesion of the tumor to the structures beneath the breast, are of the gravest prognostic significance. When the tumor is fixed to the chest wall there is little or no hope of operative cure. Many surgeons, especially the Germans, advise resection of a portion of the chest wall, and occasionally an apparent cure is obtained. This has never appealed to us as worthy of trial in view of 
the difficulties associated with less advanced cases in obtaining satisfactory operative results. In certain instances it is justifiable, perhaps and it is in this class of cases where complete removal of the disease is impossible, that some efficacious supplementary method of treatment is especially needed.

\section{Table XII.-(Greexough, Simarons and Barney)}

\begin{tabular}{|c|c|c|}
\hline & $\begin{array}{l}\text { Number of } \\
\text { cases }\end{array}$ & $\begin{array}{l}\text { Per cent. } \\
\text { successful }\end{array}$ \\
\hline Tumor adherent to the skin. & 262 & $\mathrm{I} 6.0$ \\
\hline 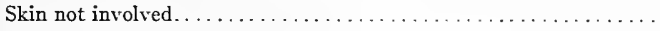 & $7 \bar{I}$ & 32.0 \\
\hline Tumor adherent to chest wall $\ldots \ldots \ldots \ldots \ldots \ldots \ldots, \ldots \ldots \ldots \ldots$ & 45 & II.O \\
\hline Tumor movable on the chest wall $\ldots \ldots \ldots \ldots \ldots \ldots \ldots \ldots$ & I 94 & $2 \mathrm{I} . \mathrm{O}$ \\
\hline Axillary glands palpable $\ldots \ldots \ldots \ldots \ldots \ldots \ldots \ldots$ & 236 & I 2.0 \\
\hline Axillary glands not palpable............. & I 7 & I9.0 \\
\hline 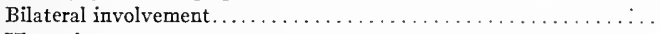 & 6 & $\infty 0.0$ \\
\hline 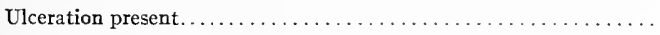 & 60 & 6.5 \\
\hline 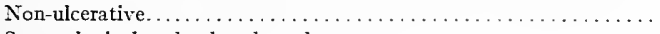 & 316 & 21.0 \\
\hline Supra-clavicular glands enlarged $\ldots \ldots \ldots \ldots \ldots \ldots \ldots \ldots$ & 40 & 0.5 \\
\hline
\end{tabular}

If the pectoral fascia only is involved, a better prognosis can be given than if the muscles are deeply infiltrated. This cannot be determined absolutely before operation. It will be observed that Greenough reports is per cent. of cures in cases with tumors adherent to the chest wall. This is a very high proportion and exceeds that of any other writer. We have rarely indeed succeeded in curing a patient of mammary carcinoma in whom the tumor was adherent to the underlying structures. Schwarzkopf reports eight cases in which the tissues underlying the breast were involved, without a cure. Ulceration and adhesion of the tumor to the skin, he believes, are not necessarily bad signs since 17 per cent. of 87 cases presenting these complications were cured by operation (three-year limit).

Warren states that only 5 per cent. of cases of this nature are cured by the radical operation. He adds that operative cure is most exceptional in patients in whom the malignant process has invaded the chest wall, or has disseminated itself throughout the pectoral skin adjacent to the breast in the form of lenticular deposits.

Primary bilateral mammary carcinoma is practically always fatal regardless of the apparent lack of metastases. In many of the cases considered to be primary, however, it is probable that the one organ is involved as a result of metastases from its fellow of the opposite side, and under these circumstances, the malignancy of the second organ denotes an advanced stage of the same process of the organ primarily involved. Cases are occasionally reported in which operation for recurrence in the breast of the opposite side has been successful in permanently curing the disease. Judd, in speaking of primary bilateral carcinoma of the breast, classifies this condition with acute carcinoma occurring during lactation as the most fatal form of the disease.

Retraction of the nipple is a late symptom when considered from the prognostic standpoint. Of our own patients well three or more years after operation, only 12 per cent. had had this symptom, and in only i 8 per cent. of the cases was attachment of the tumor to the skin noted in the history. Warren stated that 42 of his cases were cured who were operated upon before a visible growth appeared, and that only 17 per cent. were cured when a visible growth was present but before attachment to the skin took place.

The size of the tumor is believed by Schwarzkopf to have prognostic significance. 
The results of his observations relative to this point are summed up in the following classification:

\begin{tabular}{|c|c|c|c|}
\hline & Cases & Cured & Per cent. \\
\hline Tumor not larger than a hen's egg. & I98 & 37 & 34.26 \\
\hline Tumor size & 99 & .. & 12.00 \\
\hline$\ldots \ldots \ldots$ & 20 & . & 5.00 \\
\hline Multiple tumo & 9 & 2 & 22.00 \\
\hline
\end{tabular}

Those cases operated upon in Schloffer's clinic (Schwarzkopf) are grouped according to their severity in the following manner:

Tumor small and movable, axillary glands palpable.......

Tumor small and movable, clavicular glands palpable.....

Tumor small, not freely movable, axillary glands and clavicular glands palpable.....................

$\begin{array}{ccc}\text { Cases } & \text { Cured } & \text { Per cent. } \\ 24 & 8 & 33 \cdot 3 \\ 5 & 0 & 00.0 \\ 4 & 0 & 00.0\end{array}$

Jennings quotes a table which Horing constructed from the post-operative results in a series of 200 cases operated upon in the Katherine Hospital of Stuttgart, showing the relative prognostic significance of the local signs of mammary carcinoma.

\section{Horing's Classification:}

Group r.-Cases of apparently slow growth. Tumor only a centimeter in size, lying entirely in the gland substance. In axilla, one or more small glands usually first discovered at operation. Seventy-six per cent. free of recurrence three years after operation.

Group 2.-Distinct nodule present. Adhesions of the skin or deeper parts. Glands palpable in axilla. Twenty-eight per cent. free of recurrence three years after operation.

Group 3.- Greater part of the breast involved. Tumor firmly involves the skin and deeper parts, and often the supra-clavicular glands are involved. None alive three years after operation.

Edema of the tissues surrounding the breast is usually caused by cancerous lymphatic obstruction and must, therefore, be considered of grave prognostic significance. A small minority of patients presenting this complication, however, are cured by the radical operation which should not be denied them in the absence of other positive contra-indications to operation. In rare instances the same statements apply to cases with edema of the arm.

The most important local or regional complication of mammary carcinoma, from the standpoint of determining the curability of the disease, is undoubtedly that of metastatic involvement of the axillary and supra-clavicular lymph nodes. It is not always possible, however, to learn by physical methods of examination the exact condition of these structures. An absence of palpable enlargement does not invariably mean an absence of carcinomatous involvement, nor does the increase in the size of the nodes per se prove the presence of malignant metastases. This latter may be due to any one of a number of causes, usually infectious in nature, without any relationship whatsoever with the malignant process in the breast. The following remarks apply to cases in which actual involvement of these lymphatic structures had occurred as proven at the time of operation by gross examination or by microscopic studies. In this connection the work of Halsted is the most complete and extensive reported up to the present time and we have therefore included his complete list of tables. These tables show, as Halsted has remarked, that, "notwithstanding the present-day extensive operation, death from metastasis occurs in 23.4 per cent. even in cases with microscopically negative axilla." "Fortunately we no longer need the proof which our figures unmistakably give, that the slightest delay is dangerous and that other things being equal, the prognosis is quite good in the early 
stages of breast cancer, two in three being cured, and bad, three in four succumbing, when the axillary glands are demonstrably involved." In our own series of cases 90 per cent. of 59 patients dying of early recurrence, had palpable axillary involvement at the time of operation. Of I 6 patients alive after the three-year limit, 25 per cent. had demonstrable axillary involvement at the time of operation. It is evident that metastases to these structures is a late symptom of grave prognostic significance. The gravity of axillary lymph-node involvement increases as the invasion approaches the lower cervical chain. In the opinion of many surgeons, involvement of the supraclavicular glands is a contra-indication against operation. It will be observed that Halsted reports 7 per cent. of cures among 44 cases with this complication. Guleke and Finsterer each record a case of a patient well four years after operation. Pilcher has had two successful cases, one of which was well four years after the operation, the other six years after. Judd states that patients with carcinomatous involvement of the lower cervical lymph chain live longer and more comfortably if not operated upon. The experience of Schwarzkopf illustrates the possibility of cure in patients presenting this complication. In only two of the cases he reported as cured of the disease, was the diagnosis confirmed by microscopic examination however. $\mathrm{He}$ attributes the favorable outcome to a low degree of malignancy rather than to the effects of the operation. Schwarzkopf's figures are both instructive and interesting.

\section{Table XIII-Schwarzkopf.-Patients with Supra-clavicular Glandular Involvement}

Died from two to eleven months after operation. $\ldots \ldots \ldots \ldots \ldots \ldots \ldots \ldots \ldots$

Died immediately after operation $\ldots \ldots \ldots \ldots \ldots \ldots \ldots \ldots \ldots \ldots \ldots \ldots \ldots \ldots \ldots \ldots \ldots \ldots$

Died within one year after operation $\ldots \ldots \ldots \ldots \ldots \ldots \ldots \ldots \ldots \ldots \ldots \ldots$

Died within two years after operation. . . . . . . . . . . . . . . . . . 6

Died within three years after operation. . . . . . . . . . . . . . . . . 3

Living three years after operation. . . . . . . . . . . .

Cured, died thirteen years after operation of intercurrent disease $\ldots \ldots \ldots \ldots \ldots$ r

Cured, died eight years after operation of intercurrent disease $\ldots \ldots \ldots \ldots \ldots$ r

Cured, died four years after operation of marasmus $\ldots \ldots \ldots \ldots \ldots \ldots \ldots \ldots$.

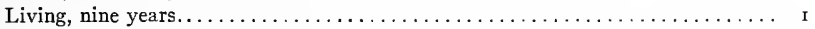

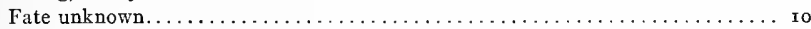

Total...............................

It is evident from the foregoing facts that the local condition of the disease is most important as a means of estimating the probability of cure by operation. Though it is not always possible to determine the degree of metastatic involvement by physical examination, the presence of palpable glands in the axillary and supra-clavicular spaces, of ulceration, adhesion of the tumor and retraction of the nipple, are local signs of grave prognostic significance.

\section{Halsted's Tables}

Symbols used in the tables

Complete axillary Group I. Supra-clavicular glands removed at the first operation. operation. Group 2, Supra-clavicular glands removed secondarily.

Letters, $A, B, C, D$, indicate the degree of axillary involvement.

A. Base of axilla only involved.

$B$. Base and mid-axilla involved.

$D$. Veins intimately adherent. 
Halsted's Table I.-Carcinoma of the Breast

Ultimate result as affected by the degree of axillary involvement

Cases operated upon three or more years prior to the last news of them

\begin{tabular}{|c|c|c|c|c|c|c|c|c|c|}
\hline \multirow{2}{*}{ involvement } & \multicolumn{4}{|c|}{ Axilla only involved } & \multicolumn{4}{|c|}{ volved } & \multirow{2}{*}{ Totals } \\
\hline & $A$ & $B$ & $C$ & Total & $B$ & $C$ & $D$ & Total & \\
\hline Cured, living 1906 to $1907 \ldots \ldots \ldots \ldots \ldots \ldots \ldots \ldots$ & 6 & $\ldots$ & $\ldots$ & 6 & $\ldots$ & $\ldots$ & 1 & I & 7 \\
\hline Cured, living in $1905 \ldots \ldots \ldots \ldots \ldots \ldots \ldots \ldots \ldots \ldots \ldots$ & 3 & 2 & 3 & 6 & $\cdots$ & $\cdots$ & $\ldots$ & $\cdots$. & 6 \\
\hline Cured, dead of other causes, three years plus........... & $\ldots$ & 2 & 2 & 4 & $\overline{\mathrm{I}}$ & $\vec{I}$ & $\cdots$ & 2 & 6 \\
\hline Cured, dead of other canses, three years minus......... & $\ldots$ & $\ldots$ & I & I & ... & $\ldots$ & $\ldots$ & .... & I \\
\hline 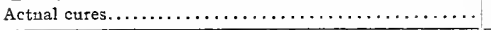 & 9 & 5 & 3 & 17 & $\mathbf{I}$ & I & 1. & 3 & 20 \\
\hline Well three years, metastases later . . . . . . . . . . . . . . & I & 4 & $\cdots$ & 5 & $\cdots$ & I & I & 2 & 7 \\
\hline Cured, three years and over $\ldots \ldots \ldots \ldots \ldots \ldots \ldots \ldots$ & Io & 9 & 3 & 22 & I & 2 & 2 & 5 & 27 \\
\hline 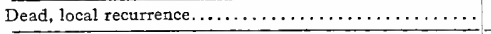 & $\mathrm{I}$ & 3 & 3 & 7 & I & 6 & 1 & 8 & 15 \\
\hline 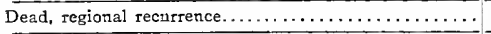 & 5 & 4 & 6 & 15 & 2 & 7 & 2 & II & 26 \\
\hline 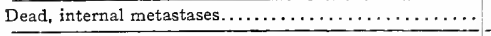 & 5 & 13 & 5 & 23 & I & $\underline{9}$ & 5 & I5 & 38 \\
\hline 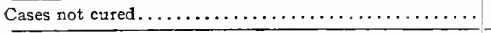 & I I & 20 & 14 & 45 & 4 & 22 & 8 & 34 & 79 \\
\hline 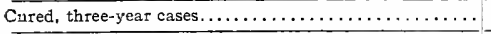 & 10 & 9 & 3 & 22 & $\mathbf{I}$ & 2 & 2 & 5 & 27 \\
\hline 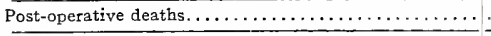 & $\ldots$ & 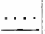 & $\cdots$ & 3 & $\cdots$ & $\ldots$ & $\cdots$ & I & 4 \\
\hline 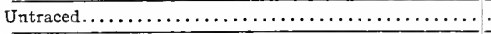 & $\cdots$ & $\cdots$ & ... & II & $\cdots$ & $\cdots$ & $\cdots$ & 3 & 14 \\
\hline \multirow[t]{2}{*}{ No data as to extent of axillary involvement............ } & $\ldots$ & $\cdots$ & $\cdots$ & 43 & $\cdots$ & $\ldots$ & $\cdots$ & I & 44 \\
\hline & 21 & 29 & 17 & 124 & 5 & 24 & Io & 44 & 168 \\
\hline
\end{tabular}

Halsted's Table II.-CaRcinoma of the Breast

Cases operated upon three or more years prior to the last news of them Ultimate results as affected by axillary
and neck involvement
Glands of the axilla positive

\begin{tabular}{l|l|l|l|} 
I & II & III & Total \\
\hline
\end{tabular}
Giands of axilla positive, glands of neck negative
Glands of axilla and neck positive

\begin{tabular}{l|l|l|l|l|l|l|l}
\hline I & II & III & Total & I & II & III & Total \\
\hline
\end{tabular}

Cured, living, heard from, I906 to 1907. . Cnred, living, heard from $1905 \ldots \ldots \ldots$

Cured, dead of other causes more than Cured, dead of other causes more than
three years post-operationem ............

Cured, dead of other causes less than

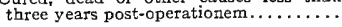

Cases actually cured.................

Cured three years after operation, metas-

\begin{tabular}{|l|l|l|l|}
\hline Cured three years after operation, metas- I & \\
\hline
\end{tabular}

tasis later........................

\begin{tabular}{ll|l|l|l|l|l|l|l|l|l}
4 & I & 20 & 25 & 4 & $\cdots$ & 5 & 9 & $\cdots$ & I & I \\
\hline
\end{tabular}

\begin{tabular}{llllll}
\hline Cases cured not less than three years.... & 13 & 3 & 35 & 51
\end{tabular}

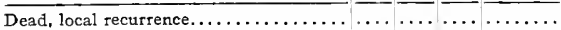

$\overline{\text { Dead, regional recurrence............. }}$ I $\ldots{ }_{3}$

\begin{tabular}{|l|l|l|l|l|l|l|l|l|l|l|l|}
\hline 4 & $\ldots$ & 3 & 7 & 4 & $\ldots$ & 3 & 7 & I & I & 2 & 16 \\
\hline
\end{tabular}

\begin{tabular}{ll|l|l|l|}
\hline Dead, internal metastasis............. & 2 & $\ldots$ & 3 & 5 \\
\hline
\end{tabular}

Cases that have not been cured........ 3 3 $\ldots \frac{}{6}$

Cases cured three years and more as above ${ }_{13} \quad 35$

$\overline{\text { Post-operative mortality............. }} \frac{16}{3} \frac{1}{41}$

Untraced.

\begin{tabular}{ll|l|l|l|l|l|l|l|}
49 & 2 & 59 & 34
\end{tabular}

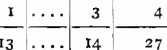

$1+35$

........................... 4

$\frac{4}{64} \frac{2}{54} \frac{1}{2} \frac{3}{68}-\frac{1}{3} \frac{40}{1}-14$

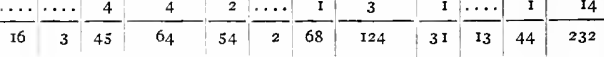


Halsted's Table III.-Carcinoma of the Breast

\begin{tabular}{|c|c|c|c|c|c|c|c|c|}
\hline & \multicolumn{8}{|c|}{ Study of cured (five-year) cases } \\
\hline & Cases & Lost & $\begin{array}{l}\text { No. of } \\
\text { cases }\end{array}$ & $\begin{array}{l}\text { Cured, } \\
\text { living }\end{array}$ & $\begin{array}{c}\text { Cured, } \\
\text { dead }\end{array}$ & $\begin{array}{l}\text { Metastases } \\
\text { after five } \\
\text { years }\end{array}$ & Total & Per cent. \\
\hline Group I $\ldots \ldots \ldots \ldots$ & 96 & 8 & 88 & 13 & 6 & 5 & 24 & 27.27 \\
\hline Group $2 \ldots \ldots \ldots \ldots$ & I6 & $\ldots \ldots \ldots$ & 16 & 3 & I & I & 5 & 31.25 \\
\hline Group $3 \ldots \ldots \ldots \ldots$ & 92 & 5 & 87 & 23 & 3 & 4 & 30 & $34.4^{8}$ \\
\hline Total.......... & 204 & 13 & I9 & 39 & IO & Io & 59 & 0.48 \\
\hline
\end{tabular}

Recurrence.-Recurrence of mammary carcinoma, after the radical operation, appears (a) at the site of the operation (local), (b) in the tissues adjacent to the site of operation (regional), $(c)$ in distant structures (metastatic), and (d), in combinations of these various locations. The comparative frequency of local and regional recurrences as given by various authors differs to some extent. Finney states that 20 per cent. of the patients who die in the first three years after operation have been shown to have had local recurrence of the disease. According to Greenough, Simmons and Barney, recurrence in the scar occurs in less than half the cases. In Vanvert's cases, the disease reappeared locally in 43 per cent. of instances. Willy Meyer states that 40.3 per cent. of fatal recurrences are metastatic. Finney, on the other hand, quotes I 7 per cent. of metastases in all cases and states that they occur early and are unassociated with local recurrence in 30 per cent. of cases. The sites of local and regional recurrences in Schwarzkopf's patients are given as follows:

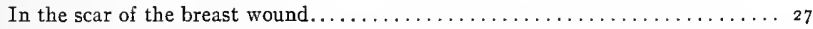

In scar of breast and axillary wounds. $\ldots \ldots \ldots \ldots \ldots \ldots \ldots \ldots \ldots$

In scar of the breast and sternum. . . . . . . . . . . . . . . . . . . 3

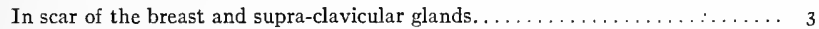

In axillary scar and supra-clavicular glands $\ldots \ldots \ldots \ldots \ldots \ldots \ldots \ldots$

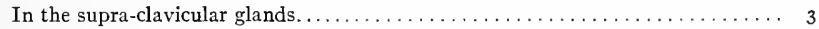

No longer determinable. . . . . . . . . . . . . . . . . . . . . 24

There is also a marked difference in the times of recurrence of the various types. Thus, local recurrences usually appear within a short period of time after the operation -in the majority of cases within the first year. Distant metastases, as a general rule, appear later, while the regional type is intermediate in position in its time of onset. Recurrences may take place from several weeks to many months after operation. Late recurrences, however, are in the minority. It has been estimated that less than 2 per cent. of local recurrences appear after the third year. Bloodgood states that he has never seen an instance of local recurrence after the third post-operative year. In Finney's experience regional recurrences are exceptional after the first year. This author says that from 49 to 60 per cent. of local and regional recurrences occur in the first six months and that 50 per cent. of these appear within three months of the time of operation. Metastatic recurrences frequently appear after the three-year limit, although I9.5 per cent. of Schloffer's cases died of this type of recurrence before the expiration of this time. This tendency to late metastatic recurrence together with the small number of local recurrences which occur after the three-year limit will not permit us to assure a permanent cure in patients who are apparently well at the end of this post-operative 
period. The average length of life in patients in whom the radical operation has been performed but who are not cured is, according to Bloodgood, 4.5 years. The same author gives 2.26 years as the average duration of life in this same class of patients who develop local recurrence, and 2.r6 years in those with regional recurrence. Finney estimates that cases operated upon but not cured live 30 to 38 months - a gain of Io months over similar cases not operated upon. In a series of $\mathrm{r} 3 \mathrm{r}$ cases in patients who died of recurrence Schwarzkopf found that death took place in the average case seven months after operation, the shortest period being seven weeks, the longest 42 months. This is the shortest average period of freedom from recurrence reported by any recent writer and it will be of interest therefore to study the operative technic employed in Wölfler's clinic, where the patients included in this series were treated. This we will do later.

Late Recurrences.- Recurrence of mammary carcinoma five or more years after operation must be considered exceptional. The probabilities of local recurrence within a year after operation have already been alluded to, as well as the greater likelihood of metastatic recurrence at later periods. It is a surprising fact, however, that in cases of so-called late recurrence - that is, in those occuring ro or more years after operation -the local type predominates. Thus Ransohoff, who has collected 37 cases in which recurrence took place seven or more years after, found that the disease reappeared locally in 26 instances. In explanation of late recurrences it has been suggested that only a few cells are left behind at the time of operation and that a number of years are necessary for that degree of malignant hyperplasia to take place which permits of clinical demonstration. It is believed by some that the so-called recurrent cancer is, in most instances, an entirely new process, entirely unrelated with the primary disease and dependent upon a cancer predisposition in the operative scar. It is a well-known fact that carcinoma develops in scars of traumatic origin many years after the receipt of the injury. The late occurrence of the carcinoma under these circumstances is used by the exponents of the latter of the above theories as an argument in support of their claim. More scientific deductions, however, can be drawn from Theilhaber's views. He believes that carcinoma is dependent upon anemic states of the tissues and that-in the case in point-late recurrences are explainable on the grounds that the production of an anemic state depends upon the contracted condition of the operative scar which in many instances, takes years for its production. It is believed by many surgeons that so-called late recurrences in the internal organs from primary disease of the breast in the majority of instances are new processes without relationship to the previous trouble. It is quite rational to believe that a patient who has had carcinoma of the breast has a more marked tissue predisposition to malignancy than one who has not had carcinoma, despite the fact that the former has remained apparently well for a number of years after operation.

We, however, are inclined to look upon the majority of cases of visceral carcinoma occurring in patients who have previously been operated upon for carcinoma of the breast, as recurrences of the original disease. We are, however, willing to admit the possibility of the development of an independent malignant process in patients who have been cured of the disease in another part of the body, as is especially true of carcinomas remote from the primary seat and without lymphatic relationship with the latter. We believe that carcinomas of the liver, lung, stomach and other organs which have direct lymphatic relationship with the breast, are instances, of true recurrence when they occur in persons who have been operated upon for mammary carcinoma, however distant, the time for such operation may happen to be. Since the operative cure of 
this disease confers no apparent immunity, a new process may of course arise de novo in these structures, but such occurrences must be extremely rare.

Late regional recurrence takes place in the cervical glands, the axillary tissues, in the tissues of the chest wall and not infrequently in the other breast. Of 35 cases reported by Rotter, 6 occurred in the opposite breast. All portions of the gastro-intestinal tract and its accessory glands, various parts of the skeletal system, the thyroid gland, the central nervous and urogenital organs have been mentioned as the sites of late recurrences of mammary carcinoma. Judd reports five cases in which late recurrence took place. The time of appearance of the disease and the areas involved in these cases were as follows: one general carcinosis (nine years after operation) one pulmonary (five years and eleven months after operation), one hepatic (six years and five months after operation), another "internal" (six years and five months after operation) and one recurred locally i 2 years after operation. The latest period at which recurrence of mammary carcinoma is said to have taken place is reported by Verneuil in a patient whose breast was amputated 30 years before a remanifestation of the disease occurred. We have seen carcinoma develop in the scar of a breast amputation which had been performed 20 years before. The following list of cases illustrates the time at which late recurrences are said to occur. It will be observed that Schröder and Finsterer collected 32 cases which appeared about the twelfth year after operation.

\section{Table XIV.-Late Recurrences}

\begin{tabular}{|c|c|c|}
\hline & $\begin{array}{l}\text { Number of years } \\
\text { after operation }\end{array}$ & $\begin{array}{l}\text { Number } \\
\text { of cases }\end{array}$ \\
\hline Verneuil....................................... & 30 & $\mathrm{r}$ \\
\hline 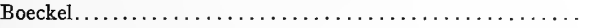 & 29 & I \\
\hline Matas. & 24 & I \\
\hline 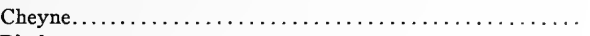 & 23 & $\mathbf{I}$ \\
\hline 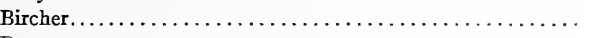 & $20-30$ & $\mathrm{r}_{5}$ \\
\hline 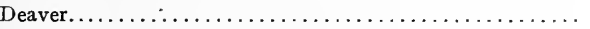 & 20 & I \\
\hline 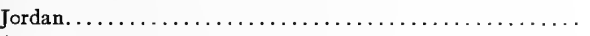 & 15 & I \\
\hline Ansperger. $\ldots \ldots \ldots \ldots \ldots \ldots \ldots \ldots \ldots \ldots \ldots \ldots \ldots \ldots \ldots$ & $6-19$ & 7 \\
\hline 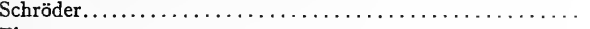 & I 2 & I5 \\
\hline 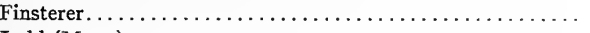 & 12 & $\mathbf{I} 7$ \\
\hline 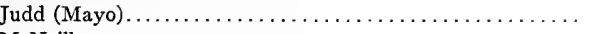 & $5^{-12}$ & 5 \\
\hline McNeill...................................... & 14 & I \\
\hline 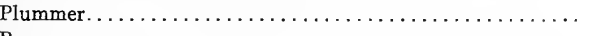 & I6 & I \\
\hline 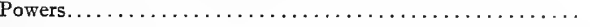 & 17 & I \\
\hline
\end{tabular}

Figures relative to the probability of operative cure of recurrent mammary carcinoma are meager, although there is a consensus of opinion among surgeons that the prognosis is very grave. We must not despair of obtaining a cure after a second operation, however. Life has undoubtedly been prolonged in several of our cases by repeated excision of nodules occurring in the line of the operative scar or by total excision of the scar-bearing area together with the adjacent tissues. Our most favorable results in cases of this kind have been obtained with the combined use of the $X$-rays and excision. (See chapter on non-operative treatment.) Warren removed carcinomatous nodules from the axillary and pectoral regions of two patients who were alive at the time of his report, Io and I $_{5}$ years, respectively, after operation. A most remarkable case is reported by Hutchinson. This patient was operated upon four times, and has remained well for I 2 years after the last operation. The treatment included amputation of the second breast and operation for a recurrence there. Wolbarst operated on a patient for local recurrence, and 22 years later the disease occurred in the tissues adjacent to the scar of the second operation. In a series of Ioo operations for recurrent carcinoma of the breast, 
Warren reports 5 per cent. of cures. A third operation is justifiable in suitable cases. The prognosis under these circumstances must be guarded as regards curative effect, but we can assure the patient that the operation will prolong life, in some instances, for many years.

The prognosis of mammary carcinoma depends to a great extent upon the method of treatment employed. From the standpoint of practice, spontaneous cures may be disregarded although they undoubtedly do occur. Packard has recently reported three instances of spontaneous cure of mammary carcinoma, together with examples of both sarcomas and carcinomas occurring elsewhere which disappeared without treatment. The methods employed by nature in effecting the cure in cases of this kind, are most obscure but there seems to be an absence of chronic inflammatory changes (peri-lymphatic fibrosis, Handley), which are associated with the atrophic scirrhus types of carcinoma in the breast, which latter is practically curative in some cases. Non-operative methods of treatment are to be considered of prognostic importance because when used as supplementary methods to operation in the treatment of inoperable cases, they materially aid in prolonging life. Their value in these conditions is discussed elsewhere. The prognostic significance of the comparative value of the various forms of operation remains for consideration. It is generally conceded that the successful treatment of mammary carcinoma demands radical removal of the affected organ at the earliest possible stage of the disease. As a general rule it may be stated, that the more radical the operation, the better will the prognosis be. Where complete eradication of the disease is impossible, it is the part of wisdom in many instances to confine ourselves to simple amputation of the breast, if indeed any operation be justified. More extensive operative procedures not infrequently excite the disease to greater activity. Bloodgood states without reservation that incomplete operations hasten death. His patients upon whom incomplete operations were performed lived on an average of 2.2 years after the operation, while in $x 6$ cases in which palliative treatment was employed, the average duration of life was 3.2 years. Operation was attempted but abandoned in 55 cases on account of the impossibility of complete eradication. 'The average duration of life in this series was I.4 years. In still another series, the complete operation was done but the disease recurred. In this group of cases the average duration of life was 4.7 years. These figures show that death is hastened in cases where the radical operation is performed but with failure to remove all of the tissues which are grossly involved. It also indicates that operations which completely remove all of the grossly involved tissues prolong life even if microscopic portions of the malignant tissue escape removal and produce recurrence later. Incomplete operations should only be employed as a means of relieving suffering. There can be no question at this time of the comparative values of the Halsted and similar radical methods of breast amputation, and the less radical procedures, in these cases which are considered operable. Simple amputation with cleansing of the axilla would suffice in many of the early cases-indeed in the majority of cases where the disease is confined to the breast. We can never be sure, however, that the malignant process is confined to the breast and, therefore, find no justification for employing a doubtful measure when the radical operation can be performed with no greater danger to life or future usefulness of the arm, and with far greater prospects of attaining a permanent cure of the disease. The prognosis; on the other hand, is better with a simple amputation of the breast in the very early stages of the disease than with the most radical operation in the very late stages. This is well shown in Schwarzkopf's work. In severe cases he employed the Rotter or Halsted 
technics, and in only 2 of 39 cases (5.r per cent.) was cure obtained. His best results followed amputation of the breast and cleansing of the axilla in early cases (no palpable lymph glands present). Eighty per cent. of cases of this type were cured. In the presence of palpable lymph glands, better results followed the radical operation-radical even to the point of resection of the ribs-than with simple amputation and cleansing of the axillary space. With the former method, 24.4 per cent. were cured and recurrence took place in I0.2 per cent. of cases. With the latter, I 9.3 per cent. of the patients were cured and in 34 per cent. of instances the disease recurred. Recurrences took place at an earlier date in Schwarzkopf's series than in that of any other recent observera fact which can be attributed, we believe, to the incompleteness of many of his operations. The prognosis of mammary carcinoma is, therefore, most favorable when the disease is subjected to the radical operation in its earliest stages. The prognosis is usually, if not always, grave in cases in which a primary incomplete operation has been followed by a radical one at a later sitting. The Mayos and others report cures in patients from whose breasts carcinomatous nodules have been excised. As a general rule, however, an incision into a carcinomatous breast for diagnostic purposes, excision of a carcinomatous mass from the breast, or other incomplete operation, render the prognosis extremely grave, if not absolutely hopeless. Such methods aggravate the disease and cause traumatic dissemination of the tumor cells. This fact is doubly important because measures of this kind are apt to be employed in the early stages of the disease when it is difficult to make the diagnosis. Not infrequently efforts of this kind turn a favorable prognosis into an almost hopeless one. Bloodgood has been most insistent as to the necessity of diagnosing the condition at the operating-table and not waiting for a microscopic diagnosis, unless this can be made immediately by frozen section. He refers in particular to this danger in relation to cysts of the breast, which are so frequently encountered in the early stages of malignant transformation.

It is difficult, if not impossible, to estimate the influence of the various modifications of the original Halsted technic on the prognosis of mammary carcinoma. Extensive removal of the skin with more extensive removal of the deep fascia, as advised by Handley, undoubtedly has served to decrease both local and regional recurrences. We believe that the prognostic effect of preserving the pectoralis major muscle is an evil one, and find our view substantiated by Vanvert who obtained only 13 per cent. of cures in a series of 23 cases in which the Murphy technic was employed (preservation of the pectoralis major muscle). Removal of the pectoralis minor muscle influences the prognosis chiefly because better access to the axillary space is thus afforded. Most of the modifications of the radical operation recently proposed are of slight prognostic significance. The most important feature, from the standpoint of prognosis, in the treatment of carcinoma of the breast, is a method of operation that meets the requirements of the original Halsted operation, performed during the incipient stage of the disease.

\section{BIBLIOGRAPHY}

Barkér. - Cited by Primrose.

BLoodgood.-Ann. Surg., I9r3, LVIII, 282.

BLOODGood.--In Kelly and Noble Gynecol. and Abdom. Surg., Phila., Igo8.

Bryant.- "Diseases of the Breast," 158 , London, 1887 .

Crile.-Tr. South. Surg. and Gynec. Assn., rgro, xxiii, 470.

Deaver.-J. Am. M. Assn., I9I3, LX, 745.

Finnex.-_Diseases of the Breast," Keen's Surgery, iii; vi, Phila., rgo8.

Dietrich.-Deutsche Ztschr. f. Chir., I892, xxxiii, $47 \mathrm{r}$. 
Fink.-Deutsche Ztschr. f. Heilk., I889, ix, 453.

FINSTERER.-Deutsche Ztschr. f. Chir., I907, Ixxxix, I43.

GEBELE,-Beitr. z. klin. Chir., I90I, xxix, I67.

Greenouge, Simmons and Barney.-Tr. Am. Surg. Assn., I907, XXV, 8I.

GREIG.-Edinburg M. J., I9I3, $\mathrm{x}$, I48.

GULEKE.-Arch. f. klin. Chir., I904, xliv, 530.

Halsted.-Ann. Surg., I894, XX, 497.

HALSTED.-J. Am. M. Assn., I913, XI, 417 .

Halsted.-Tr. Am. Surg. Assn., r907, XXV, 6 r.

HandLey.-Brit. M. J., I9०4, ii, 832 .

Handley.- "Cancer of the Breast and Its Operative Treatment," London, Igo6.

Henry.-Inaug. Dissert., Breslau, 1879.

Hildebrand.-Centralbl. f. Chir., I887, XIV, 776.

HoRIG.-Beitr. z. klin. Chir., I $9 \circ 9,1 \times i$, I 99.

HORNER.-Ibid., I894, xii, 6I9.

Jennings,-Long Island M. J., I9I4, VIII, 4I.

Joerss.-Deutsche Ztschr. f. Chir., I896, xliv, Ior.

JUDD and Sistrunk.-Surg., Gynec. and Obstet., I9I4, XVIII, 289.

LEwIN, C.- "Die bösartigen Geschwülste," Leipzig, I gog.

MaHLER.-Beitr. z. klin. Chir., I900, xxvi, 68I.

Matas.-Cited by Rodman.

Mayo, C.- J. Am. M. Assn., I910, LV, I605.

MEYer, W.-J. Am. M. Assn., 1905, XIV, 297.

MURPHY.-N. York M. J., Ig06, LXXXIII, l.

MURPHY.-Surgical Clinics, IgI $2, \mathbf{I}, \mathbf{I}$.

MurRay.-Ann. Surg., IgI 2, lv, 6I8.

OldeKop.-Arch. f. klin. Chir., I879, xxiv, 536.

PACKARD.-Surg., Gynec. and Obstet., I9I3, XVI, rgo.

Paus.-Jahresher. f. Chir., I gro, XVI, 772.

Plummer.-Brit. M. J., I909, i, 1006.

Poulsen.-Arch. f. klin. Chir., I891, xlii, 593.

Powers.-Boston M. \& S. J., IgIo, CLXII, II 4.

Primrose.-Am. J. M. Sc., I9I3, cxlv, Ioo.

Ransohoff.-Tr. Am. Surg. Assn., 1907, XXV, 187.

RAPOK.-Deutsche Ztschr. f. Chir., I $890, \mathrm{xxx}, 465$.

Rodman.- "Diseases of the Breast," Phila., I908.

Rosenstein.-Arch. f. klin. Chir., Igor, lxiii, 555 .

ROTTER.-Berlin. klin. Wchnschr., I 896, XXXIII, 69.

ScHEv.-Mitt. a. d. Grenzgeb. d. Med. u. Chir., rgo7, Suppl., iii, 893.

Schmid, H.-Deutsche med. Wchnschr., I887, xxvi, r39.

Schmid, G. B.-Beitr. z. klin. Chir., I 889, iv, 4 o.

SchMIdT, P.-Deutsche med. Wchnschr., I904, xxx, 540.

SCHRÖDER.-Beitr. z. klin. Chir., I905, xlv, 659 .

ScHWarz.-Beitr. z. klin. Chir., r905, xlvi, 660.

SCHWARzKopf.-Beitr. z. klin. Chir., I9I 2, l $\mathrm{xxx}, 3$ I 7 .

SHerld.-Lancet, I902, 1, 643 .

SHEILD.- "Diseases of the Breast," London, I 898.

Sмiтн.-Cited by Finney.

SPRENGel.-Arch. f. klin. Chir., I882, xxvii, So5.

SteINer.-Wien. med. Wchnschr., I87o, xxiv, 453.

Steinthal.--Beitr. z. klin. Chir., Igr2, lxxviii, 667.

TheIlHaber.-Deutsche med. Wchnschr., IgI 2, xxxvii, 264.

TIETZE.-Therap. d. Gegenwart, I904, xxxi, I 235 .

VANVERT.-Nord. med., IgIO, XVII, 23.

WARREN.-Ann. Surg., I 9०4, XL, 805 .

WinIwarter.- "Beiträge zur Statistik d. Carcinome, Stuttgart, 1878.

Wrlliams, W. R.- "Diseases of the Breast," London, I894.

WUNDERLI.-Deutsche Ztschr. f. Chir., Ig06, lxxxiv, 387. 


\section{TREATMENT}

\section{Operative}

Introduction. - The ultimate object of every method of treating carcinoma is removal or destruction of the cancer cells. Unfortunately, the only effective means at our disposal for accomplishing this purpose is, in the majority of cases, a more or less mutilating operation. When operation for any reason is impossible, we are compelled to resort to some method of treatment that is admittedly inferior so far as the curative effects are concerned. Perhaps the efficiency of many operations is in part dependent upon the natural powers of the body to hold in abeyance, or to destroy the tumor cells that have escaped operative removal. This hypothetical resistance of the tissues to the cancer cells does not remove the obligation to excise every particle of the new growth and its metastatic extensions in cases where operation is the indicated form of treatment. Non-operative methods of treatment including fulguration, radium, carbon dioxide snow and the $X$-rays have shown their superiority to the knife only in the treatment of certain superficial tumors of the squamous-cell variety. The field of application of radium as a curative agent may some day be extended to include the successful treatment of cancers arising in accessible mucous membranes, and, in certain instances, to internal cancers. A number of carcinomas of the breast have apparently been cured by it. Pfahler has obtained some brilliant results in cases of our own with $X$-irradiation.

These agents may promise much for the future, but their use, at the present time, should be reserved for cases in which operation is contra-indicated, or as supplementary to operation.

The Selection of Cases Suitable for Operation.-The apparent widespread disrepute in which cancer surgery is held by the laity is due, in large measure, to a willingness on the part of many surgeons to accept hopelessly advanced cases for radical operation.

When radical removal of a malignant tumor is advised, the patient and those interested are naturally led to expect some degree of benefit to follow the treatment; lest a false sense of security in the operation be engendered, the surgical limitations of the individual case should be explained in detail to some member of the patient's family and in the majority of instances, to the patient herself. In the event of local or metastatic recurrence of the disease, there will then be no justification for condemning an operation, the failure of which was anticipated by the surgeon on the grounds of neglect in permitting the disease to progress so far that operation had become a last resort. This applies also to palliative operations which are often performed without telling the patient anything of their nature. In certain instances, it is good practice to remove a sloughing painful mass, thereby insuring the patient greater comfort for a short period of time, but without the hope of prolonging life. The indications for palliative operations are seldom met with, however, and in the absence of such, any operation, the purpose of which is merely to remove as much of the malignant tissue as possible, in cases where complete removal is clearly out of the question, should be strongly condemned. Operations of this type contribute neither to the comfort of the patient nor to the prolongation of life; on the contrary, the end is frequently hastened by exciting the disease to more active growth.

The future usefulness of incomplete operations for mammary cancer may perhaps be increased if radium prove to be an efficient agent for destroying deep-seated malignant 
cells, the operation serving to remove the major portion of the diseased tissues, with post-operative irradiation for the purpose of destroying outlying foci of cancer cells.

We have performed many palliative operations in the hope that when followed by post-operative application of the $X$-rays, they would prolong life. In the majority of these cases, the end did not justify the means, and we believe that operations of this nature are usually of little if any value and, as a general rule, should not be employed.

According to Handley, the positive contra-indications to operation for mammary cancer are as follows:

(a) When the primary growth has become attached to the bony thorax.

(b) In the presence of cancer en-cuirasse, or of subcutaneous nodules or skin infiltration situated more than 2 inches from the primary growth.

(c) If there is a fixed mass of growth in the axilla, evidently adherent to its walls.

(d) If there is marked edema of the arm.

(e) If the supra-clavicular glands are enlarged hard and fixed.

( $f$ ) If there is evidence of visceral or bone metastases.

(g) If there is incurable constitutional disease, tuberculosis or diabetes for example, likely to be fatal in a few years at most or to lead to a post-operative fatality.

(h) In the acute forms of carcinoma.

Patients suffering with mammary cancer when referred for operation, are divisible into five more or less clearly defined classes, viz.:

(a) Inoperable-cases presenting absolute contra-indications to any form of operation.

(b) Inoperable - but presenting the indications for some palliative operation.

(c) Clinically malignant but apparently operable.

(d) Clinically uncertain but apparently malignant.

(e) Clinically benign but found at the time of operation to be malignant either by gross examination of the cut surface of the tumor, or by the microscopic appearance of tissue sections.

Class A.-Inoperable cases. The classification of inoperable cases as given by Handley and which we have just quoted covers practically all of the absolute contraindications to operation.

It is not always an easy matter to decide whether an existing constitutional disease should be a contra-indication to radical amputation of a carcinomatous breast. Even in advanced cases of chronic myocardial and nephritic disease the operation is often surprisingly well borne, but it goes without saying that patients with non-compensating heart disease or impending uremia the result of chronic Bright's disease, should not be operated upon.

The unmistakable evidence of the presence of distant metastatic foci naturally removes all hope of the radical removal of a cancerous breast; their presence, however does not serve as a contra-indication to the employment of any palliative measure which promises to insure the patients greater comfort, if only for a short period of time.

In a definite proportion of cases of cancer of the breast we are confronted with the problem of deciding whether some intra-abdominal, intra-thoracic, or skeletal complication is dependent upon the tumor in the breast. This becomes of the greatest importance in those cases in which the growth in the breast is small and in every respect suitable for radical extirpation, but in which symptoms suggestive of distant metastasis are present. It is important to remember that a very small and freely movable mass in the breast is not incompatible with early and widespread metastasis (see chapter on prognosis). Operation is not only futile in cases of this kind but, as explained above, is instrumental in a definite proportion of cases in hastening the death of the patient. 
It is not an easy matter in all instances to decide whether a chronic cough is due to a long-standing bronchitis or to cancerous involvement of the pleura and lungs. It is likewise difficult to determine the cause of dyspnea in a patient with a cancerous tumor of the breast. Asthmatic attacks are sometimes caused by the pressure of cancer invaded peri-bronchial lymph nodes on the bronchi; more often these attacks are merely incidental and have nothing to do with the malignant process in the breast. The differentiation of râles due to inflammatory disease of the lungs from those depending upon metastatic cancer nodes may sometimes be made by the $X$-rays.

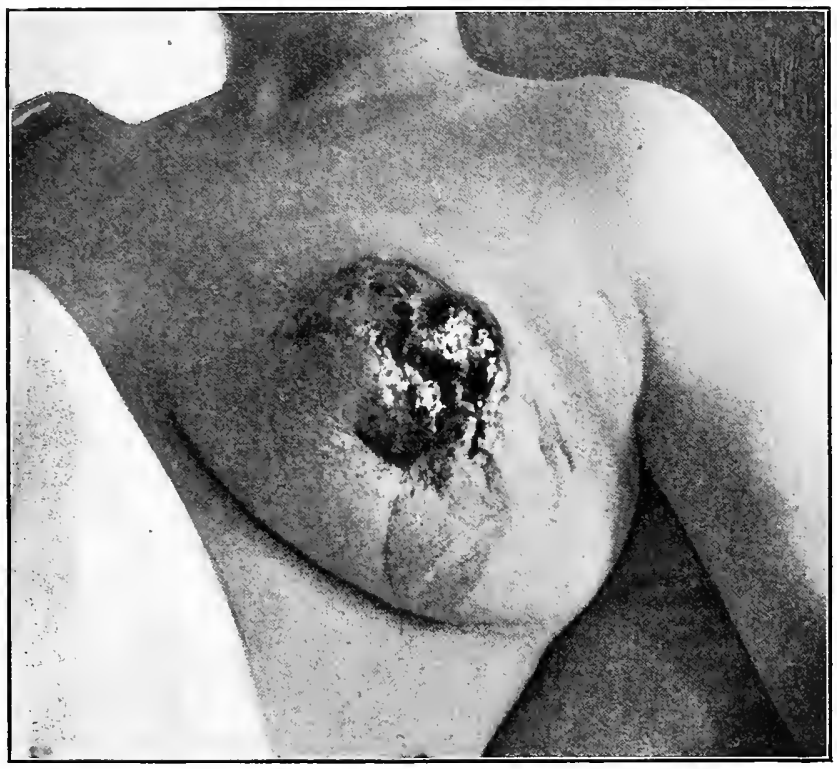

FIG. 200.-Ulcerating mammary carcinoma of the medullary variety. Inoperable.

Small amounts of pleural effusion or ascites at once suggest the probability of metastasis to the pleural or peritoneal membranes, but it must be remembered that their occurrence in a patient suffering from mammary cancer is by no means conclusive of their carcinomatous origin. Not infrequently masses of cancerous tissue are palpable in the pelves of women with a primary mammary growth. It is not unusual, however, for a pelvic tumor to occur independently of the growth in the breast so that the mere finding of a mass in this situation is not a positive contra-indication against operation. Paget found that mammary cancer is frequently associated with fibroid tumors of the uterus. Therefore, while it is advisable to examine the pelvic viscera, as a routine measure, in patients with malignant tumors of the breast, we must not conclude that every mass found during the course of such examinations, is a metastatic growth. It is advisable, according to Leaf, to perform exploratory laparotomy in all cases where 
doubt exists as to the nature of a mass in the pelvis of a woman with cancer of the breast. We have never met with such indications. Care must likewise be exercised in eliminating from operation all cases in which the liver or other of the abdominal viscera contain metastatic growths. It is often extremely difficult to determine the presence or absence of upper abdominal metastases in the absence of palpable nodules on the surface of the liver or in the absence of enlargement of the liver. Handley states that epigastric tenderness in a woman with a tumor of the breast should excite grave suspicion of cancer metastasis.

The skeletal system should be skiagraphed, as suggested by Judd, especially those parts of it in which metastatic cancer is suggested by the clinical history or by the

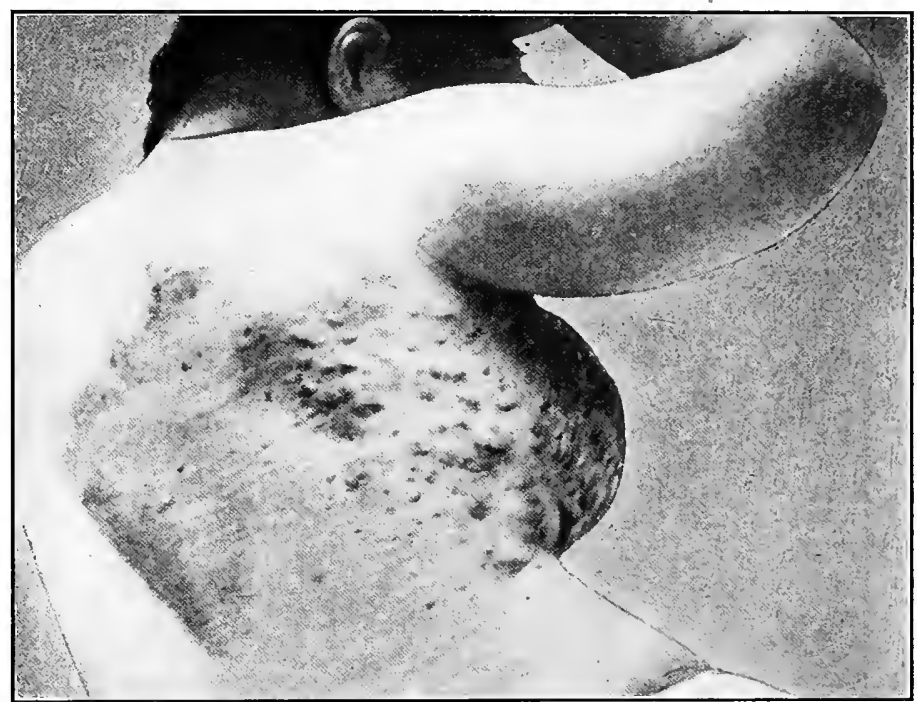

Fig, 20r.-Dorsal view of same patient as is shown in following figure. Patient of Dr. Charles H. Frazier.

physical findings. Pain in the knee or hip should immediately suggest the probability of metastasis to the "upper end of the femur, a frequent location for metastatic cancer arising primarily in the breast; lumbago, sciatica, lame back, are often due to cancerous involvement of the vertebral bodies in the lower dorsal or upper lumbar regions. The mid-point of the humerus is a frequent site for the lodgment of metastatic cancer cells from the breast and this area should always be examined. The chest in particular should be submitted to a painstaking physical and fluroscopic examination. In the presence of a tumor of the breast that has become adherent to the underlying structures, a skiagraph should be made of the ribs in relation with the tumor; involvement of the latter is an indication of inoperability of the tumor. Mistakes are, of course, inevitable despite the most careful examination, but many patients will be spared a needless operation by routine physical examination. 
It is the duty of the surgeon to determine, as far as is possible, the operability of each case of mammary cancer; yet it is no less important for the physician to make every effort to determine the presence or absence of distant metastases before attempting to discuss the prognostic aspects of the case. This applies to those cases that are apparently favorable, as well as to those in which the disease is obviously more advanced.

The local signs of inoperability in mammary cancer are extensive adhesions between the tumor and the chest wall including the periosteum of the underlying ribs and the intercostal muscles, extensive ulceration, widespread "cancer en cuirasse" subcutaneous nodules situated at some distance from the parent growth, involvement of the lymph nodes in the opposite axilla, and extensive supra-clavicular lymph-node involvement.

The dividing line between operable and inoperable cases of mammary cancer, when based entirely on the local condition of the disease, is not clearly defined, and while opinion among surgeons is not unanimous as to the proper course of procedure in cases presenting border-line complications, we advise radical operation when the physical examination indicates that all of the diseased tissues can be removed. In many of these cases, it is found at the time of operation to be impossible completely to remove the disease owing to the extensive involvement of the tissues at the apex of the axilla, or in the posterior triangle of the neck. In a larger percentage of cases, the disease recurs either locally or in the internal organs, showing that the operation was incomplete or that internal metastasis had already occurred at the time of operation.

In all border-line cases, however, we are prone to give the patient the benefit of the doubt and to attempt the radical removal of the tumor.

Class B.-Inoperable but presenting the indications for some palliative operation. The benefits to be derived from operative treatment in cases belonging to this group are problematical so that the best interests of medicine in its broadest application would be served by allowing these patients to be "living examples of ill-advised delay instead of unsatisfactory results of ill-advised surgery" (Mayo).

Many surgeons do not believe in taking "the gambler's chances in treatment" in these cases, as Bloodgood advises, since nature has given indisputable proof of her mastery in the late stages of malignancy. The records of the Johns Hopkins Hospital show that clear clinical evidence of the malignant nature of a mammary neoplasm reduces the chances of operative cure to 25 per cent. This applies to cases presenting adhesions to the skin, retraction of the nipple and other classical symptoms of the disease. A ratio of 5 per cent. of cures in cases presenting ulceration of the tumor and other more advanced symptoms would be an extremely generous estimate. Indeed, operative cure in the latter class of cases is exceptional and in our opinion should rarely be attempted, while surgical attempts at the palliation of the symptoms should only be made with the full understanding that no hope of cure is entertained.

In cases presenting the indication for some palliative operation we are inclined to follow the dictates of a moral rather than a scientific obligation; we never refuse to perform an operation of this kind where the slightest chance exists of increasing the patient's comfort. It is our belief, however, that inter-scapulo-thoracic amputation, partial resection of the chest wall and similiar extensive operations undertaken with the idea of radical removal of the disease, and in the absence of some indication for a palliative operation, are strongly to be condemned.

The fact that an occasional success is achieved after a very extensive operation does not alter the facts of the case since these, as we will show later, are most exceptional. 
Palliative operations are to be considered when the patient is suffering great pain either as the result of local ulceration or nerve pressure from a metastatic growth.

It is likewise-justifiable to remove a sloughing malodorous mass. Patients with mammary carcinoma who die as the result of internal metastasis undoubtedly suffer less pain than those in whom toxemia arising from ulceration of the primary growth is the actual cause of death. This in itself justifies excision of ulcerating tumors of the breast.

Excruciating pain referred down the arm of the affected side may become an urgent indication for operation. Division of the cords of the brachial plexus has been resorted to under these circumstances and the resulting paralysis has proved less burdensome to the patients than the pain from which they suffered before operation. It is a debatable

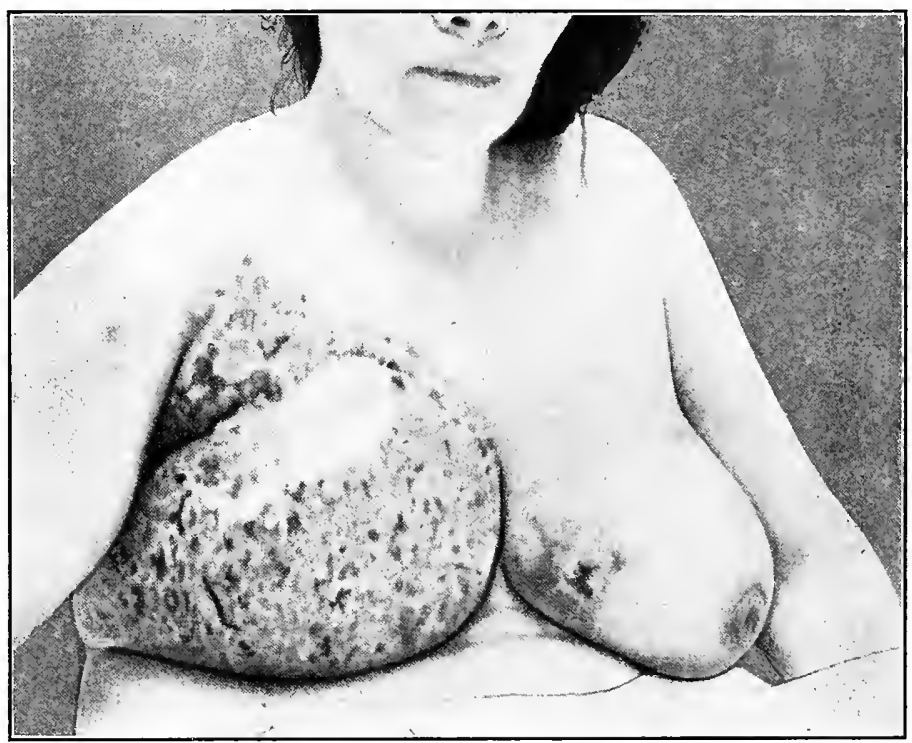

FIG. 202.- Widespread cancer en cuirasse showing numerous nodules in the skin with involvement of both breasts. Patient of Dr. Charles H. Frazier.

question whether one is justified in deluding hopeless cases with a hopeful prognosis for operations that cannot do more than give transient relief. The temporary relief from mental distress that this deception affords is, we believe, sufficient justification for its practice in many instances; the late Dr. Agnew advised radical amputation of the breast for carcinoma when it was his belief that the operation not only failed to cure the disease but actually shortened the life of the patient, this advice he gave with the firm conviction that the temporary relief from worry on the part of the patient was a legitimate indication for the operation.

On rare occasions it becomes necessary to ligate the sub-clavian artery to arrest hemorrhage from an ulcerating mammary carcinoma; in the great majority of cases, however, the bleeding can be controlled by pressure. 
In our opinion it is quite as reprehensible to undertake radical operations in hopeless cases and to refuse palliative operations when these are indicated, as it is to do incomplete operations in cases in which radical treatment alone promises a good chance of permanent cure.

Class C.-Cases which are clinically malignant but apparently operable.

The chances of cure after the most radical operation is only one in five in this class of patients. In the majority of them all of the involved tissues are removed at the time of operation, so far as can be determined by touch and sight, notwithstanding which the disease promptly recurs either locally or internally.

Palpably enlarged lymph nodes are present in the posterior triangle of the neck in a small percentage of these cases. The operative technic should include the cleansing of the subclavian triangle if any operation be attempted, although metastatic involvement of the cervical lymphatics is an extremely evil prognostic sign in carcinoma of the breast. We do not advise operation in the presence of marked supra-clavicular involvement, and never explore this space in the absence of palpable enlargement of the nodes. Some surgeons advise routine exploration above the clavicle, others advise it in the presence of palpable involvement, while still others limit supra-clavicular dissection to cases in which there is either palpable enlargement of the contained lymph nodes or in which the primary growth occupies the upper inner quadrant of the breast. The latter area, it will be remembered, is partly drained by a lymphatic trunk which leads directly to the lower cervical nodes.

The question of treatment in cases of mammary cancer complicated with enlarged cervical lymph nodes is ably discussed by Leaf who remarks, quoting Halsted, that "in 66 per cent. of cases of cancer of the breast, the lymph nodes above the clavicle are not involved when the patient is first seen," and that, therefore, "in two-thirds of the cases, invasion of this space would be entirely useless." Continuing, he says, "Even if we knew that the glands were affected in every case, it has never been proved that the procedure in any way tends to prevent the recurrences or delay their appearance."

It has been suggested that exploration of the supra-clavicular space be made in the presence of palpably enlarged nodes, as a preliminary step in the operation; if the enlargement prove to be cancerous, the radical operation can be proceeded with or dispensed with as conditions seem to warrant. It is sometimes a difficult matter to differentiate cancerous enlargement of a lymph node from that caused by inflammatory changes; in all cases of this kind where a reasonable doubt exists, it is our practice to explore the posterior triangle of the neck as the initial step in the operation. If the enlargement prove to be inflammatory in nature, the radical operation is proceeded with, if cancer metastasis is found, all attempts to remove the disease are withheld except in the very rarest instances, i.e., in cases with the nodes small in size, few in number, and unattached to the surrounding structures.

Halsted was the first to advocate routine exploration of the supra-clavicular triangle, and in his report of 76 cases of carcinoma mammæ which were free of recurrences after three or more years, there were seven cases (9 per cent.) that had had supra-clavicular involvement at the time of operation. These results would seem to justify this step in the operation, but Halsted himself has recently discontinued the practice in the majority of cases. Indeed, few surgeons invade the posterior triangle of the neck in the operation for carcinoma of the breast, in the absence of enlarged lymph nodes. Undoubtedly the disease has already invaded the anterior mediastinum in most cases where the supraclavicular lymph nodes have become palpably enlarged, and few of these cases, therefore, 
are suitable for any operation, but if the latter be attempted, dissection of the cervical nodes must not be omitted. Widespread involvement of the deep cervical lymphatics always denotes inoperability of the mammary cancer.

Classes $D$ and E.-Cases in which a positive diagnosis cannot be made but in which the clinical evidence points either to benignancy or malignancy, as the case may be. Four out of five cases that fall into either of these groups can be cured by radical amputation of the breast. The selection. of the proper form of treatment for cases of this kind demands wide experience on the part of the surgeon and the assistance, in many instances, of a pathologist. The mistake usually made is that the operations are incomplete-rarely is a mistake of this kind made by a surgeon of wide experience, but it is one of the commonest errors to the discredit of the occasional operator. The correct diagnosis is the first essential; without this it is merely a matter of good fortune if the proper thing is done. The diagnosis is made in many instances only after examination of the cut surface of the tumor and microscopic examination (frozen sections) of sections of it. The first step in the operation in cases of this kind is an incision into the tumor for the purpose of diagnosis. This incision may be made through the skin overlying the tumor or a Thomas incision may be employed to expose the neoplasm, the latter being the preferable method in the majority of cases. The Thomas incision gives better cosmetic results in the event that a simple excision of a benign tumor is all that is required, and it in no wise adds to the difficulty of the operation required, if the growth prove to be malignant. The Thomas incision is also preferable for the reason that with the posterior surface of the breast exposed, it can be bisected in several planes, and a very thorough examination made, without danger or multilation of the organ. If the mass prove to be carcinomatous, the radical operation is proceeded with immediately, otherwise a pathological report of the most suspicious areas of the mass is awaited. The common practice of excising portions of mammary tumors for diagnostic purposes, and defering operation for days or even weeks until a pathological report is received, cannot be too strongly condemned. This method has been proved to spread the disease beyond the reach of the knife in many cases, so that an originally hopeful becomes a hopeless case with the lapse of this short time.

Operation for Recurrent Mammary Carcinoma.--The rules governing the operability of local or regional recurrence of mammary carcinoma are practically the same as those applying to primary cases. As in the case of primary tumors, excision is advisable when the physical examination indicates the possibility of complete ablation of the diseased tissues. Local recurrences in the line of the scar or in the skin adjacent to the scar following a radical operation should be removed together with a segment of the healthy skin adjacent to the cancer nodules. In those cases where an incomplete operation has been done, the muscles should be removed and the axilla cleansed.

Irradiation with the $X$-rays or radium is especially useful in cases of local recurrence after the radical operation, and they, in large measure, obviate the necessity of very extensive operations. In the event of local or regional recurrences that are widespread and have involved the chest wall, it is better to depend upon irradiation than to attempt extensive operations that afford only a minimal chance of completely removing the disease.

The Modern Operation.-Each step in advance in the operative treatment of malignant disease has come as the result of a clearer understanding of the process, especially that phase of it concerned with the local dissemination of the cancer cells.

The enunciation of metastatic principles and their practical application to the surgery 
of malignant neoplasms of the breast, is generally credited to Charles Moore, a surgeon on the staff of the Middlesex Hospital of London, who, in 1867 , presented a paper before the Royal Medico-Chirurgical Society of London, that described in principle at least, the necessary steps of a radical breast amputation (Trans. Royal Med. Chir. Soc., London, Vol. $x, x 867)$.

Other leading surgeons of the day had a clear understanding of cancer dissemination to the axillary lymphatics from a primary tumor in the breast, and according to W. Watson Cheyne (The Lancet, r904, Vol. r, p. 699), Lord Lister removed the axillary fat and its contained glands in every case of mammary carcinoma as early as "the late sixties." It is questionable, however, if this measure was carried out routinely; Küster was perhaps the first to explore the axilla in every case of mammary carcinoma, a procedure that became popular in this country after the appearance in $r 880$, of the younger Gross' book, "Tumors of the Mammary Gland."

It is interesting to recall that the quarter century succeeding Moore's contribution to the surgical treatment of cancer of the breast, was pregnant with scientific strife concerning the pathogenesis of tumors.

The theory of the systemic nature of malignant processes had become deeply rooted in the minds of many investigators, so that Moóre's advocacy of a method so entirely at variance with the almost universally accepted doctrine is truly remarkable.

The surgical profession accepted the principles of radical breast amputation as laid down by Moore with a reluctance that is difficult for us to understand, but at the same time the developmental work inspired by his teachings bore fruit in the gradual evolution of the complete and truly radical operation as it is now performed and with the final perfection of which the names of Halsted, Willy Meyer, Volkmann, and W. Watson Cheyne will always be associated.

Experimentation in the processes of cancer dissemination by pathologists and surgeons whose work immediately antedates that of Halsted, and to which we have referred at length in the chapter on metastasis, should not be forgotten, since the radical operation as perfected by Halsted is merely a superstructure built on the discoveries made by these investigators.

The pathogenesis of regional recurrences after operations for the removal of cancerous breasts was entirely misunderstood before the time of Halsted's studies. Billroth, for instance, applied the term "regional recurrence" to the return of the cancer after a long period of time (about one and one-half years), which led to the conception, now believed to be false, that the recurrent growth was a new process depending either upon a cancer diathesis, or upon a local predisposition in the scar. Halsted's analysis of the statistics published by Billroth, Bergmann, Czerny, Volkmann, and other prominent authorities, demonstrated the fact that local recurrence took place in from 80 to $9 \circ$ per cent. of their cases. These operative statistics were collected over the period extending from $\mathrm{r} 867$ to $\mathrm{r} 890$, and many of the operations were performed before the practice of systematically cleansing the axilla had become the custom.

Halsted became convinced from his studies of the subject that the operation then in vogue left much to be desired, and concluded that its shortcomings were due to the incomplete removal of the cancer-laden tissues. About this time American surgeons were extremely skeptical of the value of breast amputations for carcinoma and looked upon this disease with prognostic despair. That this was not justified by the results obtained through operation seems obvious when we recall the hopeless state of affairs that had existed in the treatment of malignant disease in previous decades. 
Indeed, if we turn to the writings of Sir Astley Cooper and Velpeau, both of whom anticipated the modern viewpoint of cancer dissemination and its practical application in the treatment of mammary cancer, we find authentic records of surgical cures in this disease, results which should have, it would seem, stimulated not only the operative efforts of succeeding generations of surgeons, but also engendered a feeling of optimism as to the ultimate outcome of the disease, that seems to have been woefully lacking.

Volkmann's early advocacy of the advanced ideas as originally brought forth by Moore, together with his own excellent contributions to the pathology of malignant disease, justifies our acceptance of his methods and the results obtained as the basis of contrast between the pre-radical and radical or modern eras of the operative treatment of cancer of the breast.

Excision of the pectoral muscles was first practised by Volkmann but only in cases in which the muscles were visibly invaded by the disease. In a few cases he excised both the pectoralis major and minor muscles, more often the pectoralis major alone was removed. In the 38 cases comprising the series in which Volkmann removed the pectoral muscles, the disease was apparently far advanced, since in every instance one or both of the muscles were invaded, and this, as we now know, is a late stage of the disease. True local recurrence took place in only 35 per cent. of the cases in which the muscles were removed, and in only $5^{8}$ per cent. of cases was there either local or regional recurrence.

When we take into consideration the fact that these cases were advanced to the stage that we now look upon as practically inoperable, and furthermore, that there were 60 per cent. of recurrences in early cases in which the muscles were not removed, not only are the results obtained by Volkmann remarkable, but the inference is clear that removal of the muscles per se or through greater facility of approach to involved fascial and lymphatic structures explains the large percentage of cures.

It remained for Halsted to appreciate the sanity of removing the muscles in every case of carcinoma of the breast.

That other American surgeons recognized the advantages of a more radical procedure, is evidenced by a peculiar coincidence in the history of the operation as we now perform it. Willy Meyer prepared a paper, to be read before the section on surgery of the New York Academy of Medicine, Nov. I 2, I894, on a method of radical removal of the breast identical in all essential details with the Halsted method; the description of the latter appeared in the Annals of Surgery, Nov. 2, of the same year (1894). It is also worthy of note that $\mathrm{W}$. Watson Cheyne had devised and was using a similar technic at this same time.

The influence of foreign writings, especially those of Volkmann, is apparent in Halsted's original paper when he says: "With the exception of perhaps Billroth, Volkmann is the only one of the surgeons quoted who occasionally removed the pectoral muscles. But his operation is an imperfect one. It admits of the frequent division of tissues which are cancerous and it does not give the disease a sufficiently wide berth. Why should we shave the under-surfaces of the cancer so narrowly of the pectoralis major muscle when a part of it can be removed without danger, and without causing subsequent disability, and if there are positive indications for its removal?" Continuing, he says: "The pectoralis major muscle, entire, all except its clavicular portion, should be excised in every case of cancer of the breast because the operator is enabled thereby to remove in one piece all of the suspected tissues. The suspected tissues should be removed in one piece lest the wound become infected by the division of tissue invaded by the disease, or by 
division of the lymphatic vessels containing cancer cells, and because shreds or pieces of cancerous tissue might readily be overlooked in a piecemeal extirpation."

The principles of the block operation have now been extended to conform with the anatomy of other cancer involved organs. We have learned that there is a local predisposition to the cancer process, that auto-transplantation of cancer cells while exceedingly easy in the area primarily involved, is difficult in more remote areas, and finally that cutting into a cancer nodule during the course of an operation for its removal is attended with danger analogous to that of opening an appendiceal abscess into the free peritoneal cavity and should as assidiously be avoided.

The history of the modern operation since the time of Halsted's contribution is merely that of essentially unimportant technical improvements. Most surgeons, including Halsted himself, now begin the dissection at the apex of the axilla rather than from below, as in the original operation. This is a rational procedure for many reasons among which the elimination of the danger of traumatic dissemination of cancer cells along the lymphatics is most important. That this is not merely a theoretical possibility, has been proved by a study of the location of local recurrences of the disease after the employment of the two methods; it is a well-established fact that local recurrences are more frequent in the vicinity of the lower angle of the incisional scar when the dissection is begun above and vice versa.

Long before the removal of the pectoral muscles had become a recognized part of radical amputation of the breast, it was the practice of Gerster, the junior Gross, Kocher, and others, to begin the operation for mammary carcinoma by primary dissection of the axilla. Thus in the second German edition of Kocher's "Textbook of Operative Surgery," p. II4, the following comment is made on this step in the operation:

"It is customary in excising the mamma to make the incision along the lower border of the gland but this is opposed to the principle which we have heard Langenbeck lay down in his clinic, namely, always to begin the operation at the side whence the greatest blood supply is derived because the main vessels can then at once be seized and if necessary ligatured. But here a still more definite principle is present for matzing the incision at the upper border of the gland first and it is this, in order that the axilla may be cleared of all its fat, fascia and glands high up, and also that it may be rendered as accessible as possible both upward and downward, the incision is carried along its anterior fold and the fascia pulled downward and backward together with the tissues connecting the axillary contents with the mamma. It is, therefore, absurd to remove the gland from below and to clear out the axilla from above, as both should be removed in direct connection with the lymphatic vessels lying between."

He then describes the operative technic which consisted merely of a primary cleansing of the axilla without removal of the muscles, followed by excision of the breast.

In the interval that elapsed between the appearance of the second edition of his operative surgery and the fourth German edition of the book, r $895^{-1903}$, Kocher became convinced of the necessity of the removal of the muscles in operating for the radical cure of mammary cancer, but, contrary to the teachings of Halsted, clung to his belief in the principle which he had learned from Langenbeck, namely, to begin the dissection in the axilla and only after this has been completed, to proceed with the removal of the breast. The operation which he describes (Theodor Kocher, "Textbook of Operative Surgery," translated from the fourth German edition by Harold J. Stiles, Adam and Charles Black, I903, London, p. 159) has been slightly modified and popularized to some extent in this country by Rodman of Philadelphia.

One of the most important additions to the original operation, is the practice of removing the deep fascia wide of the limitations of the breast, a practice based on Handley's admirable studies of the processes of malignant dissemination. Acceptance 
of his views compels the surgeon in operating for carcinoma of the breast to fashion the skin flaps so that the center of the growth and not the nipple, is equidistant from the lines of the incisions, a practice which we have long employed. Handley's teachings obviate, in the ordinary early case, the necessity of extreme excision of skin areas, which should be, he says, "no greater than is compatible with easy closure of the wound." This is contradictory to the teachings of Banks, Halsted, Meyer and many other surgeons who taught, and some of whom are still insisting upon, the necessity of removing large areas of skin, so large in fact that skin grafting becomes necessary in the ordinary early case. This question is, at the present time, sub judice, but Handley's arguments which are based on careful clinical and pathological observations and sound reasoning, are most convincing and compel one to accept his views. He has added the most important refinement to the operative technic of mammary carcinoma since Halsted devised the modern operation.

Murphy adheres to the view that removal of the pectoral muscles is unnecessary and advises utilization of a portion of the major muscle to cover the denuded axillary structures. This, he maintains, minimizes the complications, neuralgia, venous stasis, etc., resulting from pressure and traction upon the axillary structures consequent upon the * healing of a dead space in the axilla.

Murphy stands practically alone among American surgeons in this contention, and, in our opinion, this method cannot be too strongly condemned. As a means of support to the axillary structures, the displaced pectoral muscle undoubtedly serves its purpose admirably in Murphy's hands, but there is no necessity for it, so far as our experience goes.

At a meeting of the Association française pour l'étude du cancer, rgog, Renaud, Delbet, Lucas-Championierè, and Schwarz were unanimous in the opinion that removal of the pectoral muscles is indicated when the tumor is adherent to these structures, but that it is of no advantage in other cases, so far as the prevention of recurrences is concerned. Statements of this kind could not come from surgeons familiar with the work of Volkmann; it was appreciation of the fallacy of this very teaching that led Halsted to devise the radical operation; it is a voice from the grave of the incomplete, imperfect surgery of carcinoma.

The pectoral muscles are frequently involved in early cases of cancer of the breast. Heidenhain was the first to prove by microscopic examination that the cancer cells invade the pectoral muscles, an observation that antedated Halsted's work by five years. Since that time, Stiles, Handley, Lockwood and Speese have confirmed the accuracy of Heidenhain's observations.

The recent work of Speese while merely confirmatory of that which had already been proven, is so conclusive that we quote at length from his paper:

"In order to ascertain how frequently the muscle (pectoralis major) is involved, and with the desire to determine whether it is ever justifiable to preserve it, the following investigation was undertaken.

"One hundred breasts with the attached pectoral muscles were examined in the order in which they came to the surgical laboratory, so that the study includes all varieties of cancer, in its early stages and late stages, and in cases arising in benign tumors. Sections of the great pectoral muscle were taken from the point nearest the tumos, and in several other areas, in all specimens. The muscle was considered as involved when the microscope revealed cancer cells in contact with the muscle on the fascial surface; when the cancer occupied lymphatics or spaces between the muscle bundles; or, 
as in the advanced cases, when the muscle tissue was destroyed by the carcinomatous invasion.

"On microscopic examination, 25 of the specimens showed involvement of the muscle by cancerous extension, and of these the fascia was involved in I8. In I9 the pectoral fascia contained the evidence of cancer and the muscle was free, therefore, we find that in 37 instances the pectoral fascia was involved. Further study of the specimens in which muscle metastasis was noted presented some unexpected findings. In nine specimens it could be determined that the muscle was involved grossly. In a few instances the microscope did not disclose muscle involvement when it was suspected from the gross appearance; the pectoral fascia although greatly thinned out and compressed seemed to limit the disease even in very large tumors. In five specimens in which the tumor was not in contact with the fascia, metastasis to the muscle occurred; these growths were situated $\mathrm{I} \mathrm{cm}$., $1.5 \mathrm{~cm} ., 2 \mathrm{~cm} ., 3 \mathrm{~cm}$., and $4 \mathrm{~cm}$. from the fascia respectively. In many of the large ulcerating carcinomas extending from the skin to the fascia and apparently to the muscle, the latter was free from involvement; on the other hand, in some of the small tumors, not grossly in contact with the fascia or muscle, the microscope revealed the presence of metastatic cells in the pectoralis major.

"The facts gained from this study do not present anything distinctly new; they serve, however, to call our attention to the importance of the complete operation. Certainly when so large a number of the cases show muscle involvement, when we are unable to foretell which tumor will metastasize to the pectoral muscle, it is better to remove the latter, minimize the danger of local recurrence, and avoid the far greater danger of further dissemination of the cancer by contraction of the muscle in which the cancer cells may lie."

Before accepting any reactionary teaching that departs from the principles of the radical operation, let us, therefore, await the report of large series of cases from those who now employ incomplete operations, showing better end results that are now obtained by Halsted and his followers.

The Halsted Operation.--The steps in the original Halsted operation as described by its originator are as follows:

r. The skin incision is carried at once and everywhere through the fat.

2. The triangular flaps of skin $A, B, C$ (vide Plate $\mathrm{x}$ ) is reflected back to its base line $C D$. There is nothing but skin in the flap. The fat which lined it is dissected back to the lower edge of the pectoralis major muscle, where it is continuous with the fat of the axilla.

3. The costal insertions of the pectoralis major muscle are severed, and the splitting of the muscle, usually between its clavicular and costal portions, is begun and continued to a point about opposite the scalene tubercle on the first rib.

4. At this point the clavicular portion of the pectoralis major muscle and the skin overlying it are cut through hard up to the clavicle. This cut exposes the apex of the axilla.

5. The loose tissue under the clavicular portion (the portion usually is left behind) of the pectoral major muscle is carefully dissected from this muscle as the latter is drawn upward by a broad sharp retractor. This tissue is rich in lymphatics and is sometimes infiltrated with cancer (an important fact).

6. The splitting of the muscle is continued out to the humerus and the part of the muscle to be removed is now cut through close to its humeral attachment.

7. The whole mass, skin, breast, areolar tissue, and fat, circumscribed by the original skin incision is raised up with some force to put the submuscular fascia on the stretch as it is stripped from the thorax close to the ribs and pectoralis minor muscle. It is well to inclucte the delicate sheath of the minor muscle when this is practicable.

8. The lower outer border of the minor muscle having been passed and clearly exposed, this muscle is divided at right angles to its fibers and at a point a little below its middle.

9. The tissue, more or less rich in lymphatics and often cancerous, over the minor muscle near its 
coracoid insertions is divided as far as possible and then reflected inward in order to liberate or prepare for the reflection upward of this part of the minor muscle.

ro. The upper outer portion of the minor muscle is drawn upward with a broad sharp retractor which until now has been holding back the clavicular portion of the pectoralis major muscle.

rr. The small blood-vessels (chiefly veins) under the minor muscle near its insertion must be separated from the muscle with the greatest care. These are embedded in loose connective tissue which seems to be rich in lymphatics and contains more or less fat. This fat is often infiltrated with cancer. These blood-vessels should be dissected out very clean and immediately ligated close to the axillary vein.

r2. Having exposed the subclavian vein at the highest possible subclavicular point, the contents of the axilla are dissected away with scrupulous care also with the sharpest possible knife. The glands and fat should be pulled away with the fingers. The axillary vein should be stripped absolutely clean. Not a particle of extraneous tissue should be included in the ligatures which are applied to the branches, sometimes very minute, of the axillary vessels. In liberating the vein from the tissues to be removed, it is best to push the tissues away from it. It may not always be necessary to expose the artery, but I think that it is well to do so, for sometimes, not usually, the tissue above the large vessels is infiltrated.

I3. Having cleansed the vessels we may proceed more rapidly to strip the axillary contents from the inner wall of the axilla-the lateral wall of the thorax. We must grasp the mass to be removed firmly with the left hand and pull it outward and slightly upward with sufficient force to put on the stretch the delicate fascia which still binds it to the chest. This fascia is cut away close to the ribs and serratus
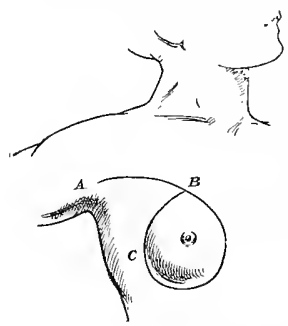

FIG. 203.-Halsted's incision. magnus muscle.

$x_{4}$. When we have reached the junction of the posterior and lateral walls of the axilla, or a little sooner, an assistant takes hold of the triangular flap of skin and draws it outward to assist in spreading out the tissues which lie on the subscapularis, teres major and latissimus dorsi muscles. The operator, having taken a different hold of the tumor, cleans from within outward the posterior wall of the axilla. Proceeding in this way we make easy and bloodless a part of the operation which used to be troublesome and bloody. The subscapular vessels become nicely exposed and caught before they are divided. The subscapular nerves may or may not be divided.

r5. Having passed these nerves the operator has only to turn the mass hack in its normal position, and to sever its connection with the hody of the patient by a stroke of the knife, repeating the first cut through the skin. All that has been removed is in one piece.

Halsted's Modification of the Original Operation.-After I9 years experience with the operation devised by himself, Halsted has recently suggested certain modifications that should claim our careful attention.

It is interesting to note in this connection that Willy Meyer, who in 1894 , devised an operation very similar to Halsted's, also recommends certain modifications of it that are essentially the same as those recommended by Halsted.

Both surgeons are firmly convinced that the excision of wide areas of skin is necessary to make an amputation of the breast truly radical and, as the preferable means of closing the defect, both recommend skin grafting.

The changes suggested by Halsted are as follows:

"The incision down the arm has been abandoned. The vertical cut to the clavicle is made as short as possible and when considerable skin has been removed, is omitted. Very often the circular incision surrounding the growth is made, but usually one or the other vertical incision have been made, one ahove, and one below the axilla, thus naturally facilitating the dissection of the axilla. Thus the triangular flap has been definitely abandoned.

"The skin of the outer flap hetween the two vertical incisions is utilized primarily to cover completely; without any tension whatever, and redundantly, the vessels of the axilla. The edge of the flap is stitched, by interrupted buried sutures of very fine silk, to the fascia just below the first rib in such way that the skin partly envelops the large vessels. Then along the entire circumference of the wound the free edge of the skin is sutured to the underlying structures of the chest wall, the wound being made as small as desirable in the process of closure, and tension on the upper or axillary part of the outer flap assiduously 
avoided. Considerable traction may, however, be exercised on the mesial flap and on the lower portion of the outer flap.

"Whatever the size and shape of the grafted defect, it should usually extend to the top of the axillary fornix. Thus the thoracic or inner wall of the apex of the axilla is always lined with skin grafts. The arm is adducted go or more degrees during the stitching of the wound and is not included in the dressing. Only the gentlest pressure is exerted by the bandage holding in place the gauze handkerchief which should be evenly applied with solicitous care. Particularly to be avoided is the placing of a wedge of gauze in the axillary fornix, and the using of this as a kind of fulcrum to he bridged over by the adducted arm. Drainage is unnecessary. Movements of the arm as free as possible are encouraged after the second day."

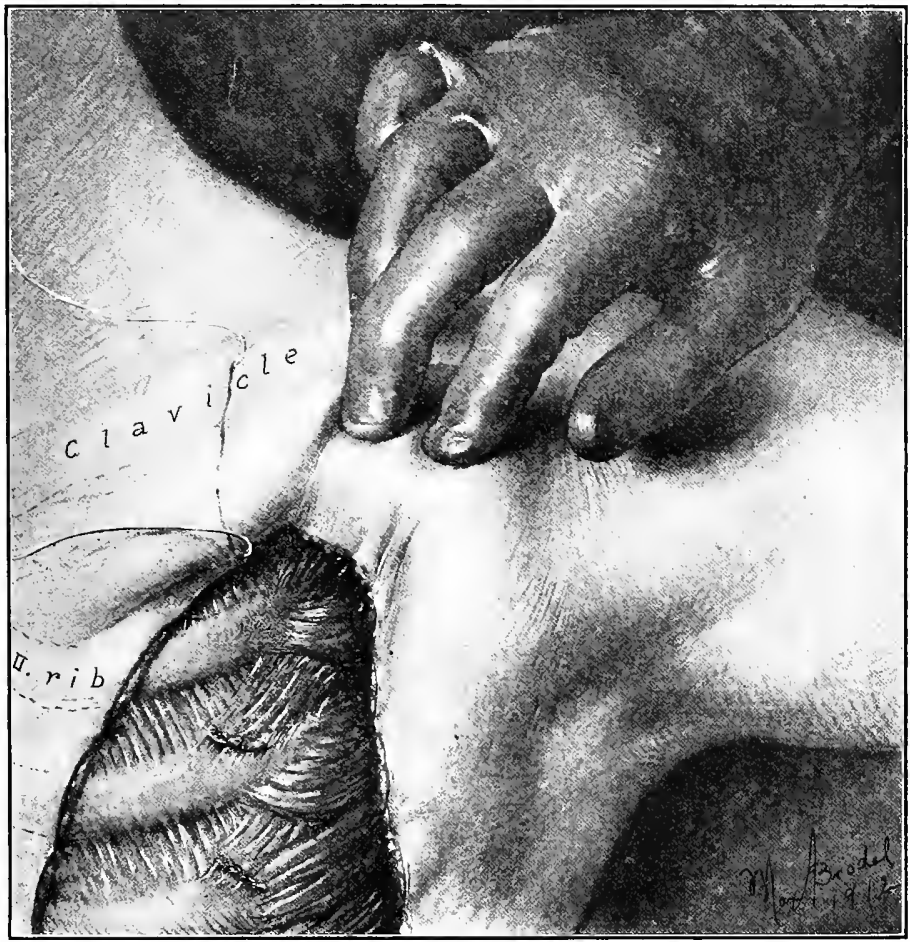

FIG. 204.- Halsted's method of radical amputation of the breast. The edges of the skin are sewed to the sides of the chest waIl and the defect is covered with Thiersch grafts.

Skin Grafting in the Operation for Carcinoma of the Breast.-Of late years we have not used skin grafts in the primary operation; complete closure of the wound is usually possible if the flaps are sufficiently undermined, and we can see no objection to this procedure. Occasionally it becomes necessary to fashion a flap to meet the exigencies of the particular case and sometimes it is necessary to make small incisions in the flaps on either side of the primary incision to relieve the tension, but this is exceptional. In rare instances, necrosis of the flaps takes place about the mid-point of the incision where the 
flaps are under the greatest tension and if the resulting defect be large, it must be closed; under these circumstances skin grafting is preferable to any plastic method.

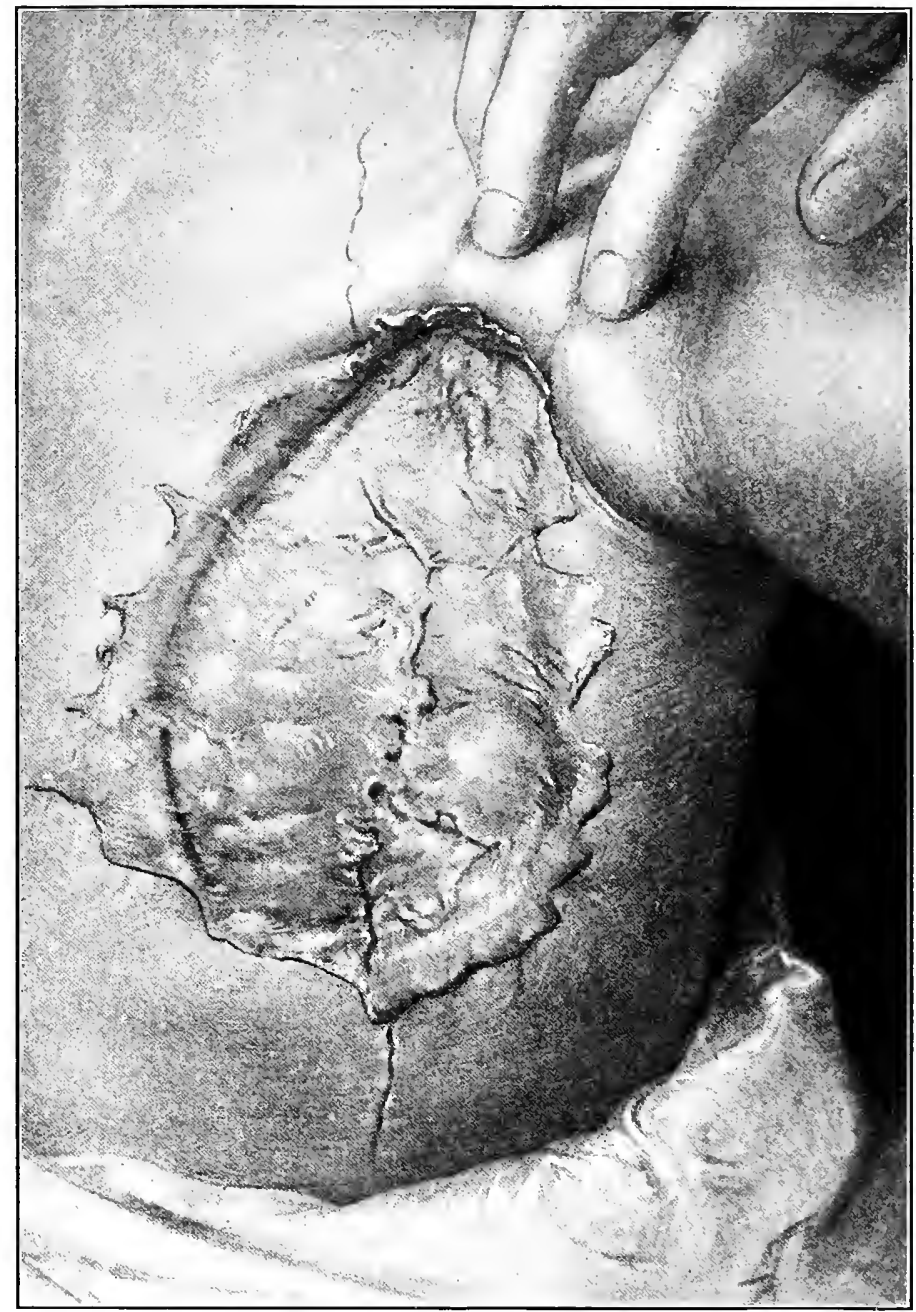

F1G. 205.---Halsted's method of skin grafting after radical amputation of the breast.

There are, however, good arguments to be advanced for skin grafting as a primary step in the operation. According to Halsted, the statistics at the Johns Hopkins Hospital 
show that the best results in the treatment of carcinoma of the breast have been obtained by those who removed the most skin. This is the best reason that could be advanced for so doing, but it does not prove that complete closure of the wound is incompatible with removal of sufficient areas of skin. The skin grafts are said to present a definite obstacle to the dissemination of cancer metastases, and on this account Halsted suggests that a moat be made around the cancer laden skin in cases of "cancer en cuirasse" by removing a strip of healthy skin and when granulation begins in the moat thus produced, that Reverdin grafts be made.

As regards the technic of skin grafting after the radical excision of the breast, this differs but little from that employed in other conditions. A dressing of silver foil is recommended by Halsted in clean cases where the dressing can be left undisturbed for a week; in secondary cases where the grafts must be placed on infected or granulating surfaces, fenestrated gutta-percha tissue is preferable to the silver foil.

Meyer preserves a stump of the pectoralis minor muscle to which the skin edge is sutured and upon the surface of which the skin grafts are placed. He, too, grafts immediately after the operation. The grafts (Thiersch) are cut as thin and long and wide as possible and are placed in the line running parallel with the long axis of the body. The ends are made to rest on the skin, their borders overlapping as the shingles of a roof. The area is bathed in normal salt solution. Imperforated rubber tissue is used to cover the grafted area.

Preparation of the Field of Operation.-The instructions given to the nurses in our clinic for the routine preparation of the field of operation are as follows:

I. Scrub and wet-shave the operative field at least I2 hours before operation; if possible give a warm tub bath. Put a clean gown upon the patient and place her in bed between clean sheets. bed.

2. Arrange solutions, bundles of sterile towels, sheets, etc., near the patient's

3. Scrub the hands thoroughly and put on sterile rubber gloves and sterile gown.

4. Surround the field of operation with sterile towels or sheets, being careful that the gloves do not come into contact with any non-sterile object.

5. Scrub the operative field with "antiseptic soap" and hot water for at least seven minutes by the clock.

6. Wash off with sterile water, rubbing away from the proposed line of incision.

7. Wash off with ether (94 per cent. ether, 6 per cent. alcohol, U. S. P.).

8. Wash off with "antiseptic cologne" (70 per cent. denatured alcohol).

9. Wash off with $\mathrm{I}-\mathrm{rooo}$ solution of bichloride of mercury.

I0. Apply sterile towel and hold in place with sterile bandage.

II. Four hours before operation protect the field of operation by sterile towels or sheets (wearing sterile gloves and gowns as before).

12. Wash off the field of operation with "antiseptic cologne," rubbing away from the proposed line of incision.

13. Cover the field of operation with sterile towels held in place by a sterile bandage.

I4. Two hours before operation, paint the field of operation with a 5 per cent. solution of iodine (iodine 5, potassium iodide 2, 95 per cent. alcohol ad. I00).

I5. Cover with sterile towel as before.

I6. Paint the field of operation with iodine solution on the operating-table. 
Since July, I9I5 we have been using a modified "McDonald solution" for preparing the field of operation in some cases; the solution recommended by McDonald has the following composition:
Alcohol. 59 parts.
Acetone. 40 parts. Pyxol I part.

A solution known as "Acetolphen", suggested by Whiting and Slocum and now employed routinely by us, has the following composition:

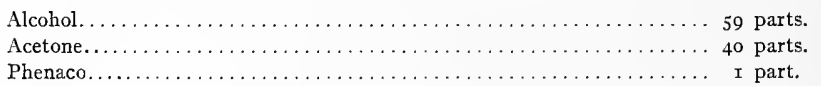

Phenaco is an ethical preparation being recognized as such by the Council of Pharmacy of the American Medical Association and, according to experimental and clinical studies made in the German Hospital clinic by Whiting and Slocum, is a more efficient germicide than is "Pyxol."

The technic is very simple: On the evening of the day of operation, the field of operation is washed, not scrubbed, with soap and water and a sterile towel is applied. Next morning the area is washed for two minutes with a piece of gauze saturated with the antiseptic solution. The field of operation is then protected with a sterile towel.

This concludes the preparation until the patient reaches the operating room where a second application of the solution is made just before incision. The solution is also used for the purpose of preparing the surgeon's hands. In emergency cases we have dryshaved the patients and applied the solution with good results.

Judging from a rather limited experience we are led to believe that this technic has merit; its simplicity is especially attractive in the preparation of cases of carcinoma of the breast since the danger of traumatic dissemination of the malignant cells is minimized through the omission of the prolonged scrubbing of the part.*

In operating upon ulcerated mammary tumors much post-operative trouble from infected wounds may be prevented by cauterizing the ulcerated surface before proceeding with the dissection. Any escharotic will answer this purpose but we prefer the actual cautery. Formalin is likewise useful for this purpose; the patient must be anesthetized before complete cauterization of the ulcerated surface can be accomplished.

Anesthesia.-Ether, administered by the drop method, is the anesthetic that we prefer in operations upon the breast, as it is, indeed, in all major operations. We have used stovain and strychnine intra-spinally in several cases of radical breast amputation and with the production of very satisfactory analgesia, but regard the method as dangerous, and believe that it should never be used in operations above the costal margins and only in exceptional instances in operations below them.

Chloroform has been given to a few of our patients in whom pulmonary complications or nephritis contra-indicated the use of ether.

Combination of nitrous oxide and oxygen is a safe anesthetic only in expert hands. We now perform a few radical breast operations under this form of anæsthesia.

Local Anesthesia.-The lowest mortality records for radical amputation of the breast have been reported from clinics where ether anesthesia is used routinely. A fact

*Note. We have lately discontinued the routine use of this technic in our clinic and are again using iodine. The solution is too irritating to the skin to use repeatedly in the preparation of the hands of surgeons and nurses. 
which would seem to indicate that local anesthesia is seldom called for. We almost invariably employ general anesthesia in operations on the breast, and can recall but few instances in which an otherwise operable case of mammary cancer was refused operation on account of the risk associated with the administration of a general anesthetic. Cases undoubtedly do occur, however, in which, on account of some systemic disease, it is desirable to eliminate every possible source of danger, and under such circumstances local anesthesia as recommended by Hirschel, Braun, Hohmeier and other German surgeons may be employed. Local anesthesia may be produced either by infiltrating the skin and subcutaneous tissue encircling the part to be operated upon, or by infiltrating the nerve trunks which send branches of supply to the part. In the technic used by Hohmeier for radical amputation of the breast, a combination of both methods is employed.

Local anesthesia conduces to incomplete operation, and in the treatment of tumors of the breast which are often diagnosable only after incision is made into them, one

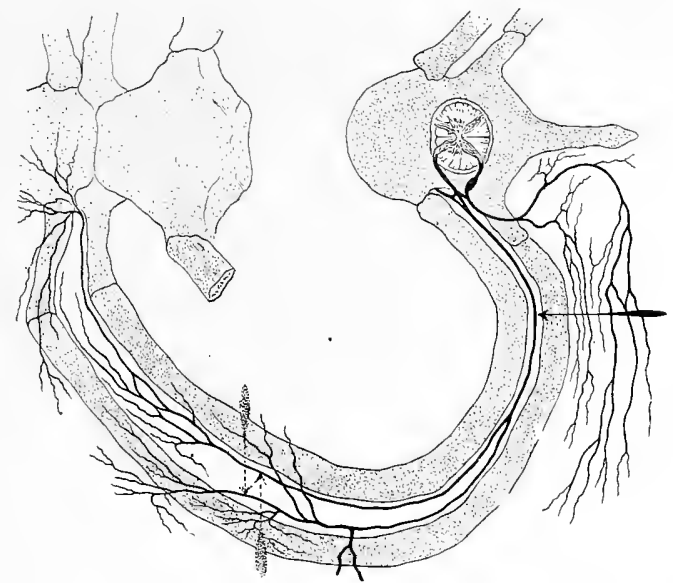

FIG. 206.-Arrows indicate sites of injection for the production of conduction anesthesia of the intercostal nerves.

should always be prepared to do the most radical operation despite the apparent simplicity of the mass to clinical examination. For this reason alone we believe that general anesthetics are preferable in all breast operations in the absence of systemic diseases which positively forbid their administration.

Conduction Anesthesia in Radical Amputation of the Breast.-The successful production of conduction anesthesia necessitates a careful mastery of the technic and a thorough knowledge of the sensory nerve supply of the part. The nerves that have to be taken into account in conduction anesthesia for the radical amputation of the breast are the intercostals, the internal and external anterior thoracic; the intercosto-humeral and the cords of the brachial plexus. The first intercostal does not give a lateral cutaneous branch to the thorax, and may, therefore, be disregarded. The lateral branches of the second and third intercostal nerves join with the lesser internal cutaneous branch of the brachial plexus to form the intercosto-humeral, which should be infiltrated independently of the others. Of the remaining intercostals, a sufficient number must 
be infiltrated to insure analgesia of the tissues at the lowest level of the operative field. This varies with the operative technic employed. It is always necessary to infiltrate a nerve below the lowest level of the operative incision to provide for overlapping of the cutaneous filaments. Interruption of conduction in the intercostal nerves may be produced by infiltrating the main trunk of the nerve at a point just posterior to the angle of the ribs: the needle is introduced midway between the ribs. A second and better method is the one advised by Hirschel in which the infiltrations are made along a vertical line immediately posterior to the mid-axillary line, in other words just behind the points of origin of the lateral cutaneous branches of the intercostal nerves. Both methods insure complete blocking of the nerves so far as their mammary distribution is concerned.

\section{The details of the technic as given by Hirschel are as follows:}

"From the point $a$ (see diagram) in the axilla the whole field of operation is circumscribed by subcutaneaus injections through $b, c$, etc., up to $k ; 0.5$ per cent. solution of novocain-suprarenin will be suffciently strong for the purpose. Then the intercostal nerves are anesthetized from the point $b, c$, etc,

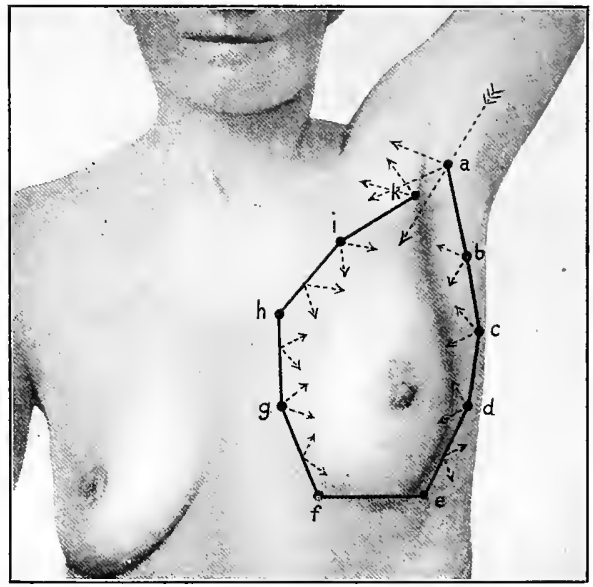

F1G. 207.-Points for injection of anesthetic for production of conduction anesthesia of the breast. (Hirschel.)

along the lateral line of circumscription (only three such injections have been indicated on the figure $b$; as a matter of fact some of the ribs are more important than others). The needle is introduced into the middle of the intercostal space and then turned, keeping in touch with the bone, first toward the border of the upper, then toward that of the lower rib. For this purpose approximately 8 to to cc. of r per cent. novocain-suprarenin solution will be required. On the medial side from points $f$ to $k$, the nerves need not be again injected; they are the points from which deep injections are carried into the pectoral muscles. The final and most important part of the procedure is the anesthetizing of the brachial plexus. This is done by introducing the needle at point $a$ and pushing it onwward under the pectoralis major toward the first rib along the course of the great vessels, which should be found by palpation; while doing this the solution should be injected all the time. The direction of the injections is indicated by arrows slanting from $a$. In addition to the brachial plexus, the conduction of the intercosto-humeral and anterior thoracic are interrupted by these injections. For anesthetizing the brachial plexus about 30 to $40 \mathrm{cc}$. of I per cent. solution of novocain-suprarenin will be required. Injury to the great vessels of the axilla has not so far occurred. The anæsthesia induced is always most satisfactory, even that of the brachial plexus." 
The method described by Hohmeier differs from the foregoing in that conduction along the intercostal nerves is not interrupted. Hohmeier injects novocain-suprarenin solution around and under the breast and along the edge of the latissimus dorsi muscle. This, together with blocking of the brachial plexus, is said to permit of radical amputation of the breast without causing the patient the least degree of pain.

Technic of Operation.-The operation for mammary carcinoma performed in the the German Hospital of Philadelphia is essentially the same as that advised by Halsted in his latest contribution on the subject, except that skin grafting is practically never employed, the wound being closed primarily, in the majority of instances.

The arm on the affected side is abducted almost to a right angle, and the forearm flexed; this position of the arm and forearm being changed from time to time in the course of the dissection. When the axillary vein is exposed and dissected free, the nurse holding the arm, is instructed not to put too much tension on the vessel. To

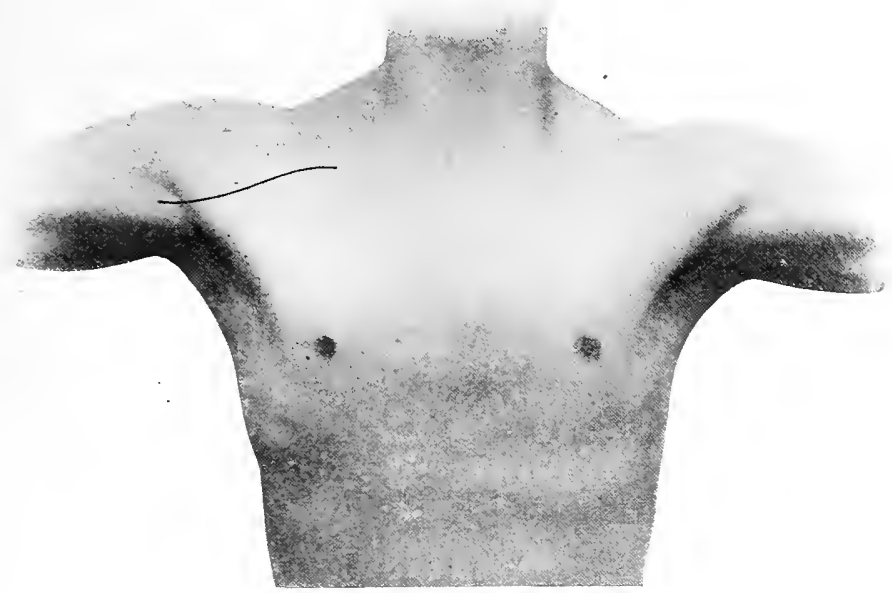

FIG. 208.-Line of the axiliary artery.

have the arm and forearm held and manipulated by an intelligent nurse is much more satisfactory to the surgeon than to bind the extremity to the table, as is the practice in some hospitals, or to a dissecting board, as advised by Turner. It also prevents any possibility of injury of the musculo-spiral nerve from pressure.

The patient's head is covered with a sterile rubber cap reinforced by a sterile towel, and her face is turned to the side opposite the field of operation; the latter is further excluded from the exhalations of the patient and the anesthetist by the disposition of sterile towels. In the absence of an experienced etherizer, the screen or towels should be omitted in order that the operator may be able to observe that the anesthesia is progressing satisfactorily. Under all circumstances, the anesthetist is provided with sterile rubber gloves, sterile ether bottle and sterile gauze. Ample protection of the operative field is afforded by sterile towels and sheets.

With these preparations completed, the surgeon determines as nearly as possible, 
by the position of the growth, the size and mobility of the breast and the mobility of the surrounding skin, the greatest distance that the incision can be carried wide of the breast to insure subsequent closure of the wound. When the growth is large, involving practically the whole breast, and the surrounding skin is not freely movable owing to a scarcity of fat in the superficial fascia, difficulty is frequently encountered in closing the wound.

Much may be accomplished by extensive subcutaneous dissection both laterally and medially. We believe that there is more danger in insufficient removal of the deep fascia in the average operable case, than of the skin likely to be involved. This method is not applicable to all cases of "cancer en cuirasse" nor where extensive ulceration has

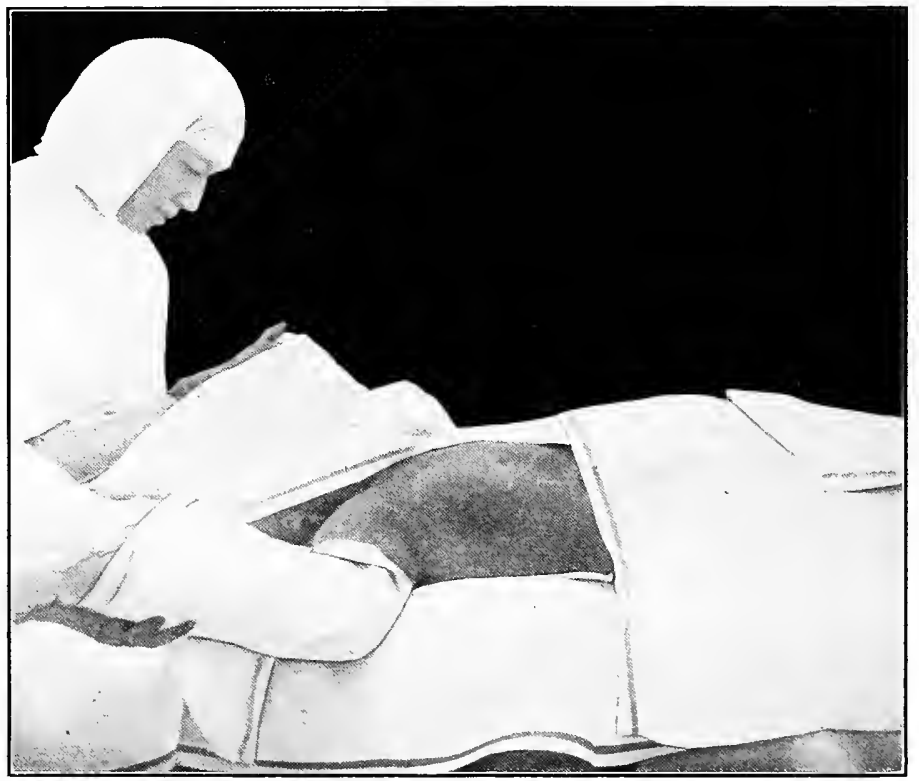

FIG. 209.-Operation for carcinoma of the breast showing the method of protecting the field of operation and the proper angle at which the arm should be held at the beginning of the operation.

occurred, but with wide dissection of the skin, the flaps being made extremely movable, the necessity for skin grafting rarely arises, and with few exceptions, necrosis of the flaps does not prolong convalescence.

When it is evident that the described method will not suffice, it may be necessary to resort either to some plastic means of wound closure, the success of which will depend upon the ingenuity of the operator, or to skin grafting.

The incision is begun on the arm at a point opposite the insertion of the pectoralis major muscle at the level of the anterior edge of the deltoid muscle. It is carried upward and inward well onto the shoulder to a point about two inches beyond the line of the anterior axillary margin, and then in a gradual curve, the concavity of which is out- 
ward, is continued to within two inches of the upper margin of the breast. This incision is placed well within the line of the anterior axillary margin so that the resulting scar will not cross the axilla obliquely and act as a band binding the arm to the side of the chest wall.

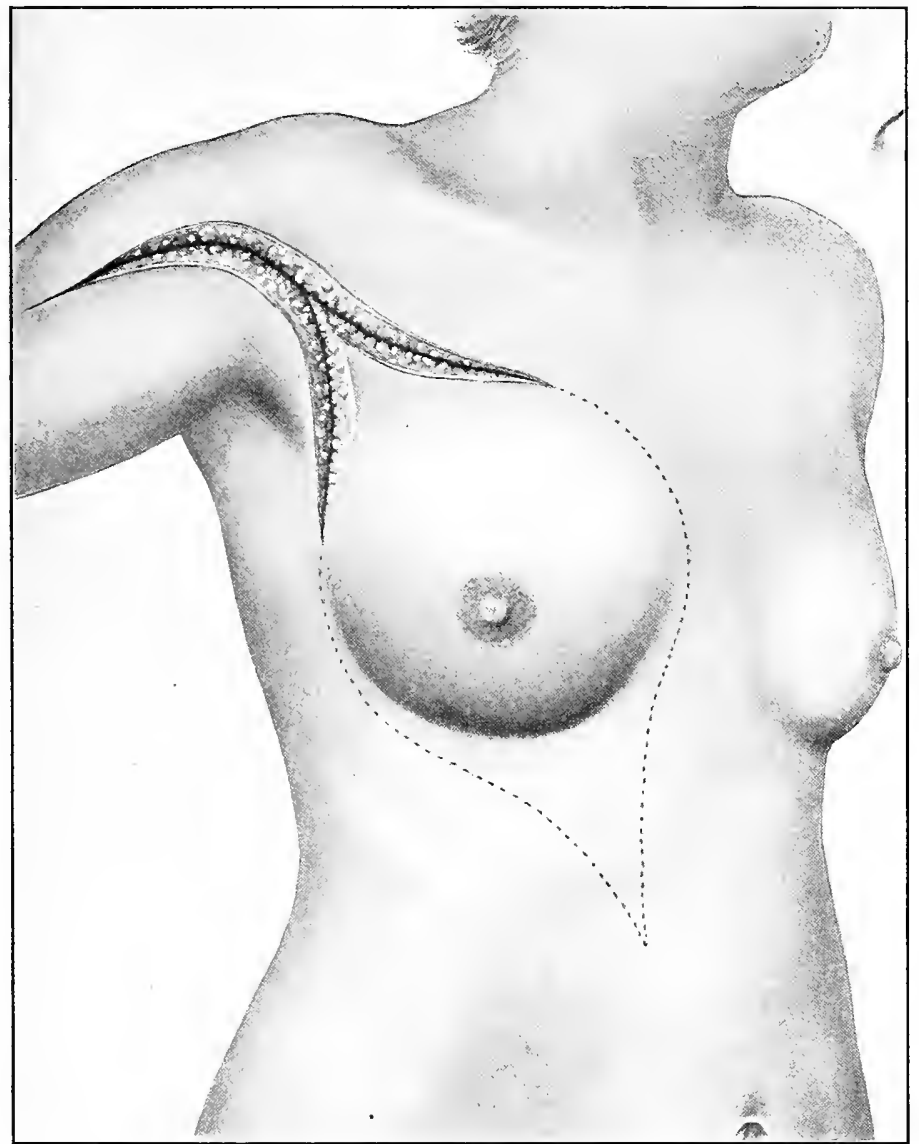

FIG. 210.-Showing the skin incision. The dotted lines indicate that part of the skin incision that is made after the axiliary dissection has been completed.

Two incisions are made to diverge from the lower end of that just described; these together form an inverted $\mathrm{V}$ the limbs of which are made to encircle the upper segment of the breast. It is our custom to mark out the remaining portions of the incision without cutting through the whole thickness of the skin as is done with the upper portions of the incision, the knife being merely permitted to cut through the epidermis. These 
superficial markings simply continue the upper incisions around the breast and are made to converge at a point about two inches below its lower margin, whence a single incision is carried downward and inward in the midline of the rectus abdominis muscle to a

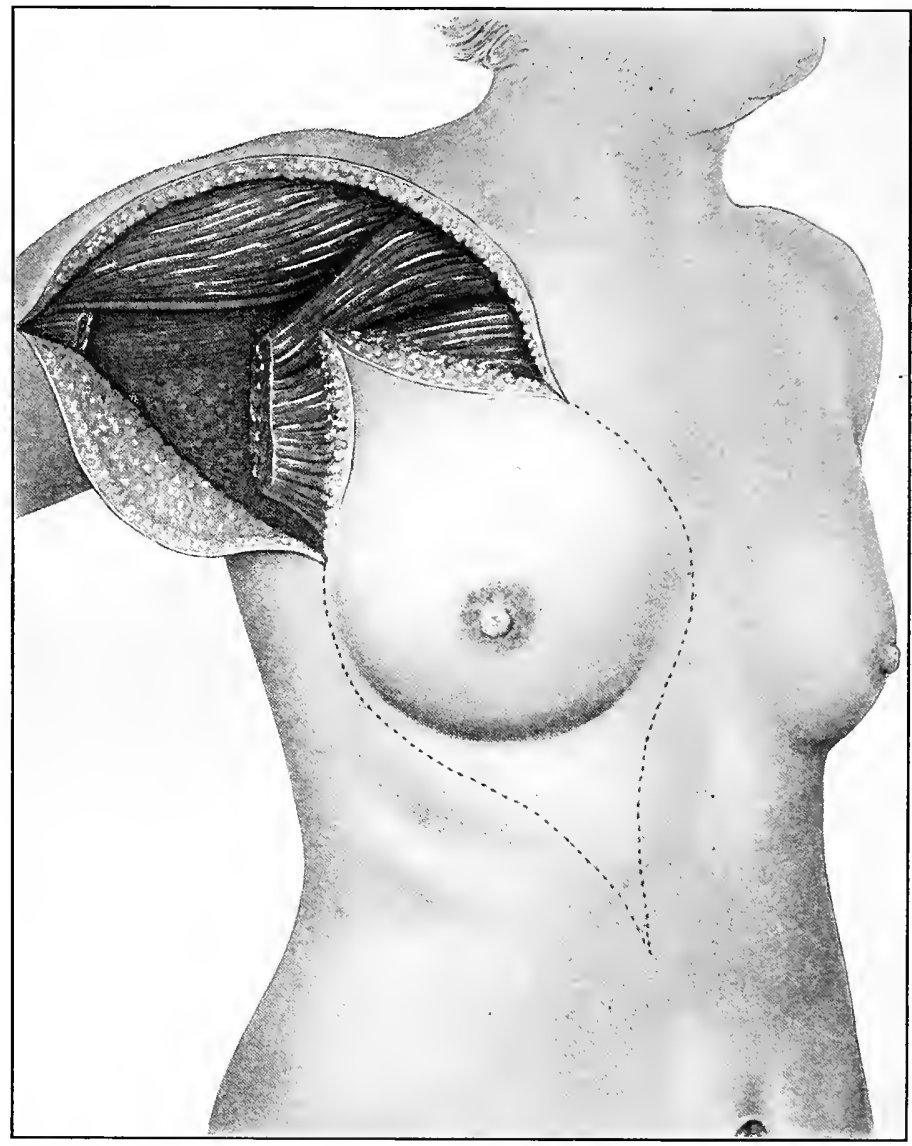

FIG. 2rr.-The upper portion of the skin flaps have been reflected and the humeral attachment of the pectoralis major muscle has been freed allowing the muscle to retract downward and inward. It will be observed that the insertions of both the clavicular and sternal heads of the pectoralis major muscle have been freed from the humerus. The cephalic vein is seen in its normal position in the deltopectoral groove.

point midway between the tip of the xiphoid cartilage and the umbilicus. The portions of the incision above the breast are deepened until the fascia covering the pectoralis major muscle is exposed. The skin flaps outlined in this manner are then reflected, the median one being dissected well beyond the edge of the sternum and in an upward di- 
rection as high as the upper border of the clavicle. The anterior portion of the deltoid muscle is exposed in this dissection. The lateral flap is dissected outward and backward well beyond the anterior edge of the latissimus dorsi muscle.

Having reflected the flaps, the exposure of the axillary space is begun by cutting the tendon of the pectoralis major muscle close to its. humeral attachment.

Formerly we removed only the sternal portion of this muscle but lately we have been removing the muscle in toto. When the muscle is freed from its insertion on the humerus, the sternal fibers recede downward and inward; the clavicular head, on the contrary, continues to obscure to a slight extent, the infra-clavicular region. The next step in the operation is to separate the latter portion of the muscle from its line of origin on the clavicle. The cephalic vein is in danger of injury at this stage of the dissection.

The second layer of the anterior axillary wall consisting of the pectoralis minor muscle and the costo-coracoid membrane is now completely exposed.

The index-finger is pushed through the costo-coracoid membrane between the pectoralis minor muscle and the acromio-thoracic artery, and close to the coracoid process of the scapula. The tendon of insertion of the muscle is then raised on the finger, care being taken to exclude the long thoracic artery which arises behind it, and the tendon severed with a pair of blunt scissors.

While strong traction is made to lift the muscle away from these structures, the tendon of the muscle is grasped with a pair of hemostats to catch the veins which traverse its substance and a branch of the long thoracic artery which frequently enters it near its scapular attachment. All danger of wounding the adjacent vessels is obviated by using the finger as a guide in cutting the muscle. The axillary space is now fully exposed.

Dissection of the axilla is the next step in the operation; this begins at its apex. The costo-coracoid membrane is cut near to the clavicle thus exposing the subclavius muscle and the deep infra-clavicular triangle.

The axillary sheath is opened with a sharp knife as near to the apex of the axilla as possible and is stripped from the subclavius muscle and the axillary vessels from above downward. This is best accomplished by gauze dissection wiping the areolar tissue and the contained lymphatics away from the vessels and nerves.

Every vestige of fibrous and fatty tissue must be removed, especially from the upper inner portion of the axillary space.' This dissection exposes the branches of the axillary artery, at their points of origin, the termination of the tributaries to the axillary vein and the terminal portion of the cephalic vein.

The arteries encountered from within outward are the superior thoracic, the alar thoracic, acromio-thoracic, long thoracic, and subscapular. The superior thoracic, usually a small vessel, arises high in the axilla so that it is usually beyond the area of dissection.

The other vessels named, with the exception of the acromio-thoracic and the subscapular, are to be ligated and cut. As a rule, we preserve the latter vessel although its sacrifice may be necessary in order that the tissues surrounding it may be removed.

The veins accompanying these arteries, except the cephalic vein, are tied near their terminations and cut. The anterior thoracic (external and internal) nerves have been severed in reflecting the pectoral muscles.

With the completion of the foregoing dissection as far outward as the origin of the subscapular artery it remains to remove the fascia and fat surrounding this vessel and its branches. The dissection begins above the teres minor muscle, is carried downward removing the fascial covering of the muscle, the teres major, subscapularis, latissimus 
dorsi, and serratus magnus muscles. In cleansing the latter, care must be taken to preserve the external thoracic nerve (nerve of Bell) which runs over it in the line of the mid-axilla. The middle or long subscapular nerve which supplies the latissimus

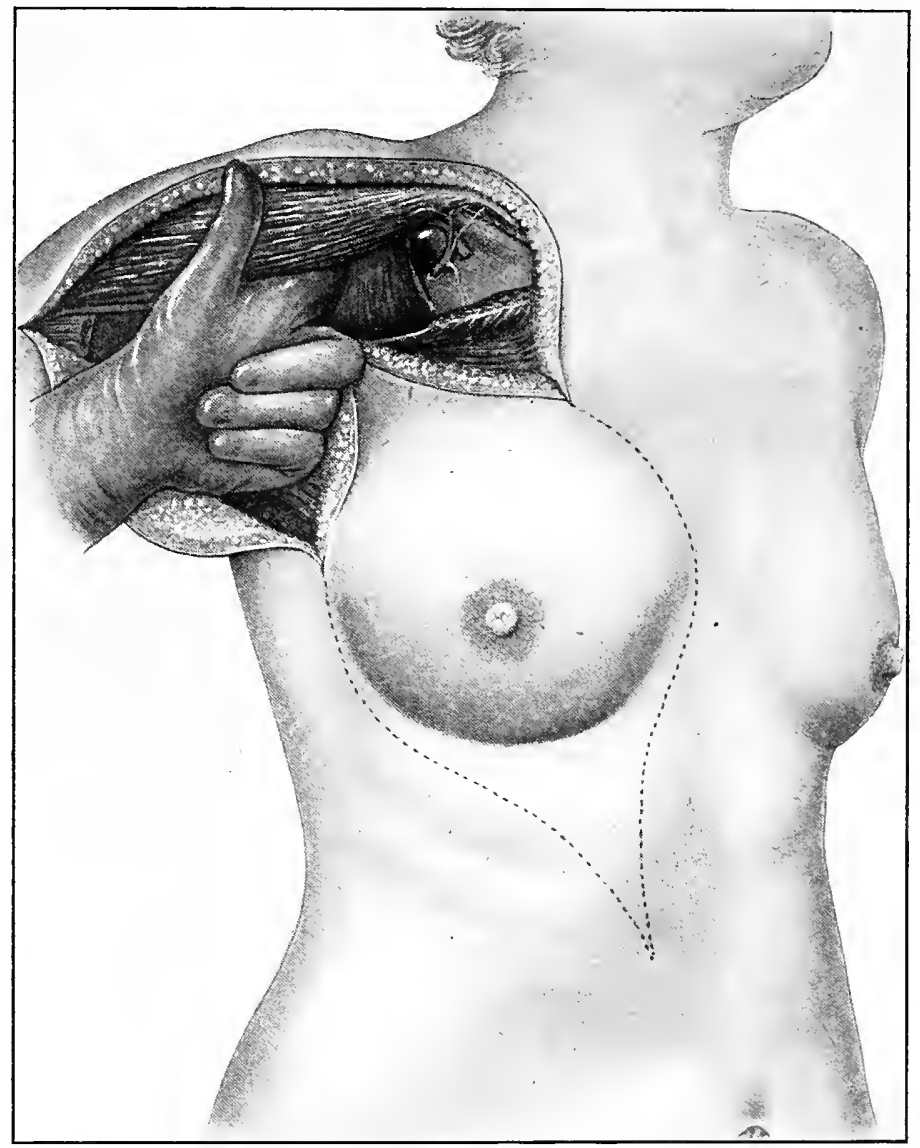

FIG. 2 I 2.- The pectoralis minor muscle has been elevated on the finger; the cephalic vein is seen above the tip of the finger. The cephalic vein and the acromiothoracic vessels are seen piercing the costo-coracoid membrane which has been pierced by the finger in elevating the muscle. The long thoracic and the acromio-thoracic arteries lie posterior to the finger so that there is little danger of wounding them when the pectoralis minor muscle is detached from the coracoid process of the scapula.

dorsi muscle must be preserved. This is not difficult to do if gauze dissection is adhered to in cleansing the costal surface of the muscle.

Having finished the dissection of the axilla the lower part of the field of operation is exposed by continuing the reflection of the skin flaps. The incisions outlined on the 
skin in the manner described above are deepened until the deep pectoral fascia is exposed. Dissection of the lateral flap is made first and exposes the lower digitations of the serratus magnus muscle and some of the upper digitations of the external oblique muscle as well as the outer half of the upper portion of the sheath of the rectus abdominis muscle. A slight amount of bleeding, from the lateral branches of the intercostal arteries, is encountered during the reflection of the lateral flap.

The median flap is now dissected well beyond the edge of the sternum. No attention is paid to the bleeding that results, at this time, from the perforating branches of the internal mammary artery, as these branches will be cut a second time when the pectoralis major muscle is removed. The breast is now grasped in the left hand and traction is exerted; this puts the pectoral muscles on the stretch which can then easily be freed from their attachments to the chest wall. The axillary contents, the pectoral muscles and the breast are removed as one mass.

In cases in which the carcinoma involves the lower outer quadrant of the breast, the sixth, seventh, and eighth digitations of the serratus magnus muscle must be removed.

Removal of the fascia covering the upper digitations of the external oblique muscle together with the upper part of the anterior rectus sheath completes the dissection.

The few bleeding points are ligated with iodine gut. A counter-incision is made in the posterior flap in such position that with the patient laying on her back the opening will be in a dependent position and just in front of the free edge of the latissimus dorsi muscles; in some instances the opening is carried through the muscle.

A fenestrated drainage tube, $1 / 4$ inch in diameter, is placed in the axillary space, care being taken that it does not come into contact with the axillary vessels and nerves. Having determined the proper position of the tube, it is anchored to the skin edges of the counter-opening with a single suture of silkworm-gut.

Before closing the wound, a final examination is made for bleeding points and hot compresses are applied to arrest the slight oozing that occurs in all cases. The transudation of serum incident to the healing process together with the slight oozing of blood justifies the employment of drainage during the first 24 hours after operation. Halsted and several other surgeons maintain that this is an unnecessary procedure, but we have always felt that a free exit for the material that collects in the axilla, minimizes the danger of infection, hastens the healing process and also minimizes the strength of adhesions that form in the axilla.

The arm is now adducted and the fiaps approximated with three or more interrupted sutures of silkworm-gut, the number depending upon the amount of traction necessary to bring the incisional edges together. As mentioned previously, the wound can be closed primarily in the great majority of instances without over-stretching if the flaps are sufficiently undermined.

The margins of the skin are sewn with interrupted sutures of fine silkworm-gut, silk or horsehair.

Sterile pads made of non-absorbent cotton covered with several thicknesses of gauze are placed in the axilla in sufficient number to hold the arm at an angle of approximately 70 degrees. The incision is covered with sterile gauze and a figure-of-eight bandage is applied to include the shoulder of the affected side, the axilla and the chest. This bandage, which should be 6 inches in width, is composed of eight thicknesses of gauze.

The patients body must be well protected with blankets on her return from the operating room. The temperature of the recovery room should be approximately $75^{\circ} \mathrm{F}$. Hot water bottles protected by towels are applied to the body. Five hundred cubic 
centimeters of normal saline solution is administered into the subcutaneous tissues of the thighs (anterior surface), if the patient is much depressed.

After complete recovery from the effects of the anesthesia, the patient is taken to the

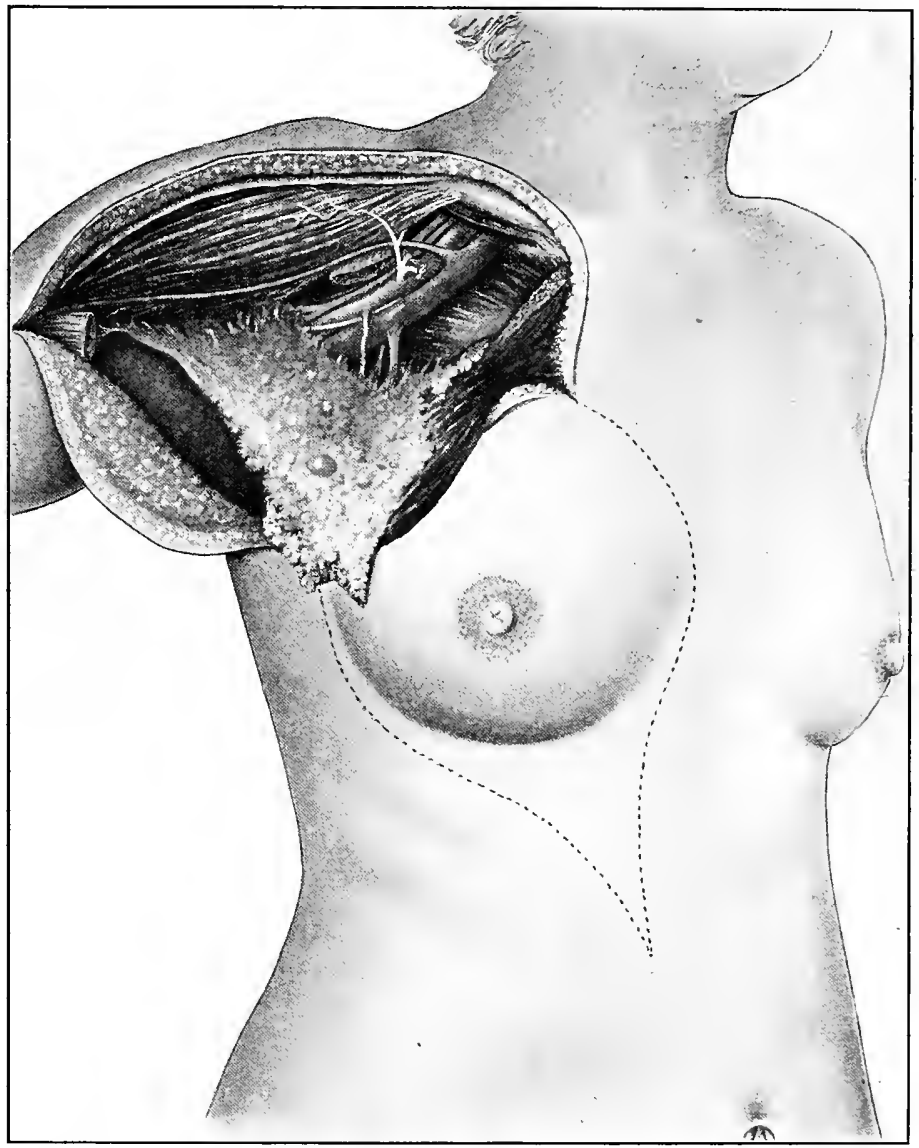

FIG. 213.- The pectoralis minor muscle has been freed from the coracoid process of the scapula. The apex of the axilla has been cleansed, and the contents are seen reflected downward and outward. In the upper portion of the wound the clavicle and subclavius muscle are visible and emerging from beneath them are the axillary vessels and nerves.

ward, and placed in bed in the semi-upright position with the arm on the operated side supported on pillows.

Post-operative Treatment.- Our patients are ordinarily kept in bed until the seventh day after operation, when the stitches are usually removed, after which they are allowed 
to be up and about and at the end of the second week they are permitted to leave the hospital. Sitting up in bed is insisted upon as soon as the patient has fully recovered from the effects of the anesthetic. The time of the first dressing will depend upon the amount of serous and bloody oozing from the wound but is usually done on the sec-

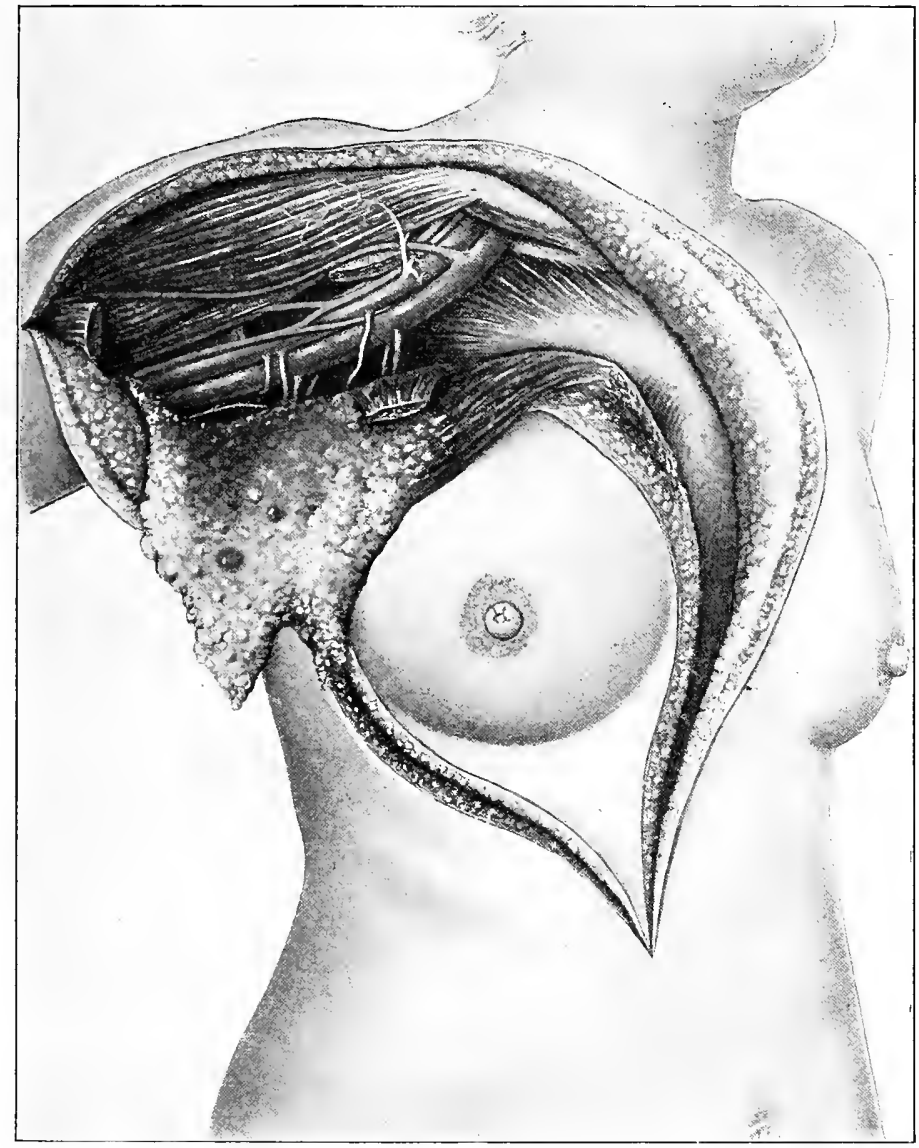

FIG. 214.-The axiliary dissection is completed with the exception of that portion in the region of the lower posterior axillary fold. The skin flaps have been completely reflected.

ond day, when, in the absence of profuse wound secretion, the drainage tube is removed; when the secretion is greater than ordinary, the tube is allowed to remain until the fourth day or in some instances a rubber-tissue drain is substituted for it.

The average time spent in the hospital by our patients, after radical breast amputations, is I6.8 days; uncomplicated cases remain I 3.9 days; complicated cases 29.8 days 
on the average. These figures are estimated from a consecutive series of 50 patients in a number of whom serious complications considerably prolonged the usual hospital time. In the uncomplicated cases, the stitches are removed on the seventh day after operation; it is advisable, however, to retain the anchorage sutures for several additional days. No additional care is required except the usual aseptic toilet of the wound, with alcohol rubbings of the surrounding skin and a dry sterile dressing.

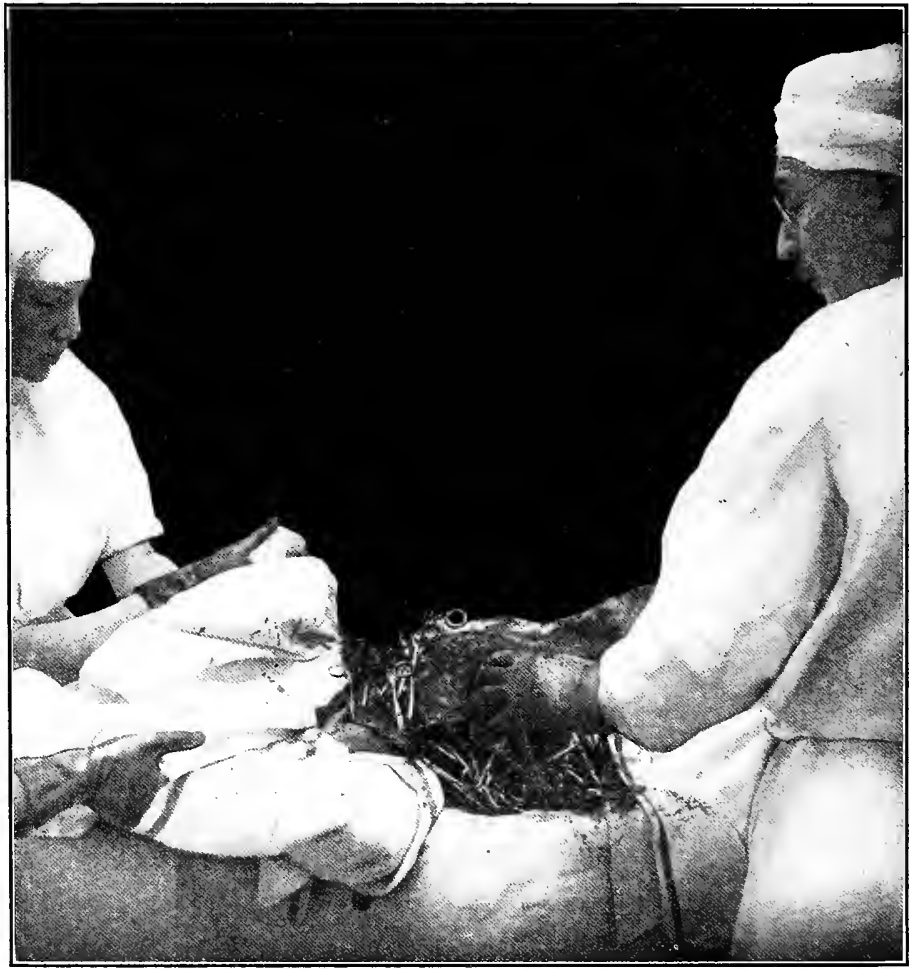

FIG. 215.-The axilla having been cleansed and the deep fascia surrounding the mammary area having been dissected free, it remains to remove the pectoral muscles and the breast. The surgeon grasps the breast with his left hand and exerts traction in a downward direction; this puts the pectoral muscle on the stretch. The muscles are then shaved from their points of attachment to the chest wall.

That position of the arm on the operated side should be chosen which gives the patient the greatest degree of comfort. Owing to the padding in the axilla it is necessary to keep the arm in a somewhat abducted position, however, and this is best accomplished by supporting the member on pillows while the patient is put in a semi-sitting position; mechanical devices to maintain the arm in a fixed position are unnecessary and may be harmful.

The after-care of patients on whom skin grafting has been done is described elsewhere. 
Post-operative Complications.--Among the 50 consecutive cases mentioned above, there were 12 more or less serious complications, including the only instance of death from sepsis complication of a breast operation that has occurred in our experience-one of the few cases in which we have been obliged to resort to intravenous saline transfusion

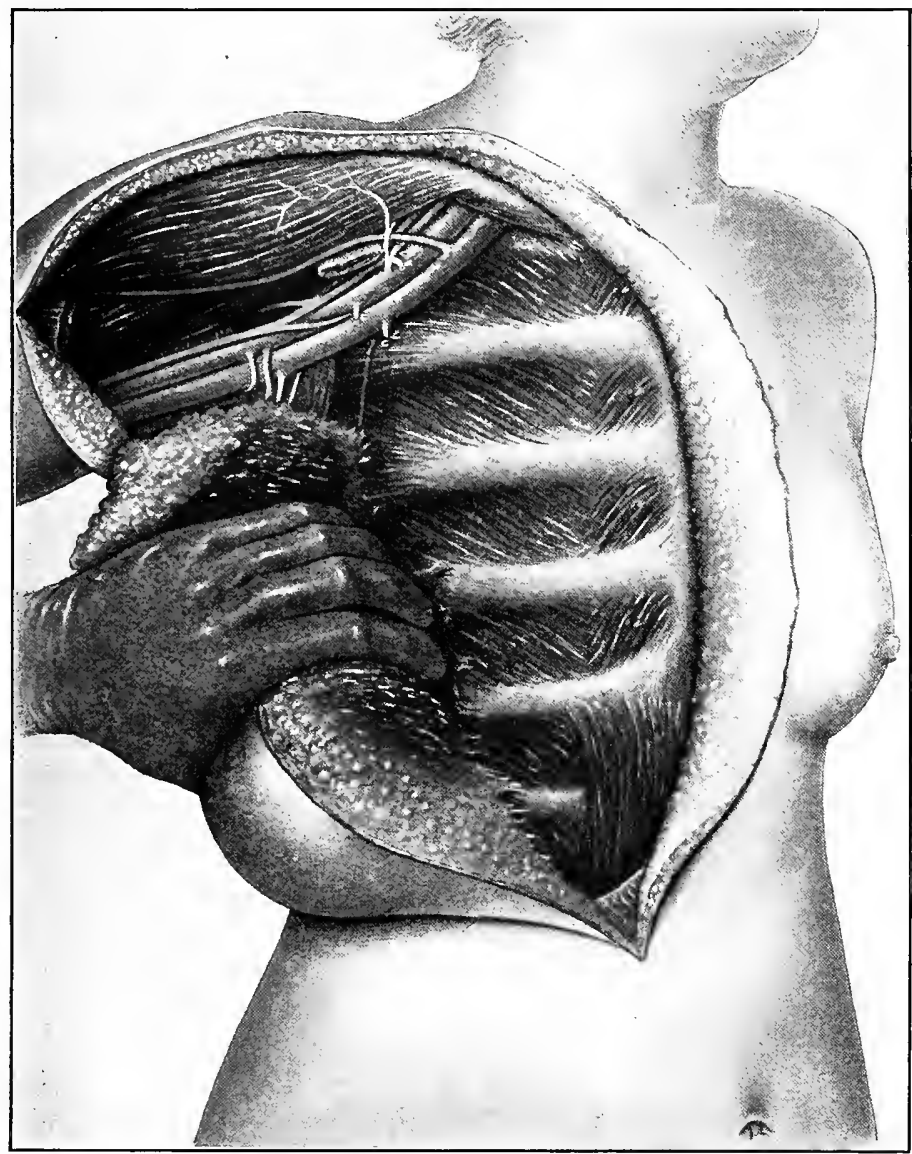

FIG. 216.- The breast and pectoral muscles are in the grasp of the left hand and are being dissected from the chest wall. It will be observed that the upper portion of the rectus abdominis sheath has been removed. The long thoracic nerve remains intact.

to combat serious post-operative shock-and the only case in which it has been necessary to make a second incision in the axilla to recover a drainage tube that had slipped into the axillary space. The series is fairly representative of the complications that may arise after the radical removal of the breast, which are as follows: 
Case 1.-Upper end of the wound "broken down."

Case 2.- Arm became very swollen and the wound opened; no infection. Arm was elevated and hot bichloride dressings applied; uneventful recovery.

Case 3.-Lower part of the wound opened; infected.

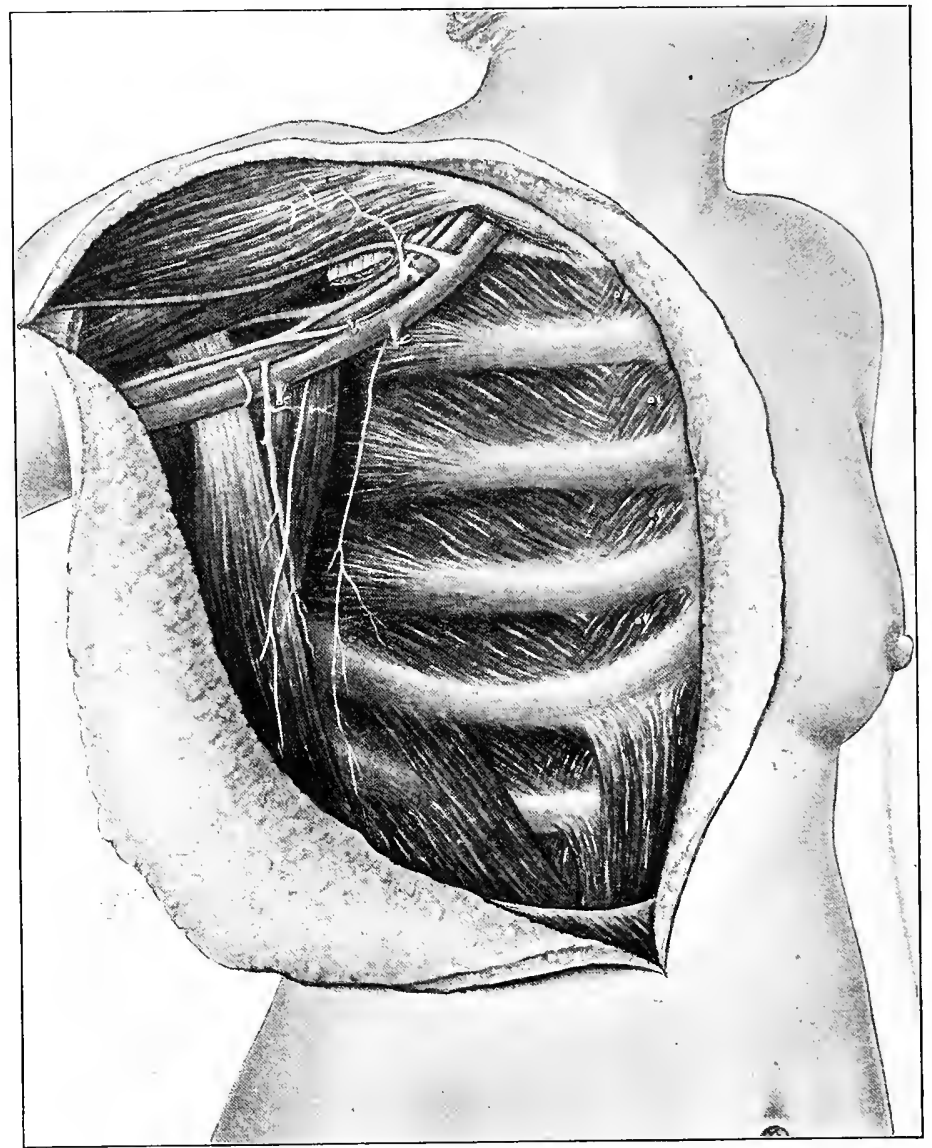

FIG. 2I7.-Dissection completed. The long thoracic and long subscapular nerves are well shown. The serratus magnus muscle has in part been removed. The illustration sbows that the subscapular vessels have been removed; this is unnecessary in the majority of instances. The fascial sheaths covering the external oblique and rectus abdominis muscles have been in part removed.

Case 4.-Central part of wound sloughed.

Case 5.-Both ends of wound opened; infected.

Case 6.-Entire wound sloughed; patient in hospital 57 days; recovered.

Case 7.-Infected drainage sinus; tube reinserted; hot boric acid douches; recovered.

Case 8.-Abscesses in incision; axilla opened; irrigations with 5 per cent. iodine; recovered. 
Case. 9.-Excessive bleeding through the tube during the night of the operation; irrigation with hot salt solution; recovered.

Case 10.-Shock; intravenous saline transfusion; recovered.

Case II.-Entire wound sloughed; flaps necrotic; several secondary operations; patient finally died of sepsis.

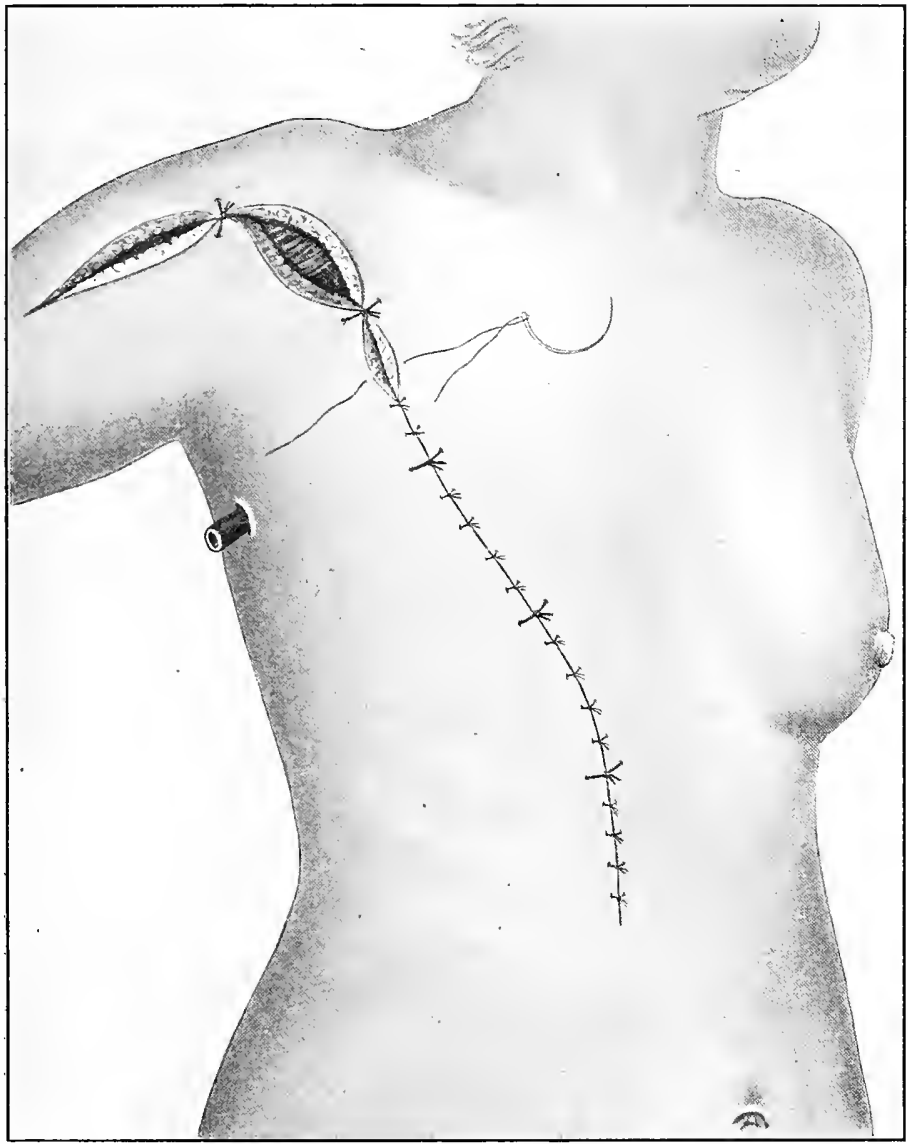

Fig. 218.-Closure of the wound. Silkworm gut is used for the purpose. The drainage tube is brought out through a counter puncture a little distance below the middle of the outer flap.

Case I2.-Drainage tube became loosened from incisional edges and slipped into the axilla; counter incision and removal; recovered.

The immediate serious complications of amputation of the breast are shock and hemorrhage. The patient may have apparently reacted from slight degrees of shock 
during the course of the operation but at its conclusion show evidences of extreme cardiac and vasomotor depression. For this reason these patients, and especially the aged, must be watched very carefully for some hours after leaving the operating room. We have never transfused a patient during the course of an operation for mammary carcinoma, but in several instances have found it necessary to do so an hour or so later, when diffusible stimulants failed to bring about reaction from the depression which had either gradually increased, or suddenly supervened, after the conclusion of the operation. Saline transfusion should not be withheld when the slightest indications for its employment exist. When the patient fails to show immediate reaction we introduce $1000 \mathrm{cc}$. of normal saline solution (temperature $100^{\circ} \mathrm{F}$.) directly into the median basilic, median cephalic or other convenient vein.

We advise hypodermoclysis (500 cc. to $1000 \mathrm{cc}$. normal saline solution) after breast amputations (where indicated). The anterior surface of the thigh is most suitable for its administration in these cases.

Hemorrhage.-Immediate post-operative hemorrhage should not occur, but despite the exercise of extreme care in applying the ligatures, it occasionally happens that one

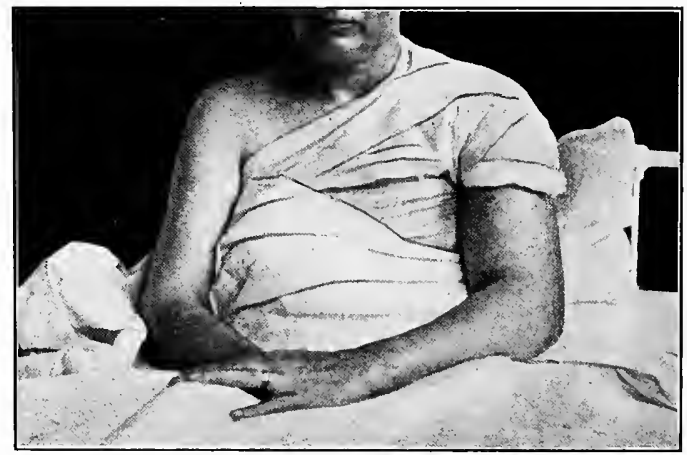

Fig. 219.-Primary edema of the arm following radical amputation of the breast.

will become dislodged, especially at the time of applying the dressings. When the postoperative reaction is not immediate and the pulse and temperature of the patient indicate the necessity of stimulation, we must always think of the possibility of hemorrhage. A considerable amount of blood may be contained in the axillary space, and if the drainage tube should become obstructed by a clot, the dressings will be but slightly stained at first. Ordinarily the dressings become saturated with blood. For this reason remove the dressings and examine the axilla when hemorrhage is suspected. When the evidence points to active hemorrhage it is best not to temporize in the hope of spontaneous arrest of the bleeding. Anesthetize the patient, open the wound, evacuate the clots, tie the bleeding point or points, and flush with hot saline solution.

Late or true secondary hemorrhage is so rare a sequel of the radical operation that we have never observed it, although in one of our cases of suppurative mastitis, alarming hemorrhage occurred some days after operation. True secondary hemorrhage occurs only in ulceration of the skin flaps after radical amputation, as illustrated in a case reported by Moschowitz, in which bleeding was first noted on the fifth day and recurred 
in increasing amounts, with extending ulceration of the flaps, until finally operation became necessary. The bleeding came from a branch of the internal mammary artery and was indirectly due to pyogenic infection of the wound. It is conceivable that ligation of the subclavian artery might be necessary to arrest bleeding from ulcerative destruction of one of the stumps of the larger branches of the axillary artery. In moderate bleeding, palliative efforts should be used before opening the wound. Pressure and the application of ice-bags suffice to arrest slight bleeding.

Lymphedema. - In at least ro per cent. of advanced cases of mammary carcinoma, edema of the arm occurs on the side corresponding to the lesion. In recurrent carcinoma it is more common and is by no means infrequent as a sequel of the radical operation without malignant recurrence. It depends upon lymphatic obstruction. Resection of the axillary vein has been followed by edema of the arm, in several of our operative cases, but was slight in degree and transient in nature. That this complication should occur in some but not in others, when a uniform operative technic is employed, can only be

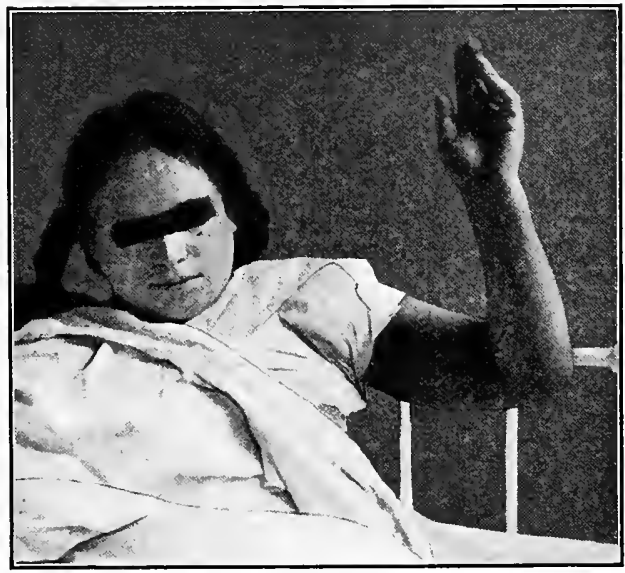

FIG. 220.--Range of voluntary motion of the arm. Second day after radical amputation of the breast.

explained by differences in the topography of the afferent lymph channels. It is difficult to understand how the lymph can be returned to the systemic circulation except by means of some trunk of communication between the lymph vessels and veins below the site of operation or by some circuitous route of which the axillary nodes are normally not a part. The swelling of the arm, when dependent upon the operation alone, appears almost immediately. When deferred for weeks or months, recurrence of the cancer is to be expected, although this late obstruction may perhaps be due to contraction of scar tissue in the axilla.

The edema varies in degree, although it is progressive as a rule, the limb becoming more and more burdensome and the seat of varying degrees of pain. In extreme cases the great discomfort and intense pain render life almost intolerable and opiates must be given in increasing doses until these fail to bring relief any longer and the patient becomes habituated to a drug which is impotent to relieve her sufferings. Pleural effusion may appear, and add dyspnea to the patient's misery. Cushing has suggested division of the 
spinal cord, high up as a relief from the condition, known as paraplegia dolorosa which may eventually supervene. Division of the antero-lateral columns of the spinal cord as has been advised and practised by Spiller and Martin (Jour. Amer. Med. Assn., May I8, I $9 \mathrm{I} 2,58, \mathrm{I} 489$ ) for persistent pain in the lower extremities might be tried as a substitution method for division of the cord. We regard both of these procedures as ultra radical, and rarely indicated. Division of the cords or trunks of the brachial plexus merits consideration and may likewise suggest itself in recurrent involvement of the plexus associated with excruciating pain in the absence of edema of the limb.

Injections of novocaine or other anesthetic drugs around the plexus (peri-neural) above the clavicle may give relicf for a short time.

Favorable results, especially the relief of pain have been obtained by $X$-irradiation. Pinch has advised the use of radium for edema of the arm complicating breast cancer.

Lymphangioplasty and amputation are operations to be considered although the employment of the latter is rarely if ever justified.

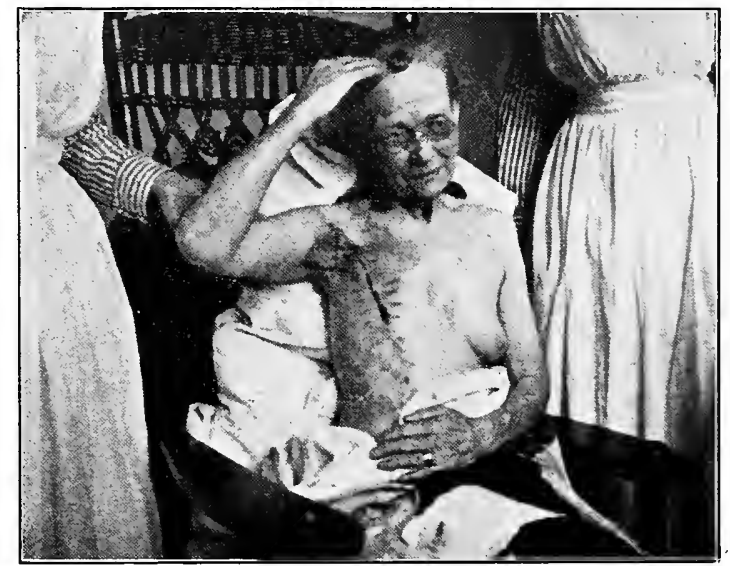

FIG. 221.-Latitude of motion of the arm five days after radical amputation of the breast.

Pneumonia complicates the post-operative period in a small number of cases. It occurs with no greater frequency, however, after radical amputation of the breast than after other major operations. The disease, in the majority of cases, is of the catarrhal type, although the one fatal case of pneumonia following a breast operation which we have observed had a frank lobar involvement of the lung on the operated side. The prophylactic measures to be employed are similar to those recommended in all cases before the administration of any anesthetic, viz., careful examination of the respiratory tract, with the exclusion of cases presenting active inflammatory troubles and pre-operative cleansing of the oral, nasal and pharyngeal cavities. Uremia and other post-operative complications after breast amputations are not more common than after other operations of equal magnitude. The most important complication arising after the operation-malignant recurrence-is considered elsewhere. The rarer complications such as air embolism, hemophilia, mania and delirium tremens have been observed but are in no way peculiar to operations on the mammary gland. 
The Handley Operation.-Many operators accept Handley's views of cancer dissemination, but few follow, in detail, the radical breast amputation devised by him to accord with those views.

The majority of surgeons attempt to remove the deep fascia wide of the tumor; few of them do it with the thoroughness advised by Handley. If the sacrifice of large amounts of skin is an unnecessary step in the operation, the various plastic methods of radical removal of the breast have a very limited field of usefulness; if removal of large areas of skin is a necessary part of a radical breast amputation for cancer, as is held by Halsted to be the case, then the plastic operations must be given serious consideration.

Operations have been devised to eliminate the incision down the arm, but, if the views held by Handley are accepted, this is a necessary step if free access to the deep fascia that

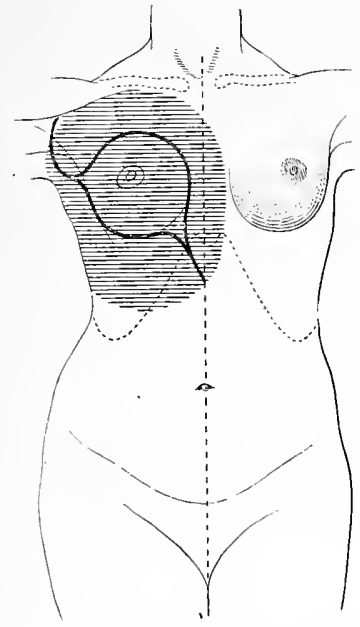

Fig. 222.-Illustrating the Handley operation for carcinoma of the breast. Shaded area shows the extent of deep fascia to be removed.

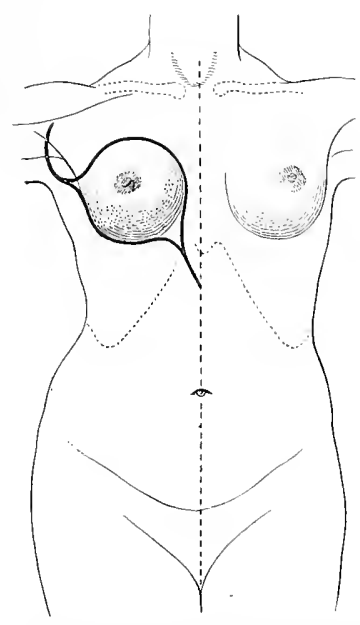

FIG. 223.-Illustrating the Handley operation for carcinoma of the breast. Skm incision.

covers the deltoid muscle and the insertion of the pectoralis major muscle, is to be gained. If the removal of this fascia be important, no incision will satisfactorily answer the purpose except one that is extended to the arm.

Whether or not there be a best routine operation for mammary carcinoma remains to be shown. The only way to settle the question is to ascertain the comparative end results in large series of cases after removal of the breast by different methods. The fact that a certain type of operation has been used "in a large number of cases during the last few years" or that "this operation has given perfect results in our hands," means practically nothing; what is the condition of a large number of patients five or more years after the operation? This is the real test of the value of any operation for cancer of the breast. 
The fundamental idea, in radical breast amputation, is the removal, by block dissection, of an area of tissue presumed to have been invaded by cancer cells; not the obtaining of a fine cosmetic result.

Our patients have not suffered with complications, after the Halsted operation, that would warrant its abandonment if it, as we believe that it does, affords the best opportunity of removing en bloc the tissues in which cancer cells are likely to have become lodged. Halsted, however, now advises that the incision down the arm be omitted.

We believe that the underlying principles of the Handley operation are of great importance and his method will, therefore, be described in detail.

A cancer of the breast, together with "its invisible microscopic extensions," is compared by Handley to "a mass shaped like a bi-convex lens." The cancer cells are supposed to permeate the tissues, surrounding the primary growth, in all directions along the plane of the deep fascia so that the outer limits of the permeated area are, roughly speaking, equidistant at all points from the center of the primary growth. It follows that the operation must vary, to a certain extent, with the position of the tumor in the breast. The object of the operation is, therefore, "the removal intact of the permeated area of the lymph vascular system which surrounds the primary growth and of the lymph glands, which may have been embolically invaded along with the trunk lymphatics of the area concerned." The operation devised to meet these requirements is described by Handley as follows:

The Skin Incision.-The skin incision is just deep enough to penetrate the subcutaneous fat without extending into the deep fascia. It consists of three parts: (a) A ring incision, as first practised by Mitchell Banks, 4 to 5 inches in diameter, accurately centered on the growth and surrounding it at a safe distance. ( $\beta$ ) A curvilinear incision for giving access to the axilla. The axilla is opened by turning forward a flap consisting of skin and a thin layer of subcutaneous fat, whose base lies along the anterior axillary fold. The axillary incision begins at the lower edge of the great pectoral muscle close to its insertion. It ends at the lower edge of the great pectoral muscle by joining the annular incision. It crosses the base of the axilla, and marks out an almost semicircular flap of skin, whose convexity reaches back nearly to the edge of the latissimus dorsi-muscle. It affords perfect access to the axilla and good drainage afterward.

(c) A linear incision coming off from the lower and inner part of the annular incision and passing downward for about 2 inches along the linea alba. Its object is to give access for the removal of the deep fascia over the upper part of the abdominal wall. Without this important step the operation cannot be properly carried out.

Elevaticn of the Skin Flaps.-The skin flaps are undermined in the mid-plane of the subcutaneous fat until the area of the deeper subcutaneous fat, forming the circle ro or 22 inches in diameter with the primary growth at its center, is exposed. The exact anatomical limits of this dissection will, of course, vary with the situation of the growth in the breast.

An assistant retracts the skin flaps as they are formed and subsequently keeps them carefully wrapped in hot towels, frequently renewed. Neglect of this precaution is likely to be followed by ulceration of the edges of the flaps. At this period of the operation no attempt to clamp the bleeding vessels should be made, as they will again be divided at a deeper level.

Delimitation of the Area of Deep Fascia to be Removed.-An annular incision, marking out the ro-inch circle of deep fascia to be removed, is now carried down to the muscles through the deeper subcutaneous fat close to the base of the skin flaps, which are meanwhile strongly retracted by the assistant.

Elevation of the Deep Fascia from the Underlying Structures. - The circular area of deeper subcutaneous fat and deep fascia, in which lies embedded the presumably permeated area of the fascial lymphatic plexus, is now dissected from the subjacent muscles for some distance from its circumferance toward its center, so as to form a wide marginal fringe of the main mass, consisting of breast, pectoral muscles, and axillary contents which is to be subsequently removed. The fringe of deep fascia is to be raised up all around the field of operation until the knife reaches either the margin of the great pectoral muscle, the margin of the axillary outlet, or the edge of the breast as the case may be. The amount of dissection 
required varies in different parts of the field of operation. At the upper limit of the field of operation hardly any freeing of the fascia will be required, since, in this region, it will come away with the great pectoral when the muscle is divided at its clavicular origin.

Toward the middle line the fascia will require dissecting up from the inner margin of the opposite great pectoral and from the sternum. In doing this the perforating branches of the internal mammary artery on the side opposite to the growth are divided, and must be secured. The division of these branches necessitates division of the lymphatics which run with them from the pectoral lymphatic plexus to the anterior mediastinal glands, and thus affords additional security against thoracic invasion. (The corresponding perforating branches on the same side as the growth are divided later during the detachment of the great pectoral.)

As regards the lower limit of the field of operation, it will be found that a Io-inch circle of deep fascia with the growth at its center will usually extend well down over the epigastric region of the abdomen. In this part of the field of operation, the anterior layer of the rectus sheath, on both sides of the middle line, should be raised up and removed with the deep fascia. In order to accomplish this, the linea alba must be split from below upward in the coronal plane. It is particularly in the epigastric region that wide and careful removal of the deep fascia is imperatively called for, so as to prevent the access of cancer cells to the peritoneal cavity.

In this part of the field of operation numerous small blood-vessels emerging from the rectus sheath and muscle will probably need attention. Toward the outer side of the field of operation the fascia must be dissected up from the serratus magnus and from the anterior edge of the latissimus dorsi. Higher up, especially if the growth lies in the outer portion of the breast, the fascia over the inner margin of the deltoid muscle and about the posterior margin of the axillary outlet must be raised if it fall within the circle marked out for removal, although requisite dissection is difficult and tedious.

Division of Muscles.-If the growth is an early one, or is situated low down in the breast, it is probably safe to leave the uppermost fibers of the pectoralis major near the margin of the deltoid muscle. With this possible exception the whole of the great pectoral is removed. It is first cut through close to its clavicular attachment; a finger is inserted beneath the muscle from above, so as to put the fibers on the stretch, when the chondral and sternal attachments are rapidly divided from above downward, close to their origin. The muscle is lifted from the chest and turned outward, and the external anterior thoracic nerve, and the vessels which run with it, are divided where they pierce the costo-coracoid membrane. The pectoralis minor then comes into view, and is best removed except in early cases. (We remove not only the pectoralis minor but the entire pectoralis major as well.)

It is divided at its costal origin. The pectoral muscles are now cut across at their respective insertions into the humerus and the coracoid process, and the whole mass is allowed to fall over toward the axilla.

Removal of the Axillary Contents. - The costo-coracoid membrane, now freely exposed, is cautiously divided just below the clavicle, and the fat at the extreme apex of the axilla brought into view. It now becomes easy to reach the highest axillary glands-subclavian in the strict sense of the word-which so easily escape notice unless they are carefully looked for. The axillary vein is sought for in this situation and is carefully cleared from above downward. As the dissection proceeds, the subscapular vein and other axillary tributaries come into view, and are secured and divided. The subscapular nerves are exposed, isolated and preserved. The inner and posterior walls of the axilla are cleaned from above downward, preserving the nerve of Bell, and the mass of tissue is now retained only where the lower and outer part of the breast overlies the serratus magnus.

The digitations of the serratus magnus muscle, which lie in direct contact with the deep surface of the breast, should be divided at their origin from the ribs. The whole mass of tissue is next freed and removed by the division, further back toward the scapula, of the same digitations of the serratus magnus.

A superficial layer of the digitations of the external oblique, which arises from the fifth and sixth ribs, should also be removed. The parts removed form a single circular bi-convex lens like mass with extensive thin edges. To its outer side a pyramidal mass of axillary fat and glands is attached. The mass shows a central circular patch of ablated skin on its superficial aspect.

The remaining steps of the operation as performed by Handley are similar in all essential details to other radical operations. He states that little or no difficulty is experienced in closing the rather extensive wound - a statement which we fully corroborate. It is advised to insert two drainage tubes, one for the purpose of draining the 
axillary space, another one to be inserted at the lower margin of the wound to give outlet to the serum that usually collects at this extremity of the wound. We have lately employed a technic quite similar to the above and have not seen the need of this second tube.

Removal of the deep fascia while adding to the time consumed in performing the radical amputation of the breast, does not add to the gravity of the operation so far as the primary mortality is concerned, and post-operative complications are, if anything, somewhat less than in cases in which large areas of skin are removed.

The ultimate results of the Handley operation are an unknown quantity as sufficient time has not elapsed since its introduction to enable one to collect a large number of cases upon which to base statistics for comparison with other methods of treatment.

The operation, however, is based on logical deductions from careful microscopic studies of cancer dissemination, and since the additional steps in the operation do not add to its gravity, it would seem to be incumbent upon surgeons to remove the deep fascia in the manner outlined above.

The Kocher Operation.-The first description of the Kocher operation is contained in the fourth German edition of his "Textbook of Operative Surgery;" it is practically

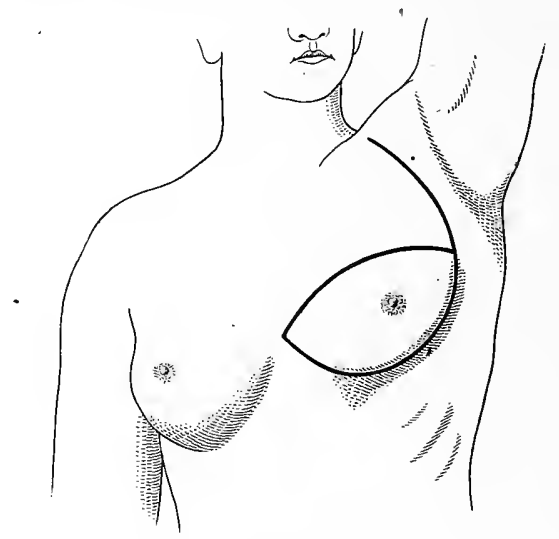

Fig. 224.--Showing skin incision in Kocher's operation.

the same as that described in more recent editions. After a brief review of the then new discoveries in the pathology of malignant disease, Kocher says:

"The pectoral fascia cannot be properly removed without at the same time removing the pectoral muscles. The operation described in the previous edition (3d German edition, 'A Textbook of Operative Surgery') must therefore be modified as follows:

"The operation is begun by employing the uppermost part of the incision shown in the illustration. The incision is at first carried only from the clavicle downward to the anterior fold of the axilla. This portion of the incision (which we employ also for the excision of glands from the axilla) is different from that of Halsted and leaves a good scar. 'Many writers describe the Kocher incision as crossing the middle of the axilla but this is not the case, as is shown in the accompanying illustration which is taken from his book.' The main incision is marked out on the skin with a few scratches of the knife so as to show the extent to be excised and is later deepened.

"After dividing the skin and the superficial-and deep fasciæ, the cephalic vein is to be avoided in the furrow between the upper border of the pectoralis major and the deltoid muscles. The vein is the 
guide to the interval between these muscles. The pectoralis major is freed by blunt dissection an inch or so from the arm. The finger is then passed underneath it and the muscle is divided, two or three artery forceps being applied to the vessels supplying it.

"The pectoralis minor muscle is then freed and divided close to the coracoid process. The nerves and large axillary vessels appear surrounded by fat. By carefully dissecting off the fat and glands downward from the clavicle and coracoid process, the axillary vein is exposed in its whole extent. The branches of the axillary vessels are grasped with forceps close to the main trunks before they are divided. With the left hand the fat and glands are further stripped off the anterior surface of the subscapularis and latissimus dorsi muscles until the surface of the serratus magnus muscle appears covering the ribs. The posterior thoracic nerve (nerve of Bell) and the long thoracic artery which lie on the chest wall, as well as the subscapular nerves on the posterior axillary wall cannot always be preserved. In this way, by removing the fat and glands along with the fascia, the axilla appears like a dissecting-room preparation. The incision is prolonged downward below the mamma to the sternum. The fascia and fat are

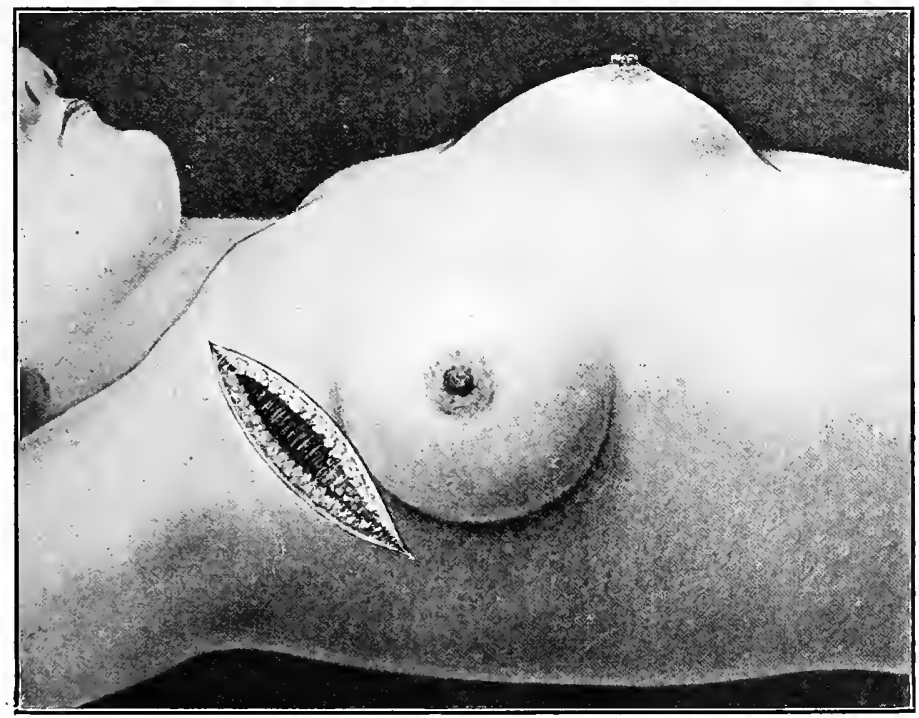

FIG. 225,-Illustrating the Rodman operation for mammary carcinoma. Primary skin incision.

stripped off the latissimus dorsi and serratus magnus muscles and the costal origins of the pectoralis minor muscle are exposed. These are detached, and the perforating branches of the intercostal vessels are secured with forceps. Passing over the ribs toward the middle line under the pectoralis major muscle, we reach its thick sternal origin, which along with the breast is separated from the ribs and intercostal muscles.

"The incision is now made through the skin above the breast and a skin flap is dissected from the subcutaneous tissue as high as the clavicle when the clavicular origin of the pectoralis major is divided close to the clavicle and the upper costal origins of the muscle cut through. Ligatures are only applied to the arteries and veins close to the main vessels, and also to the perforating branches of the intercostal vessels. In this operation, the axillary glands, the pectoral fascia, both pectoral muscles, as well as the mamma and skin covering it, are removed in one piece.

"The last step consists in cleaning the vessels behind the clavicle and removing one or two lymphatic glands which are occasionally found lying suhcutaneously close to it. If diseased glands are met with still higher up, the best procedure is to prolong the incision over the clavicle into the supra-clavicular 
triangle, so that the dissection may be continued along the subclavian vessels as far as the angle between the subclavian and internal jugular veins, where an invaded gland is often found. If necessary, the clavicle must be divided, the supra-clavicular triangle thoroughly cleaned out, and the bone wired (Madelung)." If closure of the wound is impossible, Kocher applies Thiersch grafts.

The Rodman Operation. "A straight incision is made heginning I inch below the clavicle, two fingerbreadths from and parallel with the sulcus between the deltoid and clavicular portion of the pectoralis major muscles. It extends well below the free edge of the pectoralis major muscle, and in extent will usually be from 5 to 6 inches or more, according to the stature of the patient and the size of the breast. It is rapidly carried down through skin and superficial fascia covering the great pectoral muscle. No hemorrhage of consequence is encountered thus far. I prefer to place this incision not too close to the arm, for, in my judgment, incisions extending on to the arm result in cicatrices, which often seriously interfere with the future usefulness, and less frequently cause edema of the limb.

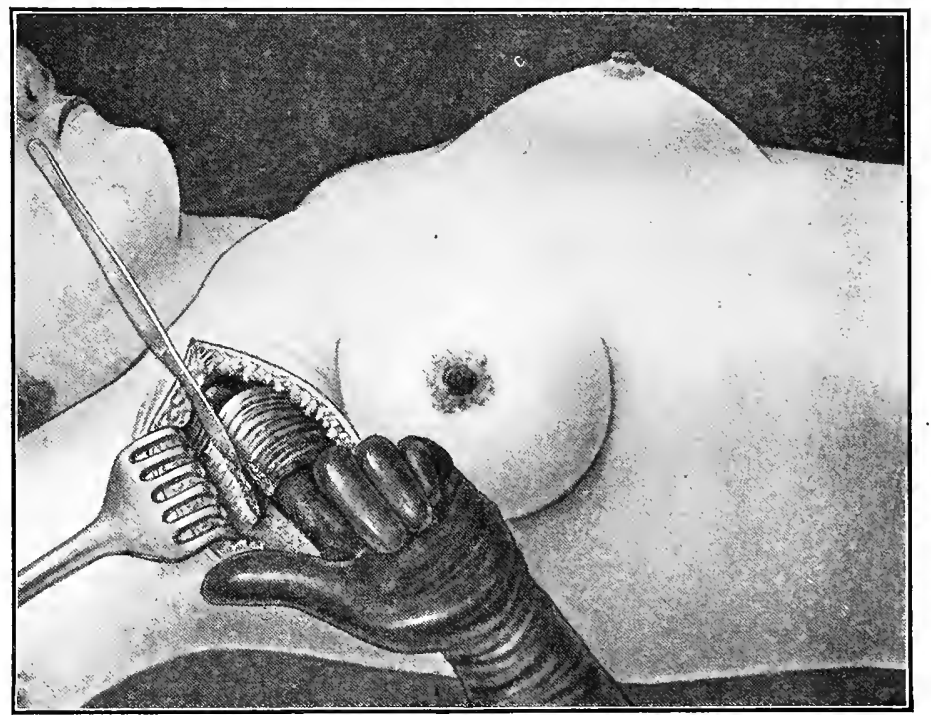

FIG. 226.-Illustrating the Rodman operation for mammary carcinoma. Division of the pectoralis major muscle near its insertion.

"The index-finger of the left hand is now introduced beneath the lower border of the tendon of the great pectoral muscle and made to emerge above its upper border, or in the interval between the costal and clavicular portions, if one wishes to remove only the costal origin of the muscle, and division of the tendon at or near its insertion into the humerus. This may be facilitated by dissecting up the external flap slightly and using retractors. I myself see no reason for removing the clavicular portion, in the average case, and, therefore, leave it unless the growth is peripheral and in the upper hemisphere. Then unquestionably the entire muscle should be sacrificed. Only a slight dissection will be necessary to expose the lower edge of the tendon of the pectoralis minor. This should be clearly identified and separated from the fascia covering the tendon and below it. Otherwise the long thoracic artery which runs in the fascia parallel with and just below the tendon may easily be wounded.

"The index-finger is now introduced underneath the muscle and made to emerge at its upper border. - Lifting up the muscle, the tendon is made tense and prominent, so that it can easily be seen that no other tissues are included with the tendon. The acromio-thoracic artery runs just above and parallel with this tendon, and, being a branch of considerable size, might cause some little embarrassment, if it were cut 
at this stage of the operation. It is divided at its insertion into the coracoid process. Therefore, we have the acromio-thoracic artery parallel with and just above the upper border of the minor pectoral tendon; the Iong thoracic parallel with and just below its lower border. Both can easily be avoided if care is taken. . . . . . . Both muscles retract inward as soon as their respective tendons are severed. This at once uncovers the axilla and makes its subsequent thorough dissection easy. The costo-coracoid membrane is now opened and largely sacrificed, which gives ready access to the subclavicular fat at the apex of the axilla -in the space of Mohrenheim. In removing a part of the costocoracoid membrane the cephalic vein at the upper and outer aspect of the wound must not be wounded. There is also in the fascia a branch of the acromiothoracic artery which, with its accompanying vein should be clamped and tied. A nerve supplying the pectoral muscle may as well be sacrificed now, as it necessarily must be later on when the muscles are removed.

"The dissection is done at the apex of the axilia and must be most carefully conducted lest injury be done to either the axillary vein or the acromio-thoracic artery. It should be from above downward, though this is perhaps somewhat more difficult than making the dissection irom below upward.

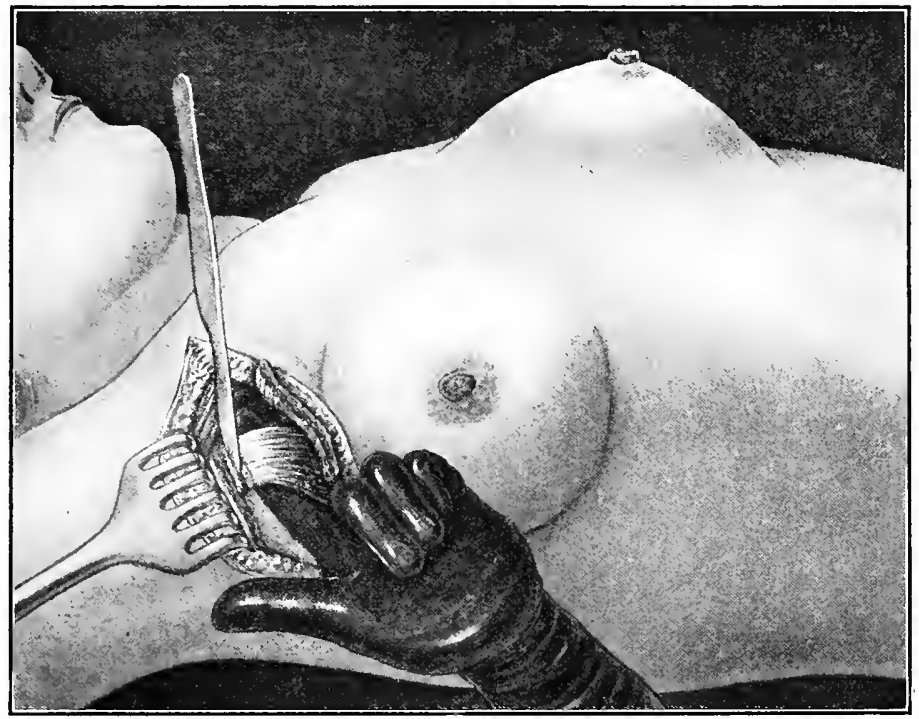

FIG. 227.--Illustrating the Rodman operation for mammary carcinoma. Division of the pectoralis minor muscle at its insertion.

"In the removal of the fat and fascia in the'upper third of the axilla, the finger, covered by several thicknesses of gauze will be all that is necessary. Instruments are rather dangerous, unless used most cautiously. Moreover, they are unnecessary.

"I now carefully make an incision through the fascia to the outer side of the axillary vessels simply to start the dissection from within out ward. This is made to the extent of the lower two-thirds of the axilla and not in the upper third where it is dangerous to cut. I continue the dissection largely with gauze, but Allis's or Mayo's blunt dissectors may be used freely and are most helpful. Occasionally a cut with scissors or a sharp knife facilitates the dissection. . . . As the sheath and fat are removed from the vessels we come down upon the acromial, long and alar thoracic branches, and the subscapular branch of the axillary artery, in the order named, from above downward, which, with their accompanying veins are to be carefully clamped in two places and divided between. The proximal ends are ligated. In this way the subsequent hemorrhage is materially lessened; in fact it is surprising how little blood will be lost during so prolonged and extensive a surgical procedure. 
"The enlarged lymphatic glands will usually be found at the hase of the axilla between the latissimus dorsi, teres major, and sub-scapularis muscles posteriorly; the serratus magnus internally; and inferior to a line formerly indicated by the situation of the lower border of the pectoralis minor. The mid-axillary and subclavian glands may, however, be infected. All such enlarged glands and surrounding fat should be carefully dissected from the several muscles, and to do this best, the fascia covering the muscles should be sacrificed. In fact, so thorough should be the axillary dissection that nothing is left on its inner aspect save the posterior thoracic or nerve of Bell; on the posterior aspect, only the long subscapular nerve, and superiorly, possibly the superior thoracic artery, if it arises as an independent branch high up on the first portion of the axillary. In such circumstances it is impossible, in my judgment, to reach it with safety. It is so deeply placed that there is great danger of doing serious damage to the vein and artery, the former particularly, if an attempt is made to secure the vessel at the root. . .

"A thorough dissection of the axilla can usually be finished in 20 minutes, and it is entirely accomplished through the single straight incision. It should invariably be irom above downward, without inward, and en massc. A piecemeal extirpation is not to be considered.

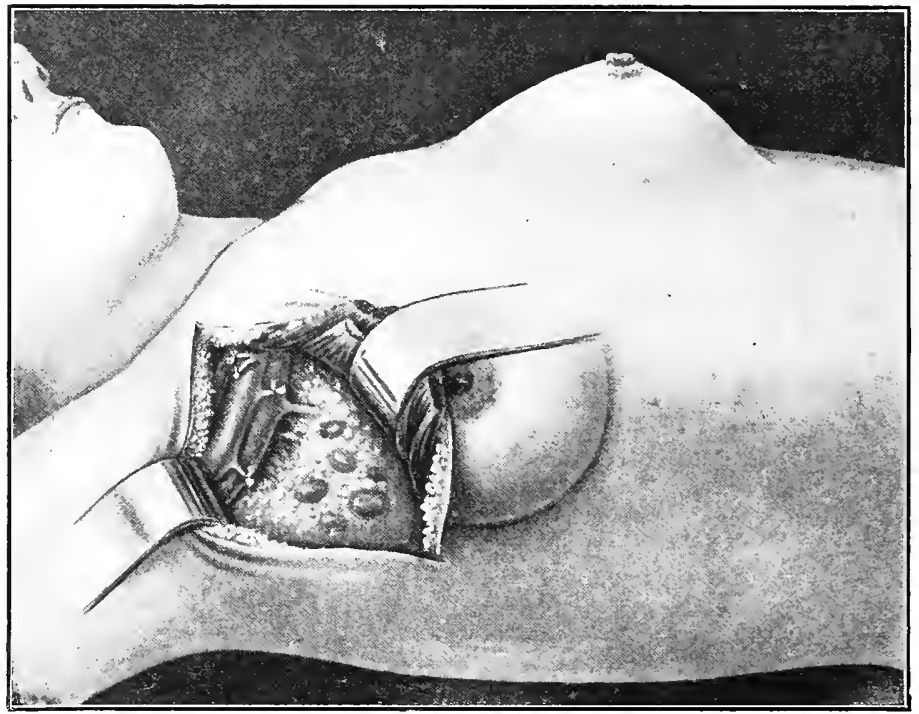

FIG. 22S.-Illustrating the Rodman operation for mammary carcinoma. Axilla freely exposed and vessels divided at their origin.

"It is best to attack the axilla before removing the breast because (as taught by Gross) the axilla may be so extensively involved that a complete eradication of the growth is impracticable and further operative steps injudicious. Although since the more thorough axillary operation has become a routine procedure, many cases considered inoperable in Gross's time would not be so now. In working toward the axilla the danger of expressing cancer cells into adjacent, even remote tissues is avoided. "Therefore, the breast should not be handled, massaged or in any way disturbed until the axillary dissection has been finished and the completion of the operation is near at hand. In my opinion this is one, indeed, the best reason for not working from sternum to axilla, and for reversing the technic of Halsted and many others. This procedure also lessens hemorrhage when the vessels are ligated at their origin.

The time of operation is shortened and shock necessarily minimized.

" "The axillary dissection having been accomplished, it now remains to complete the skin incision, whicb is made by beginning at the middle of the initial incision and circumscribing the entire breast with either a circular, oval, or broadly elliptical incision. The circular incision is only advised in a central or sub- 
areolar growth. . . "The skin incision must under no circumstances come nearer than 2 inches to the edge of the growth.'

"The knife should not be carried straight down to the muscles beneath, but slanted in such a manner as to divide the subcutaneous tissue or the para-mammary fat at least 2 inches further out than the skin has been cut, which will practically take it up near the clavicle superiorly, well beyond the sternum internally, below the border of the great pectoral inferiorly, or well on to the external oblique and rectus.

"Such extensive undermining of the skin not only removes any outlying portion of the mammary gland, but facilitates the removal of the fascia covering the opposite pectoral muscle internally, that of the rectus and the external oblique inferiorly, and that of the latissimus dorsi externally.

" 'Undermining also insures approximation of a very large wound. . . . Over the chest the intercostal muscles are exposed; inferiorly the external oblique and rectus; posteriorly the latissimus dorsi, teres major, and subscapularis, and the long subscapular nerre; at the outer aspect of the chest (the inner aspect of the axilla) the digitations of the serratus magnus and nerve of Bell.

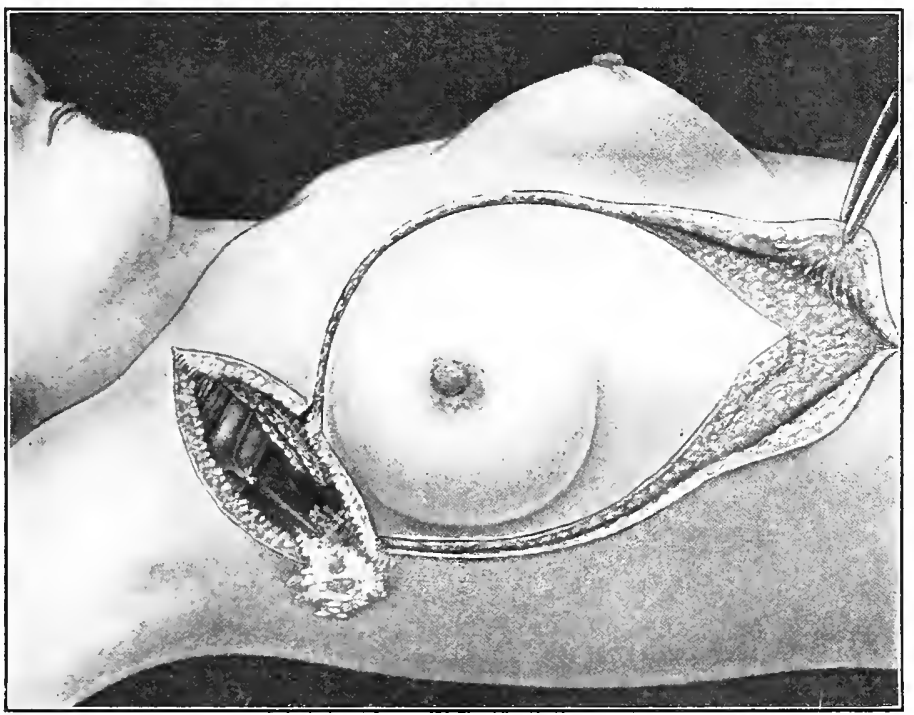

FIG. 229.-Illustrating the Rodman operation for mammary carcinoma. Second skin incision. Observe the extensive undermining anteriorly.

" 'Sternal parts of the pectoralis major and minor muscles are left at their origin' to prevent adherence to the ribs and to make a good bed for grafting should it be required.

"In tumors of the upper hemisphere the incision should be made above the clavicle and the posterior triangle of the neck explored. In tumors of the lower hemisphere, I never explore the neck. The supra-clavicular incision is also made in case I encounter infection of the glands or fat in Mohrenheim's space. If the glands just below the clavicle are involved, it is reasonable to infer that those just above it may be infected; at least it is unwise to infer that they are not.

"The closing of the wound is begun where it was started-that is near the clavicle, and can be accomplished by either interrupted or continuous suture.' In case of dificulty in approximating the flaps the central third of the wound is left unsutured and is immediately covered by suitable grafts taken from the thigh after the method of Thiersch." 


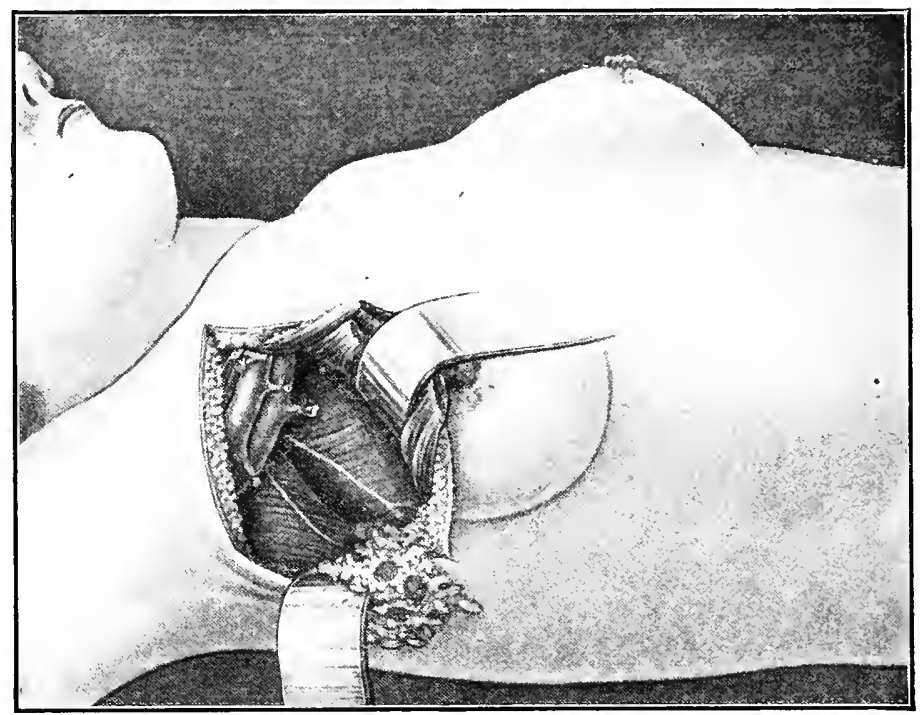

Fig. 230.-Illustrating the Rodman operation for mammary carcinoma. Axillary dissection completed. Fascia, fat and enlarged glands $e n$ masse shown at base of axilla.

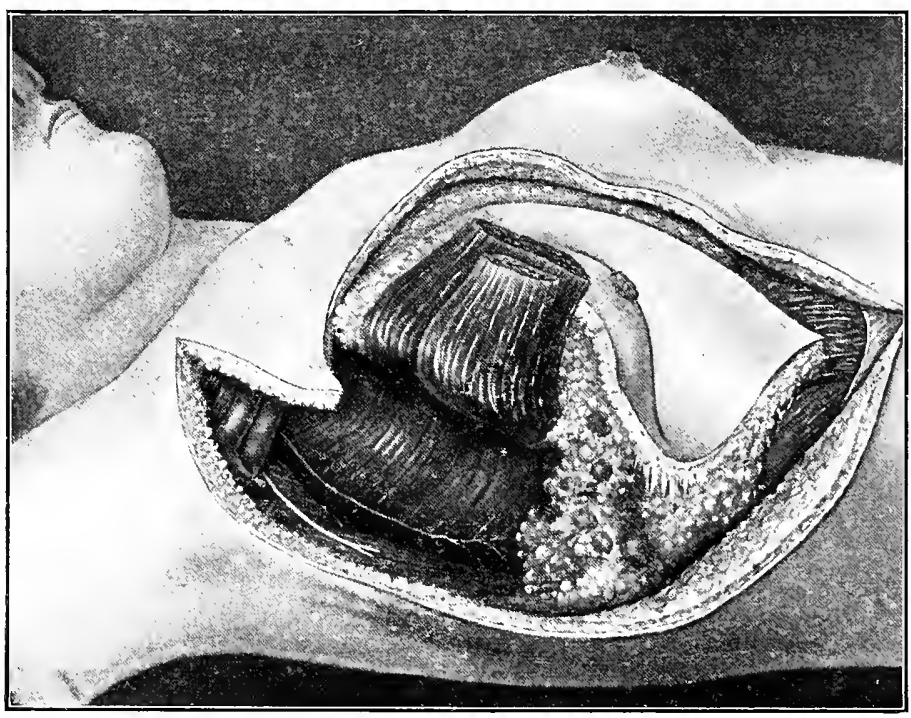

F1G. 23r.-Illustrating the Rodman operation for mammary carcinoma. Undermining inferiorly. Muscles, breast and axiliary mass being reflected prior to removal 


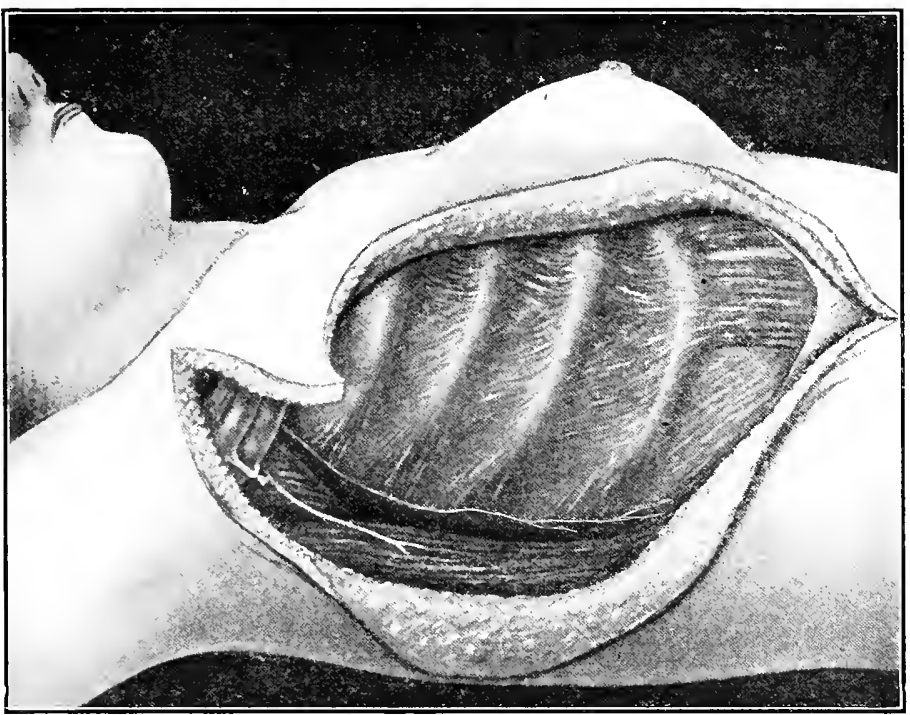

FIG. 232.-Illustrating the Rodman operation for mammary carcinoma. Appearance of the wound aiter removal of the breast, muscles and axiliary mass.

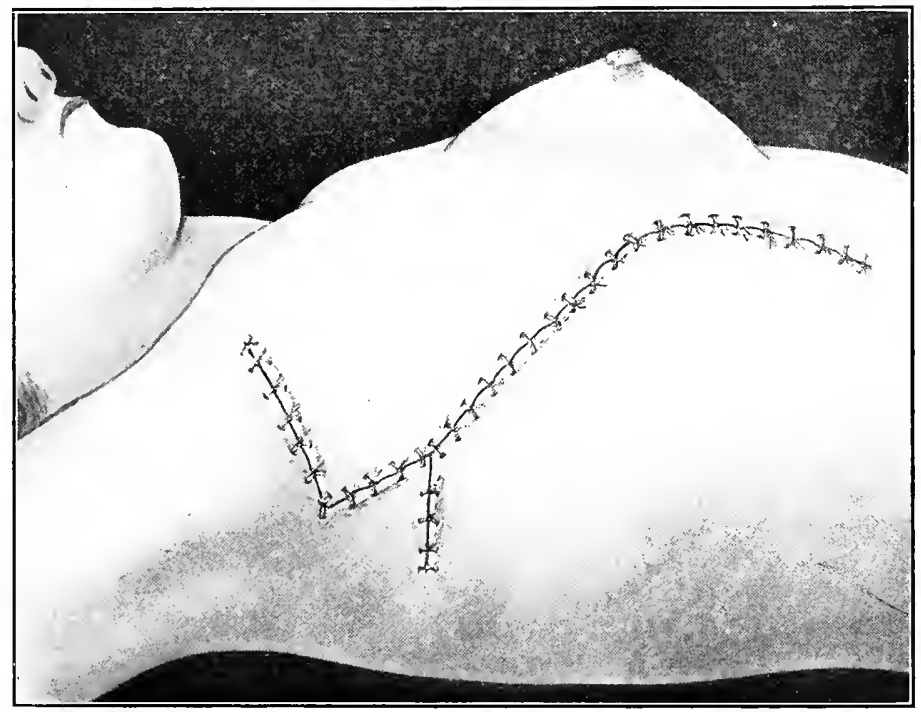

FIG. 233--Illustrating the Rodman operation for mammary carcinoma. Operation completed. 
The Stewart Operation.- Stewart says that the operation devised by him, and described below, "embodies the principles laid down by Halsted, with the following: the axilla is attacked first in order to determine the extent of the lymphatic involvement and the feasibility of radical treatment (Gross); in order to secure, once for all, at their origin, the blood-vessels supplying the breast thus minimizing hemorrhage, economizing time, and preventing shock (Meyer); in order to suppress lymphatic drainage as early as possible and prevent neoplastic dissemination (Gerster); and in order to leave the breast as a warm covering for the thorax until the final stage of the operation. The incision permits free exposure, including the subscapular space which is sometimes neglected; does not run on to the arm or through the axilla, in which situations a contracting scar may interfere with the function of the arm or press on the blood-vessels and nerves, and with

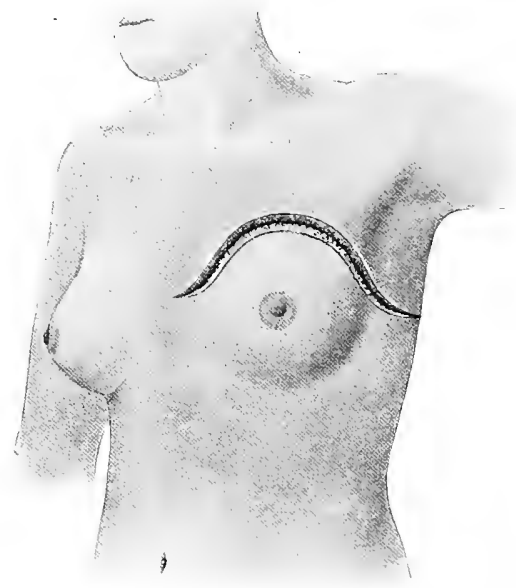

FIG. 234-- Imputation of the breast; primary incision. The towels which should be attached to the margins of the wound are not shown. (Stewart.)

extensive undermining, can almost always be closed. When primary closure cannot be obtained, the raw surface is covered with pedunculated flaps from the abdomen and back. Owing to the situation of the incision, a second opening is not needed for drainage and the dressing of the wound is simplified.

The drain when employed for lymphorrhea, is removed at the end of two days, and never replaced. Leaving the wound open and prolonging drainage mean infection and much fibrous tissue." The technic of the operation is as follows:

"An incision, skirting the upper margin of the breast, is made from a point on the edge of the sternum farthest from the growth and on a level with the nipple, to a point on the same level at the posterior axillary fold. Towels, which are not shown in the illustrations, are attached to the edges of the incision, so as to completely exclude the skin from the field of operation. The skin is undermined from the incision to the clavicle and the head of the humerus, and from the sternum to the posterior axillary" fold. The clavicular is separated from the costal portion of the pectoralis major, and the tendon of the latter severed close to the humerus. 
"The costo-coracoid membrane is divided, and the pectoralis minor cut at its point of insertion. With a self-retaining retractor of the Balfour type, and a smaller retractor held by an assistant, the entire

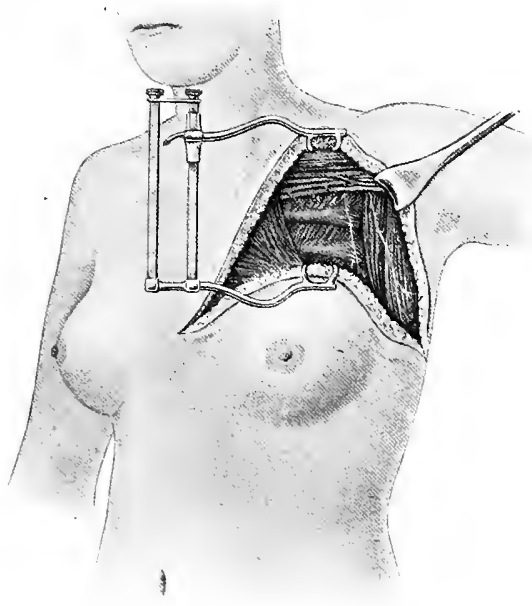

FIG. 235 - Amputation of the breast; dissection of axilla. (Stewart.)

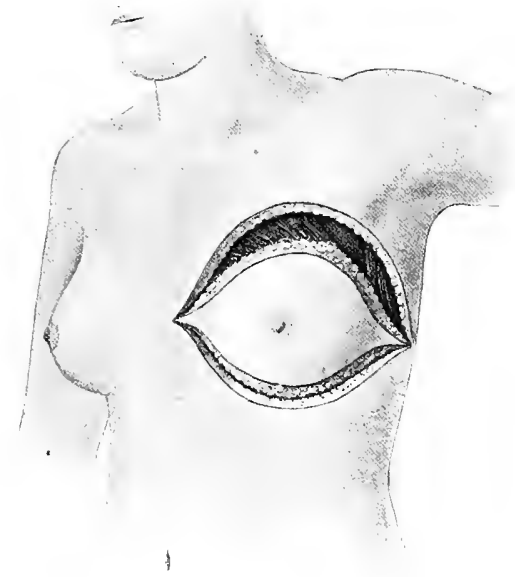

FIG. 236.-Amputation of the breast; the lower incision is made after evacuation of the asilla (Stewart.) axilla is exposed for evacuation which progresses from above and within downward and outward as in the Meyer operation. The vessels supplying the breast are cut between ligatures. The subscapular vessels are tied at each end, and, with the environing areolar tissue, pushed toward the median line, 
thus laying bare the latissimus dorsi, teres major, subscapularis, and serratus magnus. The ends of the original incision are joined by a cut which skirts the inferior margin of the breast and the skin undermined to the level of the lowest portion of the costal arch, or even lower. Through this incision one may remove, as suggested by Handley, the deep fascia over the upper portion of the abdominal muscles; we have not adopted this procedure as a routine measure. Next the breast is turned toward the opposite side of the body, the origin of the pectoralis minor cut, the perforating vessels seized before division, and the mass removed by severing the costal origin of the pectoralis major. The wound is irrigated with hot salt solution, and closed with several combined retention and coaptation sutures of silkworm-gut and a continuous suture of celluloid thread, except at the axillary end, where one suture is left untied, to provide an exit for a gauze drain which is removed in 48 hours and the suture tied.

"The arm is not bandaged, and the patient is allowed to put it in any position she desires. Edema of the arm immediately following operation we regard as a favorable sign; it indicates that the operation has been thorough, that all the lymphatic structures in the axilla have been removed, and the lymphatic

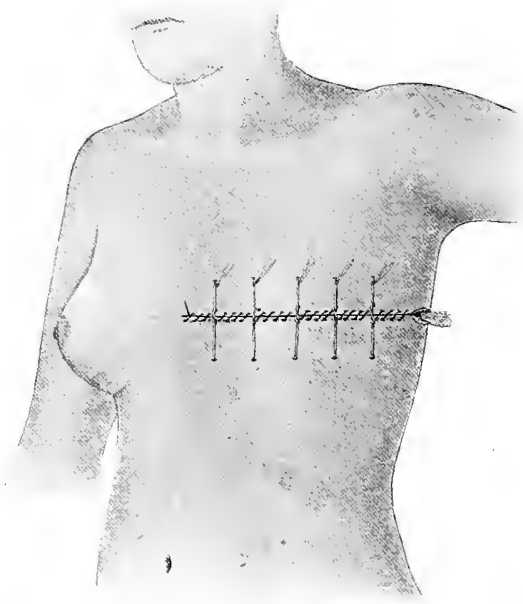

FiG. 237.-Amputation of the breast; wound closed. (Stewart.)

drainage of the arm completely interrupted. It usually disappears in from two to four months, but may last longer and indeed may be permanent. Edema appearing after an interval is due to pressure on the axillary vein by a cicatrix, by a recurrent growth; to neoplastic invasion of the vein; to venous thrombosis; to a tardy lymphthrombosis; hence is not always as is sometimes thought, a premonitory sign of early dissolution.

"We have employed the method, described above during the past five years, in 40 cases, and our colleague, Professor John H. Gibbon, has, during the past four years, used the same procedure in 47 cases, making in all 87 amputations of the breast by the transverse incision."

Murphy's Operation.-Murphy believes that post-operative neuritis and edema of the arm are "due to the compression or resistance to the return circulation by the cicatricial contraction of the tissue that forms in the axilla," and not, as is generally supposed, to lymphatic stasis. He further believes that removal of the pectoral muscles is not only an unnecessary but also an unwise procedure. As a means of preventing or minimizing the formation of scar tissue, the pectoral muscles are implanted so as to fill the dead space in the axillary angle. 
The operation as described by Murphy is performed as follows:

"We encircle the breast by making two elliptic incisions extending from the outer and upper border to the lower and inner and down to the pectoral fascia. Then we lift up the breast without traumatizing

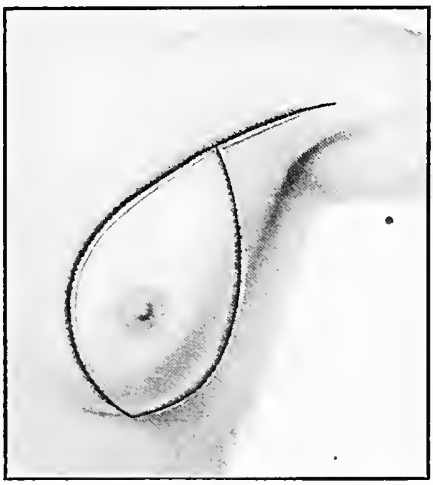

FIG. 238

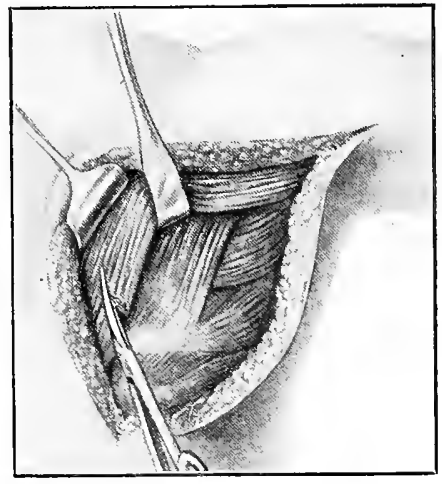

FIG. 239 .

FIG. 238.-Illustrating Murphy's operation for mammary carcinoma. Skin incision.

FIG. 230.-Illustrating Murphy's operation for mammary carcinoma. The lymphatic-bearing aponeurosis of the pectoralis major and the fascia and fat between the pectoralis major and minor have been dissected away, together with the breast, the surrounding fat, and the overlying skin. The costal and sternal attachments of the pectoral muscles are then divided with scissors.

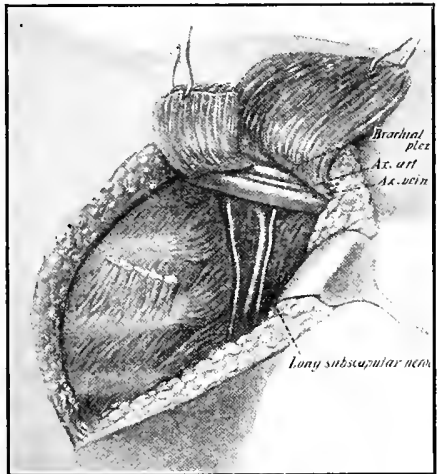

FIG. 240.

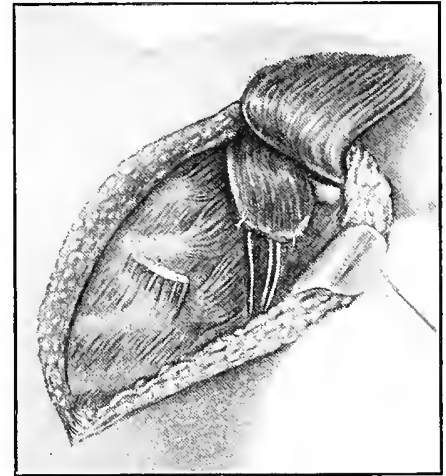

Fig. $24 \mathrm{r}$.

FIg. 240.-Illustrating Murphy's operation for mammary carcinoma. The pectoralis major and minor are dissected free from the chest wall and clavicle and retracted upward and outward out of the Geld. The axilla then lies exposed clear up to the clavicle. The axillary glands and fat are then dissected en masse from the axillary vessels and nerves, beginning at the apex of the axilla and proceeding downward and backward. The long subscapular nerve is carefully preserved.

FIG. 24I.-Illustrating Murphy's operation for mammary carcinoma. When the axilla is clean, the pectoralis minor is turned into the axillary space and sutured over the axillary structures by tacking stitches.

the tumor and remove it. Next I remove the aponeurosis of the pectoralis major muscle and all the fatty tissue. Then the pectoralis major muscle is freed from its costal attachment and reflected outward on 
the arm, splitting it well up to the clavicle. The fascia and fat between the pectoral muscles are then removed as a lymph node is usually found in this location. The pectoralis minor muscle is then detached from its costal attachment and is deflected outward. All the aponeuroses of both muscles must be removed. Dissect free the edge of each muscle with dissecting scissors, pass two fingers under each muscle, and divide with the scissors close to the ribs, so as to leave enough muscle distally to fill in the axilla. Care must be taken to preserve the blood-supply of the muscles.

"The chest portion of the muscles is elevated entirely so as to expose the fascial coverings of the ribs.

"When we have removed the gland-bearing tissue in the axilla and cleaned out the axilla, then we use the pectoralis major and minor muscles to fill all that space.

"Now we are ready to dissect the axilla. We extend the incision along the anterior axillary border up onto the arm. There will be no skin scar in the axilla. Now we commence to free the fat- and glandbearing tissue from the axillary artery and vein. We wipe out these tissues with a gauze sponge, rarely ever using the dissecting scissors. We always carry our dissection from above downward. Be careful not to injure the long subscapular nerve which supplies the latissimus dorsi muscle when dissecting the

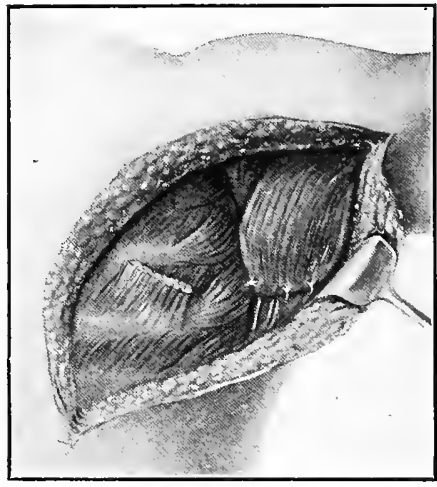

FIG, 242.-Illustrating Murphy's operation for mammary carcinoma. The pectoralis major muscle is turned over the pectoralis minor and likewise tacked in place. A stab wound is then made through the lower skinflap for tube-drainage and the incision closed. tissues along the posterior axillary fold.

"Now we have the axilla thoroughly cleaned out and we proceed to ligate the bleeding points which were clamped during the dissection.

"Now we are ready to place the pectoral muscle stumps into the axilla. By means of a few catgut sutures each muscle separately-the pectoralis minor first-is swung into the axilla and fixed to chest wall in front and the edge of the latissimus dorsi behind. Only two or three stitches are needed to do the tacking.

"The muscle pads cover all the vessels and nerves in the axilla. They fall into place readily. All you need to do is to fix them there. That is the only part of the technic that is original with us. We close the wound by putting in a considerable number of interrupted silkworm-gut tension sutures and continuous horsehair sutures for the skin incision. There-must be absolutely no tension on these flaps. We always drain these wounds to allow the wound secretion and blood to escape."

Murphy states that lie has never observed a recurrence in the pectoral muscles and that the arm is perfectly movable "not only after the operation but continuously so after it."

Eliminating the question of susceptibility of muscle tissue to cancerous invasion, the mere fact that piecemeal removal of the fascia surrounding these structures defeats the purpose of block dissection compels us to take issue with Murphy's teachings. The danger of cancer implantation is too imminent to allow of attempts at cleaning away invaded fascia from non-invaded muscle.

The Dawbarn Operation.-Dawbarn advocates Symes method of preliminary incision in to the neoplasm when the absence of cardinal symptoms of cancer raise doubts upon the diagnosis. English surgeons especially are in favor of this method, which Whiteford says should always be done after the method of plastic resection rather than by the transcutaneous route.

In addition to this advocacy of a primary axillary dissection, Dawbarn advises muscle anastomosis to insure freer use of the arm after operation. This may be accomplished by detaching an inch or more of the anterior fibers of the deltoid muscle from its origin, the muscle being split in a direction parallel to its long axis for a distance sufficient to permit the detached portion to be sutured to a stump of the adjacent pectoralis major 
muscle; the latter should correspond in size with the former. Three 20-day chromic catgut sutures are used to hold the muscles in apposition. A triangular splint is employed to support the arm after the operation.

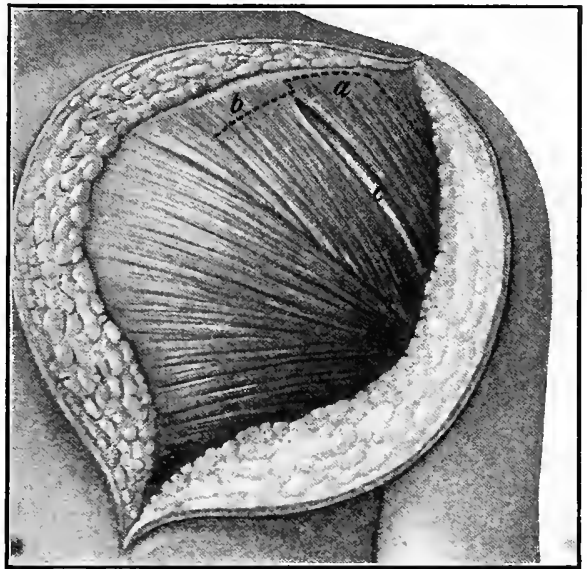

FIG. 243.-Dawbarn's operation for radical amputation of the breast. (a) Deltoid muscle. (b) The clavicular origin of the pectoralis major muscle. (c) The cephalic vein.

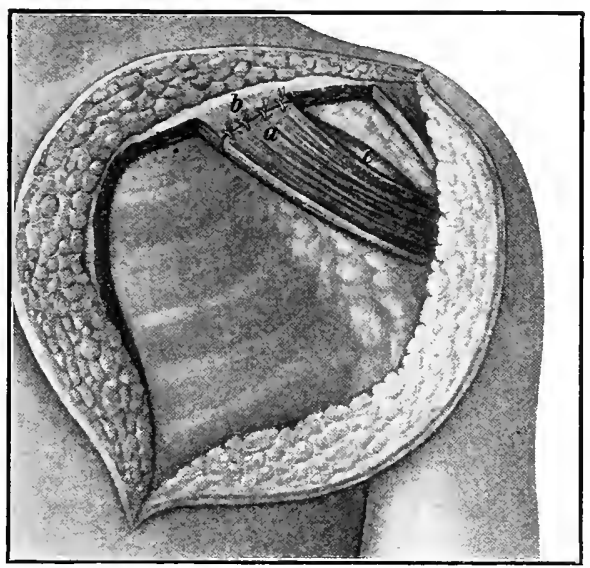

FIG. 244.-Dawbarn's operation for radical amputation of the breast. (a) Deltoid muscle. (b) The clavicular origin of the pectoralis major muscle. (c) The cephalic sein.

One serious objection to this procedure is that it is unnecessary. Perfect freedom in the use of the arm is reported by our patients after removal of both the sternal and clavicular heads of the pectoralis major muscle as well as the minor muscle and without any muscle 
anastomosis. Limitation of arm motion after the radical breast amputation is due to cicatrices and not to the absence of the pectoral muscles.

Meyer's Method.-The original method of radical amputation of the breast devised by Willy Meyer was identical in all essential details with that of Halsted. He has since abandoned, as has Halsted, the use of the cut up to the middle of the clavicle and in addition has changed the direction of the external incision. For the formation of the lower flap, the incision starts at the point of insertion of the pectoralis major muscle on the humerus; passes downward and inward a little above the border of the pectoralis major to the base of the breast, around this to a little over the middle of the body over the sternum; the flap is turned back until the border of the latissimus dorsi muscle is

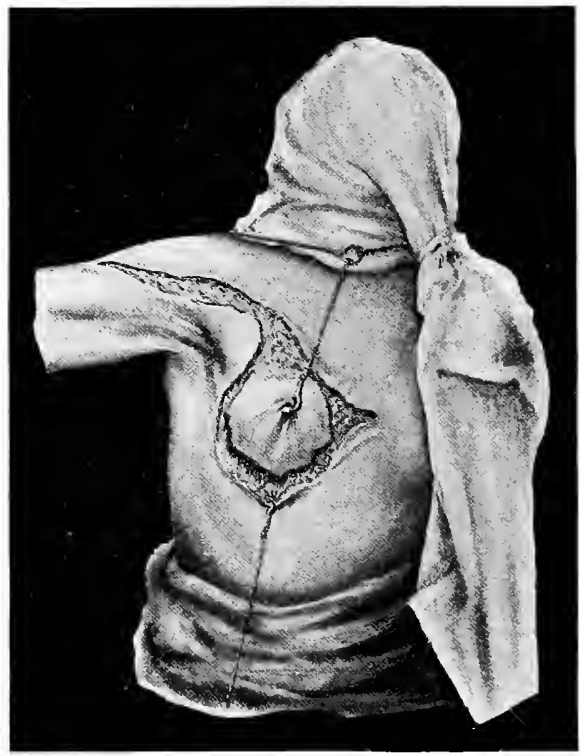

FIG. 245.-Skin incision. (Meyer.)

exposed. The upper flap is formed; the inner and outer parts of the first incision are united by an incision along the upper border of the breast. The axillary and subclavian veins are next exposed; the axillary and subclavian glands with surrounding fat are extirpated.

The fourth step consists of the formation of a pedicle over the sternum and the removal of the mass. Meyer in certain early cases preserves a small stump of the belly of the pectoralis minor muscle to which the lower two-thirds of the incisional borders can be stitched, thus materially reducing the size of the defect as well as improving its surface for grafting purposes. He advises grafting the defect immediately after the operation and states that his practice is followed by perfect mobility of the arm and that edema of the arm is unknown after the operation. 


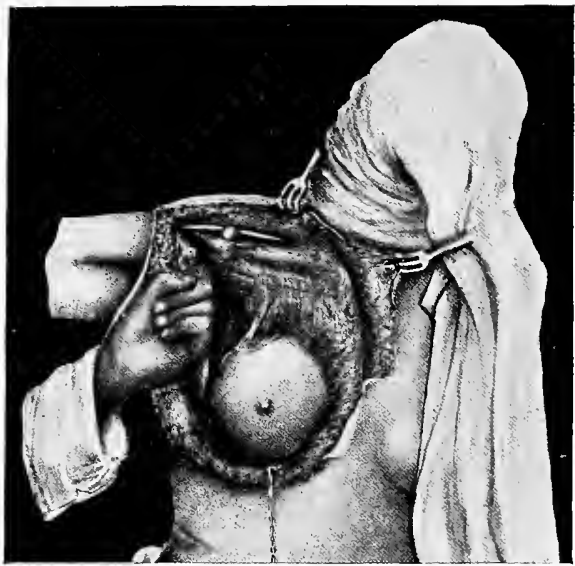

FIG. 246.-Insertion of pectoralis major muscle exposed. (Meyer.) Operator's left index finger encircling its tendon.

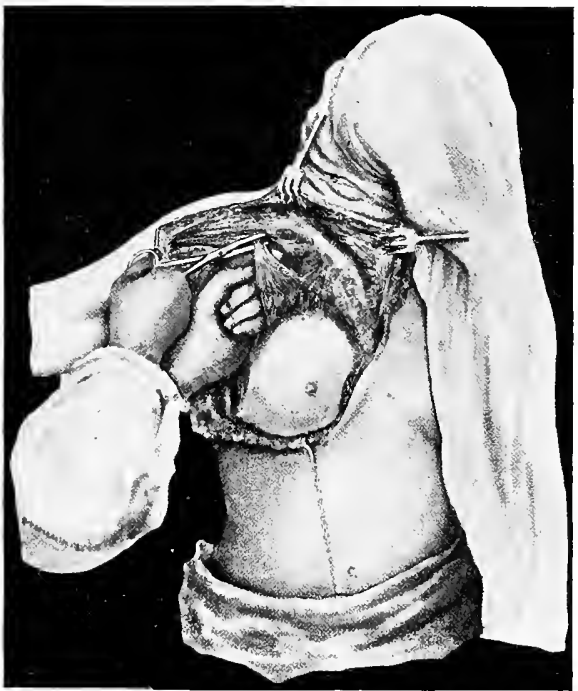

Fic. 247.-Finger under tendon of pectoralis minor muscle. (Meyer.) Above, cut surface of clavicular portion of pectoralis major parallel to clavicle is visible. (In the living, the belly of the pectoralis major is not so thoroughly detached from that of the pectoralis minor. It is done here to show the latter's tendon.) 


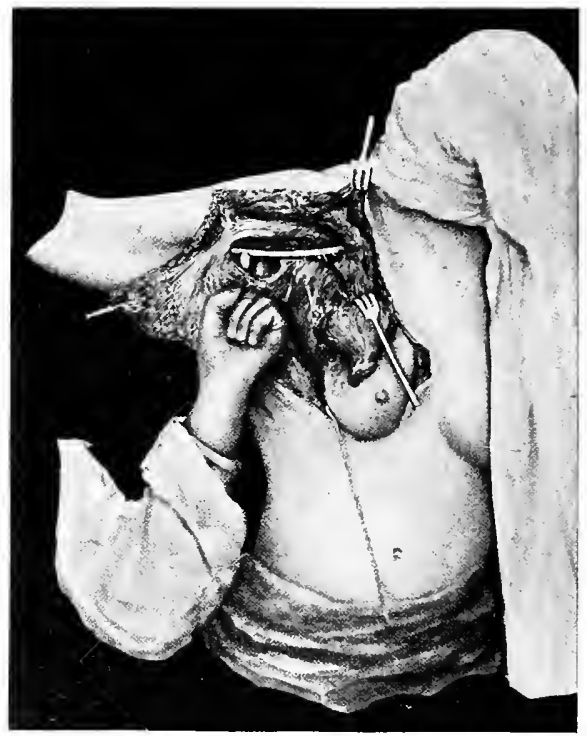

FIG. 248.-Subclavian and axillary veins fully exposed. (Meyer.) So far, glands and fat tissue not removed; smaller vessels still in connection with main trunks. Finger under fat towards sulcus bicipitalis, its nail resting on axillary vein.

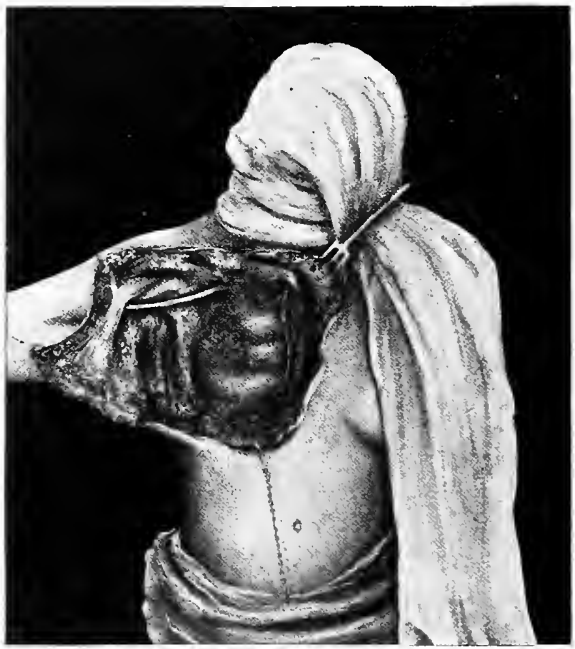

FIG. $38_{4}$-Operative field, after removal of the mass. (Meyer.) Stump of pectoralis minor muscle is visible. 
Tansini's Method.-The Tansini operation is an autoplastic procedure, the object of which is to allow of wide removal of mammary skin and its replacement by a skin flap transplanted from the back.

$A$ wide oval-shaped incision is made into the skin of the base of the breast and comprising the entire mammary region on the affected side. The incisions are made to meet under the arm, thus making it possible to remove a zone of skin, about $4 \mathrm{~cm}$. in width in the track between the manma, the axilla and the axillary contents. The usual radical amputation is then performed. This incision allows of a very wide removal of skin surface. The defect is filled in with an auto-plastic flap lifted from the dorsal region between the posterior axillary margin and the vertebral border of the scapula. The pedicle of the flap is at the extreme upper end of the axillary incision so that the transplanted flap covers the skin defect in the axillary cavity and the linear scars meet, the one corresponding to the anterior portion and the other to the posterior portion of the axilla. As first devised the operation was unsatisfactory because the flap suffered necrosis for fully one-third of its extent in the majority of cases; to remedy this defect in technic Tansini, in a second paper, gives very explicit directions for the formation of the flap.

He observed that the subscapular artery and its dorsal scapular branch were the important arteries given to this flap. The arterial ramus leads toward the surface be-

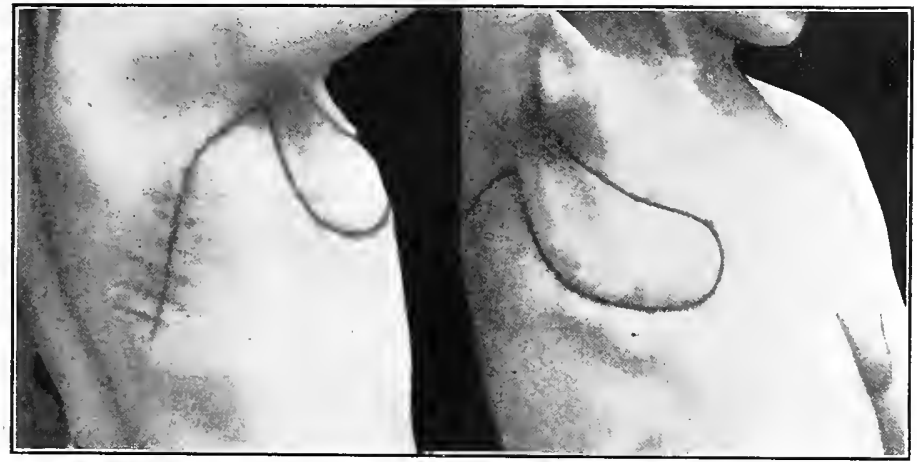

FIG. 250.-Showing the results of the Tansini operation. (Tansini.)

tween the two teres muscles and branches extend to the latissmus dorsi muscles and to the cuticle. To insure vitality of the flap he advises, therefore, to include in it the latissimus dorsi muscle and perhaps also the teres major. This procedure not only insures its vitality but provides a flap more perfect in reparation for the removed axillary structures. The pedicle should have a diameter of 6 or $7 \mathrm{~cm}$. with its center corresponding to a point about $3 \mathrm{~cm}$. from the posterior axillary line and about $5 \mathrm{~cm}$. from the spine of the scapula. This insures inclusion of the blood supply. The wound is closed by slipping the skin, made flexible by two linear incisions above and below. Complete closure is possible, as a rule.

Without doubt by this ingenious method the skin flap from the back is easily carried in front of the pectoral incision and perfectly replaces the lost skin, while the dorsal wound is closed with comparative ease. The advantages clained for the operation are: wide removal of skin surface, removal en bloc of breast, axillary contents and muscles; perfect closure of the wound with a skin flap taken from an area far removed from the danger zone, and fine post-operative functional results. The chief criterion of the value 
of any method of breast amputation is better ultimate results obtained in large series of cases than with any other methods; this is lacking in the case of the Tansini operation. DeRaulet is the latest advocate of this method, but with the exception of a few Italian surgeons, few operators have adopted the Tansini method.

Warren's Method.-In I 904 Warren reported 38 per cent. of "cures" in 60 operative cases of mammary cancer of the non-medullary type, while only 7 per cent. of 40 cases of medullary carcinoma were permanently "cured." The method which Warren employs possesses many features of merit.

"The incision employed in this operation is made from the anterior and outer margin of the axilla running a little above its upper border and the line of insertion of the pectoralis major muscle, around the lower border of the breast to a point on the boundary line of the inner and lower quadrant. If there is a serious doubt as to the malignant nature of the growth, the breast can he lifted up from below by carrying the dissection up the last half of the incision more deeply, and exploring the mammary region on its

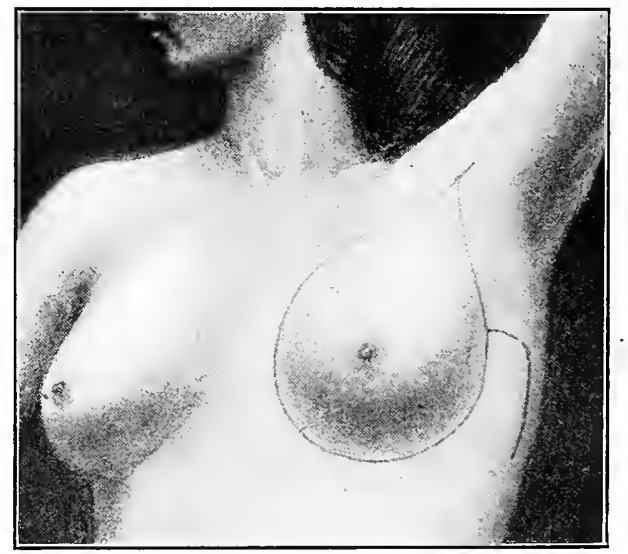

FIG. 25 r.-Illustrating Warren's operation for mammary carcinoma. Primary skin incisions.

posterior surface more deeply. It has been our practice in doubtful cases to make an incision around the periphery of the breast in its lower outer aspect through which the entire posterior surface of the organ can be explored. With the diagnosis of malignancy verified, this primary cut is merely continued in either direction as already described. Otherwise it serves as an ordinary "Thomas incision."

The second incision in Warren's operation is made beginning at the outer extremity of the outer axillary fold, gradually diverging from the first incision as it approaches the breast, and, sweeping around the upper and inner margin of the organ meets the first incision at its terminal point.

"Before proceeding to the second step of the operation a flap should be marked out on the outer side of the pectoral region; to do this the knife divides the skin above the middle of the first incision, i.e., on the outer edge of the wound, on a line drawn first at right angles to said incision and gradually sweeping round until it becomes parallel to it and terminates at a point a little below the level of the lower margin of the wound. This flap is intended to be turned into the lower portion of the wound. In case there is infection of this cervical region, an additional incision should be made from the middle of the upper half of the median incision along the posterior border of the sterno-cleido-mastoid muscle to expose the posterior cervical (subclavian) triangle.

"This incision, if necessary, is not to be made until a later stage of the operation.

"The second step of the operation is the dissection of the integuments freely on all sides, the axilla 


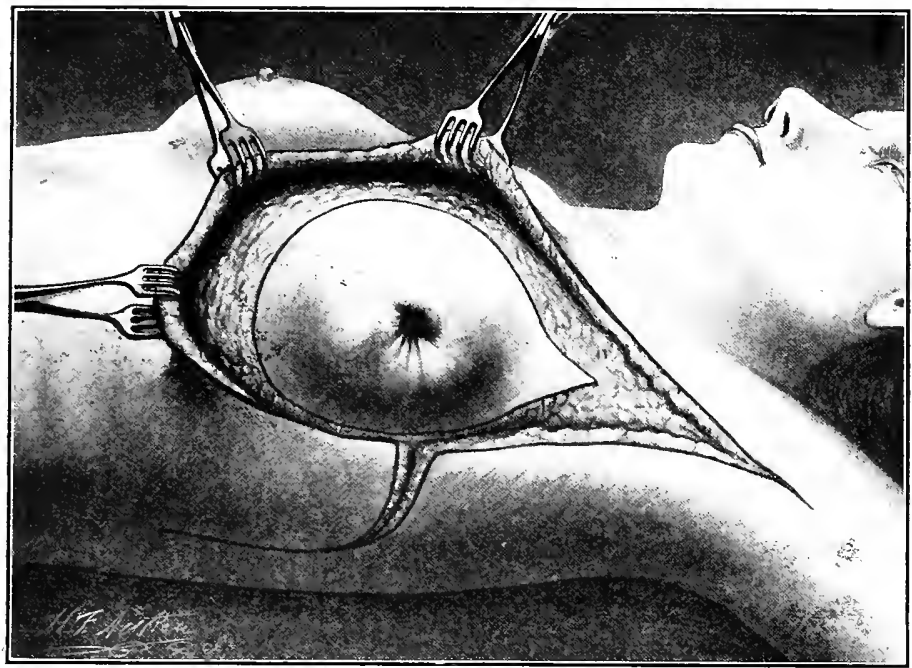

FIG. 252.-Illustrating Warren's operation for mammary carcinoma. Preliminary dissection of the skin flaps.

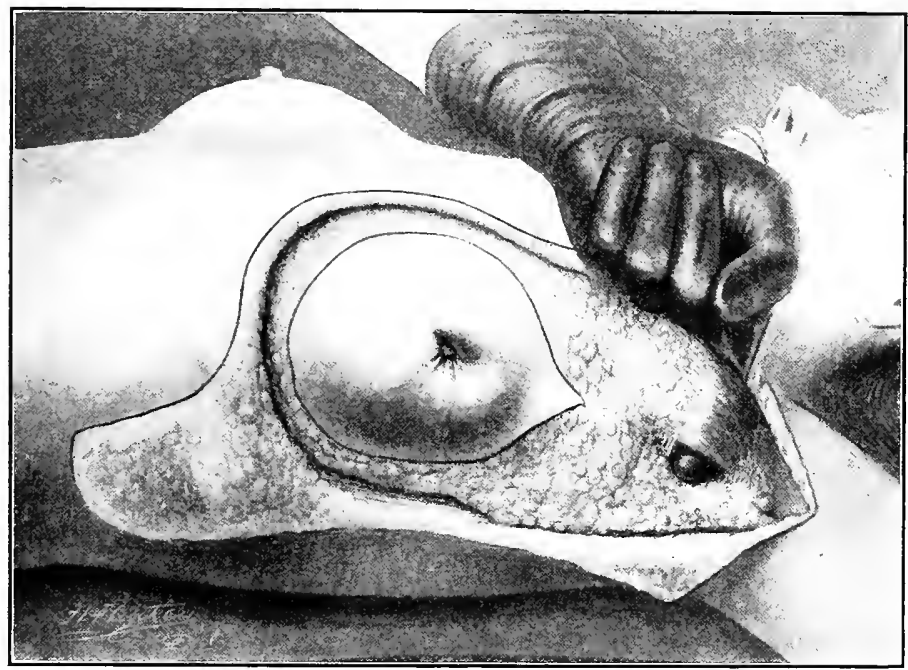

FIG. 253.- Illustrating Warren's operation for mammary carcinoma. The humeral attachment of the pectoralis major muscle is exposed and lifted on the index finger preparatory to detaching it frcm the bone. It will be observed that the anterior edge of the latissimus dorsi muscle is exposed 


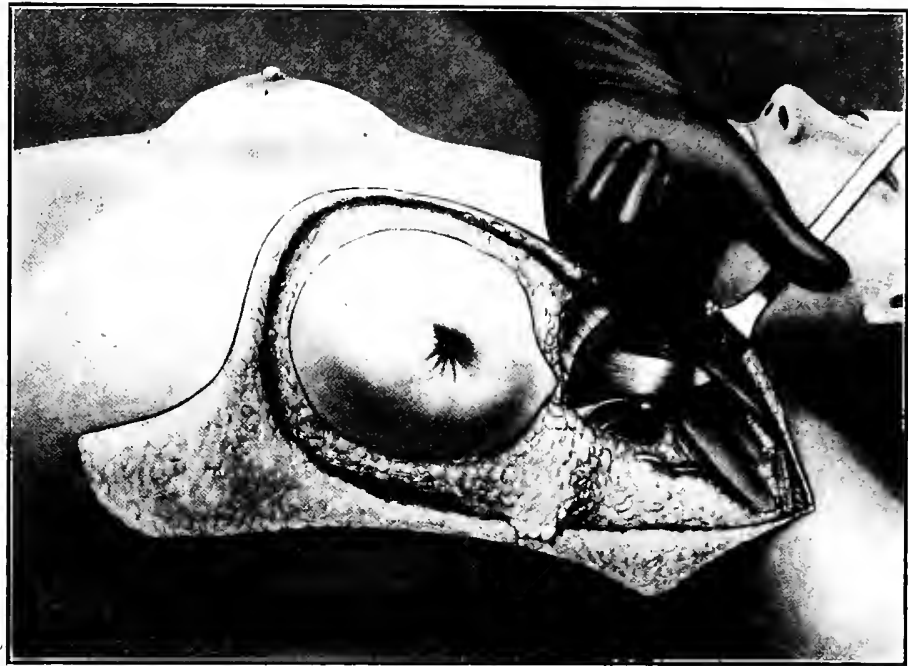

FIG. 254.-Illustrating Warren's operation for mammary carcinoma. The finger is inserted beneath the pectoralis minor muscle near its scapular attachment preparatory to detaching this muscle from the bone. The cut end of the pectoralis major muscle is shown overlying the pectoralis minor muscle; it will be observed that the former has contracted in ward to a considerable extent.

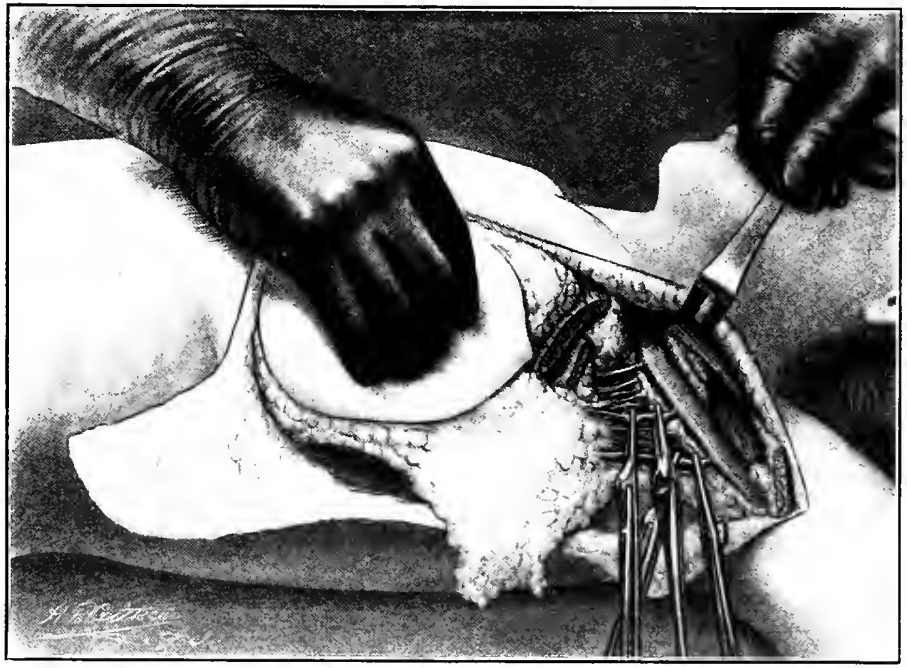

FIG. 255.-Illustrating Warren's operation for mammary carcinoma. Both pectoral muscles have been divided at their points of insertion and have retracted downward and inward, thus exposing the axilla. The illustration shows the axillary dissection almost completed. The vessels are grasped with hemostats close to the main vessels. 


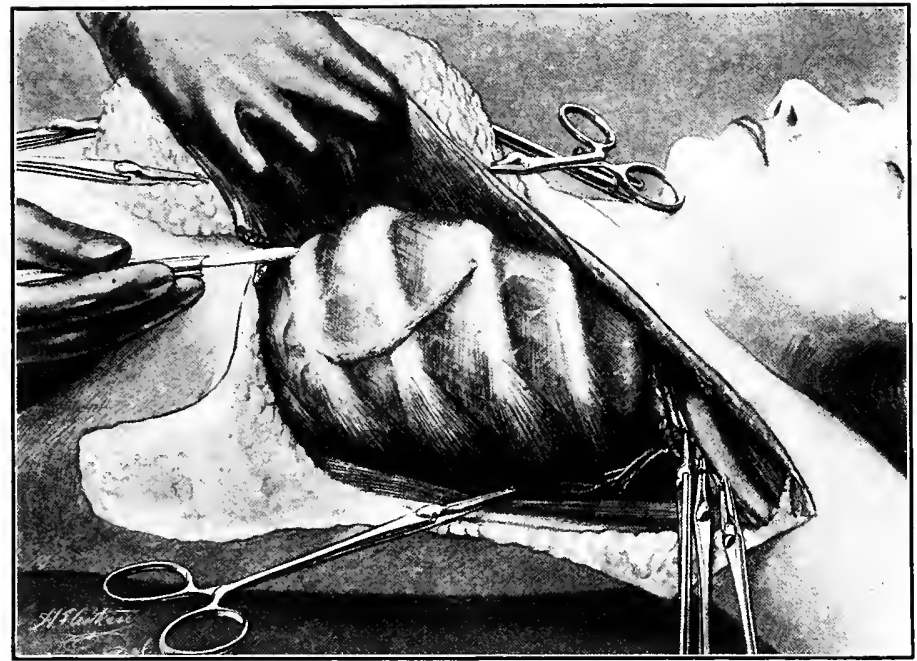

FIG. 256.-Illustrating Warren's operation for mammary carcinoma. The dissection is complete; it remains only to remove the mass from the chest wall. The breast and pectoral muscles are grasped and pulled downward and inward and the pectoral muscles are shaved from the chest wall.

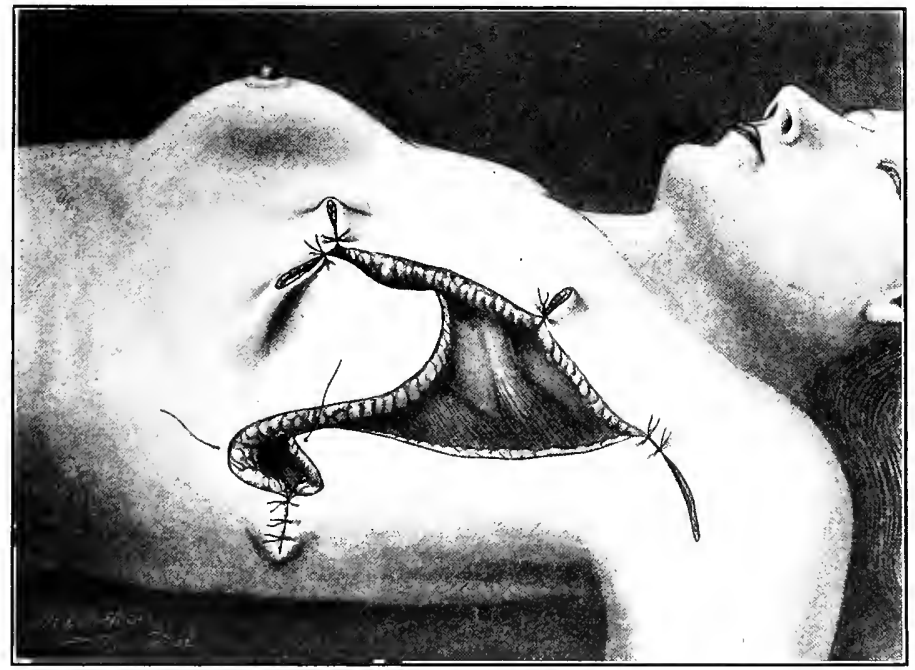

FIG. 257--Illustrating Warren's operation for mammary carcinoma. Closure of the wound. 
included, from the subjacent adipose tissues. The axillary skin and the flap are thus dissected off on the outer and lower side of the wound, and the dissection on the median line is carried well over the margin of the sternum. Above, this superficial dissection should be carried up so as to expose the clavicle. When the skin is reflected back on all sides, a cone with a broad base is exposed, the apex of which is the nipple, and which is composed of the breast, the pectoral muscles and the surrounding adipose tissue. The removal of these structures en masse constitutes the third step of the operation; this is done from without inward in a direction directly opposite to that carried out in the Halsted operation, so that the entire mass is removed toward the median line.

"Beginning with the bumeral insertion of the pectoralis major muscle, the forefinger of the left hand of the operator is slipped under the edge of the muscle from above downward and the muscle is divided a short distance from its insertion. The proximal end of the muscle is seized by hooks and pulled in the direction of its origin while its fibers are separated from those in immediate contact with the clavicle. An assistant, while bolding the books, quickly draws the breast with the other hand in the direction of the epigastrium. The finger is now hooked under the insertion of the pectoralis minor and the muscle divided. The axillary region is freely exposed and the thin fascia overlying the vessels being divided, the larger vessels are readily identified. In this way the dissection of the axilla can be carried out with great

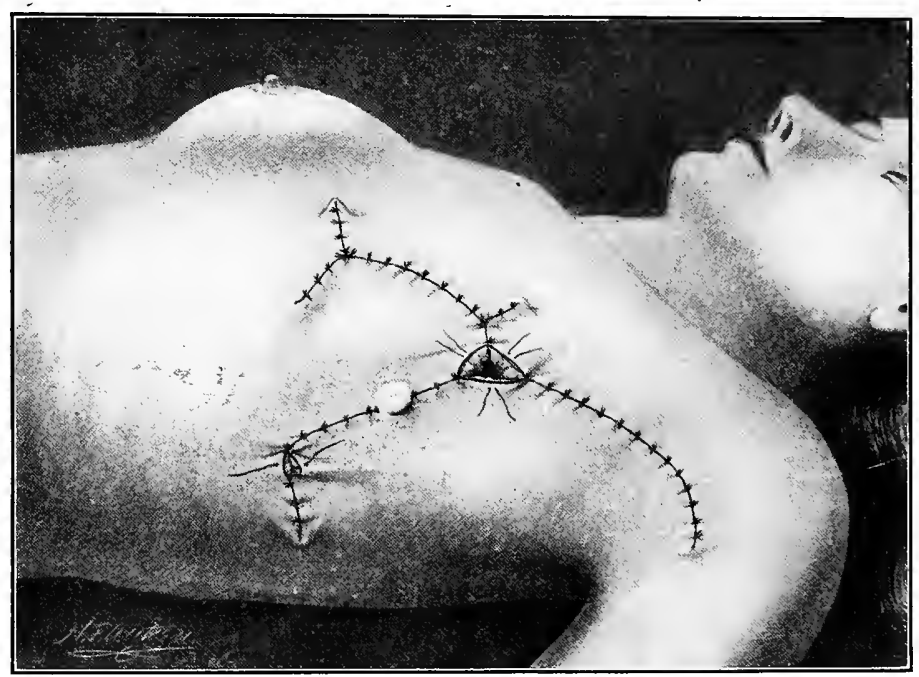

FIG. 258.-Illustrating Warren's operation for mammary carcinoma. Closure of the wound completed.

precision, and the origin of all the large branches can be secured with the ligature. A few sweeps of the knife separate the mass from the latissimus dorsi muscle. The breast is now seized by the operator and rapidly dissected off the thoracic wall from without inward. The origin of the pectoralis minor is first divided, and the final act of the operation consists in severing the origin of the pectoralis major wbile the breast and attached tissues are firmly held away from the sternal margin. Closure of the wound is begun on its outskirts at four different points, viz., at each end and on each side. A few stitches should be taken at the axillary and at the sternal ends of the wound first. The flap is then turned in and held in place by a temporary stitch. While it is gradually pushed up into place from below by sutures, firmly girding together the edges of the skin to which the flap was originally attached."

Jackson's Method.-This is another plastic method that has enjoyed a certain degree of popularity in this country. It is performed as follows: 
"The skin incision is begun about $1_{1}^{1}$ inches below the middle of the clavicle, in the sulcus, making the interval between the deltoid and the pectoralis major muscles. From this point the incision is carried in a straight line along the sulcus parallel to the inner border of the deltoid muscle until it reaches the lower border of the pectoral fold as it terminates in the arm. From the lower border of the first incision, the knife is then carried along the under margin of the pectoral fold to the chest, at a point which corresponds, as a rule, to the lower border of the mamma itself.

"The incision is next continued in the form of an ellipse about the nipple with its long axis obliquely from above downward and outward to the outer quadrant of the breast. The incision is, of course, carried through the skin and fascia to the underlying muscular structures, exposing the fibres of the pectoralis major converging well to its tendinous insertion in the humerus.

"At the lower point of this incision where it curves along the under border of the pectoralis major muscle, the index-finger of one hand is now shoved up underneath the pectoralis major and brought out again at its upper border so that the entire pectoralis major muscle is thus hooked on the index-finger and by blunt dissection separated out to its tendinous insertion. With the tendon of the pectoralis muscle thus lifted up it is divided by the scalpel very close to its insertion in the humerus. The pectoralis minor muscle is then exposed by blunt dissection by the finger and is isolated as was the pectoralis major. It is also divided close to its attachment to the coracoid process of scapula. The wound is held apart by

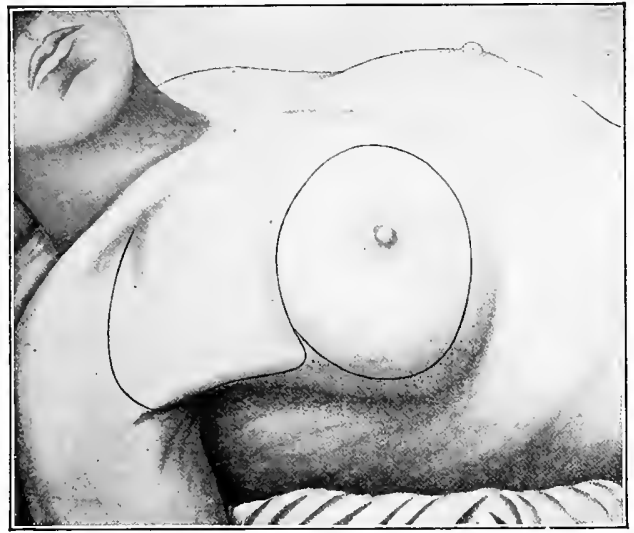

FIG. 259.-Jackson's incision.

retractors and the axillary space is now widely exposed to view. This exposure, as a rule, occurs without encountering any bleeding vessels which will require clamp or ligature.

"To the outer side of the axillary vein and parallel to it an incision is made of the fascia which surrounds the vessels. The fascia is stripped off by blunt dissection and gauze supplemented by an occasional snipping with scissors; the operator works steadily from without inward cleaning fascia glands, etc., as he goes. In this way the axillary vein and artery are isolated and the branches supplying the axilla and leading to the chest are made plainly apparent.

"These vessels should at once be ligated and clamped. . . . Beginning thus at the apex and outer border of the axilla, fascia and glands are completely cleared by gauze and scissors dissection working from the vessels inward to the chest.

"As this cleaning of the deep fascia is completed the original skin incision is also completed by carrying the horizontal incision over to the chest and marking the outer half of the ellipse so as to permit the flap to be raised and turned upward toward the clavicle, thus giving a deeper exposure of the attachments of the pectoralis muscle above and in front. It is important that a small tenaculum forceps should be placed at each angle of this flap when it is completed as it will be of much service later on.

"The point of attachment of the pectoralis minor to the ribs is cut from underneath flush with the ribs and costal vessels. From underneath the operator now loosens up the pectoralis major to its fixed points 
of origin from clavicle and sternum. While this is being done the breast is forcibly pulled back so as to expose the deep cavity of the wound. The pectoralis muscle is now severed close to its point of bony attachment and the perforating branches of the internal mammary artery which supply the vascularity of the breast are caught as soon as divided as they come through the chest wall.

"After the pectoralis major muscle has been entirely severed from beneath, the breast is allowed to drop into its normal position, the skin incision is completed and the breast and the pectoral muscles underneath are finally cleanly removed. Branches of the mammary artery which are clamped are now tied and the forceps removed. There is no bleeding of the skin incision and not more than a hatf dozen clamps were on the wound during the operation. All vessels are ligated as trunks at their point of origin instead of dealing with a large number of peripheral branches and the extent of fascia dissected is the same as in any other radical amputation of the breast.

"The quadrilateral flap of skin and superficial fascia, which originally formed the anterior covering of the axilla, is now stretched out by tenaculum forces and transferred inward to cover the defect of the chest wall created by the removal of the skin of the breast about the nipple. This flap, which is one of the distinctive features of the operation will always contract after it has been entirely loosened and will look as though it could be of but little service. A couple of tenaculum forceps in the angles, with probably another pair on either side, will spread it out until it covers a surprising amount of space. As the flap is drawn over the chest it may be fixed by attachment to the corresponding skin margin.

"Another distinctive point now consists in catching up, with the tenaculum, the margin of the lower portion of the pectoral fold, which represents the integument which formed the original floor of the axilla and which in thin subjects is often very marked. The tenaculum on this margin is placed at such a distance from the lowest point of the first vertical line that when drawn upward it will bring this skin point up to the original beginning of the first incision beneath the clavicle. This maneuver brings the loose skin from the floor of the axilla closely up around the axillary vessels and does away with the axilla as a cavity in the subsequent anatomy of the individual. These tenacula likewise are usually clamped and mark these fixed points of coaptation.

"I generally now place an approximation-suture of silkworm gut at these points to steady my subsequent suturing. The rest of the incision may be sutured either with interrupted or continuous sutures or with sub-cuticular sutures of silkworm-gut. A stab puncture in the lowest recesses of the wound space behind furnishes opportunity for drainage tube."

\section{Advantages of the operation:}

"The flap forms a covering for the chest defect, as a rule, without any tension, and no grafting is required. The operation of course can be applied only in cases in which there is healthy tissue for a flap of any character-where there has been no previous ulceration.

"The drawing of the skin up to the arm does away with the axillary fossa and thus with the large space which Nature would have to obliterate by formation of scar tissue."

Double Oöphorectomy (Beatson's Operation)._-Beatson first suggested the removal of the ovaries as a treatment of inoperable cancer of the breast on the theory that the artificial menopause thus induced would excite involutional changes not only in the normal epithelium of the breast but also in the cancer cells.

At first the operation was believed to be applicable only to patients who had not as yet passed the menopause but later some favorable results were obtained in older women, and Abbé reported an apparent cure in a woman 70 years of age. The operation has been practically abandoned, although in some of the reported cases the patients seemed to have been temporarily benefited by it. Lett found that 4 I per cent. of a collected series of cases in patients under 50 years of age were improved. This benefit was seldom lasting, however, and certainly did not justify the primary mortality of 6 per cent. that attends removal of the ovaries in patients with inoperable cancer of the breast. The post-operative administration of thyroid extract seemed to inhibit the growth of the cancer cells in four cases of recurrent cancer operated on by Herman. The latter calls attention to the fact that of $\mathrm{x} 7$ favorable results with Beatson's operation collected by Boyd in 1900 , 12 of the patients had been given thyroid extract after the operation. 
Boyd's series, comprising $7 \mathrm{I}$ cases, is the largest yet reported and in only $\mathrm{I} 7$ of them was any "clear and considerable effect" obtained. Drawing his conclusions from these cases, he says:

"Success or failure does not depend on the amount of superficial disease but on the nature of the involvement. When bone or viscera have been invaded, no improvement takes place and in several cases secondary, growths undoubtedly present at the time of the oöphorectomy have increased after it and have caused death. Evidence of success usually appears promptly; vascularity decreases and nodules begin to shrink within a week. Nodules in the skin and in the subcutaneous tissues are the first to disappear and then those in the muscles. It is possible that growths in the bones and in the viscera are benefited but there is no evidence to prove it."

Little attention has been paid to the Beatson operation since the publication of Boyd's paper, but Torek has recently reported eight cases with results that in his opinion justify its employment in cases "where we are unable to do anything.better." Inasmuch as the operation is useless in cases where internal metastasis has already occurred, and since removal of the cancerous tumor and post-operative $X$-ray therapy are more efficacious in cases where the disease is limited to the chest wall and axilla than is double oöphorectomy, it would seem that few cases would present themselves in which the latter procedure would be the best thing possible to do.

Lymphangioplasty.-Lymphangioplasty is the term given by Handley to his method of imbedding silk ligatures in the subcutaneous tissues for the purpose of forming new lymph channels between the healthy tissues above and below an area in which the lymph channels have become obstructed.

It was primarily designed for and is especially applicable in the treatment of brawny edema of the arm complicating mammary carcinoma or arising after the radical removal of the breast. The lymphedema of the arm is thought by Handley to be due to destruction of the fascial lymphatics in the region of the shoulder so that the lymphatic current is completely obstructed.

The fact that such obstruction does not always occur after complete removal of the axillary lymphatics is thought to depend upon the early establishment of a collateral circulation especially on the outer and dorsal surfaces of the shoulder and on the dorsal aspect of the chest wall; transient edema of the arm, which is commonly observed after radical breast amputation, is presumed to occur while this collateral circulation is in the process of formation.

We have seen typical cases of brawny edema after breast amputation in the absence of recurrent cancer and in such cases it is reasonable to presume the congenital absence of lymph channels necessary to the establishment of a collateral circulation. Lymphangioplasty should be considered in very severe cases after palliative measures, elevation, massage and bandaging have been tried unsuccessfully.

Accordingly to Handley, the following benefits may be expected from the operation when used in suitable cases.

(a) "Complete relief from pain within 24 hours unless the pain is partially due to some cause, such as nerve pressure, independent of the edema. (b) A marked and rapid fall in the tissue tension of the whole arm drained by the threads so. that the arm becomes soft and flabby. (c) Rapid subsidence of the swelling commencing immediately in the hand, and extending to the forearm within 24 hours. At first the upper arm is unaffected, or its diameter may be slightly increased, but within a week or two the diameter of the upper arm is also markedly lessened. The subsidence is usually permanent unless and until pleural effusion supervenes to interfere with the drainage. These effects are at first dependent upon the adoption of proper postural after-treatment, but, after a few months, elevation of the arm may be entirely abandoned without marked increase of swelling. (d) Return of power to the paralyzed arm provided 
that the paralysis is of recent date. (e) An improvement in the general condition dependent partly upon relief from pain and insomnia, and partly upon the abandonment of sedatives."

\section{Cases unsuitable for lymphangioplasty (Handley).}

"When a general anæsthetic cannot be borne and where the threads would have to pass through cancerous tissue. Inadvisable in cases where there is a growth about the shoulder, or if the pain is mainly axillary, or is a lancinating pain referred down the arm. In the presence of pleural effusion or secondary growth the operation is hardly worth doing as its effect will be transient. Amputation of the arm or inter-scapulo-thoracic amputation is the only resource in cases unsuitable for lymphangioplasty."

Technic of Lymphangioplasty.-The operation must be performed under a general anesthetic and rigid asepsis must be maintained because of the highly susceptible condition of the tissues to infection.

"A small incision is made in the skin over the flexor surface of the wrist. A long-eyed probe is threaded with a double line of No. I2 silk ligature material, which should be more than twice the length of the limb. The probe is then inserted into the incision and passed upward through the subcutaneous tissue as far as its length will permit and a second incision made over its upper end. The ligature is clamped with a hemostat at its mid-point so as to keep it from slipping out when the probe, together with the remainder of the silk ligature, is drawn through the opening of the second incision.

"This is repeated until the silk is finally brought out through a small incision placed along the posterior border of the deltoid muscle, at which point all of the ligatures are made to converge. The remaining balf of the doubled silk ligature is returned in a similar manner through the same incisions, but placed at some distance from its fellow. The strands thus placed form a loop and provide two separate channels on the flexor aspect of the limb, the double ligature serving not only to increase the size of the opening primarily, but also to minimize the likelihood of subsequent inflammatory organization of the threads.

"This procedure is repeated on the posterior (extensor) aspect of the arm, and the ends of the silk are brought through the upper incision in company with those on the flexor surface. The emerging ends of the ligatures are cut so that they will be somewhat shorter than the probe, into which they are again threaded. The probe is then thrust into the areolar tissues of the scapular region; the ligature is disengaged from the carrier and is thus embedded in normal tissue lying well above the edematous area. The process is repeated until each ligature is put into position, when the several skin incisions are closed with interrupted sutures of silkworm-gut.

"The special materials necessary are a set of suitable probes, lymphangioplasty forceps with jaws specially designed to take a firm grip of either end of the probe, and a supply of No. I 2 tubular silk."

In his original description of the operation, Handley advised embedding the ligatures 'in the loose areolar tissue in or beyond the axilla.' In the presence of edema of the chest wali, the threads may be carried to the opposite side of the body or in to the loin of the same side.

Ligation of the Axillary and Subclavian Vessels.-During the course of a radical breast amputation it becomes necessary in certain cases to ligate or excise a portion of the axillary vein owing to cancerous involvement of its sheath. When the apical lymphatic ganglia are inseparably bound down to the axillary vein, the vessel should be ligated above and below the mass and the intervening portion excised. We have resected large segments of the axillary vein without permanent ill effects, although edema of the arm is likely to occur and to persist for some time after the operation. Ligature of both the axillary vein and artery has been performed without deleterious after-effects. The cephalic vein serves to take the place of the axillary vein and it should therefore be preserved if possible.

Ligation of the subclavian artery may be necessary to arrest sudden and profuse hemorrhage from the axillary artery or one of its branches in the advanced ulcerative stage of mammary cancer. The bleeding must be temporarily arrested by placing the tips of the index and middle fingers in the subclavian triangle immediately above the clavicle and exerting pressure in a downward and backward direction. The artery is compressed in this manner between the fingers and the first rib. The patient is placed 
in a supine position with a pillow beneath the upper part of the back, and the shoulder is depressed. An incision 3 inches in length is made parallel with the upper border of the clavicle, its inner extremity corresponding to the outer border of the sterno-cleidomastoid muscle. The following structures are divided; the skin, the superficial fascia, the platysma myoides muscle, some of the clavicular branches of the cervical plexus of nerves, the superficial layers of the deep cervical fascia and the pre-vertebral layer of the fascia. The external jugular vein and some of its tributaries which lie above and in front of the artery between the deep fascial layers must be pushed aside or divided between ligatures. The posterior belly of the omo-hyoid muscle is next exposed by dividing the connective tissue at the bottom of the wound; the operator then searches for the outer border of the anterior scalene muscle along which the finger is passed in a downward direction until the pulsations of the artery are felt. The sheath covering the vessel is then opened and an aneurism needle carrying a stout silk ligature is passed from before backward away from the subclavian vein and then from below upward. Care must be taken so as not to injure the lower trunk of the brachial plexus which runs behind and almost parallel with this the third portion of the subclavian artery (see Deaver's Surgical Anatomy, Vol. II, p. I69).

Autoplasty by Means of the Other Breast.-Plastic operations to close the defect after radical breast amputations are seldom necessary and are likely to be dan-

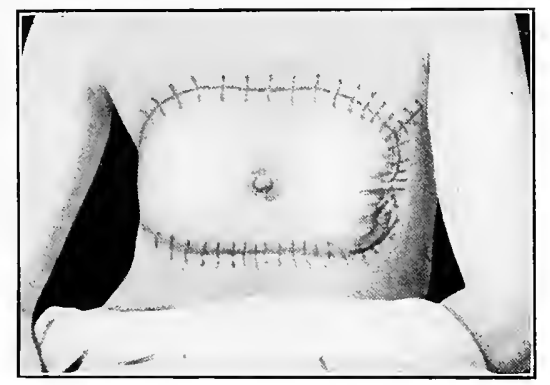

FIG. 260.-Autoplasty by means of the other breast. Cyclops operation. (Assaky.)

gerous, as the flaps may consist of tissue situated within the area of possible cancer dissemination.

Autoplasty by sliding the healthy breast over to cover the defect on the opposite chest wall, or, as in the method suggested by Payr, by forming a pedunculated flap that contains the healthy breast, and transferring this to cover the defect, is dangerous as the presence of the breast over the site of the original cancer makes the discovery of local recurrences almost impossible until they have reached a considerable size which, as Halsted suggests, is sufficient reason for not employing the method. Its origin is credited to Legueu who presented the history of the first case in which it had been employed before the Congrès française de chirurgie in 1898 . This was a patient in whom a secondary operation for recurrent cancer had been performed and in whom the sacrifice of a large area of skin necessitated a plastic method for closing the wound. The operation consists in making two horizontal and parallel incisions, one above, the other below 
the breast, loosening the organ with the aid of the fingers and drawing it "into the gaping wound" and fixing it there with sutures. A similar operation was performed about the same time by Graeve, and a year later Assaky reported his experience with the method.

A second article by Assaky (The Practitioner, Igoo, I, p. 85) contains a good illustration of the operation. Franke performed the operation described by Assaky in July, I897, and described it in the Deutsch. Zeitschr. f. Chir., Bd. 49, of that year. He, however, dissected the breast tissue from the flap and thus materially improved the cosmetic results of the operation.

In this country a few operators, notably Mixter, practised the method for a time but it has now been abandoned.

Inter-scapulo-thoracic Amputation.-Removal of the arm, scapula and a portion of the clavicle or the entire clavicle was first practised by Berger in 1887 , for mutilating injuries of the shoulder. W. Watson Cheyne is authority for the statement that Sir Joseph Lister was the first to amputate the arm at the shoulder in cases of axillary carcinoma secondary to carcinoma of the breast.

At a meeting of the Philadelphia Academy of Surgery in November, 1897, Roberts advocated as a routine procedure disarticulation at the shoulder for all cases of axillary carcinoma recurrent after an operation on the breast. In the discussion that followed the presentation of Roberts's paper, Deaver advised that the operation be performed "only as a last resort" mentioning as the indications for its employment, advanced states of the disease giving rise to brawny edema of the arm, extreme degrees of pain and recuirent hemorrhage from the axillary artery.

Since 1897 , extraordinary advances have been made in Roentgenotherapy that remove most of the indications for the ultraradical operative procedures which have practically no curative value and a primary mortality of at least 25 per cent.

Resection of the chest wall (Rixford, Lanphear, Wilms) and resection of the clavicle (Snow) for the removal of recurrent nodules of mammary carcinoma are unjustified in view of the successes attained with the $X$-rays in the treatment of such cases.

\section{BIBLIOGRAPHY}

AвbÉ.-N. York M. J., Igor, LXXIV, I93.

ARNAUD.-Lyon Med., I9II, CXXVI, 472.

Banks.- "Some Results of the Operative Treatment of Cancer of the Breast," Edinb., I882.

BEATSON.-Lancet, r 896, ii, ro4.

BECK.-Med. Rec., I906, LXX, 4I.

Beck.-Internat. J. Surg., 1909, XXII, 362.

Berger.-Rev. de Chir., I 898, xviii, 86r.

Binnie.-Am. J. Surg. and Gynec., I902, XV, III.

BloodGood.-Ann. Surg., I9I3, LVIII, 282.

Bloodgood-Med. Fortnightly, I9r3, xliv, 4I5.

Boyd.-Brit. M. J., rgoo, ii, I16r.

BrAUN.- "Die Lokalanästhesia," Leipzig, I 907.

Cheyne.-Brit. M. J., I896, i, 399.

Cheyne.-Lancet, r904, i, 699.

Crile.-J. Am. M. Assn., igo6, XLVII, 1780.

DAWBARN.-Ann. Surg., IgoS, XIVIII, 374.

Deaver.-Surgical Anatomy, Vol. I, r67, Phila., I 899.

Finney.- "Surgery of the Breast," Keen's Surgery, iii, Phila., igos.

Gerster.-Am. J. M. Sc., I 888 , xcv. 
Gross.- "Tumors of the Mammary Gland," New York, i 880.

Halsted.-Ann. Surg., I 894, xx, 497.

HALSTED.-Ibid., I907, XLVI, I.

Halsted.-Trans. Am. Surg. Assn., i 898.

Halsted,-J. Am. Med. Assn., igr 3, LX, 4I 7 .

Hander.-Brit. M. J., I904, ii, 832 .

Handey.- "Cancer of the Breast and Its Operative Treatment," London, I go6.

HANDLEY.-Lancet, I908, i, 783 .

HANDlEY.-Ibid., I906, i, 967 .

HANDley.-Choyce and Beattie: "System of Surgery," ii, 88, London, I9I 2.

Heidenhain.-Ann. Surg., I889, $x, 383$.

Herman.-Brit. M. J., I900, ii, I 67.

HERMAN.-Lancet, I 898 , i, I6 2.

Hirschel.- "Textbook of Local Anæsthesia," translated by Krohn, New York, x914.

HoHMeIER.- "Die Anwendungsweise der Lokalanästhesie in der Chirurgie," Berlin, I913.

HoHMEIER.-Cited by Hirschel.

Jackson.-J. Am. M. Assn., igo6, XLV1, 627.

JACKSoN.-Ibid., I910, LIV, I 78.

JuDD.-N. York M. J., I91 2, XCV, 867 .

Kelly.-Ann. Surg., I906, XLIV, ro4.

Kocher. - "Textbook of Operative Surgery," trans. fr. 4th German ed. by Stiles, London, I903.

Kocher.-Ibid., translated fr. 5th German ed. by Stiles and Paul, London, I9I I.

KRON.- "Die Lokalanàsthesia," Leipizig, I907.

LANPHEAR_-Med. Fortnightly, I903, XXIII-XXIV, 603.

LEAF.- "Cancer of the Breast Clinically Considered," London, I9 I 2.

Lockwood.- "Cancer of the Breast," London, I9I3.

Lockwood.-Brit. M. J., I 914 , i, I 105.

Maddex.-Rec. Egypt: School of Med., I904, ii, 67.

McDonald.-Surg., Gynec. and Obstet., I9I5, XXI, 82 .

Meyer, W.-Med. Rec., I894, XLVI, 746.

Meyer, W.-J. Am. M. Assn., 1905, XLV, 297.

Morestin.-Jour. de Chir., igi I, vii, 509.

Moore.-Trans. Roy. Med. and Surg. Soc., I867, i, 245.

Moszkowicz.-Centralbl. f. Chir., 19I4, xli, 9I.

Murphy.-Surgical Clinics, 19 2, 1, r.

Murphy.-N. York M. J., I906, LXXXIII, I.

Murphy.-Surgical Clincis, I9r4, iii.

Murphy.-Pract. Med. Series, I9 5 , ii.

Northrop.-Hahnemann Monthly, igio, XLV, 8ig.

Pfahler.-N. York M. J., I9I3, xcvii, 853.

Pfanler.-Trans. Internat. Cong. of Med., London, 19i3.

Porter.-J. Am. Med. Assn., I906, XLIX, 748.

Power, D'Arcy.-Lancet, I902, ii, 933.

RIXFORD.-Ann. Surg., I906, XLIII, 35.

RoBerts.-Ann. Surg., r 898 , xxvii, I I I.

RoDMAn.- "Diseases of the Breast," Phila., I908.

Sreild.-Diseases of the Breast," London, I 898 .

SNow.-Brit. M. J., I906, i, 258.

Speese.-Penna. State Med. Jour., April, I9I6, XIX, 7, p. 488.

Stewart.-Ann. Surg., I9I 5, lxii, 250.

Stewart.- "Manual of Surgery," Phila., I9I5.

StiLes.-Edinburg M. J., I 892, XXXVII, I099.

Stiles.-Trans. Med.-Chir. Soc., Edinb., I89I, xi, 37.

TAnsini.-Riforma Med., I896, XII, 3.

TANsini.-Ibid., I906, XXII, 757.

TAnsini.-Presse méd., r9i4, xxii, 3 .

Thomas.-N. York M. J., I882, XXXV, 337. 
Torek.-Ann. Surg., I9I4, Ix, 476 .

TURNER.-Surg., Gynec. and Obstet., 1914, XIX, 545.

VANVERTS.-Nord, méd., I9Io, XVII, 23.

Volmmann.-Beitr. z. klin. Chir., I875.

WARREN-Ann. Surg., I904, xl, 805 .

WreNER.-Ann. Surg., Igog, L, 837 .

WrLms.-München. med. Wchnschr., I9I3, Ix, 286I.

Wrlliams. - "Diseases of the Breast," London, I894. 


\section{CHAPTER XIII}

\section{NON-OPERATIVE TREATMENT OF CANCER OF THE BREAST}

\section{By George E. Pfahler*}

Non-operative methods of treatment should be reserved for those cases in which there is a distinct contra-indication for operation. These contra-indications have been discussed in a previous chapter. Fortunately, they offer considerable hope of a cure in some cases, relief from pain and discharge in others, prolongation of life in many, and some benefit in practically all.

They also, we believe, increase the total good results, when used after operation. The non-operative methods of treatment consist of radio-therapy, hyperemia, chemotherapy, electro-therapy, drug-therapy, toxin and immune-therapy, serum-therapy, vaccine-therapy, and caustics including the actual cautery.

We believe that when the hope of the complete eradication of the cancer can be reasonably entertained, and the patient is physically able to stand the operation, she should be operated upon, and that no case should be operated upon for palliative reasons unless to remove a malodorous mass. I also believe that every case of carcinoma mammæ should be treated with $X$-rays beginning immediately after the operation.

Excellent results have been obtained in the treatment of superficial cancer by the use of $X$-rays or radium, and have led some to use the methods in the treatment of Paget's disease of the nipple, which is often looked upon as superficial cancer. The results show, however, that the disease involves the deeper structures too often to be regarded as superficial, and that it should be dealt with according to the general rules laid down for the treatment of carcinoma of the breast, and be operated upon when in an operable stage.

Experience teaches, however, that there is a large percentage of cases of cancer of the breast in which operation is inadvisable. The disease is so far advanced that when operation is first considered, it is clearly impossible to excise all of the involved tissues.

Other cases though clinically operable, prove, at the time of operation, to have such extensive involvement that only a portion of the diseased substance can be removed. In the absence of some effective method of post-operative treatment, the lives of these patients are shortened rather than prolonged by surgery.

In still other cases, the disease, to all appearances, has been completely removed, but local or regional recurrence proves the incompleteness of the operation. In a definite number of instances the patient remains free of local recurrence, after the radical operation, but later develops internal metastasis.

The final group comprises early and otherwise suitable cases for operation, in which surgery is contra-indicated on account of some systemic disease.

When we consider that more than one-half of the cases of cancer of the breast that come to the surgeon, belong to one or other of the above groups, it becomes evident

* In this chapter, the personal pronoun I is employed to indicate Dr. Pfahler's individual opinion and personal experience, as contrasted with the customary one employed by the authors. Dr. Pfahler has contributed those portions of the chapter dealing with $X$-rays, radium and fulguration. 
that some effectual method of non-operative treatment is urgently demanded. Many have been proposed, but so far none is entirely satisfactory. While striking results are obtained in some cases, for the most part the methods prove only palliative. They should not, therefore, be substituted for operation in operable cases. Some inoperable cases may be rendered operable by thorough $X$-ray treatment. Undoubtedly the best results will be obtained by a careful combination of methods in the treatment of each case. This particularly applies to operation followed by thorough $X$-ray treatment.

Czerny says "There are so many methods at our command by which retrogression of malignant growths can be accomplished that we have found a combined method to be the most efficacious. Hence the cases coming for this kind of treatment are usually hopeless, and we welcome any amelioration, and shall leave it to a better instructed posterity to determine how the combined therapy may be improved."

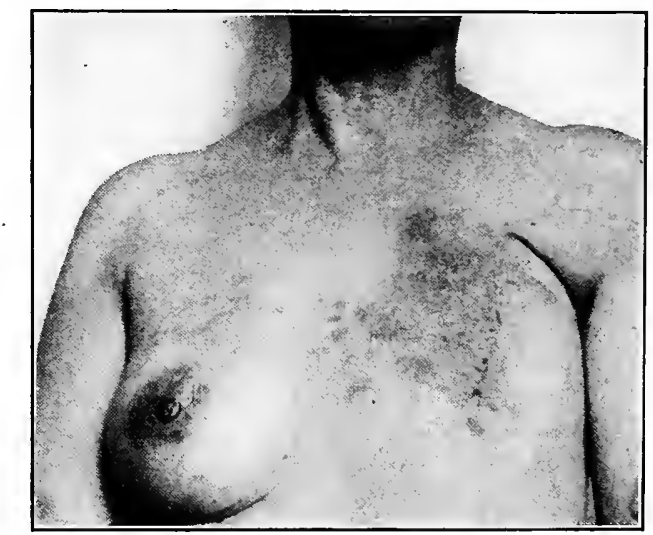

FIG. 26I.-Case No. 6. Photograph made May r, rgr4. Showing extensive recurrences and metastias with involvement of the right breast.

The list of non-operative methods of treating cancer includes the following:

r. Irradiation.

(a) Roentgen rays, or $x$-rays.

(b) Radium and its salts.

(c) Mesothorium.

2. Chemo-therapy.

3. Serum-therapy, including vaccines.

4. Electro-therapy.

5. Local applications.

6. Combined methods.

The Roentgen Rays or X-rays. - The X-rays were first used in the treatment of cancer of the breast by Gocht in $1897^{-9} 9$. The patient was relieved of pain but died from the effects of the disease three months after the beginning of the treatment. Johnson and Merrill reported the second case in I 900 , and in this, a recurrent case, the pain ceased, ulcerations healed over and the tumor became much reduced in size. General interest in the subject was aroused by these reports, and several years later Beck, Morton, Bevan, 
Williams and Pusey contributed papers on the treatment of mammary cancer by means of the $X$-rays.

My first report on the treatment of carcinoma of the breast was made in I902, and referred to six patients. The first was a woman 45 years of age who had been operated on in Philadelphia for carcinoma of the left breast three years previously. She remained well after the operation one year; then developed a small nodule in the region of the scar. At the time of beginning treatment, hard masses were felt in each breast about the size of a hen's egg, and small hard glands were detected in each axilla. At the time of the report the nodules in the right breast had completely disappeared, as well as those in each axilla, and the left breast was markedly improved. I can report now that this patient was still well I I years after beginning treatment. Since then nothing has been heard.

Beck noted decided improvement, both local and general, in four cases, with postoperative recurrences.

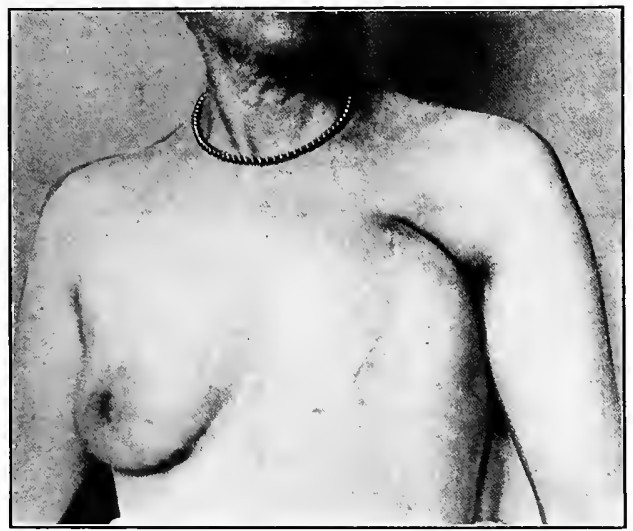

FIG. 262.-Case No. 6. Photograph made December I, I9I4. Showing the disappearance of the recurrent and metastatic nodules and decrease in the size of the right breast with the absence of the bulging in the lower and outer portion.

Bevan accomplished the disappearance of recurrent carcinoma and of large sarcoma so situated as to be within easy reach of the rays. While superficial nodules of considerable size disappeared under $x$-irradiation in recurrent cases, deeper recurrences continued to develop in spite of the treatment. This observation led Bevan to conclude that the $x$-rays were without value in the treatment of deep-seated cancers.

Morton met with success in the treatment of two extensive and inoperable cancers of the breast and of two recurrent cases. He noted relief of pain, often immediately, reduction in the size of the tumor, stimulation of reparative processes, lessening of the discharge from ulcerated areas, softening and disappearance of enlarged lymph nodes together with decided improvement in the general health of the patients. Morton believed that he had obtained several "cures" with the treatment.

Roentgen-therapy during the first I5 years of its history passed through a rapid process of evolution, and in the light of the present-day theories and technic, it seems 
perfectly remarkable that results so good as have been reported in some instances have been obtained with such inefficient equipment and undeveloped technic. It is less remarkable that the brilliant results were so few than that there were any at all.

Statistics, therefore, based upon the collection of a large amount of material, extending over I 5 or 16 years, would be of little or no value because the component parts of the statistics would be made up of so much work that could in no sense be compared with the work that should be accomplished today. Therefore, while a review of all the literature and a record of all cases might be of some historical value, it would be of little real value in drawing any conclusions of the present-day value, for we feel that the results obtained today should be at least roo per cent. better than those obtained two or three years ago.

Theory of the Effects of the Roentgen Rays on Malignant Disease.-The results obtained in the treatment of malignant disease depend primarily on the exceeding sensitiveness of pathologic cells to the Roentgen rays, for it is well known to all who have had experience with epithelioma, as an example, that with the same dose of rays given to the epithelioma and the surrounding tissue, the epithelioma undergoes degeneration, and seems to melt away, while the surrounding healthy tissues may show no effect or nothing more than a little redness. It has been shown, too, by histologic studies made on tissues that have been subjected to the effect of the rays, that these cells undergo degeneration before any effect is shown on the healthy cells. It is also well known that the more nearly cells approach the embryonal type the more sensitive they are to the rays, and among normal tissues the essential cells of glands are more sensitive than the stroma, and next to the glandular cells come the protective epithelium, such as the skin, mucous membrane, and intima of the blood-vessels, and next to this the connective tissue cells.

The more highly specialized the more sensitive is the cell to the Roentgen rays; therefore the generative cells of the ovary and testicle are the most sensitive of normal tissue, and following these the spleen, thymus, thyroid gland, liver, the lymphatics, muscle, nerves and connective tissue.

As a result of a thorough histopathologic examination of cancer tissue of the uterus and ovaries that had been subjected to irradiation, Handley found that a radiant treatment of two or three weeks' duration has a direct selective effect on cancer tissue, consisting in a primary injury to the cancerous cells, which leads to a disturbance in the growth of the cells, lack of mitosis and giant-cell formation, and, to a certain degree, to changes in the character of the cells (flat, scaly epithelium); and, finally, by karyolysis and disappearance of the non-nucleated masses of protoplasm, to complete destruction of the cells.

The connective tissue shows a new growth to replace the destroyed carcinoma cells. This new-formed connective tissue becomes sclerotic and degenerates, just as the rest of the connective tissue; the smooth muscle atrophies and disappears almost entirely, and some of the muscle fibers show hyaline degeneration. In the ovary the primary follicles are completely destroyed and the vessels show hyaline degeneration of the adventitia and media; the latter is calcified here and there. From proliferation of the intima there is obliteration of numerous vessels; the elastic fibers swell and form clumps; and the plasma cells and eosinophil leukocytes disappear with the increasing sclerosis and hyaline degeneration.

The influence of the Roentgen rays on living tissue, according to Wickham, depends, first, on the sensibility of the individual cells; second, the quantity of rays and the duration of their absorption; third, the special effect of the particular degree of hardness of 
the rays; fourth, the period of time which has elapsed between the end of the exposure and the time of the histologic examination; and fifth, the filtration of the rays through the tissues themselves.

On the special sensibility of the younger cells depends the ground principle of Roentgen treatment, that is, that these pathologic cells will be affected by the rays that have already passed through healthy tissue cells without doing them harm. He finds that the histologic changes in pathologic tissues are affected in the following order: (I) The malignant tumors; (2) the lesions of the hematopoietic organs and the blood; (3) the blood tumors; (4) keloids, and (5) skin tuberculosis. He also calls attention to the fact that the results obtained will depend largely on the individual technic.

In addition to this general theory, above described, of the action of the rays on malignant tissue, anyone who has had much experience in the treatment of malignant disease

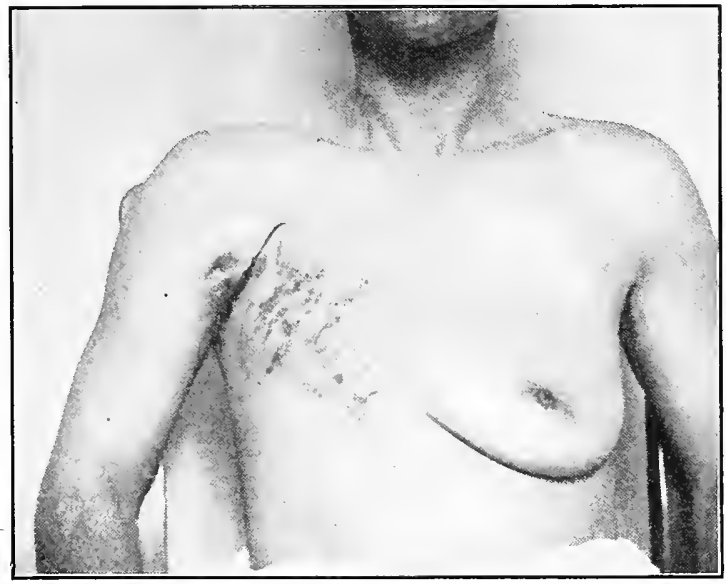

Fig. 263.-Case No. 7.-Photograph made September I9, I9 13. Showing recurrent and metastatic nodules in the operative field, swelling of the right arm, with partial fixation, and retraction of the nipple in the left breast, with bulging of the tumor above it.

recognizes that there are differences in the disease, or in the reactive power of the individual in different cases, which permit extreme cases to get well, or at least the disease to disappear, while in other cases, with apparently more favorable conditions, the disease goes from bad to worse, and shows little appreciable effect from the rays. Therefore, until the cause of these differences is explained, it is our duty to give the patient the benefit of the doubt, even though there be little reasonable hope of recovery.

Carcinoma of the breast in which $X$-ray treatment is advisable may be divided into three main groups:

I. Primary inoperable carcinoma of the breast.

2. Recurrent and metastatic carcinoma of the breast

3. Post-operative cases.

Primary Inoperable Carcinoma of the Breast.-In inoperable carcinoma of the breast $X$-ray treatment offers a reasonable hope of relieving the patient of the symptoms of the 
disease, of prolonging life, and possibly causing complete disappearance of the disease. Patients have been relieved of the symptoms of the disease for from one to eight years. No other method of treatment offers so much in this group of cases unless it be a combination of methods, such as will be shown later. The following cases will serve to illustrate what may be expected. It must be borne in mind that most of these patients were treated by technic which was very imperfect and inadequate. We believe that the results could be improved from 50 to roo per cent. today.

Case I was a patient 73 years of age, referred to me by Dr. Jdwin P. Robinson, Nov. 8, 1902. She had an adherent, ulcerating scirrhous carcinoma which was 4 inches in diameter, had bled frequently, and on two occasions profusely. It affected the left breast. It was considered inoperable because of cardiac disease and because of her advanced age. The discharge was offensive. The bleeding, the discharge and the tumor decreased progressively. She died in April, 1906, nearly four years after beginning treatment. Pain was never present, even after she was confined to her room.

Case 2.-A patient, 83 years of age, was referred to me by Dr. Ulrich, Apr. 20, 1903. The tumor had been noticed a year previously, and at the beginning of the treatment was about half the size of a fist. It was considered inoperable because she was feeble, had marked arterio-sclerosis and cardiac disease. She was seldom able to leave her room, and received her treatments there. Under treatment the tumor gradually became softer, more movable and smaller, until at the end of six months there was nothing left except a small mass of what appeared to be shrunken scar tissue. She died, about three years after stopping treatment, from carcinoma of the cervix. Recurrence in the breast did not develop. This patient, who was treated 2 years ago never got well, hut the discharge, bleeding, and tumor disappeared, and she was free from pain and lived nearly four years after beginning treatment.

Case 3 was a woman aged 50 years, and referred by Dr. Frank, Nov. 23, 1904. A tumor had been growing in her breast for two years, and was then 3 inches in diameter, with marked retraction of the nipple. It was typically a scirrhous carcinoma. It was inoperable because of her absolute refusal, and because of her age and marked atheroma of her arteries. Under $X$-ray treatment this tumor was reduced, in six months, to a small fibrous mass ahout $\mathrm{I}$ inch in diameter, about $1 / 3$ inch in thickness, and freely movable. She had a healthy appearance, never suffered from pain, and was not annoyed during the eight years that I had the opportunity of following the case. She died of general senile changes in the summer of IgI2. This patient had a typical scirrhous carcinoma of the breast, was inoperable, was made confortable, and free from any symptoms of the disease for eight years during which I observed her. She went about her usual affairs, and had the general good health of a woman 70 to 80 years of age.

Case 4.- Aged 49 years, had had an incomplete operation for carcinoma of the left hreast five years before. At that time, the tumor was said to be the size of a walnut, and was excised. Recurrence developed within two years, when she came to me with tumor tissue involving the entire mammary region, with axillary and supra-cla vicular involvement. The mass was so large that it left the impression on my mind of an extensive primary growth. It was a hard, painful, adherent nodular mass, ulcerated in several places. In a month the mass of tumor tissue was reduced to half; in two months to a third, the ulcers were healed, and in three months no tumor could be palpated. There remained, however, a scar-like mass of tissue ahout $1 / 2$ inch in diameter which was freely movable, and which was not painful. I then advised operation which was done by Dr. Babcock, Jan. I8, Igog. Pathological examination of the specimen hy Dr. Duncan shorved some evidence of malignant disease. She was returned to me in six weeks after this operation, at which time a hard nodule was felt in the supra-clavicular region about the size of a pea. This was reduced under treatment to $1 / 8 \mathrm{inch}$, and has since remained stationary. This woman was clearly inoperable when referred to me for treatment because of the extent of the disease, and the case seemed a hopeless one even for $X$-ray treatment.

Case 5.-Aged 38 years, referred by Dr. Samuel Johnson and Dr. Ernest Laplace, Jan. 8, 1909. Tumors had been noticed in her breast eight years previously. They gradually increased in size, and secondary nodules developed under the anterior axillary fold. At the beginning of treatment, there was a mass $1 \frac{1}{2}$ inches in diameter in the lower outer quadrant of the left hreast, and one $2 \frac{1}{2}$ inches in diameter in the upper and outer quadrant with a small nodule under the anterior axillary fold. Both were hard, nodular and adherent. There was a similar tumor in the right breast, I $1 / 2$ inches in diameter in the lower inner quadrant. She was considered inoperable because of the extent of the disease, and was treated three times a week. Under treatment the tumors were reduced to a fibrous mass about $1 / 2$ inch in diameter, freely movable, and not tender. Her general health had at no time been interfered 
with, and in general appearance she looked perfectly well. The treatment was carried to the point of producing erythema several times and as a result the skin was atrophic and showed a number of telangiectases. This patient remains perfectly well today, seven years after beginning treatment, even though she had disease of both breasts with metastasis.

Case 6.--Aged 60 years, referred by Dr. John McGuigan, Mar. 22, r9II. A tumor had been developing for a year and a half. When I saw her it involved the entire breast, with hard nodules in the axilla and smaller nodules the size of a pea in the supra-clavicular region. In addition she had an aneurism of the arch of the aorta, and irregular heart action. She was considered inoperable because of the aneurism and the condition of her heart, but also because of the extent of the disease. Under treatment the disease apparently disappeared, and the whole mammary area became soft and movable. This patient died suddenly, Oct. 25, rgr 3 , apparently from rupture of the aneurism.

Case 7.-Mrs. G., aged 37 years, referred to me by Dr. John B. Deaver, July I4, rgir. A carcinoma had been growing in the right breast over three years. In September, sgro, she was taken to Dr. Deaver by Dr. George Miller, but the disease had advanced so far that Dr. Deaver considered

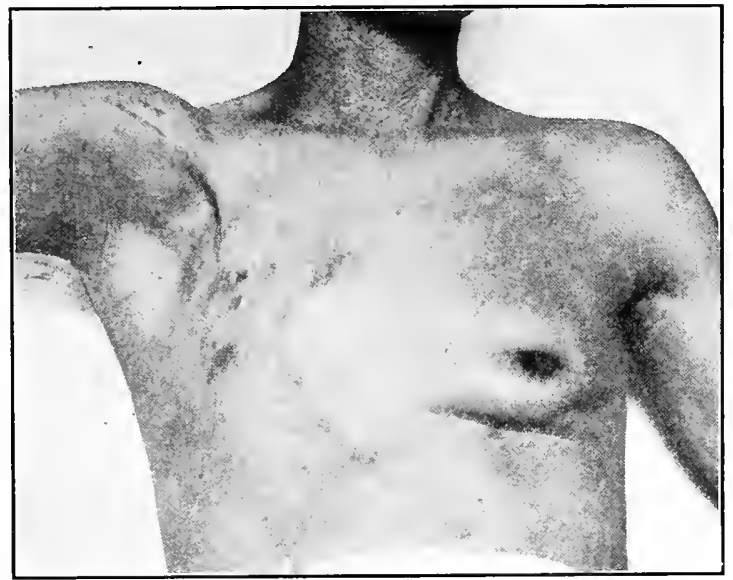

Frg. 264.-Case No. 7. Photograph made February 25, 1915. Showing disappearance of the recurrent and metastatic nodules, as well as the disappearance of the swelling of the arm, now able to raise the arm. The left breast is very much shrunken and the axillary and supraclavicular nodules have dis. appeared on both sides.

operation inadvisable. Ten months later, when the carcinoma had become an ulcerating mass, she was taken to Dr. Deaver again, and this time he referred her to me. She then had an ulcerating tumor about 4 inches in diameter, adherent to the skin and ribs, with several small metastatic nodules about the tumor. There were enlarged glands, in the axilla and the supra-clavicular regions. She suffered from severe pain. Under treatment the ulcer gradually healed, the tumor tissue disappeared, and even the scar tissue became movable upon the chest wall. There was no definite evidence of disease in this area for about a year. (In these patients it is difficult to decide when the disease has all disappeared.) About May, Igr2, a tumor developed in the upper and outer quadrant of the left breast. She was sent to Dr. Deaver, May I8, I9I2, to have him see the result in the right breast and to have him confirm the diagnosis of carcinoma in the left breast. The tumor in the right breast had nearly disappeared, and in its place was some increased frmness, which I believe was due to fibrous tissue. The disease in the opposite breast was retarded for a time, but ultimately she died of it.

Case 8.--Miss H., aged 45 years, referred by Dr. Wm. Martin, Oct. 5, Igrr. She has noticed a tumor in her right breast several months which she thought followed a bruise (walking into a rail). A sister had died from carcinoma of the uterus about a year previously. Examination showed a tumor in 
the right breast about half the size of a hen's egg, a small palpable gland in the axilla, and a palpable gland in the right supra-clavicular region. In the upper and outer quadrant of the left breast a tumor about the size of a pigeon's egg was palpable. She had signs of osteo-arthritis in the cervical and upper dorsal spine. She had a polypus in the cervix uteri. There was some doubt in the diagnosis. Therefore, I referred her to Dr. M. P. Warmuth, who amputated the right breast, cleared the axilla, and removed the small glands from the right supra-clavicular region, and the polypus from the uterus. Microscopic examination by Dr. Henry S. Wieder showed distinct adeno-carcinoma. Within two weeks after the operation, she had the excruciating pains of carcinoma, and within a month the entire operative area was indurated and showed distinct recurrence in the wound, the axilla, and the supraclavicular region, recognized by $\mathrm{Dr}$. Warmuth and myself. At the same time, the tumor in the left breast increased to the size of a fist, and there were enlarged glands in the axilla. Very active daily treatment was given to the recurrence on the right side, until a slight dermatitis appeared, when treatment was given to the left breast which was clearly inoperable, and each side was treated in turn until all evidence of recurrence had disappeared from the right side, and until the left

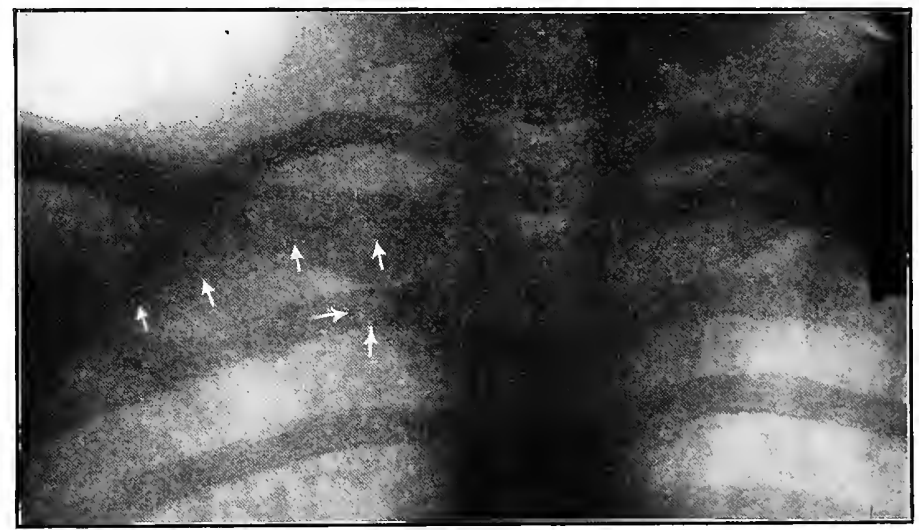

FIG. 265.-Case No. 7. Roentgenogram made at the beginining of treatment showing destruction by metastatic carcinoma of three inches of the left second rib, and focus of disease in the third left rib.

breast had become soft and all parts were freely movable. For the two sides, she had in all roo applications of the rays. In nine months, no distinct evidence of the disease could be recognized. She had returned to her usual affairs of life, was taking gymnastic exercises, and was quite well. During the early part of January, I913, she bruised the left breast. The skin which had been damaged by the rays became eroded and painful. I then referred her to Dr. Warmuth for excision of the breast. The axilla was not opened because we believed the rays had healed this glandular area. Pathological studies by Dr. Eugene Case, confirmed by Dr. Joseph McFarland, showed no evidence of malignant disease anywhere, but showed pigmentation and necrosis of the skin and chronic difuse fibrosis of the breast. This patient has remained well until the past three months, during which time she had been suffering from a severe attack of mucous colitis. She complains of dyspnea, and pains about the left shoulder. Jan. 5, I9r6, she came under my observation again. I found the mucous colitis to be due to intestinal stasis. There has been no external evidence of cancer, but a Roentgen examination of the chest shows some increase in shadows in the upper part of the mediastinum, and I believe there is some carcinomatous infiltration in this portion. On that supposition, I am treating her again over the mediastinum, and $\mathrm{I}$ believe she can be made to recover. This patient had double carninoma of the breast, and one breast amputated, followed by a rapid recurrence of which there could be no doubt. The recurrence disappeared, and the disease in the opposite breast also disappeared under treatment. She remained well at least four years, and I am hoping to cause a disappearance of the mediastinal disease and prolong her life for a considerable period. 
Case 9.-Mrs. E., aged 78 years, referred by Dr. John J. Lynch, May 27 , 191 2. She had noticed a tumor in the right breast for about two months. It was then 3 inches long, 2 inches wide, and $I$ inch thick, and occupied the upper inner quadrant. There was a smaller mass outside of the nipple, one under the anterior axillary fold, and one in the axilla. She was considered inoperable because of the extent of the disease, her advanced age, her feeble condition, and marked atheromatous and cardiac disease. Under $x$-ray treatment all signs of the disease disappeared excepting a small freely movable nodule about the size of the end of the finger which occupied the site of larger tumor. This was accomplished in eight months with 37 applications, which had to be given irregularly because of the difficulty in getting the patient to my office. At no time was there any evidence of dermatitis, and the skin was not damaged. When examined six months later, all evidence of the disease had disappeared. The result in this patient was especially good because the metastatic nodules, as well as the primary growth, disappeared without damage to the skin.

Case ro.-Mrs. K., aged 54, referred by Dr. C. H. Maxwell, Morganstown, W. Va., Aug. 26 , ig 2. She noticed a tumor growing in her left breast over a year, which had become painful during the last three months. She had been sent to two surgeons in Pittsburgh, who advised operation, but could give no encouragement as to the outcome. Examination showed a scirrhous carcinoma involving the entire breast, which was adherent, and showed marked retraction of the nipple. Three nodules could be felt in the axilla, and at least one in the left supra-clavicular region. Under $x$-ray treatment the supra-clavicular and axillary nodules disappeared. The mass in the breast shriveled to about one-half its former size, and was more movable.

Case 12.-Mrs. IV., aged 73 years, was referred for treatment Sept. I6, I9r2. She noticed a tumor in the left breast about a year before, which was 3 inches in diameter, with enlarged glands in the axilla. She refused operation, because a sister had died two years after an operation for carcinoma of the breast. She had a loud aortic systolic murmur. Under the $x$-ray treatment, the axillary nodules disappeared, and the tumor in the breast was reduced to one-third its original size, and became freely movable. She died Feb. 2, I9I4, of general exhaustion, without external appearance of the disease.

The foregoing cases illustrate the types in which no other form of treatment can be seriously considered. Therefore, the problem is not whether this or that treatment will serve us best, but whether it is worth while trying at all, and when one considers that life is prolonged, pain and discharge relieved, and that some cases are apparently cured (the cure lasting from one to eight years), we believe that $X$-ray treatment can well be recommended. The results in these cases were obtained with a technic that we now know to be very inefficient, and when compared with more modern technic, one would have a right to expect much better results than are indicated, and in fact patients that $I$ have been privileged to treat more recently show very much more decided improvement. The modern technic will be described after the next two groups of cases have been discussed.

The Treatment of Recurrences and Metastasis from Carcinoma of the Breast.Unfortunately, the majority of cases that come to the Roentgenologist fall into this group. It is unfortunate, because if these same patients could have been actively treated immediately after the operation in many, and perhaps in most instances, there would have been no recurrences. It is also unfortunate, because when the disease has spread through the system, one never can be quite sure when or where it will break out next. When metastasis has taken place, one must always be on guard during the remainder of the patient's life, and I believe one can never be sure of a cure. In this group of cases, like the former, a statistical study will be of little or no value, for no two cases are alike. The technic during this time has passed through a process of rapid evolution, extending over a period of approximately i 6 years. Therefore, any attempt to make a general statistical study of the cases treated, we believe, would be of little or no value. I will simply, therefore, choose the first case of this type that I treated I4 years ago, and then add six others that have been referred to me by Dr. Deaver. These will serve as illustrations of what may be accomplished at 
times, even with imperfect technic, and with very advanced and extensive involvement. The more recent results indicate that our modern methods should produce in the future really brilliant results, and perhaps point out the way to a real cure for this disease.

Case r.-Mrs. S., aged 45 , was referred to me by Dr. Charles Johnson of Charleston, S. C., Oct. 9, rg02. She had had her left breast amputated two years previously. During six months she had been suffering from a recurrence in the scar, $\mathrm{I} \frac{1}{2}$ inches in diameter, firmly adherent, tender and painful. Active treatment was continued with fractional doses during two years, during which a mild dermatitis had been produced several times, but which resulted in a complete disappearance of all evidence of the disease. Treatment was then interrupted, and two years later, the patient returned with a secondary degeneration, radio-dermatitis. This area then covered about $I$ inch in diameter. It was excised and examined microscopically, but was not found to be malignant. She was still living, and apparently well, when last heard from, ir years after beginning the treatment for the recurrence. In this case, the treatment by the Roentgen rays, given even during the early stages, when technic was poorly

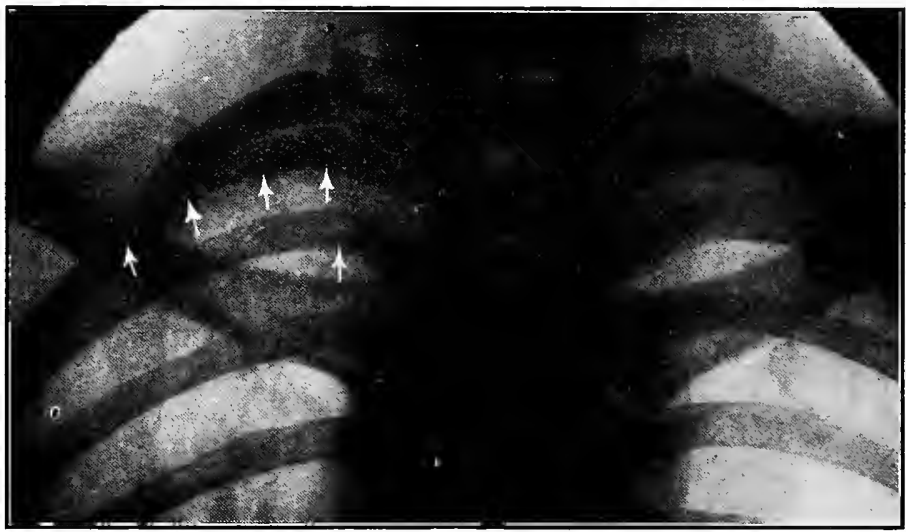

FIG. 266.-Case No. 7. Roentgenogram made February 23, 1916. Showing complete healing of the ribs previously occupied by the metastatic carcinoma.

developed, resulted in an apparent cure, which has lasted during a period of approximately $\mathrm{r}$ or probably even $x_{4}$ years. The secondary degeneration resulting from a dermatitis could probably have been a voided by present-day technic.

Case 2.-Mrs. B., aged 56, referred by Dr. John B. Deaver, Dec. x, rgro. She had an operation for removal of the breast three months previously. At the time of beginning treatment, there was distinct evidence of recurrence in the axillary and supra-clavicular regions, and we believed there was some pulmonary involvement, and as a result of a Roentgen examination believed there was involvement of the mediastinum. Under Roentgen rays there was some reduction in the disease, but in April, rgr r, Dr. Deaver still found deep axillary and supra-clavicular involvement associated with swelling of the arm, and with pain. Treatment was continued until Sept. I, I9Ir, though all evidences of the disease had dis. appeared. She then developed an exfoliative dermatitis involving both the skin and mucous membrane over the entire body. The explanation of this development is not yet clear to me. I cannot say whether it was due to the treatment or whether it occurred coincidentally. She recovered, however, perfectly, and though she has been treated from time to time during these succeeding years, she has remained generally well, and today (Feb. $7, \mathrm{rgr} 6$ ) is free from symptoms of the disease. The skin over the area which had received most of the treatment is more or less sclerotic. This could probably be avoided by presentday teclnic. When one considers the extent of the disease, and the period of Roentgenology during 
which the treatment was given, with very imperfect technic, I feel that the result is truly remarkable, and certainly nothing approaching it could have been obtained by any other known method.

Case 3.-Miss E., aged 5o, was referred to me by Dr. John B. Deaver, Dec. 3r, rgo8. She had been .operated on for carcinoma of the left hreast on Nov, 17, 1908. She was given post-operative treatment, and remained well until May 24, I 909 , when it was found that a nodule had developed in the upper portion of the scar, Dr. Deaver believed it to be malignant and advised excision. Active treatment by the rays was applied to this nodule, and when she was taken to the hospital three weeks later Dr. Deaver could not find the nodule, and refused to operate. She has remained well to this date, Jan. 26 , I9r6, over seven years from the time of beginning treatment.

Case 4.-Miss H., aged 50, referred by Dr. Deaver, Nov. 2, rgr2. She had been operated upon for carcinoma of the breast by Dr. Deaver in June, rgri. She noticed a recurrence in September, rgr 2. When first seen by me there was a tumor about the size of half a hen's egg at the middle of the scar, firmly adherent to the ribs, and Dr. Deaver considered her inoperable. Under $x$-ray treatment, this has completely disappeared. She has regained perfect health, and so far as we can tell, she is perfectly well today, over three years since the development of an inoperable recurrence. When recently examined, she was in perfect health, and has no evidence in the skin to indicate where the former disease had been nor where she had been treated. This case comes more nearly under our more modern treatment.

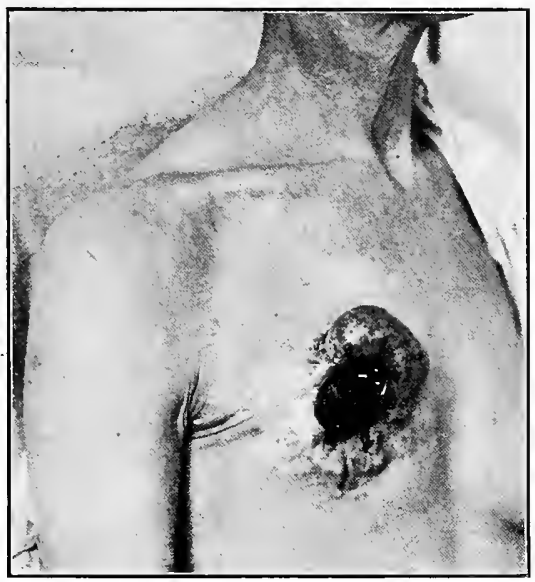

FIG. 267 -Mrs. L. Photograph made September 15, I9r4. Showing adherent, ulcerating scirrhous carcinoma before electro-coagulation and Roentgen treatment.

Case 5.-Mrs. M., aged 48 , referred by Dr. John B. Deaver, Oct. 28, 19r4. Had had her right breast amputated Sept. 22, 1913. She had noticed a tumor for nine months. For five months preceding the operation she had received some Roentgen-ray treatment in another city without improvement. Following the operation she received some post-operative treatment near her home. At the time she was referred to me, she had a recurrent carcinoma half the size of a hen's egg, firmly attached to the third and fourth ribs and the interspace between them. The patient was given eight full doses of rays through eight different areas of skin, cross-firing as much as possible upon the diseased area, each dose of filtered rays representing $20 x$, or a total of $\mathrm{r} 60 x$. This series was given Oct. 28 , Nov. 18 , Dec. 14 and Jan. 18 . When the last treatment was given, the tumor had disappeared. The patient appeared to be well and treatment was discontinued. Up to the present time, Jan. 27 , I916, there has been no evidence of recurrence of the disease anywhere in the operative field, nor in the supra-clavicular nor axillary regions which had received treatment. She returned, however, Apr. 27 , 1915, for examination by Dr. Deaver and myself on account of a small hard tumor developing in her right frontal region. . We both believed this to be metastatic carcinoma, but the patient differed in opinion, and refused treatment until June $\mathrm{I}_{5}, \mathrm{I}_{9} \mathrm{I}_{5}$, when she returned complaining of severe pains in the chest. I then made an $X$-ray examina- 
tion of the spinal column, and founcl disease of six dorsal vertebrx. I also found disease in one of the shoulders, and some evidence of disease in the lungs. With this extensive metastasis I believed it unwise to go further with the treatment, but the husband insisted, and a large series of treatments was given to the patient every month or two up to the present time. In September, r9I5, when the patient returned, she was so weak that she had to be lifted from the bed to a stretcher and to the treatment table, on pillows. She had marked dyspnea, and could not speak a sentence without interrupting to breathe. Practically the whole body, not including the lower extremities, was covered during these treat. ments. Gradually she began to gain strength, felt quite improved, and her general appearance improved in every way. Today she can get up out of bed by herself, walk, and talk and laugh freely, and her condition in every way presents the greatest encouragement. $X$-ray examination of the spine and of the shoulder-joints show a recalcification of the diseased bones, which indicates a healing process. The diseased area in the lung had increased in density, but I believe this to be due to increase in scar tissue, and to indicate a healing process. The remarkable features about this case are the facts that the local and inoperable recurrences have disappeared completely and never recurred, nor has any area in the operative field shown any evidence of any further recurrence, and second that the extensive bone and pulmonary metastases seem to be yielding to the treatment. The metastases which bad developed in many parts of the body must have taken place even before treatment began, and the fact that the extensive bone metastasis are showing evidence of repair, indicated by the recalcification, leads me to believe that this patient has a reasonable chance for recovery.

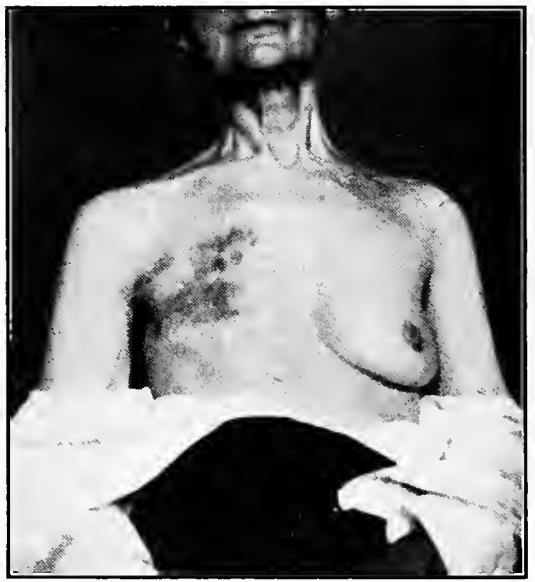

FIG. 268.-Mrs. K. I Photograph made June 20, I9I5. Showing complete disappearance of the carcinoma and healing of the skin. (See Case-History p. 662.)

Case 6.-Mrs. K., aged 52, was referred by Dr. John B. Deaver, Apr. 30, I9r4. On June 20, I912, Dr. Deaver removed the left breast on account of a carcinoma that had been growing for a year. The patient remained well until April, I9r3, when following a severe shock, she noticed little tumors developing over the operation area. These were supposed to be neurotic in origin, but they did not disappear, and after they had lasted and increased for a year, she consulted Dr. Deaver, who referred her to me. At that time the entire left mammary region was studded with nodules on both sides of the scar, extending into the axillary region and down to the left costal margin. This infiltration could then be traced across the sternal region to the opposite breast. The right breast was indurated and was believed to be carcinomatous. Within two days the patient was given a series of 20 full doses of altered rays; each representing $20 x$, or in all $400 x$ units. When she returned at the end of three weeks for a second series, there was decided improvement. These were repeated May 23, June I6, July 7, Aug. I4, and Sept. 22, or in all, six series of 20 doses each, totalling $2400 x$, and when she was examined by Dr. Deaver, Dec. I, I9I4, he could find no evidence of carcinoma. She remained mell until May 
I8, I9 5, when she again returned with recurrent nodules in the operative field. This indicated clearly that not enough treatments had been given, or at least that the treatments had been discontinued too soon. Treatment was renewed on the same basis as before, and the recurrent nodules have again disappeared. She will now be kept under closer observation, and it seems to me that her chances of recovery are fair.

Case 7.-Mrs. B., aged 32, came to me Sept. I9, I9r3. She had been operated on Aug. 20, I910, by Dr. Deaver, for carcinoma of the right breast (confirmed by pathologic examination), and for recurrence, Mar. 27, I9ri. The patient said that she had had in all four operations. Sept. ig, at the beginning of my treatment, the entire operation area on the right side was studded with nodules which were firmly adherent. These extended to the axilla, and in the right axilla there were masses from $1 / 2$ to $3 / 4$ inch in diameter firmly binding the tissues. There were large nodules in the supra-clavicular region on the right side. The left breast contained a.mass of tumor tissue. She had retraction of the nipple, and metastasis in the left axilla and in the left supra-clavicular region. There were two small nodules in the scalp. Ahout 3 inches of the second left rib and a small area in the third rib were destroyed, and about 1/2 inch of the right eighth rib, with disease of the eighth, ninth and tenth dorsal and fifth lumbar, vertebræ, and the upper part of the sacrum. Ordinarily such an extensive distribution of disease would preclude even the thought of accomplishing any good results, but this patient had an unusual amount of determination to get well. I therefore decided to see what could be accomplished.

She has received an enormous amount of treatment over the entire body during the last two years and three months, 325 or more doses, averaging I $_{5} x$, or amounting to $4875 x$ or more. As a result she has gained 17 pounds in weight, she gradually became able to look after her household duties, and when examined recently, she was doing all her housework, even her ironing. She looks and acts very much stronger. All the nodules in the right side of the chest have disappeared, as well as those in the right axilla and the right supra-clavicular region. The mass in the left breast has shriveled, and while there is considerable retraction of the nipple, the area feels like fibrous tissue, and is freely movable. The metastases in the left axillary and supra-clavicular regions have disappeared. The disease in the second rib has healed. I believe the disease in the vertebra is healing, as indicated by increase in lime salts. The disease in the fifth lumbar and sacrum is at present giving the patient most of her symptoms, and she suffers considerable pain in this region, though there has been some recalcification there. This patient is, therefore, not well, but it was the first instance that $I$ had ever known in which there was undoubted healing of metastatic carcinoma of the bone. I bave seen this demonstrated in at least two cases since this time. This evidence of the healing process in metastatic carcinoma of the bone and the marked improvement in the general health of a patient with such a general distribution of carcinoma demonstrates in the most striking manner the effect of the Roentgen rays on even the deepest form of carcinoma, and it would indicate that once we master all the elements of this work, that we may perhaps ultimately find the real cure for carcinoma. At present we must look upon this method merely as an adjunct, and must not neglect any radical means that will actually eliminate the disease.

While the foregoing cases illustrate the value of the rays in the treatment of inoperable recurrence and metastasis, we believe the greatest field for usefulness to be in the postoperative treatment, and to this group should be added the inoperable primary carcinomas and the recurrent carcinomas. The great difficulty in the treatment of metastatic carcinoma is that one is never quite sure when the patient is well or where the disease may break out next. Therefore, when one is treating metastatic carcinoma, it must be looked upon as a palliative measure, though this palliative relief may extend over many years, as is indicated by these, and many other cases that are on record.

3. Roentgen-therapy in the Post-cperative Treatment of Carcinoma of the Breast.It is in this field that we believe the Roentgen rays find their greatest field of usefulness, in the treatment of malignant disease of the breast. It is very difficult to estimate by statistics the exact value of the Roentgen rays in post-operative treatment, because up to the present time, the treatment has been applied almost exclusively in the more advanced cases in which there was already metastasis to the axilla and sometimes to the supra-clavicular and mediastinal regions. Therefore the results obtained in the past must be compared with the results obtained in the metastatic cases which were operated upon without the effect of the rays, and when this comparison is made I am 
entirely sure that there will be demonstrated a very decided improvement in the end results. This will be true especially in the cases treated in the past two years since which the technic in Roentgen-therapy has undergone a decided change. However, even during this period, the technic used in general has been most inefficient. When all cases are referred for post-operative treatment we will be in a much better position to estimate its value. When such cases are referred for post-operative treatment, the Roentgenologist should be informed as to whether metastases in the axillary and supra-clavicular regions were or were nof found at operation, for we believe that in the cases in which there is no metastasis, the amount of treatment needed will be very much less, and the period during which the treatment will have to be continued after operation will be likewise very much diminished. The prognosis following operation without Roentgen treatment has been discussed in previous chapters of this book, and therefore need not be repeated here. We believe, however, that the end results can be improved 25 per cent.

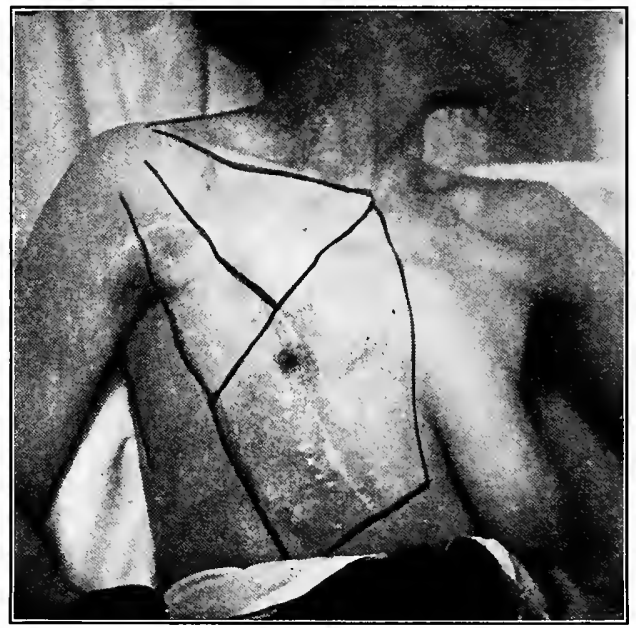

FIG. 269.-Diagram showing the usual outline of areas as portals of entry for post-operative treatment. Anterior view.

by thorough, competent, post-operative $X$-ray treatment. All surgeons recognize the danger of recurrence, and since the foregoing cases, which have been studied by Dr. Deaver and myself over a considerable period of time, show that even extensive, recurrent and metastatic disease may yield to the action of the rays, there can be no doubt as to the influence of the Roentgen rays upon the malignant tissue. If recurrence, the positive evidence of malignant disease, can be made to disappear, then it is surely reasonable to presume that if this disease be treated in its incipient recurrence, or when only a few cells have been left behind or transplanted, that if this treatment be used in time, the chances of recurrence and of the subsequent development of the disease must be very much less. It is generally recognized that if recurrence takes place in the region of the wound, cancer cells have been left behind at the time of operation or have been transplanted. It would seem therefore that the little nodules 
that one sees; from time to time, develop in the region of the stitch holes argues at once in favor of transplantation. If this were recognized, we would have the strongest possible argument in favor of immediate post-operative treatment in the open wound, and from results that $I$ have observed in this method, I believe that it is a rational procedure providing it can be safely and practically carried out.

I treated my first patient in this manner about three years ago, following an operation for recurrence of carcinoma of the breast. She has remained well these three years. I believe Dr. Foerster of Milwaukee was the first to use this method. He has recently written to me that his oldest case has remained well now seven years. Dr. Deaver does not approve of the treatment in the open wound, but urges post-operative treatment in all cases. Werner, who has had considerable experience with post-operative treatment says: "Roentgen exposures are liable to ward off recurrences when applied after operation, especially when the rays can be applied to the open wound." He also says: "Many cases of failure can be ascribed to inadequate dosage." Theilhaber also says: "The probability of success is greater when the rays are applied to the open wound." Rodman advised treatment in the open wound when it is practical.

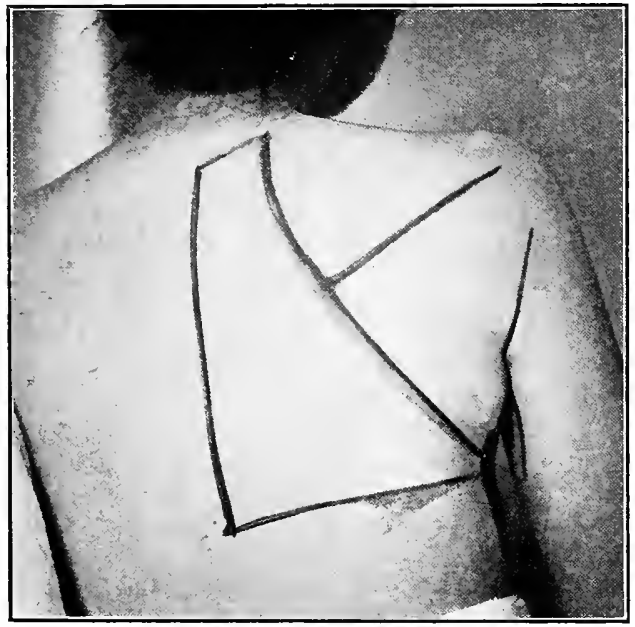

FIc. 270.-Posterior view showing the usual portals of entry for post-operative treatment.

Argument in Favor of Immediate Post-operative Treatment.-The object of this post-operative treatment is first, to cause the atrophy or destruction of outlying cells or glands that have not been reached by the surgeon, or the destruction of cells that have been transplanted into the wound; and second, to cause the obliteration of the lymphatic channels which would otherwise permit the dissemination of the disease. Therefore, the sooner the cells are destroyed or rendered inactive by the rays, the less likelihood will there be of multiplication and further development. This, in itself, forms a strong argument in favor of treatment upon the open wound before suturing, and while the patient is still under ether. As proven, the rays have a destructive effect upon the carcinoma cells, and beneficial effect upon the patient suffering from carcinoma. I need 
only refer to the cases previously reported in this chapter, as well as to those previously recorded in various scientific contributions made by myself and many others such as Boggs, Krause, Koptzenberg, Freund, etc. It is not always practical to give treatment in the open wound while the patient is still under ether. In such instances, the treatment should be given as soon after the operation as the patient can be safely moved into the Roentgen treatment room. When, for any reason, post-operative Roentgen treatment cannot be given, then treatment should be applied at the earliest sign of recurrence, for a considerable number of cases with recurrences and metastases can be cured, or rendered free from symptoms. Unfortunately, most of the inoperable and advanced cases die of the disease, sooner or later, and their friends and relatives who do not know of its advanced state are apt to ascribe death to the failure of the rays, and sometimes even believe that the rays caused the death of the patient, or even caused her disease.

All Cases should be given Post-operative Roentgen Treatment.-All Roentgenologists and most surgeons are recognizing the value of post-operative Roentgen treatment in the more advanced cases, but few seem to realize the importance of such treatment in cases in which there is no glandular involvement. The best evidence of the value in early cases is that by Dachtler, who as a result of visits to leading hospitals eight years ago to determine the value of post-operative treatment, says:

"I found that whenever unfavorable opinions were given, almost invariably on investigation, faulty methods in technic were discovered. As a rule there was not a hearty coöperation between the surgeon and the Roentgenologist, the Roentgenologist stating that usually only a short series of treatments was given while the patients were in the hospital. After returning home, they either did not come for treatment, or they returned at irregular periods. On the other hand, in some places where the surgeon would have given the method a fair trial, the facilities for Roentgen treatment were sadly inefficient. In some hospitals the work was in charge of internes, who often had not mastered the first principles of Roentgen-therapy. In other places the protection offered the $X$-ray operators was so meager that they could not be expected to push the work under conditions which meant grave danger to themselves. In one celebrated institution of learning patients were sent to the $X$-ray department (which was in charge of inexperienced internes) with a prescription calling for so many minutes of $X$-ray treatment. Absolutely no method for measurement of dosage was known or attempted. In one large charity hospital, where many cancer patients were treated, post-operative $X$-ray treatments were given only while the patients remained in the hospital."

Unfortunately, these criticisms, referring to conditions eight years ago, will apply, in many instances, today.

In Dachtler's work during the past eight years, he was able to obtain the complete coöperation of the surgeons, and bases his report on private cases only in which the subsequent history could be followed, and only treated such cases as would promise to continue the treatment long enough to produce results. All the cases were carefully diagnosed, and in all cases the surgeon reported as to the presence or absence of axillary involvement. He says that of the $\mathrm{r} 6$ cases showing no axillary glandular involvement at operation, $\mathrm{r}_{3}$, or $8 \mathrm{r}$ per cent., are alive and well, after five years. Excluding the doubtful cases that died before the five-year period had elapsed, but who were found at autopsy to be free from cancerous disease, the percentage of cures reaches roo per cent. This is a gain of at least 20 per cent. over the best records yet reported.

Though the number of cases treated by Dachtler is not great, roo per cent. of cures of cancer is so unusual as to prove the strongest sort of argument for post-operative treatment in all cases instead of limiting it only to the inoperable or advanced cases which are operated upon with the hope that the rays will eliminate the disease that the surgeon cannot remove. Dachtler believes that the immediate use of the ray on the operating 
table, or leaving the wound open for treatment before closure, is not necessary, because, according to him, the chief effects of post-operative Roentgen-therapy are the obliteration of the remaining lymphatics and lymphatic glands. In his experience, the $X$-ray treatment has entirely eliminated skin recurrences after the radical operation for cancer of the breast.

Treatment of the Ovaries.-Theilhaber says: "The genital glands apparently act favorably on the development of cancer, their influence being 'cancrigenous' while the blood-forming organs possess 'cancrilytic' action. Therefore, I attempt to produce an atrophy of the sexual glands by Roentgen treatment in women who are still menstruating. Recurrences after the breast amputation is more readily prevented if the ovaries are destroyed, the clinical experience which different operators have had with castration in inoperable carcinoma coinciding with this fact." In this treatment of the ovaries for the effect on the breast, I have had no experience, but it seems to me to be worthy of trial, and I hope soon to have the opportunity of testing it.

The same arguments that are given in a previous chapter in this book concerning oöphorectomy as unfavorably influencing the development of carcinoma cells, as well as those conceived by Lett, can be used in favor of Roentgen treatment. Since the same effects on the ovaries can be accomplished by Roentgen-therapy, an operation which has a fatality of 6 per cent. should be avoided. As Lett's results seem to indicate a distinct improvement, and as this treatment can be so easily given, it would be wise to add ovarian destruction to the treatment of cases whose ovaries are still active.

Constitutional Effects of the Roentgen Treatment.-In most patients no constitutional effects follow the treatment, but as we give massive dose treatment, multiplying our doses rapidly, some patients develop nausea, occasional vomiting, and a certain amount of prostration which continues from one to three days. I believe this to be due to the gases generated by the action of the high-tension currents on the air. On this account every possible means should be used to keep the air of the room as fresh and pure as possible. This can be done by means of a suction apparatus, originally described by Caldwell, which removes all of the gases as they develop around the tube, or by the method described by myself which makes use of an inhaling device which permits the patient continually to inhale fresh air drawn from the outside of the building. The apparatus consists of a valve chamber which is placed under the window, permitting the ingress of fresh air only while the egress of the inhaled air takes place through the valve of the inhaling mask, and practically eliminates the inhalation of the obnoxious gases from the room, though not completely because a certain amount of the gas still enters through the valve before the valve over the inhalation mask closes. As originally designed, the chamber permits the admixture of pure oxygen from an oxygen tank, but I have found that this is not essential. More recently I have installed large suction fans.

Modern Technic. ${ }^{1-}$ - Most treatments with the Roentgen rays, both in primary, recurrent and metastatic carcinoma have in the past been given by the fractional dose method. This same technic was used in the post-operative treatment, and it is rather remarkable that the results have been so good when one application after another was made upon the same area of skin, and, if of sufficient quantity, was apt to bring about dermatitis and to accomplish only sufficient deep effect to cause stimulation. During

${ }^{1}$ This technic was described at the midrwinter meeting of the Eastern Roentgenologists at Atlantic City, January, I9 5 . 
the past few years there has gradually been evolved a technic known today as deep Roentgentherapy.

With the idea of cross-firing upon the disease in the chest and axilla following carcinoma, I have, for many years, directed the treatment through the anterior, lateralposterior and supra-clavicular aspects of the chest, but during the past two years have definitely outlined the areas of skin through which to give the treatment, so that every portion of the skin receives a definite full dose so placed that the greatest amount of cross-firing will occur in the axillary and supra-clavicular regions which are the usual lines of extension of carcinoma of the breast.

Division of Areas.- - In order to prevent recurrences in the wound, the lower portion of the incision comprising the mammary region is divided into one or two areas, depending upon the length of the incision. Joining this then are three triangular areas radiating from the shoulder and lying between the clavicle and the axilla. A dose is then sent directly through the axilla; another through the posterior fold of the axilla. The space between the clavicle and the spine of the scapula is divided into two triangular areas, and a full dose is given through each. Then one or two doses are given between the scapula and the spinal column, directed toward the mediastinum and toward the mammary region. If there is suspicion of mediastinal involvement, the rays are sent, in addition, tbrough from four to six different areas toward the mediastinum. In general, for the average post-operative case, treatment is given through from six to twelve different fields, the number being limited so far as seems safe, so as to keep down expense, and the expense is approximately the same to give a full dose through one area, whether it be small or large, and is multiplied by the number of doses necessary. By this process of multiplying doses, the rays are made to cross from three to six times through the axilla and from two to four times through the supra-clavicular region, and most of the doses reach the mediastinum to a greater or lesser degree. In the treatment of primary inoperable carcinoma, one must aim to cross-fire as much as possible upon the disease wherever it is found.

Interval between Treatments.-All the above doses are given in one series, generally on one day, without interruption, but at times it is more practical to use two days to give a series. I generally repeat this series of treatments at the end of three weeks, and again at the end of four weeks. From three to six such series are generally given. The number will, of course, depend upon the degree of malignancy and the extent of the disease preceding operation. I believe that in many instances failures have been due to inefficient or insufficient treatment. During the interval between the series the patients can go about their usual affairs - at least, so far as the Roentgen treatment is concerned, and when coming from a distance (unless it be too great) can return to their homes. In cases of advanced disease, one should not set a definite number of series, but should simply increase the interval as much as seems practical until one can feel reasonably certain that the patient will remain well. In this the close coöperation of the attending physician is needed to prevent the patient from growing careless.

The Dose.-The dose refers to the amount of treatment given through each particular area of skin, and is limited by the skin toleration. We find that we can give twice the pastille dose as measured by the Sabouraud and Noire pastilles, providing the rays are passed through $3 \mathrm{~mm}$. of aluminum and one layer of sole leather before reaching either the skin or the pastille. It must be borne in mind that these pastilles have been made to be used midway between the target of the tube and the skin of the patient. After one has standardized the technic the dose can be fairly well measured by noting the time, dis- 
tance of the anode from the skin, the amount of milliamperage and the length of the parallel spark gap. These elements will vary considerably with each equipment. This technic, however, should be controlled from time to time, and can easily be done by laying one of these pastilles on the skin protected from daylight and using the same pastille on two different areas which should then be changed to the deep orange tint " $\mathrm{B}$," which records a value four times as great as when placed midway between the anode and the skin. Working with a Coolidge tube, 25 milliampere-minutes with a transformer current, with a parallel spark gap of 9 inches and the target 8 inches from the skin, will give double tint " $\mathrm{B}$," or the usual dose that we give. If this distance is changed, it must be remembered that the quantity of rays will vary inversely with the square of the distance. Over areas where recurrence has already taken place, we sometimes use a dose equal to three times tint " $\mathrm{B}$ " or the equivalent of $30 x$. When care is used, the photographic method of measurement recommended by Kienböck and adapted by myself may be employed, when the dose is recorded in $x$ units. Tint B on the Sahouraud scale $=10 x$.

Filters and Protection.-At present we are using, uniformly, $3 \mathrm{~mm}$. of aluminum over one layer of sole leather, for this work. In giving these multiple doses, the rays, of course, must be confined to the area treated. The hair must be carefully protected by sheets of lead or by the opaque rubber, and the rays should be confined about the tube so as to limit vagrant rays so far as is possible.

Time of Beginning Treatment.-When practical it is desirable to give the treatment through the open wound just as the surgeon finishes his operation, and before suturing. The layers of skin are drawn back as far as is practical; the hemostatic forceps are removed, and the whole area is covered with several areas of sterile gauze or a sterile towel. The patient, while under ether, is then turned over so as to lie on the healthy side; the arm is either drawn upward or thrown well forward. When all is in readiness beforehand (as it should be), the treatment, with our modern equipments, should not require over 20 minutes from the time the surgeon removes the clamps to the time he is ready to put in his sutures. We have not found that this jeopardized the success of the operation nor that it has interfered with the healing of the wound. At the end of a week or two the patient should receive the regular post-operative treatment as outlined above.

When it is not practical to treat the patient through the open wound, the regular post-operative treatment should be given just as soon after the operation as the condition of the patient will permit moving to the Roentgen treatment room, which is usually in from a few days to two weeks. Even when the patients must be moved from the hospital to some other place for treatment, it can easily be done within two weeks. It is a mistake to consider Roentgen treatment as post-operative when it is first started after the patient begins to have induration of the tissues, shooting pains, or other signs of recurrence. In general much skill, great care, and keen judgment are needed to produce good results.

Radium in the Treatment of Carcinoma of the Breast.-It is now pretty generally admitted that the action of radium on the cells of the body and on malignant tissue is very similar, if not identical, to the action of the Roentgen rays. Therefore, the choice of these agents will depend upon the convenience with which the radiation can be brought into contact with the malignant cells. The results will also depend upon the quantity of either form of radiation that can be best brought to bear upon the malignant tissue, for small doses of either agents are liable to cause stimulation of the deeper cells, even though the superficial cells may be destroyed. It is also generally admitted that the action of radium for efficient therapeutic effects is not over $2 \mathrm{~cm}$. in depth, while the 
action of the Roentgen rays has been shown to be repeatedly effectual in the treatment of even the deepest tissues of the body. This is illustrated by the results previously reported in the treatment of metastatic carcinoma of the bone and mediastinum. With the most modern equipment, the Roentgen rays can be applied in unlimited quantities, and from almost every direction through the surface of the body. Hence, in the treatment of inoperable carcinoma of the breast, one must always take into consideration the lymphatic glands in the axilla, supra-clavicular region, and mediastinum, as well as possible metastases to the bones. It seems, therefore, that radium should not find a very large field of usefulness in this particular group of patients with malignant disease, but that it should find its greatest field of usefulness in the treatment of malignant disease within cavities where it can be brought into direct contact with the dieased tissue, and by exerting its effects locally, to the extent of $2 \mathrm{~cm}$., may accomplish a great deal of good. Radium can, of course, be applied in the treatment of superficial nodules if these alone are to be considered. In the treatment of large masses of malignant tissue, the best results can be accomplished by inserting the radium tube in the growth, as recommended by Morton, who reported a case thus treated, seven years ago, in a patient who, to this date, has never shown any signs of recurrence. In this case a microscopical examination of a piece of the tissue removed established the diagnosis of carcinoma. This section was removed at the time of the insertion of the tube containing Io $\mathrm{mg}$. of pure radium bromide, which was left in place $\mathrm{I} 6$ hours. Sometime later it was thought best, on account of the slow healing of the radium ulcer which followed this application, to remove the breast. Microscopic examination showed cancer cells remaining in the periphery of the broken-down area. Still better than the insertion of the radium tube is the method recommended by Burnam who describes his method as follows:

"Fine, capillary tubes are filled with radium emanation and these containers are placed in hollow needles. It is possible to insert a number of such needles at a uniform distance from each other into the tissues to be radiated. By this means it is possible to radiate a given volume, as for instance the floor of the mouth, the tongue and neck, with an approximately uniformly equal and easily determinable beta and gamma radiation. It can readily be seen that where applicable this method is much more economical than distance radiation. Great care, however, must be taken that the exposure is not so long or intense as to cause sloughs or other injuries. It is proper to say in this connection that as yet the elementary facts are just being worked out. It is not known, for example, whether a short intense or a prolonged feeble radiation is preferable. The determination of this one point alone will demand a tremendous material most carefully studied, and there are many others."

Boggs thinks that radium can find a field of usefulness by placing the radium capsule tube in the axilla where it is difficult for the Roentgen rays to be applied. Even here the serious part of the malignant disease is apt to be more than $2 \mathrm{~cm}$. in depth from the surface of the axillary skin. It would seem, therefore, that the cross-firing method previously described would be more useful. Personally, I have not applied radium in the treatment of carcinoma of the breast, for I could see no good reason for its use in preference to Roentgen rays, where the Roentgen rays can be applied in sufficient doses and with the proper amount of filtration, conditions which can certainly be obtained in the treatment of carcinoma of the breast. The limitations of radium-therapy can be shown best, I believe, by quoting the opinions of those most experienced in its use. In reply to a letter regarding the results obtained in breast cancer, Dr. Howard Kelly writes:

"I think there is great hope in the near future that with a new form of $x$-ray we will be able to do all that we are now doing with radium and perhaps more too."

Abbé, of New York, who is possibly the pioneer in the use of radium in America, in answer to a letter of inquiry as to the relative value of $X$-rays and radium says: 
"I am not prepared with enough experience to take up any discussion, but having seen much of both forms, I can say that radium can dissipate recurrent nodules, cutaneous and subcutaneous, after carcinoma operations, and perhaps with less likelihood of dissemination because of its particular beta and gamma radiations. In cases of Paget's disease of the nipple, it has a beatifully curative effect. In cases of epithelioma beginning in the ducts of the nipple, I have a number of cases now cured for many years. It is hard to classify the different types in which radium has been found effective, but $I$ have seen and illustrated many cases of rapid disappearance of considerably sized masses receded to a condition of apparent inert fibrosis. In general $I$ feel that the $X$-ray is by far the most potent agent, but in many cases radium, properly used and properly screened, seems to me to fill an independent and very valuable position."

\section{Finzi says:}

"If there are multiple recurrences and indications or likelihoods of involvement of the mediastinum, it is better to use filtered $X$-rays than radium, and, although the former do not have so good an effect in destroying the cancer tissue, the great amount of rays that can be poured into the body can give larger doses to more distant parts, and have a greater effect than the small doses of radium rays that can be made to reach these parts."

\section{Newcomet says:}

"Neglected cases of carcinoma of the breast frequently come under observation where the amount of tissue involvement precludes operation. The breast is bound down to the underlying tissue, and the glands in the axilla extensively involved. Therefore, it would be natural to suppose the mediastinal glands were in the same condition, depending somewhat on the situation of the primary growth. By careful application of the $X$-ray or radium, it is possible to produce a retrograde change that will in some instances cause the local disease to become absorbed, and make it possible for a thorough operative procedure. In several instances that have come under observation, the patients were restored to perfect health."

\section{Wickham and Degrais say:}

"Under a variety of circumstances radium can be extremely useful in the treatment of cancer of the breast. In inoperable cases it can produce a distribution of the tumor, cicatrize the open wound, and appreciably relieve even very great pain, thus prolonging life for a considerable time. This is accomplished by the introduction of tubes into the depth of the neoplastic mass or by the triple application of the apparatus in the wool of the dressing."

Probably the most valuable and comprehensive report yet made upon the treatment of radium in carcinoma of the breast is that by Major Pinch in his annual report of the work carried out in the Radium Institute, London, in I9I4, in which he says:

"The number of patients with this disease applying for treatment far exceeds that of any other malignant condition. The policy of declining to treat operable cases is still rigidly adhered to, unless the patients have absolutely refused to submit to operation, and radium is used as a last resource.

"The progress of inoperable, slow-growing cases of the atrophic type is usually much retarded by the use of radium, especially when the metastases are confined to the skin, axillary, and supra-clavicular lymphatics and do not affect the lungs or abdominal viscera.

"Very small isolated cutaneous nodules on the chest wall, if few in number, may be effectively treated by unscreened exposures of one or one and a half hour's duration with a half-strength radium plate. If very numerous and closely set, prolonged exposures of 30 to 40 hours' duration to heavily screened rays are preferable, and this method of treatment should also be resorted to for the primary growth, infected glands, or ulcerated surfaces if such exist.

"Superficial ulcerations unaccompanied by much subjacent induration are peculiarly susceptible to the action of radium, and complete healing of these lesions is frequently observed. Isolated recurrent nodules - inoperable by reason of their attachment to the sternum, clavicle, ribs, or rib cartilages-are best treated by burying a small powerful emanation tube, screened with $\mathrm{r} \mathrm{mm}$. of silver in them, for a period of 24 hours.

"Little or no effect appears to be exerted in the prevention of metastatic deposits, though the treatment does not, at any rate, hasten their dissemination. Some cases in which pleurisy or ascites, depend- 
ent upon carcinomatous invasion of the pleura or peritoneum, has been present have shown remarkable improvement, and the application of powerful apparatus screened with $2 \mathrm{~mm}$. of lead over the affected pleura or peritoneum, after a preliminary paracentesis, has effectually prevented the further formation of effusion.

"A few patients have been under treatment at intervals of three or four months since the opening of the Institute in August, I9II, and it bas been observed that a stage in their treatment is reached sooner or later at wbich the response to radium fails, and the benefit derived becomes negligible.

"In rapidly growing carcinoma of the medullary type radium can do very little except relieve pain, even though enormous doses be employed.

"The number of cases of cancer of the breast was 67 ; of these $I$ was apparently cured, 40 were improved, 17 not improved, I abandoned treatment and 8 died."

Based upon the opinions expressed by those who have had most experience in the treatment of carcinoma of the breast with radium, one cannot hope for brilliant cures and only cures in a very limited number, as is indicated by Pinch's report in which only I out of 67 cases could be considered cured. Therefore, it must be understood (and this opinion is expressed by every author), that operation must not be interfered with nor delayed on account of the possibility of cure by radium.

Combined Use of Radium ond X-rays.-One often hears, chiefly from those not sufficiently informed, that one can expect good results from the combined use of radium and the $X$-rays. These two forms of radiation can be very advantageously used when the disease is located within a cavity, in which instance radium is applied directly in contact with the malignant disease in the cavity, and will produce a profound effect if used in sufficient quantities. The Roentgen rays can then be used to greater advantage by applying them by the cross-firing method in massive doses and according to the deep technic through various angles, and through the surface of the body, so as to reach the outlying lymph nodes, and prevent further dissemination of the disease. The two agents should not be used, however, over the same area of skin. This precaution will especially apply in the treatment of carcinoma of the breast, for since the two forms of radiation are very similar, and since both can be only indefinitely measured, the danger of either giving insufficient radiation, or producing a burn of the skin, is very great. In fact, the greatest caution should be taken against the use of any form of irritant to the skin when either $X$-rays or radium are to be applied. Therefore iodine, mustard plasters, liniments, massage, high-frequency currents, violet rays, etc., must always be eliminated.

Radium in Post-operative Treatment of Carcinoma of the Breast.-The use of radium after operation has been repeatedly recommended. This has probably resulted from the knowledge of the action of radium on malignant cells, but when one realizes that following carcinoma of the breast there is not only the danger of recurrence in the operative field, but of dissemination of the disease along the lymphatic tract, it will be seen that radium can, in no sense, replace the use of the Roentgen rays. And since with the $X$-rays, we have so much more power it would be wrong to attempt to replace this large volume of $X$-rays by the small quantity of radium that is usually possessed by any one person. If one have 200 or $500 \mathrm{mg}$. of radium, so that the soft rays can be filtered out, and gamma rays used almost exclusively in massive doses from various angles, I believe some good can be obtained. I have seen one such result produced by a large quantity of radium in post-operative treatment, but the small quantity of radium which is usually posses sed by individuals or even hospitals cannot be depended upon to produce such results.

Hyperemia.-The hyperemia treatment of cancer is based on the theory that the disease is primarily dependent upon a poor blood supply of the affected part. Theil- 
haber, the author of this theory, thinks it justifiable to suppose a cancerous predisposition in operative scars analogous to that in scars following burns or other forms of trauma. The treatment consists in the production of hyperemia by means of heat, $x$-ravs, counterirritants, etc. and is applicable only to superficial cancers. Prophylactic treatments are begun about ro weeks after operation at which time the scar begins to shrink. Large doses of the $X$-rays combined with high-frequency current and diathermia are applied by Theilhaber both to the operative scar and to the normal breast. Blood-letting is done every six months, an empirical practice based on the clinical observation that recurrences are less frequently noted in patients who have lost a large quantity of blood during operation. How this is correlated with the theory of local hyperemia we are unable to say. Hochnegg adds gymnastic exercises, sunbaths, and several weeks of purging to the above treatment. Kirschberg recommends a 20-minute session in a hot-air cabinet, followed by energetic massage. Leaf proposes a suction apparatus to produce hyperemia and prevent dissemination. These measures are unsupported by any proof of their practical value although any method of treatment proposed by the authorities mentioned should command our attention. Personally we have had no experience with hyperemia as a prophylactic treatment against post-operative recurrence.

Chemo-therapy.- The highest aim of modern chemo-therapy is to discover some chemical or chemical compound that will destroy malignant tumors in vivo without injuring the normal tissues of the body. Research along bio-chemical lines in tumor diseases followed the perfection of experimental transplantation of tumors in the lower animals and the discovery of Ehrlich's salvarsan. The remarkable effects of the arsenical compounds in the treatment of syphilis and other spirochetal diseases are thus far wanting in the experiments with various chemicals in the treatment of tumor diseases. The possibilities of future development in this line of experimentation are such, however, that a review of that which has been accomplished will be of some interest. It has been demonstrated that certain substances (named tumor-affines by Neuberg and Caspari) have a selective action on tumor cells. Wassermann and Keyser injected selenium-eosin into tumor-bearing mice and found that this substance was taken up by the tumor cells causing their destruction without affecting the normal tissues. The therapeutic dose was found to be too near the toxic dose, however, to insure safety in using it on the human subject. Neuberg and Caspari noted an increase of destructive processes in the tumor cells of experimental animals after the intravenous injection of various compounds, the most efficacious being a combination of copper and tin. The colloids of many of the heavy metals proved rapidly destructive to tumor cells, but the animals often succumbed either to the influence of the injected metal or to toxic products arising from the degenerated tumor. Loeb and his co-workers report the results of experiments with intravenous injections of colloidal copper in human cancer cases. They state that retrogression of the growth and relief from pain were noted in the greater number of instances. The treatment was ineffectual in rapidly growing tumors. Similar results are obtained by Gaube de Gers. Braunstein modified the technic proposed by Wassermann and applied his discovery to the human subject. Intravenous injections of electro-selenium were given to 20 cancer patients, including one breast case. Iodine-methyl-blue was given by mouth in conjunction with the injections. In almost all of the cases, improvement was noted-relief from pain, improvement of the general condition, and, in some instances, increase in weight. No bad results were noted. Ascites disappeared, the tumors diminished in size and became more mobile; associated lymph glands were also much reduced in size. The cases in this series were all inoperable and in advanced 
stages. Braunstein believes that the treatment may be of value as a post-operative aid in preventing recurrences. Bougeant and Galliot advise the use of the coral red variety of electro-selenium for intravenous injection purposes ( $\mathrm{I} \mathrm{mg}$. in $5 \mathrm{cc}$. of isotonic serum repeated every other day). Their experiments comprise 20 cases, three of which were carcinomata of the breast. No evil effects followed the treatments. Relief from pain was noted in every case; while the growth of the tumor was retarded in some instances, but was neither constant nor lasting. They express the belief that the use of electroselenium as a pre-operative measure will become a universal practice. Radium and the $X$-rays were advised to be used in conjunction with the injections as a prophylactic measure after operation.

Cholin, a substance produced by the action of radium or the X-rays on lecithin, has been used lately in the treatment of cancer. This agent depends for therapeutic properties on radio-activity. Werner found that cholin can imitate the action of radium and can be substituted for the latter in tumor-therapy. Czerny and several other European surgeons have used various salts of cholin intravenously in the treatment of inoperable cancer, but this has been too recent to speak of results.

Drug-therapy.-Various tonics and alteratives, of which iron and arsenic are the most useful, may be given to inoperable cases for the purpose of sustaining the strength of the patient. None of the many drugs advocated from time to time in the treatment of cancer has proven curative. It is unwise to burden a patient suffering with an inoperable cancer with a lot of medicines which are only placebos. The pain associated with advanced cancer of the breast may usually be relieved by the $X$-rays and other nonmedicinal means. Opiates should be reserved for the final stages of the disease, when their administration is necessary as a rule. The use of alcohol in moderation is justifiable. Every effort should be made to keep the patient comfortable by frequent changing of the dressings in cases in which ulceration has occurred. Weak solutions of carbolic acid, a mixture of pepsin and hydrochloric acid, ointments containing eucalyptus, or antiseptic powders are useful preparations for local application to malignant ulcerations. Forty per cent. formalin followed by $\mathrm{H}_{2} \mathrm{O}_{2}$ has been recommended by Stewart.

Toxin and Immuno-therapy. - It has been known for many years that erysipelas infection of a cancerous breast often retards the progress of the cancer. This clinical observation was first applied to the treatment of malignant disease by Fehleisen in I 888 . Fehleisen isolated the streptococcus erysipelatis and inoculated cancer patients with this organism with the production of attacks of erysipelas identical with the accidentally acquired disease. The therapeutic effects were likewise comparable with those following the disease when accidentally acquired. One case of mammary cancer was "cured" and four others were greatly improved. Other surgeons, including Holst and Coley, produced typical attacks of erysipelas by injecting the streptococcus into cancer patients, but they discontinued its use owing to the great danger associated with such heroic treatment. In I 89 I Lassar reported negative results with the use of a toxin derived from this organism, although Sprouck had previously reported good results with a similar toxin-therapy in the treatment of malignant tumors in experimental animals. Roger discovered that the virility of cultures of certain pathogenic microörganisms is increased by the addition of the bacillus prodigiosus, a non-pathogenic germ. This observation was first applied to the treatment of malignant tumors in the human by Coley of New York. The mixed toxins of the streptococcus erysipelatis and bacillus prodigiosus (Coley) have been used extensively in the treatment of malignant disease, and have proven of some value especially in sarcoma. In the latter class of tumors, the 
results obtained by Coley stamp the mixed toxins as the most useful of all non-operative measures in cases where irradiation is impracticable. Surgeons generally have failed to obtain the good results reported by Coley ${ }^{\mathbf{l}}$ and have to a large extent discarded the treat. ment. We have used the "Coley toxins" in a small number of cases but without beneficial results. There can be no doubt, however, that in a certain percentage of otherwise hopeless cases, the originator of this form of toxin-therapy has achieved most brilliant results. The treatment should be given a trial in deep-seated multiple inoperable sarcomas.

Cancroin, an extractive of cancerous tumors, and analogous to the cadaveric ptomaine, neurin, was discovered and used by Adamkiewicz in the treatment of inoperable cancer. This agent has not been accepted by other surgeons as a measure worthy of trial, although its discoverer reported good results in advanced cases following its use.

Serum-therapy.-Anti-streptococcus serum was used in the treatment of six cases of recurrent cancer of the breast by Emmerick. Local improvement was noted in these cases. In I900 Wlaeff isolated pathogenic blastomyces from a cancerous growth and injected them into geese. He then collected blood serum from the infected fowls and injected it into a series of eight patients with cancer of the breast. Both local and general improvement is said by Wlaeff to have followed the injections. More striking results, however, were noted in the lower animals in which he claims to have produced tumors at will by injecting of the blastomyces and to have controlled their growth by injections of the serum. We know of no further mention in the literature of this remarkable procedure.

The treatment of carcinoma with the body fluids of recovered cases (Hodenphyl) and anti-micrococcus neoformans serum (Doyen) has not met with signal success.

Actual Cautery.-The actual cautery is used by some surgeons as a palliative measure in operable cases and for the removal of local recurrent nodules. Personally we do not advise the use of the cautery in breast cancer because excision with subsequent application of the $x$-rays causes less mutilation and pain, while the results are as good or better than are those obtained by actual cauterization. Finney, on the other hand, considers the cautery superior to the knife in the treatment of recurrent nodules even when the ribs and sternum are involved.

Electro-therapy.--Under this heading there are two methods that deserve some serious consideration, but electro-therapy should, in no instance, be used in operable cases to replace operation. The two methods are electro-coagulation and fulguration. Electro-coagulation consists in the actual coagulation of the malignant tissue by means of the heat generated in the tissue by passing a high-frequency current through the tumor. The same general effect and line of treatment is often referred to under the term thermopenetration, desiccation and electro-thermic coagulation. It is a natural destructive process, and has the advantage over thermocautery that the heat used is generated in the tissues, and, because as it passes directly through the tissues from the active electrode to the inactive electrode, there remains a zone beyond the actual destruction in which sufficient heat is generated to destroy outlying malignant cells without actually destroying the healthy tissue. For the destruction of large masses the d'Arsonval type of high frequency currents will be found the most useful. The field of usefulness for this form of current is extremely limited. In all my experience I have only seen one case in which I believe it was applicable. This case is reported as follows:

${ }^{1}$ See section on Treatment of Sarcoma (Coley's fluid). 
The patient was Mrs. K. L., aged 68 referred to me by Dr. W. L. Rodman, Apr. 3, rgr4, with a large scirrhous carcinoma of the right breast. It had been growing five years and had been treated by a plister. The breast was firmly adherent to the chest wall, and was considered entirely inoperable by Dr. Rodman. We could detect no glandular enlargement in the axilla or supra-clavicular region. A Roentgenogram of the chest showed the shadow of the tumor, and in addition a number of small dense glands along the mediastinum. On account of the absence of palpable glandular involvement, and with the possibility of the mediastinal glands not being malignant, we considered the combined treatment by means of electro-coagulation and deep Roentgen-therapy as applicable. It is only in such inoperable breast cases, without axillary involvement, that we consider this method of treatment advisable.

Therefore, we destroyed the tumor by electro-thermic coagulation, cooking from the surface downward, then shaving off the cooked malignant tissue until we reached the intercostal muscles. We had to work in this way very carefully for fear of penetrating the chest wall and lung. This was preceded and followed by deep Roentgen-therapy, and today, Feb. 20, I9r6, she is still well. The wound healed very slowly requiring several months, but ultimately the healing was complete, and she has remained well to the present date.

The points of interest in this case are:

r. That it was a scirrhous carcinoma which had been aggravated by plaster treatment applied by a charlatan.

2. That it was inoperable.

3. That it was not suited for Roentgen-therapy alone.

4. That it was completely and successfully destroyed by electro-thermic coagulation and Roentgentherapy.

The Roentgen-therapy was of course applied over the supra-clavicular and axillary regions, and directed toward the mediastinum as well as over the local growth. If any metastasis had been present, it must have been reached by the Roentgen rays. Of course, one can never say whether such metastasis had or had not taken place, and it is because of this difficulty of determining the possibility of metastasis that this method of treatment must be chosen most carefully.

Fulguration.-Fulguration is a term originating with DeKeating-Hart and Rivière. It consists in the application of a long high-frequency spark, the spark measuring from 6 to 8 inches. This spark is directed through a tube upon the open wound following operation. Through this tube is forced conjointly a current of cold air to prevent the heating effect of this spark. The spark is not destructive, and is only applied following operation. It is never applied primarily or for any destructive effect. Its object is to prevent recurrence. A full estimate of its value has not been determined, but it is enthusiastically recommended by DeKeating-Hart, Rivière and Bainbridge. Following the application of this current there is a marked pouring out of lymph over the wound which DeKeating-Hart believes has an immunizing value. These authors also recommend the associated application of the Roentgen rays as the post-operative method of treatment.

Vaccine-therapy.-Delbet first proposed treating the cancer patient by means of tumor auto-inoculation vaccine-therapy. He recommended subcutaneous injections of powdered tumor material suspended in blood serum. Before this method was suggested as applicable to human cancer, Delbet had succeeded with Ehrlich in producing active immunization against mouse cancer by a similar process. It is a significant and interesting fact that Ranzi and Graff actually produced a cancer at the site of injection of Delbet's tumor suspension-a danger which Blumenthal had previously warned against. To obviate the danger of infection, autolysates of the tumor material were used but without any beneficial or other effect. Fischera later claimed cures in human cancer by the use of fœetal autolysates. A number of surgeons, including Lewin, Rovsing, Bertrand and Coan 
suggested modifications in the technic of vaccine-therapy and each reported some encouraging results. A method similar to that suggested by Rovsing was employed by Coca in the treatment of several of our own cases. This method which consisted of the subcutaneous injection of fresh tumor material is attended with grave danger of sepsis. Sterilization of the material seems to destroy any curative value that it may otherwise have. In several of our cases large abscesses formed at the site of injection; all of these patients recovered from the immediate effects of the infection-none of them was benefited.

In a recent paper by Vaughan, read before the American Medical Association, June, I9I4, on the subject of cancer vaccine and anti-cancer globulins as an aid in the surgical treatment of malignancy, he reviews the results obtained during a period of six years in Ioo cases of cancer. "The work is based on the theory first published by him in I910 which states that through chemical alteration the normal tissue cell changes into the malignant cell. If a malignant cell is chemically different in its protein content from a normal tissue cell, it should be possible to sensitize an animal to one protein and not to the other. That this is the case has been proved and it has also elicited knowledge concerning a new and extremely interesting form of sensitization to which has been given the term "transitory sensitization. The term vaccine is used to cover the number of injections of both cancer-cell vaccine and cancer residue, while the term ferment is used to include serum, unfiltered leucocyte extract, filtered leucocyte extract, globulins, and in a few cases the leucocytes in toto."

Of the roo cases of cancer treated and reported, 32 were cancers of the breast. Of this number, I 9 received little or no benefit. In some of the other cases, however, the results were so striking as to command the most serious attention. Therefore, those cases in which good results have been obtained will be reviewed briefly. It is the cases that recover or show improvement that are most instructive, for the natural course of the disease is progressive and ultimately terminates in death.

"Case 6. Mrs. F. Recurrent carcinoma of the breast. First seen Apr. 7, igr 2. Radical removal and second removal of recurrent nodule, had heen performed previously. Patient given ro injections of vaccine and 70 of ferment. Patient still living with recurrence."

"Case 7. Mrs. C. Recurrent carcinoma of the hreast following radical removal. First seen Nov. 28 , 19ro. Patient given $\mathrm{I} 8$ injections of vaccine. Patient still living without recurrence."

"Case I9. Recurrent carcinoma of the breast. First seen Jan. 20, I9I1. Recurrence in opposite breast and possibly liver. Patient given 55 injections of vaccine and 91 of ferment. Patient living, apparently well.

"Case 33. Miss R. Recurrent carcinoma of breast with abdominal metastasis. First seen July r, I9II. Patient given 23 injections of vaccine and 96 of ferment. Patient discontinued treatment because of severe reaction following the injection of ferment. Condition was improved at this time, and the patient is still living with recurrence."

"Case 35. Miss McA. Carcinoma of breast with axillary involvement. Patient refused operation. First seen July 18 , I91r. Was given 25 injections of vaccine and 48 of ferment. All signs of tumor disappeared and patient is still living without recurrence."

"Case 52. Mrs. K. Carcinoma of breast. First seen Oct. 3 r, I9Ir. As complete removal as possible was performed. The tumor was the size of the patient's two fists with axillary and supraclavicular involvement. Patient received ro injections of vaccine and 29 of ferment. Patient still living without recurrence."

"Case 56 . Mrs. M. General carcinomatosis following radical removal of carcinoma of breast. First seen Nov. 21, rgrI. Patient has received 33 injections of vaccine and roo of ferment. This patient had metastasis in ileum, vertebra, lungs, inguinal glands and opposite breast, and when first seen was confined to her bed, the slightest movement of which would bring on severe pain. At present the recurrent areas are much diminished. The patient has twice traveled from Michigan to Oregon in comparative comfort, takes daily automobile rides, and is much improved." 
"Case 57. Miss C. Recurrent in supra-clavicular glands following radical breast removal. First seen Mar. I9, I9I 2. Patient received seven injections of vaccine and 66 of ferment. Patient living without recurrence."

"Case 64. Miss G. Carcinoma of the breast. First seen May I3, I9I2. Patient given ro injections of vaccine preliminary to operation. Axillary glands were involved. Subsequently given I 7 injections of vaccine and 149 of ferment. Patient living without recurrence."

"Case 79. Mrs. P. Carcinoma of the breast. Size of two fists, with axillary involvement. First seen Feb. 24, I9I3. Radical removal attempted, following which she received ig injections of vaccine and 46 of ferment. Patient living without recurrence."

"Case 96. Miss C. Carcinoma of breast with axillary involvement. First seen June 4, I9r3. Radical removal performed. Patient given 29 injections of vaccine and 37 of ferment. Patient living without recurrence."

"Case 97. Mrs. McD. Recurrent carcinoma of breast. Small nodule. First seen July 9, I9r3. Patient given 26 injections of vaccine and 30 of ferment. Patient living without recurrence."

Referring to the entire roo cases, "5o were inoperable or possessed such a recurrence after former operation as to be classed as inoperable. Of these cases, two are apparently well and without recurrence, and four are markedly improved, which, in this division, would give 4 per cent. of apparent recoveries and 8 per cent. the outcome of which is still in doubt. The cases which show definite recurrence, which, however, was comparatively small in amount, were $\mathrm{r}_{4}$ in number. Of these six are apparently well and three improved. There are five cases which show small operable lesions in which operation was refused. Of these, four are clinically well and one improved."

"The advanced cases in which operation was performed in combination with specific treatment were $3 \mathrm{I}$ in number. Of these 23 or 73 per cent. are apparently well. One displayed rapid recurrence and seven seemed to receive no benefit. All cases except one were microscopically malignant, the one case being that of breast carcinoma in which axillary involvement was present and which refused operative interference."

"The study of the blood counts made in these cases had led to the conclusion that cases in which the percentage of large mononuclear leucocytes increases to from ro to 20 per cent. following specific treatment, do well, while those that run a high polymorphonuclear count and in which the percentage of large mononuclear cells is not materially increased are not benefited."

"With regard to the use of either vaccine or residue it should be stated that the field in which they are of service is limited. The best results are obtained in cases in which the amount of tumor tissue present is small, and in which the differential leucocyte count of the patient shows a decided reaction following the administration of the cancer protein."

"A vaccine or residue is efficient only in cases which respond with a considerable increase in the percentage of large mononuclear leucocytes, and its chief use should be in operable cases in which a single intra-peritoneal dose is given 24 hours before operation in order that the blood stream may have present as a part of its content some specific ferment which can be available for the splitting up of malignant cells not removed, and such cells as are cast into the blood or lymph channels through the operative manipulation."

"With regard to the ferment it can best be stated that all cases give evidence of marked benefit from its use during the administration of the first three or four doses, after which the ferment seems to lose its efficiency. The period during which it is active is about ro days, and subsequent injections cause but little reaction. This is easily understood if we stop to consider that the body in all probability forms an antiferment to our specific ferment which renders doses given after the formation of the anti- 
ferment inactive. This might be said to be true of any of the specific ferments now employed. As for instance, the first dose of diphtheria antitoxin is generally more efficacious than subsequent injections."

"In conclusion I would state that I do not believe that any method of specific therapy will be of much avail in cases that have large amounts of malignant tissue present. In such cases the use of large amounts of globulins may prove fatal, as in some of those reported in this series when 200 or $300 \mathrm{mg}$. were given intravenously at a time. The real value of either vaccine or ferment will be in their use in connection with operative removal in order to destroy such cells as are not removed by operation and thus reduce the percentage of recurrent cases."

It is his practice to give "intra-peritoneal injection of residue 24 hours before operation. If the increase in large mononuclear leucocytes reaches from 55 to 25 immediately before operation, that is deemed sufficient. If this does not occur then an intravenous injection of Ioo mg. of globulins is given following the operation." In all of his cases alternate vaccine and globulin injections have been given frequently for the first six months after operation, and then once a month thereafter, as by this means it is possible to see the patient frequently enough so that definite conclusions as to the progress of the case can be drawn."

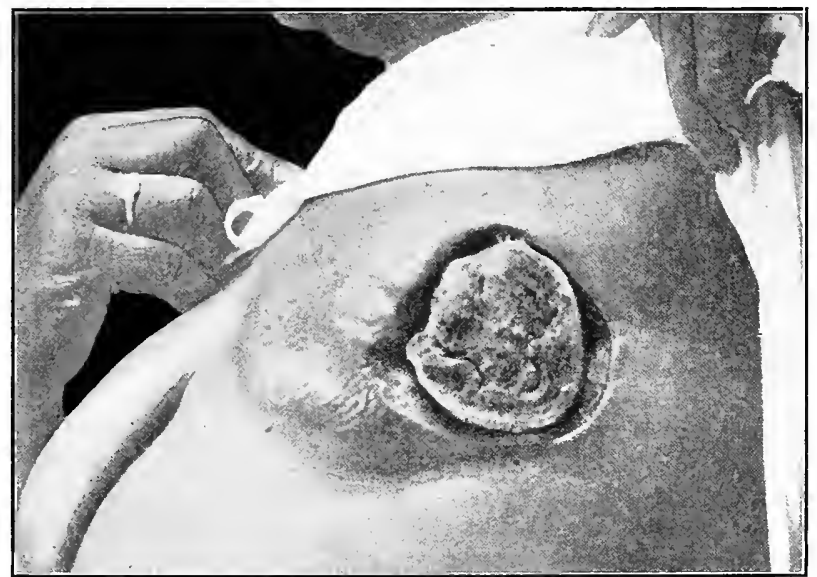

FIG. 271.-Carcinoma of the breast treated with arsenic paste showing slough and incomplete removal of the diseased tissue.

Caustics.-Escharotics have no place whatever in the treatment of carcinoma of the breast in the operable stage, but may be used in some cases where the more definite destructive agents such as the thermo-cautery, the electro-coagulation are not at hand or cannot be used. In such cases escharotics are useful to destroy large masses of tissue, prevent fetor, lessen the discharge, and to a certain extent, limit the growth of the tumor. What is of far greater importance, they diminish toxic absorption in ulcerated cancers. It is much better if the malignant mass can be removed by means of the knife, thermocautery or by electro-coagulation, but when this is not possible, the employment 
of caustics will destroy much of the malignant tissue, and odor. Practically all drugs of escharotic properties have been extolled at one time or another in the treatment of malignant ulcers, but of these, arsenic, nitric and sulphuric acids, phenol, resorcin, acetone, iodine, formalin, zinc chloride, and potassium permanganate are the most efficacious.

An ancient caustic, consisting of chloride of zinc, made into a paste with flour and extract of opium or cannabis indica, is recommended by Sheild. He also speaks of equal parts of sulphuric acid and charcoal as being "a useful, very powerful and manageable caustic."

Strong solutions of corrosive sublimate in collodion have powerful escharotic properties, but they must be used with extreme care lest "bichloride" poisoning occur.

Instead of actual destruction of the malignant mass, it is better in most instances to aim so to harden it that the discharge and fetor will be diminished. A useful method for this purpose is that recommended by Stewart, who suggests the use of formalin followed by peroxide of hydrogen solution, which has a neutralizing effect on the formalin. A saturated solution of potassium permanganate has a decided caustic action, and is a safe and satisfactory agent. Infinite patience is required in the treatment of an inoperable, sloughing cancer of the breast.

Finally, if the methods that have been carefully outlined in the treatment of carcinoma of the breast be properly combined, the greatest good will be accomplished, and the percentage of cures materially increased. By this we mean that operable cases should be operated upon as promptly as possible, and in all instances should be followed by active $x$-ray treatment. Where possible, it may be of ultimate advantage to spark or fulgurate the open wound at the time of the operation. In the inoperable cases, the use of the Roentgen rays or radium, and in some cases combined with electro-coagulation or caustics or one of the other methods outlined in this chapter, will materially prolong the life of the patient, increase the comfort, and in many instances make the patients feel that they are not dying of cancer.

\section{BIBLIOGRAPHY}

AввÉ, Robert.- "The Use of Radium in Malignant Disease," The Lancet, I9I3, 2, 524. Trans. College of Physicians, I913, Phila., Pa.

Abderhalden, E.- "Influence on Rat Tumors of Serum Containing Ferments Protecting against Some of the Tumor Elements," Med. Klin., Berlin, Feb. 9, 1914, p. 183.

Allaire.- "Traitement du cancer par les rayons X," Gaz. méd. de Nantes, 29, x, rgo4.

AlLEN.- "The Value of Radio-therapy in Cutaneous and Other Cancer," Journ. of Cut. and Gen.-ur. Dis., p. 75,1903 .

Aмaт, Сн.—“Le Traitement du cancer par les composes chimiques," Bull. gen. de therap., r899, Vol. I 37, p. 42.

BABCock, W.-Deals with the Use of Fischera's Fœtal Autolysates in the Treatment of Human Cancer, International Clinics, I9 $13,2,89$.

Beatson.- "The Treatment of Inoperable Cancer," Encyclop. Medica, Edinburgh, Vol. r2.

BECK, CARL.- "On Roentgen-therapy," J. Physital Therapy, r9o2, p. 5 I.

BÉCLÈRE.-(a) "Action des rayons $\mathrm{X}$ sur les tumeurs malignes," Gazette élect., rgo7, novembre et décembre, 1907; $(b)$ "Action des rayons $\mathrm{X}$ sur les tumeurs du sein primitives," Gazette élect. ${ }_{5}, \mathrm{j}$ jan., I908.

BÉ́ot.- "Traitement de la maladie de Paget par la radiothérapie," Archives d'élect. médicale, No. 2 I 2, p. 283 .

BERDE2.- "Le traitement des cancers," Revue médicale de la Suisse romande, r9o3, XII, 800.

BERGoniÉ.- "Effets des rayons X sur les tumeurs malignes," Bull. méd., XVIII, No. 6, rgo3.

BERgonié et Spéder.- "Carcinome du sein ulcéré traité par la radiothérapie," Archives d’élect., I9I2, XXI, p. 158. 
Bevax, Arther Dean.- "The $X$-ray as a Therapentic Agent in Carcinoma." Trans. of the Amer. Surg. Assn., r903, p. 208-2r4. "The Cure of Cancer and Cancer Cures." Trans. of the Amer. Surg. Assn., Igro, p. 414-427.

BissérIÉ.- "La technique radiothérapique dans les affections cancéreuses," Progrés méd., Igo6, No. 6. Bloodgoon, J. C. - "Radium," Progressive Medicine, rgr2, December, p. 246.

Boggs, Russell H.-(a) "The Roentgen Treatment of Carcinoma of the Breast," New York Medical Journal, Nov. 12, r9ro, p. 965; (b) "Post-operative Roentgen Treatment of Carcinoma of the Breast," Interstate Medical Journal, Vol. XIX, No. 3 ; $(c)$ "Radium and Mesothorium in Conjunction with Roentgen-therapy," The American Journal of Roentgenology, April, r9r 5, pp. $83 \mathrm{r}-836$; $(d)$ "The I.ocal Application of Radium Supplemented by Roentgen-therapy," Surgery, Gynecology and Obstetrics, Vol. XXII, No. 3, pp. $35^{8-365}$.

Bodgeaxt and Galliot.- "L'electro-selenium dans le traitement du cancer inoperable," La Clinique, I9I 2 , p. 50I.

Braunstein, A.-Deals with the Treatment of Carcinoma by Injections of Iodine Methylene Blue, Berlin. klin. Wochenschr., I913, r, I902.

Bumm, E., and K. WArnekros.- "Cure of Deep-seated Cancers by Roentgen Exposure of Surface," "Heilung tiefliegender Karzinome durch Roentgenstrahlen. von der Körperoberfläche aus," münch. med. Wchnschr., I9r4, LXI, r601-1656; Jour. A. M. A., I9r4, LXIII, $8 \mathrm{r} 3$.

Burnar, Curtis-F.- "A Brief Outline of the Status of Radium Therapeutics," The Johns Hopkins Hospital Bulletin, Vol. XXVI, No. 29r, May, I9 5 .

Case, J. T. and Jones, L. L.- "Technic and Recent Results of Deep Roentgen-therapy Using the Harder Rays," American Journal of Roentgenology, Vol. II, Nos. 8, 9 and 1o, pp. 8rr-8r6.

Cassei et BergoniÉ.- "Carcinome du sein traité par les rayons X," Gazette hebd. des sciences méd., II, déc., I904.

Chaput and Esbach._- "Cancer du sein traité par la methode de Doyen," Bull. et mém. soc. de chir., I $905,3 \mathrm{I}, 446$.

Cole, A. M., Indianapolis.- "The Massive Dose vs. The Fractional Dose in Roentgen-therapy," American Journal of Roentgenology, Vol. II, No. 7 , pp. $762-765$.

Coley.-(a) "The Present Status of the $X$-ray Treatment of Malignant Tumors," Medical Record, New York, rgo3, March; (b) Amer. Jour. Med. Sci., r893; r896, 2, 277; r897, r, r74.

Czersy.-Verhandl. d. Gesellsch. d. Naturforscher u. Aerzte, rgr 2-r3, Vol. 84, p. 39, "Über die nicht. operative Behandlung der Geschwülste." (Complete review of serum-therapy and radiotherapy in cancer.)

Dachtrer, H. W.- "The Post-operative Roentgen Treatment of Carcinoma of the Breast," Interstate Medical Journal, Vol. XIX, No. 3.

DAnlos et GASTou. “ "Cas de cancer, sarcome acrodermale d'Hallopeau et chéloïdes guéris par les rayons X," Presse méd., 22 février, rgo5.

Davis, J. Griffith.- " "History of a Case of Squamous Carcinoma Treated with Methyl Violet, r5 Per Cent. Solution in 95 Per Cent. Alcohol," New York Medical Journal, I896, LXV, p. 485.

Davizac.- “History of a Case of Mammary Carcinoma Treated with Arsenical Paste," Jour. méd. de Bordeaux, rgoo, p. 695.

DoYen.- "Le diagnostic du cancer par une réaction spécifique avec le micrococcus neoformans," Compt. Rend. Soc. de Biol., Paris, rgo8, 64, 816-8ı8.

Eijkman.-Krebs und Röntgenstrahlen. (Jena, 1902, Gustav Fischer.)

v. Elischer und Engel._ "Beiträge zur Behandlung mediastinaler Tumoren mit Röntgenstrahlen," Deutsche med. Wochenschr., Nr. 39, 47, I906.

Fenleisex,- "First Report of the Inoculation of Inoperable Tumor Patients with the Erysipelas Organism," Das Erysipelas, Berlin, I 888.

Finney.-Keen's "Surgery," Vol. 6, "Actual Cautery in Breast Cancer."

FinzI.- "Radium Therapeutics" (Henry Fronde, Publisher), Oxford Press, I9r3, p. 88.

Fowler, F.-(a) "Place of Roentgen Rays in Treatment of Cancer," Brit. Med. Jour., June I3, No. 2789, pp. I277-1336; (b) "Treatment of Malignant Disease by Accidental Erysipelas," Am. Jour. Med. Sci., I898, n.s., I I6, p. I6r.

Freund, L.- (a) "Die Bestrahlung und chirurgische Behandlung maligner Neubildungen," Deutsche med. Wchnschr., I9I3, xxxix, 20;8, by Centralbl. f. d. ges. Gynäk. u. Geburtsch. s. d. Grenzgeb., June, I9I4; (b) "Radiotherapie eines inoperablen Mammakarzinoms," Münch. med. Wochenschr., Nr. 24, p. Ir80, I905. 
Gamlen.- "A Case of Successiful Treatment of Tumor of the Breast," Archives of the Roentgen Ray, I903.

Garratr, Jorn M.-- “ $X$-ray Therapy," Buffalo Medical Journal, February, igi 5 .

Gochт.-Fortschr. a. d. Geb. der Roentgenstrahlen, I897-98, p. I4, "First Use of the $X$-ray in the Treatment of Mammary Cancer; Two Inoperable Cases."

Gocht, H., Kotzenberg and H. Derks.-Beiträge zur klinischen Chirurgie, Tübingen, June, XCII, pp. 1-866. Eppendorf Hospital Festschrift.

Gould, A. Pearce.- (a) Pearce Limits Himself to Coley's Fluid, $X$-rays and Radium in the Treatment of Inoperable Cancer, Brit. Med. Jour., I9I4, Jan. 3; (b) The Lancet, I913, I, 215.

HAHN.-(a) "Ein kasuistischer Beitrag zur Behandlung bösartiger Neubildungen mit X-Strahlen," Fortschritte Roentgenstr., VII, S. I02; (b) "Röntgentherapie bei malignen Neubildungen," Münch. med. Wochenschrift, Nr. 44, S. 1939, 1903.

Haret. - "Les rayons $X$ et le cancer ulcéré du sein," Journ. de physiothérapie, No. 25, I905.

Hart, DeKeating.- "Die Behandlung des Krebs mittelst Fulguration" (Translation), Leipzig, Igo8.

Hartzell. - "Two Cases of Paget's Disease Treated by the X-ray, with a Report of the Microscopic Findings in one of them after Prolonged Treatment," The Journ. of Cut. Dis., XXIV, 7, Igo6.

Hermann, F.- "Histology of Carcinoma Tissue after X-ray Therapy," Berl. klin. Wochnscr., Aug. Io, 5i, No. 32, P. IgI4.

HodenPhyl.-Medical Record, New York, Igro, 78, 359.

Holdrng, ARTHUR F., New York City.- "The Treatment of Malignant Conditions by Physical Methods with and without Surgery," American Journal of Roentgenology: Vol. I, No. ro, pp. 368375 .

Holst.- “Erysipelas Treatment of Cancer," Annales de l'Institut Pasteur, I888, p. 243.

Imbert, LÉon and Dupeyrac, G.- "Cancer et Radiotherapie," Étude Statistique, Congrés française de Chirur., Paris, I907, p. II4.

Johnson, Geo. C.--"The Place of the Roentgen Ray in Therapeutics," Journ. of Amer. Med. Assoc., Vol. LXIII, No. 9 .

Johnson, Wallace and Merricl, Walter H.- "The $X$-ray in the Treatment of Carcinoma. One of the Earliest Cases Reported," Phila. Med. Record, Ig00, p. II 39.

Kassabian.- "Electro-therapeutics and Roentgen Rays, Phila., i907, J. B. Lippincott \& Co., p. 465.

Kelley, Howard A.-Personal communication.

KIEnböck.-( a ) In "Physikalische Therapie" by Marcuse and Strasser, Igo7, Part 6, Radio-therapie, p. 136; (b) Archives of the Roentgen Ray, London, I904, I905, P. I 26.

Kirschberc.- "The Hyperemia Treatment of Carcinoma," Deut. med. Wochenschr.

Klein, Von Professor Dr. Gustav.- "Röntgenbehandlung bei Karzinom des Uterus, der Mamma und der Ovarien," Aus der Kgl. gynäkolog. Universitäts poliklinik in München. Sonderdruck aus der Münchener medizinischen Wochenschrift, No. I7, I913.

Knox, Robert.-Brit. Med. Jour., I9J3, I, II97.

KohIer und HerXheimer.- "Zur Röntgentherapie des Karzinoms," Fortschritte Roentgenstr., Bd. VIII, 5, I905.

Krause, P.—“Über die Behandlung der Mammacarcinome mit Röntgenstrahlen," Jub. Kong. d. deutsche Röntgen-Ges., Berl., I914, By Zentralbl. f. d. ges. Chir. u. i. Grenzgeb.

KroNFELD.- "Utber einen mit X-Strahlen dauernd geheilten Fall von Brustdrüsenkrebs," Münch. med. Wochenschr., 39, I 903 .

Lange, Sidney.- " $X$-ray Therapy in Therapy of Internal Diseases," F. Forschheimer, 1913, D. Appleton and Co., N. Y., Vol. I, p. 54I (post-operative irradiation).

Lassar.- (a) "Das Behandlungsresultat eines inoperablen Mammakarzinoms bei Röntgenbehandlung," Berl. med. Ges. für Dermat., 1904; (b) Annales de l'Institut Pasteur, 1892 , p. $88_{3}$.

Lebard, Ledoux.- "Mesothorium as an Analgesic in Inoperable Malignant Tumors," Transt 4 th International Congress of Physio-therapy, Berlin, March, 1913. Archives d. Électricité Médicale, $1913, \mathrm{I}, 467, \mathrm{P} .97$ and $\mathrm{I} 37$.

Leaf, Cecil H.-Describes a Suction Apparatus for the Treatment of Carcinoma by Hyperemia, Edinburgh Med. Jour., I9oI, 5I, 452.

LEgros.--"Cancers et radiothérapie," Gaz. d. Hôpitaux, No. II I I905.

LEONARD.-(a) "Palliative Röntgenbehandlung bei bösartigen Geschwülsten," Fortschritte, XIII, S. 334; aus the Americ. therap. soc., Phila.; (b) "The Roentgen Rays in the Treatment of Malignant Disease," Phila. Med. Jour., I903; (c) "The Roentgen Rays Treatment of Malignant Disease of the Breast," Amer. Jour. Med., Vol. VIII, No. 23 , I904; (d) "The Treat- 
ment of Malignant Dise ase by the Roentgen Rays," International Medical Magazine, November, 1902 .

LewIN, CARL.- "Die Behandlung v. Krebskranken mit Vaccination," Die Therapie d. Gegenwart, I9I3, June, p. 255.

v. Leyden and Buumenthal.- "Pioneers in Immuno-therapy," Deut. med. Wochenschr., I902, v, 28, p. 637 .

Lilienthal.— "Fulguration and Thymus Gland in the Treatment of Cancer," International Jour. of Surgery, $1913,26,156$.

Loeb, Lron, McClurg and SMeEk.-Interstate Med. Jour., 19I3, p. 9, "Intravenous Injections of Colloidal Copper in the Treatment of Carcinoma."

Lonckexbeix.-_"Zur Behandlung maligner Geschwülste," Müchen. med. Wchnschr., Jan. 6, I9I4, p. IS.

McCourt, P. J.-_"The Treatment of Cancer by Its Own Toxins," Medical Review of Reviews, I 899 . Vol. 5, p. 827 .

V. Mikulicz v. Fittig.- "Über einen mit X-Strahlen erfolgreich behandelten Fall von Brustdrüsenkrebs," Beitr. z. klin. Chir., XXXVII, 3, S. 676, 1903.

Mondarn.- "Récidive d'un cancer ulcéré du sein," Archives d'élect. médicale r3, No. 170, p. 788.

Morton, Willias J.- $(u)$ "Radiotherapy and Surgery, with a Plea for Pre-operative Radiation," Medical Record, I905, I, 443; (b) "Treatment of Cancer by the $X$-rays with Remarks on the Use of Radium," International Jour. of Surgery, I903, 289; (c) Medical Record, I902, I, 36I; (d) "Imbedded Radium Tubes in the Treatment of Cancer," Medical Record, Nov. 28 , 1914 .

Mulier, Christopher.-Deals with the Results of the Treatment of Ioo Cases, Münch. med. Wochenschr., 1912, 2, I547.

Newcouret._"Radium and Radio-therapy," Lea \& Febiger, Philadelphia, 19I4, p. 245. (b) "Treatment of Malignant Growth with the $X$-rays," Phila. Med. Journ., Io, Jan., I903.

OdDin.- "Technique et Contre-indications de la radiothérapie," (good result in case of cancer en cuirasse in woman aged 70), Bull. Soc. de dermat. et de syphil., I904, p. Io6.

Oudin and Zimmern.- "Radiothérapie," Gilbert and Cornat, "Bibliothéque de Thérapeutique," I9r3, Paris, J. B. Baillière and Sons.

Percy, J. F.-Tr. Western Surg. Assn., St. Louis, Dec., I9I3, "Inoperable Cancer; the Best Method of Discouraging Its Activity; a Study of Heat in Cancer," Abstracted Surg., Gyn. and Obst., March, I9r4, I8, 3 .

Pfahler. - (a) "Carcinoma and Tuberculosis Treated by the X-rays," Journ. of the Amer. Med. Assoc., 2, June, Igo4. (b) "Notes in X-ray Treatment of Cancers," Journ. of the Amer. Med. Assoc., Chicago, I903. (c) "The Roentgen Rays in the Treatment of Deep-seated Malignant Diseases," Amer. Journ. of Med. Sci., I909; Fortschr. Roentgenstr., XIV, 218. (d) "The Treatment of Mediastinal Carcinoma with the Roentgen Rays," Amer. Med., XL, No. 6, Feb. Io, Igo6. (e) "The Treatment of Recurrences and Metastases from Carcinoma of the Breast," Surgery, Gynecology and Obstetrics, January, 1914, pp. 90-95. Int. Cong. Med., August, r9r3. ( $f$ ) "Report of Cases of Epithelioma, Recurrent Carcinoma of the Breast, Carcinoma of the Uterus, Carcinoma of the Esophagus, Tuberculosis of the Skin and Psoriasis," The Phila. Med. Journ., Dec. I3, I902. (g) "Deep Roentgen-therapy in the Post-operative Treatment of Carcinoma of the Breast," The Interstate Medical Journal, Vol. XXII, No. Io. (h) "Roentgen-therapy in the Treatment of Deep-seated Malignant Disease," Journ. of the Amer. Med. Assoc., May I, I9I5, Vol. LXIV, pp. I477-I485. (i) "Inoperable Primary Carcinoma of the Breast," New York Medical Journal, Apr. 26, I9I3, I, 853. (i) "Some Experiments and Observations on the Technic for Deep Roentgen-therapy," American Journal of Roentgenology, Vol. II, No. 5, pp, 576-68o.

Prich, A. E. H.- "The Work Carried Out at the Radium Institute, London, in I914." Brit. Med. Journ., Feb. 27, I915, p. 367 ; Brit. Med. Journ., I913, p. I49 and I914, p. Iro7; Radium, Vol. 3 , p. 49 , I 9 I 4 .

Pinkuss.- "Die Behandlung des Krehses mit Mesothorium und Kombination mit anderen Verfahren," Deut. med. Wochenschr., I913, p. I72I.

Pusey.--(a) "Report of Cases Treated with Roentgen Rays," Journ. of Amer. Med. Assoc., April, igo2. (b) "What Can be Done in Cancer with Roentgen Rays" (General, with Special Reference to Mammary Cancer)," Journ. Amer. Med. Assoc., I9I3, Aug. 23, p. 533. (c) "Results 
of the Treatment in $1_{5}$ Primary Cases of Breast Cancer," Medical Fortnightly, r903, p. 38; Trans. Amer. Roentgen Ray Society, I903, p. 89.

ReBoul.- "Sur quelques cas de cancer et de tuberculose traités par les rayons de Roentgen," Archives d'élect. médicale 149 , p. 658 , I904.

Repin.-Revue de Chir., I895, p. 466.

Robinson.- "A Case of Mammary Carcinoma Treated by the $X$-rays," Journ. of Cut. and Gen. Dis., p. 24I, I9O3.

Rovsing.-Conf. Internat. du Cancer, I9io; Étude du Cancer, I9ir, p. 553.

Somervilte, W. F.- " $X$-rays in Malignant Disease," Glasgow Medical Journal, September, rgr 3.

Sprouck.-Amer. Jour. Med. Sci., r893, p. 506.

Stern, Samuel, Néw York City.- "Roentgen Deep Therapy and Its Application in the Treatment of Malignant Growths," American Journal of Roentgenology, Vol. II, No. 2, pp. 544-549.

Sticker, A._"Radium und Mesothoriumbestrahlung (Technic)," Strahlentherapie, 30, 1913, 3, 1-63.

Stover, George Henry. - "The Roentgen Ray Treatment of Carcinoma," The Archives of Physiological Therapy, November, 1906 .

Theilhaber. - ( a ) "Advocates the Production of Hyperemia in the Scar after Cancer Operation by Application of the $X$-rays, High-frequency Current, etc.," Wiener klin. Wchnschr., r9r2, 25, 1375; (b) "Prophylaxis of Recurrence after the Operation for Cancer," Deutsch. Zeitschr. f. Chir., r9r3, I35, r93.

Tousey._"Medical Electricity and Roentgen Rays," Phila., r907, p. 977 W. B. Saunders \& Co.

Tuffier.- - (a) "Radiothérapie dans le cancer," Bull. de la soc. de chirurg., ro79, I903; (b) "Traitement radiothérapique du cancers," La Presse médicale ig04, No. Io.

Tuffier et Haret.- “Épithélioma du sein ulcèré, non opéré, traité par la radiothérapie," Bull. et mém. de la soc. de chirurg. de Paris, Vol. XXI, p. 236, I905.

TURner.-(a) "Cancer and the Roentgen Rays," Brit. Med. Journ., ${ }_{27}$, Sept., 1902. (b) "Report on the Radium Treatment at the Royal Infirmary during the Year I9r4," Brit. Med. Journ., Feb. 27, r 9 r 5 , pp. $373-375$.

Vaughan, J. Walter. - "Cancer Vaccine and Anticancer Globulins as an Aid in the Surgical Treatment of Malignancy," Journ. of the Amer. Med. Assoc., Oct. ro, r9r4, Vol. LXIII, pp. r258$\mathrm{r}_{2} 6_{3}$; (b) "Some Modern Ideas of Cancer," Journ. of the Amer. Med. Assoc., May 7, rgro, p. 15 ro; (c) "Blood Changes Caused by the Hypodermic Administration of the Cancer Proteid," Journ. of the Amer. Med. Assoc., Nov. r6, I9r 2, p. I764.

Vaughan, V. C.- "Protein Split Products in Relation to Immunity and Disease," Philadelphia, Lea \& Febiger, I9I3, Chap. XIV.

VilLARD. - "Cancer du sein traité par les rayons-X," Lyon méd., 6, Nov., rgo4.

Werner, O.- "Die Rolle der Strahlentherapie bei der Behandlung der malignen Tumoren," Strahlentherapie, rgr2, I, roo. (A general review of the non-operative methods of treating mammary carcinoma.)

Werner und CAan.- "Über die Wirkung von Röntgenstrahlen auf Geschwülste," Münch. med. Wochenschr., I9I0, p. r455.

Wetrerer.- "Handbuch der Roentgentherapie," Band I, II, Otto Neminch, Leipzig ror. . (Twentythree Inoperable Cases of Mammary Carcinoma.)

Wickham and Degrais.-(a) "Radium and Cancer," r9r3, London, Bartholomew Press, "Cancer of the Breast," p. 56. (b) "Radium Therapy," p. I44, London, Cassel \& Co., p. 56

Williams, Francis H.- "The Roentgen Rays in Medicine and Surgery," MacMillian \& Co., N. Y., I903, Appendix, 677. (Technic of Roentgen-therapy.)

WinfELd.- "A Case of Mammary Carcinoma Treated with $X$-ray," The Journ. of Cut. Dis., May, rgo3. WLOEFF.- "Contrib. á l'étude du traitment des tumeurs malignes par le serum anticeliulaire," (Serum obtained by Wloeff by Injecting Blatomyces obtained from Human Cancer into Geese.) Compte Rendu de la Soc. de Biol., I900, p. ro3r. 


\section{CHAPTER XIV}

\section{THE DISEASES OF THE NIPPLE AND AREOLA}

A few of the morbid conditions of the nipple and areola mammæ, owe their occurrence to peculiarities of structure and function, and are therefore, independent of the breast proper. It is to give them proper consideration that the present chapter was written.

\section{THE CONGENITAL ANOMALIES OF THE NIPPLE}

Athelia, or congenital absence of the nipple, and polythelia, or congenital excess of nipples, have been discussed at more than ordinary length in special parts of this work and need no additional mention (see the chapter upon the Congenital Anomalies of the Breast).

Bifid Nipple.-Bonnet-Laborderie (Jour. de science médicale, Lille, I905, II, 5) reports a case of this deformity in the person of a woman 36 years of age, mother of seven children.

Situated at the center of a large areola, strewn with Montgomery's glands, there was a bifid nipple, on the left breast. The division passed from the tips to the base. The galactophorous ducts opened in the valley or fissure between the two halves. None of the patient's children would ever nurse from this side, presumably because when the combined portions of the nipple were placed in the mouth, the pressure of attemped suction closed instead of opened the ducts, and no milk could be withdrawn.

Imperforate Nipples. - A case of this curious anomaly is reported by Bouffe de SaintBlaise (Annales de gynécologie et d'obstétrics, I904, 2s., I, 49).

The patient was a woman, well, and otherwise well developed. Menstruation began at $r 6$ years of age, when the breasts developed. Her mother had ro children, all of which she nursed from the left breast only, her right breast showing the same anomaly as is shown by both breasts of the patient. The patient's breasts are firm, especially the right, and are normal in appearance. The nipples are retracted, umbilicated, but easy to draw out for examination. The right nipple shows no orifices. After confinenent, lactation began on the third day when the breasts became swollen and painful. There being no ducts in the right nipple, not a drop of milk could be expressed; some little could be expressed through a single orifice in the left nipple.

Inverted or Umbilicated Nipples.--These not rare malformations are easily traced to failure of one of the stages of embryonal nipple formation. In our section upon the embryology of the breast, it has been shown that the last stage in the formation of the nipple is the growth and contraction of circular muscular fibers by which its projection is effected. If this fail, instead of projecting as a rounded eminence, the foundation of the nipple forms a thimble-like depression; instead of the milk ducts opening upon the flattened surface of an eminence, they open at the bottom of a crateriform fossa.

The condition makes nursing impossible as there is no way for the child to take hold of the breast.

Treatment.-Minor grades can sometimes be overcome in part by manipulation and traction. The treatment should be commenced early in pregnancy and the nipples drawn out with the fingers, held and tugged several times a day. Or, if preferred, a breast pump can be applied or some other device employed for the purpose 
of drawing out and keeping out, for a time, the tissue of the nipple. If too much force be applied, it may be possible to do damage by rupturing one or more milk ducts, when, of course, there may be danger of the subsequent formation of galactocele. If but slight success is met with, and the baby is unable to nurse directly, it may be possible to supplement and assist by the use of a nipple shield, but in most cases the child has to be artificially fed. The question then arises as to what shall be done to prevent the same trouble when the next child is to be nourished. To overcome the difficulty, operation may be performed as follows:

Operative Treatment.-Various operative procedures have been devised for the correction of inverted and umbilicated nipples to which the term mammillaplasty has been applied. The technic devised by Axford is applicable alike to inverted and umbilicated nipples, while the other methods, which we shall describe, are to be used only in cases of umbilicated nipples. The Axford operation should, be performed only on the non-

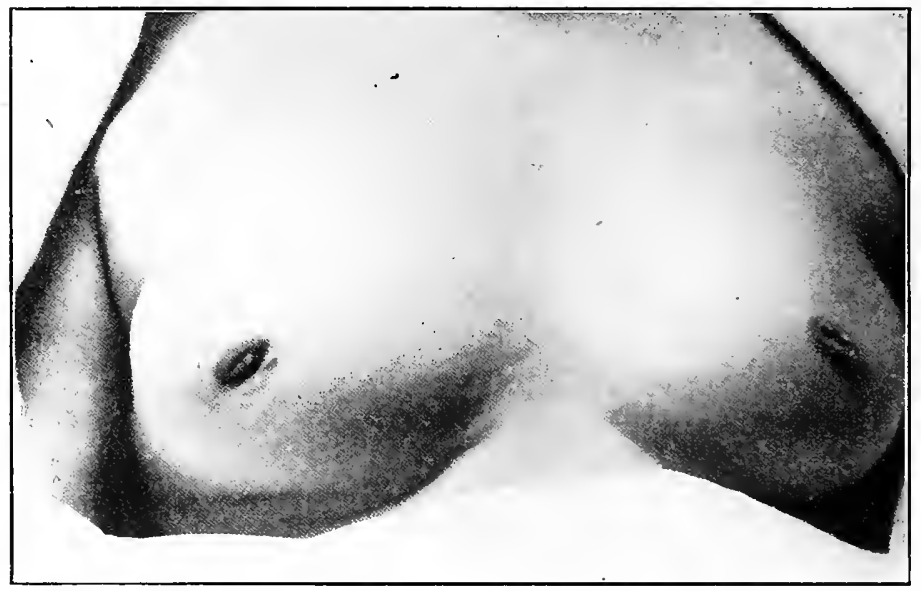

FIG. 272.-Congenital inversion (umbilication) of the nipples. Case suitable for mammillaplasty.

functioning breast; the other operations may be safely done in the early days of the puerperium. Operative treatment is contra-indicated in those cases in which the nipple cannot be readily lifted from the depression in which it lies, and restored to its normal position, without exerting undue traction. Mammillary inversion caused by neoplastic or inflammatory shortening of the ducts and peri-ductal tissues cannot be corrected by operation.

The principle underlying the Axford and similar methods of mamillaplasty is to restore the nipple to its normal position and to maintain it in that position by building a support of fibrous tissue beneath the base of the nipple. Axford accomplished this by "puckering" the fascia. Others have made use of hare-lip pins or other mechanical appliances, which are inserted beneath the nipple, and allowed to remain until nature has formed an inflammatory buttress to serve as a means of support.

The results following these operations are generally satisfactory so far as function is concerned but the cosmetic results leave much to be desired. 
The method described by W. L. Axford (Annals of Surgery, 1889, 9, 278) is as follows:

The nipple is seized with the volsella and drawn out till the skin is well on the stretch; beginning about $1 / 3$ inch from the apex two curve incisions enclosing a lune-shaped piece of skin are extended out, in the breast for $2 \frac{1}{2}$ inches, and the skin and fat down to the fascia removed.

This area of denudation should have its greatest breadth at the base of the newly formed nipple. Three such lunes radiating from the nipple are made. A catgut suture is next passed in and out, purse-string fashion, through the fascia, encircling the base of the nipple, and snugly tied at the point of entrance. This serves to pucker up the fascia so that when the volsella is removed the nipple shows no tendency to return to its inverted condition. This suture becomes completely buried when the denuded areas are closed with the continuous silk suture. The sutures are removed at the end of the seventh day and the immediate result is usually found to be excellent.

Another method of mammillaplasty devised by F. A. Kehrer is much simpler than the foregoing but is applicable only to cases in which the nipple is umbilicated; true invagination of the nipple cannot be so corrected. An umbilicated nipple is depressed so that it lies in a sort of cup with its summit below the level of the areolar surface. If left untreated, it is useless for nursing, but in many cases the deformity can be corrected by non-operative measures. Operation is indicated only when other measures have

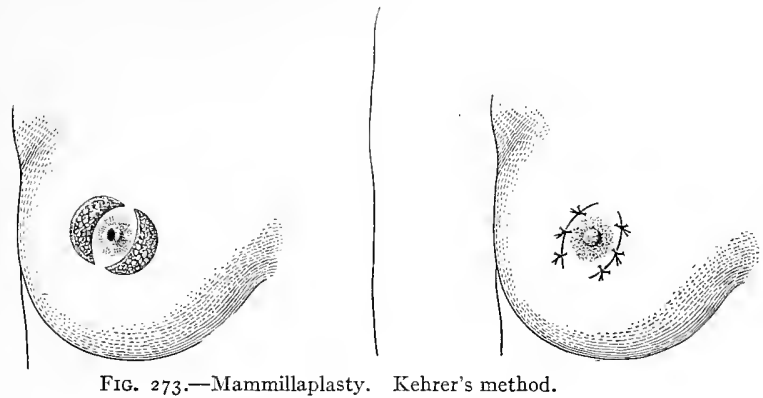

been tried without success. The operation consists in the removal of semi-lunar areas of skin and superficial fascia on each side of the areola and the subsequent closure of the defects thus produced. This has been successfully done by Herman, who advises that the areas of skin to be removed, be 2 inches in length and $\mathrm{I}$ inch in width at their widest part. In one of Herman's cases the breast, which had previously been useless on account of the mammillary defect, was so improved as to permit the baby to nurse on the fifth day after partuition. Infiltration anesthesia (novocain, I to 200 , solution) may be used.

Kehrer's operation has been improved by Williams as follows: "A circular strip of skin, together with the adjacent fibro-fatty tissue, is excised from the prominent cutaneous fold surrounding the diseased nipple. Care should be taken to avoid injuring the subjacent ducts by keeping the lines of the incisions outside of the areola. On suturing together the opposite cut edges of the skin, the nipple will be pulled into its proper position."

KeHrer, F. A.-“Über Excision des Warzenhofs bei Hohlwarzen," Beitrage z. Exper. Geburtshülfe u. Gynäk., Giessen, I879-90, 43, I70.

Herman, G. Ernest.-The Lancet, London, July 6, 2, 1889, No. I2.

Williams, W. Roger.- - "Diseases of the Breast," I 894, p. 544.

Rapin.--Rev. méd. de la Suisse Romande, I895. 
Axrord, W. L.-Annals of Surgery, I889, 9, 278.

DeLee, Joseph.—“The Principles and Practice of Obstetrics," ii, Ed., W. B. Saunders \& Co., Phila., IgI5, P. 9I4.

Digital or "fingergliedartig" nipple, in which the structures are large, cylindrical, firm and prominent are rarely seen in the white races. Ámong certain of the lower races they seem to be of frequent occurrence. They are not disadvantageous from the functional point of view, though unsightly and more or less in the way of the clothing.
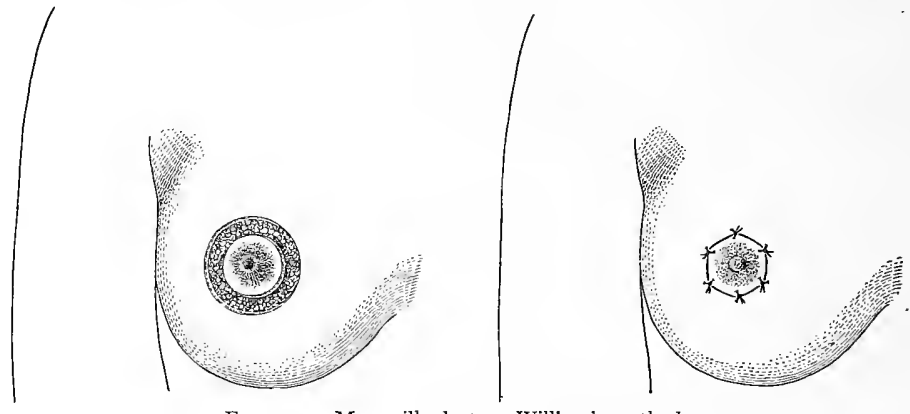

FIG. 274.-Mammillaplasty. William's method.

\section{ACQUIRED ANOMALIES OF THE NIPPLE}

A case of bilateral hypertrophy of the nipples is reported by Félegyházi (Orvosi hetil. Budapest, I907, LI, 830) but unfortunately, the journal was not available for consultation, and we are unable to give the extent of the hypertrophic enlargement.

An interesting case of disease of one nipple is reported by Ehrhardt (Deutsch.Zeitschr. f. Chir. r899, L, 373) and regarded by him as hypertrophy, but it has so many features in common with the "pedunculated tumors of the nipple" (q.v.) that we have included it among them.

Destruction and amputation of the nipples may result from ulcerative, inflammatory, and gangrenous disturbances or from accident. The former will be discussed in the following section. With the loss of the nipple, the ability to nurse an infant is set aside.

\section{INFLAMMATION OF THE NIPPLES-THELITIS}

As even mild grades of thelitis are painful, and as all grades may serve as the starting points of more severe disease of the nipple and of the breast, every case of inflammation of the nipple should receive early and careful attention.

The trouble usually begins with cracks and fissures that present themselves early in lactation and make the function so painful that it may be impossible to continue it.

In general, it seems to be more easy to prevent than to cure "cracked nipples" and to the former end, their preparation for lactation should be begun some time before the function of lactation is established. Hirst ("Textbook of Obstetrics," 6 th ed., p. 706) says: "Excavations and fissures of the nipples are due to the maceration and iritation to which they are subjected by the child's gums andmouth. Mammary abscess not infrequently results from the entrance of streptococci or of other infectious bacteria through these fissures." 
In the "American Textbook of Obstetrics," (Phila., I902, II, 272) the following excellent description is given. "Fissures of semi-lunar shape at the base of the nipple between the nipple and the areola are usually most difficult to heal, because the act of sucking almost always separates the edges and then at each repeated nursing they grow deeper and extend more and more around the nipple, sometimes even penetrating a milk duct and causing a milk fistula. Rarely the nipple is thus partially or even wholly amputated."

About one-half of nursing women suffer from erythema, erosion, ulcer or fissures of the nipples at the beginning of lactation, and suffer pain of more or less severity, and bleeding from the lesions, each time the child is applied to the breast. Blondes and patients with delicate skins seem to suffer most.

Remembering that the skin of the body constantly harbors bacteria some of which are pathogenic, and that their numbers are greatest where the skin surface is soft, warm, moist and rough, the nipple and areola are seen to be ideal sources of infection. The mouths of infants as well as those of adults also harbor bacteria that may be transferred to the nipple during nursing. It is, therefore, small wonder that infection of the breast is frequent in consequence of these morbid conditions of the nipple. The prophylaxis of thelitis, and the conditions to which it may lead are discussed in the chapter upon Mastitis.

Follicular Abscesses of the Areola.-Winckel (Lehrbuch der Frauenkrankheiten, I 886, p. 741) repeatedly saw inflammation of Montgomery's glands, with furuncular prominences and much pain. Out of 2300 nursing women there were 26 cases of follicular abscesses of the areola. Not infrequently it was necessary to incise the lesions to let out the pus. He cites Chalot (Gaz. hebd. d. sc. méd. de Montpellier, I88I, III, 253) as having observed a case in which there was a circular phlegmon of the areola.

Gangrene of the Nipples.-Vincent (Lancet, London, I902, I, 962) reports, "a case of gangrene of both nipples occurring in the puerperium" in the practice of W.S.A. Griffith.

The patient was a primipara aged 23 years. On the seventh day after delivery, hoth nipples became excoriated and were protected by nipple shields and thoroughly dusted with orthoform. On the thirteenth day an eruption broke out over the whole of the front of the chest, and afterward extended to other parts of the body and face. On the seventeenth day the nipples were grayish black in color, and one was insensitive. The next day the nipples were black and inclined to bleed. By the ninteenth day both nipples were definitely gangrenous, the lines of demarcation being around the areolæ. The next day the nipple had separated leaving a red granular surface the size of a shilling, and the right nipple had sloughed and was ready to separate, which it did the next day.

Milk could be expressed from the openings of the milk ducts at the bases of the ulcers. The progress of healing from this time on was uneventful.

Vincent strongly suspected that the cause of the gangrene was the orthoform, and in this he was probably correct as is shown by the similar experience of Wallert (Wiener klinsche Rundschau, I908, XXII,I77) who observed a woman 33 years old, who suffered from sore nipples after the birth of her second child, orthoform was applied and shortly after gangrene occurred and both nipples sloughed off.

Du Castel and Nocton (Bull. Soc. Franc. de. dermat. et syph., Paris, I904, XV, 28; Ann. de dermat. et syph., Paris, rgo4, 4s., V, 73) observed

a woman who five months after confinement, suffered from cracked nipples and abscesses of the left breast. Alcohol was first used for the nipples, then at the advice of her physician applications of phenol were made. She suffered from much pain. At the end of eight days the right nipple and areola hecame blackish and formed an eschar that exfoliated. The whole breast and a large part of the thorax were covered with an exematous dermatitis. The nipple and areola completely disappeared, leaving an 
infundibuliform crater-shaped ulceration, with a granulating surface upon which milk incessantly escaped from the milk ducts.

Wessinger (International Journal of Surgery, N. Y., I gor, XIV, I22) observed a case in which the nipples sloughed away in the course of exceptionally severe and destructive mastitis, for which both breasts finally had to be amputated. No mention is made of the treatment employed in the early stages. A suspicion that the lesions were caused by the gonococcus could not be substantiated.

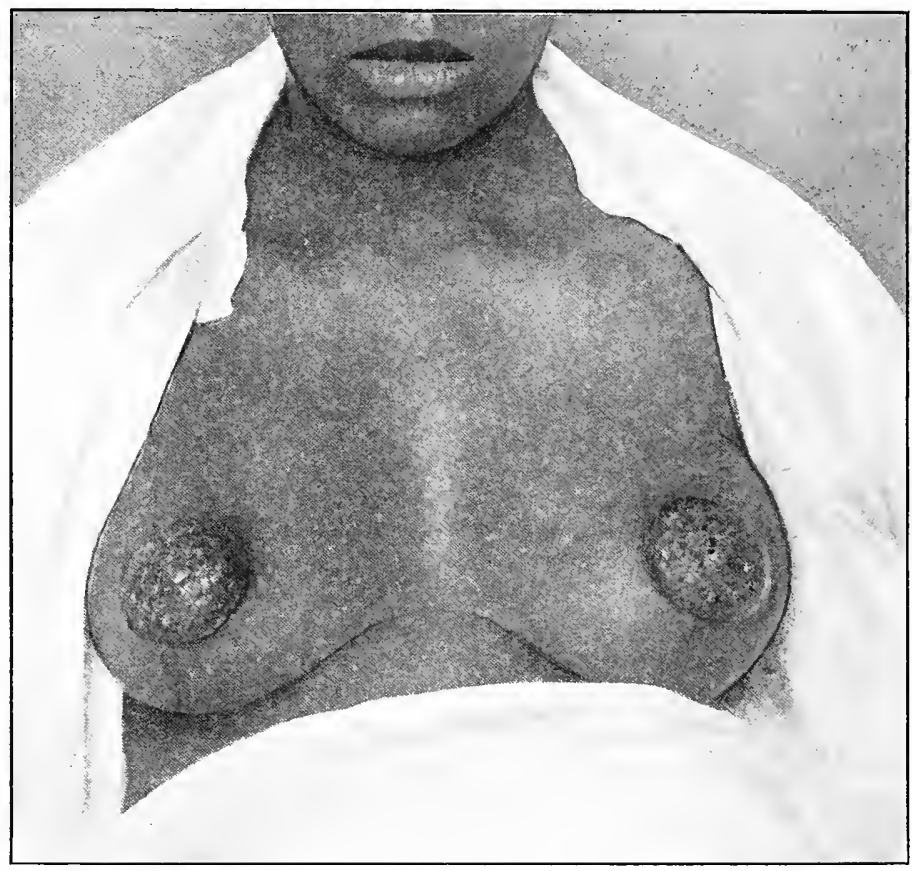

FIG. 275.-Pseudo-diphtheritic inflammation of the nipples and areolæ. (Siter.)

Odium thelitis or thrush of the nipple is occasionally seen. Such a case is reported in the collection published by De Forst (American Journal of Obstetrics, rgro, LXI, 140).

The patient was an Irish woman nursing her ninth child. In the fourth week she applied for relief from extensive fissures of the nipple and erosion of the breast adjacent to it. She stated that every morning small snow-white spots were found on the raw epithelial surface, sometimes in the fissures, sometimes in the eroded area. Examination of these spots showed small masses of thrush fungi, which were easily brushed off. The mucous membrane bled freely and gave great pain each time the child was put to the breast. By the use of boric acid solution and applications of 8 per cent. solution of nitrate of silver to the fissures and eroded surfaces, supplemented by dry boric acid used as a dusting powder in the intervals of nursing, a cure was effected within a week.

Syphilis of the nipple and areola is discussed in the section upon "Syphilis of the Breast," and need receive no added mention here. 
Diphtheritic Thelitis.-Diphtheria of the nipple and areola has occurred in rare instances through nursing infants suffering from diphtheria. Billroth (Encyclopedia, Obstet. and Gynecol., 9, I8, p. 731) mentions an interesting example of the disease arising in this manner and Caddy (Brit. Med. Jour., 2893, I, 457) has reported a similar case.

In the latter case the mother was warned against the danger of suckling and was advised to wean the infant, which she refused to do. The condition of the child began to improve on the fifth day of the disease but about the same time the mother began to complain of pain in the left breast and axilla. Both regions were tender to the touch. The breast was swollen, hard and tense. The nipple projected prominently and was covered with a tough grayish-white membrane that extended as far as the outer edge of the areola and beyond it toward the axilla. There were three other pseudo-membranous patches around the outer edge of the areola and a line of membrane along a fissure from the nipple outward. The membrane was coherent and on removal left a bleeding raw surface. The temperature reached $103.2^{\circ} \mathrm{F}$. The disease yielded to treatment and improvement began on the fourth day.

Pseudo-diphtheria of the Nipple.- One of our illustrations shows an interesting and, so far as we know, an unique case of pseudo-membranous disease of the breast. The patient was admitted to the Philadelphia General Hospital, Aug. 20, I9I4, in the service of Dr. E. Hollingsworth Siter, suffering from active secondary syphilis and in the seventh month of an illegitimate pregnancy. The mammary complication developed while the patient was in the hospital and occupied a bed beside another woman who developed pharyngeal diphtheria about the same time that her own mammary lesions occurred. This led to the supposition that the breast of the one patient became infected from the mouth of the other. A bacteriological examination of the lesion of the breast showed "pseudo-diphtheria bacilli," though true diphtheria bacilli were present in the throat of the other patient.

The disease began with pain in the breasts, followed by a considerable discharge of pus from the regions, of the nipples. The areolæ soon became covered by a white pseudomembrane that did not spread to the nipples.

\section{CYSTS OF THE NIPPLE AND AREOLA.}

Cysts of the nipple are rare and interesting. Pèraire (Bull. et mém. soc. d'anat. de Paris, I9ro, LXXV, 931) reports the following case:

A woman aged 65 years, mother of six children, had for three months a hemorrhagic discharge from the nipple followed by swelling. Upon mination, the nipple was found to be strongly retracted, swollen, blackish in color and surmounting an induration. There was no enlargement of the axillary nodes. Supposing the case to be one of cancer, the breast was amputated. When it was subsequently examined, no cancer was found, though other conditions of great interest were present. The nipple was 'the seat of a cyst from which reddish fluid spurted ont under pressure as it was incised. The cavity had a smooth wall, from the middle of which two polypoid excrescences grew. They had a reddish color and resembled fleshy buds. They were continuous with a kind of dense glandular tissue below. A report of the microscopic examination of this curious condition was promised at the close of the article, but seems not to have been made.

Sebaceous Cysts of the Nipple and Areola.-What is said about the cysts at this point must be looked upon as supplementary to the chief discussion upon the subject, which is to be found in our section upon cysts of the breast (q.v.).

Birkett (Guy's Hospital Reports, I 859) tells of a woman of middle age with a tumor 6 inches in diameter, and of ro years' duration, situated close to the right nipple. It was removed and was found to be a cyst filled with serous fluid with cholesterin crystals. It was thought to be an atheroma of the areola. 
Winckel ("Lehrbuch der Frauenkrankheiten," 1886, p. 740) cites Russel, without reference, as having seen an atheroma of the areola.

Lebert (Bull. et mém. soc. d'anat. de Paris, I852, p. 42) speaks of having "seen a case of sebaceous cyst of the breast, in Germany." Winckel refers to this case as one of atheroma of the areola; which is our reason for mentioning it here. The original text of Lebert's paper does not say where it was or give particulars about it.

How frequent sebaceous cysts of the nipple and areola may be, is difficult to say, as they are probably rarely looked upon as being of sufficient importance to publish. The only collection of cases that we have found in the literature is by Thomas Bryant in his "Diseases of the Breast," London, I887, p. 332. He reports four cases as follows:

I. A woman of 32 years of age, with a sebaceous cyst in the areola of the right breast that had been coming for months. He turned it out of its bed, as a whole, by pressure, through an incision, and the case did well.

2. A woman aged 42 years, at Guy's Hospital, who had a tumor hanging from the areola of the left nipple. It was pedunculated and the size of a small nut and had existed for three and a half years. When removed it turned out to be "of a sebaceous kind."

3. A woman aged 22 years, with a sebaceous tumor the size of a nut, above and in contact with the nipple, growing during five months. It had commenced during suckling. He removed the growth by turning it out of its bed. "It was clearly sebaceous."

"4. A woman aged 24 years, mother of one child, consulted about an ulcerating sebaceous tumor on the margin of the areola of the right breast, which she had observed to weeks. - He enucleated the tumor, and the patient rapidly recovered.

Bryant believes that these growths may become the seat of cancer and "remembers an example of epithelial cancer of the areola of a breast of a middled-aged woman, which followed a tumor that had existed for years and broke down. I believed the case at that time to have been one of fungating sebaceous cyst; the interior of the cyst, in its being emptied having become the seat of epithelial cancer in the same way as in the well-known "wens" upon the head or sebaceous cysts on other parts of the body occasionally do." We have found no special confirmation for this opinion in the literature that has been consulted in the preparation of this work, but it is a fact accepted by all pathologists and dermatologists, that squamous-cell carcinomas sometimes originate from sebaceous cysts.

\section{TUMORS OF THE NIPPLE AND AREOLA}

I. The Pedunculated Tumor of the Nipple.-A, rare and interesting tumor of which we have been able to find 33 occurrences recorded in the literature goes by the name of "pedunculated tumor." Of the reported cases, we were unable to determine the side upon which the tumor occurred in 19 , but in 14 cases in which the side is known to us, the tumors were upon the left breast in seven, and upon the right in seven. In Reverdin's case the patient had known of the presence of a little tumor since birth; Sheild's case, an old woman, had the tumor the "greater part of her life." Cliet's patient had had the tumor since the occurrence of menstruation 30 years before coming under observation; O'Ferrall's patient also dated the appearance of the tumor from the occurrence of menstruation; one of Hutchinson's patients had had the tumor for "many years;" MacSwiney's patient dated the appearance from the time of the menopause, six years before coming under observation; Shaw's patient had had the tumor for to years before coming under observation. It seems, therefore, that the pedunculated tumors may be congenital, may occur at the period of puberty, at the menopause, or at any other time, and that they may be of indefinite duration. The first appearance is that of a wart (Dreydorff, 
Green, Lepage.), on or near the nipple, that grows slowly and indefinitely. The tumors occur in unmarried as well as in married women. In the cases reported by Pilz and Sendler, the tumors grew larger during the menstrual periods. In the latter the tumor enlarged during pregnancy, as in Schmidt's case, or with each succeeding pregnancy as in Green's case.

The tumor seemed to involve the entire structure of the nipple in the cases reported by Eberhardt and by Schmidt, who looked upon it as a form of hypertrophy of the nipple. In six cases the tumor is said to have grown from the tip of the nipple, in two cases from its side, in two cases from its base, and in five cases from the areola close to

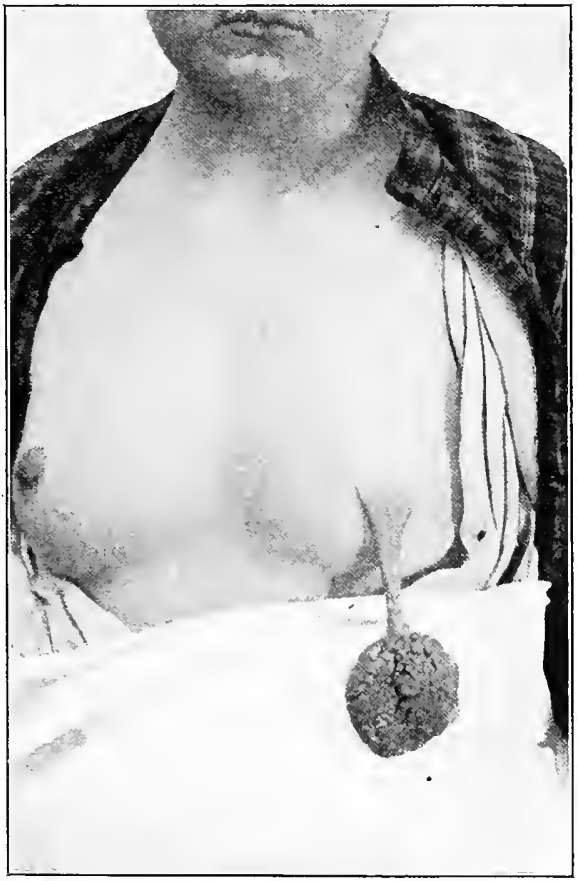

FIG. 276.-Pedunculated tumor of the nipple. (Hertzler.)

the nipple. One of the patients observed by Hutchinson had the tumor growing from the areola above the nipple, and always had to lift it up, and hold it out of the way, when her baby nursed.

Beginning with an appearance like a small wart the tumor enlarges and becomes nodular like a strawberry or more coarsely nodular like a pineapple. When very large it becomes so very nodular and complicated as to resemble a cauliflower. The size attained is rarely great. Cliet's patient, at puberty had a little tumor like a strawberry hanging from the extremity of the left nipple; at 45 years-30 years later-it had 
become the size of the fist. The tumor removed by Dreydorff, measured 10 $\mathrm{cm}$. in length. They are usually attached by a slender pedicle that may be several centimeters long, and in which, as in the cases reported by MacSwiney, O'Ferrall, and Shaw; pulsating arteries may be felt. In the specimen in the Prague collection, 495, examined by Klebs, milk ducts could be recognized in the pedicle, and when the tumor grows from the entire nipple, these may continue to the surface, as in Eberhardt's case where warty nodules on the surface of the tumor each contained the orifice of a milk duct.

The microscopic structure of the tumors has been studied in a few cases, but erroneous conclusions seem at times to have been made. Thus Salzac in his thesis, "Papillomes cutanée du mamelon," Paris, I903, described and figured the microscopic structure of the tumors he examined and concluded that they were papillomas, in which opinion he said he was supported by Cornil. The drawings, however, do not show the structure now recognized as papilloma, but rather that of a fibromatous or fibromatoid tumor, covered with a thickened epiderm. Various writers have called the tumors examined by them "fibro-cellular," "fibro-vascular," "fibroma," and three have supposed them to be the result of "hypertrophy of the glands of Montgomery." The last theory is not supported by any microscopic examination. Porter describes his case as an "erectile tumor of the nipple;" Jamain and Terrier, and Sendler call their cases "angioma cavernosum pendulum mamillæ." The fibro-vascular structure of the tumors doubtless explains the varied nomenclature.

Bryant saw a pedunculated sebaceous cyst, but we do not include it in the present category.

The tumors are rarely the source of pain or annoyance. They may, however, become troublesome when they become so large and heavy that their weight exerts painful traction upon the pedicle, when their size makes it difficult to avoid painful pressure by the clothing, or when they suffer from mechanical injury. The most objectional feature, however, is the tendency of epithelial cells, and secretions from the skin to collect in the irregularities of the surface and occasion irritation and the evolution of a disagreeable odor.

There is no reported case in which one of these tumors has become transformed to a malignant tumor, nor is there a reported case of return after removal. They are, therefore, perfectly benign.

To give an idea of the general course and appearance of these tumors, the following cases may be cited:

Cliet (Obs. méd. chir. Lyon, $\mathbf{r} 823, \mathrm{II}, 80$ ) observed a woman aged 45 years, who at 15 years of age, when menstruation began, first observed a little tumor, having the appearance of a strawberry, suspended from the extremity of the left nipple by a slender pedicle. It gradually increased in volume until it attained to the size of the fist, when she had occasional pain in the pedicle which was a little more than an inch long and about the diameter of the little finger and resembled an umbilical cord in general appearance. The tumor was inactive, and was composed of lobes, separated from one another by sulci, like the convolutions of the cerebrum. Between the convolutions a sebaceous matter collected and threw off a peculiar odor "sui generis." The pedicle was cut through with scissors close to the nipple; the little wound healed kindly.

Dreydorff (Münchener med. Wochenschrift, 1905 , LII, 557) observed a woman 32 years old, who had observed a little wart on the nipple eight years before. It grew slowly, lost the pigment that at first made it correspond with the nipple in appearance, and formed a coarsely nodular mass $\mathrm{ro} \mathrm{cm}$. in length. Deep sulci separa ted the lobules, that were covered with epidermis. It was never painful except when the clothing compressed it or dragged upon the pedicle. The pedicle was compressed with a Collin's tongue forcep, eucaine was applied, and the tumor cut off. Four stitches were used to close the wound that healed kindly. 
Ehrhardt's case (Zeitschrift für Chirurgie, $1899, \mathrm{~L}, 373$ ) is of special interest. The patient was a woman 59 years of age, in the hospital for inoperable carcinoma of the esophagus for which gastrostomy was performed. At the same time, the right nipple, which was badly diseased, was also removed. It was the seat of a pedunculated papilloma, $7 \mathrm{~cm}$. long, and $\mathrm{I} \mathrm{cm}$. thick, whose distal end was about three times the diameter of the stalk and covered with a number of warty formations-about 20 in all. On the summit of each wart was a sunken area, somewhat eccentric in position, and much like a pin prick in appearance, that was the opening of a milk duct. Both breasts and nipples had been normal until after the birth of the third child, when, without apparent cause the right breast swelled and gradually assumed its present form. The transformed nipple is still somewhat erectile, though this quality is now shown only through shortening the pedicle. He does not regard it as a tumor, but as a hypertrophy of the nipple and can find no case in the literature that even remotely resembles it except one reported by Coyne (to which no reference is given). We may be mistaken in presuming this to be a pedunculated tumor of the nipple, but it certainly has much in common with tumors of this class.

MacSwiney (Dublin Journal of the Medical Sciences, I875, LIX, 484) observed a woman 50 years of age and unmarried. Since the menopause that took place about six years before, a wart immediately adjoining the right nipple began to grow and has increased in size to form a pendulous tumor 6 or 7 inches long including the pedicle with a bulbous extremity between 5 and 6 inches in circumference. It never caused her any inconvenience of any kind, and she never told any one about it. A few weeks before coming under observation it became sore from abrasion of the cuticle, and from time to time a muddy fluid exuded and soiled the linen. The pedicle sprang from the areola, al most from the nipple and included the greater part of the latter. It was of the normal color. An artery could be felt pulsating in the pedicle, as in the umbilical cord of a child. The bulbous extremity was warty, fissured and indented, purplish in one part, grayish in another and perfectly white in the deep indentations. From the abraded portions an extremely malodorous fluid exuded. It was regarded as benign and removed.

O'Ferrall (Dublin Journal of the Medical Sciences, I847, IV, 329) reported the case of a woman 27 years of age and unmarried, who had a tumor growing from the right breast close to the nipple, carrying with it the integument peculiar to that part. The pedicle was about 2 inches in length and of a dark red color. It was funnel shaped, 1/3 inch in circumference at its upper part and very near an inch below. From this part it suddenly expanded into a tumor 5 inches in circumference of an extremely irregular figure, presenting clefts and elevations and having very much the appearance of a walnut shell, but fully double its volume. The color of the tumor was pale gray on the prominences; in the clefts it was a dark gray and here a sebaceous secretion of a remarkably fetid odor was accumulated. This fetor was, to the patient a greater source of annoyance than the bulk of the tumor itself. The consistence of the tumor was fleshy and equal; that of the pedicle was softer and in it the pulsation of a very small vessel could be felt. She stated that this tumor had been observed before the period of menstruation and that its increase in size since that time had been progressive. She had some trouble to prevent its being injured by the clothing and was hitherto most anxious to conceal it. The principal uneasiness it occasioned was that arising from the offensive odor of the secretion which constantly bedewed the fissures of the tumor. A silk thread was applied around the pedicle a short distance from its attachment and tied with a degree of tightness barely sufficient to prevent the escape of blood from the vessel. The pedicle was then divided and the cut surface touched with nitric acid which caused very little and only momentary pain. The thread was removed after six hours. No oozing, whatever, of blood took place. It completely cicatrized in a few days and left no trace of its existence in the hreast.

Reverdin (Bull. et mém. de la soc, d' anat. de Paris, 1867, XLIII, 540) observed a woman aged 40 years who had, since birth, a little tumor on the right breast that never sensibly increased in size. At the age of 16 she desired to have it removed and applied to Velpeau who declined to disturb, it. She experienced no trouble until about two months before coming under observation when she suffered a traumatic accident to the breast in endeavoring to move a bedstead. The tumor having been abraded at the time of the accident, became the seat of frequent hemorrhages. It is about the size of a pineapple strawberry (fraise ananas) and resembles the large vegetations that sometimes make their appearance on the vulva. The surface was irregular and nodular and the tumor was slightly flattened antero-posteriorly. It was suspended by a pedicle about $2 \mathrm{~cm}$. long, that was continuous with the tissue of the areola. Its color was reddish gray with a black spot-over a blood clot. The patient never observed that the tumor changed its size or color during menstruation. It was removed and she recovered perfectly.

Shaw (Trans. Path. Soc., London, I850-5I, III, I86) reported the case of a woman 44 years of age, whom he treated in the Middlesex Hospital, London. Ten years before, a small wart appeared on one breast and grew slowly becoming a pedunculated tumor that hung to the breast by a pedicle the thick- 
ness of the finger and about $\mathrm{x} / \frac{1}{2}$ inches in length. The tumor was about the size of and nearly the shape of the mammary gland.

It was removed by cutting the pedicle across with a scalpel, and after removal weighed 5 ounces. It was composed of five distinct portions, four of which were lobes somewhat pear-shaped, united loosely together at their apices, near the center, where the pedicle was situated. Each lobe was composed of a cluster of lobules of a similar shape, varying in size from a currant to that of a cherry, and attached to each other by short stems; the remaining portion was a compact mass irregularly fissured on its surface, or studded with numerous small rounded lobules like peas. In the pedicle an artery could he felt pulsating. The tumor was of a pale pink color but when the pedicle became twisted, as it was apt to do, the color changed to a dark purple, increased in size and became painful, and discharged some serous fluid; sometimes blood. The skin of the pedicle resembled that of the areola from which it was prolonged; the covering of the tumor had more the character of mucous membrane resembling that of the excrescences in enlargement of the clitoris and nymphx. It was insensitive to the touch. On injecting and afterward making sections of the tumor, the central part presented a whitish homogeneous appearance with a surface as smooth as cartilage, with a firmness like that of a kidney; a few vessels only ran through that part, while along the exterior border, under the cuticular lining, the structure for $1 / 8$ inch in thickness, was red and vascular. On submitting fine sections to microscopic examination, they were found to consist of fibrous tissue.

It scarcely seems worth while to go more extensively into case reports that are so similar. Readers particularly interested in the subject will find their way to additional information by means of the references given below.

The tumors are easy to diagnose, and the treatment is simple. Local anesthesia may be all that is necessary to enable the pedicle to be cut and the tumor removed. Large vessels in the pedicle may need to be tied, two or three stitches may be necessary. Perfect cure may be expected.

\section{Literature upon Pedunculated Tumors of the Nipple and Areola}

BIDDER.— "Fibroma pendulum mammillæ," Deutsche med. Wochenschrift, r884, X, 40.

Bryant, Thomas. - "Diseases of the Breast," London, r887, p. 333. Briefly outlines two cases seen in his practice, and mentions one in the Museum of Guy's Hospital, London.

Cliex.- "Tumeur pedonculée, du volume d'un poing, suspendu au mamelon droit, opérée avec succes," Obs. Med. Chi. Lyon, I823, pt. 2, 8o.

Coyne.-Cited without reference by Ehrhardt, as having seen a case.

DREYDORFF, H.- "Eine Brustwarzengeschwulst," Münchener med. Wochenschrift, rgo5, LII, 557.

EHRHARDT.- “Über Geschwülste der weiblichen Brustwarze," Zeitschrift für Chirurgie, I889, L, 373.

Green, G. D.- "Lobulated-fibroma of the Nipple," Trans. Path. Soc., London, r897-98, XIIX, 308.

HENRY.-Cited without reference by Shaw, as having operated upon a case.

HertzLer, A. E.- "A Treatise on Tumors," Phila., Igr 2. Gives a beautiful photograph of such a tumor with no mention of the case in the text.

Hutchinson, Jonathan.- "Polypoid Tumors of the Nipple-Areola," Archives of Surgery, r897, VIII, 36, pl. CLXIII and CLXIV. Mentions four cases.

Jamain et Terrier.- "Angioma cavernosum pendulum mamilla," Pathologie et clinique chirurgicales, 1882.

KaLISCHER.- "Fibroma pendulum mammillæ," Berliner klin. Wochenschrift, I884, XXI, 44.

Kerr.- "Cauliflower Excrescence of the Nipple," Report of the Medical Missionary Society in China, 1874 , Canton, 1875,9 .

KLEBS.- "Handbuch der path. Anatomie," I876, I, 2 aht., p. I225. States that there is an example of this affection in the collection at Prague, No. 495. In section one can recognize milk ducts in the long pedicle.

LEPAGE, G.- "Petite tumeur du mamelon rendant succion impossible; ablation; guérison," Compt. rendu, soc. d'obst. et de gynécologie et de Pédiatrics de Paris, r903, V, r92.

MacSwiney.- "Pendulous Tumor of the Mammary Areola," Dublin Jour. Med. Sciences, r875, LIX, 484 .

O'Ferral.- "Pedunculated Tumors of the Nipple and Areola," Dublin Jour. Med. Sciences, r874, IV. 329. 
Pilz, E.- "Ein Tumour der Brustwarze," Wiener klin. Wochenschrift, r\$89, II, 52 r.

Porter, F. T._ "Erectile Tumor of the Nipple," Irish Hospital Gazette, Dublin, r873, I, 30.

Reverdin.- “Tumeur papillaire pedunculée de l'areole du sein: ablation," Bull. et. mem. de la soc. d' anat. de Paris, I867, XIII, 540.

Salzac, E.- "Papillomes cutanées du mamelon," Thèse Paris, I903 (two cases).

Schurdt, G. B.—“Die Geshwülste der Brustdrüse,” Brun's Beiträge zur klin. Chirurgie, ı888, IV, 76.

Sendier.- "Ein Angioma cavernosum pendulum der Mamilla," Verhandlungen der deutschen Gesellschaft für Chirurgie, Berlin, I889, XVIII, 37 .

SHAw.- "Tumor Attached by a Pedicle to the Areola of the Left Breast," Trans. Pathological Society of London, 1850-51, III, 186.

SHerld, A. M.- "Pedunculated Fibroma of the Nipple," Brit. Med. Jour., June 20, I 896, I, I499.

Sherld, A. M.- "Diseases of the Breast," I898, London, I4. He cites the following Museum specimens of pedunculated tumors of the nipple No. 1456, in the Museum of St. Mary's Hospital; No. $209 \mathrm{I}$, in the Museum of the Middlesex Hospital.

Williams, W. R.-“Diseases of the Breast," London, I894, p. 491 . Cites a specimen No. 489 I A. in the Hunterian Museum.

2. Fibroma of the Nipple.-Winckel in his "Lehrbuch der Frauenkrankheiten," I 886, p. 740 , states that out of 2500 confinement cases, he observed one patient with a small fibroma of the nipple. He gives no description of the tumor, and no protocol of the case. It may, like that described by Lepage, have been pedunculated or may have been the starting point of a pedunculated tumor of the nipple. Concerning it nothing more can be said, and it remains an isolated observation.

3. Myoma of the Nipple.-Leiomyoma of the nipple, growing from the unstriated muscle tissue of that organ, is a very rare tumor of which very few cases appear in the literature. The first case appears to have been observed and studied by Virchow (Virchow's Archiv, I854, VI, 553).

The patient was a man aged 32 years, who in 13 years developed a cherry-sized nodule surrounded by i I smaller ones beside one nipple. Each consisted entirely of smooth muscle cells among which were so many blood-vessels, that he called them "telangiectatic myomas."

Solokow (Virchow's Archiv, 1873, LVIII, 3i6) observed a rounded ulcerated tumor the size of a small apple that grew from the inner border of the nipple of a woman aged 24 years. Upon microscopic examination it proved to be a pure leiomyoma growing from the normal muscle of the nipple. It was of two years' duration.

Axel Key and Santesson (Hygiea, I880) reported a case of myoma of the male breast, but we have been unable to refer to the original contribution for details.

Niklas in 1889 , published an Inaugural Dissertation upon "Leiomyoma mammæ, seine Gewebsstructur verglichen mit der Uterusmyoma," Würzburg, I889, but again, we were disappointed in not being able to obtain access to the publication. Klob (Path. Anat. der weiblichen Sexorgane, 1864 ) also describes a myoma of the nipple, but again we are unable to secure access to the text. Heibaum (Prager med. Wochenscbrift, $1895, \mathrm{XX}, 315)$ published with illustrations, a case of a cystic myoma of the base of the nipple, in a 44-year-old woman, mother of 1 i children. It formed a small, firm, uneven node. J. Bland Sutton ("The Practitioner," November, 1897 ) described a specimen in the Museum of the Middlesex Hospital; it was removed by Dr. Henry from a woman 40 years of age, and formed an orangesized mass attached to a pedicle. It is thought that the tumor was congenital, and it is said to be a fibromyoma mamilla.

4. Sarcoma of the Nipple.- The only reference of sarcoma of the nipple that has come under our observation is that made by Klebs (Handbuch der pathologgisch. Anatomie, I876, I, abt. 2, p. I225) to specimen 456 in the pathological collection of the University of Prague. He describes it as an ulcerated large-cell sarcoma of the nipple, the size of half a walnut, situated on the side of an elongated and thickened nipple. The large spindle cells are separated by narrow bands of interstitial connective tissue, and the tumor contained extraordinarily large and thin walled blood-vessels. 
5. Intra-cystic Papilloma of the Nipple.-Robinson (Transactions of the Pathological Society of London, $\mathrm{r} 890$, XLI) described the following case of this rare infection:

The patient was a woman 46 years of age, who had had for three years a little tumor in and beside the left nipple, that gradually attained to the size of a hazelnut. Three months before coming under observation it began to swell and cause considerable pain. When pressed upon, some fluid escaped from the nipple. A tumor occupied the upper outer quadrant of the breast, and numerous small nodules could be felt. The breast was amputated. When examined it was found that the tumor of the nipple consisted of dilated milk ducts with papillary excrescences from the cyst walls, each covered with a single layer of columnar epithelial cells. The breast elsewbere contained cysts flled with brownish and bloody fluid.

Pollard (Trans. Path. Society of London, r886, XXXVI) observed a woman 50 years of age, mother of six children. Twelve years before coming under observation, and during a pregnancy, she observed a bloody discharge from the left nipple. Three years later a little excrescence appeared and projected from the tip of the nipple. It was repeatedly treated by snipping it off, ligating it, or brushing it with caustics. A year ago a hard node was found in the lower outer quadrant of the breast, which was then amputated. The case turned out to be a duct papilloma that grew out through the nipple to appear externally as well as into the deeper ducts which it dilated, and where it formed the starting point of carcinoma.

Linfors (Monatschrift für Geburtshülfe and Gynäkologie, rgoo, XI, 763) observed a young woman of 28 years who had had a little vesicle at the tip of the left nipple for about $\mathrm{r} 8$ months, during which time it grew to the size of a hazelnut. It formed a tense elastic ovoid, broad at the top and constricted at the base. The skin covering it showed fne injected vessels, and at the summit there was a thin transparent area. It was excised, and there was no return after three years. When the excised portion was subjected to microscopical examination, it was found that the formation was composed of cystic milk ducts from the walls of which papillary excrescences grew. The breast was otherwise apparently normal and the axillary glands were normal.

6. Squamous-cell Carcinoma or Epithelioma of the Nipple.-This form of cancer may arise from the squamous epithelium covering the nipple and areola, but probably more frequently arises from the invagination of the epithelium that descends the milk ducts to join the columnar epithelium near the ampullæ. In spite of the traumatic and infectious disturbances that so frequently affect the nipple, squamous-cell carcinoma of its tissues is rare. It is to be differentiated in the mind of the reader from the malignant dermatitis of the nipple and areola usually called "Paget's disease" that is to be considered below.

The disease occurs in both sexes and at various ages, but the number of reported cases is so small that few generalizations can be made.

Battle and Mayberry (The Lancet, London, I913, I, 22) have reported a case that occurred in a little girl $\mathrm{rr}$ years of age. The tumor formed a node of hazelnut size. It was removed and its malignant disposition was shown through local recurrence and metastasis to the lymph nodes. Histological examination of the tissue showed the tumor to be squamous-cell carcinoma.

Kroell H. (Praktischer Arzt. Wetzler., I878, XIX, 25; 49) was consulted by an unmarried woman 28 years of age who had a linear ulcer several millimeters long on the outer side of the right nipple at the junction with the areola. She later married and became pregnant, when the ulcer enlarged and deepened. She nursed the child from both breasts in spite of the ulcer. Two years later, the lesion was still linear in shape and $\mathrm{I} .5 \mathrm{~cm}$. in length. It was excised, and when examined by von Recklinghausen, was found to be a cancroid-i.e., squamous-cell carcinoma. It no doubt arose from the skin.

The other type of tumor, that arises from the termination of the milk ducts can be exemplified by the case reported by Morestin (Bull. et mém. de la soc. d'anat. de Paris, r907, LXXXII, 608). The patient was an unmarried woman aged $47^{\circ}$ years who came for medical advice because of a change in the size and appearance of the right nipple associated with enlargement of the right breast. The nipple had lost its elasticity, was almost rigid, was enlarged, but was neither sensitive nor tender nor was there any bleeding. The gland was firm and somewhat indurated. The axillary nodes were not enlarged. It was thought that the disease was "maladie du Reclus." The breast was removed, and Cornil studied 
the tissues microscopically. He found a squamous-cell carcinoma beginning in the termination of the milk ducts, centering in the nipple, and descending into the tissues of the breast.

Bruch d'Alger (Bull. et. mém. soc. de chirurgie de Paris, 1885) observed a man 44 years of age with a hard tumor of the nipple. It was removed and examined microscopically, and found to be a squamouscell carcinoma with cornified cells and some calcification.

7. Carcinoma of the Nipple-Cancer of the Nipple.-A number of cases appear in the literature under this caption, some of which must at once be eliminated as belonging elsewhere. Thus, cancer of the nipple in a man, commonly turns out to be a carcinoma of the male breast (glandular cancer) that has destroyed the nipple. Cancer of the breast may extend along the ducts or along the lymphatics so as to invade and destroy the nipple, yet have no primary relation to that structure at all. In case the disease of the nipple should outweigh in visible importance the more deeply seated disease of the breast, the condition might appear in print as "cancer of the nipple." It is difficult to account for primary cancer of the nipple, as its histological structures are not such as lead to cancer development. Presumably the disease arises in close juxtaposition to the nipple, though really apart from it, and at once invades it.

Making every effort to eliminate cases not properly falling in the group-i.e., all cases of squamous-cell carcinoma, of Paget's disease, of papillary cystic dilatation, etc., we find cases reported by the following:

Batties.-Trans. Path. Soc. London, I888, XXXIX.

Brodie, Sir Benjanin.- "Lectures on Pathology and Surgery," London, i 846.

Cooper, Sir Astley.- "Principles and Practice of Surgery," London, r8 36 , II.

Hauser.-Inaugural Dissertation, Heidelberg, i 806.

KARG.-Deutsche Zeitschrift für Chirurgie, XXXIV.

Oldekopp.-Archiv für klinische Chirurgie, XXIV, 547.

Robinson.-Trans. Path. Soc. London, I890, XII.

Schmrd.-Brun's Bẹiträge zur klinischen Chirurgie, IV.

In addition to these cases Sheild ("Diseases of the Breast," London, I 898) mentions a case of Prescott-Hewitt, of which the specimen-No. I3A, series B-is now in the Museum of St. George's Hospital in London, that was a cylindrical-cell' carcinoma growing from the milk ducts and invading the nipple.

Schreiner (Buffalo Medical Journal, I9I 2, LXVIII, 509) reports the case of

a woman aged 42 years who for about a year had a lump in the left breast with enlargement of the left breast and left nipple. After operative removal, the tissues were examined, and no malignant disease discovered except that below the enlarged left nipple there was a cylindrical-ceil carcinoma of hazelnut size and alveolar structure, growing from the cells of the milk ducts.

Hoffman, M. B., has published a paper entitled "Über Carcinoma der Mamilla," München, I905, but it was not available to us. The same was true of what ought to be an interesting paper. . . Moriri, K., "Two Cases of Cancer of the Nipple in Male Children," Chiba Igakukwai Zasshi. Tokyo, I9oI, No. 48, 4-I2.

Mandry, G., "Primäres Carcinom der Brustwartze," Beiträge zur klinischen Chirurgie, Tübingen, I893, X, 23 I, reports a case:

A woman aged 6I years, who injured the left breast two years before coming under obscrvation, and gradually developed a nipple on that side that was broad and flat, felt hard and presented over the greater part of the surface a llat, slightly bloody ulcer that extended here and there to the areola. The tissues about the nipple, to a breadth of $1 / 2$ to $\mathrm{I} \mathrm{cm}$. were infiltrated, and the skin was bluish and moist. Beyond the areola the skin was normal. The breast seemed normal, but in the left axilla there were two pea-sized hard lymph nodes. The breast was removed. Microscopic examination was made, and the tumor was looked upon as primary carcinoma of the nipple. 


\section{Weil, J. (Prager med. Wochenschrift, I893, XVIII, 8I) reports a case:}

A woman aged 4r years, to years married, mother of five children, all of whom she nursed. Five years before coming under observation she observed a node slowly growing at the tip of the left nipple. It gave no distinct pain, hut for a short time had been constantly moist. The left breast, when examined appeared normal, except that the areola was moist and macerated and that at the tip of the nipple there was a knob-shaped tumor of almost cartilaginous hardness. It was flattened, rounded, measured 0.5 by $3 \mathrm{~cm}$. in diameter, and was excavated at the center. A diagnosis of carcinoma of the nipple was made, and the breast was amputated. When examined microscopically, the tumor was found to be carcinoma of the nipple.

Paget's Disease of the Nipple or Malignant Papillary Dermatitis.-In the "Leçons orales du clinique Chirurgicale faites a l'Hôspital de la Charite," I840-4I, II, Velpeau described a "scabby degeneration of the nipple" in the following words:

"Dégénérescences Croûteuses-Le mamelon se couvre quelquefois d'une affection squammeuse, tenant le milieu entre l'eczèma chronique et la psoriasis. Je l'ai observée deux fois chez dames qui avaient depuis long temps cessé d'allaiter. Les croûtes qui recouvraient l'organe étaient d'un gris verdâtre dans un cas, d'un gris jaunâtre dans l'autre, assez épaisses, fendillées et adhérents. Dés qu'on cherchait à les détacher, on voyait survenir sur les petites plaies un suintement sanguin assez abondant."

It is thought by Wiggin and Fordyce, and by Jopson and Speese, that the condition thus described, was the first published account of the disease in question, but it attracted no attention, and the condition was not recognized as a disease until after Sir James Y. Paget, published his description of it in the St. Bartholomew's Hospital Reports, London, I $874, \mathrm{X}, 87-89$, in the following words:

"I believe it bas not yet been published that certain chronic affections of the skin of the nipple and areola are very often succeeded by the formation of scirrhus cancer in the mammary gland. I have seen about ${ }_{5} 5$ cases in which this has happened, and the events were in all of them so similar that one description may suffice.

"The patients were all women, various in age from 40 to 60 or more years, having in common nothing remarkable but their disease. In all of them the disease began as an eruption on the nipple and areola. In the majority it had the appearance of a florid, intensely red, raw surface, very finely granular, as if nearly the whole thickness of the epidermis were removed; like the surface of very acute diffuse eczema, or like that of an acute balanitis. From such a surface, on the whole or greater part of the nipple and areola, there was always copious, clear, yellowish viscid exudation. The sensations were commonly tingling, itching, and burning, hut the malady was never attended by disturbance of the general health. I have not seen this form of eruption extend beyond the areola, and only once have seen it pass into a deeper ulceration of the skin after the manner of a rodent ulcer.

"In some of the cases the eruption has presented the characters of an ordinary chronic eczema, with minute vesications, succeeded by soft, moist, yellowish scabs or scales, and constant viscid exudation. In some it has been like psoriasis, dry, with a few white scales slowly desquamating; and in both these forms, especially in the psoriasis, I have seen the eruption spreading far beyond the areola in widening circles, or, with scattered blotches of redness, covering nearly the whole breast. I am not aware that in any of the cases which I have seen the eruption was different from what may be described as long persistent eczema, or psoriasis, or by some other name, in treatises on diseases of the skin; and $I$ believe that such cases sometimes occur in the breast, and after many months' duration are cured, or passed by, and are not followed by any other diseases. But it has happened that in every case which $I$ have been able to watch, cancer of the mammary gland has followed within at the most two years, and usually within one year. The eruption has resisted all the treatment, both local and general, that bas been used, and has continued even after the affected part of the skin has been involved in the cancerous disease.

"The formation of cancer has not in any case taken place first in the diseased part of the skin. It has always been in the substance of the mammary gland, beneath or not far from the diseased skin, and always with a clear interval of apparently healthy tissue. In the cancers themselves, $I$ have seen in these cases nothing peculiar. They have been various in form; some acute, some chronic, the majority following an average course, and all tending to the same end; recurring if removed, affecting lymph glands and distant parts, showing nothing which might not be written in the ordinary history of cancer of the breast. 
Plate VIII

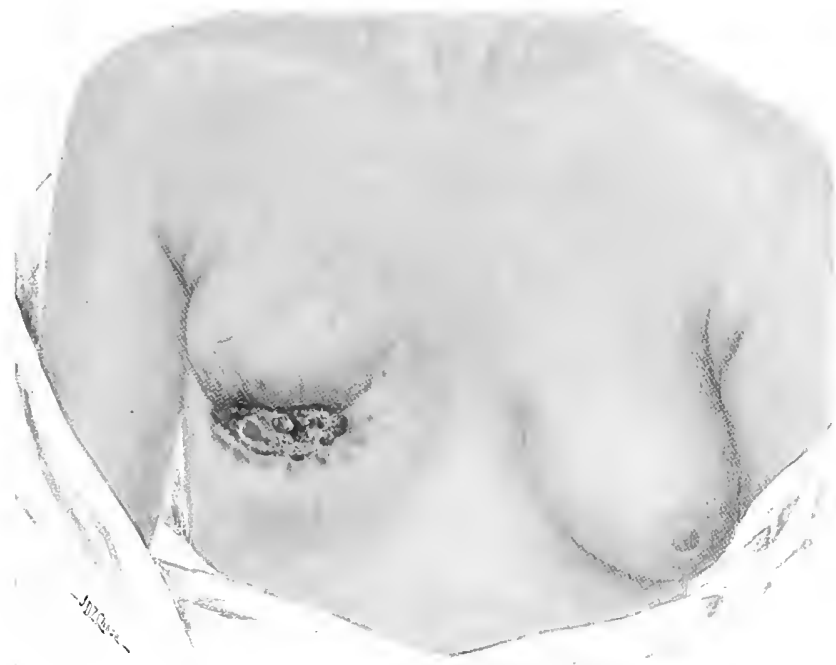

Paget's disease. (Hirst.) 

"The single noteworthy fact found in all these cases is that which $I$ have stated in the first sentence, and I think it deserves careful study."

From the appearance of this contribution to the present time, increasing interest has been taken in the disease, which has become universally known as Paget's disease, and many case reports, pathological studies and monographs have appeared in print. How frequent the disease is, is difficult to say for not all cases, by any means, have been published, and doubtless many of the cases that have been published as such are not what is now recognized by pathologists as Paget's disease. The literature appended to this section contains references to approximately 300 cases of what has been recognized as Paget's disease by those who have studied and reported them, about 250 having probably been the real thing.

The description given by Paget shows that the clinical appearance of the ${ }_{5} 5$ cases that he observed was not uniform, and leaves one in some doubt whether all of his cases were of precisely the same nature. A review of the cases since reported, and an examination of a number of specimens that surgeons have considered to be Paget's disease, lead to the inevitable conclusion that several different conditions, having different origins and a different pathology are confused with it. To Paget, to many later, and to some present-day surgeons and dermatologists, the disease is a clinical entity, with fairly definite clinical manifestations; to pathologists, and to most dermatologists, Paget's disease is a definite pathological entity with characteristic histological changes.

The first histological studies were made by Butlin (Medico-Chirurgical Transactions, London, I876, IX, ro7) upon two of Paget's own cases, so that it may be assumed that there can be no doubt of the clinical diagnosis of the lesions being correct, and two other cases operated upon by Savory and Smith. Butlin believed that he was able to show a direct relationship between the eczematous condition "of the skin" and the subsequently developing carcinoma in the breast. What he described was amplified by later studies, especially by Bowlby (Medico-Chirurgical Transactions, London, I89o-9r, LXXIV, 34I) who examined the tissue of 13 cases in all of which he found a histological appearance that tallied with what Butlin had described, and that may, therefore, by inference, be regarded as typical of the disease. In his "Surgical Pathology and Morbid Anatomy," Chicago, I 907 , p. 476 , Bowlby writes as follows:

"The nature of the process has been carefully described by Mr. Butlin; and in I3 breasts which I have myself examined I found nearly the same conditions that were seen by him.

"The process originates in an inflammation of the derma, with small cell exudation beneath the epithelium. The latter, in its turn, is implicated, its cells being loosened from one another by fluid exudation, and finally cast off. The derma being exposed, the inflammatory process advances more rapidly, and proceeds to the formation of pus and the destruction of the true skin. The inflammation now extends along the ducts, causing their epithelial lining to proliferate, the cells sometimes collecting in masses, which fill the tubes. Following this, there is a tendency for the epithelial cells in the acini or ducts to grow out into the surrounding tissue, and to take a cancerous growth, an event which is generally preceded by inflammatory changes in the connective-tissue stroma of the mamma, indicated by exudation of leucocytes and fibrous thickening. The cancerous growth is sometimes directly continuous with the nipple, but is more of ten quite separate from it and placed deep in the breast. It is usually a spheroidalcelled scirrhus carcinoma, though columnar-celled tumors have been described.

"A microscopical examination shows in the epidermis numerous round or oval vacuolated cells, which are most numerous in the superficial layers of the epithelium. These cells are of constant occurrence in the disease, but are not absolutely peculiar to it, being occasionally present in other acute inflammatory conditions, of the epidermis. Paget's disease must not be confused with an eczematous condition of the nipple which is sometimes seen as a sequel to a cancerous growth, and which appears to result from some irritating discharge from the ducts." 
Prior to this work by Bowlby, confirming Butlin, Thin (Trans. Path. Soc. of London, I 88 I, XXXII, 2r8) made careful microscopical studies of several cases of Paget's disease. He showed that there were distinct differences between the microscopic features of true eczema and Paget's disease, but he did more than this, and really was the first to foreshadow one of the present-day controversies of the nature of the disease, for he arrived at the conclusion that the superficial lesions were secondary to the presence of duct carcinoma, and that the changes observed in the skin were caused by the poisonous effect of cancer epithelium in the subjacent connective tissue. He called the disease malignant papillary dermatitis.

It was not long before the dermatologists became interested in the disease and notable contributions were made by Duhring (Amer. Jour. Med. Sci., I 883 n.s., LXXXVI, I 6 ) and Duhring and Wile (Amer. Jour. Med. Sci., I884, n.s., LXXXVIII, I4I) who could not accept Thin's view that the cancer preceded the Paget's disease, presenting in evidence one of Duhring's cases in which the Paget's disease existed for Io years before the appearance of the cancer.

A few years later, the study of the disease received a new and unexpected impetus through the announcement by Darier (Compt. rendu de la Soc. de Biol. de Paris, I889, g.s., I, 294) confirmed by Wickham (Congrès internat. de dermatol. et de syphilis, I889-Archiv de méd. exper. et d'anat. de Paris, I892, II, 46) and Malassez (Archiv. de méd. and exp. et d'anat. Pathol., I 890, No. I02), that "psorosperms" or parasites related to the coccidia were found in and were doubtless the cause of Paget's disease. A lengthy debate accompanied by the study of many cases, and the publication of many papers followed, until it became finally settled that the bodies observed and described by Darier and by Wickham were vacuolated and degenerated cells and not parasites. It should be remembered that the settlement of that question did not prove that Paget's disease was not an infectious disease.

Karg (Deutsche Zeitschrift für Chirurgie, I 892 , XXXIV) came to the conclusion that Paget's disease was a malignant process arising in the epiderm and subsequently invading the deeper tissue of the breast, and believed that he could trace a direct connection between the primary change in the skin and the secondary one in the breast.

Unna ("Die Histopathologie der Hautkrankheiten," Berlin, I894, p. 745) who made careful histological studies of Paget's disease, came to the conclusion that it was unique, differed as much from eczema as from cancer, did not lead directly or of necessity into cancer, but "prepared the soil" in such manner as to predispose to the occurrence of cancer in the course of some years. This view of the disease makes a strong appeal to those who cling to the hope that cancer may eventually prove to be an infectious disease, for surely the superficial dermatitis occurring in Paget's disease may open avenues by which a microörganism might find its way deeply into the breast.

But the most active controversy was still to come. Following the deduction of Thin, that the cancer is the primary condition and the Paget's disease secondary, papers have been published by Jacobeus (Kongress für innere Med., Stockholm, r9o4; Virchow's Archiv, CLXXVIII, I 24), von Schambacher (Deutsche Zeitschrift für Chirurgie, I905, LXXX, 332), von Ribbert (Deutsche med. Wochenschrift, I 905, XXXV, I 218 ) Hirschel (Beiträge zür allg. Path. u. path. Anat., ı 905, VII, Suppl. 573; Münchener med. Wochenschrift, I9ıo, II, 2633), von Kyrle (Archiv für Dermatol. u. Syphilis, I907, LXXXIII, I 87), Hannemüller and Landois (Beiträge zur klin. Chirurgie, I908, LX, 296) and Handley (Choyce and Beattie's "System of Surgery," I g 2 , Vol. II), in support of the second- 
ary nature of Paget's disease. Handley perhaps expresses this view of the disease most clearly in the following words:

"My own views upon Paget's disease may be distinctly stated as follows: A carcinoma which may be either a duct carcinoma or one of the acinous type originates in the breast. Frequently this carcinoma is of the atrophic variety and it has been known that an atrophic scirrhus may be present in the breast for years without producing any palpable lumps. While still in the impalpable stage, the carcinoma may permeate the lymphatics of the breast, many of which may be subsequently converted into solid strands of connective tissue by fibrosis. Considerable disturbance of the lymphatic circulation results, especially in the region of the nipple, which in an aged woman is the most dependent part of the breast. Eczema of the nipple is merely a secondary manifestation of impaired lymphatic return from the skin of the areolar district, though it may precede by some years the stage in which the original carcinoma can be felt as a distinct lump. Eczema as the result of lymphatic obstruction is frequently seen upon the sodden skin of the leg in elephantiasis, and even in venous obstruction is competent to produce a like condition as in the common case of varicose eczema. The swelling and vacuolation of the deeper layers of the epidermis of the areola and the round-cell infiltration of the derm are to be explained as the result of the lymphatic obstruction."

On the other hand, the dermatologists, whose acquaintance 'with the disease is not limited to the nipple and areola, as is that of most of the surgeons, maintain the opinions of Butlin, Bowlby, Duhring and Wile, Karg and others, that the Paget's disease is primary and the occurrence of the cancer secondary and often long postponed. Among the more recent writings upon this view, those of Stelwagon ("Diseases of the Skin," Phila., r9ro, 6th ed., p. 839) Hartzell (Jour. of Cutaneous Diseases including Syphilis, Igo6, XXIV, 289; Jour. of Cutaneous Diseases, August, I910) Sequiera ("Diseases of the Skin," 2d ed., I915) may be cited. Surgeons, among whom are Jopson and Speese (Annals of Surgery, August, I9I5, p. 213) sometimes arrive at the same conclusion.

The controversy seems to depend largely upon differences, in the material examined. Thus when the Paget's disease comes early under observation it seems so independent of associated conditions as to impress the observer as a condition primary in occurrence and sui generis in character; when it comes under observation late, and a cancer is present in the breast, the acini of cancer cells may be so clearly followed to the surface as to make it almost as certain that the cancer was primary and the dermal lesion secondary.

Two facts of immense importance must not be overlooked. The first is the great length of time that sometimes elapses between the occurrence of Paget's disease and the appearance of the carcinoma in the breast. Thus, Jamison ("Diseases of the Skin," 4th ed., p. 537) observed a case in which Paget's disease existed 20 years without the occurrence of cancer in the breast; Masland and Babcock (International Medical Magazine, February, I 899) one in which it existed i 3 years and completely destroyed the nipple without the occurrence of carcinoma; Duhring (Amer. Jour. of Med. Sci., r883, n.s., LXXXVI, I I6) one in which it existed ro years without cancer; O'Neill (Brit. Med. Jour., r $89 \mathrm{r}, \mathrm{I}, 846$ ), one in which it existed seven years before carcinoma developed; and Sheild ("Diseases of the Breast," London, I 898, p. I63) one in which it was of eight years' duration and involved an area to by I I inches in extent, though no carcinoma could be found in the amputated breast, and in which one removed axillary lymph node showed squamous-cell carcinoma.

The second important consideration has to do with the localization of the disease. The surgeon is accustomed to see it in its most frequent seat, the breast, but the dermatologist is familiar with it in other localizations. Thus, Hartzell (Jour. of Cutaneous Diseases, I9I0, XXVIII, 379) observed a case of Paget's disease of the forearm, associated with melano-carcinoma. Interest in the extra-mammary localization being 
aroused, he collected 18 cases from the literature. Among these, one is reported by Crocker (Trans. Path. Soc. London, I889, XL, I87) in which the glans penis was affected; one by Darier and Couillard (Annals de dermatologie, r893, p. 33) in which the disease was upon the arms and perineum; cases by Dubreuilh (Brit. Jour. of Dermatology, I90I, XIII, 407) in which the lesions were upon the penis, scrotum and vulva; by Fordyce (Jour. of Cut. Dis., I905, XXIII, I93) in which they were upon the pubic, perineo-anal and gluteal regions; by Fox and MacLeod (Brit. Jour. of Dermatology, 1904, XVI, 43) in which the lesion centered about the umbilicus of a man 65 years of age and continued for I I years; by Jungmann and Pollitzer (Dermatologische Zeitschrift, I904, XI, 39I) in which the disease affected the lips, nose and axilla; by Morris (Medico-Chirurgical Transactions, LXIII) in which it affected the skin in the neck which became cancerous after six years; Neisser, Pospelow and Tarnowsky (cited by Croker, "Diseases of the Skin," I 903, p. I006) in which it affected the penis and scrotum; by Pick (Deutsche med.Zeitung, Nov. 5, I89I; Prager med. Wochenschrift, I89I) in which it affected the penis; Ravogli (Jour. of Cut. Dis., I894, p. 222) in which it affected the nose of an old lady; by Rosenberg (Monatsschrift für prakt. Dermatologie, XLIX, 235) in which it occurred upon the vulva and by Sheild (Dermatological Journal, I897) in which it affected the penis. But there is another source of confusion. To many surgeons Paget's disease is a clinical entity, whose chief characterization is ulceration about the nipple and areola. In the preparation of this writing, we carefully read the accounts of Paget's disease in 20 textbooks of surgery, and were astonished to find that it was exceptional to find either a correct or adequate statement regarding it. The most common mistakes were the statements that Paget's disease was squamous-cell carcinoma of the nipple and areola, or that Paget's disease was the result of the invasion of the skin by carcinoma of the breast! Ulcerations about the nipple and areola do occur in squamous-cell carcinoma of the nipple and areola, and may depend upon the upward growth of scirrhus or other mammary carcinoma with invasion of the skin. In both cases the lesions may be such as to bear a resemblance to Paget's disease, but microscopically are quite different from what the dermatologist and pathologist recognize as Paget's disease, and have nothing whatever to do with it. They should be carefully excluded just as simple chronic eczema running a prolonged course or syphilitic eczema or psoriasis, which all resemble Paget's disease somewhat closely at times, yet have nothing to do with it, ought to be excluded from consideration with it.

Paget's disease is a rare affection. Among the 575 breast cases that form the basis of the pathological studies in this work there was only one case that answered the requirements of the histopathology of the disease, though there were several that had been sent to the laboratory with the surgical diagnosis of Paget's disease.

Histology.-Our studies of the limited material in our own collection, supplemented by sections lent by kind friends, lead us to the confirmation of the findings and description of earlier writers.

The earliest change seems to consist in a lymphocytic and plasmacytic infiltration of the corium of the skin, soon followed by looseness and apparent weakness of the resisting power of the tissue, which permits the epithelial pegs of the epiderm to grow downward a short distance and the cells to separate slightly. Though they thus extend and loosen from one another, the epithelial cells do not tend to become invasive but undergo certain changes that are the chief histopathological characteristics of the disease, that is, they lose the "prickles" by which they cling to one another, swell, and transform into the large pale vacuolated bodies that Darier and his followers mistook for psorosperms. 
These changes apparently begin in the prickle-cell layer and extend both upward toward the surface and downward to the Malpighian layer.

The cells become almost double the normal size, clear and hyaline, smooth on the surface, and contain a relic of a nucleus that varies from a swollen vesicle to a shrunken remnant, may be pushed to one side so as to give a "seal-ring" appearance, or may show abortive or aberrant mitotic figures. At first such cells can be noted here and there among fairly normal cells, but later they form the greater number of the epidermal cells, which lose all power of cornification and explain the desquamation, oozing and incrustation at the skin surface, as the infiltration of the corium by the lymphocytes and plasma cells accounts for the induration that is usually to be felt below.

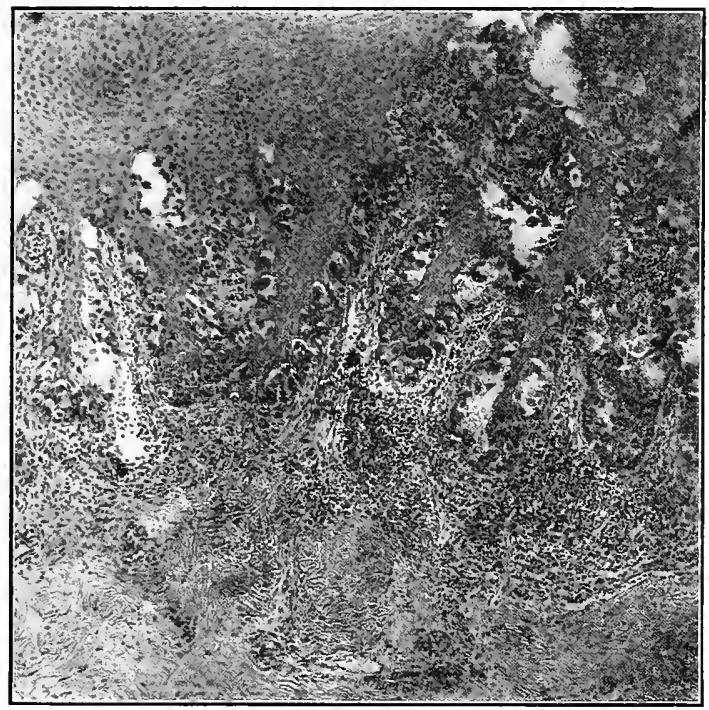

FIG. 277.-Paget's disease of the nipple, showing the Malpighian layer of the skin, with the vacuolated epithelial cells and the lymphocytic and plasmocytic infiltration of the corium.

The swollen vacuolated epidermal cells are the "Paget cells" and they in no way bear the slightest resemblance to cancer cells, and von Winiwarter (Archiv f. Dermatol. u. Syphilis, I907, LXXXV, 239) was able to demonstrate all the intermediate stages between the normal epidermal and true Paget's cells.

With the thinning of the epiderm caused by the destruction and desquamation or colliquation of the cells, the epithelial pegs become shortened, the papillæ of the corium broadened, and in one case that had continued for $x_{3}$ years (the case reported by Masland and Babcock) there seemed no longer to be any papillary layer, the Malpighian layer, very thin, appearing to form a flattened layer upon an equally flattened corium. This case was, however, difficult to study and the changes were difficult to interpret because of the extensive superficial destruction and the thick superimposed crusts which were included in the sections that had to be rather thick in consequence. 
The capillary blood-vessels of the corium appear numerous and are full of corpuscles. Presumably their number is increased as in granulation tissue which the infiltrated corium resembles.

In our sections the disturbance was entirely superficial and stopped at a depth below the epithelium that would not have been twice the thickness of a normal epiderm. At occasional. points, chiefly where larger vessels were situated, the cellular infiltration of lymphocytes and plasma cells descended more deeply. In the beautiful tissue given us by Dr. Michael J. Wohl, there was no sign of cancer, and the donor assures us that he was unable to find any deeply situated cancer in the breast. The details of this case are as follows:

The patient was a woman aged 38 years, married, mother of four children. She suffered from eczema of the right nipple of two years' duration. Four months before admission to the Samaritan Hospital of Philadelphia, she thought that she found a "lump" in the breast.

The breast was amputated and the axilla cleansed. Dr. Wohl, who examined the specimen, found no cancer in the breast and no disease of the axillary nodes. The patient died four months later of nephritis (according to the statement to her attending physican, who adds that there was no reason for supposing that she had internal cancer). No autopsy was permitted.

The skin covering the nipple and areola presented an ulcerating red, moist and angry-looking appearance. The tissue beneath the nipple was indurated and firm and somewhat nodular in character, extending downward for about $\mathrm{I}$ inch and laterally for about $3 / 4$ inch in each direction.

When milk ducts are adjacent to the effected surface, they participate by what one might look upon as an analogous process. That is, the cells increase greatly in number and distend them, the condition appearing to us more like the products of a catarrhal condition of mild type than as a malignant one. From the surface of the skin the cells readily become detached; in the milk ducts they must be retained.

Jopson and Speese (Annals of Surgery, August, I9I5, 228) observed, as had Bowlby before them, that the "epithelial hyperplasia becomes so active in the smaller ducts and acini that the cells broke through and infiltrated the breast stroma as a malignant tumor." This we have not observed but it is a most important contribution if the interpretation be correct and confirms the opinion that the Paget's disease is primary and the cancer secondary. They were unable to corroborate the observation of Duhring that the infiltration of the breast was met with in the ducts about $\mathrm{I}$ or $\mathrm{I} / 2 / 2$ inches from the nipple.

If Paget's disease were caused by carcinomatous invasion of the derm, it ought to be easy to trace the invasion, which few claim to have done except in cases associated with well-developed cancer; if the cancer of the breast follow the Paget's disease one would naturally expect the cancer to be of the squamous-cell variety. But this is so rarely the case that when it is reported, one is inclined to wonder whether the ulcerative disease was not a rodent ulcer or some other form of squamous-cell carcinoma mistaken for Paget's disease.

Of course the interesting question is, how can the disease of the squamous epithelial surface eventuate in glandular cancer of the breast? The apparent explanation is to be found in the demonstration of Bowlby and Duhring and corroborated by Jopson and Speese, that when the Paget's disease extends to the ducts, they sometimes become so distended with proliferated and desquamated cells that their walls yield and invasion of the breast by the multiplying and escaping cells takes place.

Pathology.--The true nature of Paget's disease is unknown. There was absolutely no ground for the opinion expressed by Fournier (Bull. méd., Paris, r 903, XVII, 30I) that it might be a late manifestation of syphilis, though it may at times be simulated by 
syphilis as in the case reported by Walker (Bull. et mém. soc. de chir., Paris, I9I4, n.s., $\left.\mathrm{XL}, 78_{3}\right)$.

It is reasonably certain that the psorosperms of Darier, Wickham and Malassez are not parasitic microörganisms, and that the yeast found by Fabry and Trautman (Archiv für Dermatologie u. Syphilis, I904, LXIX, 37) have no etiological significance. It is neither certain nor impossible that Paget's disease is not caused by an infectious microörganism.

Vignolo-Lutate (Monatsschrift für prakt. Dermatologie, I909, XLV, 21) in making a histological examination of a case of the disease, observed the first nervous disturbances that seem to have been reported, in a perineuritis and interstitial neuritis of the deeper plexuses of the nerves running from the mammary gland. He endeavors to connect this with the dermal lesions in one of three ways:

I. There is a dystrophic disturbance of the epiderm brought about by the disturbance of the nerves which in its turn is the result of some autointoxication.

2. There is a congenital dystrophy of the epidermis by which the diseased appearances of the nerves, etc., is brought about secondarily.

3. There is an external irritant that provokes a superficial dermatitic appearance in which the superficial nerves participate.

We have not found this view of Paget's disease to have met with acceptance. The chief interest of Paget's disease, at the present moment, centers about its relation to cancer of the breast, and embraces three possibilities.

I. That the disease is secondary to the occurrence of cancer in the breast, and results from the action of the cancer toxin upon the epiderm, as supposed by Thin, or from the upward growth of the cancer cells and their invasion of the skin, as supposed by a number of observers whose names have already been quoted.

This view of the disease is inconsistent with the fact that Paget's disease occurs in some 10 per cent. of cases in localizations that would make such origin impossible, as well as with the fact that cases occur in the breast without any discoverable cancer, and not infrequently occur long years before the presence of a cancer can be demonstrated.

2. That the disease is primary, may occur without antecedent or subsequent cancer or after a varying length of time may lead to cancer of squamous-cell variety through the disturbances in the papillary layer of the skin, or to glandular cancer, when a gland is subjacent, by extending into the ducts where they communicate with the diseased skin. This is thoroughly consistent with such known facts as that the disease leads to squamouscell carcinoma when in extra-mammary localizations, sometimes to squamous-cell carcinoma when mammary, though generally to glandular (scirrhus) cancer when mammary. It also explains why the cancer follows the Paget's disease after a variable but prolonged interval, and why most of the cases in which the cancer precedes the Paget's disease, turn out to be simple cancerous infiltration of the skin and not Paget's disease when carefully examined.

3. That the disease is an independent entity having no more to do with the occurrence of cancer than the lupus of the skin that is occasionally followed by squamous-cell carcinoma, and is pre-cancerous only in opening an avenue by which the true cause of cancer may be admitted to tissues in which it finds a suitable nidus for its development.

Of these three possibilities it seems to us that the first is supported by the least amount of evidence, and is contradictory to the known facts regarding the disease. Our sympathy is, therefore, with the other two which cannot be said to be contradictory with the facts regarding the disease or with one another. In both Paget's disease is regarded 
as a pre-cancerous process though the subsequent development of the cancer is differently accounted for in each.

It is interesting to see that the conclusions of Jopson and Speese so nearly tally with our own. They say:

r. Paget's disease of the nipple is a primary affection beginning in the cells of the rete Malpighii, potentially malignant, although lacking the ordinary characteristics of malignant disease.

2. It is identical with the disease known under the name of Paget occurring in other regions.

3. It is commonly, though not invariably, followed by glandular carcinoma in the underlying breast tissue.

4. It is pre-cancerous in the sense that it induces epithelial changes in the superficial milk ducts and acini, which are followed by carcinoma. Occasionally, although rarely, it is followed by squamous-cell carcinoma of the nipple.

5. The disease is characterized by edema and vacuolization of the prickle-cells, thickening of the rete, and active mitosis, also by an inflammatory reaction in the corium and a secondary hyperplasia in the milk ducts.

6. It is sharply differentiated from true eczema and scirrhous carcinoma ulcerating at the nipple, and should not be confused with superficial metastases of diffuse cancer situated near the skin.

7. The resulting tumors of the breast and the regional metastases resemble the type of breast cancer usually encountered. When the tumor originates in the skin it infiltrates and metastasizes in the form of squamous carcinoma.

8. The common association of cancer in the breast with Paget's disease, demands as the treatment for Paget's disease, the radical operation which is practised in breast cancers in general.

As regards the age incidence in Paget's disease, cases have been observed before the thirtieth year of life, Alcock (Lancet, London, I90I, II, 847) observed a case 28 years of age, and as late as the seventieth year, although the great majority of cases occur during the fourth and fifth decades of life. It is much more frequent in women than in men, though Forrest (Glasgow Med. Jour., I885, XIV, 457), Gaucher and Bricourt (Bull. Soc. franç. de dermat. et syph., I9I2, XXII, I48), Gintrac (Jour. de méd. de Bordeaux, I 856,2 s., I, 280) and Jonas (Interstate Med. Jour., St. Louis, I9Io, XVII, 674) have reported cases in men.

The disease is rare in virgins and in those who have not lactated. Traumatism incidental to rursing has been mentioned as a predisposing factor. Mastitis is given as the predisposing factor in an interesting case reported by Gaucher and Bricourt. Their patient, a man 47 years of age had suffered with chronic mastitis from his twentieth year and during the five years preceding the appearance of the disease, he had noticed redness around the nipple. As regards the influence of heredity very little is known. although Jonas operated upon a man for bilateral Paget's disease, whose father, brother, daughter and an aunt had died of cancer of the breast.

Clinical Course and Symptoms.-Paget's disease is a chronic affection. The duration varies from several months to many years. It usually terminates in carcinoma of the breast with ultimate metastasis, and finally, if untreated, commonly causes the death of the patient. The usual first indication of its presence is a dry, scaly, eczematous patch at the base of the nipple, but the initial change may, in more rare cases, be pustular or vesicular, and cases have been reported in which a fissure of the nipple preceded the development of the eczematous lesion. The appearance of the cutaneous lesion is sometimes preceded by sensations of burning or itching in the region of the nipple. The lesion slowly spreads to the areola and adjacent mammary skin, forming a rounded patch which attains to the size of a silver dollar or even larger. In rare instances, the disease appears in the form of concentric rings with intervening areas of healthy-looking skin. The most frequent and important clinical sign of associated malignant disease is retrac- 
tion of the nipple which takes place, as a rule, within one year of the onset of the disease, the nipple may eventually be completely destroyed and its location marked by a depression in the center of the skin lesion. Induration of the involved skin is invariable in true Paget's disease and this sign together with the inversion of the nipple is most suggestive of the true nature of the condition.

Cancerous invasion of the glandular tissue of the breast, followed later by enlargement of the axillary lymph nodes usually presents itself in from one to three years after the appearance of the skin lesion, although some cases run a more acute course attaining their full development in several months, and others are delayed for many months or even for many years.

Although bilateral occurrence has been reported by several writers, Paget's disease does not seem to appear simultaneously in both breasts, a period of months intervening between the time of onset of disease in the two organs. Thus, in the case reported by Jonas, in a man aged 6I years, the patient noticed a scaly red patch on the right nipple two years before presenting himself for treatment, at which time there were extensive ulcerations in the region of both areolaé with total destruction of both nipples. The edges of the ulcerations were hard, raised, rolled outward and the entire area was covered with a sero-purulent fluid. There was an intervening area of healthy skin between the two ulcers. Radical amputation of both breasts was performed but the patient developed unmistakable symptoms of metastasis to the spinal cord within six months after the operation and died a month later of a terminal pyelo-nephritis.

The surface appearance of well-developed cases of Paget's disease varies considerably; when ulceration takes place, the surface usually becomes fissured, intensely red, and granular in appearance. In this, moist variety of the disease, the surface exudes a seropurulent fluid which forms, upon drying, adherent scabs or crusts that upon removal, leave a raw and bleeding surface. In the $d r y$ variety of Paget's disease the ulcerative process is insignificant and the skin lesion presents the appearance of ordinary chronic eczema. A third variety, to which Paget himself first called attention, resembles psoriasis and has scaly desquamation as its characteristic feature.

Not infrequently, in this variety of the disease, islets of healthy skin are found between the areas of disease, and healing occasionally occurs in the older areas.

A parchment-like induration of the involved skin occurs in all varieties of true Paget's disease and in certain instances the skin underlying involved lymph nodes becomes reddened and edematous in the advanced stages of the condition.

Diagnosis.-Every chronic eczematous lesion of the nipple and areola should excite the suspicion of Paget's disease. True eczema does occur in this situation, however, so that one must be certain of the diagnosis before he expresses an opinion or advises treatment. Fortunately, true eczema readily responds to simple local treatment. If after persistent treatment no improvement be noted, or if the lesion should continue to progress, the patient should be prepared for a radical breast amputation.

Prognosis.-The prognosis of Paget's disease is generally favorable, the progress of the disease and the development of the associated cancer usually being very slow, and metastasis to the lymph nodes long delayed.

Treatment.-Good results have been obtained with non-operative methods especially radio-therapy, and radium in early cases of Paget's disease, that will not or cannot be operated upon.

At a meeting of the Dermatological Section of the Royal Society of Medicine held in London in October, I9I2, Davis reported a case of Paget's disease which had apparently 
been cured by the use of radium, and in the discussion that followed, Morris also reported excellent results with radio-therapy in two similar cases. Notwithstanding these results, however, the concensus of opinion among the surgeons present was to the effect that amputation of the breast is the safest procedure to follow in the treatment of Paget's disease, and Whiteford, stated that he had observed cancerous invasion of the breast tissue almost to the pectoral muscles, in association with a very small and insignificant looking lesion. When the Paget's disease is still superficial, and painstaking examination of the breast fails to give evidence of an associated malignant tumor, it would seem as though the $x$-rays might be given a trial. Cases so treated, with varying success, have been reported by Belot, Hartzell, Langlet, Meek, Taylor, Terzogli and others, the references to whose contributions are given at the end of this section. In a personal letter to the author, Pfahler mentions six cases, diagnosticated Paget's disease, four of which could not, for one or another reason, be operated upon and were referred to him for $x$-ray treatment. All of them he says are now "well or "apparently well."

So soon as the Paget's disease effects deep ulceration, the chances of preventing the occurrence of the associated tumor diminish and it becomes wiser to advise operation. If a tumor, or any "lump" suggesting a tumor, can be found in the breast, the entire aspect of the case changes, the chief diagnosis is no longer Paget's disease but cancer, and it is no longer the Paget's disease but the cancer that must be treated.

\section{Literature upon Paget's Disease}

Abrahams, R.-J. Cut. Dis. incl. Syph., N. Y., I907, XXV, r87.

Agnew, D. Hayes.- "Principles and Practice of Surgery," Phila., I889, III, 682.

Alcock.- "A Case of Paget's Disease of the Nipple Occurring in a Young Subject," Lancet, London, IgOI, II, 847 .

Aldridge, N. E.- "Paget's Eczema of the Nipple," Brit. Med. Jour., Igrr, II, 620.

Anderson, F. Mc.- "Note on Paget's Disease of the Nipple," Glasgow M. J., I882, n.s., XVIII, 241. Ashrurst, John, JR.— "The Principles and Practice of Surgery," Phila., I893, 6th ed., p. 865.

Asselbergs.—“Un cas de maladie de Paget," Presse méd. belge., Brux., r905, LVII, ro5o.

AtleE, W. F.- "The Present State of Knowledge Respecting the Connection between Eczema and an Affection Resembling Eczema, and a Malignant Disease of the Breast," Amer. Jour. Med. Sci., Phila., r884, n.s., LXXXVII, 469.

Audry, C.- "Note sur un cas de maladie de Paget," etc., Bull. Soc. Franç. de Dermat. et Syph., Paris. I896, VII, 350; Ann. de dermat. et syph., Paris., I896, 3s., VII, 644; Ann. de Dermat, et syph., Paris, Igo6, 4s., VII, 529.

Bargues. - "Maladie de Paget du sein," Gaz. hebd. d. sc. méd. de Bordeaux, rgog, XXX, 556.

Barling, G.- "Carcinoma of the Breast Following Eczema of the Nipple," Trans. Path. Soc. Lond., I889-90, XLI, 2I9; Brit. Med. Jour., I889, II, I392.

BATtLE and MAYBERRY.-Lancet, IgI3, I, I52I.

Bauby.- "Un cas de maladie de Paget," Toulouse méd., I902, 2s., IV, 65 ; Echo méd. Toulouse, rgo2, 2s., XVI, i6r.

Beaussenat et Bender.- "Un cas de maladie de Paget du mamelon," Bull. et mém. et la soc. d'anat. Paris, rgo2, No. 4 .

Brackon.- "Malignant Disease of the Nipple; A Statistical Study Based on the Records of the Middlesex Hospital, I904-08, inclusive, "Archives of the Middlesex Hospital, r909, XV, 74.

Begouin and Petges. - "Un cas de maladie de Paget," Gaz. hebd. d. sc. méd. de Bordeaux, igog, $\mathrm{XXX}, 379$.

BELOT._-"Traitement de la maladie de Paget du mamelon et cutanée par la radiothérapie," Verhandl. d. deutsch. Röntg.-gesellsch, Hamb., r9o7, III, I 20. Archiv d'Electric Med., Bordeaux, I907, XV, 283; Archiv Röntg. Ray, London, I907-08, XII, 67.

Bender, $\mathrm{X}$. and Vandescal.-Note sur trois cas de maladie de Paget du mamelon," Bull. Soc. d'obst. et de gynéc. de Paris, r9i4, III, 489. 
Benjamins, C. E.- “Een Geval van Paget's Disease of the Nipple,” Nederl. Tijdscher v. Geneesk. Amst., I898, 2r., XXXIV, d.I, 914-926, r pl.

Bowlby, A. A.- “Thirteen Cases of Paget's Disease of the Nipple, with Special References to the Causation of the Disease by Psorosperms," Medico-Chirurgical Transactions, London, I89o-9I, LXXIV, 34I, I pl.

Bunch, J. L.- "A Case of Paget's Disease of the Nipple," Brit. Jour. of Dermatol., r9r4, XXVI, 326 ; Proc. Roy. Soc. Med. Dermat. Sec., I9I3-I4, VII, 255.

Butrin.- "Upon the Microscopic Anatomy of Two Breasts Whose Areolæ Were the Seat of Longcontinued Eczema." Medico-Chirurgical Transactions, London, 1876, IX, 107.

Cantreli, J. A.- "Eczema of the Breasts and Nipple," Ann. Jour. of Obst., N. Y., 1896, XXXIII, 2 ro.

Chalor.- "Cancer de l'areole et de bout du sein, simulant un eczema," Compt. rend. Soc. de méd."et chir. pract. de Montpel., I 882-23, 7-10.

Chambers, T.- "Eczema of the Nipple on Both Breasts," Tr. Obst. Soc., Lond. (1880), I88I, XXII, 266.

Cheatre, G. S.- "Paget's Disease of the Nipple," Med.Press and Circular, Lond., r9o6, n.s., LXXXII, 669.

Chlenoff, M. A.- "O Paget ovǒi bolŭzeni," Paget's diseases, Khirurgia Mosk., I903, XIV, 339.

Clarke, J. J.- "A Note on Two Cases of Paget's Disease of the Skin," Trans. Path. Soc. Lond., I896-97, XIVIII, 219.

Clejat et Espinasse.- "Maladie de Paget," Jour. de méd. de Bordeaux, 1905, XXXV, 4 I8.

CORNIL.- "Tumeurs du sein," I 908 .

Crocker.- "Diseases of the Skin," Phila., 3d ed., I903, p. 1004. Trans. of the Lond. Path. Soc., I889, $\mathrm{XL}, \mathrm{I} 87$.

Dalche, P. and Galup, J.- "Maladie de Paget avec signes addisoniens et divers autres troubles glandulaires," Bull. et Mem. Soc. Med. d. hg. de Paris, I909, 3s., XXVI, I 2 I 8.

Dambrin and Creraront.- "Un cas de maladie de Paget 'du sein,", Toulouse méd., I9o6, 2s., VIII, r39.

Danel.- "Maladie de Paget du mamelon et cancer du sein," Jour. d. soc. méd. de Lille, I9I I, I, 385.

Darier, J.- "Maladie de Paget," Mems. de I'Hôs., St. Louis, Iconog. d. mal. cutarı. et syph., Paris (I897?), 247 ; Piet. "Atlas of Skin Diseases and Syphilis, St. Louis Hospital," London and Phila., r895-97, 223. "Sur une nouvelle forme de psorospermose cutanées; la maladie de Paget dụ mamelon," Compt. rendu soc. de biol. Paris, r889, 9s., r, 294; Précis de dermatologie, r909, 644.

Darier and Covillaud.-Annals de dermatologie, I 893, p. 33; cited by Crocker, "Diseases of the Skin," I903, 3d ed., p. гоo6.

Dartigues and Latteux.- "Sur deux rares formes de tumeurs de la mamelle: maladie de Paget," Paris Chirurg., rgI 1 , III, 2 I 7.

Davis, H.-“A Case of Paget's Disease of the Nipple," Proc. Roy. Soc. Lond., r912-13, Dermat., Section 5 .

Dawson.- "Paget's Disease of the Breast," Brit. Jour. of Dermatol., Lond. 1907, XIX, I9.

DE Keating-HaRT, W.- "Maladie de Paget, operée par la fulguration," Rev. mens. de gynéc., d'ostét et de pédiat. Paris, I9o9, IV, rg.

Delber, P.-Traité de Chirurgie (Duplay et Reclus), 2d ed., Paris, I898, V, $871-874$.

DePage.-Ann. d. Soc. Belge de Chir., I894.

Drvawin.- "Ein Fall von Paget's Disease," Prakt. Wratsch., I909, viii, No. Ir, p. 203; Ref. Monatschr f. prakt. Dermat., XLIX, 4I.

DE Schweintz, G. E.- "A Case of Paget's Disease of the Nipple and Areola," Med. News, Phila., I 884 , XIIV, 126.

Diday, P.—“Nouvelles contributions a la maladie de Paget," Lyon méd., I89o, LXIV, 579, 6 I 2.

DIETRICH, A.- "Üher beginnenden Pagetkrebs und über ekzem bei Karzinom der Mamma," Verhandl. d. deutsch. path. Gesellschaft, Jena, I9I4, XVII, 329, Discussion, p. 338.

Dubois-Havenith._- "Coupes histologique de deux cas de maladie de Paget," Soc. Belge de dermat. et de syph. Bull., Brux., I90x, I, 57 .

DUBReuilh.-Brit. Jour. of Dermatol., I90I, XIII, 407.

Dubreuilh. - "Un cas de maladie du sein de Paget," Mem. et bull. Soc, de méd. et. chir. de Bordeaux (1892), ז893, 647.

DubreuilH, W.- "Un cas de maladie de Paget," Gaz. hebd. d. Soc. med. de Bordeaux, I908, XXIX, 405. Du Castel.- "Maladie de Paget," Bull. Soc. Franç. de dermat. et syph., i895, VI, 373; Bull. Franç. de dermat. et syph., Paris, r895, VI, 3s., roI 5. 
DuHring, L. A.—“Two Cases of Paget's Disease of the Nipple," Ann. Jour. Med. Soc., Phila., I883, n.s. LXXXVI, II6.

Duhring, L. A. and Wile, H.- "On the Pathology of Paget's Disease of the Nipple," Ann. Jour. Med. Sci., Phila., I 884, n.s., LXXXVIII, I4r.

Duncan, R. B.- "Two Cases of Paget's Eczema of the Nipple Associated with Carcinoma of the Breast," Intercolon. Med. Jour. Australas, Melbourne, Ig08, XLII, 420

Dupouy.-Thèse de Bordeaux, Igog-ro.

Ehrhardt, OSCar.— "Über Geschwülste der weiblichen Brustwarze," Deutsche Zeitschrift für Chirurgie, 1899, L., 373 .

Ehrhardt.- "Ü̉ber Paget's Disease," Deutsche Zeitschrift für Chirurgie, I899, LIV, I 30.

Elbogen, G. A.- "Zur Kenntnis von Paget's Disease of the Nipple," Festschrift-Hans Chiari-Wien u. Leipzig, I908, 143 .

Eliıotr, G. T. - "A Case of Paget's Disease Treated with Fuchsin," Jour. Cut. and Genito-urinary Dis., N. Y., I892, X, 272 .

Evans, W.-"A Case of Paget's Disease," Proc. Royal Soc. of Med., Lond., rgo8-og, II; Dermat., Sec. 162 .

Fabry, J. and Trautarann, H.--"Beiträge zur Pagetschen Erkrankung," Archiv für Dermat. u. Syph., I904, LXIX, 37 .

FORDYCE.-Jour. Cut. Dis., I905, XXIII, I93.

Forrest, R. W.- "Case of Cancer of the Mamma in the Male, Preceded by So-called Eczema of the Mammary Areola; Paget's Disease of the Nipple," Glasgow Med. Jour., I88o, XIV, 457.

Fournier. - "A propos de la maladie de Paget considerée comme manifestation de syphilis héréditaire tardive," Bull. méd., Paris, I903, XVII, zor.

Fox.—"Circumscribed Eczema of Left Breast," Jour. Cut. Dis. incl. Syph., I9og, XXVII, I65.

Fox and MaCLEOD.-Brit. Jour. Dermatol., I904, XVI, 43.

GaArenstroom, G. F.-Nederl. Tijdschr. v. Geneesk. Anst., IgI3, I, 3 I 2.

Gaucher et Bricourt.-Bull. Soc. de dermat. et de syph., Igr 2 , I48.

Gaucher et Bricour.- " Maladie de Paget du mamelon gauche avec noyaux secondaires de la peau et envahissement ganglionaire chez un homme," Bull. Soc. Franç. de dermat. et syph., Paris, I9I 2, XXIII, I 48 .

Gintrac. - "Eczema du mamelon chez l'homme," Jour. de méd. de Bordeaux, r856, 2s., I, 280.

Grant, J. A.- "Cancer of the Breast in Its Relation to Paget's Disease of the Breast," Canada Med. and Sur. Jour., Montreal, $188_{2}-83$, XI, I29.

Grisel et Salmon.-- "Un cas de maladie de Paget," Bull. Soc. Franç. de dermat. et syph., Paris, 1898, IX, 418; Ann. de Dermat. et Syph., Paris, 1898, 3s., IX, II 26.

Hallopeat.- "Maladie de Paget," Ann. de dermat. et syph., Paris, 1889, 2s., X, 216; Reunion clin. de l'Hôp. St. Louis., C. r. Paris, I888-89, 62.

HaNdieY:-Choyce and Beattie's "System of Surgery," Igr 2, II.

HANNEMÜlLER K. und LANDors, F.-Beiträg. zur. klin. Chir., 1908, LX, 296.

HarTzeli, M. B.--“"Two Cases of Paget's Disease Treated by $X$-rays with a Report of the Microscopic Findings in One of Them after Prolonged Treatment," Rev. Pract. d. Mal. Cutan, Paris, I906, V, 372; Jour. Cut. Dis. incl. Syph., I906, XXIV, 289.

HartzelL, M. B.- "Extra-mammary Paget's Disease, with Report of a Case Occurring on the Forearm, Associated with Melano-carcinoma, with Analysis of 18 Cases in the Literature," Jour. Cut. Dis., I910, XXVIII, 379.

Hauser, A.—“Über das Epithelcarcinome der Mamma und über Paget's Disease," Heidelb., r 886.

Hearn, J.- "A Case of Paget's Disease," Phila. Med. Times, $188_{3}-84$, XIV, 698.

Herzfeld, B.- "Morbus Pageti," St. Petersb. med. Wochenschr., IgII, XXXVI, 472.

Hertzog, M.- "A Case of Paget's Disease (Malignant Papillary Dermatitis)," Medicine, Detroit, I899, $\mathrm{V}, 44$.

Hil.bers, J. J. P.—“Paget's Disease," Nederl. Tijdschr. v. Geneesk. Ams., Igra, I, IO82.

Hirschel, G. - "Über Pagetsche Krankheit," Beiträge z. path. Anat. u. allg. Path., I905, VII, suppl. 573 .

Hirsches, George.-“Die klinische Bedeutung des sogennanten Pagetschen Brustkrebses (Krebsekzem der Brust)," Münchener med. Wochenschrift, I9Io, II, No. 50, p. 2633 .

Hume.- "Paget's Disease of the Nipple and Breast," Rep. Prac. Northumb. and Dublin Med. Soc. Newcastle-upon-Tyne, I $890-91$, I 7 .

Hutchinson, J. JR.-“"On Paget's Disease of the Breast," Proc. Roy, M.-Chir. Soc., Lond., I89o-91, 3s., 
III, I47; Lancet, London, I89o, i, 649; Brit. Med. Jour., I89 r, p. 278. "Psorosperms in Chronic Eczema of Breast (Paget's Disease)," Tr. Path. Soc. Lond., I889-9o, XLI, 214; Brit. Med. Jour., I89o, I, 664 .

Jackson, G. T.- "A Case of Paget's Disease of the Nipple," Jour. Cut. and Genito-urinary Dis., N. Y., $1896, \mathrm{XIV}, 428$. "A Case of Paget's Disease of the Nipple (with Pathological Report by O. H. Schultze)," Jour. Cut. Dis. incl. Syph., N. Y., r903, XXI, 20r. "A Case of Paget's Disease of the Nipple, etc.," Jour. Cut. Dis. incl. Syph., N. Y., 1903, XXI, 201. JaCoBAEus, H. C.- "Paget's Disease und sein verhältniss zum Milchdrüsenkarzinom," Virchow's Archiv, CLXXVIII, I24; Kongresz f. innere Med. Stockholm, I904; Abstract: Centralblatt f. allgemeine Pathologie u. pathologische Anatomie, March I 5, 1905, p. I89.

JAmrson.- "Diseases of the Skin," 4th ed., p. 537.

JonAs, E.- "Paget's Disease of the Nipple; Report of an Interesting Case," Interstate Med. Jour., St. Louis, r9io, XVII, 674 .

Jones, H. MacN.- "Cancer of the Mamma Following Eczema of the Nipple," Tr. Path. Soc. Lond., I 887 , XXXII, 242.

Jones, T.-Lancet, Aug. 3I, I895.

Jopson, J. H. and Speese, John.- "Paget's Disease of the Nipple and Allied Conditions," The Annals of Surgery, I9I5, XXXVII, 213 .

Jungmann, A. and Pollitzer, I.-“Über Paget's Disease; ein klinisch-therapeutischer Beitrag.," Dermat. Zeitschr. Berl., I904, XI, 39 I.

KARG.-Deutsche Zeitschrift für Chirgurgie, r 892 , XXXIV.

KEEN and Whrte.- "American Textbook of Surgery," Phila., I897, p. I024.

Ketscenk.-K. D. Russ. Derm. Gesellsch., St. Petersburg, igo8, March, Ref. Monatsche f. prakt. Dermatol., XLVI, 494 .

Kingsbury.- "Paget's Disease of the Nipple," Jour. Cut. Dis. incl. Syph., N. Y., I9I3, XXXI, 575.

Kollarits, B.- "Pagetsche Krankheit und Carcinoma Mammæ, bei einem Manne," Ungar. Med. Presse, Budapest, I904, IX, 6r6; Orvasi. hetil., Budapest, I904, XLVIII, 725 .

Krerbich, C.-“Zum Wesen der Pagetschen Krankheit," Berl. klin. Wochenschr., I 9I I, XLVIII, 2 I 93.

Kroell, H.- "Theoretisches und Praktisches über die Brustdrüse im Anschluss an einem Fall von Cancroide der Brustdrüsenwarze," Prakt. Arzt. Wetzlar, i 878, XIX, 25, 49.

KrogiUs, A.- "Beitrag zur Kenntniss von Paget's Disease of the Nipple," Deutsche Zeitsch. f. klin Chir., 1904, LXXX, 165 .

KyrLe, J.— "Drüsen Krebs der Mamma unter dem klinischen Bilde von Paget's Disease," Archiv f. Dermat. u. Syph., Wien u. Leipzig, I907, LXXXIII, I87.

Lacaille, E.- "Sur un cas de maladie de Paget familial," Bull. Soc. Franç. d'electrothérapie, Paris, I90I, VIII, I 99.

LANG, E.-"Dermatosis epithelialis (degenerativa) circumscripta eczemiformis (Paget's Disease), Weiner klin. Wochenschr., I905, p. 330.

LANGlet.- "La radiothérapie gueri-t-elle la maladie de Paget?" Bull. et mém. Soc. radiol. méd., Paris, I 909, I, 204.

LARINI, S.- "Contribuzione alle psorospermose cutane; un caso di morbo di Paget," Comment. Clin. d. Mal. Cut. and Genito-urinar, Siena, I894, 2s., I I 2.

Lawson, G.- "A Case of Cancer of the Breast, Following Long-standing Eczema of the Nipple," Tr. Clin. Soc. Lond. ( $1879-80$ ), I880, XIII, 37. "Case in which the Breast was Removed on Account of Incurable Eczema of the Nipple (Malignant Papillary Dermatitis) and Afterward Found to be Affected by Cancer," Tr. Clin. Soc. Lond. (I880-8I), I88I, $\mathrm{XIV}, 222$.

Lecène et Lenormont.-Cited by Delbet, as having studied Paget's disease igir.

LEwrs, D.- "A Case of Paget's Disease of the Nipple," Medical Record, N. Y., I887, XXXI, 64I.

LINDT, R.- "Über Paget's Krankheit," Mitth. d. klin. u. Med. Inst. d. Schweiz., BaseI u. Leipzig, I 895 , 2I., 49I-530, I pl.

Ludram.-_- "Paget's Nipple," Clinique, Chicago, r893, XIV, i I6.

Macalium, A. B._- "Note on the Diagnosis by Means of the Microscope of Paget's Disease of the Nipple and Breast," Canad. Prac., Toronto, I890, XV, 472.

MacConnel, W. G. for Dr. J. Hearn.- “A Case of Paget's Disease," Trans. Phila. Path. Soc., I886, XII, 230, May $23, \mathrm{I} 884$.

Macewen, J. A. C._- "Paget's Disease of the Nipple," Glasgow Med. Jour., I904, LXI, I39.

Malapret.- "Sur un cas de maladie du sein de Paget," Poitou méd. Poitiers, I9Io, XXY, Ior. 
Malassez.- "Sur les nouvelles psorospermoses chez l'homme," Archiv de med. exp. et d'anat. path., 1890 , Nos. 1 and 2.

Malinowski, F.- "Unusual Case of Metastasis of Cancer of the Breast to the Skin and Its Relation to Paget's Disease," Przezl. Chorob. Skor. i. Wen., Warszawa, r9o6, I, 527; Monatschr. f. prakt. Dermat. Hamb., r907, XLIV, 329.

MALlORY.-."The Principles of Pathological Histology," Phila., I914, 604.

Marcorelles and Pizon.- "Maladie de Paget du mamelon; ablation du sein après biopsie; dégénérescence néoplasmique de la glande," Bull. et mém. soc. anat. de Paris, Igog, LXXXIV, 4I9.

Martini._" "Sulla mastite carcinomatosa," Gior. d. r. Acad. di Med. di Torino, r9i I, 4 s. XVII, 306; Morgagni., Milano, I9I I, LIII, 457.

Masland and BABCOCK.-- "A Case of Paget's Disease of the Breast of 13 Years' Duration, not Showing Carcinomatous Involvement of the Mammary Gland," Internat. Med. Mag., February, I 899 .

Maunsell, R. C. B. and Wigham.- "Paget's Disease of the Nipple," Tr. Roy. Acad. M. Ireland, Dublin, I9 4, XXXII, 89.

Matzenauer, R.- "Pagetsche Krankheit," Monats. f. Prakt. Dermat. Hamb., I902, XXXV, 205.

McKenty.- "On Paget's Disease of the Breast," Surg., Gynec. and Obstet.,Chicago, I9I 2, XV, 457.

Meek, E. R.- "A Case of Paget's Disease Treated by $X$-rays," Boston Med. and Surg. Jour., I $9 \circ 3$, CXLVIII, 668.

Mèneau.- "Un cas de maladie de Paget," Bull. et mém. Soc. méd. de et chir. de Bordeaux ( 1895 ), I $896,483-485$.

Milligan, IV. A.—“Paget's Disease," Abst. Trans. Hunterian Soc., r9oI-02, London, I903, I37.

Morrrs.-" "Dermatitis Maligna of the Skin of the Neck," Medico-Chirurgical Transactions, LXIII.

Munro._- "Paget's Disease of the Nipple," Glasgow Med. Jour., I882 (4s.), XVIII, I74.

MurPHy.--"Paget's Disease; Amputation of the Breast," Surg. Clin., Chicago, rgr 3, II, 99.

NAPIER, A.- "A Case of Eczema of the Nipple and Areola, with Remarks on the Nature and Diagnosis of the Affection, Glasgow Med. Jour., I882 (4s.), I77.

Neisser, Pospelow and Tarnowsky.-Cited by Crocker, p. Ioo6.

Nicolas, J., Mutot H. and Gravile, S.- "Un cas de maladie du Paget du sein," Bull. Soc. méd. d. Hôp. de Lyon, I9I3, XI, 433; Lyon Med., I9I3, CXX, II95.

O'Brien, C. M.- “Carcinoma Cutis with Notes of Two Cases: (a) Cancer en cuirasse; (b) Paget's Disease," Dublin Jour. Med. Sci., May, rgo6.

O'Nerll, H.- "Report of a Case of Paget's Disease of the Right Nipple Following Seven Years after its First Appearance by Carcinoma of the Breast; Removal of the Breast by Operation; Recurrence of Carcinoma in the Right Arm and Axilla and Liver Seven Months after the Operation," Brit. Med. Jour., I891, I, 846.

ORтн._-"Lehrbuch der speziellen pathologischen Anatomie," I894, III, 737.

Paget, Sir J. Y.- "On Disease of the Mammary Areola Preceding Cancer of the Mammary Gland," St. Bartholomew's Hospital Reports, London, I874, X, 87-89.

Periol et Bosquette.- "Sur un cas de maladie de Paget du mamelon," Dauphine méd., Grenoble, I9I0, XXXIV, 256.

Pfahler, GeORGE E.-Personal communication, January, I9i6.

Pfeiffer.- "Die Protozoen als Krankheitserreger," I 893.

PICK.- "Über den Befund von Psorospermien in einem Fall von Paget's Krankheit der Glans," Prager med. Wochenschrift, I89I; Dentsche med. Zeitung, Nov. 5, I89I.

Polland.- "Fall von Paget's Disease," Mitt. d. Ver. d. Aerzte in Steiermark. Graz., I905, XLII, 40

Porter, C. B.- "A Disease of the Mammary Areola Preceding Cancer of the Mammary Glands; Paget's Disease," Boston Med. and Sur. Jour., I 882, CVI, 4I 2.

Pospeloff, A. I._“'Morbus Pageti; Paget's Disease of the Nipple,” Russk. Med., St. Petersburg, 189 I, $\mathrm{XV}$, I 19.

Potherat, E.- "Carcinose cutanée chez une malade operée de tumeur maligne des mamelles vingt. quatre et vingt-trois ans auparavant," Bull. et mém. Soc. de chir. de Paris, Igog, n.s., XXXV, roo7.

Prat.- "Un caso de enfermedad de Paget," Rev. Med. d. Uruguay, I9Io, XIII, 321.

Ravogli, A.- "Paget's Disease of the Nose," Atti. d XI Cong. Med. Internaz., I8 94, Roma, I895, V, Dermat., 78-82; Jour. Cut. Dis., I 894 , p. 222.

Rasch, C.-"A Case of Paget's Disease," Hosp. Fid. Kbeuh., r9I4, 5r., VII, I3r8. 
Remy et Vanderlinden.- "Psorospermose du sein ou maladie de Paget," Ann. Soc. de Med. de Gand., I 890 , LXIX, 244.

Repetto, N.-"Enfermedad de Paget," An. d. Circ. Med. Argent. Buenos Aires, r897, XX, 28r; Deutsche med. Wocbenschr., I905, XXXI, I 2 I 8.

Reuter, B. W.-“Über Pagetkrebs der Mamma," Leipzig, r91 2, E. Lehmann, 62, p. 8o.

Ribbert, H.- “Über den Pagetkrebs,” Deutsche med. Wocbenschr., I 905, XXI, I 2 I8. “Das Karzinom des Menschen," Bonn, I9ı I, p. 247. "Beiträge zur Entstehung der Geschwülste," Bonn, r906.

Reigner.- "Ein typischen Fall von Pagetschen Brustdrüsenerkrankung," Jahresber d. Schles. Geselleschaft für vaterl. Cultur, I897; Bresl., I898, LXXV, I; abt. Med., Sec. 7.

Rosenberg, J.-“"Zur Pagetsche Krankbeit," Monatschr. f. prakt. Dermat. Hamb., rgo9, XLI, 235; Prezezl. chorob. skor. i. wen., Warszawa, I909, IV, 47.

Rossi, E.- "Contribuzione allo studio del morbo de Paget della cute," Gior. d. Assn. Napol. de Med. e. Nat., Napoli, 1893-94, IV, 377.

Sabouraud, R.- “De l'eczèma du sein chez la femme," Clinique, Paris, I9 I 2, VII, I55.

SAxtorph, S.-“Paget's Disease,” Med. Aarsskr. Kjobenh., I892, 182.

Schambacher, A.- "Anatomisches iber Paget's Disease of the Nipple," Deutsche Zeitschr. f. Chir., I905, LXXX, 332.

Af Schultén, M. W.- "Über Paget's Disease of the Nipple nebst Mitheilung eines typischen und hochgradigen Falles dieser Krankheit," Archiv f. klin. Chir. Berl., 1894, XLVIII, 9r 7 . Nord. Med. Ark., Stockholm, I893, n.f., III, 2 Hft. I-I 5 .

SEqueira.- "Diseases of the Skin," 2 d ed., 19r 5 .

SHEILD.- "Diseases of the Breast," 1898 , p. 163 .

Sheild.- "Paget's Disease of the Skin of the Pubes," Dermatol. Jour., I897.

Sherweli, S.— "Paget's Disease of the Nipple,". Jour. Cut. and Ven. Dis., N. Y., ı882-83, I, I84.

Sherwell, H._- "Paget's Disease or Malignant Papillary Dermatitis," Am. Jour. Med. Sci., Phila., r 884 , n.s., LXXXVII, 170.

Shoemake R, J. V.—“Paget's Disease," Jour. Cut. and Genito-urinary Dis., N. Y., I895, XIII, 208.

Srmpson.-Quarterly Bulletin of the Northwestern University; Medical School, Chicago, June, I 909.

Srnozerski, A. A.- "Paget's Disease," Khirurg. Arkh. Velyaminowa., S. Petersb., r913, XXIX, 336.

Sirte, H._- "A Case of So-called Eczema of the Nipple and Areola; Destruction of the Areola; Arrest of Development of the Cancer," Lancet, London, I 882, I, 684.

Snow, H. L.- "The Diagnosis of Paget's Disease of the Nipple," Brit. Med. Jour., Lond., I882, II, r 206.

Soudakewitsch.-Ann. de l'Inst. Pasteur, VI.

Stelwagon.- "Diseases of the Skin," Phila., 19 ro, 6th ed., p. 839 .

Stowers, J. H.- "Paget's Disease of the Nipple," Trans. Dermat. Soc. Gr. Brit., Lond., I goI-02, XIII, I 9.

Swexztzkr.- "Ein typischer Fall von Pagetscher Krankheit," Letopis russkoi Chirurgie, 1897, Heft $i$, Hildebrand's Jahresberichte für die gesammt Chir., I897, III, p. 476 .

Swolfs, O.- "Ce qu'on entend par maladie de Paget," Ann. Soc. Med. Chir. du Brabant Brux., I9o2, XII, I2.

TAylor, J.- "A Case of Paget's Disease Treated by X-rays," Archiv Roentg. Ray., Lond., 1907-08, XII, I00. Brit. Med. Jour., Lond., r907, II, 643 .

Temple, J. A.- "Paget's Disease of the Nipple," Dominion Med. Monthly, Toronto, I901, XVII, 299. Terzaghi, R. and Campana.- "The Effects of Roentgen Rays on Paget's Disease of the Breast," Jour. Cut. Dis. incl. Syph., N. Y., r 908, XXVI, I 23.

Thin, G.- "On the Connection between Disease of the Nipple and Areola and Tumors of the Breast," Tr. Path. Soc., Lond., I88I, XXXII, 218. "Malignant Papillary Dermatitis of the Nipple and the Breast Tumors with Which it is Found Associated," Brit. Med. Jour., r881, I, 760.

Tomasolr.- "Paget's Disease of the Penis," Giornali ital., I 893, XXVIII, Fas. 4.

Towle, H. P._- "Paget's Disease of the Nipple," Jour. Cut. Dis. incl. Syph., N. Y., I9o6, XXIV, 27.

Tschlenoff, M. A.- “Über die Pagetsche Krankheit,” Dermat. Zeitschrift, 1905, XII, 91; $237-293$. UNNA._- "The Histopathologie of Diseases of the Skin," I 896.

Velpeau.- "Leçons orales de clinique chirurgicale faites a l'Hôpital de la Charité," Paris, I840-4I, II. VERNEUIL.- "Squirre de la mamelle avec adénopathie axillaire consecutif à un eczèma chronique du mamelon; examen histologique de la tumeur," Semaine méd., Paris, 1883, 2s., III, 369 .

Vignolo-Lutati, C.- "Über ein seltener Fall von Pagetscher Krankheit. Histologischer Beitrag," Monatschr. f. prakt. Dermat. Hamb., I906, XLII, 253 ; Monatschr. f. prakt. Dermat. Hamb., I909, XLV, 2 I. 
Volterrani, G.- "Contributo allo studio della malattia di Paget," Gazz. d. osp., Milano, 1908, XXIX, I32I.

WaldsteIN, L.- "Ein Fall von Ekzem mit Krebs der Brustdrüse," N. Y. Med. Press, r886, II, 227.

Walter, C.- "Eczéme du mamelon avec large plaque de mammite specifique simulant une maladie de Paget," Bull. et mém. soc. de chir. de Paris, 1914, n.s., XL, 783 .

Warren, J. Collins.- "The Surgeon and Pathologist," Jour. Amer. Med. Asso., 1905, II, XLV, 153. Wicкнast, L.- "Anatomie pathologique et nature de la maladie de Paget du mamelon," Arch. de méd. éxper. et d'anat. patb., Paris, I890, II, 46. Abst. Cong. Internat. de dermat. et de syph. C. S., 1889, Paris, 189o, 385-390. Abst. Ann. de Dermat. et Syph., Paris, 189o, 3s., I, 44,138 .

WiGGin and ForDyCE.-_"Paget's Disease," New York Med. Jour., r897, LXVI, 445.

VINFIELD.—“Paget's Disease on the Lip," Brooklyn Med. Jour., Marcb, I8g6.

von Winiwarter, H.- “Über Pagetsche Krankheit," Archiv f. Dermat. u. Sypb., Wien und Leipzig, I907, LXXXV, 239.

WoHL, DR. M. J.-Personal communication, with gift of specimen.

Zieler, K.- "Über die unter dem Namen von Paget's disease of the nipple bekannte Hautkrankheit und ihre Beziehungen zum Karzinom," Virchow's Archiv, I904, XVII, 293.

Zeisler, J.- "Paget's Disease of the Nipple and Areola, etc.," Bull. Northwestern University Medical School, Chicago, Igog-10, XI, 60.

8. Miscellaneous Affections of the Nipple.-Ichthyosis circumscription of the areola mammæ has been observed by Friolet (Münchener med. Wochenschrift, I905, LII, I8I8).

The patient was a woman 28 years old, who like her mother before her, had a peculiar keratosis of the papillæ of the skin of each areola mammæ. This formed a thick cluster of closely approximated brownish-black pigmented excrescences that surrounded the normal nipple like a wreath. Much dirt collected between the excrescences, and it was only when this was cleaned out that the papilla was brought to view. Each horny papilla was either sessile or flask-shaped, and between them were deep recesses. The disease first made its appearance at the age of $x 2$ years. It bad never been the source of any irritation or pain, though it was annoying because it interfered with cleanliness.

Molluscum contagiosum of the female breast has been observed by Heath (The Lancet, London, May 6, I87 I, i, 603) who mentioned it casually and without detail or description. An interesting case affecting the areola mammæ has been reported by Klauber (Prager med. Wochenschrift, I904, XXIX, 65, 663).

It occurred in a woman 37 years of age, married for 20 years and the mother of five children, the last of whom she nursed three years ago. A week before admission to the bospital the patient felt a burning sensation beneath the left nipple and found a little tumor there. The breast was well formed, the nipple normal, the areola pale brown. At the border of the areola, in the lower outer quadrant, with its long axis parallel to the areolar border, is a prominent hard tumor 18 by 6 by $6 \mathrm{~mm}$. It is sessile, and its upper surface is intensely red and appears like granulation tissue. In the part of the tumor directed toward the nipple there was one large and several small whitish pin-bead prominent points that were supposed to be glands of Montgomery, though they were remarkably large for the non-pregnant areola. When the breast was pressed, nothing escaped from the tumor and no blood appeared upon its surface. There were no enlarged axillary nodes. Under the suspicion that it might be a malignant tumor of the areola, possibly arising from the sebaceous glands, it was excised, leaving the nipple. Perfect healing followed. Upon microscopic examination it was found to be molluscum contagiosum.

Dr. M. G. Wohl brought one of us, within a year, a small tumor excised from the breast of a patient in a hospital in Philadelphia. It had been removed under the supposition that it was a form of skin cancer, but microscopic examination at once showed the unmistakable structure of molluscum contagiosum. 


\section{AUTHORS INDEX}

A.

AbBatucci, 345

АBBÉ, 630, 656

ABDERHALDEN, 540

ABELL, 260, 264

ABERNETHY, 270

ABRAHAM, 206, 2 IO

Abramow, S. S., 368

ADAM, 84

ADAMI, 484

ADAMKIEWICZ, 66 $\mathrm{I}$

AdDison, $347,35^{\circ}$

ADLER, 239

AGNew, 572

AHLFELD, 55

Albers, 5

Albert, i io, 356

AlCOCK, 694

AlibERT, 346

Allen, 405

AllessandrI, 326

Allix, 433

Altarop, 362

Altmann, I60

Amado, 434

Amaya, 434

A MBRosoli, 243

Ammentrop, 236

ANCEL, I4

ANDERSON, 380, 434

ANDREJEW, 317

ANGERER, I63, 237

ANGIER, 238

Ansieux, 142, I 50

ANSPACH, 203, 207

Antoni, 398

ARMSTRONG, 434

ARNOLD, 400

Aschoff, 255

AshHurst, 382

AshHuRst, JoHN JR., 434

AsHWELL, 447

Asmus, 367

ATKINS, $35^{2}$

A UDEBERT, 362,367

AutofaGE, 390,438

AVlandi, 434

AXFORD, 672
BABCOCK, 689

BABES, 204

BAHAUD, 206

BAINBRIDGE, 662

BAJARDI, 364

BAKER, 35I

BAMBERGER, 509

BANES, 386,578

BANTOCK, 434

VON BARDELEBEN, 84

BARDENHEUR, I 79

BARKER, 548

BARNEY, 56r

BARREY, I9I

BARTEL, I I 2, I 50

BARTELS, 55

BARTHELEMY, 243

BARTON, 357, 452

BARTSCH, 203, 207

VON BAsCH, I6

BASCH, I 86

Battle, 400, 434, 514, $68+$

BAUCHET, 408

BAUMGARTEN, I 76

BAUMGARTNER, I69

BEADLES, 287,344

Beatson, 389,630

Beatties, 287

BEAU, $142,145,150$

BECK, 638

BECKTON, 398, 400

BEDOR, I 50

BEER, 246

BÉgouin, 353

Belcher, H. E., I5o

BELL, $27^{\circ}$

BELOT, 696

BENDA, IO

BENEKE, 255, 407, 434

Benger, Miss, 52

BENIANS, I 84

Benmosche, 4+t I

BENOIT, IO7

BERG, I 85

BERgER, 2 I 6

VON BERGMANN, 4I5, 575

Berka, F., 9, 20, 280 
Bernheim, I 82 , I 83

BERNS, I5O, 518

BERTHERAND, 150

BERTRAND, 662

BETAGH, 393, 434

DE BEuRmaNn, 249, 250, $25 \mathrm{I}$

Bevan, 638

BIEHLER, I 84

Bille R, 160

Billings, 152

BillRoth, 98, I08, 244, 353,358, 368, 384, 387 , $390,575,676$

BinaUd, 210,452

Birkett, 85, I50, 310, 677

Birsch-Hirschfeld, 245

BISEL-Z WICKAU, 237

BJORKGVIST, 85

BLACK, 577

Bland-SuTton, 497

BlodgetT, 5 I 4

BloODGOOD, 207, 258, 269, 276, 288, 308, 485, $548,564,571$

Blumenthal, 662

BoCKENHEIMER, 434

BODDAERT, 392

BoerhaAve, I 43, I 50,330

BOERICKE, 174

Boggs, 652,656

BogolubOFF, II 4

BorsSARD, I67, I 77

Bollinger, 234

BONET, 400, 434

BONIN, 459

BONNET-LABORDIÈre, 67I 。

BoNNEY, 287

BoNZANI, $47 \mathrm{I}$

BOODYATT, 454

BornatT-Legueule, 390

BORREL, 339

BORST, 278, 397, 409

Bossi, 399

Bottle, 360

BOUCHACOURT, 262

Bouchereau, 150

Bougennt, 660

Bourn, It

BowLby, 298, 308, 35I, 687

BOyd, 630

Braendee, 203, 206

Brandsburg, 217

Braquehaye, 452

BRAUN, 163,585

BRAUnSTEIN, 659

BREEKS, 150

BRENSER, 3 I 4

BREWER, 5 I 4

BRIEGER, $5+0$

BrissaUd, 280
BRODIE, 270, 298, 352

Broussais, 330

BROWN, 85

BRUANT, I5I

BRUC, 246

BRUCH, 408

VON BRUNN, 99

BRUNS, 434

BRYAN, 5 I 4

BRYANT, I $51,244,267,348,363,365,384,473$, 678

BRYK, 354

BUFF, 393

BuLL, 504

Bumm, 174

BUNDSCHUH, 216

Bunts, II 7

BURCI, 434

BURKITT, 259

BURNAM, 656

BuRROW, 353

Busch, 17,98

Bush, 151

Butlin, 298, 310, 393, 687

BUtTER WORTH, 397

C

САBOT, 380

CAILlot, 47

CALDTELL, 653

Calkins, 338

Cameron, 56, 460

Canto, 435

CAPELlaRi, I 86

CARL, 365

Carmichael, 5 I 4

CARNIL, 393

CARr, 207

Carrara, I4I, I5 I

CARrel, 476

CAse, 388, 4I 3

Caspari, 659

Castrati, 15

Cattani, 262

Cezilly, 328

Chalot, 675

Chambers, 51, I42, I 5 I, 386

Champneys, 55

Chaput, 174

Chassot, I 69

Chaussier, 13

Cheatle, 287

Chevrier, 359

Cheyne, 575, 634

ChIARL, 255

ChOYCE, 287

Christopherson, I 40, I5I 
Cignozzi, 206

Clarke, 338, 389, 400

Claypole, I 5

Cliet, 678, 680

Cloquet, I 5 I

Clutton, 262

COAN, 662

COCA, 663

COE, I44, I 5 I

CÖ̈N, 435

Coenen, 4 Io, 44I

Cohen, I 40

Connhein, 337

Coler $, 373,383,386,393,419,521,660$

Collignon, I5I, 4I6, 4I9, 5 I 8

ColzI, 367

CONNEll, +15

Contagne, I44, I 5 I

COOPER, 264, 270, 358

.Cooper, Astley, 202, 352, 400, 406

COPLIN, I 52, 305

Cornil, 98, 298, 358, 395, 680

Coste, 185

COWLEy, I 52

COYNE, 298, 310, 435

Creasy, I 52

CREDÉ, 393

Creighton, 7,278

CrILE, 54I

CRISPIN, I 52

CROCKER, 347

Cropper, 339

CruveilhieR, I 45, I 52, 259, 358

Cuneo, 38, 506

CurschianN, I 86

Cushing, 435, 601

Czerny, $398,575,638,660$

D

DACHTLER, 652

DACosta, 262, 399

DAMEN, 320

DAMOURETTE, 176

DANEL, 410

DANIEL, 357

DARBEFEUILLE, 320

DARBY, 4

DARGAN, I6

DARIER, 688

DARTIN, 55

DaVAine, 328

Davidsohn, 359

DAVIES, II 3

Davis, 2 =8, 695

DAWBARN, 6I 8

DEFORST, 676

Degrais, 657
DEHNER, II 8

DEHRNEAN, 4 I 9

DEISS, I69

Delage, 355

DELAMERE, 38

Delbet, 207, 257, 578, 662

DElFino, 2 I 8

Delfiz, IO8, I I6

Delgrange, I 88

Delval, 359

DEMKER, 98

DEMME, 204, 207, 208

DENCKER, 397

Denenholtz, 473

DENNIS, I 52

DeRoulet, 435

DERVAUX, I 77

DESCHWEINITZ, 435

DESCO, 204

Desgoutté, I63

DEsprés, I63, 200

Destrée, I 86

DetTling, I52

DÉVE, 318

DIEBERG, 347

DOCK, 397

DoR, 407

DORSCH, 4I 2

Douglas, 239

DowD, 459

DOYEN, 338, 66I

DREYDORFF, 678,680

DRumaond, 16 I

Dubar, 203, 207

Dubreuil, 2 I I

Dubreiule, 690

Du Castel, 675

DUdLey, 352

Duguet, I9I

Duhring, 688, 689

VON DUMREICHER, 266

DẗMS, I9I

v. DUNGERN, 539

DURAND, I 72

DURHAM, I 52, 400

Durston, IO4

DUVAL, 5 I

DUvergey, 200, 201, 206, 217

EberhardT, 679

VON EBERTS, 207, 2 I4

Eccles, 309

EhrenhaUs, IO7

EHRHARDT, 674

EICHER, I 75, I 79

Elliot T, 435 
ELLIS, I4I

ElsberG, 387, 435, 54I

ELzE, I

EMmerick, 66I

ENGLÄNDER, II I

ENGLISCH, 435

ENGSTRÖM, I 8, I 45

ENTZ, 435

ERDHEIM, 84, 408

ERDMANN, I69

ERICHSEN, 384

Escherich, Th., I60

Evans, J. H., 307

EvE, I 49, I52

\section{F}

FABIAN, 397

FAGGE, 347

FavVey, 432

Febiger, 339

Fehleisen, 660

Felégyházi, 674

Ferguson, 207

FERRAN, 259

Fiaschi, 473

FiNDLAY, 435

FINK, 495

FinNey, 548, 554, 56I

FinSEN, 3I4

FinstereR, 372, 398, 4I6, 424, 460, 504, 559

Finzi, 657

Fioriani, 393

FirfarofF, II 5

Fischer, 436

FischerA, 662

FleChSIG, 86

FOÁ, I 5

Foerster, 46I, 65I

Foges, 84 , I 12

FOOT, I $44, \mathrm{I}_{5} 2$

Forbes, 98

Forbes, W. S., 305

Fordyce, 686

Forget, 262

ForNaCA, I 86

Forrest, 694

Foucher, 359

Fournier, 24I, 242, 692

Fox, 690

FrafNkel, II6, 207

Franco, 2 I 6

Frank, 540, 642

Franklin, John, I6

Frazier, $57^{\circ}$

FreUND, $65^{2}$

FRICKE, 2 I 7

FriedLÄNDER, 204
Friend, 436

Friolet, 702

Froriep, 46

Fuller, 203

GaDsBy, 310

Gaillet, 408

GaLEN, 330

GALLIET, I 43, I53

Galliot, 660

Gangitano, I 53, 458, 473

GARCIÁ, 436

GARDENER, 85

GARNIER, I69, 205

Gastinel, 339

Gates, H., 328

Gaube de Gers, 659

GAUDIER, 205

GAY, $245,384,388$

GAY, G. W., 3 I I

GAYLORD, 338

Gebele, 372, 398, 436

Geissler, 203

Geist, 373, 54I

GEORGIEFF, I 53

GERDY, 320

Germatz, 4 I9

Gerota, 36

Gerster, 577, 6I4

GEYL, 55

GiBB, 4

GibBons, I77

Gilchrist, 379, 393

Gilette, 264

GinsBerG, 239

GinsBURG, I44, I 53

Gintrac, 694

GIRARD, II 9

GLUCK, 98

GLÜCK, 436

GOCHT, 638

GODLEE, 239

GoINARD, 3 I 8

GoldmaN, 497, 509

Goltz, I6

Gorescu, 339

GORHAM, 54 I

GorhaM, 406

GorhaM, J., I43, I 53

GoRRÉ, 55, 85

GORRINGE, I 53

GotTheil, 242

GOUGERT, 249, 25 I

GOULD, 262

GözE, 3I4

GrAEFE, 404 
GRAFF, 662

GRAHAM, 184

GRÄHS, I 12

Gratia, 317

GravaGNA, 242

GREEN, 678

GREENHOW, 47

Greenough, 290, 308, 454, 528, 556, 56I

Gregorini, I 53

Griffith, 84, I90, 675

GroHe, 406

Groma, 245

Gross, $287,298,302,358,380,398,417,42 \mathrm{I}$, $4.53,577$

Gross, S. D., 384,385

Gross, S. W., 373

GrossmaN, 32

Groszbieckes, 436

GRUBER, I53, I6I

Gruget, 436

GuermonPrez, 326

Guilbaud, 400,436

GULEKE, 559

Guthrie, I IO, $35^{6}$

VON HACKER, 400

HACQUARD, 93

HAECKEL, 46, 353,394, 406, 408

de HAEN, 320

HAHN, IO2

HAKE, 366

HALBAN, 4

Hall, 5 I 9

HALPERN, 539, 542

HALSTED, 203, 487, 504, 527, 532, 546, 558, 573 , $575,579,582,633$

HAMMOND, I 4,15

HANAU, 239,476

HANDLEy, 3, 26, 34, 287, 344, 497, 502, 507,

HANDYSIDE, I 4 I, I 54 $565,568,603,631,640,689$

HANES, 503

HANNEMÜLLER, 688

HANRIOT, I 87

HAPPEL, 359

HARE, I 53

HARE, SAM'L., I 43

HARDOÜIN, 205

HARGENS, I 54

HARLAN, 17

HARRISON, 476

HARRISS, 57

HARTUNG, 86

HARTzEll, 689, 696

HASSLER, I 42, I 43, I 45, I 54, I9O

Haussman, 328

HeATH, 350, 384, 702
Невв, 207, 210

HECK, I 74

Hedren, 412, 44I

Heibaum, 683

HeidenhaIN, 40, 578

Heitzhiann, 98

Hektoen, 249

Heller, 246

Henderson, 508

HeNNig, 199

HenNing, 245

HERCZEL, I I 2

Hermian, 540, 630

Hermiann, 259, 260

Herxheimer, 44 I

Heurtaux, 400,436

Heuter, 400

Hewson, 436

HEY, I08

Heyfelder, 207

Hiebaum, 408, 436

HILL, I5

HilleR, I46, I 54

HIRSCHBERG, 303

HIRSCHBERGER, 205

Hirschel, 585, 586, 688

Hirshland, I

HiRsT, 85, I $74,448,674$

HrTT, 436

HochNEGG, 659

VON HockER, 436

HODENPHYL, 66I

Hoenigsberger, I 13,351

HOFFMAN, I $54,384,388,5$ I 8

HofFman, M. B., 685

HOFFMAN, S., 367

HoHMEIER, $585,5^{87}$

HOLDER, 400, 436

Hollopeau, I 54

Holst, 660

HOME, 5 I 4

HoOver, 4I5

HORING, $55^{8}$

Horner, $373,398,400,436$

HorT, 526

HORTELOUP, I 54, 207, 393, 424

HOUZEL, 386, 436

HowaRD, 348,384

HOY, $I 08$

HuBbard, 509

HUBER, 396

Hubert, 48

HuETER, $3 \mathbf{I} 7$

HUGUET, I9I

Humbold, I 6

HUNTER, I 54, 259

HUNTER, JOHN, 330

Hutchinson, $47, \mathbf{I} 54,348,350,380,458,563,678$ 
708

I

ILL, 299

IMAGE, 366

INGIER, 207, 21 5,280

ISRAEL, I47, 154

ISRAEL, J., 240

IsRAEL, O., 240

I WAI, 85

JACKSON, 437, 628

JACOBEUS, 688

JACOBI, 437

JACOBORICI, 437

JACOBSON, 437

JACOBSTAHL, 237

JACOULET, 98

JAGER, I8I

JAMAIN, 239, 680

JAMISON, 689

JANSSEN, 155

JENNINGS, 558

JENSEN, 476

JESSIEN, 85

JEWELL, 263

JoHnson, 140, 437, 638

JoNAS, 695

JONES, 345

DE JONG, 39 I

JoPSON, 437, 454, 5I $5,686,694$

JUDD, 432, 516, 546, 548, 559, 570

JUNGMANN, $69^{\circ}$

K
AUTHORS INDEX

Khesin, 206, 207

KIENBÖCK, 432, 655

KilPatrick, 85

KING, 47

KIRSCHBERG, 659

KLAPP, 183

KLAUBER, 702

KLEBS, 204, 362, 363, 683

KLOB, 408,683

KLOSE, 216

KNOPFELMACHER, 4

КосH, 338

KOCHENBERGER, I42, I 55

KOCHER, 577

KOEHLER, I69

KöllikeR, Тн., 4

KONJETZNY, 407

KOPTZENBERG, 652

KOSTER, I44, I 55

KRABBE, 3 I 4

KRAMER, 204

KRAUSE, 652

KRAVEHENKO, 44I

KRAWTSCHENKS, 345

KRIEG, I55

KRIEGER, 155

KROELL, H., 684

KROMPECHER, 7, IO, 278

VON KRYLE, 688

KÜCHENMEISTER, 314

KÜRSTEINER, 406, 437

KURU, 279

KÜSTER, 505, 549, 575

KuTtNER, Ir 8, 396

LABBÉ, 155, 298, 310

LACASSAGNE, 156

LAHN, 407

DE LAMBBELL, 260

LAMBERT, I63, 503

LANCEREAUX, 243,437

LANDOIS, 688

LANDOUZY, 25I

LANE, I 5

LANGE, 359

LANGENBECK, 234, 366, 393, 577

LANGER, 2, 34

LANGHANS, 39,280

LANGLET, 696

LANNELONGUE, 364

LANPHEAR, 348, 634

LARDENNOIS, $383,398,437$

LASSAR, 660

LASSEN, 398

LATARGET, I 72

LAUNAY, 259 
LAURENT, 52, 156

LAURIE, 437

LAWRENCE, 396, 437

LEAF, 34, 4I, 569

LEBEAU, 102

LEBEDEFF, 3 I 7

LEBERT, 678

LECÈNE, I69, 405, 407, 437

LE CONTE, 318,320

LE DOUBLe, 108

LEGRAIN, 437

Legued, 633

LeHEMANN, 320

LEICHTENSTERN, 52

LEMBERT, I 56

LENDET, I $87, \mathrm{I} 88$

LENMORANT, I69

LÉoN, I 56

LEPAGE, 683

LERAT, 252, 304

LEREBOULLET, I 43, I 56

LESER, 358

VON LESER, 38I, 400, 437

LETT, 630, 653

LEUCKART, 270, 3I 5

LEVÉque, I9I

LEVIN, 500, 519

LEWIN, 662

LEWIN, Carl, 500

LEXER, I 56

LICHTENHAHN, 280 .

LiChTHEIM. I 88

LiCiNI, 398

LIEBER, I 42, I 56

LIHOTZKY, 317

LilienthaL, 31 8, 392

LINFORS, 684

LIPPENS, 437

LIPPMANN, 44. ${ }^{\circ}$

LISTER, $338,575,634$

LISSER, 54I

LisTON, 366

LÖBKER, 354

LOCKWOOD, 578

LOEB, 659

LOEB, LeO, 337

LOECK, 244

LORAIN, I 4

LORRAIN, 39I, 416

LOUSIER, 46

LOZBECK, IO9

LUCAS-ChAMpionitire, 578

LUdKe, 540

LUKE, I 42, I 56

LUSCHKA, 4

LuTz, 249

LVOFF, II 5

Lyon, 501

MACCARThy, 277

Mackellar, 300

Macleod, 690

MACSWINEY, 345, 680, 68I

MALAPERT, 362, 365

Malassez, 693

Malleat, I03

Malloizel, 390, 438

MALY, 280

Mandelbaum, 392

MANdRy, 685

Manley, 258

Manson, 326,438

MANTELLI, 218

MANZ, 437

MARANGONI, 2IO, 2 II

MarCaNo, 393

MaRChaND, 254, 377

MARESCH, 280

MARIE, 85

Marignac, 438

Markoe, 438

MARLOTH, 354

MAROTTE, 56

Marouis, 205, 206

MARShall, I4, I5, 310

MARTEL, 146, 157

MarTin, 98, 459, 602

Masland, 689

Massabiau, 355

MassabuaU, 217

Masse, 353

Massoulard, Igo

MaUpin, 199

MAUte, 357

MAYBerRy, 684

MAYBURY, 514

MAYO, 526, 565, 57I

MCARTHUR, 237

MCConkey, I86

MCCONNELL, 157

MCCREA, I 85

McGillicuddy, $47^{\circ}$

MCGRAW, 437

MCJUNkin, 437

McWilliams, 397, 437, 52 I

MeCKEL, 55

MeEK, 696

Meldon, 353, 354

MÉnard, 39I, $4 \mathrm{I} 6$

Mencke, I63

MENDEL, 335

MERKEL, 356

Mermet, 438

MERRILL, 638

METCHNIKOFF, 338 
Meunier, 438

Meyer, 583, 620

Meyer, WILLy, 56I, 576

Michaelis, 320

Michaelson, 326

Michaux, 3 II

MiChel, I 18

Miel, 438

MIELECKE, 512

MilefF, 238

MinTz, 280

Mitchell, 16

Mitchell, S. Weir, I 5.

von MiKulicz, 434

MODEL, $43^{8}$

MOIZARD, I57, I90

MonOD, 380,438

Montauban, I6

MontÈGRE, I6

MONTEIL, 107

MONTGOMERY, I 57

MoORE, 327, 392, 438, 575

MORALES, 44I

MORESTIN, I79, 684

Morgan, I 44, I 57

DeMorgan, 30I, 4I 3

MoRgani, 400

Morichau-Beauchaut, 362

MORIRI, 685

Mornard, 438

MoRrIS, 438

Morton, 360, 386, 638, 656

Morton, Chas. A., 309

Moschowitz, 600

von Mosetig, 438

Mouchet, 438

Moure, 383, 391, 398, 438

Mourne, 98

Mouski, 438

MUCHANOFF, II 3

MülleR, 279, 330

MÜLler, JohanNS, 406

MuRPHY, 303, 495, 507, 578

MURRAY, 157

$$
\mathrm{N}
$$

NAGLE, 506

NANCRÈDE, 438

NAUNYN, 314

NeILson, 98

NeISSER, 690

NÉlaton, I 43, I57, I67, 238, $35^{8}$

Nepveu, 269

Neuberg, 659

NEugebauter, 46, 84, 157

Neuhor, 5+I

Neumans, $2+5,438$
Newcomet, 657

NEWMANN, 407

NicholLs, 484

NiCLOT, I90

Nicolas, 204

NiEPCE, 205

NiKLAS, 683

Nocton, 675

NOHL, I 82

NolAND, $52 \mathrm{I}$

NoRdMANN, 260, 262, 345

NunN, 167, 393, 509

VON NUSSBAum, 438

O

O'Donoghue, I5

O'Ferrall, 680, 68I

O'FlyNN, I7

OHNACKER, 203

OLLIER, 459

Olphan, I 57

OLSNER, 39

O'NEILL, 689

ORTH, 4I3, 44I

ORTHMANN, 204

OTT, I6

\section{$\mathrm{P}$}

PACKARD, 564

PAGET, 270, 438, 508, 569, 686

Painter, 349

Pallas, 314

Paltauf, 509

PARIN, II5

PARIOT, 362, 367

PAROUNAGIAN, 242

PARSON, 266

PARSONS, 205, 207

PARTSCH, 236

PASQUier, 206

Pasteur, 338

Paterson, 535

Paton, 326

Patterson, 247

PAUL, F. T., 287

PaUlicky, 142, I44, I57

Paull, 47

PAYR, 633

Peachell, 300

PeAR, 47

PEAU, 3I 7, 438

PEDRO, IO2

PELANDER, 320

Peraire, 98 I9I, 205

PerCy, 52

Perelzweig, 157 
Perker, 262

Perkins, 346, 249

Peter, I 43

Peters, I 57

Peterson, 432, 438

Petgès, 242, 459

Petit, 358, 438

Petrìquin, I44, I45, I 57

Pfahler, 432, 567,637

Pfeiffer, 4I I

Pflanz, III, I4I, I57

Phelps, 519

PhILliP, 5I5

Phillips, 349

PICK, 380

Pik̀rRe-NADAL, 439

Pigot, 518

Pilcher, 559

Pilliet, 438

Pilz, 679

Pinch, 602, 657

Pinkuss, 540

Pitha, 439

Pitzorno, 98, 460

Ploss, H. H., 6

Pluyette, 204

Polrier, 32, 38, 207, 506

POLAILlON, I42, I 58

POLlard, 307, 310, 684

PONCET, 407

Pollitzer, 690 .

PONS, 3 I $\mathrm{I}$

PORTA, 439

PORTER, I I I, 680

Pospelow, 690

Post, 439

Poulsen, 373, 398, 4I $8,422,438,53$ I

Pousson, II 8

POWELL, 239

Powers, 203, 389, 439

Primrose, 455, 516, 556

Prudden, T. M., 433

Prym, 407, 439

Puech, 17, 264

PuLs, $45^{8}$

Pusey, 639

Putzu, 207, 386, 416

Puyhaubert, 354, 355

\section{Q}

QUEIREL, 352

QuÉNu, 250, 252, 505, 527

QUERVAIN, $45^{2}$

$\mathrm{R}$

RAGGI, I 4 I, I 47, I 58

RAMSEY, 5 I9
RAND, 515

RANDOLPH, 4I5, 439

RANSOHOFF, 562

RaNvier, 298, 393, 395

RANZI, 662

RapiN, 85

RATHMANN, 354, 355

RAVENEL, 204

Ravogli, 690

RAYER, I 58

v.RECKLINGHAUSEN, 500

ReClus, 27 I

Referent, 280

REICHEL, 236, 238

REID, 397

REMFRY, 46

REMY, I7

RENAUD, 578

Renauldin, 47, 142, 158

Ressiguie, 207

REVEL, 218

REVERDIN, 439, 68 I

REY, 360 .

REYNOLDS, I6I

RheinofF, 439

Ribbert, I6, 204, 256, 379, 478

RICHARD, 362

RicheLOT, 439

RicheT, 439

RICHTER, I 58, 243

RIED, 396, 439

RIEDEL, 384, 39 I

Rilliet, 199

Risley, 541

RIVIERE, 662

RIXFORD, 634

RoBELIN, I 58,190

ROBERT, 85

RoBERTS, 634

RoBIN, 439

RoBinson, 2 I 8, 399, 684

RODMAN, 216, 4I 8, 453,5I6, 522, 546, 65I

ROEFFEL, 39

ROGEAU, 298

ROGER, I69, I86, 660

ROGERS, 205

RÖMER, 400, 439

ROPKE, 52 I

RosenOW, 334

Rosenstein, 439

ROSENTHAL, 246

Rosinski, 109

Ross, 339

RothMANN, 400, 439

ROTTER, 546, 563

RouAnet, 243

Rous, 339

ROUSLACROIX, 252. 
Roux, 203, 320

Rovsing, 662

DE Rouville, 98

RuBEsCH, 262

Ruediger, 250

Russel, 300,678

\section{S}

VON SAAR, 7, I0, 278, 280

SABRAZĖ, 210

SACASA, 158

SAILER, I 48, I 58, 35 I

SAINT-Hilaire, 46

ST. JaCQUES, 207

SALEWSKY, 85

SALMON, 177

SALTZMANN, 264

SALzAC, 680

SAMELSON-KLIWANSKI, 280

SANTESSON, 683

SANTY, 320

SAPPEY, 38,502

SARFERT, I69

SASSE, 299

SATTERTHWAIT, 439

SAUL, 339

DE SAUVAGES, 245

SAVITZKY, I42, I 58

SAXON, 336

SCANZONI, 46

SCARPA, 26I, 263

SCHADEL, 439

VON SCHAMBACHER, 688

SchaumanN, I42, I 45, I 58

SCHEDE, 207

SCHEIBER, I 44, I 58

SCHEIDIGGER, 2 I 6

SCHENCK, B. R., 249

SCHICKELE, I

SCHILLER, I 76, I8 I

SCHIMMELBUSCH, 299, 459

SCHLAGENHAUFER, 4 I $3: 442$

SCHLEIDEN, 330

SCHLEY, 203, 210

SCHLOFFER, 548, $56 \mathrm{I}$

ScFMIDT, I, 32, 206, 373, 398, 399, 407, 415, 499,679

ScHMIDT, H., I

SCHMIT, I43, I 58

SCHMiTT, I

SCHMUCKERT, 439

SCHREIBER, I I 4

SCHroedER, 398, 400, 439, 563

SCHUCHARDT, I 59, 373, 4I 6, 5 I 7

SCHUFELDT, I 40,144

Schultze, O., I

SCHUMAN, 479
SCHUOLER, 373,439

SCHUYFELDT, I 59

SCHWANN, 330

SCHWARTZ, 439

SCHWARZ, 412,578

SCHWARZKOPF, 516, 548, 557

ScoTt, I6, I63, I98, 203, 206, 21 5,302

SCOTT, SIDNEY, 207

SCUDDER, I98, 203, 213

SÉcousSE, 4I I, 439

SÉDILLOT, I9O

SEGOND, 439

SEHRT, 237, 360, 400, 439

SELL, 440

SENDLER, 679, 680

Sequiera, 689

SERGENT, 3 I 8

SHATTOCK, 2 I $8,300,308$

SHAw, 678

SHEILd, I 78, I99, 266, 349, 363, 392, 417, 42 I,

SHERE, 440 $455,666,685$

SHIELD, I 72

ShoEMAKer, G. E., 299

Siebert, 440

SICK, 360

VON SIEBOLD, 314

Simmons, 290, 300, 308, 454, 528, 56I

SimoN, 396, 440

SIMPSON, 399

SISTRUNK, 55 I

Siter, 677

SiTTENFIELD, 500

SLOCUM, $5^{84}$

Stye, 5 I9

Slye, Maude, 335

SмITH, 353,548

SNow, 238, 504, 634

Socinus, 84

Solokow, 683

SOMMER, I 59, 239

Souligoux, I74

SPEDIACCI, 204

SPEESE, 269, 4I9, 448, 454, 473, 495, 515, 578 .

SPENCE, I I 686,694

SPENCER, 217,301

SPILler, 602

SPLENDORE, 249

SPROUCK, 660

StarLING, 15

STEFANINI, 359

Steinthal, 549

STELWAgON, 689

STEINBERGER, $44^{\circ}$

Stieda, I 45, I59

Stiles, 33, 507, 577

STILLING, $400,44^{\circ}$ 
STOERK, 408,440

STOKES, 440

STONE, 393, 440

STrAHL, I

Strasser, 300

Stratz, C. H., 5

Stromberg, 217

Strong, L. W., 368

Stropeni, 98

StudsgaARD, 440

SutTon, 92, 364, 400, 683

Sutton, J. B., 306

SWANN, 440

SyMONDS, 326

SZÉNÁSY,392

$\mathrm{T}$

TADDEI, 365

TAKANO, 409

TARNIER, 169

TARNOWSEY, 690

TATChell, I 59

TAYLOR, 239, 696

TERRIER, 239,680

TERRILL, 108

Terzogli, 696

Testut, 45

TEUTChOFF, 46, 48

THAYER, I 86,188

Theilmaber, 440, 562, 653

THIELE, 279

ThIN, 688

THIRIAR, 440

Thomas, I 79

Thomas, T. G., 463

Thompson, $5 \mathrm{I} 4$

Thomson, 46, 159

Tietze, 288, 299, 440

Tillaux, 380

TOKANO, 442

TOREK, 63 I

TöröK, 506

Tremarne, 405

TRENEL, 199

Triebig, $54^{\circ}$

TRILLOT, I 72

Trinithek, 396,440

TRIPIER, 369

TUFNell, 144, I 59

TURNER, 587

TyRRELL, 259

TYzzer, 495

UNNA, 255, 379, 393, 688

UNTIEDT, I 64

UРсотт, 462
V

VACCARI, I 9 I

VACHÈRE, I I 8

VALUDE, $44^{\circ}$

VANDEN BERG, 462, 475

VANVERTS, 56I

VARIOT, 4,18

VAUGHAN, 663

VEILLARD, 32 I

VelpeAU, I I 2, I67, I 90, 262, 270, 348, 353, 394 , 455,686

VENNES, 242

VÉNOT, 440

VERChÈre, 204

VERCOULLIE, 392

VERNEUIL, 204, 211,267

VERRIER, 362

VERSE, 237

VIALLE, I63

VIEREGGE, 393

VIGNARD, 206, 304, 380

VIGNERAT, 392, 440

Vignolo-Lutate, 693

VILLARD, 362, 367

VilleneUVe, I45, 159

VINCENT, 675

VIRCHOW, 270, 330, 337, 345, 406

VON VOLKMANN, 3I $7,440,479,575$

W

WACKER, 393

WAGNER, I 43 , I 59

WALKER, 693

WALL, IO3

WALLERT, 675

WALTHER, 2 I 7

WANNIENHENHUYSE, 2 IO

WARD, 440

WARDEN, 2 I I

WARREN, 84, II 2, I 59, 272, 276, 287, 343, 352, $359,415,454,487,516,546,557,563$

WASSERMANN, 659

WATSON, 400

WEBER, I42, I 59

WEHNER, 4 I I

WEIGANDT, 44 I

WEIL, 500, 686

WEINBERG, 321

Weinberger, 396

WEINLECHNER, $44 \mathrm{I}$

WELCH, WM. H., 433

WELJAMINOW, 239

WENNING, I99

WERNER, 65I, 660

WESSINGER, 676

West, Caroline, I 86, I 87 
WHARTON, 4HI

WhitACRE, 98

WOHLSECKER, 278

WOLBARST, 563

WÖLFLER, 548

WhITE, 437, 454, 5 I 5

WhITING, 584

WHITSON, 44I

WHYTE, 47

WICKHAM, 639, 657, 688

WOLFSOHN, 539, 540

WOODYATT, $47 \mathrm{I}$

WULLSTEIN, 366

WIEBRINGHAUS, I69, I $8 \mathrm{I}$

WYaT, 52

WIGGIN, 686

WILE, 688

WILEMINSKY, I 86

Williams, 48, I59, 259, 264, 349, 362, 364, 373, $4 \mathrm{I} 4,453,455,459,495,509,540$, 639

WYETH, I 44, I6o

Young, 17,442

Z

Williams, J. T., 201

WILMS, 408, 634

ZAMBIANCHI, 44I

WILSON, IO2

WILTSHIRE, I47, I60

WINCKEL, I $68,169,393,675,678$

ZANGMEISTER, I 82

ZAPPERT, I66

WINFIELD, 44I

VON WINIWARTER, 5I6, 69I

ZELENEFF, I45, I60

ZERENIN, 44I

ZIEHEN, 97

WINSLOW, 4I5, 44I

WiTkOWSKI, 84

WITTELSHOFER, 506

ZILOCCHI, I4I, I47, I60

ZimMERMAN, 47

ZIRONI, 217

WLAEFF, 66I

ZOTT, 163

WOHL, 692, 702

ZURAKOFF, I06 


\section{SUBJECT INDEX}

\section{A}

Abderhalden's test, 539

Abnormal involution, 17, 269

diagnosis, 287

etiology, 272

morbid anatomy, 274

pathology, 280

prognosis, 288

symptoms, 273

treatment, $29 \mathrm{I}$

Abscess, see Mastitis.

areolar, 675

intra-mammary, 178

Desmorest's operation, I 79

Sheild's operation, 178

mammary, I 7 I

Bier's treatment, $18 \mathrm{I}$

chronic, 196

diagnosis, 196

pyogenic, 196

treatment, 198

in infants, 4

Morestin's incision, 179

subcutaneous, 178

treatment, 177

vaccine treatment, 184

of Roux, 215

retro-mammary, I 8I

"shirt-stud," I 8 I

Accessory mammary gland, 5I

Acephalocyst, 316

Acetolphen, 584

Actinomyces bovis, 234

Actinomycosis, 234

diagnosis, 24I

primary, 235

prognosis, 240

secondary, 238

treatment, 240

"Acute miliary carcinosis," 484

Adeno-carcinoma, 482, 485

cylindromatosum, 482

of Halsted, 482

Adeno-cystic-sarcoma, 38x

-cystoma papilliferum mammæ epitheliale, 273

-cysto-sarcoma, 402

-fibroma, 442

Adenoma, cystic, 449

pure, 442
Adeno-sarcoma, 38I, 402, 45I

Adiposity of breast, I Io

Agalactia, 16 unilateral, i7

Ahlfeld's theory of polymastia, 55

Alveolar sarcoma, 378

Amastia, 45

embry ology, 2

surgery, I0o

tabulation, 48

unilateral, 46

Amazia, 45

Ampullo, 9

Amputation, inter-scapulo-thoracic, 634 of breast, 574

conduction anesthesia, 585

hypertrophied, 117

in gynecomastia, $\mathbf{1} 48$

Anesthesia, 584

conduction, 585

local, $5^{8} 4$

Anatomy, comparative, 63 surgical, 26

Angioma, 36r

arteriale racemosum, 362

cavernosum pendulum mamillæ, 680

cavernous, $36 \mathbf{I}$

cutaneous, 363

diffuse, 366

intra-mammary, 364

mamillary, 363

para-mammary, 363

pectoral, 364

racemose, 362

simplex, 36 I

subcutaneous, 363

Angio-sarcoma, 377, 398

Anomalies, acquired, IO2

congenital, 45

of nipple, $67 \mathrm{I}$

Antitrypsin reaction, 540

Apex of axilla, 32

Aplasia of mammary gland, 48

Areola, 8

abscess, 675

cysts, 677

diseases, $67 \mathrm{I}$

tumors, 678

Athelia, 5I, 67I

embryology, 2

surgery, Ioo 
Atheromas, 254

Atrophy of mammary gland, 160

Autogenous infections, 168

Autoplasty, 633

Axford operation, 672

Axilla, apex, 32

Axillary artery, ligation, 632

fascia, 34

lymph nodes, 40

in sarcoma, 422

vein, ligation, 632

\section{B}

Bacteriology of mastitis, 169 tuberculous, 217

"Basket cells," Io

Beatson's operation, 630

Benign tumor, 34I

tumors, see Fibro-epithelial tumors.

Bier's treatment in mastitis, $\mathrm{I} 8 \mathrm{I}$

Bifid nipple, 67 I

Blood supply of mammary gland, 35

Bone metastases in carcinoma, 508

Brachial lymph nodes, 4I

Breast, abscess, I 7 I

pyogenic chronic, 196

actinomycosis, 234

adiposity, I Io

anatomy, comparative, 63

surgical, 26

anomalies, 45

acquired, 102

congenital, I

burns, 163

blood supply, 35

classification, 6

contusions, 162

cysts, 254

development, 3

fibrosis, 193

fistula, 198

foreign bodies, 163

hematoma, I62

hypertrophy, I04

inflammation, subcutaneous, 173

in infancy, 4

in maturity, 6

in pregnancy, $\mathrm{I} 74$

lymphatics, 37

nerve supply, 36

puberty, 4

sporotrichosis, 249

tuberculosis, 202

tumors, classification, 343

wounds, gunshot, $16_{3}$

incised, 162

lacerated, I62
Breast inflammation wounds, stab, 163

Breasts, pendulous, II 8

Brodie's disease, 269

tumor, 299

Budding breast, 5

Bumm's compress, 174

"Burgeons primordea11x," I

Burns, of breast, 163

\section{C}

Cachexia, 342

Calchospheres, 377

Cancer, see Carcinoma.

Cancer atrophicans, 482 cysts, 269

"Cancer en cuirasse," 484

Cancer of nipple, 685

Cancerous pachydermia, 503

"Cancer verolique," 245

"Cancroide ovalaire," 346

Cancroin therapy, 66I

Carcinoma, 476

Abderhalden's test, 539

acinal, 482

acinar, 482

acinous, 482

adenomatosum, 482

age, $5^{14}$

antitry psin reaction, $54^{\circ}$

bone metastasis, 508

caustic therapy, 665

cautery therapy, 661

colloides, 482

cylindromatosum, 482

diagnosis, 525

differential, 536

drug-therapy, 660

v. Dungern's test, 539

electro-therapy, 66x

embolism, 497

encephaloid, 480

escharotic therapy, 665

etiology, 476, 5I 4

fulguration therapy, 662

gelatinous, 482,485

hard, 480

hemolytic reaction, 540

heredity, 518

lymphatic permeation, 502

lymph nodes in, 504

involved, 36

mastitoides, 479,483

medullare, 482

medullary, 482

meiostagmin reaction, 539

metastasis, 494

bone, 508 
Carcinoma metatasis, embolic, 497 retroperitoneal, 510

thoracic, 5 Io

visceral, $5 \mathbf{I}$ o

morbid anatomy, 489

mucoid, 482

myxomatous, 482

nipple, 684

operation, 574

operative cures, 548

mortality, 546

statistics, $55^{\circ}$

pain, 527

parietal dissemination, 504

pathology, 476

permeation, 502

post-operative complications, 597

treatment, 594

prognosis, 543

pyogenic mastitis, 523

race, 521

radium therapy, 655

recurrence, $56 \mathrm{I}$

recurrent operation, 574

retraction of nipple, 534

sarcomatodes, 409

scirrhosum, 482

scirrhus, 480

sero-diagnosis, 539

serum-therapy, 66I

sex, 517

simplex, 482, 484

skin reaction, $54 \mathrm{I}$

soft, 480

solidum, 482

medullare, 482

scirrhosum, 482

simplex, 482

squamous-cell, 483

symptomatology, 535

symptoms, 525

terminology, $48 \mathrm{I}$

trauma, 519

treatment, 567

chemo-therapy, 659

fulguration, 662

hyperemia, 658

immuno-therapy, 660

non-operative, 637

operative, 567

contra-indications, 568

radium, 655

serum, 66I

toxin, 660

vaccine, 662

$X$-ray, 638

tumor, 529

ulceration, 533
Carcinoma ulceration, vaccine-therapy, 662 with sarcoma, 488

$X$-rav, 638

Carcino-sarcoma, 409

Cartilaginous tumors, $35^{8}$

Caustic therapy, 665

Cautery therapy, 66I

Cavernoma, $36 \mathrm{I}$

Champney's theory of polymastia, $6 \mathrm{r}$

Chancre of breast, 24I

Cheloid, 346

Chemo-therapy, 659

Chloroma, 395

Cholesteatoma, 405

Cholin therapy, 660

Chondrifying sarcoma, 377

Chondroma, $35^{8}$

Chondro-sarcoma, 400

Chromatophores, 379

Chromatophoroma, 379

Chromatophoro-sarcoma, 379

Cicatrix keloid, 348

Circulus venosus of Haller, 36

Circumscribed scleroderma, $35^{\circ}$

Classification of breasts, 6

Coley's fluid therapy, 432

"Coley toxins," 66I

Colliquation cysts in tumors, $3 \mathrm{I} 3$

Colloid cancer, 482

Colostrum, I2

Comedo-carcinoma, 482

Condyloma latum, 243

Contusions, breast, I 62

Costo-coracoid membrane, 3 I

Cutaneous angioma, 363

Cylindroma, 378

Cyst, cancer, 269 colliquation in tumors, $3 \mathrm{I} 2$

dermoid, 254

echinococcus, 270, 3I 3

exudation in tumors, 312

false, 254

hemorrhagic, 3 I I

hydatid, 3 I 3

in stroma, 3 Io

in tumor, 312

involution, 273

lacteal, 260

lymphatic, 3 ro

of breast, 254

of nipple, 677

parasitic, 3 I 3

retention, 260

in tumors, 312

sebaceous, $25 t$

serous, 265

simple, 265

true, 254 
Cyst-adeno-carcinoma, 482

Cyst-adeno-fibroma, 445

Cystadenoma, 269, 449

intra-canaliculare, 273

Cystadenoma papilliare, 296

Cystadenoma papilliferum, 273

Cyst-adeno-sarcoma, 402

Cystic adenoma, 449

Cystic disease of breast, 269

Cystic mamma, 27 I

Cystic mastitis, 269

Cysticercus bovis, 325

Cysticercus cellulosa, 325

Cysticercus disease, 324

Cystoma, 27 I

Cystoma mammæ papilliferum, 296

Cysto-sarcoma, 402

Cysto-sarcoma phyllodes, 273, 402, 446

\section{D)}

Darwin's Theory of polymastia, 6I

Dawbarn's operation, 618

Deaver's operation, 587

Dermatolysis, 345

Dermoid cysts, 254

Desmorest's operation, I79

Diffuse fibro-adenoma, 273

phlegmon, 172

Diffusing mastitis, I $7 \mathbf{I}$

Digital nipple, 674

Diphtheria of nipple, 677

Drug-therapy, 660

Duct papilloma, 296

v. Dungern's test, 539

Dystrophia adiposogenitalis, I4

\section{$\mathrm{E}$}

Eccles operation, 309

Echinococcus cyst, 270, 3I3

diagnosis, 320

etiology, 3 I 4

symptoms, 3 I 9

treatment, 322

unilocularis, 3 I 8

Elirlich's athrepsia theory, 497

Electro-therapy, 66I

Elephantiasis, I 13

Embolism in carcinoma, 497

Embryology, I

Empire bandage, 470

Encephaloid cancer, 480,482

Endothelioma, 378

Epigastric triangle, 34

Epithelioma intra-canaliculaire, 296 of nipple, 684
Epitheliome dendritique du sein, 296

Escharotic therapy, 665

Evolution, I

Exogenous infections, I68

Exudation cysts in tumors, 3 I 2

\section{F}

Fascia, axillary, 34 clavi-pectoral, 30 pectoral deep, 30 superficial, 28

Fausse keloĩde, 346

Fibro-adenoma, 442 physical signs, $46 \mathrm{I}$

Fibro-epithelial tumors, 442 etiology, 453

in polymastia, 459

in supernumerary breasts, 459

malignant change, $45^{\circ}$

morbid anatomy, 448

nipple in, 46I

of male breast, $47 \mathrm{I}$

pathological histology, 443

pathology, 442

physical signs, 46I

prognosis, 462

symptoms, $45^{8}$

treatment, 463

Fibroma, 344

diffusum, 345

intra-canaliculare papillare, 345

molluscum, 345

of nipple, 683

plexiforme, 345

tuberosum, 345

Fibrosis of breast, 193

Field of operation, preparation, 583

Filaria medinensis, 328

Filariasis mammæ, 328

"Filtrable viruses," 339

"Fingergliedartig" nipple, 674

Fissure of nipple, I75

Fistula, lactic, I62

mammàry, 198

Foramen of Langer, 34

Foreign bodies in breast, 163

Fulguration therapy, 662

Fungus hematodes, 382

G

Galactocele, $26 \circ$

etiology, 263

fluid, 262

infiltrating, 262

solid, 262 
Galactorrhœa, 17

Gangrene of nipple, 675

Geissler, solitary tuberculosis, 203

Gelatinous carcinoma, 482, 485

Giant-cell sarcoma, 390

Girard's mastopexy, I I 9

Glands of Montgomery, embryology, 2

Guinea-worm, 328

Gumma of breast, 243

Gynecomastia, I40 amputation, 148 diagnosis, 147 in pseudohermaphroditism, 142 morphology, I 45 prognosis, I 47 summary, I 49 tabulation, 150 theories, I 40 treatment, I 47

$\mathrm{H}$

Halsted, adeno-carcinoma, 482 operation, 579 modified, 580 skin-grafting, $58 \mathrm{I}$

Handley operation, 603

Hard cancer, 480

Hemangioendothelioma, 378

Hemangioma, 36I

Hemangio-sarcoma, 398

Hematogenous injections, 169

Hematoid myxoma, 357

Hematoma breast, I62, 3 I I

Hemolytic reaction in cancer, $54^{\circ}$

Hemorrhage, post-operative, 600

Hemorrhagic cysts, 3 I I

Hepatic lymph nodes, 43

Heteroplastic tumor, 340

Histology, 9

"Hollow nipples," 5 I

Homoplastic tumor, 340

Hydatids, 270

Hyperemia therapy, 658

Hypermazia, 5 I

Hyperplasia, 332

Hypertrophy mammary, virginal, Iot of breast, amputation, I 7

diagnosis, I I 3

etiology, I I I

infantile, IO2

mastopexy, I I 9

prenatal, 102

prognosis, I I 5

tabulation, I20

treatment, I 6

Hypoplasia of mammary gland, 49
I

Ichthyosis circumscription, 702

Immuno-therapy, 660

Imperforate nipple, 671

Infant breast, 3 mammary abscess, 4

Infantile hypertrophy, 102

Infection, autogenous, I68 exogenous, I68

retro-mammary, 173

Infectious diseases of breast, I65

Inflammation of breast, subcutaneous, I73 of nipple, I 75

Inflammatory fibroses, I93

Infra-clavicular triangles, 3 I

Intercostal lymph nodes, 43

Inter-scapulo-thoracic amputation, 634

Interstitial mastitis, 193

Intra-acinous cystic epithelioma, 27I

-canalicular cystadenoma, 296

fibroma, 446

-cystic papilloma, 296

diagnosis, 302

differential, 307

etiology, 30 I

history, 298

pathology, 297

prognosis, 308

symptoms, 302

treatment, 309

-glandular lipomas, 35 I

-mammary abscess, I 78

Desmorest's operation, I79

Sheild's operation, I 78

polymastia, 93

Inverted nipple, 5I, 67 I

"Invisible microōrganisms," 339

Involution, I7

abnormal, 17

cyst, 273,296

presenile, I 7

senile, I 7

Irregular-cell sarcoma, 389

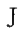

Jackson's operation, 628

K

Kehrer's operation, 673

Keloid, 346

cicatrix, 348

diagnosis, 350

false, 346

histology, 349

of Addison, $35^{\circ}$ 
Keloid of Alibert, 347

spontaneous, 347

treatment, $35^{\circ}$

true, 346

"Knospen-brust," 5

Kocher's operation, 606

L

Lactation, 13

in male, 14

mastitis, $x 66$

Lacteal cysts, 260

Lactic fistula, 162

Langer, foramen of, 34

Leiomyoma of nipple, 683

Leukemic tumors, 397

Ligation, axillary artery, 632 vein, 632

subclavian artery, 632

Lipoma, 350

bilateral, $35 \mathrm{r}$

diffuse, 356

histology, 355

morbid anatomy, 355

retro-mammary, 353

subcutaneous, 353

symmetrical, $35 \mathrm{I}$

unilateral, $35^{2}$

Liposarcoma, 356

Lymphangioendothelioma, 378

Lymphangioma, 36I

Lymphangioplasty, 631

Lymphangio-sarcoma, 398

Lymphatic cysts, 3 Io

Lymphatics, 36

of thoracic muscles, 40

of thorax, 37

Lymphedema, post-operative, 60 I

Lymph nodes, 40

axillary, 40

brachial, 4I

hepatic, 43

intercostal, 43

internal mammary, 43

in tuberculosis, 214

involved in carcinoma, 36

pectoral, $4 \mathrm{I}$

retro-pectoral, 42

retro-sternal, 43

subclavian, $4 \mathrm{r}$

sub-diaphragmatic, 43

sub-scapular, $4^{\mathrm{I}}$

supra-xiphoid, 43

M

Maladie de Reclus, 269

Kystique de la Mamelle, $27 \mathrm{I}$

nouetuse, $27 \mathrm{I}$
Malignant tumor, 34I

papillary dermatitis, 686

Mamillary angioma, 363

Mammæ erraticæ, 81

Mammary abscess, see Mastitis. chancre, $24 \mathrm{r}$

secretion, 26r

sinus, 198

Mammillaplasty, 672

Mastitis, I65

adolescentium, 5, 166 treatment, 166 virilis, 5

bacteriology, 169

Bier's treatment, 181

carcinosa, 479,483

chronic, in male, I 90

treatment, 195

cirrhosing, 271

cystic, 269

hypertrophic in male, 190

in male, 190

interstitial, 193

treatment, 195

lactation, I 66

neonatorum, 3, 165

treatment, 166

obliterans senescentium, 22

primary diffuse, $x 72$

pubescentium virilis, $5^{\circ}$

puerperal, I66

diagnosis, 174

diffusing, $17 \mathrm{I}$

incidence, $x 69$

ordinary, I 71

pathogenesis, 168

prophylaxis, $\mathbf{I} 74$

treatment, 174

pyogenic, I 71

in male, 189

traumatic, 200

syphilitic, diffuse, 243

tuberculosa obliterans, 2 I 5

tuberculous, $2 \mathrm{O}_{4}$

atypical forms, 216

bacteriology, 217

diagnosis, 218

miliary, 214

nodular, 214

prognosis, 2 I 8

sclerosing, 215

treatment, 2 I 9

with neoplasms, 216

typhoid, I 85

treatment, 189

vaccine therapy, 184

with parotitis, 199

Mastopexy, II8 
Mastoptosis, II 8

McDonald's solution, $5^{8} 4$

Medullary cancer, 482

Meistagomin reaction, 539

Melanin, 395

Melanoid cancer, 483

Melanotic cancer, 483 sarcoma, 378, 393

Metastasis, $3+2$ in carcinoma, 494 lymphatic permeation, 502 mechanism, 495 visceral, table, 5 Io

Meyer's operation, 620

Micromastia, 45, 47

"Milch-leisten," I

Milk-lines, I

Mixed-cell sarcoma, 389

Mixed toxins of erysipelas and prodigiosus, 4.32

Molluscum contagiosum, 702 fibrosum, 345

Morenheim, space of, 32

Morestin's incision, 179

Morphea, 347, $35^{\circ}$

Mucoid carcinoma, 482

Mucous patch, 243

Murphy's operation, 6I6

Myeloplaxes, 390

Myoma, 368 of nipple, 683

Myxo-lipoma, 355 .

Myxoma, 357 canalicular, $4+6$ intra-canalicular, 446 peri-canalicular, 446 peri-ductal, 446

Myxomatous carcinoma, 482

Myxo-sarcoma, 378, 391

\section{$\mathrm{N}$}

Nematode parasites, 328

Nerve supply of breast, 36

Neuroma, 369

Nipple, 8 absence of, $5^{\mathrm{I}}$ anomalies acquired, 674 congenital, 67 I

bifid, 67 I

breeding from, 303

carcinoma, 684

cysts, 677

digital, 674

discharge from, 534

diseases, $67 \mathrm{I}$

embryology, 2

epithelioma, 684

fibroma, 683
Nipple fissure, 175

gangrene, 675

hollow, $5 \mathrm{I}$

imperforate, $67 \mathrm{I}$

in fibro-epithelial tumors, $46 \mathrm{I}$

inflammation, 175,674

intra-cystic papilloma, 684

inverted, 5I, 671

treatment, 672

myoma, 683

Paget's disease, 686

pseudo-diphtheria, 677

retraction in cancer, 534

sarcoma, 683

shield, I 75

supernumerary, 9 I

syphilis, 676

thrush, 676

tumors, 678

umbilicated, $67 \mathrm{I}$

Upcott's line, 462

Nippleless mamma, 2

Nodular tuberculous mastitis, $2 x_{4}$

\section{$\mathrm{O}$}

Obese sexual infantalism, $\mathrm{x} 4$

Odium thelitis, 676

Oöphorectomy in carcinoma, 630

Operation, autoplasty, 633

Axford's, 672

Beatson's, 630

Dawbarn, 6I 8

Deaver's, 587

Desmorest's, 179

for carcinoma, 574

for intra-mammary abscess, 178

Halsted, 579 modificd, 580

Handley's, 603

in mammary cancer, contraindications, 568

Jackson's, 628

Kehrer's, 673

Kocher's, 606

mammillaplasty, 672

Meyer's, 620

Morestin's, I8I

Murphy's, 616

preparation of field, 583

Rodman's, 608

Sheild's, 178

Stewart's, 6I4

Tansini's, 623

Warren's, 624

Orange skin, 532

"Organoid tumors," 336

Ossifying sarcoma, 377 
Osteo-chondroma, 358

Osteoma, 358

Osteo-sarcoma, 400

Ovaries, $X$-ray treatment, 653

\section{$\mathrm{P}$}

"Paget's disease," 484

Paget's disease, 686

histology, 690

pathology, 692

symptoms, 694

treatment, 695

Pain in carcinoma, 527

in fibro-epithelial tumors, $45^{8}$

in intra-cystic papilloma, 305

in mammary tuberculosis, 2 I I

Papillary cystadenoma, 296 cystoma, 296

Papilloma, intra-cystic, 296

Para-mammary angioma, 363 structures, fibro-epithelial tumors, 459 tumors, 459

Parasitic cysts, 3 I 3

Parotitis with mastitis, 199

Pathology of carcinoma, 476 of fibro-epithelial tumors, 442 of Paget's disease, 692 of sarcoma, 373 of tumors, 330

Pectoral angioma, 364 fascia, deep, 30 superficial, 28 lymph nodes, $4 \mathrm{I}$

Peri-canalicular fibroma, 446

Peri-ductal fibroma, 445 intra-canalicular, 445 peri-canalicular, 445 mastitis, $27 \mathbf{r}$ myxoma, 446 sarcoma, 450

Peri-lymphatic fibrosis, 503

Perithelioma, 377

Physiology, I2

Pig skin, 532

Plastic operation, 633 resection of breast, 465

Pleiomazia, $5 \mathrm{I}$

Plexiform fibroma, 27 I

Plural births in polymastia, 85

Pneumonia, post-operative, 602

Polycystadenoma mammæ, 27 I

Polycystoma, 27x proliferum, 296

Polymastia, 47, 5I

Ahlfeld's theory, 55

Champney's theory, 55

Darwin's theory, 6I
Polymastia embryology, 2

fibro-epithelial tumors, 459

heredity, 54

intra-mammary, 93

plural births, 85

statistics, 86

surgery, 97, 100

table, 65

tuberculosis, 86

Polymazia, 5I

Polythelia, 65, 91, 67 I

statistics, 93

surgery, 97, IOI

Post-operative complications in carcinoma, 597

hemorrhage, 600

lymphedema, 6or

pneumonia, 602

treatment of cancer, 594

$X$-ray therapy, 649

Pre-cancerous adenopathy, 504

Pre-senile involution, 17

Primary epithelial hyperplasia, 277

Proliferating cystadenoma, 296

Proliferous cyst, 296

Prosoplasia, 332

Psammo-carcinoma, 483

Psammosarcoma, 377

Pseudo-diphtheria of nipple, 677

Pseudolipoma, 356

Puerperal mastitis, 166

"Pure adenoma," 442

Pyogenic abscess, chronic, 196

mastitis, I 7I

traumatic, 200

$\mathrm{R}$

Radium therapy, 655

in sarcoma, $43^{\circ}$

Ray fungus, 234

Recurrence of carcinoma, $5^{61}$

Retention cysts in tumors, 3 I2

Retro-mammary abscess, I8I

infections, 173

lipoma, 353

Retro-pectoral lymph nodes, 42

Retro-sternal lymph nodes, 43

Reverdin grafts, 583

Rodman's operation, 608

Roentgen-therapy, 638

in sarcoma, 432

Round-cell sarcoma, 386

Roux's abscess, 215

"Sable hydatique," 318

Sarco-carcinoma, 409 
Sarcoma, 372

alveolar, 378

axillary nodes, 422

cases, 425

chondrifying, 377

classification, 428

Coley's fluid therapy, 432

diagnosis, 427

giant-cell, 390

incidence, $4 \mathbf{I} 3$

indigenous, $379,45^{\circ}$

irregular-cell, 389

melanotic, 378,393

mixed-cell, 389

non-indigenous, 379

of nipple, $68_{3}$

operative mortality, 420

ossifying, 377

pathology, 373

peri-ductal, $45^{\circ}$

perithelial, 377

prognosis, 420

radium therapy, 430 .

round-cell, 386

spindle-cell, 387

table, 4 I4

treatment, $43^{\circ}$

non-operative, 432

with carcinoma, 488

$X$-ray therapy, 430

Schimmelbusch's disease, 279

Scirrhus cancer, 482

Scleriasis, $35^{\circ}$

Scleroma, 350

Sclerosing tuberculous mastitis, 2 I 5

Sebaceous cysts, 254

Senile atypical parenchymatous hypertrophy, 273

involution, 17 , I9

Sero-diagnosis of cancer, 539

Serous cysts, 265

Serum-therapy in cancer, $66 \mathrm{I}$

Sheild's operation, I 78

Shield for nipple, I75

"Shirt-stud" abscess, I 8I

Simple cysts, 265

Sinus mammary, 198

Skin grafting, 583

post-operative, $58 \mathrm{I}$

Soft cancer, 480

Space of Morenheim, 32

Sparganum disease, 326

Spindle-cell sarcoma, 387

Spontaneous keloid, 347

Sporotrichosis, 249

diagnosis, 253

treatment, 253

Sporotrichotic chancre, 25 I
Sporotrichotic gummas, 251

Squamous-cell carcinoma, 483, 486 epithelioma, 483

Steatomas, 254

Stewart's operation, 6I4

Stroma, 28

Subclavian artery, ligation, 632 lymph nodes, 41

Subcutaneous angioma, 363

Sub-diaphragmatic 1ymph nodes, 43

Sub-scapular lymph nodes, 4 I

"Sulphur grains," 235

Supernumerary mammary gland, 5 I fibro-epithelial tumors, 459 location, 65

morphology, 84

surgery, 97

nipple, 9 I

Supra-xiphoid lymph nodes, 43

Surgical anatomy, 26

Syphilis of breast, 241

congenital, 244

diagnosis, 245

secondary, 243

tertiary, 243

treatment, 248

of nipple, 676

Syphiloma of breast, 243

\section{$\mathrm{T}$}

Tænia echinococcus, 3 I 4

Tail of mamma, I I

Tansini's operation, 623

Telangiectasia, 362

Thelitis, I75, 674

diphtheritic, 677

Thiersch grafts, $5^{83}$

Thomas' incision, 465

Thoracic muscles, lymphatics, 40

Thorax, lymphatics, 37

Thrush of nipple, 676

Toxin-therapy, 660

Triangle, epigastric, 34 infra-clavicular, 31

Tuberculin in tuberculous mastitis, 2 I 9

Tuberculosis, 202

atypical forms, 216

bacteriology, 2 I 7

diagnosis, 218

etiology, 207

incidence, 206

lymphnodes, 2 I 4

miliary, 2 I 4

nodular, 214

pathological types, $2 \mathrm{I}_{4}$

primary, 204

prognosis, 2 I 8 
Tuberculosis, sclerosing, 2 I 5

secondary, 204

solitary of Geissler, 203

symptoms, 2 II

treatment, 2 r 9

with neoplasms, 216

Tuberculous mastitis, 204

Tubular scirrhus carcinoma, $48 z$

Tubuli galactophori, 9 lactiferi, 9

Tumors, benign, $34 \mathrm{I}$

cartilaginous, 358

classification, 343

definition, 33I

etiology, 334

exciting causes, 337

fibro-epithelial, 442

fibroma, 344

heterologous, 340

heteroplastic, 340

homologous, $34^{\circ}$

homoplastic, $34^{\circ}$

in carcinoma, 529

leukemic, 397

malignant, $34 \mathrm{r}$

mammary, table, 4I 4

non-indigenous, 344

pathology, $33^{\circ}$

phylogenetic influences, 334

predisposing causes, 334

table, $4 \mathrm{r} 5$

Tumor-affines, 659
Typhoid mastitis, 185

treatment, 189

$\mathrm{U}$

Umbilicated nipple, 671

Upcott's nipple line, 462

\section{V}

Vaccine-therapy, 662

in mastitis, 184

Vanishing tumor, 274

Vicarious menstruation, 303

Villous papilloma, 296

Virginal hypertrophy of breasts, 104

Vraie keloide, 346

W

Warren's operation, 465,624

Wounds, gunshot, of breast, 163 incised, of breast, 162

lacerated, of breast, I62 stab, of breast, 163

\section{$\mathrm{X}$}

$X$-ray therapy, 638

in carcinoma, 638

in sarcoma, 430 post-operative, 649 treatment of ovaries, 653 

COUNTWAY LIBRARY OF MEDICINE

RG

491

D 34

RARE BOOKS DEPARTMENT 


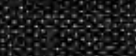

2018:

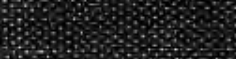

H

Hor

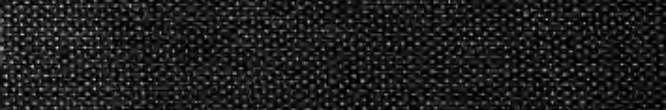

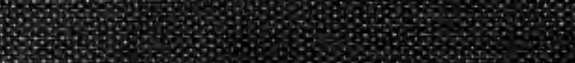

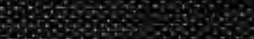

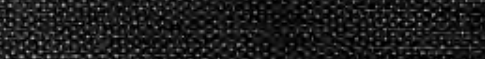

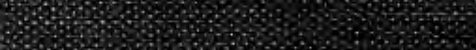

\%

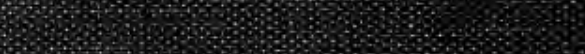

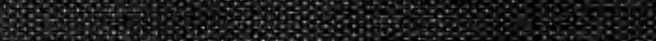

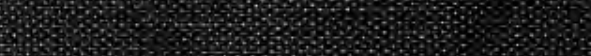

98.

(4)

$30 \%$ \%

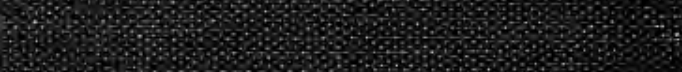

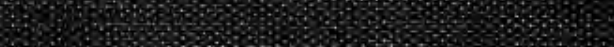

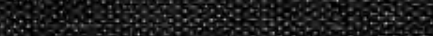

(3)

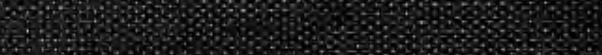

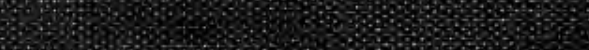

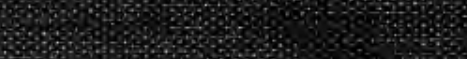

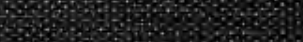

(1)

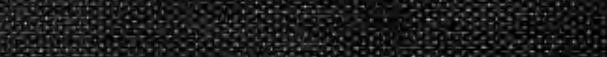

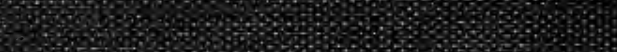

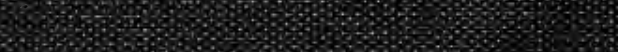

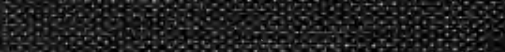

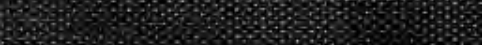

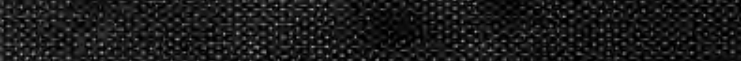

(1)

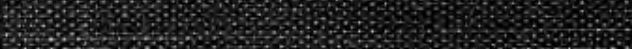

(3)

10030

(2)

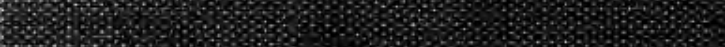

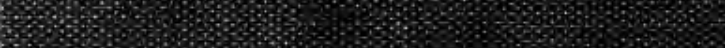

